\title{
NEW CHALLENGES IN
}

ECONOMIC AND BUSINESS DEVELOPMENT 2021

14/05/2021/Riga University of Latvia

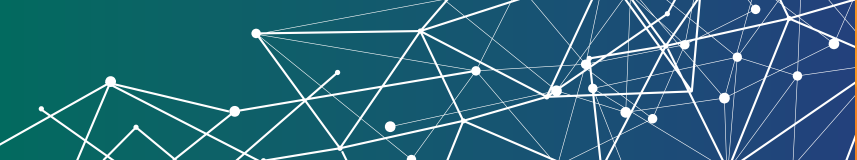

\section{PROCEEDINGS}




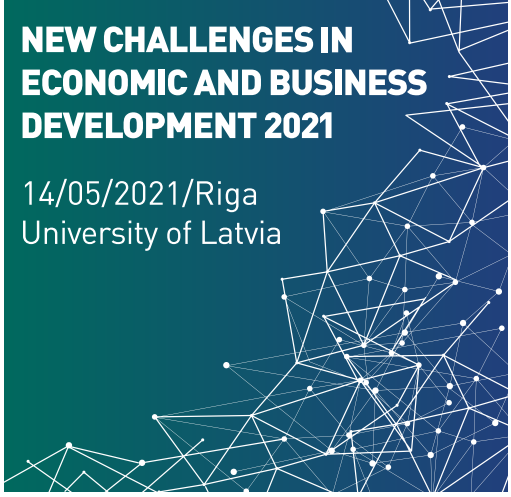

International Scientific Conference

New Challenges in Economic and Business Development 2021: Post-Crisis Economy

\section{PROCEEDINGS}

Organised by Faculty of Business, Management and Economics,

University of Latvia

May 14, 2021

Riga, University of Latvia

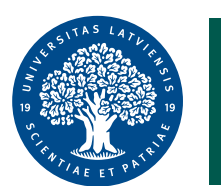

UNIVERSITY OF LATVIA

FACULTY OF BUSINESS,

MANAGEMENT

AND ECONOMICS 
The 13th international scientific conference "New Challenges in Economic and Business Development - 2021: Post-Crisis Economy": Riga, Latvia, May 14, 2021.

Proceedings. Riga: University of Latvia, 2021, 484 p.

\section{Scientific Programme Committee}

Chair, Dr. Inna Romanova, Professor, University of Latvia (Latvia)

Dr. Jean David Avenel, Professor, University Paris-Est Creteil (France)

Dr. Signe Balina, Professor, University of Latvia (Latvia)

Dr. Alan Barrell, Professor, University of Cambridge (United Kingdom)

Dr. Frank Bezzina, Associate Professor, University of Malta (Malta)

Dr. Gundars Berzins, Professor, University of Latvia (Latvia)

Dr. Andrejs Cekuls, Professor, University of Latvia (Latvia)

Dr. Rasa Daugeliene, Associate Professor, Kaunas University of Technology (Lithuania)

Dr. Vida Davidaviciene, Professor, Vilnius Gediminas Technical University (Lithuania)

Dr. Tomasz Dorozynski, Assistant Professor, University of Lodz (Poland)

Dr. Ksenija Dumicic, Professor, University of Zagreb (Croatia)

Dr. Margarita Dunska, Professor, University of Latvia (Latvia)

Dr. Nicolas Gavoille, Associate Professor, Stockholm School of Economics in Riga (Latvia)

Dr. Simon Grima, University of Malta (Malta)

Dr. Arto Haveri, Professor, Tampere University (Finland)

Dr. Gundars Kaupins, Professor, Boise State University (USA)

Dr. Jan Koernert, Professor, University of Greifswald (Germany)

Dr. habil. Natalia Kuznetsova, Professor, Saint Petersburg State University (Russia)

Dr. Pierpaolo Marano, Associate Professor, Università Cattolica del Sacro Cuore (Italy)

Dr. Ibish Mazreku, Associate Professor, University Haxhi Zeka (Kosovo)

Dr. Marco Menichetti, Professor, University of Liechtenstein (Liechtenstein)

Dr. Eda Merisalu, Professor, Estonian University of Life Sciences (Estonia)

Dr. Shin'ya Nagasawa, Professor, Waseda University (Japan)

Dr. Josef Neuert, Professor, University of Salzburg (Austria)

Dr. Tiiu Paas, Professor, Tartu University (Estonia)

Dr. Gunnar Prause, Professor, Tallinn University of Technology (Estonia)

Dr. Janis Priede, Professor, University of Latvia (Latvia)

Dr. Alari Purju, Professor, Tallinn University of Technology (Estonia)

Dr. Trond Randoy, Professor, University of Agder (Norway)

Dr. Jurgita Raudeliuniene, Professor, Vilnius Gediminas Technical University (Lithuania)

Dr. Ramona Rupeika-Apoga, Professor, University of Latvia (Latvia)

Dr. Bruno S. Sergi, Professor, University of Messina (Italy), Harvard University (USA)

Dr. Biruta Sloka, Professor, University of Latvia (Latvia)

Dr. Ligita Simanskiene, Professor, Klaipeda University (Lithuania)

Dr. habil. Inna Steinbuka, Professor, University of Latvia (Latvia)

Dr. Erika Sumilo, Professor, University of Latvia (Latvia)

Dr. Eleftherios Thalassinos, Professor, University of Piraeus (Greece)

Dr. Osman Titrek, Professor, Sakarya University (Turkey)

Dr.habil. Renata Walczak, Professor, Warsaw University of Technology (Poland) 


\section{Conference Organizing Committee}

Chair, Dr. Inna Romanova, Vice Dean for Research, Professor, Faculty of Business, Management and Economics, University of Latvia

Dr. Gundars Berzins, Dean, Professor, Faculty of Business, Management and Economics, University of Latvia

Dr. Andrejs Cekuls, Professor, Faculty of Business, Management and Economics, University of Latvia

Dr. Margarita Dunska, Professor, Faculty of Business, Management and Economics, University of Latvia

Dr. Janis Priede, Professor, Faculty of Business, Management and Economics, University of Latvia

Dr. Ramona Rupeika-Apoga, Professor, Faculty of Business, Management and Economics, University of Latvia

Dr. Biruta Sloka, Professor, Faculty of Business, Management and Economics, University of Latvia

Dr. Erika Sumilo, Professor, Faculty of Business, Management and Economics, University of Latvia

Evija Ansonska, Public Relations Manager, Faculty of Business, Management and Economics, University of Latvia

Liene Berzina, Public Relations Specialist, Faculty of Business, Management and Economics, University of Latvia

Sofija Kristele, Executive Director, Faculty of Business, Management and Economics, University of Latvia

Kristine Liepina, Dean Assistant, Faculty of Business, Management and Economics, University of Latvia

Annija Apsite, University of Latvia, Latvia

\section{Reviewers}

Daira Baranova, University of Latvia, Latvia

Anda Batraga, University of Latvia, Latvia

Kristine Berzina, University of Latvia, Latvia

Atis Berzins, University of Latvia, Latvia

Frank Bezzina, University of Malta, Malta

Monika Bolek, University of Lodz, Poland

Inta Bruna, University of Latvia, Latvia

Ilze Buligina, University of Latvia, Latvia

Andrejs Cekuls, University of Latvia, Latvia

Rasa Daugeliene, Kaunas University of Technology, Lithuania

Vida Davidaviciene, Vilnius Gediminas Technical University, Lithuania

Tomasz Dorozynski, University of Lodz, Poland

Margarita Dunska, University of Latvia, Latvia

Egils Fortins, University of Latvia, Latvia

Nicolas Gavoile, SSE Riga, Latvia

Agata Gniadkowska-Szymanska, University of Lodz, Poland

Simon Grima, University of Malta, Malta

Sandra Jekabsone, University of Latvia, Latvia

Henrijs Kalkis, University of Latvia, Latvia

Inese Kalnina, University of Latvia, Latvia

Gundars Kaupins, Boise State University, United States of America

Viesturs Pauls Karnups, University of Latvia, Latvia

Renata Korsakiene, Vilnius Gediminas Technical University, Lithuania

Silvija Kristapsone, University of Latvia, Latvia

Juris, Krumins, University of Latvia, Latvia

Marina Kudinska, University of Latvia, Latvia

Natalia Kuznetsova, Saint Petersburg State University, Russia

Adam Manowicz, Fachhochschule Bielefeld, Germany

Pierpaolo Marano, Università Cattolica del Sacro Cuore, Italy

Ilze Medne, University of Latvia, Latvia

Marco Menichetti, University of Liechtenstein, Liechtenstein

Tiiu Paas, University of Tartu, Estonia

Jurgita Pauzuoliene, Klaipeda State University of Applied Sciences, Lithuania

Dancho Petrov, University of Economics - Varna, Bulgaria

Gunnar Prause, Tallinn University of Technology, Estonia

Janis Priede, University of Latvia, Latvia

Alari Purju, Tallinn University of Technology, Estonia 
Karlis Purmalis, University of Latvia, Latvia Jurgita Raudeliuniene, Vilnius Gediminas Technical University, Lithuania Inna Romanova, University of Latvia, Latvia Kristine Rozite, University of Latvia, Latvia Ramona Rupeika-Apoga, University of Latvia, Latvia Svetlana Saksonova, University of Latvia, Latvia Jelena Salkovska, University of Latvia, Latvia Baiba Savrina, University of Latvia, Latvia Ligita Simanskiene, Klaipeda University, Lithuania Roberts Skapars, University of Latvia, Latvia Daina Skiltere, University of Latvia, Latvia Irina Skribane, University of Latvia, Latvia Biruta Sloka, University of Latvia, Latvia Irina Solovjova, University of Latvia, Latvia Santa Sproge-Rimsa, University of Latvia, Latvia Erika Sumilo, University of Latvia, Latvia Daiva Tamuleviciene, Vilnius University, Lithuania Eleftherios Thalassinos, University of Piraeus, Greece Natalja Tocelovska, SSE Riga, Latvia

George Varlamov, Pskov State University, Russia

Inesa Voroncuka, University of Latvia, Latvia

Renata Walczak, Warsaw University of Technology, Poland

Stefan Wendt, Reykjavik University, Iceland

Manuel Woschank, University of Fulda, Germany

\section{LEGAL NOTICE}

The University of Latvia, nor any person acting on its behalf may be held responsible for the use to which information contained in this publication may be put, nor for any errors which may appear despite careful preparation and checking. 


\section{CONTENTS}

Inese Abolina, Andzela Veselova

REMOTE WORK: THE NECESSITY OF TODAY

Annija Apsite

EMPLOYER BRANDING PECULIARITIES FROM A GENERATIONAL PERSPECTIVE: CASE OF BALTIC STATES

Elina Apsite Berina, Girts Burgmanis, Toms Skadins, Liga Feldmane, Zaiga Krisjane

REGIONAL DIFFERENCES AND CHALLENGES OF SUBJECTIVE WELL-BEING IN LATVIA DURING THE COVID-19 PANDEMIC

FIRST WAVE.....

Diana Araja

POTENTIAL DISRUPTIVE AND SUSTAINING INNOVATIONS IN HEALTH CARE

Diana Bachtijeva, Daiva Tamuleviciene

THE RELATIONSHIP BETWEEN THE CREATIVE ACCOUNTING AND CORPORATE SOCIAL RESPONSIBILITY: UNFAIR

ADVANTAGE AND A THREAT TO THE ECONOMIC WELL-BEING.

Olegs Baranovs, Janis Salmins, Irina Skribane

PRODUCTIVITY FACTORS AND DYNAMICS IN LATVIA

Benjamin Basner

THE CHARACTERISTICS OF MATURITY MODELS

Baiba Bela

INTERNATIONAL DIMENSION OF THE CAREER EXPERIENCE OF RETURN MIGRANTS AND TRANSNATIONALS.

Kristine Berzina, Ilze Medne

THE ROLE OF DIGITAL INFORMATION SOURCES IN TRAVEL PLANNING PROCESS

Maris Berzins, Zaiga Krisjane, Janis Krumins, Magnuss Spude

ETHNIC AND REGIONAL DISPARITIES OF AGEING IN LATVIA: MEASURING RESIDENTIAL SEGREGATION BY AGE.

Olga Bogdanova

THE ROLE OF INFRASTRUCTURE DEVELOPMENT IN THE COMPETITIVENESS OF A COUNTRY.......

Larisa Bule, Ramona Rupeika-Apoga, Inna Romanova, Liga Leitane

ASSESSMENT OF LATVIAN PENSION SYSTEM IN THE CONTEXT OF EUROPEAN PILLAR OF SOCIAL RIGHTS.

Harsh Chauhan, Henrijs Kalkis

EFFECT OF INTRA-ORGANISATIONAL COMPETITION ON ORGANISATIONAL PERFORMANCE.

Edgars Cirulis

PRACTICALLY APPLICABLE MODEL FOR ASSESSMENT OF IT GOVERNANCE IN THE PUBLIC SECTOR

Martins Danusevics

GROCERY RETAIL MARKET CONCENTRATION CONVERGENCE IN EASTERN EUROPEAN AND BALTIC EU MEMBER STATES IN 2010-2019

Klaus Dänner

THE IMPACT OF DIGITIZATION ON LEAN MANAGEMENT IN MANUFACTURING COMPANIES 
Zanda Davida

CONSUMER PERSONAL DATA DRIVEN DIGITAL MARKETING. 150

Agata Gniadkowska - Szymanska, Monika Bolek

IS THE GROWTH OF COMPANIES INFLUENCING THEIR FINANCIAL CONDITION DEPENDING ON THEIR SIZE - S\&P 500

LISTED COMPANIES EXAMPLE.

Kaspars lesalnieks

BUSSINESS CYCLE MANAGEMENT: CAPITAL INVESTMENTS.

Sandra Jekabsone, Irina Skribane, Antonina Broyaka

IMPACT OF THE CORONAVIRUS PANDEMIC ON THE ECONOMIC DEVELOPMENT OF UKRAINE.

Aina Joppe, Ilze Sproge, Ramona Rupeika-Apoga

THE PHENOMENON OF FAMILY BUSINESS AND TAXATION.....

Inese Kalnina

EFFECTS OF STATES GOVERNMENTS RESTRICTIONS RELATED ON CORONAVIRUS DISEASE (COVID-19) ON STATES

ECONOMY - COMPARISON OF BALTIC STATES, SWEDEN AND BELARUS.

Oksana Katalkina, Svetlana Saksonova

COMPARATIVE ANALYSIS OF THE EUROPEAN UNION CROWDFUNDING SERVICE PROVIDERS REGULATION AND

REGULATORY BARRIERS FOR CROWDFUNDING IN THE BALTIC STATES.

Matiss Kite, Anda Batraga, Jelena Salkovska

LATVIAN PHARMACEUTICAL MARKET: A REVIEW OF MARKETING COMPONENTS AND DEVELOPMENT TRENDS.....

Jeannine Kopp

REVEALING THE IMPACT OF WORKING HOURS ON THE WORK-LIFE BALANCE AND JOB SATISFACTION OF FRONT-LINE

EMPLOYEES IN THE TOURISM AND HOSPITALITY INDUSTRY BY MEANS OF A QUANTITATIVE STUDY.

Olegs Krasnopjorovs, Konstantins Kovalovs

PRODUCTIVITY ANALYSIS OF LATVIAN COMPANIES USING ORBIS DATABASE

Matthias Kretschmar

THE IMPACT OF TRUST IN A VIRTUAL TEAM ON INDIVIDUAL SATISFACTION AND TEAM PERFORMANCE

Juris Krumins, Aleksandrs Dahs

DEMOGRAPHIC INEQUALITIES AS DETERMINANTS AND CONSEQUENCES OF THE COVID-19 PANDEMIC IN LATVIA.... 246

Kate Lase, Biruta Sloka

REGIONAL DIFFERENCES BETWEEN JOB SEEKERS: CASE OF LATVIA.....

Andris Litins, Silvija Kristapsone

THE SUBJECTIVE AND OBJECTIVE EVALUATION OF ACCOMODATION IN LATVIA IN THE AFTERCRISIS PERIOD

Siyi Liu, Kuznetsova Natalia

NEW MECHANISM OF ONLINE MARKETING DURING EPIDEMIC SITUATION: CASE STUDY OF THE 12TH TMALL 11.11

GLOBAL SHOPPING FESTIVAL OF ALIBABA GROUP 
Leila Neimane, Janis Kaminskis, Kamil Kowalczyk, Severine Michalak, Liga Ozolina, Iveta Stamure A MULTIPURPOSE, MULTIDIMENSIONAL AND INTEREST-DRIVEN MARINE CADASTRE AS AN INTEGRAL PART OF MARITIME SPATIAL PLANNING FOR THE BALTIC SEA REGION

leva Ozolanta

THE IMPACT OF TECHNOLOGY COMPLEXITY ON PROJECT MANAGER'S SKILLS.

Jurgita Pauzuoliene, leva Kavecke, Ilvija Pikturnaite

GREEN LOGISTICS PRACTISE AND SOLUTIONS FOR TRANSPORT ORGANIZATIONS

Dancho Petrov, Evgeniya Tonkova, Svetlana Todorova

EU HOUSEHOLD INDEBTEDNESS PRIOR TO THE COVID-19 GLOBAL PANDEMIC CRISIS.

leva Puke

CLASSIFICATION OF MARKETING CAPABILITIES

Marina Reshetnikova

CHINA'S RACE LEADERSHIP IN ARTIFICIAL INTELLIGENCE

Andreas Rams

MARKET INTEREST RATES, CAPITAL STRUCTURE - AND ZOMBIFICATION?

IImars Rimsevics

COVID-19 MITIGATION MEASURES, THEIR ECONOMIC IMPACT AND WAY BACK TO THE OLD NORMAL

Bjarne Erik Roscher

TWO DECADES OF CIO EFFECTIVENESS RESEARCH IN THE LIGHT OF THE PRINCIPAL-AGENT THEORY: SUGGESTIONS FOR

FUTURE RESEARCH

Sabine Rusmane, Marina Kudinska

LONG-TERM SOCIO-ECONOMIC IMPACT OF COVID-19 ON SPORT SECTOR

Svetlana Saksonova, Neli Abramishvili, Oksana Katalkina

FACTORS INFLUENCING PREMIUMS AND DISCOUNTS FOR CONTROL IN ASSESSING THE VALUE OF A BUSINESS

Jelena Salkovska, Anda Batraga, Liene Kaibe

POSSIBILITIES OF USING CHATBOTS IN DIGITAL MARKETING STRATEGY OF LATVIAN COMPANIES

Baiba Savrina, Signe Martisune

SHORTAGES, SKILLS AND OLDER WORKERS IN INFORMATION TECHNOLOGY LABOUR MARKET OF LATVIA

Ligita Simanskiene, Arnoldas Petrulis, Julija Melnikova

CORRELATIONS BETWEEN ETHICAL LEADERSHIP AND LEADERSHIP STYLES

Biruta Sloka, Ginta Tora, Juris Dzelme, Ilze Buligina

SOME ASPECTS FOR MODERN SOLUTIONS FOR STRENGTHENING SOCIAL RESILIENCE AS GUARANTEE FOR THE FUTURE

WELL-BEING OF AN OPEN AND INCLUSIVE SOCIET

Inna Steinbuka, Olegs Baranovs, Normunds Malnacs, Aldis Austers

SOCIO-ECONOMIC IMPLICATIONS OF THE CORONAVIRUS PANDEMIC IN LATVIA 
Yulia Stukalina

INCREASING INTERNAL AND EXTERNAL BRAND AWARENESS IN HIGHER EDUCATION.

Yuilia Stukalina

MANAGEMENT OF UNIVERSITY RESEARCH: USING INTERNATIONAL STANDARDS OF EXCELLENCE FOR RESEARCH

EVALUATION.

Ekaterina Usacheva, Aleksey Chechulin, Nikita Grishanin

THE OFFICIAL TOURISM WEBSITE OF THE MODERN CITY: USING FOCUS GROUPS TO STUDY THE PERCEPTION 448

Aliaksei Varonin, Siarhei Baslaviak

CENTRAL BANK DIGITAL CURRENCY: THE HISTORICAL VIEW, TECHNOLOGIES AND PERSPECTIVES.

Andzela Veselova

PARTICULARITIES OF CONSUMER'S BEHAVIOR IN THE CONTEXT OF COVID 19 PANDEMIC

Edgars Vitols, Sandra Jekabsone

PUBLIC DEBT SUSTAINABILITY AND THE IMPACT OF THE COVID-19 PANDEMIC: THE CASE OF LATVIA. 


\title{
REMOTE WORK: THE NECESSITY OF TODAY \\ Inese Abolina, University of Latvia \\ Andzela Veselova, University of Latvia
}

\begin{abstract}
Global pandemic COVID-19 has increased the level of digitalization which allows public and private sector organizations in the world to employ people remotely outside office premises and crossing borders of the world. Remote work is one of the new employment forms caused by the impact of digitalization, which keeps conquering and strengthening the positions on our daily professional lives. It means extended use of different new employment forms, including the digital transition of administration processes and business management, improvement of digital skills and competences, contributing to development of areas of services and products with higher benefit (Breaugh, Farabee, 2012). Research aims to study basic principles and tendencies of remote work organization based on theoretical aspects, draw conclusions and elaborate proposals for improvement of remote work. In order to achieve the goal, the tasks are as follows: 1) provide the explanation of remote work organization; 2) describe secondary data from a conducted survey by Milasi, S., Fernandez - Macias, E., Gonzalez-Vazquez, I. 2020, European Commission; 3) conduct survey about remote work.
\end{abstract}

Keywords: public and private sector organizations, employee, remote work.

JEL code: D24, M54

\section{Introduction}

Remote work is part of a modernising trend in public and private sector organizations, which focuses on result-based management and objectivedriven performance to increase efficiency of operations. It allows greater flexibility for work organisation and a better work-life balance of employee by increasing autonomy and making better use of new information technology (IT). Remote working is a method of organising and executing work outside the workplace with help of information and communication technologies (ICT). It aims to help companies to achieve a more productive, result-oriented working environment, which is conducive to a positive work-life balance (Felsted, Henseke, 2017). Additionally, it has a beneficial impact on the environment by limiting commuting and improves the continuity of public and private sector organizations.

\section{Literature Review}

Although, remote work (also known as telework) was foreseen as early as 1950 (Castillo-Frick, 2017), it did not become possible until the entrance of personal computers and portable modems in the early 1970s (Nippert-Eng, 1996). In 1973, the term "working remotely" was introduced to emphasize that remote work could replace daily commute (Nilles, 1994). In the beginning, public and private sector organizations considered remote work as a way to make them less dependent on fuel and oil, especially during the fuel crisis in the early and mid-1970s (Tolbert, Simons, 1994). At the time, the number of remote work employees grew to more than ten-fold in a decade, to about 11.1 million (Shellenbarger, 1994).

Several factors have contributed to the emergence of remote work. First, numerous companies are trying to lower the costs of office space. Second, faced with increased competition, many companies adopt extended workdays and flexible work schedules to respond better to customer needs and to retain and attract skilled employees. Third, ICT are becoming increasingly affordable and cost-effective, which enables a strong penetration of ICT in public and private sector organizations (Brimsek Bender, 1995). Remote work has grown from its modest beginnings in the early 1970s to achieve an unprecedented level today.

The terms "remote work", and working remotely are used interchangeably, and it is a quite accepted practice in this area of research. In 1975, Jack Nilles (1975) was the first scholar to coin the term "working remotely". In 2002, Bailey and Kurland (2002) defined it as, "working outside the conventional workplace and communicating with it by way of telecommunications or computer-based technology". Meta-analysis by Gajendran, Harrison, 2007 expand further definition where "remote" is defined as the substitution of communication technology for work-related travel, and can include paid work from home, a satellite office, a remote work centre or any other workstation outside of the main office for at least one day per working week (Verbeke, Schulz, Greidanus, Hambley, 2008).

New ICT have revolutionised everyday work and life in the 21 st century. They enable people to connect with friends and family - as well as with colleagues and supervisors - at any point of time; however, they also facilitate the encroachment of paid work into the spaces and times normally reserved for personal life. The uncoupling of paid work from traditional office spaces has been a crucial factor in the development of 
remote work. Today's office work is supported by Internet and can be executed from practically any location and at any time. This new spatial independence has transformed the role of technology in the work environment, offering both new opportunities and new challenges. (Messenger, Gschwind, 2016)

Remote work is a growing trend around the globe. Although a vast majority of research on employees utilizing flexible work arrangements has focused on those who work from home intermittently, it is not known how remote employees experience the work-life balance (Mulki, Bardhi, Lassk, Nanavaty-Dahl, 2009; Breaugh, Farabee, 2012). The research indicate that employees prefer to work from home part-time rather than to work solely from home (Bailey, Kurland, 2002; Wight, Raley, 2009). There is a necessity of research that investigates the work-life balance of remote work employees and their management of work-life boundaries as well as the related effects to work-life conflict and stress.

Due to the high flexibility and autonomy associated with working from home, an employee can control where, when, and how work is executed and the management of work -life balance demands is believed to be facilitated (Bailey, Kurland, 2002). A meta-analysis of 46 studies by Gajendran and Harrison (2007) demonstrated that working from home lowers work-life conflict and that the benefits increase for those who work from home more frequently. Research also show that most remote work from home going on an average of 1 to 3 days per week (Raghuram, Wiesenfeld, 2004; Golden, Veiga, Simsek, 2006; Gajendran, Harrison, 2007). Scholars have lamented over the little theory on the effects of remote work and the lack of empirical research exploring this phenomenon (Bailey, Kurland, 2002; Gajendran, Harrison, 2007; Kossek, Kalliath, 2012).

Boundary theory captures how individuals create and maintain boundaries between work and life balance so as to simplify and order the world around them (Ashforth et al., 2000; Dumas, Sanchez-Burks, 2015). It describes how individuals erect "mental fences" around work and life balance to construct boundaries between these roles and the consequences of these "mental fences" for boundary management (Nippert-Eng, 1996; Kreiner et al., 2009). In turn, boundary management is characterized as a tool that assists in the handling of work and life responsibilities and helps to shape workplace identity and relationships (Eddleston, Mulki, 2015). The most important skills a successful remote worker should master include the following: time management, organizational skills, communication, self-discipline. The growth in remote working seen during COVID - 19 global pandemic has been strongly skewed towards highly paid employment, raising concerns about the emergence of a new division between those who can work remotely and those who cannot. Nonetheless, enforced closures of economic activities due to confinement measures resulted in many new remote employees amongst low and mid-level and administrative employees who previously had limited access to this working arrangement. Remote work is growing faster than ever before and shows no sign of slowing down. (Gish, 2020).Remote work enthusiasts argue that working remotely is "the future of work," with benefits for both employer and employee Nevertheless, some businesses remain sceptical, worrying that remote work employees will be more easily distracted and less able to participate in the public and private sector organizations culture (Breaugh, Farabee, 2012).

\section{Research results and discussion}

Remote work has reached a tipping point as more and more public and private sector organisations have introduced this work arrangement in an effort to keep their employees safe, while ensuring the continued delivery of critical services. Yet, differences in prior remote work experience and other factors make the transition more challenging for some employees and employers. Taking stock of pre-outbreak trends, the remote work had already been increasing over the past decade, (Gish, 2020). Albeit at a slow pace and mostly as an occasional work pattern except for the selfemployed.

Milasi et al. (2020) found a higher prevalence in knowledge - and ICT-intensive services, whereas much fewer remote work employees were found in administrative and support services, or in sectors that require physical interaction such as manufacturing or face-to-face interaction with the public (Milasi et al. 2020). High-skilled professionals and managers in knowledge-intensive activities were already quite used to working from home, as they do most of their work on computers and enjoy high degrees of autonomy.

Since the outbreak of the COVID -19 working from home has become the norm (Gish, 2020) for millions of employees in the EU and worldwide. Early estimates from Eurofound (2020) suggest that close to $40 \%$ of those currently working in the EU began to remote work fulltime as a result of the pandemic. A recent Joint Research Centre study provides a rough estimation of around 25\% of employment in remote work able sectors in the EU as a whole. Considering that before the outbreak just 15\% of the employed in the EU had ever remote worked, large numbers of employees and employers alike are, in all probability, facing challenges in dealing with the sudden shift to remote work. The extent of these difficulties, however, is likely to vary considerably, depending among other factors on the level of prior experience with remote work. (FernándezMacías, Fana, Tolan, Torrejón, Brancati, 2020) 
Remote work "home-office" turned out to be a necessary practice for many companies and employees during the first lockdown period of the COVID-19 crisis in spring 2020. During that time, societies have undergone a large scale "forced experiment" where sectors, companies and employees have continued to operate while being physically separated, provided they had the necessary technological, legal, and digital security conditions. Remote work has potentially large impacts on businesses of all kinds, whether they had embraced remote working in the past or not (OECD, 2020). It should also be kept in mind that, while remote work allowed some companies and employees to better 'weather the storm', especially those who used remote work before, the ability to remote work during the crisis was not open to all and differential access to remote work may well have exacerbated existing inequalities. For instance, many employees - especially young, less educated employees at the bottom of the wage distribution - during pandemic COVID-19 work in jobs requiring physical presence (Brussevich, Dabla-Norris, Khalid, 2020). In fact, as of 2019, only 5.4\% of employed in the EU-27 usually worked from home - a share that remained rather constant since 2009. (Milasi, Fernandez Macias, Gonzalez-Vazquez, 2020)

However, over the same period, the share of employed working at least sometimes from their homes increased from $5.2 \%$ in 2009 to $9 \%$ in 2019. (Eurostat, 2020) Working from home was considerably more common among the self-employed than dependent employees, although it increased in a similar way for both categories over the past decade. In 2019, almost 36\% of self-employed was sometimes or usually working from home in the EU-27, up from 30\% in 2009. (Milasi, Fernandez-Macias, Gonzalez-Vazquez, 2020). The prevalence of remote work among dependent employees was just above 11\% in 2019, up from 7.5\% in 2009 (Eurostat LFS, 2020). Prevalence of remote work by sector can be seen in Figure 1.

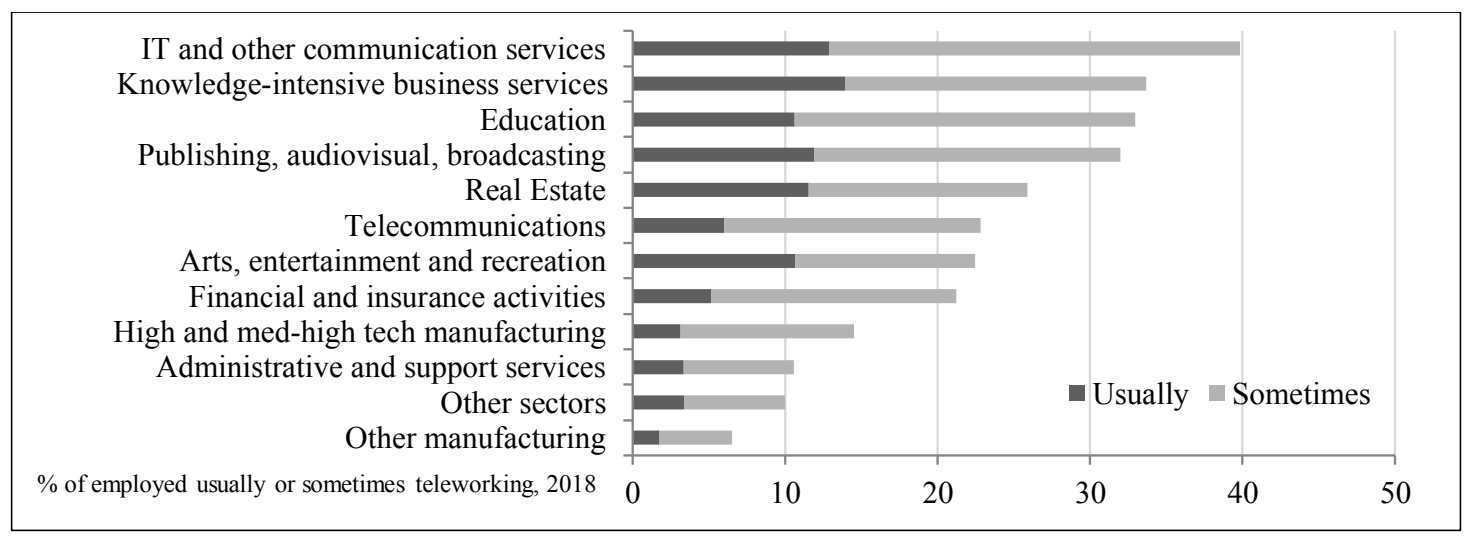

Source: authors, based on Milasi, Fernandez-Macias, Gonzalez-Vazquez, 2020

Notes: The group "Knowledge-intensive business services" includes the following sectors: Legal and Accounting Activities - Activities of Head Offices; Management Consultancy Activities - Architectural and Engineering Activities; Technical Testing and Analysis - Scientific Research and Development - Advertising and Market Research - Other Professional, Scientific and Technical Activities. The group IT and other communication services include the following: Computer Programming, Consultancy and Related Activities - Information Service Activities.

\section{Fig. 1. Prevalence of remote work by sector, EU-27}

The prevalence of remote work varies strongly across sectors and occupations. It was particularly high in ICT and knowledge- and -intensive business services. Indeed, as shown in Figure 1 more than 40\% of employees in IT and other communication services were already working from home regularly or at least with some frequency in 2018 in the EU-27. The share of regular or frequent remote employees was above $30 \%$ in a range of knowledge-intensive business services, as well as in education and publishing activities. It was also high - around 20\% - in telecommunications, finance, and insurance. Conversely, the share of remote employees was rather low in administrative and support services, as well as in the sectors that involve the physical manipulation of materials and/or objects, such as manufacturing.

Until the COVID-19 outbreak, remote work had mostly been used by high-skilled employees who do most of their work on computers, enjoy high degrees of autonomy, and are employed in knowledge-intensive activities. Within this group, the highest prevalence of remote work was found among teachers $(43 \%)$ - largely reflecting the occasional time spent at home preparing for face-to-face classes and coursework. ICT professionals, managers and professionals working in legal, business, administration, and science also showed similarly high rates of remote working (see Fig. 2)

Beyond the nature of their work, high rates of remote working before the pandemic among some professionals may also reflect the extent to which they performed informal overtime work at home, as well as the fact that some of them are more likely to work as self-employed. This is particularly the case for professionals (e.g. lawyers) who can more easily determine their own work schedules and pace of work. More generally, differences in rates of remote work across professions reflect the fact, that depending on the work content, some tasks can be performed easily from home (e.g. write a prescription), while others not or with more difficulty (e.g. visit a patient). 
For many other people remote work is an almost new experience. The confinement has likely induced a spread of remote work among employees who, despite working intensively with ICT, so far had only limited experience with this form of work organisation. For instance, in 2018, less than $20 \%$ of ICT technicians and $10 \%$ of general keyboard employees and other support employees had experienced some form of remote work.

Prevalence of remote work by occupation can be seen in Figure 2.

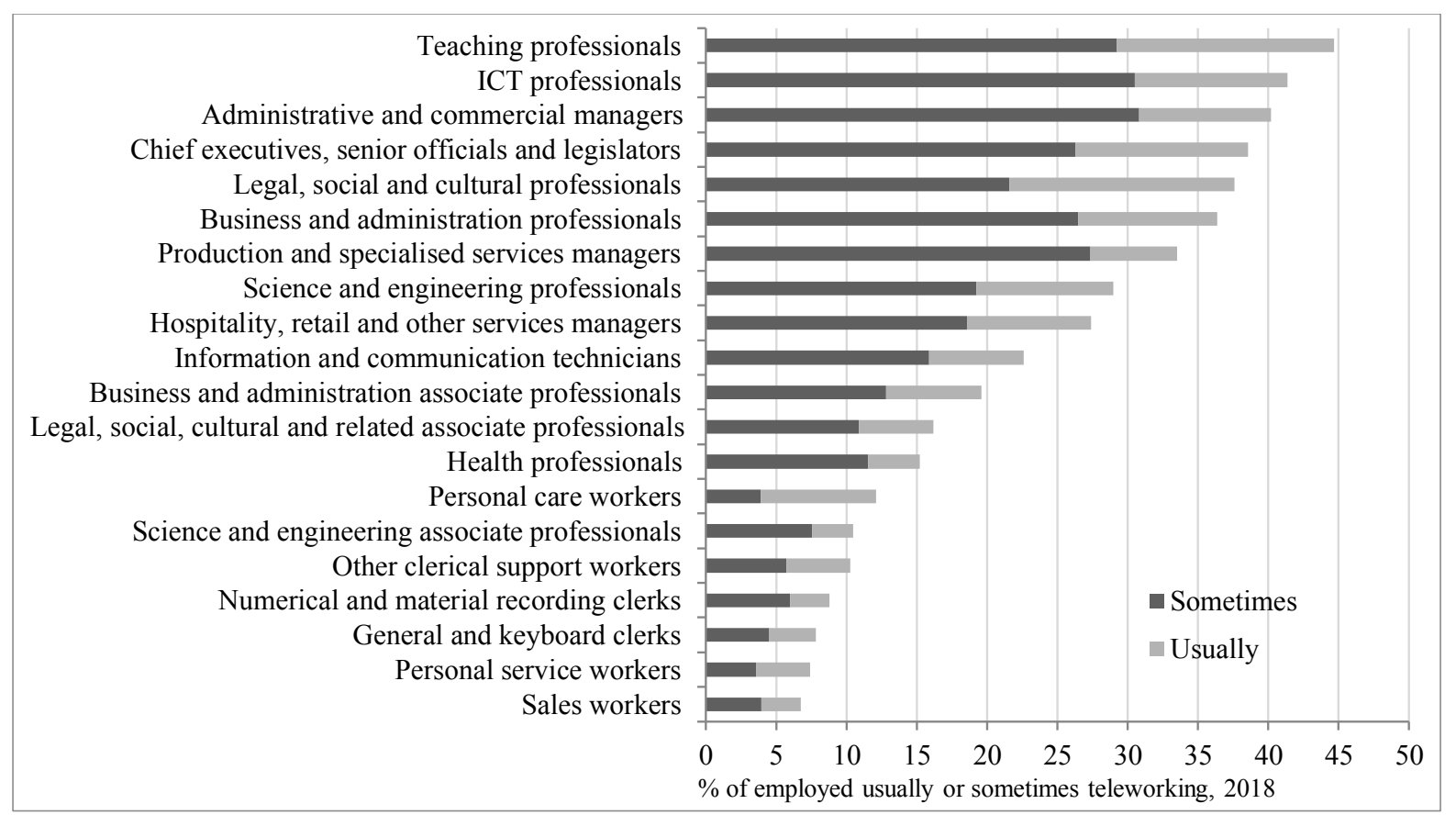

Source: Milasi, Fernandez-Macias, Gonzalez-Vazquez, 2020

\section{Fig. 2. Prevalence of remote work by occupation, EU-27}

For example, many companies, lacking the right ICT infrastructures, may have found difficult to reorganise their work from home in the immediate aftermath of the outbreak. Furthermore, the fact that in several EU countries more than a half of those who are currently remote working had no prior experience arguably makes the transition even more difficult. This has important implications on employment, companies' work effort, and employees' well-being, at least in the short - to medium - term.

Customer services employees, keyboard employees, and junior professionals had much lower access to remote work than most managers and senior professionals, despite often showing similarly intensive use of computers at work. This can be partially explained by the fact that these employees are more often subject to close monitoring and supervision of their performance, and therefore have less autonomy over their working time and place.

As COVID-19 exacerbates the divide between those who can easily transition to working from home and those who cannot, inequality is set to increase, starting from an already high level. The median monthly earnings of managers and professionals - people who are now mostly working from home - are on average more than twice those of employees, such as assemblers, plant and machine operators, who mostly have to work onsite (Eurostat LFS, 2020).

Previous experience (Felsted, Henseke, 2017) can support the current large-scale transition to remote work triggered by COVID-19. For instance, since the pandemic began, countries where remote work was already more widespread have seen smaller drops in the number of online job advertisements. Unfortunately, some of countries most affected by the pandemic had a very low prevalence of remote work before the crisis. As of 2019 , the share of employed working from home regularly or at least sometimes was above $30 \%$ in a handful of countries, including Sweden, Finland, and the Netherlands, whereas it was below 10\% in half of EU Member States (Figure 3). Between these two extremes, there were countries such as Belgium, France, and Portugal where the share of remote work ranged from 15 to 24\%. Countries in Northern Europe showed the largest growth in the prevalence of remote work over the past decade, albeit sizable increases also took place in other Member States, notably in Portugal, Estonia, and Slovenia. (Milasi, Fernandez - Macias, Gonzalez-Vazquez, 2020) 


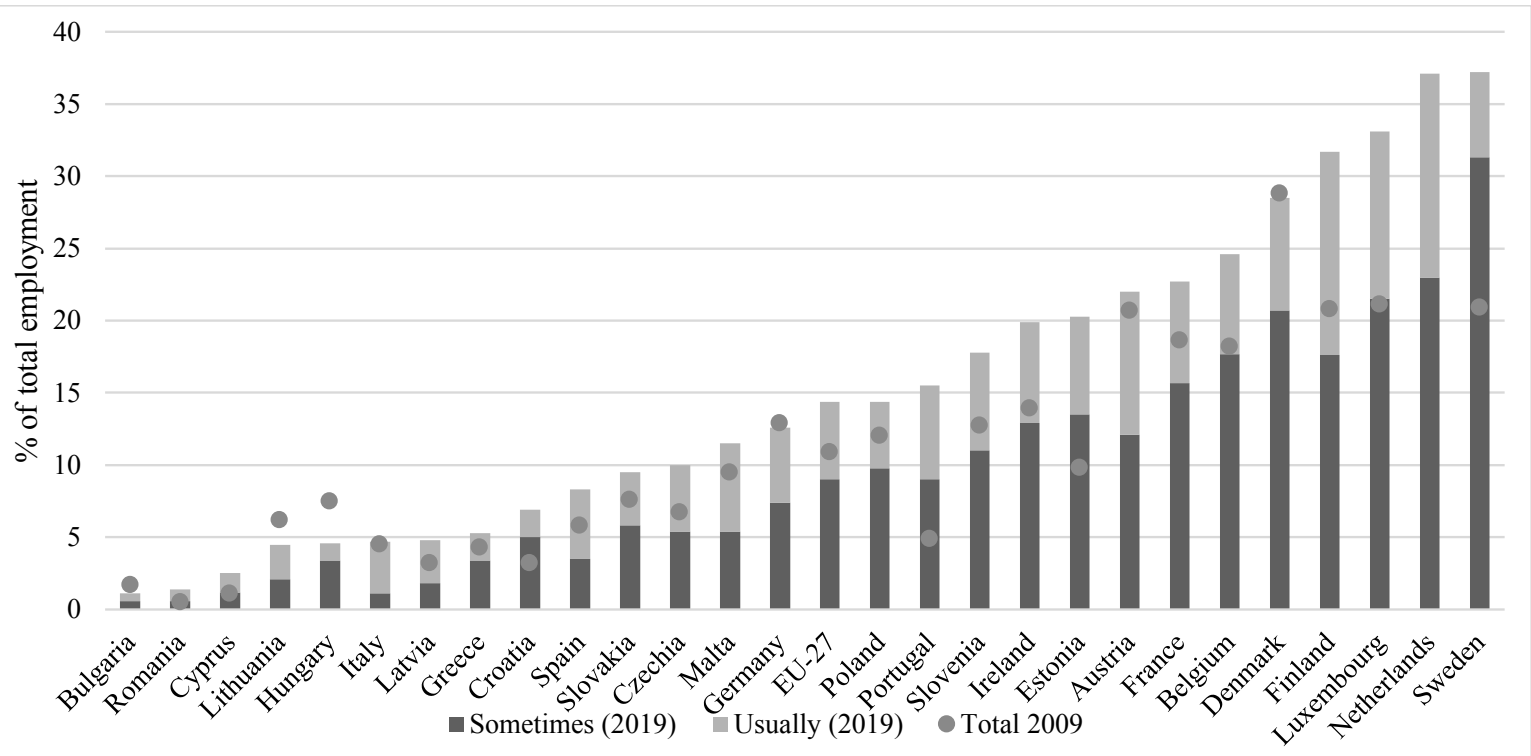

Source: Eurostat, LFS, 2020

Fig. 3. Prevalence of remote work across EU Member States

Differences within sectors: The occupational composition of sectors (see Figure 4), can be very different across EU Member States. For example, survey data shows, that the shares of high-skilled occupations in ICT and communication was close to $90 \%$ in Sweden, whereas this fraction was around $65 \%$ in France. As a result, the portion of employees in this sector who occasionally or regularly worked remotely in 2018 was as high as $70 \%$ in Sweden and only around 40\% in France (see Figure 3.). However, even within the same professional occupation, the prevalence of remote work can vary considerably across countries. For instance, while more than $60 \%$ of ICT professionals in the Netherlands was regularly or occasionally working from home in 2018, only 32 and $11 \%$ were doing so in Germany and Italy, respectively. This suggests that employees in a given occupation can have more access to remote work in some countries than in others depending on management and supervisory styles, the organization of work, and country-specific policies regarding aspects such as work flexibility. Figure 4 shows Occupational mix and remote work by sector.

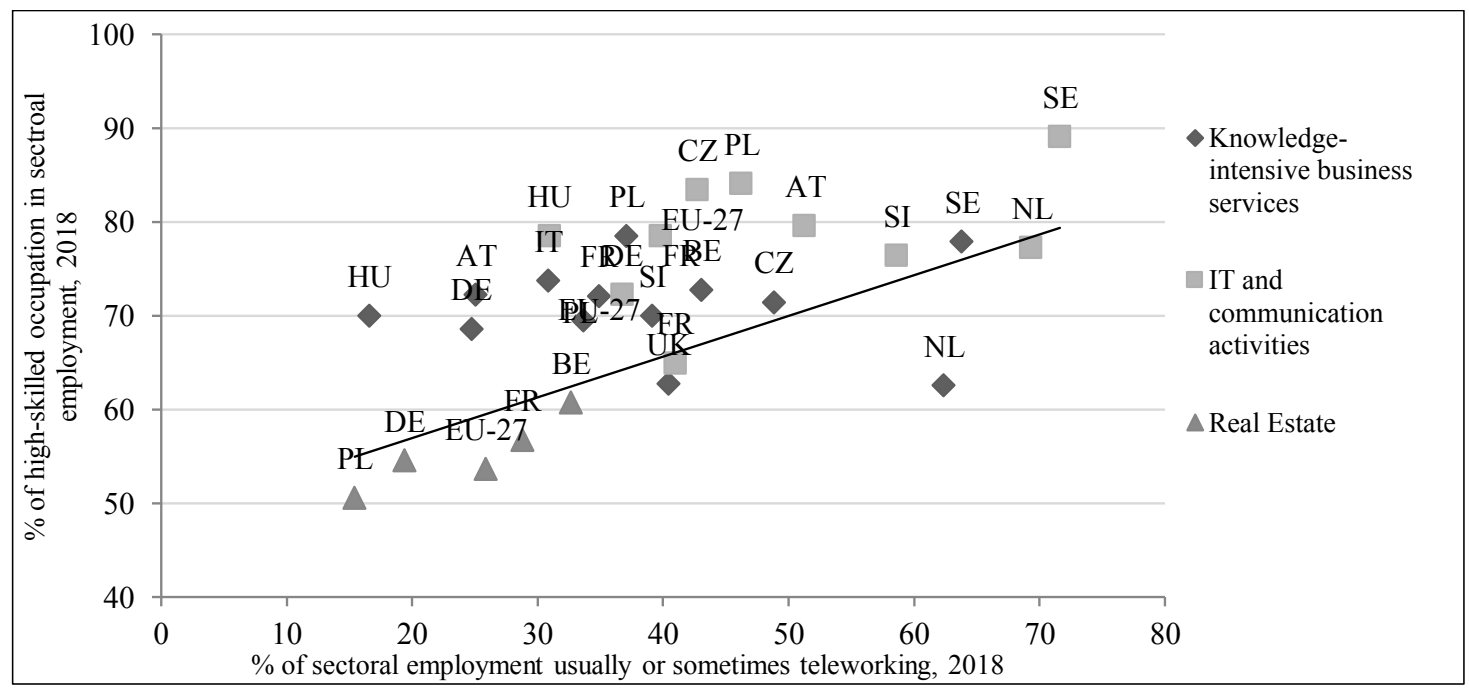

Source: authors, based on JRC calculations from Eurostat, ad-hoc extractions of EU-LFS data, 2020

Fig. 4. Occupational mix and remote work by sector

The distribution of employment by company size: Larger companies are typically more likely to adopt remote work than smaller ones. For instance, countries such as the Netherlands, Sweden, and Finland, where companies with 50+ employees accounted for a larger share of total employment in knowledge-intensive business services, showed before the pandemic a larger share of remote employees in that sector than countries like Italy and Croatia, where medium-large companies employed less than 15 per cent of employees in that sector. As the pandemic evolves, the adoption of remote work could be more difficult in countries and sectors where small companies account for larger shares of employment. 
Employees' digital skills: employees with strong digital skills are arguably better positioned to respond to the demands of remote work during COVID-19. Employees' level of digital skills, however, vary considerably across EU countries, tending to be lower in countries that had limited prevalence of remote work. For example, see Figure 5, in 2019, the share of employees in non-manual occupations with low or no digital skills ranged from $10 \%$ in the Netherlands to $40 \%$ in Bulgaria - against an average of $20 \%$ in the EU-27 as a whole (Milasi, Fernandez-Macias, GonzalezVazquez, 2020).

Remote work in the longer-term will depend on a broad range of factors, including its effect on work effort and working conditions, as well as its contribution to broader policy objectives such as Europe's digital and green transitions. Evidence suggests that in normally people working from home can sustain, or even enhance, their work effort, while enjoying a better work-life balance (Felsted, Henseke, 2017).

Yet, under the current exceptional circumstances work effort, working conditions, or both, may be deteriorating for many employees due to, among other problems, lack of childcare, unsuitable working spaces, and ICT tools.

Public policies and co-operation among social partners are crucial to ensure that new, efficient, and welfare-improving working methods, emerging during COVID-19, are maintained, and developed once physical distancing is over (OECD, 2020).

From September $1^{\text {st }}$ to $30^{\text {th }}, 2020$, the authors executed a research which aimed to detect the attitude of employees towards remote work. 395 inhabitants/respondents of Latvia took part in the survey. The respondents of this survey have worked remotely for different periods of time. Answering the question regarding the amount of time they worked remotely, the most popular response was "one year to four years" with $42 \%$ of respondents selecting it, followed by "more than four years" with $34 \%$ of respondents, then "less than six months" with $13 \%$ of respondents, and "six months to eleven months" with $11 \%$ of respondents. The survey participants were also asked regarding their work areas. $21 \%$ of the respondents pointed out that their job was related to IT. Other industries represented were: Retail (9\%); Marketing (9\%); Other (7\%); Financial Services (9\%); Media and Publishing (11\%); Education (14\%); E-commerce (6\%); Medical and Healthcare (2 \%); Consumer products (5\%); Travel and Tourism ( $2 \%)$; Non-profit organisations (1\%); Government organisations (2\%); Legal Services $(2 \%)$. In the framework of research authors identified professional spheres, according to the respondents' opinions, whether it would be acceptable to execute work remotely. Answers are categorised in the following way: $14 \%$ Engineering, $25 \%$ Marketing and Advertising. Other remote work options are: Finances (1\%), Human Resources (3\%); Data (9\%), Sales (4\%); Other (5\%); Customer Support (6\%); Product management (8\%); Operations (7\%); Design (7\%); Management (11\%).

The answer to the following question "Would you like to work remotely for at least some time?" were, that $98 \%$ or 387 respondents provided a positive answer, meaning that they would like to work remotely, and only $2 \%$ answered negatively. Since the respondents' attitude to remote work is mostly positive, $97 \%$ would also recommend others to work remotely. Figure 5 depicts the time respondents spent working remotely.

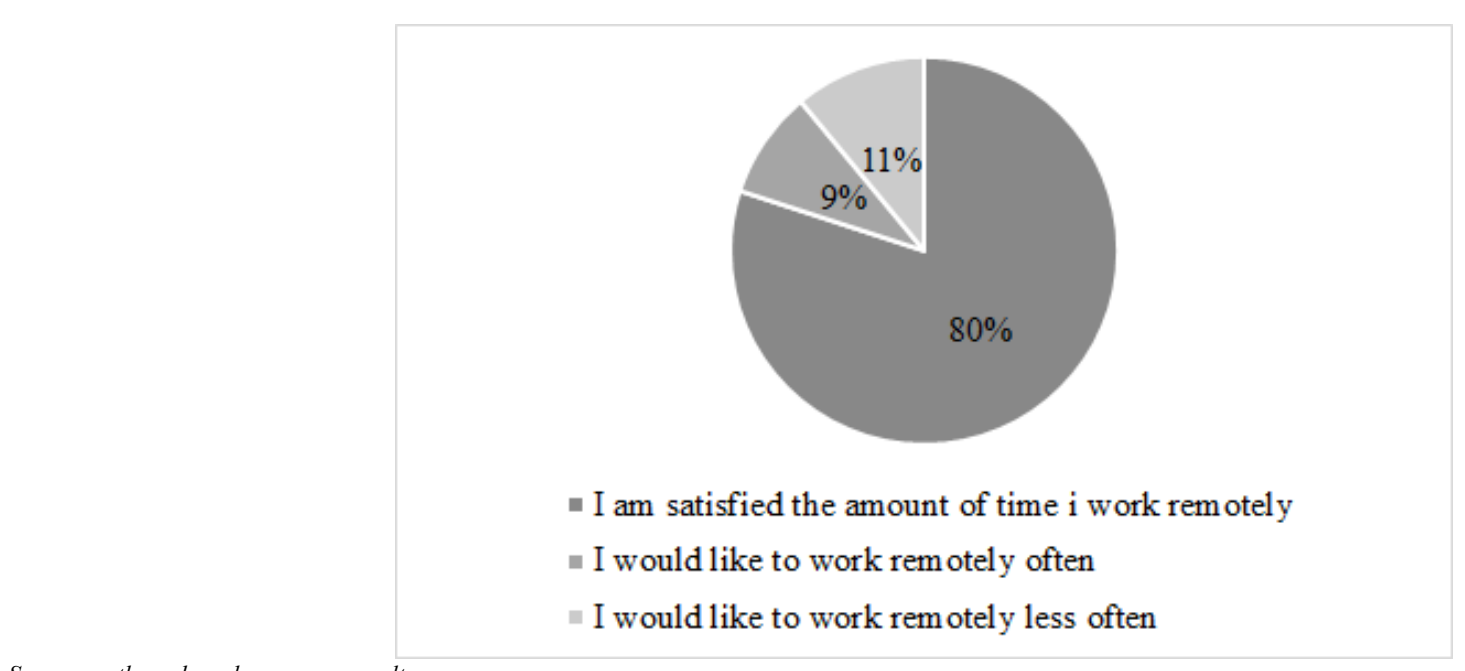

Source: authors, based on survey results

Fig. 5. Satisfaction with remote work

There are challenges that come with remote work, though they vary from person to person. In this context, challenges are difficulties in collaboration and the feeling of loneliness. $80 \%$ or 316 respondents pointed out that they were confident with the amount of time they are currently working remotely, $9 \%$ or 36 respondents would like to work remotely more often, and $11 \%$ or 43 respondents would like to work remotely less often. Respondents answers to the question: "What is the benefit of remote work"? are shown in Fig. 6. 


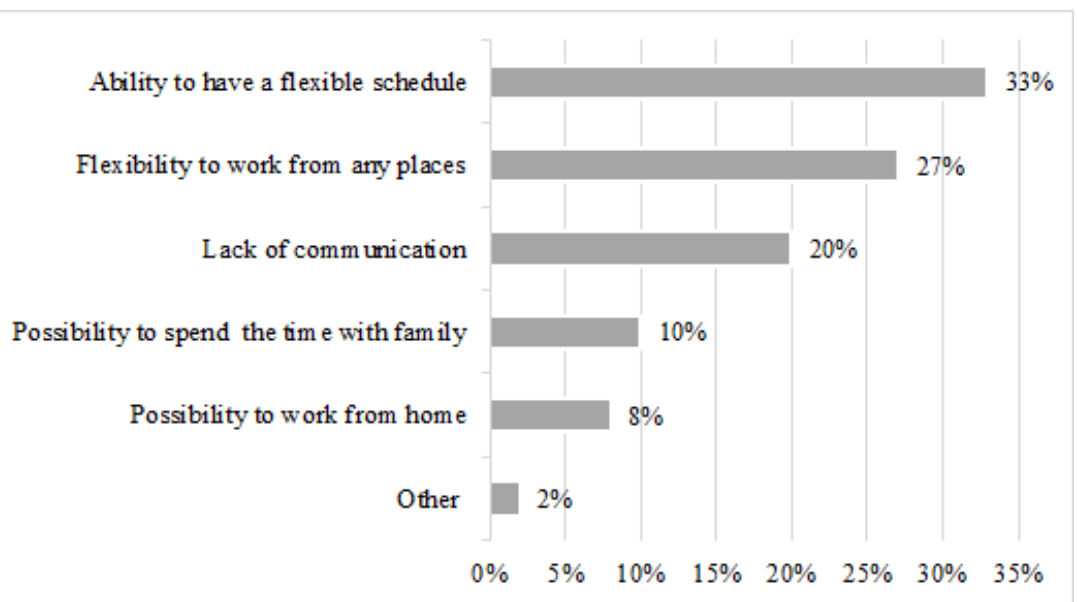

Source: authors, based on survey results

Fig. 6. The benefit of remote work

The primary benefit of remote work in this survey is flexibility. Concerning the challenge of the remote work, data is shown in Figure 7.

Source: authors, based on survey results

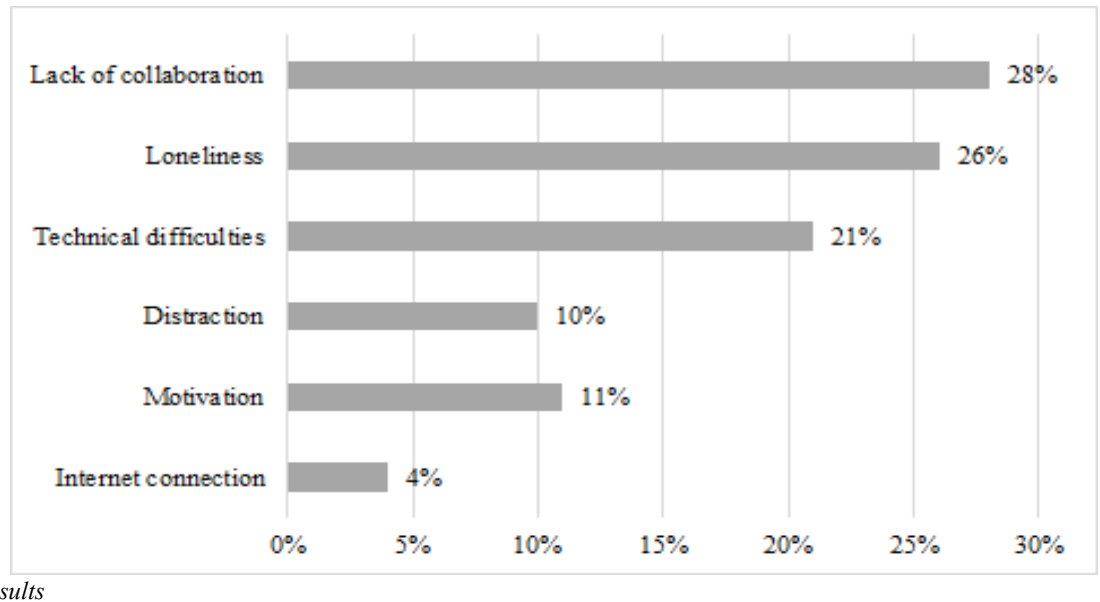

Fig. 7. Remote work challenges

The figure above shows that the most frequent answer was 'lack of collaboration"' (28\% or 111 respondents). $26 \%$ or 103 respondents pointed out loneliness as problem of remote work. $21 \%$ or 83 respondents were not able to switch and get concentrated on full time job. For $10 \%$ of the respondents it was a problem to due to distraction, $11 \%$ mentioned difficulty to stay motivated, and $4 \%$ do not have internet connection.

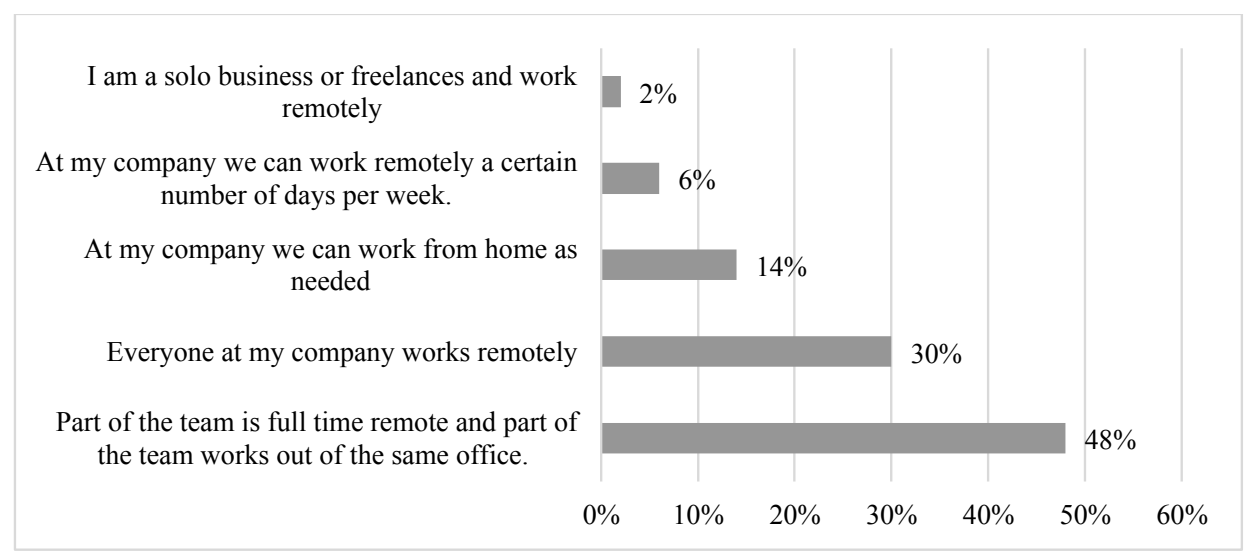

Source: authors, based on survey results

\section{Fig. 8. The workplaces stance on remote work or respondents}

Authors identified "why collaboration is a struggle when there are many collaboration tools", "why do some people not recommend remote work to others?", "how often do people would prefer to work remotely?". $53 \%$ of the respondents work remotely $100 \%$ of their work time. $17 \%$ work remotely from $76 \%$ until $99 \%$ of their work time. It turns out that a vast majority of respondents work remotely most of the time. When it comes to splitting work between remote work and office-based, the challenge of effective communication remains as an issue. It requires for the in 
digital collaboration tools across the organization. Remote work employees are happier when they spend more than $76 \%$ of their time working remotely.

Authors concluded that the more time respondents spend working remotely, the more they tend to be confident about it. The less time they spend working remotely, the less they are satisfied with it. Remote work allows to work from anywhere, thus, employees have the chance to travel while performing their work duties. The benefits of remote work are more than just convenience and work-life balance. Remote work is changing the future of work, it changes the future of global society actions.

Nowadays there are a lot of digital products and tools to solve the problem of remote work collaboration. The availability of endless tools helps remote work employees to better collaborate; these tools might primarily aim to support remote work teams. Many people are starting to work remotely while their company remains office based. In case not all employees are collaborating in the same way, it might be a challenge. Collaboration are still the core issue as it affects every employee.

In the survey, authors asked questions about specific remote work-related expenses that companies might cover for their remote employees. The expenses are such as household internet bills, drinks or food, and mobile phone bills. Over $70 \%$ of respondents have consistently selected "No" (their companies do not cover the expenses). Authors included an open-ended question asking respondents to share other expenses that their companies cover. Different answers were received, that fell into the categories such as: computers, office equipment, and software. It seems that companies are more likely to pay for the one-time expenses involved in remote work, like setting up a home office, and less likely to pay for recurring monthly bills like household internet, mobile phone.

The lack of affinities with digital tools and knowledge both in companies and among employees' and prior experience with remote work arrangements may limit its uptake and productivity. There is a danger that organisations respond to this challenge by using intrusive digital tools to monitor employees' work productivity, which has troubling implications in terms of job quality, privacy, and autonomy.

Companies often want to support their remote work employees but are unsure of what to provide and how to manage remote work specific policy. Even simple benefits like high-speed internet and equipment, which create the environment for work and engagement, are often difficult to implement. Recommendation to remote work employees in this situation is to communicate their needs to employers. Most employers are quite receptive but may lack the contextual information to make the employee perform at their best.

\section{Conclusion, recommendations}

1. Working remotely, monitoring work productivity is much more difficult and, thus, requires a higher level of trust. In this sense, the expansion of remote working could shift cultural and organizational norms, expanding levels of work autonomy, and making more accessible what so far has often been a privilege associated with high professional status.

2. The lack of companies and employees' affinities with digital tools and prior experience with remote working arrangements may limit its uptake and effectiveness. There is also a danger that organisations respond to this challenge by using intrusive digital tools which have troubling implications in terms of job quality, privacy, and autonomy.

3. Decisions concerning the introduction or implementation of remote work should be made in a transparent way, respecting the existing information and consultation structures and procedures. Remote work should be designed so that it is favourable both, for the company and for the employee.

4. Recognizing that the company has the right to issue guidelines on the proper use of its equipment and communication facilities, a remote worker has the same right as other employees in the company to communicate with his/her colleagues, using this equipment and facilities. This right must include communicating about matters relating to work, to which the remote worker belongs or with other bona fide personnel representatives.

5. As a rule, systems of compensation should be defined for costs generated by remote working. They should also cover insurance to cover damage to the equipment and any damage that may be caused to third parties or to the premises where the remote work is being carried out.

6. To maximise a welfare profit, characteristic for the use of wider remote work, management would have to invest into the remote work process organisation as well as solve possible problems connected with employees wellbeing in the context of long term remote work. 


\section{Bibliography}

Ashforth, B. E., Kreiner, G. E., Fugate, M., 2000. All in a Day's work: Boundaries and Micro Role Transitions. Academy of Management Review, $25,472-491$.

Bailey, D. E., Kurland, N. B., 2002. A Review of Telework Research: Findings, New Directions, and Lessons for the Study of Modern Work. Journal of Organizational Behavior, 23(4), 383-400.

Breaugh, J. A., Farabee, A. M., 2012. Telecommuting and Flexible Work Hours: Alternative Work Arrangements that Can Improve the Quality of Work Life. In W. Glatzer L. Camfield (Eds.), Work and Quality of Life-International Handbooks of Quality-of-Life (pp. 251-275). Dordrecht, The Netherlands: Springer.

Brimsek, T. A., Bender, D. R., 1995. Making Room for the Virtual Office. Association Management, 47(12), 71-75.

Brussevich, M., Dabla-Norris, E., Khalid, S., 2020. Who will Bear the Brunt of Lockdown Policies? Evidence from Tele-workability Measures Across Countries, IMF Working Paper, No. WP/20/88.

Dumas, T. L., Sanchez-Burks, J., 2015. The Professional, the Personal, and the Ideal Worker: Pressures and Objectives Shaping the Boundary between Life Domains. The Academy of Management Annals, 9, 803-843.

Eddleston, K. A., Mulki, J., 2015. Toward Understanding Remote Workers Management of Work-Family Boundaries: The Complexity of Workplace Embeddedness. Journal of Group and Organization Management, 42(3), 346-387.

Eurostat, LFS, 2020. COVID-19: Statistics serving Europe. [Online] Available at: https://ec.europa.eu/eurostat/data/database?node_code=lfsa_ehomp [Accessed 12.10.2020].

Eurostat, ICT Usage Survey, 2020. Work from Home, from an External Site or on the Move. [Online] Available at:http://appsso.eurostat.ec.europa.eu/nui/show.do?dataset=isoc_iw_hem\&lang=en[Accessed 12.10.2020].

EU Science Hub, 2020. Coronavirus Pandemic Reveals Large Differences in the Prevalence of Telework Across the EU. Available at https://ec.europa.eu/jrc/en/news/coronavirus-pandemic-reveals-large-differences-prevalence-telework-across-eu_[Accessed 12.09.2020].

Fernández-Macías, E., Fana, M., Tolan, S., Torrejón, S., Brancati, C., 2020. The COVID Confinement Measures and EU Labor Markets. Available at: https://ec.europa.eu/jrc/en/publication/covid-confinement-measures-and-eu-labour-markets [Accessed 05.10.2020].

Gajendran, R. S., Harrison, D. A., 2007. The Good, the Bad, and the Unknown about Telecommuting: Meta-Analysis of Psychological Mediators and Individual Consequences. Journal of Applied Psychology, 92(6), 1524.

Golden, T. D., Veiga, J. F., Simsek, Z., 2006. Telecommuting's Differential Impact on Work-Family Conflict: Is there no Place Like Home? Journal of Applied Psychology, 91, 1340-1350.

Kossek, E. E., Kalliath, T., Kalliath, P., 2012. Achieving Employee Wellbeing in a Changing Work Environment: An Expert Commentary on Current Scholarship. International Journal of Manpower, 33, 738-753.

Kurland, N. B., Bailey, D. E. 2000. Telework: The Advantages and Challenges of Working Here, There, Anywhere, and Anytime. IEEE Engineering Management Review, 28(2), 49-60.

Milasi, S., Fernandez - Macias, E., Gonzalez-Vazquez, I., 2020. Telework in the EU Before and After the COVID-19: Where We were, Where We head to. Available at: https://ec.europa.eu/jrc/sites/jrcsh/files/jrc120945 policy brief__ covid and telework_final.pdf [Accessed 11.09.2020].

Mulki, J., Bardhi, F., Lassk, F., Nanavaty-Dahl, J., 2009. Set up Remote Workers to Thrive. MIT Sloan Management Review, 51, 63-69.

Nilles, J.M., 1994. Making Telecommuting Happen: A Guide for Telemanagers and Telecommuters. Van Nostrand Reinhold: New York.

Nippert-Eng, C. E., 1996. Home and Work. Chicago, IL: University of Chicago Press.

OECD, 2020. Supporting People and Companies to Deal with the COVID-19 Virus: Options for an Immediate Employment and Social-Policy Response, OECD Policy Responses to Coronavirus (COVID-19). [Online] Available at: http://www.oecd.org/coronavirus/policyresponses/supporting-people-and-companies-to-deal-with-the-covid-19-virus-options-for-an-immediate-employment-and-social-policy-responsed33dffe6/ [Accessed 07.09.2020].

Olson-Buchanan, J. B., Boswell, W. R., 2006. Blurring Boundaries: Correlates of Integration and Segmentation Between Work and Nonwork. Journal of Vocational Behavior, 68, 432-445.

Productivity Gains from Teleworking in the Post COVID-19 Era: How Can Public Policies Make it Happen? Available at https://read.oecdilibrary.org/view/?ref=135_135250-u15liwp4jd\&title=Productivity-gains-from-teleworking-in-the-post-COVID-19-era [Accessed 10.09.2020]. 
Martinez, A., 2016. Remote and On-Site Knowledge Worker Productivity and Engagement: A Comparative Study of the Effect of Virtual Intensity and Work Location Preference. Available at https://etd.ohiolink.edu/!etd.send_file?accession=case1459176938\&disposition=inline [Accessed 02.09.2020].

Messenger, J., Gschwind, L., 2016. Three Generations of Telework: New ICTs and the (R)evolution from Home Office to Virtual Office. New Technology. Work and Employment, 31(3), 195-208.

Shellenbarger, S., 1994, Jan 1., Overwork, Low Morale Vexes the Mobile Office. Wall Street Journal: B1.

Sostero, M., Milasi, S., Hurley, J., Fernandez-Macias, E., Bisello, M., 2020. Telework Ability and the COVID-19 Crisis: a New Digital Divide? A Joint European Commission-Eurofound Report. Available at https://ec.europa.eu/jrc/sites/jrcsh/files/jrc121193.pdf [Accessed 02.09.2020].

Tolbert, P. S., Simons, T., 1994. The Impact of Working at Home on Career Outcomes of Professional Employees.

Verbeke, A., Schulz, R., Greidanus, N., Hambley, L., 2008. Growing the Virtual Workplace: the Integrative Value Proposition for Telework. Edward Elgar Publishing.

Wight, V. R., Raley, S. B., 2009. When Home Becomes Work: Work and Family Time Among Workers at Home. Social Indicators Research, 93, 197-202 


\section{EMPLOYER BRANDING PECULIARITIES FROM A GENERATIONAL PERSPECTIVE: CASE OF BALTIC STATES}

\section{Annija Apsite, University of Latvia}

Abstract. Companies have currently acknowledged that it does matter, how current and potential employees see them. Several companies see that they can develop their competitive advantage by creating and sustaining an attractive image of the company. It takes more than beautiful promises, future illusions and lovely pictures of the company - it has to be a culture based on certain values, which are attractive for the potential and current employees. It certainly is especially important for companies, who are operating in fields, where there is a lack of high skilled workers and where headhunting is inevitable. In the existing literature most of the researches are about attracting employees. However, being able to attract is as equally important as being able to create and sustain the loyalty of the current employees since low job satisfaction leads to high employee turnover and thus lower productivity. The aim of the research is determine, which are the most important work-related factors, which employees evaluate as attractive. The method used in the research is survey method with over 6000 respondents from the Baltic States. The results show that there are statistically significant differences among different age groups - although almost all given factors were evaluated as either very important or rather important by all age groups, there are different priorities depending on the age and stage of the career of respondents.

Keywords: employer brand, organizational values, job satisfaction.

JEL Code: M14, J28

\section{Introduction}

Companies have acknowledged that it does matter, how current and potential employees see them. If at the beginning of 19th century labour force was perceived as an extension of machines, then nowadays the tables seem to have turned and labour force is not only an important resource, but it can be as a great advantage for many companies due to the specifics of their industry. Several companies see that they can develop their competitive advantage by creating and sustaining an attractive image of the company. It takes more than beautiful promises, future illusions and lovely pictures of the company - it has to be a culture based on certain values, which are attractive for the potential and current employees. It certainly is especially important for companies, who are operating in fields, where lack of high skilled workers is prominent and headhunting inevitable. In author's opinion, however, employer branding is not only a mean of ensuring that the company will have proper employees, but also a way how to make sure that the needs of employees will be met, thus there is a greater chance that emotional and physical needs, while also their professional ambitions will have a higher chance of realisation. The main questions of the research are which of the employer branding elements are the most important ones for employees and how does age influence the results? The findings of the research are important for the Baltic countries particularly since employer branding as a term has not yet been widely used and there has not been enough attention brought to the particular topic. Currently there is a very limited scientific attention towards employer branding topic in the Baltic States and this is the first extensive research particularly in Latvian labour force market. In order to reach the aim of the research the author analyzed the results from the conducted survey in spring 2020 by using statistical methods of analysis using SPSS. The sources used to create a theoretical background for the research are scientific articles of the employer branding topic. The limitations of this research include the geographical limitations - the respondents in the survey come from Latvia, Lithuania and Estonia, thus there could possibily be different results for other geographical locations. Also, there can be a risk that there could be elements missing, which could possibly influence the perception of a company.

Clearly, after having the results of the research, there is a discussion, how to implement the results in the practice of the companies and until what extent should companies adapt the results into their strategy. However, in author's opinion it is especially important for the human resource management to have a clear overview of the elements, which are important not only for labour force as such, but also for specific age groups. Thus, it can help not only to build the strategy of the employer brand, but also to be able to apply the data, when building the motivation strategy for employees. Also, it could be worth to take a deeper analysis and see not only how age influences the choices of the potential employee, but also gender, education, industry and other factors.

\section{The concept of employer brand in the literature and the role of generational differences}

Although there have been similar ideas as employer branding before, employer brand as a term attained a concrete definition and reached more attention only after 1996, when Ambler and Barrow published a research paper with the same title. Authors schematically showed the connection between employees and products that they create - they believe that good employees are a prerequisite in order to sustain entrepreneurship in a 
good quality, that in order to create a good quality product it is necessary to have high level employees. They define employer brand as a „the package of functional, economic and psychological benefits provided by employment, and identified with the employing company. Until 1996 the terms used to describe similar ideas were corporate culture \& identity, internal marketing and corporate reputation. Backhaus however points out that over time, there has been a shift in the employer branding literature. At the very beginning employer branding did not focus on the desire of an organization to be the "employer of choice." Ambler and Barrow came up with the employer brand concept as value-neutral, an employer brand was simply a brand identity that help to characterize the employer. The shift can be noticed in the definition of other scholars (Martin et al. 2011, pp.3618-19), who define employer brand as "a generalized recognition for being known among key stakeholders for providing a high quality employment experience, and a distinctive organizational identity which employees value, engage with and feel confident and happy to promote to others"

Aggerholm et al. in their research also created a framework of how they see, what employer branding is particularly in sustainable organizations. They are suggesting "a dynamic link between the corporate strategy and the merging of corporate branding, strategic HRM and CSR as integrated communicative processes in sustainable organizations" (Aggerholm et al, 2011).

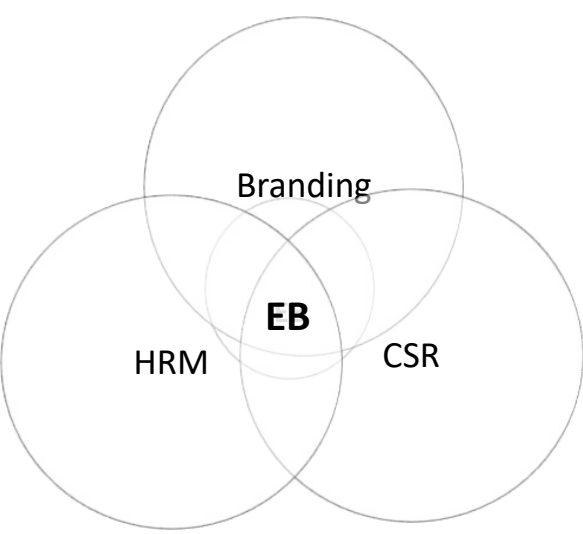

Source: created by author based on Aggerholm et al. (2011)

Fig. 1. Employer branding processes in sustainable organizations

In author's opinion employer brand is a perception of the company - a mix of the activities that the company does or is involved in creates an image, which then is individually processed and creates a certain perception of the particular company. The way, how the individual will perceive the company is dependent not only on objective attributes, but also on subjective attributes, which include personal values, wishes and aspirations.

In 2003 The Economist conducted an employer brand survey among readers over the world, including HR professionals. The most common definitions of the employer brand were:

1) promotion of a special image of the company as an employer

2) part of corporate advertising

3) appearance and content hiring announcement,

thus we can clearly see that the perception of the term employer brand differs from an individual to individual (Kucherov, 2012).

Which elements could make the company attractive as a potential employer? In the current literature there is a limited classification of employer brand attributes. There are researchers, who see employer brand elements as both rational and emotional (Mosley, 2007), while Lievens (Lievens, 2007) offers a division of symbolic and instrumental elements. However, Kucherov (Kucherov, 2012) offers to group employer brand elements into four groups:

1) Economic elements (a decent salary, fair system of bonuses and rewards, a convenient work schedule, stable guarantees of employment)

2) Psychological elements (strong corporate culture, a good team-work, objective assessment of work, positive interaction and interpersonal relations in company)

3) Functional elements (work content, opportunities to have a growth in career, training perspectives, opportunities to make a full use of the skills and knowledge of employees) 
4) organizational elements (leadership in market segment, reputation of the company, products and top-managers, managements style, scope of activity (local or international)).

There is also an important part of researchers, who have created a concept of employer brand dimensions. Some of the researchers see employer brand as consisting of 5 dimensions, while others - as a term consisting from 12 dimensions. For example, in a research done in 2017, researchers came up with 5 dimensions which constitute employer brand - growth and development opportunity, company's reputation, acceptance and belongingness, work-life balance and ethics and CSR. They also found a meaningful linkage between intention to join and the perception of employer brand. (Sharma, 2018) While Hillebrandt and Ivens in 2013 (Hillenrband, et al, 2013) published an article, where they had come up with 12 dimensions of employer brand respectively - culture, teams spirit, tasks, international environment and career, benefits, reputation, work and life balance, training and development, clients, versatility, autonomy and corporate social responsibility.

Looking at employer brand in the generational perspective, studies about the generational issues have increased in the past decade in the academic and managerial literature (Benson, et al. 2011; Constanza, 2012; Lyons, et al. 2014). The key idea for the existing researches is that there might be significant differences between generations currently in the labour market, which could cause not only internal conflicts within the workplace, but "could also bring the need for rethinking people management practices, such as recruitment, compensation, development, performance assessment, and feedback, among others" (Reis et al., 2015). Studies point out that at least three generations interact in the workplace today, the Baby Boomers, Generation X, and Generation Y or the so called Millenials. There are apparent differences among researchers about the time cuts for each generation, the start and end years differ for some years, but generally they are as follows - Baby Boomers (1946-1964), Generation X (1965-1980) and Millenials (1981-1996).

However, it is notice to point out that most of the studies are done in United States, while others are also from Canada and Australia, thus it is important not to overgeneralize and to see whether the current results and conclusions of the existing research is compatible with different cultural environments. For example, in the case of Baby Boomers and Generation X, who were born in the time span of 1946-1964 and 1965-1980 respectively there were important environmental and cultural differences between aforementioned countries and the USSR. For example, Sandeen (Sandeen, 2008), an American researcher, in her paper describes Baby Boomers (1946-1964) as people of the time of great optimism, at the time children became the main focus of this generation and that this was the first generation to enjoy the benefits of television and other advancements of technology.

\section{Empirical research of the employer brand in the Baltic States}

The survey was conducted in 2020 by headhunting company Amrop in cooperation with sociological research company Factum. Their aim was to detect, which companies are the most favourable in the market and why. However, the data offers an extensive range of further analysis to evaluate how do different factors like age, gender, education, country affiliation and other factors influence, for example, what is important and what isn't important for potential employees. In the context of this research, the author has chosen to analyse the generational differences and to evaluate if there is a statistically significant difference on what different generations perceive important for them.

As a result of the survey, Amrop received data from 5095 respondents from Latvia, Estonia and Lithuania. Similarly as mentioned in the literature review, 4 groups of elements were chosen to describe employer brand - Rational benefits, Job Characteristics, Social values and benefits and Employer reputation and Image (Image 2.1.) and under each of the elements several element-characterizing factors were offered for respondents. Respondents were asked to evaluate each of the factors in the following scale: "Not important at all", "Rather not important", "Rather important", "Very important" and "Can't say". 
A list of employer brand elements used for the research

\begin{tabular}{|c|c|c|c|}
\hline Rational benefits & Job characteristics & Social values and benefits & $\begin{array}{c}\text { Employer reputation and } \\
\text { image }\end{array}$ \\
\hline $\begin{array}{ll}\text { 1. } & \text { Competitive/fair base } \\
\text { salary } \\
\text { 2. }\end{array}$ & $\begin{array}{l}\text { 7. Reasonable amount of } \\
\text { work } \\
\text { 8. Convenient location } \\
\text { 9. Good working conditions } \\
\text { 10. Flexible or convenient } \\
\text { working hours } \\
\text { 11. Care on job safety issues } \\
\text { 12. Possibility to receive } \\
\text { training and further } \\
\text { education } \\
\text { 13. Good opportunities for } \\
\text { professional development } \\
\text { 14. Interesting and versatile } \\
\text { work tasks, } \\
\text { responsibilities } \\
\text { 15. Possibility to work from } \\
\text { home } \\
\text { 16. Good relationship and } \\
\text { cooperation with direct } \\
\text { superior } \\
\text { 17. Autonomy in tasks' } \\
\text { execution }\end{array}$ & $\begin{array}{l}\text { 18. Good internal } \\
\text { relationship, friendly } \\
\text { environment } \\
\text { 19. Organisation's values } \\
\text { are in line with your } \\
\text { personal values } \\
\text { 20. This job makes you } \\
\text { feel good about } \\
\text { yourself, more self- } \\
\text { confident } \\
\text { 21. Organisation will value } \\
\text { and make use of your } \\
\text { skills and talents } \\
\text { 22. Creative and dynamic } \\
\text { work environment } \\
\text { 23. Dynamic internal } \\
\text { environment - team } \\
\text { activities, healthy life } \\
\text { style promoting } \\
\text { activities, sports } \\
\text { 24. Interesting industry } \\
\text { sector }\end{array}$ & 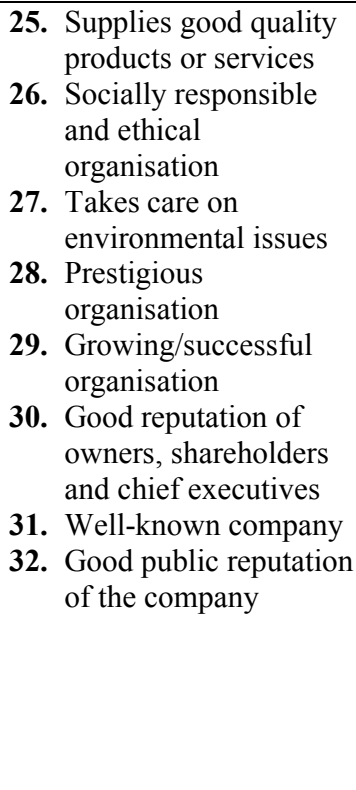 \\
\hline
\end{tabular}

Source: author's creation based on survey used for the research

It should also be mentioned that due to the fact that the available data is separated into three age groups - 18-30, 30-50, 50+, there partly is an overlap of the generations within the age groups. According to theory 18-30 age group refers mostly to Millennials, who are born in the time span between 1981-1996, the group 30-50 consists of a mix of early Millennials and Generation X, while in the group 50+ there is a mix of early Generation X and Baby Boomers. Since there aren't strict and generally accepted time cuts for each generation, it does not interfere with the ability to make conclusions about generational differences.

\section{Results}

The results show that most of the respondents are in the age group 31-50 (2609), who are followed by the age group 51+(1706) and 18-30 (780). Also, most of the respondents (3364) have attained higher education and 52\% of the respondents are females, while 47\% are males. From all respondents $58.4 \%$ are working either full time or part time, the others are either entrepreneurs $(8.4 \%)$, students, temporarily not working, retired or have never been employed and are not working now as well.

First of all, author took a look at which employer brand elements are the most important ones and which elements are less important. It is possible to conclude that on average none of the elements were evaluated as "not important at all", which means that the elements chosen for the research are meaningful for the respondents. Another conclusion is that there is a difference on meaningfulness for respondents, when comparing the 4 great subgroups - rational benefits, job characteristics, social values and benefits and employer reputation and image. Further author will analyse each subgroup separately.

In the following tables author has indicated the most popular answer within the particular age group. Also, author has added indexes ${ }^{\mathrm{a}},{ }^{\mathrm{b}}, \mathrm{c}$ for every factor. Index a shows that there are no statistically significant differences among all three age groups. The index ${ }^{\mathrm{b}}$ shows that there are slight differences among groups, where usually one group stands out of the others, while the index ${ }^{c}$ shows statistically significant differences among all three age groups. 


\section{Evaluation of rational benefits in the generational cut}

Rational benefits Competitive/fair base salary ${ }^{\text {a }}$ Overtime pay/compensation ${ }^{\mathrm{c}}$ Performance related bonuses $b$ Good promotion opportunities $\mathrm{c}$

Good reference for future career International career opportunities, foreign assignments $\mathrm{b}$
18-30

\begin{tabular}{ccc} 
Very important $(79.2 \%)$ & Very important $(80.1 \%)$ & Very important $(77.7 \%)$ \\
Very important $(62.9 \%)$ & Very important (44\%) & Very important $(53.2 \%)$ \\
Very important $(47.8 \%)$ & Very important $(55.6 \%)$ & Very important $(51.7 \%)$ \\
Very important $(49.2 \%)$ & Rather important $(43.2 \%)$ & Rather important 40.6\%) \\
Very important $(43.2 \%)$ & Rather important (42.7\%) & Rather important 39\%) \\
\hline Rather not important (31\%) & Rather important (31.7\%) & Rather not important \\
\end{tabular}

Source: author's created using data of the survey

As stated before, in the table it is possible to see, which was the most popular answer within the particular age group. Clearly rational benefits are statistically more important for the younger generation than it is for older respondents. The factor, which happened to have similar answer division between "rather important" and "rather not important" and was similarly comparatively low evaluated, was "international career opportunities and foreign assignments". While competitive/fair base salary happened to be the most important factor for all age groups and there are no statistically significant differences among age groups.

Table 3

From the

\section{Evaluation of job characteristics elements in the generational cut}

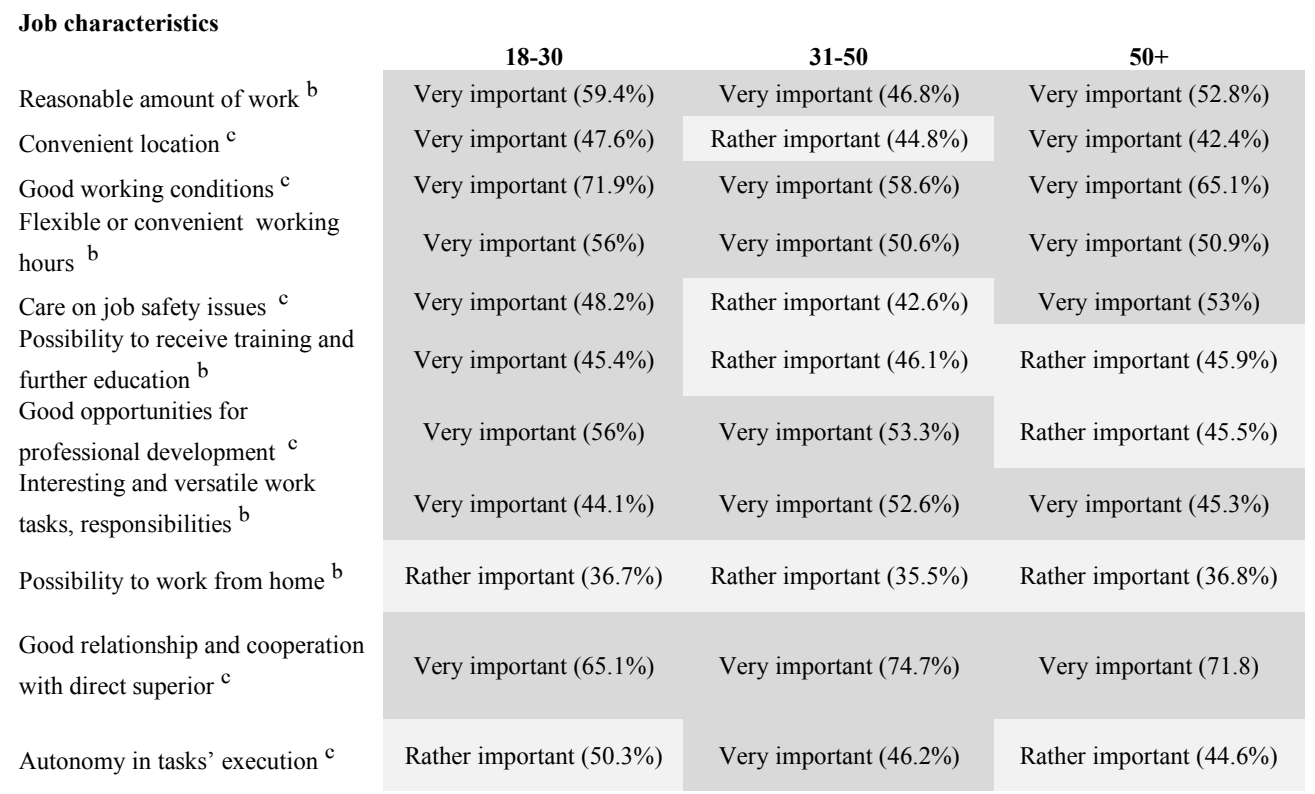

Source: author's created using data of the survey

Table 4 it is possible to conclude that for younger people elements of job characteristics are more important than for older respondents as the most popular answer was "very important" in 9 out of 11 elements. The most important elements for all age groups was good working conditions and good relationship and cooperation with direct superior, while comparatively the least important factor of job characteristics elements was possibility to work from home. However, in all age groups all elements of job characteristics were on average evaluated as at least rather important. What is specific about this particular group of elements is that for all elements there are either slight or large statistically significant differences among the age groups. 
Table 4

\section{Evaluation of the elements social values and benefits in the generational cut}

\begin{tabular}{|c|c|c|c|}
\hline Social values and benefits & 18-30 & $31-50$ & $50+$ \\
\hline $\begin{array}{c}\text { Good internal relationship, friendly } \\
\text { environment }{ }^{b}\end{array}$ & Very important $(65.8 \%)$ & Very important (64\%) & Very important $(69.5 \%)$ \\
\hline $\begin{array}{c}\text { Organisation's values are in line with } \\
\text { your personal values } \mathrm{c}\end{array}$ & Rather important (45\%) & Very important $(51.9 \%)$ & Very important (46.2\%) \\
\hline $\begin{array}{l}\text { This job makes you feel good about } \\
\text { yourself, more self-confident }{ }^{\text {a }}\end{array}$ & Rather important (57.1\%) & Very important (55.1\%) & Very important (53.1\%) \\
\hline $\begin{array}{l}\text { Organisation will value and make use } \\
\text { of your skills and talents } c\end{array}$ & Very important $(51.7 \%$ & Very important $(60.7 \%)$ & Very important $(56.1 \%)$ \\
\hline $\begin{array}{c}\text { Creative and dynamic work } \\
\text { environment }\end{array}$ & Rather important (47.4\%) & Rather important (47.5\%) & Rather important (48.8\%) \\
\hline $\begin{array}{l}\text { Dynamic internal environment - } \\
\text { team activities, healthy life style } \\
\text { promoting activities, sports } b\end{array}$ & Rather important (39.5\%) & Rather important (44.7\%) & Rather important $45 \%$ ) \\
\hline Interesting industry sector $b$ & Rather important (44.5\%) & Rather important (47.7\%) & Rather important (49\%) \\
\hline
\end{tabular}

Source: author's created using data of the survey

In the Table 4 it is possible notice that all of the elements are either rather important or very important for all age groups. Some of the social values and benefits are more important for all age groups than others. The most important elements are good internal relationship, friendly environment and organisation that will value and make use of one's skills and talents. While creative and dynamic work environment, dynamic internal environment and interesting industry sector are all evaluated a bit lower - as rather important. Although for the element "This job makes you feel good about yourself, more self-confident" the dominating answer is slightly different among age groups, overall the statistical differences are insignificant. Insignificant differences among age groups are also for the element "creative and dynamic work environment". However, significant statistical differences among all age groups are for 2 elements marked with the index “c”.

Table 5

\begin{tabular}{|c|c|c|c|}
\hline $\begin{array}{l}\text { Employer reputation and } \\
\text { image }\end{array}$ & $18-30$ & $31-50$ & 50+ \\
\hline $\begin{array}{l}\text { Supplies good quality } \\
\text { products or services }\end{array}$ & Rather important (44.5\%) & Very important (48.1\%) & Very important $(46.3 \%)$ \\
\hline $\begin{array}{l}\text { Socially responsible and } \\
\text { ethical organisation } b\end{array}$ & Rather important (48.8\%) & Rather important (48.6\%) & Rather important (47.1\%) \\
\hline $\begin{array}{c}\text { Takes care on environmental } \\
\text { issues } b\end{array}$ & Rather important (49.2\%) & Rather important (51.9\%) & Rather important $(50.7 \%)$ \\
\hline Prestigious organisation ${ }^{a}$ & Rather important (44\%) & Rather important (46.2\%) & Rather important $47.5 \%)$ \\
\hline $\begin{array}{c}\text { Growing/successful } \\
\text { organisation }^{b}\end{array}$ & Rather important (49.9\%) & Rather important (53.1\%) & Rather important (53.7\%) \\
\hline $\begin{array}{c}\text { Good reputation of owners, } \\
\text { shareholders and chief } \\
\text { executives } b\end{array}$ & Rather important (45.6\%) & Rather important (48.9\%) & Rather important (51.1\%) \\
\hline Well-known company $b$ & Rather important (35.9\%) & Rather not important (39.3\%) & Rather important (42.4\%) \\
\hline $\begin{array}{l}\text { Good public reputation of the } \\
\text { company }\end{array}$ & Rather important (51.3\%) & Rather important $(52.6 \%)$ & Rather important $(50.5 \%)$ \\
\hline
\end{tabular}

The fourth group "Employer reputation and image" is clearly different with the fact that although within all age groups the average evaluation of almost all elements is "rather important", overall this is the least important group of elements for respondents in the Baltic States. In author's opinion it indicates a tendency that respondents are more concerned with those elements, which have a direct influence on them and which aren't 
emotionally that distant for them, which leads to results that elements like reputation and CSR are not equally important. Another conclusion is that within the $4^{\text {th }}$ group of elements the differences among age groups are the least significant.

To sum up, the data proves that there are statistically significant generational differences among age groups - they have different priorities, aspirations, needs and experience, which determine how their priorities of their potential employee are being shaped.

\section{Conclusions, proposals, recommendations}

It is possible to notice that job characteristics as one of the 4 components of employer branding is the most important component for all age groups. It is especially important for younger generation, who are still at the beginning of their career and it is important for them to make sure that the particular employee they choose will contribute to their future career as well. It is also possible to conclude that social values and benefits are slightly more important for older generations. When analysing particular elements, which happen to be the most important ones overall, it is possible to conclude that the greatest attention has been given to the following elements:

1) Competitive/fair base salary, as well as overtime compensation

2) Good working conditions

3) Good relationship and cooperation with direct superior

4) Good internal relationship and friendly environment

5) Reasonable amount of work

6) Flexible working hours

In the following research it could be possible to also measure the differences between other variables as gender, education level, occupation and other factors. As well, it could be possible to measure the differences among the Baltic States to see whether labour force has different priorities in Latvia, Estonia and Lithuania. Also, for the future analysis of the generational differences among employees author has planned to use several other statistical research methods as data mining or cluster analysis to receive even more detailed results and to test the current results with other methods.

It is still also an open discussion whether the differences among age groups are due to different stages of career or are they really different due to peculiarities specific to each of the generations.

\section{Bibliography}

Aggerholm, H., Andersen, S., Thomsen, C., 2011. Conceptualising Employer Branding in Sustainable Organisations. Corporate Communications: An International Journal. 16. 105-123. 10.1108/13563281111141642.

Ambler, T., Barrow, S., 1996. The Employer Brand. Journal of Brand Management. 4, 185-206.

Benson, J., Brown, M., 2011. Generations at Work: Are There Differences and Do They Matter? International Journal of Human Resource Management, 22(9), 1843-1865. doi:10.1080/09585192.2011.573966

Constanza, D. 2012. Generational Differences in Work-related Attitudes: a Meta-analysis. Journal of Business Psychology, 27, 375-294. doi:10.1007/s10869-012-9259-4

Hillebrandt, I., Ivens, B.S., 2013. Scale Development in Employer Branding. Impulse für die Markenpraxis und Markenforschung, Sringer Fachmedien, Wiesbaden, pp. 65-86.

Kucherov, D., Zavyalova, E., 2012. HRD Practices and Talent Management in the Companies with the Employer Brand. European Journal of Training and Development, 36(1), 86-104. https://doi.org/10.1108/03090591211192647.

Lievens, F., 2007. Employer Branding in the Belgian Army: The Importance of Instrumental and Symbolic Beliefs for Potential Applicants, and Military Employees. Human Resource Management, 46(1), 51-69.

Lyons, S., Kuron, L., 2014, Generational Differences in the Workplace: A Review of the Evidence and Directions for Future Research. Journal of Organizational Behavior, 35(1), S139-S157. doi:10.1002/job.1913

Martin, G., Gollan, P. J., Grigg, K., 2011. Is There a Bigger and Better Future for Employer Branding? Facing Up to Innovation, Corporate Reputations and Wicked Problems in SHRM. International Journal of Human Resource Management, 22, 3618-3637. doi:10.1080/09585192.2011.560880

Mosley, R., 2007. Customer Experience, Organizational Culture and the Employer Brand. Journal of Brand Management, 15(2), 123-134. 
Reis, G.G., Braga, B.M., 2016. Employer Attractiveness from a Generational Perspective: Implications for Employer Branding. Revista de Administraçã, 51(1), 103-116. https://doi.org/10.5700/rausp1226.

Sandeen C., 2008, Boomers, Xers and Millenials: Who are They and What Do They Really Want from Continuing Higher Education? Continuing Higher Education Review, 72, 11-31.

Sharma R., Prasad A., 2018. Employer Brand and its Unexplored Impact on Intent to Join. International Journal of Organizational Analysis, 26(3), 536-566. 


\section{REGIONAL DIFFERENCES AND CHALLENGES OF SUBJECTIVE WELL-BEING IN LATVIA DURING THE COVID-19 PANDEMIC FIRST WAVE}

Elina Apsite Berina, University of Latvia

Girts Burgmanis, University of Latvia

\section{Toms Skadins, University of Latvia \\ Liga Feldmane, University of Latvia \\ Zaiga Krisjane, University of Latvia}

Abstract. We investigate regional differences of the Covid-19 pandemics and the extent subjective well-being (SWB) of the population of Latvia has been effected. Using a local population survey during the first wave of Covid-19 outbreak and employing econometric computations, we derive shifts in typical behavioural patterns and estimate regional differences for the challenges of SWB. This paper is constructed around two main research questions. 1) How national emergency regionally has affected overall subjective well-being in Latvia and to what extent income drop is responsible for this? 2) To what extent Covid-19 has affected aspects of individuals' daily life patterns and remote work?

Our findings make an original contribution by revealing that SWB has decreased in the capital, and densely populated regions in Latvia. Among the negatively influencing aspects in regional variation, we find change of income level, remote work and need to engage in the educational process. Such aspects of daily life behaviour patterns as work-life balance, alcohol usage and work regime shows variations among the regions. We conclude that during the first wave emergency, the well-being of residents of core parts of the country was affected more compared to other regions.

Keywords: subjective well-being, regional differences, Latvia, Covid-19.

JEL code: $131, \mathrm{R} 2$

\section{Introduction}

Since early 2020 Europe had to face and find innovative ways to respond to the challenges raised by the Covid-19 pandemic. Uncertainty arising with the "wicked problem" (Logue, 2009; Cohen and Cromwell, 2020) - the uncontrollable spread of the virus has thoroughly affected groups of populations globally (Cheng et al. 2020). Besides medical implications or virus itself, also lockdown measures introduced by numerous governments substantially has affected the economic and social conditions of the population. There are several studies related to the aspects of subjective wellbeing under the impact of Covid-19 (Cheng et al. 2020; Brand et al., 2020; Hu et al. 2020; Blasco-Belled et al. 2020; Möhring et al. 2020; Fao et al. 2020; Pieh et al., 2020). Most studies employ the term of subjective well-being relating to the adverse effects on mental health (Martínez et al. 2020) escalating the level of stress, increasing emotional misbalance (Brooks et al. 2020; Holmes et al. 2020), well-being in families (Prime et al. 2020).

The paper provides timely evidence of the Covid-19 imposed challenges to the subjective well-being issues at the regional level in Latvia. Relying on survey "Behaviours and attitudes in response to the Covid-19 pandemic" data during the first wave of Covid-19 pandemic in March and April 2020, we examine:

1. How national emergency regionally has affected overall subjective well-being in Latvia and to what extent income drop is responsible for this?

2. To what extent Covid-19 has affected aspects of individuals' daily life patterns and remote work regionally?

The paper is structured around literature review of the aspects of subjective well-being which are examined regionally with the particular attention to the impacts of Covid-19 first wave. Besides the description of the methodological approach, the main results are discussed. Firstly, we evaluate emergency state impact on the subjective well-being and income drop reported in this period. Secondly, look at the extent to which Covid19 pandemic affected individual daily life and remote work patterns at the regional level.

\section{Literature review}

The research on human happiness is proliferating, and some sources even present a new field of science, the science of happiness, which aims to measure happiness, identify the main factors of influence and determine their relative importance (Ballas, Tranmer, 2012). Although the concept of happiness was initially associated with psychology for many decades, in recent years it has been explored in interdisciplinary research, in fields of economics, sociology, politics, management science, and also in geography. 
Recent studies show that human happiness could be conceptualize through unifying term - "subjective well-being" related to several aspects of lives of people (David et al., 2014; Ballas, Tranmer, 2012). Subjective well-being mostly is interpreted as a combination of various aspects of human life that can be measured including family, work, health (Kau and Wang, 1995), demographical variables (Keng et al., 2000), consumption, wages and rents, land plots, local amenities (Ballas, Tranmer, 2012).

Thus subjective well-being is a multidimensional concept, and in literature, subjective well-being has been conceptualised most often in two main dimensions (for example, Maggino, 2015; Pittau et al., 2009): the cognitive dimension and the affective dimension. The cognitive dimension most frequently is understood as satisfaction with life as whole or different life domains. In contrast, the affective dimension is associated with either positive or negative range of emotions and affect related to particular activities or situations in life, for example, work and family. However, sometimes third dimension or eudemonic well-being in the literature is identified (Kapteyn et al., 2015), which is related to psychological needs, such as autonomy, personal growth, or purpose in life.

The concept of subjective well-being has been studied also in Latvia, and it is not considered a homogeneous concept also among local researchers. Subjective well-being is usually seen as a subjective assessment of life, which is at the same time an integrative indicator of the quality of the objective conditions of existence (Koroleva, 2011). Also in Latvia subjective well-being is most often identified with life satisfaction, happiness, success and achievements (Koroḷeva, 2011; Lonska, 2013; Feldmane et al., 2018), at the same time it is just one of the components of life quality (Sīlis, 2010).

Several authors studying cognitive dimension of subjective well-being or life satisfaction have found a correlation between the place of residence and the satisfaction of the population with life in general. For example, a survey of citizens in European countries shows that there are differences in life satisfaction between countries and regions (Pittau et al., 2010). Northern European countries, such as Denmark, Sweden, the United Kingdom, Ireland and Finland, have more stable and consistently higher levels of satisfaction, while southern European countries - Spain, Portugal, Italy, Greece - have lower levels of satisfaction. Although the study analysed several variables of regional characteristics and numerous income and employment rates, it was found that there is also an unexplained regional level impact on life satisfaction. Aforementioned confirms that geographical location must be taken into account as a factor influencing the level of satisfaction of the population. Furthermore, it was found that in developing countries and regions, life satisfaction is more related to economic factors, while in rich regions it is more related to intangibles or the 'culture' factor (Pittau et al., 2010).

\section{Data and Methods}

In this research, we combine officially available statistical data from two sources. Firstly, we chronologically explore Government decisions related to COVID-19 pandemic outbreak in Latvia, which is provided by the Cabinet of Ministers. Secondly, we work with the data compiled by the Centre for Disease Prevention and Control of Latvia (Slimību profilakses un kontroles centrs or SPKC) showing the main trends of Covid-19 cases over time. Data mentioned above can be accessed for further analysis from the Latvian Open data portal.

Besides the analysis of the available statistical data, we explore the results from a survey which took place in May - July 2020. The total number of survey respondents is 1473 . The survey was organised as a computer-assisted web interview and geographically cover all regions of Latvia. Upon the survey design stratification by gender and age of the population, on a regional level, as well as on urban and rural levels was performed.

The questionnaire included questions related to the changing patterns of typical behaviour patterns; overall impact of Covid-19 initiated a nationallevel state of emergency on the aspects of well-being as well as the level of threat individual's experience. Moreover, for this study aforementioned key subjects were analysed according to the division of the statistical regions of Latvia.

Descriptive statistics of the survey sample are shown in Table 1. Respondents are divided into groups based on their geographic location and based on their socio-demographic and socio-economic characteristics and compared among those who acknowledge the positive or negative impact of Covid-19. 
Characteristics of the survey sample. Descriptive statistics

\begin{tabular}{|c|c|c|c|}
\hline Variable & $\begin{array}{l}\text { Positive Covid- } \\
19 \text { impact }\end{array}$ & $\begin{array}{c}\text { Negative } \\
\text { Covid-19 } \\
\text { impact }\end{array}$ & $\begin{array}{c}\text { Total } \\
\%\end{array}$ \\
\hline \multicolumn{4}{|l|}{ Gender } \\
\hline Men & $48 \%$ & $52 \%$ & $48,9 \%$ \\
\hline Women & $41 \%$ & $59 \%$ & $51,1 \%$ \\
\hline \multicolumn{4}{|l|}{ Age group } \\
\hline $18-24$ years old & $47 \%$ & $53 \%$ & $10,3 \%$ \\
\hline 25-34 years old & $43 \%$ & $57 \%$ & $21,9 \%$ \\
\hline 35-44 years old & $46 \%$ & $54 \%$ & $22,0 \%$ \\
\hline $45-54$ years old & $43 \%$ & $57 \%$ & $22,4 \%$ \\
\hline 55- 64 years old & $43 \%$ & $57 \%$ & $23,4 \%$ \\
\hline \multicolumn{4}{|l|}{ Educational level } \\
\hline Primary education & $42 \%$ & $58 \%$ & $1,8 \%$ \\
\hline Secondary education & $47 \%$ & $53 \%$ & $11,5 \%$ \\
\hline Vocational education & $50 \%$ & $50 \%$ & $14,9 \%$ \\
\hline Tertiary education & $45 \%$ & $55 \%$ & $71,8 \%$ \\
\hline \multicolumn{4}{|l|}{ Occupational status } \\
\hline Employed & $45 \%$ & $55 \%$ & $85,3 \%$ \\
\hline Unemployed & $38 \%$ & $62 \%$ & $6,8 \%$ \\
\hline Retired & $31 \%$ & $69 \%$ & $5,0 \%$ \\
\hline Students, pupils & $56 \%$ & $44 \%$ & $2,9 \%$ \\
\hline \multicolumn{4}{|l|}{ Region } \\
\hline Riga & $46 \%$ & $54 \%$ & $33 \%$ \\
\hline Vidzeme & $47 \%$ & $53 \%$ & $10 \%$ \\
\hline Kurzeme & $44 \%$ & $56 \%$ & $12 \%$ \\
\hline Zemgale & $36 \%$ & $64 \%$ & $12 \%$ \\
\hline Latgale & $42 \%$ & $58 \%$ & $13,5 \%$ \\
\hline Pieriga & $47 \%$ & $53 \%$ & $19,5 \%$ \\
\hline \multicolumn{4}{|l|}{ Household type } \\
\hline Single households & $47 \%$ & $53 \%$ & $17,4 \%$ \\
\hline Larger households & $43 \%$ & $57 \%$ & $82,6 \%$ \\
\hline
\end{tabular}

Source: Authors' survey "Behavioural patterns and attitudes towards the Covid-19 pandemic in Latvia", 2020, N=1473

Majority of respondents indicate a more negative Covid-19 impact, though, among groups, the distribution between positive and negative impact does vary. Also, for some groups, the opinion is split, or more respondents indicate a positive impact.

Both men and women tend to have a more negative view on the impact of Covid-19, with a higher share for the latter group. The pessimistic view is prevalent among all age groups. However, the youngest group and respondents aged 35-44 have slightly more positive respondents. All but one educational group has a more pessimistic view on the impact. There are some notable differences in terms of economic status. Unemployed and retired respondents are more negative than those who are employed. Interestingly, the majority of students consider the impact to be positive. As for the regional divide, once again, there are more negative respondents among all groups, though the share of negative responses varies considerably. The analyses of survey data employ descriptive statistics methods. Chi-square tests were used to evaluate differences between groups. The software of PASW Statistics 20 was used for the analysis. Econometric data analysing methods such as 1) Pearson Chi-square tests and 2) analysis of variance (factorial two-way ANOVA and factorial one-way ANOVA) were used in this study. 
To study the factors affecting subjective well-being, we designed an additive index of well-being that include seventeen variables on aspects affecting respondents' emotional, physical, social, workplace and societal well-being during the emergency when COVID-19 outbreak happened in spring. All variables on how the emergency affected various behaviours were obtained from the survey and measured in Likert scale, namely (1) did not affect at all, (2) somewhat not affected, (3) rather affected and (4) affected significantly. Each of the questionnaire answers was given 1 to 4 points. Each respondent could thus accumulate a maximum score of 68 points for this aspect of the questionnaire. Next, for each individual, we calculated the additive index of subjective well-being (mean total value points). Thus, the level of each individual's subjective well-being could range between 1 and 4 . The acquired index was used as the dependent variable in further analysis. The acquired index was used as the dependent variable in further analysis. The purpose of constructing a subjective well-being index was to determine whether or not the region of residence and the change of income level during the emergency affects the well-being of residents.

\section{Research results and discussion}

National lockdown measures in Latvia were effective from March 12, 2020, until June 9 when the presumed first wave of the outbreak ended. This was similar to other European countries which introduced suggested lockdown measures in mid-March (Möhring et al. 2020). At the beginning of the emergency, there were six new confirmed cases, as shown in the chronological summary of the main events (Table 2). In total, until June 9, 1089, persons got infected.

Table 2

Timeline of key dates and events during the COVID-19 outbreak in early 2020

\begin{tabular}{|c|c|c|}
\hline $\begin{array}{l}\text { March } 12 . \text { A state of } \\
\text { emergency is declared. } \\
\text { Number of new confirmed } \\
\text { cases }-6 \text {. }\end{array}$ & $\begin{array}{l}\text { March } 17 \text {. International } \\
\text { passenger transport is } \\
\text { suspended. Number of } \\
\text { confirmed cases - } 23 \text {. }\end{array}$ & $\begin{array}{l}\text { March } 25 . \text { Ex panded } \\
\text { precautions are } \\
\text { implemented Number of } \\
\text { confirmed cases - } 24 \text {. }\end{array}$ \\
\hline $\begin{array}{l}\text { March } 29 . \text { Stricter rules of } \\
\text { social distancing are } \\
\text { introduced. Number of } \\
\text { new confirmed cases }-42 \text {. }\end{array}$ & $\begin{array}{l}\text { April } 7 . \text { State of } \\
\text { em ergency is ex tend until } \\
\text { May } 15 . \text { Number of } \\
\text { confirmed cases - } 6 \text {. }\end{array}$ & $\begin{array}{l}\text { May } 7 . \text { State em er gency is } \\
\text { ex tended to June } 9 \text {. } \\
\text { Number of confirmed } \\
\text { cases }-9 \text {. }\end{array}$ \\
\hline $\begin{array}{l}\text { May } 15 . \text { Travel between } \\
\text { Baltic states is allowed. } \\
\text { Number of new confirmed } \\
\text { cases - } 8 \text {. }\end{array}$ & $\begin{array}{l}\text { June } 1 \text {. Activities in some } \\
\text { areas can place on-site. } \\
\text { Number of confirmed } \\
\text { cases - } 0 \text {. }\end{array}$ & $\begin{array}{l}\text { June } 9 . \text { Covid- } 19 \\
\text { emergency com es to an } \\
\text { end Number of confirmed } \\
\text { cases - } 1 \text {. }\end{array}$ \\
\hline
\end{tabular}

Source: Authors' compilation based on The Cabinet of Minister's data

Majority of municipalities ( 79 out of 119; almost 70\%) had at least one confirmed case by the time measures were lifted on June 9. Figure 1 shows the geography of total confirmed Covid-19 cases. Of those municipalities which had at least one confirmed case, nearly $80 \%$ had 10 cases or less. These municipalities were scattered all over the country. $20 \%$ of municipalities had 50 cases or less, and these included some of the largest urban areas, as well as two clusters of municipalities bordering Riga and in Northern Latvia. Riga had a higher share of confirmed cases, which accounted for over $50 \%$ of the total at the end of Covid-19 emergency. 


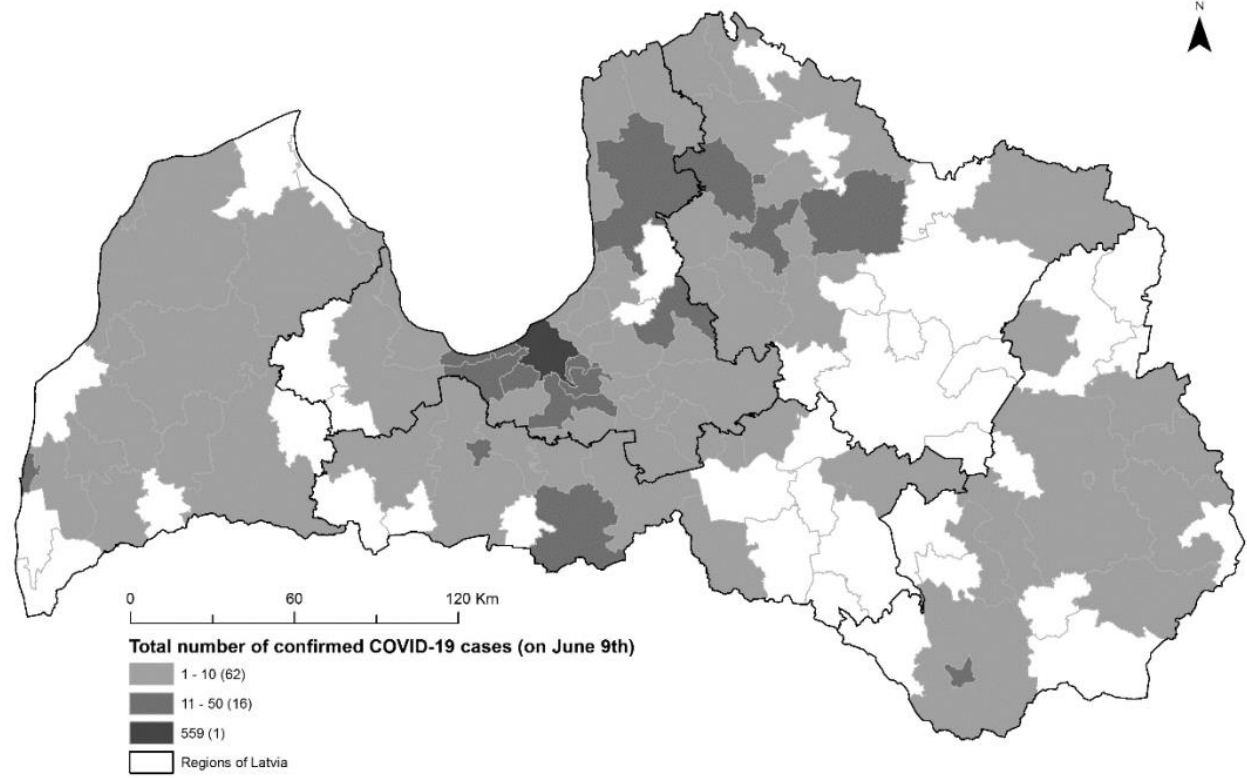

Source: authors' calculations, based on SPKC data

Fig. 1. The geography of confirmed Covid-19 cases in Latvia on June 9, 2020

RQ1: How national emergency regionally has affected overall subjective well-being in Latvia and to what extent income drop is responsible for this?

A factorial two-way ANOVA was conducted to compare the effects of the region of residence and change of prosperity as well as their interaction effects on the subjective well-being during the emergency initiated by the first wave of COVID-19 pandemic (see Table 3).

Table 3

Factorial two-way ANOVA model reports the effect of change of income and region of residence on the subjective well-being during the emergency

\begin{tabular}{ccccc}
\hline & $\boldsymbol{F}$ & $\boldsymbol{d} \boldsymbol{f}$ & $\boldsymbol{p}$ & $\boldsymbol{n} \boldsymbol{p}^{\mathbf{2}}$ \\
\hline Change of income & 6.64 & 3 & 0.000 & 0.012 \\
Region of residence & 9.32 & 5 & 0.000 & 0.017 \\
Change of prosperity x Region & 4.35 & 15 & 0.637 & 0.008 \\
Error & 540.18 & & & \\
\hline
\end{tabular}

Note: ${ }^{*} p<0.05 ;{ }^{* *} p<0.01$

Region of residence and change of income effects were statistically significant at $\mathrm{p}<0,001$. The main effect of the residence region yielded an effect size 0,017 , indicating that $1,7 \%$ of the variance in the well-being during the emergency was explained by region of residence. The main effect of change of income yielded an effect size of 0,012 , indicating that $1,2 \%$ of the variance in the well-being. The interaction effect was not significant, indicating that there was no combined effect for the region of residence and change of income on the well-being during COVID-19 emergency.

Post hoc comparison using Tukey HSD test indicated that during an emergency the well-being of residents living in Riga (M=2,62, $\mathrm{SD}=0,58)$ was affected significantly more than the well-being of residents living in Vidzeme $(\mathrm{M}=2,31, \mathrm{SD}=0,62)$, Kurzeme $(\mathrm{M}=2,45, \mathrm{SD}=0,63)$ and Latgale $(\mathrm{M}=2,40, \mathrm{SD}=0,61)$. At the same time, the well-being of residents living in Pieriga $(\mathrm{M}=2,55, \mathrm{SD}=0,59)$ and $\mathrm{Zemgale}(\mathrm{M}=2,51, \mathrm{SD}=0,56) \mathrm{did}$ not significantly differ from the well-being of residents living in Riga. There were also significant differences between the well-being of residents living in Pieriga, Vidzeme and Latgale; moreover, the well-being of those living in Pieriga was affected more during an emergency than for those who live in Vidzeme and Latgale.

Furthermore, post hoc comparison indicated that the well-being of residents whose prosperity decrease significantly during the emergency $(\mathrm{M}=2,74, \mathrm{SD}=0,66)$ was affected more than the well-being of residents whose prosperity decrease only little $(\mathrm{M}=2,54, \mathrm{SD}=0,59)$, did not change $(\mathrm{M}=2,47, \mathrm{SD}=0,59)$ and increase $(\mathrm{M}=2,55, \mathrm{SD}=0,61)$. 
RQ2: To what extent Covid-19 has affected aspects of individuals' daily life patterns and remote work?

An analysis of variance (see Table 4) showed that the effect of region of residence on individuals' daily life patterns and health during the emergency was significant. Results show that work-life balance $F(5,1717)=6,84, p=0,000$ alcohol usage $F(5,1717)=3,89, p=0,002$ and work regime $F$ $(5,1717)=3,890 \mathrm{p}=0,002$ of residents was affected differently in various regions along with the implementation of emergency. Such factors as regional differences in terms of values and beliefs, senses of loneliness, sleep and anxiety were not observed.

Table 4

One-way ANOVA model reports changes in aspects of individuals' daily life patterns and health during the emergency based on residents' region of residence

\begin{tabular}{|c|c|c|c|c|c|c|c|c|c|}
\hline & \multicolumn{3}{|c|}{ Work-life balance } & \multicolumn{3}{|c|}{ Alcohol usage } & \multicolumn{3}{|c|}{ Work regime } \\
\hline & $M$ & $S D$ & $F$ & $M$ & $S D$ & $F$ & $M$ & $S D$ & $F$ \\
\hline Riga & 2.66 & 0.99 & $\begin{array}{c}6.84 \\
* *\end{array}$ & 1.71 & 0.94 & $\begin{array}{c}3.89 \\
* *\end{array}$ & 2.79 & 1.07 & $\begin{array}{c}3.80 \\
* *\end{array}$ \\
\hline Vidzeme & 2.26 & 0.93 & & 1.59 & 0.80 & & 2.37 & 1.10 & \\
\hline Kurzeme & 2.58 & 1.05 & & 1.49 & 0.74 & & 2.60 & 1.14 & \\
\hline Zemgale & 2.67 & 0.96 & & 1.54 & 0.76 & & 2.70 & 1.10 & \\
\hline Latgale & 2.32 & 0.98 & & 1.52 & 0.73 & & 2.59 & 1.09 & \\
\hline Pieriga & 2.67 & 0.97 & & 1.75 & 0.89 & & 2.77 & 1.13 & \\
\hline
\end{tabular}

Post hoc comparison using Tukey HSD test indicated that during an emergency the balance between private and work life duties of residents living in Riga, Pieriga and Zemgale (for mean and standard deviation values see Table 2) were affected significantly more than for those residents who live in Vidzeme and Latgale. The alcohol usage was affected more for residents living in Riga and Pieriga comparing to those who live in Kurzeme. Finally, the work regime during the emergency was affected more for residents living in Riga and Pieriga than for those who live in Vidzeme.

Regional differences for several employment-related aspects are summed up in Table 5. Overall, the situation had been relatively uniform, as evidenced by the fact that most respondents from all regions did not experience temporary or permanent closure workplace. Whilst the differences in share were not as significant, only Pieriga region had more respondents who had either studied remotely or who were a parent of someone studying remotely. Share of those who worked remotely and those who did not were more similar than for the other three aspects. Still, only Riga and Pieriga region had more respondents who worked remotely, and differences in share for respondents from Kurzeme and Vidzeme were rather notable.

Regional differences among employment-related aspects

\begin{tabular}{|c|c|c|c|c|c|c|c|}
\hline & & Riga & Vidzeme & Kurzeme & Zemgale & Latgale & Pieriga \\
\hline & No & $44,5 \%$ & $64,5 \%$ & $72,8 \%$ & $56,5 \%$ & $58,8 \%$ & $47,9 \%$ \\
\hline Remote work*** & Yes & $55,5 \%$ & $35,5 \%$ & $27,2 \%$ & $43,5 \%$ & $41,2 \%$ & $52,1 \%$ \\
\hline & No & $62,1 \%$ & $70,9 \%$ & $61,1 \%$ & $63,3 \%$ & $57,3 \%$ & $48,6 \%$ \\
\hline $\begin{array}{l}\text { Remote education (as a } \\
\text { student or parent) } * * *\end{array}$ & Yes & $37,9 \%$ & $29,1 \%$ & $38,9 \%$ & $36,7 \%$ & $42,7 \%$ & $51,4 \%$ \\
\hline & No & $88,1 \%$ & $90,1 \%$ & $84,4 \%$ & $89,8 \%$ & $86,4 \%$ & $87,5 \%$ \\
\hline $\begin{array}{l}\text { Temporary closure of the } \\
\text { workplace }\end{array}$ & Yes & $11,9 \%$ & $9,9 \%$ & $15,6 \%$ & $10,2 \%$ & $13,6 \%$ & $12,5 \%$ \\
\hline & No & $97,7 \%$ & $99,3 \%$ & $96,7 \%$ & $96,6 \%$ & $94,5 \%$ & $97,2 \%$ \\
\hline $\begin{array}{l}\text { Permanent closure of the } \\
\text { workplace }\end{array}$ & Yes & $2,3 \%$ &, $7 \%$ & $3,3 \%$ & $3,4 \%$ & $5,5 \%$ & $2,8 \%$ \\
\hline
\end{tabular}


National statistical office of Latvia confirms that in Riga, one-third of employees were doing some form of remote work, until June the share dropped to nearly 25 per cent. In other territories, besides Riga, the overall share of remote workers was half of those as mentioned earlier. For example, in April 16,4 per cent of all employees were doing remote work and it decreased down to around 10 per cent by June 2020.

Similar to studies in other countries (Pieha et al., 2020; Kimhi et al., 2020), the results of our research indicate that subjective well-being has declined in Latvia among its residents during the early stages of Covid-19 pandemic. Although several of recent studies do not reveal regional differences in people subjective well-being and psycho-emotional state at this period (Zacher, Rudolph, 2020; Parsons Leigh et al., 2020; Smith et al., 2020), the results of research in Latvia indicate that regional factor should be taken into account. According to findings of our research the well-being of residents living in Riga, Pieriga and Zemgale were affected significantly more than the well-being of residents living in other regions, and it can be explained with several influencing factors.

Firstly, as it was observed in China, those residents who experienced more disruptions in daily life during lockdown would display more indicators of psychological ill-being (Zhou et al., 2020). In the case of Latvia during the first stage of the pandemic, Riga and Pieriga were the regions where the highest number of persons got infected with Covid-19. Besides findings of our research indicate that daily routine regarding working regime was affected significantly more in Riga, Pieriga and Zemgale than in other regions. According to recent studies (Mohring et al., 2020; Tuzovic, Kabadayi, 2020), remote working during pandemic has a direct negative impact on families' well-being. As a result, the people of these regions had a much more significant impact on the overall subjective well-being. At the same time, contrary to our results, a study in Italy reveals that residents of regions which were less affected by the pandemic were more emotionally affected because of the fear of the unknown (Buzzi et al., 2020).

Secondly, regional differences in subjective well-being can be explained by leisure opportunities. According to previous studies (Geng et al., 2020; Lades et al., 2020), the importance of outdoor activities in gardens, parks and other natural areas increased significantly during the early stages of Covid-19 pandemic and was associated with a positive effect to the physical and mental health and well-being of individuals. Therefore, it is not surprising that residents of smaller towns and rural areas with more open access to the leisure opportunities possibly are psychologically coping with the pandemic to a better degree than residents of more densely populated regions and big cities (Sturman, 2020; Zhang et al., 2020). In Riga and its suburban area, where approximately half of the country's population is concentrated (Apsite-Berina et al. 2020), access to natural objects and outdoor activities are more limited compared to less densely populated areas.

\section{Conclusions, proposals, recommendations}

The conclusions, drawn from the data analysis, are addressing the highly relevant topic on the regionally observed changes of subjective well-being during the first wave of Covid-19 outbreak in Latvia. The main findings of the study are:

1. Similar to other countries a significant decrease in the subjective well-being of the residents of Latvia has been observed during the early stages of COVID-19 pandemic, and findings of our research evidence that regional factor should be taken into account.

2. There are statistically significant regional differences for the change of income level uniform higher-income drop corresponds to a higher drop in subjective well-being, however, no combined effects of region and income drop on subjective well-being were found.

3. Regionally residents of geographical and functional core territories - Riga, Pieriga and Zemgale were more exposed to the negative effects of the Covid-19 lockdown measures, as it to a higher extent required changes in a daily routine.

4. It was found that work-life balance was significantly more disturbed to those living in a more densely populated core parts of the country. According to the study and also the latest statistical data, remote work was more common in Riga and Pieriga. Moreover, involvement in remote education has put additional pressure on the assessment of subjective well-being and work-life balance on those living in Pieriga region. Targeted emotional and practical local, regional or national level support to families with under aged children and those in full time employment would allow to harmonise daily work-life duties, particularly targeting exposed groups such as women, for example.

5. Regional differences in subjective well-being can be explained not only with changes in daily routine - remote work and education - but also with population density and outdoor leisure opportunities. Subjective well-being of residents is affected to a lesser extent in those regions where population density is lower and access to outdoor activities more open.

6. Further studies on the assessment of Covid-19 regional and individual impact would be recommended to provide new knowledge strategies employed for core and peripheral territories. 


\section{Bibliography}

Apsite-Berina, E., Burgmanis, G., Prusakova, L. 2020. Regional Human Capital Disequilibria: The Case of Youth Migration in Latvia. Folia Geographica, 18, 28-35. DOI: 10.22364/fg.18.4.

Attālināti nodarbināto darbinieku skaits // CSB. URL: https://www.csb.gov.lv/lv/statistika/covid19/attalinati-nodarbinato-darbinieku-skaits (access date: 1.12 .2020$)$.

Barnettf, Y., López-Sánchezg, G.F., Martinh, S., Butleri, L., Tullyj, M.A., 2020. Correlates of Symptoms of Anxiety and Depression and Mental Well-Being Associated with COVID-19: a Cross-sectional Study of UK-Based Respondents. Psychiatry Research, $291,113138$.

Blasco-Belled, A., Tejada-Gallardo, C., Torrelles-Nadal, C., Alsinet, C., 2020. The Costs of the COVID-19 on Subjective Well-Being: An analysis of the Outbreak in Spain. Sustainability, 12(15), 6243.

Brand, R., Timme, S., Nosrat, S., 2020. When Pandemic Hits: Exercise Frequency and Subjective Well-Being During COVID-19 Pandemic. Frontiers in Psychology, 11, 2391.

Brooks, S. K., Webster, R. K., Smith, L. E., Woodland, L., Wessely, S., Greenberg, N., Rubin, G. J., 2020. The Psychological Impact of Quarantine and how to Reduce it: Rapid Review of the Evidence. The Lancet (British Edition), 395(10227), 912-920. https://doi.org/10.1016/s0140$6736(20) 30460$.

Buzzi, C., Tucci, M., Cipranid, R., Brambilla, I., Caimmi, S., Ciprandi, G., Marseglia, G.L., 2020. The Psycho-Social Effects of COVID-19 on Italian Sdolescents' Attitudes and Behaviors. Italian Journal of Pediatrics, 46, 69.

Cheng, T. C., Kim, S., Koh, K., 2020. The Impact of COVID-19 on Subjective Well-Being: Evidence from Singapore. IZA Institute of Labor Economics, IZA DP No. 13702.

Cohen, A. K., Cromwell, J. R., 2020. How to Respond to the COVID-19 Pandemic with More Creativity and Innovation. Population Health Management. 24(2), 153-155.

COVID-19 apstiprināto gadījumu skaits un 14 dienu kumulatīvā saslimstība pa administratīvajām teritorijām // Data.gov.lv. URL: https://data.gov.lv/dati/lv/dataset/covid-19-pa-adm-terit (access date: 1.12.2020).

COVID-19. Valdības aktualitātes saistībā ar COVID-19. // Cabinet of Ministers. URL: https://mk.gov.lv/lv/content/covid-19 (access date: 1.12.2020).

Diener E., 2009. Subjective Well-Being. In: Diener E. (eds) The Science of Well-Being. Social Indicators Research Series, vol 37. Springer, Dordrecht. https://doi.org/10.1007/978-90-481-2350-6_2

Feldmane, L., Apsīte-Beriṇa, E., Burgmanis, G̦., 2018. Apmierinātība ar dzīvi un ǵeogrāfiskā mobilitāte: teorētiskais ietvars. Folia Geographica: Geogrāfija kopìgai nākotnei Latvijas simtgadēs, 16, $102-108$.

Foa, R., Gilbert, S., Fabian, M. O., 2020. COVID-19 and Subjective Well-Being: Separating the Effects of Lockdowns from the Pandemic. Available at SSRN 3674080

Holmes, E. A., O'Connor, R. C., Perry, V. H., Tracey, I., Wessely, S., Arseneault, L., Ballard, C., Christensen, H., Silver, R.C., Everall, I., Ford, T.,John, A., Kabir, T., King, K., Madan, I., Michie, S., Przybylski, A. K., Shafran, R., Sweeney, A., ... Bullmore, E., 2020. Multidisciplinary Research Priorities for the COVID-19 Pandemic: a Call for Action for Mental Health Science. The Lancet Psychiatry, 7(6), 547-560. https://doi.org/10.1016/S2215-0366(20)30168-1

Hu, Z., Lin, X., Kaminga, A. C., Xu, H., 2020. Impact of the COVID-19 Epidemic on Lifestyle Behaviors and their Association with Subjective Well-Being among the General Population in Mainland China: Cross-Sectional Study. Journal of Medical Internet Research, $22(8)$, e21176.

Kapteyn, A., Lee, J., Tassot, C., Zamarro, G., 2015. Dimensions of Subjective Well-Being. Social Indicators Research, 123, 625-660.

Kimhi, S., Eshel, Y., Marciano, H., Adini, B., 2020. A Renewed Outbreak of the COVID-19 Pandemic: A Longitudinal Study of Distress, Resilience, and SubjectiveWell-Being. International Journal of Environmental Research and Public Health, 17, 7743.

Koroḷeva, I., 2011. Subjektīvā labklājība: Apmierinātības un dzīves sasniegumu vērtējums jauniešu pārejā uz pieaugušo statusu. Doktora disertācija, Latvijas Universitāte. 223.

Krišjāne, Z., 1998. Dzīves kvalitātes teritoriālo atškirību izpēte Latvijā (Doctoral dissertation).

Logue, D., 2009. Moving Policy Forward:‘Brain Drain' as a Wicked Problem. Globalisation, Societies and Education, 7(1), 41-50. 
Lonska, J., 2013. Latvia's „Success Story” in the Context of Real and Subjective Well-being. Proceedings of the 14th Annual International Scientific Conference ,Economic Science for Rural Development” Latvia University of Agriculture, Jelgava: Nr.31, 122-128

Maggino, F., 2015. Subjective Well-being and Subjective Aspects of Well-being: Methodology and Theory. Rivista Internazionale di Scienze Sociali, 123(1), 89-121.

Martínez, L., Valencia, I., Trofimoff, V., 2020. Subjective well-being and mental health during the COVID-19 pandemic: Data from three population groups in Colombia. Data in Brief, 32, 106287.

Möhring, K., Naumann, E., Reifenscheid, M., Wenz, A., Rettig, T., Krieger, U., ... Blom, A. G., 2020. The COVID-19 pandemic and subjective well-being: longitudinal evidence on satisfaction with work and family. European Societies, 23(1), S601-S617.

Nowok, B., Van Ham, M., Findlay, A. M., Gayle, V., 2013. Does Migration Make you Happy? A Longitudinal Study of Internal Migration and Subjective Well-Being. Environment and Planning A, 45(4), 986-1002.

Parsons Leigh, J., Fiest, K., Brundin-Mather, R., Plotnikoff, K., Soo, A., Sypes, E.E., et al., 2020. A National Cross-Sectional Survey of Public Perceptions of the COVID-19 Pandemic: Selfreported Beliefs, Knowledge, and Behaviors. PLOS ONE, 15(10), e0241259.

Pieh, C., Budimir, S., Probst, T., 2020. The Effect of Age, Gender, Income, Work, and Physical Activity on Mental Health during Coronavirus Disease (COVID-19) Lockdown in Austria. Journal of Psychosomatic Research, 136, 110186.

Prime, H., Wade, M., Browne, D. T., 2020. Risk and Resilience in Family Well-Being during the COVID-19 Pandemic, American Psychologist, 5(75), 631-643.

Sīlis, V., 2006. VESELĪBA UN DZĪVES KVALITĀTE. Dzīves kvalitāte Latvijāa, 179.

Sīlis, V., 2010. Latvijas iedz̄ivotāju veselības uzvedība un dzīves kvalitāte. Promocijas darbs, Rīgas Stradiṇa universitāte.

Smith, L., Jacobb, L., Yakkundic, A., McDermottd, D., Armstronge, N.C., Sturman, E.D., 2020. Coping with Covid-19: Resilience and Psychological Well- Being in the Midst of a Pandemic. Journal of Social and Clinical Psychology, 39(7), 561-570.

Tuzovic, S., Kabadayi, S., 2020. The Influence of Social Distancing on Employee Well-Being: a Conceptual Framework and Research Agenda. Journal of Service Management, 32(2), 145-160, https://doi.org/10.1108/JOSM-05-2020-0140.

Zacher, H., Rudolph, C.W., 2021. Well-being During the Early Stages of the COVID-19 Pandemic. American Psychologist. 123, 625-660. http://dx.doi.org/10.1037/amp0000702

Zacher, H., Rudolph, C. W., 2020. Individual Differences and Changes in Subjective Wellbeing During the Early Stages of the COVID-19 Pandemic. American Psychologist, 76(1), 50-62.

Zhang, Z., Yao, B., Zhang, X., Xu, H., 2020. Effects of Irritability of the Youth on Subjective Well-Being: Mediating Effect of Coping Styles. Iran Journal of Public Health, 49(10), 1848-1856.

Zhou, T., Nguyen, T.T., Zhong, J., Liu, J., 2020. A COVID-19 Descriptive Study of Life after Lockdown in Wuhan, China. Royal Society Open Science, 7, 200705.

\section{Acknowledgement}

This work was supported by the National Research Program Project grant number VPP-IZM-2018/1-0015 and ERDF grant 1.1.1.2/VIAA/1/16/184. 


\section{POTENTIAL DISRUPTIVE AND SUSTAINING INNOVATIONS IN HEALTH CARE}

\section{Diana Araja, Riga Stradins University}

Abstract. The rapid development of medical technologies maintains the relevance of the concept of innovation in healthcare. Healthcare innovations more often are perceived as 'disruptive innovations' and associated with technological innovation, artificial intelligence, biomedicine, precision medicine and other medical developments. At the same time, the proposed medical technology does not always correspond to the nature of 'disruptive innovation', but receives support defined for this category of innovation in policy planning documents. The aim of this study is to investigate the relevance of the term 'disruptive innovation' used in healthcare to its original nature and to draw conclusions on most appropriate term. Within the framework of this research, the analysis of scientific literature and policy planning documents was performed. No specific medical technologies were analysed, however, one of the directions of medical development defined in policy planning documents was chosen, which is presented as 'disruptive innovation' - it is 'precision medicine'. The analysis has shown that 'precision medicine' does not correspond to the initial nature of the term 'disruptive innovation', which implies that disruptive innovation describes a process by which a product or service takes root initially in simple applications at the bottom of a market and then relentlessly moves up market, eventually displacing established competitors. It was concluded that precision medicine is mostly correspond with 'sustaining innovation' - both 'continuous innovation (evolutionary)' and 'discontinuous innovation (revolutionary)' - by improving existing products or services through technological developments or by creating entirely new exclusive expensive solutions, which are not intended for widespread use at the bottom of a market. Consequently, it is proposed to use a more appropriate term for innovations in medicine, for example by referring to 'precision medicine' as a 'sustaining innovation' and its evaluation as sustaining innovation and longitude significant investment.

Keywords: disruptive innovations, sustaining innovations, healthcare.

JEL code: I11

\section{Introduction}

The term 'disruptive innovation' was introduced more than 20 years ago and was originally devoted to market issues, business models, product and service advancement. Later, the use of the term expanded to other areas, including healthcare. The term 'disruptive innovation' was used in healthcare already ten years ago, but has become particularly relevant in recent years, given the rapid development of artificial intelligence and medical technologies. At the same time, in some cases there is no certainty that the proposed medical technology is in line with the essence of 'disruptive innovation' and that this term is not used as a sound marketing element. Consequently, a research question arose as to whether the term 'disruptive innovation' currently used in healthcare corresponds to its original definition and nature. Accordingly, the aim of the study is to assess the relevance of the term 'disruptive innovation' used in healthcare to its original nature and to draw conclusions about the most appropriate term. To achieve the aim of this study the following tasks were defined:

1) analyse the literature on the original nature of 'disruptive innovation',

2) perform the literature review on conceptual issues of term 'disruptive innovation' in healthcare;

3) evaluate the use of the term 'disruptive innovation' in policy planning documents and identify the areas in which the term is more often attributed to healthcare,

4) draw conclusions, on more appropriate approach to innovations' definition in healthcare.

Within the framework of this research, the analysis of scientific literature and policy planning documents on the nature of the term 'disruptive innovation' and its application in healthcare was performed. The scientific literature search on conceptual issues of term 'disruptive innovation' in healthcare was performed in database Medline (via PubMed) - with focus to the systematic reviews and meta-analyses, without time period restrictions. The following search key words were used in database without any other filters or restrictions: ('disruptive innovation') OR ('disruptive changes') AND ('healthcare') OR ('medicine') AND ('systematic review') OR ('meta-analysis') AND ('concept') OR ('appraisal'). Within the scope of the study, no specific medical technologies and medicine branches were analysed. The literature review found that the use of the term 'disruptive innovations' in healthcare has received a weak conceptual and systemic attention in previous researches, so this study touches on insufficiently researched topic and could contribute to in-depth discussions and new approaches to evaluation of innovations in healthcare. 


\section{Literature Review}

\section{Original nature of 'disruptive innovation'}

The term 'disruptive innovation' becomes topical in contemporary medicine, and the specific objective of the article is to propose the discussion on applicability and performance of this concept in modern healthcare. The notion of 'disruptive innovation' was coined by the Harvard Business School's Professor Clayton M. Christensen more than twenty years ago, proposing to divide the term 'innovations' into 'sustaining innovations' (continuous and discontinuous) and 'disruptive innovations' (Fig.1).

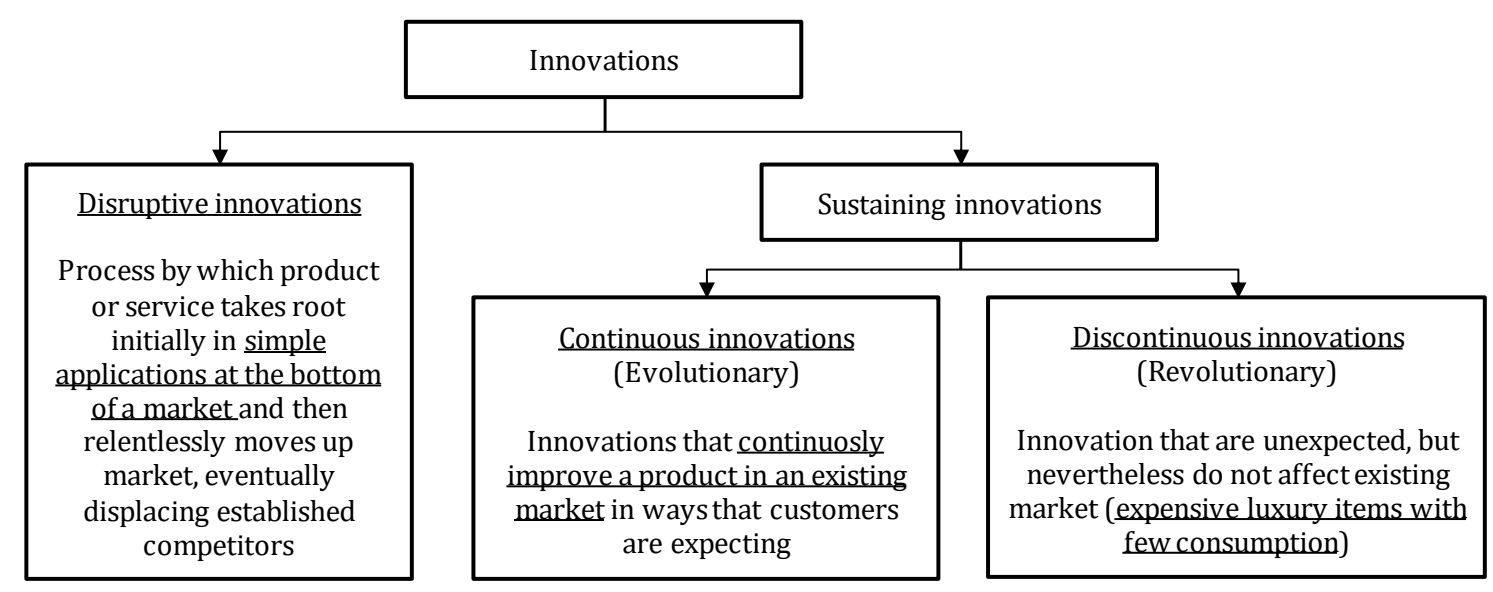

Source: author's construction based on (Christensen, 1997)

\section{Fig. 1. Types of innovations initially defined by Clayton M. Christensen}

The 'sustaining innovation' does not create new markets or value networks, but rather especially evolves existing ones with better value. Continuous innovation improves a product in an existing market in ways that customers are expecting, and discontinuous innovation is an innovation that is unexpected, but nevertheless does not create a new market. Companies pursue the 'sustaining innovations' at the higher tiers of their markets because this is what has historically helped them succeed: by charging the highest prices to their most demanding and sophisticated customers at the top of the market, companies will achieve the greatest profitability. However, by doing so, companies unwittingly open the door to 'disruptive innovations' at the bottom of the market. An innovation that is disruptive allows a whole new population of consumers at the bottom of a market access to a product or service that was historically only accessible to consumers with a lot of money or a lot of skill. Characteristics of disruptive businesses, at least in their initial stages, can include: lower gross margins, smaller target markets, and simpler products and services that may not appear as attractive as existing solutions when compared against traditional performance metrics. Because these lower tiers of the market offer lower gross margins, they are unattractive to other firms moving upward in the market, creating space at the bottom of the market for new disruptive competitors to emerge. C. M. Christensen described, that typically, disruptive innovations were technologically simple and consisted of commonly accepted components built into product architecture, often simpler than previous approaches (Christensen, 1997).

In later literature, the term 'disruptive innovations' was extended beyond the category of 'product' to add the notions of disruptive processes, technologies, services and business models (Thomond et al., 2003). So then, a disruptive product innovation, focusing on developing simpler, less functional, cheaper but 'enough good' products to serve the market which is overlooked by mainstream products (Gilbert and Bower, 2002; Christensen and Raynor, 2003; Govindarajan et al., 2011). Technological disruptive innovation (more appropriate for healthcare) focuses on developing a more concise and convenient technology that the mainstream markets do not value to enter a niche market or new market, and then the technology is gradually improved to flow into the mainstream market from niche market or new market (Christensen, 1997; Danneels, 2004; Carayannopoulos, 2009). The business model, from its side, is composed of four elements - a value proposition, the resources, processes and profit formula required to deliver that value proposition to targeted customers (Hwang et al., 2017). It disrupts established models or redefines the meaning of value creation and acquisition (Cozzolino et al., 2018).

Indeed, the widespread technologies often fail to meet expectations that they will transform the industry. The concept of 'disruptive innovation' initially used in academic literature to explain certain phenomena in industry. Recent literature announces the use of 'disruptive innovation' in healthcare and suggests that this type of innovation is based on 'simplifying' technology, which, however, needs to be embedded in innovative 
business models and value networks. In reality, the modern hospitals are overflowing with countless sophisticated technologies, however, it seems that healthcare is only becoming more expensive and inaccessible. The reason is that most technologies - even radical breakthroughs - are designed to sustain the functioning of the current system. Only truly disruptive innovations can make healthcare affordable and available (Hwang et al., 2017).

The term 'disruptive innovation' is often casually applied to many unrelated situations of innovation (Wilson and Tyfield, 2018). This theory, or its variants, have been applied to so many irrelevant situations that C.M. Christensen himself expressed concerns about some of the ways in which the theory had been applied (King and Baatartogtokh, 2015).

\section{Conceptual issues of term 'disruptive innovation' in healthcare}

The PRISMA diagram of the selection process for systematic reviews and meta-analyses on conceptual issues of term 'disruptive innovation' in healthcare is not used because only one of the 193 publications selected in the Medline database fully met the selection criteria. The systemic review and appraisal on recognition of disruptive innovations in the healthcare was found in one publication, which authored by Sounderajah et al. (Sounderajah et al., 2021). In this publication the authors noted, that the concept 'disruptive innovation' has diffused into the healthcare industry, with the five most cited disruptive innovations in healthcare: 'omics' technologies, mobile health applications, telemedicine, health informatics and retail clinics. However, its use remains inconsistent and the recognition of disruption is obscured by other types of innovation. The current definition does not accommodate for prospective scouting of disruptive innovations, a likely hindrance to policy makers. Redefining disruptive innovation within the healthcare sector is therefore crucial for prospectively identifying cost-effective innovations (Sounderajah et al., 2021).

Across the 245 included studies, the following are some of the most fundamental errors and deviations from C.M. Christensen's principles were defined (Sounderajah et al., 2021):

a) describing the technologies themselves as disruptive innovations, as opposed to the process of market upheaval: a prominent example of this flaw is describing the software offering a telemedicine service as a disruptive innovation.

b) describing theoretical market effects of products yet to reach the open market as a 'prospective' disruptive innovation: disruptive innovation, in its truest sense, may only be truly labelled as such retrospectively. This error is evident by the multiple references to artificial intelligence (AI) as being a burgeoning disruptive innovation. Although there have been prominent applications of AI within academic medical research, there is no guarantee that it will achieve disruption within its intended market.

c) describing innovations as 'disruptive' which would be more accurately described as 'sustaining innovation': one such example is the concept of drug eluting stents. Given that this technology was based on the original innovation of bare metal stents, which had replaced the role of open surgery in many cases, it can be argued that drug eluting stents are more accurately described as an incremental innovation.

d) according to C.M. Christensen, disruptive innovations eventually always supplant the incumbent market leader: long-standing coexistence is not classically in keeping with true disruption. Therefore, the suggestion that laparoscopic surgery, as an entire practice, is a disruptive innovation is misleading as there is still huge scope for open surgery globally. This error once again demonstrates the flaw in labelling an entire practice as a disruptive innovation.

This summary with concrete examples demonstrates the inconsistency in using the term 'disruptive innovation' in healthcare. At the same time, disruptive innovations are broadly defined in policy planning documents as priority actions to be supported, although their nature is not clear.

\section{3. 'Disruptive innovation' in policy planning documents and practical issues}

In public sector the concept of the 'disruptive innovation' has been introduced for analysing ways to improve health outcomes and reduce costs in the United States' (US) healthcare system. C.M. Christensen singles out four specific solutions to the present crises for the US health care system; (1) create - and then embrace - a system where the physicians skill level is matched to the level of the medical problem, (2) invest less money in high-end complex technologies, and more in technologies that simplify complex problems, (3) create new organizations to do the disrupting and (4) overcome the inertia of regulation (Jonsson, 2017).

In the European Union (EU) the Expert Panel on Effective Ways of Investing in Health (EXPH) which was established in accordance with European Commission's Decision (European Commission, 2012), takes a focus on the implications of disruptive innovations and other progressive issues in healthcare of European countries. The Expert Panel has described the 'disruptive innovation' in healthcare as a type of innovations that creates new networks and new organizational cultures involving new players, and that has the potential to improve health outcomes and the value of health care. The 'disruptive innovation' is conceptualized as complex and multidimensional, subdivided into five dimensions of disruptive 
innovation: business model typology, implementation flow, health goals, application areas, and pivoting values. Five strategic areas for disruptive innovation have been identified:

- translational research,

- $\quad$ access to new innovative technologies,

- precision medicine,

- health and care professional education,

- health promotion.

It has been pointed, that the implementation of any innovation should carefully address the issues of relevance, equity (including access), quality, cost-effectiveness, person- and people-centeredness, and sustainability (EXPH, 2016).

Disruptive innovations displace older systems and ways of doing things. This means that there will be uncertainty about the consequences in clinical practice, and that it may take long time to reveal these. In context of mentioned considerations, author pays attention to such issues, as interaction between Policy on Universal Health Coverage and Concept on Precision Medicine, which is defined as an example of 'disruptive innovation' at the EXPH document.

12 December 2012, the United Nations General Assembly endorsed the resolution on Global Health and Foreign Policy urging countries to accelerate progress toward Universal Health Coverage - the concept anticipated that all individuals and communities receive the health services they need without suffering financial hardship (United Nations, 2012). All United Nations Member States have agreed to try to achieve Universal Health Coverage by 2030, as part of the Sustainable Development Goals. Financial resources should be used to extend coverage to those individuals who previously were not covered, to services that previously were not covered or to reduce the direct payments needed for each service. These dimensions of coverage reflect a set of policy choices about benefits and their rationing that are among the critical decisions facing countries in their reform of health financing systems towards universal coverage (Fig. 2). It is indicated, that choices need to be made about proceeding along each of the three dimensions, in many combinations, in a way that best fits their objectives as well as the financial, organisational and political contexts (World Health Organization, 2017).

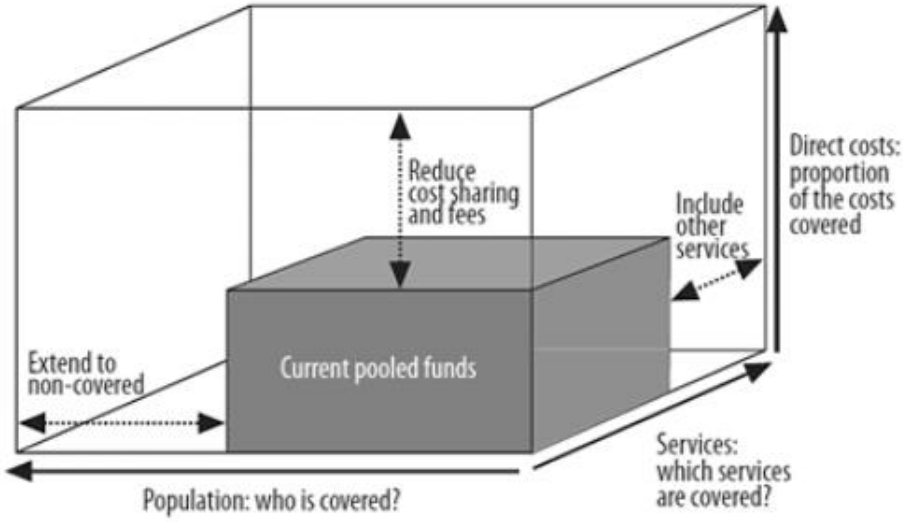

Fig. 2. Three dimensions of the Universal Health Coverage (World Health Organization, 2017)

The World Health Organisation has defined, that extending the coverage from pooled funds along the three dimensions calls for health financing reforms and actions leading to an increase of available funds for health, to an increase in the share of these funds collected through prepayment and the arrangements for pooling them, to efficiency gains and to upholding and increasing the quality of health services.

At the same time, 'precision medicine' is defined as one of the leading disruptive innovations in health care. In accordance with US Food and Drug Administration (FDA) 'precision medicine' is an innovative approach to tailoring disease prevention and treatment that takes into account differences in people's genes, environments, and lifestyles. The goal of precision medicine is to target the right treatments to the right patients at the right time (US FDA, 2013).

The European Union's Health Ministers in their Council conclusions on personalised medicine for patients, published in December 2015, defined personalised medicine as a medical model using characterization of individuals' phenotypes and genotypes (e.g. molecular profiling, medical 
imaging, lifestyle data), additionally notifying, that personalised medicine should be seen as an evolution of medicine, rather than a revolution, and many challenges remain before its successful application across healthcare systems (The Council of the EU, 2015).

\section{Research results and discussion}

One of the previously mentioned challenges, in author's view, is the interaction of Precision Medicine and Universal Health Coverage concepts in decision-making on budget allocation in restricted resources circumstances (Fig. 3). Universal Health Coverage concept means that all people have access to the health services they need, when and where they need them, without financial hardship. It includes the full range of essential health services, from health promotion to prevention, treatment, rehabilitation, and palliative care.

In the current circumstances, 'precision medicine' requires significant resources, but it is applied to a limited number of patients. Rapidly rising costs push the state budget administrators to forefront of choosing to pay for expensive diagnostic procedures for a limited number of patients or to allocate funds for the conventional approach towards the Universal Health Coverage (Fig. 3), taking into account the theory of opportunity costs. This situation would be avoided, if 'precision medicine' is truly in compliance with the nature of 'disruptive innovations' concept and provides a convincing benefit to a wide range of patients at reasonable costs, which is not observed currently.

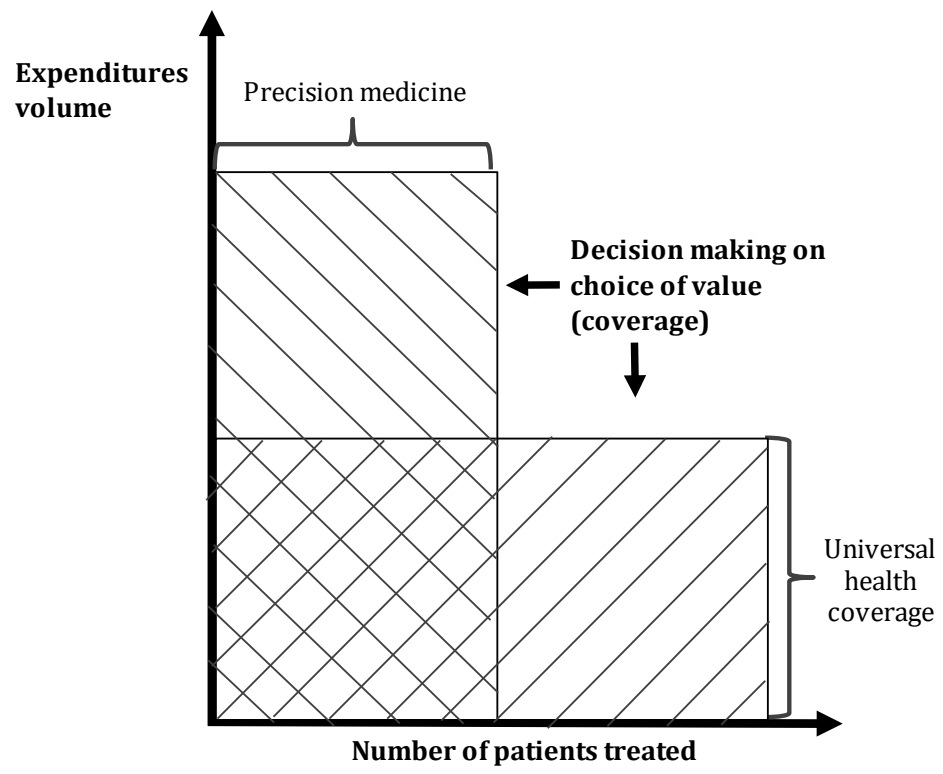

Fig. 3. Interaction of Precision Medicine and Universal Health Coverage concepts in decision-making on budget allocation in restricted resources circumstances (author)

At the same time, the 'epigenetics' is becoming a topicality in research and practice. The term 'epigenetics' was coined by the British scientist Conrad Hal Waddington in 1942 as the processes by which the genotype brings the phenotype into being (Cavalli and Heard, 2019). The epigenetics' concept assumes an environmental impact on genetic assimilation of certain phenotypic characteristics. Therefore, the genetic testing in framework of 'precision medicine' not always guarantees a high level of certainty of results, but provides guaranteed high costs.

In these circumstances, it has to hope that 'precision medicine' in future will become the process by which complicated, expensive products and services are transformed into simple, affordable ones, as J. Hwang, C.M. Christensen and J.H. Grossman have described the dis ruptive innovation theory in the last version of 'Innovator's Prescription' (Hwang et al., 2017). Presently, one might assume that the term 'precision medicine' is an example when essentially 'sustaining innovation' is called as 'disruptive innovation', taking into account, that 'precision medicine', in its current form, does not serve the purpose of the classic 'disruptive innovation', due to predominant expensiveness and availability to only a narrow range of patients.

Additional issue for discussion is interaction of a patient and healthcare system, but in an unconventional angle. There are many definitions on 'patient-centred healthcare', and it could be defined as a significant element of 'disruptive innovations' in health care, but in literature is practically not mentioned in this tandem. All definitions of 'patient-centred healthcare' more or less proclaim that the patient should be an active participant in treatment process, not a passive victim. However, the patients' empowerment and engagement perform slowly and with resistance from both sides - patients and healthcare givers. In these circumstances, it would be helpful to explore the patient's feelings, role and place in healthcare organisation. 
The importance of people is completely associated with the healthcare organisation, so the organizational behavioural approach is quite important for healthcare management. The effectiveness of the disease prevention and treatment process is crucially dependent on the patient's behavioural pattern and preferential decisions. It should be borne in mind that the consumer chooses a comparative advantage. Consequently, patients' behaviour patterns and preferential decision-making require in-depth research.

The behaviour patterns are also representative for healthcare organisation, such as: the segmentation of healthcare avoids the final responsibility for treatment outcomes; the payment for the treatment process, not for the results is more popular in healthcare; the concept of 'incurable illnesses' and 'chronic diseases' allows to continue payments for the process and not to seek alternatives to medication for the full recovery of the patient.

Looking the healthcare organisation in light of the organisational theories' contemporary approaches, the 'system approach' is more applicable, as the healthcare organisation represents all attributes of open system. The system approach assumes that an organisation takes in inputs (resources) from the environment (society) and transforms or processes these resources into outputs that are distributed into the environment (society). In these circumstances the healthcare organisation takes a high-level responsibility not only for individual patient's treatment outcomes, but also outcomes for whole society. Therefore, the society should be involved in the management process, for example, through 'Population-based Accountable Care Organisations'.

Individual patient health care could be viewed as team work in a 'Complex Adaptive System (CAS)', where patient acts as an equal partner and creates a new value network. Consequently, the effective team-work in CAS needs a trust, clarity of goals and processes, communication skills, competences and willingness to achieve the significant results. Patient should have motivation, self-reflection and engagement in the treatment process. This means careful consideration of the design and delivery of the treatment programmes and assessment of outcomes, with respects and attends to the diversity of patients and their needs.

Mentioned innovations related to patient-centred healthcare can be defined also as 'sustaining innovation' or 'hybrid innovation'. Distinctly there are many technological innovations in healthcare that significantly improve the functional effectiveness, and as soon as these innovations also deliver economic efficiency, they should be attributed to 'disruptive innovations'.

\section{Conclusions, proposals, recommendations}

1. In healthcare, there is a tendency to attribute the status of 'disruptive innovations' to innovations, which are 'sustaining innovation' by nature. Originally, the 'disruptive innovation' was meant to be a process by which a product or service takes root initially in simple applications at the bottom of a market and then constantly moving up the market, eventually displacing established competitors. Consequently, the original mission of 'disruptive innovations' is not always achieved - to help more people who previously had no access to this type of product or service for technological or financial reasons.

2. Precision medicine, which mostly perceived as a 'disruptive innovation', should be consider in light of 'sustaining innovation' - both 'continuous innovation (evolutionary)' and 'discontinuous innovation (revolutionary)' - by improving existing products or services through technological developments or by creating entirely new exclusive expensive solutions which are not intended for widespread use at the bottom of market.

3. Consequently, use of more appropriate term for innovations in medicine is appreciated, for example, precision medicine should be perceived as a 'sustaining innovation' and longitude significant investment. Only initially and continuously cost-effectiveness medical method can be considered as a disruptive innovation.

4. The healthcare organisation model with active engagement of patients in organisation, evaluation and performance of healthcare, should be considered as a potential disruptive innovation in healthcare, creating the added value networking. At the same time, the main challenge for any type of innovations remains its successful implementation into practice.

5. The literature review found that the use of the term 'disruptive innovations' and 'sustaining innovations' in healthcare have not received sufficient conceptual investigation in previous research, so this study could contribute to in-depth discussions and new approaches to evaluating innovations in healthcare. 


\section{Bibliography}

Carayannopoulos, S., 2009. How Technology-Based New Firms Leverage Newness and Smallness to Commercialize Disruptive Technologies. Entrepreneurship Theory and Practice, 33(2), 419-438.

Cavalli, G., Heard, E., 2019. Advances in epigenetics link genetics to the environment and disease. Nature, 571, 489-499.

Christensen, C.M., 1997. The Innovator's Dilemma: When New Technologies Cause Great Firms to Fail. Harvard Business Press.

Christensen, C.M., Raynor, M.E., 2003. The Innovator's Solution: Creating and Sustaining Successful Growth. Harvard Business Press, Boston.

Cozzolino, A., Verona, G., Rothaermel, F.T., 2018. Unpacking the Disruption Process: New Technology, Business Models, and Incumbent Adaptation. Journal of Management Stududies, 55(7), 1166-1202.

Danneels, E., 2004. Disruptive Technology Reconsidered: a Critique and Research Agenda. Journal of Product Innovation Management. 21(4), 246-258.

European Commission Decision of 5 July 2012 on Setting up a Multisectoral and Independent Expert Panel to Provide Advice on effective ways of investing in health (2012/C 198/06) 6.7.2012 Official Journal of the European Union C 198/7

Expert Panel on effective ways of investing in Health (EXPH), Report on Disruptive Innovation, 2016

Gilbert, C., Bower, J.L., 2002. Disruptive Change. When Trying Harder is Part of the Problem. Harvard Business Review, 80(5), 94-101.

Govindarajan, V., Kopalle, P.K., Danneels, E., 2011. The Effects of Mainstream and Emerging Customer Orientations on Radical and Disruptive Innovations. Journal Of Product Innovation Management, 28(s1), 121-132.

Hwang, J., Christensen, C.M., Grossman, J.H., 2017. The Innovator's Prescription: A Disruptive Solution for Health Care. McGraw-Hill.

Jonsson, B., 2017. Disruptive Innovation and EU Health Policy. European Journal of Health Economics. 18(3), $269-272$.

King, A.A., Baatartogtokh, B., 2015. How useful is the theory of disruptive innovation? MIT Sloan Management Review, 57(1), 77-90.

Sounderajah, V., Patel, V., Varatharajan, L, Harling, L., Normahani, P., Symons, J., Barlow, J., Darzi, A., Ashrafian, H., 2021. Are Disruptive Innovations Recognised in the Healthcare Literature? A Systematic Review. BMJ Innovations, 7, 208-216.

The Council of the European Union, 2015. Council Conclusions on Personalized Medicine for Patients (2015/C 421/03). Official Journal of the European Union, C 421/2., 17.12.2015.

Thomond, P., Herzberg, T., Lettice, F., 2003. Disruptive Innovation: Removing the Innovators' Dilemma. Knowledge into Practice British Academy of Management Annual Conference, Harrogate, UK.

United Nations, 2012. Resolution 67/81 Global health and foreign policy, adopted by the General Assembly on 12 December 2012. Sixty-seventh session Agenda item 123.

U.S. Department of Health and Human Services U.S. Food and Drug Administration, 2013. Paving the Way for Personalized Medicine: FDA's Role in a New Era of Medical Product Development. FDA report, October 2013.

Wilson, C., Tyfield, D., 2018. Critical Perspectives on Disruptive Innovation and Energy Transformation. Energy Research \& Social Science, 37 , 211-215.

World Health Organization. Universal coverage - three dimensions. Geneva: World Health Organization, 2017 


\title{
THE RELATIONSHIP BETWEEN THE CREATIVE ACCOUNTING AND CORPORATE SOCIAL RESPONSIBILITY: UNFAIR ADVANTAGE AND A THREAT TO THE ECONOMIC WELL-BEING

\author{
Diana Bachtijeva, Vilnius University
} \\ Daiva Tamuleviciene, Vilnius University
}

\begin{abstract}
Corporate social responsibility is an integral part of sustainable relationship between a business and a stakeholder. The information presented in the enterprise's financial accounting and reporting is also important for this relationship. However, the widespread usage of creative accounting in recent decades has made these relationships unstable and unsustainable. The practice of creative accounting methods is becoming a tool to manipulate financial information that directly affects stakeholders' decisions rather than a way to search for some creative ways to present an accurate picture of the condition the company is in. The aim of this article is to assess the relationship between the creative accounting and corporate social responsibility as well as their compatibility. After conducting the analysis of scientific sources, the following are presented: the concept of corporate social responsibility, methods of corporate social responsibility assessment, anatomy of creative accounting as well as the application of creative accounting methods for selfish purposes to manipulate the company's financial information. The (in)compatibility of corporate social responsibility with creative accounting methods is analysed and their impact on the reliability of the provided information is presented. Based on the study it has been determined that the application of creative accounting methods unjustly helps companies to obtain a higher corporate social responsibility level as well as an unfair advantage in the market. Creative accounting is incompatible with the concept of corporate social responsibility and causes conflict of interest. In the long run it might cause a relationship crisis, their termination or even the collapse of the company itself.
\end{abstract}

Keywords: creative accounting, corporate social responsibility, the reliability of information.

JEL code: M14, K42

\section{Introduction}

In the beginning of the 20th century F. W. Taylor (1911) was trying to solve such management issues as profitability of an enterprise, the increase of labour productivity and efficiency. However, the modern management focuses on the relations of people, overall culture and values both inside and outside the organization. Corporate social responsibility has not only become one of the most important notions of modern management, it is also a precondition to a better life. In the scientific works important issues regarding corporate social responsibility, such as, eco-management, stakeholders, competitive advantage, satisfaction, sustainability, difficulties in implementing moral behaviour, involvement in social responsibility initiatives (Sims, 2003; Fray, 2007; Aguilera et al., 2007; Kotler, Lee, 2007; Juščius, 2007; Lindgreen et al., 2009; Garavan, McGuire, 2010; Korschun at al., 2014; Revelli, Viviani, 2015; Vitell, 2015; Feng, Zhu, Lai, 2017; Gavronski, 2018; Herrera, Heras-Rosas, 2020; Beniulytė, Šeinauskienė, Rūtelionienė, 2020, etc.) are often discussed. Yet, it is worth mentioning that literature does not pay enough attention to the financial accounting of socially responsible enterprises. At the end of the 20th century, when the theory of creative accounting became popular, scientists started to worry. When applying creative accounting, legal means and actions which disrupt financial statements data and show the preferred results are used. Even though creative accounting is not illegal, we must take into account the relationship between the creative accounting methods application and corporate social responsibility as well as the accuracy and reliability of the information that the enterprises present. This article is aimed at pointing out the issue of creative accounting application in enterprises and at answering the question whether an enterprise that applies the creative accounting methods can call itself socially responsible and how should the information such enterprises present be assessed. The aim of this study is to estimate the relationship between the creative accounting and the corporate social responsibility, their compatibility as well as the reliability of the information presented by such enterprises. Whilst preparing for this study, the following methods were used: scientific literature analysis, information classification, comparison, elaboration, systematization, generalization.

\section{The concept of corporate social responsibility}

Respectful behaviour towards socially vulnerable groups and the whole society could be called a social responsibility. This term is also used in business to define honest, respectful and moral behaviour towards employees, clients, business partners and the society as a whole. People first started speaking about the corporate social responsibility in the 1920's. E. M. Dodd (1932) emphasized the progress when assessing a businesses as an institution that has a social service function. Since then, the issue of social responsibility of organizations has received a lot of attention not only 
from the scientific community but from the society as well. Over 90 years the concept of corporate social responsibility has changed drastically. At first, it was associated only with charity and philanthropy, later a belief that corporate social responsibility is one of the most fundamental tools to shape and maintain a civil society began to prevail (Diskienè, Seiliūtè, 2012).

There are various definitions of corporate social responsibility in literature: it is the organization's commitment to make decisions and take actions in order to meet the needs and interests of society and the organization itself and to create wealth (Daft, 2006); it is the organization's commitment to increase welfare of the society by implementing an independent business practice and using the enterprise's resources (Kotler, Lee, 2007); it is the commitment of the business to behave morally, contribute to the welfare of its employees and their families, and to help improve the quality of life of the local community and the whole society via economic development (Gudoniené, Leipuviené, 2007); a concept whereby companies integrate social and environmental concerns in their business operations and in their interaction with their stakeholders on a voluntary basis (The European Commission, 2001) etc. Dalhsrud (2008) wanted to define the concept of corporate social responsibility clearly, so he studied the scientific literature and carried out the content analysis. The results of this scientific study showed that there are many available definitions of corporate social responsibility and they are consistently referring to five dimensions: the environmental dimension; the social dimension; the economic dimension; the stakeholder dimension; the voluntariness dimension. In conclusion, we can say that the corporate social responsibility is a voluntary commitment of an enterprise to coordinate the goals and activities not only with their own economic interests but with environmental matters, stakeholders and the whole society.

The issue of corporate social responsibility raised many discussions both in the business world and in the society. Due to increasing arrogance of businesses and constant scandals caused by false information or actions that harm the environment and the society, the society pressured businesses into taking social responsibility. However, businesses tried very hard to resist and this explains why an unanimous definition of corporate social responsibility had not been formalized for quite a long time (Whitehouse, 2003). Nevertheless, due to strong pressure from groups concerned and the society, in 2010 the International Standard ISO 26000 “Guidance on social responsibility" was adopted. It was designed for all organizations (from both public and private sectors) in the developing and developed countries. The social responsibility guidelines standard ISO 26000 provide different means and tools for enterprises to evaluate and improve their application of corporate social responsibility in the following key areas: human rights; labour practices; environment; fair operating practices; consumer issues; community involvement and development.

While developing the concept of corporate social responsibility, Carroll (1991) made a hierarchy pyramid of corporate social responsibility that consists of four areas of social responsibility. The foundation of social responsibility is the economic responsibility. The main criteria of economic responsibility are maximizing earning per share; maintaining a strong competitive position; maintaining a high level of operating efficiency. Another equally important area of social responsibility is called legal responsibility. It is important because the enterprises are expected to comply with federal, state, and local regulations. Not only the enterprise's activities should meet the expectations of the government and legal requirements but the goods and services provided by that enterprise should too. Ethical (moral) responsibility means that an enterprise makes a commitment to do what is right. Their activities and goals must comply with the customs of the society, it's ethical and moral norms. Philanthropic responsibility is associated with voluntary charity work to support education, art, and science as well as to contribute to the projects that improve the quality of life within the community. The pyramid of corporate social responsibility is the foundation that helps us understand the nature of the economic, legal, ethical and philanthropic responsibilities of an enterprise. Regardless of the type of the enterprise, its structure, the nature of its activities or other characteristics, the pyramid of social responsibility can be used as the basis of assessing the corporate social responsibility.

Carroll (1991) considers the terms ethics and morals in the context of an organization synonyms and notes that every action and every decision an enterprise makes must be ethical. It is not enough only to comply with legal norms because ethical and moral norms go beyond the law. Ethical behaviour is oriented not so much towards the letter of the law, but rather towards the spirit of the law. Sims (2003) states that the management of an enterprise should take into account the social responsibility of a businesses and not only the business itself, and the strategic actions must be ethical. A manager must make sure that the decisions of an enterprise are honest and meet high ethical standards because it affects the environment of the enterprise.

Donaldson, Preston (1995) presented the Stakeholder Theory of the Corporation which states that mutual relations develop between the enterprise and stakeholders: investors, employees, customers, suppliers, trade associations, communities, political groups, governments. The theory emphasizes that in mutual relations neither side has an advantage against the other and their relations are equal. According to Sims (2003) every business has a moral obligation towards stakeholders because it is the stakeholders that influence the enterprise and they reasonably expect moral 
behaviour from the enterprise. Ethical and socially responsible behaviour is important for the vitality of all organizations because they try to react to the expectations of the stakeholders.

Elkington (1998) suggests estimating the corporate social responsibility on the basis of 3P (Profit, People, Planet) or the Triple Bottom Line which consists of economic, environmental and social responsibility. Economic responsibility is associated with the profitability of an enterprise, financial risk management; environmental responsibility is associated with the damage to the environment caused by the activities and management of an enterprise; social responsibility is associated with the cooperation with the employees, customers, stakeholders and the society (Gižiené, Palekienè, Simanavičienè, 2011).

According to Slapikaite (2016), one can estimate the results of an enterprise's activities based on the Triple Bottom Line. She conducted an empirical study to determine the criteria of corporate social responsibility for the investors of the enterprises. She concluded the results of the study and presented an integrated system to assess the corporate social responsibility. This system consists of four category groups and significance ratios are assigned to each of them. The data suggested that the most significant and most important criteria for assessing the corporate social responsibility are in the economic - financial group. This group consists of three subcategories: profitability ratios (gross margin, net profit ratio, operating profit ratio, EBITDA, ROA, ROE, ROI), liquidity ratios (current ratio, quick ratio, liquidation value) and debt ratios (debt to total assets, debt to equity, debt to EBITDA, interest coverage). The next most significant group is the governance group where three criteria are emphasized: corruption and bribery, reputation, management effectiveness. In the social group the following criteria are listed: labour and workers rights, compliance with the labour standards, health and safety norms; health and safety of the workers; consultations for the employees, preparation and agreement on any resettlement (physical or economic) that may be required as a result of a transaction; impact on local communities, indigenous people, minorities, women and other vulnerable groups; impact on cultural religious heritage. In the environmental group we find such criteria: pollution and pollution abatement, impact on water quality and quantity, air emission, solid and other waste streams, impact of land-use change, resource use efficiency, commitment to address ecosystem service risks and issues.

It makes no difference which model one would choose to estimate the corporate social responsibility: the pyramid of social responsibility by Carroll (1991), the Triple Bottom Line by Elkington (1998), the system of estimation by Slapikaite (2016) or International Standards; what is important is to estimate the corporate social responsibility in a complex way, as an entirety of many factors and categories. The corporate social responsibility should not be considered only as an environmental or charitable activity, while the employees are being exploited and enterprises act dishonestly towards market participants.

The corporate social responsibility is not something sporadical; rather it is a constant, systematic behaviour and the needs of different stakeholders must be addressed (Lindgreen, Swaen, Johnston, 2009). Only when the enterprise is guided by values and acts morally for a long period of time, it is possible to ensure sustainability not only within the enterprise but in relations with other organizations as well. These values are the elements that ensure stability and longevity of an enterprise (Fray, 2007), and the success of many global enterprises largely depends on strong values (Kotter, Heskett, 1992). The corporate social responsibility must not be misinterpreted as a prize or a badge awarded to an enterprise. It should be understood as a value system of an enterprise on which the enterprise's activities are based. The compatibility of values between the enterprise and the customer including the activities that the enterprise undertakes according to its social responsibility, determines how the customer sees the enterprise and how they behave (Beniulytè, Šeinauskienè, Rūtelionè, 2020). 


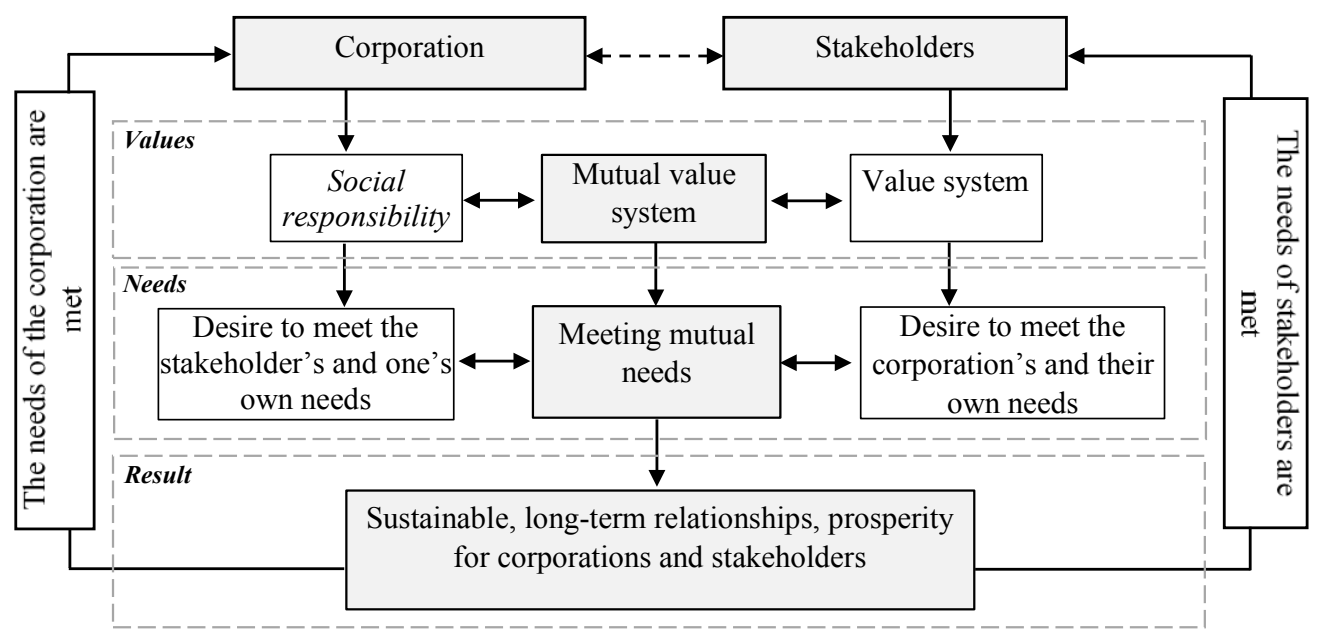

Source: authors' construction

Fig. 1. The concept of corporate social responsibility

The essence of the social responsibility paradigm is an honest and correct enterprise's behaviour with the whole environment; it is a value system, where philanthropy sits at the top. You can see from Figure 2 that both the enterprise and the stakeholders are guided by the values in their activities. The enterprise bases its activities on social responsibility, moral and respectful behaviour with its employees, customers, society, environment. Stakeholders also have a value system, and they appreciate respect and morality in relations. The values of both the enterprises and the stakeholders coincide and make up a mutual value system, which is why they find each other attractive. Both the enterprise and the stakeholders have needs based on mutual values (for example, one side might want to attract investments that would help to decrease the pollution of the enterprise, the other side might want to get return on investment, knowing that it helps to contribute to the welfare of the society, and so on). Naturally, each side wants to fulfil its needs but in doing so they watch the needs of others and try to react. We get a situation where both parties of these relations try to fulfil their needs and then fulfil each other's needs. This is a very satisfactory situation for both parties and it leads to a longterm cooperation, strong partnership, mutual satisfaction.

\section{Creative accounting: a tool to make the enterprise more attractive}

The main goal of enterprises and businesses who carry out economic and commercial activities is to make as much as profit possible. High profit shows that the enterprise is successful and is able to attract investors, creditors, employees who seek a stable salary and social guarantees. The main source of information where one can find data about the financial situation of an enterprise is the financial statements. With the help of financial analysis one can perform an extensive analysis of the enterprise's past and present financial and economic activities and their results, anticipate prospects. This would help the users of information to find out the true situation of the enterprise, the processes happening within it and its trends, based on which one could make correct and economically justified decisions. That is why it is especially important to provide accurate data in the financial statements which would depict the true and fair view of the enterprise's situation. Different legal acts, standards and rules regulate the financial statements. Because of the variety of enterprises and their activities, it is impossible to manage accounting according to the same rules. That is why the legislator allows enterprises to choose which accounting methods to use themselves, so that it would represent the true situation of the enterprise as closely as possible. To ensure that the financial accountability to reflect the true and fair view of the enterprise, the accountant not only must be professional but creative as well when managing the accounting. This way of searching for creative methods is called creative accounting, and the term has been adopted relatively recently (Watts, Zimmerman 1986; Griffiths, 1986). Practice shows that creative accounting has a huge impact on the accounting results because the accountants are able to manipulate the financial accounting data. However, when we cannot precisely regulate the situations and the enterprise and its accountant are left with the possibility to decide for themselves which accounting methods to use, a problem arises because there is a possibility that the accounting methods can become a manipulation object, and the information that is shown in the financial statements regarding the financial situation of the enterprise is distorted and does not show the true and fair view. Enterprises can manipulate their true financial situation to achieve different goals-to present the enterprise's financial situation better than it is (to present a better image to investors, to receive better conditions from a credit company when applying for a loan, to sell the enterprise for a higher price) or to present it worse than it is (trying to make the financial situation worse, pay less taxes). Mackevičius, Savickas (2015) associate the creative 
accounting term not only with the search of creative methods. According to them, this choice of accounting methods (usually used to make more money and improve the enterprise's image) helps the management to present those financial results and activities that they prefer to present.

Those who apply creative accounting methods can manipulate various areas of the enterprise's accounting: non-current assets accounting, inventories accounting, equity accounting, liabilities accounting, recognition of income and expenses, accounting policy, the need for working capital, treasury, expenses of assets, profitability, etc. (Lakis, 2011; Gherai, Balaciu, 2011; Giriūnienė, 2012; Mačiuitytė- Radickienė, Subačienė, 2012; Bachtijeva, Tamulevičienė, 2019). The main goal of creative accounting is to satisfy the enterprise's wish to present the results of its activities in the financial statements as they wish. Yet in doing so they mislead the other users of information because the information presented in the financial statements is distorted. Mockevičiūtè, Rudžionienè (2011) conducted an empirical study of Lithuanian enterprises which verifies that the enterprises who choose their accounting policies decide which creative accounting methods to apply and what outcome they seek. The results of the study showed that small enterprises prefer to apply accounting methods which increase their profits, whereas larger enterprises choose accounting methods which decrease their profits.

During a study carried out in India, it was attempted to find out the view of accountants and managers regarding the application of creative accounting (Bhasin, 2016). The results of the study showed that the application of creative accounting is appropriate and purposeful when choosing those creative accounting methods that would help them gain unfair advantage against other enterprises. Creative accounting is applied to adjust financial data and achieve a desired goal, to meet certain financial prospects and in doing so gain advantage. The results of another study showed that more than half of respondents apply creative accounting to reduce the tax burden (Cernusca et al., 2016). The study by Balaciu et al. (2012) showed that as many as $68 \%$ of auditors in Romania think that creative accounting is a frequent process and it can affect the financial accounting results in ways that the persons concerned want. Moreover, as many as $44 \%$ of auditors who participated in the survey think that the financial statements presented by the companies who apply creative accounting are not transparent enough. Other studies have shown that creative accounting does not let the users of information to see the true and fair financial state of the enterprise (Malhotra, 2013) and the use of creative accounting methods has a negative impact on the reliability of financial reporting (Yousif, Ismael, 2017).

It must be noted that the flexibility of legal acts and alternative accounting methods is not a problem in itself and does not have a negative impact on the reliability of financial information. On the contrary, different alternatives allow the accountants to use their competence and creative abilities to seek optimal methods (Malhotra, 2013; Cernusca et al., 2016). Due to the variety of enterprises and activities, they all have to be flexible in accounting to a certain extent but this has to be done in order to present true results rather than distort them (Gherai, Balaciu, 2011). Nevertheless, studies show that creative accounting is widely applied in various countries to deliberately gain advantage in the market, decrease tax benefits, show that the profits are higher or lower than in reality. The phenomenon of creative accounting has not only become the tool of attractiveness but it also has a huge influence on the quality of the financial statements because they do not reflect the true and fair view of the enterprise and are not reliable. Since financial statements are the primary source of information for the customers making decisions, the application of creative accounting is harmful not only to the users of information (creditors, investors, suppliers, employees, public authorities) but it can have a disastrous effect on the enterprise itself; because of it the management might lose its integrity and the enterprise might ruin its image.

\section{Conflict between the creative accounting and the corporate social responsibility, the impact on the reliability of information and development of economic prosperity}

Economic (financial) responsibility is one of the elements of the corporate social responsibility. It is the basis of all social responsibility which gives rise to all other responsibilities. Economic responsibility is associated with the enterprise's profitability, efficiency, financial risk management, and so on, and we can get nearly all the above mentioned data from the financial statements presented by enterprises. At the end of the 20th century after harmonizing the legal norms that regulate accounting, all enterprises were in the same position and the information that they presented in their financial statements became publicly available and understandable to the stakeholders. Not only was the legal framework made uniform for all enterprises, the requirements for preparing and presenting the financial statements were standardized and the notion of "true and fair" view was introduced which means that the accounting of the enterprise must be carried out in the way that financial statements would reflect the true and fair view of the enterprise's financial state and the results of its activities. Such harmonization was necessary so that all market participants would have the same conditions and they could communicate with each other using the same financial language and, therefore, understand each other. Nowadays, financial statements are one of the main information sources that informs us about the financial state of the enterprise and the results of its activities. Although we must admit that creative accounting has become a tool for manipulating the data of financial statements so they would 
reflect the preferred results. We must note that the aforementioned study results show that creative accounting is used to adjust the financial data which is why financial statements may lack transparency, reliability and quality. It is a very important aspect when assessing the level of corporate social responsibility since the enterprise which applies creative accounting publicly presents unreliable and low-quality data regarding its financial state.

Before making any decisions regarding the enterprises, stakeholders must take into account the enterprise's capability, financial adequacy, they should anticipate the potential development or risk of the enterprise. That is why enterprises have various performance indicators. Slapikaite (2016) presented a system for estimating the corporate social responsibility and in its economic-financial group one finds estimation of the enterprise's profitability, liquidity and debt ratios. It is worth noting, though, that when an enterprise applies creative accounting, the information presented in the enterprise's financial statements is unreliable. Since all the aforementioned indicators are calculated by taking numbers from the data from the financial statements, the calculations will be unreliable and misleading as well. Slapikaite (2016) notes that the criteria from the economic-financial group are the most significant (0.534). So, even if an enterprise obtains a maximum score in the other three category groups, it would not be enough to admit that the corporate social responsibility level is very high. Therefore, the assessment of the economic-financial group is decisive in determining the social responsibility level. Such situation gives rise to a threat that the enterprise seeking a higher grade of its social responsibility level, might deliberately manipulate the financial data and in doing so become a more attractive and economically stronger enterprise. The enterprise's wish to receive a higher social responsibility grade by manipulating the financial data might risky to stakeholders and result in profit losses.

A study carried out by Arnold et al. (2017) showed that professional investors make their decisions based on the financial as well as non-financial information about the enterprise. The investors from the USA and Germany prefer to choose the enterprises with higher social responsibility level when making personal investment decisions or making recommendations even though they know that this might mean lower return on investments, since they believe that activities carried out by such socially responsible enterprises are beneficial for society. The enterprises whose management is oriented towards stakeholders and seeing that social responsibility level has an impact on investors are likely to disclose more information about the business, especially its policies regarding social and environmental responsibility (Chanatup, Aujirapongpan, Ritkaew, 2020).

Another especially important negative aspect of creative accounting application is the fact that most decisions are made on the basis of financial information. The financial statements data analysis and interpretation of them help stakeholders to make economically reasonable decisions and thus reduce the risk of wrong decisions. Stakeholders expect that the financial information that the enterprise discloses is correct. Yet the financial reporting of the enterprise is unreliable and incorrect because of the creative accounting which may mislead the stakeholders or they might even incur losses because of this. The study by Chanatup, Aujirapongpan, Ritkaew (2020) showed that the enterprises where management is oriented towards the shareholders and which consider maintaining benefits for them a priority, the financial accountability has a positive connection with the risk of investment, which means that the information an enterprise presents might have an impact on the investors' confidence in the enterprise and affect their behaviour. Moreover, the study by Arnold et al. (2017) shows that the enterprise which manipulates the information presented in the financial statements, can deliberately shift the attention of the investors towards specific information that is beneficial only to the enterprise and on the basis of which, investors will make their decisions. Therefore, we can say that application of creative accounting allows enterprises to manipulate not only the financial information, but the stakeholders as well. In such cases a situation arises where the creative accounting allows the enterprise to manipulate certain data and get an unfair advantage regarding the stakeholders, and influence their decisions. Such advantage cannot be considered as equivalent relations with stakeholders. They are not based on values, morals, and cause a conflict between the enterprise and the needs of stakeholders. Such relations are short lived and unsustainable.

Ethics is one of the enterprise's values both within the organization and in relations with its environment. Caroll (1991) names three views on ethical management: immoral, amoral and moral behaviour and management. She considers immoral management as decisions, actions and behaviour that are contrary to ethics. An enterprise makes decisions and behaves contrary to the principles of ethics and adopts a strategy to exploit resources to seek maximum gain. She also writes that amoral behaviour contradicts the ethics, although this type of behaviour is caused by carelessness, short-sightedness, or lack of awareness because such enterprises do not understand the role of ethics in business. Management is considered moral when and enterprise adopts a management strategy to seek profit by adhering to ethical norms and principles of honesty and fairness. The application of creative accounting is always a deliberate action with specific intentions that is why the use of it can be called as the most arrogant and indecent action allowing enterprises to abuse their power and violate the interests of others when trying to achieve a specific goal 
without adhering to the ethical and moral norms. Beniulyte், Šeinauskienè, Rūtelionienè (2020) note that the connection between the moral ideologies of a consumer and the enterprise's values, which are indirectly affected by such enterprise's activities as the corporate social responsibility, shows that the ethical view is reflected in the consumers' decision making-how much do they trust the enterprise and how they behave.

In the scientific works on accounting, the issue of the creative accounting ethics is often discussed (Balaciu et al. 2012; Malhotra, 2013; Bhasin, 2016; Yousif, Ismael, 2017 and others). Gowthorpe, Amat (2005) claim that the manipulations of creative accounting are unethical because thus enterprises abuse their power and are unfair to the consumers. Other authors associate the practice of creative accounting with the ethics of an accountant. Seeking to evaluate the influence of ethics on the application of creative accounting, Malhotra (2013) carried out a study in which he paid focused on the theory by Gray (1988) which states that the ethical belief system of an individual affects his professional values. The study showed that ethical thought is more important than smart principles of accounting and the strict regulation of this issue, and the flexibility of accounting policy is part of the practice, so the good will and moral values are important for an accountant. Malhotra (2013) notes that ethics and morality should be the rule in the business world rather than an exception. We must take into account, though, that if an accountant presented the financial statements only to the executive of the enterprise and this information would not leave the enterprise doors, one could discuss only about the accountant's ethics and his responsibility. Yet financial statements are made public. They are the main source of information about the enterprise's activities, and users make economically based decisions based on that information. In this case, the executive of the enterprise is responsible for the reliability of the data of financial statements. So, one can say that the use of creative accounting is not only an ethical issue of the accountant and the manager, it is the issue of the whole enterprise. The practice of creative accounting should be considered as unethical behaviour of the whole enterprise, which is contrary to the concept of socially responsible enterprises.

Social responsibility must not be a tool to improve the enterprise's reputation or to manipulate the stakeholders' decisions. When an enterprise seeks to become socially responsible not because of its values but because of selfish purposes and manipulation of financial information, the enterprise might be attractive at first since the relations with stakeholders are based on lies, not on values and a mutual need to satisfy each other's needs. Figure 2 shows what happens when an enterprise and the stakeholders do not share a mutual value system. Stakeholders have their own value systems, and they expect the enterprise to adhere to the same principles because it states that it is socially responsible. Meanwhile in reality the behaviour of the enterprise is based on selfish reasons and the main wish of the enterprise is to fulfil its interests without taking into consideration the needs of stakeholders. The enterprise wishes to fulfil its needs and, therefore, it starts applying creative accounting methods, and manipulating the financial information in order to gain an unfair advantage in the market. Stakeholders, unaware of the true situation, may find such enterprises very attractive and thus the enterprises manipulates their decisions. This image of the enterprise is based not on its values, but lies which lead to the conflict of interest and after a while stakeholders begin to feel dissatisfied with and disappointed in the enterprise. Naturally, the enterprise achieves its short-term goals but it does not satisfy the stakeholders' interests or satisfies them only to an extent and such relations cannot be sustainable and lasting. Stakeholders may be so dissatisfied that they may refuse to purchase the enterprise's production, not extend long-term contracts, not invest any more, and thus push the enterprise out of the market.

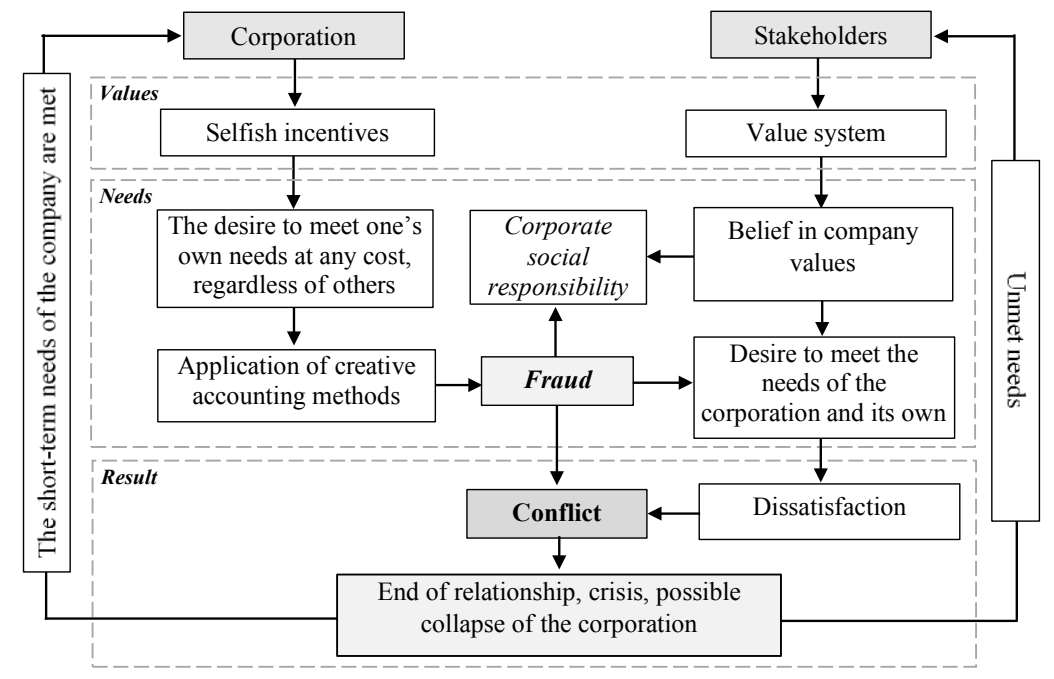


Fig. 2. The conflict of creative accounting and corporate social responsibility

The application of creative accounting methods is incompatible with the concept of corporate social responsibility because they are fundamentally contrary to each other. A company which selfishly manipulates its financial data and stakeholders' decisions and provides unrealistic information about its financial state, cannot call itself a socially responsible enterprise. Corporate social responsibility and creative accounting methods are completely contradictory and are incompatible (see Figure 3). The higher the level of the social responsibility the more reliable the financial information provided by the company. Such companies adhere to values and behave honestly, that is why they are very attractive to stakeholders and contribute to the development of economic well-being. When a company applies creative accounting methods, the financial information is distorted and does not show the true and fair view about the company's condition and the results of its activities. An unfair advantage in the market prevents other participants from contributing to the development of economic well-being and such manipulations are unethical, that is why companies that apply creative accounting methods cannot call themselves socially responsible. Companies that do not adhere to values and manipulate their financial information are not attractive to stakeholders. The information that these companies provide should be assessed carefully and critically.

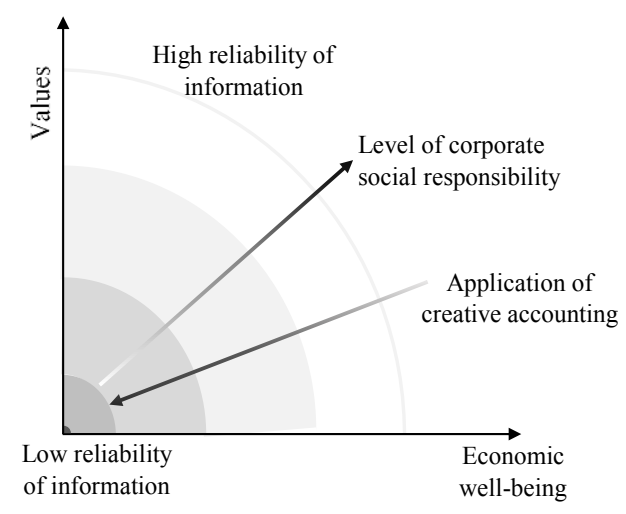

Source: authors' construction

Fig. 3. The relationship between the creative accounting and corporate social responsibility and their relation to the economic well-being

All relationships based on manipulations and lies are fake and they lead to dissatisfaction and conflict. Such companies pretend to care about the environment, and they donate to charitable foundations, but, these are just tools to improve their reputation and are just one of their many means of manipulation. Dishonest and unethical behaviour with stakeholders and trying to achieve goals by any means necessary by disregarding all moral values, might be beneficial in the short run. Because of wide dissemination and easy access of information in today's society, news about improper behaviour or a dishonest company might spread very quickly and this could be a significant blow for the company's reputation and the prospects of its activities. A company should improve its reputation through its actions: correct financial reporting, ethical, honest and respectful behaviour. This shows that a company is mature and only mature companies can call themselves socially responsible, therefore, be attractive and maintain sustainable relationships with investors, creditors, employees and the whole society.

\section{Conclusions}

1. The concept of corporate social responsibility is based on the idea that the company and stakeholders seek to have a common value system and to fulfil mutual needs. It is attractive because it leads to trust, close cooperation and sustainable relationships. The corporate social responsibility level, regardless of the selected theory or system, should be assessed in a complex way, taking all elements into account, rather than sporadically.

2. The globalization of companies' activities led to the necessity of harmonizing legal regulation framework for the preparation of financial statements of the accounting processes and corporate social responsibility. This should have made all market participants equal and foster easier cooperation. On the contrary, the application of creative accounting methods gives the company an unfair advantage against others, and the information provided in the financial statements is unreliable, and, therefore, should be assessed critically. The analysis of such inaccurate financial statements showed that companies might be given their social responsibility level unfairly. On the other hand, stakeholders that make decisions regarding the company can be misled deliberately and thus companies can manipulate not only the financial data, but the stakeholder decisions as well and they may incur losses. 
3. Companies who seek to have an advantage in the market and fulfil their needs by manipulating act immorally. One of the values of socially responsible companies both within the organization and in relationship with its environment, is ethics. Such actions are not only incompatible with the concept of corporate social responsibility, but are completely opposite. A socially responsible company that manages accounting cannot use the methods of creative accounting and if a company uses such methods, it cannot call itself a socially responsible enterprise. In the long run, the application of creative accounting methods in the company that calls itself socially responsible might cause a relationship crisis with stakeholders, the end of the relationship or even the collapse of the company itself. And this does not contribute to the development of economic well-being.

\section{Bibliography}

Aguilera, R. V., Rupp D. E., Williams C.A., Ganapathi J., 2007. Putting the S Back in Corporate Social Responsibility: A Multilevel Theory of Social change in organizations. Academy of Management Review, 32(3), 836-863.

Arnold, M. C., Horner, Ch., Martin, P., Moser, V. D., 2017. German and US Investment Professionals' Use of Corporate Social Responsibility Disclosures in Their Personal Investment Decisions and Recommendations to Vlients. Available at: https://papers.ssrn.com/sol3/papers.cfm?abstract_id=3020887 [Accessed 27.04.2020].

Bachtijeva, D., Tamulevičienė, D., 2019. Organization of the Process of Creating a Company's Accounting Policy: Theoretical Aspects. Sustainable Development of the Economy: International and National Aspects. International Conference, Polotsk, Belarus, April 18-19, 2019: Proceedings. Polotsk University, 596-602.

Balaciu, D., Bogdan, V., Mester, I.T., Gherai, D., 2012. Empirical Evidences of Romanian Auditors Behavior Regarding Creative Accounting Practices. Accounting and Management Information Systems, 11(2), 213-238.

Beniulytè, D., Šeinauskienè, B., Rūtelionienè, A., 2020. Received Influence of Corporate Social Responsibility on Consumer Loyalty: the Role of Ethical Ideology. Entrepreneurship and Sustainability Issues. 8(1), 291-300.

Bhasin, M., 2016. Survey of Creative Accounting Practices: an Empirical Study. Wulfenia Journal, 23(1), 143-162.

Boatright, J. R., 1996. Business Ethics and the Theory of the Firm. American Business Law Journal, 34(2), 217-238.

Carroll, A. B., 1991. The Pyramid of Corporate Social Responsibility: Toward the Moral Management of Organizational Stakeholders. Business Horizons, July-August, 39-48.

Cernusca, L., David D., Nicolaescu, C., Gomoi, B. C., 2016. Empirical Study on the Creative Accounting Phenomenon. Studia Universitatis Economics Series, 26(2), 63-87.

Chanatup, S., Aujirapongpan, S., Ritkaew, S., 2020. The Influence of Corporate Governance Mechanism on the Integrated Financial Reporting and Investment Risk of Thai Listed Companies. Entrepreneurship and Sustainability Issues. 7(4), 2818-2831.

Daft, L. R., 2006. The New Era of Management. Mason: South - Western.

Dalhsrud, A., 2008. How Corporate Social Responsibility is Defined: an Analysis of 37 Definitions. Corporate Social Responsibility and Environmental Management, 15, 1-13.

Diskienè, D., Seiliūte, J., 2012. Corporate Social Responsibility: Comparative Analysis of the State of Play in Lithuania and Belarus. Ekonomika, 91(3), 129-146.

Dodd, E. M., 1932. For Whom are Corporate Managers Trustees? Harvard Law Review, 45, 1145-1163.

Donaldson T., Preston L. E., 1995. The stakeholder theory of the corporation: concepts, evidence, and implications. Academy of Management Review, 20(1), 65-91.

Elkington, J., 1998. Cannibals with Forks: the Triple Bottom Line of 21st Century Business. US. New Society Publishers.

Green Paper, 2001. Promoting a European Framework for Corporate Social Responsibilities, 2001. Commission of the European Communities, [Online] Available at: https://ec.europa.eu/commission/presscorner/detail/en/DOC_01_9 [Accessed 29.04.2020].

Feng, Y., Zhu, Q., Lai, K.H., 2017. Corporate Social Responsibility for Supply Chain Management: a Literature Review and Bibliometric Analysis. Journal of Cleaner Production, 158, 296-307.

Fray, A. M., 2007. Ethical behavior and social responsibility in organizations: process and evaluation. Management Decision, 45(1), 76-88.

Garavan, T. N., McGuire, D., 2010. Human Resource Development and Society: Human Resource Development's Role in Embedding Corporate Social Responsibility, Sustainability, and Ethics in Organizations. Advances in Developing Human Resources, 12(5), $487-507$.

Gavronski, I., Klassen R.D., Johnson P.F., Naranjo F., 2018. Management Temporal Orientation: Linking Operational Investment to Corporate Social Responsibility. Academy of Management Proceedings, 1. [Online] Available at: https://journals.aom.org/doi/10.5465/AMBPP.2018.256 [Accessed 12.05.2020]. 
Gherai, D. S., Balaciu, D. E., 2011. From Creative Accounting Practices and Enron Phenomenon to the Current Financial Crisis. Annales Universitatis Apulensis Series Oeconomica, 13(1), 34-41.

Giriūnienè, G., 2012. Kūrybinès apskaitos metodikos ir jų taikymo sritys įmonèje. İ̌̌valgos, 1(7), 124-134.

Gižienė, V., Palekienè, O, Simanavičienè, Ž., 2011. State Social Responsibility in the Context of Knowledge-Based Economy. Economics \& Management, 16, 485- 492.

Gowthorpe, C., Amat, O., 2005. Creative Accounting: Some Ethical Issues of Macro- and Micro-Manipulation. Journal of Business Ethics, 57, 5564.

Griffiths, I., 1986. Creative accounting. London: Sidgwick \& Jackson.

Gudonienė, V., Leipuvienè, K., 2007. Socialiniu iniciatyvu versle analizė: nauda, kaštai, ịtaka verslui ir visuomenei. Taikomojo mokslinio tyrimo ataskaita. Vilnius: UAB „Ekonominès konsultacijos ir tyrimai“.

Herrera, J., De las Heras-Rosas, C. 2020. Corporate Social Responsibility and Human Resource Management: towards Sustainable Business Organizations. Sustainability, 12(3), 1-25.

Juščius, V., 2007. Verslo socialinės atsakomybės teorijų raida. Ekonomika, 78, p. 48-64.

Korschun, D., Bhattacharya, C.B., Swain, S.D., 2014. Corporate Social Responsibility, Customer Orientation, and the Job Performance of Frontline Employees. Journal of Marketing, 78, 20-37.

Kotler, Ph., Lee, N., 2007. Corporate Social Responsibility. Doing the Most Good to Your Company. New Jersey: John Wiley \& Sons.

Kotter, J. P., Heskett, J. L., 1992. Corporate Culture and Performance. New York: Free Press.

Lakis, V., 2011. Manipuliacijų finansine informacija priežastys ir būdai. Buhalterinès apskaitos teorija ir praktika, 9, 33-45.

Lindgreen, A., Swaen, V., Johnston, W. J., 2009. Corporate social responsibility: an empirical investigation of U.S. organizations. Journal of Business Ethics, 85, 303-323.

Mačiuitytė - Radickienè, R., Subačienė, R., 2012 Manipuliavimo pajamomis ir sąnaudomis būdų analizè. Ǐžvalgos, 1 (7).

Mackevičius, J., Savickas, V., 2015. Manipuliacinès kūrybinès apskaitos anatomija ir jos informacijos naudojimas. Informacijos mokslai. 71, 124134.

Malhotra, A., 2013. Curbing Creative Accounting: Role \& Effectiveness of Ethics. International Journal of Finance and Policy Analysis, 5(2), 1527.

Mockevičiūtè, A., Rudžionienè, K., 2011. Apskaitos politikos ịtaka pelnui. Buhalterinès apskaitos teorija ir praktika, 9. 54-61.

Revelli, C., Viviani, J.L., 2015. Financial Performance of Socially Responsible Investing (SRI): What Have we Learned? A Meta-Analysis. Business Ethics: A European Review, 24(2), 158-185.

Sims, R. R., 2003. Ethics and Corporate Social Responsibility: why Giants Fall. Greenwood Publishing Group, Inc.

Slapikaite, I., 2016. Practical Application of CSR Complex Evaluation System. Intellectual Economics, 10(2), 101-107.

Taylor, F. W., 1911. The Principles of Scientific Management. New York and London: Harper and brothers Publishers.

Vitell, S. J., 2015. A Case for Consumer Social Responsibility (CSR): Including a Selected Review of Consumer Ethics/Social Responsibility Research. Journal of Business Ethics, 130, 767-774.

Watts, R.L., Zimmerman, J.L., 1986. Positive Accounting Theory. New Jersey: Prentice-Hall.

Whitehouse, L. A., 2003. Corporate Social Responsibility, Corporate Citizenship and the Global Compact: a New Approach to Regulating cCorporate Social Power. Global Social Policy, 3, 299-318.

Yousif, A., Ismael A., 2017. The Impact of Creative Accounting Techniques on the Reliability of Financial Reporting with Particular Reference to Saudi Auditors and Academics. International Journal of Economics and Financial Issues, 7(2), 283-291. 


\section{PRODUCTIVITY FACTORS AND DYNAMICS IN LATVIA \\ Olegs Baranovs, Ministry of Economics \\ Janis Salmins, Ministry of Economics \\ Irina Skribane, University of Latvia}

Abstract. Productivity is crucial factor for the growth of Latvia's economy and prosperity. Although Latvia has achieved significant growth since joining the European Union, productivity growth has slowed in recent years. Today, the world is experiencing a strong shock due to Covid19 crisis, the impact of which on productivity has not yet been widely studied.

The aim of this study is to analyse the dynamics of productivity in Latvia, structural changes in technological intensity, as well as the analysis of productivity-related factors. The impact of the Covid-19 pandemic on productivity is also analysed based on researchers' assessments and available information. The research is based on statistical data, studies, and policy documents. It aims to integrate the available data from a broad range of international and domestic sources from the perspective of Latvia. To determine the impact of the redistribution of labour resources on the overall productivity dynamics in the Latvian economy, the shift share analysis method was used.

The study shows that the low level of productivity in Latvia is largely related to structural factors - the low level of manufacturing and the dominant position of low-tech industries, the small share of knowledge-intensive industries, the business sector is dominated by SME companies, export structure, etc. The research argues that the redistribution of labour resources in Latvia in favour of more productive sectors is insufficient to have a significant impact on the faster growth of the overall productivity level of the economy. To facilitate productivity, it is important to strengthen innovation and investment in R\&D, the new technologies, especially digitization, as well as investing in human capital, improving people's skills and competences.

Keywords: productivity, economic policy, structural factors.

JEL code: E24, J24, L60, O15, O30, O40

\section{Introduction}

Productivity is crucial factor for the growth of Latvia's economy and prosperity. Although Latvia has achieved significant growth since joining the European Union, productivity growth has slowed in recent years, and solutions need to be found to ensure faster productivity convergence. Today, the world is experiencing a strong shock due to Covid-19 crisis, the impact of which on productivity has not yet been widely studied.

Productivity dynamics are influenced by several factors, the identification and research of which is important not only for researchers, but also for public policy makers. Without an understanding of the factors that determine productivity dynamics, it is not possible to apply appropriate policy instruments to ensure sustainable economic growth.

The aim of this study is to analyse the dynamics of productivity in Latvia, structural changes in technological intensity, as well as the analysis of productivity-related factors. The impact of the Covid-19 pandemic on productivity is also analysed based on researchers' assessments and available information.

The research is based on statistical data, studies, and policy documents. It aims to integrate the available data from a broad range of international and domestic sources from the perspective of Latvia. To determine the impact of the redistribution of labour resources on the overall productivity dynamics in the Latvian economy, the shift share analysis method was used.

The research questions need to be answered: What are trends and dynamics of productivity and structural changes in technological intensity? What is the impact of the redistribution of labour resources on the overall productivity dynamics? How the Covid-19 pandemic affects productivity growth? What are the key reforms to boost productivity?

The first section of the study gives an insight into the literature on the subject and main conclusions on Latvia's productivity. In the second chapter, the authors describe the dynamics of productivity in Latvia and the pace of convergence. The third chapter deals with the productivity analysis by key industries and structural changes in technological intensity. The fourth, concluding chapter gives a description of productivity factors in Latvia such as innovation, R\&D investment, digitalization, human capital. The article concludes with the main conclusions, proposals and recommendations of the study. 


\section{Literature Review}

Productivity has been extensively studied in the world scientific literature. Many monographs and articles in scientific research journals, etc. have been published. International organizations, such as the Organization for Economic Co-operation and Development (OECD), the International Monetary Fund (IMF), the European Commission (EC), etc., also study productivity and look for solutions to promote it.

In particular, the issue of productivity has become relevant in recent decades, when there has been a decline in productivity growth in the world, especially in developed countries. The OECD points to several obstacles to productivity growth, including demography, education, inequality, globalization, the environment and debt. The pace of productivity growth is also significantly affected by the decline in knowledge-based capital accumulation and business start-up growth. One of the biggest problems according to the OECD, is the slowdown in the spread of innovation in the economy (OECD, 2015).

There has been growing recognition that promoting pro-productivity policies can be a particularly daunting task. Such a task is further complicated by the fact that when it comes to productivity, there is neither a silver-bullet solution, nor a standard set of reforms that can be implemented in the same way in every country (Renda, 2017, p. 197).

In order to achieve sound policy decisions based on independent analysis and recommendations, special bodies have been set up in several OECD countries - the Productivity Councils, which act as supervisory and advisory bodies in the field of economic policy, structural reform and regulation. In 2015, the OECD established the Global Productivity Forum (GFP), which aims to promote international cooperation between Productivity Councils. The EC has also set up a productivity analysis dialogue platform, like the OECD GFP.

In Latvia, too, awareness of the role of productivity in growth and prosperity is growing. Latvia's productivity promotion policy issues are included in several policy planning documents, for example, in the Latvian National Reform Program for the Implementation of the Europe 2020 Strategy, the National Development Plan, the Latvian Smart Specialization Strategy and others.

Research on Latvia's productivity and competitiveness, factors closely related to productivity, such as investment, innovation, digital technologies, employment, etc. is carried out both by international organizations such as the OECD, the IMF, the EC, etc., and Latvian researchers and state institutions.

The OECD studies on economic trends in Latvia highlight several factors that hamper productivity. The OECD Economic Surveys: Latvia 2017 (OECD, 2017) note that Latvia's low productivity is due to the relatively low participation in global value chains and the specialization of exporting companies in low-tech manufacturing. Reference is also made to the slow uptake of modern technologies, hampered by skills shortages and inadequacies. Conversely, limited access to vocational and higher education for low-income students and limited affordability of affordable housing in the region of Riga, which has the highest employment growth, are hampering skills development and better matching. Productivity growth is also hampered by underinvestment in R\&D and weak innovation and cooperation between science and industry.

The 2019 OECD Economic Survey on Latvia pointed out that Latvia needs stronger productivity growth to improve its quality of life. Productivity growth has slowed down after 2008, as the financial crisis impaired the credit channel impeding stronger capital deepening and investment in innovation. The lack of skills, especially those needed to acquire digital technologies, and weak competition in some sectors with significant participation by state and municipal enterprises are also holding back productivity growth (OECD, 2019).

The IMF researchers point out that productivity growth is key to maintaining the pace of income convergence and that Latvia has made significant progress in raising productivity. At the same time, it is stated that maintaining productivity growth will not be simple, as easy gains have likely already been exhausted and firms are approaching their technology frontiers. Continued progress in implementing structural reforms will be needed to reduce the productivity gap improving the governance of public enterprises, improving the business environment, modernizing public infrastructure, and strengthening the judiciary (IMF, 2016).

Similar conclusions can be found in the European Commission's materials. The Staff Working Document states: "Latvia remains a catching-up economy and its main national development focus is on increasing its GDP per capita. As evidenced by falling productivity growth rates, the easy gains of the early catch-up stage have been exhausted. This means that productivity growth will have to increasingly rely on knowledge-intensive activities. Latvia's weakest point has been innovation, which requires investments in research and development, in developing people's knowledge and skills, and in other intangible assets. Latvia would also benefit from boosting the economic potential of its peripheral regions - increasing their accessibility, and promoting energy efficiency, employment and investment opportunities. Finally, investments in social inclusion and healthcare are needed in order to tackle high inequality and uneven access to employment and public services "(European Commission, 2019, p.4). 
In 2011, the Riga School of Economics commissioned by the State Chancellery to conduct an assessment of Latvia's competitiveness (Stockholm School of Economics in Riga, 2013). The competitiveness concept chosen by the authors of the Latvia Competitiveness Report (LCR) focuses on productivity in a broad sense. The LCR indicates the causes of the biggest problems in Latvia's competitiveness. It sets out priorities for action and recommends reforms in public administration. The authors of the study believe that the policy should focus on three thematic priority areas: reducing the shadow economy, improving the quality of the education system and improving transport infrastructure. A large informal sector leads to a significant misallocation of the scarce resources of the economy, shifting them to labour-intensive, low-productivity activities, especially in the services sector. The huge share of the informal economy forces entrepreneurs to focus on exploiting short-term opportunities rather than long-term investments to increase productivity. Education was chosen as a priority area both because it is relevant to all sectors of the economy (especially important for direct areas of competitiveness such as innovation) and because it has a long implementation period. In turn, improved transport infrastructure can have a positive impact on both production and the reduction of inequalities

The authors of LCR considered that if the above issues are successfully addressed, in the medium term it should have a significant impact on other key areas, such as income inequality, innovation, productivity, industrial growth, GDP and capital markets. development. The LCR study concludes that there must be a political will to develop a permanent process for assessing and monitoring competitiveness, and that adequate and stable funding must be provided for this purpose. Further competitiveness assessment and monitoring should be carried out by an independent body outside the government, for example by setting up a Competitiveness Institute.

Certain aspects of productivity in the Latvia's context have been also looked at in the following research publications: productivity measurement (Fadejeva L., Melihovs A., 2009. Measuring Total Factor Productivity and Variable Factor Utilisation: Sector Approach, the Case of Latvia, Bank of Latvia Working Paper); effects of export entry on productivity, employment and wages (Benkovskis K., Masso J., Tkacevs O., Vahter P., Yashiro N., 2018. Export and productivity in global value chains: Comparative evidence from Latvia and Estonia); effects on productivity due to resource misallocations in Latvia during 2007-2014 (Benkovskis K., 2018. Misallocation, productivity and fragmentation of production: the case of Latvia Journal of Productivity Analysis, 2018 - Springer).

K.Benkovsky's study indicates that Latvia's productivity lag is mainly explained by low total factor productivity, significant differences in the quality of production resources (human and capital). The study concludes that the distribution of resources between Latvian companies is far from efficient, and this means that without changing the productivity level of each individual company, we can significantly increase GDP only by moving labour or capital between companies (Benkovskis, 2015).

One of the most recent researches on productivity development in Latvia is the monograph "Raising Productivity: Trends and Future Challenges" (editor-in-chief - Inna Steinbuka), published in May 2019. The core study of the monograph (O.Baranovs, D.Baranova, G.Berzins, I.Skribane) provides comprehensive insights into the existing research on productivity in Latvia, identifies the topicality of productivity research, and the factors determining productivity. The authors analyse the dynamics of productivity in Latvia, including sectoral aspects. This study has identified main productivity enhancing policies in Latvia, in particular ensuring a stable macroeconomic environment, improving the quality of the business environment, improving the availability and quality of the workforce, promoting higher value-added production, and ensuring sustainable development; strengthening the competitiveness of Latvian regions and Riga. The authors discuss each policy domain in detail and argue that only systemic implementation of all policies and structural reforms can provide a desirable outcome (Steinbuka, 2019, p.8).

Latvia's competitiveness and the development of productivity-related factors in the international context are also characterized by ratings created by various organizations. For example, the Global Competitiveness Index (GCI) rating, published annually by the World Economic Forum (WEF), is a globally recognized tool for assessing national competitiveness (WEF, 2019). In general, it can be concluded from the GCI rating that the problems of sustainable growth of the Latvian economy must be solved complexes with the problems of increasing competitiveness, which in turn is not possible without changing the existing economic model. In creating a new economic model based on knowledge and innovation, special attention must be paid to the existing problems, such as the quality of the institutional environment, increasing the dynamism of business, strengthening the capacity for innovation.

Several conclusions can be drawn from the literature review on Latvia's productivity.

First, the productivity gap in Latvia from developed countries, although it has narrowed in recent decades, is still large. Latvia's productivity lag is mainly explained by low total factor productivity, significant differences in the quality of production resources (human and capital). 
Second, productivity growth has slowed down after 2008, as the financial crisis impaired the credit channel impeding stronger capital deepening and investment in innovation. Maintaining productivity growth will not be simple, as easy gains have likely already been exhausted and firms are approaching their technology frontiers. Productivity levels in almost all sectors are about a third of the EU-15 average. Closing such gaps will require continued progress on structural reforms.

Third, increasing productivity and competitiveness requires a comprehensive and broader approach: strong performance in one area cannot compensate for poor performance in another. Productivity dynamics are influenced by several factors, the identification and research of which is important not only for researchers and entrepreneurs, but also for public policy makers. Without an understanding of the factors that determine productivity dynamics, it is not possible to apply appropriate policy instruments to ensure sustainable economic growth. Every measure of improving the factors influencing productivity must be assessed in the context of the common economic system, where changes in one element undoubtedly require qualitative and quantitative changes in other elements as well.

Fourth, productivity growth will have to increasingly rely on knowledge-intensive activities. Latvia's weakest point has been innovation, which requires investment in research and development, in developing people's knowledge and skills, and in other intangible assets. However, policy makers must not forget the "old" problems, such as weak institutions, infrastructure gaps, regional inequalities, etc. In addition, declining population poses an additional challenge to productivity growth, as declining users put pressure on infrastructure efficiency and other activities that provide only a local market.

Fifth, given the small domestic market, Latvia's main prospects lie with exporting higher value-added goods and services and growing its export market shares. Latvia's low level of productivity is determined by the relatively weak participation of producers in global value chains and the specialization of exporting companies in low-tech production. Therefore, the opportunities to increase the level of productivity of Latvian companies are mainly related to its ability to perform technological modernization and innovation, to expand participation in world value chains.

Sixthly, there must be the political will to develop a permanent process for assessing and monitoring competitiveness, and adequate and stable funding must be provided for this purpose. Further competitiveness assessment and monitoring should be carried out by an independent body outside government.

In general, we must agree with the conclusion in the monograph "Increasing Productivity: Trends and Future Challenges" that the research of productivity-related aspects in Latvia is fragmentary and lacks a systemic approach (Steinbuka, 2019). The research has been carried out mostly at the macro level, moreover, there is very little research based on company-level data, but cross-sectoral (meso-level) aspects are practically not analysed, which is largely related to the availability of data. This limits the scope for research-based and science-based structural policy recommendations. The impact of the Covid-19 pandemic on productivity has not been studied at all. It is true that too little time has passed to draw far-reaching conclusions about the impact of this pandemic on productivity.

1.Productivity dynamics in Latvia

The analysis of statistical data shows that the dynamics of productivity in Latvia since the mid-1990s has been rapid (Figure 1). Productivity in Latvia has increased almost 3 times since 1996. However, productivity growth rates in Latvia tend to decline. Faster growth was observed until 2008, especially after Latvia's accession to the EU, which became a significant stimulus for the inflow of foreign investment (mainly in the form of debt-generating flows).

The global financial crisis has affected not only the slowdown in economic activity but also productivity dynamics. In the first two years of the economic recession (2008 and 2009), it declined by almost 3 percent. However, it should be noted that the decline in productivity compared to the decline in GDP (by 17.4\%) was insignificant and was mainly driven by strong labour market adjustments. By adapting to the new conditions and optimizing the attraction of resources, entrepreneurs reduced the demand for labour and the number of employees decreased by almost $15 \%$, which partially compensated for the decrease in productivity.

Positive productivity dynamics have resumed since 2010 but are much more moderate than before the crisis. In the last nine years (2011-2019), productivity has increased on average by $2.6 \%$ annually, i.e. almost 2.5 times slower than in 2007 . The decline in productivity growth is mainly due to the slow transformation of human and physical capital into science-intensive activities. The financial crisis has worsened access to credit, hampering the deepening of capital and investment in innovation. 


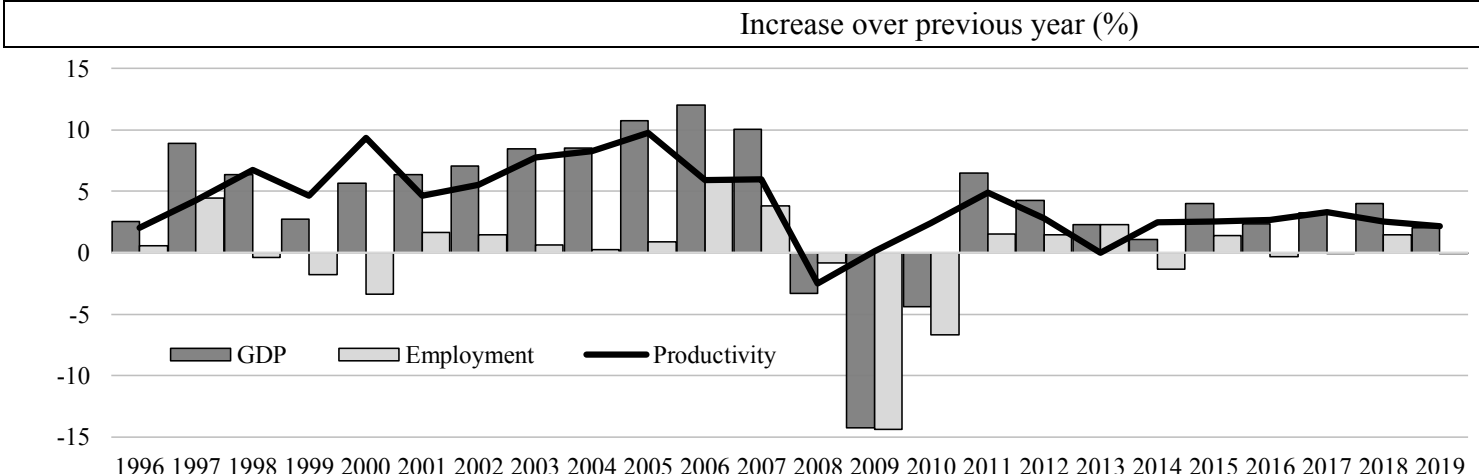

Source: author's construction based on the Eurostat data, 2020

Fig. 1. Annual productivity growth rates in Latvia

Although Latvia's productivity growth rates are among the fastest in the EU, compared to the EU's highly developed countries, there is still a large lag. In 2019, the productivity level in Latvia was only 49.8\% (68.8\% in Purchasing Power Standards) of the EU average, which is one of the lowest indicators in the EU (Figure 2).

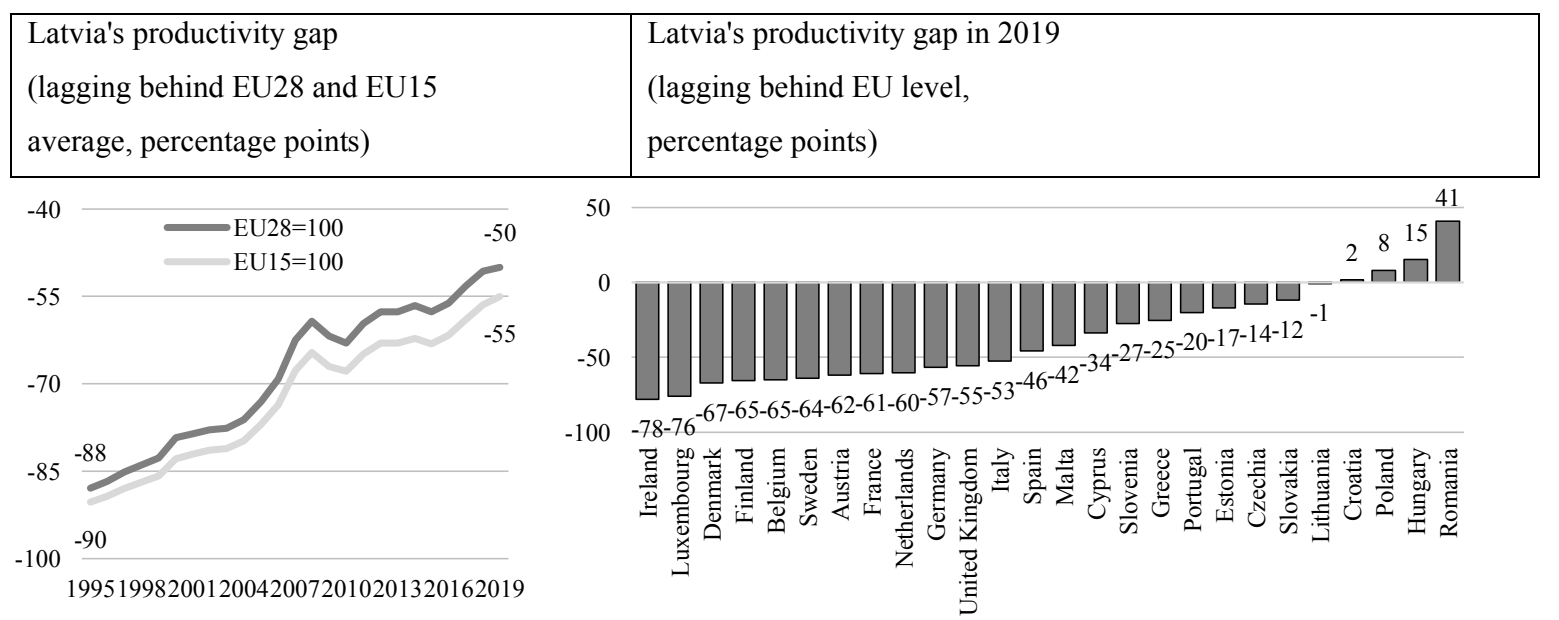

Source: author's construction based on the Eurostat data, 2020

\section{Fig. 2. Productivity convergence of Latvia with EU28 and EU15 average}

In 2020, the Covid-19 pandemic has had a strong and lasting global impact on the socio-economic situation. As in almost all countries of the world, the economy in Latvia has entered a recession in 2020 due to the Covid-19 pandemic and the labour market has been significantly affected. However, its impact on productivity is unclear.

The impact of the Covid-19 pandemic has changed not only the labour market, but also poses significant challenges in accurately measuring productivity. The temporary closure of enterprises, the increase in teleworking and the introduction of social distancing affect data collection. Government support measures, such as downtime benefits, affect the recording of labour productivity (output per number of employees), as a person may not work (be idle), but statistics perceive it as a worker.

In this case, the productivity measured as output per hour worked seems a more appropriate measure of the efficiency at corporate level. However, the use of this indicator is also not ideal because a number of uncertainties regarding the use of short-time work schemes (European Commission, 2020a, p. 48-49).

In the conditions of "normal" economic growth, changes in productivity are similar, both in terms of output per the number of employees and against output per hour worked, then the results are very different due to the crisis. This is mainly due to both the peculiarities of labour market adjustments and the expected duration and depth of the crisis in companies' assessments. 
By comparison, at the beginning of the 2008-2010 financial crisis, the number of hours worked continued to grow, while the number of employees decreased. As production or services declined, companies became more redundant, while existing workers worked more. At the same time, it should be noted that with the actual collapse of the current global financial system, it was clear in 2008 that the forthcoming crisis would be long-lasting the economic model of the previous decade based on rapid credit growth ceased to exist.

In turn, the crisis of 2020, when it started, was perceived as relatively short and quick to overcome. Initially, the most optimistic scenarios predicted a recovery of the V-type economy, believing that strict measures to limit the spread of the virus would yield good results and that the economy would return to stable growth in the second half of the year.

In terms of the number of hours worked, in the second quarter of 2020, which was the worst quarter affected by the Covid-19 crisis so far, productivity in Latvia has increased. On the other hand, in terms of the number of employees, it has decreased. Market sectors with relatively higher productivity levels are not more resilient to the Covid-19 pandemic shock than other sectors.

2.Productivity analysis by key industries and structural changes in technological intensity

Despite the slowdown in productivity in the post-crisis years, in most Latvian sectors they were faster than the EU average, which contributed to the reduction of the productivity gap with the EU also at the sectoral level.

In the period from 2000 to 2019, faster convergence of Latvia was observed in the primary sectors (agriculture and mining), where the productivity gap has narrowed by almost 40 percentage points. The slowest convergence rates were in the energy supply, professional and scientific services sectors (see Figure 3).

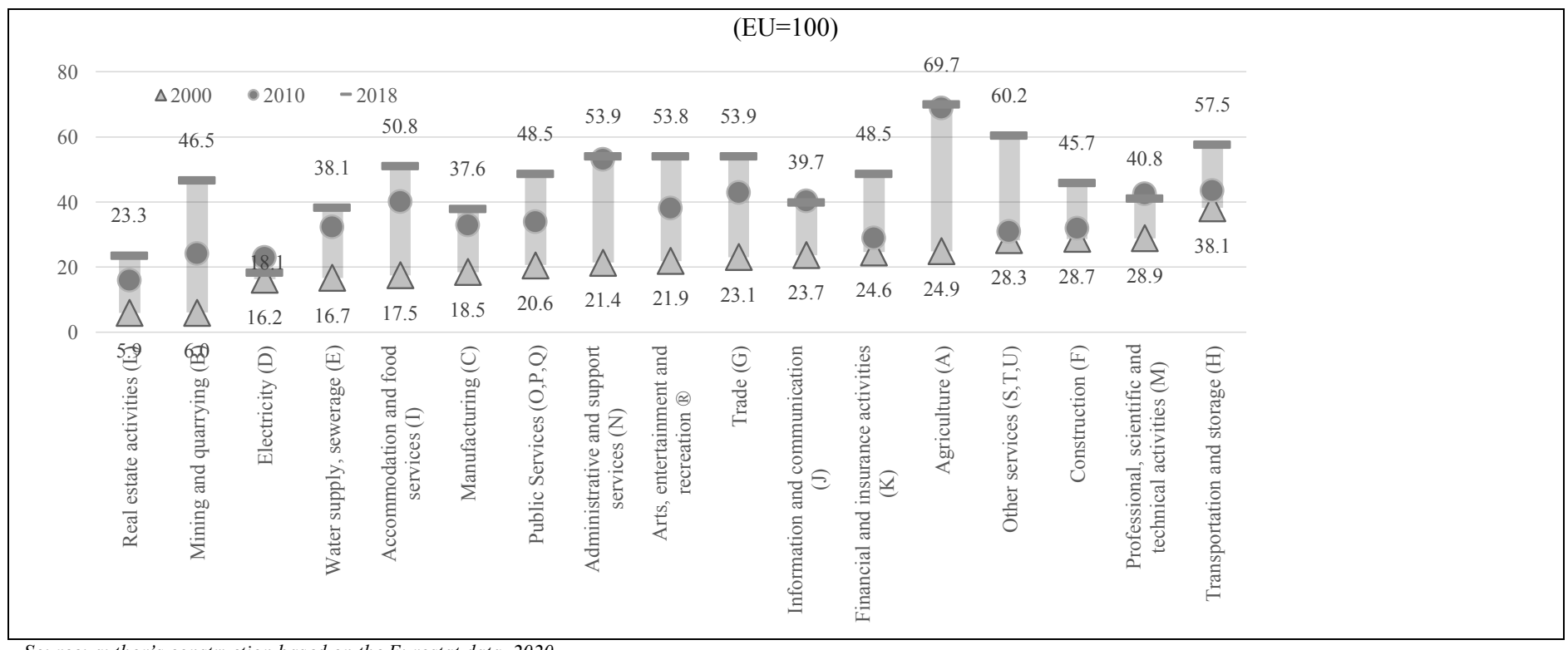

Source: author's construction based on the Eurostat data, 2020

Fig. 3. Latvia's productivity gap with the EU changes from 2000 to 2018

Analysis of the data shows that since 2011 the pace of convergence has slowed in some sectors. For example, in sectors such as agriculture, administrative services, IT services, professional and scientific services, productivity convergence to the EU average was faster until 2010, while it was very weak in the following years. Slowing down the convergence momentum could signal a "productivity trap" that requires overcoming structural reforms and significantly improving innovative solutions.

The low level of productivity is largely determined by the extremely low productivity in the manufacturing. In 2019, productivity in Latvia's manufacturing industry was almost 38\% (52\% in Purchasing Power Standards) of the EU average, which can be assessed as very low. Compared to 2000 , the productivity gap has narrowed by almost 19 percentage points, reflecting a weak pace of convergence.

(2019, by number of employees) 


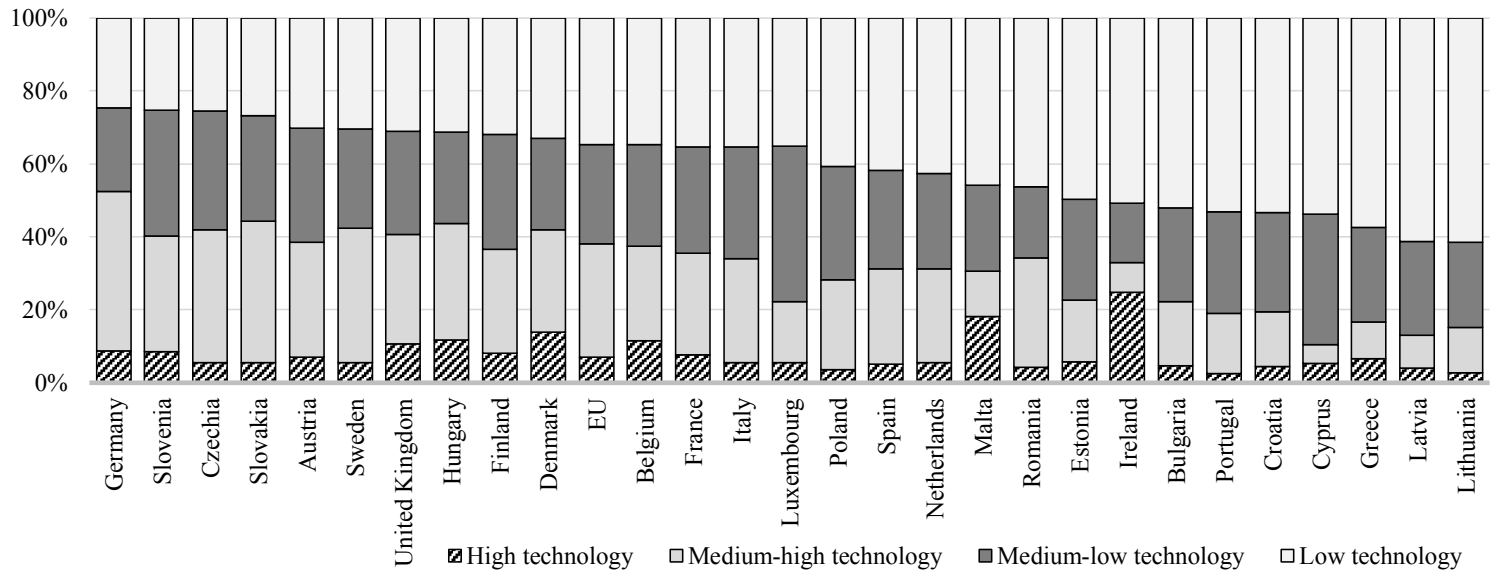

Source: author's construction based on the Eurostat data, 2020

Fig. 4. Manufacturing industry structure by technological intensity in the $\mathbf{E U}$

The relatively low level of productivity and moderate dynamics of Latvia's manufacturing industry is largely determined by structural factors. The structure of Latvia's manufacturing industry is strongly dominated by low-tech industries, which in recent years account for more than half of the total value added of manufacturing and is almost one and a half times more than the EU average (see Figure 4).

Technological factors, such as the modernization of production, the improvement of existing technologies and the introduction of new technologies, play a key role in raising productivity levels. The transition from old to newer technologies contributes to productivity growth at the company and industry level. However, the effectiveness of such changes in raising overall productivity levels depends to a large extent on the redistribution of resources from the lowest to the highest productivity sectors, as well as on sectors with faster productivity dynamics.

To determine the impact of the redistribution of labour resources on the overall productivity dynamics in the Latvian economy, the shift share analysis method was used (see description of method: Ministry of Trade and Industry Republic of Singapore, 2018). This method makes it possible to determine the extent to which changes in total productivity affect individual sectors, assuming no change in the number of employees, and the extent to which they are affected by the movement of workers to higher productivity sectors as well as to more productive sectors.

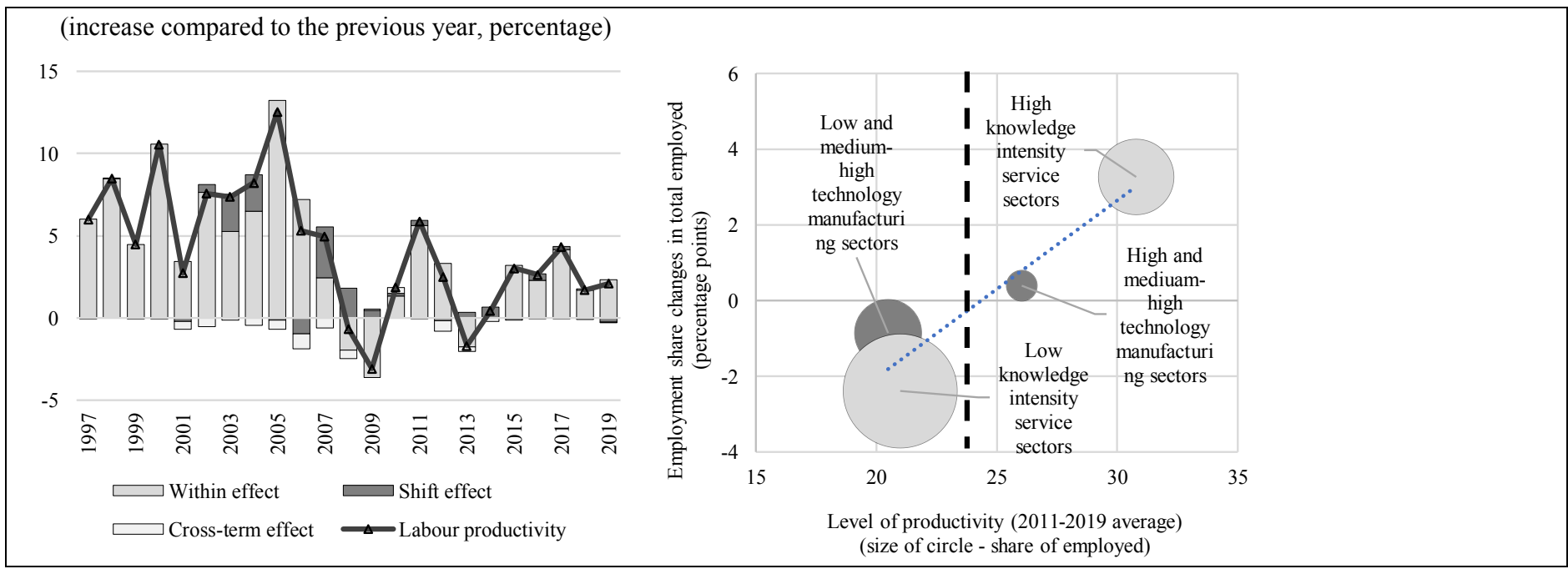

Source: author's construction based on the Eurostat data, 2020

Fig. 5. Shift-share analysis of productivity in the market economy in Latvia

Fig. 6. Changes in the structure of employees in sectors with different productivity levels (2011-2019) in Latvia

In the period from 1997 to 2019 productivity dynamics in Latvia were mainly influenced by the within-sector effects, which show that productivity improvements mostly take place in each individual sector, under the influence of such factors as more skilled management, technology improvement, innovations, employee training, favourable market conditions and other sectors. due to specific factors (see Figure 5).

The shift effect of labour resources in Latvia is relatively weak - about 0.5 percentage points of annual productivity growth (1997-2019). The positive redistribution effect shows that in the analysed period the sectors with higher productivity have attracted more labour than the sectors with 
lower productivity. However, their contribution to overall productivity growth was relatively small. Third effect (Cross-term effect), i.e., the impact of labour migration on sectors with faster (slower) productivity growth on overall productivity dynamics over the period under analysis was negative ( 0.2 percentage points on average per year). This means that industries with faster productivity dynamics attracted less labour than industries with slower productivity growth. Empirical studies show that in many cases this effect reduces overall productivity in the country. There are several interpretations of this phenomenon, for example, productivity growth is often linked to the optimization of production costs, redundancies and labour migration to sectors with slower productivity dynamics.

The analysis shows that employment is growing in sectors with above-average productivity, such as computer and electronic equipment, while employment is declining in some low-productivity sectors, such as light industry. However, many jobs are still being created in sectors with relatively lower productivity levels, such as accommodation and food service activities. In general, the redistribution of labour resources in favour of productive sectors is insufficient to have a significant impact on the faster growth of the overall productivity level of the economy (see Figure 6). 3.Productivity factors

Productivity growth is determined by several fundamental factors. These include investment and capital intensity, the ability to integrate into global value chains and increase export potential, innovation and investment in R\&D to develop new products, services and methods, the benefits of new technologies and the role of scientific and technological progress in intensifying production, especially digitization, as well as investing in human capital, improving people 's skills and competences, and increasing the body of knowledge that motivates people to be productive.

The organization and management of the production process, the specialization and concentration of production, the territorial location of production facilities, as well as the establishment of cross-sectoral horizontal and vertical links are also important for increasing productivity.

Here we analyse some of the above factors, namely innovation, R\&D investment, digitization and human capital.

As it was mentioned before, Latvia's weakest point has been innovation.

In terms of innovation capacity, Latvia is ranked 52nd in the GCI 4.0 rating. In the assessment of this pillar, Latvia lags far behind not only the EU's innovative economies, but also all EU countries, except Romania. Latvia's low innovative capacity is not favourable for the future and is currently significantly limited by the low quality of research institutions, weak international cooperation in science and research, weak cooperation between scientists and entrepreneurs, low level of investment in research and development and other factors (see Figure 7).

(distance to the leader, rating from 0-100)

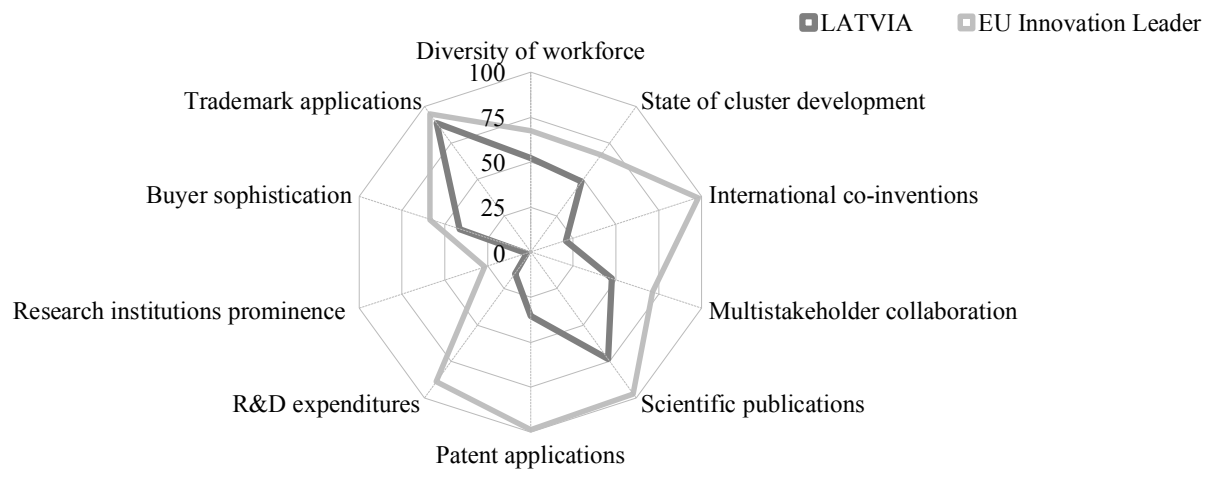

Source: author's construction based on the Global Competitiveness index data, 2019

Fig. 7. Comparison of Latvian and $E U$ innovative economies by innovation capabilities

In the European Innovation Scoreboard 2020, published annually by the European Commission, Latvia ranks 23rd among 27 EU countries and is included in the group of moderate innovators for the fifth year in a row. Latvia's innovation index (Innovation Index) has increased by $22.6 \%$ since 2012 (EU average - by 8.7\%) (European Commission. 2020c). The basic conditions for innovation, which include an innovation-friendly environment and financial support, are marked as Latvia's strongest drivers of innovation performance. Since 2012, the assessment of such dimensions of innovation performance as the availability of qualified and educated labour force, the attractiveness of the research system has increased. However, the activities of Latvian entrepreneurs in the field of innovation have remained relatively weak for a long time. This is evidenced by low business investment in research and development (R\&D) and a small share of innovative companies. 
Since 2000, the level of investment R\&D (\% of GDP) has increased almost 1.5 times, which was mainly due to a significant increase in investment R\&D until 2007. In the following years, it averaged $0.6 \%$ of GDP, which is twice the target of $1.5 \%$ of GDP by 2020.

Private sector funding is small, accounting for about $1 / 4$ of total R\&D investment ( $0.2 \%$ of GDP), which is significantly lower than the EU average, where entrepreneurs provide more than half of total R\&D investment funding. In the long run, the level of R\&D investment by companies has not increased, but in recent years there has even been a downward trend.

The low level of business investment in research is influenced by both supply-side factors (such as the poor quality of research institutions) and demand-side factors, i.e. low share of R\&D intensive industries (especially manufacturing) in the structure of the economy. High and medium high R\&D intensity sectors in Latvia 2010-2018 was 5.2\% of GDP on average, including 2\% of GDP in manufacturing. In most EU Member States, on the other hand, the share of these sectors is much higher.

The development of the Latvian research and innovation system is also hindered by the imbalance of human capital and the fragmentation of the management of the research and innovation system in Latvia. The European Commission's Staff Working Document report points out that human capital imbalances, skills shortages and still weak links between research and industry, as well as weak cooperation within industry, are important factors hindering the development of Latvia's research and innovation system (European Commission, 2020d). Overcoming structural barriers is a significant challenge for Latvia's progress towards an innovative and knowledge-based economic model.

A breakthrough in innovation requires a change in public attitudes (innovation is not a hobby, but a necessary condition for prosperity growth) and the incentives for innovation need to be improved accordingly. The legal framework for the innovation system also needs to be improved, including the roles and responsibilities of the institutions and non-governmental organizations involved, and the system of state support for the creation, commercialization and practical implementation of intellectual property. The state should consider the possibility of coordinating the commercialization of outstanding innovative products in Latvia, so that our inventions are realized in our country and not sold to others (Steinbuka, 2019). Latvia's performance in the field of innovation could benefit from a more active involvement of the largest state-owned companies, which have the resources to afford significant investments.

Digitization is another determinant of productivity. Latvian companies lag significantly behind in the use of digital technologies, entrepreneurs lack digital skills and knowledge, skills, as well as appropriate tools (eg productivity tools for digital trade, cross-border online trade, etc.) compared to OECD member states.

Although after the introduction of high-speed broadband network Latvia exceeds the OECD and EU average level, only a few Latvian companies use new digital technologies, such as analysis of large databases, radio frequency identification technology, etc.

In the ranking of Digital Economy and Society Index (DESI) 2020, Latvia ranks 18th among 28 countries. Latvia's level of digital development generally corresponds to the EU average. In terms of connectivity (4th place) and digital public services (5th place), Latvia's indicators exceed the EU average, but in terms of the use of Internet services (19th place), human capital (24th place) and digital technology integration (23rd place) aspect lags behind (European Commission. 2020b).

Regulation plays an important role in the digital economy. Policymakers need to be aware that there are areas where there is limited scope for new business models, so the challenge is to create a regulatory framework when new business models enter the market. The current regulatory models are based on the institutional framework, while entrepreneurs do not base their activities on the institutional framework, but on specific functions. The crisis caused by COVID-19 revealed the importance of digitalisation for society's ability to adapt quickly to new circumstances. It also showed Latvia's weaknesses and became a strong impetus for the faster introduction of digital technologies in several areas. It is important to continue to promote understanding of the wide range of applications of digital technologies, as well as to improve the range of state tools to support digital transformation processes.

The availability and quality of the workforce play an important role in increasing productivity. The main directions of improving the availability and quality of labour force that are relevant for Latvia are the following:

addressing demographic and migration issues;

improving the availability and quality of education at all levels; promotion of retraining and further training.

The availability of labour is significantly affected by negative demographic changes - population decline and aging, relatively high mortality, negative natural growth and negative migration balance. 
In 2019, the Latvian labour market was rapidly approaching its potential. The levels of employment and economic activity of the population in 2019 reached historically high marks. The high level of relative labour market indicators was influenced by economic growth, but also to a large extent by negative demographic trends. The total population has been declining for a long time, the share of the retirement age population is increasing, and the working age population is declining.

The shortage of labour affects both the increase in wages and labour costs - the increase in the average gross wage in the period from 2017 to 2019 was $7.8 \%$ per annum. Meanwhile, labour productivity growth has remained almost three times lower over the period considered. With the increase in labour costs, Latvia is rapidly losing its competitive advantage in low-cost market segments.

As in most countries of the world, the labour market in Latvia in 2020 is affected by the economic shock caused by Covid-19. The Covid-19 package has significantly curtailed economic activity in almost all sectors of the economy, primarily and most deeply affecting sectors such as passenger transport, travel agency and tour operator reservation services, accommodation and catering services, arts and cultural activities, sports centres and other sectors directly related to population movements and assemblages. The number of jobs in the directly affected sectors is about 60-70 thousand jobs, which is $7 \%$ of the total number of jobs in the economy. It should be noted that in many of these areas' activity may remain low for a long time.

Productivity growth will be largely driven by the restructuring of the economy from low- and medium-low-tech to medium-high and high-tech industries, thus affecting not only aggregate labour demand but also its structure, increasing the share of high-skilled jobs on the one hand and reducing low-skilled jobs. and the share of medium-skilled jobs on the other hand. One of the key factors for the future competitiveness of economies will be the ability of education systems and entrepreneurs to adapt to the new requirements of economic transformation.

In order to promote the development of human capital, several reforms have been implemented or started in Latvia, for example, the reform of the content of vocational education, the arrangement of the network of general education institutions, the introduction of a new higher education financing model, etc. However, the impact of the reforms is slow, and their positive effects on overall productivity levels can only be expected in the medium to long term.

The Ministry of Economics of Latvia forecasts that in the medium and long term, if the current structure of labour force training is maintained the following significant labour market disproportions are expected (Ministry of Economics, 2020):

- $\quad$ Lack of highly qualified specialists in natural sciences, ICT and engineering.

- $\quad$ Surplus of the workforce with higher qualifications in social sciences, business and humanities sciences.

- $\quad$ Shortage of labour force with vocational secondary education.

- $\quad$ Surplus of the workforce with secondary general education, basic education and lower levels of education.

In order to reduce possible labour market disproportions in the future, the problems need to be addressed in a complex way. For example, it is difficult to increase the number of students in science and engineering if students in primary and secondary education already have poor knowledge and little interest in the exact subjects. It should also be borne in mind that possible solutions in higher education, secondary, vocational secondary education and basic education will have a significant impact in the long term. Changes in formal education have relatively little effect on mediumterm problems.

Seeing that the problem of labour shortage will intensify in the future, it is necessary to strengthen the adult education system in order to ensure the transition of labour from unproductive to growing sectors. The main directions should be to increase digital skills for the society, with a specific focus on each target group, to reduce the share of the low-skilled, and to acquire skills demanded in the labour market in the future.

The main impediments to the creation of an effective lifelong learning system are the low interest of the population, as courses and programs for building individual competencies and leisure interests are mainly required, without linking it with the possibility to increase one's income in the labour market. Weak regional mobility should also be mentioned as a barrier. It is not uncommon for potentially low pay not to motivate longer training courses. On the corporate side, more active involvement in employee training is limited by the existing economic model, which is dominated by "low-cost" strategies and does not pay to invest in employee education. The effective development of the system is also limited by the mismatch between the supply and demand of curricula, as the adult education market often has cheap, lower-quality offers. In turn, publicly monitored educational institutions are limited by administrative and funding mechanisms, which are currently not motivating.

The economy is constantly undergoing greater or lesser structural change. In order to prepare for and adapt to these changes, it is necessary to make anticipatory changes in the labour market, which include medium- and long-term labour market forecasting, dialogue between the parties involved 
and decision-making on changes in the training structure. Such a well-functioning system can prevent labour market disproportions in the future and is an important element in facilitating the adjustment of labour supply and demand.

Although Latvia has been working on such a system for several years, the restructuring that precedes change in the Latvian labour market is still incomplete and insufficiently targeted, and a structured and integrated restructuring management model has not been developed to address labour market issues. There are also insufficient comprehensive discussions at all levels in Latvia about the future trends and needs of the labour market.

\section{Conclusions, proposals, recommendations}

1. Addressing productivity is gaining more momentum in scientific, public and political debate. However, the research of productivity-related aspects in Latvia is fragmentary and lacks a systemic approach. The research has been carried out mostly at the macro level, moreover, there is very little research based on company-level data, but cross-sectoral (meso-level) aspects are practically not analysed, which is largely related to the availability of data. This limits the scope for research-based and science-based structural policy recommendations.

2. The analysis of productivity dynamics in Latvia shows that it has been quite rapid in recent decades and has exceeded the EU average growth rates. Since 1996, it has increased almost 3 times. However, productivity growth rates in Latvia tend to decline.

3. Compared to the EU's highly developed countries, there is still a significant gap. Latvia's productivity lag is mainly explained by low total factor productivity, significant differences in the quality of labour and capital. The study shows that the low level of productivity in Latvia is largely related to structural factors - the low level of manufacturing and the dominant position of low-tech industries, the small share of knowledgeintensive industries, the business sector is dominated by SME companies, export structure, etc.

4. In 2020, the Covid-19 pandemic has had a strong and lasting global impact on the socio-economic situation. However, its impact on productivity is unclear. In terms of the number of hours worked, in the second quarter of 2020, which was the worst quarter affected by the Covid-19 crisis so far, productivity in Latvia has increased. On the other hand, in terms of the number of employees, it has decreased. The analysis shows that market sectors with relatively higher productivity levels are not more resilient to the Covid-19 pandemic shock than other sectors.

5. The low level of productivity in the economy is largely determined by the extremely low productivity in the manufacturing. In 2019 , productivity in Latvia's manufacturing industry was almost 38\% (52\% after PPS) of the EU average. The relatively low level of productivity and moderate dynamics of Latvia's manufacturing industry is largely determined by structural factors. The structure of Latvia's manufacturing industry is strongly dominated by low-tech industries, which in recent years account for more than half of the total value added of the manufacturing industry, which is almost one and a half times more than the EU average.

6. The analysis shows that employment is growing in sectors with above-average productivity levels, such as the manufacture of computer and electronic equipment, while employment in some low-productivity sectors, such as light industry, is declining. However, many jobs are still being created in sectors with relatively lower productivity levels, such as accommodation and food service activities. In general, the redistribution of labour resources in favour of more productive sectors is insufficient to have a significant impact on the faster growth of the overall productivity level of the economy.

7. Productivity growth is determined by several fundamental factors. These include investment and capital intensity, the ability to integrate into global value chains and increase export potential, innovation and investment in R\&D to develop new products, services and methods, the benefits of new technologies and the role of scientific and technological progress in intensifying production, especially digitization, as well as investing in human capital, improving people 's skills and competences, and increasing the body of knowledge that motivates people to be productive.

8. Innovation activity in Latvia is relatively small. Small investments in research and development, low overall results in the field of innovation and average results in the field of education have a negative impact on Latvia's efforts to achieve higher productivity. Latvia's performance in the field of innovation could benefit from a more active involvement of the largest state-owned companies, which have the resources to afford significant investments.

9. Making full use of digital opportunities is essential to maintain productivity and improve living standards. In Latvia, the fixed broadband coverage of households still lags the EU average, and a digital divide has developed between urban and rural areas. Half of the Latvian population lacks basic digital skills that prevent them from using the Internet effectively. The integration of digital technologies in companies is well below the EU average. Latvia has not developed a comprehensive strategy for the digitization of companies. The lack of highly qualified professionals, including ICT professionals, is becoming an increasing barrier to investment and innovation and will be exacerbated in the future. 
10. The availability and quality of the workforce play an important role in increasing productivity. The main directions of improving the availability and quality of labour force that are relevant for Latvia are the following:

- $\quad$ addressing demographic and migration issues;

- $\quad$ improving the availability and quality of education at all levels;

- $\quad$ promotion of retraining and further training.

11. In order to reduce possible labour market disproportions in the future, the problems need to be addressed in a complex way. For example, it is difficult to increase the number of students in science and engineering if students in primary and secondary education already have poor knowledge and little interest in the exact subjects. Changes in formal education have relatively little effect on medium-term problems.

12. The economy is constantly undergoing greater or lesser structural change. In order to prepare for and adapt to these changes, it is necessary to make anticipatory changes in the labour market, which include medium- and long-term labour market forecasting, dialogue between the parties involved and decision-making on changes in the training structure. Such a well-functioning system can prevent labour market disproportions in the future and is an important element in facilitating the adjustment of labour supply and demand.

\section{Bibliography}

Benkovskis K., 2015. Misallocation of Resources in Latvia: did Anything Change During the Crisis? Latvijas Banka, Working Paper, No. 5. Available at: https://www.macroeconomics.lv/sites/default/files/wp_5_2015-en.pdf

Central Statistical Bureau of Republic of Latvia, 2020. Available at: https://www.csb.gov.lv/en/sakums

European Commission, 2019. Staff Working Document. Country Report 2019. SWD (2019) 1013 Final. Available at: https://ec.europa.eu/info/sites/info/files/file_import/2019-european-semester-country-report-latvia_en.pdf

European Commission. 2020a. European Economic Forecast: Autumn 2020, Institutional Paper 136, November 2020. Available at: https://ec.europa.eu/info/publications/economic-and-financial-affairs-publications_en

European Commission. 2020b. Digital Economy and Society Index (DESI) 2020. Available at: https://ec.europa.eu/digital-single-market/desi

European Commission. 2020c. European Innovation Scoreboard 2020. Available at: https://ec.europa.eu/docsroom/documents/42981

European Commission. 2020d. Staff Working Document. Country Report 2020. SWD (2020) 513 final. Available at: https://op.europa.eu/en/publication-detail/-/publication/6b686de2-5946-11ea-8b81-01aa75ed71a1

Eurostat, 2019. Available at: https://ec.europa.eu/eurostat

International Monetary Fund. Republic of Latvia: 2016 Article IV Consultation-Press Release; Staff Report; and Statement by the Executive Director for the Republic of Latvia. June 16, 2016. Available at: https://www.imf.org/en/Publications/CR/Issues/2016/12/31/Republic-of-Latvia2016-Article-IV-Consultation-Press-Release-Staff-Report-and-Statement-by-43983

Ministry of Economics of Republic of Latvia._2020. Report on medium and Long-Term Labour Market Forecasts. Riga, 2020. Available at: https://www.em.gov.lv/lv/ekonomikas_attistiba/darba_tirgus/videja_un_ilgtermina_darba_tirgus_prognozes/

Ministry of Trade and Industry Republic of Singapore. 2018. Economic Survey of Singapore 2017. Box 2.1. A Shift-Share Decomposition Analysis of Labour Productivity Growth in Singapore. February 2018. Available at: https://www.mti.gov.sg/-/media/MTI/Legislation/PublicConsultations/2018/A-Shift-Share-Decomposition-Analysis-of-Labour-Productivity-Growth-in-Singapore/ba21_aes2017.pdf

OECD. 2015. The Future of Productivity, OECD Publishing, Paris.

OECD. 2015. OECD Economic Surveys: Latvia 2015, OECD Publishing, Paris. Available at: http://www.oecd.org/economy/surveys/Overview_Latvia_2015_Eng.pdf.

OECD, 2017. OECD Economic Surveys: Latvia 2017, OECD Publishing, Paris [Online]. Available at: http://dx.doi.org/10.1787/eco_surveys-lva2017-en

OECD. 2019. OECD Economic Surveys: Latvia 2019, OECD Publishing, Paris. Available at: https://doi.org/10.1787/f8c2f493-en

Renda A., Dougherty S. 2017. Pro-Productivity Institutions: Learning From National Experience, OECD Productivity Working Papers, Paris, 201707 .

Steinbuka, I. (editor-in-chief.), 2019. Produktivitātes celšana: tendences un nākotnes izaicinājumi (Raising Productivity: Trends and Future Challenges). Riga, 2019 [Online]. Available at: https://doi.org/10.22364/pctni 
Stockholm School of Economics in Riga and Baltic International Centre for Economic Policy Studies, 2013. Latvia Competitiveness Report. Available at: http://www.biceps.org/assets/docs/LCR2013

World Economic Forum. 2018. The Global Competitiveness Report 2018. Geneva, $2018 . \quad$ Available at: http://www3.weforum.org/docs/GCR2018/05FullReport/TheGlobalCompetitivenessReport2018.pdf

World Economic Forum. 2019. The Global Competitiveness Report 2019. Geneva, $2019 . \quad$ Available at: http://www3.weforum.org/docs/WEF_TheGlobalCompetitivenessReport2019.pdf

\section{Acknowledgement}

The research was supported by the national research programme project "Towards the Post-pandemic Recovery: Economic, Political and Legal Framework for Preservation of Latvia's Growth Potential and Increasing Competitiveness ("reCOVery-LV")" (VPP-COVID-2020/1-0010). 


\section{THE CHARACTERISTICS OF MATURITY MODELS}

\section{Benjamin Basner, University of Latvia}

Abstract. Digital Transformation and the term digitalization become very famous. In the past analog data were transferred into digital, so that it allows that machines can use these data and developed further. In addition to that also digitalization of the company process was strongly discussed. Over time the technology has been improved and creates new opportunities for companies. In literature and articles are many different fields which are researched but the question which are the right investments in digitalization is unanswered. This article is a first analysis of a literature review and the first step of preparation to get closer of answering this question. Firstly this paper reviews maturity models which are available in the literature after this the paper provides a deeper analysis of existing maturity models that are used in literature for digitalization purposes. The results are that many different dimensions were used in the context of maturity models and this result is important to know which dimensions play a role in possible investments in the context of digitization. Further analyses of what details are hidden behind the individual dimensions are required.

Keywords: Digitalization, Maturity Models, Degree of Digitalization.

JEL code: M15, M21, O16

\section{Introduction}

In the scale of digital transformation most diverse areas are addressed. It affects the working conditions, leadership, organizational structures, business models value chains and processes. Every team leader has to self-determine, which areas are affected and how to react to digital transformation. Some are more, some are less and some are not affected by the change. Those who are affected have to pull their conclusions and preferably achieve a better position for the company. The desire to become more profitable, improving a process, being more efficient faster and better than the competitor to conquer the remaining market shares is in the nature of each concern's philosophy. Digitalization is one modern tool for companies to reach these goals. The fact is that the digital degree of digitalization for companies represents a crucial success of competitive factors. This degree of digitalization is important in order to exist in the long term period and to be able to develop further (Berghaus et al. 2018, $\mathrm{p}$. 429). In 2013, the Federal Ministry described that the digitalization of business process is essential to be competitive and successful in the dynamic and customer orientated market. The pressures to be more profitable and cost orientate increases constantly (BMWi (Hg) 2013, p. 6). For that reason to do the first step into digitalization is recommendable, because digitalization is one tool and one possibility to reach the goal of efficiency. In the scale of digitalization the literature and articles provides many different fields which are researched but the question for companies is still open "how is the optimal degree of digitalization and what is the right investment decision in the scale of digitalization"? So that the question arises, how exactly can be created a bridge between optimal degree and right investment decision in digitalization. It pointed out, that maturity models are the right tool for it because they showed the current situation in a company and it can be shown what potentials in the scale of digitalization is possible.

\section{Literature Review}

In fact that the digitalization process is important and advantages outweigh, companies hesitate to implement the digitalization process. Berghaus confirmed that the digital transformation of business process face-off different challenges and problems (Berghaus et al. 2018, p. 429). Barriers for companies are the complexity, financial resources, legal uncertainty, and missing infrastructure (Leyh and Bley 2016, p. 37) other barriers like missing capacity, missing know-how support the restrained behavior. The research from Oswald and Krcmar figured out, that $60 \%$ of the surveyed companies have the opinion that the evaluation in investment in digital technology is more difficult than in traditional investments. This result represents another barrier that is, to convinced responsible person to do the investment in digital technologies (Oswald und Krcmar 2018, p. 53). In addition to the above-mentioned barriers, another challenge for the implementation of digitalization is to combine the existing IT infrastructure and do not replace immediately everything so that the previous investments which be made are saved. It is necessary to ensure not to effect functioning production processes. It is about to figure out the missing functionalities in the existing system and compensate them with new methods, with increasing the degree of digitalization and finally create an added value for the company as well as strengthen the market position. (Bauernhansl et al. 2014, p. 584) Company managers start small-scale attempts to implement digitization initiatives. So it is digitized step by step and is called "Use Cases" (Reifenberger Sabine 2019, p. 64). The high investment cost for digitalization has a deterrent effect.

For all these barriers and challenges there are many opportunities to improve the business in growth, profitability, cost reduction, etc. Federal Ministry for economic and energy wrote that analysts forecast the economic performance in Germany could be increased to 82 billion Euros by 2020 if the technologies and ability to use them constantly driven by German companies. (BMWi (Hg) 2016, p. 6) 
In order to achieve the desired added value for the companies, the right investment decision is needed and for this purposes, the optimal degree of digitalization can act as a support. To determine the optimal degree, the individual processes must be analyzed because there is a connection between the degree of digitalization and the company processes. The processes exist in all areas of the company's activities. They consist of sequences of tasks to be performed that transform an input into a multi added value output. Thus, processes form the central of any company, as they serve to achieve organizational and company goals. Trough a sustainable optimization of the processes is an increase in the quality expected. Quality is understood as an efficiency increase of the entirety. (Koch 2015, p.1-2)

Will the implementation of each activity supported by an IT system it is a matter of a digitized process. Does the IT system perform individual activities independently; a digitized automated process is created. (Appelfeller and Feldmann 2018, p. 5)

To be able to determine and measure the degree of digitalization in a company it is mandatory to use a tool. For this approach is an appropriate tool maturity models. A maturity model which is specialized in digitalization could determine the degree of digitalization and illustrate the current situation. In addition to that a maturity model shows the maximum degree (Becker et al. 2009, p. 249). To create an efficient process it is important to know the current status of the company. Maturity models are exactly suitable for this approach they are able to provide such the current statusi. Maturity models are also able to show stepwise to improve structure, processes, ability, or general conditions of a company (Becker et al. 2009, p. 249). Which digital process changes are moving in a more efficient position is first of all important to know the current status of an organization and which of all these processes should focus on.

Nowadays, it exists many different maturity models. The book "Quality is free" by Crosby set up the origin for Capability Maturity Models in 1979. He designed the Quality Management Maturity Grid. The basic idea for this model was to support companies in the area of quality management (Crosby 1979).

The Software Engineering Institute at Carnegie Mellon University developed the first Capability Maturity Model (CMM) (Paulk et al. 1993). This model is based on a specialization in the software development process and should evaluate the maturity of software processes. As the model became more and more famous, the model was expanded for other areas such as Management, Enterprise, Architecture, Management Knowledge (Rosemann und Bruin 2005) and they have a widespread and range from cognitive science to business application and engineering (Kohlegger et al. 2009, p. $51)$.

Because of this huge variety the following table provides an overview and shows an example about the different models and for which concerns they used for.

Variety of Maturity Models

\begin{tabular}{|l|l|l|l|l|l|}
\hline Name & $\begin{array}{l}\text { Analysis } \\
\text { Capability } \\
\text { Maturity Model } \\
\text { (ACMM) }\end{array}$ & $\begin{array}{l}\text { Business Process } \\
\text { Management Maturity } \\
\text { (BPMM) }\end{array}$ & $\begin{array}{l}\text { Capability Maturity } \\
\text { Model Integration } \\
\text { (CMMI) }\end{array}$ & $\begin{array}{l}\text { Documentation } \\
\text { Process Maturity } \\
\text { Model (DPMM) }\end{array}$ & $\begin{array}{l}\text { E-Learning Maturity } \\
\text { Model (eMM) }\end{array}$ \\
\hline $\begin{array}{l}\text { Used } \\
\text { for }\end{array}$ & $\begin{array}{l}\text { Evaluate } \\
\text { process of } \\
\text { organizations. }\end{array}$ & $\begin{array}{l}\text { Focus on all processes in } \\
\text { an organization.(Hogrebe } \\
\text { and Nüttgens 2009, } \\
18)\end{array}$ & $\begin{array}{l}\text { Focus on software } \\
\text { development } \\
\text { process.(Hogrebe und } \\
\text { Nüttgens 2009, p. 18) }\end{array}$ & $\begin{array}{l}\text { Specialized on } \\
\text { documentation as sub } \\
\text { aspect in software } \\
\text { development process. }\end{array}$ & $\begin{array}{l}\text { Special for } \\
\text { Universities to } \\
\text { development and } \\
\text { implementation for } \\
\text { E-Learning }\end{array}$ \\
\hline Name & $\begin{array}{l}\text { IS/ICT } \\
\text { Capability } \\
\text { Maturity } \\
\text { Framework } \\
\text { (IS/ICT CMF) }\end{array}$ & $\begin{array}{l}\text { Enterprise Architecture } \\
\text { Maturity Model }\end{array}$ & $\begin{array}{l}\text { European Foundation } \\
\text { for Quality } \\
\text { Management (EFQM) }\end{array}$ & $\begin{array}{l}\text { Process Maturity } \\
\text { Model (PMM) }\end{array}$ & $\begin{array}{l}\text { Project Management } \\
\text { Maturity Model } \\
\text { (PMMM) }\end{array}$ \\
\hline $\begin{array}{l}\text { Uscellence Model } \\
\text { for }\end{array}$ & $\begin{array}{l}\text { Focus on IT- } \\
\text { Management. }\end{array}$ & $\begin{array}{l}\text { Increase in performance, } \\
\text { effectiveness, efficiency } \\
\text { and value generation in } \\
\text { terms of planning, } \\
\text { development, and } \\
\text { operation according to } \\
\text { the strategy (Meyer et al. } \\
\text { 2011, p. 186). }\end{array}$ & $\begin{array}{l}\text { Support organizations } \\
\text { to achieve business } \\
\text { excellence through } \\
\text { continuous } \\
\text { improvement and } \\
\text { development process } \\
\text { (Young Kim et al. } \\
\text { 2010, p. 685). }\end{array}$ & $\begin{array}{l}\text { Focus on process to } \\
\text { improve the } \\
\text { efficiency }\end{array}$ & $\begin{array}{l}\text { Focus on project } \\
\text { Management to } \\
\text { improve quality and } \\
\text { reduce risks of } \\
\text { projects (Demir and } \\
\text { Kocabaş 2010, p. } \\
\text { 1642). }\end{array}$ \\
\hline
\end{tabular}


This table illustrates just an example of this variety. More than 150 maturity models have been developed in this area (Bruin 2005). In addition to that, there are many other maturity models in other fields like biology, sociology, or psychology (Greenberger and Sorensen 1974, p.331). As can be seen in this table 1 the row used for, shows that basically every different model and area is about focusing on increasing efficiency. The definition from Kohlegger et al. for Maturity Model reflects this quite well.

"A Maturity Model conceptually represents phases of increasing quantitative or qualitative capability changes of a maturing element in order to assess its advances concerning defined focus areas" (Kohlegger et al. 2009, p. 59).

Maturity models can be either used in a descriptive way explaining changes observed in reality or in a normative way. In the latter sense, the maturity model is intended to guide owners, managers, or other committed individuals interventions into making changes in maturity of maturing elements more effective or efficient. (Kohlegger et al. 2009, p. 59) A survey from Bitkom described the goal of digitized business processes and it is recognized that this has the same meaning. The goal of digitized business process is to increase margins, efficiency and productivity (Britze et al. 2020 , p. 5). The keyword in this sentence is business process. The different dimensions are used in a business process, therefore it is important to know the dimensions. As previously mentioned the business process has a connection between the degree of digitalization and the different business processes. The various dimensions are addressed in a business process and the purpose to answering the main question needs to figure out which of these dimensions needs to be identified and admitted. Due to this purpose in order to make an investment decision on the scale of digitalization, it is important to know what effect this has and therefore which dimensions are addressed. The effect need to be figure out by a survey and requires more researches. It depends on which dimensions the authors have used for their maturity models. This is because the maturity models cannot determine the effect, but can represent the maximum maturity level.

At the beginning, the diversity of maturity models were addressed, and it is important to focus at maturity models which are related to the topic digitalization. The next step requires analyzing which maturity models for digitization exist and which dimensions the authors have used for them. Only through the dimensions can further research be conducted to answer the question of what effect which investments have in the area of digitization. In literature, authors use various dimensions and amounts of dimensions, is various a lot and differs from author to author. For example the author Appelfeller uses 10 dimensions and Berghaus uses 9 dimensions, Bitkom uses 4 dimensions and Fitzgerald uses just 3. The similar amounts in dimensions suggested a match in these dimensions. But the result of the comparison between these is that it exists just a few matches.

The maturity model, which is specifically designed for digitization, is intended to help identify the dimensions. It therefore serves the purpose of finding the right way to which dimensions should be specified for further research.

\section{Research Objectives and Questions}

The overall purpose of this paper is to bring the maturity model and the optimal degree in connection so that the long term goal of creating a model for industrial companies that the right investment decisions concerning digitalization can be made. The result can be reached if the investigation will be done step by step. The long term research question is: What is the right investment decision for possible digitized measures for industrial companies. The problem statement of investments in possible digitization measures is the lack of knowledge in which areas can be digitized and the amortization of certain digitization measures. To reach this goal it is necessary to figure out in which area of digitalization are the possible digitalization measures. For that purpose it is essential to research more about the maturity models. With the maturity model, the authors must necessarily examine all aspects of digitization. This is the only way to illustrate the maximum degree of digitization with the maturity model. In this research, the focus is not to determine the maximum maturity level of digitalization, but to explore which dimensions were used in the respective maturity models. The dimensions are indispensable for illustrating the maximum degree of digitization. The maturity levels help to know in which dimensions possible investments can occur.

This challenging question cannot be answered in one paper it requires further researches. In this paper, the maturity models and the different dimensions are explained. The literature review has shown that it exists in many different dimensions. Does the question arise on which dimensions should be focused on? Because of these various dimensions and the few matches a separate analysis is important. The table below shows which parameters were used in the analyzing process. 
Parameter for Analyzing Dimensions

\begin{tabular}{|l|l|l|}
\hline No. & Author & Name of the Author \\
\hline \multirow{5}{*}{$\begin{array}{c}\text { Consecutive } \\
\text { Number }\end{array}$} & Title & The title of the publication including subtitle \\
\cline { 2 - 3 } & Year & Year of publication \\
\cline { 2 - 3 } & Amount of Dimension & Number of elements \\
\cline { 2 - 3 } & Names of Dimensions & Name of the elements \\
\cline { 2 - 3 } & Short description & At which page the dimensions were found \\
\hline
\end{tabular}

Source: created by Author

Essential in this analysis are the different dimensions and to compare these to each other. Before the analysis can be done the potential dimensions must be figured out. In the case that the dimension is used in respective maturity models, the focus on the literature review is on maturity models. As previously described it exist a lot of different maturity models in different areas. Therefore the first focus during the literature review is on maturity models in the context of digitalization. For this search query is used the publication databases from EBSCO, SpringerLink, Emerald, Web of Science, Scopus and Google Scholar. Following search terms and the combination was used in a period until 2020: (Digital Maturity Models or Maturity model and Digitalization, or Maturity Model for Digitalization, or Degree of Digitalization, or Optimal Digitalization Level). All search terms were used in German and English language. The result is 16 papers that are suitable in the scale of digitalization and for the purpose of this research. The author analyzed these 16 papers and the analyzing results of these papers are is in table 3 shown.

Table 3

\section{Analyzing Dimensions}

\begin{tabular}{|c|c|c|}
\hline No. & Author & (Appelfeller and Feldmann 2018, p. 19) \\
\hline \multirow{6}{*}{ D1 } & Title & $\begin{array}{l}\text { Die digitale Transformation des Unternehmens; Systematischer Leitfaden mit zehn Elementen zur } \\
\text { Strukturierung und Reifegradmessung }\end{array}$ \\
\hline & Year & 2018 \\
\hline & Amount of Dimension & 10 \\
\hline & Names of Dimensions & $\begin{array}{l}\text { Supplier; Digital Machines and Robotic; Digital Employee; Digital Products and Services; Customer; } \\
\text { Digital Data; Digital Network; IT- System; Digital Process; Digital Business Model }\end{array}$ \\
\hline & Page & 19 \\
\hline & Short description & $\begin{array}{l}\text { The author focuses on digital transformation and which dimensions are considered in a company. It } \\
\text { explained how the dimension can be measured based on this a maturity model is created. }\end{array}$ \\
\hline No. & Author & (Berghaus and Back 2016, p. 104) \\
\hline \multirow{6}{*}{ D2 } & Title & $\begin{array}{l}\text { Gestaltungsbereiche der Digitalen Transformation von Unternehmen: Entwicklung eines } \\
\text { Reifegradmodells }\end{array}$ \\
\hline & Year & 2016 \\
\hline & Amount of Dimension & 9 \\
\hline & Names of Dimensions & $\begin{array}{l}\text { Customer Experience; Product innovation; Strategy; Organization; Process Digitalization; Working } \\
\text { Together; ICT- Operation and Development; Culture and Expertise; Transformationsmanagement }\end{array}$ \\
\hline & Page & 104 \\
\hline & Short description & In this study, a new maturity model was developed to assess the digital maturity of companies \\
\hline No. & Author & (Canetta et al. 2018, p. 5) \\
\hline \multirow{6}{*}{ D3 } & Title & Development of a Digitalization Maturity Model for the manufacturing sector \\
\hline & Year & 2018 \\
\hline & Amount of Dimension & 5 \\
\hline & Names of Dimensions & Strategy; Processes; Technology; Product and Service; People \\
\hline & Page & 5 \\
\hline & Short description & $\begin{array}{l}\text { This article provides a systematic analysis of the } \\
\text { studies carried out in the research and industrial field, to assess } \\
\text { the current level of maturity of industries in the domain of } \\
\text { Industry 4.0. }\end{array}$ \\
\hline No. & Author & (Carolis et al.2017, p.5) \\
\hline \multirow{5}{*}{ D4 } & Title & $\begin{array}{l}\text { Guiding Manufactoring Companies Towards Digitalization, } \\
\text { A methodology for supporting manufacturing companies in defining their digitalization } \\
\text { roadmap }\end{array}$ \\
\hline & Year & 2017 \\
\hline & Amount of Dimension & 5 \\
\hline & Names of Dimensions & $\begin{array}{l}\text { Design and Engineering; Production Management; Quality Management; Maintenance Management; } \\
\text { Logistic Management }\end{array}$ \\
\hline & Page & 3 \\
\hline
\end{tabular}




\begin{tabular}{|c|c|c|}
\hline & Short description & $\begin{array}{l}\text { Manufacturing companies were guided and understand their digital readiness, based on empirical } \\
\text { evidence on the current digital readiness of manufacturing companies. }\end{array}$ \\
\hline No. & Author & (Colli et al. 2018, p. 1350) \\
\hline \multirow{6}{*}{ D5 } & Title & Contextualizing the outcome of a maturity assessment for Industry 4.0 \\
\hline & Year & 2018 \\
\hline & Amount of Dimension & 5 \\
\hline & Names of Dimensions & Technology; Governance; Value Creation; Competences; Connectivity; \\
\hline & Page & 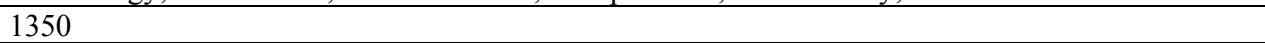 \\
\hline & Short description & $\begin{array}{l}\text { The Authors bringing up the importance of a contingency approach within the digital assessment } \\
\text { framework and in proposing an approach to cope with that. }\end{array}$ \\
\hline No. & Author & (Jahn and Pfeiffer 2014, p. 87) \\
\hline \multirow{6}{*}{ D6 } & Title & Die digitale Revolution - Neue Geschäftsmodelle statt (nur) neue Kommunikation \\
\hline & Year & 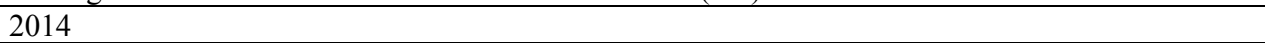 \\
\hline & Amount of Dimension & 4 \\
\hline & Names of Dimensions & Digital Leadership; Digital Technology; Customer Agility; Company Success \\
\hline & Page & 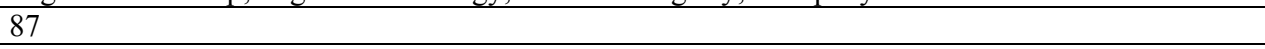 \\
\hline & Short description & $\begin{array}{l}\text { This study shows that the digitization of communication and sales channels become an efficient } \\
\text { driver of success if the top management strategically supports the initiatives and the agility of the } \\
\text { company in dealing with customers can be increased. }\end{array}$ \\
\hline No. & Author & (Leino et al.2017, p. 44) \\
\hline \multirow{6}{*}{ D7 } & Title & VTT Model of Digimaturity \\
\hline & Year & 2017 \\
\hline & Amount of Dimension & 6 \\
\hline & Names of Dimensions & $\begin{array}{l}\text { Strategy; Business Model; Customer Interface; Organisation and Processes; People and Culture; } \\
\text { Information technology }\end{array}$ \\
\hline & Page & 44 \\
\hline & Short description & $\begin{array}{l}\text { Authors developed VMoD model which provide visual estimation of a company maturity based on } \\
\text { the six dimensions. This model is also useful to compare and benchmark the maturity with other } \\
\text { companies. }\end{array}$ \\
\hline No. & Author & (Valdez-de-Leon 2016, p. 21) \\
\hline \multirow{6}{*}{ D8 } & Title & $\begin{array}{l}\text { A Digital Maturity Model for } \\
\text { Telecommunications Service Providers }\end{array}$ \\
\hline & Year & 2016 \\
\hline & Amount of Dimension & 7 \\
\hline & Names of Dimensions & Strategy; Organization; Customer; Ecosystem; Operations; Technology; Innovation \\
\hline & Page & 21 \\
\hline & Short description & This paper provides a maturity model for telecommunication service provider. \\
\hline No. & Author & (Lichtblau et al. 2015, p. 21) \\
\hline \multirow{6}{*}{ D9 } & Title & Industrie 4.0-Readiness \\
\hline & Year & 2015 \\
\hline & Amount of Dimension & 6 \\
\hline & Names of Dimensions & $\begin{array}{l}\text { Strategy and Organization; Smart Factory; Smart Operations; Smart Products; Data-driven Services; } \\
\text { Employee }\end{array}$ \\
\hline & Page & 21 \\
\hline & Short description & $\begin{array}{l}\text { This study shows the current status of digitalization for machinery and plant engineering. This study } \\
\text { represents also the barriers and motivation of companies. }\end{array}$ \\
\hline No. & Author & (Leyh et al.2016, p. 110) \\
\hline \multirow{6}{*}{ D10 } & Title & $\begin{array}{l}\text { Assessing the IT and Software Landscapes } \\
\text { of Industry 4.0-Enterprises: The Maturity } \\
\text { Model SIMMI 4.0 }\end{array}$ \\
\hline & Year & 2017 \\
\hline & Amount of Dimension & 4 \\
\hline & Names of Dimensions & $\begin{array}{l}\text { Vertical Integration; Horizontal Integration; Digital Product Development; Cross Sectional } \\
\text { Technology Criteria }\end{array}$ \\
\hline & Page & 110 \\
\hline & Short description & $\begin{array}{l}\text { The purpose of this paper was to develop a maturity model for the classification of a company's IT } \\
\text { system landscape in the context of the Industry } 4.0 \text { requirements. }\end{array}$ \\
\hline No. & Author & (Schuh et al.2020, p. 23) \\
\hline \multirow[b]{5}{*}{ D11 } & Title & Industrie 4.0 Maturity Index, Managing the Digital Transformation of Companies \\
\hline & Year & 2020 \\
\hline & Amount of Dimension & 4 \\
\hline & Names of Dimensions & Resources; Information Systems; Organisational Structure; Culture \\
\hline & Page & 23 \\
\hline
\end{tabular}




\begin{tabular}{|c|c|c|}
\hline & Short description & $\begin{array}{l}\text { Study about maturity index, it presents six consecutive development stages for four key areas for } \\
\text { every company. }\end{array}$ \\
\hline No. & Author & (Schumacher et al. 2018, p. 411) \\
\hline \multirow{6}{*}{ D12 } & Title & $\begin{array}{l}\text { Roadmapping towards industrial digitalization based on an Industry } 4.0 \\
\text { maturity model for manufacturing enterprises }\end{array}$ \\
\hline & Year & 2018 \\
\hline & Amount of Dimension & 8 \\
\hline & Names of Dimensions & $\begin{array}{l}\text { Technology; Products; Customer and Partners; Value Creation Processes; Data and Information; } \\
\text { Corporate Standards; Employees; Strategy and Leadership }\end{array}$ \\
\hline & Page & 411 \\
\hline & Short description & $\begin{array}{l}\text { Created a maturity model for industrial manufacturing companies. The main contribution in } \\
\text { developing and offering an approach to lead from first contact in Industry } 4.0 \text { until the definition of } \\
\text { concrete timelines, } \\
\text { resources and responsibilities for company-specific realization projects. }\end{array}$ \\
\hline No. & Author & (Bloching et al. 2015, p. 20) \\
\hline \multirow{6}{*}{ D13 } & Title & Die Digitale Transformation der Industrie \\
\hline & Year & 2015 \\
\hline & Amount of Dimension & 4 \\
\hline & Names of Dimensions & Digital Data; Automatization; Digital Customer Access; Network \\
\hline & Page & 20 \\
\hline & Short description & $\begin{array}{l}\text { A study on order of federal association German industry. The study investigates the causes and effect } \\
\text { on digital transformation. }\end{array}$ \\
\hline No. & Author & (Britze et al. 2020, p. 20) \\
\hline \multirow{6}{*}{ D14 } & Title & Reifegradmodell Digitale Geschäftsprozesse \\
\hline & Year & 2020 \\
\hline & Amount of Dimension & 4 \\
\hline & Names of Dimensions & Technology; Data; Quality; Organization \\
\hline & Page & 8 \\
\hline & Short description & Created a maturity model which is industry neutral. \\
\hline No. & Author & (Fitzgerald et al.2013,p. 6) \\
\hline \multirow{6}{*}{ D15 } & Title & Embracing Digital Technology; A New Strategic Imperative \\
\hline & Year & 2013 \\
\hline & Amount of Dimension & 3 \\
\hline & Names of Dimensions & Customer Experience; Internal Operations; New Business Model \\
\hline & Page & 6 \\
\hline & Short description & $\begin{array}{l}\text { The survey focuses on digital transformation and the use of new digital technologies to enable major } \\
\text { business improvements. }\end{array}$ \\
\hline No. & Author & (Hentrich 2020, p. 6) \\
\hline \multirow{6}{*}{ D16 } & Title & Digitalisierungsbarometer \\
\hline & Year & 2014 \\
\hline & Amount of Dimension & 4 \\
\hline & Names of Dimensions & $\begin{array}{l}\text { Processes and Infrastructure; Vision, Strategy and Business Model; Customer Engagement; People, } \\
\text { Culture, Governance and Organization }\end{array}$ \\
\hline & Page & 6 \\
\hline & Short description & $\begin{array}{l}\text { A company and population survey, results are given which degree of digitalization exist in } \\
\text { companies and population. }\end{array}$ \\
\hline
\end{tabular}

The tables are sorted with first preference academic or practical paper. Second preference is the surname of the first mentioned author. Academics papers are from number D1 to D12 and from number D13 to D16 are practical papers. Table 3 shows the result of the literature review which maturity models where used from different authors and practitioners which belong to the main topic digitalization. Pointing out of this result is the different dimension and how they named it. This table provides an idea of different dimensions and the following table shows a deeper analysis about the dimensions. 
Frequencies of Dimensions

\begin{tabular}{|l|l|}
\hline Dimensions & Number of Frequencies \\
\hline Customer & 9 \\
\hline Technology & 8 \\
\hline Employee and Culture & 8 \\
\hline Strategy & 7 \\
\hline Product and Service & 7 \\
\hline Organization & 7 \\
\hline Processes & 6 \\
\hline Digital Data & 5 \\
\hline Digital Business Model & 4 \\
\hline Network & 3 \\
\hline Automatization & 3 \\
\hline Operations & 3 \\
\hline Leadership & 2 \\
\hline Governance & 2 \\
\hline Quality & 2 \\
\hline Eco System & 1 \\
\hline Value Creation & 1 \\
\hline Company Success & 1 \\
\hline Maintenance Management & 1 \\
\hline Logistic Management & 1 \\
\hline Corporate Standards & 1 \\
\hline Design and Engineering & 1 \\
\hline Vision & 1 \\
\hline Supplier & 1 \\
\hline Source: created by Author & \\
\hline
\end{tabular}

Table 4

In this evaluation analysis, the frequencies of the listed dimensions were counted. The different authors sometimes use different terms, although similar content is indicated. For greater clarity, these terms have been grouped accordingly. For example, the term "strategy" and the term "digital strategy" have been grouped and counted into one category, namely "strategy". Because to guarantee also a better overview, not all single responses were listed in the table. These which are listed were only done by way of example, but all single responses were taken into account in the assessment. The authors have focused on maturity in their scientific articles and these different dimensions have been mentioned with their respective frequencies. Depending on the objective of the author, the most different dimensions were included and examined. With regard to this paper, a different objective is pursued, namely which investment decisions are made in the case of possible digitalization measures. The different dimensions listed give the author an idea of which dimensions can be found in the context of digitization. This means that the dimensions listed in the table are not necessarily unusable with only a few mentions. Now it has to be considered on which dimension should be focused and which criteria should be defined within this dimension.

The selection of dimensions is partly based on the stakeholder approach. The stakeholders of a company are: Owners, lenders, management, employees, suppliers, customers and the general public. (Baden 2001, p. 398)

The goal which the author pursues is the stakeholders: customers, suppliers and employees, as they have the greatest influence on digitization and possible investment decisions. The other stakeholders: owners, lenders, management, or the general public are not considered because the influence on these is not given and is not founded as a dimension. The other three dimensions customer, supplier, employees which are represented from the stakeholder approach are also listed in the literature analysis. The customers are listed with nine nominations; the employees are listed with eight nominations and the supplier with one nomination. Based on the other dimension the author considers digital products likewise. The numerous other dimensions are not applicable in this context. It is now important to define what is to be understood by the dimensions which are selected.

Customer:

Appelfeller and Feldmann address the distribution channels and the customer is connected to the digitalized processes. They distinguished between business to customer (B2C) and Business to Business (B2B). The goal of B2C is to have a personalized exchange with the customer at any time and any location. For B2B customers is the goal to generate an efficiency increase for the handling of cross-company processes. In the end to connect the customer to their own IT structure is an instrument to bind the business relationship with the customer. (Appelfeller and Feldmann 2018, p. 5) 
Teichert understood the customer as benefit from digitization; personalization of products/services; utilizing digital services to engage customers; focus on customer value; digitization of customer touchpoints; creating value out of data, customer participation and empowerment.( Teichert 2019, p. 1681)

The author's interpretation for the dimension customer is primarily, to connect the customer with the own company IT structure. The digitally connected customer has the customer's digital access to the system so that the exchange for data can be ensured. The aim is to gain advantages for the customer and themselves. The advantages for the customer are to get data or information very fast and through automotive processes every time on time. From the customer perspective, the customer is able trough the digital access to use it for their own company's purpose. One of these advantages for the company is an efficiency increase in handling the company-wide processes. The connection to the digital processes can be cause high efforts and costs on both sides customers and companies so that the connection of the customer can also be seen as a binding instrument.

Supplier:

The procedure is the same as the previously mentioned approach with the customer. This is the view of the procurement side and the supplier is connected to the company IT structure. The systems are connected so that the data can be exchanged directly. Appfelfeller and Feldmann pointed out, that the connection can be for example an easy exchange via email or a supplier portal. In most cases, an exchange via email is a connected process which is linked to the supplier portal. The exchange via email should not be seen as a separate solution. They also address, that a further intention of digital supplier integration is often to simplify the joint development of products (Appelfeller und Feldmann 2018, p. 5).The main objective is to ensure like the customer side, increase efficiency in the process. (Appelfeller and Feldmann 2018, p. 5) The supplier integration focuses on that objective and not on developing products, because in the customer perspective is the purpose of safe process costs through simplifying and streamline processes. On the other hand, from the supplier perspective it is nowadays a must have to offer their customer those solutions.

Employee:

The employees of the company will be equipped besides of classic computers with smart devices, smartphones, tablets, or other modern devices. The goal is through that digitalization with the help from these tools to increase the efficiency of the employees. (Appelfeller and Feldmann 2018, p. 6) Handling the work easier, faster and with less error rates. Also, the new forms of working organization as previous mentioned, setting up a digital working place or working environment contributes to an efficiency increase. Leino interprets human resources as a group or individual which have an effect on the organization (Leino et al., p. 44).

The evaluation has shown which varieties of dimensions are available. The explanation of which dimensions are focused on was given as well as the meaning and what is understood by the individual dimensions. In order to decide which investments should be made in which digitalization activities, it is necessary to know which digitization activities are available for the respective dimensions.

The paper from Cuylen (Cuylen, et al. 2016, p. 115), deals with the digital online invoice process. This measure is definitely a digitalization measure and belongs to the group of Employee dimension. Other digitization measures are the implementation of data management systems or equipping the employees with hardware. Equipping employees with hardware can be seen from a different perspective and has different purposes of fulfillment. For companies where employees are on the road outside their own company and doing fieldwork, they can use their tablet or cell phone to document the recorded hours and send them to the central accounting office. The accounting office has direct access to the system and can work with these recorded hours. Another way of fulfilling the purpose would be to use the hardware to document his work and send it to the central accounting office, where the invoice for the customer can be created.

These and other possible digitization measures will be examined to see how much they have generated added value for the company.

\section{Conclusion}

This article has exposed the literature analysis in which maturity models exist related to digitization. The meaning of the maturity models, how they were created and what they are suitable for were explained. Upon closer examination and analysis it turned out that the maturity models and the existing selected dimensions of the authors were very different. More than twenty-four different dimensions were listed. Of these twenty-four different dimensions, the author has filtered out the strongest characteristics and explained the individual dimensions and what is meant by them.

Further research and the following articles will focus on and further explore the strongest pronounced dimensions. This is because further research is aimed at finding out what details are hidden behind the individual dimensions. In order to decide which investments should be made in which digitization measures, it is necessary to know which digitization measures are available for the respective focused dimensions. 


\section{Bibliography}

Appelfeller, W., Feldmann, C., 2018. Die digitale Transformation des Unternehmens. Systematischer Leitfaden mit zehn Elementen zur Strukturierung und Reifegradmessung. Berlin: Springer Gabler. Online verfügbar unter http://dx.doi.org/10.1007/978-3-662-54061-9.

Baden, A., 2001. Shareholder Value- oder Stakeholder-Ansatz? In: WiSt - Wirtschaftswissenschaftliches Studium, 30(8), 398-403. DOI: 10.15358/0340-1650-2001-8-398.

Bauernhansl, T., Hompel, M., ten, Vogel-Heuser, B. (Hg.), 2014. Industrie 4.0 in Produktion, Automatisierung und Logistik. Anwendung, Technologien, Migration. Wiesbaden: Springer Vieweg (SpringerLink). Online verfügbar unter http://dx.doi.org/10.1007/978-3-658-04682-8.

Becker, J., Knackstedt, R., Pöppelbuß, J., 2009. Developing Maturity Models for IT Management. Business Information Systems Engineering, 1(3), 213-222. DOI: 10.1007/s12599-009-0044-5.

Berghaus, G., Kessler, R., Dmitriyev, V., Gómez, Jorge M., 2018. Ermittlung der Digitalisierungspotenziale von nicht-digitalen Geschäftsprozessen. In: $H M D$ 55(2), 427-444. DOI: 10.1365/s40702-018-0403-0.

Berghaus, S., Back, A., 2016. Gestaltungsbereiche der Digitalen Transformation von Unternehmen. Entwicklung eines Reifegradmodells. Die Unternehmung, 70(2), 98-123. DOI: 10.5771/0042-059X-2016-2-98.

Blondiau, A., Mettler, T., Winter, R., 2013. Design and Implementation Challenges of Maturity Models for Healthcare Organizations. An Experience Report 2013. In: 16th International Symposium on Health Information Management Research (ISHIMR). - Halifax, Canada. 2013, 2532.

Bloching, B., Leutiger, P., Oltmanns, T., Rossbach, C., Schlick, T., Remane, G., Quick, P., Shafranyuk, O., 2015. Die digitale Transformation der Industrie. Eine europäische Studie von Roland Berger Strategy Consultants im Auftrag des BDI. München, Berlin.

BMWi (Hg), 2013. Mittelstand-Digital. IKT-Anwendungen in der Wirtschaft. Stand September 2013. Berlin: BMWi.

BMWi (Hg), 2016. Digital strategy 2025. Berlin: Bundesministerium für Wirtschaft und Energie (BMWi) (De.Digital).

Britze, N., Schulze, A., Fenge, K., Woltering, M., Gross, M., Menge, F., Mucke, A., Ensinger, A., Keller, H., Oldenburg, L., Wederhake, A., Backers, S., Braunschweig, von M.-C., Wankerl, A., Rapp, C., Strum, T., Hofmann, G., Laux, M., Schröder, T., Zibell, M., Hoffmann, D., Streif, M., Wörner, A., Halstenbach, V., 2020. Reifegradmodell Digitale Geschäftsprozesse. Leitfaden. In: Bundesverband Informationswirtschaft, Telekommunikation und neue Medien e.V, S. 1-30.

Bruin, T. de, 2005. Understanding the Main Phases of Developing a Maturity Assessment Model. In: Proceedings of the 16th Australasian Conference on Information Systems (ACIS 2005), November 30 - December 2, 2005, Sydney, Australia.

Canetta, L., Barni, A., Montini, E., 2018. Development of a Digitalization Maturity Model for the Manufacturing Sector. In: 2018 IEEE International Conference on Engineering, Technology and Innovation (ICE/ITMC). 2018 IEEE International Conference on Engineering, Technology and Innovation (ICE/ITMC). Stuttgart, 17.06.2018 - 20.06.2018: IEEE, S. 1-7.

Carolis, A. de, Macchi, M., Negri, E., Terzi, S. , 2017. Guiding Manufactoring Companies Towards Digitalization. A Methodology for Supporting Manufacturing Companies in Defining their Digitalization Roadmap. In: International Conference on Engineering, Technology and Innovation (ICE/ITMC), S. 1-10.

Colli, M., Madsen, O., Berger, U., Møller, C., Wæhrens, B. V., Bockholt, M., 2018. Contextualizing the Outcome of a Maturity Assessment for Industry 4.0. In: IFAC-PapersOnLine 51 (11), S. 1347-1352. DOI: 10.1016/j.ifacol.2018.08.343.

Crosby, P. B.,1979. Quality is Free. The Art of Making Quality Certain. New York: Mentor.

Cuylen, A., Kosch, L., Breitner, M. H., 2016. Development of a Maturity Model for Electronic Invoice Processes. Electronic Markets, 26(2), 115127. DOI: $10.1007 / \mathrm{s} 12525-015-0206-\mathrm{x}$.

Demir, C., Kocabaş, I., 2010. Project Management Maturity Model (PMMM) in Educational Organizations. In: Procedia - Social and Behavioral Sciences, 9, 1641-1645. DOI: 10.1016/j.sbspro.2010.12.379.

Fitzgerald, M., Kruschwitz, N., Bonnet, D., Welch, M., 2013. Embracing Digital Technology. A New Strategic Imperative. Findings from the 2013 Digital Transformation Global Executive Study and Research Project. In: MIT Sloan Management Review 2013.

Greenberger, E., Sorensen, A. B., 1974. Journal of Youth and Adolescence. A Multidisciplinary Research Publication. 4. Aufl. 3 Bände. Dordrecht, New York, NY: Springer; Plenum Press.

Hentrich, C., 2014. Digitalisierungsbarometer. In: Study PWC 2014.

Hogrebe, F., Nüttgens, M., 2009. Business Process Maturity Model (BPMM). Konzeption, Anwendung und Nutzenpotenziale. HMD : Praxis der Wirtschaftsinformatik, 46(266), 17-25. 
Jahn, B., Pfeiffer, M., 2014. Die digitale Revolution — Neue Geschäftsmodelle statt (nur) neue Kommunikation. Marketing Review St. Gallen, 31(1), 79-93. DOI: 10.1365/s11621-014-0323-5.

Koch, S., 2015. Einführung in das Management von Geschäftsprozessen. Six Sigma, Kaizen und TQM. 2. Aufl. Berlin: Springer Vieweg. Online verfügbar unter http://ebooks.ciando.com/book/index.cfm/bok_id/1883137.

Kohlegger, M., Maier, R., Thalmann, S., 2009. Understanding Maturity Models Results of a Structured Content Analysis. In: Proceedings of IKNOW'09: 9th International Conference on Knowledge Management and Knowledge Technologies ; Proceedings of I-SEMANTICS '09, 5th International Conference on Semantic Systems, Graz, Austria, September 2 - 4, 2009, S. 51-61. Online verfügbar unter http://hdl.handle.net/10419/44444.

Lichtblau, K., Stich, V., Bertenrath, R., Blum, M., Bleider, M., Millack, A. et al., 2015. Industrie 4.0-Readiness. Frankfurt: IMPULS-Stiftung.

Leino, S.-P., Kuusisto, O., Paasi, J., Tihinen, M., 2017. VTT Model of Digimaturity. Towards a New Era in Manufacturing: Final Report of VTT's For Industry Spearhead Programme. In: VTT Technical Research Centre of Finland, Vol. 288, S. 41-46.

Leyh, C., Bley, K., 2016. Digitalisierung. Chance oder Risiko für den deutschen Mittelstand? - Eine Studie ausgewählter Unternehmen. HMD Praxis der Wirtscahtsinformatik, 53(1), 29-41. DOI: 10.1365/s40702-015-0197-2.

Meyer, M., Helfert, M., O'Brien, C., 2011. An Analysis of Enterprise Architecture Maturity Frameworks. In: Perspectives in Business Informatics Research: $10^{\text {th }}$ International Conference, BIR 2011, Riga, Latvia, October 6-8, 2011, Proceedings. Berlin [u.a.]: Springer, S. $167-177$.

Oswald, G., Krcmar, H. (Hg.), 2018. Digitale Transformation. Fallbeispiele und Branchenanalysen. Wiesbaden: Springer Gabler (SpringerLink Bücher). Online verfügbar unter http://hdl.handle.net/10419/182356.

Paulk, M. C.; Curtis, B.; Chrissis, M. B.; Weber, C. V., 1993. Capability Maturity Model, Version 1.1. IEEE Software, 10(4), 18-27. DOI: $10.1109 / 52.219617$

Reifenberger S., 2019. CFOs an der Seitenlinie. In: Finance 2019; Blockchain Was bleibt vom Hype? (November/Dezember), S. 64-65.

Rosemann, M., Bruin, T. de, 2005. Towards a Business Process Management Maturity Model. In: Proceedings of the $13^{\text {th }}$ European Conference on Information System (ECIS).

Schuh, G., Anderl, R., Dumitrescu, R., Krüger, A., Hompel, M. ten, 2020. Industrie 4.0 Maturity Index. Managing the Digital Transformation of Companies - UPDATE 2020. In: acatech Studie 2020. Online verfügbar unter https://i40mc.de/wpcontent/uploads/sites/22/2016/11/acatech_STUDIE_Maturity_Index_de_WEB.pdf, zuletzt geprüft am 26.08.2020.

Schumacher, A., Nemeth, T., Sihn, W., 2018. Roadmapping towards Industrial Digitalization Based on an Industry 4.0 Maturity Model for Manufacturing Enterprises. In: Procedia CIRP, S. 409-414. DOI: 10.1016/j.procir.2019.02.110.

Teichert, R., 2019. Digital Transformation Maturity. A Systematic Review of Literature. Acta Universitatis Agriculturae et Silvicilbrurae Mendelianae Brunensis, 67(6), 1673-1687. DOI: 10.11118/actaun201967061673.

Valdez-de-Leon, O., 2016. A Digital Maturity Model for Telecommunications Service Providers. Technology Innovation Management Review, 6(8), 19-32. DOI: 10.22215/timreview/1008.

Young Kim, D., Kumar, V., Murphy, S. A., 2010. European Foundation for Quality Management Business Excellence Model. International Journal of Quality \& Reliability Management, 27(6), 684-701. DOI: 10.1108/02656711011054551. 


\title{
INTERNATIONAL DIMENSION OF THE CAREER EXPERIENCE OF RETURN MIGRANTS AND TRANSNATIONALS \\ Baiba Bela, University of Latvia
}

\begin{abstract}
The global competition for talent capable of promoting smart growth, is leading to a rapidly increasing migration of high-skilled professionals. Since Latvia's accession to the European Union, Latvian residents have been actively using the opportunities for free movement in the EU. In the context of Latvia's demographic sustainability and economic competitiveness, return migration is of great importance. What are the difficulties to enter the labour market in Latvia and how the career experiences of return migrants and transnationals develop? The aim of this study is to explore the career experience of return migrants and transnationals in Latvia, addressing the role of international migration in the development of their careers. Entrance in the labour market in Latvia and factors that shape careers of high-skilled professionals are studied. This study is based on analysis of 15 semi-structured interviews with 11 transnationals and 4 Latvians studying abroad (2019) and on media analysis - 28 interviews with return migrants in the weekly magazine IR thematic series "Back Home" (published in 2018 and 2019). Analysis is based on the grounded theory, using open and focused coding procedures. The main results and findings suggest that Latvia is seen as place of opportunities that offer high quality of life. For many not only decent salary is important, but also feeling of meaningful work. Research identifies personal, professional and family related factors, shaping careers of return migrants and transnationals.
\end{abstract}

Keywords: return migration, transnational migrants, career experience.

JEL code: J61

\section{Introduction}

The global competition for talent capable of promoting smart growth, is leading to a rapidly increasing migration of high-skilled professionals. Talent return migration and diaspora engagement for many countries with high emigration rates play an increasingly important role for economic competitiveness and development. The contribution of the diaspora and return migrants is linked not only to the transfer of knowledge and skills, but also to the transfer of new values, ideas, practices, identity and social capital (Levitt \& Lamba-Nieves, 2011; Kuznetsov, 2013; Šūpule, 2020).

In the context of Latvia's demographic sustainability and economic competitiveness, emigration and return migration receive a special attention. Since Latvia's accession to the European Union, Latvian residents have been actively using the opportunities for free movement in the EU to improve their wellbeing and gain new experience (Hazans, 2018; Mierina, 2015). Latvia's population is one of the most mobile in Europe, and although emigration is declining since 2012, emigration rates are still high. Around 20 thousand people leave Latvia per annum, 15.8 thousand in 2018 (Central Statistical Bureau, n. d.). Since 2013, 4.8-6.5 thousand emigrated residents of Latvia have returned per annum, 4852 in 2018 (Central Statistical Bureau, 2019). Studies carried out so far show that nearly half of all emigrants have left Latvia several times, and many of those who had returned plan to leave again. $15-17 \%$ of Latvian migrants identify themselves as transnationals, indicating that they reside in two places simultaneously (in Latvia and destination country) (Hazans, 2016; Mierina, 2015). The adaptation of return migrants in Latvia and their integration into the labour market have been studied using quantitative data. The results indicate employment acquisition (for $40 \%$ of return migrants and transnationals) and adoption of the local labour culture (31\%) to be the main challenges. Also, there is very strong correlation between job satisfaction and prospects to stay in Latvia (Hazans, 2016; Zača, Hazans, Bela, 2018). A recent mixed-methods study that primarily focused on the integration of high-skilled migrants into the labour market of the host country is useful here. With the use of life course analysis, the study illuminates also working life trajectories in regard to the motives for return migration (Šūpule, 2020). Less is known about the opportunities and individual gains in the career experiences of return migrants and transnationals. Also, findings on the difficulties to enter the labour market in Latvia regarding the role of personal networks that play too important role comparing to open competition through job advertisements (Hazans, 2016, Zača, Hazans, Bela, 2018) can be revisited. An in-depth understanding of this is of crucial importance for fostering return migration and decreasing repeated emigration.

The aim of this study is to explore the career experience of return migrants and transnationals in Latvia. The research questions are:

- What is the role of international migration in the development of their careers?

- What are the difficulties entering the labour market in Latvia?

- What are the opportunities and individual gains entering the labour market in Latvia?

- What are the other important factors shaping their careers? 
Research is conducted under the national research programme Towards sustainable development and inclusive society in Latvia: response to demographic and migration challenges. The programme aims to analyse challenges and possible strategies for sustainable development and an inclusive society with a focus on demographically linked drivers of migration. This study is part of broader research project under WP5 where the complex relations and interactions between demographic change, migration and social sustainability are explored. This study is based on analysis of 15 biographical semi-structured interviews with 11 transnationals and 4 Latvians studying abroad (2019) and on media analysis - 28 interviews with return migrants' in the weekly magazine IR thematic series "Back Home" (published in 2018 and 2019). Research participants and heroes of media interviews are skilled and high-skilled professionals aged between 25 and 40 . Among interviewees one is older and among protagonists of media interviews very few are without a university degree or college level professional education. These were helpful for comparison, to better understand the role of cohort generation, education and variety of career pathways. Almost all are success stories, so they do not represent full picture of possible career experiences. Also, difficulties are overlooked in the both sets of the interviews. This poses a question on the rules of selfperformance in semi-public or public milieu. Analysis is based on the grounded theory, using open and focused coding procedures (Bryant $\&$ Charmaz, 2019; Charmaz, 2006).

The novelty and relevance of the research is the in-depth analysis of return migrant career experiences in the new EU economy. It is novel and topical both for Latvia and internationally. In the context of Latvia is important to develop evidence-based policy recommendations to improve diaspora policy in order to foster return migration and to reduce repeated emigration. Internationally there is limited literature on career experiences of return migrants and transnationals in European contexts, especially in new EU economies like Latvia. An in-depth understanding of young highskilled return migrant decision making, experienced challenges and gains is vital for subsequent development and reduction of socio-economic disparities among EU countries. The return of high-skilled young professionals is recognised as a positive resource and an important instrument contributing to economic innovation and development in the country of origin (Suciu \& Florea, 2017).

\section{Return migration and value of foreign experience}

Broader context for this study is informed by the growing importance of international migration that has become a defining feature of many societies across the globe. Prior to the disruptions to migration flows caused by the COVID-19 pandemic in 2020, the number of internationa migrants had grown over the past two decades, reaching 281 million people (UN, 2021). Some researchers even propose to see mobility as a new ontological condition (Ozkazanc-Pan, 2019). As EU creates especially favourable conditions for mobility, it is of utmost importance to explore how young people craft their personal and professional lives that span beyond nation-state borders and boundaries, forging new experiences, lives and selves under conditions of mobility.

The most studied topic of youth migration is their education abroad (e.g. Cairns, 2014; Hazans, 2018), but it is recognised as a positive resource only whenyoung people bring back the education and experience gained abroad and use it in their country of origin. Several studies have focused on the return migration of young professionals. Yet, ew afocus on the development, accumulation, transformation and implementation of human capital or social capital through migration (Glorius, 2019; Staniscia, Deravignone, Gonzalez-Martin et al. 2019). Others focus on the foreign experience consequences on their integration in the labour market incountry of origin (Crescenzi, Holman \& Orru', 2017; Kurekova \& Žilinčíková, 2018; Rerat, 2014; Tverdostup \& Masso, 2016). The results imply a stronger role of experience gained abroad on earnings for youth (Tverdostup \& Masso, 2016) and that migration experience signals to employers a set of skills that differentiate young returnees from young stayers in a positive way - foreign work experience is an asset for (re)integration into the home labour market (Kurekova \& Žilinčíková, 2018). Referring to individua gains, an important finding is that acquired soft skills and informal and tacit competences are considered to be as important as formal and explicit ones (Staniscia, Deravignone, Gonzalez-Martin et al. 2019). Simultaneously, research suggests that migration patterns and integration in homeland's labour market is country specific. For example, brain circulation as a migratory pattern predominates for young Italians, and the human capital gained during migration results in better employability and earnings; for young Spaniards, circulation and return are more difficult in spite of their enriched human capital (ibid). It is important to see whether the role of experience abroad is similar also for young return migrants in Latvia.

Latvia is EU country with highly mobile citizens. In 2018 11.8\% or 149000 of Latvian citizens aged 20-64 resided in one of EU/EFTA countries and $31 \%$ of them had higher education (Šupule, 2020). Existing research on return migrants indicates that the motivation for return is largely dominated by non-economic factors - lack of family and friends (50\%), longing for Latvia (38\%), other family and personal conditions (23\%). All the other factors are less pronounced. The main difficulty after the return, as mentioned before, is to find a job for yourself (40\%), for your spouse (14\%), the difficulty of getting used to the different culture of work (31\%) and the uncertainty about taxes (30\%); only $15 \%$ had no re-integration 
difficulties (Zača, Hazans, Bela, 2018). The survey shows that return to Latvia is linked to a significant deterioration in material conditions. Thisalso explains why so many return migrants do not know whether they will stay in Latvia, as well as plan to leave again (ibid). Regarding integration into the labour market, existing quantitative data suggests that many return migrants experience down-skilling - 23\% in Riga, 26\% in other cities and $33 \%$ in towns, villages and countryside where a simpler job is valued above one's qualification. A concerning share of return migrants believe that employers do not value experience and skills acquired abroad - 35\% in Riga, yet more than half (51-52\%) in other regions (Mierina, Bela, 2020). This suggests that there are considerable differences between high value of foreign experiences observed in some other EU countries and more limited value of the foreign experiences in Latvia. Qualitative studies suggests that return migrants sometimes are seen as losers (return is interpreted as failure to integrate abroad) or as overqualified for Latvia (Zača, Hazans, Bela 2018; Šūpule, 2020). These findings indicate that qualification and experience abroad is not just a straightforward asset. Therefore, additional research on difficulties, opportunities and gains from mobility of young professionals and their career experiences in Latvian labour market is of significant importance.

\section{Research results and discussion}

Young skilled and high-skilled professionals, both return migrants and transnationals alike, are open to mobility and taking advantage of free movement. This section is addressing the role of international migration in shaping careers of high-skilled professionals, when entering the Latvian labour market. Particular attention will be paid to difficulties, opportunities, gains and other important factors that craft professional lives across nation-state borders. The life trajectories and career experiences demonstrate heterogeneity, high mobility and flexibility.

It must be stressed that emigration motives for young people differ from emigration motives for older age cohorts (that are predominantly economic). Findings of this and earlier research suggest that young people in Latvia are more like other EU15 migrants, who list the search for autonomy, lifestyle reasons and personal relationships as most important motivators for mobility (Koikkalainen, 2017; Zača, Hazans, Bela, 2018). The migration patterns of young generation differ. Qualitative data analysis suggests that however majority migrated between Latvia and one destination country, many of research participants and protagonists of media stories freely moved between more than two and three countries, with shorter or longer periods in each, including shorter or longer periods in Latvia. Even in this small sample of less than 40 individuals (not counting their spouses) places of residence where at least six months were spent cover almost all EU15 and EEA countries, as well as USA, Australia, Canada, Papua New Guinea, Trinidad, Singapore and few African countries. Observed mobility trajectories challenge conceptual orientations built on binaries of difference between mobility and stasis. Therefore, it is indeed necessary to coin a new framework on how we address relationships between mobility and immobility, localisation and transnational connection, experiences and imaginaries of migration, rootedness and cosmopolitan openness (Shiller \& Salazar, 2013).

Before focusing on the career experiences of young professionals and their integration into the Latvian labour market, some words must be said about their educational and career abroad, addressing the role of international migration in the development of their careers. For 10 out of 15 transnationals the international migration contributed to their educational achievements. Many are completing undergraduate studies in Latvia and then are studying abroad either because of expected higher quality of education or because a specific field of study they are interested in is not available in Latvia. For those who were interested in specific fields of study (like gender studies and violence, development cooperation), return is more complicated, because there is no or very limited demand for such specific knowledge in the labour market in Latvia. The media interviews show greater variety for the role of education on career development. This includes brain waste, when a person does not formally utilise his or her qualifications gained in Latvia. However, their cultural capital allows them to establish successful entrepreneurship abroad. In few cases also without formal professional education, but through practical training, persons develop professional skills and successful careers (like in sport and hospitality). Some protagonists of media interviews are starting their international careers with education gained completely in Latvia. For example, after graduation, some started work at international companies in Latvia and only then moving abroad in search for new professional achievements. However, less represented in this sample are returnees who migrate back right after completing higher education abroad (see more in Zača, Hazans, Bela, 2018). Almost all interviewees were satisfied with their career developments abroad. Only for two or three return migrants their careers abroad were not developing according their expectations (when you are willing to work in your profession but cannot) due to very high global competition in London or strong preference to locals in rural France.

Career experiences will be analysed further in relation to difficulties, opportunities, gains, and other key factors crafting professional lives when integrating into Latvian labour market. 
Interestingly, but research participants and protagonists of media interviews had not faced serious difficulties or chose to reveal only a few aspects of negative experiences. The negative experiences is related to the communication with state authorities (like State Revenue Service, State Social Insurance Agency, The Office of Citizenship and Migration Affairs), stressing the bureaucratic approach and controlling attitude they faced. In contrast is stressed positive and supporting attitude from bureaucrats in host country authorities. Some difficulties are mentioned also in relation to housing (limited market of quality housing). However previous research indicates that personal contacts are important recruitment channel in Latvia (Zača, Hazans, Bela, 2018; Mierina, Bela 2020), in these interviews this factor does not seem to be defined as obstacle. If one's education and first labour experience is abroad, you simply do not have necessary professional contacts. Instead, here proactive agency is highlighted, both by studying job advertisements and by writing to the company one wants to work. Or establishing your own business. Difficulties to find a job according one's speciality arise when one studied subject not available in Latvia - these areas are not requested in labour market either. Earlier research finding suggest that one of difficulties is that the local workplace culture and management style are not acceptable for many with foreign experience, and it is difficult for people to find a like-minded co-workers. Also, people with foreign experience often have higher claims against wages and labour rights (Hazans, 2016; Zača, Hazans, Bela, 2018). All these factors may be indicative of why many return migrants and those who identify themselves as transnationals report a particularly high plan for re-emigration (Hazans, 2016). Interestingly, but these interviews show various strategies return migrants use to establish network of like-minded friends, neighbours, or co-workers (using social networking sites, through NGO Ar pasaules pieredzi Latvijā etc.).

In the forefront of the narratives, both research interviews and media interviews alike, Latvia is the place of opportunity - weather it is opportunity for rapid career development, or it is opportunity to develop something of your own. This is new and promising discourse, confronting the discourse of return as failure and Latvia as failed state. It is repeatedly stressed, that in old economies it is not possible for early career stage professionals to reach top prominent positions within two years of work (see also Zača, Hazans, Bela, 2018). For many, life in Latvia presents an opportunity to develop something of your own. It is confirmed also by quantitative data - among return migrants, $18 \%$ of men and $9 \%$ of women are self-employed or entrepreneurs (compared to $11 \%$ and $6 \%$ of the total population), while to be self-employed or entrepreneur is even more prevalent among transnationals (26\% and $15 \%$ respectively) (Hazans, 2016). In the same time life in Latvia presents also an opportunity to be the master of your own life, to live according your own life philosophy, to practice sustainable lifestyle or to live according to Latvian traditional values and way of life (especially in rural areas). This is rarely possible in post-industrial, highly competitive large cities with intense life pace (like in London). Attitudes return migrants learned abroad, like - take initiative, try new things, not give up, openness to diversity, tolerance, a positive mindset, believe in yourself, are helping to find new path in Latvia labour market. A loss of fear for new adventures and change of mindset are important contributing factors that strengthens capability and contributes to a successful career in Latvia.

For many return migrants, not only a decent salary, but also a feeling of sense and meaningful work is important - that their work contributes not only to their own welfare and wellbeing, but also has some added value to society. Work in Latvia is interpreted as contributing to the development of their home country, while work abroad is interpreted as only personally beneficial. Sense of belonging is important factor for return - elsewhere one is just a guest that is reminded in different ways. Return migrants highlights that one feels needed in Latvia, it is the place where you belong to. Some also see their mission here: to challenge and change the system (especially in medicine), to improve something, to transfer experiences, as well as values and attitudes, acquired abroad, such as self-respect, tolerance, kindness, and positive attitudes towards life and one another.

The other important factors shaping careers are related to profession itself and to family related factors. Not all professions travel easy or are equally relevant for national labour markets. The specific nature of the profession appears to be particularly important, highly defining mobility opportunities and constraints, as well as possibilities and limitations of integration. Some need excellent local language skills, some do not. Some need procedures for recognition of qualifications, some do not. Working for international companies means that you can pay less attention to local language, culture, and people, if you do not want to. Working for a local company or running your own small business abroad means that you are obliged to know local language, culture, and people. For transnationals, the experiences of mobility and transnational family ties stand out - almost all note traveling as hobby, have resided in more than one country and have close relatives abroad, sometimes even in three different countries. Mobility trajectories show that profession's specificities combine with the different national contexts, as well as family related factors. If a person has a stable relationship and if there are children in this relationship, freedom of movement is much more limited and often subordinated to the developmental needs of children (see also Šūpule, 2000). Parents of minors are ready to adjust their work trajectories to parenting priorities. Rapid 
assimilation of children, noticed in previous research (Kārkliņa \& Kamerāde, 2016), is experienced also by protagonists of media interviews and served as powerful motive for return migration. Latvians from Switzerland see also long parental leave and parental allowance as positive factor for better work-life balance after childbirth. Important factor is also partner's preferences regarding place of residence.

Important factors that shape careers of transnationals, differ. Those transnationals, who choose Latvia as their place of residence, but work abroad, stress the importance to maintain a decent quality of life in material terms (which is more difficult with remuneration available locally), stress the importance to be part of a diverse and globalised space, but at the same time having high quality of life in terms of slow life, accessible nature, quality food, family, and friends nearby. In contrast, transnationals, to whom the feeling of global diversity is more appealing, choose to stay in global cities, sustaining intense relations with home country.

Even this limited qualitative study identifies the same trends as quantitative research. Those who have worked abroad are tend to more critically evaluate employer's attitudes and tend to have higher demands in terms of working conditions and wages as they realize the value of their work (Mierina, 2015). It reveals also less researched issues, like return migrants are fostering the entry of new values and relationship models into society, the change of work culture in Latvia, is contributing to the transfer of knowledge, skills, competences, contacts, innovative approaches to manufacturing or management processes (Bela \& Mierina, 2018). The purpose of future studies would be to identify the benefits of the Latvian society and the labour market from the social transfers of diaspora engagement and return migrants.

\section{Conclusions}

1. The experience of international migration has strong positive role in the career development of high skilled return migrants and transnationals. Obtaining education abroad can be a part of a mobility pattern, but equally possible is the successful search of economic security or professional advancement abroad after receiving professional or higher education in Latvia.

2. Moving back to Latvia can be seen for many as a project of life quality, seeking meaningful work and better living conditions. For some, this meant getting out of an intense job in global cities. For many, it is a search for professional self-fulfilment in Latvia, creating their own company or working differently, bringing foreign experiences and trying to change something in Latvia. For others, it is a return to the roots in a country where children can speak Latvian and grow up with Latvian identity. Here, the work will play an instrumental role, combining with return as identity project. Sense of belonging is a key factor in both cases.

3. However, previous findings suggests that $40 \%$ of return migrants face difficulties to enter the labour market in Latvia and $31 \%$ experiences the difficulty of getting used to the different culture of work. This research allows to understand those who do not experience difficulties when entering labour market. Instead, proactive agency is highlighted - by studying job advertisements, by writing to the company one wants to work, by establishing one's own business. Return migrants uses various strategies to establish network of like-minded friends, neighbours, or coworkers.

4. Latvia is seen as place of opportunities - for rapid career, to start business of your own, to live according your life philosophy, to have feeling of sense and meaning, to have high quality of life.

5. The other important factors shaping return migrants careers are personal, professional and family related. Personal factors are high openness to mobility and change, as well as creative transfer of knowledge, skills, competences, ideas, attitudes and mindsets. Professional factors are related to the nature of profession, like necessary language skills, qualification recognition regulations. Family factors are related to partner's choices and interpretation of parental duties.

6. This study is developed with the support of National Research Programme «Towards sustainable development and inclusive society in Latvia: response to demographic and migration challenges» (Nr. VPP-IZM-2018/1-0015). Author thanks the students of master study programme "Sociology" at University of Latvia, who conducted 15 semi-structured interviews for this research during the course "Migration and Integration" (2019). 


\section{Bibliography}

Bela, B., Mieriṇa, I., 2018. Diasporas ieguldījums Latvijā un tā apzināšanas iespējas. Rīga: LU SZF SPPI Diasporas un migrācijas pētījumu centrs. [Online] Available at: https: www.diaspora.lu.lv/petijumi [Accessed 20.12.2020].

Bryant, A., Charmaz, K., 2019. The SAGE Handbook of Current Developments in Grounded Theory. London: SAGE Publications Ltd. DOI: $10.4135 / 9781526485656$.

Cairns, D., 2014. Youth Transitions, International Student Mobility And Spatial Reflexivity: Being Mobile? UK: Palgrave.

Centrāāā statistikas pārvalde, 2019. Imigrācija, emigrācija un saldo. [Online] Available at: https://www.csb.gov.lv/lv/statistika/statistikastemas/iedzivotaji/migracija/galvenie-raditaji/imigracija-emigracija-un-saldo [Accessed 16.11.2020].

Crescenzi, R., Holman, N., Orru', E., 2017. Why do they return? Beyond the economic drivers of graduate return migration. Annals of Regional Science, 59(3), .627-.603. DOI 10.1007/s00168-016-0762-9.

Charmaz, K., 2006. Constructing Grounded Theory. London, Thaousand Oaks, New Delhi: SAGE Publications.

Glorius, B., 2019. Transnational Social Capital in Migration: The Example of Student Migration from Bulgaria to Germany. Social Inclusion. 7(4), 232-242 . DOI: 10.17645/si.v7i4.2390.

Hazans, M., 2016. Atgriešanās Latvijā: remigrantu aptaujas rezultāti. Rīga: LU Diasporas un migrācijas pētījumu centrs. [Online] Available at: https: www.diaspora.lu.lv/petijumi [Accessed 20.12.2020].

Hazans, M., 2018. Labour Market Policy Thematic Review 2018: An in-depth Analysis of the Emigration of Skilled Labour. Latvia. Brussels: European Commission, Directorate-General for Employment, Social Affairs and Inclusion. European Centre of Expertise (ECE). [Online] Available at: https://www.researchgate.net/publication/328912663_An_in-depth_analysis_of_the_emigration_of_skilled_labour_Latvia [Accessed 16.11.2020].

Kārkliña, I., Kamerāde, D., 2016. "Nenāc manā istabā, es nesaprotu latviski”: Latvijas emigrantu bērnu valodas un identitātes veidošanās. Rīga: LU Filozofijas un sociolog̣ijas institūts. [Online] Available at: «Nenāc manā istabā, es nesaprotu latviski»: Latvijas emigrantu bērnu ... (slideshare.net) [Accessed 20.01.2021].

Koikkalainen, S., 2017. Finnish Highly Skilled Migrants and the European Economic Crisis. Baltic Journal of European Studies, 7(2), 168-181.

Kurekova, L. M., Žilinčíková, Z., 2018. What is the Value of Foreign Work Experience for Young Return Migrants? International Journal of Manpower. 39(1), 71 - 92. [Online] Available at: https://datubazes.lanet.lv:5879/insight/content/doi/10.1108/IJM-04-2016-0091/full/html [Accessed 16.11.2020].

Kuznetsov, Y. (ed.), 2006. Diaspora Networks and the International Migration of Skills: How Countries Can Draw on Their Talent Abroad. The World Bank, Washington DC. https://doi.org/10.1596/978-0-8213-6647-9.

Kuznetsov, Y. (ed.), 2013. How Can Talent Abroad Induce Development at Home? Towards a Pragmatic Diaspora Agenda. Washington DC: Migration Policy Institute.

Levitt, P., Lamba-Nieves, D., 2011. Social Remittances Revisited. Journal of Ethnic and Migration Studies, 37(1), 1-22.

Masso, J., Tverdostup, M., Mierina, I., Espenberg, K., 2018. Labour Market Inequalities in Conditions of Limited Social Dialogue: the Case of the Baltic States. In: Reducing Inequalities in Europe. Edward Elgar Publishing.

Mierina, I. (red.), 2015. Latvijas emigrantu kopienas: cerību diaspora. Rīga: LU Filozofijas un socioloǵijas institūts.

Mieriņa, I., Bela, B., 2020. Remigrantu atgriešanās reǵionos: izaicinājumi un iespējas. Latvijas mantojums un nākotnes izaicinājumi valsts ilgstspējai. Latvijas Zinātnes padome, Izglītîbas un zinātnes ministrija, Latvijas Universitāte, Vidzemes augstskola, Latvijas Zinātnuu akadēmija, Latvijas Nacionālā bibliotēka, Rīga, 27.10.2020. [konferences prezentācija]

Ozkazanc-Pan, B., 2019. "Superdiversity": a New Paradigm for Inclusion in a Transnational World. Equality, Diversity and Inclusion: An International Journal, 38(4), 477-490. DOI: 10.1108/EDI-07-2018-0134.

Schiller, N. G., Salazar, N. B., 2013. Regimes of Mobility Across the Globe. Journal of Ethnic and Migration Studies, 39(2), 183.-200. DOI:10.1080/1369183X.2013.723253.

Suciu, M. C., Florea, C. A., 2017. An Empirical Study on the Migration Among Young Skilled and Creative People. Amfiteatru Economic, 19(46), 727-741. [Online] Available at: https://www.researchgate.net/publication/318860022_An_Empirical_Study_on_the_Migration_Among_Young_Skilled_and_Creative_People [Accessed 16.11.2020].

Šūpule, I., 2020. Latvijas augsti izglītotie emigranti: izglītības un arba pieredze Latvijā un ārvalstīs. Rīga: Latvijas Universitātes Apgāds. 
Staniscia, B., Deravignone, L., Gonzalez-Martin, B., Pumares, P., 2021. Youth mobility and the development of human capital: is there a Southern European model? Journal of Ethnic and Migration Studies. 47(8), 1866-1882. DOI: 10.1080/1369183X.2019.1679417.

United Nations, 2021. International Migration 2020 Highlights. UN DESA. [Online] Available at: https://www.un.org/development/desa/pd/news/international-migration-2020 [Accessed 20.01.2021].

Tverdostup, M., Masso, J., 2016. The labour market performance of young return migrants after the crisis in CEE countries: the case of Estonia. Baltic Journal of Economics, 16(2), 192-220. DOI: 10.1080/1406099X.2016.123372.

Zača, E., Hazans, M., Bela, B., 2018. Atgriešanās apstākḷi un nosacījumi. Rīga: LU SZF SPPI Diasporas un migrācijas pētījumu centrs. [Online] Available at: https: www.diaspora.lu.lv/petijumi [Accessed 20.12.2020]. 


\title{
THE ROLE OF DIGITAL INFORMATION SOURCES IN THE TRAVEL PLANNING PROCESS
}

\section{Kristine Berzina, University of Latvia \\ Ilze Medne, University of Latvia}

\begin{abstract}
World Economic Forum's Digital Transformation Initiative emphasizes that digitalisation in tourism is transforming the industry at an exponential rate across the globe. Current tourist behaviour patterns are changing not so much in travel habits as in the ways of finding and using travel information. These digitalisation changes are evident at all travel stages starting from dreaming about the future trip, planning and booking necessary tourism services, as well as sharing information and evaluating experiences. Tourist destination organisations and companies need to make strategic decisions, when sharing information, to reach the target audience in a smart and efficient way. The purpose of the study is to analyse the current use of travel web sites and applications in different travel stages. The survey was chosen as the quantitative research method based on five travel stages in order to study digital tourism informatin usage patterns. A personal interview survey was conducted in 2019 with 437 tourists. Main findings indicate the major differences in the use of digital information sources at the planning stage of travel between age groups and depending on the intensity of travel. The results of this study can be applied by marketing organisations and company managers to make better decisions when submitting travel information on web sites and applications.
\end{abstract}

Keywords: applications, digital information, travel planning, travel sites, travel stages.

JEL code: M31, L83

\section{Introduction}

Many international tourism organisations, including World Economic Forum's Digital Transformation Initiative (World Economic Forum, 2017), emphasize that digitalisation in tourism is transforming the industry at an exponential rate across the globe. Models of tourist behaviour are changing nowdays not so much in travel habits as they are chaging in the ways of finding and using travel information. Information technologies make travelling today more affordable, accessible and convenient than ever before. These digitalisation changes are evident at all travel stages starting from dreaming about the future trip, planning and booking necessary tourism services, as well as sharing information and evaluating experiences. Tourists worldwide now have an abundance of localised and personalised options for where to stay, what to do and how to get around. Destination marketing organisations (DMOs) and tourism companies, for their part, need to make strategic decisions when sharing information to reach the target audience in a smart and efficient way. Mobile digital platforms allow DMOs to communicate with visitors through all stages of their experience, from awareness to interest, from interest to booking, visiting and post-visit.

The aim of the study is to analyse the current use of travel web sites and applications in different travel stages. Two research questions were raised:

- What digital information resources do travelers most often use in the dreaming and planning stages of travel?

- How does the use of digital information resources differ in the dreaming and planning stages of a trip in different segments of travelers?

The survey was chosen as the quantitative research method based on Robertson travel stages (2015) in order to study digital tourism informatin usage patterns. A personal interview survey was conducted in 2019 with 437 tourists. Main findings indicate the major differences in the use of digital information sources at the planning stage of travel, crosstabulations are applied for different age groups. The results of this study can be applied by marketing organisations and company practitioners to make better decisions when submitting travel information on web sites and applications.

\section{Literature review}

Already since the 1980s, Information Communication Technologies have been changing the tourism industry. Starting with the development of Computer Reservation Systems and later on in the 1990s with the use of Internet, it transformed tourism industry and travellers' behaviour, created opportunities for the tourism industry and facilitated continuous technological innovations (Buhalis, 1998; Buhalis, Law, 2008, Amaro, Duarte, 2015, Xiang, Magnini, Fesenmaier, 2015, Navío-Marco, Ruiz-Gómez, Sevilla-Sevilla, 2018). The emergence of the electronic market gave opportunity for travellers to easily compare products, get lower prices, save planning and buying time (Heung, 2003), in the second half of the 1990s, the evolution of the online travel agencies (OTAs) revolutionised the whole travel purchase process (Heung, 2003, Amaro, Duarte, 2015). Web 2.0 further transformed tourism industry and included new tools such as meta search engines, fare aggregators, new virtual communities that 
enable travellers to compare a wide range of offers and prices conveniently (Xiang, Wang, O'Leary, Fesenmaier, 2015). Online sales, as a part of total tourism market sales, are constantly increasing (Sabanoglu, 2019).

Because of the wide range of information available, searching on the internet has become an increasingly dominant source of information for travellers (Tjostheim, Tussyadiah, Hoem, 2007; Xiang, Gretzel, 2010; No, Kim, 2015; Gyódi, 2019), mobile travel applications are the 7th most downloaded application as more than half of global smartphone users have downloaded travel applications on their devices (GoodWorkLabs, 2016).

Scholars outline that research on information technology is lacking the analysis of tourist behavior related to information technology development (O'Connor, Murphy, 2004) and only over the last dacade has gained more pronounced attention from reserachers (Dastjerdi, Kaplan, e Silva, Nielsen, Pereira, 2019). Researchers also indicate that travellers often use a combination of different sources of information (Money, Crotts, 2003; Gursoy, Umbreit, 2004), therefore marketing specialists need to analyse not only the frequency of use of information sources, but also the particular combination of information sources used by travellers (Tjostheim, Tussyadiah, Hoem, 2007; Medne, Berzina, 2020).

New digital information sources require tourism companies to innovate the travel selling process. Amadeus (2017) indicates the main trends in tourism digitalisation - exponential increase of data and information related to traveller behaviour, their spending patterns; as well as the increasing scale of computing power, enabling assimilation and processing of complex data sources.

Current tourist behaviour patterns are changing not so much in travel habits as in the ways of finding and using travel information. Digital information channel usage is determined by the customer's attitude, compatibility and perceived risk (Duarte and Amaro 2015, Huang, Li, Zhang, Zhang, Yan, 2020). Diffusion and assimilation of the tourism information technology innovation depends both on the readiness of consumers as well as practitioners (Tan, Ooi, 2018).

As the infrastructure of mobile networks evolved, mobile applications emerged as a new industry (Hoehle and Venkatesh, 2015; Chang, Chou, Yeh, Tseng, 2016). Digital information sources can be reasearhed by analyzing browsing, reservation, booking and reviewing patterns in tourism web sites, in online web applications (Wen, 2012); in social media (Ayeh, Au, Law, 2013; Chathoth, Ungson, Altinay, Chan, Harrington, Okumus, 2014; Book and Tanford, 2015), in mobile technologies like mobile applications and devices (Chang et al., 2016; Lai, 2015; Okazaki and Hirose, 2009; Ukpabi and Karjaluoto, 2017). Individualized marketing and travel decisions influenced by social networks are potentially powerful from the tourist behavior perspective, and gain rapid increase in use due to their competitive costs for decision makers and wide access to the general public of travellers (Dastjerdi, Kaplan, e Silva, Nielsen, Pereira, 2019).

Previous tourist behavior studies indicate that web applications remain as important tools for traveler engagement, and that mobile applications are the preferred channel due to their speed and additional functionality (MacHale, 2018).

\section{Use of digital information sources in the five stages of travel}

Adoption of the Internet for travel planning has brought digital information channels to be the number one source of information in trip planning, even creating such a situation that travellers become intensely technology dependent in all stages of travel (Xiang, Magnini, Fesenmaier, 2015). As one of the approaches that can be applied for analyzing digital information source usage in different stages of travel is Google's "five stages of travel" (Robertson, 2015):

- dreaming,

- planning,

- booking,

- experiencing,

- sharing.

Every trip starts with a dream, future travellers spend significant time thinking about their vacations and consult seemingly endless sources to find information, therefore it is important for marketers to reach the dreamer through social media by encouraging their followers to share their travel stories and interact with their online community.

For tourism web sites and other internet information technology applications, it is important to not only attract the attention of travellers, but also to convert lookers into bookers (Robertson, 2015).

In the travel planning stage, searching for information about the travel destination can be considered a fundamental component because of the need to obtain a substantial amount of information for future travel plans (Xiang, Wang, O'Leary, Fesenmaier, 2015). Pre-trip planning helps travellers to make decisions and build expectations for their future trip (Gretzel, Fesenmaier, O'Leary, 2006). Research as a part of the travel planning 
process serves as a lens that allows to understand a potentially wide range of travel behaviours. Scholars have been analysing Internet users' travel planning taking into account general demographic profiles, gender, educational level, etc. (Xiang, Wang, O’Leary, Fesenmaier, 2015). Previous research (for example Tan, Ooi, 2018) indicates that there are differences in mobile travel application usage between different age groups as well as genders.

During the experiencing stage, tourists use the Internet to obtain information on trip details, share their experiences and compare services related to the trip. Tourists browse photos, videos and blogs, use online maps, compare customer ratings and evaluation systems in order to organize trips or contribute experiences and recommendations. This way of using the Internet for travel planning currently is becoming generalized as Travel 2.0 (Parra-López, Bulchand-Gidumal, Gutiérrez-Taño, Díaz-Armas, 2011)

Social media can be used during all travel stages starting from dreaming about the future trip, planning and booking necessary tourism services, as well as sharing information and evaluating experiences (Sigala, Christou, Gretzel, 2012, Chung, Koo, 2015). Tourism marketers need to make strategic decisions, when sharing information, to reach the target audience in a smart and efficient way.

\section{Research results and discussion}

In order to empirically test the use of digital information channels in different stages of travel, the survey was conducted using questionnaires in English, and was supervised in person while respondents were filling it in. The questionnaire included three parts, starting with the questions about the use of devices during travel; continuing with the patterns of digital tourism information usage; and finishing with the profile of the respondent.

The objectives of the study are:

- to identify the digital information sources used by travelers in the dreaming and planning stages of the trip,

- to identify the differences in the usage of digital information sources among different traveler segments based on age and frequency of travel.

The primary data was obtained by surveying foreign tourists in Riga (Latvia) in September-October 2019. The survey was conducted by a team of interviewers, a total of 437 questionaires with non-transit international visitors from 54 countries were collected. Tourist segmentation was carried out not based on motivation, but by grouping them based on frequesncy of travel - travelling once a year, 2 to 3 times a year, more then 3 times a year. The respondent profile is presented in the table 1.

Table 1

Profile of respondents

\begin{tabular}{|l|r|c|c|}
\hline & & Frequency & $\%$ \\
\hline Gender & Male & 214 & $49 \%$ \\
\hline Age & Female & 223 & $51 \%$ \\
\hline & Up to 30 & 263 & $60.6 \%$ \\
\hline Travel frequency & 31 to 50 & 133 & $30.6 \%$ \\
\hline & More than 50 & 38 & $8.8 \%$ \\
\hline & Once a year & 79 & $18 \%$ \\
\hline & 2 to 3 times a year & 186 & $42.6 \%$ \\
\hline
\end{tabular}

Source: Tourist survey data 2019

The study found out which devices travelers typically use while traveling. The smartphone is the unquestionable leader, both overall among all respondents and in individual segments. Depending on the segment, $90 \%$ to $98 \%$ of respondents use their smartphone while traveling (Table 2 ). In all segments, except travelers over the age of 50, the second device most commonly used while traveling is the laptop (travelers over the age of 50 prefer tablets). Other devices used, while traveling, include smart watches, GPS navigation devices and headphones. 
Using digital devices while traveling (\%)

\begin{tabular}{|l|c|c|c|c|c|c|c|}
\hline \multirow{2}{*}{ Devices } & \multirow{2}{*}{$\begin{array}{c}\text { All } \\
\text { respondents }\end{array}$} & Up to 30 & 31 to 50 & $\begin{array}{c}\text { More than } \\
50\end{array}$ & Once a year & $\begin{array}{c}2 \text { to } 3 \text { times } \\
\text { a year }\end{array}$ & $\begin{array}{c}\text { More than } 3 \\
\text { times a year }\end{array}$ \\
\cline { 3 - 7 } & $95 \%$ & $94.3 \%$ & $97.7 \%$ & $89.5 \%$ & $96.2 \%$ & $91.9 \%$ & $97.7 \%$ \\
\hline Smartphone & $26.8 \%$ & $27 \%$ & $29.3 \%$ & $15.8 \%$ & $27.8 \%$ & $28.5 \%$ & $23.8 \%$ \\
\hline Taplet & $14.6 \%$ & $15.2 \%$ & $12 \%$ & $18.4 \%$ & $15.2 \%$ & $17.7 \%$ & $11.6 \%$ \\
\hline $\begin{array}{l}\text { Other } \\
\text { devices }\end{array}$ & $4.1 \%$ & $5.7 \%$ & $1.5 \%$ & $2.6 \%$ & $3.8 \%$ & $2.7 \%$ & $5.8 \%$ \\
\cline { 2 - 7 } & & Smartwatch & $\begin{array}{c}\text { Head- } \\
\text { phones }\end{array}$ & $\begin{array}{c}\text { GPS } \\
\text { navig. } \\
\text { device }\end{array}$ & Smartwatch & $\begin{array}{c}\text { Smart- } \\
\text { watch, GPS } \\
\text { navig. } \\
\text { device }\end{array}$ & $\begin{array}{l}\text { Smartwatch, } \\
\text { GPS navig. } \\
\text { Device, } \\
\text { Headphones }\end{array}$ \\
\hline
\end{tabular}

Source: author's calculations based on tourist survey data 2019

The most common web sites and applications on the smartphone of the respondentare tourist accommodation reservation platform Booking.com, tourist accommodation sharing platform Airbnb, travel platform TripAdvisor, and digital map platform GoogleMaps. (Figure 1)

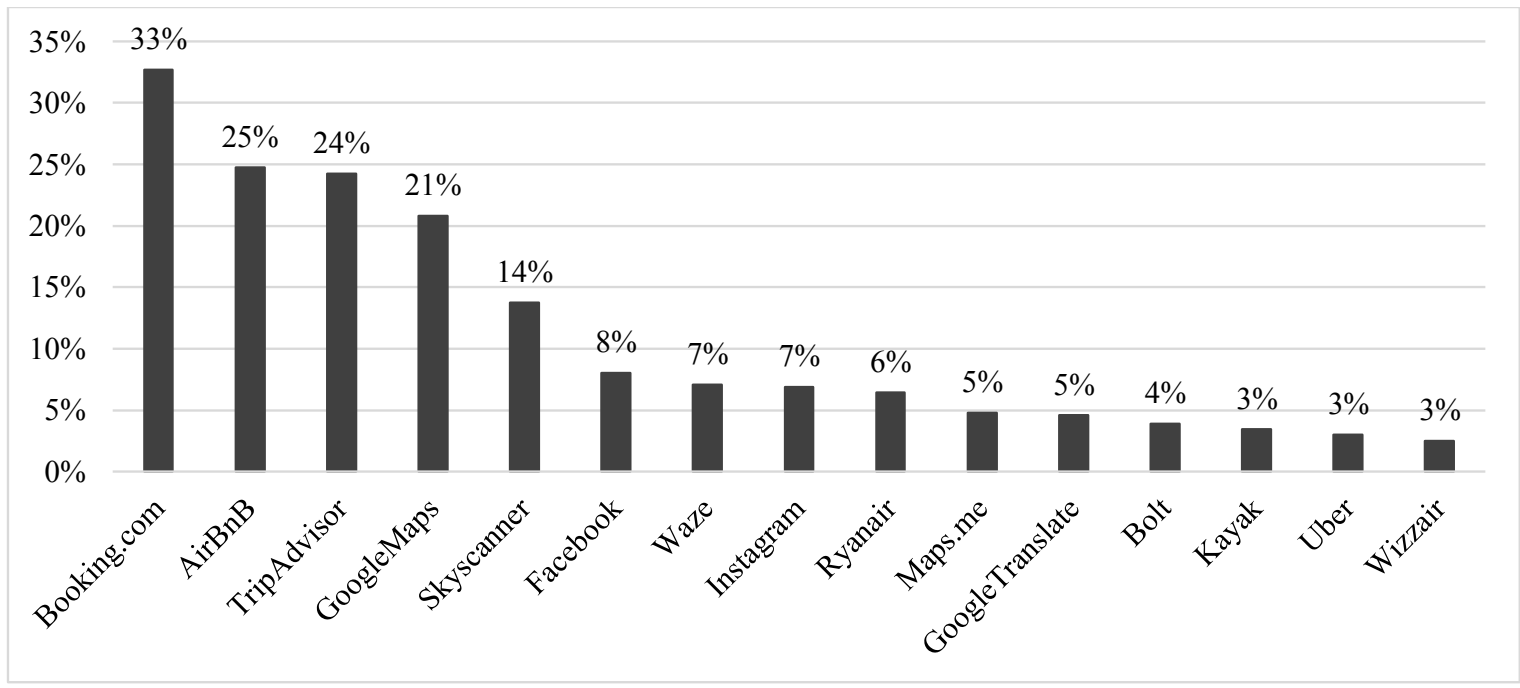

Source: author's construction based on tourist survey data 2019

Fig. 1. The most common web sites and applications on the respondent's smartphone

The number of travel related applications downloaded on smartphones ranges from 1 to 19. In total, 143 different applications were named in response to this survey.

\section{Use of digital information sources in dreaming and planning stages of the trip}

To determine a more detailed pattern of digital information source usage, $n$ further research focus was directed towards the first three or pretravel stages, respectuvely dreaming, planning, booking. Due to the similarity of sources, two of which are combined, thus the use of web sites and mobile applications in the 'dreaming' stage and the planning and booking stage were analyzed.

Several studies in recent years show that sites such as Facebook, YouTube, Instagram and TripAdvisor are the most used sites by travelers during trip planning, and Instagram is emerging as a popular social media site used not only for trip planning, but also when choosing the destination. (Matikiti-Manyevere, Kruger, 2019)

The results of this study confirm that digital information sources such as Instagram, TripAdvisor and Facebook are the most used $\mathrm{s}$ in the dreaming stage before the next foreign trip (Table 3). Younger travelers under 30 prefer the social networking platform Instagram, at the same time, travelers over the age of 30 prefer the world's largest travel platform TripAdvisor. During the pre-trip stage, the travel platform TripAdvisor is also used more frequently by travelers, who travel more often, among travelers, who travel less frequently, the social networking site Instagram is more popular. Travel blogs are less popular in all age groups, however, for travelers, who travel less frequently, travel blogs are used as inspirations as often as the travel platform TripAdvisor. 
Travel web sites and applications used by travelers when dreaming about the future trip to any foreign destination

\begin{tabular}{|c|c|c|c|c|c|c|c|}
\hline & \multirow[b]{2}{*}{$\begin{array}{c}\text { All } \\
\text { respondents }\end{array}$} & \multicolumn{3}{|c|}{ Age } & \multicolumn{3}{|c|}{ Travel frequency } \\
\hline & & Up to 30 & 31 to 50 & More than 50 & $\begin{array}{c}\text { Once a } \\
\text { year }\end{array}$ & $\begin{array}{c}2 \text { to } 3 \text { times } \\
\text { a year }\end{array}$ & $\begin{array}{l}\text { More than } 3 \\
\text { times a year }\end{array}$ \\
\hline Instagram & $59.3 \%$ & $71.1 \%$ & $49.6 \%$ & $7.9 \%$ & $67.1 \%$ & $62.4 \%$ & $53.5 \%$ \\
\hline TripAdvisor & $53.3 \%$ & $50.6 \%$ & $58.6 \%$ & $55.3 \%$ & $32.9 \%$ & $52.2 \%$ & $64 \%$ \\
\hline Facebook & $46.9 \%$ & $47.1 \%$ & $52.6 \%$ & $23.7 \%$ & $44.3 \%$ & $49.5 \%$ & $44.8 \%$ \\
\hline Travel blogs & $35 \%$ & $38.8 \%$ & $33.8 \%$ & $15.8 \%$ & $32.9 \%$ & $34.9 \%$ & $36 \%$ \\
\hline & $11.9 \%$ & $11.4 \%$ & $11.3 \%$ & $18.4 \%$ & $12.7 \%$ & $10.8 \%$ & $12.8 \%$ \\
\hline Other & & $\begin{array}{c}\text { Google, } \\
\text { Booking. } \\
\text { com, } \\
\text { Pinterest, } \\
\text { Youtube }\end{array}$ & Google & $\begin{array}{c}\text { Google, } \\
\text { Booking.com }\end{array}$ & $\begin{array}{c}\text { Pinterest, } \\
\text { Google, } \\
\text { Airbnb, } \\
\text { Youtube }\end{array}$ & $\begin{array}{c}\text { Google, } \\
\text { Pinterest, } \\
\text { Booking. } \\
\text { com }\end{array}$ & $\begin{array}{l}\text { Google, } \\
\text { Pinterest }\end{array}$ \\
\hline
\end{tabular}

Source: author's calculations based on tourist survey data 2019

For all respondents in each of the segments, the social networking site Instagram is most commonly used during the 'dreaming' stage, and it is most often combined with another social networking site Facebook. (Table 4) In all of these segments, the travel platform TripAdvisor comes in second, while travel blogs rank third.

Table 4

The most used web sites and applications combined with the social networking site Instagram in 'dreaming' stage

(in individual segments)

\begin{tabular}{|c|c|c|c|c|}
\hline Rank & $\begin{array}{c}\text { All respondents } \\
\mathrm{n}=259\end{array}$ & $\begin{array}{c}\text { Age group up to } 30 \\
\mathrm{n}=187\end{array}$ & $\begin{array}{c}\text { Travel frequency: once a } \\
\text { year } \\
\mathrm{n}=53\end{array}$ & $\begin{array}{c}\text { Travel frequency: } 2-3 \\
\text { times a year } \\
\mathrm{n}=116\end{array}$ \\
\hline 1 & Facebook $(56.8 \%)$ & Facebook $(52.4 \%)$ & Facebook $(50.9 \%)$ & Facebook $(62.1 \%)$ \\
\hline 2 & TripAdvisor $(51 \%)$ & TripAdvisor $(51.3 \%)$ & TripAdvisor $(35.8 \%)$ & TripAdvisor $(49.1 \%)$ \\
\hline 3 & Travel blogs $(39 \%)$ & Travel blogs $(41.7 \%)$ & Travel blogs $(32.1 \%)$ & Travel blogs $(39.7 \%)$ \\
\hline
\end{tabular}

Source: author's calculations based on tourist survey data 2019

Respondents in the age groups over 30, who most often use the travel platform TripAdvisor during the pre-trip 'dreaming' stage, most often combine it with the social networking site Facebook. (Table 5) Respondents, who travel abroad more than 3 times a year, are more likely to combine TripAdvisor with Instagram.

Table 5

The most used web sites and applications combined with the travel platform TripAdvisor in 'dreaming' stage

(in individual segments)

\begin{tabular}{|c|c|c|c|}
\hline Rank & $\begin{array}{c}\text { Age group: } 31 \text { to } 50 \\
\mathrm{n}=78\end{array}$ & $\begin{array}{c}\text { Age group: more than } 50 \\
\mathrm{n}=21\end{array}$ & $\begin{array}{c}\text { Travel frequency: more than } 3 \\
\text { times a year } \\
\mathrm{n}=110\end{array}$ \\
\hline 1 & Facebook $(50 \%)$ & Facebook $(28.6 \%)$ & Instagram $(51.8 \%)$ \\
\hline 2 & Instagram $(43.6 \%)$ & Travel blogs $(9.5 \%)$ & Facebook $(40 \%)$ \\
\hline 3 & Travel blogs $(32.1 \%)$ & Instagram $(4.8 \%)$ & Travel blogs $(33.6 \%)$ \\
\hline
\end{tabular}

Source: author's calculations based on tourist survey data 2019

Unlike the 'dreaming' stage, a variety of service booking platforms are used more often during the travel planning stage. (Table 6) The most popular digital platform by far for all age groups regardless of travel intensity is a travel metasearch engine for accommodation reservations Booking.com.

Airbnb, a sharing platform, has become increasingly popular among young people in recent years. This study also shows that Airbnb is the next most popular digital platform in the travel planning and booking stage, both in the age group under 30 and in the age group 31 to 50 . Over the age of 50, the second most popular digital platform in this travel planning stage is travel platform TripAdvisor. Travel platform TripAdvisor is also more intensively used by frequent travelers. Unlike other digital information sites included in the study, only the flight search platform Skyscanner shows a high frequency of use similar to the other digital platforms mentioned above. However, this digital platform is not popular in the segment over 50, where high usage rates are indicated for web sites Hotels.com and Expedia. 
Web sites and applications used by travelers when planning and booking the future trip to any foreign destination

\begin{tabular}{|c|c|c|c|c|c|c|c|}
\hline & \multirow[b]{2}{*}{$\begin{array}{c}\text { All } \\
\text { respondents }\end{array}$} & \multicolumn{3}{|c|}{ Age } & \multicolumn{3}{|c|}{ Travel frequency } \\
\hline & & Up to 30 & 31 to 50 & $\begin{array}{c}\text { More than } \\
50\end{array}$ & Once a year & $\begin{array}{l}2 \text { to } 3 \\
\text { times a } \\
\text { year }\end{array}$ & $\begin{array}{c}\text { More than } \\
3 \text { times a } \\
\text { year }\end{array}$ \\
\hline Booking.com & $78 \%$ & $74.9 \%$ & $86.5 \%$ & $71.1 \%$ & $62 \%$ & $80.1 \%$ & $82.6 \%$ \\
\hline Airbnb & $56.3 \%$ & $62.7 \%$ & $52.6 \%$ & $28.9 \%$ & $59.5 \%$ & $54.3 \%$ & $57 \%$ \\
\hline TripAdvisor & $54.7 \%$ & $57.4 \%$ & $52.6 \%$ & $44.7 \%$ & $35.4 \%$ & $54.8 \%$ & $63.4 \%$ \\
\hline Skyscanner & $45.3 \%$ & $52.9 \%$ & $39.8 \%$ & $13.2 \%$ & $30.4 \%$ & $47.3 \%$ & $50 \%$ \\
\hline Hotels.com & $20.6 \%$ & $17.1 \%$ & $23.3 \%$ & $31.6 \%$ & $17.7 \%$ & $19.4 \%$ & $22.7 \%$ \\
\hline Kayak & $13.3 \%$ & $12.2 \%$ & $17.3 \%$ & $5.3 \%$ & $12.7 \%$ & $15.6 \%$ & $11 \%$ \\
\hline Trivago & $13 \%$ & $13.3 \%$ & $12 \%$ & $15.8 \%$ & $5.1 \%$ & $10.8 \%$ & $19.8 \%$ \\
\hline Expedia & $12.4 \%$ & $9.9 \%$ & $12.8 \%$ & $28.9 \%$ & $7.6 \%$ & $12.4 \%$ & $14.5 \%$ \\
\hline Lonely Planet & $8.2 \%$ & $6.5 \%$ & $11.3 \%$ & $10.5 \%$ & $2.5 \%$ & $6.5 \%$ & 12.8 \\
\hline Priceline & $6.4 \%$ & $6.5 \%$ & $6.8 \%$ & $5.3 \%$ & $7.6 \%$ & $8.6 \%$ & $3.5 \%$ \\
\hline Yahoo!Travel & $5.3 \%$ & $5.3 \%$ & $6.8 \%$ & $0 \%$ & $0 \%$ & $6.5 \%$ & $6.4 \%$ \\
\hline Viator & $4.3 \%$ & $3 \%$ & $6 \%$ & $7.9 \%$ & $2.5 \%$ & $6.5 \%$ & $2.9 \%$ \\
\hline Orbitz & $3.7 \%$ & $4.2 \%$ & $3 \%$ & $2.6 \%$ & $2.5 \%$ & $4.8 \%$ & $2.9 \%$ \\
\hline Travelocity & $3.2 \%$ & $1.9 \%$ & $3.8 \%$ & $10.5 \%$ & $3.8 \%$ & $3.2 \%$ & $2.9 \%$ \\
\hline HomeAway & $2.1 \%$ & $1.1 \%$ & $2.3 \%$ & $7.9 \%$ & $0 \%$ & $3.2 \%$ & $1.7 \%$ \\
\hline Travel Zoo & $1.8 \%$ & $1.1 \%$ & $3 \%$ & $2.6 \%$ & $1.3 \%$ & $3.2 \%$ & $0.6 \%$ \\
\hline Hotwire & $0.9 \%$ & $0 \%$ & $3 \%$ & $0 \%$ & $0 \%$ & $0 \%$ & $2.3 \%$ \\
\hline Travel blogs & $21.1 \%$ & $22.4 \%$ & $21.8 \%$ & $10.5 \%$ & $12.7 \%$ & $26.9 \%$ & $18.6 \%$ \\
\hline Other & $8.9 \%$ & $9.5 \%$ & $8.3 \%$ & $7.9 \%$ & $6.3 \%$ & $10.8 \%$ & $8.1 \%$ \\
\hline
\end{tabular}

Source: author's calculations based on tourist survey data 2019

For all age groups, as well as for those segments that travel abroad more than once a year, during the travel planning and booking stage the booking platform Booking.com is most often combined with a travel platform TripAdvisor. (Table 7) The second place is taken by the sharing platform Airbnb, Skyscanner ranks third in most segments. Unlike most segments, digital platform combinations are common to those who travel rarely and those over the age of 50 .

Table 7

The most used web sites and applications combined with the booking platform Booking.com in planning and booking stage (in individual segments)

\begin{tabular}{|c|c|c|c|c|}
\hline \multirow[b]{2}{*}{ Rank } & \multirow[b]{2}{*}{$\begin{array}{l}\text { All respondents } \\
\quad \mathrm{n}=341\end{array}$} & \multicolumn{3}{|c|}{ Age } \\
\hline & & $\begin{array}{l}\text { up to } 30 \\
n=197\end{array}$ & $\begin{array}{c}31 \text { to } 50 \\
n=115\end{array}$ & $\begin{array}{c}\text { more than } 50 \\
n=27\end{array}$ \\
\hline 1 & TripAdvisor (57.2\%) & TripAdvisor $(60.4 \%)$ & TripAdvisor (53.9\%) & TripAdvisor (51.9\%) \\
\hline 2 & Airbnb $(54.5 \%)$ & Airbnb (59.9\%) & Airbnb (53\%) & Airbnb $(25.9 \%)$ \\
\hline 3 & Skyscanner (50.4\%) & Skyscanner (59.4\%) & Skyscanner (45.2\%) & $\begin{array}{c}\text { Hotels.com (22\%) Expedia } \\
(22 \%)\end{array}$ \\
\hline \multirow[b]{2}{*}{ Rank } & \multicolumn{4}{|c|}{ Travel frequency } \\
\hline & $\begin{array}{c}\text { once a year } \\
n=49\end{array}$ & \multicolumn{2}{|c|}{$\begin{array}{c}2-3 \text { times a year } \\
n=149\end{array}$} & $\begin{array}{l}\text { more than } 3 \text { times a year } \\
n=142\end{array}$ \\
\hline 1 & Airbnb (59.2\%) & \multicolumn{2}{|c|}{ TripAdvisor (57.7\%) } & TripAdvisor (65.5\%) \\
\hline 2 & Skyscanner $(34.7 \%)$ & \multicolumn{2}{|c|}{ Airbnb (52.3\%) } & Airbnb (54.9\%) \\
\hline 3 & TripAdvisor (32.7\%) & \multicolumn{2}{|c|}{ Skyscanner (51.7\%) } & Skyscanner $(54.2 \%)$ \\
\hline
\end{tabular}

It can be concluded that only 3 to 4 most popular web sites and applications dominate in all tourist segments, the only difference between segments is the way these 3 to 4 most popular web sites and applications are combined during the travel planning and booking stage.

\section{Conclusions, proposals, recommendations}

The following conclusions outline the most important research findings, as well as proposals and recommendations.

1. Survey results show that travelers in the pre-travel 'dreaming' stage tend to use only a small number of web sites and applicationss. Especially for small and medium size tourism companies, it is important the identify and focus only on the most important web sites and applications of their travel segment and not invest resources in a large number of digital information channels.

2. The results of the study showed that there are differences in the use of digital information sources in the pre-travel stages, both between age groups and depending on the frequency of travel. Younger travelers are more likely to use social networking and sharing platforms. Older 
travelers are less likely to use social networking platforms, and are more likely to use more traditional information and booking platforms. This should be taken into account in the promotion and communication of tourism products to different age groups.

3. The weakness of the study is that it does not identify which devices (smartphones or PC) are used in the travel planning process (dreaming planning - booking) to obtain digital information from web sites and carry out booking activities, so further refining research is needed to develop recommendations for tourism destination and business professionals, who develop digital information and reservation platforms.

4. The study should be continued to understand what changes may occur in the use of devices and digital information in pre-travel stages, as well as in the sharing of information during and after travel, evaluating the services used.

5. Based on the results of this study recommendations on decisionmaking process for marketing organisations and company managers have been developed. Tourist marketing organizations (DMOs) must strive to make the right strategic decisions on which digital platforms to use for disseminating information and communicating with potential visitors to reach the target audience in a smart and efficient way. DMOs must use mobile digital platforms to reach and communicate with their visitors during all stages of the journey.

\section{Bibliography}

Amaro, S., Duarte, P., 2015. An Integrative Model of Consumers' Intentions to Purchase Travel Online. Tourism Management, 46, 64-79.

Ayeh, J.K., Au, N., Law, R., 2013. Predicting the Intention to use Consumer-generated Media for Travel Planning. Tourism Management, 35, 132143.

Book, L. A., Tanford, S., Montgomery, R., Love, C., 2015. Online Traveler Reviews as Social Influence: Price is no Longer King. Journal of Hospitality \& Tourism Research, 42(3), 1-31.

Buhalis, D., 1998. Strategic use of Information Technologies in the Tourism Industry. Tourism Management, 19(5), 409-421.

Buhalis, D., Law, R., 2008. Progress in Information Technology and Tourism Management: 20 Years on and 10 Years after the Internet - the State of eTourism Research. Tourism Management, 29(4), 609-623.

Chang, I., Chou, P., Yeh, K., Tseng, H., 2016. Factors Influencing Chinese Tourists' Intention to use the Taiwan Medical App. Telematics and Informatics, 33, 401-409.

Chathoth, P.K., Ungson, G.R., Altinay, L., Chan, E.S.W., Harrington, R., Okumus, F., 2014. Barriers Affecting Organisational Adoption of Higher Order Customer Engagement in Tourism Service Interactions. Tourism Management, 42, 181-193.

Chung, N., Koo, C., 2015. The use of Social Media in Travel Information Search. Telematics and Informatics, 32(2), 215-229.

Dastjerdi, A.M., Kaplan, S., e Silva, J.A., Nielsen, O.A., Pereira, F.C., 2019. Use intention of mobility-management travel apps: The role of users goals, technophile attitude and community trust. Transportation Research Part A: Policy and Practice, 126, 114-135.

AMADEUS, 2017. Defining the Future of Travel through Intelligence: Turning Big Data into Meaningful Insights. Available at https://amadeus.com/en/insights/ research-report/defining-the-future-of-travel-through-intelligence

[Accessed 29.01.2020].

Gretzel, U., Fesenmaier, D. R., O'Leary, J. T., 2006. The Transformation of Consumer Behaviour. In D. Buhalis, C. Costa (ed.) Tourism Business Frontiers: Consumers, Products and Industry, Burlington, MA: Elsevier, 9-18.

Gyódi, K., 2019. Airbnb in European Cities: Business as Usual or True Sharing Economy? Journal of Cleaner Production, 221, 536-551.

Heung, V.C.S., 2003. Internet Usage by International Travellers: Reasons and Barriers. International Journal of Contemporary Hospitality Management, 15(7), 370-378.

Hoehle, H., Venkatesh, V., 2015. Mobile Application Usability: Conceptualization and Instrument Development, MIS Quarterly, 39(2), 435-472.

GoodWorkLabs, 2016. How Mobile App Benefits Travel and Tourism Industry. Available at_http://www.goodworklabs.com/how-mobile-appbenefits-travel-and-tourism-industry/ [Accessed 16.02.2020].

Huang, X., Li, M., Zhang, J., Zhang, L., Yan, S., 2020. Tourists' Spatial-temporal Behaviour Patterns in Theme Parks: A Case Study of Ocean Park Hong Kong'. Journal of Destination Marketing \& Management, 15, 541-554.

Lai, I.K.W. (2015). Traveler Acceptance of an App-Based Mobile Tour Guide. Journal of Hospitality \& Tourism Research, 39(3), 401-432.

MacHale, D., 2018. 58\% of People Prefer to Use Apps to Search for Travel. What Does that Now Mean for You? Travelport. Available at https://blog-digital.travelport.com/travelport-digital-research-reveals-role-of-mobile-in-travel-0 [Accessed 15.02.2020]. 
Matikiti-Manyevere, R., Kruger, M., 2019. The Role of Social Media Sites in Trip Planning and Destination Decision-Making Processes. African Journal of Hospitality, Tourism and Leisure, 8(5), 1-10.

Medne, I., Berzina, K., 2020. Use of Information Sources in Outbound Travel Planning: Case of the Netherlands and Belgium. In: New Challenges in Economic and Business Development 2020: Economic Inequality and Well-Being. Riga: University of Latvia, 283-292

Navío-Marco, J., Ruiz-Gómez, L.M., Sevilla-Sevilla, C., 2018. Progress in Information Technology and Tourism Management: 30 Years on and 20 Years after the Internet - Revisiting Buhalis \& Law's Landmark Study about eTourism. Tourism Management, 69, 460-470.

No, E., Kim, J.K., 2015. Comparing the Attributes of Online Tourism Information Sources. Computers in Human Behavior, 50, 564-575.

O'Connor, P., Murphy, J., 2004. Research on Information Technology in the Hospitality Industry. International Journal of Hospitality Management, 23(5), 473-484.

Okazaki, S., Hirose, M., 2009. Does Gender Affect Media Choice in Travel Information Search? On the Use of Mobile Internet. Tourism Management, 30(6), 794-804.

Parra-López, E., Bulchand-Gidumal, J., Gutiérrez-Taño, D., Díaz-Armas, R., 2011. Intentions to Use Social Media in Organizing and Taking Vacation Trips. Computers in Human Behavior, 27(2), 640-654.

Robertson, M.J.H., 2015. Heritage Interpretation, Place Branding and Experiential Marketing in the Destination Management of Geotourism Sites, John Benjamins Publishing Company Culture \& Society issue, 289-309.

Sabanoglu, T., 2019. Retail e-commerce sales as share of retail trade in selected countries from 2014 to 2018. Statista. Available at https://www.statista.com/statistics/281241/online-share-of-retail-trade-in-european-countries/ [Accessed 15.02.2020].

Sigala, M., Christou, E., Gretzel, U. (eds), 2012. Social Media in Travel, Tourism and Hospitality: Theory, Practice and Cases. Burlington, VT: Ashgate Publishing Company, 316.

Tan, W.H.G., Ooi, K.B., 2018. Gender and age: Do they really moderate mobile tourism shopping behavior? Telematics and Informatics, 35(6), 1617-1642.

Tjostheim, I., Tussyadiah, I., P., Hoem, S.O., 2007. Combination of Information Sources in Travel Planning A Cross-national Study. In: Sigala M., Mich L., Murphy J. (eds.) Information and Communication Technologies in Tourism. Vienna: Springer, 153-162.

Ukpabi, D.C., Karjaluoto, H., 2017. Consumers' Acceptance of Information and Communications Technology in Tourism: A review. Telematics and Informatics, 34(5), 618-644.

Wen, I., 2013. Online Shopping of Travel Products: a Study of Influence of each Dimension of Travelers' Attitudes and the Impact of Travelers' Online Shopping Experiences on their Purchase Intentions. International Journal of Hospitality \& Tourism Administration, 14(3), $203-232$.

World Economic Forum, 2017. Digital Transformation Initiative: Aviation, Travel and Tourism Industry. White Paper. Available at http://reports.weforum.org/digital-transformation/aviation-travel/ [Accessed 23.01.2020].

Xiang, Z., Gretzel, U., 2010. Role of Social Media in Online Travel Information Search. Tourism Management, 31(2), $179-188$.

Xiang, Z., Magnini, V.P., Fesenmaier, D.R., 2015. Information Technology and Consumer Behavior in Travel and Tourism: Insights from Travel Planning Using the Internet. Journal of Retailing and Consumer Services, 22(C), 244-249.

Xiang, Z., Wang, D., O’Leary, J.T., Fesenmaier, D.R., 2015. Adapting to the Internet: Trends in Travelers' Use of the Web for Trip Planning. Journal of Travel Research, 54(4), 511-527. 


\title{
ETHNIC AND REGIONAL DISPARITIES OF AGEING IN LATVIA: MEASURING RESIDENTIAL SEGREGATION BY AGE
}

\author{
Maris Berzins, University of Latvia \\ Zaiga Krisjane, University of Latvia \\ Janis Krumins, University of Latvia \\ Magnuss Spude, University of Latvia
}

\begin{abstract}
Abstract. Ethnic and age segregation has often considered as a challenge for integration processes and sustainability of local communities. High spatial concentrations of ethnic minorities can lead to the establishment of parallel societies with low interaction between minority and majority populations. In Latvia, a relatively homogeneous Russian-speaking minority form a considerable part of the population, giving Latvia one of the highest proportions of ethnic minorities in Europe. Besides the more known form of ethnic segregation, there is an essential dimension in residential differentiation regarding a demographic trait such as individuals age. Moreover, this dimension has not attracted as much attention in population studies because it is viewed as less problematic than ethnic injustice or socioeconomic inequality. Nevertheless, all the dimensions of residential segregation exist simultaneously and overlap each other, so to interpret the ethnic segregation, it is vital to have a basic awareness and understanding of age dimension. Even though most ethnic minorities have lived in Latvia for decades, little is known about their residential patterns and concentrations, especially across the different age groups. Using individual-level census and population register data, this paper aims to understand how age intersects with ethnicity in residential segregation patterns. We present evidence on whether, and to what degree, residential age segregation has changed across the regions over time (2000-2019).
\end{abstract}

Keywords: age distribution, sociodemographic composition, ethnicity, spatial inequality, regional development.

JEL code: J110, J150, I310, R580

\section{Introduction}

Spatial differentiation and segregation between populations of different ages, ethnicities and socioeconomic statuses have be en prominent in population studies (Piekut, A. et al., 2019). The ethnic segregation is a much-studied topic and may occur due to discrimination, the marginalised position of ethnic groups in society, group preferences, and differences in society (Boterman, 2020). The study of ethnic residential segregation in Europe has evolved from describing the levels of segregation and emergent ethnic geographies to the analysis of how individuals and households adapted to urban housing markets (Wessel et al., 2018). More classic contributions argue that ethnic residential segregation results from growing international migration and cultural diversity across different geographic scales (Andersson, 1998; Bolt et al., 2008). A more recent approach that received significant attention was decomposing residen tial changes on demographic categories (Simpson, Finney, 2009; Wessel et al., 2018). When immigrants arrive in a new host society, they tend to settle in larger cities and often in ethnically concentrated neighbourhoods to live together with their co-ethnics. Although research into ethnic residential segregation has a long tradition, we are only beginning to understand the exact drivers behind ethnic concentration and segre gated neighbourhoods' impacts on the people involved (Catney, 2018). However, there are several reasons for being concerned about ethnic residential segregation. People who live in ethnically segregated residential milieus (neighbourhoods) are not only geographically separated, but they are also exposed to different life chances in terms of housing, educational and employment opportunities. They are often worse than for the majority ethnic group and weaken minority competitiveness in the broader society. Living in ethnically segregated nei ghbourhoods may also raise issues with cultural adaption and is often considered an obstacle to integrating ethnic minorities into society (Gijsberts, Dagevos, 2007). Ethnic segregation can be very persistent and can remain unchanged for decades affecting intergenerational ge ographies (Dawkins, 2005; Vanderbeck, 2007). Ethnicity has a considerable impact on how age segregation plays out. Nevertheless, the relationship between age, ethnicity and space remains an under-researched field of empirical enquiry. This paper seeks to enhance understanding of ethnic and regional disparities of ageing in Latvia by investigating whether, and to what degree, residential age segregation has cha nged over the past nearly 20 years. We ask whether the residential segregation of the elderly relative to young people has increased over the observed decades. To address this research question, we examine patterns of residence of young adults (aged 15-34) compared to older adults (aged 60 and over) for main ethnic categories (Latvians / non-Latvians) across the statistical regions. Thus, the paper provides empirical evidence 
and a brief insight into the transforming spatial relationships between younger and older members of society for majority/min ority ethnic divisions. This will complement the current debates on population ageing and spatialities of this process (Krūmiņš, Krišjāne, 2019).

\section{Literature Review}

The main ethnic groups in Latvia are Latvians and the Russian-speaking minority, which is the largest minority group comprising people who speak either Russian, Ukrainian, or Belarusian as their mother tongue. The Russian-speaking minority was mainly formed during the Soviet era and has lived in the country for decades. Moreover, during the Soviet period the formation of minority groups in Baltic countries, particularly in Estonia and Latvia, was shaped by the interrelated processes of immigration, industrialization and urbanization (Kulu 2003; Gentile, Sjöberg 2010). Immigration was part of a deliberate political, and ideological agenda used to disperse predominately Russianspeaking workforce through 'organized channels' of migration (Gentile, Tammaru 2006; Lindemann 2013). Approximately half of all Sovi et immigrants came from the present territory of the Russian Federation. During the 1970s and 1980s, the share of Belarusian and Ukrainian immigrants increased (Monden, Smits 2005). The majority of these people consider Russian as their mother tongue or speak it fluently. Thus, the common identity of Russian-speakers is mainly based on the Russian language. Simultaneously, the Russian-speakers group is diverse, taking into account their ethnic backgrounds, beliefs and attitudes towards culture. The immigrants were mostly located in the largest industrial cities with their ethnic infrastructure and were given priority to access the newest and better urban housing (Hess et al. 2012; Kährik, Tammaru 2010). Because of large-scale immigration, the share of ethnic minorities reached half of the total urban population (Krišjāne et al. 2016). Previous studies reveal that Russian-speaking immigrant population often settled in the newest and better urban housing units of the time (Hess et al. 2012; Gentile, Tammaru 2006; Kährik, Tammaru 2010). This resulted in high levels of ethnic residential segregation since the collapse of the Soviet Union, and there were no significant new waves of immigration in Latvia. Due to disparities in arrival time, the share of the non-Latvian minority is different in different age groups. Ethnic minorities experience both more shrinking numbers and more significant ageing process compared to Latvians (Zvidriņš, Bērziņšs, 2019). Similarly, the residence-based differences are still evident as the most non-Latvians live in the capital city Riga and most Eastern region of Latgale. For this reason, ethnic divisions have received quite a lot of public and academic attention. Geographers have mostly focused on ethnic differences in residential locations (Krisjane, Berzins 2014; Krisjane et al. 2016; Krisjane et al. 2019). For example, sociologists have studied ethnic differenc es in education and the labour market, as well as identity and integration policy (Pisarenko 2006; Rozenvalds 2010; Paalzow et al. 2010; Muiznieks et al. 2013). All these different studies have helped to unravel the nature of ethnic segregation in Latvia, the drivers behind ethnic divisions, and the effects of segregation on people's lives. However, among these numerous studies on ethnic divisions, there is a lack of research on ethnic residential segregation from the individuals' perspective. For example, we do not know much about how the ethnic residential context changes for people depending on age or residential milieu.

\section{Data and methods}

The paper draws on individual-level population census (2000) and register data (2019) under the conditions of mutual agreement between the Central Statistical Bureau of Latvia and the University of Latvia. Preliminary analysis of gender age structure for the ethnic majority (Latvians) and minority (non-Latvians) populations (see fig. 1) led to the selection of two age groups for the main analysis of age segregation focusing on young adults (aged 15-34) relative to older adults (aged 60 and over). The latter group consists of people who have reached or are nearing retirement age. The young adult group comprises people at the education stage, entering the labour force and building a career. At the same time, this age band corresponds to their prime childbearing years, building a family. The use of these two specific age groups facilitates the interpretation of the results. For instance, those aged 18 to 21 would reflect higher education students' concentrations in university locations rather than more general social processes. However, the meaning of ageing may be changing. 

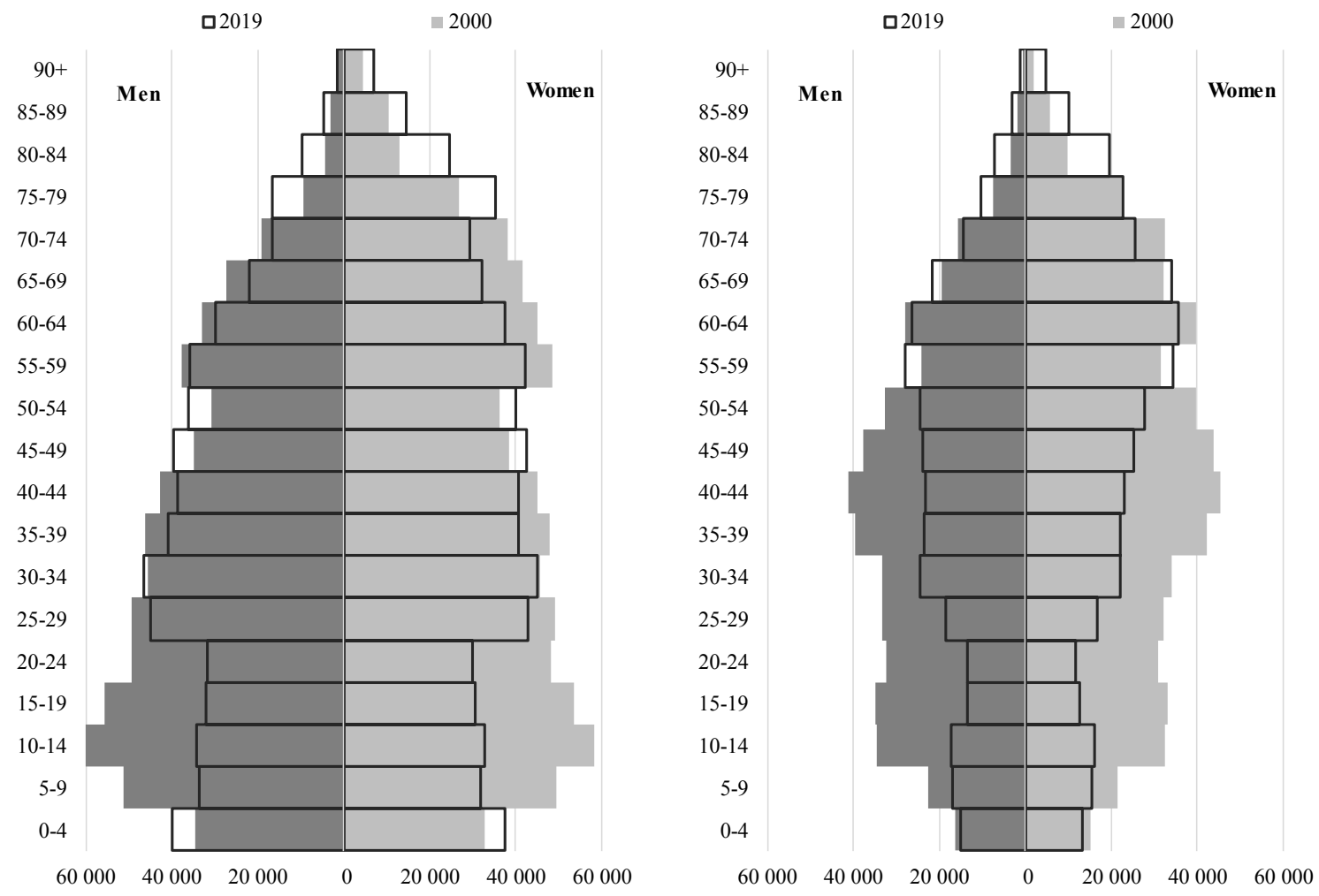

Source: author's construction based on Census (2000) and population register data (2019)

Fig. 1. Population gender-age pyramids of Latvians (on the left) and non-Latvians (on the right)

For statistical analysis, we have used geocoded individual-level data on the population's demographic and ethnic structure across all statistical regions of Latvia. The available data sets enable us to research entire populations, not samples, while analysis can be performed at the individual level in residential milieus. Besides, the analysed data sets are the most reliable source of information on ethnic and age structure. Unfortunately, the census and population register data does not support fine-grained spatial or small area units. Therefore, to achieve homogenous spatial coverage for proper statistical analysis, we produced a $1 \mathrm{~km}^{2}$ hexagon grid and converted available data sets to cells of this grid for each statistical region of Latvia. The availability of geocoded individual-level census and population register data allowed us to operationalize such a hexagon grid. Although the created grid and the cells do not precisely correspond to the administrative boundaries of statistical regions, it does provide the geographically most consistent spatial scale widely used in segregation studies across the world (cf. Brown, Chung, 2006; Martin et al., 2011; Li et al., 2016; Zwiers et al., 2019). The adopted approach of analysing small area data offers unique information to what degree age segregation is observed along with an ethnic and regional breakdown in Latvia.

Residential segregation is a spatial process, and numerous indices have developed over a long period for measuring spatial inequalities of different population groups (Duncan, Duncan, 1955; Massey, Denton, 1988; Johnston et al., 2005). The paper presents evidence of residential segregation changes by age both for Latvians and non-Latvians, with particular attention to change at the regional level. For simplicity, we refer to the global and local patterns of age segregation analysing them sequentially. First, age segregation is measured by an index of dissimilarity (ID), one of the most commonly applied indexes in segregation studies (Reardon, O'Sullivan, 2004). ID provides a measure of (un)evenness, showing the degree to which two populations are distributed differently. The ID values vary from 0 to 100 , where 0 indicates a completely even distribution (integration) and 100 indicates an entirely uneven distribution (segregation). The dissimilarity index (ID) indicates higher segregation levels when unit sizes or minority proportions are small (Allen et al. 2015). However, when comparing different age groups with the same size, it meets the needs. In the case of our paper ID indicates how unevenly distributed older adults (aged 60 and over) are relative to young adults (aged 15-34) across the selected regions. The dissimilarity index was calculated for both age and majority/minority ethnic groups using the standard formula: 


$$
I D=\frac{1}{2} \sum_{i=1}^{n}\left|\frac{x_{i}}{X}-\frac{y_{i}}{Y}\right| \times 100
$$

where $x_{i}$ is the number of people in first category in spatial unit $i ; X$ is the number of people in first category; $y_{i}$ is the number of people in the second category in spatial unit $i$; and $Y$ is the number of people in the second category. Multiplying by 100 expresses the share as a percentage, where 0 reveals no segregation and 100 total segregation. ID values less than 30 indicates low segregation, 30 to 60 indicate moderate segregation, and values over 60 reveals high segregation (Massey, Denton, 1998). The ID can also be interpreted as the percentage of the population who would have to move to create an even distribution of older adults to young adults in the hexagon grid that matches the larger geographical unit (statistical region). Notably, ID is not affected by the composition of the population at the regional level. Therefore, when examining age segregation across grid cells, for example, a grid with a high share of elderly (and a small number of young population) can have the same ID as a grid with a low share of elderly (and many young populations). We will calculate the location quotients (LQ) of both analysed age groups for Latvians and non-Latvians across the selected regions during the second stage of the adopted approach. Thus, the second stage of analysing the results characterizes broad region patterns and local geographies of age segregation for both majority/minority ethnic groups. LQs will be independently calculated and scaled for the region(s) with higher ID values to demonstrate the spatial patters of age segregation or concentration of both age groups along ethnic lines. The location quotients were calculated using the formula:

$$
L Q=\left(\frac{x_{i}}{t_{i}}\right) /\left(\frac{X}{T}\right)
$$

where $x_{i}$ is the number of people in first category in spatial unit $i ; t_{i}$ is the total population of unit $i ; X$ is the total number of people in first category, and $T$ is the total population of a region (Isard et al., 1960). LQ maps help to visualise the relative spatial concentration or dispersion of both age groups in the residential milieus. If the calculated ratio is more than 1 , a certain group is overrepresented in the given grid cell; if the ratio is less than 1, a certain group is underrepresented in the given grid cell.

\section{Research results and discussion}

Before we focus on age segregation and the geographical spread of the 60 and over group relative to younger adults (15-34), it is worth highlighting some regional differences among Latvians and non-Latvians older groups. Table 1 shows the population distribution and share of ethnic minorities in all the statistical regions. The results indicate that regions with a lower proportion of ethnic minorities are more exposed to the ageing of non-Latvians.

Table 1

Population sociodemographic trends in the regions of Latvia

\begin{tabular}{|l|c|c|c|c|c|c|c|c|}
\hline \multirow{2}{*}{ Region } & \multicolumn{2}{|c|}{$\begin{array}{c}\text { Population distribution, } \\
\text { 2019 }\end{array}$} & \multicolumn{2}{|c|}{$\begin{array}{c}\text { Population } \\
\text { change, } \\
\mathbf{2 0 0 0 - 2 0 1 9}\end{array}$} & $\begin{array}{c}\text { Share of } \\
\text { ethnic } \\
\text { minorities } \\
\text { 2019 }\end{array}$ & \multicolumn{2}{c|}{$\begin{array}{c}\text { Mean age } \\
\text { (Latvians) }\end{array}$} & \multicolumn{2}{c|}{$\begin{array}{c}\text { Mean age } \\
\text { (non-Latvians) }\end{array}$} \\
\cline { 2 - 10 }$y$ & Thous. & $\%$ & $\%$ & $\%$ & 2000 & 2019 & 2000 & 2019 \\
\hline Rīga & 632.6 & 32.9 & -17.5 & 52.9 & 38 & 40 & 41 & 45 \\
\hline Pierīga & 370.6 & 19.3 & 3.5 & 27.9 & 36 & 39 & 40 & 45 \\
\hline Latgale & 260.2 & 13.6 & -32.5 & 54.0 & 38 & 42 & 40 & 47 \\
\hline Kurzeme & 240.1 & 12.5 & -25.5 & 23.1 & 36 & 41 & 40 & 49 \\
\hline Zemgale & 230.3 & 12.0 & -21.5 & 28.3 & 36 & 40 & 40 & 48 \\
\hline Vidzeme & 186.1 & 9.7 & -27.3 & 12.7 & 36 & 42 & 42 & 51 \\
\hline LATVIA & 1919.9 & 100.0 & -19.4 & 37.6 & 37 & 40 & 40 & 46 \\
\hline
\end{tabular}

Source: author's calculations based on Census (2000) and population register data (2019). Note: ${ }^{1}$ non-Latvians of whom the largest groups are Russians, Belarusians, Ukrainians, Poles and Lithuanians 
Figure 2 shows the increase in polarisation between the considered age groups over the past two decades. The figure clearly shows that this polarization has increased especially among non-Latvians. Increased polarization of both age groups is most evident in Vidzeme, followed by Kurzeme, Zemgale and Latgale region.
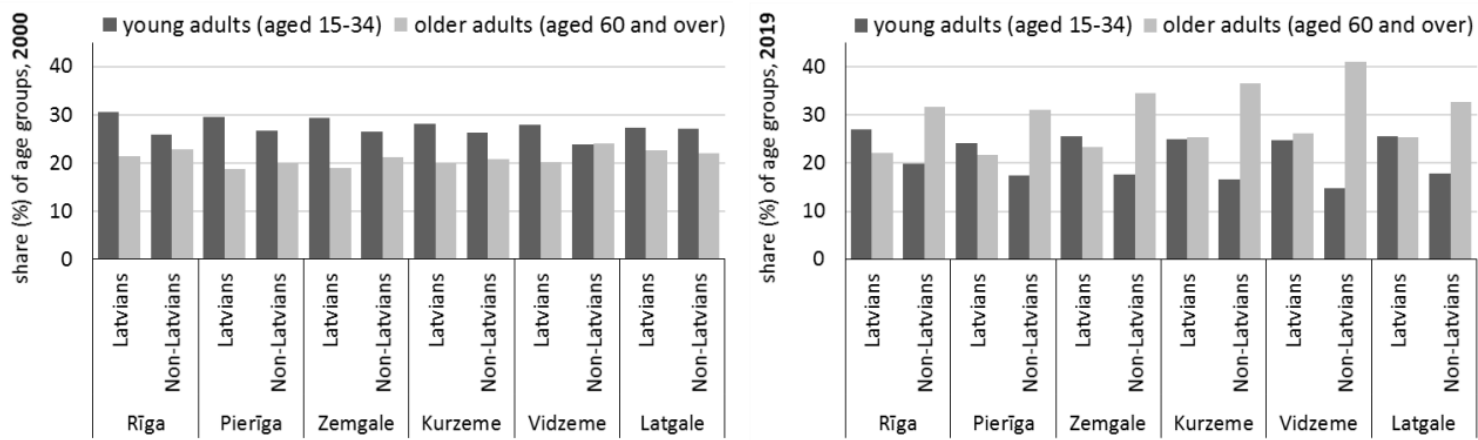

Source: author's construction based on Census (2000) and population register data (2019)

Fig. 2. Shares of young and older adults among Latvians and non-Latvians across the regions, 2000 and 2019

While the first set of findings demonstrates a trend of increasing age polarization across the regions, it is possible that this may hide considerable heterogeneity at the intra-regional scale. To examine this, Figure 3 shows intra-regional variations in residential age segregation by calculating ID for fine-graded spatial level ( $1 \mathrm{~km}^{2}$ hexagon grid). The results reveal at least three important aspects of change.

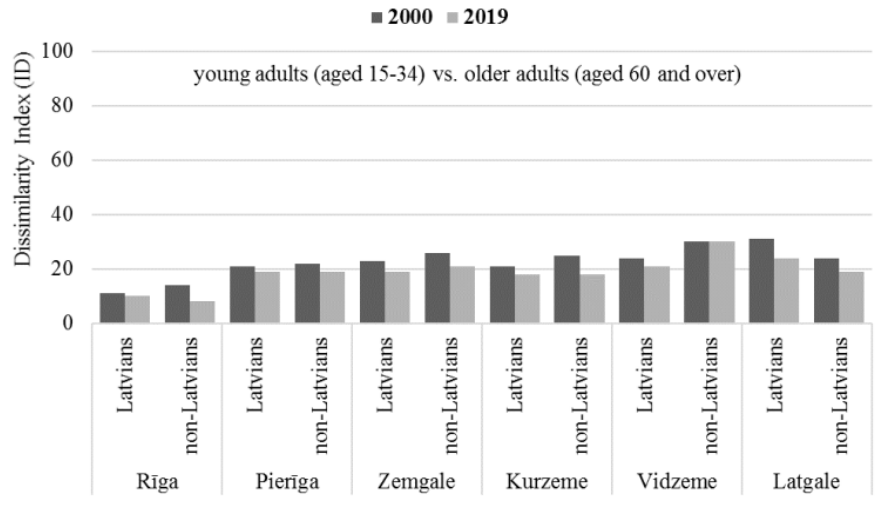

Source: author's construction based on Census (2000) and population register data (2019)

Fig. 3. Residential segregation (evenness) by age across hexagon grid in statistical regions, 2000 and 2019

Our findings indicate that spatial unevenness between older and younger age groups in all the regions has decreased for both Latvians and nonLatvians. Despite the decline of the ID in both years, the segregation of young and old adults was low in referring to the literature (Massey, Denton, 1988). As for the ethnic dimension of age segregation, the dissimilarity index values suggest a small difference in the overall spatial distance between young and older adults (see Fig. 3). The ID indicates the degree to which the sociodemographic distance is accompanied by spatial distance. Indices of dissimilarity between both age categories show that higher distances are observed between Latvians in Latgale and non-Latvians in Vidzeme with the more dissimilar spatial distribution.

The second descriptive measure is the location quotient (LQ). This measure describes how concentrated an age category is compared with the region's average. As the highest values of the ID were observed in Vidzeme region, this region was targeted for further inquiry. Thus, we focus on spatial distribution and local concentrations of both age groups in Vidzeme among non-Latvians. 

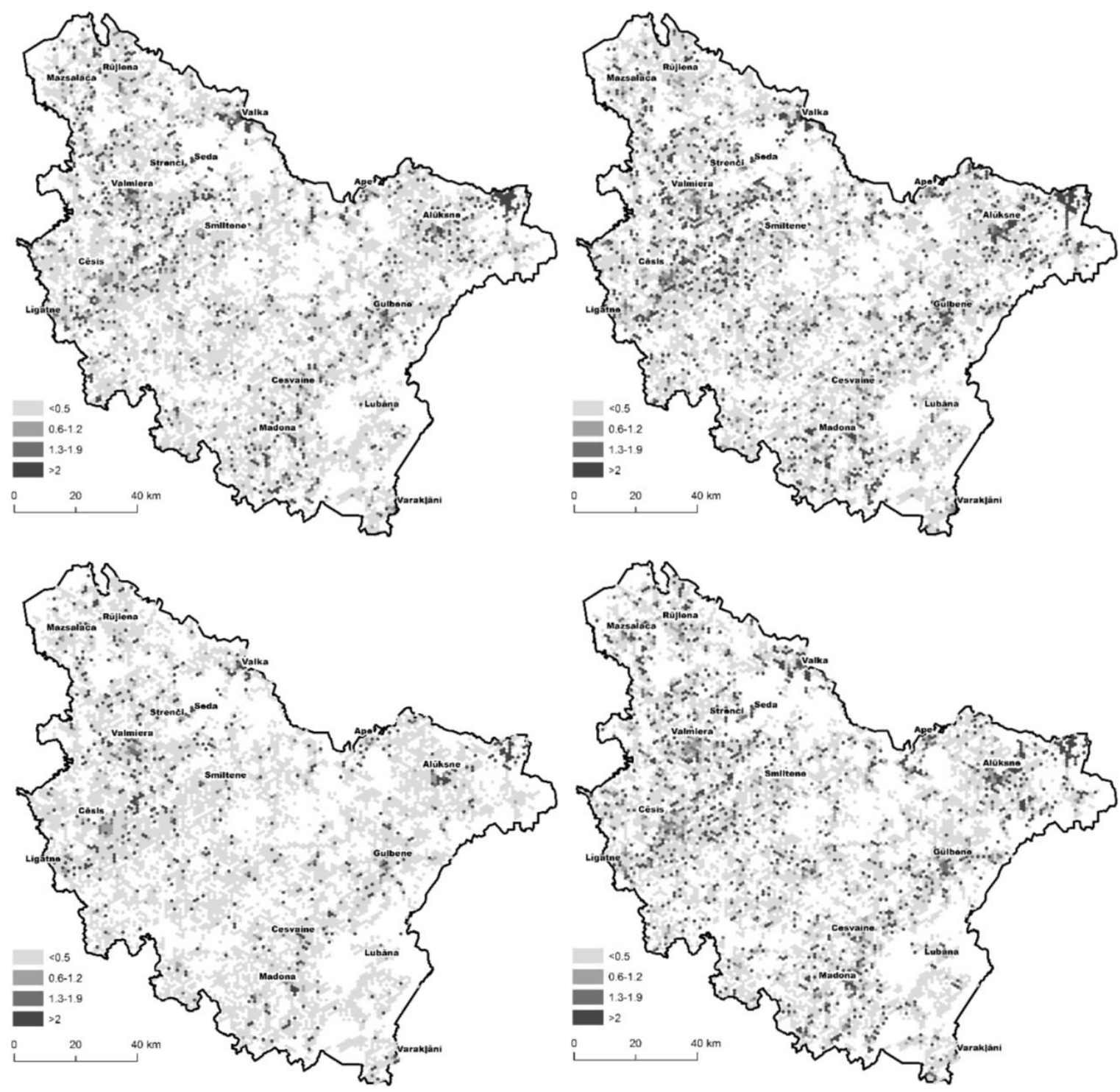

Fig. 3. Location quotient (LQ) maps for young (15-34) and older (60+) adults in 2000 (upper) and 2019 (lower)

\section{Conclusions, proposals, recommendations}

While there is an increasing interest in studies on the geographies of both ageing populations and young adults, previous res earch has almost entirely ignored residential segregation by age, generally assuming that it is not a harmful proce ss. However, there are potentially substantial implications in socioeconomic change, local service provision, political participation and intergenerational cont acts outside the family. Increasing age segregation can have a negative impact not only on the regional economic development but may have adverse consequences for social cohesion. For instance, age segregation can become exclusionary by geographically separating one age group from another, with potentially serious implications such as fostering distrust, stereotypic thinking, and misunderstanding. The identified aspects contribute to further deterioration of ageing regions in terms of people's wellbeing.

The results of the study reveal that all regions of Latvia are facing ageing. Moreover, ageing is more evident for ethnic minorities, particularly in regions where they are less represented (e.g. Vidzeme and Kurzeme). Overall, the article's findings confirm that spatial unevenness between older and younger age groups in all the regions is at low levels and remains stable over the observation period marked by 2000 and 2019. This is supported by the analysis of the index of dissimilarity. As for the ethnic dimension of age segregation, the dissimilarity indexes' values show a slight difference in the overall spatial distance between older and younger age groups among ethnic minorities. The only exception is the Vidzeme region, where the spatial exclusion of non-Latvians for the studied age groups in the highest in both years of consideration. The most important finding from this study is that age differences between younger and older age groups are 
more pronounced among non-Latvians. Our main empirical finding is that polarisation between older and younger age groups in Latvia is evident, but its spatial extent has decreased across main ethnic divisions and over time (2000-2019). Nevertheless, Latvian regions outside the capital and its metropolitan region are characteristic of the notion of' ageing in place'. This may be explained by resid ential immobility and highlights one possible mechanism expected to increase age segregation and therefore needs to be addressed in the current policy focus As the population ages, the low levels of residential mobility among the elderly can act as drivers of age segregation in particular places.

In sum, this study indicates that further analysis of residential segregation by age, including its drivers and consequences, is needed in order to develop policies that mitigate the potentially negative social and economic, as well as political, consequences despite the recent evidence of rather low spatial separation between older and younger age groups in statistical regions of Latvia. There should also be more in-depth studies with a focus on internal differences within each region as well as on certain hierarchical levels of the settlement system

\section{Bibliography}

Andersson, R., 1998. Socio-Spatial Dynamics: Ethnic Divisions of Mobility and Housing in Post-Palme Sweden. Urban studies, 35(3), 397-428.

Allen, R., Burgess, S., Davidson, R., Windmeijer, F., 2015. More Reliable Inference for the Dissimilarity Index of Segregation. The Econometrics Journal, 18(1), 40-66.

Bolt, G., Van Kempen, R., Van Ham, M., (2008). Minority Ethnic Groups in the Dutch Housing Market: Spatial Segregation, Relocation Dynamics and Housing Policy. Urban Studies, 45(7), 1359-1384.

Boterman, W. R., 2020. Intersection of Class, Ethnicity and Age: Social Segregation of Children in the Metropolitan Region of Amsterdam. In Handbook of Urban Segregation. Edward Elgar Publishing.

Brown, L. A., Chung, S. Y., 2006. Spatial Segregation, Segregation Indices and the Geographical Perspective. Population, Space and Place, 12(2), 125-143.

Catney, G., 2018. The Complex Geographies of Ethnic Residential Segregation: Using Spatial and Local Measures to Explore Scale-Dependency and Spatial Relationships. Transactions of the Institute of British Geographers, 43(1), 137-152.

Dawkins, C. J., 2005. Evidence on the Intergenerational Persistence of Residential Segregation by Race. Urban Studies, 42(3), 545-555.

Duncan, O. D., Duncan, B., 1955. A Methodological Analysis of Segregation Indexes. American Sociological Review, $210-217$.

Gentile, M., Tammaru, T., 2006. Housing and Ethnicity in the Post-Soviet City: Ust'-Kamenogorsk, Kazakhstan. Urban Studies, 43(10), 1757-1778.

Gentile, M., Sjöberg, Ö., 2010. Spaces of Priority: the Geography of Soviet Housing Construction in Daugavpils, Latvia. Annals of the Association of American Geographers, 100(1), 112-136.

Gijsberts, M., Dagevos, J., (2007). The Socio-Cultural Integration of Ethnic Minorities in the Netherlands: Identifying Neighbourhood Effects on Multiple Integration Outcomes. Housing Studies, 22(5), 805-831.

Hess, D. B., Tammaru, T., Leetmaa, K., 2012. Ethnic Differences in Housing in Post-Soviet Tartu, Estonia. Cities, 29(5), $327-333$.

Isard, W., Ketilson, L. H., Fulton, M., Fairbairn, B., 1960. Methods of Regional Analysis: an Introduction to Regional Science. MIT, Cambridge, Massachusetts.

Johnston, R., Poulsen, M., Forrest, J., 2005. On the Measurement and Meaning of Residential Segregation: a Response to Simpson. Urban Studies, 42(7), 1221-1227.

Kährik, A., Tammaru, T., 2010. Soviet Prefabricated Panel Housing Estates: Areas of Continued Social Mix or Decline? The Case of Tallinn. Housing Studies, 25(2), 201-219.

Krišjāne, Z., Bērziņš, M., 2014. Intra-Urban Residential Differentiation in the Post-Soviet City: The Case of Riga. Hungarian Geographical Bulletin, 63(3), 235-253.

Krišjāne, Z., Bērziņš, M., Kratovitš, K., 2016. Occupation and Ethnicity. In: Tammaru, T., Van Ham, M., Marcińczak, S., Musterd, S (eds.) Socio-Economic Segregation in European Capital Cities. Routledge.

Krišjāne, Z., Bērziņš, M., Sechi, G., Krūminš̌, J., 2019. Residential Change and Socio-demographic Challenges for Large Housing Estates in Riga, Latvia. Hess, D., Tammaru, T. (eds.) Housing Estates in the Baltic Countries. Cham, Springer, 225-245.

Krūmiṇš, J., Krišjāne, Z. (red.), 2019. Tautas ataudze Latvijā un sabiedrības atjaunošanas izaicinājumi. Rīga, LU Akadēmiskais apgāds, 300 lpp.

Kulu, H., 2003. Housing Differences in the Late Soviet City: the Case of Tartu, Estonia. International Journal of Urban and Regional Research, 27(4), 897-911. 
Li, S., Juhász-Horváth, L., Harrison, P. A., Pintér, L. Rounsevell, M. D., 2016. Population and Age Structure in Hungary: a Residential Preference and Age Dependency Approach to Disaggregate Census Data. Journal of Maps, 12(1), 560-569.

Lindemann, K., 2013. The School Performance of the Russian-Speaking Minority in Linguistically Divided Educational Systems: A Comparison of Estonia and Latvia. In Integration and Inequality in Educational Institutions, Springer Netherlands, pp. 45-69.

Martin, D., Lloyd, C. Shuttleworth, I., 2011. Evaluation of Gridded Population Models Using 2001 Northern Ireland Census Data. Environment and Planning A, 43(8), 1965-1980.

Massey, D. S., Denton, N. A., 1988. The Dimensions of Residential Segregation. Social Forces, 67(2), 281-315.

Monden, C. W., Smits, J., 2005. Ethnic Intermarriage in Times of Social Change: The Case of Latvia. Demography, 42(2), 323-345.

Muiznieks, N, Rozenvalds, J., Birka, I., 2013. Ethnicity and Social Cohesion in the Post-Soviet Baltic States. Patterns of Prejudice, 47(3), 288-308.

Paalzow, A, Sauka, A, Pauna, D, Kilis, R. Dombrovsky, V., 2010. Policies ans Strategies in Riga. How to Enhance the City's Competitiveness 10.9, AMIDSt, University of Amsterdam.

Piekut, A., Pryce, G., van Gent, W., 2019. Segregation in the Twenty First Century: Processes, Complexities and Future Directions. Tijdschrift voor Economische en Sociale Geografie, 110(3), 225-234.

Pisarenko, O., 2006. The Acculturation Modes of Russian Speaking Adolescents in Latvia: Perceived Discrimination and Knowledge of the Latvian Language. Europe-Asia Studies, 58(5), 751-773.

Reardon, S. F. O’Sullivan, D., 2004. Measures of Spatial Segregation. Sociological Methodology, 34(1), 121-162.

Rozenvalds, J., 2010. The Soviet Heritage and Integration Policy Development Since the Restoration of Independence. In How Integrated is Latvian Society? An Audit of Achievement, Failures and Challenges, Riga, University of Latvia Press, pp. 33-60.

Simpson, L., Finney, N., 2009. Spatial Patterns of Internal Migration: Evidence for Ethnic Groups in Britain. Population, Space and Place, 15(1), $37-56$.

Vanderbeck, R. M., 2007. Intergenerational Geographies: Age Relations, Segregation and Re-Engagements. Geography Compass, 1(2), $200-221$.

Zvidriņš, P., Bērziņš, A., 2019. Etniskais sastāvs. Krūmiņš, J., Krišjāne, Z. (red.) Tautas ataudze Latvijāa un sabiedrības atjaunošanas izaicinājumi. Rīga, LU Akadēmiskais apgāds.

Zwiers, M., van Ham, M., Kleinhans, R., 2019. The Effects of Physical Restructuring on the Socioeconomic Status of Neighbourhoods: Selective Migration and Upgrading. Urban Studies, 56(8), 1647-1663.

Wessel, T., Turner, L. M., Nordvik, V., 2018. Population Dynamics and Ethnic Geographies in Oslo: the Impact of Migration and Natural Demographic Change on Ethnic Composition and Segregation. Journal of Housing and the Built Environment, 33(4), $789-805$.

\section{Acknowledgement}

This study was supported by the Fundamental and Applied Research Project No. 1zp-2020/2-0280 and the National Research Program Project No. VPP-IZM-2018/1-0015. We are grateful to the editors and two anonymous reviewers for their insights and suggestions. 


\section{THE ROLE OF INFRASTRUCTURE DEVELOPMENT IN THE COMPETITIVENESS OF A COUNTRY}

\section{Olga Bogdanova, University of Latvia}

Abstract. Infrastructure projects financing is usually associated with considerable opportunities and risks for economy. The currently available EU funding provides wide possibilities, and it is highly important to identify those infrastructure projects that would contribute to economic growth, productivity and competitiveness of a country. The scientific purpose of the paper is to analyse the role of infrastructure development in the competitiveness of economy, as well as define the criteria for the infrastructure projects facilitating competitiveness and being important to overcome the Covid-19 crisis. Within the research, a comprehensive analysis of the Latvian previous positive and negative practise, the experience of other countries, as well as evaluation of the current opportunities and threats was conducted. The analysis of scientific and professional literature, surveys of the Latvian and foreign infrastructure companies, as well as interviews with senior officials and stakeholders on efficiency and public investment in infrastructure were carried out. It was concluded that intensifying investments in infrastructure is an important tool eliminating the pandemic crisis damage. It could increase productivity, competitiveness and facilitate transition to the green and digital economy. However, in case of weak project governance the output from the infrastructure investment could be even negative. The research demonstrated that a country could benefit the most from the projects corresponding to the three criteria: the productivity criteria, reflecting the major challenges highlighted in the global indexes, the efficiency criteria, facilitating selection of the most efficient and appropriate project, and the financing criteria, indicating the external funding possibilities of a certain initiative.

Keywords: infrastructure, development, efficiency.

JEL code: 047,018

\section{Introduction}

Infrastructure projects financing carries one of the most considerable risks in eliminating the Covid-19 crisis consequences. The currently available EU funding provides wide possibilities, and the application process is on a way. It is highly important to identify those infrastructure projects that would contribute to economic growth, productivity and international competitiveness of a country. Historically, the share of infrastructure projects is dominating among other applications. Probably, this year will be not an exception. Due to this, the analysis of the previous positive and negative practise, the experience of other countries, as well as evaluation of the current opportunities and threats (SWOT) is particularly important. Moreover, the globally recognized need for transition to the green economy and digitalization requires ambitious steps, integrated view on cross-sectoral correlations also in such comparatively conventional field as infrastructure.

The aim of the research is to identify how infrastructure projects could facilitate the development of a country, as well as define the necessary criteria for the projects which could contribute the most to the economic growth and elimination of the consequences of Covid-19.

Within the research the following tasks were fulfilled: the role of infrastructure projects in economic development and recovery was analysed; the former experience and trends in Latvia and other countries in relation to infrastructure projects was evaluated; SWOT analysis of Latvia's infrastructure sector was performed; based on SWOT analysis the project assessment criteria relevant to competitiveness of a country were defined.

For the research, the author has used generally accepted quantitative and qualitative methods of economic science, inter alia grouping, comparative analysis, synthesis, inductive, deductive, logically constructive, statistical data processing and parameter estimation. The survey on the public opinion in the Baltic states on necessity to invest in infrastructure, the survey on the opinion of 14 key infrastructure companies of Latvia on impact of Covid-19 on infrastructure and the role of infrastructure in the competitiveness of Latvia, as well as the survey on the opinion of the energy infrastructure companies from 24 countries on current situation and the role of infrastructure in the competitiveness of economy, was conducted. Focus interviews with the Deputy state secretary responsible for infrastructure field at the Ministry of Transportation of Latvia, the Director of the Latvian Investment and Development Agency, the Director of City Development Department at Riga City Council, as well as Deputy state secretary for EU funding issues at the Ministry of Finance were organized.

The informative basis of the research is works and investigations of foreign and Latvian scientists, materials published by the government administration and related institutions (the Ministry of Finance, the Ministry of Transportation, the International Monetary Fund, the European Commission, Standard\&Poor's Rating Agency, the World Bank, the World Economic Forum, MSCI Infrastructure indexes, FTSE Infras tructure index, CMS Infrastructure index, OECD, the United Nations, Cornell University, INSEAD, and WIPO, NordPool Power exchange, the Foreign Investors' Council in Latvia, and other) as well as data from other electronic databases, published scientific works and investigations, publications in mass media and specialised editions, as well as materials and experience gathered from international scientific conferences and seminars. 
As a result of the research the role of infrastructure development projects in strengthening the economy of a country in crisis and post-crisis conditions was evaluated. Based on in-depth interviews, an analysis of governmental documents, scientific and professional literature the SWOT analysis of the Latvian infrastructure was performed. The consequent recommendations on the criteria for the infrastructure projects facilitating competitiveness of a country and being important to overcome Covid-19 crisis were developed.

\section{Literature Review on the role of infrastructure in the development of economy}

The role of infrastructure in the development of economy is widely discussed topic in scientific and professional literature. The economists of Keio University highlight that a significant correlation between investments in infrastructure and economic development exists in the developing countries. However, it is not usually mentioned as a critical development precondition per se in the developed countries. It is considered that the developed countries should focus mainly on innovations, high technologies ensuring added value and increasing efficiency of infrastructure. At the same time, investments in infrastructure are crucial when a country faces rapid development of economy. Another example, when infrastructure development had a high importance after WWII as most of infrastructure was damaged or destroyed and there was an obvious need to recover it. Infrastructure is relevant not only for manufacturing sector, but also for the productivity of services sector. Moreover, in cities this importance is higher than in rural area. Availability of public infrastructure decreases poverty, encourages minimization of inequality of incomes, growth possibilities, as well as has social function. Despite this fact, it does not mean direct and absolute correlation of infrastructure projects with economic growth (Naoyuki Y., Masaki N., 2020; Bogdanova, 2012).

The methodologies of the global indexes (e.g. MSCI Infrastructure index, FTSE Infrastructure index, S\&P Dow Jones Indexes) also usually separate infrastructure in the developed and the developing countries. The global indexes comparing different infrastructure-related criteria of countries provide valuable informative support to investors and economists. Within the research the following indexes were analysed reflecting what kind of infrastructure is particularly highlighted in the corresponding methodologies: Doing Business, Global Competitiveness index, Sustainable Development index, S\&P Infrastructure index, MSCI Infrastructure index, FTSE Infrastructure index, CMS index (see Table 1).

Table 1

Infrastructure reflection in the global indexes

\begin{tabular}{|c|c|}
\hline Index & Kind of infrastructure \\
\hline Doing business & - Electricity connection \\
\hline $\begin{array}{l}\text { Global } \\
\text { competitiveness } \\
\text { index }\end{array}$ & $\begin{array}{l}\text { - Transportation infrastructure (road connectivity, quality of road infrastructure, rail density, efficiency of train services, } \\
\text { airport connectivity, efficiency of air transport services, connectivity of liner shipping, efficiency of maritime transport); } \\
\text { - Service infrastructure (electricity availability, quality of electricity supply, safe availability of drinking water, reliability } \\
\text { of water supply). }\end{array}$ \\
\hline $\begin{array}{l}\text { Sustainable } \\
\text { Development } \\
\text { aims monitoring }\end{array}$ & $\begin{array}{l}\text { - Water supply and sewerage quality; } \\
\text { - Access to electricity, access to clean fuels, share of renewable energy in electricity, level of energy intensity in primary } \\
\text { energy, } \\
\text { - Value added of production in GDP, CO2 per GDP, investment in research and development, infrastructure flows per } \\
\text { capita, use of technology, } 3 \mathrm{G} \text { network coverage. }\end{array}$ \\
\hline $\begin{array}{l}\text { S\&P } \\
\text { Infrastructure } \\
\text { index }\end{array}$ & $\begin{array}{l}\text { - Energy, 20\% (Oil and gas extraction, oil and gas equipment and services, oil and gas storage and transmission); } \\
\text { - Transport, } 40 \% \text { (airport services, motorways, railways, seaports and services, aviation); } \\
\text { - Public services } 40 \% \text { (electricity, gas, water, multifunctional services, independent electricity producers and energy } \\
\text { traders, electricity from RES); } \\
\text { - Telecommunications (wireless telecommunications services, integrated telecommunications services). }\end{array}$ \\
\hline $\begin{array}{l}\text { MSCI } \\
\text { Infrastructure } \\
\text { indexes }\end{array}$ & $\begin{array}{l}\text { - Telecommunications infrastructure, } 33 \% \text { (alternative suppliers, integrated telecommunications services, wireless } \\
\text { telecommunications services); } \\
\text { - Public services, } 33 \% \text { (electricity, gas supply, water supply multifunctional services); } \\
\text { - Energy infrastructure (oil and gas storage and transmission) and transport infrastructure (airport services, highways and } \\
\text { railways, seaports and services), social infrastructure (education services, health services) } 33 \% \text {. }\end{array}$ \\
\hline $\begin{array}{l}\text { FTSE } \\
\text { Infrastructure } \\
\text { index }\end{array}$ & $\begin{array}{l}\text { - Basic infrastructure: pipelines, heavy construction, railways, transport services, business support services, transmission } \\
\text { and entertainment services, travel and tourism, fixed line telecommunications, mobile telecommunications, traditional } \\
\text { electricity, natural gas distribution, multifunctional services, water supply, diversified real estate services, specialized } \\
\text { real estate services, telecommunications equipment; } \\
\text { - The infrastructure capacity index additionally includes: aluminium, iron and steel, availability of construction materials, } \\
\text { delivery services, maritime transport, road transport, air transport; } \\
\text { - Transport infrastructure (roads, bridges and tunnels; ports, airports, railways, terminals and depots, inland waterways); } \\
\text { - Energy infrastructure (electricity generation, distribution and transmission; water supply, pipelines); } \\
\text { - Telecommunications (fixed lines - telephone and data transmission; transmission line and towers, wireless transmission } \\
\text { towers, transmission satellites). }\end{array}$ \\
\hline$C M S$ & - Transport infrastructure, energy infrastructure, public service infrastructure, telecommunications. \\
\hline
\end{tabular}


Global

Innovation index

- Information and communication technologies (ICT access: fixed telephone connections per 100 inhabitants, mobile telephone connections per 100 inhabitants, use of international Internet by Internet users, share of households with Internet access; use of ICT: share of Internet users, share of fixed Internet connections, active proportion of mobile internet users; government's online services, e-participation);

- General infrastructure (electricity generation per 1 million inhabitants; logistics performance: customs border administration, trade and transport infrastructure, ease of organizing competitive maritime transport, competence and quality of logistics services, traceability, frequency of deliveries on time; gross capital investment);

- Ecological sustainability (GDP per unit of energy used, environmental indicators, ISO 14001 environmental certificates).

Source: author's analysis based on World Bank, World Economic Forum, United Nations, MSCI Infrastructure index, FTSE Infrastructure index, S\&P Dow Jones Indexes methodologies

As a result of the analysis of the indexes reflected in Table 1, it could be concluded that the approach of different methodologies for defining the main framework of infrastructure generally is similar. In addition, sometimes infrastructure services are particularly separated. At the same time, in some indexes other sectors which are closely connected to infrastructure, are also included in the methodology.

It is possible to define the following three kinds of infrastructure reflected in the global indexes:

- Basic infrastructure: transportation, electricity, natural gas, water supply, telecommunication;

- Quality services, which are available using the basic infrastructure (for example, utilities);

- Other sectors correlating with the basic infrastructure and creating demand for the basic infrastructure (business support services, transmission and entertainment services, travelling and tourism, diversified real estate services, specialized real estate services) and are required for infrastructure development (aluminium, iron and steal, construction materials, construction engineering networks).

The focus on the related sectors demonstrated in the global indexes could be connected with intensity of infrastructure use and economic activity and, consequently attractiveness for investments.

According to the macroeconomic theory, public investments stimulate economic activity by increasing short-term demand, consequently increasing the productivity of private capital and promoting economic growth. It should be noted that global scientists (such as Sturm J. and Groote, Wanner, Furceri, and Li) acknowledge the positive correlation of public investment with economic growth, mostly in the short to medium term (Schwartz G., Manal F., Torben H etc., 2020). At the same time, it should be noted that these conclusions have been drawn mainly from the assessment of the development of basic infrastructure projects.

Scientists estimate that a public investment shock of $1 \%$ of GDP in developed countries will ensure an average $0.2 \%$ increase in output in the current year and a $1.2 \%$ increase in output in the following four years. However, a public investment shock of $1 \%$ of GDP in developing countries could ensure an average increase of $0.2 \%$ in output and $0,5 \%$ increase in output in four years. Researchers from the International Monetary Fund (hereafter - IMF) explain this difference by the level of project management efficiency. Countries with strong project management can deliver returns of up to $0.8 \%$ in the current year and $3.2 \%$ in four years, while in weak governance countries the returns are negligible or even negative. For example, many countries increased public spending in response to the global financial crisis, which later resulted in economic challenges: ten years later, public debt reached unprecedented levels, requiring fiscal consolidation.

Nevertheless, according to the IMF, increasing investment in infrastructure could be an important step in supporting economic activity in the post-crisis recovery phase. This can increase the region's productive capacity in the long term and accelerate the transition to a green and digita economy (IMF, 2020). Also, according to the assessment of the Foreign Investors' Council in Latvia (hereinafter - FICIL), even in a crisis situation, the state must continue infrastructure development projects, as they can significantly stimulate the economy (FICIL, 2020).

The country's economic competitiveness is affected not only by the existence of infrastructure as such, but also by the efficiency of infrastructure use. Technological development is the cornerstone of the next stage of economic development. For example, in terms of energy sector infrastructure, electricity storage, end-user sector electrification, digital technologies, new networks, mobile generation are considered to be 'disruptive technologies' or technologies that have the potential to have a significant impact on every sector and individual (World Energy Council, 2019).

The G20 Infrastructure Working Group to develop recommendations covering two areas: infrastructure as an asset and principles for infrastructure quality investment. The World Bank notes that technology maximizes infrastructure returns by improving sustainability, integrity and resilience. The potential for economic efficiency provided by technology increases the return on projects throughout their life cycle. Infrastructure technologies provide governments with valuable tools in meeting the challenges of the Covid-19 health and economic crisis (World Bank, 2020).

The impact of public investments on the economy can be described in two ways:

- efficiency (the value obtained for the given money shows the efficiency of the use of financial resources); 
- productivity (how the created infrastructure affects the economy).

According to the IMF, on average, countries lose more than a third of public resources in the implementation of investment projects. Good investment project management increases the potential for a positive correlation between investment and economic growth. Strong infrastructure management not only improves efficiency, but is also critical to macroeconomic stability, economic growth and fiscal sustainability. This is particularly important for countries with high debt levels, low revenue collection and a small fiscal space. According to the IMF, effective governance plays a considerable role in all three stages of project development - planning, selection and implementation (IMF, 2019).

It is important to take into account the above-mentioned considerations of scientists and economists when selecting the projects to be implemented, as well as when assessing the further implementation of the projects.

\section{SWOT analysis of the Latvian infrastructure}

Productivity of infrastructure project depends on the target which is defined to be reached as a result of its implementation. If a project addresses properly justified needs, productivity of the project is supposed to be high. To identify the most topical needs in the infrastructure sector of Latvia, the SWOT analysis of the Latvian infrastructure sector was conducted.

The analysis shows that based on the comparison of the Baltic Global Competitiveness Index indicators, Latvia's weakest point is the quality of road infrastructure, as the value of this indicator ( 95 out of 141 countries in the world) is both significantly lower than neighbouring countries and Latvia's overall Global Competitiveness Index indicator. However, it is also necessary to pay attention to such indicators as airport connectivity, liner shipping connectivity, and reliability of water supply, as Latvia has relatively low indicators in the mentioned positions. Nonetheless, Latvia's strengths are the efficiency of air transport services, the quality of electricity supply, the efficiency of train services and, similarly to other Baltic countries, the availability of electricity (World Economic Forum, 2019).

According to the Energy Trilemma Index 2020 developed by the World Energy Council (hereafter - WEC), Latvia is ranked 22nd out of 128 countries, maintaining this position also compared to the 2019 index. Latvia shows good results in energy security position; however its biggest challenge a balanced energy policy is high energy price. When promoting new infrastructure projects, it is important to assess the impact of projects on the market or return of investment. In addition, sustainable policies must be also given greater prominence looking for cost-effective solutions, as Latvia's relative position on sustainability has slightly decreased in 2020 comparing to 2019 (WEC, 2020, 2019).

At the beginning of 2016, the United Nations defined 17 Sustainable Development Goals (SDGs) for 2030. Latvia's infrastructure-related IAM indicators, namely water and sanitation standards and infrastructure, are below the OECD average. Water and sanitation standards include the proportion of the share using improved drinking water sources and improved sanitation, the pressure on water resources: the share of fresh water used in relation to available fresh water resources and the total official water supply and sewerage flows to the user. In Latvia, the intensity of infrastructure use is low increasing the cost of its use. Latvia's IAM indicator "energy" (which includes the share of the population with access to electricity, the share of the population primarily using clean fuels and technologies, the share of RES in total energy consumption, the level of energy intensity in primary energy) and the "climate" are above the OECD average. However, in general, the biggest challenges of Latvia in achieving the IAM goals are related to poverty and health (OECD, 2017).

Latvia's indicator, which characterizes the infrastructure of the Global Innovation Index (hereafter - GII), is ranked the 46th out of 131 countries in the world. Taking into account that the overall rating of Latvia's GII is 36, the infrastructure indicator is one of the weakest points. Moreover, Latvia's infrastructure indicator is significantly lower than in neighbouring countries, as Estonia is ranked the 5th and Lithuania - the 38th. In terms of components of the infrastructure indicator, Latvia has a relatively good rating (i.e. the place is higher than 36, which is Latvia's total rating in the GII) in such positions as ecology, environment, ISO 14001 environmental certificates, use of ICT. At the same time, Latvia demonstrates poor results (the place is less than 60) in such positions as public sector online services, online e-participation and logistics infrastructure, which includes customs border management, trade and transport infrastructure, competitive simplicity of maritime transportation, the ability to trace consignments, as well as the share of consignments delivered on time. Moreover, the authors of the index also assess ICT access as a weakness of Latvia in its group of income level countries. It should be noted that these results are also worse for Latvia than for Lithuania and Estonia (Cornell University, INSEAD, and WIPO, 2020).

Assessing the factors influencing productivity of the Latvian economy, FICIL also emphasizes the fragmentation of ICT competence and infrastructure in the country. FICIL draws attention to the report published by the State Audit Office in 2019 on the efficient use of ICT infrastructure 
in public administration. The report concludes that ICT related policy planning documents usually have objectives in the form of 'designs', without specific deliverables and benchmarks and without any measurable indicators (FICIL, 2020).

Assessing the situation with attracting foreign investment, the director of Latvian Investment and Development Agency (hereafter - LIDA) Rožkalns K. noted in an interview that investors usually mention the lack of labour, high electricity prices (mostly energy-intensive companies), regulation of employed sick leaves, as well as a lack of coordination between different organizations. Another reason for the non-entry of potential investors in Latvia is related to the lack of interest of the municipality in promoting the location of manufacturing companies in their territory. Moreover, according to the information provided by LIDA, the lack of suitable premises is relatively often mentioned among the reasons for noninvestment, despite the fact that there are many vacant premises in Latvia that were or may be used for production (Bogdanova O., 2020). Within the research, the information on 17 cases of non-investment in Latvia in 2017-2019, was evaluated. In general, the decisions could be justified by 6 reasons. Two of them are related to the infrastructure problem, namely a lack of well-maintained infrastructure in the Freeport and the refusal of the municipality due to its lack of interest in the industry, as well as the lack of suitable premises and the need to demolish buildings with historical heritage status (Bogdanova O., 2020).

A capital plays an important role in the development of the national economy. In an interview, a Head of the City Development Department of the Riga City Council Purmale I., noted that in order to promote Latvia's competitiveness, it is important to ensure that various infrastructure elements are interconnected, otherwise their potential is not used optimally. It is necessary to ensure unhindered traffic movement from bypasses to ports, to develop railway bypass, ensuring movement of cargo to ports, reducing infrastructure load in the centre of Riga and providing faster and more convenient transport corridor to the destination point. Different approaches in different municipalities may hinder the development of an optimal solution (Bogdanova O., 2020).

With rapid technological progress, many infrastructure development opportunities bringing a higher productivity, are associated with the introduction of appropriate technologies. At the same time, the optimal implementation of infrastructure technologies vary depending on each technology and the degree of readiness of a country to implement it. Some countries with a high degree of readiness will introduce emerging and relative expensive technological solutions. Other countries will be more selective and focus on solutions with a higher degree of maturity, thus minimizing financial, technological and implementation risks. However, in more innovations conservative countries, a smaller area (e.g. a city), having appropriate capacity and competence, can make the technological breakthrough (World Bank, 2020). The director of the Swiss IMD Competitiveness Center prof. Arturo Bris believe that countries with smaller population have advantage from being more flexible to implement innovative projects, despite the lack of capacity and competencies (BMDA, 2020).

Taking into account the challenge of Latvia related with high infrastructure prices and high poverty rate it is generally recommended to use technologies with a higher degree of maturity, as they are associated with lower costs and risk. Nevertheless, individual projects can also choose emerging technologies, carefully assessing the possibility of gaining leadership positions. The three factors are still important for the successful implementation of the innovative technology project: legal and institutional framework, staff capacity, and IT systems (IMF, 2019). Regarding the personnel capacity in Latvia, FICIL believes that the active implementation of digital transformation would be facilitated by ensuring the digitization competence at the management board level at the infrastructure company (FICIL, 2020).

According to IMF experts, the following opportunities emerge by introducing new technologies in infrastructure: improve the efficiency of infrastructure use and reduce user costs; increase the economic, social and environmental value; change the demand for infras tructure and create new markets (World Bank, 2020).

The importance of cross-sectoral connectivity to unlock the future potential of infrastructure has been highlighted in a number of discussions. At World Energy Week in October 2020, one of the main conclusions of the WEC Director General was that the successful transition of the energy sector to a sustainable model requires close cooperation between sectors: transport, energy, industry, social affairs, finance, digital, etc. (WEC, 2020).

The head of the City Development Department of the Riga City Council Purmale I. emphasized the wide possibilities of mutual coordination of plans of different sectors. Public transport plays an important role in the city's infrastructure agenda. Motivating city residents and guests to use public transport rather than private road transport reduces the intensity of transport in the city centre and contributes to the achievement of sustainable goals. The expert pointed out that the location of social infrastructure plays an important role in urban traffic flows (Bogdanova O., 2020). The deputy state secretary of the Ministry of Transportation Merirands D. acknowledged that there is great potential for project implementation by 
coordinating common interests of different sectors, such as military projects and various types of civil transport needs (the case of Rail Baltica). At the same time, Latvia should look for solutions to increase the intensity of infrastructure use. Given the significant reduction in the volume of transit, the intensity of rail use could be increased by using it for local freight transport (timber, grain, construction materials), which has not been a priority in rail transport so far. Regarding the quality of roads, the expert noted that the length of the Latvian road network is relatively large in relation to the population of the country, which, in addition to insufficient funding, makes it difficult to maintain roads of adequate quality. Moreover, the attractiveness of using public transport is significantly influenced by how different of kinds of transport are coordinated (Bogdanova O., 2020).

By 2019, the IMF has performed an assessment of investment project management according to the Public Investment Management Assessment (hereinafter - PIA) method in 50 countries of the world, incl. 9 EU countries, developing recommendations for the improvement of the investment project management process. Although the recommendations cover a wide range of issues, one of the most common national mistakes is the lack of identification of alternative infrastructure projects. According to the World Bank, the cost of a project can vary considerably depending on the technologies and approaches chosen to achieve the objectives (IMF, 2019). Analysing the PIA recommendations made in 2018 to Estonia for the elimination of non-compliances, it can be concluded that several shortcomings identified in Estonia are also relevant in assessing the effectiveness of investment projects in the case of Latvia, for example, lack of reflection of the relevant investment project and their measurable performance targets in national and sectoral plans, lack of appropriate coordination between the parties involved in the project, with a clear division of responsibilities, lack of detailed financial, economic, technical and legal analysis, as well as an evaluation of alternative solutions to achieve the project objective, a summary of projects funded from different sources that address the reported problem, etc. (IMF, 2019).

Regarding the Covid-19 impact on infrastructure projects, as a result of the survey of the main infrastructure companies of Latvia, as well as energy experts of 24 other countries it was concluded that in general, the situation in the infrastructure sector, due to the specifics of its regulated business, can be described as relatively stable (except for sectors related to physical movement). At the same time, part of the project is postponed. In Latvia $77 \%$ of infrastructure companies believe that they can provide support to the economy, mostly through their activities and by implementing funded projects that are important for the economy (Bogdanova O., 2020).

In September 2020, another survey the view of the population of the three Baltic States regarding the state support in relation with Covid-19 pandemic was conducted. The answers reflect the public's view that the needs for basic infrastructure in the Baltic States are generally met, while increasing economic efficiency is a high priority in the eyes of the population, which can be interpreted as a concern about high infrastructure costs. It is noteworthy that the low public acceptance of the greener economy as a priority could be a challenge. This shows the fact that the government must pay attention to the development of cost-effective green solutions and educating the public about the role and importance of a greener economy for the state and the life of each individual (Austers A., N̦ikišins J., 2020).

As a result of the research it was concluded that the main risks connected with infrastructure sector come from extreme weather conditions, lack of cybersecurity, weak governance of infrastructure projects, lack of digitalization competence in companies and institutions, lack of coherence between state institutions, municipalities (including between different municipalities), lack of municipality interest in infrastructure projects, lack of coherence between different sectors, strong negative reaction from society towards changes and low support to green course activities.

However, the key opportunities in infrastructure field of a country are associated with improvement of connectivity, optimizing of existing infrastructure use, modern analytics for planning, application of user-oriented technologies, decrease of transport and supervision costs due to technologies, flexible/ remote labour organization, real time data and analytics (reporting, visualisation supporting decision making), effective support unit (automation of processes, artificial intellect), increase of economic value bringing synergy from different sectors, increase of social value (higher resilience against catastrophes, pandemic, better crisis management, real time traffic governance), environment protection value increase (e-mobility, water and sewage modern technologies), creation of new markets developing as well as mobility as service, 3D printing, 5G and connectivity technologies, municipality motivation rising for business establishment facilitation., identification of cross-sectoral benefits (empty buildings infrastructure adjustment, natural gas infrastructure for partial use of hydrogen and biomethane), signal scanning radar application for society opinion monitoring, private principle application in state-owned companies and institutions, more active use of PPP cooperation, and other.

The EU project co-financing significantly increases the opportunities for the implementation of infrastructure projects necessary for the Latvian economy. At the same time, Eberhard A., deputy state secretary of the Ministry of Finance emphasizes that the EU countries should provide assessment of their current challenges and the country specific recommendations made by the European Commission in 2019. With regard to the Resilience and Recovery Found (hereafter - RRF), countries should reflect the solutions in the following areas of action: strengthening the EU's 
economic, social and territorial cohesion; strengthening resilience; mitigating the effects of the social and economic crisis; providing support for the green and digital transition (Bogdanova O., 2020). According to the SWOT analysis, the priorities set by the RRF for Latvia are highly topical, thus receiving EU funding to finance the projects in the respective directions, rather than implementing them using budget funds, tariffs or other revenues, would reduce the financial burden on infrastructure users.

\section{Infrastructure projects evaluation criteria}

Based on the SWOT analysis, the author has developed a set of criteria for the evaluation of infrastructure projects, which are essential for promoting competitiveness and overcoming the consequences of the Covid-19 crisis. The criteria are divided into three groups: the productivity, efficiency and funding criteria (see Fig.1).

\begin{tabular}{|c|c|c|}
\hline Productivity criteria & Efficiency criteria & Financing criteria \\
\hline $\begin{array}{l}\text { Criteria for key challenges: } \\
\text { 1. Increases the intensity of infrastructure } \\
\text { use } \\
\text { 2. Increases electricity consumption } \\
\text { 3. Increases the liquidity of the market of } \\
\text { the respective field (thanks to the } \\
\text { infrastructure project, the price of the } \\
\text { product / service of the field is reduced) } \\
\text { 4. Reduces infrastructure use costs } \\
\text { 5. Reduces transport emissions } \\
\text { 6. Improves sector connectivity } \\
\text { 7. Improves the operational resilience of } \\
\text { infrastructure services to respond to } \\
\text { pandemics and other crisis situations } \\
\text { 8. Reduces the cyber vulnerability of } \\
\text { Latvian critical infrastructure operators } \\
\text { 9. Improves resistance to natural disasters } \\
\text { Controlling criteria } \\
\text { 1. Existing infrastructure is used for other } \\
\text { purposes } \\
\text { 2. No parallel infrastructure is created } \\
\text { 3. Performance has been assessed not only } \\
\text { in the core sector, but also in other sectors } \\
\text { 4. In addition to the basic objective, new } \\
\text { opportunities for the use of infrastructure } \\
\text { in support of a low-carbon future have } \\
\text { been defined } \\
\text { Impact on world index performance } \\
\text { 1. Improving the Global Competitiveness } \\
\text { Index (critical indicator: road quality) } \\
\text { 2. Sustainable development goals (critical } \\
\text { indicators: water, sewerage, infrastructure, } \\
\text { including transport) } \\
\text { 3. Improving the Energy Trilemma Index } \\
\text { (critical indicators: energy price, including } \\
\text { sustainability) } \\
\text { 4. Improve the Global Innovation Index } \\
\text { (critical indicators: online government } \\
\text { services, online e-participation, logistics } \\
\text { services) }\end{array}$ & 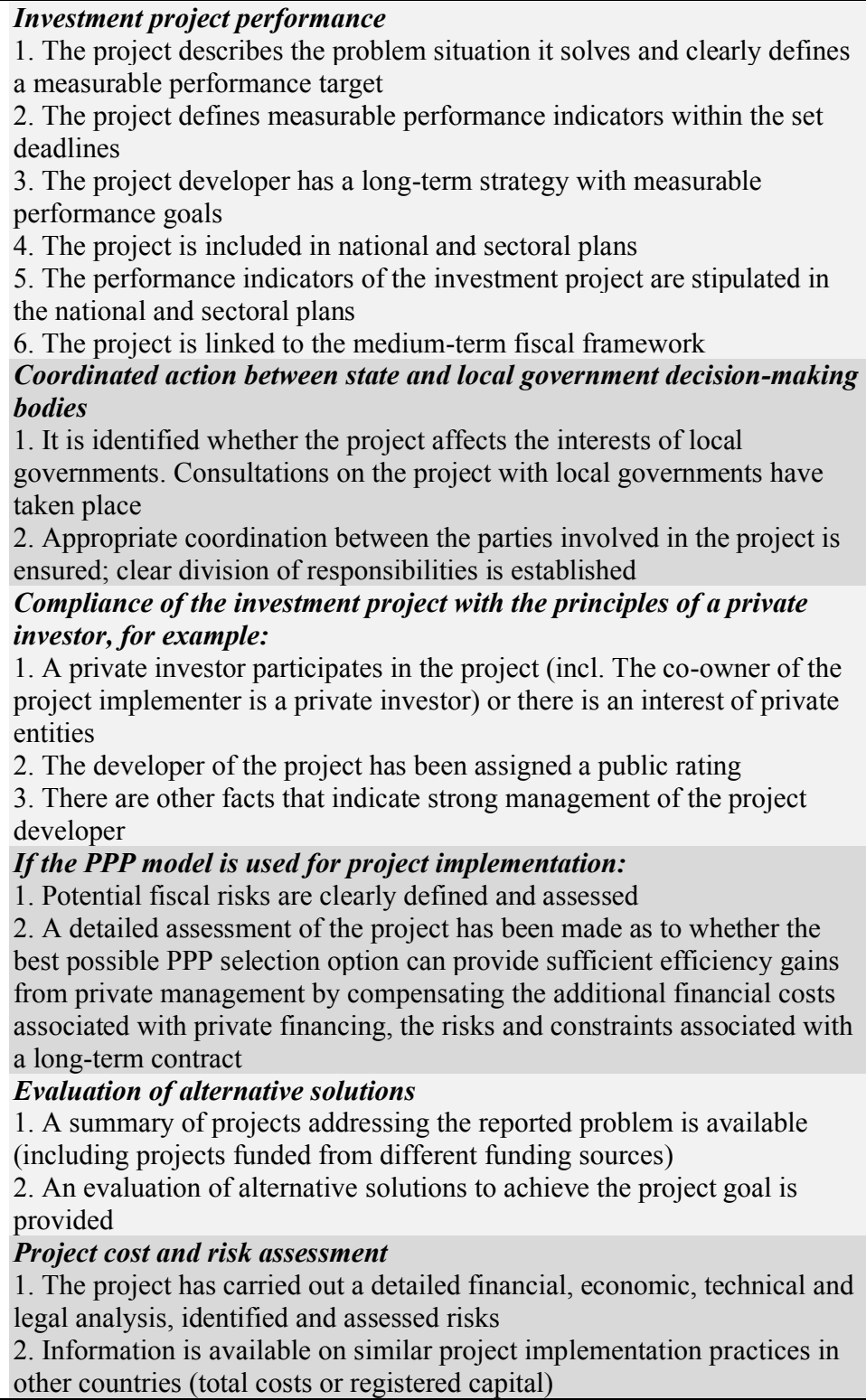 & $\begin{array}{l}\text { Eligibility for RRF } \\
\text { support or other } \\
\text { financial } \\
\text { instrument: } \\
\text { 1.Promotes the } \\
\text { EU's economic, } \\
\text { social and territorial } \\
\text { cohesion } \\
2 \text {. Strengthens } \\
\text { durability } \\
\text { 3. Reduces the } \\
\text { social and } \\
\text { economic impact of } \\
\text { the crisis } \\
4 \text {. Supports green } \\
\text { and digital } \\
\text { transition } \\
\text { Eligibility for or } \\
\text { other financial } \\
\text { instrument }\end{array}$ \\
\hline
\end{tabular}

Source: author's construction based on sources used for SWOT analysis

\section{Fig. 1. Infrastructure investment projects evaluation methodology}

The productivity criteria provide an assessment of the adequacy of the goal set by the proposed project, and answer the principal question "what does Latvia intend to achieve with the project (e.g., to improve the quality of roads, increase the intensity of infrastructure use, etc.)?". The list of criteria for the basic challenges of productivity has been compiled based on the most critical assessments of Latvia in the SWOT analysis, namely, the issues that are recommended to be addressed as a matter of priority. This list is not exhaustive and may be supplemented by other topical issues identified in Latvia. At the same time, while focusing on key challenges, it is important to meet the controlling criteria that provide additional 
benefits and eliminate potential risks. The productivity criteria also demonstrate the impact on the ratings of the leading world indices which refer to the infrastructure issues. It helps to assess an importance of a footprint of a particular project in moving towards a balanced policy.

The main task of the efficiency criteria is to support the most efficient and appropriate project selection process to achieve the objectives of the productivity criteria (e.g. evaluation of alternative projects, effective management, etc.). The list of these criteria has been compiled taking into account typical mistakes and risks of a project implementation, which are referred to the SWOT analysis.

The funding criteria reflect the priorities for the available funding, identifying external financing opportunities for the initiative (e.g. reducing the negative impact of Covid-19, supporting green and digital transitions, etc.). The available external funding undoubtedly facilitates the implementation of the project, partially removing the financial impact of the project from the users of the respective infrastructure. The funding criteria currently proposed reflect the priorities of the RRF, but the list of these criteria may be supplemented, depending on the current calls for funding programs. It is important to note that the positive fulfilment of the funding criteria or compliance with the priorities of the currently available funding programs cannot be dominant when deciding on the implementation of the respective project. In order to achieve the country's long-term competitiveness, a country has to ensure the fulfilment of the productivity and the efficiency criteria, regardless of the source of project financing. The author recommends the governmental institutions of Latvia to use the set of the infrastructure project evaluation criteria, when selecting infrastructure projects that are essential for the promotion of national competitiveness and overcoming the consequences of the Covid-19 crisis. At the same time, these criteria can be applied to other infrastructure projects implemented in Latvia, for which a decision is not made at the government level. It should be noted that the proposed set of criteria is based on and justified by the sources of information shaping the content of the SWOT analysis, and it is not exhaustive. The set of criteria could be supplemented depending on the topicality; however, it is recommended to adhere to the principle of the principle of the methodology, namely, checking the characteristics of the project productivity, efficiency and financing.

\section{Conclusions, proposals, recommendations}

As a result of the research, the following main conclusions, proposals and recommendations were formulated.

1. One of the main reasons for investment in infrastructure in developed countries is the growth of the national economy and population growth, when the existing basic infrastructure is no longer sufficient. However, infrastructure projects in developing countries address the basic infrastructure needs.

2. The implementation of projects essential for sustainable competitiveness provides a strong impulse for economic activity in the short and medium term, as well as significantly promotes long-term economic development. Despite this fact, a poor project management, incl. planning, selection and implementation hides significant risks to the economy. Countries with strong project management can deliver returns of up to $0.8 \%$ in the current year and $3.2 \%$ in four years, while in weak governance countries the returns are negligible or even negative.

3. Economic development requires priority implementation of infrastructure projects that address the weaknesses of the Latvian infrastructure sector reflected in the key international indexes, like Global Competitiveness index, Doing Business index, Sustainable development aims monitoring, Global Innovation index, Energy Trilemma index, and other (related to road quality, high energy prices, water and sanitation standards, online public administration services, ICT access, low infrastructure use intensity, etc.), as well as limits the main risks associated with cyber security, poor project management, extreme weather, etc, reflected in the recent reports of such organizations as OECD, IMF, WEC, and other. At the same time, it is necessary to evaluate the implementation of projects that reveal the new potentials, ensuring optimization of the use of existing infrastructure, modern planning and management analytics (digital twins, real-time event reporting, etc.), reduction of transport and monitoring costs (drones, etc.) economic value from sectoral synergies, social value (resilience and crisis management, real-time traffic management, etc.), service, $5 \mathrm{G}$, etc.) highlighted in the recommendations of IMF, the World Bank, and other organizations.

4. When identifying infrastructure projects strengthening national competitiveness and overcoming the consequences of the Covid-19 crisis, it is recommended to apply the methodology proposed in the article evaluating: the productivity criteria, which determine the goal Latvia intends to achieve with a project and is based on the SWOT analysis; the efficiency criteria, the main task of which is to support the selection process of the most efficient and appropriate projects in order to achieve the objectives set by the productivity criteria; as well as the funding criteria identifying funding opportunities for the initiative. Good project management is important regardless of the funding available (also when a project is fully or partially funded by a grant from external sources).

\section{Bibliography}

Austers A., N̦ikišins J., 2020. Sabiedriskās domas aptaujas rezultātu apkopojums. Septembra posms. Rīgā: Latvijas universitāte, 32 lpp. 
Baltic Management Development Association (BMDA), 2020. Annual Conference "Multidisciplinary Approach in Business and Education to Stay Competitive” (15.-16.10.2020.) The discussion moderated by BMDA president, Ph.D.V.Kundrotas. Dr.oec.Bogdanova O., prof. Arturo Bris participated.

Bogdanova O., 2012. Latvijas attīistības modeḷi Eiropas Savien̄̄bas iekšējā tirgū. Promocijas darbs, RTU, 36.-43.lpp. Available at: https://ortus.rtu.lv/science/lv/publications/13400/fulltext [Accessed: 20.08.2020].

Bogdanova O., 2020. Interview with the Director Latvian Investment and Development Agency (LIDA) Rožkalns K. and Head of LIDAA Investment Projects Department Project development division, as well as not published LIDA information. Interviewed: Bogdanova O. Riga, 9.10.2020.

Bogdanova O., 2020. Interview with the Director of the City Council Development Department of Riga City Council I.Purmale Interviewed: Bogdanova O. Riga, 9.10.2020.

Bogdanova O., 2020. Interview with Merirands D., Ministry of Transportation. Interviewed Bogdanova O. Riga, 9.10.2020.

Bogdanova O., 2020. Interview with Eberhards A., Ministry of Finance. Interviewed Bogdanova O. Riga, 14.10.2020.

Cornell University, INSEAD, and WIPO, 2020. The Global Innovation Index 2020: Who Will Finance Innovation? Ithaca, Fontainebleau, and Geneva. ISBN 978-2-38192-000-9.

Foreign Investors' Council in Latvia (IMF), 2020. Ārvalstu investoru padomes Latvijā nostāja attiecībā uz enerǵētikas politiku un atkritumu apsaimniekošanu nostāja attiecībā uz energètikas politiku un atkritumu apsaimniekošanu. Pozīcija nr.11. 2020.gada 10.septembris. Available at: https://www.ficil.lv/position-papers/ficil-position-paper-on-the-energy-sector-and-waste-management-policy/ [Accessed: 15.10.2020.].

Foreign Investors' Council in Latvia (FICIL), 2020. Arvalstu investoru padomes Latvijā Taktiskās darba grupas Rekomendācijas Latvijas pēckrīzes ekonomikas atveselošanai. 2020. Available: https://www.ficil.lv/wpcontent/uploads/2020/06/16062020ficil_task_force_recommendations-LAT.pdf [Accessed: 12.10.2020].

Foreign Investors' Council in Latvia (FICIL), 2020. Ārvalstu investoru padomes Latvijā nostāja attiecībā uz digitalizāciju. Pozīcija nr.6. 2020.gada 10.septembris. Available at: https://www.ficil.lv/wp-content/uploads/2020/09/FICIL-6.Digitalisation-Position-Paper-2020-LAT.pdf [Accessed: 21.10.2020].

FTSE, 2020. FTSE Infrastructure Index. Methodology. https://www.ftserussell.com/products/indices/infraS\&P Dow Jones Indices: Index Methodology (2020). A Division of S\&P Global. May 2020, 39 p. Available at: https://www.spglobal.com/spdji/en/indices/equity/sp-globalinfrastructure-index/ [Accessed: 21.10.2020].

International Monetary Fund (IMF), 2019. Public Investment Management Assessment (PIMA). Strengthening Infrastructure Governance. Washington, DC: International Monetary Fund. 7 p. Available at: https://www.imf.org/external/np/fad/publicinvestment/pdf/PIMA.pdf [Accessed: 30.10 .2020$]$.

International Monetary Fund (IMF), 2019. Public Investment Management Assessment (PIMA). Strengthening Infrastructure Governance. Washington, DC: International Monetary Fund. 7 p. Available at: https://www.imf.org/exteral/np/fad/publicinvestment/pdf/PIMA.pdf [Accessed: 16.10.2020].

International Monetary Fund (IMF), 2020. Regional Economic Outlook. Europe: whatever it takes: Europe's response to COVID-19. Washington, DC: International Monetary Fund, 2020, 45 p. ISBN: 9781513558257.

International Monetary Fund (IMF), 2019. Technical Assistance Report - Public Investment Management Assessment. Republic of Estonia. IMF Country Report No. 19/152. Washington, DC: International Monetary Fund. 63 p. ISBN: 9781498318235/1934-7685.

MSCI, 2017. MSCI Infrastructure indexes. Methodology Available at:

https://www.msci.com/eqb/methodology/meth_docs/MSCI_Infrastructure_Indices_Methodology_Sep2017.pdf [Accessed: 10.10.2020].

Naoyuki Y., Masaki N., 2000. The Role of Infrastructure in Economic Development (Preliminary Version). Keio University. Available at: http://fs0.econ.mita.keio.ac.jp/staff/dikamiya/pdf00/seminar/1205.pdf [Accessed: 01.08.2020].

OECD, 2017. Measuring Distance to the SDG Targets. An Assessment of where OECD Countries Stand. June, 2017. OECD, 59 p. Available at: https://www.oecd.org/sdd/measuring-distance-to-the-sdgs-targets.htm [Accessed: 18.11.2020].

Schwartz, Gerd, Manal Fouad, Torben Hansen, and Geneviève Verdier, eds., 2020. Well Spent: How Strong Infrastructure Governance Can End Waste in Public Investment. Washington, DC: International Monetary Fund. 341 p. ISBN: 978-1-51353-205-9. 
United Nations, 2020. The Sustainable Development Goals Report 2020. United Nations. NY: Department of Economic and Social Affairs. ISBN: 978-92-1-101425-9.

World Bank, 2020. Doing Business 2020. Washington, DC: World Bank. DOI:10.1596/978-1-4648-1440-2. License: Creative Commons Attribution CC BY 3.0 IGO Available at: https://openknowledge.worldbank.org/bitstream/handle/10986/32436/9781464814402.pdf [Accessed: 28.10.2020].

World Bank, 2020. Infratech Value Drivers. World Bank, Washington, DC. (C) World Bank. License: CC BY 3.0 IGO. Available at: https://openknowledge.worldbank.org/handle/10986/34320 [Accessed: 30.11.2020]

World Economic Forum, 2019. Global Competitiveness Report 2019. Insight Report. Switzerland: World Economic Forum, 666 p. ISBN-13: 9782-940631-02-5. Available at: www.weforum.org [Accessed: 26.10.2020].

World Energy Council Organized World Energy Week (7.-9.10.2020), Participated Bogdanova O. The Conclusions Presented by the Secretary General, CEO Dr Angela Wilkinson.

World Energy Council, Wyman O., 2020. World Energy Trilemma Index 2020. London: World Energy Council, 2020 - 69 p. Available at: https://www.worldenergy.org/publications/entry/world-energy-trilemma-index-2020 [Accessed: 15.11.2020].

World Energy Council (WEC), Wyman O., 2019. World Energy Trilemma Index 2020. London: World Energy Council, 2019 - 79 p. Accessed at: https://www.worldenergy.org/publications/entry/world-energy-trilemma-index-2019 [Accessed: 15.11.2020].

\section{Acknowledgement}

The research was supported by the national research programme project "Towards the Post-pandemic Recovery: Economic, Political and Legal Framework for Preservation of Latvia's Growth Potential and Increasing Competitiveness ("reCOVery-LV")" (VPP-COVID-2020/1-0010). 


\title{
ASSESSMENT OF LATVIAN PENSION SYSTEM IN THE CONTEXT OF EUROPEAN PILLAR OF SOCIAL RIGHTS
}

\author{
Larisa Bule, University of Latvia \\ Ramona Rupeika-Apoga, University of Latvia \\ Inna Romanova, University of Latvia
}

Liga Leitane, University of Latvia

\begin{abstract}
Latvian pension system is considered to be one of the most sustainable, but it should be mentioned that financial sustainability may be achieved in different ways and sometimes the aspects of sustainability are estimated without considering system's ability to provide equity, equality and adequacy of retirement provision.

The European Pillar of Social Rights has been proclaimed in 2017. According to this statement delivering on the principles and rights defined under the Pillar is the joint responsibility of the EU institutions, member states, social partners and other stakeholders. The 3rd chapter devoted to social protection and inclusion establishes the key approaches to determining the minimum income, old age income and pensions. In particular, everyone lacking sufficient resources has the right to adequate minimum income benefits ensuring a life in dignity at all stages of life, and effective access to enabling goods and services; workers and the self-employed in retirement have the right to a pension commensurate to their contributions and ensuring an adequate income; everyone in old age has the right to resources that ensure living in dignity.

The aim of the paper is to estimate actual compliance of Latvian pension system with the requirements of the European Pillar of Social Rights.

The main findings show that the European Pillar of Social Rights creates completely new challenges to Latvian pension system, e.g. an ability to stay financially sustainable and comply with the principles of adequate income provision and ensuring living in dignity. Therefore more extensive and complex options of system's improvement should be proposed and assessed.
\end{abstract}

Keywords: pension system, European Pillar of Social Rights.

JEL code: $\mathrm{H} 55$

\section{Introduction}

The European Pillar of Social Rights has been proclaimed by the European Parliament, the Council and the European Commission at the Social Summit for Fair Jobs and Growth in Gothenburg on 17 November 2017. In general it has stated new and more effective delivery of rights for citizens. One of its 3 categories has been dedicated to social protection and inclusion and obviously has determined new standards and challenges for European systems of social protection. Taking into consideration growing demographic pressure, thus, the increasing needs of older population, the $15^{\text {th }}$ paragraph approves the rights for old age income and pension: "workers and the self-employed in retirement have the right to a pension commensurate to their contributions and ensuring an adequate income. Women and men shall have equal opportunities to acquire pension rights. Everyone in old age has the right to resources that ensure living in dignity" (European Commission, 2017).

According to 2016 Allianz Pension Sustainability Index Latvian pension system is addressed as one of the most sustainable amongst 54 countries (Allianz, 2016); however, sustainability statement is based mostly on the aspects of financial sustainability, which constantly exists under the impact of huge amount of different risks. We assume that system's non-compliance with the requirements of the European Pillar of Social Rights may create additional risks for the sustainability of Latvian pension system in future; thereby, it is necessary to assess pension system's capability to provide:

1) resources that ensure living in dignity and

2) a pension commensurate to contributions and ensuring an adequate income.

\section{Literature review}

The Concept of Dignity

Scientific literature shows significant historical evolution of the concept of dignity already since Roman times. Despite its relative significance in the development of ideas, dignity began to enter legal, and particularly constitutional and international legal, discourse in any particularly sustained way in the first half of the $20^{\text {th }}$ century. At the same time dignity still remains one of the most disputable terms amongst researchers.

Implementation of dignity in international and regional human rights texts derives from the use of dignity in the Universal Declaration of Human Rights. Dignity is mentioned there in different context; however, the context of social security also exists. Article 22, on the right to social security, provides: 'everyone, as a member of society, has the right to social security and is entitled to realization, through national effort and international co-operation and in accordance with the organization and resources of each State, of the economic, social and cultural rights indispensable for his 
dignity and the free development of his personality'. Article 23(3), set in the context of right to work, provides that 'everyone who works has the right to just and favourable remuneration ensuring for himself and his family an existence worthy of human dignity, and supplemented, if necessary, by other means of social protection' (United Nations, 1948). From our point of view dignity here is achieved as a result of certain activities, i.e. social protection or working.

Human dignity is also considered as a foundational concept of the global human rights regime, "the 'ultimate value' that gives coherence to human rights" (Hasson, 2003). The Vienna Declaration of the 1993 World Human Rights Conference claims "all human rights derive from the dignity and worth inherent in the human person" (United Nations, 1993). The 1966 International Human Rights Covenants declare "these rights derive from the inherent dignity of the human person" (United Nations, 1966) Mentioned documents and others, such as the European Pillar of Social Rights, are unclear as to the exact definition of human dignity and how it gives rise to or grounds human rights (Henkin, 1992; Beyleveld \& Brownsword, 1998)

The authors agree with J.Donnelly and other authors considering that it is not possible to find an explicit definition of the expression "dignity of the human person" in international instruments or in national law (Donnelly, 2009; McCrudden, 2008; Meyer, 2002). No one jurisdiction has a coherent judicially interpreted conception of dignity across the range of rights, and no coherent conception of dignity emerges transnationally. It is clear that the idea of dignity has become a central organizing principle in the idea of universal human rights, although with interesting differences between jurisdictions, and that there are several different strands of metaphysical and philosophical thinking feeding these differences.(McCrudden, 2008)

Human rights thus are based on but not reducible or equivalent to human dignity. Human rights are one particular mechanism - a particular set of practices - for realizing a certain class of conceptions of human dignity (Donnelly, 2009). At present leading comprehensive doctrines across the globe participate in a two-level overlapping consensus, on the idea that the social and political implications of one's deepest beliefs are appropriately summarized in the idea of human dignity and that internationally recognized human rights provide a detailed specification of certain basic prerequisites of human dignity in contemporary circumstances and essential practices for realizing those that underlying conception of human dignity (Donnelly, 2009; McCrudden, 2008). Human rights, in other words, are both a roadmap and a set of practices for constructing a life of dignity in the conditions of the contemporary world. Rather than providing substantive meaning, a significant use of dignity is institutional: providing a language in which judges can appear to justify how they deal with issues such as the weight of rights, the domestication and contextualization of rights, and the generation of new or more extensive rights (McCrudden, 2008), therefore it is possible to predict future, judicial popularity of dignity in human rights adjudication.

\section{Adequate Income Dimensions}

Adequacy of pensions is one of the latest trends of scientific research. It is one of the main aspects of sustainability policy makers and scientists are concerned about. In some cases financial sustainability is achieved via the amount of retirement benefits and such scenario is not acceptable anymore as far as sustainability becomes jeopardized by political and social risks. In other words, society starts to disrupt the implementation of pension rules.

There does not seem to be a broad consensus in policymaking circles and academic literature on what constitutes the best measure of pension adequacy. While various indicators have been developed and used, no single measure appears to offer a clear indication of the extent to which reforms will impact on the achievement of pension system goals. That is why some studies pretend to define the term of adequacy or assess a limited range of adequacy indicators (Rajevska, 2016; EuropeanCommission \& Committee, 2018; Saunders \& Wong, 2011; Chybalski \& Marcinkiewicz, 2016). Another direction of research tries to formulate the systemic approach to measuring pension adequacy (Grech, 2013; Alonso-Garcia, et al., 2018; Alonso-Fernandez, et al., 2018 and its contribution to the efficiency of pension system in general (Chybalski, 2016).

The Organization for Economic Cooperation and Development (OECD) considers an adequate pension system to be one that "replaces a worker's earnings at a level which enables him or her to maintain a standard of living in retirement comparable to that enjoyed in working lifeeven though retirement income often do not just replace earnings". (OECD, 2013)

According to Chybalski and Marcinkiewicz (2016) pension system adequacy should be perceived as a multidimensional category consisting of the following three dimensions:

- Dimension I: Protecting against poverty

- Dimension II: Consumption smoothing

- Dimension III: Differences in adequacy between the genders. 
In the framework of estimating protection against poverty the at-risk-of-poverty rate for pensioners is considered as one of the most representative indicators. It characterizes the group of people whose main activity status is 'retired' and it expresses the share of pensioners with an equalized disposable income below the at-risk-of-poverty threshold. This indicator is the main measure of monetary poverty included in the EU list of indicators, it is a relative one - net income less than $60 \%$ of national median (European Commission , 2011).

Concerning consumption smoothing, usually there are two essential measures based on income: the replacement rate, which is the most commonly used in studies discussing pension adequacy, as well as the relative median income ratio for the population aged $65+$. The replacement rate is defined in a number of ways, by applying different numerators and denominators, nevertheless, it is always some kind of relationship between income in the retirement period and income in the period of economic activity. According to the methodology applied by Eurostat, the aggregated replacement ratio is defined as the ratio of the median individual gross pensions of the 65-74 age category relative to median individual gross earnings of the 50-59 age category, excluding other social benefits (European Commission, 2020). This indicator is usually criticized as far as it takes into account gross income, but social insurance contributions paid by pensioners are usually much lower than by working people.

Eurostat also provides methodology for measuring the last dimension of pension system adequacy, i.e. income disproportions between the genders. Absolute differences between the values of relevant indicators are calculated separately for men and women (European Commission, 2020). These are:

- Gender differences in the at-risk-of-poverty rate of elderly people 65+;

- Gender differences in the aggregate replacement ratio;

- Gender differences in the relative median income ratio of elderly people $65+$.

\section{Latvian Pension System Compliance Assessment \\ 1.1.''Living in dignity" estimation}

As many other countries around the Globe, Latvia proclaims dignity in the Constitution of the Republic of Latvia (Satversme). This document does not provide precise definition of dignity. The term is included in the chapter, determining fundamental human rights. From the formulation of the chapter, i.e. 'The State shall protect human honour and dignity" (Constitutional Assembly, 1922), it is not possible to specify, if dignity is the foundation of human rights in Latvia or one of them. Taking into consideration, that dignity statement is included in the list of traditional human rights together with the right to social security in old age, human health protection and guarantee of basic level of medical assistance for everyone, the right to education etc., dignity in Latvia is supposed to be one of the fundamental human rights. Latvian legislation usually determines financial thresholds for the rights, which maintain some minimum core. In other words, it is possible to specify what amount of financing must be provided for ensuring basic education or health protection, however, financial bottom line for dignity or "'living in dignity" does not exist. Latvian legislation doesn't provide a particular explanation in what way living in dignity is achieved, but the authors assume that it might be a result of the implementation of traditional human rights such as the right to social security in old age, health protection and other.

The Ombudsman of the Republic of Latvia (the main independent person, which keeps trace of compliance with the law by Governmental and municipal institutions) constantly receives claims of Latvian citizens being sure, that the amount of old age provision does not provide living in dignity. Only in 2019 the Ombudsman seven times informed Latvian Government about the non-compliance of social benefits (including retirement benefits) with the idea of dignity, equity and equality and twice submitted claims to the Constitutional Court of the Republic of Latvia (Ombudsman of the Republic of Latvia, 2020). The analysis of these reports shows, that the Ombudsmen and the Constitutional Court interpret dignity as a result of realizing the fundamental human rights.

The authors conclude, that it is impossible to assess if Latvian pension system and benefits provided provide an opportunity to live in dignity without estimating the adequacy of realizing other human rights regarding retirees. However, pension provision is an essential element of social protection in old age, thus provision of adequate pension benefits is one of the steps in achieving living in dignity.

\subsection{Adequacy of retirement benefits}

Assessment of indicators according to the three-dimensional approach does not demonstrate positive performance of Latvian pension system. Data shows, that in 2018 the at-risk-of-poverty rate for pensioners in Latvia is the second highest in the EU (European Commission, 2020).

Fig.1. demonstrates historic development of the at-risk-of-poverty rate for pensioners in Latvia. Since 2011 the rate is constantly increasing, that is to say, Latvian pension system itself does not provide an opportunity to avoid the risk of poverty for the majority of retirees. Gender differences 
in replacement ratio lead to much higher the at-risk-of poverty rate for female. For example, in 2018 female indicator was 53,9 and male indicator 43,5 .

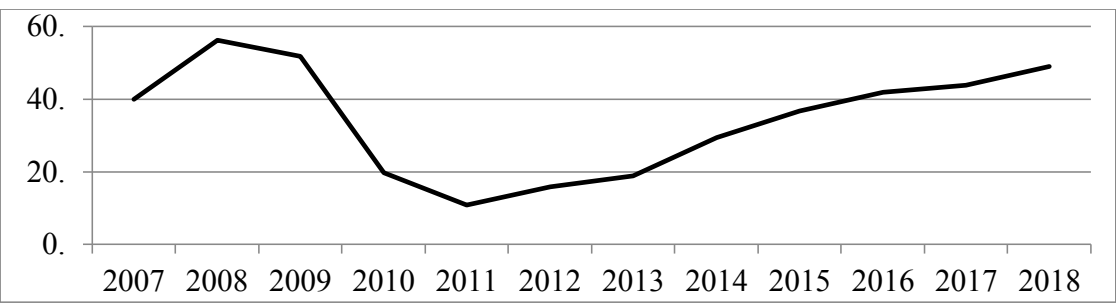

Source: European Commission, 2020

Fig. 1. At-risk-of-poverty rate for pensioners in Latvia 2007-2018, \%

As for the second dimension of adequacy- replacement ratio- the results of assessment are almost similar to the previous comparison: in 2018 aggregate replacement ratio for pensions in Latvia is the third lowest in the EU and its development trend shows constant negative dynamics since 2011 (see Figure 2). Figure 2 also shows non-compliance with the $3^{\text {rd }}$ dimension of pension adequacy. According to the methodology of the European Commission the aggregate replacement ratio is gross median individual pension income of the population aged 65-74 relative to gross median individual earnings from work of the population aged 50-59, excluding other social benefits.

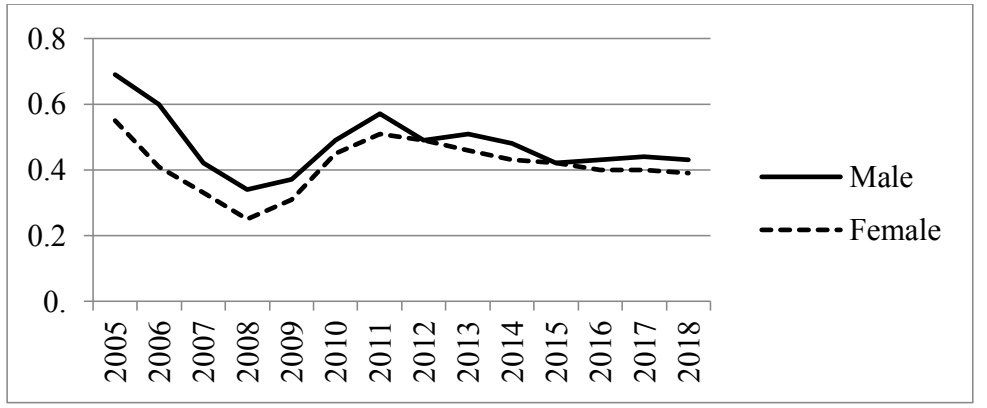

Source: European Commission, 2020

Fig. 2. Aggregate replacement ratio for pensions by sex in Latvia 2018

Obvious question here is the dynamics of replacement ratio in future. Worth mentioning, that different projections of future replacement ratio show different dynamics. For example, the forecast of the Bank of Latvia, carried out in 2019 (see Figure 3), demonstrates twice lower replacement ratio in 2060 (Tkačevs \& Kalniņš, 2019). It is necessary to mention, that this replacement ratio takes into consideration the amount of average gross pension benefits provided by 2 mandatory levels of Latvian pension system and average gross salary, not median indicators.

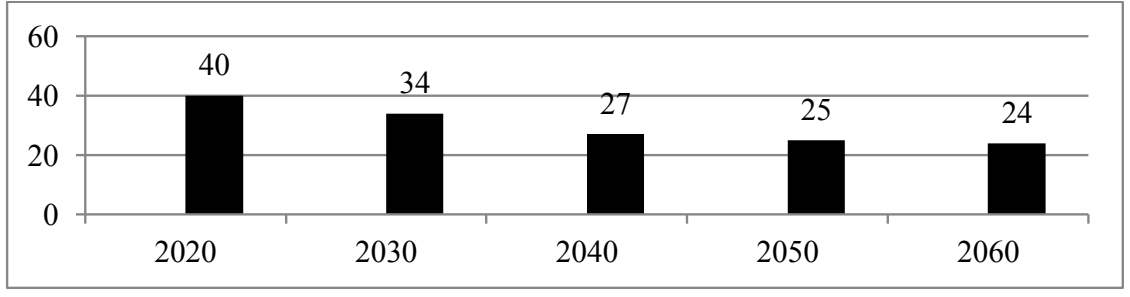

Source: Tkačevs \& Kalniňš, 2019

Fig. 3. Replacement ratio forecast for pensions in Latvia 2020- 2060, \%

Other projections also show the decrease in replacement ratio but more moderate. Net theoretical replacement ratio projection of the European Commission shows 10\% drop down for Latvia in 2016- 2056 based on the assumption of male worker at the standard pensionable age after an uninterrupted 40-year career on a standard employment contract, for longer working career the projected decrease is 6\%., (European Commission, 2018). Due to differences in assessment methodology the differences in replacement ratio appear. 
The approach of the Bank of Latvia is not common in assessing the replacement ratio, but the authors suppose it to be rather valuable. This approach discovers the main risk, which may jeopardize the sustainability of the system and create barriers in attaining its goal of providing equity, equality and finally living in dignity. Table 1 shows the development of average and median salaries and wages in Latvia.

Table 1

Average gross and median monthly salaries and wages in Latvia in 2011-2019, euro

\begin{tabular}{|l|c|c|c|c|c|c|c|c|c|}
\hline Indicator & 2011 & 2012 & 2013 & 2014 & 2015 & 2016 & 2017 & 2018 & 2019 \\
\hline $\begin{array}{l}\text { Average } \\
\text { monthly } \\
\text { wages and } \\
\text { salaries }\end{array}$ & 660 & 685 & 716 & 765 & 818 & 859 & 926 & 1004 & 1076 \\
\hline $\begin{array}{l}\text { Median } \\
\text { wages and } \\
\text { salaries }\end{array}$ & NA & NA & NA & NA & NA & NA & 707 & 774 & 832 \\
\hline $\begin{array}{l}\text { Median as } \\
\% \text { of } \\
\text { average }\end{array}$ & NA & NA & NA & NA & NA & NA & 76,3 & 77,1 & 77,3 \\
\hline
\end{tabular}

Source: Central Statistical Bureau of Latvia, 202

Unfortunately, median income is supposed to be an experimental statistics in Latvia, that's why data prior to 2017 is not available. Median gross salaries and wages in Latvia are more than $20 \%$ lower, than average. Such distinction at present reflects income stratification and demonstrates, that half of Latvian taxpayers contributes to pension capital accumulation from relatively small income. As far as the pension system provides benefits commensurate to contributions, insufficient contributions lead to inadequate benefits.

Latest assessment and projection of Latvian NDC scheme show rather positive development prospects, claiming the theoretical pre-tax replacement ratio of $47 \%$ and after-tax ratio of $65 \%$ (European Commission, 2015; Palmer \& Stabina, 2019)

In 2019 the population aged 50-59 has higher concentration of 41,3\% in the interval of 700-1000 euro monthly salary and wages. The population aged 40-49 mostly (41,8\%) concentrates in the interval of 1000-1500 euro and has higher concentration in income intervals above 1500 euro. Also the population aged 20-49 concentrates more in the interval of 1000-1500 euro. At the same time the population aged 50-59 has higher concentration in the intervals below 700 euro (Central Statistical Bureau of Latvia, 2020). It is possible to assume, that the median income of population aged 5059 is very close to the median income of the whole population - 832 euro- or even lower. Consequently, even relatively high $60 \%$ replacement ratio assessed according to the methodology of the European Commission at present locates a person directly at the at the risk of poverty line. In other words, the pension system is not responsible for low pension provision, low salaries and wages are the basis for inadequacy. It is worth to mention, that the second tier of Latvian pension system- mandatory funded scheme- at present is not able to increase pension benefits substantially. The main reason is the same: low salaries, thus, low contributions lead to insignificant amount of accumulated capital. Moreover, the efficiency of private fund managers is also a very disputable topic in Latvia (Bule \& Leitāne, 2017).

Inadequate pension benefits create the best motivation to continue working after achieving the retirement age- the goal pension reformers fight for. Pension recipients are ready to work for low salaries, which younger workers can't accept. The authors consider this phenomenon as one of the main driving factors of severe emigration, which in turn, is supposed to be one of the main risks of pension system's financial sustainability.

\section{Social sustainability as an additional risk for financial sustainability}

Latvian pension system is financially stable, but its sustainability is achieved mostly by supporting low level of retirement benefits, this seems to be financially fair: low salaries- low pension insurance contributions- low pensions. In 2018 the authors have carried out a representative survey with the aim to figure out the main aspects of people's attitude towards Latvian pension system. $66 \%$ of respondents agreed with the statement, that their opinion on pensions is shaped by the experience of their parents and grandparents, thus, negative experience creates negative attitude. 86,5\% claimed, that current level of poverty amongst pensioners eliminates motivation to undertake pension insurance contributions (Bule, Leitane, \& Rozite, 2018).

Retirees usually are the most active voters in Latvia. Current ratio of population over the working age is already $23 \%$, but the amount of pensioners is close to $30 \%$ (Central Statistical Bureau of Latvia, 2020). Political impact of this group is very significant. Taking into consideration demographic trends, it is possible to assume, that in future this impact will become even stronger and under this pressure policymakers will have to change the norms of the system as it already happens. There are few examples of such activities changing the context of financial sustainability. One of the latest is the correction of capital indexing procedures. Previously pension capital (not retirement benefits) has been indexed according 
to the development of total amount of all taxable salaries, in case of decrease the index has been negative. The retirees appealed against this norm and the Constitutional court agreed with the objection, that's why indexation doesn't reduce pension capital anymore, even if general taxable income is falling, so to say, indexation creates liabilities not covered by working population.

Most of retirees are not satisfied with the amount of pension benefits. As it has been mentioned previously, the amount is commensurate to contributions, but pension recipients don't agree, that it is adequate and fair as far as benefits are compared with an average salary. Table 2 indicates, that the absolute majority of retirees are the recipients of benefits much lower than median and average salary, therefore, EU-SILC 2018 shows extremely low level of satisfaction with financial position amongst pensioners (Central Statistical Bureau of Latvia, 2020). It is not surprising, that this group of voters creates enormous political pressure and Latvian pension system doesn't have immunity against it.

Table 2

\section{Number of pension recipients by average size of pension granted in 2019, persons}

Source: Central Statistical Bureau of Latvia, 2020

\begin{tabular}{|l|l|}
\hline$\leq 100.00$ & 18037 \\
\hline $100.01-150.00$ & 19389 \\
\hline $150.01-200.00$ & 7686 \\
\hline $200.01-250.00$ & 16132 \\
\hline $250.01-300.00$ & 70937 \\
\hline $300.01-400.00$ & 185456 \\
\hline $400.01-500.00$ & 64824 \\
\hline $500.01-1000.00$ & 58245 \\
\hline$>1000.01$ & 9773 \\
\hline
\end{tabular}

Assessing the financial situation and the opinion of retirees, the younger population forms negative attitude towards the pension system in general (Bule \& Leitāne, 2017). As a consequence the following problems emerge:

1) the absence of confidence in the long-term sustainability of the pension system and therefore

2) low pension insurance contributions and traditionally high tax avoidance ( $1 / 3$ of socially insured contribute from the minimum salary), thus low savings and small pensions.

\section{Conclusions}

The European Pillar of Social Rights together with demographic and economic changes obviously will create new challenges for Latvian pension system. At present the system does not comply with the requirement of the European Pillar of Social Rights, furthermore, its financial stability and sustainability are under the risk of negative social impact.

Being well-designed, financially smart and fair, the system suffers from local population's severe critics, hatred and defiance. The authors assume, that without parametric corrections and financing model's reestimation Latvian pension system alone will hardly be able to guarantee living in dignity and adequate income for all if income stratification and demographic and social risks will continue to develop in the same way like at present. Latvian policymakers should not rely only on raising the retirement age and must consider an opportunity of parametric corrections, like other Baltic states do. It is also necessary to improve protection of the system itself against social risk via:

1) reassessing the system of healthcare and social assurance;

2) increasing the level of financial literacy and motivation to avoid shadow economy activities;

3) developing real welfare growth and decreasing income stratification.

\section{Bibliography}

Allianz, 2016. Allianz Pension Sustainability Index. Retrieved from https://www.fiapinternacional.org/wp-content/uploads/2016/10/PensionSustainability-Index-2016.pdf

Alonso-Fernandez, J., Meneu-Gaya, R., Devesa-Carpio, E., Devesa-Carpio, M., Dominguez-Fabian, I., Encinas-Goenechea, B., 2018. From the Replacement Rate to the Synthetic Indicator: A Global and Gender Measure of Pension Adequacy in the European Union. Social Indicators Research, 138(1), 165-186.

Alonso-Garcia, J., Boado-Penas, M., Devolder, P., 2018. Adequacy, Fairness and Sustainability of Pay-as-You-Go-Pension-Systems: Defined Benefit Versus Defined Contribution. European Journal of Finance, 24(13), 1100-1122.

Beyleveld, D., Brownsword, R., 1998. Human Dignity, Human Rights, and Human Genetics. Modern Law Review, 61(5), 661-680. 
Bule, L., Leitane, L., 2017. Contribution of Private Fund Managers to the Accumulation of Pension Capital of the Second Tier of Latvian Pension System in 2012-2016. European Research Studies Journal, 20(3A), 624-634.

Bule, L., Leitane, L., Rozite, K., 2018. Assessment of Funded Pension Capital Inheritance Opportunity In Latvia. Proceedings of the 10th International Scientific Conference "New Challenges of Economic and Business Development 2018:Productivity.. Riga: University of Latvia, 7988 .

Central Statistical Bureau of Latvia, 2020. Retrieved from: http://www.csb.gov.lv

Chybalski, F., 2016. The Multidimensional Efficiency of Pension System: Definition and Measurement in Cross-Country Studies. Social Indicators Research, 128,15-34.

Chybalski, F., Marcinkiewicz, E., 2016. The Replacement Rate: An Imperfect Indicator of Pension Adequacy in Cross-Country Analyses. Social Indicators Research, 126, 99-117.

Constitutional Assembly, 1922. The Constitution of The Republic of Latvia. Retrieved from Legal Acts of the Republic of Latvia: https://likumi.lv/ta/en/en/id/57980

Donnelly, J., 2009. Research Project on Human Dignity: Human Dignity and Human Rights. Geneva: Geneva Academy of International Humanitarian Law and Human Rights, 90 p.

European Commission, 2011. THE MEASUREMENT OF EXTREME POVERTY. Retrieved from European Commission https://ec.europa.eu/eurostat/ramon/statmanuals/files/UNECE_Guide_on_Poverty_Measurement.pdf

European Commission, 2015. The 2015 Pension Adequacy Report: Current and Future Income Adequacy in Old Age in the EU. Volume I \& Volume II.. Retrieved from European Commission https://op.europa.eu/en/publication-detail/-/publication/2a4451ef-6d06-11e5-9317-01aa75ed71a1

European Commission, 2017. European Pillar of Social Rights. Retrieved from An official website of the European Union: https://ec.europa.eu/commission/priorities/deeper-and-fairer-economic-and-monetary-union/european-pillar-social-rights_en

European Commission, 2020. Aggregate replacement ratio for pensions. Retrieved from Eurostat: https://ec.europa.eu/eurostat/web/productsdatasets/product?code=tespn070

European Commission, 2020. Data. Retrieved from Eurostat: https://ec.europa.eu/eurostat/data/database

European Commission, 2020. Gender Pay Gap Statistics. Retrieved from Eurostat: https://ec.europa.eu/eurostat/statisticsexplained/index.php/Gender_pay_gap_statistics

European Commission Social Protection Committee, 2018. The 2018 Pension Adequacy Report: current and future income adequacy in old age in the EU. Retrieved from https://op.europa.eu/en/publication-detail/-/publication/f0e89c3f-7821-11e8-ac6a-01aa75ed71a1/language-en

Grech, A., 2013. Assessing the Sustainability of Pension Reforms in Europe. Journal of International and Comparative Social Policy, 29(2), 143162

Grech, A., 2013. How best to measure pension adequacy. LSE Research Online Documents on Economics, 1-39.

Hasson, K. J., 2003. Religious Liberty and Human Dignity: A Tale of Two Declarations. Harvard Journal of Law \& Public Policy 27(1), 81-92.

Henkin, L., 1992. Human Dignity and Constitutional Rights. In W. M. Parent, The Constitution of Rights: Human Dignity and American Values. Ithaka: Cornell University Press, p.248

McCrudden, C., 2008. Human Dignity and Judicial. The European Journal of International Law, 19(4), 655-724.

Meyer, M. J., 2002. Dignity as a (Modern) Virtue. In The Concept of Human Dignity in Human Rights Discourse. The Hague: Kluwer Law International, $313 \mathrm{p}$.

OECD, 2013. Pensions at a Glance 2013: OECD and G20 Indicators. Retrieved from https://www.oecd-ilibrary.org/docserver/pension_glance2013-4-en.pdf?expires=1548881696\&id=id\&accname=guest\&checksum=D2683980A1C54402A7664EFCA6B1CFA4

Ombudsman of the Republic of Latvia, 2020. Tiesības uz sociālo nodrošinājumu. Retrieved from Ombudsman of the Republic of Latvia: http://www.tiesibsargs.lv/lv/pages/cilvektiesibas/socialas-un-ekonomiskas-tiesibas/tiesibas-uz-socialo-nodrosinajumu

Palmer, E., Stabina, S., 2019. The Latvian NDC Scheme: Success Under a Decreasing Labor Force. World Bank Discussion Paper No1902, 38 p.

Rajevska, O., 2016. Doctoral Thesis: Adequacy and Equity of Pensions as a Function of Pension System Instituional Design: a Case of the Baltic States. Rīga: Latvijas Universitāte,182 p. 
Saunders, P., Wong, M., 2011. Pension Adequacy and the Pension Review. The Economic and Labour Relations Review, 22(3). 7-26.

Tkačevs, O., Kalniņš, G., 2019. Cik zaḷi dzīvosim vecumdienās? Pensiju sistēmas ilgtspējas šķietamība. Retrieved from Bank of Latvia: https://www.makroekonomika.lv/cik-zali-dzivosim-vecumdienas-pensiju-sistemas-ilgtspejas-skietamiba

United Nations, 1948. Universal Declaration of Human Rights. Retrieved from United nations: https://www.un.org/en/universal-declarationhuman-rights/index.html

United Nations, 1966. International Covenant on Economic, Social and Cultural Rights. Retrieved from United Nations: https://www.ohchr.org/EN/ProfessionalInterest/Pages/CESCR.aspx

United Nations, 1993. Vienna Declaration and Programme of Action,. Retrieved from United Nations : https://www.ohchr.org/EN/ProfessionalInterest/Pages/Vienna.aspx

\section{Acknowledgments}

This paper forms part of the project funded by INTERFRAME-LV. 


\title{
EFFECT OF INTRA-ORGANISATIONAL COMPETITION ON ORGANISATIONAL PERFORMANCE INDICATORS
}

\section{Harsh Chauhan, University of Latvia \\ Henrijs Kalkis, University of Latvia}

\begin{abstract}
The objective of the research is to investigate intra-organisational competition (IOC) emerging from the interactions of internal social comparison (ISC) and intra-organisational evolution (IOE) effecting organisational performance (OP). Communication between subordinates, comparing contribution, ability to perform and business management strategies resulting in IOC. The attention is on recognised social dimensions and equal emphasis is on business management practices. The literature attempts' to recognise ISC and IOE and its effect on OP balances the conceptual paper. For the purpose Google Scholar, Emerald Insight, EBSCO Host and Science Direct database has been used. Literature relies on human tendency to compare and coordinate work activities. It identifies the response towards comparison and pressure created within work environment affecting employees ability to operate and function efficiently. The concentration is on business process and employee's irrational behaviour affecting individual performance. The study assesses consequences of IOC on employees followed by its outcome on organisation's performance. The application is on variables (ISC, IOE \& OP) and critical factors that affects work environment due to intra-organisational strategy of competitive behaviour implemented by employers' in encouraging "Intra-organizational competition".
\end{abstract}

Keywords: Intra-organisational, Competition, Internal Social Comparison, Evolution, Performance.

JEL Code: L20, L21, M1, M10

\section{Introduction}

The internal social comparison starts developing into intra-organisational competition affecting work related activities. Intra-organisational competition is the resultant of the employees comparing individual performance, contribution, engagement and remuneration within organisation's team, departments or manufacturing units (Baumann, Eggers \& Stieglitz, 2019). As a result employees find collaboration between different departments challenging. Internal social comparison is influenced by day-to-day work routine. Stakeholders such as employees, team leaders, supervisors and managers comment on individual abilities influences working environment and affects behavioural attitude (Marino and Zabonik, 2004).

The concept of intra-organisational evolution is based on strengthening organisation's business management structure and to develop healthy internal competition (Campbell, 1965). Organisations involved in marketing, sales and manufacturing of complex product and services commonly exhibit IOC. For this purpose organisation's tends to make variations in its business management, focus on selection of methods which improves distribution process and concentrate on retention of those strategies which has desired outcomes (Campbell, 1969).

When internal social comparison and intra-organisational evolution interacts with each other over a period of time it transform into intraorganisational competition. Work behaviour and engagement, remuneration and contribution are primary variables of ISC. Variation, selection and retention are variables associated with IOE. Intra-organisational competition drivers are comprises of size, nature and experience in organisation, followed by knowledge transfer and organisational learning are related to organisation's performance.

The objective of the research is to investigate intra-organisational competition (IOC) emerging from the interactions of internal social comparison (ISC) and intra-organisational evolution (IOE) effecting organisational performance (OP). The limitation of the research is strongly connected with the variables and the literature collected for study. Previous researches envisaged on intra-organisational competition with major attention on social comparison between teams, departments and business units, the author concluded that there is a lack of systematic literature review which aims to test theoretical gap between ISC, IOE and IOC effecting "organisational performance".

\section{Research results and discussion}

\section{Internal Social Comparison}

The intra-organisational competition theories focus on relative performance across organisations by comparing individual contribution and behaviour of employees at work. It is a part of process that have successive influence on internal social comparison. The Internal social comparison is a primary stage of competition and during the period of times it develops into full fledge intra-organisational competition (Baumann, Eggers \& Stieglitz, 2019). 
Internal social comparison exists within departments, divisions, teams and business units (Gartenberg \& Wulf, 2017). Subordinates working for the same organization often aim to outperform colleagues treat co-workers as competitors (Fehr \& Falk, 1999). The internal social comparison give rise to the competitive behaviour that leads to internal competition followed by intra-organizational competition (Baumann, Eggers \& Stieglitz, 2019).

The psychology of internal social comparison is influenced by process of interaction between individuals at the work place, primarily focused on achieving the targets set by organisation (Becker \& Kernan, 2003). Employees, managers and team leaders working in the organisation practice internal social comparison. The effect of social comparison between colleagues and subordinates working within the organisation have the tendency to create competitive working environment. The action and reaction between influencer and influence' shape attitude and work behaviour and engagements (Garcia, Tor \& Schiff, 2013).

It is quite controversial to practise and encourage internal competition having its sustained effect on behavioural attitude of employees. The macro and micro level studies conducted at the social comparisons have identified effects on work environment including the coordination between teams and departments (Kacperczyk, Beckman \& Moliterno, 2015). The group dynamics can be compromised as a result of internal competition (Blader et al., 2015). The extensive internal competition includes increased sense of discomfort, uneasiness, distress and tension mounts between employees that reflects in their day-to-day work (Marino and Zabonik, 2004).

Another dimension of internal competition from workplace point of view, where employees are competing against each other for full time employment has seen different challenges (Bartling, Fehr \& Schmidt, 2010). The intensity of competition increases as employees working for organisation purposely aim hard in order to receive permanent position, more salaries, remuneration or promotion (Nickerson \& Zenger, 2008; Charness, Masclet, \& Villeval, 2013; Chan, Li, \& Pierce, 2014).

The internal social comparison at workplace offer significance of wage distribution among employees. The co-workers give importance to the salaries earned and inequality between subordinates (Cohn et al., 2011). It has been observed that employee comparing salaries with colleagues and team members sizeably reduces their work and effort level inconsideration to the difference of remuneration paid by organisation (Gachter and Thoni, 2010).

The literature concentrates on the emergence of intra-organisational competition. The employee's perspective has been highlighted in consideration to internal social comparison which takes place within organisation on daily basis. Social comparison between employees give rise to intra-organisational competition. Previous research articles have been evaluated for developing conceptual paper. The methodology of selection process has been systematised by reviewing journals from recognised scientific databases (see Table 1). Specific terms and meaningful statement have been used for selecting relevant literatures.

Table 1

The methodology of selecting relevant literature

\begin{tabular}{|c|c|c|c|c|}
\hline Terminologies & $\begin{array}{c}\text { Google } \\
\text { Scholar }\end{array}$ & $\begin{array}{c}\text { Emerald } \\
\text { Insight }\end{array}$ & EBSCO & $\begin{array}{c}\text { Science } \\
\text { Direct }\end{array}$ \\
\hline Internal social comparison between employees in organisations & 18 & 13 & 9 & 11 \\
\hline Internal competition between employees within business units & 15 & 10 & 12 & 17 \\
\hline
\end{tabular}

Author's construction base on the methodology of selecting relevant literature

The following methodology has been used and the number of literatures is listed under the following headings (see Table 2).

\section{Construction base on the literatures collected}

\begin{tabular}{|c|c|c|c|c|c|}
\hline $\begin{array}{c}\text { Abstract } \\
\text { Revision/ } \\
\text { Full Article } \\
\text { Reading }\end{array}$ & $\begin{array}{c}\text { Research } \\
\text { Approach/ } \\
\text { Methodology } \\
\text { Used }\end{array}$ & $\begin{array}{c}\text { Theories } \\
\text { and } \\
\text { Concepts } \\
\text { Used }\end{array}$ & $\begin{array}{c}\text { Data Collection \& } \\
\text { Statistical Analysis } \\
\text { Test/Experiment }\end{array}$ & $\begin{array}{c}\text { Research } \\
\text { Implication/ } \\
\text { Findings }\end{array}$ & $\begin{array}{c}\text { Limitation } \\
\text { \& Future } \\
\text { research } \\
\text { Suggestion }\end{array}$ \\
\hline $48 / 51$ & $37 / 41$ & 27 & $31 / 19$ & $25 / 17$ & 22 \\
\hline
\end{tabular}

Author's construction base on the literatures collected

Previous researches and other empirical studies have been considered for examining internal competitive work environment of organisation. In order to establishing the connection between internal social comparison and intra-organisational competition selected literatures have been analysed.

\section{Intra-organisational Evolution}

The intra-organisational evolution in organisational perspective comprises of growth, profitability, efficiency and effectiveness of business management (Carol \& Tomas, 1995). The term intra-organisational ecology, organisation evolution has been widely used to address intra- 
organisational evolution (Weeks and Glaunic, 2017). In the context of organisational strategies, the concentration is on relationship factors for analysing the mechanism of variation, selection and retention. The intra-organizational evolution develops through a process of internal "variation, selection and retention" in organization's business management (Campbell, 1997 \& 1965). Variation in general is associated with decentralisation of command, selection is commonly known for the method of distributing scares resources and retention is an execution of managerial strategy and critical decision making that strengthens business operations and functions (Campbell, 1969). Further the uncertainty in business environment, cost of duplication, overlap of business activities and the equivalent authority of leadership leads to intra-organisational competition (Williamson, 1975). Under intra-organisational evolutionary process the organisations spend more time and energy in developing autonomous process through internal experiments and selection process (Weeks and Glaunic, 2017).

The intra-organisational evolution process is more dependent on the unit of cultural selection and social phenomena closely related to intraorganisational competition. The process of interaction within organisations, competition between daily routines, selection mechanism and replication process leads to the possibilities for reproducing temporary goods and services. It overlaps between the structure of two or more business units in the single organisation (weeks \& Glaunic, 2003). This trend is very likely in businesses involved in structuring departments, groups and developing multiple teams of employees working for production or delivery. The extent of intra-organisational competition has been found in many divisions, departments and team's work environment in consideration to the allocation of resources for contribution towards organisational performance (Benndrof \& Holger, 2012).

Organisations such as Google and Microsoft are very well known for using strategies to sustain intra-organisational competition. Managers and team leaders use stack ranking charts \& boards (Peters \& Waterman, 1988). General Electric corporation deliberately encourage direct intraorganisational competition between teams, units and employees. Studies has shown that management practices are targeted towards developing consistent competition and it has been embedded in their organisational culture (Baumann, Eggers \& Stieglitz, 2019). There are other organisations like P\&G, J\&J, IBM, Fuji Xerox, Ericsson \& Lucent and Fidelity use one or another form of intra-organisational competition (Kanter et al. 1997).

The concept of intra-organisational evolution highlights the perspective of "Variation, Selection and Retention". Organisations use internal competition as a strategic ploy for employees to compete against each other for making substantial contribution towards the progress and development within the boundaries of organisation.

There are scientific literatures which has been selected with the help of using different terminologies (see Table 3).

The methodology of selecting relevant literature

\begin{tabular}{|c|c|c|c|c|}
\hline Terminologies & $\begin{array}{c}\text { Google } \\
\text { Scholar }\end{array}$ & $\begin{array}{c}\text { Emerald } \\
\text { Insight }\end{array}$ & $\begin{array}{c}\text { EBSCO } \\
\text { Science } \\
\text { Direct }\end{array}$ \\
\hline Intra-organisational evolution within the boundaries of organisation & 12 & 15 & 13 & 17 \\
\hline Intra-organisational conflict between the departments and teams & 18 & 14 & 11 & 21 \\
\hline
\end{tabular}

The following methodology has been used and the number of literatures are listed under the following headings (see Table 4).

\section{Construction base on the literatures collected}

\begin{tabular}{|c|c|c|c|c|c|}
\hline $\begin{array}{c}\text { Abstract } \\
\text { Revision/ } \\
\text { Full Article } \\
\text { Reading }\end{array}$ & $\begin{array}{c}\text { Research } \\
\text { Approach/ } \\
\text { Methodology } \\
\text { Used }\end{array}$ & $\begin{array}{c}\text { Theories } \\
\text { and } \\
\text { Concepts } \\
\text { Used }\end{array}$ & $\begin{array}{c}\text { Data Collection \& } \\
\text { Statistical } \\
\text { Analysis Test } \\
\text { /Experiment }\end{array}$ & $\begin{array}{c}\text { Research } \\
\text { Implication// } \\
\text { Findings }\end{array}$ & $\begin{array}{c}\text { Limitation \& } \\
\text { Future } \\
\text { research } \\
\text { Suggestion }\end{array}$ \\
\hline $54 / 61$ & $49 / 67$ & 43 & $36 / 28$ & $25 / 33$ & 47 \\
\hline
\end{tabular}

Author's construction base on the literatures collected

The theories of Intra-organisational evolution have been taken into consideration to establish the corelation between evolution and intraorganisational competition. Number of scientific articles has been selected to test the feasibility of literature including the analysis of previous studies conducted on intra-organisational competition.

\section{Intra-organisational competition}

Intra-organisational competition perspective comprises of internal social comparison and intra-organisation evolution. The employee's perspective is to strive for better and higher remuneration, recognition and position. The organisations perspective is to gain work efficiency, profitability and productivity. To ensure the achievement of objectives organisations concentrate on maximising employee's individual contribution, 
engagement and work performance. In the light of previous literatures the following theoretical concepts has been taken into consideration for establishing the relationship between internal social comparison and intra-organisational evolution resulting in intra-organisational competition (see Table 5).

The concept of intra-organisational competition based on theories of ISC \& IOE

\begin{tabular}{|c|c|}
\hline Internal social comparison & Intra-organisational evolution \\
\hline 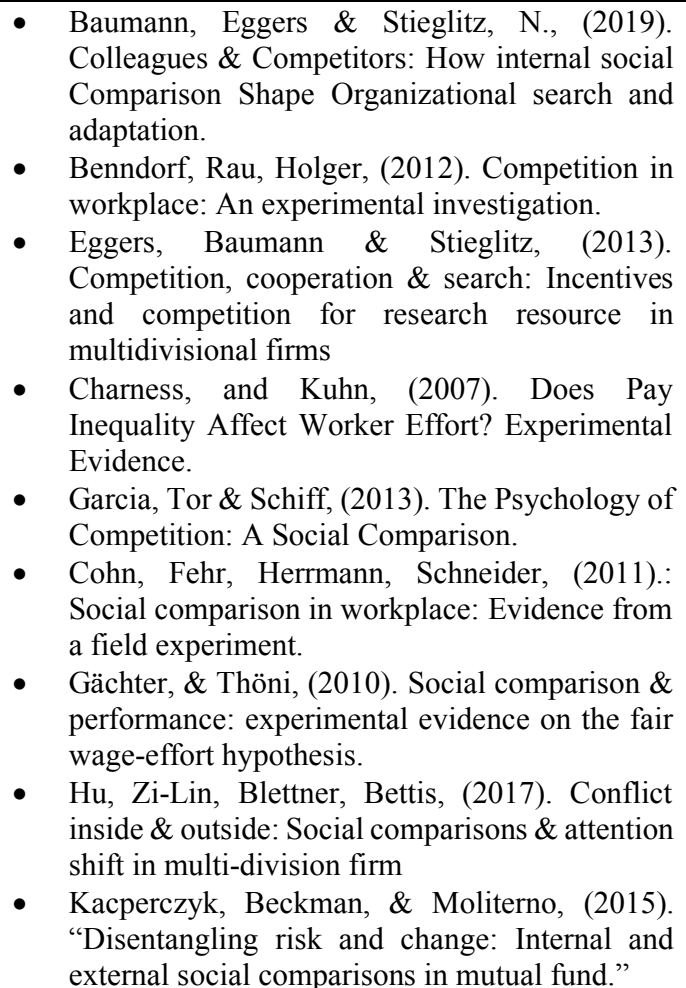 & 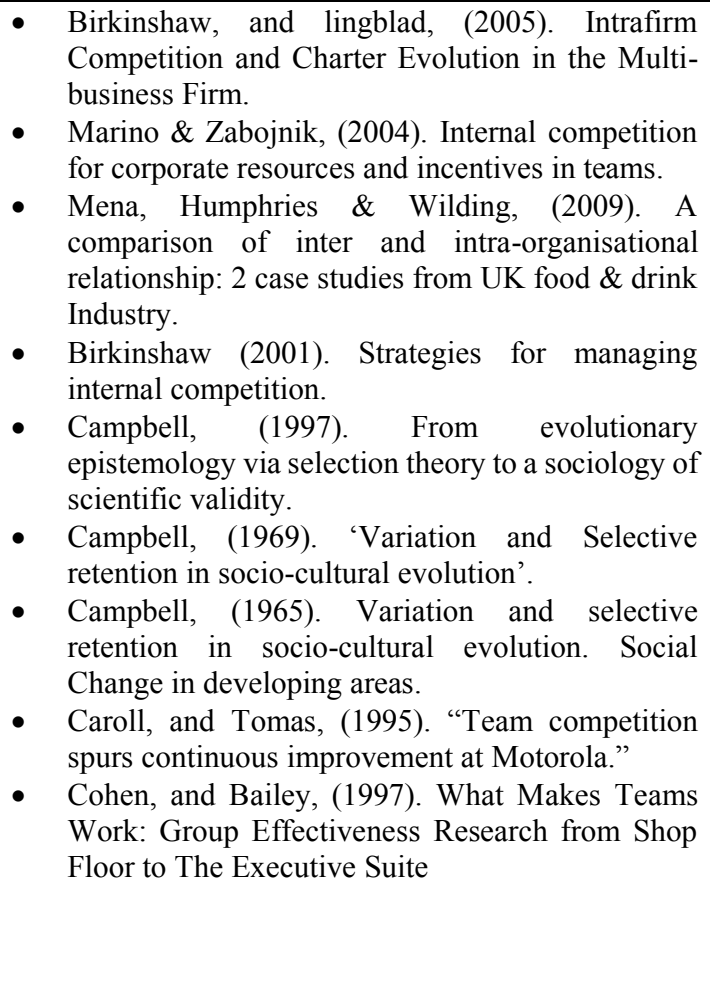 \\
\hline
\end{tabular}

\section{Organizational performance}

Organisational performance is defined as the optimum utilisation of resources for achieving set of objectives (Lebas and Euske, 2007). Organisational performance is a major component of organisational effectiveness (Venkatraman and Ramanujan, 1986). Organisational performance has been distinguished as the functionality of organisation in the absence of strain and fault, engaging in legitimate activities, resource acquisition and accomplishing stated goals (Cameron, 1986). Organisational performance in the management of business has been quoted as the achievement of performance for both financial and non-financial indicators in-terms of desired results (Zainal et al., 2009). The antecedents of organisational performance indicators refer to the operational performance and financial performance (Combs et al., 2005). Production efficiency, customer satisfaction and the satisfaction of stakeholder are by and large most popular categories of defining organisation's performance (Hitt, 1988). Nonfinancial performance indicators include variables such as partnership, competences, customer and employee's satisfaction, internal and external relationship, organisational learning and knowledge management (Ayoup et al., 2013). Another set of non-financial performance qualitative indicators are mentioned in the category of learning, knowledge and innovation having significant effect on organisational performance (Kaplan and Norton, 1992).

Organisations learning ability enables positive influence on non-financial performance (Grant 1996; Spender, 1996). Learning is responsible for transforming and refining organisation's knowledge resources. Both organisational learning and knowledge management are critical drivers for creating organisation's performance (Decarolis and Deeds, 1999). Organisational learning and business performance is directly proportional to each other. (Ellinger et al., 2002). The studies analysed organisational learning and knowledge management have positive effect on business performance (Haas and Hansen, 2005). The researches have shown significance of theoretical and empirical links between knowledge management and business performance (Choi and Lee, 2003; Chuang, 2004). The success of business performance is entirely based on learning different types of knowledge. The knowledge management is considered as a main basis for competitive advantage (Amin and Cohendet, 2004). Knowledge is the key factor for 
sustaining competitive advantage but also recognises the importance of how organisations can develop, retain, transfer and use knowledge for learning process in organisation (Argote and Ingram, 2000).

The research on organisational performance is closely scrutinised to acclaimed the effect of intra-organisational competition. The methodology of selecting relevant literature has been used to encompass IOC affecting organisational performance. It has been represented categorically (see Table 6)

Table 6

The methodology of selecting relevant literature

\begin{tabular}{|c|c|c|c|c|}
\hline Terminologies & $\begin{array}{c}\text { Google } \\
\text { Scholar }\end{array}$ & $\begin{array}{c}\text { Emerald } \\
\text { Insight }\end{array}$ & $\begin{array}{c}\text { EBSCO } \\
\text { Science } \\
\text { Direct }\end{array}$ \\
\hline Organisational performance in the context of financial \& non-financial indicators & 12 & 18 & 8 & 16 \\
\hline Identification of organisational performance indicators & 13 & 14 & 10 & 11 \\
\hline
\end{tabular}

Author's construction base on the methodology of selecting relevant literature

The following methodology has been used and the number of literatures is listed under the following headings (see Table 7).

Construction base on the literatures collected

\begin{tabular}{|c|c|c|c|c|c|}
\hline $\begin{array}{c}\text { Abstract } \\
\text { Revision/ Full } \\
\text { Article } \\
\text { Reading }\end{array}$ & $\begin{array}{c}\text { Research } \\
\text { Approach/ } \\
\text { Methodology } \\
\text { Used }\end{array}$ & $\begin{array}{c}\text { Theories } \\
\text { and } \\
\text { Concepts } \\
\text { Used }\end{array}$ & $\begin{array}{c}\text { Data Collection \& } \\
\text { Statistical Analysis } \\
\text { Test/Experiment }\end{array}$ & $\begin{array}{c}\text { Research } \\
\text { Implication/ } \\
\text { Findings }\end{array}$ & $\begin{array}{c}\text { Limitation \& } \\
\text { Future } \\
\text { Research } \\
\text { Suggestion }\end{array}$ \\
\hline $28 / 41$ & $29 / 33$ & 21 & $23 / 16$ & $22 / 19$ & 24 \\
\hline
\end{tabular}

Author's construction base on the literatures collected

To elaborate the significance of organisational performance indicators systematic literature review has been conducted. There are number of scientific researches have been selected and collected for the purpose of developing the conceptual paper. The researches have emphasized on organisational performance measurement and repeatedly elaborated the importance of key indicators. As mentioned, both financial and non-financial indicators are equally responsible for organisational performance. The following organisational theories has been taken into consideration for emphasizing the role of key indicators in access to organisational performance (see Table 8).

Table 8

The theories of organisational performance

\begin{tabular}{|c|c|}
\hline Financial Indicators & Non-Financial Indicators \\
\hline $\begin{array}{l}\text { - Net worth \& Earnings - (Lebas and Euske, 2007; } \\
\text { Tseng and Lee, 2014). } \\
\text { - Stockholders value - (Venkatraman and } \\
\text { Ramanujan, 1986; Cameron, 1986). } \\
\text { - Capital Returns - (Zainal et al., 2009; Holsapple } \\
\text { \&Wu, 2011; Combs et al., 2005). }\end{array}$ & $\begin{array}{l}\text { - Production Efficiency, Customer \& employee } \\
\text { satisfaction, Stakeholder satisfaction - (Connolly, } \\
\text { Conlon, Deustch, 1980; Hitt, 1988; Zammuto, } \\
\text { 1984). } \\
\text { Partnership \& Competences - (Ayoup et al., } \\
\text { 2013; Chen and Liang, 2011, Cotora, 2007). } \\
\text { Internal and external relationship - (Kaplan and } \\
\text { Norton 1996, Neely, 2002, Neely et al., 2002). } \\
\text { - Organisational learning, knowledge management } \\
\text { \& Innovation - (Cangelosi and Dill, 1965; Slater } \\
\text { and Narver, 1995; Calantone et al., 2002; } \\
\text { Brokman and Morgan, 2003; Droge et al., 2003; } \\
\text { Stata, 1989; Stewart, 1997; Soo et al.. 2004). }\end{array}$ \\
\hline
\end{tabular}

Author's construction base on the theories of organisational performance

\section{Conceptual framework}

The conceptual framework is shown in Figure 1, which is based on intra-organisational theories proposed by (Baumann, Eggers \& Stieglitz, 2019) and the theories of intra-organizational evolution "variation, selection and retention" researched by (Campbell, 1997, 1969 \& 1965). The organisational performance indicators such as organisational learning and knowledge management has been selected from scientifically recognised previous researches. 


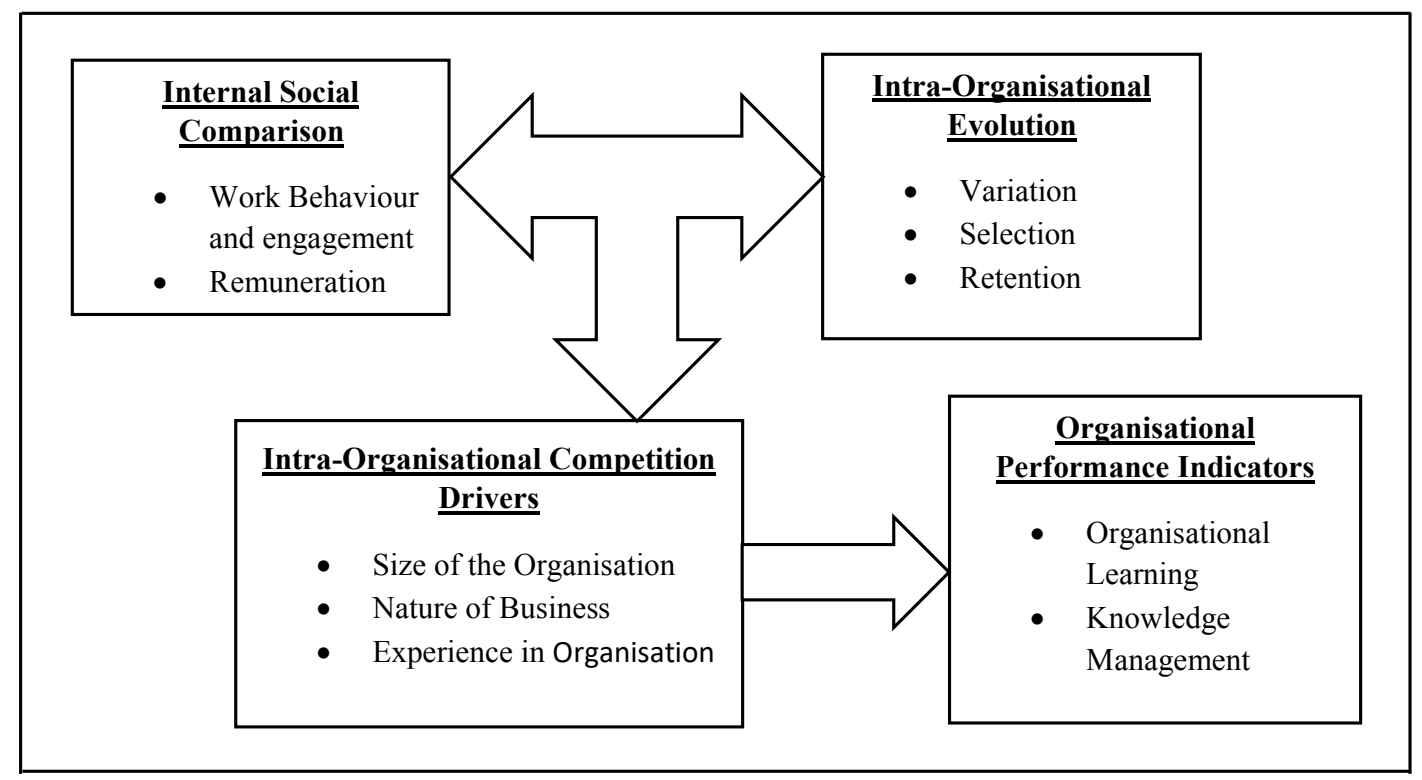

Source: author's creativity of conceptual framework based on theoretical research

Fig. 1. The conceptual framework of Intra-organisational competition effecting organisational performance indicators

The conceptual framework depicts intra-organizational competition variables intra-reacting with each other. Intra-organizational evolution factors of "variation, selection and retention" (decentralization of command, allocation of scares resources and managerial strategy) are synchronized with factors of Internal social comparison (work behaviour, engagement, remuneration and contribution) in the light of strategic business management practices. Simultaneously organization's efficiency and effectiveness in business operations and critical decision making in business functions plays a crucial role in sustaining IOC.

Organisational learning and knowledge management goes hand by hand. Employees who are target driven and have high self-esteem can adapt and learn quickly, they have an ability to create distinct advantage over their co-workers (Joseph and Wilson, 2017). Employees working in organisation needs to learn and gain knowledge and understand the reason behind the existence of intra-organisational competition. They are also required to accumulate the level of competitiveness within organisation and gradually adapt themselves to the extent of competitive behaviour in working environment (Benndrof \& Holger, 2012). In essence the effectiveness of internal social comparison in the context of intra-organisational competition is to create an advantage for increasing organisational performance through exchanging ideas and inter learning process, the colleagues very often imitate teammates practices for better personal outcomes (Cabrales \& Charness, 2011).

On the other hand organisations purposely use intra-organisational evolutionary theories for enhancing organisational capabilities. The mechanism for allocation of resources within the organisation's boundaries have reconcile business units and employees to compete for availability of resources (March \& Simon, 1958). The concept of "coevolving companies" allows cooperation and collaboration while competition coexist between employees and business management (Eisenhardt \& Galunic, 2000). Further the concept of introducing the "intra-enterprise cannibalism" can be managed significantly during internal competition for consistent and successful organisational performance (Nadler \& Tushman, 1999). The key traits regarding environment uncertainty and duplication of cost leads to intra-organisational competition (Birkinshaw, 2001). The impact of corporate strategy, selection and adaptation of evolutionary management are directed towards organisational performance (Burgelman, 1991). Also, environment equivocality, market heterogeneity, normative integration between units, and fungibility of unit capabilities encourages intraorganisational competition (Eisenhardt \& Galunic, 2000).

\section{Conclusion}

The organisations has evolved during the period of times and gone through with various structural and functional aspects of business development (Campbell, 1997). The intra-organisational competition in working environment is regarded as a dynamic process that affects employee's work behaviour, engagements and individual contribution (Baumann, Eggers \& Stieglitz, 2019). The studies have shown the organisations willing to learn and execute knowledge management successfully have technological competitive advantage over rivals. Organisations having different business units competing in the production for developing two product categories or two groups trying to solve the same problem 
is very common feature for developing competitive product capabilities leading one more step closer to intra-organisation competition having significant influence on organisational performance (Nadler \& Tushman, 1999). The strong sense of intra-organizational competition within work environment positively effect organizational performance.

\section{Bibliography}

Amin, A., Cohendet, P., 2004. Architecture of Knowledge. Firms, Capabilities and Communities, Oxford University Press, Oxford.

Argote, L., Ingram, P., 2000. Knowledge Transfer: A Basis for Competitive Advantage in Firms. Organizational Behaviour and Human Decision Processes, 82(1), 150-169.

Ayoup, H., Omar, N., Abdul Rahman, I. K., 2013. Implementation of balance scorecard (BSC) in a Malaysian GLC: perception of middle. AsiaPacific Management Accounting Journal, 7(2), 99-126.

Bartling, B., Fehr, E., Schmidt, K., 2010. Screening, Competition, and Job Design: Economic Origin of Good Jobs. American Economic Review, $102(2), 834-864$.

Baumann, O., Eggers, J. P., Stieglitz, N., 2019. Colleagues and Competitors: How Internal Social Comparison Shape Organizational Search and Adaptation. Administrative Science Quarterly, 64(2), 275-309.

Becker, T. E., Kernan, M., 2003. Matching Commitment to Supervisors and Organizations to In-Role and Extra-Role Performance. Human Performance, 16(4), 327-348.

Benndrof, V. R., Holger, A., 2012. Competition in Workplace: An Experimental Investigation. DICE, Discussion paper, No. 53, ISBN 978-386304-052-9, Dusseldorf.

Birkinshaw, J., Lingblad, M., 2005. Intrafirm Competition and Charter Evolution in the Multi-Business Firm. Organization Science, 16(6), 674686.

Birkinshaw, J., 2001. Strategies for Managing Internal Competition. California Management Review, 44(1), 21-38.

Blader, S., Gartenberg, C., Henderson, R., Prat, A., 2015. The Real Effects of Relational Contracts. American Economic Review Papers and Proceedings, 105, 452-456.

Brokman, B. K., Morgan, R. M., 2003. The Role of Existing Knowledge in New Product Innovativeness and Performance. Decision Sciences, 34(2), $385-419$.

Burgelman, A. R., 1991. Intra-Organizational Ecology of Strategy Making and Organizational Adaptation: Theory and Field Research. Organizational Science, 2(3), 239-262.

Cabrales, A., Charness, G., 2011. Optimal Contracts with Team Production and Hidden Information: An Experiment. Journal of Economic Behaviour \& Organisation, 77(2), 163-176.

Calantone, R. J., Cavusgil S. T., Zhao, Y., 2002. Learning Orientation: Firm Innovation Capability and Firms Performance. Industrial Marketing Management, 31(4), 515-524.

Cameron, K., 1986. A Study of Organizational Effectiveness and its Predictors. Management Science, 32(1), 87-112.

Campbell, D. T., 1997. From Evolutionary Epistemology via Selection Theory to a Sociology of Scientific Validity. Evolution Cognition, 3(1), 538.

Campbell, D. T., 1969. Variation and Selective Retention in Socio-Cultural Evolution. General Systems, 16, 69-85.

Campbell, D. T., 1965. Variation and Selective Retention in Socio-Cultural Evolution. In H. R. Barringer, C. I. Blanksten, R. W. Mack, eds. Social Change in Developing Areas: A Reinterpretation of Evolutionary Theory. Schenkman, Cambridge, MA.

Cangelosi, V. E., Dill, W. R., 1965. Organizational Learning Observations: Towards a Theory. Administrative Science Quarterly, 10(2), 175-203.

Caroll, B., Tomas, S., 1995. Team Competition Spurs Continuous Improvement at Motorola. National Productivity Review, 14(4), 1-9.

Chan, T. Y., Li, J., Pierce, L., 2014. Compensation and peer effects in competing sales teams. Management Science, 60(8), $1965-1984$.

Charness, G., Masclet, D., Villeval, M. C., 2013. The Dark Side of Competition for Status. Management Science, 60, 38-55.

Charness, G., Kuhn, P., 2007. Does pay inequality affect worker effort? Experimental evidence. Journal of Labour Economics, 25(4), 693-723. 
Chen, D. N., Liang, T. P., 2011. Knowledge Evolution Strategies and Organizational Performance: A Strategic Fit Analysis. Electronic Commerce Research and Application, 10(1), 75-84.

Choi, B., Lee, H., 2003. An Empirical Investigation of Knowledge Management Styles and their Effect on Corporate Performance. Information \& Management, 40(4), 403-417.

Chuang, S., 2004. Resource-Based Perspective on Knowledge Management Capability and Competitive Advantage: An Empirical Investigation. Expert Systems with Applications, 27(3), 459-465.

Cohn, A., Fehr, E., Hermann, B., Schneider, F., 2011. Social Comparison in the Workplace: Evidence from Field Experiment. IZA Discussion Paper, No. 5550, Institute for the Study of Labour, Bonn.

Cohen, S.G., Bailey, D.R., 1997. What Makes Teams Work: Group Effectiveness Research from Shop Floor to The Executive Suite. Journal of Management, 23(3), 239-290.

Combs, J. G., Crook, T. R., Shook, C. L., 2005. The Dimension of Organisational Performance and its Implications for Strategic Management Research. In D. J. Ketchen \& D. D. Bergh (Eds.). Research Methodology in Strategic and Management, pp. 259-286. San Diego: Elsevier Publication.

Connolly, T., Conlon, E. J., Deutsch, S. J., 1980. Organizational Effectiveness: A Multiple-Constituencies Approach. Academy of Management Review, 5(2), 211-217.

Cotora, L., 2007. Managing and Measuring the Intangibles to Tangibles Value Flows and Conversion Process: Romanian Space Agency Case Study. Measuring Business Excellence, 31(1), 84-101.

Decarolis, D. M., Deeds, D. L., 1999. The Impact of Stock and Flows of Organizational Knowledge on Firm Performance: An Empirical Investigation of the Biotechnology Industry. Strategic Management Journal, 20(7), 953-968.

Dorge, C., Claycomb, C., Germain, R., 2003. Does Knowledge Meditate the Effect of Context on Performance? Some Initial Evidence. Decision Sciences, 34(2), 541-568.

Eggers, J. P., Baumann, O., Stieglitz, N., 2013. Competition, Cooperation \& Search: Incentives and the Competition for Research Resources in Multidivisional Firms. No. 35, DRUID celebration conference, Barcelona, Spain.

Eisenhardt, K. M., Galunic, D. C., 2000. Coevolving: At Last, a Way to Make Synergies Work. Harvard Business Review, 78(1), 91-102.

Ellinger, A. D., Ellinger, A. E., Yang, B., Howton, S. W., 2002. The Relationship Between the Learning Organization Concept and Firm's Financial Performance. Human Resource Development Quarterly, 13(1), 5-21.

Fehr, E., Falk, A., 1999. Wage Rigidity in a Competitive Incomplete Contract Market. Journal of Political Economy, 107(1), $106-134$.

Gartenberg, C., Wulf, J., 2017. Pay Harmony? Social Comparison and Performance Compensation in Multi-Business Firm. Organization Science, 28(1), 39-55.

Garcia. S.M., Tor, A., Schiff. M.T., 2013. The Psychology of Competition: A Social Comparison Perspective, 8 Perspective on Psychology Science. Journal of Psychology Science, 8(6), 634-650.

Gachter, S., Thoni, C., 2010. Social Comparison \& Performance: Experimental Evidence on the Fair Wage Effort Hypothesis. Journal of Economic Behaviour \& Organization, 76(3), 531-543.

Grant, R. M., 1996. Prospering in Dynamically-Competitive Environments: Organizational Capability as Knowledge Integration. Organizational Science, 7(4), 375-387.

Haas, M. R., Hansen, M. T., 2005. When Using Knowledge Can Hurt Performance: the Value of Organizational Capabilities in a Management Consulting Company. Strategic Management Journal, 26(1), 1-24.

Hitt, M. A., 1988. The Measuring ofOorganizational Effectiveness: Multiple Domains and Constituencies. Management International Review, 28(2), 28-40.

Holsapple, C. W., Wu, J., 2011. An Elusive Antecedent of Superior Firm Performance: The Knowledge Management Factor. Decision Support System, 52(1), 271-283.

Joseph, J., Wilson, J. A., 2017. The Growth of the Firm: An Attention-Based View. Strategic Management Journal, $39(6), 1-22$.

Kacperczyk, A., Beckman, C. M., Moliterno, T., 2015. Disentangling Risk and Change: Internal and External Social Comparisons in the Mutual Fund Industry. Administrative Science Quarterly, 60(2), 228-262. 
Kanter, R. M., Kao, J. J., Wiserman, F. D., 1997. Innovation: Breakthrough ideas at 3M, Dupont, GE, Pfizer and Rubbermaid. New York: Harper Business.

Kaplan, R. S., Norton, D. P., 1992. The Balance Scorecard: Measures that Drive Performance. Harvard Business Review, 70(1), 71-79.

Lebas, M., Euske, K., 2007. A Conceptual and Operational Delineation of Performance. Business Performance Measurement: Theory, pp. 65-79.

Levinthal, D. A., March, J. G., 1981. A Model of Adaptive Organizational Search. Journal of Economic Behaviour and Organization, $2,307-333$.

March, J. G., Simon, H.A., 1958. Organizations. New York: Wiley, US.

Marino, A., Zabojnik, J., 2004. Internal Competition for Corporate Resources and Incentives in Teams. RAND Journal of Economics, 35(4), 710727.

Mena, C., Humphries, A. S., Wilding, R., 2009. A Comparison of Inter and Intra-Organizational Relationship: The Two Case Studies from UK Food and Drink Industry. International journal of Physical Distribution and Logistics Management, 39(9), 762-784.

Nadler, D. A., Tushman, M.L., 1999. The Organization of the Future: Strategic Imperative Core Competencies for $21^{\text {st }}$ Century. Organization Dynamics, 47, 45-60.

Neely, A., 2002. Business Performance Measurement: Theory and Practices. Cambridge University press, Cambridge.

Neely, A. Adams, C., Kennerley, M., 2002. The performance prism: The scorecard for measuring and managing business, Financial Times-Prentice Hall, London, UK.

Nickerson, J. A., Zenger, T. R., 2008. Envy, comparison costs, and the economic theory of the firm. Strategic Management Journal, 29,1429-1449.

Peters, T. J., Waterman, R. H., 1988, In search of excellence: Lessons from America's best-run companies. New York: Warner Books.

Slater, S. F., Narver, J. C., 1995. Market orientation and the learning organisation. Journal of Marketing, 59(7), 63-74.

Songcui. H., Zi-lin. H., Blettner, D. P., Bettis, R. A., 2017. Conflict inside and outside: Social comparison and attention shifts in multidivisional firms. Strategic Management Journal, 38(7), 1435-1454.

Soo, C. W., Devinney, T. M., Midgley, D. F., 2004. The role of knowledge quality in firm's performance, In Tsoukas, H. and Mylonopoulus, N. (Eds.). Organizations as knowledge systems. Knowledge, Learning, and Dynamic capabilities, Palgrave Macmillan, Basingstoke. UK.

Spender, J. C., 1996. Making knowledge the basis of a dynamic theory of the firm. Strategic Management Journal, 17, 45-62.

Stata, R., 1989. Organisational learning: The key to management innovation, Sloan Management Review, 63-74.

Stewart, T. A., 1997 Intellectual Capital. The new wealth of organisations. Currency Doubleday, New York, US.

Tseng, S. M., Lee, P. S., 2014. The effect of Knowledge management capability and dynamic on organisational performance. Journal of enterprise information management, 27(2), 158-179.

Venkatraman, N., Ramanujam, V., 1986. Measurement of business performance in strategy research: A comparison of approaches. Academy of Management Review, 1(4), 801-814.

Weeks, R. J., Glaunic, C. D., 2017. Intraorganizational ecology. In Baum, ed. A companion to organization. Blackwell publication, Oxford, England.

Weeks, J., Galunic, C., 2003. A evolutionary theory of the cultural evolution of the firm: The intra-organizational ecology of memes. Organizational studies, 24(8), 1309-1352.

Williamson, O. E., 1975. Market and Hierarchies: Analysis \& Anti-trust Implications. The Free Press, New York, US.

Zainal, A. M., Abdullah, H. H., Othman, R., Uli, J., 2009. Make or buy strategy and origin of sourcing material and their relationship with firms performance. International Review of Business Research paper, 5(3), 142-155.

Zammuto, R. F., 1984. A comparison of multiple constituency models of organizational effectiveness. Academy of Management Review, 9(4), 606616. 


\section{PRACTICALLY APPLICABLE METHODOLOGY FOR ASSESSING COMPLETENESS OF IT GOVERNANCE IN THE PUBLIC SECTOR \\ Edgars Cirulis}

Abstract. The realization of innovations is not only the ability of the private sector, but also the willingness of the public sector to do it effectively. Since ICT is the one of a major added-value innovation sector, IT governance in the public sector is also important. IT governance is a complex process, and it is therefore essential to identify the possibilities of ensuring its assessment as easily as possible. Because identifying the current situation is the starting point for development, this paper defines a simple-use methodology for assessing completeness of IT governance in the public sector. The methodology has been developed based on an analysis of the definitions of IT governance, identifying the most important characteristics of IT governance in the public sector for which the most important features have been identified. These features are used for a qualitative evaluation of IT governance. Based on the defined methodology, an IT governance completeness assessment of the Latvian State Administration has been carried out. As a result of research, the methodology has been defined and practically applied for assessing completeness of IT governance of the Latvian State Administration, conclusions have been reached regarding the IT governance of the Latvian State Administration, as well as defined directions for further research.

Keywords: IT governance, Public sector.

JEL code: M15

\section{Introduction}

Innovation plays an important role in the private sector as it promotes the competitiveness of companies. The role of innovation in public administration is often undervalued. Innovation and creativity in the public sector are even more important in the financial and economic crisis. Interest in public sector innovation is linked to the expectation that innovation will help the public sector to improve its performance. There is an essential need for a new creative public sector. To arrive at innovation in the public sector, we must understand the need for a new mode of governance and the role of the public sector in the creative economy (Cankar \& Petrovsek, 2013). Given the active cooperation between the public and private sectors in terms of innovation, it is essential to promote the capacity of the public sector in delivering and ordering innovations.

The digital era is not only driving innovation in the enterprise sector, but it also seems to influence developments in the public sector as well. The governmental digitalization is one of the promising themes, with more prospects of being developed in the future (Reis \& Amorim \& Melao \& Matos, 2018). For digital transformation to be successful, it is important to ensure an efficient and comprehensive IT governance.

The public sector IT governance needs to be further developed in the context of new challenges. Given that public officials often focus on content and operational issues, a methodology should be established to easily identify the missing aspects of IT governance. The problem that has been observed is that a full analysis of IT governance requires considerable time, labour, and financial resources. Therefore, it is essential to find the way to analyse IT governance more easily and with less resources.

The aim of the research is to define an practically applicable methodology to assess the completeness of IT governance of public administrations, based on theoretical analysis. This assessment is from point of view whether it deals with basic characteristics that ensure possibility to realise IT governance. The maturity and quality of IT governance will not be assessed. This has been done with intent since the identification of the completeness of IT governance is the basis for its development. This research is not tended to compare the maturity of IT governance in various public administrations.

The added value of this research is to define the theory-based methodology which:

1) Allow to assess easily (with minimal resources) the completeness of IT governance in public sector (not only for particular country or governance level but for every public administration);

2) Can be used as the basis to develop methodologies, guidelines, and models for assessing the maturity and quality of IT governance in public sector.

The methodology allows to identify the main characteristics and must-have features for good IT governance in public administration to address fields that must be improved. This is easy to use tool to determine the top-priority activities for developing IT governance in particular public administration which are assessed. The main focus of this methodology is to assess whether all main characteristics and must-have features for good IT governance in public administration are present in IT governance of particular (assessed) public administration. The methodology doesn't determine the criteria for assessing the quality of realisation for concrete features. 
The definitions express the substance of IT governance in a concise and an accurate manner. For this reason, they have been taken as a basis for defining the essential characteristics of IT governance which are used for further studies in this paper. Based on the characteristics identified, their qualitative evaluation features are identified in this paper. These evaluation features are based on publications and practical experience in the field of IT governance.

To ensure the approval of this methodology, assessing completeness of the IT governance of the Latvian public sector is carried out in accordance with the specified characteristics of IT governance and its evaluation features. The public sector is understood as a set of direct public administrations in this paper, i.e. IT governance is not analyzed in the municipalities and in the derived public administrations. This is done based on an analysis of legislative and policy planning documents. In view of the analysis of the IT governance documents for the various programming periods, this allows assess the trends of the IT governance development over the last 7-8 years.

\section{Literature Review}

IT governance main characteristics

The concept of IT governance emerged in the late nineties as a subject matter for academic research (Campbell\& McDonald\&Sethibe, 2009). There are many definitions of IT governance in different sources. The summary of IT governance definitions from several sources (research papers, books, COBIT 5 framework for governing and managing enterprise IT) is given in Table 1.

Table 1

The summary of IT governance definitions

\begin{tabular}{|c|l|l|}
\hline No. & IT governance definition alternatives & Source \\
\hline 1. & $\begin{array}{l}\text { IT governance is the structure of relationships, processes and mechanisms used to } \\
\text { develop, direct and control IT strategy and resource allocation so as to achieve the } \\
\text { goals and objectives of an enterprise }\end{array}$ & $\begin{array}{l}\text { Campbell } \\
\text { McDonald } \\
\text { Setthibe, 2004 }\end{array}$ \\
\hline 2. & $\begin{array}{l}\text { IT Governance is the organisational capacity exercised by the Board, Executive } \\
\text { Management and IT management to control the formulation and implementation of } \\
\text { IT strategy and in this way ensure the fusion of business and IT }\end{array}$ & $\begin{array}{l}\text { Van Grembengen \& } \\
\text { DeHaes } \\
\text { Guldentops, 2004 }\end{array}$ \\
\hline 3. & $\begin{array}{l}\text { IT governance is the responsibility of the Board of Directors and Executive } \\
\text { Management. It is an integral part of enterprise governance and consists of the } \\
\text { leadership and organizational structures and processes that ensure that the } \\
\text { organization's IT sustains and extends the organization's strategy and objectives }\end{array}$ & $\begin{array}{l}\text { Van Grembengen \& } \\
\text { Guldentops, 2004 }\end{array}$ \\
\hline 4. & $\begin{array}{l}\text { Governance is a collection of management, planning and performance reporting and } \\
\text { review processes with associated decision rights, which establish controls and } \\
\text { performance metrics over key IT investments, delivery services and new or change } \\
\text { authorizations and compliance with regulations, laws and organizational policies. It } \\
\text { formalizes and clarifies oversight, accountability and decision rights }\end{array}$ & Selig, 2016 \\
\hline 5. & $\begin{array}{l}\text { Information technology governance, essentially defined as a set of decision-making } \\
\text { structures, processes, and relational mechanisms, is an organizational capability that } \\
\text { plays a significant role in value delivery from information technology (IT) } \\
\text { investments }\end{array}$ & $\begin{array}{l}\text { Tonelli \& de Souza } \\
\text { Zuppo \& Zambalde, } \\
\text { 2015 }\end{array}$ \\
\hline 6. & $\begin{array}{l}\text { Governance ensures that stakeholder needs, conditions and options are evaluated to } \\
\text { determine balanced, agreed-on enterprise objectives to be achieved; setting direction } \\
\text { through prioritisation and decision making; and monitoring performance and } \\
\text { compliance against agreed-on direction and objectives }\end{array}$ & $\begin{array}{l}\text { ISACA, 2012 } \\
\text { IT governance: Specifying the decision rights and accountability framework to } \\
\text { encourage desirable behaviour in the use of IT }\end{array}$ \\
\hline 7. & Weill, 2004 \\
\hline
\end{tabular}

As it can be seen in all definitions, the central aim of IT governance is enterprise goals achieving (value delivery). In other words, the main role of IT governance is business and IT aligning. Alignment describes when "business and IT are working together to reach a common goal" and "everyone is rowing in the same direction" (Winkler, 2013).

Another common characteristic of IT governance is responsibility of senior executive management to develop, direct and control IT strategy. IT governance is ultimately the responsibility of senior executive management (Campbell \& McDonald \& Setthibe, 2004). The senior executive management must implement the comprehensive IT management system in the framework of concrete business goals and objectives.

From the definitions in Table 1, it can be defined some key aspects for implementing and directing IT governance:

- decision making structures;

- processes; 
- relational mechanisms;

- performance monitoring (reporting).

Also, in other researches (Tonelli \& de Souza \& dos Santos \& Zuppo \& Zambalde, 2015; Van Grembengen \& DeHaes \&Guldentops, 2004) IT governance is composed of a set of practices grouped into three categories: decision-making structures, processes, and relational mechanisms. From authors point of view and IT governance definitions (Campbell \& McDonald \& Setthibe, 2004; Van Grembengen \& DeHaes \&Guldentops, 2004; ISACA, 2012; Selig, 2016), these categories must be measured and this is another one category of a set of practices.

It can be concluded that the IT governance must have three main characteristics:

- IT goals must align to the business goals;

- IT governance is responsibility of senior executive management;

- IT governance includes four main practices: decision making structures, processes, relational mechanisms and performance monitoring.

IT governance in public sector

In chapter 1 author has analysed IT governance definitions and has defined its main characteristics. It was maintained for IT governance in general. There are systemic differences between private and public sector organizations suggesting that a one size fits all approach to IT Governance may not apply (Campbell \& McDonald \& Setthibe, 2004). This chapter highlights public sector specific property for main characteristics of IT governance specified in previous chapter.

Public governance goals are broader than business goals in a classical private company. Creating public value can be thought of as more complex than 'simply' maximizing profit. Besides improving government operations, it requires to consider the broader political and social returns. Cascading such goals down in the organizations, suggests that also the goals of IT governance are more multifaceted and more difficult to measure than in private sector (Winkler, 2013). Public governance goals depend on political changes. In contrast, business goals in private sector depend on behaviour of the market. These circumstances make the public sector less affected by cyclical movements in the economy but clearly more susceptible to political changes. There is also the issue of political influence and periodic structural change within the public sector which can destabilize governance mechanisms. Political cycles can cause periodic disruption in top-level management. Program priorities in the departments can change significantly with each new administration (Campbell \& McDonald \& Setthibe, 2004). Public sector IT governance address some issues which are public sector specific. For example, public IT governance needs to deal with diverse stakeholders, e.g. political and administrative groups and target at aligning these to a greater extent than in private sector (Winkler, 2013).

Responsibility of senior executive management is differently expressed compared to private company. There are, classically, Board of directors and senior executive management which, to a large extent, realise IT governance. Public sector has legislative authority and execution authority. These authorities approve laws and regulations which determine framework for public sector governance and for IT governance as a part of public sector governance. Every institution has its executive manager, and, for the authors sake, executive manager is one of the stakeholders for IT governance. Having regard that the executive manager is responsible for compliance with regulatory enactments and responsibility for achieving public administration objectives, for the authors sake, executive manager is important stakeholder for IT governance. However, in contrast with private company, his or her ability to act is strictly limited by politicians (legislative authority and execution authority). The most important difference between the public sector and private sector is that stakeholders are not strictly limited. Must be assumed that society (its needs and demands) drives public IT governance. While politicians and senior executive management are primary responsible for the objectives and its achievement, as well as, the regulatory enactments define the basic principles of IT governance, society is a key stakeholder.

IT governance main practices are varied across the public un private sectors. Generally, public policy processes can make investments and decision-making difficult for public sector IT managers and reduce implementation success (Campbell \& McDonald \& Setthibe, 2004). As an example, public procurement imposes certain restrictions on the realisation of IT governance. Relational mechanisms take different forms in the public and private sector. On the one hand, relations are more formal and more difficult to implement (particularly between different institutions and levels of power). On other hand, public sector political leaders, department heads and IT heads as well as departmental and IT employees can create a culture of collaboration and foster horizontal knowledge sharing which are e.g. problem awareness and a common language (Winkler, 2013). This is almost impossible in the private sector due to mutual competition. IT governance performance monitoring also has some variety of features but there is a lot in common. Aligning public IT spending with strategic priorities appears even more important for public sector and it must be monitored regularly. Post-implementation, the IT governance literature emphasizes the role of certain metrics and monitoring mechanisms 
(Winkler 2013). IT governance performance monitoring is important for both the public and private sectors, but there are different objective, stakeholders, form, and reporting regularity. For example, the public sector has multi-level and hierarchical monitored objectives (society, legislative, executive, institutional), while the private sector classically has two-level monitored objectives: for Board of directors and for senior executive management.

\section{Research results and discussion}

Good IT governance principles in public sector

As a part of this research, a simple and qualitative methodology will be developed to allow for assessing completeness of public sector's IT governance. This methodology will be used to assess whether the basic principles of IT governance are being implemented. The basic principles of IT governance are expressed through characteristics and their features. This methodology can be used to assess both: IT governance of the entire public sector in the country and IT governance of each given public authority. The main characteristics of IT governance described in the previous chapters will be used as a basis for this methodology. The author will offer qualitative features and criteria for every characteristic that will be used for evaluating the completeness of IT governance in public administration.

Table 2

IT governance completeness evaluation methodology for public sector - summary

\begin{tabular}{|l|l|l|}
\hline $\begin{array}{l}\text { IT } \\
\text { characteristic }\end{array}$ & Evaluation features & Criteria \\
\hline Business and IT alignment & $\begin{array}{l}\text { Interdependence between public } \\
\text { administration and IT governance } \\
\text { objectives } \\
\text { Change management for providing business } \\
\text { and IT alignment }\end{array}$ & $\begin{array}{l}\text { Every IT governance objective is } \\
\text { correlated to one or several public } \\
\text { administration objectives }\end{array}$ \\
\hline Stakeholders & $\begin{array}{l}\text { Focus on society as a key stakeholder } \\
\text { Cooperation with legislative, executive, } \\
\text { institutional stakeholders }\end{array}$ & $\begin{array}{l}\text { Exists solution to ensure cooperation } \\
\text { with society, as well as decision-making } \\
\text { authority, executive and authority } \\
\text { management as public ambassadors in } \\
\text { public administration }\end{array}$ \\
\hline $\begin{array}{l}\text { Decision making } \\
\text { structures }\end{array}$ & Basis for decision making & $\begin{array}{l}\text { Exists decision-making procedures and } \\
\text { definition of responsibilities for } \\
\text { different level of the decisions }\end{array}$ \\
\hline Processes & $\begin{array}{l}\text { Practices or standard for process framework } \\
\text { processes is managed on a unified basis }\end{array}$ \\
\hline Relational mechanisms & $\begin{array}{l}\text { Clear responsibilities for institutions and } \\
\text { officials, collaboration }\end{array}$ & $\begin{array}{l}\text { The existence of a mechanism for } \\
\text { cooperation }\end{array}$ \\
\hline Performance monitoring & $\begin{array}{l}\text { Measures for public sector and IT } \\
\text { governance performance }\end{array}$ & $\begin{array}{l}\text { The performance measurement structure } \\
\text { is in place }\end{array}$ \\
\hline
\end{tabular}

It is very important to identify the correlation of public administration and IT objectives. This is the basis for IT governance, and it is therefore very important to focus on the mechanism that provides it. This aspect must be assessed from two points of view:

1) Ensuring the correlation between public administration objectives and IT governance objectives at the initial stage;

2) Ensuring the continued assurance of the commitment of objectives, i.e. ensuring that IT governance is continuously perforated in line with public administration needs.

The assessment of these aspects gives a complete picture of how the continuous correlation between public administration objectives and IT governance is ensured. The main criteria for assessing this feature are presence of correlation between IT governance objectives and public administration objectives, i.e., every IT governance objective must be correlated to one or several public administration objectives.

As mentioned above, society is the key stakeholder of IT governance for public sector in general and in each public institution particularly. This is a main distinction between the public and the private sector. Cooperation with other IT governance stakeholders (legislative, executive, and institutional) is not less important. For this reason, it is essential to assess whether a solution exists to ensure cooperation with society, as well as decision-making authority, executive and authority management as public ambassadors in public administration.

Decision-making can appear to be more methodical and compliance oriented in the public sector (Campbell \& McDonald \& Setthibe, 2004). From this point of view, it is necessary to assess whether the IT governance sets out the decision-making procedures and responsibilities. It is not less important to define what decisions can be taken at what level, since, for example, part of decisions can only be taken by stakeholders, part - by 
senior executive management, part - by IT managers, but operational decisions can be taken by public sector officials. For the decision-making body to operate, the above should be ensured and assessed within the framework of the IT governance evaluation.

In view of the relative uniformity of IT governance and management processes, regardless of the scope of the public sector body, should be ensured that processes are managed on a unified basis. Best practice or standard support (e.g. ITIL or ISO20000) may be used for this purpose or IT governance may develop its own framework for IT processes. Practice shows that the public sector is based on industry-popular frameworks or standards. IT governance assessments should assess compliance with a unified process management, which is an essential factor for the realisation of IT governance.

Relational mechanisms involve the organization's capability to provide active participation of and collaborative relationships among the board, IT management, and line managers (Tonelli \& de Souza \& dos Santos \& Zuppo \& Zambalde, 2015). IT governance can only be successful if the parties involved are able to cooperate. This is particularly true in the public sector, where the number of stakeholders involved in IT governance is higher than in the private sector. For this reason, the existence of a mechanism for cooperation should be assessed by analyzing the comprehensiveness of IT governance.

The measurement of any area of governance is the basis for its development since it allows for the tracking of development and is the relatively objective assessment of maturity and the necessary improvements. IT governance is not an exception to this. It is important to realize that two aspects need to be measured:

1) How IT management is implemented for public administration purposes, i.e. measuring the impact of IT governance on performance of public administration;

2) How IT management develops, i.e. its effectiveness should be measured as such.

The evaluation of the performance measurement structure is an essential element in assessing the overall nature of the IT governance. IT governance- regulatory enactments and policy planning documents in Latvia

In the long term, IT governance and management were not regulated at a sufficient level in the Latvian State Administration. The National Information Systems Act, adopted in 2002, is still in force. Even though the law is out of date since the digital environment and technologies have changed significantly since the beginning of the 2000's, this law does not provide an overall framework for IT governance and management within the Latvian public sector. The purpose of the Law is to ensure the availability and quality of the information to be provided by State and local government authorities in the State information systems (Saeima, 2002). As can be seen, the law does not apply to all IT sector, but only to part of it - to State information systems. The Law shall not apply to information systems which State and local government institutions create and maintain for the circulation of internal user information. National information system: a structured set of information technologies and databases, using which it ensures the initiation, creation, collection, storage, processing, use and destruction of information necessary for the performance of national functions (Saeima, 2002). This Law does not cover all information systems used in public administration, as well as other technologies such as other information systems (which do not directly support public functions), hardware, standard software, etc.

In recent years, active efforts have been made to secure the legislative framework. This has resulted in a new draft law covering the entire subject-matter of information and communication technologies. It was originally directed as an ICT governance law, but it has now transformed into an E-Governance law. The draft law is currently under consideration in the Parliament. The aim of the law is to create and maintain a common ICT management system throughout the public administration (Saeima, 2019). The law applies to State administration. The scope of the draft law includes information resources and technological resources to be used in public administration (in general, ICT resources), including platforms. The draft law also governs the provision of IT services, the provision of sharing services and other aspects that are commonplace in the current public sector IT governance.

Even though the general principles of IT governance have not been established at the level of the law so far, in 2010's there has been a significant development of public-sector IT governance and IT management. In 2013, a concept defining the organisational model for IT governance and IT management has been developed and approved. The concept "Organising Model for National Information and Communication Technology Management" is a document setting out the objective of ICT governance as well as the To-Do list (Cabinet of the Ministers, Order Nr. 57, 2013). This policy planning document offers a conceptual solution for organizing national ICT governance, identifies the necessary action to implement this solution, as well as the To-Do list for further improving public ICT governance (Cabinet of the Ministers, 2015). 
An information report on further consolidation of national information and communication technology resources and competences has been prepared and conducted in 2020. The information report is designed to inform the Cabinet of Ministers about the draft reforms prepared in the field of national information and communication technology governance and IT management. The reform will be implemented to improve the efficiency and quality of public sector ICT governance. This will be achieved by removing barriers to the efficient sharing of ICT resources held by the public administration and by promoting the development of specialized centres of competences providing ICT services for sharing (VARAM, 2020a). This information report provides for further progress in the development of the IT governance of public administration by defining integrated activities within all public administrations.

Key elements for providing IT governance are policy planning documents defining the strategic orientations for the long-term period: “Information Society Development Guidelines 2014-2020" (Cabinet Of Ministers, Nr.468, 2013) and "Digital Transformation Guidelines for 20212027" (in development phase) (VARAM, 2020b). The objectives of these policy planning documents are as follows:

1) enabling everyone to take advantage of the opportunities provided by information and communication technologies, building a knowledgebased economy and improving the overall quality of life by contributing to improving the efficiency of public administration and the competitiveness of the country, economic growth and job creation (Cabinet Of Ministers, Nr.468, 2013);

2) establishing a single digital development policy for public administration, the economy and society (VARAM, 2020b).

These documents come from the National Development Plans (Saeima, 2013; Saeima, 2020) which are the highest national planning documents in the country and have been approved by the Saeima. The National Development Plans define the medium-term objectives of the country and public sector.

Based on the regulatory enactments and policy planning documents referred to in this chapter, Latvian public sector IT governance will be analysed in the next chapter.

Assessment of Public sector IT governance in Latvia

As part of this chapter, the Latvian public-sector IT governance will be measured according to the above-mentioned IT governance characteristics: Business and IT alignment, Stakeholders, Decision making, Processes, Relational mechanisms, Performance monitoring. These characteristics will be evaluated according to evaluation features defined in Table 2 . The analysis will be based on a comparison of the two planning periods of the strategy, i.e. by highlighting the trends of the last 7-8 years in the field of IT governance in the Latvian public sector.

The analysis of the laws shows that they do not include a direct link between national policy objectives and the objectives of the IT governance. Both the National Information Systems Law and the E-Governance Law define, respectively, the State Information System Management and eGovernment Participants, Bodies, Liability Levels, etc., but it is not defined how this management contributes to the achievement of the objectives of the State administration. Consequently, the law does not define the interaction between public administration objectives and the objectives of IT governance. Linking public administration objectives and public sector IT governance objectives is based on two policy planning documents: “Information Society Development Guidelines 2014-2020" (Cabinet Of Ministers, Nr.468, 2013) and "Digital Transformation Guidelines for 20212027" (VARAM, 2020b). These documents define matters of substance that can be done in seven years. Both documents relate to policy planning documents which define the organizational structure of the IT governance, as well as to the National Development Plans of the respective periods Although the policy planning documents did not identify a direct correlation between public administration objectives and IT governance (including the maintenance of the correlation between these objectives), the documents define developments on which to base the management of the ICT sector of public administration.

The laws under consideration do not directly define the IT governance responsibility in front of the society, which is the main stakeholders. Cooperation with the other stakeholders (responsibility to them) is not well defined as well. The policy planning documents follow the role of the public as the main stakeholder (based on the National Development Plans); however, the documents "Information Society Development Guidelines 2014-2020” (Cabinet Of Ministers, Nr.468, 2013), “Digital Transformation Guidelines for 2021-2027” (VARAM, 2020b), “Organising Model for National Information and Communication Technology Management" (Cabinet Of Ministers, Nr.57, 2013) and "The consolidation of resources and competences of state information and communication technologies" (VARAM, 2020a) primary focus is on defining IT governance, not on how to address the needs of stakeholders with ICT resources. This stems from the objectives defined in the National Development Plans and in the IT governance Policy Planning documents. 
In the framework of the National Information Systems Law, decision-making shall be delegated to the authorities involved in the management of information systems. E-Government Law delegates decision-making to the Cabinet of Ministers and institutions on a number of key issues, such as the identification of key challenges for ICT management, ICT policy making, ICT architecture building, procedures for requesting funding, etc. A fundamental difference between the two laws is that, from a nearly completely decentralized IT governance decision-making model, the National Information Systems Act has made the transition to a partly centralized decision-making model in the E-Government Act, which defines a number of scale for ICT management: national scale, industry scale, institution scale, the scale of the service and the scale of the ICT resource. IT governance policy planning documents "Organising Model for National Information and Communication Technology Management” (Cabinet 0f Ministers, Nr.57, 2013) and "Consolidation of National Information and Communication Technology Resources and Competencies" (VARAM, 2020a) define the decision-making principles as well as the implementation of this decision-making mechanism (in particular the Organising Model for National Information and Communication Technology Management).

The legislation discussed does not define the framework for ICT management processes. Instead, the information systems management process is defined in the National Information Systems Law, as well as the compliance of IT governance with the principles of good practice in the EGovernance Law. These principles are general (value orientation, succession, step-by-step, etc.). Policy planning documents address standardization of IT governance and IT management processes, but only the Digital Transformation Guidelines for 2021-2027 document (VARAM, 2020b) defines the need to standardize IT management processes in ICT competence centers according to the ISO20000 standard. No overall practical direction was identified for implementing generic ICT management processes for more effective public sector IT governance.

The National Information Systems law clearly defines the functions and cooperation principles of the authorities involved in information systems management. The e-Government Law addresses this issue in an even wider context and defines the responsibilities and rights of the authorities involved in ICT governance and management. Therefore, these aspects are already identified at the level of the law in sufficient detail. Policy planning documents detail the principles laid down by law. The "Organising Model for National Information and Communication Technology Management" (Cabinet Of Ministers, Nr.57, 2013) and "Consolidation of National Information and Communication Technology Resources and Competencies" (VARAM, 2020a) are oriented on defining the responsibilities and rights of the authorities involved in IT governance. Of all the characteristics of IT governance, this is best developed and is the most mature.

Neither the National Information Systems Law nor the E-Governance Law set out the principles for measuring the performance of IT governance and the impact of IT governance on the achievement of public administration objectives. The E-Governance Law establishes the responsibility of all the authorities concerned for ICT efficiency. Only the documents "Information Society Development Guidelines 2014-2020" (Cabinet 0f Ministers, Nr.468, 2013) and “Organising Model for National Information and Communication Technology Management” (Cabinet 0f Ministers, Nr.57, 2013) define the results to be achieved in an aggregated form. However, they are identifiable as the objectives of the IT governance. The correlation of these targets with national targets has not been identified. The other policy planning documents discussed did not identify such objectives at all. While there are other sources of performance indicators, such as national budget documents or EU structural fund project documents, there is a clear lack of measurable indicators to assess objectively the level and trends of the IT governance and its impact on national development.

\section{Conclusions}

1. IT governance in public sector differs from IT governance in private sector which states that the methodologies for evaluating IT governance completeness differ between these sectors.

2. The IT governance completeness evaluation methodology for public sector is defined based on theoretical approach by analyzing of IT governance and public sector administration.

3. There are 6 main characteristics which allow to access the completeness of IT governance of public administration: Business and IT alignment, Stakeholders, Decision making structures, Processes, Relational mechanisms, Performance monitoring.

4. Every characteristic has features and evaluation criteria which allows to assess IT governance completeness in particular public administration.

5. As part of this document, it has been done for the IT governance of public administration of Latvia.

6. In Latvian public administration documents:

- not direct correlation between public administration targets and IT governance targets, i.e. not an exact hierarchy of targets;

- not exact definition of the responsibility in front of stakeholders; 
- a decision-making mechanism is in place;

- not clearly defined the transition to standardized ICT management processes is defined;

- clear responsibilities for institutions and collaboration is in place;

- there is a poorly realized mechanism for measuring public-sector IT governance and its impact on national development.

7. The methodology can be used for assessing completeness of IT governance in the public sector.

\section{Further research}

1. The methodology needs to be developed and further standardized to ensure straightforward evaluation of IT governance completeness, for example by defining concrete (quantitative) criteria for assessing features etc

2. It is possible to extend the methodology to the next steps and to use not only for the general assessment (completeness assessment) of IT governance, but also for the degree and quality of the key features, i.e. to assess IT governance maturity.

\section{Bibliography}

Campbell, J., McDonald, C., Sethibe, T., 2009. Public and priveta sector IT governance: identifying contextual differences. Australaian Journal of Information Systems, 16, 5-18.

Cankar, S.S., Petrovsek, V., 2013. Private And Public Sector Innovation And The Importance Of Cross-Sector Collaboration. The Journal of Applied Business Research, 29(6), 1597-1606.

Hoch, D., Payan, M., 2008. Establishing good IT governance in the public sector. Transforming government, March 2008, p. 45-55.

ISACA, 2012. COBIT 5: A Business Framework for The Governance and Management of Enterprise IT. Rolling Meadows, IL: Information Systems Audit and Control Association.

Ministru Kabinets (Cabinet of Ministers of Republic of Latvia), 2013. Par koncepciju "Valsts informācijas un komunikācijas tehnologiju pārvaldības organizatoriskais modelis" (Conception "Organising Model for National Information and Communication Technology Management"), Order Nr. 57, accepted 19.02.2013.

Ministru Kabinets (Cabinet of Ministers of Republic of Latvia), 2013. Par Informācijas sabiedrības attīstības pamatnostādnēm 2014.-2020.gadam (About the Information Society Development Guidelines 2014-2020), Order Nr. 468, accepted 13.10.2013.

Ministru Kabinets (Cabinet of Ministers of Republic of Latvia). (2015). Par koncepcijas "Valsts informācijas un komunikācijas tehnologiju pārvaldības organizatoriskais modelis" isstenošanas gaitu līdz 2015.gada 15.jūnijam" (Conception "Organising Model for National Information and Communication Technology Management” implementation by 15 June 2015), Order Nr. 649, accepted 21.10.2015.

Nfuka, E.N., Rusu, L., 2009. Critical success factors for efective IT governance in the Public sector organisations in a Developing country: the case of Tanzania. Proceedings of the 42nd Hawaii International Conference on System Sciences - 2009.

Reis, J., Amorim, M., Melao, N., Matos, P., 2018. Digital Transformation: A Literature Review and Guidelines for Future Research. [Online] Available https://www.researchgate.net/publication/323994364 Digital Transformation A Literature Review and Guidelines for Future Research [Acessed 11.11.2020]

Saeima (Parliament of Republic of Latvia), 2002. Valsts informācijas sistēmu likums (State information systems Law), accepted 02.05.2002.

Saeima (Parliament of Republic of Latvia), 2012. Latvijas nacionālais attīstības plans 2014.-2020.gadam (National Development Plan of Latvia 2014-2020), accepted 20.12.2012.

Saeima (Parliament of Republic of Latvia), 2020. Latvijas nacionālais attīstības plans 2021.-2027.gadam (National Development Plan of Latvia 2021-2027), accepted 02.07.2020.

Saeima (Parliament of Republic of Latvia), 2019. E-pārvaldības likums, projekts (E-governance Law, draft).

Selig, G.J. 2016. IT Governance-An Integrated Framework and Roadmap: How to Plan, Deploy and Sustain for Improved Effectiveness. Journal of International Technology and Information Management, 25, 54-76.

Tonelli, A.O., de Souza Bermejo, P.H., dos Santos, P.A., Zuppo, L., Zambalde. A.L., 2015. IT governance in the public sector: a conceptual model. [Online] Available at: https://www.researchgate.net/publication/284914531_It_governance_in_the_public_sector_a_conceptual_model [Acessed 11.11.2020]. 
Van Grembergen, W., De Haes, S., Guldentops, E., 2004. Structures, processes and relational mechanisms for information technology governance: Theories and practices. in Strategies for information technology governance, W. Van Grembergen (ed), Idea Group Publishing. Hershey (PA). p. $1-36$.

VARAM (Ministry of Environmental Protection and Regional Development of Republic of Latvia), 2020a. Informatīvais ziņojums „Par valsts informācijas un komunikācijas tehnologiju resursu un kompetenču konsolidāciju”, projekts (Information report "The consolidation of resources and competences of state information and communication technologies", draft).

VARAM (Ministry of Environmental Protection and Regional Development of Republic of Latvia), 2020b. Digitālās transformācijas pamatnostādnēm 2021.-2027.gadam, projekts (Digital Transformation Guidelines 2021-2027, draft).

Weill, P., Ross, J., 2004. IT Governance: How Top Performers Manage IT Decision Rights for Superior Results. Boston, MA:Harvard Business Review Press.

Winkler, T.J., 2009. IT Governance Mechanisms and Administration/IT Alignment in the Public Sector: A Conceptual Model and Case Validation, Wirthschaftsinformatik Proceedings 2013, p. 831-845. 


\title{
GROCERY RETAIL MARKET CONCENTRATION CONVERGENCE IN EASTERN EUROPEAN AND BALTIC EU MEMBER STATES IN 2010-2019 \\ Martins Danusevics, University of Latvia
}

\begin{abstract}
The paper analyses market concentration development in the Chech Republic, Estonia, Hungary, Latvia, Lithuania, Poland, Slovakia and Slovenia. It is determined that these countries have a converging market concentration tendency indicating a decrease in the competition level and becoming more homogeneous. At the same time there are strong indications for market concentration being linked also to retail turnover.
\end{abstract}

Keywords: retail, competition, market concentration.

JEL code: L11, L81

\section{Introduction}

This paper looks into potential convergence of market concentration. The territory of research encompasses the eastern European and Baltic countries that joined the EU in 2004. The period of research starts in 2010 to coincide with the period after the 2008 financial recession to avoid usage of data from economically volatile periods. The latest data stems from 2019. One of the main questions is weather the grocery retail markets have become more concentrated due to increasing power of leading retail chains and if this process is converging among countries due to effects of the single EU market. Tools of analysis will be Herfindahl-Hirschman Index, variance statistics, models of main tendency and correlation analysis.

\section{Literature Review}

Development of the retail sector has been analysed in different contexts during past ten years. Authors in different countries have observed the development of this industry as well as the influence on other characteristics of retail. In some cases the analysis has been purely descriptive and showed an increase in market concentration in the Russian retail sector (Sigarev, 2018), an increase in most Central European countries in 20102015 with the exception of Hungary (Špička, 2016) and the same tendency in Croatia (Kovac, 2020). Also, in Slovakia similar trends have been observed in a research looking into concentration from the point-of-view of supply chains (Kita, 2019) and concluding that this concentration growth can be linked to radical changes in distribution channels. There seems to be a quite typical development in many European countries for larger retailers to increase their dominating role in the retail sector. Concentration analysis has been topical also in other regions. An extensive research has been done in Australia (Hambur, 2019) spurred by the fast growth of price comparison technologies and emergence of highly integrated global supply chains. The results indicated a certain market concentration increase in last two decades with a slight decrease during the last few years before the research was done.

From a broader point of view, several factors have been attributed as the influencing force for increasing market concentration. In a research done in the United States of America investment in intangible capital has been argued to influence the concentration in industry (Crouzet, 2019), although the effects have been not the same in all industries.

Further research on this topic outside of current methodology in the region analysed could include analysis not only of the whole retail industry, but also segments within the industry. This notion is based on similar analysis done in Saint-Petersburg, Russia (Dengov, 2016) where the authors concluded that emergence of multiformat chains had changed the competition landscape. The segmentation of the industry had led to a situation, where concentration can be analysed within a segment of the retail industry, thus creating a more detailed overview of the market development. Another potential direction of analysis is a combination of prisoners' dilemma game model with concentration (Ezeala-Harrison, 2016) where USA market analysis indicates a higher concentration leading to increased pricing and possible collusion between the competitors.

If market concentration is increased, certain negative results can be observed. It has been suggested to be an enhancer of bargaining power imbalances (Rebolledo, 2020) that is a certainly an unwelcome trait in a free market system. Another negative effect discussed in literature is the impact on end-consumers. A merger of two German retail companies has led to an increase of average prices (Rickert, 2018) and no significant increase in regions that did not experience rise of concentration.

\section{Research results and discussion}

The chosen territory includes countries that joined the EU in 2004. This enlargement included eastern European and Baltic countries - the Czech Republic, Estonia, Hungary, Latvia, Lithuania, Poland, Slovakia, Slovenia. The author chose to analyse this group of countries due to several reasons. These countries have a common historical background, all of them have been part of the communist bloc in the $20^{\text {th }}$ century, all these countries have a geographic proximity, they joined the EU during the same year. As a result, the author believes that these countries have been in a 
similar development trend and that allows for a coherent analysis of processes in the retail market. Additionally, many of these countries share the same retail chains.

The main indicator for analysis is the distribution of market shares in these 8 countries of grocery retail stores. The data comprises the time period from 2010 to 2019 and includes a varied number of companies in each market. Different development has been observed in each country.

The Czech Republic had a relatively large number of retailers active with the number of retail grocery stories varying from 35 in 2010 down to 29 in 2019 . At the same time the market share of the market leader has increased from $18.6 \%$ to $26.7 \%$ in this time period. A close-by country, Hungary, had the opposite tendency in the number of retailers. From 2010, the number has increased from 21 up to 24 in 2019 . And moreover the leading retailer had a decrease in the market share. If at the peak in 2011 the top retailer controlled 17.3\%, it was down to $12.5 \%$ in 2019 . This makes Hungary a unique country with a decrease in the leader position and an increase in the number of stores. Poland is in a sense similar to the Czech Republic in the general tendencies of its retail market. The number of retailers has varied from 32 to 28 . But the leader position is significantly different from other neighbouring countries and was $11.2 \%$ in 2019 and increased to $20.9 \%$ in 2019 . This doubling of the leading position is a strong sign for a high change in market concentration, but it will be analysed in greater depth later in the paper. Slovakia has experienced moderate change in retailers' quantity but also a significant increase of the leading position. If the number of companies has changed only from 28 to 32 , the leader had an increase of approximately $50 \%$ from $19.2 \%$ in 2010 up to $30.3 \%$ in 2019 . Slovenia, on the other hand, had a very small increase of companies from 14 to 15 and an uncharacteristic decrease in leader market share from $33.3 \%$ to $28 \%$. It must be noted that the leader has been a different company in different time periods.

In the Baltic region, Estonia had an increase in number of grocery retail chains from 26 to 28 in the period from 2010 to 2019 and the market leader had a significant market share growth. In general, this is a very stable situation in the observed territories with no significant changes for almost a decade. Latvia, however, had a decrease of retailers from 31 to 26 in the period of 2010-2019 and the leader had a slight increase from $23.3 \%$ up to $27.5 \%$ in 2019 . The third Baltic country is Lithuania and, compared to others, it had a quite a moderate development in these numbers. The number of retailers has decreased from 34 to 32 and the leader had lost appr. 2 percent points by going down from $37.7 \%$ in 2010 to $35.4 \%$ in 2019.

The variance in market shares and number of companies cannot be used as a meaningful statistic to come to conclusions in regard of the level of competition in these countries. Thus, a market concentration indicator must be used. The basic approach would be to refer to the concentration ratio of $n$ leading retailers, but this ratio is not applicable in this case. One reason is the necessity for the analyst to choose the value $n$ for the number of top retailers to be included in the analysis. That leads to a certain level of subjectivity. Another reason is the simplicity of this indicator that can lead to incoherent conclusions in countries with several large retailers.

To compensate for these deficiencies, the author will rely on the Herfindahl-Hirschman Index for market concentration analysis. This index has a general advantage over concentration ratio in that it uses all the market shares of all companies without ignoring smaller members of the market. The HHI index is calculated as sum of squared market shares. The expected range is from 0 to 2500 points. A higher number indicates a higher market concentration.

An HHI value below 100 points indicates a highly competitive industry. There are a lot of small companies competing in the market. A value above $\quad 100$ points and still below 1500 points signifies an unconcentrated industry. Once the HHI reaches 1500 points and more, up to 2500 points, we can conclude that we have a moderate concentration level in the market. 1500 points is usually considered as a border between high and low concentration. If the HHI is above 2500 , then the market analysed has a high concentration.

Table 1

Development of Herfindahl-Hirschman Index in selected countries from 2010 till 2019

\begin{tabular}{|l|r|r|r|r|r|r|r|r|r|r|}
\hline Year & 2010 & 2011 & 2012 & 2013 & 2014 & 2015 & 2016 & 2017 & 2018 & 2019 \\
\hline The Czech Republic & 906 & 947 & 982 & 1030 & 1136 & 1183 & 1198 & 1224 & 1253 & 1285 \\
\hline Estonia & 1233 & 1247 & 1244 & 1260 & 1274 & 1290 & 1290 & 1300 & 1318 & 1282 \\
\hline Hungary & 775 & 789 & 803 & 771 & 800 & 797 & 805 & 789 & 791 & 803 \\
\hline Latvia & 1283 & 1294 & 1329 & 1323 & 1356 & 1391 & 1428 & 1502 & 1573 & 1595 \\
\hline Lithuania & 1875 & 1855 & 1818 & 1848 & 1842 & 1930 & 1761 & 1656 & 1661 & 1700 \\
\hline Poland & 322 & 422 & 472 & 543 & 637 & 679 & 734 & 799 & 843 & 875 \\
\hline Slovakia & 1173 & 1211 & 1233 & 1326 & 1381 & 1447 & 1492 & 1526 & 1557 & 1627 \\
\hline Slovenia & 1634 & 1588 & 1546 & 1510 & 1445 & 1411 & 1402 & 1386 & 1391 & 1397 \\
\hline
\end{tabular}


Source: author's calculations based on Euromonitor

The countries under analysis show a large variety of development trends for the analysed market concentration. If we consider the initial period of the research in 2010 and a few following years, there is a considerable variety among the countries. Poland has a low value of 322 compared to Lithuania with a very high level of 1875 . So, there is reason to believe that there was a very different starting point in these countries. On the other hand, in 2019 the situation has become much more stable. Poland has been surpassed by Hungary as the country with the lowest HHI value with 803 points. And the leading country is still Lithuania, but now the concentration by HHI has decreased to 1700 points. Overall, there are different tendencies. For the sake of ease of comparison, Eastern European countries have been analysed separately from the Baltic countries.

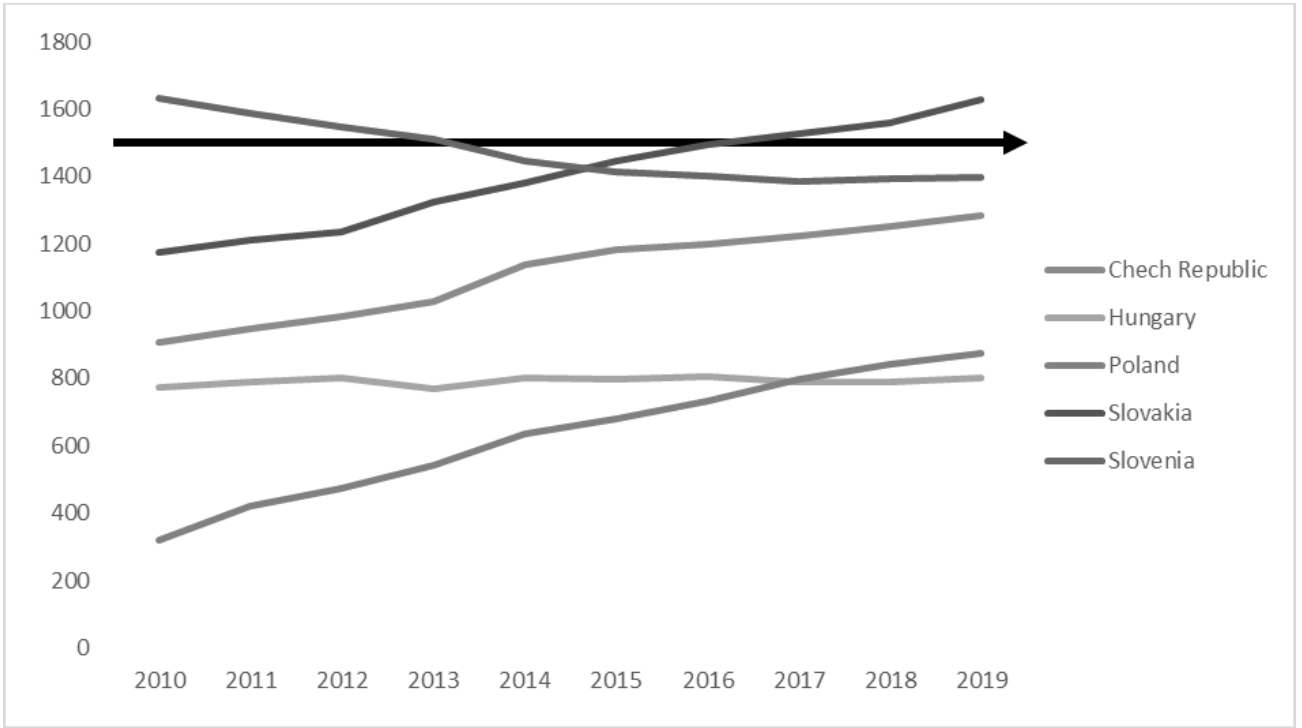

Source: author's construction based on Euromonitor

Fig. 1. Dynamics of market concentration in selected Eastern European countries from 2010 till 2019

In the region of Eastern Europe the highest growth has been observed for Poland. On average the HHI score has been increasing by $11.8 \%$ per year and the total growth rate was $172 \%$. No other country has demonstrated such a significant change in the market situation. Poland is followed by the Czech Republic and Slovakia with similar growth tendencies. The Czech Republic had an HHI increase of $41.9 \%$ and average increase of $4.0 \%$ per year and Slovakia had an $\mathrm{HHI}$ increase of $38.7 \%$ and an average increase of $3.7 \%$ per year. On the other end of the spectrum are Slovenia and Hungary. Slovenia is the only country with decrease in HHI and thus market concentration in general, and Hungary had no significant change at all. Slovenia had a $14.5 \%$ total HHI decreased averaging to $1.7 \%$ per year, and Hungary had a mere $3.6 \%$ total increase averaging to $0.4 \%$ per year - basically a stall.

$$
2500
$$

2000

500

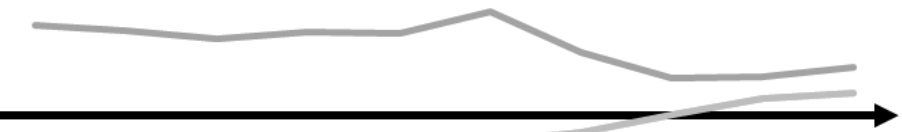

1500
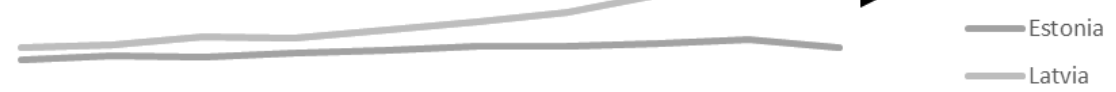

1000 
Fig. 2. Dynamics of market concentration in selected Baltic countries from 2010 till 2019

If we observe the Baltic States, these three countries seem quite different from one another in their development tendencies but are very similar when compared to Eastern European countries in general. Latvia is the country with the growing market concentration and had an overall HHI growth by $24.2 \%$ and an average growth rate of $2.4 \%$ per year. Estonia is the country with a stable market and HHI has increased only by $3.9 \%$ and average of $0.4 \%$ per year. Lithuania is the country with the decrease and had the HHI drop by $9.7 \%$ in total and by $1.1 \%$ per year.

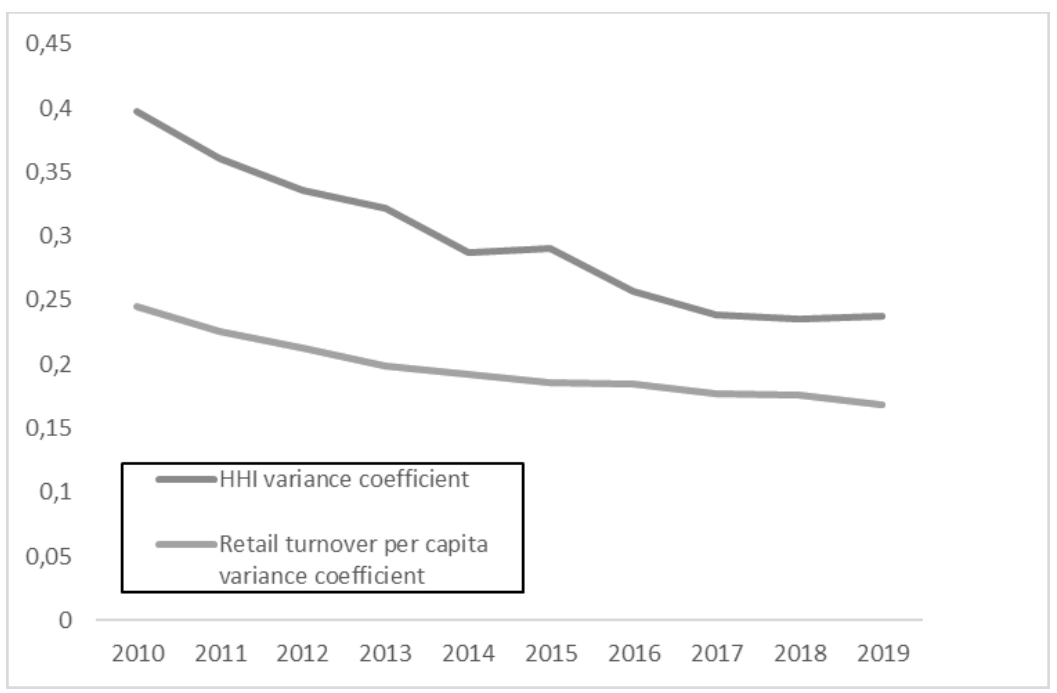

Source: author's construction based on Euromonitor

Fig. 3. Convergence of market concentration and retail turnover per capita in Eastern European and Baltic countries, 2010-2019

The author assumed a convergence tendency in the analysed countries. The assumption was based on several possible development factors. By joining the single market, the analysed countries started a growth of retail markets in general and that contributed to interest of larger companies to invest in these markets. All countries observed economic growth in the period from 2010 to 2019 that contributed to an increased retail market value in total. Due to policies by the European Union aimed at developing the new member states, economic growth in these states was relatively higher than in older member states of the European Union. Thus, the GDP growth in new member states and general convergences of economic development have been the objective of the European Union from the start. At the same time the author assumes that there could be additional effect of market concentration also converging in the analysed countries. To analyse market concentration convergence, a specific value must be used. One of the options for analysing convergence is to calculate the standard deviation for each year for all observed countries. These values show a decrease of the Standard deviation. In 2010 the Standard deviation of Herfindahl-Hirshman index was 457 points; in 2019 it had decreased to 314 points. Thus, we can assume that there was a convergence of market concentration. At the same time the mean level of market concentration increased from 1150 points to 1320 points. So, at the same time we can observe a favourable process of convergence and a less favourable process of increasing domination of a few large retailers.

Since the author mentioned an increasing retail value, it was determined to check if the retail value of these markets also increases. To compare such different countries, the retail value of these countries was recalculated per capita for each year observed. For the resulting data to be tested for convergence, standard deviation was also calculated for each year. It also showed a decrease from 0.31 million euro per 1000 inhabitants in 2010 to 0.29 million euro per 1000 inhabitants in 2019 .

The calculations of standard deviation do not allow it to compare convergence of both market concentration and relative retail value. To fix this issue the variance coefficient was used to make these values comparable, as can be seen in Figure 3. Based on the development of the variance coefficient we can say, that there truly is both a convergence of Herfindahl-Hirshman index and retail turnover per capita in the eight observed countries from 2010 till 2019. 
Correlation between Herfindahl-Hirshman index and Retail value in million euros from 2010 to 2019

\begin{tabular}{|c|c|c|c|c|c|c|c|}
\hline $\begin{array}{c}\text { The Czech } \\
\text { Republic }\end{array}$ & Estonia & Hungary & Latvia & Lithuania & Poland & Slovakia & Slovenia \\
\hline 0,747179 & 0,906334 & 0,335215 & 0,908515 & $-0,79115$ & 0,963389 & 0,991771 & $-0,64816$ \\
\hline
\end{tabular}

The use of the Herfindahl-Hirshman index is definitely advantageous compared to the basic concentration ratio. Nevertheless, there appears to be a tendency that the concentration ratio is different based on the development of the retail market as such. To test it, the author assumed the possibility, that the total retail value of each country influences the market concentration, correlation coefficients were calculated for the relationship between Herfindahl-Hirschman index and total retail value in million euros. The results indicate a strong correlation in most countries. The only countries with weak correlation were Hungary and Slovenia. At the same time, these countries also showed very low change in market concentration. If the market concentration changed significantly, the retail value in total also changed. This leads to a conclusion that market concentration can be influenced by the market growth

\section{Conclusions, proposals, recommendations}

It can be concluded that there is, in fact, convergence among the analysed countries of the market concentration. During the time period from 2010 to 2019 Eastern European countries and the Baltic countries all together experienced mainly increase of market concentration and a higher level of domination by market leaders in grocery retail sector. At the same time the retail value per capita has also converged among these countries.

There results of this research can be recommended for consideration for respective Competition oversight authorities in the countries analysed, since most countries had an increase in market concentration and this could mean a possible abuse of dominant power by the largest retail companies in each country.

\section{Bibliography}

Ahn, D.Y., 2020. Competition and Mergers in the Retail Market for Toys. Applied Economics, pp.1-19.

Allain, M.L., Chambolle, C., Turolla, S., Villas - Boas, S.B., 2017. Retail Mergers and Food Prices: Evidence from France. The Journal of Industrial Economics, 65(3), 469-509.

Caraganciu, A., 2018. IMPACT ASSESSMENT OF ECONOMIC CONCENTRATIONS PARTICULAR FOR FOOD RETAIL MARKETS IN REPUBLIC OF MOLDOVA. Revista Economică, 70(5), 26-38.

Crouzet, N., Eberly, J.C., 2019. Understanding Weak Capital iInvestment: The Role of Market Concentration and Intangibles (No. w25869). National Bureau of Economic Research.

Dengov, V., Gregova, E., Maksimov, A., 2016, October. Globalization in the Field of Food Retail St. Petersburg: Analysis of the Price Policy. In Proceedings of the 16th International Scientific Conference of Globalization and its Socio-Economic Consequences, Part (Vol. 1, pp. 362-374).

Ezeala-Harrison, F., Baffoe-Bonnie, J., 2016. Market Concentration in the Grocery Retail Industry: Application of the Basic Prisoners' Dilemma Model. Advances in Management and Applied Economics, 6(1), 47-67.

Hambur, J., La Cava, G., 2019. Business Concentration and Mark-ups in the Retail Trade Sector. RBA Bulletin, December, viewed, 22.

Kita, J., Kita, P., Kita, P., Kollár, P., Jánska, M., 2019. Retail Environment in the Context of Defining Consumption Patterns on the Example of Slovakia. Studia Ekonomiczne, 384, 38-50.

Kondej, A., 2018. Multi-Formatted Character of the Concentration of Retail Food Market in Poland. Optimum. Economic Studies, 94(4), 286-301.

Kovac, I., 2020. Differences and Particularities Connected To Retail Market Concentration: The Evidence From Croatia. Economic and Social Development: Book of Proceedings, pp.320-332.

Maksimov, A.V., Dengov, V.V., Tulyakova, I.R., 2016. Globalization in the Field of Food Retail St. Petersburg: Concentration and Competition. In GLOBALIZATION AND ITS SOCIO-ECONOMIC CONSEQUENCES, 16 TH INTERNATIONAL SCIENTIFIC CONFERENCE PROCEEDINGS (pp. 1277-1286). EDIS-Zilina University Publisher.

Rebolledo, M., 2020. M\&A, Uncertainty, and Bargaining Power: Evidence from the German Retail Sector (No. 116). CAWM Discussion Paper

Rickert, D., Schain, J.P., Stiebale, J., 2018. Local Market Structure and Consumer Prices: Evidence from a Retail Merger (No. 280). DICE Discussion Paper. 
Sigarev, A.V., Kosov, M.E., Buzdalina, O.B., Alandarov, R.A., Rykova, I.N., 2018. The Role of Chains in the Russian Retail Sector.

Silvius, S., Alexandra, V.O., Maria-Alexandra, S., Bogdan, B.D., FOOD RETAIL IN ROMANIA. MARKET OVERVIEW.

Smith, D., Ocampo, S., 2020. The Evolution of US Retail Concentration.

Smith, D.A., 2018. Concentration and Foreign Sourcing in the US Retail Sector.

Špička, J., 2016. Market Concentration and Profitability of the Grocery Retailers in Central Europe. Central European Business Review, 5(3), 5-24.

Vukmirović, G., Marić, R., Damnjanović, J., 2018. Impact of Retail Market Concentration on Differences in Retailers' Productivity and Business Results. Industrija, 46(3), 145-161.

Yanine, F., Cordova, F.M., Valenzuela, L., Isla, P., 2019. A Fresh Look at an Old Problem: Saturation in the Retail Market and How it Affects both Retailers and Consumers. 


\title{
THE IMPACT OF DIGITIZATION ON LEAN MANAGEMENT IN MANUFACTURING COMPANIES
}

\section{Klaus Daenner, University of Latvia}

\begin{abstract}
What effects does digitization have on existing lean management processes in manufacturing companies? The study examines the implementation of new technologies in existing lean management systems via the areas of intraorganization, implementation, aversion and fear. The aim of the current research project is to provide managers in manufacturing companies with recommendations for suitable digitization options to further develop existing lean management methods. This ongoing research project makes use of both basic literature from authors as well as current scientific research, which includes comparable previous research on the topic under investigation. This research includes secondary and primary research methods. It will be developed using various qualitative and quantitative methods. In order to remain competitive in a globalized environment, companies must continuously develop their existing production systems and meet the changing demands of the markets. Companies need to streamline and integrate digital technologies such as autonomous driving, artificial intelligence, bionic enhancement, block chain, low-cost sensors, drones, 3D printing, Internet of Things, cloud computing, robotics and automation, freight congestion, digital identifiers, digital twin, big data analytics, virtual reality and analytics. The result of this contribution is the derivation of the research model from the existing knowledge gap. Based on current research, digitisation offers considerable opportunities for the economy. Opportunities from macroeconomic effects, in cooperation strategies, increasing added value, increasing production efficiency but also new business models, new products and services are another important aspect.
\end{abstract}

Keywords: Globalization, Digitalization, Lean Management, Innovation Management, Transformation.

JEL code: $\mathrm{O} 32$

\section{Introduction}

Lean Management is an important approach to improving operational productivity and business performance. It is a systems philosophy that focuses on meeting customer needs, minimizing waste and committing to a culture of continuous improvement. (Tay, 2017) Digitization can be understood as an extension to lean management and thus as an expected fourth industrial revolution. Therefore, intelligent digitization and automation of products must be implemented along the value chain. It is about the integration of real and virtual production worlds in which products, production facilities, people and objects merge and grow into intelligent and distributed systems with integrated software. (HirschKreinsen, et al., 2018) With the new digital collaborative "Lean" approach, value creation increases with less waste in planning, processes and costs while continuing process and product innovation. Digital connections enable every company in the chain to make forecasts or simply order. (Blakemore, 2011) This reorganization of resources around a generic and globally accessible coordination platform has enabled many companies to quickly evolve into a global start-up. (Autio, 2016) The vertical integration of the factory must implement flexible and reconfigurable manufacturing systems, i.e. Smart Factory, is one of the most important features of digitization. (Kocsi, 2017) Over the past 20 years, the development of digital technologies, new methods and new technologies in the world, and their implementation in production, has challenged companies worldwide to constantly monitor these developments and carry out modernizations and automations of their production processes in order to remain competitive (Karabegović, 2018) Intelligent robots will completely replace workers in the production process, and at the same time workers will work on more effective creative tasks. (Karabegović, 2018) The development of digital, sensor and robotics technology with other technologies and new materials introduces intelligent industrial development to the "Smart Factories". The contact model with the end customer often goes into the virtual world, which is a change that is directly reflected in the creation of distribution channels. The changes taking place are called the Fourth Industrial Revolution and we are its eyewitnesses. (Szozda, 2017) This solution is used for mass products with a limited number of product groups. The second model is the mass personalization of production. The functioning of such companies is based on meeting the individual needs of the customers, the production takes place in small quantities, while the products are strongly individualized and delivered for specific customer orders. There is a very wide range of products. The third archetype is the so-called e-factory, which focuses on both individualisation and remote operation. These companies operate on a small scale and produce only limited quantities of products. They concentrate on low investments in order to maintain cost competitiveness. (Szozda, 2017)

\section{Research gap and difficulties}

Although lean management applications have an impressive track record in manufacturing companies, digitization is a limited concept. The main problem is that the classical approach of lean management is completely different from the methods of digitization. This is due to the difficulty 
for manufacturing companies that lean management places the employee at the centre of all activities and that digitisation aims to rationalise the employee. These difficulties are due to the specific characteristics of such companies. There are also few scientific papers that deal with the transfer of digitisation to concepts such as lean management to manufacturing companies. The topics "Lean Management" and "Digitisation" have already been dealt with in detail in the scientific literature as independent areas but are not yet sufficiently linked. Therefore, practitioners do not have a systematic process model at their disposal. This paper deals with the necessity of a methodical design of the influence of digitization on lean management methods for manufacturing companies. This paper aims to close the existing research gap. The paper investigates whether digitization can be transferred to lean management methods in manufacturing companies and what positive consequences this has. Solution proposals for the identified further development potentials will be developed and presented.

\section{Novelty}

- Structured table of contents on digitization possibilities that contribute to extended lean management systems, based on earlier, similar research that puts the different ideas on the topic in a comprehensible order.

- Developed model for the relationship between digitization and the impact on the results of lean management systems.

- Empirical results from European production companies confirming the extent to which digitisation opportunities have an impact on the results of lean management.

- Empirical evidence for the current management challenge to use digitization as a basis for strategically desired performance results, especially for lean management results.

- Evaluated and condensed digitization concept to support lean management, derived from the results that can be recommended to executives.

- International insights into the perception of digitisation as influencing factors for Lean Management by European experts, which provide a rich basis for future research fields.

\section{Purpose of the research}

The aim of the research project is to provide managers in manufacturing companies with recommendations for suitable digitization options for the further development of existing and new lean management methods and to open future fields of research for scientists.

\section{Objective of the research}

The aim of this thesis is to examine in detail the influence of digitization on lean management in manufacturing companies. Based on the basic literature and the analytical analysis of earlier studies on digitization, the influence and role of digitization on lean management will be investigated. By collecting empirical findings from manufacturing companies and international lean and digitization experts, the relationship between the two phenomena will be demonstrated. Building on this, the aim of this research is to derive recommendations for executives and scientists.

\section{Tasks}

1. Analyse and explore the theoretical concepts of success factors for lean management in general with a focus on organisational values and culture and compare different contemporary views on the subject.

2. Conduct an in-depth content and frequency analysis of digitization opportunities that support lean management in previous similar studies to obtain a defined and condensed overall profile.

3. Evaluate and discuss the different approaches to measuring lean management performance and the possibilities for digitisation and development of appropriate research design.

4. Empirical study of the impact of digitisation on the results of lean management and collection of data from manufacturing companies.

5. Analyse the results with statistical methods and structure the data to make predictions and explanations.

6. Validate the results with findings from international lean management and digitisation experts to understand the multiple implications of the topic.

7. Derive leadership implications for managers and executives that are important for further improving lean management performance in manufacturing companies.

8. Developing recommendations for future research areas for scientists and recommendation possible directions to practitioners, universities and government institutions to increase lean management approaches in manufacturing companies.

9 . 


\section{Hypothesis and research questions}

The main hypothesis of this dissertation is formulated as follows:

H0: The higher the degree of maturity of digitization in a manufacturing company, the higher the performance of that company's production system. The following research questions arise from the information in the topicality section:

1. What does a general digital lean management system look like in companies that supports successful production performance?

2. Are there any digital lean management methods that contribute more to production performance than others? Are there different intensities of impact between the methods identified?

3. How strong are the identified digital lean management methods characteristic for manufacturing companies?

4. To what extent do digital lean management methods explain and determine the results of production performance?

\section{Methodology}

This research project embeds both basic literature by authors and contemporary scientific research, which includes comparable earlier research on the topic under study. This research includes secondary and primary research methods. It will be developed with different qualitative methods and quantitative methods.

\section{Research boundaries}

Questions such as the overall influence of digitisation on the success of a company are not dealt with in this paper. It deals with the aspects of lean management methods and approaches and their impact on production performance. Neither the theoretical, nor the analytical and empirical parts are sufficiently analysed, and other types of improvement management are considered in detail. Furthermore, this work is limited to the industrial sector of manufacturing companies. It focuses on companies in Europe.

\section{Preliminary studies}

In the preliminary studies of the dissertation to be developed, the significance of digitization and lean management for manufacturing companies will be determined by literature research. The results of the preliminary studies provide a summary of concrete values, which will be crystallized by the implementation of the digitization of existing lean management methods. The topic "preliminary study" deals with the analysed results of the empirical investigation of digitization and lean management in manufacturing companies. It contains remarkable opinions from international experts, so the aim here is to deepen the understanding of the topic and gain empirical insights to fully answer the research questions and test the main hypothesis.

\section{Literature Review}

Due to globalization and progressive demographic change, e.g. changing market requirements, the manufacturing industry is facing new challenges. Instead of concentrating only on technological improvements, it is now necessary to consider people as a central component of the production system, to increase overall productivity and to compete in globalised markets. (Wolf, 2018) This advantage accelerates the transition from digitization from science to reality. In practice, new solutions must offer users added value and an acceptable risk. The integration of digitisation solutions, which are usually associated with a high cost level, especially in areas where cost-saving and simple methods of lean production do not or do not fully meet today's requirements, is a particularly lucrative investment. (Becker, et al., 2019)

\section{Definition Digitization}

In recent years, the term "digitisation" has been widely used in German-speaking countries. It originally described the digital representation of information or the conversion of analogy signals into digital signals. (Bibliographisches Institut GmbH, 2019) In recent years, the understanding of the concept of digitisation has changed and today describes the increasing introduction of modern digital technologies in business, society and production. (Plattform Industrie 4.0, 2019) This includes the increased use of information and communication technologies in existing applications as well as the introduction of new business models based on information and communication technologies. (Mertens, et al., 2016) Digitisation is a continuous process of change that affects not only technical but also organisational aspects. (Jung, et al., 2016) In this paper digitisation is understood as follows: Examples of digitization in production are the introduction of autonomous driving, artificial intelligence, bionic improvement, blockchain, low-cost sensors, drones, 3D printing, Internet of Things, cloud computing, robots and automation, freight overload, digital identifiers, digital twin, big data analytics, virtual reality and analytics. (Paul, 2016) In the context of digitization, industry 4.0 is worth mentioning. In 2011, the German federal government announced the term in the context of the digital agenda together with an associated funding programme. Other 
regions such as the USA, China and Europe adapted it shortly afterwards and established similar programmes. (Xinhua, 2016) Today, the term "industry 4.0" is ubiquitous not only in German-speaking countries, but also in the digital world.

\section{Definition Lean Management}

Lean management is a management system that has Japanese roots and can be translated as "lean management". (Brunner, 2008) The term "Lean Production" has been further developed over time, so that "Lean" today stands for a management philosophy that considers the entire environment of a product. (Wildemann, 1992) Lean Management is the attempt to eliminate recurring sources of error and to avoid any kind of waste in order to be able to carry out an intended process reorientation in small steps. (Shingo, 1992) In the context of today's permanent industrialisation, a confrontation with operators of a company to become competitive factories is inevitable if one wants to react to the requirements of globalisation with modernisations. Company goals such as faster and better realisation of production and adaptation to the needs of customers are synonyms for lean approaches in international competition. (Bösenberg, 1993) Lean management is characterised by a decentralised organisational form, in which problems are solved promptly, and this with the inclusion of strict customer and quality orientation, group work and planning of activities. (Womack, et al., 1992) Lean management as a term was coined by the authors Pfeiffer and Weiss. (Pfeiffer, et al., 1994) These represented the transfer of the principles of Lean Production to other areas along and parallel to the production process. Without exception, all functions, structures and processes as well as value creation networks of the companies were included. (Pfeiffer, et al., 1994) For the project, the identical foundations are to be laid for the processing of the Lean Production topic complex. Lean Production became world-famous through the publication of the book "The Machine That Changed the World". (Womack, et al., 1992) The authors and researchers of MIT Womack, Jones and Ross described the results of a fouryear study of the International Motor Vehicle Program (IMVP). The aim of this study was to compare the performance of motorists worldwide. Japanese motorists, Toyota, were examined more closely, as their performance indicators significantly exceed those of their competitors. (Womack, et al., 1992)

\section{Digitalization as an extension of Lean Management}

The application of digitisation to established lean production could reduce the integration risk due to existing guidelines for organisational integration. In addition, the production processes in Lean Production are more standardized, transparent and reduced to the essentials compared to other organizational forms. This makes them less complex and supports the installation of digitization. (Kolberg, 2015) Product development is already undergoing major change. Products are becoming ever more complex, global competition and price pressure are increasing, customer requirements are becoming ever more individual and difficult to meet. This complexity often leads to increased effort and lead time in product development. In recent decades, the introduction of principles and methods of lean management has attempted to address these conflicts with instruments to increase efficiency. (Rauch, 2016) Lean will not fade with Industry 4.0. On the contrary, "lean principles" are likely to gain in importance. The fourth industrial revolution could make it possible for the real lean company. Industry 4.0 enables a much broader understanding of customer demand and enables the immediate exchange of demand data across complex supply chains and networks. Intelligent factories can produce faster and with less waste. Industry 4.0 enables a much faster one-piece flow of custom products. It has the potential to radically reduce inventory levels in the supply chain. (Netland, 2015) On the other hand, with radical changes in the environment, changes come in "lean" as an exercise. There will probably be fewer physical bank types, fewer cables, fewer whiteboards and similar technical "lean" solutions in future factories. But that's not a shame; Toyota has never considered these tools and practices as goals in themselves, they're just technical solutions to minimize wasteful processes. One of the most promising technological advances is the ability to trade information in real time in a coordinated end-to-end supply chain. This enables a radically improved form of immediate just-in-time pull production. (Netland, 2015) This means that the industry now has the benefits of integrating the entire factory in real time while minimizing waste. Research shows that SMEs in Germany in Industry 4.0 can be positive with the perspective of streamlining their production halls. However, there is a need for further research to highlight the importance of continuous improvement over the dimensions of lean production. Increasing computing power and reduced size lead to the constant development of new technologies. Improvements or adaptations to the development of these new technologies must be analysed through their impact on lean manufacturing. In addition, some research in Industry 4.0 was purely theoretical and not readily adaptable to an application. 


\section{Summary}

Application-oriented research must be developed in relation to the criteria for implementing lean manufacturing. Future research must focus on creating a conceptual framework and a cyberphysical work system that integrates these parameters into a fully functional production environment. (Sanders, 2016) Future research activities will focus primarily on a method for identifying company-specific target states, improved maturity accuracy, and strategic steps to achieve the desired levels of maturity. In addition, roadmaps will be developed after improving the maturity of specific articles and related dimensions to define strategic programs and projects. Based on the results of this generic maturity model, a more domain-specific model is planned to assess industry 4.0 maturity in automotive manufacturers. In summary, the maturity model is not seen as a direct path to industry 4.0 maturity. However, our maturity model can help with the difficult task, considering the current capabilities related to Industry 4.0 and the subsequent decision on the respective strategies and action plans. (Schumacher, 2016) This new type of industry is based on the Smart Factory model.

\section{Research model and research methodology}

This section introduces the research model, the research methods, and explains how indicators are operationalized. It also justifies target groups and clarifies instruments of data collection. The model shows how the digitization of certain factors determines and influences the performance of lean management in manufacturing companies.

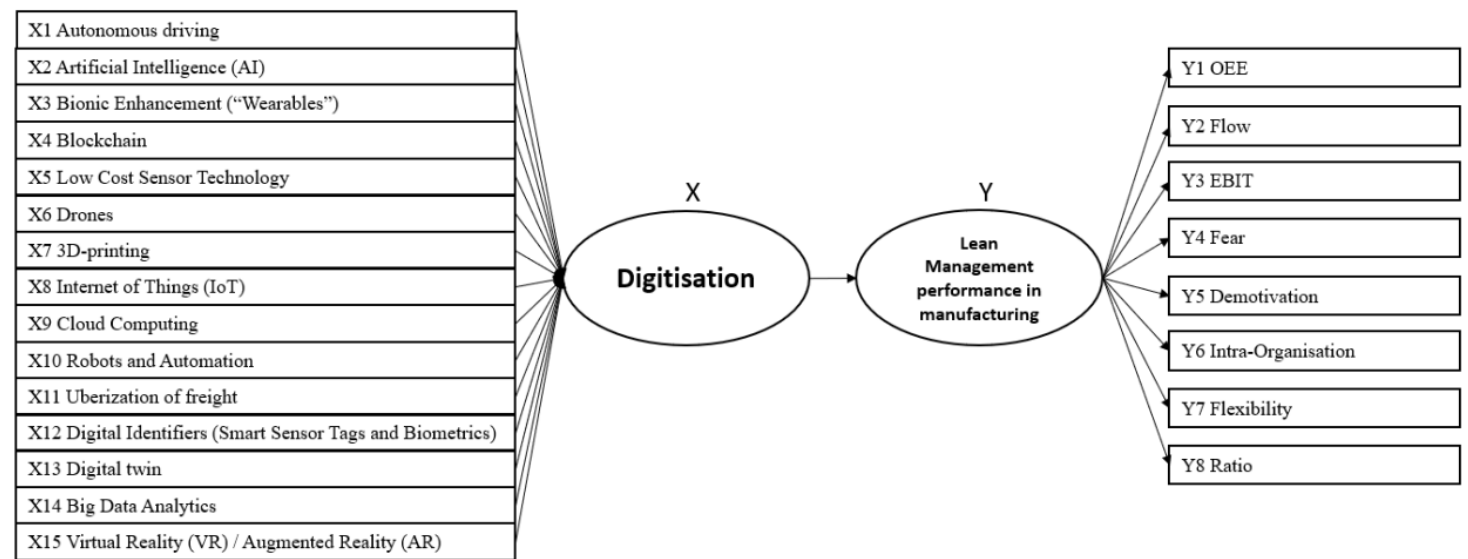

Fig. 1. Research model

The purpose of this research is to understand the impact of defined properties of digitization on lean management methods in enterprises. In order to gain a deeper understanding of the phenomenon of digitization and lean management, mixed method research must be considered. Recently, mixed method approaches have become more and more important and popular in the business research. Thus, the results of an investigation can be used in the following areas: comparison with the results of another research strategy. Two different empirical approaches will be used for this purpose: One quantitative cross-sectional, correlation research design with the organization as level of analysis to test the hypothesis and the model, and to answer the research Questions. A qualitative cross-sectional, confirmatory research design to validate the results from the first research strategy onwards in order to compare the results and possibly find others. Aspects that stimulate further research, as outlined in the introduction and timeliness of this work, quantitative research in the field of digitization and lean management must be a research gap worth closing. It is therefore obvious that quantitative research has a major priority in data collection. Thus, the two studies do not have the same weight here - the focus is on quantitative research, but the second is that a qualitative study can greatly improve and underpin the initial.

\section{Conclusion and opportunities of Digitization}

The advancing digitalisation and its penetration into the manufacturing sector offers considerable opportunities for the German economy. (Demary, et al., 2016) According to the study, it is noticeable that many studies deal with specific problems and challenges related to digitisation and much less with the resulting opportunities. (Eichhorst, 2016) Within the various studies, macroeconomic effects, sector-related potentials and opportunities are addressed. (Warnecke, 2018) However, there is no generally applicable standard for the approach, as the majority of the studies are based on surveys or potential estimates. (Reinheimer, 2017) Opportunities exist in cooperation strategies in order, on the one hand, to withstand 
globalisation and, on the other hand, to focus on achieving sustainable competitive advantages. (Kasperk, et al., 2012) As will be shown later, cooperation can therefore be interpreted as a company-specific adaptation strategy to the individual challenges posed by globalisation. (Wrona, et al., 2003) Increases in value added: Depending on the study, the growth in sales through value added without deducting costs and intermediate inputs amounts to between 20 and 145 billion euros, according to new studies. (Berger Strategy Consulting, 2015; Geissbauer Strategy\&, 2014; Manyika - McKinsey \& Company, et al., 2013) Various studies predict high value creation potential in European industry if the digitization process is successfully implemented. According to studies, there is a potential of up to $2.2 \%$ per year in the chemical industry, the electrical industry and in mechanical and plant engineering after successful digitization. (Kelkar - MHP, et al., 2014) Further studies show that productivity increases that have already been achieved through the effects of digitisation have been achieved and that additional jobs have been created. (Demary, 2016) Germany will have a great opportunity in the next two decades, as the country will be severely affected by demographic change. The acceleration of productivity growth can have a positive impact here. (Preißing, 2014) According to all studies, overall economic productivity will improve. While in Germany the focus is more on industry, in the USA, for example, the focus is also on administrative areas. (Frey, 2015) However, the considerable increase in production efficiency, especially in industry, does not necessarily lead to a reduction in the input factors required, since digitisation also entails considerable additional value creation potential. (Heyse, et al., 2018) Individual economic potentials: Efficiency increases can be achieved by using operational data and optimally coordinating them with all other processes. Optimal matching of the data allows peaks in under- and overload to be predicted and countermeasures to be initiated. (Mayer-Schönberger, 2013) Ultimately, digitisation in the form of "big data", for example, contributes to better process control and to the reduction of logistics, material, maintenance and production costs. (Fasel, 2016) According to various surveys in the supply industry, interfaces between the various actors within the value chains are often not yet digitalised. This reveals great potential for faster order processing and increased productivity. (Bousonville, 2017) New business models, new products and services are another key aspect of the opportunities and possibilities offered by digitization. These should cover new needs and customer benefits and should open new sales areas. (Noll, 2016) Especially in the supply industry, openness and collaboration are becoming increasingly important, as for example Local Motors. (Redlich, 2017) To be successful on the market as an entrepreneur, the innovative content of the concept (Entrepreneurial Design), its early empirical verification (Proof of Concept) and the use of professional service providers are crucial. (Faltin, 2016) Small and medium-sized enterprises are the driving force behind innovation processes. These companies take advantage of their variety and diversity to drive and develop innovations. (Schumpeter, 1908) Opportunities arise from the low level of internal bureaucracy and the resulting flexibility and specialisation of small and medium-sized enterprises. (Eriksson, et al., 2006) According to the latest findings, the innovation performance of SMEs in Germany is stagnating at present and is distributed among fewer and fewer companies. (Demary, et al., 2016)

\section{Bibliography}

Autio, E., Zanda, I., 2016. Lean Internationalization. London, Imperial College Business School and Aalto University School of Science

Becker, W., Eierle, B., Fliaster, A., Ivens, B., Leischnig, A., Pflaum, A., Sucky, E., 2019. Geschäftsmodelle in der digitalen Welt. Strategien, Prozesse und Praxiserfahrung. Springer Fachmedien Wiesbaden GmbH

Berger, R., 2015. Die digitale Transformation der Industrie. Was sie bedeutet. Wer gewinnt. Was jetzt zu tun ist. Berlin, Bundesverband der Deutschen Industrie e.V. (BDI).

Bibliographisches Institut GmbH: digitalisieren. URL http://www.duden.de/node/716435/revisions/1375044/view [Accessed 01.09.2019]

Blakemore, J., 2011. Lean and Digital. A Fast Supply Future. Manufacturers' Monthly, Reed Business Information Australia, Ltd., a Division of Reed Elsevier, Inc.

Bösenberg, D., Metzen, H., 1993. Lean Management. $3^{\text {rd }}$ edition, Vorsprung durch schlanke Konzepte. Hamburg, Mannheim, Verlag Moderne Industrie.

Bousonville, T., 2017. Logistik 4.0. Die digitale Transformation der Wertschöpfungskette. Springer Fachmedien Wiesbaden GmbH.

Brunner, F. J., 2008. Japanische Erfolgskonzepte. Kaizen, KVP, Lean Production Management, Total Productive Maintenance, Shopfloor Management, Toyota Produktion Management. Wien, Carl Hanser Verlag

Dao, D.-K., Kelkar, O., Heger, R., 2014. Studie Industrie 4.0 -Eine Standortbestimmung der Automobil-und Fertigungsindustrie, Mieschke Hofmann und Partner (MHP) Gesellschaft für Management-und IT-Beratung mbH, 
Demary, V., Engels, B., Röhl, K.-H., Rusche, C., 2016. Digitalisierung und Mittelstand: Eine Metastudie. Köln, Institut der deutschen Wirtschaft (IW).

Eichhorst, W., Hinte, H., Rinne, U., Tobsch, V., 2016. Digitalisierung und Arbeitsmarkt: Aktuelle Entwicklungen und sozialpolitische Herausforderungen, Bonn, IZA Standpunkte Nr. 85.

Eriksson, T., Kuhn, J., 2006. Firm Spin-offs in Denmark 1981-2000 - Patterns of Entry and Exit. International Journal of Industrial Organization, 24, 1021-1040.

Faltin, G., 2016. Entrepreneurship: Problemlagen und Handlungsansätze, Springer Fachmedien Wiesbaden GmbH.

Fasel, D., Meier, A., 2016. Big Data. Grundlagen, Systeme und Nutzungspotentiale. Springer Vieweg Fachmedien, Wiesbaden.

Frey / C., Osborne / M. A., 2013. The Future of Employment: How Susceptible are Jobs to Computerization? United Kingdom, Oxford, Department of Engineering Science, University of Oxford, OX1 3PJ.

Geissbauer, R., Schrauf S., Koch V., Kuge, S., 2014, Industrie 4.0. Chancen und Herausforderungen der vierten industriellen Revolution. PwC.

Goldmann, S. L., Nagel, R. N., Preiss, K., Warnecke H.-J., 1996. Agil im Wettbewerb: Die Strategie der virtuellen Organisation zum Nutzen des Kunden. Heidelberg, Berlin, Springer Verlag.

Heyse V., Erpenbeck J., Ortmann, S., Coester S., 2018. Mittelstand 4.0 - eine digitale Herausforderung. Führung und Kompetenzentwicklung im Spannungsfeld des digitalen Wandels. Münster, New York, Waxmann Verlag.

Hirsch-Kreinsen, H., Ittermann, P., Niehaus, J., 2018 Digitalisierung industrieller Arbeit. $2^{\text {nd }}$ Edition Die Vision Industrie 4.0 und ihre sozialen Herausforderungen. Nomos Vertragsgesellschaft

Jung, R., Nüesch, R., Plazibat, A., Barón, J. F., 2016. Digitalization Strategy: Drivers, Potentials and the Road to Implementation - A Case from the Media Company Ringier. Controlling, 28(4-5), 248-253.

Karabegović, I., 2018. The Role of Industrial and Service Robots in the 4th Industrial Revolution - Industry 4.0, CTA Technica Corviniensis Bulletin of Engineering, 12(2), 11-16.

Kasperk, G., Drauz, R., 2012. Kooperationsstrategien von Automobilproduzenten entlang der sich neu ordnenden Wertschöpfungskette, Wiesbaden, Gabler Verlag Springer Fachmedien

Kocsi, B., Oláh, J., 2017. Potential Connections of Unique Manufacturing and Industry 4.0. Scientific Journal of Logistics, 13(4), 389-400.

Kolberg, D., Zühlke, D., 2015. Lean Automation enabled by Industry 4.0 Technologies. Department of Innovative Factory Systems (IFS), Kaiserslautern, German Research Centre for Artificial Intelligence (DFKI) GmbH.

Manyika, J., Chui, M., Bughin, J., Dobbs, R., Bisson, P., Marrs A., 2013. Disruptive Technologies: Advances that will Transform Life, Business, and the Global Economy. McKinsey Global Institute, McKinsey \& Company.

Mayer-Schönberger, V., Cukier, K., 2013. Big Data, $2^{\text {nd }}$ Edition, Die Revolution, die unser Leben verändern wird. München, Redline Verlag.

Mertens, P., Barbian, D., 2016. Digitalisierung und Industrie 4.0 - Trend mit modischer Überhöhung? In: Informatik-Spektrum,39(4), 301-309.

Netland, T., 2015. Industry 4.0. Where does it leave lean? Lean Management Journal, 5, 22-23.

Noll, E., Zisler, K., Neuburger, R., Eberspächer, J., Dowling, M., 2016. Neue Produkte in der digitalen Welt. BoD - Books on Demand.

Paul, H., 2016. Industrie 4.0: Annäherung an ein Konzept. Institute for Work and Technology (IAT), Westfälische Hochschule, University of Applied Sciences.

Pfeiffer, W., Weiss, E, 1994. Lean Management: Grundlagen der Führung und Organisation lernender Unternehmen. Berlin, Erich Schmidt Verlag.

Plattform Industrie 4.0, Was ist Industrie 4.0.

URL http://www.plattformi40.de/I40/Navigation/DE/Industrie40/WasIndustrie40/was-ist-

industrie40.html;jsessionid=D7ED4118DED525F176F382A8F939369D [Accessed 01.09.2019]

Preißing, D., 2014. Erfolgreiches Personalmanagment im demographischen Wandel, $2^{\text {nd }}$ Edition. München, Oldenbourg Wissenschaftsverlag $\mathrm{GmbH}$.

Rauch, E., Dallasega, P., Matt, D. T., 2016. The Way from Lean Development (LPD) to Smart Product Development (SPD), Science direct, 26th CIRP Design Conference. 
Reinheimer, S., 2017. Industrie 4.0. Herausforderungen, Konzepte und Praxisbeispiele. Wiesbaden, Springer Vieweg.

Sanders, A., Elangeswaran, C., Wulfsberg, J., 2016. Industry 4.0 Implies Lean Manufacturing: Research Activities in Industry 4.0 Function as Enablers for Lean Manufacturing, Journal of Industrial Engineering and Management, 9(3), 811-833.

Schumacher, A., Erol, S., Sihn, W., 2016. A Maturity Model for Assessing Industry 4.0 Readiness and Maturity of Manufacturing Enterprises, Elsevier B.V.

Schumpeter, J., 1908. On the Concept of Social Value. Quarterly Journal of Economics, 23(9), 213-232.

Shingo, S., 1993. Das Erfolgsgeheimnis der Toyota-Produktion, $2^{\text {nd }}$ Edition. Eine Studie über das Toyota-Produktionssystem- genannt die „,schlanke Produktion“. Landsberg, Verlag modere industrie.

Szozda, N., 2017. Industry 4.0 and its Impact on the Function of Supply Chains. Scientific Journal of Logistics, 13(4), 401-414.

Tay, H. L., Kiat, L., Wee, S., 2017. Digitalization of learning resources in a HEI - a lean management perspective. International Journal of Productivity and Performance Management, 66(5), 680-694.

Redlich, T., Moritz, M., Wulf, S., 2017. Digitale Produktion: Bottom-up-Ökonomie, Springer Fachmedien Wiesbaden GmbH.

Warnecke, D., Heyn, J., Teuteberg, F., 2018. Nachhaltigkeit durch betriebliche Umweltinformationssysteme (BUIS)? Entwicklung und Evaluation eines Reifegradmodells für kleine und mittlere Unternehmen (KMU). Lecture Notes in Informatics (LNI), Bonn, Gesellschaft für Informatik, P. 145.

Wildemann, H., 1992. Lean Management. Der Weg zur schlanken Fabrik. München, Gesellschaft für Management und Technologie-Verlags KG

Wolf, J., 2011. Organisation, Management, Unternehmensführung: Theorien, Praxisbeispiele und Kritik. Wiesbaden, Gabler Verlag,

Wolf, M., Kleindienst, M., Ramsauer, C., Zierler, C., Winter, E., 2018, Current and future industrial challenges: Demographic change and measures for elderly workers in industry 4.0, A NNALS of Faculty Engineering Hunedoara - International Journal of Engineering

Womack, J. P., Jones, D. T., Roos, D., Sammons, D., 1992. Die zweite Revolution in der Autoindustrie. Konsequenzen aus der weltweiten Studie aus dem Massachusetts Institute of Technology, Frankfurt am Main, New York, Campus Verlag.

Wrona, T., Schell, H., 2003. Globalisierungsbetroffenheit von Unternehmen und die Potenziale der Kooperation. Wiesbaden, Springer Fachmedien.

Xinhua: 'Made in China 2025' plan unveiled. In: China Daily 2015. URL http://www.chinadaily.com.cn/bizchina/201505/19/content_20760528.htm [Accessed 01.09.2019] 


\title{
CONSUMER PERSONAL DATA DRIVEN DIGITAL MARKETING Zanda Davida, University of Latvia
}

\begin{abstract}
As long as trading has existed, business tries to explore consumers to maximize their profits. Today's digitalisation brings such new technologies in the European Single Market as artificial intelligence, big data, digital tools of data gathering and knowledge generation. Consumer profiling is not a new phenomenon, but big data have changed the scale on which business can explore consumers. The average consumers do not understand how it works and has no idea of its impact on their free choice. It promotes digital asymmetric relations between consumers and business, where the losers are consumers. On the one hand, the author argues that in the digital era use of consumer personal data are normal and even desirable, because both consumers and business are benefitting from it. But, on the other hand, it must be acknowledged that at present data driven marketing is not sufficiently monitored and legally restricted. The targeted advertising is one of the forms of data driven marketing. The article aims to determine the risks of targeted advertising which can affect traditional consumer values and contribute development of digital asymmetric relations between consumer and business. As the main result of the article the author puts forward the development of a new concept in law consumer digital vulnerability as a solution to the risks identified in this article. It could strengthen a balance between businesses and technology, on the one hand, and the protection of the traditional legal values of consumers, on the other. The author argues that the concept cannot be legal, because of its narrow understanding. Therefore, the author raises the question for discussion - can consumer digital vulnerability be an economic concept? The paper is based on the scientific publications and consumer' behaviour, businesses technological practices, economic studies of consumer detriment researches analysis, and method of legal analysis.
\end{abstract}

Keywords: data driven marketing, targeted advertisings, consumer, law.

JEL code: D11, D12, D18, P46, M31, M37

\section{Introduction}

Digitalisation has fundamentally changed people lives in ways that could not have been imagined a generation ago. K. Schwab argues that we are in the midst of the Fourth Industrial Revolution that builds on the electronic and information technology of the Third Industrial Revolution in a way that combines technologies and blurs the distinctions between the physical, digital, and biological (Schwab, 2016). The consumer market has changed irreversibly, but last year the digitalization grew at an accelerated pace thanks to the explosion of online sales during the COVID-19 pandemic. Therefore, compliance with marketing and advertising laws becomes increasingly important for businesses of all sizes. But in the European consumer and data protection laws, there is so much uncertainty that even national authorities do not know how to interpret them correctly. This is because no political agreement has been reached on a common vision about the chosen way forward. Namely, at present the European legislator has not been able to set clear boundaries for fair and ethical consumer personal data driven digital marketing, as digital marketing practices and tools are constantly evolving and changing.

More often, consumers do not have to pay money to use search platforms, social media, mobile apps, personal assistants, online news portals, map tools, global positioning systems (GPS) and other digital services. Until recently it was stressed that the opinions of authors, who argued that in the digital world free pricing is an inevitable and normatively acceptable approach to pricing internet services (Anderson, 2009), were provocative (Hoofnagle, Whittington, 2014). Despite resistance today digital services where the business model entails making money from the consumer's data have become commonplace in the digital economy (Howells, 2020). A perfect example is online meeting platforms, which have become in high demand during the COVID-19 pandemic. Researches show that one of the most popular and as the best recognized online meeting platform is Zoom, because of its politic strategy (Keough, 2020; Columbus, 2020). Namely, it is offering free basic service to everyone. The business does not work for free; it means that someone pays for "free" services. Therefore, while offering many benefits to consumers and businesses, the data driven business models also pose risks for consumers and challenges to consumer laws. The traditional core values of consumer protection law seem capable of applying to the digital environment, but we need new regulatory models to meet the challenges of an increasingly technological society may call for some new regulatory practices - Europa needs an appropriate modification of law and it understanding (Howells, 2020). Recent scientific publications (for example, Mathur, Narayanan, Chetty, 2018; Mathur, Acar, Friedman ..., 2019) and previously conducted research (for example, Forbrukerrådet study, 2020) have indicated that there is a digital asymmetry between consumer and business, which reflects on the European Digital Single Market financial development, business economic activity, and consumers trust to the digital market.

The article aim is to analyse consumer personal data driven digital marketing, identify the main legal problems and offer their solution. Consumer personal data driven digital marketing have a wide spectrum of different business technological practice forms. Due to the limited capacity 
of this article, it is not possible to qualitatively analyse all these forms, therefore the author delimits research subject to the most common consumer personal data driven digital marketing form, namely, targeted advertising. Namely, the marketing practice of tailoring personalised adverts to consumers based on their preferences and behaviour, to increase the probability of acquiring the costumer (OECD, 2018b). The tasks of the research are 1) to determine the most common consumer personal data driven digital marketing form at the European digital market; 2) to analyse most common marketing form posed risks and problems which is accrued from digital asymmetric relations between consumer and business; 3 ) to determine the red lines of this form of marketing from the traditional consumer values point of view and develop criteria and proposals that the process of consumer personal data driven digital marketing is fair and transparent while striking a balance between businesses and technology, on the one hand, and the protection of the values of a traditional consumer, on the other. The research question which needs to be answered: what business needs to take into consideration doing consumer personal data driven digital marketing - targeted advertising? The author intends to initiate an interdisciplinary scientific discussion about the development trends of consumer and data protection rights and its problems and gaps which is affected marketing management. The practice shows that the sanctions have recently begun to follow one after the other, for example, Facebook was fined 10 million EURs by the Italian Competition Authority for unfair commercial practices for using its subscribers' data for commercial purposes (Italian Competition Authority, 2018). This confirms the mutual misunderstanding between business and national authorities. Therefore, the findings of the research contribute to the interdisciplinary discussion and exchange of ideas about challenges and prospects for economic and business development in digital marketing. Future analysis is required in a context, which covers more consumer personal data driven digital marketing forms, namely, technological practice forms used by a business.

The main research methods used are scientific publications and consumer' behaviour, businesses technological practices (including digital advertising, digital marketing, digital design, and architecture), economic studies of consumer detriment researches analysis and method of legal analysis. The author studies consumer personal data driven digital marketing and its impact on consumer behaviour and the development of new business models. Scientific papers, empirical studies and other sources which were used for analysis were selected based on the following criteria: 1) quality of sources, objectivity and high international scientific evaluation (for example, most of scientific publications are indexed in the Scopus or Web of Sciences databases); 2) articles by leading European researchers in the field (for example, H.-W. Micklitz, who is one of the leading Professor of Economic Law in Europe and N. Helberger, who is professor of Law and Digital Technology, with a special focus on artificial intelligence); 3) latest researches and articles (it is important because technological tools and practice are constantly evolving and changing); 4) major empirical studies in Europe in recent years, which are carried out by adequately resourced institutions (for example, OESD, European Commission, European University Institute); 5) recent authorities' researches, which are carried out by European leading auth orities with a wealth of practical information and employees who are professionals in various fields, including technology, economic, marketing, law, consumer behavior and psychology. Therefore, the article is based on an analysis of large-scale voluminous empirical studies, which complement each other, and double confirm the objectivity and veracity of the research results. The scientific publications are important sources of the research paper. The author uses publications in various sciences and disciplines - from legal and consumer behaviour scientific publications to economical, business and technology scientific publications.

\section{Literature Review}

There are many empirical studies on consumer personal data driven digital marketing and its impact on consumer behaviour. At the European level key researches were carried out by the European Commission, OESD and European leading authorities. For instance, the Forbrukerrådet study (Norway) analyse a sample of settings in Facebook, Google and Windows 10, and shows how default settings and dark patterns, techniques and features of interface design meant to manipulate users, are used to nudge users towards privacy intrusive options. The findings include privacy intrusive default settings, misleading wording, giving users an illusion of control, hiding away privacy-friendly choices, take-it-or-leave-it choices, and choice architectures where choosing the privacy friendly option requires more effort for the users (Forbrukerrådet study, 2018). Sweden Consumer Agency estimated the scope of consumer detriment in Sweden, both in total and distributed across various markets, including the digital market. The estimated level of consumer detriment includes direct financial costs and time loss, but not other aspects such as adverse effects on health or psychological detriment (Sweden Consumer Agency, 2018). Competition and Markets Authority (United Kingdom) made a market study into online platforms and digital advertising. The study has assessed how well the markets for search, social media, and digital advertising are working, and the role of Google and Facebook within them (Competition and Markets Authority, 2020). These studies revealed the main problems of consumer personal data driven digital marketing but did not provide a solution. Important academic publication in the field is ARTSY project 
study (Jabłonowska, Kuziemski ..., 2018). It presented 25 research questions and stated that questions must be addressed not only to lawyers, but also to interdisciplinary teams comprising engineers, data scientists, normative scientists and governance experts. In the field are many new academics publications in various sciences and disciplines - from legal and consumer behaviour scientific publications to economical, business and technology scientific publications. Draper asks - maybe involving marketing experts in research projects regarding consumer law and ads is a good idea? (Draper, Turow, 2017). Therefore, with the article author starts discussion about interaction between consumer law and consumer personal data driven digital marketing.

1.The most common form of consumer personal data driven digital marketing

Today's digitalization brings in the marketing and advertising of new technologies, such as artificial intelligence, big data, digital tools of data gathering and knowledge generation. Consumer profiling is not a new phenomenon, but the use of big data and artificial intelligence now has changed the scale on which traders can explore consumers (Draper, Turow, 2017). A chance to reach the exact consumers who might purchase the product is a dream come true for businesses. Therefore, marketing has been a hot theme in conversations of artificial intelligence and digital technology business, but online advertising is becoming more and more personalised. Moreover, nowadays these digital tools have become more accessible for business. As consumer' behaviour studies have shown, highly personalised and targeted online advertisements influence consumer commercial decision radically more effectively compared to their offline counterparts or general content digital advertisements (Riefa, Clausen, 2019), for example, the Mobile Health Apps' study shows that 50,3\% of mobile users believe that personalised commercial content, such as personalised ads, is in general perceived as more persuasive than generic content. Interestingly, users have, compared to non-users, significantly more confidence in the persuasiveness of such personalised commercial content in general: $62,0 \%$ of Mobile Health app users versus $47,5 \%$ of non-users. Both users and non-users mention that personalised ads could more easily "make you click". For instance, the precise behaviour of the consumers is described by one of the survey participants: "If advertisers know my buying behaviour, for example by using cookies and showing me targeted ads, the chance I will fall for certain offers is much bigger.” (Sax, Helberger, Bol, 2018).

The researchers of the ARTSY project emphasise that targeted and personalised advertising is the party that nowadays seems best prepared and where everyone wants to be (Jabłonowska, Kuziemski, ..., 2018). But empirical marketing studies confirm that now targeted advertising are the most common practice among other consumer personal data driven digital marketing forms (for example, European Commission Study, 2016; European Parliament Study, 2010). There are other forms of consumer personal data driven digital marketing which also are very popular in the business world, for example, personalised pricing (Graaf, 2019), price steering (Mikians, Gyarmati, Erramilli, ..., 2012). But with the development of artificial intelligence as a technological tool algorithm which create targeted advertising can be done once. Hereafter it is working alone without significant human resource consumption. It is very profitable and convenient for business. Therefore, targeted advertising can reach the consumer at any time and in any situation which is recognized as economically viable by an algorithm. A significant advantage of such an algorithm is the ability to learn itself (Citron, Pasquale, 2014). Consequently, it can develop and improve without a man. But the consumer personal data are the fuel in recent developments in machine learning (Alpaydin, 2016). Thus, there is no doubt that targeted advertising currently takes up the largest part of the consumer personal data driven digital marketing industry in the European digital market. Therefore, it is relevant, important and necessary to analyse targeted advertising role in marketing, identify the risks and problems which accrue by the growing industry of targeted advertising.

For this study, it is important to emphasise that names of consumer personal data driven digital marketing forms are not officially approved, therefore various authors use a different definition for them. This paper has used the name "targeted advertising", which is understood as the marketing practice of tailoring personalised adverts to consumers based on their preferences and behaviour, to increase the probability of acquiring the customer (OECD, 2018b). Therefore, it is important for the reader of this study to take into account that in the literature and research other definitions may be used, the content of which corresponds to the definition (targeted advertising) used by the author.

2.Strike a balance and decrease the risks of digital asymmetric

Rott states that this is not new that advertisements are invasive, but personalised advertising feels more invasive because it shows that someone knows more about us than we have meant to tell them (Rott, 2019). OECD has made categories of personal data collected online (OECD, 2018b). The categories show different mechanisms of consumer data collection process: requiring consumers to fill an online form (volunteered data), installing cookies in consumer' devices (observed data) and using advanced data analytics or machine learning to infer certain consumer characteristics (inferred data). For instance, volunteered data are consumer name, phone number, e-mail address, date of birth, address of delivery, responses to surveys, professional occupation, level of education. Observed data - IP address, operating system, past purchases, website visits, 
speed of click through, user's location, search history, "likes" on a social network, but inferred data are income, health status, risk profile, responsiveness to ads, consumer loyalty, political ideology, behavioural bias, hobbies. Every time consumer opens an app like Grindr advertisement networks get his GPS location, device identifiers and even the fact that consumer uses a gay dating app. This is a material violation of users' EU privacy rights, says Max Schrems, founder of the European privacy non-profit NGO (Forbrukerrådet press release, 2010). Those examples are not exhaustive. Examples of inferred data are the most disturbing and fearing because inferred data discover sensitive and anti-discrimination law protected consumer information. Even more, the average consumer does not know that businesses gather such information about him, and the consumer usually does not consent business to gather and use this information. The research of the Norwegian Consumer Council shows that consumers are still pervasively tracked and profiled online and have no way of knowing which entities process their data and how to stop them (Forbrukerrådet study, 2020). 75\% of people around the world are worried about how businesses use their online data (Riefa, 2017). Howells emphasises that advances in technology should not in themselves be an excuse for deregulation (Howells, 2020). There is no doubt that businesses must be allowed to take advantage of modern technology, but this is not an excuse to reduce or even destroy a balance between businesses and technology, on the one hand, and the protection of the values of a traditional consumer, on the other.

Digital asymmetric relations between consumer and business has led to that the targeted advertising can posed the following risks: 1) risk of consumer discrimination (Davida, 2020a); 2) risk to use consumer vulnerability, prejudice and other conditions that make consumer less protected (risk of aggressive advertising) (Reich, Micklitz, Rott ..., 2014.; Davida, 2020b); 3) risk of seeing only the content falling into historically revealed preferences (risk of missing out) (Jabłonowska, Kuziemski ..., 2018); 4) risk of manipulation (targeted advertising is not transparent) (Forbrukerrådet study, 2020); 5) risk of uncontrolled data flow (consumer does not have a choice to turn off or select data which he transfers to a trader) (Jabłonowska, Kuziemski ..., 2018, Davida, 2020b) and 6) the creation and offering of targeted advertising is based on disproportionate advantages of business, such as the business's monopoly position in the field of consumer data (Mak, 2018). The list of risks identified in this article is not exhaustive. Nevertheless, each case must be assessed autonomously, that is, separately, because situations may be different. This complicates the solution to the problem.

Consumer law is full of open-textured notions that call for interpretation, for example, influence, fairness, vulnerability. It is the lawyers' role to ask whether and how behavioural findings can inform the interpretation of such notions, for example by borrowing distinctions or typologies to distinguish between different kinds of influence, different categories of vulnerable consumers or different drivers of consumer weakness and asking whether these can be used to fine tune interpretation of a legal category (Sibony, 2014; Micklitz, Sibony, Esposito, 2018). As a solution to the problems identified in this article author puts forward the development of a new concept - consumer digital vulnerability. As pointed out by H.-W. Micklitz consumer digital vulnerability is not justified to use as a legal concept (Micklitz, 2020). Therefore, the author raises the question for discussion - can consumer digital vulnerability be an economic concept? The author will look for the answer to this question in her further research, as the scope of this article does not allow for a full and qualitative review.

In the next sub section of the paper the author analysis the new business model, namely, consumer personal data as payment, because it is not clear when the targeted advertising as one of the forms of marketing ends. Namely, when starts offering contract, when - contracting, when - use personal data in target marketing at the time of the contractual relationship and when - terminating the contractual relationship. This creates confusion not only for consumers but also for businesses, therefore in the next sub section the author asks - if the new Digital Content Directive will clear it?

3.New business model: consumer personal data as a payment

In 2015 the European Commission adopted a Digital Single Market Strategy for Europe. It is built on three pillars: 1) better access for consumers and businesses to online goods and services across Europe; 2) creating the right conditions for digital networks and services to flourish and 3 ) maximising the growth potential of the European Digital Economy. The economic studies of the digital single market show that European Union consumers could save EUR 11.7 billion each year if they could choose from a full range of European Union goods and services when shopping online. $61 \%$ of European Union consumers feel confident about purchasing via the Internet from a retailer located in their Member State while only 38\% feel confident about purchasing from another European Union Member State (Digital Single Market Strategy for Europe, 2015). The businesses have suffered the cost of between EUR 4 and 8 billion, because of contract law differences in the Member States (Commission working document, 2015). In general, a Digital Single Market Strategy stressed a necessary to abolish differences between the online and offline worlds and break down barriers to the cross-border online activity which is caused by law differences between the Member States, including harmonising the rules for the 
supply of digital content and online sales of goods. This initiative resulted in recently adopted two mutually related directives on consumer sale. Namely, the Sale of Goods Directive will apply to sale contracts between a consumer and a seller for goods, including goods with a digital element (for example, smart TVs, smart fridges or smartwatches) regardless of whether concluded physically in the shops or online (Sale of Goods Directive, 2019). The Digital Content Directive will apply to any contract where the trader supplies digital content (for example, movies, photos, e-books) or digital service (for example, apps, cloud storage, streaming services) to the consumer (Digital Content Directive, 2019). Digitalisation has empowered the rise of an overflow of new business models for the delivery of digital content. Consumers can choose between "on-demand" offerings, "near-on-demand" content, on-demand downloading, streaming, webcasting, IP-based TV, subscription to purchase e-books, e-journals, and e-newspapers, social broadcasting, cloud computing, apps, in-app purchases, and many, many more. Similarly varied are the forms of payment, ranging from monetary prices to services in kind, attention (in particular to advertising), or personal data (Helberger, Loos, Guibault ..., 2012). After analysis of the Digital Single Market Strategy, Katri Havu argues that the use of consumer or user data for commercial purposes constitutes a concrete area that calls for analysis and development of the legal framework (Havu, 2017). The Digital Content Directive seeks to resolve this ambiguity. It determines that directive will apply also to the business models when the consumer does not pay for the service but provides its data in return for the digital content or service as a "payment", except where the personal data are exclusively processed to supply the digital content/service or for allowing the trader to comply with its legal obligations. The protection afforded to consumers in respect of digital content and digital services that are provided in exchange for personal data may have a significant impact on certain business models such as social media platforms and search services. Namely, free has become the default price of internet services (Hoofnagle, Whittington, 2014). More and more products and services rely on collecting and processing personal data: health and fitness devices, personal efficiency apps, personal assistants, search engines, social networks, smart TVs, and connected devices in the Internet of Things (Helberger, Borgesius, Reyna, 2017). In a general business model where consumer personal data are used as payment is not ill-affected or unethical. The author argues that in the digital era it is even normal and desirable because both consumers and business is benefitting from this business model, for example, potentially any consumer can use monetary free service in exchange for his data because every one of us has personal data. It provides equal access to digital content or services from poor to affluent consumers. In turn, free of charge collected consumer data give a chance to business develop and test new technologies without monetary investment. The cost to develop artificial intelligence can be very individual, because it depends on several factors, including engineers, data scientists' cost, a period of development (Polachowska, 2019). Understandably, companies do not want to disclose these costs, but it is pointed out that the costs are significant, measured in millions of euros (Micklitz, 2020). But focusing on the price rather than the cost of free services has led consumers into a position of vulnerability (Hoofnagle, Whittington, 2014). Many studies show that European Union Member States consumers are still poorly or wrongly informed about their major consumer rights regarding e-commerce and online shopping (Kraleva, Dimitrova, 2018), but data driven digital design, marketing and e-commerce are more incomprehensible and more untransparent for the average online consumer. Therefore, businesses are welcome to develop business models in which the consumer does not pay for the service, but the unequal relationship between business and consumer and the risks which is accrued from information asymmetric relations need to be avoided (Larsson, 2018). Namely, business models in which the consumer does not pay for the service need to be transparent (Larsson, Heintz, 2020), understandable, consumers need to have the possibility to choose what data traders collect about them (Davida, 2020). Namely, digital markets and data driven marketing challenges consumer behaviour, therefore a more equal and balanced consumer-business relationship need to be achieved.

The Sale of Goods Directive and the Digital Content Directive are maximum harmonisation Directives meaning that the Member States cannot deviate from their requirements (for example, by giving consumers or traders more or less protection in the areas covered by the Directives), unless expressly permitted by the Directives. This is designed to ensure that the consumer law landscape across the European Union is more consistent than it is currently, which in turn should encourage more traders to offer their products to consumers in the other Member States, and give consumers greater confidence when making cross-border purchases. The Ministry of Economics of the Republic of Latvia has publicly announced the draft legal act for transposition of the Directives into Latvian law. This act provides that the amendments will be introduced into the Latvian Consumer Rights Protection Act which is the main legal act in Latvia on the regulation of protection of consumer rights. The Directive needs to be implemented in the national laws of Member States by 1 July 2021. The Latvian Consumer Rights Protection Act is planned to be supplemented with the provision that this law shall also apply where the trader supplies or undertakes to supply digital content or digital service to the consumer, and the consumer provides or undertakes to provide personal data to the trader, except where the personal data provided by the consumer are exclusively processed by the trader to supply the digital content or digital service by this Directive or for allowing the trader to comply with legal requirements to which 
the trader is subject, and the trader does not process those data for any other purpose (Draft legal act, 2020). Such regulatory changes provide for consumer protection by stipulating that, even in such cases, the consumer is entitled to appropriate and high-quality digital content or a service, as it would be the case if he was paid for it (Report, 2020). The European Commission included in the scope of the Digital Content Directive the socalled "free services" (for example Facebook, YouTube, Instagram), which ensures that they are subject to the same requirements in terms of consumer protection. In turn, Smit and Romain argue that the Digital Content Directive might lead to more complexity and legal uncertainty for suppliers of digital content (Smit, Romain, 2018). Does this mean that the European Union legislator gives the blessing of legislation, that personal data may have commercial value? The European Data Protection Authority argues - no - personal data cannot be assimilated to money, nor considered a commodity. Personal data are related to the fundamental right to the protection of personal data laid down in Article 8 of the European Union's Charter of Fundamental Rights, and as such can neither be monetised, nor the subject of a commercial transaction (even if the data subject wants to be a party to such transaction). (EDPS Opinion 4/2017, 2017). European Data Protection Authorly arguments (that consumer who does not have an alternative currency than their data to pay for a service will likely make this sacrifice; consumers should not be encouraged to bargain one of their fundamental rights) contradicts the thesis put forward in this article - potentially any consumer can use monetary free service in exchange for his data. It provides equal access to digital content or services from poor to affluent consumers. Therefore, business model where consumer personal data are used as payment is not ill-affected or unethical. Moreover, the digital era it is even normal and desirable because both consumers and business are benefitting from this business model. The European Commission justifies the inclusion of digital content contracts in which consumers pay with data by pointing out that covering only digital content paid for with money would discriminate between different business models and would provide an unjustified incentive for businesses to move towards offering digital content against data (Impact Assessment, 2015; Manko, 2016). The author argues that in the Digital Content Directive understanding of personal data are distinguished by the values: commercial and fundamental rights values. The Digital Content Directive stated that it does not prejudice data protection law. Therefore, it is not reasonable to destroy the business model where consumer personal data are used as payment. The law must adapt to the reality of society's development.

With the Digital Content Directive business models where consumer personal data are used as payment are recognised as contractual relationships, which is a prerequisite for European consumer law with the right 1) to call upon the trader to supply the digital content or digital service (remedy for the failure to supply), 2) to call upon the trader to bringing the digital content or digital service into conformity (remedies for lack of conformity), 3) to terminate the contract to apply, for example, a consumer will have the right to cancel long term contracts, it might discourage suppliers from supplying digital goods and demanding payment for them if the goods lack conformity or trader failure to supply goods. Also, the Digital Content Directive attaches some specific consequences to the termination of such contracts by consumers in cases where data were used as payment: 1) the obligation for suppliers to stop processing these data and 2) the right for consumers to retrieve their data. Those provisions are very similar to some of the provisions of the General Data Protection Regulation. It might lead to confusion regarding the interaction between the Digital Content Directive and the General Data Protection Regulation (Smit, Romain, 2018). Attention should be paid that the Digital Content Directive does not give the consumer right to receive a proportionate reduction in the price in case of a lack of conformity when consumer personal data are used as payment. This provision is hidden in the Directive, while in the Latvian Draft legal act it is even more difficult to read. To prevent misapplication of the law and reduce disputes between the business and consumers, I would recommend the Latvian legislator to make clear and unambiguous provisions, that consumers do not have the right to receive a proportionate reduction in the price if he pays with personal data.

In the end it should be emphasised that even though the Digital Content Directive is maximum harmonisation it gives two freedoms for the Member States: 1) Member States are remained free to extend the application of Directive to such situations or to otherwise regulate such situations, which are excluded from the scope of this Directive and 2) Member States are however remained free to determine whether the requirements for the formation, existence and validity of a contract under national law are fulfilled. Therefore, the author agrees with other schoolers, for example, J.Hoekstra and A.Diker-Vanberg (Hoekstra, Diker-Vanberg, 2019), that the Digital Content Directive unlikely will fully harmonised contractual rights in the area concerning the supply of digital content or digital services across the European Union because the Member States still have enough freedom to create a different regulation between the Member States and some provisions of the Digital Content Directive are not thoughtful and they are short-sighted and sustainable. With the Latvian Draft legal act, Latvia did not use the possibility to extend the application of the Directive to such situations or to otherwise regulate such situations, which are excluded from the scope of this Directive. It is clear from the legislative documents (Report, 2020) that the need to use such freedom was not assessed at all. 
The Member States' freedom to determine whether the requirements for the formation, existence and validity of a contract under national law are fulfilled will vary between the Member States. Therefore, in the Digital Single Market of Europe will not be common understanding when businesses are doing marketing, when - offering contract (Jabłonowska, Kuziemski ..., 2018), when - contracting, when - use personal data in target marketing at the time of the contractual relationship and when - terminating the contractual relationship. Also, there is a period after the termination of the contractual relationship, during which the businesses continue to make various forms of offers and carry out marketing. This creates confusion not only for consumers but also for businesses. The Digital Content Directive did not use the possibility to clear it.

\section{Conclusions, proposals, recommendations}

1. Research results confirm the consumer personal data driven digital marketing has various forms, but in the Europe the most common form is targeted advertising. Currently, it takes up the largest part of the digital marketing industry in the European digital market. Marketing business including targeted advertising must be allowed to take advantage of modern digital technology, but the development of digital technology and world technology competition is not excused to reduce a balance between business and technology, on the one hand, and the protection of the traditional values of a consumer, on the other.

2. Digital asymmetric relations between consumer and business has led to risks that can be posed by targeted advertising, for example, risk of consumer discrimination, risk to use consumer vulnerability, risk of manipulation, risk of uncontrolled data flow and others. The list of risks identified in this article is not exhaustive, but the management need to take into consideration this risks as red lines for doing consumer personal data driven digital marketing, including targeted advertising.

3. Digital asymmetric relations between consumer and business ask for a universal and unprecedented solution - development of a consumer digital vulnerability concept in law. It cannot be a legal concept, because of its narrow understanding and the fact that the European legislation is aimed to protect consumer' economic interests. Therefore, for future investigations and for discussion of policy makers and management the author raises the question - can consumer digital vulnerability be an economic concept and if yes, what will be its content?

4. In a general business model where consumer personal data are used as payment is not ill-affected or unethical. In the digital era it is even normal and desirable because both consumers and business is benefitting from it. Therefore, it is not reasonable to destroy the business model where consumer personal data are used as payment due to the inability to separate commercial and human fundamental right values. The policy makers must adapt the law and management must interpret it according to the reality of society and digital technology development.

5. The author recommends Latvian policy maker to develop clear and unambiguous provisions in the Latvian Consumer Rights Protection Act, that consumers do not have the right to receive a proportionate reduction in the price if he pays with personal data. Otherwise, it could lead to an increase in disputes between consumers and the business.

6. The Digital Single Market of Europe do not have a common understanding when businesses are doing marketing including targeted advertising, when - offering contract, when - contracting, when - use personal data in target marketing at the time of the contractual relationship and when - terminating the contractual relationship. Besides, there is a period after the termination of the contractual relationship, during which the businesses continue to make various forms of offers and carry out marketing. This creates confusion not only for consumers but also for businesses. The Digital Content Directive did not use the possibility to clear it, but the author recommendations for policy makers is to fix it by implementing the Digital Content Directive at the national laws till 1 July 2021.

Alpaydin, E., 2016. Machine Learning: The New AI. London: MIT Press.

\section{Bibliography}

Anderson, Ch., 2009. Free: The Future of a Radical Price. Now York: Hyperion.

Citron, D. K., Pasquale, F., 2014. The Scored Society: Due Process for Automated Predictions. Washington Law Review, 89(1), 1-33.

Columbus, L., 2020. Which Web Conferencing Software Is the Most Popular with Its Users? Forbes. [Online] Available at: https://www.forbes.com/sites/louiscolumbus/2020/04/20/which-web-conferencing-software-is-the-most-popular-with-theirusers/?sh=50e2a5615440. [Accessed 16.11.2020].

Commission working document, 2015. A Digital Single Market Strategy for Europe - Analysis and Evidence Accompanying the Document Communication from the Commission to the European Parliament, the Council, the European Economic and Social Committee and the Committee of the Regions A Digital Single Market Strategy for Europe, COM (2015) 192 final. [Online] Available at: https://eurlex.europa.eu/legal-content/EN/TXT/?uri=CELEX\%3A52015SC0100\#footnoteref41. [Accessed 16.11.2020]. 
Competition and Markets Authority, 2020. Online Platforms and Digital Advertising. Market Study Final Report. [Online] Available at: https://assets.publishing.service.gov.uk/media/5efc57ed3a6f4023d242ed56/Final_report_1_July_2020_.pdf. [Accessed 16.11.2020].

Davida, Z., 2020a. Patērētāju tiesību aizsardzības izaicinājumi digitalizācijas laikmetā: tehnologiiskais totalitārisms. In: Latvijas Universitātes 78. starptautiskās zinātniskās konferences rakstu krājums Starptautisko un Eiropas Savienības tiesību piemērošana nacionālajās tiesās. Riga: LU Akadēmiskais apgāds, 295-302.

Davida Z., 2020b. Consumer Rights and Personalised Advertising: Risk of Exploiting Consumer Vulnerabilities. SOCRATES, 1(16), 83-94.

Digital Content Directive, 2019. Council Directive (EU) 2019/770 of 20 May 2019 on certain aspects concerning contracts for the supply of digital content and digital services. OJ, L 136, 22.05.2019, 1-27.

Digital Single Market Strategy for Europe, 2015. Communication from the Commission to the European Parliament, the Council, the European Economic and Social Committee and the Committee of the Regions of 6 May 2015. COM (2015) 192 final. [Online] Available at: https://eurlex.europa.eu/legal-content/EN/TXT/?uri=celex\%3A52015DC0192. [Accessed 16.11.2020].

Draft legal act, 2020. Amendments into the Consumer Rights Protection Act. [Online] Available at:

https://em.gov.lv/lv/Ministrija/sabiedribas_lidzdaliba/diskusiju_dokumenti/. [Accessed 16.11.2020].

Draper, N. A., Turow, J., 2017. Audience Constructions, Reputations, and Emerging Media Technologies: New Issues of Legal and Social Policy. In: editors R. Brownsword, E. Scotford \& K. Yeung. The Oxford Handbook of Law, Regulation and Technology. Edition. Oxford: Oxford University Press, 1143-1168.

EDPS Opinion 4/2017, 2017. On the Proposal for a Directive on Certain Aspects Concerning Contracts for the Supply of Digital Content. [Online] Available at: https://edps.europa.eu/sites/edp/files/publication/17-03-14_opinion_digital_content_en.pdf. [Accessed 16.11.2020].

European Commission Study, 2016. Study on the Impact of Marketing through Social Media, Online Games and Mobile Applications on Children's Behaviour. Final Report. [Online] Available at:

https://ec.europa.eu/info/sites/info/files/online_marketing_children_final_report_en.pdf. [Accessed 16.11.2020].

European Parliament Study, 2010. Study on Misleading Advertising on the Internet. [Online] Available at: http://www.europarl.europa.eu/RegData/etudes/etudes/join/2010/440289/IPOL-IMCO_ET\%282010\%29440289_EN.pdf [Accessed 16.11.2020].

Forbrukerrådet Press Release, 2010. New Study: The Advertising Industry is Systematically Breaking the Law. [Online] Available at: https://www.forbrukerradet.no/side/new-study-the-advertising-industry-is-systematically-breaking-the-law/. [Accessed 16.11.2020].

Forbrukerrådet Study, 2020. Out of Control. How Consumers are Exploited by Online Advertising Industry. [Online] Available at: https://fil.forbrukerradet.no/wp-content/uploads/2020/01/2020-01-14-out-of-control-final-version.pdf. [Accessed 16.11.2020].

Graaf, de T., 2019. Consequences of Nullifying an Agreement on Account of Personalised Pricing. EuCML, 5, 184-193.

Havu, K., 2017. The EU Digital Single Market from a Consumer Standpoint: How do Promises Meet Means? Contemporary Readings in Law and Social Justice, 9(2), 146-183.

Helberger, N., Borgesius, F. Z., Reyna A., 2017. The Perfect Match? A Closer Look at the Relationship between EU Consumer Law and Data Protection Law. Common Market Law Review, 54(5), 1427-1466.

Helberger, N., Loos, M. B. M., Guibault, L., Mak, Ch., Pessers, L., 2013. Digital Content Contracts for Consumers. Journal of Consumer Policy, $36,37-57$.

Hoekstra, J., Diker-Vanberg, A., 2019. The Proposed Directive for the Supply of Digital Content: is it Fit for Purpose? International Review of Law, Computers \& Technology, 33(1), 100-117.

Hoofnagle, Ch. J., Whittington J., 2014. Free: Accounting for the Costs of the Internet's Most Popular Price. UCLA Law Review, 607, 606-670.

Howells G., 2020. Protecting Consumer Protection Values in the Fourth Industrial Revolution. Journal of Consumer Policy, 43, $145-175$.

Impact Assessment, 2015. Accompanying the document Proposals for Directives of the European Parliament and of the Council (1) on Certain Aspects Concerning Contracts for the Supply of Digital Content and (2) on Certain Aspects Concerning Contracts for the Online and Other Distance Sales of Goods. Commission Staff Working Document. [Online] Available at: https://eur-lex.europa.eu/legalcontent/EN/TXT/PDF/?uri=CELEX:52015SC0274R\%2801\%29\&from=EN. [Accessed 16.11.2020]. 
Italian Competition Authority, 2018. Facebook Fined 10 Million Euros by the ICA for Unfair Commercial Practices for Using its Subscribers' Data for Commercial Purposes. [Online] Available at: https://en.agcm.it/en/media/press-releases/2018/12/Facebook-fined-10-million-Euros-bythe-ICA-for-unfair-commercial-practices-for-using-its-subscribers\%E2\%80\%99-data-for-commercial-purposes. [Accessed 16.11.2020].

Jabłonowska, A., Kuziemski, M., Nowak, A. M., Micklitz, H.-W., Pałka, P., Sartor, G., 2018/ Consumer Law and Artificial Intelligence Challenges to the EU Consumer Law and Policy Stemming from the Business' Use of Artificial Intelligence. Final report of the ARTSY project, EUI Working Paper LAW 2018/11, 1-79.

Keough, B., 2020. The Best Videoconferencing Service. Wirecutter. [Online] Available at: https://www.nytimes.com/wirecutter/reviews/bestvideo-conferencing-service/. [Accessed 16.11.2020].

Kraleva, V., Dimitrova, I., 2018. Protecting the e-Consumer: Legal Awareness and Consumer Behavior of Bulgarian Youngsters. Proceedings. In: 10th International Scientific Conference "New Challenges of Economic and Business Development - 2018: Productivity and Economic Growth, Riga, Latvia, May 10-12, 2018: Proceedings. Riga: University of Latvia, 348-357.

Larsson, S., Heintz, F., 2020. Transparency in Artificial Intelligence. Internet Policy Review, 9(2), 1-16.

Larsson, S., 2018. Algorithmic Governance and the Need for Consumer Empowerment in Data-Driven Markets. Internet Policy Review, 7(2), 1-13.

Manko, R., 2016. Contracts for Supply of Digital Content: A Legal Analysis of the Commission's Proposal for a New Directive. European Parliament Research Service, In-depth analysis, PE 582.048, 1-36.

Mak, V., 2018. Gedachten bij een gepersonaliseerd consumentenrecht. Tijdschrift voor consumentenrecht \& handelspraktijken, 6, $274-276$.

Mathur, A., Acar, G., Friedman, M.J., Lucherini, E., Mayer, J., Chetty, M., Narayanan, A., 2019. Dark Patterns at Scale: Findings from a Crawl of $11 \mathrm{~K}$ Shopping Websites. Proceedings of the ACM on HumanComputer Interaction, 3, 1-32.

Mathur, A., Narayanan, A., Chetty, M., 2018. Endorsements on Social Media: An Empirical Study of Affiliate Marketing Disclosures on YouTube and Pinterest. Proceedings of the ACM on HumanComputer Interaction, 2, 1-26.

Micklitz, H.-W., Sibony, A-L., Esposito, F., 2018. The Bright and Adventurous Future of Consumer Law Research. In: Research Methods in Consumer Law. London: Edward Elgar Publishing.

Micklitz, H.-W., 2020. Digital Vulnerability and Digital Asymmetry in the Directive 2005/29/EC on Unfair Commercial Practices. Speech at the Conference Digital Conference: Consumers and Businesses in Digital Markets - An Unequal Relationship, Maastricht University. [Online] Available at: https://www.youtube.com/watch?v=jrc-AovoFqM\&feature=youtu.be\&app=desktop. [Accessed 16.11.2020].

Mikians, J., Gyarmati, L., Erramilli, V., Laoutaris, N., 2012. Detecting Price and Search Discrimination on the Internet. Conference Proceedings 11th ACM Workshop on Hot Topics in Networks, 79-84.

OECD, 2018a. Improving online disclosures with behavioural insights. [Online] Available at: https:/www.oecd-ilibrary.org/docserver/39026ff4en.pdf? expires $=1606820524 \& \mathrm{id}=\mathrm{id} \&$ accname $=$ guest\&checksum=76DFBA39AA76F351F81662A5ED1C9357. [Accessed 16.11.2020].

OECD, 2018b. Background Note by the Secretariat, Personalised Pricing in the Digital Era, DAF/COMP 13. [Online] Available at: oecd.org/daf/competition/personalised-pricing-in-the-digital-era.htm [Accessed 16.11.2020].

OECD, 2019a. Online Advertising Trends, Benefits and Risks for Consumers. [Online] Available at: https:/www.oecdilibrary.org/docserver/1f42c85d-en.pdf?expires=1606820323\&id=id\&accname=guest\&checksum=0AC2CC225A9002043096A5854A880671. [Accessed 16.11.2020].

OECD, 2019b. Challenges to Consumer Policy in the Digital Age. [Online] Available at: http://www.oecd.org/sti/consumer/challenges-toconsumer-policy-in-the-digital-age.pdf. [Accessed 16.11.2020].

Polachowska, K., 2019. How Much do AI Projects Cost? Neoteric. [Online] Available at: https://neoteric.eu/blog/how-much-do-ai-projects-cost/. [Accessed 16.11.2020].

Report, 2020. Ministry of Economic of Republic of Latvia Report on Initial Impact Assessment for the Draft Legal Act Amendments into the Consumer Rights Protection Act. [Online] Available at: https://em.gov.lv/lv/Ministrija/sabiedribas_lidzdaliba/diskusiju_dokumenti/. [Accessed 16.11.2020].

Riefa C., Clausen L., 2019. Towards Fairness in Digital Influencers' Marketing Practices. EuCML, 2, 64-74. 
Reich, N., Micklitz, H.-W., Rott P., Tonner, K., 2014. European Consumer Law. 2 nd edition. Cambridge: Intersentia.

Riefa C., 2017. G20 Consumer Summit on Building a Digital World Consumers Can Trust. EuCML, 3, 124-129.

Rott, P. A., 2019. Consumer Perspective on Algorithms. In: Editors Almeida, de. L., Gamito, M. C., Durovic, M., Purnhagen, K. P. The Transformation of Economic Law: Essays in Honour of Hans-W. Micklitz. Edition. London: Hart, 43-63.

Sale of Goods Directive, 2019. Council Directive (EU) 2019/771 of 20 May 2019 on Certain Aspects Concerning Contracts for the Sale of Goods, Amending Regulation (EU) 2017/2394 and Directive 2009/22/EC, and repealing Directive 1999/44/EC. OJ, L 136, 22.5.2019, 28-50.

Sax, M., Helberger, N., Bol, N., 2018. Health as a Means Towards Profitable Ends: mHealth Apps, User Autonomy, and Unfair Commercial Practices. Journal of Consumer Policy, 41(2), 103-134.

Sibony, A-L., 2014. Can EU Consumer Law Benefit from Behavioral Insights? An Analysis of the Unfair Practices Directive. ERPL, 6(901), 130 .

Schwab, K., 2016. The Fourth Industrial Revolution. World Economic Forum, 1-184.

Smit, L., Romain, R., 2018. The Proposal for a Directive on Digital Content: a Complex Relationship with Data Protection law. ERA Forum, 19, 159-177.

Sweden Consumer Agency, 2018. Consumer Detriment in Sweden. What do Unsuccessful Purchases Cost? [Online] Available at: https://www.konsumentverket.se/globalassets/publikationer/var-verksamhet/comsumer-detriment-in-sweden-konsumentverket.pdf. [Accessed 16.11.2020]. 


\title{
IS THE GROWTH OF COMPANIES INFLUENCING THEIR FINANCIAL CONDITION DEPENDING ON THEIR SIZE - S\&P 500 LISTED COMPANIES EXAMPLE Agata Gniadkowska-Szymanska, University of Lodz
}

\section{Monika Bolek, University of Lodz}

\begin{abstract}
The goal of this paper is related to the analysis of the relationship between the earnings per share growth and the financial condition of companies as measured by Altman Z-Score Model in relation to the size of entities taken into consideration. The research is made on the example of S\&P500 Index listed companies in a period 1996 - 2018 and their 3 and 5 years EPS growth. The linear and non-parametric relationship analysis were applied to verify the nature of the relation between the variables taken into consideration. It was found, that the relationship between the EPS growth and Altman Z-scores is not linear and moreover it was found that the smallest the company, the higher the growth index it is characterized by. In the second step the OLS models were tested providing the following results: in most of cases the growth of EPS influences the Altman scores in a positive way meaning that the higher EPS growth results in a better financial condition of a company. Interestingly medium size of the companies may affect its EPS growth process in relation to financial condition in a negative way.
\end{abstract}

Keywords: company growth, economic condition, Altaman Model, S\&P 500 index.

JEL code: G30, G32, G33, M2

\section{Introduction}

The issue of the growth of companies together with their financial condition is a vital topic on the capital market regarding the value growth of listed companies. There are some features related to the growth that need to be discussed. First of all the growth in itself that might be represented by the growth of sales, assets, equity and finally earnings per share (EPS) as mentioned by Danbolt, Hirst and Jones (2013). The growth of EPS legitimizes the growth of value and it is directly related to the company's goal that is the value maximization. The growth of value should be related to the financial condition of company as reflected for example by Altman Z-Score Model, that can signal not only the distress but also the standing of the business. Altman Model is often used as a tool for accessing the financial condition of companies that can be good or bad (Altman and Hotchkiss, 2006).

The growth of mature companies is rather less dynamic than the growth of younger and smaller business entities and this difference related to the size may influence the relationship between the EPS growth and financial condition. The sustainable growth in itself may not affect the financial condition in a negative way because it is harmonious and related to the market development, while the more dynamic growth may be related with more aggressive strategies, when companies use more resources, operate faster and put a lot of energy to the growth that may cause the distress.

The goal of this paper is related to the analysis of the relationship between the growth of companies and the assessment of the 3 and 5 years EPS growth influence on the financial condition as measured by Altman Z-Score Model, depending on the size of companies taken into consideration. It is expected that there is the relationship between the phenomena taken into consideration and the EPS growth influence on the financial condition of companies as it was described in the model proposed by authors. The US market with S\&P 500 listed companies is taken into consideration as the example of developed economy that can be used as the one to follow by less developed markets.

The growth of companies is necessary to build strong economy according to many authors, for example Levine and Zervos (1999) found that larger, more efficient stock markets positively influence economic growth. More recently Pradhan (2018) examined the long-run relationship between the development of the stock market and economic growth in G20 countries and found the relationship between the development of the stock market and per capita economic growth. From the other hand the early warning distress models are commonly used and they can signal that the bad condition of a company is related to the higher growth of EPS and value creation. This is why one needs to be careful when assessing the business basing just on the distress models and scores. Risky strategies affecting Altman Z-Sores in a negative way may result in higher growth of value. From the other hand the growth of EPS in itself can affect the condition of company, higher growth can improve or worsen it and this is why this issue needs to be analysed. From the other hand the economic condition of a company can influence its growth making it more or less intense (Kaplan et al. 2005)

In this paper the problem of the influence of EPS growth on financial condition of companies will be discussed and presented in the following sections. In the first step the literature related to the topic of a paper will be discussed, next the data and methods followed by the results description. The conclusions are related to the main findings and some recommendations for the future research. 


\section{Literature Review}

Managing the company's value should lead to its maximization, not only optimization or coverage of minimum requirements of investors. Such management can therefore be defined as the concept of managing the enterprise from the point of view of the owners and their contribution (Lantos, 2001). The company's growth is related to the increase in capitals, which enables financing the growing assets as a result of the implementation of investment projects (Stubelj, 2010). The company's financial decisions consist of obtaining the cheapest possible capital necessary to finance their activity, which is adapted in the organizational form of the economic unit, its development phase, and thus - the risk (Schleifer et al., 1997; Fama, 1980). The growth of business entities is a crucial process on a capital market because otherwise investors would not receive the expected yield. If the market is efficient and investors discount the information on the company's performance in a rational manner, the market rate of return should reflect the company's current situation (Muhammed, Scrimgeour, 2014).

The development of the company is closely related to the growth, a measurable category while the development is a qualitative category, which can be used to describe the company's changing status (Davision et al. 2006; El Hakioui, Louitri, 2017; Perényi, Yukhanaev, 2016). Earnings per share and their growth is a measure of effectiveness that should be paid special attention to, especially that they are the basis of most research conducted in the area of company's growth. However, it should be remembered that the method of cost management is also an important factor in assessing the effectiveness of the company's operations, as they significantly affect the level of operating result, which in turn translates into EPS (de Wet, 2013; Battall, Sabri, 2020). The use of modern cost management methods solves many problems related to, for example, continuous technological development, which contributes to the increase in indirect costs in the company. This is the reason for inadequate mapping of unit costs in traditional costing methods, which in turn affects profits (Kuta, Rudnicki, 2015). Gentry and Pyhrr (1973) presented a model that simulates the long-run financial planning process of the firm. It is assumed in their findings that the financial objective of top management is the long-run growth in earnings per share (EPS). It is a notion that serves as a decision criterion for evaluating investment alternatives. This performance measure is the rate of return required on new investment that is required by top management (Choudhary, 2011).

Growth is a multi-dimensional aspect, and one should not only refer to a single measure of growth, such as sales or assets. The selection of as many measures as possible allows for a better assessment of the company's growth, however, it creates research limitations due to the number of models that should be analyzed. For this reason, there should be one overarching measure that best describes growth - and that is, earnings per share and its growth. Growing earnings per share should translate into a growing market value of the company and the rate of return on investment in its shares. From the other hand the profits are measured taking into account certain errors which, in consequence, may affect the ir forecasted values. Moreover high level of return on equity leads to a decline in future profits, and this is because new enterprises are emerging on the market, encouraged by high margins, which increase competitiveness in the sector and as a result reduces margins (Fama, Fremch, 2007).

Business growth can be measured by sales, assets, or equity growth, but such a growth may not add value to owners because profits may not increase when the organization implements negative NPV investment projects (Arnold et al., 2002). Danbolt, Hirst and Jones (2013) presented an analysis of the relationship of investment profitability with future earnings per share, which reflect the company's growth. They found moreover that the growth opportunity measures do not influence the growth of EPS. Why earnings do not grow according to the expectations is an important question bothering researchers dealing with modelling of business performance. There is a possibility that the effectiveness of the implemented investment projects does not cover the cost of capital, and thus does not translate into profits. This problem relates to the method of determining the value of the cost of capital, which is not uniform and produces different results through various analyzes. Additionally, development decisions may be made by managers for reasons other than maximizing shareholder value, which in turn is related to the corporate governance issue and the behavioural aspects of decision making. Another possibility to explain the paradox of non-increasing profits with the simultaneous growth of the enterprise, even when successful investment projects are carried out, is the fact that current profits can be offset by lower profits generated by old assets. There is also a hypothesis that the companies taken into consideration in previous papers are in different stages of development or that managers simply manipulate profits.

The growth of a company is related to the various sources of capital used in different stages of development based on the growth opportunity taken into consideration by investors (Borgman et al., 2006). Mueller (2008) studied the influence of the benefits of control on the capital structure and the growth of limited liability companies in UK observed for up to 5 years. It was presented in the findings that companies where existing owners would lose more control if they expanded, had smaller equity increases, were more levered and grow slower. Moreover Akhmadi and Robiyanto (2020) examined the antecedent factors of debt policy on the influence of firm growth on firm value. The results prove that the firm 
growth, proxied by asset growth or sales growth, did not have a significant influence on the debt policy. Further, there was no significant influence of debt policy on firm value when using debt ratio and also dividend policy as a control variable. In contrast, there was a positive and significant influence on the firm value when using debt to equity ratio proxy, both with or without using the control variable. Therefore, the debt policy was not proven as an antecedent on the influence of firm growth on firm value (Pilotte, 1992; Bates, 2005). However, Burton et al. (1999) show that the market reaction to joint venture announcements is significantly positive, whilst similar announcements from individual companies do not elicit any response. They found that the market reaction to single company investments is positively related to the size of the expenditure, but only for projects that immediately generate cash. Cooper et al. (2008) test the impact of an investment in assets on the returns by examining the cross-sectional relationship between growth of assets and subsequent returns on stocks. The rate of asset growth is a strong predictor of future abnormal returns. Asset growth remains predictable even with large-cap stocks (Berk et al., 1999). By comparing the growth rates of assets with the previously documented determinants of returns (i.e. accounting ratios to market value, firm capitalization, delayed returns, accruals and other growth measures), it turns out that the annual growth of the firm's assets appears as an economically and statistically significant predictor of US cross-section stock returns (Platt et al., 1995). Moreover, the relationship between the growth of companies as measured by EPS growth and economic condition as measured by Altman model may reflect the critical moment of value creation depending on the condition assessment (Altman 1968; Altman 1983; Altman, Hotchkiss 2006). It is interesting to find out if the growth in itself can influence the financial condition of companies in return.

It should be noted that many researchers are beginning to refer in their papers to the bankruptcy prediction models to help assess the condition of a company (see: Piotroski, 2000; Grice, Ingram, 2001; Griffin, Lemmon, 2002; Franzen et al., 2007; Xu, Zhang, 2009). The economic condition of a company can influence its growth making it more or less intense (Kaplan et al., 2005). From the other hand the growth of company referring to its value as measured by the EPS growth can influence its financial condition as measured by Altman Model and this new approach will be tested in the following sections.

\section{Methods and Data}

This article examines companies from US market which were included in S\&P 500 Index in the last quarter of 2018. The source of data on prices and characteristics of companies comes from the Bloomberg database. Prices of shares and ratios have been adjusted for any transactions that could artificially affect the rate of return, such as splits, subscription rights, dividends, share buybacks, etc., according to the methodology data provider. The survey is carried out on data from the period October 30, 1996 - December 31, 2018. The survey was conducted on rates calculated on the basis of prices from the last day of each year.

Earnings per share is the factor that reflects corporate growth in terms of value maximization, it is taken directly from the Bloomberg database as a continuous growth index calculated in terms of 3 and 5 years.

One of the most popular discriminatory methods of accessing the condition of company is Altman Z-Score Model. If the function result is 2.99 or more, company is said to be in a good financial condition, if the function value is less than 1.81, then the company is called a bankrupt. Based on Altman and Hotchkiss (2006) the classification criteria for companies was developed and presented in Table 1. 
Table 1

Criteria for classification of companies in the Altman's system

\begin{tabular}{|c|c|c|}
\hline Economic conditio & $\mathbf{Z}$ value & Rating \\
\hline \multirow{9}{*}{ Safe range } & 8,15 & AAA \\
\hline & 7,6 & $\mathrm{AA}+$ \\
\hline & 7,3 & AA- \\
\hline & 7 & AA- \\
\hline & 6,85 & $\mathrm{~A}+$ \\
\hline & 6,65 & A \\
\hline & 6,4 & A- \\
\hline & 6,25 & $\mathrm{BBB}+$ \\
\hline & 5,85 & BBB \\
\hline \multirow{6}{*}{ Insecure range } & 5,65 & BBB- \\
\hline & 5,25 & $\mathrm{BB}+$ \\
\hline & 4,95 & $\mathrm{BB}$ \\
\hline & 4,75 & BB- \\
\hline & 4,5 & $\mathrm{~B}+$ \\
\hline & 4,15 & $\mathrm{~B}$ \\
\hline \multirow{5}{*}{ Dangerous range } & 3,75 & B- \\
\hline & 3,2 & $\mathrm{CCC}+$ \\
\hline & 2,5 & $\mathrm{CCC}$ \\
\hline & 1,75 & CCC- \\
\hline & 0 & $\mathrm{D}$ \\
\hline
\end{tabular}

Source: Altman, E.I., Hotchkiss, E., 2006, Corporate Credit Scoring-Insolvency Risk Models, in Corporate Financial Distress and Bankruptcy, provided by stockwatch.pl.

It can be said that the Altman's Model has ceased to serve only a warning function, but has also become a tool for assessing the economic condition of a company, which on the capital market should translate into value. Therefore good condition should be associated with an increase in earnings per share representing the growth of value.

The analysis related to the 3 and 5 year EPS growth and condition assessment of companies listed on the S\&P 500 is presented with the correlation analysis and OLS models parameters estimations. The cross-sectional OLS models are applied with Altman Model scores as logarithmic variable that is explained by the growth of EPS index and the size of companies as measured by natural logarithm of Total Assets.

The model for the total sample is presented in the equation 1.

$$
\log A S_{t}=a_{1 t}+a_{2} \ln T A_{t}+a_{3} E P S_{t=-n+t}+e_{t}
$$

For the portfolio's, after the assets significance verification, the model is simplified as presented on the equation 2 .

$$
\log A S_{t}=a_{1 t}+a_{3} E P S_{t=-n+t}+e_{t}
$$

Where:

AS - Altman Z-Score Model,

TA - Total Assets,

EPS - Earnings Per Share,

$\mathrm{N}-3$ or 5 years period.

The companies taken into consideration are divided for 5 portfolios reflecting their size from the smallest to the largest.

\section{Results}

In this section the results of the analysis of the companies' growth are presented. In the first step the statistics of variables are provided for the total sample and subsamples reflecting 5 portfolio of companies divided basing on their assets size. 
Statistics of variables

\begin{tabular}{|c|c|c|c|c|c|}
\hline Variable & Mean & Median & S.D. & Min & Max \\
\hline \multicolumn{6}{|c|}{ Total sample } \\
\hline EPS 3 & 28.42 & 12.93 & 224.3 & -1608 & 15855 \\
\hline EPS 5 & 29.57 & 13.40 & 153.4 & -1393 & 9523 \\
\hline $\mathrm{AS}$ & 5.660 & 4.543 & 6.043 & 0.0058 & 116.1 \\
\hline TA & 24558 & 6164 & 92442 & 0.3080 & 218748 \\
\hline \multicolumn{6}{|c|}{ Portfolio 1} \\
\hline EPS 3 & 40.31 & 22.86 & 182.4 & -1608. & 3333 \\
\hline EPS 5 & 42.25 & 22.17 & 150.0 & -1393. & 2000 \\
\hline $\mathrm{AS}$ & 10.94 & 7.297 & 12.63 & 0.0505 & 116.1 \\
\hline TA & 663.2 & 628.7 & 429.3 & 0.308 & 1483 \\
\hline \multicolumn{6}{|c|}{ Portfolio 2} \\
\hline EPS 3 & 33.16 & 15.52 & 325.0 & -1600.0 & 15804 \\
\hline EPS 5 & 30.10 & 16.01 & 88.29 & -929.0 & 1093 \\
\hline $\mathrm{AS}$ & 6.738 & 5.597 & 4.692 & 0.0406 & 61.69 \\
\hline TA & 2722 & 2666 & 767.1 & 1483 & 4162 \\
\hline \multicolumn{6}{|c|}{ Portfolio 3} \\
\hline EPS 3 & 32.44 & 13.25 & 315.7 & -410.2 & 15855 \\
\hline EPS 5 & 32.56 & 13.94 & 272.6 & -929.0 & 9523 \\
\hline AS & 5.275 & 4.561 & 4.178 & 0.0058 & 72.41 \\
\hline TA & 6377 & 6164 & 1517 & 4162 & 9438 \\
\hline \multicolumn{6}{|c|}{ Portfolio 4} \\
\hline EPS 3 & 26.32 & 10.96 & 105.9 & -166.8 & 2126 \\
\hline EPS 5 & 34.61 & 12.18 & 113.5 & -40.77 & 1277 \\
\hline AS & 4.387 & 3.844 & 3.439 & 0.0058 & 61.69 \\
\hline TA & 14896 & 14325 & 3825 & 9438 & 22877 \\
\hline \multicolumn{6}{|c|}{ Portfolio 5} \\
\hline EPS 3 & 16.54 & 9.145 & 72.93 & -382.0 & 1669 \\
\hline EPS 5 & 17.30 & 9.873 & 47.45 & -33.05 & 999.9 \\
\hline AS & 3.681 & 3.439 & 2.589 & 0.0072 & 35.23 \\
\hline TA & 98107 & 42716 & 189305 & 22877 & 218748 \\
\hline
\end{tabular}

Source: own study

Basing on the average results it can be found that the smaller the company, the higher its growth on average. The largest companies are characterized by the lower growth rate in shorter ( 3 year) and longer ( 5 year) periods. What is interesting the smallest companies in the sample are characterized by the higher Altman score indicating their economic condition to be much better than the large companies. I can be concluded that the larger the company is, the lower the assessment of its economic condition with Altman Z-Score.

It is worth noticing, that in case of the growth indices the standard deviation is the highest for medium sized companies included to the portfolios 2 and 3 , and the smallest in the portfolio 5, representing the largest companies that grow slower and in a more sustain way according to the evidence. The highest standard deviation for Altman score is in the group of the smallest companies and the lower in the group of the largest companies.

In the next step the correlation analysis between the measures is provided and presented in Table 3 . The Pearson and Spearman correlation ratios are calculated to assess the function characteristic for the relation between variables of growth and condition assessment regarding their different nature. 
Correlation analysis of variables

\begin{tabular}{|c|c|c|c|c|}
\hline & \multicolumn{2}{|c|}{ Pearson correlation } & \multicolumn{2}{|c|}{ Spearman rho correlation } \\
\hline & EPS 3 & EPS 5 & EPS 3 & EPS 5 \\
\hline \multicolumn{5}{|c|}{ Total sample } \\
\hline Cor. with AS & 0.09411138 & 0.04964825 & 0.25041897 & 0.24051101 \\
\hline Observations & 10845 & 10228 & 10845 & 10228 \\
\hline t-stat & 9.84439 & 5.0273 & 26.9367 & 25.0593 \\
\hline p-value & 0.0000 & 0.0000 & 0.0000 & 0.0000 \\
\hline \multicolumn{5}{|c|}{ Portfolio 1} \\
\hline Cor. with AS & 0.17835800 & 0.04631789 & 0.22989829 & 0.18510042 \\
\hline Observations & 1328 & 898 & 1208 & 898 \\
\hline t-stat & 6.60559 & 1.38948 & 8.21033 & 5.64438 \\
\hline$p$-value & 0.0000 & 0.1650 & 0.0000 & 0.0000 \\
\hline \multicolumn{5}{|c|}{ Portfolio 2} \\
\hline Cor. with AS & 0.03249095 & 0.00013752 & 0.13687493 & 0.10960820 \\
\hline Observations & 2133 & 1999 & 2133 & 1999 \\
\hline t-stat & 1.50137 & 0.00614 & 6.38155 & 4.93031 \\
\hline$p$-value & 0.1334 & 0.9951 & 0.0000 & 0.0000 \\
\hline \multicolumn{5}{|c|}{ Portfolio 3} \\
\hline Cor. with AS & $-0,00980384$ & 0.00135348 & 0.09011435 & 0.07141323 \\
\hline Observations & 2390 & 2294 & 2390 & 2294 \\
\hline t-stat & $-0,47931$ & 0.064826 & 4.42347 & 3.42914 \\
\hline$p$-value & 0.6318 & 0.9483 & 0.0000 & 0.0000 \\
\hline \multicolumn{5}{|c|}{ Portfolio 4} \\
\hline Cor. with AS & 0.05142843 & 0.04100091 & 0.23102969 & 0.21279780 \\
\hline Observations & 2405 & 2369 & 2405 & 2369 \\
\hline t-stat & 2.52543 & 1.99729 & 11.6449 & 10.6002 \\
\hline $\mathrm{p}$-value & 0.0116 & 0.0459 & 0.0000 & 0.0000 \\
\hline \multicolumn{5}{|c|}{ Portfolio 5} \\
\hline Cor. with AS & 0.04281618 & 0.06669886 & 0.21353065 & 0.21297519 \\
\hline Observations & 2701 & 2660 & 2701 & 2660 \\
\hline t-stat & 2.22725 & 3.44768 & 11.3594 & 11.2422 \\
\hline p-value & 0.0260 & 0.0006 & 0.0000 & 0.0000 \\
\hline
\end{tabular}

Correlation analysis between the growth of EPS in 3 and 5 years and Altman scores show, that the Spearman coefficients are higher and more significant than the linear correlation analysis with Pearson coefficient indicating their non-linear relation. This correlation is similarly high for the smallest and largest companies included in portfolios 1, 4 and 5, and significantly lower for medium companies included in portfolios 2 and 3 . The Spearman correlation between the growth indices and Altman scores is higher for shorter, 3-years growth of EPS in all portfolios but the 5, representing the largest business entities.

The results of OLS estimation for Altman scores and the EPS growth of companies, that may influence the financial condition of business entities are presented in Table 4 with the Total Assets as a control variable. The model as presented in equation (1) was tested in a first place. Since the results confirm the significance of Total Assets in a financial condition assessment of analysed companies, in the next steps the sample was divided for 5 portfolios, and the influence of the growth indices on the condition of companies was analysed according to the equation 2 . 
OLS Dependent variable: $\log A S$

\begin{tabular}{|c|c|c|c|c|c|c|c|c|c|}
\hline $\log \mathrm{AS}$ & Coef. & St. error & t-ratio & p-value & Mean.dep.var & Adj Rsq & F-stat & $\mathrm{P}$ val. $(\mathrm{F})$ & $\mathrm{N}$ \\
\hline $\begin{array}{l}\text { Model } 1 \\
\text { Total sample }\end{array}$ & & & & & 1.425844 & 0.159291 & 1028.511 & 0.000000 & 10847 \\
\hline const & 3.33289 & 0.0437925 & 76.11 & $<0.0001$ & & & & & \\
\hline $\operatorname{lnTA}$ & -0.212370 & 0.00477402 & -44.48 & $<0.0001$ & & & & & \\
\hline EPS 3 & 0.000398378 & 0.00000673 & 5.919 & $<0.0001$ & & & & & \\
\hline $\begin{array}{l}\text { Model } 2 \\
\text { Total sample }\end{array}$ & & & & & 1.421086 & 0.161236 & 984.1654 & 0.000000 & 10227 \\
\hline const & 3.46404 & 0.0471575 & 73.46 & $<0.0001$ & & & & & \\
\hline $\operatorname{lnTA}$ & -0.224246 & 0.00508627 & -44.09 & $<0.0001$ & & & & & \\
\hline EPS 5 & 0.000153844 & 0.0000078 & 1.972 & 0.0487 & & & & & \\
\hline $\begin{array}{l}\text { Model } 3 \\
\text { Portfolio } 1 \\
\end{array}$ & & & & & 2.007613 & 0.022011 & 28.21016 & 0.0000 & 1208 \\
\hline const & 1.97548 & 0.0271696 & 72.71 & $<0.0001$ & & & & & \\
\hline EPS 3 & 0.000782598 & 0.000147345 & 5.311 & $<0.0001$ & & & & & \\
\hline $\begin{array}{l}\text { Model } 4 \\
\text { Portfolio } 1\end{array}$ & & & & & 2.038617 & 0.002552 & 3.300120 & 0.069608 & 898 \\
\hline const & 2.02259 & 0.0312483 & 64.73 & $<0.0001$ & & & & & \\
\hline EPS 5 & 0.000371284 & 0.000204381 & 1.817 & 0.0696 & & & & & \\
\hline $\begin{array}{l}\text { Model } 5 \\
\text { Portfolio } 2 \\
\end{array}$ & & & & & 1.732015 & 0.002379 & 6.089822 & 0.013674 & 2133 \\
\hline const & 1.72400 & 0.0139537 & 123.6 & $<0.0001$ & & & & & \\
\hline EPS 3 & 0.000343193 & 0.000139071 & 2.468 & 0.0137 & & & & & \\
\hline $\begin{array}{l}\text { Model } 6 \\
\text { Portfolio } 2 \\
\end{array}$ & & & & & 1.764980 & 0.000013 & 0.026145 & 0.871564 & 1999 \\
\hline const & 1.76425 & 0.0139982 & 126.0 & $<0.0001$ & & & & & \\
\hline EPS 5 & $2.65296 \mathrm{e}-05$ & 0.000164073 & 0.1617 & 0.8716 & & & & & \\
\hline $\begin{array}{l}\text { Model } 7 \\
\text { Portfolio } 3 \\
\end{array}$ & & & & & 1.470965 & 0.000153 & 1.365528 & 0.242698 & 2390 \\
\hline const & 1.47559 & 0.0139095 & 106.1 & $<0.0001$ & & & & & \\
\hline EPS 3 & -0.000177571 & 0.000151957 & -1.169 & 0.2427 & & & & & \\
\hline $\begin{array}{l}\text { Model } 8 \\
\text { Portfolio } 3 \\
\end{array}$ & & & & & 1.486843 & 0.002540 & 6.843902 & 0.008953 & 2294 \\
\hline const & 1.49922 & 0.0139794 & 107.2 & $<0.0001$ & & & & & \\
\hline EPS 5 & -0.000494055 & 0.000188853 & -2.616 & 0.0090 & & & & & \\
\hline $\begin{array}{l}\text { Model } 9 \\
\text { Portfolio } 4\end{array}$ & & & & & 1.241407 & 0.002293 & 6.528787 & 0.010675 & 2405 \\
\hline const & 1.23210 & 0.0154206 & 79.90 & $<0.0001$ & & & & & \\
\hline EPS 3 & 0.000367016 & 0.000143638 & 2.555 & 0.0107 & & & & & \\
\hline $\begin{array}{l}\text { Model } 10 \\
\text { Portfolio } 4 \\
\end{array}$ & & & & & 1.246303 & 0.001057 & 3.508624 & 0.061173 & 2369 \\
\hline const & 1.23779 & 0.0155454 & 79.62 & $<0.0001$ & & & & & \\
\hline EPS 5 & 0.000232265 & 0.000123998 & 1.873 & 0.0612 & & & & & \\
\hline $\begin{array}{l}\text { Model } 11 \\
\text { Portfolio } 5 \\
\end{array}$ & & & & & 1.047890 & 0.001206 & 4.261888 & 0.039072 & 2701 \\
\hline const & 1.04165 & 0.0152374 & 68.36 & $<0.0001$ & & & & & \\
\hline EPS 3 & 0.000423389 & 0.000205087 & 2.064 & 0.0391 & & & & & \\
\hline $\begin{array}{l}\text { Model } 12 \\
\text { Portfolio } 5\end{array}$ & & & & & 1.052763 & 0.003824 & 11.21426 & 0.000823 & 2660 \\
\hline const & 1.03578 & 0.0158705 & 65.26 & $<0.0001$ & & & & & \\
\hline EPS 5 & 0.00108647 & 0.000324438 & 3.349 & 0.0008 & & & & & \\
\hline
\end{tabular}

Source: own study

When total sample is taken into consideration both the 3 and 5 years growth indices influence the condition assessed by Altman score in a positive way. It can be concluded that the higher the growth of EPS, the more scores in the Altman Model. For the group of companies from portfolio 1 only the 3 years growth indices influence the condition assessed by Altman score in a positive way. In the case of 5-year growth, such a dependence is no longer observed for small companies. In portfolio 3 representing medium companies the growth affects the Altman scores in a negative way. In portfolio 2 the growth indices are not significant in the OLS estimation for the 5 year growth period and 3 year period in portfolio 3 . In portfolio 
4 and 5 is taken into consideration both the 3 and 5 years growth indices influence the condition assessed by Altman score in a positive way, but this influence is very weak.

\section{Conclusions}

In the analysis presented in this paper it was found that the smallest the company, the higher its growth index, when EPS 3 and 5 years growth periods are taken into consideration. The smallest companies in the sample are characterized by the higher Altman Model scores and the highest standard deviation of this index indicating less linear growth in this group. From the other hand the larger the company, the lower the assessment of its financial condition as measured by Altman Z-Score Model.

The correlation between the EPS growth and Altman Model scores is no linear and it is the smallest for medium companies. Moreover it is stronger for shorter, 3-years period of EPS growth and Altman score for all portfolios but the last one, representing the largest business entities where it is almost equal. In most of cases the growth of EPS influences the Altman scores in a positive way meaning that the higher the growth the better the financial condition of company. In portfolio 3 representing medium companies surprisingly the growth affects the Altman scores in a negative way. In portfolio 2 the growth indices are not significant in the OLS estimation for the 5 year growth period and 3 year period in portfolio 3. Medium size of companies may affect the growth process in a negative way - companies are not as flexible as small business entities and no resistant (too large to fall) as the largest companies. They are characterized by the highest standard deviation of earnings, either.

It can be concluded that in most of cases the growth influences the companies' scores in the Altman Model in a positive way meaning that the higher growth of EPS, the better the financial condition according to the measures taken into consideration. It is not true for medium companies where the EPS growth influence the financial condition in a negative way. EPS growth influences not only the value of the company but also its financial condition.

Post-crisis business may try to grow faster to make up for time, loss of profits and opportunities. When US companies included in S\&P 500 Index are taken into consideration it can be seen that the greater the EPS growth, the better condition of small and large companies. Medium companies growth affects the financial condition in a negative way. European companies may behave similarly to the US business entities to be more competitive in a global market and attempt more risky strategies resulting in a higher growth that can result not only in value creation but also a better financial condition. Medium companies need a special attention to pay for because their behaviour is different from the small and large business entities.

Further research can be related to the analysis of companies that went bankrupt and their growth before the distress, weather it had been faster than the market average or not, to determine new factor influencing the bankruptcy, that may be the EPS growth rate. Moreover the analysis of companies regarding the size and stage of development in the light of the growth of value should be extended.

\section{Bibliography}

Akhmadi, A., Robiyanto, R., 2020. The Interaction between Debt Policy, Dividend Policy, Firm Growth, and Firm Value. The Journal of Asian Finance, Economics, and Business, 7(11), 699-705.

Altman, E.I., 1968. Financial Ratios, Discriminant Analysis and the Prediction of Corporate Bankruptcy. Journal of Finance, 23(4), 589-609.

Altman, E.I., 1983. Corporate Financial Distress. A Complete Guide to Predicting, Avoiding, and Dealing with Bankruptcy.Wiley Interscience, John Wiley and Sons.

Altman, E.I., Hotchkiss, E., 2006. Corporate Credit Scoring-Insolvency Risk Models, Corporate Financial Distress and Bankruptcy.

Arnold, T., Shockley, R., 2002. Real options analysis and the assumptions of the NPV rule. Baton Rouge, LA, USA.

Bates, T.W., 2005. Asset Sales, Investment Opportunities, and the Use of Proceeds. The Journal of Finance, 60(1), 105-135.

Battall, A.H., Sabri, B.A., 2020. Analysis of Common Stocks and their Impact on Market Value An Applied Study on the Banking Sector Companies Listed on Iraq Stock Exchange. Tikrit Journal of Administration and Economics Sciences, 16 (49 part 1), 253-269.

Berk, J.B., Green, R.C., Naik, V., 1999. Optimal Investment, Growth Options, and Security Returns. The Journal of Finance, 54(5), $1553-1607$.

Borgman, R.H., Strong, R.A., 2006. Growth Rate and Implied Beta: Interactions of Cost of Capital Models. The Journal of Business and Economic Studies, 12(1), 1-11.

Burton, B.M., Lonie, A.A., Power, D.M., 1999. The Stock Market Reaction to Investment Announcements: the Case of Individual Capital Expenditure Projects. Journal of Business Finance \& Accounting, 26(5-6), 681-708. 
Choudhary, N., 2011. Optimal Balance of Financial Instruments: Long-Term Management. Market Volatility \& Proposed Changes in Rights and Liabilities of Affected Parties.

Cooper, M.J., Gulen, H., Schill, M.J., 2008. Asset Growth and the Cross-Section of Stock Returns. Journal of Finance, 63(4), $1609-1651$.

Danbolt, J., Hirst, I.R., Jones, E., 2013. The Growth Companies Puzzle: Can Growth Opportunities Measures Predict Firm Growth?. The European Journal of Finance, 17(1), 1-25.

Davidsson, P., Delmar, F., Wiklund, J., 2006. Entrepreneurship and the Growth of Firms. Edward Elgar Publishing.

de Wet, J., 2013. Earnings per Share as a Measure of Financial Performance: Does it Obscure More than it Reveals?. De Wet, JH v H, 265-275.

El Hakioui, M., Louitri, A., 2017. Paradigmatic Debate on Entrepreneurship and Firm Growth-Essay on the Positioning of High-Growth.

Fama, E.F., 1980. Agency Problems and the Theory of the Firm. The Journal of Political Economy, 88(2), 288-307.

Fama, E.F., French, K.R., 2007. The Anatomy of Value and Growth Stock Returns. Financial Analysts Journal, 63(6). 44-54.

Fama, E.F., French K.R.., 2007. Migration. Financial Analysts Journal, 63(3), 48-58.

Franzen, L.A., Rodgers, K.J., Simin, T.T., 2007. Measuring Distress Risk: The Effect of RandD Intensity. The Journal of Finance, 62(6), 29312967.

Gentry, J.A., Pyhrr, S.A., 1973. Simulating an EPS Growth Model. Financial Management, 3(6), 68-75.

Grice, J.S., Ingram, R.W., 2001. Tests of the Generalizability of Altman's Bankruptcy Prediction Model. Journal of Business Research, 54, 53-61.

Griffin, J.M., Lemmon, M.L., 2002. Book-to-Market Equity, Distress Risk, and Stock Returns. The Journal of Finance, 57(5), $2317-2336$.

Kaplan, R.S., Norton, D.P., 2005. The Balanced Scorecard: Measures that Drive Performance. Harvard Business Review, 83(7), 172.

Kuta, K., Rudnicki, K., 2015. Activity-ased costing jako metoda ustalania wyniku operacyjnego w służbie zdrowia. Journal of Capital Market and Behavioral Finance, 1(1), 49-59.

Lantos, G., 2001. The Boundaries of Strategic Corporate Social Responsibility. Journal of Consumer Marketing. 19. 205-230.

Levine, R., Zervos, S., 1999. Stock Market Development and Long-Run Growth. The World Bank.

Mueller, E., 2003. Private Benefits of Control, Capital Structure and Company Growth. GROWTH.

Muhammad, N., Scrimgeour, F., 2014. Stock Returns and Fundamentals in the Australian Market. Asian Journal of Finance \& Accounting, 6(1), 271-290.

Perényi, Á., Yukhanae, A., 2016. Testing Relationships between Firm Size and Perceptions of Growth and Profitability: An Investigation into the Practices of Australian ICT SMEs. Journal of Management \& Organization, 22(5), 680-701.

Pradhan, R.P., 2018. Development of Stock Market and Economic Growth: the G-20 Evidence, Eurasian Economic Review, 8(2), 161-181.

Pilotte, E., 1992. Growth Opportunities and the Stock Price Response to New Financing. Journal of Business, 55(3), 371-394.

Piotroski, J.D., 2000. Value Investing: The Use of Historical Financial Statement Information to Separate Winners from Losers. Journal of Accounting Research, vol. 38, Supplement: Studies on Accounting Information and the Economics of the Firm, 1-41.

Platt, H.D., Platt, M.B., Chen, G., 1995. Sustainable Growth Rate of Firms in Financial Distress. Journal of Economics and Finance, 19(2), 147151.

Schleifer, A., Vishny, R.W., 1997. A Survey of Corporate Governance, The Journal of Finance, 52(2), 737-783.

Stubelj, I., 2010. Valuation of Slovene Publicly Traded Companies with a Valuation Model Based on Expected Earnings and Growth Opportunities. Managing Global Transitions, 8(1), 23-47.

Xu, M., Zhang, C., 2009. Bankruptcy Prediction: the Case of Japanese Listed Companies. Review of Accounting Studies, 14, $534-558$. 


\section{BUSINESS CYCLE MANAGEMENT AND COMPANIES PERFORMANCE: CAPITAL INVESTMENTS}

\section{Kaspars Iesalnieks, School of Business and Finance}

Abstract. Purpose: the purpose of the research paper is to observe and analyse how major companies in the Baltic States (Latvia, Lithuania and Estonia) behave during the last business cycle in terms of capital investments in order to identify different investment management strategies across various countries and industries in different business cycle phases. Research paper analyses whether companies adapt counter-cyclical or cyclical behaviour during different business cycle phases taking into account GDP indicators for each country.

Approach: statistical analysis from year 2007 to year 2012 encompassing 1387 largest businesses in the Baltics by their opera ting revenue. In the research paper clustering and mainly comparison methods are applied in order to identify how businesses are reacting to different business cycle phases.

Findings: In summary dynamics are more evident during the capital investment activities in different business cycle phases. More activities in counter cyclical behaviour can be seen in all countries but somewhat rarer in Latvia. In comparison with previous analysis of inventories, hiring habits and collection period Lithuania has shown more counter-cyclical behaviour. There is an indication for further in depth analysis for Lithuania and Estionia during crisis period as these two countries had significant counter-cyclical behaviour and arises question whether this behaviour has provided competitive advantage against their peers.

Research implications: research paper demonstrates that various industries adapt different strategies during the business cycle and there are differences both on country and industry levels that opens door for further research in order to develop a holistic instrument how to adapt to different business cycle phases.

Originality: first research paper that summarizes in-scope major Baltic state companies behaviours during the last business cycle on both country and industry level as well as provides comparison between them.

Keywords: Business cycle management, capital management, companies performance, capital investments.

JEL code: M21

\section{Introduction}

Global economic crisis from 2008 onwards is considered one of the worst financial crises since 1930 Great depression which had overwhelming effect on every country poor and wealthy (Reuters, 2009; Li and Tallman, 2011; Ma, Yiu and Zhou, 2014; Conti, Goldszmidt and de Vasconcelos, 2015). One of the first major signs of Global financial crisis was on September 15th 2008 when Lehmann Brothers bankrupted. Equally US real estate bubble burst, both issues directly affected every internationally operating bank and their national economies. Moreover in 2008 Europe faced consequences of irresponsible debts carried by countries such as Greece, Spain and Italy. Soon Greece discovered it could not pay off their debts and EU is still suffering because of that, as bailout amounted to 130 billion Euros (Eurozone crisis explained..., 2012). During time period from 2008 to 2009 many of main macroeconomic indicators have decreased globally. From here arise major problems: redundancy, decrease of standard of living, bankruptcy of businesses, contraction of world trade, poverty, collapse of housing markets and et cetera that had an effect on Latvia, Estonia and Lithuania also.

Therefore due to enormous effect of the economic changes it has an enormous impact on also how businesses behave during different cycle phases and thus different financial indicators can be analysed. This paper is one of the author's paper series (Sarnovics and Iesalnieks, 2017; Iesalnieks, 2018, 2019) that analyses different financial indicators during different business cycle phases and has same theoretical framework and methodology as previous papers. Thus it is recommended to read this paper in context with other ones.

\section{Theoretical framework of the research}

To recap business cycle management (further in text - BCM) is a term that encompasses strategy of applying countercyclical actions and if applied in a timely way during the different business cycle phases it can improve companies performance in relative to their competitors (Navarro, Bromiley and Sottile, 2010) In essence, BCM's aim is to utilize business cycle phenomenon via countercyclical response to different business cycle phases (Navarro, Bromiley and Sottile, 2010) It must be emphasized that according to Navarro et al. (2010) response to business cycle phases does not necessarily involve forecasting macroeconomic movements rather it embraces timely response. Based on the performed literature review regarding business cycle management (Sarnovics and Iesalnieks, 2017) that summarizes and categorizes current business cycle associations or factors that are used by businesses to cope with business cycles in further text taking into account theoretical groundwork and some of the identified short-comings first level analysis is carried out to identify the differences between countries and industries behaviour. Also literature review showed 
that research regarding business cycle is established however ways how management can utilize business cycle theory from managerial standpoint somehow has been missed in the academia (Navarro, 2009; Navarro, Bromiley and Sottile, 2010; Lorange and Datson, 2014; Conti, Goldszmidt and de Vasconcelos, 2015). In addition research in business cycle management is fairly fragmented and overall lacks holistic view on the phenomenon and as several academics have stated in their work that there is lack of holistic and comprehensive research performed in the academia regarding business cycle management as well as no heterogeneous model of business cycle management behaviour is developed, thus in the business cycle management area there is potential for further work in order to add value to the management studies and this research paper is one of the paper series to respond to identified research gap. In particular this paper carries out analysis of capital investments behaviour and whether companies in different industries behave counter-cyclically as several researchers in the academia argue that companies can take advantage of business cycle by countercyclical behaviour (Navarro, 2006; Navarro, Bromiley and Sottile, 2010; Escribano and Stucchi, 2014; Abbasoglu, Genc and Mimir, 2015; Kampouridis, G. Yiannopoulos, Giannopoulos and Tsirkas, 2015; Kaya, 2015). In this instance if industries do behave counter-cyclically during crisis for instance then do these companies have better results against their peers to work out better results after crisis during expansion and peak in terms of capital investments (Navarro, Bromiley and Sottile, 2010; Conti, Goldszmidt and de Vasconcelos, 2015). In order to understand that this paper carries out first phase of analysis to identify if there are any industries that in fact behave counter-cyclically to provide groundwork for further research.

In total whole concept about taking into account company's business strategy and especially functional strategy e.g. human resource management, quality management, creditor and debtor management, marketing mix and in particular capital investments author based its model on Porter (1985) and Heerde, Gijsenberg, Dekimpe and Steenkamp (2013) also taking into GDP and industry specifics that can have an impact e.g. on market share, revenue and profit (Lamey et al., 2007). Main focus thus is how and whether cyclical or counter-cyclical behaviour impacts results (e.g. market share, revenue or profit). Below in Figure 1 can be seen main concept presented graphically where on the left hand-site is environment that needs to be taken into account when reviewing both business and functional strategies and eventually current environment and different behaviours in business and functional strategies that have an impact on the results e.g. profitability.

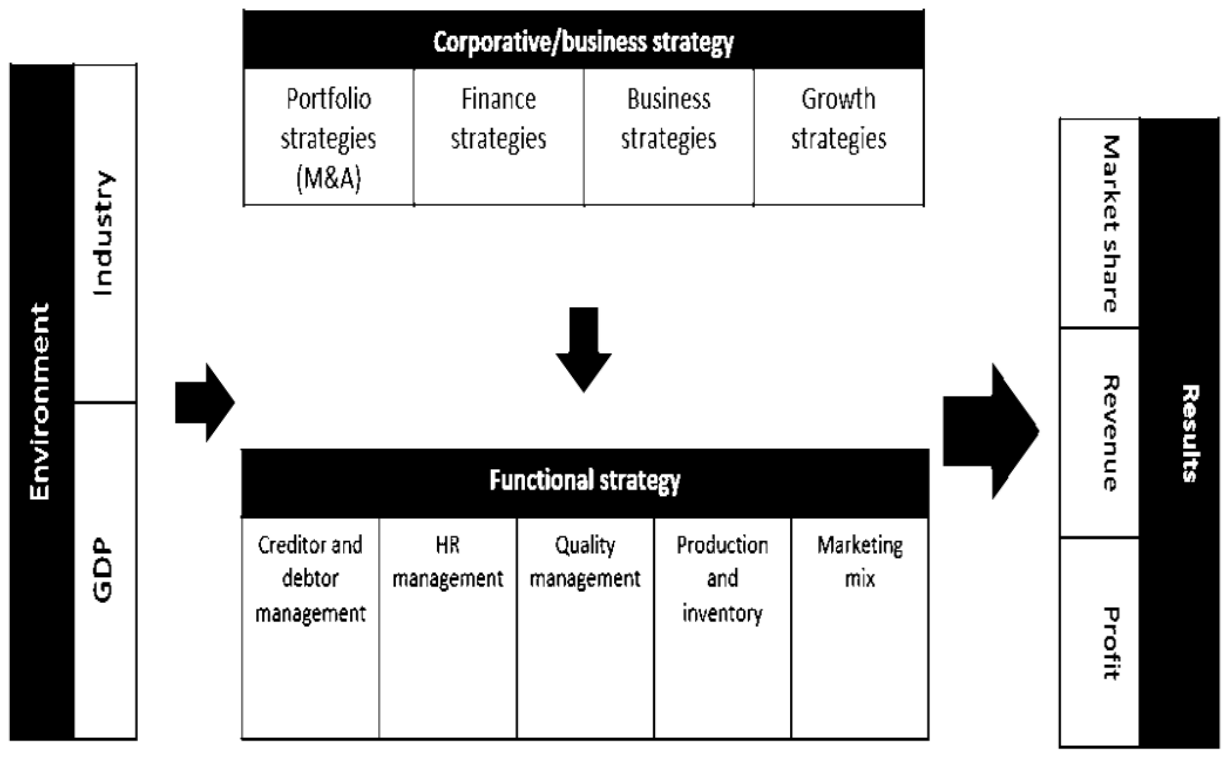

Source: Author's based model on Porter (1985) and Heerde, Gijsenberg, Dekimpe and Steenkamp (2013)

Fig. 1. Main concept and research framework

Thus taking into account the model this paper series addresses identified shortcoming from the literature review in order to identify potential patterns in different business cycle phases how different industries behave in diverse countries emphasising what functional strategies are utilized by different industries and in particular case how capital investments are managed from business strategy point of view (Sherman and Sherman, 2008; Springs, 2010). 


\section{Research methodology}

Data is comprised from 1387 companies that are in Baltic States from range of 17 industries that are classified taking into account NACE codes. Author has chosen 1387 companies that are the largest companies in Baltic States by their operating revenue and includes large and medium enterprises, with more than 50 million EUR turnover for large companies and between 50 and 10 million EUR turnover for medium size enterprises respectively according to classification of European commission (2003). Such choice has been made due to more availability of information for larger companies. All information was acquired via secondary database "Orbis" more detailed information can be seen below.

In terms of the time period from 2007 to 2012 it has been chosen due to the fact that this is the last full business cycle with all the phases from expansion to expansion including recession and trough as this is the latest time period where full business cycle can be observed and thus analysed how different industries and countries behave during it.

One of the main variables are states of the economy that consists of - Counter|peak, Non-Counter|peak, Counter|expansion, NonCounter|expansion, Non-Counter|recession, Counter|recession, Non-Counter|trough and Counter|trough. Meaning that each year of companies' financial and non-financial data has been indicated in which business cycle phase it is according to GDP (gross domestic product) fluctuations. Taking into account mentioned fluctuations capital investment data about each of the company are analysed by following method - taking into account capital investments for each company depending on the results (increase or decrease of inventories) data is connected to GDP resulting in cyclical and non-cyclical behaviour summarizing results on industry and country levels.

Therefore in order to understand whether major companies in Baltic States increase capital or perform other activities during recession and increase capital or perform other activities in anticipation of a recovery capital investment indicators are reviewed (Ramey and Vine, 2004; Muller, 2011; Caro and Gallien, 2012). This research paper analysis is carried out in comparable manner how companies have performed in comparison to previous years thus not looking in detail whether capital investment was good or bad but more on a generalized level.

In order to analyse relevant data following approach was utilized:

1. Data is taken from secondary database "Orbis" - Orbis has information on over 275 million companies across the globe. It is the resource for company data. Orbis captures and treats data from almost 160 separate providers, and hundreds of own in-house sources;

2. Data consists of 1387 companies financial and non-financial in 17 NACE categorized industries across three Baltic States - Latvia, Lithuania and Estonia;

3. Data consists of following companies financial indicators - operating revenue, inventory turnover, capital investments, staffing, capitals investments and M\&A activities and non-financial data such as NACE industry categories;

4. Data is analysed on industry level by comparing behaviour by each industry during each business cycle phase with regards to research hypothesis concluding it by whether industry encompassed companies behave counter-cyclically or cyclically with proportional percentage where significant result is above $60 \%$ to conclude it as cyclical or counter-cyclical behaviour and anything below $60 \%$ is considered as balanced behaviour for each industry. Thus for instance if there are 10 companies within certain industry and more than 6 of those companies have shown counter-cyclical behaviour then the conclusion in the research results section will show that this particular industry behaved counter-cyclically if compared with GDP movement. Same applies the other way around for cyclical behaviour and where anything is below $60 \%$ is balanced with no particular emphasis on counter or non-counter behaviour. During the analysis of capital investments author has applied same approach as per other indicators. Below can be summarized main results of the analysis as well as conclusions at the end. 


\section{Analysis of research results}

During the peak we can see in the below graph the dynamics between different countries. As it can be seen Latvia and Estonia have counter cyclical behaviours however Lithuania as indicated in the previous analysis has behaved in a more cyclical way also during the peak.

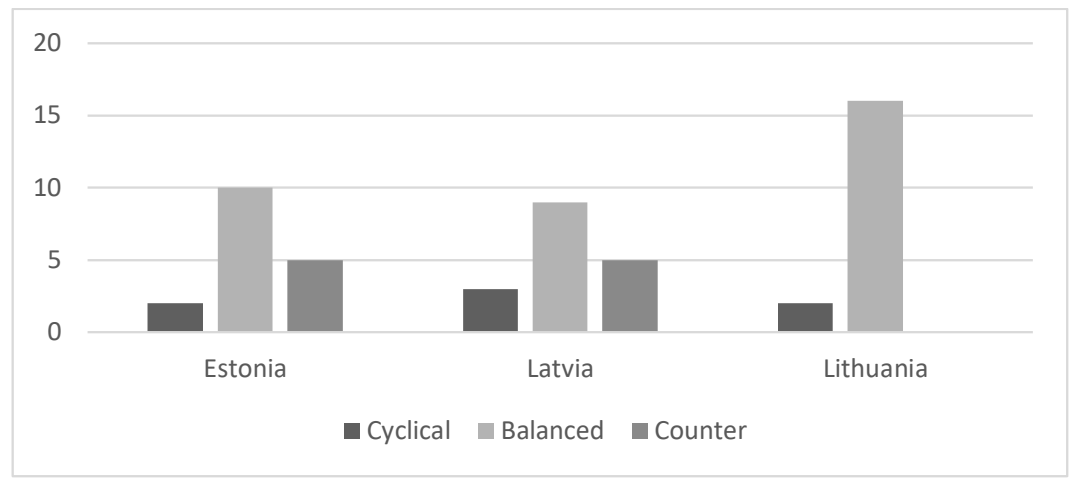

Source: Database “Orbis” (data 2007-2012)

Fig. 2. Capital investment during peak

If we look at industry level then Estonia has shown counter cyclical behaviour within these industries:

- Agriculture, forestry and fishing;

- Construction;

- Information and communication;

- Professional, scientific and technical activities;

- Water supply; sewerage; waste management and remediation activities.

- Whereas Latvia:

- Administrative and support service activities;

- Human health and social work activities;

- Information and communication;

- Public administration and defence; compulsory social security;

- Water supply; sewerage; waste management and remediation activities.

We can conclude that in both Latvia and Estonia overlapping industries are Information and communication and Water supply; sewerage; waste management and remediation activities that should be taken into account for the further parts of the dissertation. Also meaningful observation is that Lithuania had none counter cyclical behaviours as mentioned before.

In terms of non counter behaviour Estonia has following industries:

- Arts, entertainment and recreation;

- Electricity, gas, steam and air conditioning supply.

- Whereas Latvia:

- Agriculture, forestry and fishing;

- Construction;

- Professional, scientific and technical activities.

- And Lithuania:

- Construction;

- Water supply; sewerage; waste management and remediation activities.

Interestingly we can see that only Lithuania and Latvia have one overlapping industry which is Construction. At the peak it well correlates with global financial crisis due to credit bust as it was mainly based on mortgages and thus capital investments to nurture the direction.

In terms of capital investment during expansion we can see that results are more similar between countries and all countries have indication of all behaviour types (cyclical, balanced and counter-cyclical). 


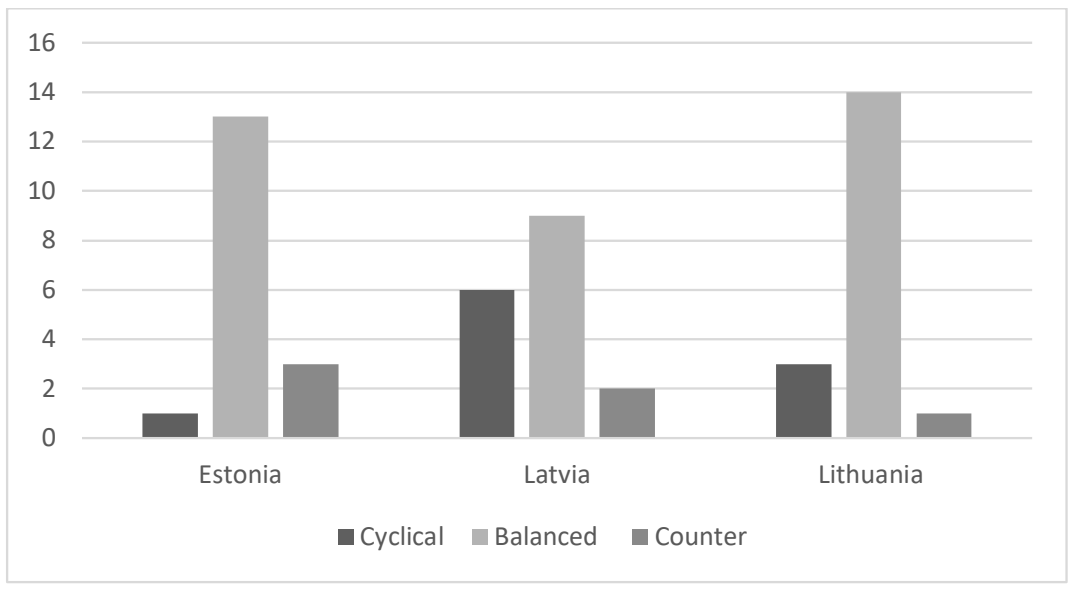

Source: Database “Orbis” (data 2007-2012)

Fig. 3. Capital investment during expansion

For Estonia it was observed that following countries behaved in counter:

- Agriculture, forestry and fishing;

- Professional, scientific and technical activities;

- Water supply; sewerage; waste management and remediation activities.

Where as Latvia:

- Human health and social work activities;

- Public administration and defence; compulsory social security.

- And Lithuania:

- Mining and quarrying.

However there cannot be identified any overlapping industries between counties during the expansion that would have counter-cyclical behaviour.

In terms of non-counter behaviour, we can see that Estonia has only one industry Arts, entertainment and recreation.

However in Latvia there are several instances:

- Administrative and support service activities;

- Electricity, gas, steam and air conditioning supply;

- Information and communication;

- Mining and quarrying;

- Professional, scientific and technical activities;

- Water supply; sewerage; waste management and remediation activities.

And in Lithuania:

- Accommodation and food service activities;

- Administrative and support service activities;

- Information and communication.

We can see that between Latvia and Lithuania there are two industries overlapping which are Administrative and support service activities and Information and communication.

As in the previous analysis Latvia has only had recession. 


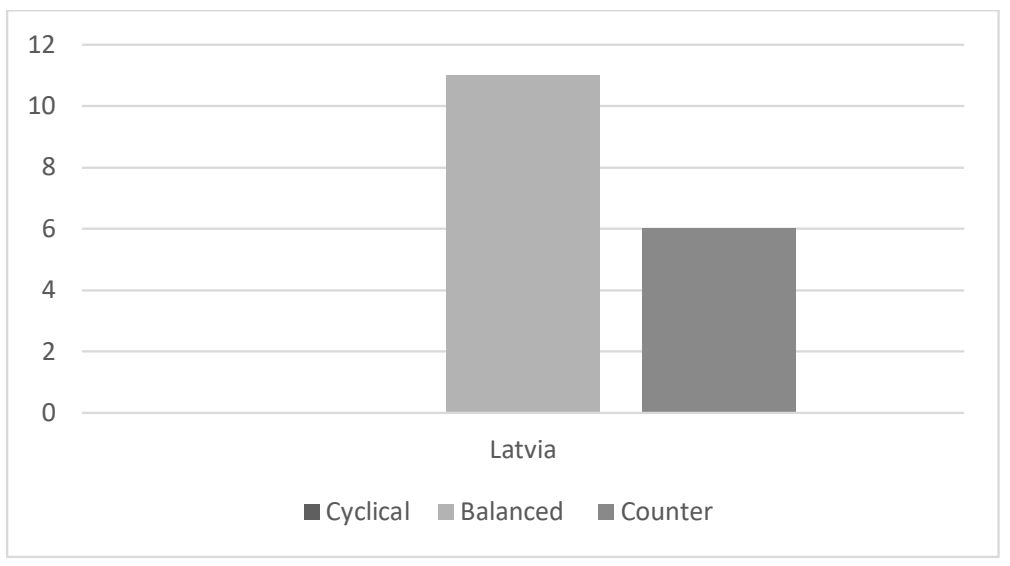

Source: Database “Orbis” (data 2007-2012)

Fig. 4. Capital investment during recession

However, we can see very interesting results and considerable amount of industries have chosen counter cyclical behaviour. Those are:

- Agriculture, forestry and fishing;

- Human health and social work activities;

- Manufacturing;

- Professional, scientific and technical activities;

- Real estate activities;

- Water supply; sewerage; waste management and remediation activities.

Taking into account the cause of the crisis investing more in the capital in the real estate activities is an odd behaviour and needs to be taken into account in the further analysis to understand if there are any overlaps in the other factors.

In terms of capital investment behaviour we can see in the below chart that there is more dynamic behaviour between countries.

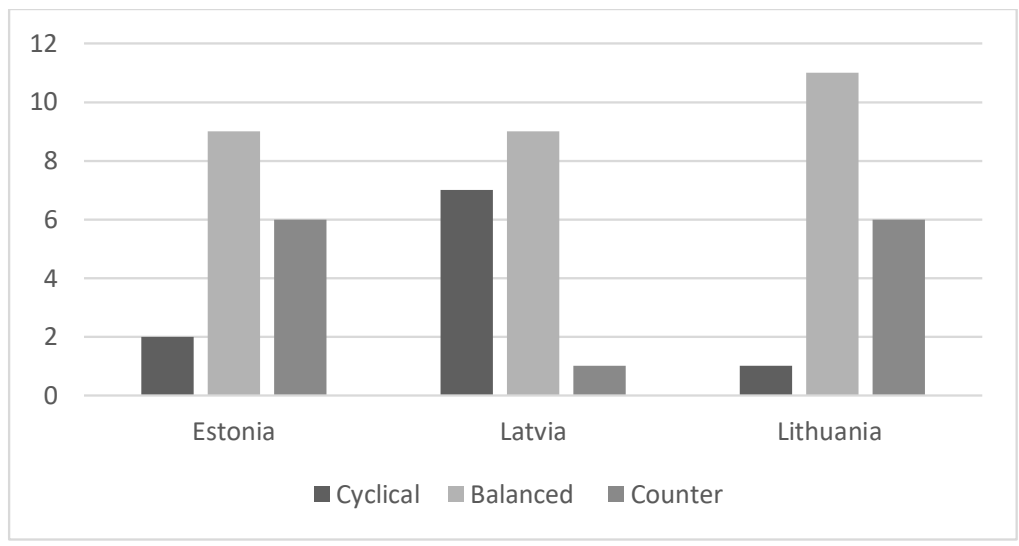

Source: Database “Orbis” (data 2007-2012)

Fig. 5. Capital investment during crisis

During the crisis Estonia has following industries that behaved counter cyclically:

- Administrative and support service activities;

- Agriculture, forestry and fishing;

- Arts, entertainment and recreation;

- Professional, scientific and technical activities;

- Water supply; sewerage; waste management and remediation activities;

- Wholesale and retail trade; repair of motor vehicles and motorcycles.

Whereas Latvia had only one industry behaving counter cyclically during crisis - Public administration and defence; compulsory social security. 
Lithuania had also several industries similarly to Estonia:

- Agriculture, forestry and fishing;

- Construction;

- Information and communication;

- Mining and quarrying;

- Transporting and storage;

- Water supply; sewerage; waste management and remediation activities.

There are only overlapping industries between Estonia and Lithuania that are Agriculture, forestry and fishing and Water supply; sewerage; waste management and remediation activities.

\section{Conclusions}

In summary dynamics are more evident during the capital investment activities in different business cycle phases. More activities in counter cyclical behaviour can be seen in all countries but somewhat rarer in Latvia especially when compared with hiring habits and inventory management. In comparison with previous analysis of inventories, hiring habits and collection period Lithuania has shown more counter-cyclical behaviour in capital investments area. In terms of question whether major companies in Baltic states counter-cyclically invest in capital during recession in order to provide advantage for the recovery stage seems that there is some evidence of such behaviour in Estonia and Lithuania (around $30 \%$ of companies invest in capital during crisis) but not applicable to Latvia as it has only one industry with counter-cyclical behaviour. Thus this research indicates more possibilities for in further depth-analysis in terms of Estonia and Lithuania to study whether companies have had any competitive advantage of such behaviour and what was those companies profile.

In terms of scientific benefits this paper is one of the author paper series about different business cycle behaviours during different phases and this paper provides continuous research ground and work for further analysis as identified during the literature review there is academic gap in this field and there has not been performed comparative analysis between different countries as well as several business cycle associations (Sarnovics and Iesalnieks, 2017). Regarding practical value of the paper businesses in particular industries can relate to particular business cycle associations and when needed or when the timing comes can adapt similar functional or business strategies in order to potentially gain competitive advantage against their peers as business cycle has massive impact on any company in any industry from revenue, market share and profit point of views and provides additional information during the decision making whether about capital investments or hiring, debt management, inventory management, marketing and other business cycle associations.

As in other papers limitations are following:

1. Geographical - only Baltic States (Latvia, Lithuania and Estonia) wide companies are taken into account;

2. Time - very important limitation in terms of business cycle area since research paper looks at the last full business cycle that has all business cycle phases (from expansion to expansion);

3. In scope are only large companies - companies that have more than 50 million EUR turnover and medium size enterprises that have turnover between 10 million and 50 million. Limitation is due to data availability for smaller companies;

4. One indicator is reviewed, meaning that associations for business cycle can be even more.

\section{Bibliography}

Abbasoglu, O. F., Genc, S., Mimir, Y., 2015. Cross-Sectional Facts on Bank Balance Sheets over the Business Cycle. Central Bank Review, 15(2), $31-60$.

BBC News, 2012. Eurozone Crisis Explained - BBC News, BBC News. Available at: https://www.bbc.com/news/business-13798000 (Accessed: 15 April 2019).

Caro, F., Gallien, J., 2012. Clearance Pricing Optimization for a Fast-Fashion Retailer. Operations Research, 60(6), 1404-1422. doi: 10.1287/opre.1120.1102.

Conti, C. R., Goldszmidt, R.,de Vasconcelos, F. C., 2015. Strategies for Superior Performance in Recessions: Pro or Counter-cyclical? RAE Revista de Administracao de Empresas, 55(3), 273-289. doi: 10.1590/S0034-759020150304.

Escribano, Á. and Stucchi, R., 2014. Does Recession Drive Convergence in Firms' Productivity? Evidence from Spanish Manufacturing Firms. Journal of Productivity Analysis, 41(3), 339-349. doi: 10.1007/s11123-013-0368-5. 
Iesalnieks, K., 2018. Business Cycle Management and Company Performance Hiring Habits. Journal of Business Management, 15, 37-44.

Iesalnieks, K., 2019. Business Cycle Management and Companies Performance: Inventory Management, in. Vilnius Gediminas Technical University. doi: 10.3846/cibmee.2019.042.

Kampouridis, G. Yiannopoulos, A. C., Giannopoulos, G. I., Tsirkas, S. A., 2015. The Relationship Between TQM And Financial Performance Of Greek Companies Of Structural Construction Sector During Crisis Period. Journal of Economics and Business, 18(1), 61-78.

Kaya, H. D., 2015. Impact of Business Cycles on Retail and Wholesale Firms' Asset Values Leverage Ratios and Cash Flows: Evidence from U.S. Listed Firms. Journal of Financial Management and Analysis, 25(2), 39-50.

Lamey, L. Deleersnyder, B., Dekimpe, M., Steenkamp, J.-B., 2007. How Business Cycles Contribute to Private-label Success: Evidence from the United States and Europe. Journal of Marketing, 71(15), 1-15. doi: 10.1509/jmkg.71.1.1.

Li, S., Tallman, S., 2011. MNC Strategies, Exogenous Shocks, and Performance Outcomes. Strategic Management Journal, $32(10), 1119-1127$. doi: $10.1002 /$ smj.918.

Lorange, P., Datson, E., 2014. Business Cycles: Looking Beyond the Downside for Competitive Advantages. Journal of Business Strategy, 35(1), 9-19. doi: 10.1108/JBS-02-2013-0013.

Ma, X., Yiu, D. W., Zhou, N., 2014. Facing Global Economic Crisis: Foreign Sales, Ownership Groups, and Corporate Value. Journal of World Business, 49(1), 87-100. doi: 10.1016/j.jwb.2013.02.002.

Muller, M., 2011. Essentials of Inventory Management. 2nd edn. New York; Atlanta; Brussels; Chicago; Mexico City; San Francisco; Shanghai; Tokyo; Toronto; Washington, D.C: AMACOM Division of American Management Association International.

Navarro, P., 2006. Praise for The Well-Timed Strategy:Managing the Business Cycle for Competitive Advantage. New Jersey: Prentice Hall.

Navarro, P. ,2009. Recession-Proofing Your Organization. MIT Sloan Management Review, 50(3), 45-51.

Navarro, P., Bromiley, P., Sottile, P., 2010. Business Cycle Management and Firm Performance: Tying the Empirical Knot. Journal of Strategy and Management, 3(1), 50-71. doi: 10.1108/17554251011019413.

Ramey, V., Vine, D., 2004. Why Do Real and Nominal Inventory-Sales Ratios Have Different Trends. Cambridge, MA. doi: 10.3386/w10703.

Reuters, 2009. Three Top Economists Agree 2009 Worst Financial Crisis Since Great Depression; Risks Increase if Right Steps are Not Taken. Available at: http://icsidfiles.worldbank.org/icsid/ICSIDBLOBS/OnlineAwards/C3004/C-164_Eng.pdf (Accessed: 20 April 2019).

Sarnovics, A., Iesalnieks, K., 2017. Business Cycle Management and Companies' Performance: Current Knowledge and the Way Forward. Journal of Business Management, (12), 113-123.

Sherman, H. J., Sherman, P. D., 2008. Why is this Cycle Different from all Other Cycles?' Journal of Economic Issues, 42(1), 255-268. doi: $10.1080 / 00213624.2008 .11507126$.

Springs, C. G., 2010. Making the Most of Opportunities During a Recession. Management Review, 48(1), 71-91. 


\title{
IMPACT OF THE CORONAVIRUS PANDEMIC ON THE ECONOMIC DEVELOPMENT OF UKRAINE AND LATVIA
}

\author{
Sandra Jekabsone, University of Latvia \\ Irina Skribane, University of Latvia \\ Antonina Broyaka, Vinnytsia National Agrarian University
}

Abstract. The COVID-19 pandemic that has swept the world has created a number of diverse threats to the development of the countries' economies, including Ukraine and Latvia. An adequate assessment of these threats is very difficult and, moreover, often has a probabilistic character due to their singularity and novelty. The COVID-19 crisis mainly affected the tertiary sector, in particular companies involved in tourism, international passenger transport, accommodation, catering, entertainment, and cultural events, where demand fell sharply, and jobs fell. They were also followed by a contraction in demand in the manufacturing and transport sectors, which were mainly oriented towards external demand and exports. At the same time, there was a shortage of specialists and an increase in employment in areas such as information and communication technology and healthcare.

The purpose of the article is to study the state and trends of the impact of COVID-19 on the economic situation in Ukraine and Latvia, in particular, to determine the socio-economic losses incurred by countries due to quarantine.

The study identifying the possible economic policies in order to select the most appropriate instruments COVID-19 mitigation, as well as Latvian and Ukrainian economic structure improvement.

Keywords: COVID-19 pandemic, economic growth, economic sectors, development scenarios.

JEL code: E60, O10, O11, O50

\section{Introduction}

The entire world community, since mid-December 2019, has come under the enormous influence of the global epidemic of coronavirus disease, which is called COVID-19. The pandemic caused by this virus has already led to millions of human losses around the world, imposed significant restrictions on the socio-cultural life of the population and radically changed the trends of the global economy. Today it is difficult to predict what the final human and economic losses will be incurred by states in the short, medium and long term.

The problem of the study is to consider individual forecasts of economic development and measures that have been chosen by the governments of Ukraine and Latvia to overcome the negative consequences of the COVID-19 pandemic and to compare them.

The purpose of the article is to study the state and trends of the impact of COVID-19 on the economic situation in Ukraine and Latvia, in particular, to determine the socio-economic losses incurred by countries due to quarantine. This will help to form a real vision of the possible course of economic processes that will directly affect the standard of living of the population for using each other's experience to optimize and increase the effectiveness of the measures taken.

The tasks of the research are: to assess the impact of COVID-19 on the economic growth of Latvia and Ukraine, to compare the measures taken during the pandemic to support certain sectors, to provide an assessment of the consequences of the pandemic in cases of different action scenarios.

The methodological and information base for the study is represented by research papers, periodicals materials, official statistical publications, departmental materials, and online resources.

In analyses there are used different qualitative and quantitative analysis methods, such as scientific literature and empirical research analysis, modeling tables, charts and schemes, calculations of average and relative values, grouping, comparisons and other.

\section{Research results and discussion}

An active discussion of the problem of the of coronavirus disease spreading takes place in the media, where ministers, representatives of government agencies, leading economic experts, sociologists and political scientists, and other leading experts on this issue express their views. In particular, these are Grigorenko Y. (2020), Blinov A. (2020), Kulytsky S. (2020), Amelin A., Lavryk Ya., and Monin (2020), Zgurovsky M. (2020), Dolbneva D. (2020) and others.

All European Union (EU) countries conduct research and study their specific situations in order to find out as soon as possible the solutions which can have a direct recovery effect and help mitigate the impact of the crisis, including overcoming new outbreaks. In Latvia, on April 30, 2020, the government approved the State Research Program for Mitigation of Consequences of COVID-19 and allocated funds for its implementation in the amount of five million euros from the state budget (Ministry of Education and Science, 2020). 
Latvia's economy has weathered the COVID-19 crisis first wave better than most EU countries. Over the second quarter of 2020, Latvia's GDP fell by 7.1\% (Latvia's Macro Profile, October 2020). Factors such as balanced economic growth and sound government finances before the crisis, accommodative monetary and fiscal policy implemented already at the outset of the crisis as well as timely unwinding of the pandemic-related restrictions supported an improvement in the market participants' sentiment and, in the summer, led to a rapid recovery of several economic sectors like retail trade, manufacturing and exports of goods.

Trying to determine the future prospects of economic development under the COVID-19 conditions it is advisable to take into account the previous experience of the flow of events during epidemics. We can observe a certain cyclicality.

Over the last two decades, mass infectious diseases (pandemics) have become more frequent/ They begun to have an increasingly significant impact on human health, social development, and the economies of countries and world regions:

- From November 2002 to May 2004, an outbreak of severe acute respiratory syndrome (ARI) caused by the previously unknown coronavirus SARS-CoV occurred in 35 countries. A total of 8,461 cases of SARS were identified, of which 916 ended in death. Mortality was $10.83 \%$;

- From January 2009 to August 2010, most of countries in the world were affected by the swine flu, which escalated into the H1N1 pandemic. From 700 million to 1.4 billion people suffered from the disease, 150 to 575 thousand people became its victims. The mortality rate was below $1 \%$;

- In 2014-2015, West Africa, the USA, and Europe embraced pandemic Ebola, or so-called hemorrhagic syndrome. The number of people infected with the Ebola virus amounted to more than 9 thousand personas, 4450 people died. The mortality rate was $50 \%$;

- The beginning of 2020 was sadly marked by the fastest and most massive coverage of almost the entire world community by the COVID-19 (SARS-CoV-2) coronavirus pandemic. As of mid-October 2020, about 29 million patients were recorded in the world, about 1 million people died. The world average death rate hovers around $3.5 \%$;

We can observe that the occurrence of pandemics within the indicated period time interval is cyclical with an approximate occurrence period about five to six years. In order to analyze the impact of these pandemics on the global economy, let's compare them on the time axis with the following fundamental periodic processes:

- Nikolai Kondtatiev's 40-50-year economic cycles based on changes of societies technological structure (Kondratiev N. A.,1979, Diebolt C., 2009);

- 7-11 year Clement Juglar's cycles associated with fluctuations in capacity utilization and fluctuations in investment in fixed assets (the focus of business investment) (Besomi D., 2009, Korotayev, A.V., Tsirel, S.V., 2010);

- the Dow Jones Industrial Average, which reflects the total capitalization of the 30 largest American companies, whose activities collectively determine the trends of the world economy.

Fig. 1 shows that in 2020-2021 the downward wave of the 5th Kondratiev cycle comes to the end Next it switches to the upward wave of the 6th Kondratiev cycle under the transition to the next techno-economics paradigm. This indicates the objective conditions for a further long-term recovery of the world economy.

At the same time, the beginning of economic recovery in the time period 2020-2021 is significantly weakened by the rupture of traditional economic chains as a result of the COVID-19 pandemic and a significant "dispersion" (lack of focus) of investments in various businesses (both outdated and prospective), that leads to reaching the next bottom of the Juglar's cycle and fall by $30-40 \%$ in the Dow Jones Industrial Average (Dow Jones Industrial Average, 2020). According to Juglar, this decline should continue for about a year, during which time investments will be redirected to technologies of the 6th order. After exceeding the contribution to world GDP by more than 5-7\% due to technologies of the 6th cycle, the rise of the global economy should begin both according to Kondratiev and Juglar. 


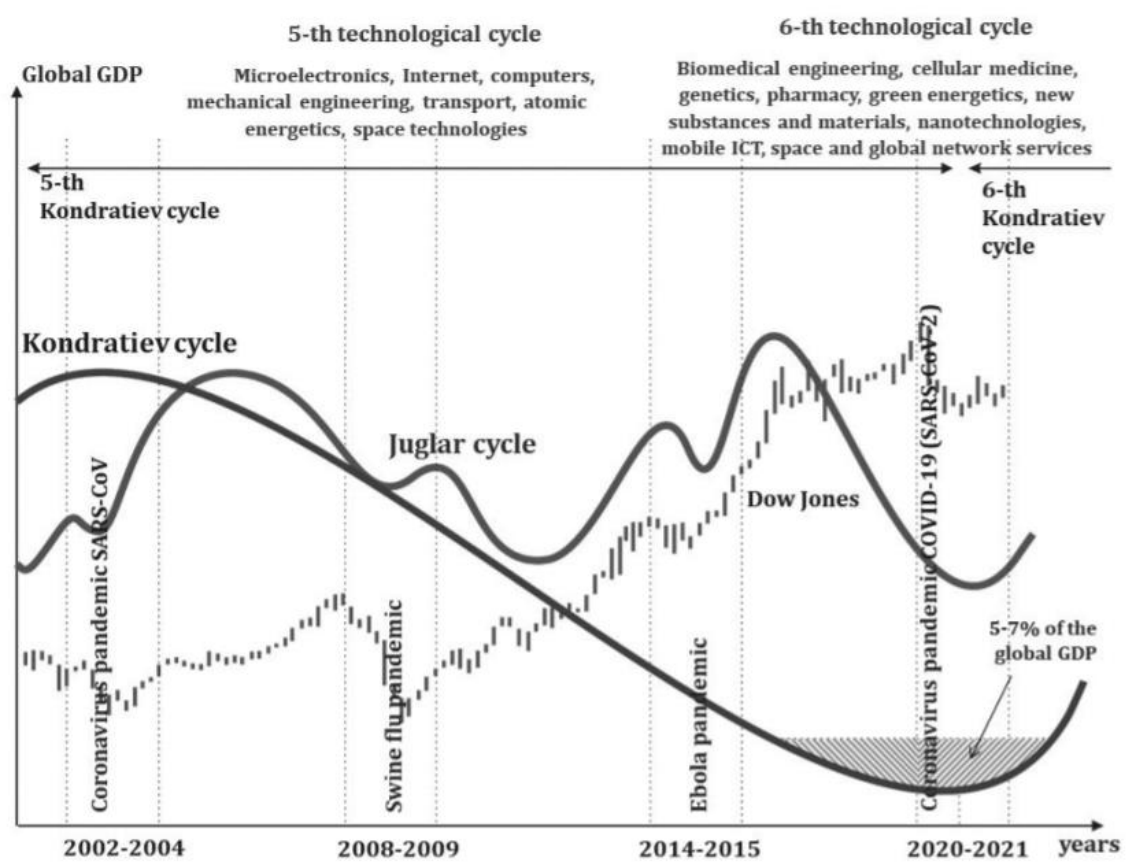

Source: Zgurovsky M. Z., 2020

Fig. 1. The impact of pandemics of infectious diseases on the economy and society development

The COVID-19 pandemic, which has swept the world, has created a number of diverse threats to the development of the economies of countries, including Ukraine and Latvia. An adequate assessment of these threats is very difficult and, moreover, often has a probabilistic character due to their singularity and novelty. Pandemic significantly influenced the development of the world economy, leaving aside any country. According to expert Blinov (Blinov A.,2020), in 2020, the economic situation at the global level will be close to recession: many economies will face a reduction in exports, imports, GDP, attracting investments, incl. in the real estate market, the production sector will deteriorate significantly. Analysts predict that the losses to the global economy due to the coronavirus pandemic in the worst-case scenario could reach $\$ 2.7$ trillion (Orlik T., Rush J., Cousin M., Hong Bloomberg J., 2020). However, it is impossible to calculate accurately the expected losses, because the situation changes almost every day. Our states also already have some experience of their own in combating the COVID-19 pandemic on their territory. With a certain degree of convention, such measures can be attributed to the following categories: technical and organizational, financial and economic, socio-political and information-psychological. At the same time, the above division is somewhat arbitrary, since all activities are interconnected in their origin and functioning, and all of them, either directly or indirectly, affect the economic processes in the country and have a certain economic tinge, since they require appropriate funding. In particular, the problem of revealing additional financial resources for resistance the spreading of the SARS-CoV-2 coronavirus and the redistribution of the corresponding, mostly rather limited, financial and material resources is becoming acute.

Many events in Ukraine are financed by the reserve funds of the state and local authorities, sponsorship of caring citizens and philanthropists so far without making radical changes to the state and local budgets. Ukraine requires the attraction of appropriate financial resources to purchase the necessary materials, drugs and medical equipment, especially tests to screen patients for the presence of coronavirus.

On April 13, the Verkhovna Rada of Ukraine adopted amendments to the current state budget, which provides for the creation of a fund to combat COVID-19 in the amount of UAH 64.7 billion. The fund will be administered by the Ministry of Finance. Also this year, the financing of the Pension Fund has been increased by UAH 29.7 billion. The Ministry of Health in 2020 will receive an additional UAH 15.5 billion (Kulytsky S., 2020).

Since the COVID-19 outbreak, all European countries have taken fiscal measures to address the health crisis and limit the adverse impact on the economy. The 25 countries covered in European Fiscal Monitor (EFM) have committed around EUR 1 trillion or a total of around 7\% of GDP in discretionary fiscal stimulus, and injected nearly EUR 2 trillion, or about 14\% of GDP into liquidity measures (EFM, 2020). But there are substantial differences between countries. Lithuania has the largest relative amount of discretionary measures (about 21\% of GDP), while Latvia's discretionary 
measures related to the COVID-19 crisis amounted to 3\% of GDP ((EFM, 2020). Latvia's expenditure on liquidity measures, which mainly consists of loans and guarantees, was 6.8\%, close to the EU average, while in Estonia and Lithuania it was 9.2\% and 6.6\%, respectively (see Figure 2).

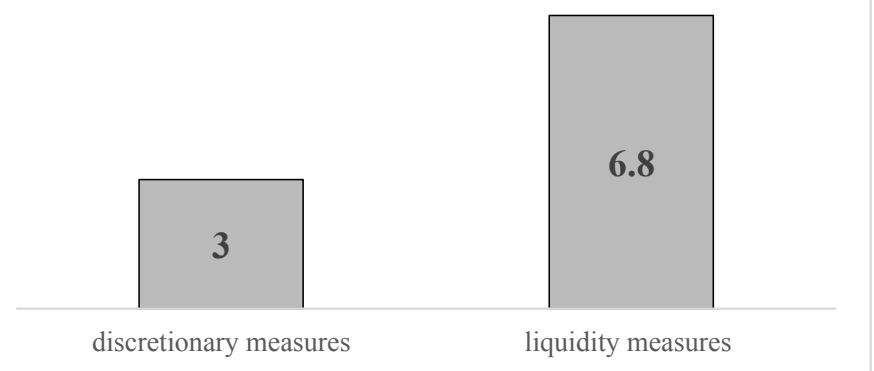

Source: LV PEAK, 2020

Fig. 2. COVID-19 -related discretionary and liquidity measures in Latvia (\% of GDP)

Carrying out relevant scientific research is also extremely important now. Moreover, Ukraine and Latvia have their own material, technical and personnel base for this. It should be borne in mind that the current costs of testing the population for COVID-19, relevant biomedical research, other similar technical and organizational measures of struggle COVID-19 in countries can subsequently not only save significant amounts of funds but, possibly, repaid with certain income from the export of some drugs and medical supplies. Note that the Ukrainian pharmaceutical industry occupies an outstanding position, at least in the Post-Soviet economic space.

A significant technical-organizational step in the fight against coronavirus is the strict quarantine measures introduced by the governments of the countries: closing of shopping and entertainment centers, a ban on attending all mass events, restrictions on movement both within the country and abroad, a reduction in production (through the establishment of limits for simultaneous employees staying in the same space), etc. Some companies have transferred their employees to work from home on-line, while others are forced to send their employees on vacation. At the same time, there are cases of abuse and violations by some employers of the terms of the employment contract, which require employees to write applications for dismissal of their own free will or take leave at their own expense. All this negatively affects the well-being of the population, their financial situation and in the near future will lead to a reduction in their demand for a number of goods and services. The directions of transmission of economic consequences are shown in Figure 3.

\begin{tabular}{|c|}
\hline \multicolumn{2}{|c|}{ Direct influence } \\
\hline $\begin{array}{c}\text { Impact of internal mesuers } \\
\text { Closing shops, restaurants, etc. } \\
\text { Suspension of international and national flights, } \\
\text { trains, etc. }\end{array}$ \\
\begin{tabular}{|c|} 
Impact of external shocks \\
Decreased demand for exports of goods and \\
services \\
Decreased remittances
\end{tabular} \\
\hline Secondary consequences \\
\hline $\begin{array}{c}\text { Impact on the demand side: falling consumption and investment for most sectors } \\
\text { of the economy Economic policy responses (fiscal and monetary policy) }\end{array}$ \\
\hline \\
Cumulative economic impact \\
\hline
\end{tabular}

Source: compiled by authors

Fig. 3. Directions of transmission of economic consequences

According to a number of public opinion polls conducted by the sociological group "Rating", it was revealed that 51\% of respondents in Ukraine believe that the economic situation of their households has deteriorated over the past six months, $42 \%$ believe that it has not changed, and only $6 \%$ saw improvements. At the same time, assessing changes in the financial situation in the nearest future, $61 \%$ noted a deterioration over the past month, 35\% mentioned that they did not feel any changes, only 3\% noticed an improvement (група РЕЙТИНГ, 2020). Older people and poorer 
respondents were pessimistic in their assessments. Among those who had a job prior the introduction of quarantine, $40 \%$ indicated that they continue to work as usual after the imposition of restrictions, $23 \%$ - work remotely, $11 \%$ - take payed vacation, $18 \%$ - are on vacation of their own free will and $8 \%$ - lost their job. $55 \%$ of respondents said that their savings should last for less than a month if they stopped earning income, $17 \%$ stressed that they will have enough savings for up to 2 months, $8 \%$ - up to 3 months, $9 \%$ - up to six months or more. Along with this, $82 \%$ said they had started saving money during quarantine, $16 \%$ said they did not. The latter are more among men and wealthier citizens (Ukraine under quarantine, 2020). Other organizations received similar survey results. Thus, the above research results have shown that the introduction of quarantine to fight the COVID-19 epidemic in Ukraine has already affected the economic condition, assessments and expectations of citizens.

Also in Latvia, the COVID-19 pandemic in 2020 has affected several life areas - work, shopping, rest, financial planning, socialization, opportunities to move, etc. Research results of "Swedbank" Institute of Finances show that due to pandemic $42.3 \%$ of households in Latvia have felt the worsening of the financial situation, including 14\% of households indicate that situation has worsened considerably (Swedbank's Institute of Private Finances, 2020). Besides the same number of people (42\%) evaluate, that financial situation has remained unchanged this year. In turn, $14 \%$ of respondents indicate that in the last 12 months financial situation of household has improved. Although statistical data indicate on the increase of household savings, however survey results show the tendency, that people have more often used savings for financing the current expenditures.

Saving amount has decreased almost for $46 \%$ respondents. Also, when evaluating financial situation for next year, households are very pessimistic. Almost $38 \%$ of respondents expect financial situation to become worse, but $26 \%$ forecast that situation will not change. Positive evaluation gives only $16 \%$ of Latvia's inhabitants. Researchers indicate that this is the strongest negative evaluation of household financial situation since 2013. Authors consider that in circumstances when activities of several sectors are limited by the government measures to limit further spread of COVID-19 pandemic, households should be granted with considerable state support to stabilize their financial situation. Without considerable state support, it will be hard for inhabitants to recover from financial turmoil.

Due to the coronavirus pandemic and the imposed quarantine measures, the decline in Ukrainian GDP, according to the Ministry of Economic Development, Trade and Agriculture, in the first half of 2020 was 6.5\%. According to the forecast of the National Bank of Ukraine, the fall in GDP in 2020 may be at least $6 \%$. At the same time, according to the IMF, the Ukrainian economy will decrease by $8.2 \%$ by the end of 2020 (Ukraine in 2020-2021, 2020).

Quarantine brought down consumer sentiment, almost stopped several industries - retail trade, hotel and restaurant business, air travel. The amount of state budget revenues has decreased. Due to the introduction of quarantine, Ukrainian companies have frozen investments and production chains.

The consumer demand sectors, where quarantines have recently eased, are recovering rapidly, primarily retail and services. The situation with industry and investment demand is worse. The fall in industrial production slowed to $12.2 \%$. A certain activation of external demand against the background of optimism caused by the gradual easing of quarantine, and an increase in budget expenditures for the purchase of certain engineering and metallurgical products (in particular, for medical equipment, military products) led to a weakening of the decline in metallurgy, mining of metal ores and mechanical engineering. However, a deep decline remained in the production of equipment for other industries (metallurgy, agriculture, railways) and vehicles, which indicates still weak domestic demand. The gradual fading away of the rush demand for antiseptics and medicines led to a slowdown in growth in the pharmaceutical industry. The chemical industry has resumed its recession due to a decline in the production of fertilizers and cleaning products. But the use of online banking services grew at a steady pace (Impact of..., 2020).

Reduction in production leads to an increase in unemployment. According to the State Employment Service, as of 1st of July 517,284 unemployed were registered in Ukraine, as of June 1 this indicator was 511,388 people, as of May 1 - 457,005 people, as of April 1 - 349,424 people (State Employment Center, 2020). Thus, over several months of the quarantine period (from early April to early July), the number of unemployed increased by more than $48 \%$. For comparison, as of $1^{\text {st }}$ of July $2019,287,086$ unemployed were registered in Ukraine (1.8 times less than on July 1 , 2020). The COVID-19 crisis has also contributed to growing structural imbalances in the Latvian labor market at the level of individual occupational groups and sectors. On November 30 number of registered unemployed in Latvia was 67,124 and From 01.03.2020. number of registered unemployed an increase of 8,552 unemployed or 15\% (Latvian State Employment Service, 2020). The rise in unemployment was significantly curbed by downtime benefits, which were introduced in Latvia immediately after the declaration of the emergency (State of emergency), reducing the negative impact of the COVID-19 crisis on the labor market. 
The COVID-19 crisis increased the share of remote workers in both the public and private sectors, as well as accelerated the digitalisation of the economy and the automation of jobs, thus increasing the productivity potential of the workforce on the one hand and changing the structure of skills demand in the labor market on the other.

The introduction of quarantine immediately affected wages. In April, for the first time since March 2016, real wages fell by $0.5 \%$ due to low business activity and lower demand for labor. A third of Ukrainians have completely lost their income or work, and in more than a third the regular households income has decreased.

The slowing down of the recession in the basic industries supported the labor market somewhat, although the demand for labor remained weak than in quarantine. Thus, the growth of average wages accelerated to 3.0\% in nominal terms, and their growth in real terms also resumed (by $1.4 \%$ ).

The most optimistic about the recovery of production volumes are construction companies, pessimistic - service sector enterprises that have suffered the most from the introduction of quarantine. Among the main concerns are a decrease in production and sales of products, services, and new orders volume, as well as a reduction in the number of employees. The sector crisis has already negatively impacted production, capital investment and employment. This worsened the financial position of a significant part of enterprises and households. The result was the first problems with servicing loans and a decrease in demand for the services of financial institutions. In general, according to National Bans of Ukraine estimates, the current crisis may result in banks losing more than $10 \%$ of their working loan portfolio.

So, the main economic consequences of the pandemic both in Ukraine and in Latvia include the following:

1) a decline in economic growth rates of countries, a deep protracted recession;

2) slowdown in the development of markets for goods and services;

3) a significant decrease in the income of airlines and maritime transport;

4) significant deterioration in the state of the tourism industry;

5) a decrease in the income of the population, a significant drop in the effective demand of the population;

6) growth of unemployment;

7) deterioration in the quality of life;

8) reduction of expenses for travel, visiting restaurants and cafes, entertainment events, will lead to a crisis in the hotel and restaurant and tourism business and services;

9) an increase in the production and sale of pharmaceutical products, in particular medical equipment;

10) deterioration of the investment climate, growth in investor demand for less risky assets;

11) mass bankruptcy of small and medium businesses;

12) deficit of external financing and narrowing opportunities for access to international capital markets

13) narrowing of foreign sales markets, etc.

Assessing the economic impact of the coronavirus outbreak is challenging due to the uncertainty and unpredictability of its development. Experts from the Ukrainian Institute of the Future made calculations of the losses of the Ukrainian economy from quarantine in the context of the development of two scenarios (see Table 1) 
Table 1

Forecasts of experts from the Ukrainian Institute of the Future on the losses of the Ukrainian economy in the context of the development of two quarantine scenarios

\begin{tabular}{|c|c|c|}
\hline Forecast & $\begin{array}{l}\text { Scenario } 1 \text { "basic" Scenario } 2 \\
\text { "moderately pessimistic" }\end{array}$ & Scenario 2 "moderately pessimistic" \\
\hline Fall in official employment & $\begin{array}{l}860 \text { thousand people - total in a } \\
\text { quarter; } \\
14 \text { thousand people - per day of } \\
\text { quarantine, based on the duration } \\
\text { of quarantine } 60 \text { days }\end{array}$ & $\begin{array}{l}\text { In the second quarter of } 2020: 862 \\
\text { thousand people - in just a quarter; } 14 \\
\text { thousand people - during the day of } \\
\text { quarantine. In the third quarter of } 2020 \text { : } \\
845 \text { thousand people - in just a quarter; } \\
14 \text { thousand people - during the day of } \\
\text { quarantine. For two quarters of } 2020 \text {, } \\
1.7 \text { million people will be left without a } \\
\text { source of income. }\end{array}$ \\
\hline Fall in real GDP & $\begin{array}{c}14.6 \% \text { - for the second quarter of } \\
2020 \text { (against the quarter of } 2019 \text { ); } \\
6.4 \% \text { - at the end of } 2020\end{array}$ & $\begin{array}{l}14.6 \% \text { - for the second quarter of } 2020 \\
\text { (before the quarter of } 2019 \text { ) } 23.5 \% \text { - for } \\
\text { the third quarter of } 2020 ; 10.3 \% \text { - at the } \\
\text { end of } 2020\end{array}$ \\
\hline $\begin{array}{l}\text { Economic losses during } \\
\text { quarantine }\end{array}$ & $\begin{array}{c}\text { UAH } 2.5 \text { billion per day (added } \\
\text { value lost) }\end{array}$ & $\begin{array}{l}\text { UAH } 2.5 \text { billion per day per day in the } \\
\text { second quarter of } 2020 \text { (lost added } \\
\text { value); UAH } 4.7 \text { billion per day in the } \\
\text { third quarter of } 2020\end{array}$ \\
\hline $\begin{array}{l}\text { Budget losses based on the } \\
\text { decline in employment } \\
\text { (estimated by the unified social } \\
\text { contribution and personal } \\
\text { income tax) }\end{array}$ & $\begin{array}{l}\text { at the level of UAH 1.5-2 billion } \\
\text { per month (instead of UAH } 23-24 \\
\text { billion per month, EUB-personal } \\
\text { income tax fees are envisaged at } \\
\text { the level of UAH } 21.5-22 \text { billion) }\end{array}$ & $\begin{array}{l}\text { at the level of UAH 5-7 billion per } \\
\text { month }\end{array}$ \\
\hline $\begin{array}{l}\text { Average annual exchange rate of } \\
\text { the hryvnia against the dollar }\end{array}$ & UAH 30 & UAH 32 \\
\hline
\end{tabular}

According to consensus estimates, Ukraine will show a deep fall - 4.2\% in 2020, inflationary processes will accelerate to $7 \%$ versus $4.1 \%$ (calculated in December against December of the previous year) in 2019. All elements of demand will have negative dynamics, but the biggest fall in investment will be $14.8 \%$. To maintain the demand of the population and mitigate the negative consequences of the introduced quarantine measures, budget support will increase, which, in the context of a reduction in income, will lead to a significant increase in the budget deficit to $5.6 \%$ of GDP [0]. Retail and wholesale trade, transport, metallurgy and mechanical engineering will hold back the economic dynamics the most. Small and medium-sized businesses will be the most vulnerable in terms of business scale.

Analysts expect that by the end of the year the transport industry in Ukraine will lose the most - 11.2\% under the optimistic scenario, $14.2 \%$ under the baseline scenario and $24.1 \%$ under the pessimistic scenario. A decline is also expected in agriculture: by $7.8 \%$, $8.9 \%$ and $12.9 \%$, respectively (see table 2 ).

Table 2

Scenarios of the dynamics of the development of sectors of the Ukrainian economy at the end of $2020, \%$

\begin{tabular}{|l|c|c|c|}
\hline \multicolumn{1}{|c|}{ Branch } & Optimistic & Basic & Pessimistic \\
\hline Agriculture & -7.8 & -8.9 & -12.9 \\
\hline Industry & -3.3 & -5 & -8.1 \\
\hline Trade, repair services & -6.4 & -8 & -13.1 \\
\hline Transport & -11.2 & -14.3 & -24.1 \\
\hline
\end{tabular}

Source: compiled by authors based on Grigorenko Y. (2020)

COVID-19 pandemic has considerably changed the dynamics of sectoral development, that was reflected also in the sectoral forecast adjustments. As we can see in Table 3, at the end of 2019, analysts of the Ministry of Economics forecasted positive dynamics for the next year in all sectors except transport services sector. Already in the middle of 2020 forecasts of sectoral development were considerably adjusted. According to the evaluation of the Ministry of Economics, sectors that suffer the most from the COVID-19 pandemic are related to the gathering of the people and services - mainly these sectors are accommodation and catering, transportation services, art and recreation sectors. Most optimistic evaluations of experts about the possible "V" shape scenario of crisis management have not fulfilled, because in the autumn of 2020 the number of infected persons increased again and new measurements were introduced to limit the spread of the virus. Analysts indicate that along with the worsening of 
epidemiologic situation it is expected that in the $4^{\text {th }}$ quarter of 2020 economic growth rate could slow down again and could reach the annual decrease of $7-8 \%$. In total in 2020, GDP could decrease by 5,5 percentage (see Table 3 ).

Table 3

Forecast of the dynamics of the development of sectors of the Latvian economy at the end of $2020 \%$

\begin{tabular}{|l|c|c|}
\hline & estimated in 2019 & estimated in 2020 \\
\hline Agriculture, forestry & 3,3 & 1.9 \\
\hline Manufacturing & 2,3 & -3.4 \\
\hline Other industry & 3,0 & -1.7 \\
\hline Construction & 1,9 & 1.1 \\
\hline Trade, accommodation & 3,2 & -10.7 \\
\hline Transport and storage & $-1,4$ & -17.5 \\
\hline Other business services & 3,0 & -6.2 \\
\hline Public services & 2,8 & 1.0 \\
\hline
\end{tabular}

Source: compiled by authors based on Economic Development of Latvia, 2020

The labor market situation will remain difficult until the end of 2020. Unemployment will be long-term due to a grate economic decline and considerable structural changes. Migrants will slowly return to places of work outside of Ukraine, both due to persisting risks of infection and due to economic problems in the world. The unemployment rate will be significant. The expected reduction in employment of workers in the context of sectors of the economy due to the introduction of quarantine in Ukraine is presented in Table 4.

Table 4

Expected reduction in employment in the context of economic sectors due to the introduction of quarantine in Ukraine

\begin{tabular}{|l|c|c|}
\hline \multicolumn{1}{|c|}{ Sector of the national economy } & $\begin{array}{c}\text { Expected reduction in } \\
\text { employment in 2020, } \% \text { per } \\
\text { quarter }\end{array}$ & $\begin{array}{c}\text { Expected reduction in } \\
\text { employment in 2020 with the } \\
\text { extension of quarantine, } \%\end{array}$ \\
\hline Temporary accommodation and catering & -64 & -36 \\
\hline Arts, sports, entertainment and recreation & -28 & -28 \\
\hline Trade & -24 & -21 \\
\hline The property & -20 & -32 \\
\hline Industry & -19 & -17 \\
\hline Transport & -19 & -21 \\
\hline $\begin{array}{l}\text { Activities in the field of administrative and } \\
\text { support services }\end{array}$ & -15 & -21 \\
\hline Construction & -10 & -22 \\
\hline Financial and insurance activities & -9 & -21 \\
\hline Professional, scientific and technical activities & -9 & -19 \\
\hline Health care and social assistance & -7 & -1 \\
\hline Education & -3 & -7 \\
\hline Information and telecommunications & -2 & -5 \\
\hline Agriculture, forestry and fisheries & 0 & 0 \\
\hline $\begin{array}{l}\text { Public administration and defense, compulsory } \\
\text { social security }\end{array}$ & 0 & -5 \\
\hline Other economic activities & -14 & -17 \\
\hline Source: compiled by authors based on Dolbneva $D . V \cdot(2020)$ & & \\
\hline
\end{tabular}

Source: compiled by authors based on Dolbneva, D. V. (2020)

The fall in production and the situation on the labor market will have a significant negative impact on the poverty of the population (the poverty level, according to experts, will increase by $10-20 \%$ compared to the level at the beginning of the year) According to experts, the biggest threats to economic recovery in Ukraine are:

1) long-term continuation and strengthening of internal quarantine measures;

2) the lack of a clear anti-crisis plan of measures to support the economy and protect the population of the country during a pandemic;

3) a deep drop in economic activity in the countries - main trading partners of Ukraine, in accordance with a significant deterioration in the situation on world commodity markets.

It is assumed that in 6 months after the final completion of all quarantine restrictions in the world, there will be a recovery in demand from Ukrainians for international transportation and travel services.

Changes in the investment activities of economic entities after the end of the pandemic will be insignificant, but in some sectors of the economy they can be grate due to changes in the structure of demand (as well as due to the possible introduction of incentives to invest in certain sectors) 
Changes in the Ukrainian economy will accelerate towards the transition to a new quality, the processes of digitalization, robotization and the use of the "remote workplace" modality will activated.

In 2021, economic growth in Ukraine is expected at the level of $2.4 \%$, but it will not compensate for the fall in 2020. Inflation will slow down to $5.9 \%$ (calculated in December against December of the previous year). All elements of demand will have a positive trend. The largest growth is expected in investments - as a low base effect $-6.9 \%$. The unemployment rate will gradually decline to $9.1 \%$, but will not reach the pre-pandemic level.

According to Latvijas Banka's December forecasts, Latvia's GDP is expected to decline by $4.7 \%$ in 2020 and to increase by $2.8 \%$ in 2021

(Bank of Latvia, 2020). Improvement in the economic sentiment and investment growth is expected to be supported by the financing provided to the Member States under the Next Generation EU recovery plan agreed among EU leaders.

\section{Conclusions}

1. The speed of economic recovery from the economic downturn caused by the pandemic both in Ukraine and in Latvia will depend on the duration and depth of internal quarantine measures, external environment, state support through fiscal and monetary policy, possible future changes in consumer and investor behavior.

2. The nature of the recovery will depend primarily on the existing "adaptive quarantine" regime, as well as further measures to weaken or strengthen it. At the same time, the World Health Organization no longer recommends that states take full quarantine measures, since they affect the economy much worse than the coronavirus itself.

3. Given that the quarantine has been extended, and Ukraine is breaking records for the incidence of COVID-19, the situation for certain service and entertainment industries will remain difficult.

4. According to all forecasts, a V-shaped recovery scenario is expected for the Ukrainian economy in 2021. Most likely, the downtrend in economic development will continue until the first quarter of 2021, and the recovery will begin only in the second quarter.

5. However, the IMF warns that the recovery of the Ukrainian economy after the crisis may drag on until 2024. The National Bank of Ukraine (NBU) adds that the pace of economic recovery will be restrained by low consumer and investment demand.

6. The NBU is confident that in 2021-2022 the country's economy will grow thanks to monetary and fiscal stimulus and increased external demand, and private consumption will be the main driver of economic growth. Unfortunately, the investment component of GDP will lag significantly behind the consumption component.

7. The most optimistic evaluations of experts about the possible "V" shape scenario of crisis management in Latvia have not fulfilled, because in the autumn of 2020 the number of infected persons increased again and new measurements were introduced to limit the spread of the virus.

8. Nevertheless, with a high degree of uncertainty regarding the further course of the COVID-19 pandemic in the world as a whole, and in Ukraine and Latvia in particular, the probable directions of development of the domestic economy analyzed above may require revision in a few months.

\section{Bibliography}

Amelin, A., Lavryk, Ya., Monin, D., 2020. Forecast of Losses. What Will be the Economic Losses of Ukraine due to the Coronavirus Pandemic. URL: $\quad$ https://dt.ua/ECONOMICS/prognoz-zbitkiv-yakimi-budut-ekonomichni-zbitki-ukrayini-cherez-pandemiyu-koronavirusa-342951_.html [Accessed 29 November 2020].

Bank of Latvia, 2020. On Macroeconomic Forecasts by Latvijas Banka. December 2020. URL: https://www.macroeconomics.lv/macroeconomicforecasts-latvijas-banka-december-2020 [Accessed 12 December 2020].

Besomi, D., 2009. Clément Juglar and his Contemporaries on the Causes of Commercial Crises, European Journal of Social Sciences. URL: https://journals.openedition.org/ress/110\#article-110 [Accessed 12 December 2020].

Blinov, A., 2020. Recession Virus: what Will Turn on the COVID-19 Epidemic and Who Will Suffer the most? URL: https://www.slovoidilo.ua/2020/03/18/pogljad/ekonomika/virus-recesiyi-chym-obernetsya-epidemiya-covid-19-xto-postrazhdaye-najbilshe [Accessed 29 November 2020].

Broyaka A., Skribane I., 2020. Assessment of the Economic Development of Latvia and Ukraine. International Scientific Conference "New Challenges in Economic and Business Development - Riga: University of Latvia” Proceedings, Riga, University of Latvia. pp. $426-439$.

Diebolt, C., 2009. Business Cycle Theory before Keynes. Paris: Association Française de Cliométrie, AFC Working Paperr no. 11.

Dolbneva, D.V., 2020. The Impact of COVID-19 on the World's Economies. The Problems of Economy. 1(43), 20-26, doi.org/10.32983/2222$0712-2020-1-20-26$ 
Dow Jones Industrial Average, 2020. URL: https://www.bloomberg.com/quote/INDU:IND [Accessed 29 November 2020].

Economics Development of Latvia, 2020. Ministry of Economics of the Republic of Latvia, Rīga, 2020.

European Fiscal Monitor, 2020. Network of EU Independent Fiscal Institutions, Brussels URL: https://www.euifis.eu/download/efm.pdf [Accessed 29 November 2020].

Grigorenko Y., 2020. Forecast for Years: how Soon the Ukrainian Economy will Begin to Recover. URL: https:/gmk.center/ua/posts/prognoz-naroki-yak-skoro-pochne-vidnovljuvatisya-ukrainska-ekonomika/ [Accessed 29 November 2020]

Impact of COVID-19 and quarantine restrictions on the economy of Ukraine, 2020. NGO "Center for Applied Research" Representation of the Konrad Adenauer Foundation in Ukraine. 54 p.

Kondratiev, N. A., 1979. The Long Waves in Economic Life. Review, Fernand Braudel Center, vol. 02, no. 04, Spring, 1979, p. $519-562$.

Korotayev, A.V., Tsirel, S.V., 2010. Spectral Analysis of World GDP Dynamics: Kondratieff Waves, Kuznets Swings, Juglar and Kitchin Cycles in Global Economic Development, and the 2008-2009 Economic Crisis. Structure and Dynamics, 4(1). 5-22, URL: https://escholarship.org/uc/item/9jv108xp [Accessed 29 November 2020].

Kulytsky, S., 2020. Problems of Economic Development of Ukraine Caused by the Pandemic of Coronavirus COVID-19 in the World, and the Search for Ways to Solve them. Ukraine: Events, Facts, Comments, 9, 47-53. URL: http://nbuviap.gov.ua/images/ukraine/2020/ukr9.pdf [Accessed 29 November 2020].

Latvia's Macro Profile, October 2020. URL: https://datnes.latvijasbanka.lv/macroprofile/2020-2/Latvia_Macro_Profile_Oct_2020.pdf [Accessed 12 December 2020].

Latvian State Employment Service, 2020.. URL: https://www.nva.gov.lv/en/unemployment-statistics-2 [Accessed 12 December 2020].

LV PEAK, 2020. Latvian Productivity Report 2020, Riga, University of Latvia, December $2020 . \quad$ URL: https://www.bvef.lu.lv/fileadmin/user_upload/LU.LV/Apaksvietnes/Fakultates/www.bvef.lu.lv/6.ZINATNE/Instituti/LV_PEAK/LPZ_2020_.pdf [Accessed 29 January 2021].

Ministry of Education and Science Republic of Latvia, 2020. URL: https://www.izm.gov.lv/en [Accessed 12 December 2020].

Orlik, T., Rush, J., Cousin, M., Bloomberg, H.J., 2020. Coronavirus Could Cost the Global Economy \$2.7 Trillion. URL: https://www.bloomberg.com/graphics/2020-coronavirus-pandemic-global-economic-risk/ [Accessed 29 November 2020].

State Employment Center, 2020. Analytical and Statistical Information URL: https://www.dcz.gov.ua/analitics/68 [Accessed 29 November 2020].

Swedbank's Institute of Private Finances, 2020. Survey “Annual financial events in households", November 2020. URL: https://pt.slideshare.net/SwedbankPFI/ptjums-gada-finanu-notikumi-mjsaimniecbs [Accessed 9 January 2021].

Ukraine in 2020-2021: the consequences of the pandemic. Consensus forecast, 2020. The Ministry of Economic Development, Trade and Agriculture of Ukraine. Kyiv. 30 p. URL: https://www.me.gov.ua/Documents/Detail?lang=uk-UA\&id=5d3fea53-45e7-4641-8d48f0c865a24471\&title=VipuskukrainaU2020-2021-Rokakh-NaslidkiPandemii-Konsensusprognoz-kviten2020- [Accessed 29 November 2020].

Ukraine under quarantine: monitoring of public 2020. http://ratinggroup.ua/en/research/ukraine/7ffba32fbbac0ba2a21713d0a9f2c5d5.html [Accessed 29 November 2020].

Zgurovsky, M.Z., 2020. Foresight COVID-19: transformation of the COVID-19 post-pandemic world, European context. URL: http://wdc.org.ua/uk/covid19-transformation-after-pandemic-europe [Accessed 29 November 2020].

група РЕЙТИНГ, 2020. Україна на карантині: моніторинг суспільних настроїв, 10-12 квітня $2020 . \quad$ URL: http://ratinggroup.ua/files/ratinggroup/reg_files/rg_ua_cc_iii_wave_press.pdf [Accessed 9 January 2021]. 


\title{
THE PHENOMENON OF FAMILY BUSINESS AND TAXATION
}

\author{
Aina Joppe, University of Latvia \\ Ilze Sproge, University of Latvia

\section{Ramona Rupeika-Apoga, University of Latvia}

\begin{abstract}
Our research aims to explore and understand specifics of taxation for family business. We have to appreciate the potential of small-scale entrepreneurship, social business, family sustenance farming, mutual support within communities considering neglected policy options, finding ways to reduce obstacles built by conventional conceptualizations of economics. Survivability - the necessary step to sustainability in hard times; taxation policy should have its say.

The authors believe that small-scale entrepreneurship, family business is the one of the most important economy development factors political and social condition stabilization.
\end{abstract}

Keywords: family business, small enterprise, state aid, tax, taxation.

JEL code: M21, D19

\section{Introduction}

Promotion and support of business development is one of the state instruments for economic development. It is essential for the development of the national economy in the country. Small business, incl. family business from economically makes up more than half of the national income. The role of the family in society is defined in the Satversme, as well as the family is the place where most knowledge is transferred, but there is no definition of family business. Therefore, the authors consider this topic to be considered topical.

The aim of the study is to promote the taxation of family companies in Latvian conditions and to develop practical measures to stimulate the tax effect of family companies on their development.

To achieve the aim of this research, the following research tasks are defined:

- to explore the nature of family businesses from a theoretical point of view;

- to explore family business taxation practices;

- to analyze family business practices in Europe and their taxation;

- to assess the practice of Latvian family companies and state aid problems for the support and development of family enterprises.

The research methods (quantitative and qualitative) used to perform the research tasks are theoretical (literature analysis, document content analysis, electronic resource analysis) and empirical research methods. The selected research work covers multidisciplinary aspects, combining organization type and tax treatment.

\section{Literature Review}

The complexity of the family as a social institution has long attracted the attention of researchers in various branches of science - economists, jurisprudence. Preserved fundamental works in which the authors began to study the family business, for example, in the 19th century in the 19th century J. Bachofen (Johann Jakob Bachofen, 1815-1887) began to study family history in Europe; The "ancient society" of the American L.G. Morgana (1877) studies the family phenomenon, followed by other economists and sociologists, such as M. Weber, E. Durkheim, F. Engels. It is worth noting that in the West the problems of family businesses were studied by Smith, J. Trokshinis, Jay. In the works of M. Keynes, P. Samuelson and other most visible economists, among modern researchers were R. Zinder, N. Luna, E. Giddens, G.L. Parsons, R.K. Merton. In their research, the authors tried to find out what a family business is, a family business, what are its advantages in comparison with others, forms of entrepreneurial activity and what taxes are taxed in other countries of the world.

A family business is a business in which two or more family members are involved, and most are owned by them. All major decisions were made and are also made by members of the same family. A small family business is a generally recognized form of organizing production activities, the advantage of which is that it strengthens or creates a set of interests; joint work brings family members, including spouses, closer to each other. helps to strengthen family ties.

European Family Business organization stand up for a sustainable, competitive, and entrepreneurial European economy. European Family Businesses is the EU federation of national associations representing long-term family-owned enterprises, including small, medium-sized and larger companies. The organization was created in 1997. According European Family Business analysis more than 14million family Businesses in the EU. 
More than 60 million jobs in the private sector. Around 50\% of GDP. Family businesses make up between 65 to $80 \%$ of all European companies, accounting for on average more than 40 to $50 \%$ of all jobs (see map page 4). Family businesses constitute a substantial part of existing European companies and have a significant role to play in the strength and dynamism of the real economy. (European Family Businesses)

The authors believe that family business is the very form of organizing entrepreneurial activity. Today it is recognized as an important and dynamic part of the global economy. There are both strengths and weaknesses in the family business. Strong family ties and relationships between relatives can provide a powerful incentive for business development, and family problems and conflicts can damage even the most successful company. There are many ways to strengthen and strengthen a company.

\section{Family Business Classification and Business Schools}

The family is the foundation of the development of society, the universal cultural values of man, the custodian of national traditions, intergenerational experiences and norms of behavior. The family is the only social institution in a society responsible for remanufacturing human resources, since a small social group is founded on the basis of marriage, parents and parents. The family is the oldest social institution, as well as one of the first forms of an economic organization. Family businesses originate in deep antiquity when private property families were created, and people's business was transformed into a business, an independent "business", i.e. the production of goods for other families and individuals.

The family is considered a kind of "firm" that, when consuming resources at no specified cost, makes goods to meet him and all the needs of the public.

Family Business (SB) is an internationally established, strategically sound, economically important national development instrument that provides employment for the population, as well as ensuring stability in society.

The authors consider that small forms of family business have high potential for synergy, resulting from a combination of roles and capabilities of owner and business, evidence of job motivation, staff psychological compatibility, management and organizational unity in achieving the goal.

The family-owned business is just one form of small-scale business that involves economic studies that reveal the impact of family businesses on both the national and global economy. Indeed, in Europe, family businesses, many of which are very old, make up small and medium-sized businesses, Germany, France, England, and a multi-family hotel and restaurant aged 150-200. Today, however, the concept has not been sufficiently studied, although for more than two centuries it has been studied by various local and foreign scientists.

The authors believe that the main source of well-being should generally have been the official salaries of senior family members, spent entirely on meeting the needs of the entire family. At the same time, family relations provided the basis for a variety of shadow business structures that continued to exist outside the elective economy.

The authors in their study offer major contemporary science schools for family business.

Scientists such as R. Lics, J. Craig, P. Sharma, J. Astrachang, V.Perston, Russian researchers such as M.V. Vasilyev, D.A. Volkov, O. Osipenko, I. S. Platonov and others are at the beginning of this science.

The positions of the various scientific schools in this direction were created by different groups of factors: national, market, infrastructure, science community and family.

At the same time, in different countries, these factor groups have contributed to both progress, depression and the development of a scientific community view on problems related to family businesses.

Let us present the main scientific schools of today's foreign and local research in the field of family business.

Major scientific theories and family business schools. Research has shown that there are several strands of family business schools in world practice:

- $\quad$ North American School (1990 s),

- European School (2000-2003),

- $\quad$ Russian school (1990 s).

The North American School's fundamentals are M. Gallo, J.G. Sven, J.G.Kristmans P.J.Sarma, J.G.Chua. Those researchers studied family's companies under the age of 200 , clarified differences in family and family business management. The main problem the school solved was the preparation and building of the team and all of the company's staff. The state did not actually influence school formation. It was created at universities, consulting firms. About 60 leading scientists were identified as active researchers. This school has had several generations of followers 
who have established a course within the school. Specialized scientific journals (of which 3 leads on the subject) were published, included in the rankings of the world's 100 best journals.

European School. The family company under the age of 700, which is considered to be our ancestral heritage, is the main object of the study. The main direction is the development of an original family company management school. In addition, the country is the main consumer of research results. Most studies have focused on maintaining driver training and management traditions (intergenerational business transfer). Schools were set up in universities as well as in the European Commission. Several hundred scientists are active in the study, of which about 50 lead. As in the North American school, there are several generations of followers who make the flow inside the school. Professional national and international scientific associations have been established. There are specialized publications as well as monographs for family businesses. (Касьяненко, 2017)

\section{The Russian School (its Researchers 1290.1290. I.V.Marshev, V.I.Marshev)}

The development of family businesses up to the age of 25 is research facilities for Russian scientists. The attitudes of the family company have not been informed. There is no uniform definition of Sb. The main direction of the study is research into the phenomenon of a family company. At the same time, State research did not currently take part. The main problem of safety management is the peculiarities of family leaving business. There are research centers to which the school would belong. More than 60 researchers study the subject annually. There are no specialized journals - publications of the results of studies are carried out in general articles journals and in stocks of scientific conference articles.

Latvian researchers S.Saksonova also pay attention to credit opportunities in the development of the family company, as well as to the development of small family businesses. (Saksosnova S. (2013), Saksonova S., Papiashvili T. (2019) )

Neither Latvian researchers nor foreign researchers have a common position, which is a family company. EFB offers a definition of its family company. The common feature of these companies is that of the family dimension, where business and ownership are intertwined. Family businesses can be small, medium sized or large, listed or listed. Family businesses in Europe have been widely equated to Small and Medium - Sized Enterprises (SMEs) in public and policy discussions. However, this neglects the fact that there is also a large family businesses.

\section{A firm, of any size, is a family business, if:}

- The majority of decision-making rights are in the possession of the natural person(s) who established the firm, or in the possession of the natural person(s) who has/have acquired the share capital of the firm, or in the possession of their spouses, parents, child or children's direct heirs;

- The majority of decision-making rights are indirect or direct.

- At least one representative of the family or kin is formally involved in the governance of the firm.

- Listed companies meet the definition of family enterprise if the person who established or acquired the firm (share capital) or their families or descendants possess $25 \%$ of the decision-making rights mandated by their share capital. (European Family Businesses)

\section{Family business model in the world}

There are a lot of companies with family capital these days. Family businesses tend to be small, medium or large. There are family companies gigantic too.

Analysts at Ernst \& Young say it's no secret that the family's business model is the oldest, traditional and, in some parameters, still the most efficient type of business. Familiar names like Morgan, Rothschild, Krapp. Sony, Samsung, Prada, Etro, BMW, Toyota, who are bright family business representatives established for generations, and their effectiveness has been proven world-wide. (Ernst \& Young)

Over the past 20 years, $90 \%$ of small and medium-sized enterprises in the US are family enterprises; in small Finland $90 \%$ of companies with fewer than 20 employees - also family companies; $80 \%$ of all German industrial companies - family companies; the apparent leader, Italy, stands on traditional family grounds - there are $94 \%$ of all family companies registered in the State register. family enterprises (Ассоциация Семейного

\section{Бизнеса...)}

Research has shown that in Western countries, the family business works better thanks to the established effective state policy in the family business, which allows owners to open up and expand the presence of such companies in various regions of Western countries. This distinctive feature allows you to talk about the fact that if there is an adequate and understandable policy regarding family business, its form can also be developed successfully in Latvia. 


\section{Research results and discussion}

In order to develop family businesses in Latvia, it is necessary to clarify the existing problems related to the establishment of family businesses at government level and at micro-level.

The following can be mentioned as the main problems at national level:

- No strategy has been developed on the development of family businesses;

- Not formulated what a family company is;

- Tax Law does not prescribe special tax arrangements and tax breaks;

- Not sorted, collected statistics for family businesses.

The following can be mentioned as the main problems at family level:

- Missing the knowledge, skills to manage the family business correctly;

- Internal financing challenges;

- Missing Knowledge, Resources, Equipment, Fixed Assets.

Like any other business, private and family enterprises aim to reduce red tape, strengthen economic stability, reduce interest rates, stimulate employment, create a more efficient tax and legal framework, and ensure investment in infrastructure.

Let us mention the most important facts about family business. In Europe, this unique category plays a vital role for the economy:

- Family businesses account for an important part (on average 40 - 50\% of all jobs) of European private employment based on European Family Businesses report.

- Family businesses reinvest profits responsibly preferring equity as opposed to debt financing.

- Act as responsible owners because of their long-term strategy towards stakeholder interests, including employees, customers, shareholders and local communities.

- Transmission of family values with a high sense of social responsibility.

- Special concern for the local or regional base.

- Natural incubators of an entrepreneurial culture, they foster the next generation of European entrepreneurs.

- Stewards of social and economic capital from one generation to the next. (European Family Businesses)

Studies have shown that family companies have a vital segment of the global economy, and they are able to contribute even more to market growth and renewal if they receive adequate support at the right time.

Only three markets (Singapore, Turkey and Malta) agree that their governments are doing everything they can to help the private business, a family company.

At the same time, businesspeople from countries such as Australia, Denmark, France, Romania, the U.S., Italy, South Africa, Russia and Greece are expressing some discontent with the support mechanism for family companies in their own country.

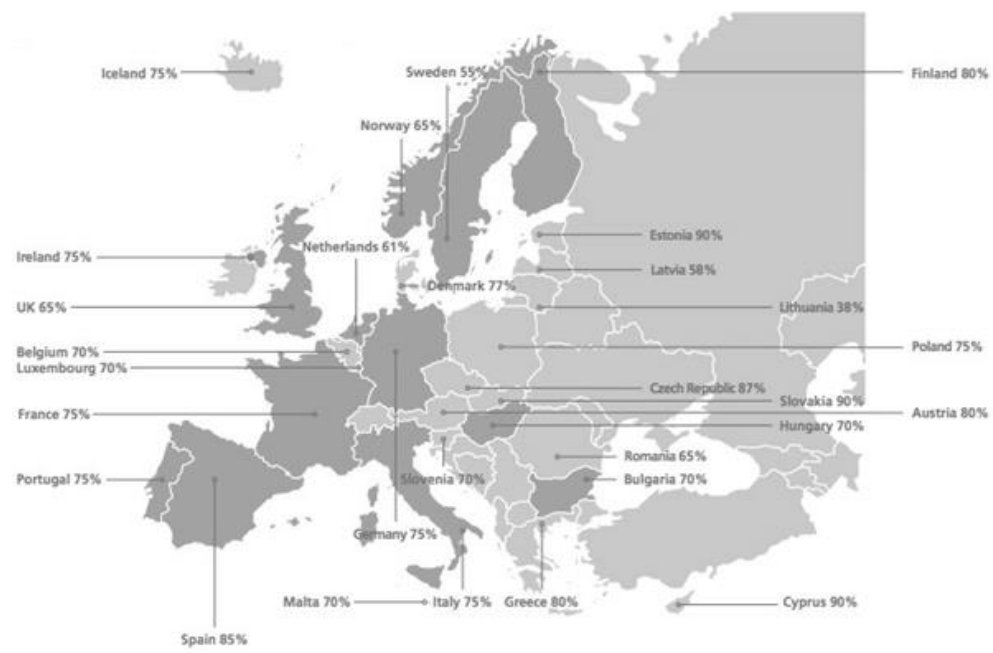

Source: Facts \& Figures European Family Businesses 
Fig. 1. Family business across Europe, \% of total of companies

Data taken from Overview of Family Business Relevant Issues' Kmu Forschung Austria Report (January 2009), Statistical Pilot Project on Family Businesses from the EC (2016) and individual statistical offices from different Member States. (European Family Businesses)

The form of family businesses is pretty widespread in China's economy. The largest number of family businesses is in East China, but their concentration is the highest in the manufacturing industry.

An important question, what form of business for family businesses is, or need registration as an individual company. It should be noted that three countries (New Zealand, Canada, USA) do not need registration at all or in certain cases, or that it is sufficient to notify the authorities concerned. So there is no need for registration in New Zealand and if your status changes from employee to individual entrepreneur, you must notify the Internal Revenue Service to obtain the taxpayer's registration number. In Germany, Sweden, Norway, such registration is necessary and has the nature of the notification. In Norway, however, you can choose the option: free of charge, in the central coordination register of legal persons or in the business register for payment. If you have more than 5 employees or have traded, you need registration in the Enterprise Register. (Семейный бизнес)

Research has shown that private entrepreneurs want the state to provide them with a more efficient and less advantageous business transfer process, or to cancel all payments entirely if one family manages assets for five years. Family companies are assigned to heirs. For example, the German government has changed the system of paying inheritance tax, transferring business, significantly reducing tax breaks and incentives, in addition to granting grants and promotion measures to support scientific research activities and investments in new technologies.

Meanwhile, the Singaporean government offered a series of important initiatives to boost support for small and medium-sized family businesses. One of these initiatives helps business to transform its activities from domestic to international level, provides expert advice on first steps. There is such a large number of relief in Singapore that private and family companies are demanding help from firms such as PwC to identify the most appropriate relief for them (for example, the production company is entitled to more than 90 different relief programs).

\section{Taxation of family businesses}

KPMG's 2020 Global Tax Monitor explores the situation of taxation on family businesses in 54 countries, regions, and jurisdictions. It explores the principal factors impacting the transfer of business and succession process across the globe. The main theme of 2020's monitor is "Charting a path for the future", something that has been made more challenging thanks to the continuing impact of COVID-19 (KPMG Global family ...).

KPMG's 2020 Global Tax Monitor explores the situation of taxation on family businesses in 54 countries, regions, and jurisdictions. It explores the principal factors impacting the transfer of business and succession process across the globe.

Germany. Family business valued to EUR26 million can qualify for a tax exemption of 85 or 100 percent. The exemption decreases by 1 percent every additional EUR750,000, becoming zero at EUR90 million and above. A tax exemption for gifts to children amounting to EUR400,000 is granted every 10 years. (KPMG Global family ...)

Israel Inheritance is generally not subject to tax; gifts are subject to capital gains tax, however with an exemption if the recipient is an Israeli resident. Modifications to the tax law have been made with respect to tax-exempt structures, providing families with greater flexibility in structuring the family business. (KPMG Global family ...)

India India discontinued its Estate Duty Tax in 1985. However, there has been undercurrent of a potential re-introduction since the past few years.

Ireland. The tax-free threshold for inheritances or gifts from parents to children was increased from EUR320,000 to EUR335,000. Family businesses may qualify for additional relief depending on the age of the parent/business owner, as well as the extent and duration of the children's involvement in the business.

Italy. The Italian tax regime favors family succession planning, with minimal or no tax for intrafamilial transfers of the family business by inheritance or gift. (KPMG Global family ...) The tax burden on medium - sized companies in Italy over eight years has decreased from 40 to $32.3 \%$. In 2019, thanks to taxes burden reduction, so-called family businesses Italy was able to increase its contribution to the country's economic development. Thus, the share of the average business in the total value added in output increased from 12.4 to $18.6 \%$ in revenue - from 14.6 to $19.8 \%$ and in exports - from 15.6 to $18.7 \%$. However, big business in Italy is still in a more favorable position, with a tax burden of $27.6 \%$. Recall that Italy is in a difficult economic situation. The budget has an excessive deficit (2.4\% of GDP), the state debt reaches $130 \%$ of GDP (more than $€$ 2 trillion). The state spends the largest amount of public debt in the EU - 69.6 billion a year. This means that every Italian pays 1450 euros a year 
as a percentage of the government loan. $* * *$ However family businesses in Italy pay more taxes than large companies (according to current data $27.6 \%$ (Налоговая нагрузка ...)

However, family companies in Italy pay more taxes than big companies (27.6\% according to current data).

Mexico Family business transmission by inheritance or gift are tax exempt, however it is important to consider that in certain states for real estate that is part of the business it can be mandatory to pay "Capital Transfer Tax" and/or "Real Estate Acquisition Tax.

The Netherlands. Exemptions only apply for business assets that have been part of the business at least 5 years before a gift transfer, one year in case of death, and shares must be held and the business continued for at least 5 years after the transfer. Income tax is not actually exempted, but is deferred to the next generation. There is political pressure to reduce the current 83 percent exemption for gift and inheritance tax.

Russia. There are no inheritance taxes, real estate transfer tax (RETT) wealth taxes, intrafamily gifts and inheritance are also not subject to personal income tax. Specific tax planning opportunities may be considered depending on the successor`s future plans for the business. Russia will introduce a family patent for micro-enterprises as a measure economic recovery in 2021. The patent management of the Russian micro-enterprise family is included in the National Economic Recovery Plan on 2021. in the list of measures presented at the government meeting on 23 September. The deadline for its implementation specified "indefinitely". It was assumed that business owners will be enough once a year to pay Russian Federal Tax the amount of the patent and not to make documents for each relative. It was expected that such a patent will make effect as early as December this year. Experts are convinced that this initiative will help a little to survive the business losses from a pandemic, however, a collective patent $d$ Unemployment can only fall on paper without actually changing number of employees (Малому бизнесу найдут ...)

This type of tax has the potential to benefit about 5 million entrepreneurs in Russia. Probably a family patent In Russia, the tax system will become as popular as the profession national income tax for the self-employed. After According to Dmitry Ivanov, the patent originally provided for reduced income tax rates - $4 \%$ and $6 \%$, as well as for the self - employed (depending on the amount of profit and the category of clients - natural or legal person). Moratorium preparation of additional documents for all family members within 1 year can significantly stimulate entrepreneurship initiative and will provide additional assistance to micro-enterprises (Бизнес - дело семейное ...)

South Africa. Tax liabilities for family business transmission by inheritance or gift can be excessive, depending on the value of the business. Despite changes in the South African tax legislation regarding the use of trusts as vehicles to hold family assets, it is evident that the non-tax benefits of trusts still hold true.

Spain. Terms of taxation vary greatly among the various autonomous regions. There is currently no schedule or program to unify the inheritance and gift tax treatment. The new government plans to introduce legislative amendments that may increase tax rates, such as increasing the personal income tax (PIT) on capital gains, from 23 percent to 27 percent.

South Korea. A reform plan for the transfer of family business will shorten the post-management period from 10 years to 7 years and the obligation to maintain the industry, employment and assets will be eased. The plan is intended to expand use of the family-operated business deduction system, to encourage succession and incentivize employment and investmen

UK. A document published by the Office of Tax Simplification in July 2019 proposed a number of changes that would affect business property relief, potentially exempt transfers and obtaining a capital gains uplift upon death. Because of the inheritance tax (IHT) exemption, there is flexibility for planning with family business shares to use trust or company structures to hold their interests in the businesses for the purposes of succession planning for future generations

US. The exclusion for taxable gifts and estates was raised to USD10 million, with an annual inflation adjustment, beginning in 2017, but with a 2026 sunset provision. In 2019 the Internal Revenue Service (IRS) issued regulations clarifying how the tax would be administered, so that if a gift is made with the increased exclusion and the gifter then dies after the exclusion is reduced, there will be no clawback or recapture of taxes calculated with the higher exclusion.

France is a good example of the benefits family businesses can realize with proper planning to take advantage of available allowances. While the tax rate is quite high -45 to 50 percent - a number of allowances and incentives are offered that can reduce the effective tax rate to 15 to 25 percent. (KPMG Global family ...)

Notably, Italy, the world's eighth-largest economy, has among the lowest tax burdens in Europe for business transfers, with zero tax realized for the business cases presented in our report. The tax liability in Germany also drops to zero after exemptions for intra-family transfer of a EUR10 million business by inheritance or by gift, reflecting the country's strong family business culture. However, larger family businesses do not receive 
the same favorable treatment. For transfer of a EUR100 million business, whether by inheritance or gift, Germany has one of the highest tax burdens in Europe, even after exemptions. (KPMG Global family ...)

Small business, family business is one of the most important factors for есоnomic development, political and social stabilization. (Семейный бизнес. ..)

The authors consider that Family firms are important, not only because they make an essential contribution to the economy, but also because of the long-term stability they bring, the specific commitment they show to local communities, the responsibility they feel as owners and the values they stand for. These are precious factors against the backdrop of the current financial crisis."

Europe's family businesses may not see climate change as a major priority for the EU at the moment, but that's likely to change as the next generation takes control. The next generation is more deeply committed to sustainability and environmental issues, and we expect to see them demand more action from the European government on these issues). (KPMG, 2019)

Think of the family-owned businesses all across our Union. They were not built solely on shareholder value or the next bonuses. They were built to last, to pass down generations, to provide a fair living to employees. They were built on passion for quality, tradition and innovation.

(Ursula von der Leyen, 2019)

\section{Conclusions, proposals, recommendations}

Based on research by the authors provides conclusions and make recommendations on national regulatory issues economic, social, organizational and legal efforts to build a family business conditions small families company successful development.

\section{Conclusions:}

1. Small and average company development, which one component is the families business, is the important economy development factor, socio economic and political condition stabilization in the country

2. Is the big unused Options such private company association international cooperation. Such cooperation will allow exchange with experience and to master own progressive idea efficiency.

3. Removing unnecessary administrative barriers in its path; support for small businesses, especially at the beginning of the journey; simple, straightforward and growth favourable tax system.

\section{Recommendation:}

1. 1.The tax system is only an instrument that can help to achieve the goals that it should use to support a family business. They waiting how to the government will develop and will accept special measure complex, who will help private and families firms to develop and grow.

2. Required well-thought-out, clear and stable family business legislation, family's business-friendly, simplified mode to Country provide more effective and advantageous business transfer process heirs.

3. In order to successfully develop family businesses, the creation of a database for family businesses is necessary operational informative security, in force existing law giving and regulatory everything levels bases improvement.

4. Availability of credit on favorable terms for family businesses, property supports provision.

5. Reduce the administrative burden on the family business by ensuring an attractive tax regime.

6. Stimulate to increase productivity and investment in research and development, to develop exports, to motivate to show profits In Latvia and to improve the balance sheets of companies.

7. To promote start-ups of new family businesses, as well as to motivate local governments to attract and retain own territory private companies.

\section{Bibliography}

Antonio Longo, Italy: Italy As The New Tax Eldorado For Private Individuals , 9 July 2019, [Online] Available at: https://www.dlapiper.com/en/uk/insights/publications/2019/07/new-tax-incentives-for-attracting-humancapital/?utm_source=Mondaq\&utm_medium=syndication\&utm_campaign=LinkedIn-integration [Accessed 20.11.2020].

Asare, A., 2016. DB, Ģimenes biznesa plusi un mīnusi, 21.03.2016, [Online] Available at: https://www.db.lv/zinas/gimenes-biznesa-plusi-unminusi-447084 [Accessed 19.11.2020].

Astrachan, J.H., 2005. Family / J.H. Astrachan, P. Alcorn, A.K. Strider // Kenyon-Rouvinez D., Ward J. L. Family Business. Key Issues. - New York. Palgrave Macmillan.

Ernst \& Young, 2011. Succeeding for Generations. Stories of the World's Most Enduring Family Businesses. https://familybusiness.eyvx.com/pdfs/s4gbook-26.5.11.pdf [Accessed 07.12.2020]. 
European Family Businesses [Online] Available at: http://www.europeanfamilybusinesses.eu/ [Accessed 16.11.2020].

Ģimenes biznesā vieglāk saglabāt augstu kvalitātes latiņu, [Online] Available at: https://www.lonas.lv/lonas+/gimenes-bizness-kad-visi-zurijasdalibnieki-v, [Accessed 20.11.2020]

Joppe, A., Sproge, I. (2019). Models of Tax Payments of Performers of Economic Activity in Latvia. New Challenges of Economic and Business Development - 2019: Incentives for Sustainable Economic Growth. Proceedings Paper Pages: 366-374

KPMG European family business barometer. Succession top of mind as business families eye their legacy (2019) [Online] Available at: https://assets.kpmg/content/dam/kpmg/xx/pdf/2019/11/european-family-business-barometer.pdf [Accessed 25.11.2020]

KPMG Global family business tax monitor, Charting a path for the future ,October 2020 (2020) [Online] Available at: https://assets.kpmg/content/dam/kpmg/xx/pdf/2020/10/global-family-business-tax-monitor.pdf [Accessed 1.11.2020]

Miller D. (2005) Managing for the long run: lessons in competitive advantage from great family business / D. Miller, I. Le Brenton-Miller // Harvard business school press. - P. 12-23.

Petrāne L., Ģimenes jahtu bizness: Valsts atbalstu neprasām, bet sakārtotu infrastruktūru gan, [Online] Available at: https://www.delfi.lv/bizness/biznesa_vide/gimenes-jahtu-bizness-valsts-atbalstu-neprasam-bet-sakartotu-infrastrukturu-gan.d?id=52564891, DELFI, Bizness, Biznesa vide 17.10.2020 [Accessed 25.11.2020]

PWC, Italy, Individual - Income determination, 10 August 2020, [Online] Available at: https://taxsummaries.pwc.com/italy/individual/incomedetermination [Accessed 05.12.2020]

Saksonova S. (2013) Approaches to Improving Asset Structure Management in Commercial Banks, Book Series: Procedia Social and Behavioral Sciences, Volume: 99, Pages: 877-885

Saksonova, S., Papiashvili, T., 2019. Small Business In A Small Country And The Role Of Government (The Case Of Georgia), New Challenges Of Economic And Business Development - 2019: Incentives For Sustainable Economic Growth, Proceedings of 11th International Scientific Conference, Riga, University of Latvia, 719-727.

Tax treatment for family members working in the family business, [Online] Available at: https://www.irs.gov/newsroom/tax-treatment-for-familymembers-working-in-the-family-business, FS-2019-14, October 2019 [Accessed 05.12.2020].

Vincencováa, E., Hodinkováb, M., Horák, R., 2015. The Tax Effects of the Family Business Succession, Business Economics and Management 2015 Conference, BEM2015, [Online] Available at: https://core.ac.uk/download/pdf/82448227.pdf [Accessed 05.12.2020].

von der Leyen, U., 2019. Speech by President-elect von der Leyen in the European Parliament Plenary on the occasion of the presentation of her College of Commissioners and their programme Available at: https://ec.europa.eu/commission/presscorner/detail/es/speech 19 6408 [Accessed 10.11.2020].

Ассоциация Семейного Бизнеса Казахстана [Online] Available at: https://fba.kz/?p=1254 [Accessed 16.11.2020].

Бизнес - дело семейное: нужен ли бизнесу «семейный патент»? [Online] Available at: https://4s-info.ru/2019/09/26/biznes-delo-semejnoenuzhen-li-biznesu-semejnyj-patent/ [Accessed 25.11.2020].

Всемирное исследование частного и семейного бизнеса [Online] Available at: https://www.pwc.ru/ru/new-site-content/fbs/global-familybusiness-survey-2016.pdf [Accessed 2.12.2020].

Касьяненко, Т.Г. (2017) Эволюция понятия «семейный бизнес» по исследованиям российских и зарубежных ученых / Т.Г. Касьяненко, А.М. Воротилкина // Экономика и управление: проблемы, решения. №2. - С. 36-44.

Малому бизнесу найдут семью. ДОЛГ.РФ. [Online] Available at: https://долг.pф/news/nalog_na_pribyl/malomu_biznesu_naydut_semyu_ [Accessed 10.11.2020].

Налоговая нагрузка на семейный бизнес в Италии снизилась (2019) [Online] Available at: https://rossaprimavera.ru/news/772ce53a [Accessed 10.11.2020].

Семейный бизнес. «Экономическая Газета» [Online] Available at: https://neg.by/novosti/otkrytj/semejnyj-biznes-8318 [Accessed 10.11.2020]. 


\title{
EFFECTS OF STATES GOVERNMENTS RESTRICTIONS RELATED ON CORONAVIRUS DISEASE (COVID-19) ON STATES ECONOMY - COMPARISON OF BALTIC STATES, SWEDEN, AND BELARUS Inese Kalnina, University of Latvia
}

\begin{abstract}
In order to limit the spread of COVID-19, states have gradually implemented restrictions mandating school and kindergarten closures, postponing academic semesters and prohibiting visits to nursing homes to protect the elderly, borders were closed, states prohibited physical contact with more than one person from outside one's household, and other restrictions. This paper examines the economic effects of policies to contain Covid-19 in Baltic States by comparing they with experience of Sweden and Belarus where approach was less stringent and based more on social responsibility than legal obligations compared to the other European states.
\end{abstract}

Keywords: Covid-19, restrictions, economy, GDP, Baltic States, first stage of lockdown.

JEL code: K29, E61

\section{Introduction}

When the World Health Organization declared a pandemic, national governments acted. Virtually all European States imposed restrictions on the spread of COVID with the declaration of the state of emergency (Al Zobbi et al., 2020). By comparison, the national restrictions are quite similar. Many countries have imposed aggressive containment and social distancing measures, in an effort, to slow the spread of Covid-19 (Goniewicz et al., 2020). While the pandemic and containment measures undoubtedly lead to significant economic fallouts, the effects of the latter are still debated. The exceptions in the European region are Sweden and Belarus, where mandatory restrictions were practically not introduced, relying on the sensible actions of the people, social responsibility towards each other and the awareness that the people must acquire immunity.

With the aim to find out and evaluate to what extent the restrictions have affected the economy in the Baltic States in the first half of 2020, comparing the indicators of the Baltic States - Latvia, Lithuania, and Estonia with the indicators of Sweden and Belarus; examining the questions whether there has been such an effect; the extent of the impact; whether the magnitude of the impact differed in countries with restrictions compared to countries without restrictions using WHO, Eurostat and national official data.

The analysis employs different qualitative and quantitative analysis methods, such as: political documents analysis, scientific literature and empirical research analysis, modelling tables, charts and schemes and other. When comparing the results achieved, as well as by examining the economic impact of the number of macroeconomic indicators, it is finally concluded that it has been influenced by national governments' policies in adopting restrictions.

\section{Research results and discussion}

\section{Restrictions}

Latvia

On March 12, the Latvian government decided to declare a state of emergency in the country. The government is imposing restrictions to reduce crowding and the spread of Covid-19. Training in schools will take place remotely; public events were prohibited. From As far as possible, state and local government institutions should provide services remotely. "Home quarantine" will be mandatory for people returning from the Covid-19 affected area. Prime Minister: The aim is to limit people's gatherings for the next four, maybe several weeks. The President: If the government's guidelines are followed, Covid-19 will be restricted in Latvia. Minister of Health: The capacity to transmit and receive analyzes needs to be expanded. The Infectious Diseases Center organizes a mobile test site. all organized sports and leisure activities in and outside sports clubs have been abolished. Consequently, sports venues that work indoors will also have to close, although the number of participants is small (Cabinet of Ministers of Republic of Latvia, 2020).

In Latvia, the emergency situation announced on March 12 for the control of the new coronavirus Covid-19 ends on June 10 . The virus is still circulating and there are no drugs or vaccines against it, so a number of restrictions and precautions remain in place (The Covid-19 Emergency ..., 2020).

\section{Lithuania}

To control the spread of coronavirus (COVID-19), the Government decided to declare quarantine on the entire territory of the Republic of Lithuania (Nikolajenko et al., 2020). The quarantine regime was effective from 16 March 2020 until 16 June 2020 (Ministry of Health of The Republic of Lithuania, 2020a). In pursuance with Article 21(3)(1) of the Law of the Republic of Lithuania on the Prevention and Control of 
Communicable Diseases in Humans, Article 21 (2)(1) of the Law on Civil Protection, having regard to the adverse epidemic situation of COVID19 (coronavirus infection) and the proposal by the Minister for Health, also to the recommendation by the Emergency Commission of the Government of the Republic of Lithuania of 14 March 2020, the Government of the Republic of Lithuania has resolved (Lietuvos Respublikos Vyriausybè, 2020):

1. To declare the tertiary (absolute preparedness) level of preparedness of the civil protection system;

2. To declare quarantine on the entire territory of the Republic of Lithuania;

3. To endorse the quarantine regime regarding: 1) cross-border and domestic movements; 2) the activities of public and private sectors; 3) the organisation of work in educational establishments; 4) the organisation of work in health care institutions; 5) the organisation of work in social service establishments. The Ministry of Health from 4 April 2020 was tightening the conditions of the quarantine in Lithuania to stop the spread of coronavirus infection and protect the population (Ministry of Health of The Republic of Lithuania, 2020b).

Estonia

The emergency situation was effective from 12 March when the government of Estonia approved the emergency measures at cabinet meeting (The Government has ..., 2020). According to the government's decision, the emergency situation in Estonia remained in effect until 1 June Measures was taken to prevent the spread of the coronavirus in order to protect the overriding public interest, human health and life. The change in the way of life concerned schools, cultural life and leisure, and visits to institutions (Government approves emergency..., 2020).

Additional new measures concerned people-to-people distance in public space and the closure of shopping malls and additional entertainment facilities starting at 25 March. First, it was agreed by the emergency committee that at least 2 meters distance between people should be kept in public places, such as outdoor playgrounds, sports grounds, beaches, promenades, health and hiking trails and indoors, except in homes and when this cannot be ensured. Up to two people were allowed to be together in public space. This restriction did not apply to families living and moving around together, and to people performing public duties.

Second, the emergency committee agreed to close shopping centers, except for grocery stores, pharmacies, telecommunication outlets, bank offices, parcel stations, and stores selling or renting assistant and medical devices on the basis of an assistant card or medical device card.

Shopping centers eateries were only allowed to sell food as take away. In shops that remained open people must adhere to the principle that they may move alone or in pairs and keep at least 2 meters distance from other people.

Thirdly, it was decided that restaurants and bars should be closed at $10 \mathrm{pm}$ in the evening, and that only take-away and home delivery will be allowed after that time. Fourth, entertainment venues, for example bowling and billiard halls, hookah cafés, adult clubs, was closed (Government Communications Unit, 2020).

The government specified the easing of restrictions after the Emergency situation from 1 June 2020 (The government specified..., 2020). The restrictions and easing of restrictions were approved by the Government by categories: restrictions to alcohol sales, quarantine, restrictions on crossing the state border and quarantine (The Government approved..., 2020).

Sweden

Sweden has largely relied on voluntary social distancing guidelines since the start of the pandemic, including working from home where possible and avoiding public transport. Sweden has refrained from universal school closures, stay-at-home orders, and mandatory business closures. In addition, while it has often been reported that restaurants remained opened in Sweden, it is rarely mentioned that they actually operated under several restrictions, including mandatory social distancing rules. Retailers, sports clubs, and hair salons were also subject to a set of guidelines.

There's also been a ban on gatherings of more than 50 people, restrictions on visiting care homes, and a shift to table-only service in bars and restaurants. The government has repeatedly described the pandemic as "a marathon not a sprint", arguing that its measures are designed to last in the long term. Sweden's authorities never said achieving herd immunity was their goal, but they did argue that by keeping more of society open, Swedes would be more likely to develop a resistance to Covid-19 (Savage, 2020).

Belarus

On 9 April, a mandatory 14-day self-isolation requirement was issued by the government for foreign and Belarusian citizens with either confirmed COVID-19 diagnosis, or the status of first- or second-level contact. The penalties for breaking the requirement included administrative detention, fine and imprisonment (The Government of the Republic of Belarus, 2020). 
According to the government's decision Citizens of Belarus, foreigners and stateless persons should be placed on self-isolation in the following cases: if they have a COVID-19 infection; if they relate to contacts: of the first level with persons with COVID-19 infection - within 14 calendar days from the date of the last contact; second level with persons with COVID-19 infection, in the presence of one or more respiratory symptoms for the period of the indicated symptoms. For this period, people would be issued a certificate of incapacity for work if they, as well as themselves, was payed compulsory insurance premiums. The periods of stay of citizens in self-isolation can be extended by the decision of doctors. Recommendations for seniors and seniors (over 60 years old) on the prevention of coronavirus infection (COVID-19 infection) and Recommendations for social distancing during the period of registration of cases of infection with COVID-19 (coronavirus infection) was adopted by Ministry of Health (Ministry of Health of The Republic of Belarus, 2020).

An analysis of the national restrictions leads to the conclusion that, there are also similarities in the containment measures across the Baltic States. In Sweden, the restrictions were much lower (Bricco, Misch \& Solovyeva, 2020). In Belarus, on the other hand, there were mainly recommendations. (Table 1). Color coding refers to strictness of measures implemented in each category. The darker the grey the more stringent is the containment measures, white - no restrictions, O means - open with some restrictions (obligations for service of customers to wear a masks). Lockdown refers to the period of mid-March/beginning June.

Table 1

Containment Measures in the Baltic States, Sweden, and Belarus (March - July 2020)

\begin{tabular}{|c|l|c|c|c|c|c|c|c|c|}
\hline No. & State & $\begin{array}{c}\text { Visiting } \\
\text { elderly }\end{array}$ & $\begin{array}{c}\text { Closed } \\
\text { Borders }\end{array}$ & Assemblies & $\begin{array}{c}\text { Secondary } \\
\text { school \& } \\
\text { higher }\end{array}$ & Restaurant & $\begin{array}{c}\text { Primary } \\
\text { Schools } \\
\text { \& } \\
\text { earlier }\end{array}$ & $\begin{array}{c}\text { Retailers } \\
\text { Sports } \\
\text { Clubs, } \\
\text { Hair } \\
\text { Salons }\end{array}$ \\
\hline 1. & Latvia & $\mathrm{X}$ & $\mathrm{X}$ & $>2$ & $\mathrm{X}$ & $\begin{array}{c}\text { Take out } \\
\text { only }\end{array}$ & $\mathrm{O}$ & $\mathrm{O}$ & $\mathrm{X}$ \\
\hline 2. & Lithuania & $\mathrm{X}$ & $\mathrm{X}$ & $>2$ & $\mathrm{X}$ & $\begin{array}{c}\text { Take out } \\
\text { only }\end{array}$ & $\mathrm{X}$ & $\mathrm{O}$ & $\mathrm{X}$ \\
\hline 3. & Estonia & $\mathrm{X}$ & $\mathrm{X}$ & $>2$ & $\mathrm{X}$ & $\begin{array}{c}\text { Take out } \\
\text { only }\end{array}$ & $\mathrm{O}$ & $\mathrm{O}$ & $\mathrm{X}$ \\
\hline 4. & Belarus & $\mathrm{O}$ & & & & $\mathrm{O}$ & & $\mathrm{O}$ & \\
\hline 5. & Sweden & $\mathrm{X}$ & $\begin{array}{c}\text { Non- } \\
\mathrm{EU}\end{array}$ & $>50$ & $\mathrm{X}$ & $\mathrm{O}$ & & $\mathrm{O}$ & $\mathrm{O}$ \\
\hline
\end{tabular}

Source: author's created table partly based on the International Monetary Fund Working Paper (Bricco, Misch \& Solovyeva, 2020)

\section{Health outcomes}

As of the 1 August, Sweden's reported Covid-19 cases per capita, also Belarus reported cases, have surpassed Baltic States. (Figure 1). There is robust cross-country evidence that the stringency of containment strategies affects the number of Covid-19 cases.

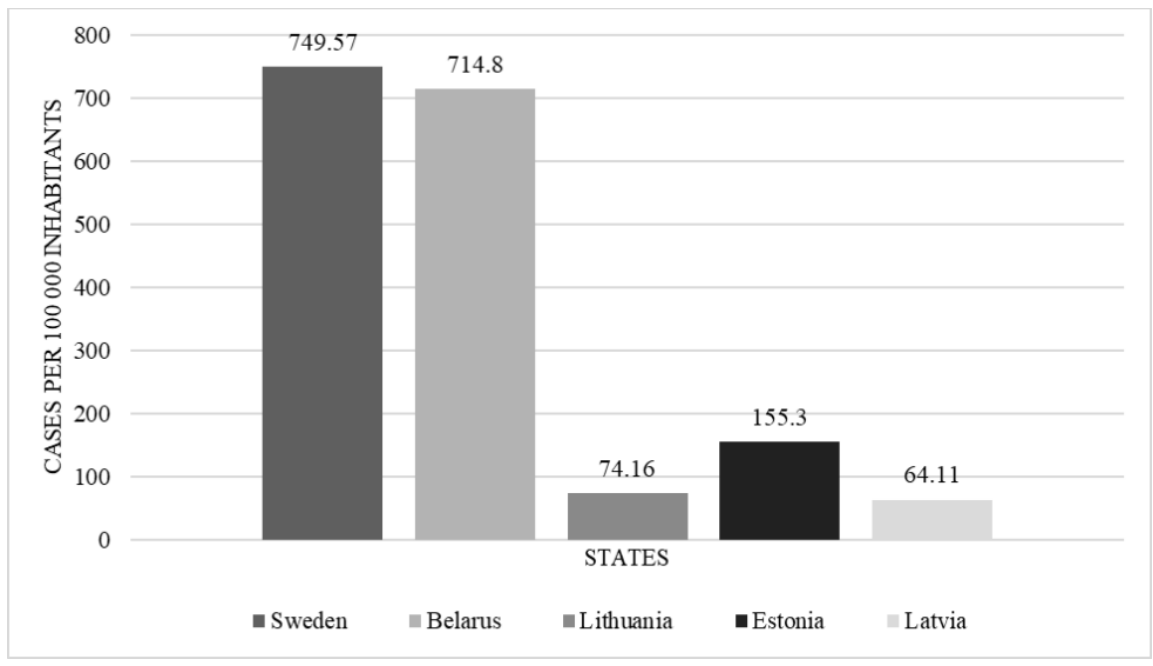

Source: author's construction based on data of the World Health Organization (World Health Organization, 2020)

Fig. 1. Total Number of Reported Covid-19 Cases (till August 1, 2020) per 100000 inhabitants 
If Sweden explained, why it chose the scenario of combating the coronavirus, which provides for the absence of tough measures, then the Belarusian authorities limit themselves only to general statements that they have everything under control. Health Minister Vladimir Karanik noted in this regard that each state chooses its own strategy (Boguslavskaya, 2020).

While Sweden's death toll per capita is much higher than in Baltic States (Figure24). Errors in the attribution of deaths in Sweden are unlikely as reported Covid-19 deaths explain a large share of currently observed excess mortality, suggesting that official statistics are rather accurate and do not underreport Covid-19 deaths contrary to statistics in some other countries (Bricco, Misch \& Solovyeva, 2020).

The difference in numbers in the Belarusian Ministry of Health is explained by the epidemiological surveillance system that has survived since Soviet times, which began to work even before the first cases of infection in the country (Boguslavskaya, 2020).

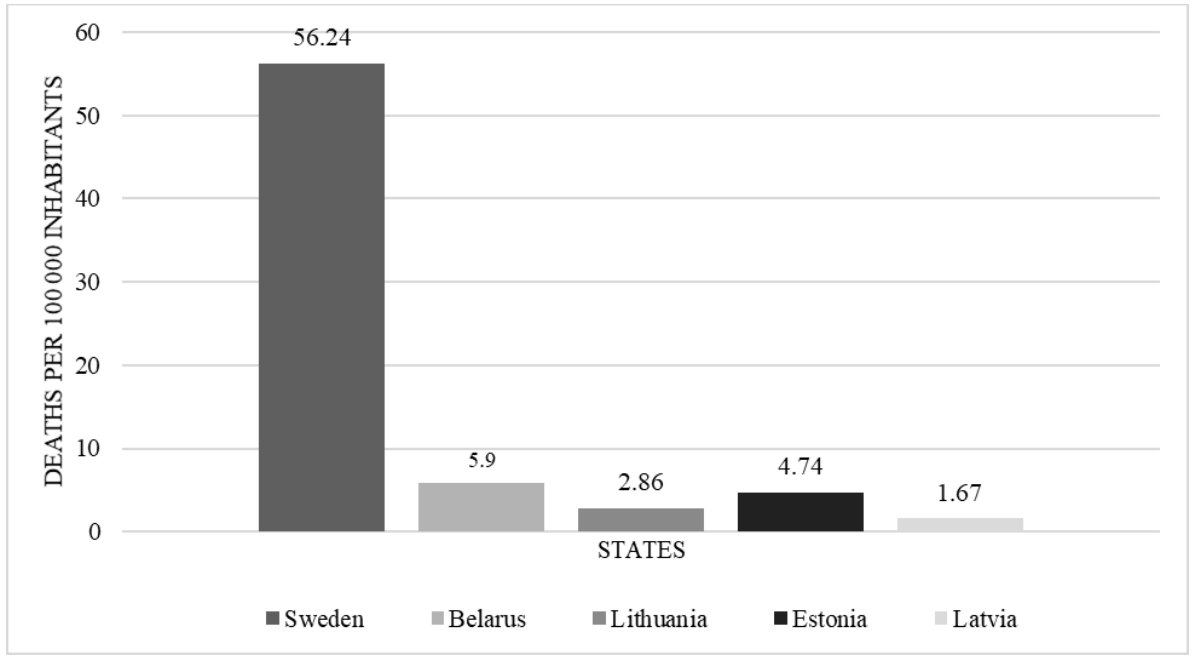

Source: author's construction based on data of the World Health Organization (World Health Organization, 2020)

Fig. 2. Total Number of Reported Covid-19 Deaths (till August 1, 2020) per 100000 inhabitants

When the incidence in Belarus was high, the percentage of deaths among patients with COVID-19 was in sharp contrast to similar data from neighbors, because it was several times less. Let's take Sweden for comparison - a country with a comparable population, the number of cases of coronavirus and the absence, like ours, of strict quarantine. But the digital picture of the pandemic is different there. Firstly, more than 10 times more people died from COVID-19 in Sweden than in Belarus. Secondly, with a decrease in the number of cases in Sweden, mortality also decreases. It is clear, that initially in Belarus the criteria for setting the cause of death were so defined that coronavirus infection was called the cause in exceptional cases. Indeed, as shown, the study of the SATIO company, which studied the perception of the situation with COVID-19 among residents of Belarusian cities, even after contact with infected people, citizens are not ready to go to polyclinics. $73 \%$ of those who believe that they have not survived the virus say they are ready to go to a medical institution only after the onset of symptoms, of which $24 \%$ - only after serious symptoms. And only $23 \%$ of those who think they have carried the virus went to medical institutions. Almost a third of respondents justify hiding the disease (Spasjuk, 2020).

\section{Effect on Economy}

In this subsection, will be consider the effects of containment policies on aggregate economic activity. Available data on the number of monthly unemployment rate in countries provide valuable insights into the impact of the crisis and containment policies. 


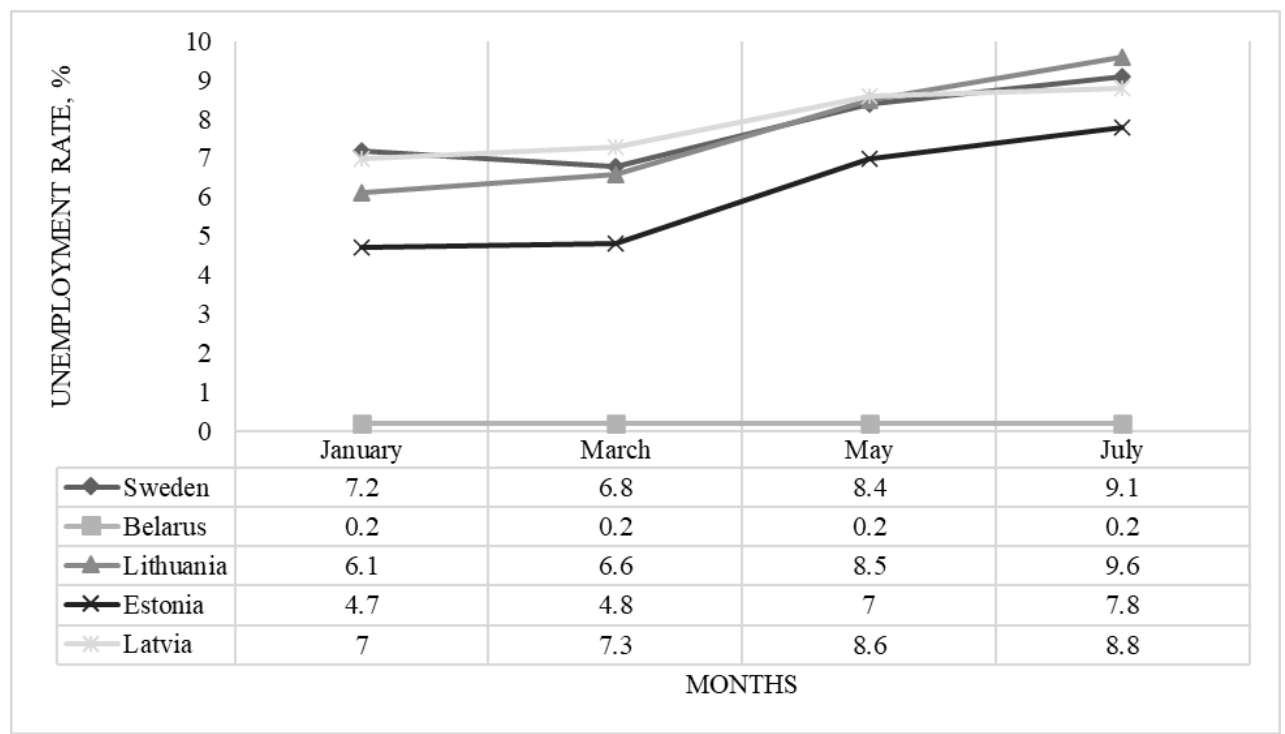

Source: author's construction based on data of the Eurostat. (Eurostat, 2020)

Fig. 3. Monthly unemployment rate, 2020 (January, March, May, July), as \% of active population aged 15 to 74 years

The increase in the number of unemployment rate in Sweden, Lithuania, Latvia, and Estonia, has followed different trends. In Sweden, the increase has been somewhat slower, but Sweden remained on a steady upward trend. In Belarus, unemployment remained stable throughout the period. This could be due to both the absence of Covid - 19 restrictions and the specificities of the economy.

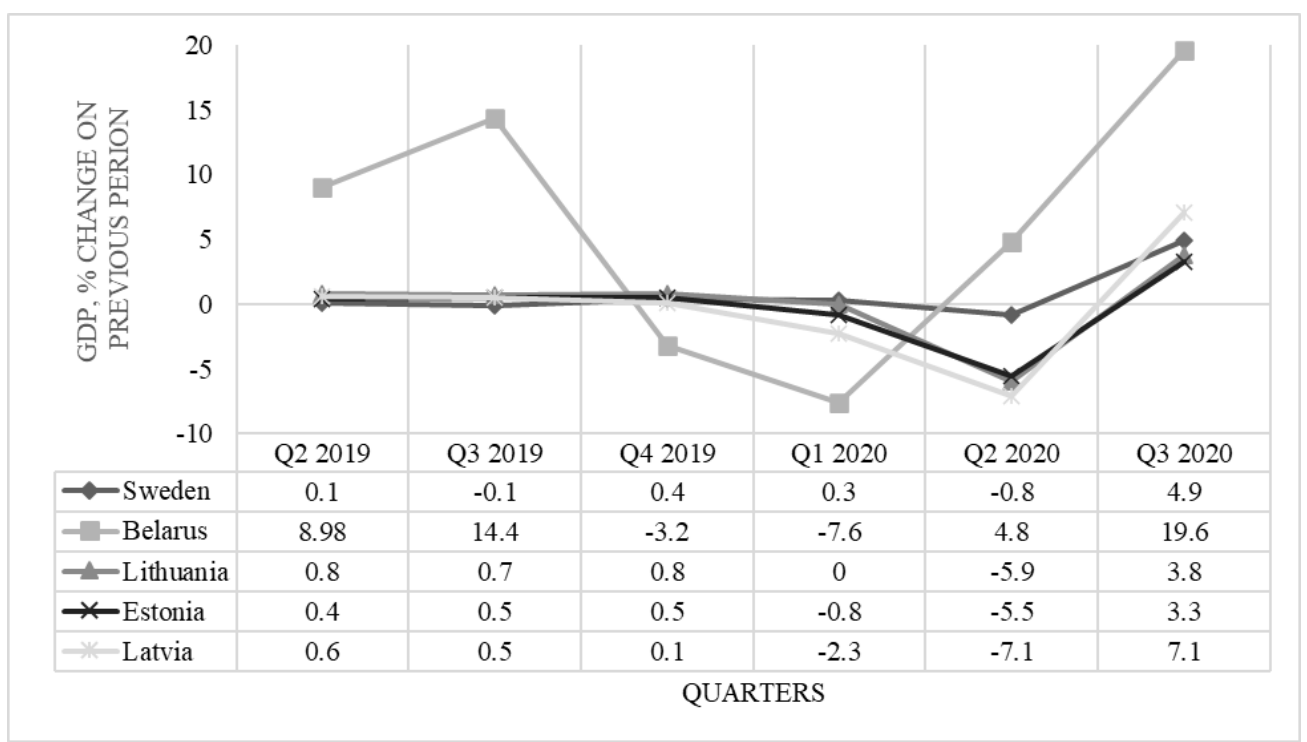

Source: author's construction based on data of the Eurostat. (Eurostat, 2020)

Fig. 4. GDP Percentage change on previous period, (Q2 2019-Q3 2020)

The growth outcome in the first quarter of 2020 provides some initial clues about the effects of containment policies on economic activity. Till August 2020, economies of all countries faced a challenge, which was also reflected in GDP. According to states released first-half GDP data, the simple average of these estimates is, that a GDP had decline in second quarter, similar way in all States where had restrictions and where had not. Sweden did not record an economic contraction in the first quarter of 2020 contrary to almost all other economies. 2020:Q1 data show positive GDP growth of 0.2 percent QoQ. Obviously, the first quarter coincides with the onset of the crisis, which started to intensify only in March.

2020:Q1 growth outcomes across advance economies appear to be correlated with the length and intensity of containment measures. However, there remain several caveats, and it is too early to draw definitive conclusions. There is a large variation in growth outcomes across advanced economies that cannot be explained by differences in containment strategies alone, and a range of other factors, including infection rates, supply 
chain disruptions or declining exports, may matter as well. The sample size is small, and hence it is not possible to control for confounding unobserved effects (Bricco, Misch \& Solovyeva, 2020).

\begin{tabular}{|rr|r|r|r|}
\hline & $\begin{array}{r}8000 \\
7000\end{array}$ \\
\hline 2000 & & & & \\
\hline \\
\hline
\end{tabular}

Source: author's construction based on data of the Eurostat. (Eurostat, 2020)

Fig. 5. Balance of payments by country - quarterly data Million euro (Q3 2019-Q2 2020)

The Balance of payments provides harmonized information on international transactions which are part of the current account (goods, services, primary and secondary income), as well as on transactions which fall in the capital and the financial account.

To help prevent the spread of the Covid-19 pandemic, countries around the world have taken a variety of restrictive measures, which have negatively affected international trade in goods.

Amount of the exports and imports fell in all countries. But looking at the international trade balance, it must be concluded that it is sufficiently stable during the period of the restrictions.

The fluctuation of the balance sheet in Sweden and Belarus had occurred before the accession of the Covid -19 and therefore cannot be linked to restrictions.

\section{Conclusion}

At a time when the Baltic States were imposing austerity Covid-19 restrictions in March, April and May 2020, here had a negative impact on the economy during this period. However, the general trend in Sweden, which was not severely constrained, also indicates a deterioration in economic performance over this period.

In Sweden and Belarus, the government did not impose strict restrictions, which was reflected in the many times the number of people infected with Covid -19 compared to the Baltic countries considered. Although the number of cases was similar in both countries, the number of deaths in Sweden was disproportionately higher than in Belarus.

Unemployment is rising in all countries with the same trend, with the exception of Belarus, so it cannot be linked to the government restrictions.

The overall decline in GDP in the first six months of 2020 has been smaller in Sweden than in other countries. In Belarus, on the other hand, changes in GDP are similar to those process in the Baltic States.

Amounts of exports and imports fell in all countries. But looking at the international trade balance, it must be concluded that it is sufficiently stable during the period of restrictions.

Governments should have a long-term plan, this includes continuous revision of the lockdown policies, restrictions, and procedures. The policies should compromise between preventing an over-limit outbreak and mitigating economic loss. Limited capacity is defined as the ultimate capacity for intensive care units in the public health system. Governments should be concerned about finding the optimal planning response and restrictions, which include restricting travel, isolating people with the virus and their contacts, social distancing, growing health system capacity, and others.

\section{Bibliography}

Al Zobbi, M., Alsinglawi, B., Mubin, O., Alnajjar, F., 2020. Measurement Method for Evaluating the Lockdown Policies during the COVID-19 Pandemic. International Journal of Environmental Research and Public Health, 17(15), 5574, 1-9. 
Богуславская, А. (Boguslavskaya A.), 2020. Почему в Беларуси не принимают жестких мер в борьбе с коронавирусом (Why Belarus is not taking tough Measures in the Fight Against Coronavirus) 30.03.2020. [Online] Available at: https://p.dw.com/p/3aBc9 [Accessed 20.10.2020].

Bricco, J., Misch, F., Solovyeva, A., 2020. What are the Economic Effects of Pandemic Containment Policies? Evidence from Sweden. International Monetary Fund Working Paper, 20(191), 1-30.

Eurostat, 2020. European Statistical Recovery Dashboard. [Online] Available at: https://ec.europa.eu/eurostat/data/database [Accessed 24.09.2020].

Goniewicz, K., Khorram-Manesh, A., Hertelendy, A.J., Goniewicz, M., Naylor, K., Burkle, F.M., 2020. Current Response and Management Decisions of the European Union to the COVID-19 Outbreak: A Review. Sustainability, 12(9), 3838. [Online] Available at: https://doi.org/10.3390/su12093838 [Accessed 11.10.2020].

Government Approves Emergency Measures, 2020. [Online] Available at: https://www.valitsus.ee/en/news/government-approves-emergencymeasures [Accessed 24.09.2020].

Government Communications Unit, 2020. Additional Measures to the Emergency Situation. [Online] Available at: https://www.kriis.ee/en/news/additional-measures-emergency-situation [Accessed 24.09.2020].

Lietuvos Respublikos Vyriausybe (Government of the Republic of Lithuania), 2020. Resolution No 207 Declaring Quarantine on the Territory of the Republic of Lithuania, 14 March 2020, Vilnius. [Online] Available at:

https://lrv.lt/uploads/main/documents/files/DECLARING\%20QUARANTINE\%20ON\%20THE\%20TERRITORY\%20OF\%20THE\%20REPUBL IC\%20OF\%20LITHUANIA(1).pdf [Accessed 24.09.2020].

Latvijā beidzas Covid-19 ārkārtējā situācija; daudzi ierobežojumi paliek spēkā (The Covid-19 Emergency is Coming to an End in Latvia; Many Restrictions Remain in Place), 2020. [Online] Available at: https://www.lsm.lv/raksts/zinas/latvija/latvija-beidzas-covid-19-arkarteja-situacijadaudzi-ierobezojumi-paliek-speka.a363101/ [Accessed 24.09.2020].

Lietuvos Respublikos sveikatos apsaugos ministerija (Ministry of Health of The Republic of Lithuania), 2020a. Relaxing Lockdown Rules. [Online] Available at: https://sam.lrv.lt/en/news/relaxing-lockdown-rules [Accessed 24.09.2020].

Lietuvos Respublikos sveikatos apsaugos ministerija (Ministry of Health of The Republic of Lithuania), 2020b. Quarantine conditions to be tightened. [Online] Available at: https://sam.lrv.lt/en/news/quarantine-conditions-to-be-tightened [Accessed 24.09.2020].

Ministru Kabinets (Cabinet of Ministers of Republic of Latvia) Order of the Cabinet of Ministers No. 103 "On the Emergency Situation" Cabinet of Ministers Order No. 103. Riga, March 12, 2020 (protocol No. 11 § 1). [Online] Available at: https://www.vestnesis.lv/op/2020/51A.1 [Accessed 24.09.2020].

Министерство здравоохранения Республики Беларусь (Ministry of Health of The Republic of Belarus), 2020. Рекомендации для лиц старшего и пожилого возраста (старше 60 лет) по вопросам профилактики коронавирусной инфекции (инфекции COVID-19) (Recommendations for Seniors and Seniors (over 60 years old) on the Prevention of Coronavirus Infection (COVID-19 Infection)); Рекомендации по социальному дистанцированию в период регистрации случаев инфекции COVID-19 (коронавирусной инфекции) (Recommendations for Social Distancing During the Period of Registration of Cases of Infection with COVID-19 (Coronavirus Infection)). [Online] Available at: http://minzdrav.gov.by/ru/dlya-belorusskikh-grazhdan/COVID-19/ [Accessed 24.09.2020].

Nikolajenko, J., Viederyte, R., Šneideriene, A., Anicas, I., 2020. Components for Measuring the Efficiency of the Intervention Measures to Support Business, Initiated and Implemented by the Government of Lithuania during the First Lockdown. Sustainability 13, 1031. [Online] Available at: https://doi.org/10.3390/ su13031031 [Accessed 24.09.2020].

Savage M., 2020. Did Sweden's coronavirus strategy succeed or fail? [Online] Available at: https://www.bbc.com/news/world-europe-53498133 [Accessed 24.09.2020].

Совет Министров Республики Беларусь (The Government of the Republic of Belarus), 2020. Постановление Совета Министров Республики Беларусь,. 8 апреля 2020 г. № 208. “О введении ограничительного мероприятия”. [Online] Available at: https://pravo.by/document/?guid=12551\&p0 $=\mathrm{C} 22000208 \& \mathrm{p} 1=1 \& \mathrm{p} 5=0$ [Accessed 24.09.2020].

Спасюк Е. (Spasjuk.E.)., 2020. COVID-19. Белорусы болеют меньше, а умирают все так же (COVID-19. Belarusians get sick less, but still die the same way). [Online] Available at: https://naviny.online/article/20200722/1595402374-covid-19-belorusy-boleyut-menshe-umirayut-vse-takzhe [Accessed 24.09.2020].

The Government Approved the List of Restrictions and Easing of Restrictions in Force after the End of the Emergency Situation,.2020. [Online] Available at: https://www.kriis.ee/en/news/special-notice-government-approved-list-restrictions-and-easing-restrictions-force-after-end [Accessed 24.09.2020].

The Government has Extended the Emergency Situation in Estonia until May 17, 2020. [Online] Available at: https://www.kriis.ee/en/news/specialnotice-government-has-extended-emergency-situation-estonia-until-may-17 [Accessed 24.09.2020]. 
The Government Specified the Easing of Restrictions after the Emergency Situation, 2020. [Online] Available at: https://www.kriis.ee/en/news/government-specified-easing-restrictions-after-emergency-situation [Accessed 24.09.2020].

World Health Organization, 2020. WHO Coronavirus Disease (COVID-19), Dashboard. [Online] Available at: https://covid19.who.int/ [Accessed 24.09.2020].

THIS RESEARCH WAS SUPPORTED BY A MARIE CURIE RESEARCH AND INNOVATION STAFF EXCHANGE SCHEME WITHIN THE H2020 PROGRAMME (GRANT ACRONYM: NEW MARKETS, NO: 824027) 


\section{COMPARATIVE ANALYSIS OF THE EUROPEAN UNION CROWDFUNDING SERVICE PROVIDERS REGULATION AND REGULATORY BARRIERS FOR CROWDFUNDING IN THE BALTIC STATES Oksana Katalkina, University of Latvia \\ Svetlana Saksonova, University of Latvia}

Abstract. The issue of conflicting national frameworks on crowdfunding and dispersed structures of investors and products has drawn significant attention in the European Union. Some Member States introduced national rules to regulate their crowdfunding platforms, while others left some aspects of the activity unregulated. This variation of national licensing, diverging definitions of business models and application of existing EU legislation are considered to contribute to crowdfunding market fragmentation. Some surveys demonstrate that crowdfunding regulatory heterogeneity in the Member States negatively affects the market. In the paper, this heterogeneity is revised on the example of Latvia, Lithuania, and Estonia, since the crowdfunding market is fully regulated only in Lithuania. From this point of view, the Regulation (EU) 2020/1503 on European Crowdfunding Service Providers for Business was an ultimately expected event for the crowdfunding market. Therefore, the aim of the paper is to analyse the regulatory barriers for crowdfunding in Latvia, Lithuania, and Estonia and to compare them with those of the European Union Crowdfunding Service Providers Regulation. To achieve the aim of the paper, generally accepted methods of research have been used, including literature source study, comparative analysis and synthesis, legal act analysis. The paper results include the analysis of existing regulatory barriers for crowdfunding in the Baltic States and their comparison with the Regulation, highlighting crucial aspects and revealed differences. In addition, the comparison of current crowdfunding market performance with the actual regulatory barriers in force in the states is provided in the paper.

Keywords: Crowdfunding, crowdlending, European Crowdfunding Service Providers Regulation, the Baltic States.

JEL code: G23, K22, O16

\section{Introduction}

Crowdfunding is a method to obtain money from large audiences, where each individual provides a small amount, instead of raising large sums from a small group of sophisticated investors (Belleflamme, Lambert, et al., 2014). It seems to represent an important alternative form of finance, bridging financing gaps for small and medium-sized enterprises (SMEs) and therefore expanding financial inclusion, as well as a valuable investment opportunity in terms of diversification, and an instrument for entrepreneurship development (Zelgalvis, Joppe, 2014). Considering this, the issue of conflicting national frameworks on crowdfunding and dispersed structures of investors and products has gained significant critical attention in the last years. Several studies showed that it contributes to the information asymmetry that makes challenging for investors to assess the quality of crowdfunding proposals, particularly in cross-border funding deals. Some Member States introduced national rules to regulate their crowdfunding platforms, while others left some aspects of the activity unregulated. This great variation of national licensing and investor protection schemes, diverging definitions of business models and application of existing EU legislation are considered to contribute to crowdfunding market fragmentation (Kramer, Gimeno, 2018). Surveys, such as that conducted by Cicchiello (2019), demonstrate that crowdfunding regulatory heterogeneity in the Member States negatively affects the market.

Moreover, it is stressed out by the European Union (EU) Parliament that crowdfunding service providers should be subject to prudential requirements, since their clients are exposed to potential operational risks (The European Parliament..., 2020) Furthermore, the necessity of supervision and regulation of financial intermediaries has been highlighted in numerous studies as a crucial element of access to finance for European SME’s (Rupeika-Apoga, 2014), (Rupeika-Apoga, Saksonova, 2018).

Given this, the Regulation (EU) 2020/1503 of the European Parliament and of the Council of 7 October 2020 on European Crowdfunding Service Providers for Business, and amending Regulation (EU) 2017/1129 and Directive (EU) 2019/1937 (hereinafter - the Regulation) was an ultimately expected event. The Regulation normalises financial-return crowdfunding in the Member States (crowdfunding, in this paper), which consists in the provision of funds for business by internet users (the 'crowd' to other individuals or enterprises under the form of loans (lending-based crowdfunding - crowdlending) or equity investments (investment-based crowdfunding - crowdinvesting)) through an online platform facilitating the operation.

The European Parliament and the Council highlight in the Regulation that it aims to foster cross-border funding of business (The European Parliament.., 2020, Discloser (8)) and to ensure a high level of investors' protection (The European Parliament.., 2020, Discloser (7)).

Despite the fact that Baltic platforms take a crucial place in the European crowdfunding market, there have been little comparative analysis made devoted to crowdfunding regulatory barriers in the Baltic States in the frame of this Regulation. 
Therefore, the paper aims at analysing some aspects of regulatory barriers for crowdfunding in Latvia, Lithuania, and Estonia and comparing them with those of the Regulation.

To achieve the aim of the paper, the following objectives have been set:

- To analyse the crucial aspects of the Regulation;

- $\quad$ To analyse the current practise of regulatory barriers for crowdfunding in Latvia, Lithuania, and Estonia;

- To emphasise the differences of crowdfunding service supply between the three Baltic States;

- To compare the Regulation's aspects with the crowdfunding service supply in the countries.

The research methodology used in this paper starts with a literature review to shed light on major controversial issues of the Regulation stressed out in the previous studies. Due to explanatory nature of the paper, generally accepted methods of economic research were used including comparative analysis and synthesis, legal act analysis. The analysis conducted in the paper is based mainly on the initial data gathered at crowdfunding providers' web-sites (operated by legal entities registered in Latvia, Lithuania and Estonia). In order to identify crowdfunding providers registered in the countries, some official lists of licensed organisations are used, such as the List of crowdfunding platform operators (Bank of Lithuania, 2020 (1), and the List of operating licenses for acting as a financial institution (Ministry of Economic Affairs..., 2020) This paper does not observe reward and donation-based crowdfunding models, since these crowdfunding models are not in the scope of the Regulation.

\section{Literature Review}

Some attempts known to us to explain differences in regulatory barriers in the Baltic States are the papers by Sadzius (Sadzius, Sadzius, 2018) and Sorainen researchers (European Crowdfunding Network, 2017). However, little attention has been paid to the issues of conjunction of the barriers with the upcoming event - the EU crowdfunding service providers Regulation, which has gained a number of critics at the stage of Proposal. The group of EU crowdfunding law researchers has concluded that the creation of a single EU regulation should take into account three main issues, namely: it should cover all the existing business models of crowdfunding; it should clarify whether MiFID licence would allow provision of crowdfunding on cross-border basis; it should clarify how other EU laws affect crowdfunding (European Crowdfunding Network, 2017). Meanwhile, surveys of the Regulation such as that conducted by Macchiavello (2019) conclude that the Regulation fails to address such issues like, for instance, the problems deriving from the 'institutionalisation' of crowdfunding (i.e. the presence as crowd-investors/lenders of, for example, banks and investment funds and, therefore, from the risk of cherry-picking by these at the expenses of retail investors), relevant booming subsectors, such as invoice trading (recently overtaking both P2P business lending and equity crowdfunding) and crowdfunding through Initial Coin Offerings (ICO). The scrupulous study of the Regulation demonstrates that the ICO topic remained unsolved. The only remark provided by the Regulation (The European Parliament.., 2020, Discloser (15)) is that the characteristics of ICO differ significantly from crowdfunding services regulated under the Regulation. This indicates a need to understand the various perceptions of ICO that exist among the Member States, such as that provided by the Financial and Capital Market Commission (Financial and Capital Market Comission 2019).

The European Parliament has highlighted the diversity of crowdfunding regimes in the Member States as a crucial factor which rendered crowdfunding business models less easily 'passportable' across the EU (European Parliament, 2018). One of the most significant "pre regulation" discussions was about the fragmented regulatory landscape within the EU, which leaded to the fact, that platforms operate mainly in the country of registration (Wenzlaff, Odorovic et al., 2020). However, some studies have shown high performance of cross-border financing of crowdfunding platforms of the Baltic States (Ziegler, Shneor, et al., 2019). In addition, the idea of cross-border financing scores an advantage in the scope of taxation regimes and their differences (Zelgavis, Joppe, 2013). Socially oriented taxation indirectly contributes to this, as well (Lvova, Pokrovskaya, et al., 2017). Recently, researchers have revealed an interest in crowdfunding services as a business value raising tool (Abramishvili, Lvova, 2019). A considerable amount of literature has been published on the role of crowdfunding services for sales increasing purposes (Salkovska, Praude, et al., 2018) and for sales stimulation (Batraga, Praude, et al., 2018). The crowdfunding data are rather controversial, and there is no general agreement about the priority of issues to be solved in the field. Recent developments of crowdfunding services have heightened the need for stricter assessment of investment risks (Cekuls, Koehn, 2019), particularly for the cases where the platforms apply payments in crypto-currencies (Kuzmina-Merlino, Saksonova, 2019). The issue of augmented competition in financing for business (Konovalova, Trubnikova, 2018) and related minimisation of clients' risks (Konovalova, Caplinska, 2020), (Saksonova, 2013) as a crucial facet for regulated 'traditional' banking sector has been revised in some studies. It is necessary to note, that development of financial technologies (FinTech), like crowdfunding requires new knowledge and 
competencies (Kuzmina-Merlino, Saksonova, 2018) and a higher level of internal awareness of organisations (Cekuls, 2016). Therefore, regulated crowdfunding market has potential impact on activity and efficiency of various sectors of national economy.

\section{Results and discussion}

The Regulation's discloser delineates the ideas and the problems to be solved by adaptation of the Regulation in each Member State. The authors of the Regulation stress out some crucial facets of it, namely: obstructing of cross-border provision of crowdfunding services because of the differences between the existing national rules, creating of additional legal costs for retail investors who are often discouraged from investing crossborder. These reasons lead to the situation where crowdfunding services still remain largely national, thus depriving business of access to crowdfunding services, especially when those businesses operate in smaller national markets. Therefore, first of all, the Regulation aims to foster cross-border funding of businesses, and excludes from its scope the crowdfunding services in relation to lending to consumers (Discloser 7, 8). Secondly, the Regulation prioritises the effective protection of investors and the provision of a mechanism of market discipline (Discloser, 16). In regard to the scope and subject of the Regulation, these are 'uniform requirements for the provision of crowdfunding services, for the organisation, authorisation and supervision of crowdfunding service providers, for the operation of crowdfunding platforms as well as for transparency and marketing communications in relation to the provision of crowdfunding services in the Union' (Chapter I, Article 1(1). Hence, the Regulation has multilevel aims and tasks and covers a number of activities and aspects.

Taking this into account, the paper provides an overview of the regulatory frameworks in the Baltic States. To shed light on the regulatory frameworks in force, to delineate its diversity, and to compare those with the Regulation, the authors of the paper relied on 'Review of Crowdfunding Regulation' conducted by Sorainen (European Crowdfunding Network, 2017), and on the study of related laws and explanations of the supervisory authorities, such as (Bank of Lithuania, 2020 (2); Financial and Capital Market Comission 2019). The results of the review are summarised in Table 1, and show, inter alia, the diversity of regulatory barriers for crowdfunding services in Latvia, Lithuania, and Estonia.

Table 1

Comparison of regulatory barriers for crowdfunding service providers for business in force in Latvia, Estonia, and Lithuania in 2020 with EU Regulation

\begin{tabular}{|c|c|c|c|c|}
\hline & Latvia & Lithuania & Estonia & EU Regulation \\
\hline $\begin{array}{l}\text { Regulations } \\
\text { (inter alia) }\end{array}$ & $\begin{array}{l}\text { Crowdfunding is not a } \\
\text { specifically regulated } \\
\text { activity. It might fall under } \\
\text { one of the regulations } \\
\text { applicable to financial and } \\
\text { capital market participants in } \\
\text { general: } \\
\text { 1)Financial } \quad \text { Instrument } \\
\text { Market Law (FIML) (MiFID } \\
\text { I regime) } \\
\text { 2)“Law on Alternative } \\
\text { Investment Funds and its' } \\
\text { Managers" (AIFM Law) }\end{array}$ & $\begin{array}{l}\text { 1)The Law on } \\
\text { Crowdfunding of the } \\
\text { Republic of Lithuania No } \\
\text { XII-2690 } \\
\text { 2)Law on Managers of } \\
\text { Collective Investment } \\
\text { Undertakings for } \\
\text { Professional Investors of } \\
\text { the Republic of Lithuania } \\
\text { (MiFID II regime) }\end{array}$ & $\begin{array}{l}\text { Crowdfunding is not a } \\
\text { specifically regulated activity. } \\
\text { It might fall under one of the } \\
\text { regulations applicable to } \\
\text { financial and capital market } \\
\text { participants in general: } \\
\text { 1) Estonian Securities Market } \\
\text { Act (MiFID II regime) } \\
\text { 2) Credit Institution Act }\end{array}$ & $\begin{array}{l}\text { Regulation (EU) } \\
2020 / 1503 \text { of the European } \\
\text { Parliament and of the } \\
\text { Council of } 7 \text { October } 2020 \\
\text { on European crowdfunding } \\
\text { service providers for } \\
\text { business }\end{array}$ \\
\hline $\begin{array}{l}\text { Scope / } \\
\text { Financial } \\
\text { instruments }\end{array}$ & $\begin{array}{l}\text { Transferable securities, inter } \\
\text { alia, (a) shares in joint stock } \\
\text { companies and other } \\
\text { securities equivalent to } \\
\text { shares in companies } \\
\text { (excl.shares in private } \\
\text { limited liability companies), } \\
\text { including convertible } \\
\text { securities; (b) bonds or other } \\
\text { forms of securitised debt; or } \\
\text { (c) any other securities } \\
\text { giving the right to acquire or } \\
\text { sell any such transferable } \\
\text { securities or giving rise to a } \\
\text { cash settlement determined } \\
\text { by reference to transferable }\end{array}$ & $\begin{array}{l}\text { 1) Investing and lending } \\
\text { crowdfunding. } \\
\text { model can be used only by } \\
\text { public limited liability } \\
\text { companies with share } \\
\text { capital of } € 50000 \text { ). }\end{array}$ & $\begin{array}{l}\text { 1) Securities, inter alia, (a) } \\
\text { shares in public limited } \\
\text { companies and other } \\
\text { transferable securities } \\
\text { equivalent to such shares; (b) } \\
\text { bonds or other forms of } \\
\text { securitised debt; (c) investment } \\
\text { fund units; or (d) any other } \\
\text { securities giving the right to } \\
\text { acquire or sell any such } \\
\text { transferable securities or the } \\
\text { price of which is determined by } \\
\text { reference to transferable } \\
\text { securities, currencies, interest } \\
\text { rates or yields, commodities or } \\
\text { other indices or measures. }\end{array}$ & $\begin{array}{l}\text { Provision of crowdfunding } \\
\text { services (investing and } \\
\text { lending crowdfunding } \\
\text { models) for business in the } \\
\text { EU }\end{array}$ \\
\hline
\end{tabular}




\begin{tabular}{|c|c|c|c|c|}
\hline & $\begin{array}{l}\text { securities, } \\
\text { interest rates or yields, } \\
\text { commodities or other indices } \\
\text { or measures. }\end{array}$ & & & \\
\hline $\begin{array}{l}\text { Authorisation } \\
\text { and } \\
\text { registration } \\
\text { required for } \\
\text { providers of } \\
\text { the services }\end{array}$ & $\begin{array}{l}\text { For investment service } \\
\text { providers authorisation under } \\
\text { the FIML in Latvian Finance } \\
\text { and Capital Market } \\
\text { Commission (FCMC)* }\end{array}$ & $\begin{array}{l}\text { 1) Authorisation and } \\
\text { registration in the List of } \\
\text { crowdfunding providers } \\
\text { managed by the Bank of } \\
\text { Lithuania (Bank of } \\
\text { Lithuania, } 2020 \text { (1) }\end{array}$ & $\begin{array}{l}\text { 1)Where an online } \\
\text { Crowdfunding platform } \\
\text { facilitates the offering of } \\
\text { transferable securities, or acts } \\
\text { as a securities broker, it will } \\
\text { require an investment firm } \\
\text { license by the Estonian } \\
\text { Financial } \\
\text { Authority (FSA).** Supervision } \\
\text { 2) If a company uses the } \\
\text { Lending Model in Estonia by } \\
\text { gathering money from lenders } \\
\text { and borrowing it on its own } \\
\text { account (take deposits), such } \\
\text { activity would most require a } \\
\text { credit institution license. }\end{array}$ & $\begin{array}{l}\text { Authorisation as a } \\
\text { crowdfunding service } \\
\text { provider by competent } \\
\text { authority of the Member } \\
\text { State }\end{array}$ \\
\hline $\begin{array}{l}\text { Maximum } \\
\text { offers } \\
\text { (prospectus } \\
\text { requirement) }\end{array}$ & $\begin{array}{l}\text { Where transferable securities } \\
\text { are offered to public, and the } \\
\text { offer is expressed to more } \\
\text { than } 150 \text { individuals in each } \\
\text { EU Member State, it might } \\
\text { be subject to publish a } \\
\text { prospectus approved by the } \\
\text { FCMC under the FIML. } \\
\text { Loans do not qualify as } \\
\text { financial instrument (under } \\
\text { the FIML), therefore no } \\
\text { prospectus is required for } \\
\text { lending models. }\end{array}$ & $\begin{array}{l}\text { If the securities are offered } \\
\text { through a crowdfunding } \\
\text { platform and it assumes to } \\
\text { be below } € 5 \mathrm{~m} \text { in a } 12 \\
\text { month period - no } \\
\text { prospectus is required. } \\
\text { Offerings above } € 5 \text { million } \\
\text { require preparation of the } \\
\text { prospectus, which must be } \\
\text { approved by the Bank of } \\
\text { Lithuania. }\end{array}$ & $\begin{array}{l}\text { Prospectus requirement for } \\
\text { public offering of securities. } \\
\text { Exceptions apply, e.g. if the } \\
\text { number of Investors is less than } \\
150 \text { per EEA country or total } \\
\text { amount of investments is less } \\
\text { than EUR } 100,000 \text {. } \\
\text { Lending models are not subject } \\
\text { to prospectus requirements. }\end{array}$ & $\begin{array}{l}\text { More than } € 5 \text { million per } \\
12 \text { months per project. }\end{array}$ \\
\hline $\begin{array}{l}\text { Maximum } \\
\text { investment } \\
\text { limits (for } \\
\text { investors) }\end{array}$ & $\begin{array}{l}\text { No specific regulatory } \\
\text { barriers. }\end{array}$ & $\begin{array}{l}\text { Investors are able to invest } \\
\text { in Crowdfunding projects } \\
\text { without limitations. } \\
\text { Investors have to do an } \\
\text { appropriateness test. If the } \\
\text { results of the test are } \\
\text { negative, the platform must } \\
\text { provide disclaimer (than } \\
\text { the investor can invest on } \\
\text { its own risk.) }\end{array}$ & No specific regulatory barriers. & $\begin{array}{l}\text { For sophisticated and } \\
\text { professional investors - } \\
\text { without limits; } \\
\text { For non-sophisticated - the } \\
\text { higher of either } € 1000 \text { or } \\
5 \% \text { of the investor's net } \\
\text { worth. }\end{array}$ \\
\hline
\end{tabular}

From the comparison provided in Table1, it is possible to conclude that the major barriers for crowdfunding platforms derive from the fragmented level of laws applicable to the crowdfunding in different jurisdictions. There is no single or general law in the states (excluding Lithuania) applying to crowdfunding, but several different laws which have to be followed depending on the crowdfunding model. The barriers in the countries differ from each other, but mostly they address to certain financial instruments. Moreover, there are stricter limitations for companies which seek for investment-based financing (the case of Lithuania). In this sense, the EU Regulation could accelerate the development of investingbased crowdfunding, since it regulates both crowdlending and crowdinvesting, providing more concise criteria for investing-based models. If we turn to the scope of the regulatory barriers and compare it with one of the Regulation, the Regulation does not explain and address the issue of ICOs, contenting itself with a short phrase in the Disclose (15): 'ICOs' characteristics differ considerably from crowdfunding services regulated under this Regulation'. This leads to assumption that the Regulation leaves room for different interpretations and misreading, as well as for further overlapping of the Regulation with national regulatory barriers compared in the Table. The same assumption derives from the fact that the Regulation is more concentrated on the issues of funds collecting from 'the crowd', than on regulating and giving explanations on funds' further distribution mechanisms (and/or models). 
Moving on to the field of authorisation and registration requirements, it should be noted that, in fact, the duly registration for crowdfunding service providers exists in Lithuania, for today. Where the licensing for lending to consumers (this is a subject to consumer crediting regulation in each of the countries) is not necessary, the registration and authorisation under another regulation of the countries is not conducted by the providers. In the case of Estonia, when authorisation as a credit institution (a bank) is necessary in order to take deposits from the public, the providers utilise the registration under the legal form of saving and loan organisation (SLO) instead. This provides rights to take savings, which are in fact very equal to deposits in their nature.

A few more controversial issues could be allocated from the analysis of the scope of the Regulation, namely, whether the crowdfunding service providers duly authorised for lending to consumers should be a subject to the registration as a crowdfunding service provider under the Regulation. It is maintained in the Discloser (8) of the Regulation that 'crowdfunding services in relation to lending to consumers ... should not fall within the scope of the Regulation.' Therefore, the logical conclusion is that those providers who have the license for lending to consumers should not register themselves as crowdfunding service providers, despite the fact that they collect funds for lending from the 'crowd'.

In authors' opinion, the most positive facet of the Regulation is that it provides certain criteria for prospectus requirements, which are similar to those indicated by the Law on Crowdfunding of Lithuania. Therefore, a company applying for funding at a crowdfunding platform duly registered under the Regulation should not have any uncertainty about the issue. Meanwhile, the Regulation does not make any distinction between the investing and lending crowdfunding models. Hence, there would not be room left for crowdfunding of' "bigger" projects (more than 5 million EUR per year) under the lending model, as it is in the case of Estonia and Latvia for today.

The comparison of investment limitations in force with those of the Regulation presented in Table 1 shows that the Regulation has the protection of investors in its focus. The investors of crowdfunding platforms should be divided to sophisticated and non-sophisticated ones (upon certain criteria), providing some limitations for non-sophisticated investors. As it could be seen from the Table, limitations for investing were not revealed in the regulatory barriers in force in the countries. Meanwhile, some of crowdfunding service providers (for instance, registered in Estonia,) have prepared themselves for the Regulation, implementing the investors' questionnaires (knowledge and loss-simulation tests) on their platforms. The rather high level of complaints of Estonian crowdfunding platforms to the Regulation could be explained by the fact that a public-private cluster organisation 'Finance Estonia' had created together with market participants a non-binding Best Practice for the crowdfunding industry. A number of Estonian crowdfunding platforms adhere to the principles of the Practice.

In authors' opinion, another one crucial issue left unclarified in the Regulation is the crowdfunding business model of 'loan originating'. When assessing the structure and business models of the platforms of the states, one could notice that the most utilised crowdfunding business models (in Latvia, for instance) is exactly the 'loan originating'. (A 'loan originator' crowdfunding platform accumulates funds for lending them to consumer lending companies duly authorised for this activity (have a relevant license) in their states.)

To gain insight of the approximate crowdfunding market volume and applied business models, which have been formed under the existing regulatory barriers in Latvia, Estonia, and Lithuania, 'Top 7' (by total financing volume) of the crowdfunding platforms of the countries are mirrored in Table 2. The platforms in Table 2 are those, which address the EU investors (in addition to the country of their registration). The representatives of investing-based crowdfunding business model of crowdinvesting are not included in the Table because no one of them has been revealed in the 'top'. 
'Top 7' crowdfunding platforms by total financing volume in Latvia, Estonia, and Lithuania

\begin{tabular}{|c|c|c|c|c|}
\hline \multirow{2}{*}{$\begin{array}{c}\text { Crowdfunding } \\
\text { provider's } \\
\text { regis tration country }\end{array}$} & \multicolumn{2}{|c|}{ Crowdfunding platforms' operators } & \multirow{2}{*}{$\begin{array}{c}\text { License } \\
\text { for } \\
\text { lending to }\end{array}$} & \multirow{2}{*}{$\begin{array}{l}\text { Amount of financing } \\
\text { in total as of October, } \\
2020 \text { ( } € \text {, million)* }\end{array}$} \\
\hline & Crowdlending & Loan originators & & \\
\hline \multirow{8}{*}{ Latvia } & & Mintos Marketplace, JSC & & 5696.9 \\
\hline & & Twino, LLC & & 728.9 \\
\hline & & AV Marketplace, LLC & & 343.3 \\
\hline & & Viainvest, LLC & Yes & 227.4 \\
\hline & & Viventor, LLC & & 136.5 \\
\hline & & Lenndy, LLC ** & & 38.1 \\
\hline & & Prosperitu, LLC & & 27.4 \\
\hline & \multicolumn{3}{|r|}{ Total: } & 7198.5 \\
\hline \multirow{8}{*}{ Estonia } & \multicolumn{2}{|c|}{ Bondora Capital, LLC } & Yes & 386.3 \\
\hline & Estateguru, LLC & & & 259.9 \\
\hline & & Swaper Platform, LLC & & 178.6 \\
\hline & Iuvo Gro & up, LLC & Yes & 144.5 \\
\hline & Crowdes tate, LLC & & & 97.8 \\
\hline & Crowdestor, LLC *** & & & 42.9 \\
\hline & Bulkestate, LLC & & & 17 \\
\hline & \multicolumn{3}{|r|}{ Total: } & 1127 \\
\hline \multirow{8}{*}{ Lithuania } & & Neo Finance, LLC & & 60.1 \\
\hline & \multicolumn{2}{|c|}{ Finansu bite, LLC } & & 39.4 \\
\hline & Bendras finans avimas, LLC & & Yes & 32 \\
\hline & Trecia diena, LLC & & & 7.2 \\
\hline & Nords treet, LLC & & & 10.3 \\
\hline & Heavy Finance, LLC & & & 1.5 \\
\hline & Profitus, LLC & & & 18.4 \\
\hline & \multicolumn{3}{|r|}{ Total: } & 168.9 \\
\hline
\end{tabular}

* indicated on the platforms $* *$ business address in Lithuania $* * *$ business address in Laltia

Source: authors' construct based on review of crowdfunding platforms of Latvia, Estonia, and Lithuania

The results in the Table show that the 'top' of the crowdfunding platforms registered in Latvia apply the model of financing 'loan originating'. The market volume of Latvian crowdfunding platforms is significant because of the 'giant' Mintos, which is (according to various estimates), is in the top 10 crowdfunding platforms of the world. Some of the platforms of the countries have licenses for lending to consumers therefore they should not be a subject to the Regulation. Also, several platforms cover two or sometimes three business models. For instance, Iuvo Group (Estonian platform) is a loan originator and a crowdlending platform and holds a license for lending to consumers. In addition, it could be noticed that Lithuania (the only country in the Baltic States where the law on crowdfunding exists) significantly lags behind Latvia and Estonia by crowdfunded financing volume. Hence, one could conclude, that per se unregulated crowdfunding activity has raised the markets of Latvia and Estonia to the top European level by their funding volumes.

Considering this result, it is reasonable to notice that the paper did not aim to reveal the factors influencing the crowdfunding market and analyse their impact on the market growth and volume. The importance of the comparative approach in this matter is worth noting, since only its use makes it possible to determine the gap for further quantitative research of the phenomenon.

\section{Conclusions}

Based on the results of the analysis conducted in the paper, it can be concluded that there is significant diversity of regulatory barriers for crowdfunding service providers in Latvia, Estonia and Lithuania. Most of the barriers, excluding Lithuania where the crowdfunding law exists, address to certain financial instruments and their managers. These barriers should be applied depending on the business model a crowdfunding provider uses, whilst the Regulation is more concentred on the issues of funds collecting than on regulating and giving explanations on funds' further distribution models. The only funds' distribution distinction made by the Regulation is that it covers both crowdlending and crowdinvesting business models. Therefore, in authors' opinion, the issue of 'loan originating' business model, which is hardly regulated by existing regulatory barriers in the countries, remains unclear in the Regulation, as well. The regulatory barriers existing in Latvia and Estonia do not regulate the way of funds collecting from the 'crowd', therefore, till now, no limitations there were for investments made by individuals via crowdfunding platforms. 
Furthermore, the investments according to Lithuanian Crowdfunding Law are not limited as well. From this point of view, the Regulation will be more investors' protection oriented, since it introduces limitations for non-sophisticated investors of crowdfunding platforms. The Regulation does not cover lending to consumers, therefore, the crowdfunding platforms holding a relevant license will not be a subject to the Regulation. While the Regulation has left outside of its attention the issue of ICOs, it provides clear criteria for prospectus requirements, including both investing and lending models, making no difference between them in this matter. The issue to be solved is whether the local regulatory will apply the same prospectus limits for business funding by means of other financial intermediaries. Also, the authors conclude that the regulatory barriers play a substantial role in the formation of the crowdfunding sector. Further research may be devoted to the study of quantitative impact on the crowdfunding market in Latvia, Lithuania, and Estonia after the introduction of the Regulation in the countries.

\section{Bibliography}

Abramishvili, N., Lvova, N., Voronova, N., 2019. Is it Possible to Assess the Corporate Market Value in the Emerging Market? New Challenges of Economic and Business Development - 2019: Incentives for Sustainable Economic Growth. International Conference, Riga, Latvia, May 16-18, 2019: Proceedings. Riga: University of Latvia, 12-21

Bank of Lithuania, 2020. (1) List of Crowdfunding Platform Operators. [Online] Available at: https://www.lb.lt/en/sfi-financial-marketparticipants?list $=36$ [Accessed 30.10.2020.]

Bank of Lithuania, 2020. (2) The Law on Crowdfunding of the Republic of Lithuania No XII-2690. 03.11.2016 [Online] Available at: https://www.lb.lt/en/operators-of-crowdfunding-platform\#ex-1-5 [Accessed 30.10.2020.]

Batraga, A., Praude, V., Salkovska, J., 2018 The Influence of Sales Stimulation Methods on the Behaviour of Consumers While Making the Decision on Purchase of Products in the Latvian Market, Consumer Behaviour, Organisational Strategy and Financial Economics. Book Series: Eurasian Studies in Business and Economics, Volume: 9, 3-23.

Belleflamme, P., Lambert, T., Schwienbacher, A., 2014. Crowdfunding: Tapping the Right Crowd. Journal of Business Venturing, 29(5), 585-609.

Cekuls, A., 2016. Opportunities of Raising the Internal Awareness of an Organisation, Book Series: International Multidisciplinary Scientific Conferences on Social Sciences and Arts, Vol.IV, 467-473.

Cekuls, A., Koehn, M.B., 2019. Bitcoin and Stock Market Indices: Analysis of Volatility's Clusters During the Bitcoin Bubble Based on the Dynamic Conditional Correlation Model. New Challenges of Economic and Business Development - 2019: Incentives for Sustainable Economic Growth. International Conference, Riga, Latvia, May 16-18, 2019: Proceedings. Riga: University of Latvia, 159-170.

Cicchiello A.F., 2019. Harmonising the Crowdfunding Regulation in Europe: Need, Challenges, and Risks. Journal of Small Business and Entrepreneurship, 32, 585-606.

European Crowdfunding Network, 2017. Review of Crowdfunding Regulation 2017. [Online] Available at: https://www.sorainen.com/UserFiles/File/Publications/ECN.pdf.

European Parliament, 2018. Establishing a basis for European crowdfunding service providers. Briefing. EU Legislation in Progress. 05.06.2018. [Online] Available at: https://www.europarl.europa.eu/RegData/etudes/BRIE/2018/621903/EPRS_BRI(2018)621903_EN.pdf.

Financial and Capital Market Comission (Finanšu tirgus un kapitāla komisija), 2019. Skaidrojums par virtuālo aktīvu un ICO izmantošanas iespējām un piemērojamo regulējumu (Explanation of the possibilities of using virtual assets and ICOs and the applicable regulation) press release 23.01.2019. [Online] Available at: https://www.fktk.lv/wp-content/uploads/2019/05/ICO_skaidrojums_23012019.pdf

Konovalova, N., Caplinska, A., 2020. Impact Analysis of Factors Influencing Bank Capital Management. Journal Entrepreneurship and Sustainability Issues, Volume 8, Number 1, 2020, $484-495$.

Konovalova, N., Trubnikova, N., 2018. Adjustment of Banking Activity According to Basel III Requirements: Experience and Problems of Eastern Europe Countries. Reliability and Statistics in Transportation and Communication, Lecture Notes in Networks and Systems, 36, 617-626.

Kramer, E., Gimeno, M., 2018. European Crowdfunding Service Providers for Business. Initial Appraisal of a European Commission Impact Assessment. European Parliamentary Research Service. [Online] Available https://www.europarl.europa.eu/RegData/etudes/BRIE/2018/621814/EPRS_BRI(2018)621814_EN.pdf.

Kuzmina-Merlino, I., Saksonova, S., 2018. The Knowledge and Competencies Required the Fintech Sector, $10^{\text {th }}$ International Scientific Conference on New Challenges of Economic and Business Development - Productivity and Economic Growth, International Conference, Riga, Latvia, May 10-12, 2019: Proceedings. Riga: University of Latvia, 387-395.

Kuzmina-Merlino, I., Saksonova, S., 2019. Cryptocurrency as an Investment Instrument in a Modern Financial Market. Ekonomika - St.Petersburg University Journal of Economic Studies, 35(2), 269-282. 
Lvova N.A., Pokrovskaya N.V., Ivanov V.V., 2017. Socially Oriented Taxation and How It Is Perceived (Case Study of a Survey of EconomistsTo-Be). Economic and Social Changes: Facts, Trends, Forecast, 4, 196-211.

Macchiavello, E., 2019. What to Expect When You Are Expecting a European Crowdfunding Regulation: The Current "Bermuda Triangle" and Future Scenarios for Marketplace Lending and Investing in Europe. European Banking Institute Working Paper Series - No. 55 (2019).

Ministry of Economic Affairs and Communications of Estonia, 2020. List of operating licenses for acting as a financial institution. [Online] Available at: https://mtr.mkm.ee/taotluse_tulemus [Accessed 30.10.2020].

The European Parliament and the Council of the European Union, 2020. European crowdfunding service providers for business, and amending Regulation (EU) 2017/1129 and Directive (EU) 2019/1937. Regulation (EU) 2020/1503 of 07.10.2020.

Rupeika-Apoga, R., 2014. Access to Finance: Baltic Financial Markets. Procedia Economics and Finance, 9, 181-192.

Rupeika-Apoga, R., Saksonova, S., 2018. SME’s Alternative Financing: The Case of Latvia. European Research Studies Journal, $21(3), 43-52$.

Sadzius, T., Sadzius, L., 2018. Crowdfunding Regulation in the Baltic Region. International Journal of Business and Social Science, 9(2), 99-110.

Saksonova, S., 2013. Approaches to Improving Asset Structure Management in Commercial Banks. Book Series: Procediea Social and Behavioral Sciences, 99, 877-885.

Salkovska, J., Praude, V., Batraga, A., Afoniceva, O., 2018. Consumers' Behaviour in Decision-Making in Foodstuff Purchasing Process. Consumer Behaviour, Organisational Strategy and Financial Economics, Springer, Cham, 25-36.

Wenzlaff, K., Odorovic, A., Ziegler, T., Shneor, R., 2020. Crowdfunding ir Europe: Between Fragmentation and Harmonization. Advances in Crowdfunding. Research and Practice. Palgrave Macmillan, 373-390.

Ziegler, T., Shneor, R., Wenzlaff, K., Odorivica, A., Johanson, D., Hao, R., Lukas, R., 2019. Shifting Paradigms - The 4th European Alternative Finance Benchmarking Report. Cambridge, UK: Cambridge Centre for Alternative Finance.

Zelgalvis, E., Joppe, A., 2014. National Innovation Policies and Instruments to Promote Entrepreneurship in the Regions. Economic Science for Rural Development: Finance and Taxes - New Dimensions in the Development of Society. Book Series: Economic Science for Rural Development, 33, 169-177.

Zelgavis, E., Joppe, A., 2013. Comparison of the Taxation Systems of the Baltic Countries. Economic Science for Rural Development: Production and Cooperation in Agriculture / Finances and Taxes. Book Series: Economic Science for Rural Development, 30, $166-174$. 


\title{
LATVIAN PHARMACEUTICAL MARKET: A REVIEW OF MARKETING COMPONENTS AND DEVELOPMENT TRENDS
}

\author{
Matiss Kite, University of Latvia \\ Anda Batraga, University of Latvia \\ Jelena Salkovska, University of Latvia
}

\begin{abstract}
In-depth market assessment is crucial prior making investments into product development and decisions on marketing strategy, especially in markets with small volume and low value like Latvian pharmaceutical market. Transparent market data and constant market reviews are expected to retain already existing pharmaceutical suppliers and attract new ones; although annual reports of general market figures are available publicly, reviews of pharmaceutical market marketing figures and activities are not being published. By assessing and studying Latvian pharmaceutical market and its marketing components the possible risks and development trends can be outlined and further addressed by pharmaceutical producers and suppliers.

Purpose of the article: The purpose of the research is to assess Latvian pharmaceutical market figures, trends of its marketing key components and their influence on pharmaceutical entrepreneur marketing activities. The findings of this article could later be used by pharmaceutical entrepreneurs to align their marketing strategies for Latvian market and by governmental institutions to better understand pharmaceutical market composition and how the market could be governed to make it more attractive to pharmaceutical entrepreneurs.

Objective: To review Latvian pharmaceutical market, its figures and trends of marketing components and outline market specifics for the use of potential entrepreneurs.

Methodology/methods: In order to attain the goal and objectives, the following quantitative and qualitative methods were used: secondary data research of governmental reports and industry databases, content analysis of the recent scientific and professional literature available and in-depth interviews of pharmaceutical industry experts. The study is based on scientific papers published by foreign scholars, non-governmental organizations and reports from international organizations, governmental and industry bodies.

Findings: Latvian Pharmaceutical market is quite dependent on supplies from foreign producers, but due to low pharmaceutical product prices and small market volume, there is a risk for product supply disruptions and shortages. Over the counter pharmaceutical product demand and promotion activities are linked to seasonal trends; for prescription products relationships with key opinion leaders and other public relations are the main focus of marketing activities.
\end{abstract}

Keywords: Pharmaceutical Market, Pharmaceutical Pricing, Pharmaceutical distribution, Marketing.

JEL code: M31

\section{Introduction}

Pharmaceutical product constant supplies and availability of novelty pharmaceutical products is a prerequisite for a solid and secure health care system, especially during the challenging times of COVID-19 pandemic. In markets with low volume and value, like Latvian Pharmaceutical market, keeping sufficient pharmaceutical product supplies and healthy competition could easily become a challenge if market is not managed properly. Therefore, it is important to assess the market figures and trends from the producers and suppliers perspective in order outline possible risks and opportunities for the entrepreneurs and challenges for the competent authorities.

Studies of the marketing key components in specific market is important as they can serve as one of the potential frameworks for the market assessment and can be further used by entrepreneurs to develop their marketing strategies - by defining specific product market figures, distribution channel specifics, pricing levels and promotion trends the producers and suppliers can generally asses if their product has potential in the corresponding market and if company has the required resources and expertise to enter the market. Furthermore, by studying and assessing these key figures of pharmaceutical market the governing bodies can outline the required steps that would make the market more attractive for pharmaceutical product producers and suppliers, thus potentially increasing their availability.

The objective of the research is to review and study Latvian pharmaceutical market, its figures and trends of marketing components, outline market specifics, possible risks and opportunities for the entrepreneurs. 
In order to achieve this objective, the research was based on secondary data research of governmental reports and industry databases, content analysis of the most recent scientific and professional literature available and in-depth interviews of pharmaceutical industry experts representing State Agency of Medicines, Latvian Pharmacists Society, local and foreign pharmaceutical producers and local distributor.

Research shows that Latvian Pharmaceutical market is quite dependent on product imports and supplies from foreign producers, but due to low pharmaceutical product prices and small market volume, there is a risk for product supply disruptions and shortages. Product price and quality are the main components that affect the key opinion leaders (pharmacists) attitude towards the producers. Over the counter pharmaceutical product demand and promotion activities are linked to seasonal trends; for prescription products relationships with key opinion leaders and other public relations are the main focus of marketing activities.

\section{Literature Review}

Reports by State Agency of Medicines of Republic of Latvia and nongovernmental research organizations were used to outline Latvian pharmaceutical market data and trends; also World Health organization, OECD reports were used to compare Latvian pharmaceutical market with international market trends.

Pharmaceutical product market and State reimbursement system reports from State Agency of Medicines of Republic of Latvia and National Health Service were used to analyze pharmaceutical product pricing levels in Latvia.

Articles from Journal of Clinical and Translational Research, Journal of Management Research and Analysis, International Journal of Physical Distribution \& Logistics Management, International Journal of Pharmaceutical and Healthcare Marketing and other related sources were used as information sources.

One of the first steps for creating a well-designed marketing strategy is by assessing the market, customer, possible competitors and trends of marketing key components - product, place, price and promotion. For pharmaceuticals the product and its specifics are the key components that directly or indirectly affects other marketing components. As defined by the European Commission Directive 2001/83/EC pharmaceutical products are specific with their ability of having properties for treating or preventing disease in human beings or they may be used for restoring, correcting or modifying physiological functions of human body or to perform a medical diagnosis. As pharmaceutical product research and development takes at least 9 Years for originator products and at least 2-3 years to bring generic products to the market (Heus, J. J., de Pauw, E. S., Leloux, M., Morpurgo, M., Hamblin, M. R., Heger, M., 2017) it is highly important to do an in-depth market research of the potential pharmaceutical product prior developing and/ or launching it into the corresponding market.

During the content analysis of the pharmaceutical marketing components it has been noted that Panigrahi, Aware and Patil (2018) have already outlined the classical $4 \mathrm{P}$ 's of marketing as important key components when applying integrated marketing communications in pharmaceutical industry. Although their study is more focused on the pharmaceutical industry promotion activities, the authors of this study emphasizes the role of product, its specifics, pricing level and distribution channel as equally important for pharmaceutical producers and distributors willing to enter a new pharmaceutical market. It is worth mentioning that Wieringa and Leeflang in their study (2013) have concluded that the introduction of new pharmaceutical brands in the market (f.e. Dutch pharmaceutical market) tends to be faster when it receives more marketing support, and also tends to reach a higher level of sales, thus outlining the importance of considerable and reasonable investments for promotion activities.

With the wide variety of active pharmaceutical ingredients (more than 7`000 International Nonproprietary Names identified by WHO in 2017), multiple routes of administration, variable possible dosages and possible indications pharmaceutical producers have a variety of products to produce and develop. As noticed by Rossetti, Handfield and Dooley (2011) the pharmaceutical producers and distributors are tending towards their product portfolio specialization, therefore outlining the importance of forethought product portfolio for the specific market. Furthermore, they ${ }^{\prime} v e$ stressed out that for successful and prosperous partnership with local supply chain companies, wholesalers and agents are expected to receive their fair share of the margin with regards to the services they provide as limited margins might lower their possibility to withstand market disruptions, thus increasing the risk of pharmaceutical product supply issues; the fee for service model has been outlined by Rossetti, Handfield and Dooley (2011) as one of the applicable alternatives.

Kauppinen-Räisänen, Owusu and Bamfo (2012) have outlined the importance of the product packaging design noting that the local market specifics and demand should be taken into consideration, as during the purchase process it attracts attention, provides sensory stimulation, communicates the brand, product and product group, and eventually influences consumers' behavior. Furthermore, the brand recognition has been 
outlined as important factor as it plays a significant role in the decision making and perception of price, thus outlining the importance of including product and company brand name in the promotion activities.

\section{Research and results}

Authors of this study conducted a representative survey of Latvian pharmacists regarding their attitude towards basic product and packaging components as price, quality, pack size and design. Additionally, interviews of Latvian pharmaceutical experts representing multiple fields of action (local producer, foreign producer, distributor, NGO and competent authority) to discuss outlined pharmaceutical market components (product specifics, price, supply chain and promotion) and their trends in Latvian market. The findings from the survey and expert interviews were further assessed and analysed by market data in public and commercial databases and official statements by competent authorities and international organisations.

The representative survey of 207 Latvian pharmacists was conducted in April 2020 - heads of pharmacy (66), pharmacists (96), their assistants (34) and other pharmacy specialists were questioned (in scale of 5) about the factors that they find important when offering pharmaceutical products to patients. As shown in figure 1. the product quality was outlined as the mayor factor followed by the product price; factors like packaging design and size received medium or lower rating, although packages with practical design and larger volume/ more units received better results.

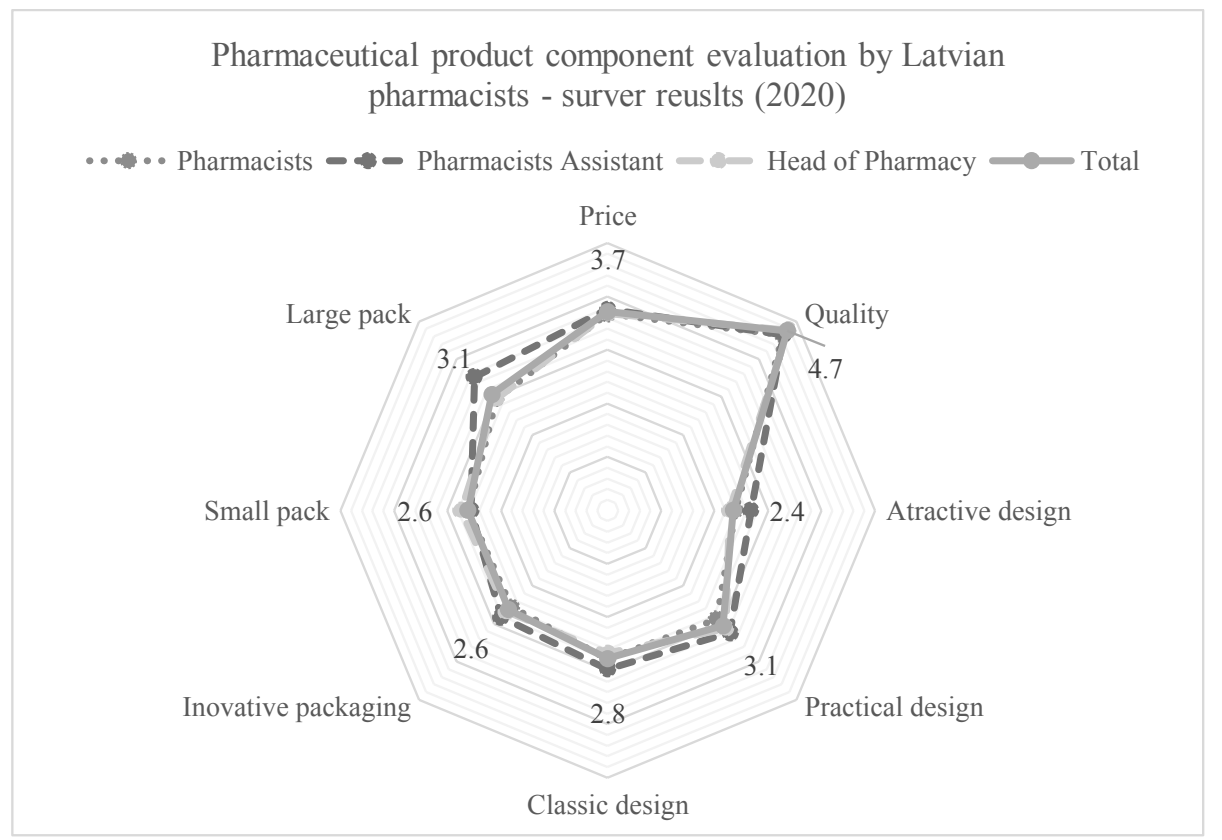

Source: author's construction based on Latvian pharmacists' survey results, 2020

Fig. 1. Latvian pharmacists' attitude towards pharmaceutical product components and packaging

The survey also showed that majority of the pharmacists were keen to suggest switching of pharmaceutical product to an alternative product (with the same INN) with lower price offer and the price reduction should be at least 21-35\%. Furthermore, considerable part of pharmacists (38.2\%) were open to offer pharmaceutical products in foreign language packages if their pricing would be $21-35 \%$ less, thus outlining the potential for generic pharmaceutical distributors and parallel importers to supply the products from other markets in cases of significant price or availability difference.

Multiple interviews of experts in pharmaceutical field were conducted, including experts from State Agency of Medicines responsible for supervising Latvian pharmaceutical market, Latvian Pharmacists society representing pharmacist's opinion, representatives of local and foreign pharmaceutical producers and a local distributor conducting product, distribution promotion and sales in Latvia. During the in-depth interviews of expert from Latvian pharmaceutical producers and distributors multiple distribution strategies were outlined. Depending on the pharmaceutical producers marketing strategy and presence in the market the products could be distributed under the following conditions:

1. Directly to pharmaceutical wholesalers, therefore increasing the sales margin/ price flexibility as the producer avoids intermediaries and agents that would expect to take their part of the revenue. But in this case a local sales driving force should be required as these activities traditionally are not covered by the wholesalers. 
2. Establish a local representative office with local sales force that does the promotion, generates the demand and distributes the products via pharmaceutical wholesalers (or acquire pharmaceutical wholesalers licence themselves). This is a more costly option as it is followed by regular employment, administration and promotion costs, but it allows the manufacturer to keep full control over the product distribution and revenue margin. This option is more convenient for companies with considerable product portfolio and sales dynamics.

3. Cooperate with a local distribution company/ agent by outsourcing the product distribution and promotion activities, therefore avoiding direct involvement in the market and sharing a larger part of product revenue. This is a considerable strategy for manufacturers with limited product portfolio in the market and irregular sales.

Furthermore, during the expert interviews' multiple trends of Latvian pharmaceutical market were outlined and confirmed:

- As considerable part of pharmaceutical products in Latvia are registered via EU centralised registration procedure (in all EU member states at once), the products not always are actually present in the market. Furthermore, approximately $9 \%$ of the pharmaceutical products approved in state reimbursement A list (list of generic products) have constant supply issues.

- An increase in web-pharmacy sales have increased during the Covid-19 pandemic, but still the sales volumes are low and takes only a tiny, insignificant fraction of the market. Experts noted that the low e-commercial activity in the pharmaceutical market could be explained by the main customer segment of the pharmacies that is aged generation with low competence of e-commerce possibilities. Still an increasing trend of pharmaceutical e-commerce is expected as the population continues its maturing process and the trends from the younger population eventually transfers to elderly population.

- The vertical integration of Latvian pharmaceutical market bring both positive and negative effects on the product distribution from the manufacturers perspective. It is easier for the pharmaceutical manufacturer to distribute their product as the vertically integrated distribution networks cover the full supply chain from Manufacturer till end customer. But still, as there are several vertically integrated holding groups in Latvian pharmaceutical market, the competition sometimes brings some tension and the exchange of products between the vertically integrated structures might sometimes be disrupted, thus bringing challenges of the product availability to end customer

- During the Covid-19 pandemic the face-to-face communication of pharmaceutical producers and distributors with physicians and pharmacists is limited or not possible, thus limiting the communication and promotion activities. Nonetheless, pharmaceutical producers are tackling this challenge by arranging online meetings, conferences and discussions with the physicians, professional and patient organisations.

\section{Latvian pharmaceutical market description and pharmaceutical product specifics}

Availability of novelty pharmaceutical products as well as low competition for generic products is challenging in smaller pharmaceutical markets like Latvia and other Baltic states. Competent authorities and experts of Latvian pharmaceutical market have outlined and addressed this challenge by taking efforts to make market date more transparent and accessible to industry.

Latvian State agency of medicines runs a convenient pharmaceutical market database that includes up to date information of product availability in the market, official registered price, prescription and reimbursement status, also having the option to compare multiple pharmaceutical products; the selected data can be downloaded and further assessed with analytical software. Agency also publishes annual bilingual report on pharmaceutical market, pharmaceutical product consumption and their dynamics - main suppliers, distributors, market volume, consumption and other relevant market information, thus sharing essential data that could be used for market assessment by pharmaceutical entrepreneurs.

The data shows that total Latvian pharmaceutical market in retail pharmacies has steadily risen from 266.05 Million $€$ in Year 2012 to 370.80 Million $€$ in Year 2019. Although there has been a 0.64\% market drop in 2019 (2.38 Million $€$ less than in Year 2018) the up to date tendencies of pharmaceutical wholesaler sales indicates that market is expected to continue its growth in Year 2020.

By looking at pharmaceutical market composition (Year 2018 data) 58\% of the market volume (packs sold) is prescription products (vs. 42\% over the counter products) that also take $82 \%$ of market value (vs. $18 \%$ over the counter products), thus indicating that in Latvian pharmaceutical market the prescription products have higher volume and value, thus having higher potential than over the counter products.

Furthermore, as local pharmaceutical producers take only $4.5 \%$ of the market value and are more focused on over the counter pharmaceutical product market (59\% of packs sold and $39 \%$ of sales value) the market is highly dependent on prescription pharmaceutical product importing.

State reimbursed pharmaceutical product statistic annual reports are published by National health service and summarises the state reimbursed pharmaceutical product consumption and their reimbursement value. Being part of State reimbursement list is crucial for the suppliers of such 
products as it gives the opportunity for regular supplies to patients with chronic diseases. State reimbursement is fully price competition driven and the supplier with the lowest price offer receives full reimbursement (reference supplier) - for other suppliers the price difference between their offer and reference supplier price has to be covered by end customer, thus considerably reducing the demand. Therefore the available reimbursement statistics are important for potential pharmaceutical suppliers in order to assess their competitiveness in Latvian market.

Reimbursement market data shows that it has been increasing from 109.56 Million $€$ in Year 2011 to 171.23 Million $€$ in Year 2018. Infectious and parasitic diseases have received the most amount of reimbursement (33.76 Million $€$ ) followed by Oncology diseases (29.76 Million $€$ ) and endocrine, nutritional and metabolic diseases (27.85 Million $€$ )., thus outlining the therapeutical groups with the highest potential for pharmaceutical suppliers.

\section{Pharmaceutical product distribution channel specifics}

Similarly to other EU pharmaceutical markets also in Latvia there`s a regulated distribution chain for pharmaceutical product distribution - the products can be sold to end customer/ patient only via certified pharmacies under pharmacists provision. There are two kinds of pharmacies in Latvian pharmaceutical market - 775 retail pharmacies, 76 pharmacy affiliates and 30 hospital pharmacies (State Agency of Medicines of Republic of Latvia, 2020).

Hospital pharmacies, a prerequisite for a well-functioning hospital, are operated as subsidiaries within hospitals and are responsible for the supplies of pharmaceutical products and other products required for inpatient treatment. Alternatively, the pharmaceutical products can be ordered and acquired by a physician directly - this is more as an exception used by nursing homes and smaller clinics with low consumption of products where sustaining a pharmacy would be economically irrational.

Retail pharmacies are the supply chain key component where, in contrary to hospital pharmacies, end customer participates in the decision process and can directly choose out of multiple products available by interacting with a pharmacist. Retail pharmacies are scattered around the whole country, although majority of them are located in the capital city of Riga (258) and other major cities: Daugavpils - 38; Liepāja - 30; Jelgava - 24; Jūrmala - 20; Rēzekne - 16; Ventspils - 14; Valmiera - 10; Jēkabpils - 10 (State Agency of Medicines of Republic of Latvia, 2020). By summarising the locations of retail pharmacies, a trend may be noticed that many of the pharmacies are located in shopping centres or close to hospitals, clinics or other health institutions. As per OECD Health at a Glance 2019 report there are approximately 40 retail pharmacies per $1000^{`} 000$ population and that is the $4^{\text {th }}$ highest rate in European Union (average rate: 29 retail pharmacies per 100 ` 000 population) and therefore Ministry of Health has already initiated public discussion on the need of more even retail pharmacy placement settings and count reduction. And although only minority of pharmacies are located in the rural areas they still play a significant role in such areas by being recognised as the local first aid and health assistance points.

Web-pharmacies have been introduced in Latvian market during recent decades - although initially not commonly used, they have shown their specific role during the Covid-19 pandemic by offering contactless pharmaceutical care and product supplies for quarantined Covid-19 patients and high-risk patients who were instructed to avoid public places. Legally the web-pharmacies can only be operated by a certified pharmacy that has a specific licence for web-sales. With the increasing trends of e-commerce, the elderly population becoming more acquainted with the smart technologies and challenges of Covid-19 Pandemic it is expected that the role of web-pharmacies and e-commerce in pharmaceutical field will continue to increase.

By looking further into the supply chain of pharmaceutical market, pharmacies can order and buy the pharmaceutical products only from certified pharmaceutical wholesalers. There are 87 certified pharmaceutical wholesalers and they are mostly located in capital city Riga (60) and its closest suburbs - 13 in Mārupe, Garkalne and Stopini (State Agency of Medicines of Republic of Latvia, 2020). Pharmaceutical, medicinal and other healthcare products are acquired by pharmaceutical wholesalers directly from producers (local and foreign), pharmaceutical distributors or other wholesalers, thus being the crucial supply chain component from the pharmaceutical entrepreneur perspective.

Recently the public has outlined concerns regarding vertical integration of pharmaceutical companies in Latvia - it has been noted that all of mayor retail pharmacy chains have an integrated pharmaceutical wholesaler and several retail pharmacy chains have integrated laboratories, clinics, physician practices and/ or pharmaceutical production companies (Public broadcasting of Latvia, 2017; Veselības projekti Latvijai, 2016). A/S "Repharm" should be outlined as the major vertically integrated pharmaceutical holding group that includes the largest retail pharmacy chain ("Mēness aptiekas"), largest wholesaler (A/S "Recipe plus"), local pharmaceutical producer (A/S "Rīgas farmaceitiskā fabrika"), one of the largest clinic chains (A/S “Veselības centru apvienība”) and medical laboratory (SIA „Centrālā laboratorija”). It is stipulated that the vertical integration 
of pharmaceutical companies in Latvia has been fostered by the strict pricing limitations with limited margins on product distribution, thus pushing companies for cost containment and keeping the profit within the holding.

Low market volume and value might hold back pharmaceutical distributors to enter Latvian market due to high production costs and low revenue, the market is keen to accept multilanguage pack (combining Latvian wording with other language packs) distribution in Latvian pharmaceutical market, thus potentially optimising the production costs. It is a common practice to combine Latvian, Lithuanian and Estonian languages on a unified Baltic pack, therefore combining the demand of these 3 small markets - this action is promoted and supported by State agencies of Medicines of the three Baltic states. Furthermore, as outlined by experts in cases of product shortages Latvian pharmaceutical market is flexible enough to accept foreign language packaging as long it has patient information leaflet in Latvian added to the pack, therefore on specific occasions pharmaceutical manufacturers and producers can distribute their products from other, larger market stocks.

It is wort mentioning that under National regulation pharmaceutical product dispensation has to be done under the provision of pharmacist and therefore practices of pharmaceutical product sales in gas stations, supermarkets or via dispensing machines is not allowed in Latvia, although these practices are common for distribution of food supplements and medical devices.

\section{Pricing assessment of Latvian pharmaceutical market}

Pharmaceutical product prices in Latvia are regulated by the government as the price has to be officially registered prior launching the product in the market. The maximum market price is limited by the markup set for retail and wholesale - pharmacy markup cannot exceed $10-40 \%$ (depending on the wholesale price level) and wholesale markup cannot exceed 10-18\% (depending on the manufacturer price level), therefore product market price directly depends on the price manufacturer sells the product to wholesalers. The price has to be officially set by manufacturer and it is publicly available in the State Agency of Medicines database. Although this seems as a fair and transparent pricing model the industry outlines that the limited markups on wholesale and retail level are tight and sometimes barely covers the distribution and service costs. The wholesalers and retailers limited margin lowers the business profitability, thus urging the distributors to delude with the product official pricing and setting undisclosed agreements between the product suppliers and wholesalers (marketing service agreements, rebates), thus gaining higher profitability for distributors. Also, the officially set maximum price outlines the maximum markup of the product, but the products can always be sold at a lower markup, meaning that the actual market price could be lower than the officially set price. In result the pharmaceutical product official maximum price might sometimes be misleading as it does not always represent the price at which the manufacturer/ supplier actually sales the product to wholesaler and the actual market price. Nonetheless the officially set maximum price of the product indicates the product pricing level in Latvian pharmaceutical market and it can be compared with the official prices set elsewhere in European markets. Therefore, in order to avoid possibility of suppliers reducing their investment or fleeing the market the competent authorities should identify potential risks and conduct an indepth assessment when updating the pharmaceutical product pricing regulations. The potential risks and their effect on entrepreneur investments has been studied and described by S.Saksonova and I.Kuzmina-Merlino (2019).

As there's no combined database available for officially set market prices of European pharmaceutical markets the authors of this study have used the data from IQVIA database that is also commonly used by pharmaceutical industry entrepreneurs for market assessment. In order to review and asses Latvian pharmaceutical market product pricing levels a set of products were chosen for the study - 3 most used ATC 's of over the counter, prescription and state reimbursed products together with 3 over the counter, prescription and state reimbursed products by their market value (total $€$ spend) as reported by State Agency of Medicines of Latvia and National Health Service. 
Comparison of average single unit price (EUR) of selected pharmaceutical products in Latvia, Estonia, Lithuania and European Union, Year 2019

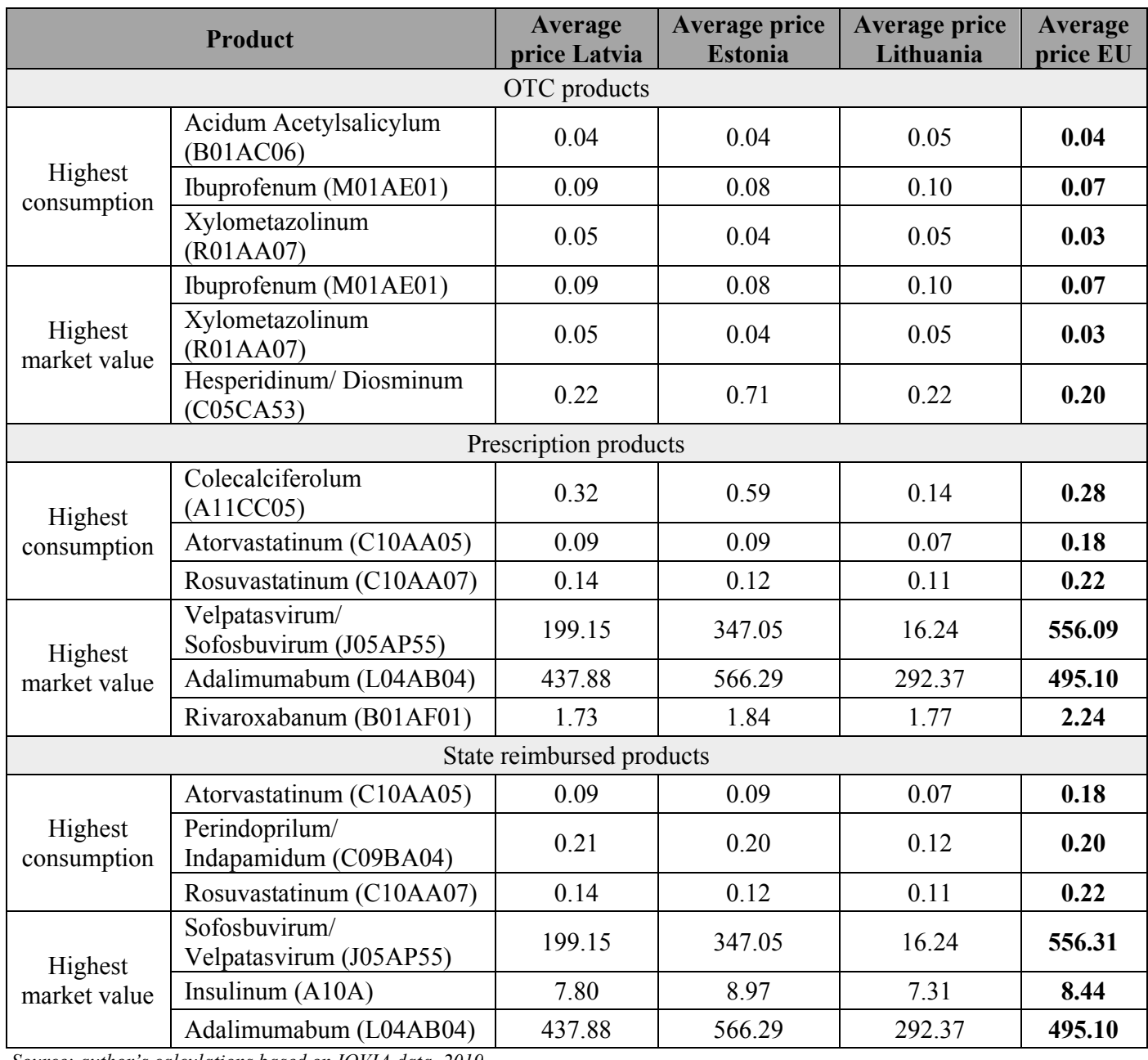

Source: author's calculations based on IQVIA data, 2019

The market review outlines that the prescription pharmaceutical products in Latvia tend to have lower price than elsewhere in Europe and are below the average market prices, but over the counter pharmaceutical products on the contrary tend to have higher prices than elsewhere in Europe and are above the average; similar trends has been noticed also for Lithuanian and Estonian markets, thus outlining pricing similarities in Baltic pharmaceutical markets (see Table 1). The trends could be explained by the strict regulation on the prescription product promotion as no public promotion is allowed for such products, resulting that demand cannot be generated by customers, the state reimbursement system is price competition driven and with current Baltic States economic situation (lower purchasing power parity than elsewhere in Europe) patients cannot afford higher prices. Nonetheless, the pricing of pharmaceutical products in Latvia can be higher than elsewhere in Europe as seen with over the counter products, thus proving that if proper marketing activities are targeted toward the end customers some price elasticity can be achieved, despite the previously mentioned economic factors.

It is worth noting that during the pharmaceutical product pricing review of the outlined products a trend (although weak) has been identified over the counter pharmaceutical products in markets with higher competition level and market volume tend to have lower market price than smaller markets with lower competition. Nonetheless, further studies of such trend should conducted in order to confirm such hypothesis.

\section{Pharmaceutical product promotion specifics}

As mentioned above specific promotion limitations are applied for pharmaceutical products in Latvia - public promotion is not allowed for prescription products, also free sample distribution is strictly controlled and therefore is not commonly applied in practice. Nonetheless, over the counter pharmaceutical products can be promoted publicly with exception to discounting as public pharmaceutical product discounts are not allowed. Therefore, most of the promotion activities outline product specifics, its use and indications in order to inform end customer and draw special 
attention to product trade name. Video and audio promotions specifically outline the product trade name acting as a reminder, thus by highlighting trade name vocalisation the promotions seek the product to sink into customer memory. In addition to trade name highlighting it was noted that web and flyer promotions include more detailed information on product indications and use.

Although prescription product public promotion is prohibited, the promotion to physicians and pharmacists is allowed and is widely used as theses specialists are the ones that make the decision on which prescription products will be used and act as the key opinion leaders for the over the counter products. Sales representatives are commonly used for visits to physician practices and retail pharmacies, promotions and articles are published in professional magazines (Doctus, Materia Medica) and websites, product presentations are being displayed during physician and pharmacist professional conferences.

It should be noted that consumption of over the counter pharmaceutical products is affected by seasonal trends and prescription medicinal products are mostly used for chronic disease treatment; thus the promotional activities should be aligned accordingly. By reviewing the over the counter promotional trends over the Year some seasonal promotions can be outlined - cold and flu pharmaceutical product are more common during autumn and winter season; antiallergic products are more common during spring; sunburn, rash and bruise treatment is more common during summer; gastric and digestion product promotion is often linked to events traditionally associated with feasting (easter, midsummer eve, Christmas). As for prescription medicinal products the promotional communication is more linked to public occasions linked with specific diseases international disease day (for example - world diabetes day on November $14^{\text {th }}$ ), physician congresses, patient organisation activities.

Pharmaceutical producers whose product portfolio is mostly combined of prescription products are more dependent on the key opinion leader (physician and pharmacist) attention towards the company, thus increasing the public relations role in such cases. In Latvian pharmaceutical market most commonly used public relation practices includes sponsoring and partaking into the public events related to specific diseases, patient groups, physicians, therefore building and maintaining close relations with patient, physician and pharmacist organisations. Also, sponsorship of public entities (sport teams, culture events, universities) are being used to raise company recognition among the public and potential customers. As outlined by nongovernmental organisation Health projects for Latvia research done in 2018 such public relation activities may be abused as hidden promotion, therefore pharmaceutical producers and distributors should be discreet and precautious with such public activities. Nonetheless the Association of International Innovative Pharmaceuticals Producers and Latvian Generic Medicines Association that represent and promote activities of international pharmaceutical producers have implemented a Good Practice and Code of Ethics for their members that is well respected and acts as a self-regulating tool for the promotion of pharmaceutical products in Latvia.

With the development of mobile technologies, everyday use of smartphones and increasing mobile technology skills among the elderly population the potential of health care mobile applications increases (Palmer, M. J., Barnard, S., Perel, P., Free, C., 2018). The situation is also recognised by pharmaceutical entrepreneurs by designing mobile application for health issues related to their product and service portfolio. Such trend is also noted in Latvian pharmaceutical market where multiple mobile applications are available for end customers and physicians - retail pharmacy chain applications with maps outlining pharmacy locations, promotions, available stock and contact forms; pharmaceutical manufacturer applications for specific patient groups that offer tracking of pharmaceutical product use, health stats, sharing reminders and recommendations. It should be noted that the elderly population might not be convenient of using mobile applications in foreign languages and therefore pharmaceutical producers and distributors willing to develop and offer mobile applications for patients in Latvia should consider also including Latvian language in the mobile application.

Although the need for digitalisation skills and competences has already been studied and addressed for multiple industries, for example for Fintech sector (as example) by Kuzmina-Merlino and S.Saksonova (2018), further in depth studies of digitalisation trends and opportunities in pharmaceutical industry should be addressed.

\section{Conclusions, proposals, recommendations}

1. Prescription pharmaceutical products make up the majority of Latvian pharmaceutical market by value and volume. The pricing level of prescription pharmaceutical products in Latvia is below the average of pricing level in other European markets that could be explained by the strict regulation on promotion activities and importance of pricing level in state reimbursement system. Over the counter pharmaceutical product pricing level, on the contrary, is above the average pricing level in other European markets. Due to low market share of local pharmaceutical producers' Latvian pharmaceutical market is quite dependent on the product imports from foreign producers, outlining an opportunity for pharmaceutical distributors. 
2. Latvian pharmaceutical market is keen to accept products in multilanguage and foreign packs, thus giving the pharmaceutical producers and distributors chance to combine the demand from multiple markets and optimise the production costs.

3. Pharmacists, as integral part of the pharmaceutical product distribution chain and acting as key opinion leaders to end customers, gives high importance to product quality and price, outlining the importance of these factors during the promotion and public relations. Also, products with practical design and more units per pack are valued higher than product with simple design and small units per pack.

4. Web-pharmacy role have been increasing during recent decades outlining its significant role during the Covid-19 pandemic. Also, mobile applications are being introduced into pharmaceutical market offering them to end customers (pharmacy locations, promotions, available stock, contact forms), physicians and specific patient groups (product use tracking, health stats, reminders, recommendations).

5. Latvian Pharmaceutical market significant vertical integration outlines several major stakeholders with strong position in the market, meaning that by choosing one of the major local distribution companies pharmaceutical product producers have deeply integrated access to the market.

6. Over the counter pharmaceutical product promotion activities are affected by seasonal trends; prescription product promotion, on the other hand, is strictly regulated and is targeted towards key opinion leaders and patient organisations, thus increasing the importance of public relations activities.

7. With respect to continuous digitalisation processes in multiple industries, also including pharmaceutical, there is a potential for further marketing component improvements and alignment with the needs of digital consumers. In order to keep up with the digitalisation trends pharmaceutical companies are expected to further invest into their employees and improve their digital skills and competence.

8. Digitalisation skills and competences has already been studied for multiple industries, still further digitalisation trends and specific needs of pharmaceutical industry should be addressed in more details during future studies.

\section{Bibliography}

Association of International Innovative Pharmaceuticals Producers, Latvian Generic Medicines Association, 2020. Good Practice and Code of Ethics, accepted 01.12.2020.

European Medicines Agency, 2020. Wholesale and Distribution Authorisations, EudraGMP Database. [Online] Available at: http://eudragmdp.ema.europa.eu/inspections/view/wda/searchWDA.xhtml [Accessed 03.12.2020.].

European Parliament and Council, 2001. Directive on the Community Code Relating to Medicinal Products for Human Use, Directive 2001/83/EC, amended 25.10.2012.

Heus, J. J., de Pauw, E. S., Leloux, M., Morpurgo, M., Hamblin, M. R., Heger, M., 2017. Importance of Intellectual Property Generated by Biomedical Research at Universities and Academic Hospitals. Journal of Clinical and Translational Research, 3, 250-259.

Huber, M., Dippold, K., Forsthofer, R., 2012. Which Factors Drive Product Sales in OTC Markets. International Journal of Pharmaceutical and Healthcare Marketing, 6, 291-309.

Kauppinen-Räisänen, H., Owusu, R., Bamfo, B., 2012. Brand Salience of OTC Pharmaceuticals Through Package Appearance. International Journal of Pharmaceutical and Healthcare Marketing, 6, 230-249.

Kuzmina-Merlino, I., Saksonova, S., 2018. The Knowledge and Competencies Required for the Fintech Sector. New Challenges of Economic and Business Development - 2018: Productivity and Economic Growth. International Conference, Riga, Latvia, May 10-12, 2018: Proceedings. Riga: University of Latvia, 387-395.

Ministry of Health of Republic of Latvia, 2020. Plāno noteikt jaunus kritērijus, lai atvērtu aptiekas (Plans to establish new criteria to open a pharmacy) [Online] Available at: https://lvportals.lv/dienaskartiba/318851-plano-noteikt-jaunus-kriterijus-lai-atvertu-aptiekas-2020 [Accessed 03.12.2020.].

National Health Service, 2019. Reimbursed Medicinal Product Consumption Statistics. [Online] Available at: http://www.vmnvd.gov.lv/lv/kompensejamie-medikamenti/statistika [Accessed 03.12.2020.].

OECD, 2020. Health at a Glance 2019 [Online] Available at: https://www.oecd-ilibrary.org/docserver/4dd50c09en.pdf?expires=1607029435\&id=id\&accname=guest\&checksum=C7A1D5B38121CF925F1B2B7111BD4BF1 [Accessed 03.12.2020.].

Palmer, M. J., Barnard, S., Perel, P., Free, C., 2018. Mobile Phone-Based Interventions for Improving Adherence to Medication Prescribed for The Primary Prevention of Cardiovascular Disease in Adults. Cochrane Database of Systematic Reviews 2018, Issue 6. Art. No.: CD012675 [Accessed 03.12.2020.]

Panigrahi, A., Aware, K., Patil, A., 2018. Application of Integrated Marketing Communication in Pharmaceutical Industry. Journal of Management Research and Analysis, 5(2), 133-139. 
Public Broadcasting of Latvia, 2017. "Invisible Power of Pharmacy": Vertical Integration [Online] Available at: https://www.lsm.lv/raksts/zinas/ekonomika/veselibas-ministre-caksa-un-vinas-prieksgajeji-kutri-iegrozot-lielos-zalu-tirgonus.a224854/ [Accessed 03.12.2020.]

Rossetti, C. L., Handfield, R., Dooley, K., 2011. Forces, Trends, and Decisions in Pharmaceutical Supply Chain Management. International Journal of Physical Distribution \& Logistics Management, 41, 601-622.

Saksonova, S., Kuzmina-Merlino, I., 2019. Cryptocurrency as an Investment Instrument in a Modern Financial Market. St Petersburg University Journal of Economic Studies, 35(2), 269-282.

State Agency of Medicines of Republic of Estonia, 2019. Baltic Package Procedure [Online] Available at: https://ravimiamet.ee/en/baltic-packageprocedure-0 [Accessed 03.12.2020.].

State Agency of Medicines of Republic of Latvia, 2019. Statistics on medicines consumption 2018. [Online] Available at: https://www.zva.gov.lv/sites/default/files/2019-06/2018.pdf [Accessed 03.12.2020.].

State Agency of Medicines of Republic of Latvia, 2020. Annual Statistics on Medicinal Consumption [Online] Available at: https://www.zva.gov.lv/lv/publikacijas-un-statistika/oficiala-statistika/zalu-paterina-statistika-gada-griezuma [Accessed 03.12.2020.].

State Agency of Medicines of Republic of Latvia, 2020. Medicinal Product Register of Latvia, Database of SAM. [Online] Available at: https://www.zva.gov.lv/zvais/zalu-registrs/en [Accessed 03.12.2020.].

State Agency of Medicines of Republic of Latvia, 2020. Register of Licensed Pharmaceutical Companies [Online] Available at: https://www.zva.gov.lv/zvais/fdu-registrs/?\&lang=en [Accessed 03.12.2020.].

State Agency of Medicines of Republic of Latvia, 2020. Vienots iepakojums (Unified packaging) [Online] Available at: https://www.zva.gov.lv/lv/industrijai/zalu-registracijas-apliecibu-ipasnieki/pec-registracijas/vienots-iepakojums [Accessed 03.12.2020.].

State Medicines Control Agency of Lithuania, 2019. Tarptautinis bendradarbiavimas (International Cooperation) [Online] Available at: https://vvkt.lt/Tarptautinis-bendradarbiavimas [Accessed 03.12.2020.].

Veselības projekti Latvijai (Health Projects for Latvia), 2016. Integrācijas struktūras ārstniecības un farmācijas nozarē Latvijā (Integration Structures in the Medical and Pharmaceutical Sector in Latvia). [Online] Available at: http://www.veselibasprojekti.lv/upload/Petijumi/Petijums_integracija_farmacija_18112016_FINAL.pdf [Accessed 03.12.2020.].

Veselības projekti Latvijai (Health projects for Latvia), 2018. Kādi kritēriji jāievēro, lai informācija par zālēm medijos nekl̦ūtu par zālu slēpto reklāmu? (Criteria to Follow so the Media Information on Pharmaceutical Products does not Become a Hidden Promotion?) [Online] Available at: http://www.veselibasprojekti.lv/upload/raksti/Zinojums_VM_un_VI_\%20Informaci\%20ja\%20vai\%20zalu\%20rek1\%C4\%81ma_Final.pdf [Accessed 03.12.2020.]

Wieringa, J., Leeflang, P., 2013. Modelling the Effects of Promotion Expenditures on Sales of Pharmaceuticals. Applied Economics, 45, 3389-3399.

World Health Organization, 2017. Guidance on the use of International Nonproprietary Names (INNs) for Pharmaceutical Substances [Online] Available at: https://www.who.int/medicines/services/inn/FINAL_WHO_PHARM_S_NOM_1570_web.pdf?ua=1. 


\section{REVEALING THE IMPACT OF WORKING HOURS ON THE WORK-LIFE BALANCE AND JOB SATISFACTION OF FRONT-LINE EMPLOYEES IN THE TOURISM AND HOSPITALITY INDUSTRY BY MEANS OF A QUANTITATIVE STUDY \\ Jeannine Kopp, University of Latvia}

Abstract. The factors work-life balance and job satisfaction play an important role in many professions - especially in the tourism and hospitality industry - because those elements are important for the individual and for the success of a company or organization. The increasingly difficult reconciliation of family and work as well as the irregular working hours associated with the work in the tourism and hospitality branch can lead to an imbalance between family and company. The work-life balance in the tourism and hospitality management is strongly influenced by the interaction of both family and business systems. This blurring of both systems also causes that some employees feel disturbed in their privacy by this situation. Regardless, there are few factors in this branch that make it unattractive to potential employees. This paper focuses on the impact of the working hours on the work-life balance and job satisfaction of the employees in this branch and may provide useful information for further research. The paper provides an overview of the general literature and illustrates the research that relates specifically to the work-life balance in the tourism and hospitality industry. Aim of this paper is to identify the impact of working hours on the work-life balance and in further distance on the job satisfaction of front-line employees in this sector. The core data being used in this study is gathered from a quantitative employee questionnaire and analysis has been conducted by using SPSS software for statistical data processing. Research findings indicate that a correlation exist.

Keywords: work-life balance, job satisfaction, working hours, tourism and hospitality industry.

JEL code: Z32

\section{Introduction}

The tourism and hospitality industry is an interesting area for the study of work-life balance issues, because the workforce is often characterised by its youth, feminisation, high proportion of immigrants, non-standard employment patterns, low coverage of collective agreements, low pay and high level of job turnover (Deery et al., 2018). For many tourism industry employees, working in front-line positions of 24/7 operations, it is difficult to maintain a healthy lifestyle (Deery \& Jago, 2009). Especially front-line employees in the tourism and hospitality industry are in a unique position to contribute to problem resolution and to communicate trends in customer service needs and the impact of company policies on service delivery. Their job satisfaction and work motivation are mostly the company's financial success, because they have the tools and authority to resolve problems on the spot.

A culture of long working hours makes it difficult for employees to combine family life with work life. Flexible working hours have advantages for employers and those are also advantageous for employees, because they are able to work from home and at the same time in a flexible manner, thus harmonizing family and job, but this is unfortunately not always possible in the tourism and hospitality industry. For this reason, separating private and working life is becoming more and more difficult and reveals that there is an increased risk of burnout. Especially for front-line employees it is more likely to cause problems with the compatibility of work and leisure than other sectors, for example by not having the appropriate working hours, little control over scheduling and little support at the workplace. Moreover, demographic developments and changed family structures have intensified the discussion of the so-called work-life balance. Furthermore, the employment in this branch is often considered to be poorly paid and offers little opportunity for further education. Reflections about flexible deployment times and locations even in the hospitality and tourism industry are therefore essential. For this reason it is important to confirm empirically that the working hours have an impact on the worklife balance and job satisfaction of the front-line employees. The novelty of this paper is to find limitations and recommendations for further research and the object of the study are front-line employees, who are active in the tourism and hospitality industry. The research question arises how the hospitality and tourism industry can contribute to a better balance of the employees active in this branch and in further distance also improve their job satisfaction. 


\section{Literature Review}

The work-life balance has taken on great relevance in human resource literature and the practices focused on this balance are considered the most relevant in organizations at present (McCarthy et al., 2010). Although many definitions exist, work-life balance in general can be defined as 'an individual's ability to meet both their work and family commitments, as well as other non-work responsibilities and activities' (Parkes and Langford, 2008). Hoff et al. (2005) describe in their paper that the term 'work-life balance' identifies the relationship between the main areas of life, work and life. Hämmig et al. (2009) define work-life balance as the balance between work and family demands, as well as the balance between work and other role expectations and responsibilities in private life -e.g., sport, charity, education, etc. Murphy and Doherty (2011) state in their paper that it is not possible to measure work-life balance in an absolute way as there are personal circumstances which influences the perception establishing a harmony that reflects an individual's priorities. In this context, Sun et al. (2020) describe in their paper that it is often difficult to maintain a work-life balance over the long-term. Efforts of tourist organizations that will make them stay with the company in the long term and actively participate in realizing its strategic goals (Bednarska, 2013). For this reason, according to Padmanabhan \& Kumar (2016), it is important to manage and balance the expectations of family and work, at a time it can affect oneself in balancing the role expectations of work and home and the conflicts surrounding both.

Due to the abundance of different activities, it is difficult to find a work-life balance as the boundaries of work and private life almost vanish. In particular, Lucia-Casademunt et al. (2015) highlight in their paper the need for managing working hours to let employees fulfill their professional and family responsibilities. In this context, work-life balance describes the balance between the number of hours and thus the time that a person devotes to their leisure and work role (Greenhaus et al., 2003). Furthermore, Thompson \& Bunderson (2001) take the view that the balance approach makes sense here, as the time factor is a fixed resource that has to be divided between two areas of life. When researching scientific models of the work-life balance, one finds that a number of different concepts exists, which, however, are rarely based on a scientific model. McNall et al. (2010) gauged the consequences of work-life balance drawing on the existing typology into three main groupings e.g. work, non-work and health. Most approaches are designed to be more action-oriented and a scientific foundation is scarcely represented in practice.

Anyhow, since some models contain interesting approaches and thought-provoking, a few models will be presented and compared in Table 1. The work-life balance is inextricably linked to the concept of satisfaction. When considering concepts of the work-life balance, the question arises as to which factors influence and which have a moderating or mediating character. It is assumed that different living areas as well as their specific requirements are relevant. These, according to the present ideas, act as an independent variable on satisfaction. Hence, Maslow's Hierarchy of Needs and Alderfers model as well as different stress models, personality development models, health models and concepts of workload and strain are also correlated to the concept of satisfaction.

Table 1

Comparison of different theories relating to work-life balance

\begin{tabular}{|l|l|}
\hline \multicolumn{1}{|c|}{ Theory / Modell } & \multicolumn{1}{c|}{ Description } \\
\hline $\begin{array}{l}\text { Maslow's Hierarchy of Needs (1954) and } \\
\text { Alderfer (1972) }\end{array}$ & $\begin{array}{l}\text { The central needs of the human being, which develop in dependence on the situation of } \\
\text { the individual. }\end{array}$ \\
\hline Stress models (e.g. from Lazarus, 1966) & Stressors and aspects that can influence or cushion the stress effect. \\
\hline $\begin{array}{l}\text { Personality development models / } \\
\text { Life stage models (e.g. from Montada, 1998) }\end{array}$ & $\begin{array}{l}\text { Development in eight main phases, each with specific conflicts and crises, identifying the } \\
\text { consequences of a successful or less successful mastering of development tasks. }\end{array}$ \\
\hline Health models (e.g. from Sachse, 1995) & $\begin{array}{l}\text { Identification of causes, influencing factors and conditions that influence the development } \\
\text { of psychosomatic diseases. }\end{array}$ \\
\hline $\begin{array}{l}\text { Concepts of workload and strain (e.g. from } \\
\text { Richter and Hacker, 2013) }\end{array}$ & $\begin{array}{l}\text { Identification of burdens, especially at the workplace, triggering conditions and resulting } \\
\text { stress sequences in the form of short-term, medium- and long-term reactions. }\end{array}$ \\
\hline Source: Table based on Collatz, A., \& Gudat, K., 2011. Work-Life-Balance. Hogrefe Verlag
\end{tabular}

With reference to the service industry such as that of tourism, the link between job satisfaction of the employees and organization commitment has also been well demonstrated by the 'service profit chain' which reveals an explicit link between satisfied employees and loyalty to their employers and degree of productivity (Yew, 2008). A great deal of the literature according to Yang (2010) illustrates a strong relationship between job satisfaction and organizational commitment. Job satisfaction contains positive influence on the performance of the work force as it enhances 
job involvement and in a further consequence makes employees feel more satisfied and committed to the organization. For this reason, the need of committed employees is necessary. This includes for one side the engagement of the employees to behave toward the goals of the company and on the other side the commitment of the employees to stay in the organization. Disposing of the knowledge of factors that are motivating employees and knowing why they put their efforts into their work and are satisfied with their job is probably the secret of organizational success. For this reason, an organization has to be aware of factors that help maintaining a balance between the work and family as well as finding factors that are motivating and satisfying to the employees in order to stimulate them to perform their job as best as possible and to remain in the company.

In fact, employees enjoying a high level of job satisfaction are characterised to be loyal towards their companies and their habits, attitudes and behaviours are conducive to providing quality services, maintaining a positive and long-term rapport with customers (Heskett et al. 1994). Job satisfaction is defined by Locke (1969) as a positive emotional feeling, a result of one's evaluation towards his job or his job experience by comparing between what he expects from his job and what he actually gets from it. Zopiatis et al. (2014) state in their paper that low levels of job satisfaction is impacted by routinization, role conflict and lack of promotional opportunity and this in further consequence can have a deleterious effect on the organization and can lead to frequent turnover. In the literature, there are extensive number of empirical studies that have investigated the effects of various organizational variables on front-line employee performance and job satisfaction (e.g., Brown \& Peterson, 1993; Churchill et al., 1985). By contrast, less empirical attention has been paid to the impact of the working hours on the work-life balance and job satisfaction of the employees active in this branch.

\section{Research results and discussion}

In general, to ensure service quality, front-line staff has to be friendly, hospitable and able to cope with pressure. The work environment within the hospitality and tourism industry generates irregular and unpredictable working hours, difficult demands, tension and often stress for the working personnel. Moreover, employees are also struggling with daily as well as seasonal fluctuations. Often hospitality and tourism employees are overworked, including weekends and holidays and are on duty when other employees are on vacation (Lin et al., 2015). For this reason, longer working hours, having a greater and complex workload and experiencing a lot of work pressure, makes it difficult for front-line employees perceiving a balance between work and life as well as being satisfied with the job.

The study was conducted from November 2017 to February 2018 and the core data being used in this study is gathered from a quantitative employee questionnaire with a sample size of 200 questionnaires. 73 of them were rejected, because of missing responses to some of the items. Thus, 127 of the front-line employees working in the tourism businesses in Tyrol, were all completing the survey of the quantitative research in order to indicate whether 'working hours' have an impact on the work-life balance and job satisfaction. Analysis has been conducted by using SPSS software for statistical data processing. In order to characterize the sample, descriptive statistics have been used.

Table 2

Differences in dimensions of job satisfaction scales separated into 'working hours'

\begin{tabular}{lcccc}
\hline & $\begin{array}{c}\text { Part-time } \\
(\mathrm{n}=33)\end{array}$ & $\mathrm{M}$ (Mnor Employment & \multicolumn{2}{c}{ Full-time Employment } \\
& $\mathrm{M}$ & $\mathrm{n}=85)$ & $\mathrm{SD}$ \\
\hline Working Conditions & $*$ & 0.85 & 3.46 & 0.99 \\
\hline Task Identity $\dagger$ & 3.94 & 0.95 & 3.80 & 1.02 \\
\hline Task Significance $\dagger$ & 4.18 & 0.73 & 4.04 & 0.89 \\
\hline Task Variety $* * *$ & 4.38 & 0.65 & 3.57 & 0.66 \\
\hline Working Hours $* *$ & 4.24 & 1.13 & 3.22 & 0.97 \\
\hline
\end{tabular}

Source: Author's table

Legend: $\%: p>=.05$ und $p<.10 ; *: p>=.01$ und $p<.05 ; * *: p<.01$ und $p>.001 ; * * *: p<.001$

The majority of the sample is female $(n=73,62 \%) .44$ probands in this sample claim to have been born before the year 1965, therefore they are 53 years old or older at the time of the survey. Another 20 (17\%) of the sample were born between 1966 and 1980, that means they are between 38 and 52 years old at the time of data collection. When asked about their working time, 85 (72\%) persons reveal that they have a full-time job, 21 $(18 \%)$ have a part-time job and $12(10 \%)$ working in a minor employment condition, as obvious in Table 2 . The evaluation of the work-life balance is positively influenced if the persons are younger, employed in smaller companies and not acting in a full-time employment. By evaluating the 'working hours' the interviewees have been divided into two groups, the first group includes those who are working in a minor employment or parttime, the second group includes all persons working full-time. 
The dimension 'working conditions' $(\mathrm{F}(1,116)=6.01, \mathrm{p}=.016)$ differs according to the 'working hours' of the employees. 'Working conditions' are rated higher by the group with shorter 'working hours' $(\mathrm{M}=3.94, \mathrm{SD}=0.85)$ than by full-time employees $(\mathrm{M}=3.46, \mathrm{SD}=0.99)$. Although the result is not significant for the 'task identity' scale $(\mathrm{F}(1,116)=3.45, \mathrm{p}=.066)$, a trend can be observed. 'Task identity' is higher for shorter 'working hours' $(\mathrm{M}=4.18, \mathrm{SD}=0.95)$ than for those working full-time $(\mathrm{M}=3.80, \mathrm{SD}=1.02)$. Even with the 'task significance' $(\mathrm{F}(1,116)$ $=3.88, \mathrm{p}=.051)$ a statistical tendency can be registered. The evaluation $(\mathrm{M}=4.38, \mathrm{SD}=0.73)$ is better for probands with shorter 'working hours' than for full-time employees $(M=4.04, S D=0.89)$. Highly significant is the difference with the factor 'task variety' $(F(1,116)=24,82 ; p<.001)$. Interviewees with shorter working hours rate 'task variety' more positively $(\mathrm{M}=4.24, \mathrm{SD}=0.65)$ than employees who work full-time $(\mathrm{M}=3.57$, $\mathrm{SD}=0.66)$. There is also a significant result for the factor 'working hours' $(\mathrm{F}(1,116)=7,33 ; \mathrm{p}=.008)$. Full-time employees rate the factor 'working hours' as more negative $(M=3.22, \mathrm{SD}=0.97)$ than employees with no full-time employment $(\mathrm{M}=3.79, \mathrm{SD}=1.13)$.

Furthermore, in this research it is analyzed whether interdependencies or interactions consist of the interoperation of the combinations of two variables. However, in this research the interdependency between gender and age is significant in the factor 'working hours' $(F(3,114)=3, p$ $=.034)$. In Figure 1 it is observable that the difference between men and women is significantly lower for those born after 1980, compared to those born before 1980. Women in this group are particularly high satisfied with the 'working hours'.

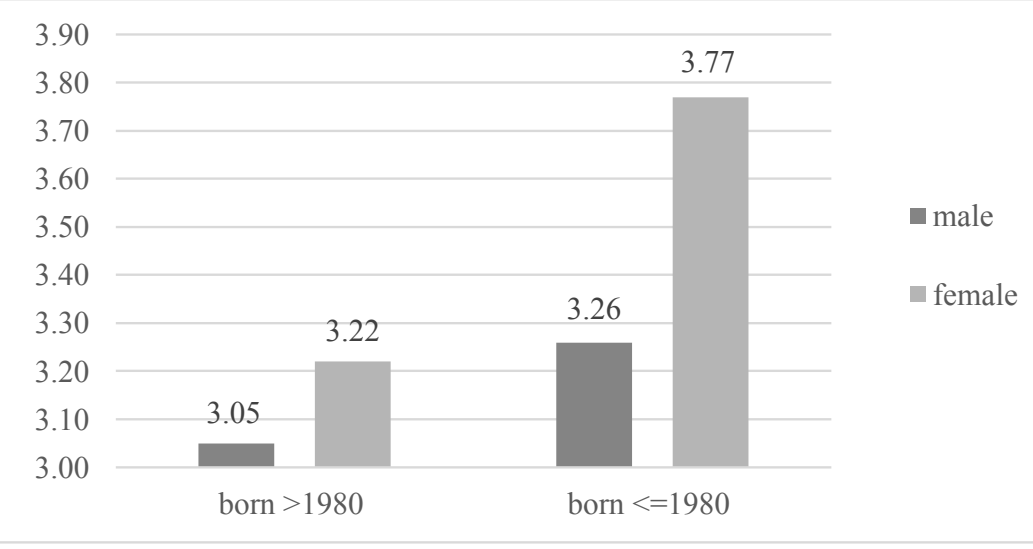

Source: Author's chart

Fig.1. Interdependency of gender and age in the scale of 'working hours'

To sum up, employees working in a part-time or minor employment show a better rating $(\mathrm{M}=3.55, \mathrm{SD}=0.95)$ than the full-time employees $(\mathrm{M}=2.99, \mathrm{SD}=1.09)$. Moreover, part-time or minor employed people have a more positive rating $(\mathrm{M}=4.02, \mathrm{SD}=0.67)$ at this dimension than those working full-time $(\mathrm{M}=3.70, \mathrm{SD}=0.84)$. And concerning the factor 'age', especially women born after 1980 are particularly high satisfied with the 'working hours'.

\section{Conclusions, proposals, recommendations}

The present study examined the impact of the working hours on the work-life balance and job satisfaction of front-line employees who are active in the tourism and hospitality industry. It comes as no surprise that working hours are considered to be a significant predictor of work-life balance. Employees who work full-time are less satisfied with the work-life balance than those with part-time or in a minor employment. In practice, the form of flexibilisation supported and desired by companies does not necessarily coincide with the ideas of employees seeking a balance between work and non-work activities. In particular, if flexible forms of work are to be compatible with family, this requires other flexibility criteria and a family-friendly employment exists when the scope and location of working time allows employees to combine their private life with work.

Measures and recommendations for the creation of a work-life balance in order to enable a categorization structured according to functions and starting points and to create a basis for a differentiated discussion include: Measures that directly affect the employees and their work. These contain measures that change aspects of working time, place of work, work processes, work content and work organization in the direction of work-life balance. Further corresponding measures include job sharing, flexibilisation of working time models and places of work (teleworking and home work). Another recommendations contain those attributed to employees' financial and social support, such as eg. child bonuses, child care facilities, health programs and household services. They do not directly affect 
the work of the employee, but have effects on the individually perceived work-life balance's goal. And finally, further measures flank those measures: For example, the company's information and communication policy, which informs about measures offered, or the corporate and management philosophy, which illustrates the basic attitude of the company towards work-life balance.

Concerning political incentives and in order to strengthen the work-life balance of employees working in the tourism and hospitality industry, unpaid work (household, care, self-employment and volunteer work) should be upgraded in relation to paid work and secured under social law in order to stimulate this discussion is the task of the state. With regard to politically short- to medium-term measures and in addition to statutory working time regulations and participation rights as framework conditions for adequate individual solutions at company level, the childcare infrastructure, political measures, the company culture and social ideas of a fair division of labor between gender have to be reconsidered.

In summary, it can be stated that work-life balance measures should be enforced in all businesses in order to motivate the employees and to avoid fluctuation. It needs a clear concept and a strategic approach to target work-life balance measures. The job satisfaction and well-being of front-life personnel is of utmost importance as they are the first point of contact for the guests in tourism destinations. By reducing time and resource conflicts, the work-life balance and, subsequently, job satisfaction can be positively influenced. This reveals that there is definitely further need for research and measures in the field of work-life balance and job satisfaction of front-line employees in the tourism and hospitality industry. The just mentioned recommendations should be thought-provoking impulses for further investigations in order to further explore a field of research that is becoming increasingly important.

\section{Bibliography}

Alderfer, C. P., 1972. Existence, relatedness, and growth: Human needs in organizational settings.

Bednarska, M. A., 2013. Quality of Work Life in Tourism-Implications for Competitive Advantage of the Tourism Industry. Journal of Travel \& Tourism Research, 13, 1-17.

Brown, S. P., Peterson, R. A., 1993. Antecedents and Consequences of Salesperson Job Satisfaction: Meta-Analysis and Assessment of Causal Effects. Journal of Marketing Research, 30(1), 63-77.

Churchill, Jr, G. A., Ford, N. M., Hartley, S. W., Walker Jr, O. C., 1985. The Determinants of Salesperson Performance: A Meta-Analysis. Journal of Marketing Research, 22(2), 103-118.

Collatz, A., Gudat, K., 2011. Work-Life-Balance. Göttingen: Hogrefe Verlag.

Deery, M., Jago, L., 2009. A Framework for Work-Life Balance Practices: Addressing the Needs of the Tourism Industry. Tourism and Hospitality Research, 9(2), 97-108.

Deery, M., Jago, L., Harris, C., Liburd, J., 2018. Work Life Balance for Sustainable Tourism Development. Collaboration for Sustainable Tourism Development, 151-167.

Greenhaus, J. H., Collins, K. M., Shaw, J. D., 2003. The Relation between Work-Family Balance and Quality of Life. Journal of Vocational Behavior, 63(3), 510-531.

Hämmig, O., Gutzwiller, F., Bauer, G., 2009. Work-Life Conflict and Associations with Work-and Nonwork-Related Factors and with Physical and Mental Health Outcomes: a Nationally Representative Cross-Sectional Study in Switzerland. BMC Public Health, 9(1), 435-439.

Heskett, J. L., Jones, T. O., Loveman, G. W., Sasser, W. E., Schlesinger, L. A., 1994. Putting the Service-Profit Chain to Work. Harvard Business Review, 72(2), 164-174.

Hoff, E. H., Grote, S., Dettmer, S., Hohner, H. U., Olos, L., 2005. Work-Life-Balance: Berufliche und Private Lebensgestaltung von Frauen und Männern in Hoch Qualifizierten Berufen. Zeitschrift für Arbeits-und Organisationspsychologie A\&O, 49(4), 196-207.

Lazarus, R. S., 1966. Psychological stress and the coping process.

Lin, J. H., Wong, J. Y., Ho, C. H., 2015. The Role of Work-to-Leisure Conflict in Promoting Frontline Employees' Leisure Satisfaction: Examining the Job Demand-Control-Support Model. International Journal of Contemporary Hospitality Management, 27(7), 1540.

Locke, E. A., 1969. What is Job Satisfaction?. Organizational Behavior and Human Performance, 4(4), 309-336. 
Lucia-Casademunt, A. M., García-Cabrera, A. M., Cuéllar-Molina, D. G., 2015. National Culture, Work-Life Balance and Employee Well-Being in European Tourism Firms: the Moderating Effect of Uncertainty Avoidance Values. Tourism \& Management Studies, 11(1), 62-69.

Maslow, A., Lewis, K. J., 1954. Maslow's Hierarchy of Needs. Salenger Incorporated, $14,987$.

McNall, L. A., Nicklin, J. M., Masuda, A. D., 2010. A Meta-Analytic Review of the Consequences Associated with Work-Family Enrichment. Journal of Business and Psychology, 25(3), 381-396.

Montada, L., 1998. Justice: Just a Rational Choice? Social Justice Research, 11(2), 81-101.

Murphy, F., Doherty, L., 2011. The Experience of Work life Balance for Irish Senior Managers. Equality, Diversity and Inclusion, 30(4), 252-277.

Padmanabhan, M., Kumar, S. S., 2016. Work-Life Balance and Work-Life Conflict on Career Advancement of Women Professionals in Information and Communication Technology Sector, Bengaluru, India. International Journal of Research-Granthaalayah, 4(6), 119-130.

Parkes, L. P., Langford, P. H., 2008. Work-life balance or work-life alignment? A test of the importance of work-life balance for employee engagement and intention to stay in organisations. Journal of Management \& Organization, 14(3), $267-284$.

Hacker, W., Richter, P., 2013. Psychische Fehlbeanspruchung: Psychische Ermüdung, Monotonie, Sättigung und Stress: Springer-Verlag.

Sachse, R., 1995. Der psychosomatische Patient in der Praxis: Grundlagen einer effektiven Therapie mit" schwierigen" Klienten: Kohlhammer.

Sun, X., Xu, H., Köseoglu, M. A., Okumus, F., 2020. How do Lifestyle Hospitality and Tourism Entrepreneurs Manage their Work-life Balance? International Journal of Hospitality Management, 85, 102-359.

Thompson, J. A., Bunderson, J. S., 2001. Work-Nonwork Conflict and the Phenomenology of Time: Beyond the Balance Metaphor. Work and Occupations, 28(1), 17-39.

Yang, J. T., 2010. Antecedents and Consequences of Job Satisfaction in the Hotel Industry. International Journal of Hospitality Management, 29(4), 609-619.

Yew, L. T., 2008. Job Satisfaction and Affective Commitment: A Study of Employees in the Tourism Industry in Sarawak, Malaysia. World Review of Entrepreneurship, Management and Sustainable Development, 4(1), 85-101.

Zopiatis, A., Constanti, P., Theocharous, A. L., 2014. Job Involvement, Commitment, Satisfaction and Turnover: Evidence from Hotel Employees in Cyprus. Tourism Management, 41, 129-140. 


\section{PRODUCTIVITY ANALYSIS OF LATVIAN COMPANIES USING ORBIS DATABASE}

\section{Olegs Krasnopjorovs, University of Latvia}

\section{Konstantins Kovalovs, University of Latvia}

Abstract. This research study uses ORBIS microdata at the company level to analyse productivity of 167 thousand economically active Latvian companies over 2011-2018. The aim of the study is twofold - to find factors consistently associated with productivity at the company level; and to recommend possible criteria for companies to receive a state support (from the view of enhancing aggregate productivity in the long term). Our research results show that productivity of Latvian companies is positively related to their size, age, as well as location closer to Riga and other big cities. However, there is a substantial within-group variation in productivity between companies. Multivariate regression results show that location, size, age and economic sector explain only up to $19 \%$ of productivity differences between companies. In addition, distribution of companies by productivity has a positive skewness. This suggests that there is a small number of highly productive companies, while for most companies the productivity is lower than the average. Finally, we propose three criteria for companies to receive a state support: (1) high relative productivity given size, age, sector and location; (2) belonging to a group of companies with a higher probability of survival; (3) carrying out a significant part of economic activity in areas with a high unemployment rate.

Keywords: productivity, micro data, ORBIS, company size, company age, company location.

JEL code: C31, L60, R32

Introduction

Economic slowdown resulted from the Covid-19 pandemics has increased the scale and scope of state support not only to households, but also to companies worldwide. In case of short-run lockdown, even a non-targeted broad support measures to companies are not likely to alter a medium term fiscal sustainability of the country. However, if the disease will appear persistent, there might be an increasing tension towards targeting support measures. Moreover, short-run state support to companies should ideally also enhance productivity developments in the longer term. State support should not be targeted to zombie companies which cannot function without a permanent state intervention, as income redistribution from productive companies to unproductive ones would negatively affect aggregate productivity of the economy. With this in mind we began analysing micro data of Latvian companies, aiming to propose such criteria for receiving a state support, which would be beneficial for longer term productivity developments.

In recent years, micro data has been increasingly used in scientific research, which is driven by both the increased availability of such databases and the increased computer capacity. Micro data provide an opportunity for in-depth research on topics for which only aggregated data were previously available. For instance, although aggregated data on productivity by economic sector are available, it is the micro data of particular companies that allow to analyze the productivity variance within a particular sector. Moreover, the use of company micro data allows analysing productivity in dimensions where aggregated data are not available - by company size, age and location. In addition, micro data allows the simultaneous assessment of the impact of all these factors on productivity of the company.

This research study employs company-level micro data from the ORBIS database. ORBIS is the world's largest company-level database maintained by Bureau Van Dijk, a subsidiary of Moody's Analytics. As of autumn 2020, it included about 375 million company data from several countries around the world. The main advantage of the database is that it collects information both on large listed companies and on small limited liability companies with only a few employees. ORBIS includes information on companies' financial indicators, number of employees, capital structure and many other indicators. ORBIS data are widely used in academic research. For example, Alviarez et.al. (2020) ass ess the role of firm productivity in cross-country income disparities. Ahmad et.al. (2020) examine whether the productivity of firms with foreign capital is higher compared to firms with local owners. OECD (2019) assesses the extent to which the digital transformation of EU countries has affected firm productivity. Opazo-Basáez et.al. (2018) found that car manufacturers that purposefully reduce emissions achieve higher productivity growth. Kancs and Siliverstovs (2016) show that research and development (R\&D) investments have a positive but nonlinear impact on firm productivity.

After checking ORBIS data representativity by sectors and regions for the case of Latvia, this research study estimates the links between the productivity of the company and its age, size, sector and location. The link between these factors and productivity is often examined in academic research. For example, De Kok et.al. (2006) assess the non-linear relationship between firm age and productivity. Coad et.al. (2016) examine whether younger firms are more focused on productivity-enhancing innovative solutions. Cucculelli and Mannarino (2019) study the effects of age and ownership on productivity. Biesebroeck (2005) concludes that firms with more employees also have higher productivity. Diaz and Sanchez 
(2008) explore the relationship between firm size and technical progress (and productivity). Aiello et.al. (2014) determine whether there is a close correlation between firm location, R\&D spending and productivity level. Yang (2020) compares the productivity and viability of firms located in large and small cities. Rizov and Walsh (2010) analyze productivity levels as a function of a firm's distance from the capital.

Based on established links between company productivity and its observable characteristics, we propose criteria which should be fulfilled by companies to receive a state support. When developing these criteria, we perform an additional analysis estimating the persistency of productivity at the company level over time, as well as estimating the probability of survival in different groups of companies (subject to size, age, sector, location and productivity level). Our proposed criteria target state support to companies which are able to achieve high relative productivity and have high probability of survival. Furthermore, these criteria not discriminate companies which have relatively low productivity due to objective reasons. Criteria also allow policy makers to prioritize job retention in areas with the highest unemployment prevalence.

It should be acknowledged that our proposed list of criteria is not exhaustive. First, criteria reflecting the short-term decrease of economic activity in the company (such as the magnitude of turnover decrease) are beyond the scope of this study. Second, incorporation of some important company indicators into criteria is precluded by the respective micro data unavailability. For instance, although export potential of the company and its engagement in R\&D activities are also important for maintaining the long-run potential of the economy, ORBIS database does not have export and R\&D data for Latvian companies; thus, analysis of these indicators is left for further research.

Research results and discussion

\section{Data description}

The ORBIS database contains information on 418 thousand Latvian companies in the period from 2011 to 2018/19 (some companies still do not have 2019 data). We narrow the sample of companies to those in which economic activity was observed for at least one year during 2011-2018 (about 167 thousand companies).

Economically active companies, information on which can be found in the ORBIS database, in 2018 covered more than 714 thousand workplaces, which is $79 \%$ of the total number of workplaces in the country. Most of these companies (covering about 630 thousand workplaces) also have data necessary to calculate productivity. In most sectors of the economy, the data on workplaces in the ORBIS database almost coincide with the respective data from Central Statistical Bureau of Latvia (CSB), with the exception of public administration and education (almost not covered by ORBIS). The ORBIS database is also representative in a regional breakdown, covering from two thirds of workplaces in Latgale, up to almost $90 \%$ in Pieriga.

In this study, productivity is defined as value added per employee. In turn, value added was calculated as a sum of corporate profits and personnel costs (companies, for which personnel costs were not available, these were considered to be $70 \%$ of the company's administrative costs; data on administrative costs come from Lursoft database). In order to obtain real productivity values (at 2015 prices), the nominal indicators (at current prices) were divided by gross domestic product deflator. Such productivity calculations are widely used in academic literature (e.g., Chevalier et al. (2012), Hadengue and Warrin (2013), Barnett et al. (2014)).

\section{Productivity of the company and its relation with size, age, location and sector}

Our research results imply that in Latvia productivity is positively related to the size of the company. For example, large companies (more than 250 employees) on average have by half higher productivity than the small ones (11-50 employees; Figure 1).

However, there is a significant variation in productivity within each group of companies. Particularly, productivity level in some micro companies (10 employees or less) is higher than in the majority of large companies. In addition, the distribution of productivity by companies is not symmetric. Instead, there is a positive asymmetry (i.e., the median productivity is lower than the average). A small number of companies have very high productivity, which significantly increases the average productivity level. For most of the companies, however, productivity is below the average. This is especially true in the group of large companies, where three quarters of employees are employed in companies with below-average productivity. 


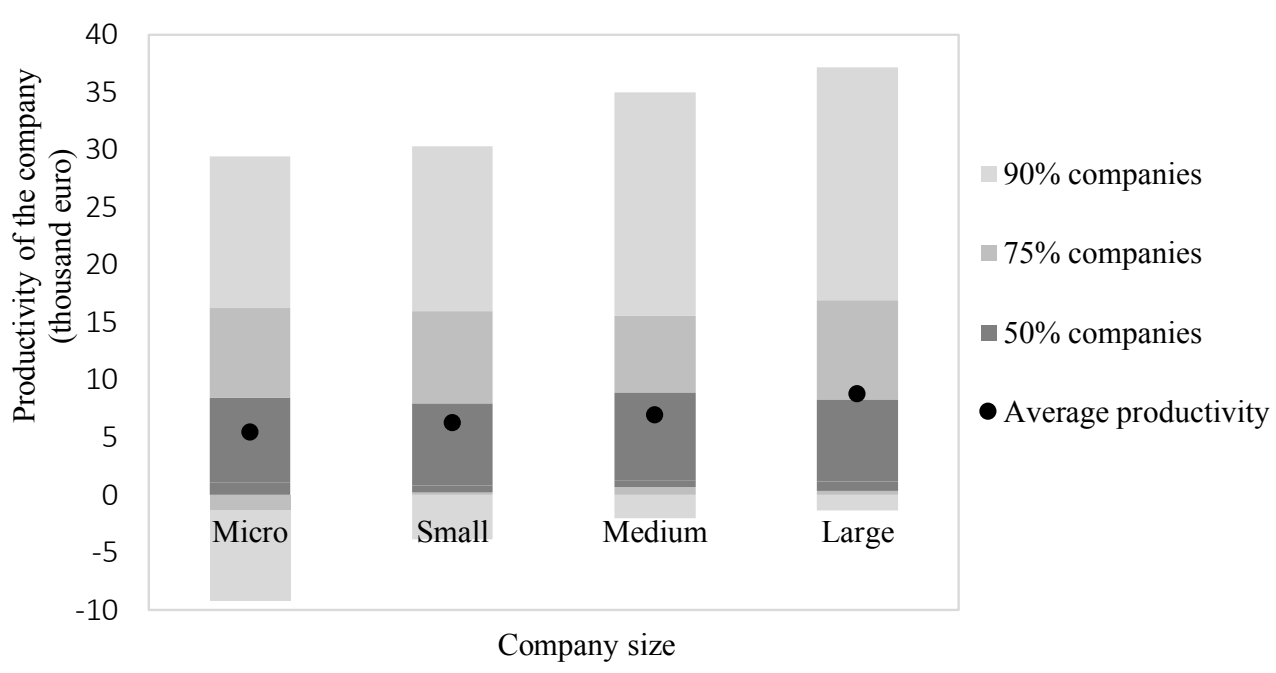

Source: authors' construction based on ORBIS micro data

Note. Companies are divided into four groups according to the number of employees: micro (10 employees or less), small (11 - 50 employees), medium (51 - 250 employees), large (more than 250 employees). Companies are weighted by the number of workplaces.

\section{Fig. 1. Productivity variation subject to company size (during 2015-2019 on average)}

Next, the relationship between productivity and the age of companies was examined. Our results show that the productivity of companies tends to increase with age, but the relation is not linear. In the first years of a company's operation, the level of productivity is usually relatively low, while it is the highest for companies aged 10-15 years (Figure 2). However, even in this case, there is a large variation in productivity in each group of companies, as well as a positive asymmetry in the distribution of companies (especially for companies older than 10 years). Thus, it can be concluded that although larger and older companies have higher productivity on average, age and size are not crucial productivity factors.

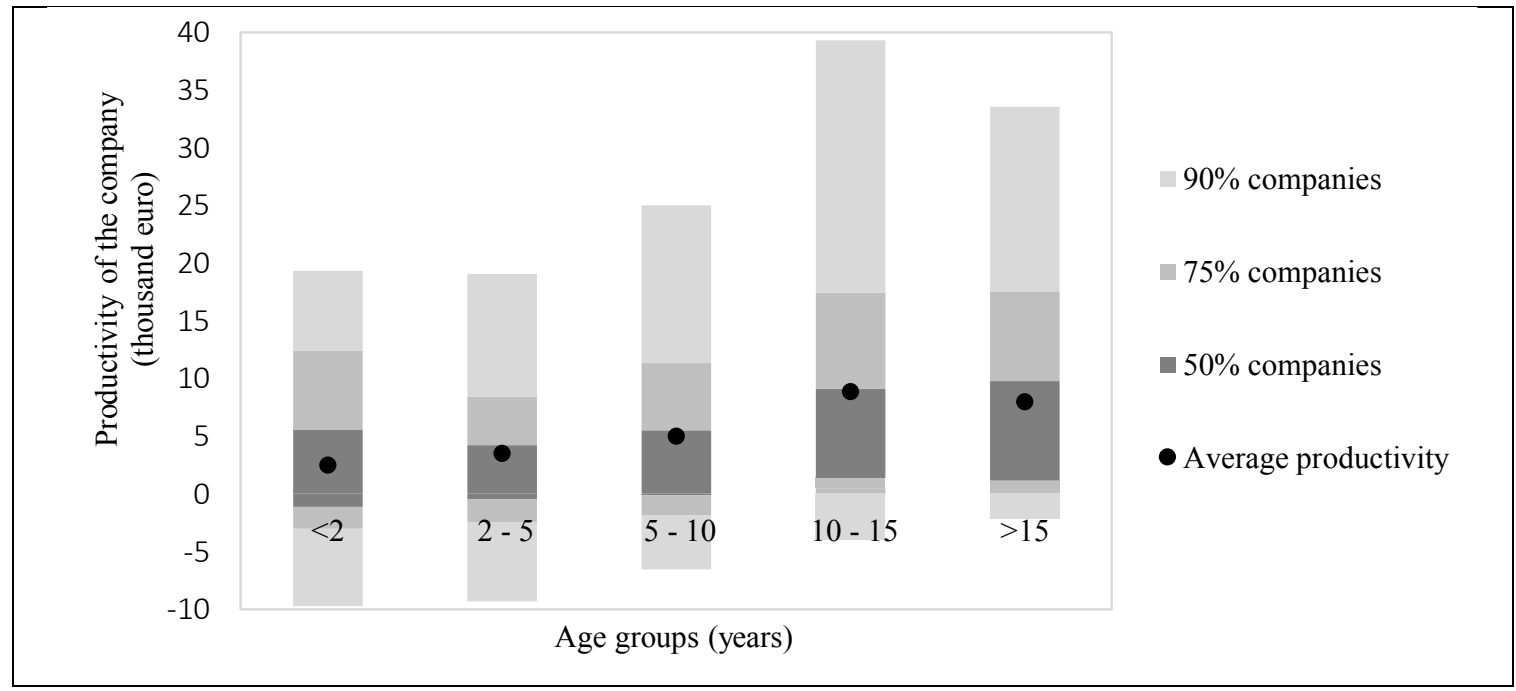

Source: authors' construction based on ORBIS micro data

Note. Companies are weighted by the number of workplaces.

Fig. 2. Productivity variation subject to company age (during 2015-2019 on average)

When analysing the relationship between productivity and the location of the company, the location was determined by the geographical coordinates of the postal code of the company's legal address. Although the legal address may not always reflect the place where economic activity is implemented (especially for large companies), the relation between the company's legal address and place of economic activity is also obvious. To determine the distance between the coordinate point for each of the 709 Latvian postal codes to Riga and to the nearest other big city (Daugavpils, Jekabpils, Jelgava, Jurmala, Liepaja, Rezekne, Valmiera, Ventspils) latitudes and longitudes were obtained with the Google Cloud Geocoding API service function. Then, the distance in kilometers was calculated using the Haversine formula.

Our research results imply that the productivity of companies is positively related to the location closer to Riga and other big cities. For example, the average level of productivity for a company located within a ten-kilometer radius from Riga center is almost twice higher than for a company 
located a hundred kilometers away from Riga. Also, a company located closer than ten kilometers from any big city is on average 1.6 times more productive than a company located more than 50 kilometers from a big city (Figure 3). However, also in these cases there is a significant variation of productivity (and a pronounced positive asymmetry) in each group of companies. Namely, both in Riga and in other regions, the productivity of most companies is lower than the average of respective group.

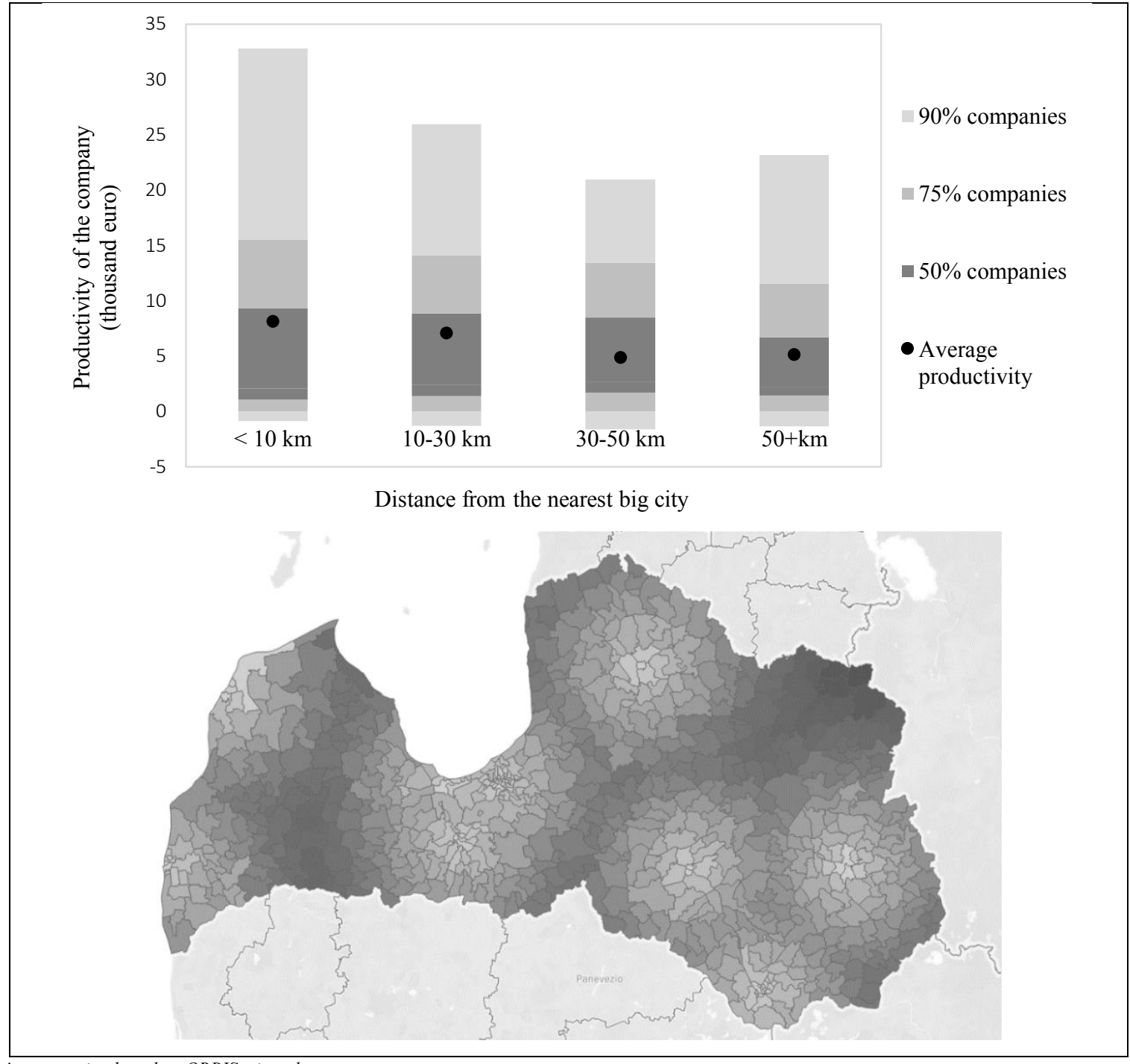

Source: authors' construction based on ORBIS micro data

Notes. The upper panel shows the productivity variation in different groups of companies subject to distance from a big city. The lower panel shows map with 709 separate postal codes and their distance to big cities (lighter colour reflets closer distance to big city). Companies are weighted by the number of workplaces.

Fig. 3. Productivity variation subject to company distance from a big city (during 2015-2019 on average)

ORBIS data also confirm that company productivity differs significantly even within a single economic sub-sector. For example, although the manufacturing of food products has, on average, a relatively modest level of productivity, some companies from this sub-sector are more productive than a typical company in pharmaceutical or wood sub-sectors (Figure 4). 


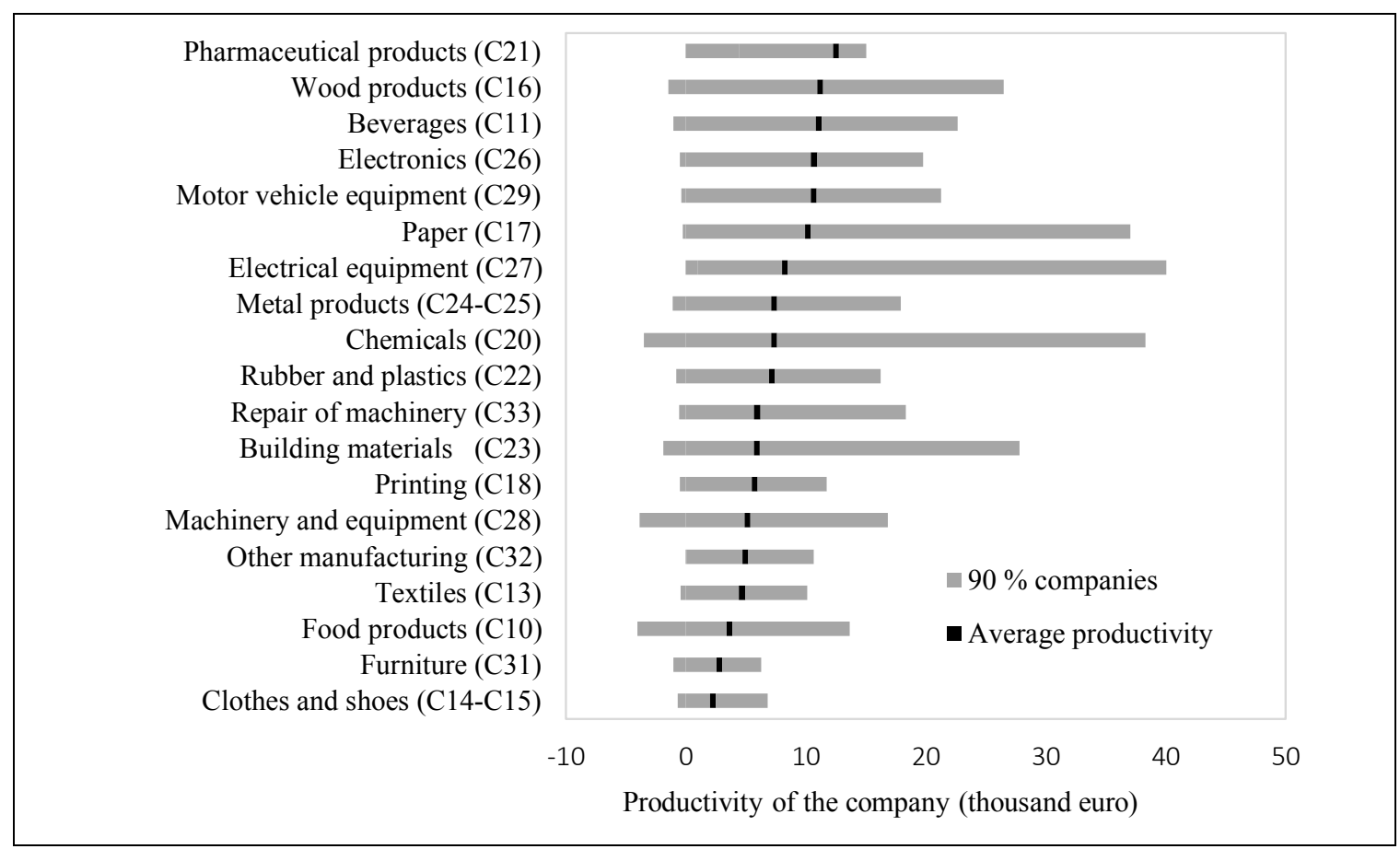

Source: authors' construction based on ORBIS micro data

Notes. Companies are weighted by the number of workplaces. The following companies were excluded (outliers, which significantly affected the average productivity): Elme Messer Metalurgs LLC, I.S.D. LLC (chemicals C20), SCHWENK Latvija LLC, Valmieras Stikla Skiedra JSC (building materials C23), KVV Liepajas Metalurgs JSC (metal products C24-25), EUROLCDS LLC, Mikrotikls LLC (electronics C26).

Fig. 4. Productivity variation of manufacturing companies by sub-sectors (during 2015-2018 on average)

Next, we analyse the simultaneous impact of all the above mentioned factors on productivity at the company level. Multifactor regression results confirm the negative correlation between productivity of the company and its distance from economic centres. For example, $1 \%$ additional distance from Riga is associated with lower productivity by about $0.12-0.15 \%$ (other factors holding unchanged; see Table 1). In turn, the size and age of a company have a positive but non-linear relationship with productivity. Particularly, the larger is the company, the less further increase in workforce is associated with higher productivity. The model assessment also took into account that companies in different sectors tend to have different productivity.

Results of multifactor regression model show that all the above factors together can explain only a small part of productivity differentials between the companies. When controlling by economic sectors, the model explains $10 \%$ of the differences in productivity (coefficient of determination; model 2), but without controlling economic sectors - only $2 \%$ (model 1). In models where companies were weighted by the number of workplaces (i.e., big companies have a greater impact on model results), the explanatory power is slightly higher - $4 \%$ without control of economic sector (model 3) and 19\% with control of economic sector (model 4). The use of a weighted regression is justified by the fact that in small companies productivity tends to be more affected by one-off factors. However, even in case of a weighted regression, largest part of productivity difference between companies remains unexplained.

Table 1

Factors associated with company productivity: multifactor regression model

Dependent variable: log (productivity of the company; average level over 2015 - 2018)

Companies are not weighted by the number of workplaces:

\begin{tabular}{|r|c|c|}
\hline & Model 1 & Model 2 \\
\hline $\log$ (kilometres from Riga) & $-0.123^{* * *}(-21.1)$ & $-0.153^{* * *}(-25.6)$ \\
\hline Number of workplaces & $0.000(1.0)$ & $0.001^{* * *}(4.3)$ \\
\hline Number of workplaces squared & $-0.000 \quad(-1.1)$ & $-0.000^{* * *}(-3.8)$ \\
\hline Company age (years) & $0.026^{* * *}(6.6)$ & $0.018^{* * *}(4.7)$ \\
\hline Company age squared & $-0.001^{* * *}(-4.9)$ & $-0.001^{* * *}(-5.4)$ \\
\hline Constant & $8.216^{* * *}(248.6)$ & $7.908^{* * *}(150.7)$ \\
\hline Economic sector & & Included \\
\hline Coefficient of determination (R2) & 0.02 & 0.10 \\
\hline Number of companies & 28271 & 28256 \\
\hline
\end{tabular}


Companies are weighted by the number of workplaces:

Source: authors' calculations based on ORBIS micro data

\begin{tabular}{|r|c|c|}
\hline & Model 3 & Model 4 \\
\hline $\log$ (kilometres from Riga) & $-0.121^{* * *}(-23.1)$ & $-0.136^{* * *}(-26.2)$ \\
\hline Number of workplaces & $-0.000^{* * *}(-13.6)$ & $-0.000^{* * *}(-10.9)$ \\
\hline Number of workplaces squared & $0.000^{* * *}(9.2)$ & $0.000^{* * *}(6.5)$ \\
\hline Company age (years) & $0.031^{* * *}(18.6)$ & $0.028^{* * *}(18.0)$ \\
\hline Company age squared & $-0.000^{* * *}(-5.1)$ & $-0.000^{* * *}(-5.8)$ \\
\hline Constant & $8.036^{* * *}(291.3)$ & $7.182 * * *(196.9)$ \\
\hline Economic sector & & Included \\
\hline Coefficient of determination (R2) & 0.04 & 0.19 \\
\hline Number of companies & 28271 & 28256 \\
\hline
\end{tabular}

Notes: table contains multifactor regression coefficient values (and t-values in parentheses).

Models exclude firms with missing value added or number of workplaces data over 2015-2018, firms with negative productivity, firms for which the year of establishment or legal address was not indicated. The economic sector is included at the NACE letter level.

$*, * *$ and $* * *$ defines statistical significance at $10 \%, 5 \%$ and $1 \%$ level respectively.

Therefore, it can be concluded that company productivity is positively related to the size and age of the company, as well as its location closer to Riga and other big cities. However, these factors are not crucial to firm productivity. Even when controlled by the economic sector, these factors can explain 10 to $19 \%$ of productivity differences between companies.

\section{Defining criteria for companies to receive a state support}

Our research results show that the level of productivity at the company level is persistent over time. This means that companies that were productive yesterday (with rare exceptions) are productive today; and the same companies are likely to show high productivity also tomorrow. For example, there is a positive and statistically significant correlation between the productivity of manufacturing companies during 2016-2018 and 2013-2015 (Figure 5).

This can also be seen when selecting 15 most productive manufacturing companies in 2018 and analysing the relative productivity of these companies during the previous years. Those manufacturing companies that were the most productive in 2018 also showed relatively high productivity over 2013-2017 (Table 2). For instance, LLC "Technics SA" (aircraft repair and maintenance) - the company with the highest productivity in 2018, has never fallen below the $3^{\text {rd }}$ place in the productivity rating over 2013-2017. LLC "Kronospan Riga" (production of veneer sheets and wood panels) with the $2^{\text {nd }}$ highest productivity in 2018, in the previous five years was never lower than the $8^{\text {th }}$ place, but LLC "Mikrotikls" (production of communication equipment) with the $3^{\text {rd }}$ place in 2018 - was never below the $6^{\text {th }}$ place. It should be noted that the total number of manufacturing enterprises for which it was possible to calculate the level of productivity for each of the years from 2013 to 2018 is almost four thousand. Thus, even the rank of 200 or 400 reflects a very high relative productivity (higher than $95 \%$ and $90 \%$ of all manufacturing companies for which data were available, respectively).

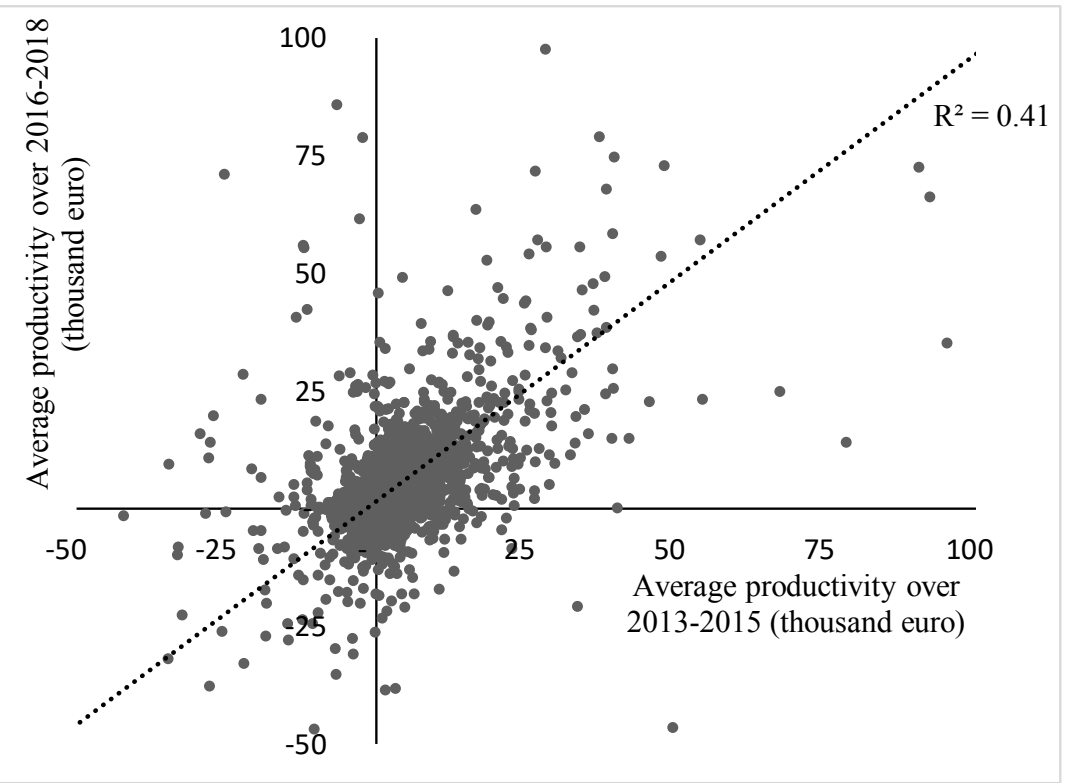

Source: authors' construction based on ORBIS micro data 
Fig. 5. Productivity of manufacturing companies over 2013-2015 and 2016-2018

Productivity rank of Latvian manufacturing companies during 2013 - 2018

(sample: 15 most productive companies in 2018)

\begin{tabular}{|l|l|c|c|c|c|c|c|}
\hline \multirow{2}{*}{ Company } & \multicolumn{2}{|c|}{ NACE sub-sector } & \multicolumn{5}{c|}{ Rank } \\
\cline { 3 - 8 } & & 2018 & 2017 & 2016 & 2015 & 2014 & 2013 \\
\hline Technics SA LLC & aircraft repair and maintenance & 1 & 1 & 3 & 2 & 3 & 1 \\
\hline Kronospan Riga LLC & manufacture of veneer sheets and wood panels & 2 & 3 & 4 & 8 & 7 & 5 \\
\hline Mikrotikls LLC & manufacture of communication equipment & 3 & 5 & 1 & 1 & 2 & 3 \\
\hline BSI Import LLC & repair of equipment & 4 & 31 & 75 & 107 & 45 & 299 \\
\hline & manufacture of electricity distribution and & & & & & & \\
Embedded Systems LLC & control apparatus & 5 & 6 & 9 & 15 & 22 & 48 \\
\hline Tibnor LLC & metal structures & 6 & 12 & 6 & 4 & 12 & 9 \\
\hline BMS Tehnologija LLC & repair of electronic and optical equipment & 7 & 8 & 8 & 12 & 34 & 19 \\
\hline Severstal Distribution LLC & metal surface treatment and coating & 8 & 10 & 24 & 75 & 193 & 45 \\
\hline Evolution Print LLC & printing of other publications & 9 & 52 & 20 & 17 & 28 & 61 \\
\hline Burlat LLC & repair of electronic and optical equipment & 10 & 173 & 201 & 215 & 287 & 80 \\
\hline Wonderwoord LLC & manufacture of other products of wood & 11 & 21 & 27 & 55 & 76 & 201 \\
\hline Vilomix Baltic LLC & manufacture of prepared feeds for farm animals & 12 & 15 & 36 & 31 & 33 & 78 \\
\hline JI Tehnologijas LLC & repair of other equipment & 13 & 14 & 81 & 120 & 14 & 397 \\
\hline Hansa Timber Trade LLC & sawing, planing and impregnation & 14 & 9 & 45 & 38 & 35 & 89 \\
\hline Ilstone LLC & manufacture nec & 15 & 93 & 87 & 206 & 373 & 347 \\
\hline
\end{tabular}

Source: authors calculations based on ORBIS microd

Note: manufacturing companies that were economically active every year from 2013 to 2018 were ranked in descending order of productivity (3998 companies in total).

Thus, our first proposed criterion for companies to receive a state support is that in the medium term the company has been able to achieve higher productivity than other similar companies (in the same size and age group, industry and location (distance from Riga and other large cities)).

This criterion ensures that state support is received mainly by those companies that are likely to show high productivity in the future (i.e., their financial difficulties are a short-term phenomenon). State support is not spent on preserving companies that are unproductive in the long term these companies are allowed to close down quickly; thus, to free up production factors (labour, capital and land) for more productive businesses. Thus, state support may not increase the share of zombie companies in the economy and does not support companies that cannot function without the state intervention in the long run.

Zombie companies and their detrimental impact on productivity are considered to be one of the causes of Japan's economic stagnation during the 1990s (Caballero et al., 2008). There is also evidence that the share of zombie companies in EU countries has increased significantly since the global financial crisis (Storz et al., 2017; Andrews and Petroulakis, 2019). The presence of zombie companies not only reduces the average level of productivity in the economy, but also slows down the development of productive companies, reducing their opportunities to invest, innovate and recruit new employees (Peek and Rosengren, 2005; Caballero et al., 2008).

At the same time, this criterion takes into account objective reasons why a given company's productivity is high or low. For example, this criterion stipulates that the threshold for granting state support (in terms of productivity) to small companies located far from Riga should be lower than to large companies located close to Riga. Similarly, beverage manufacturers should have a higher productivity threshold (to qualify for state support) than food manufacturers.

There has been a long academic discussion on whether state industrial policy should adapt to the existing comparative advantage of the economy or try to develop it in the desired direction (Lin and Chang, 2009). This criterion does not support one or another approach. Instead of supporting sectors in which Latvia already has a comparative advantage, or high-productivity sectors in which Latvia has the potential to develop its comparative advantage, this criterion offers support to companies that have already proven their high productivity. There are two reasons for this criterion, which result from the analysis of ORBIS micro data. First, the level of productivity at the company level is persistent over time. Second, the economic sector (as well as any factor by which companies can be divided into groups - size, age, location) tends to unite both companies with 
high productivity and companies with low productivity; thus, belonging to a certain group of companies does not yet guarantee high productivity in a particular company

An additional criteria should include a possibility that the company will go out of business soon after receiving a state support. The analysis of the ORBIS database shows that different companies have quite different probabilities of survival - depending on the industry, age, size, sector or even productivity level. For instance, across sectors, manufacturing companies have the highest probability of survival. Regarding company breakdown by size and age group, probability of survival is the highest for larger and older companies. Particularly, of all micro companies (ten employees and less) that were economically active in 2011 , only $86 \%$ remained economically active until 2018 , while in other size groups the rate of survival was at least $95 \%$. Of those companies that were less than two years old in $2011,82 \%$ remained until 2018 (compared to $91 \%$ of enterprises aged 15 and over). Thus, the second (additional) criterion for receiving state support is that the company belongs to a group of companies with a higher probability of survival. It should be noted that the probability of survival is positively and systematically related to the level of productivity, ensuring the consistency with the first (main) criterion. In particular, among the active companies in 2011 which showed negative productivity in the medium term, $81 \%$ remained until 2018 (compared to $90 \%$ with positive productivity).

When granting state support to companies, significant differences in the labour market situation in different regions of Latvia must also be taken into account. In high unemployment areas maintaining jobs is as important priority as promoting productivity. Latgale traditionally stands out with high unemployment - in several municipalities the number of unemployed registered with the State Employment Agency varies around 20\% of the working age population (corresponding to about $30 \%$ of the economically active population). Although during the Covid-19 outbreak the fastest unemployment increase was observed in large cities, the highest unemployment rate still remains in the municipalities located in the eastern part of the country. Thus, the third (additional) criterion for receiving state support is that a significant part of the company's economic activity is carried out in areas with a high unemployment rate.

Third criterion will allow companies operating in municipalities with a high unemployment rate to be eligible for state support even if their productivity is below a certain threshold. Note that this criterion includes precisely the place of the economic activity and not the legal address of the company, since the latter can be easily changed if such criterion will be introduced.

It should be noted also that the relative importance of the criteria may vary depending on the phase of the economic cycle. For example, the relevance of job retention increases during the economic crisis - this can be taken into account by increasing the weight of the unemployment criterion. In turn, in the expansion phase of the economic cycle, ensuring the long-term pace of economic development becomes more important, which can be promoted by redistributing the factors of production in favour of more productive companies (i.e., increasing the weight of the productivity criterion).

\section{Conclusions, proposals, recommendations}

\section{Conclusions:}

1. Productivity of Latvian companies is positively related to their size, age, as well as location closer to Riga and other big cities. For example, in large companies (more than 250 employees) productivity is by half higher than in small companies (11 - 50 employees). In the first years of a company's operation, the level of productivity is usually relatively low, while it is the highest for 10-15 years aged companies. Also, in a company located within a ten-kilometres radius from the center of Riga, productivity is almost twice higher than in a company located further than hundred kilometres from Riga.

2. There is a significant variation in productivity in all the above groups of companies. Multivariate regression results show that location, size, age and economic sector explain only up to $19 \%$ of productivity differences between companies in the medium term.

3. Productivity distribution of companies has a positive skewness. This suggests that there is a small number of highly productive companies, while for most companies the productivity is lower than the average. For example, in the group of large companies, three quarters of employees are employed in companies with productivity lower than the average.

\section{Proposals and recommendations:}

Based on this study, three criteria for companies to receive a state support (from the point of view of enhancing aggregate productivity) are defined: 1. First (main) criterion - in the medium term the company has been able to achieve higher productivity than other similar companies (in the same size and age group, industry and location (distance from Riga and other Republican cities)). This criterion is justified both by the fact that belonging to a certain group of companies does not guarantee high productivity, as well as given that company productivity level is persistent over time. This 
main criterion ensures that state support is received by the companies which are highly likely to show high productivity in the future. State support is not spent on companies that are unproductive in the long term. At the same time, objective reasons for differences in productivity are taken into account - receipt of state support does not discriminate, for instance, small and young companies located far from Riga.

2. Second (additional) criterion - the company belongs to a group of companies with a higher probability of survival. The results of this study show that survival probability is higher for manufacturing companies, as well as older companies with more than ten employees.

3. Third (additional) criterion - a significant part of economic activity in the company is carried out in areas with high unemployment rate. The third criterion takes into account significant labour market differences between Latvian municipalities and allows policy makers to prioritize job retention in areas with the highest unemployment prevalence.

\section{Bibliography}

Ahmad S., Oliver S., Peters C., 2020. Can Trade Barriers Explain Productivity Differences Between Foreign and Domestic Servic es Firms? U.S.
International
Trade
Commission
Working
Paper
$\mathrm{Nr}$.
2020-05-B

https://www.usitc.gov/publications/332/working_papers/trade_barriers_productivity_differences_services_2020-05-b.pdf

Aiello, F., Pupo, V., Ricotta, F., 2014. Explaining Total Factor Productivity at Firm Level in Italy: Does Location Matter? Spatial Economic Analysis, 9(1), 51 - 70. https://www.tandfonline.com/doi/pdf/10.1080/17421772.2013.863428?needAccess=true

Alviarez, V.I., Cravino, J., Ramondo, N., 2020. Firm-Embedded Productivity and Cross-Country Income Differences. NBER Working Paper 27915, National Bureau of Economic Research. https://www.nber.org/system/files/working_papers/w27915/w27915.pdf

Andrews, D., Petroulakis, F., 2019. Breaking the Shackles: Zombie Firms, Weak Banks and Depressed Restructuring in Europe. European Central Bank Working Paper No. 2240. https://www.ecb.europa.eu/pub/pdf/scpwps/ecb.wp2240 61e2d9dfec.en.pdf

Barnett, A., Chiu, A., Franklin, J., Sebastia-Barrel, M., 2014. The Productivity Puzzle: A Firm-Level Investigation into Employment Behaviour and Resource Allocation Over the Crisis. Bank of England Working Paper No. 495, pp. 1 - 36. https://www.bankofengland.co.uk//media/boe/files/working-paper/2014/the-productivity-puzzle-a-firm-level-investigation-into-employment.pdf

Biesebroeck, J., 2005. Firm Size Matters: Growth and Productivity Growth in African Manufacturing, Economic Development and Cultural Change, 53(3), 545 - 583. https://www.jstor.org/stable/10.1086/426407?seq=1

Caballero, R., Hoshi, T., Kashyap, A., 2008. Zombie Lending and Depressed Restructuring in Japan, American Economic Review, 98(5), 19431977. https://www.aeaweb.org/articles?id=10.1257/aer.98.5.1943

Chevalier, P.-A., Lecat, R., Oulton, N., 2012. Convergence of Firm-Level Productivity, Globalisation, Information Technology and Competition: Evidence from France, Economics Letters, 116(2), 1 - 44. https://www.sciencedirect.com/science/article/abs/pii/S0165176512000626.

Coad, A., Segarra, A., Teruel, M., 2016. Innovation and Firm Growth: Does Firm Age Play a Role? Research Policy, $45(2), 387$ - 400. https://www.sciencedirect.com/science/article/abs/pii/S0048733315001687.

Cucculelli, M., Mannarino, L., Pupo, V., Ricotta, F., 2014. Owner-Management, Firm Age, and Productivity in Italian Family Firms, Journal of Small Business Management, 52(2), 352 - 343. https://www.tandfonline.com/doi/abs/10.1111/jsbm.12103.

De Kok, J., Brouwer, P., 2006. On the Relationship Between Firm Age and Productivity Growth, Scientific Analysis of Entrepreneurship and SMEs,

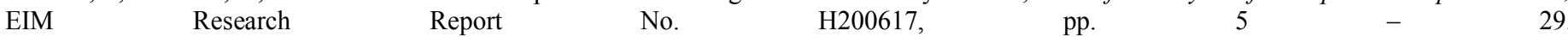
https://www.researchgate.net/publication/5012594_On_the_relationship_between_firm_age_and_productivity_growth.

Diaz, M. A., Sanchez, R., 2008. Firm Size and Productivity in Spain: a Stochastic Frontier Analysis, Small Business Economics, $30(3), 315$ - 323. https://www.jstor.org/stable/40650914?seq=1.

Hadengue, M., Warrin, T., 2013. Patterns of Specialization and (Un)Conditional Convergence: The Cases of Brazil, China and India, CIRANO Scientific Publications, 17, 1 - 31. https://papers.ssrn.com/sol3/papers.cfm?abstract_id=2326584.

Kancs, A., Siliverstovs, B., 2016. R\&D and Non-linear Productivity Growth. Research Policy, 45(3), 634-646. https://doi.org/10.1016/j.respol.2015.12.001.

Lin J., Chang H-J., 2009. Should Industrial Policy in Developing Countries Conform to Comparative Advantage or Defy it ? A Debate Between Justin Lin and Ha-Joon Chang. Development Policy Review, 27(5), 483-502. https://doi.org/10.1111/j.1467-7679.2009.00456.x.

OECD, 2019. Digitalisation and Productivity: In Search of the Holy Grail - Firm-level Empirical Evidence From EU countries. OECD Economics Department Working Paper Nr. 1533. https://doi.org/10.1787/18151973. 
Opazo-Basáez M., Vendrell-Herrero F., Bustinza O.F., 2018. Uncovering Productivity Gains of Digital and Green Servitization: Implications from the Automotive Industry. Sustainability, 10, 1524; https://www.mdpi.com/2071-1050/10/5/1524/pdf.

Peek, J., Rosengren, E., 2005. Unnatural Selection: Perverse Incentives and the Misallocation of Credit in Japan. American Economic Review, 95(4), 1144-1166. https://www.aeaweb.org/articles?id=10.1257/0002828054825691.

Rizov, M., Walsh, P. P., 2011. Is There a Rural-Urban Divide? Location and Productivity of UK Manufacturing, Regional Studies, 45(5), 641 656. https://www.tandfonline.com/doi/pdf/10.1080/00343401003713449?needAccess=true.

Storz, M., Koetter, M., Setzer, R., Westphal, A., 2017. Do We Want These Two to Tango? On Zombie Firms and Stressed Banks in Europe. European Central Bank Working Paper No 2104. https://www.ecb.europa.eu/pub/pdf/scpwps/ecb.wp2104.en.pdf.

Yang, Y., Mukhopadhaya, P., Yu, Z., 2020. Relationship Between City Size and Firm Productivity - a New Interpretation Using the Chinese Experience. Economic Modelling, 93, 546 - 558. https://www.sciencedirect.com/science/article/abs/pii/S0264999320311937.

\section{Acknowledgement}

The research was supported by the national research programme project "Towards the Post-pandemic Recovery: Economic, Political and Legal Framework for Preservation of Latvia's Growth Potential and Increasing Competitiveness ("reCOVery-LV")" (VPP-COVID-2020/1-0010). 


\title{
THE IMPACT OF TRUST IN A VIRTUAL TEAM ON INDIVIDUAL SATISFACTION AND TEAM PERFORMANCE
}

\section{Matthias Kretschmar, Fulda University of Applied Sciences}

\begin{abstract}
Modern economies are very much characterized by an increasingly virtual working environment. Information technologies foster the possibilities to organize work in groups consisting of team members who do not necessarily have direct contact with each other. This development has been accelerated in the current Covid-crisis which requires virtual teamwork to an extent that was not known before. An antecedent for working in virtual teams is a certain degree of mutual trust of the team members organizing themselves without having direct contact with and control over their teammates.

In contrast to most other publications on trust, this paper focuses on team members' trust into their own team and relates their team trust to their satisfaction with their teamwork and team performance. It will be shown that team members who have trust into their own team are more satisfied with the teamwork than people who have a lower degree of trust into their team. Contractionary to initial expectations, no statistically significant relation between trust into the team and team performance could be observed.
\end{abstract}

The study was conducted with 24 virtual student teams which worked on several group assignments. The data was analysed in a structural equation model (Smart PLS3).

Keywords: teamwork, trust, satisfaction, performance.

JEL code: M54, D83

\section{Introduction}

As part of the increasing worldwide division of labour and with the possibilities that modern electronic communication channels provide, people are increasingly faced with the challenges of working in virtual teams. This does not only apply to business environments but also to learning environments. When work is divided between the members of a virtual team and everyone takes on specific tasks that are crucial for the success of the team, decisions must be taken mutually, different opinions must be dealt with and the success of the teamwork depends on the efforts of the individual team members. An antecedent for teamwork is trust. In teamwork, a certain degree of trust into the team must be developed. In this study it will be investigated how team trust impacts team performance and team satisfaction.

The study was conducted with students of Fulda University of Applied Sciences who worked in virtual teams in summer semester 2020. The team members had to co-operate during the lockdown situation due to the Covid-crisis in the spring of 2020. Therefore, they were forced to team up virtually and did not have the possibility to get into direct contact. This allows to transfer the results of this study also on teamwork situations in large, multinational organizations.

\section{Literature Review}

\section{Concept of Trust}

Every commercial transaction also contains an element of trust, especially when it is conducted over a period of time. This applies in particular in financial markets, where people part with their money in exchange for promises (Sapienzia \& Zingales, 2012). However, although trust is central to all transactions, economists often do not discuss the term in depth in their research and there is a heterogeneity of concepts of trust in management and economic literature (Castaldo et al., 2010).

An often-cited definition in literature refers to trust as "a psychological state comprising the intention to accept vulnerability based upon positive expectations of the intentions and behavior of another" (Rousseau et al., 1998). The key elements of that definition, the intention to be vulnerable and the positive expectations regarding the behaviour of the trustor, are both rooted in several earlier conceptualizations of trust (Colquitt et al., 2007). This concept implicitly relates trust to the acceptance of risk as risk is inherent in vulnerability (Mayer \& Gavin, 2005). These definitions do not directly connect the concept of trust to possible consequences, which can be of various types of risk-taking of the trustor, like cooperation, sharing sensitive information, and voluntarily allowing the trustee control over issues that are important to the trustor (Mayer \& Davis, 1999).

Other views on trust do not explicitly refer to vulnerability, but simply conceptualize trust as one party having confidence in an exchange partner's reliability and integrity (Morgan \& Hunt, 1994), or trust is defined as willingness to rely on an exchange partner in whom one has confidence (Moorman et al., 1992; Colquitt \& Rodell, 2011). Trust in that sense can be seen as an expectation that the trustee can be relied upon to fulfil obligations, and that she/he will negotiate and behave in a predictable way, even when the possibility for opportunism exists (Zaheer et al., 
1998). It is the willingness to ascribe good intentions to and have confidence in the counterpart (Cook \& Wall, 1980). One step further is the definition of trust rather with regard to its results, like Anderson's and Narus' $(1986,1990)$ concept which refers to trust as the belief that another party will perform actions that will result in positive outcomes for the trustor and will not take unexpected actions that would result in negative outcomes.

Considering the different recurring dimensions in research, a multifaceted definition of trust shall be applied for this study. It is based upon a meta content analysis on conceptualizations of trust by Castaldo et al. (2010). Trust is defined as the trustor's expectation that a trustee, distinguished by specific characteristics, will perform future actions aiming at positive results for the trustor in situations characterized perceived risk and vulnerability (Castaldo et al., 2010).

\section{Trust in a Team}

Most conceptualizations of trust are based upon the view that a person trusts a third party. But trust can also emerge in teamwork situations which shifts the perspective because trust within a team is driven by each individual team member's perception of how the other teammates positively contribute to the team (Dennis et al., 2012). This perspective might be taken on an individual level (team member's trust into her/his team) or on team level. The second can be described as intraorganizational or intrateam trust and is the aggregation of the interpersonal levels of trust that team members have about each other (De Jong et al., 2016; Langfred, 2004). It is a generalized expectation for all fellow teammates (De Jong \& Elfring, 2010). These two perspectives of trust from a team members' perspective on her/his team are illustrated in figure 1 on the righthand side. On the left side of the table, a person's trust into another person (individual trust) and in an organization she/he is not part of (organizational trust) is shown.

The object of trust is marked in grey. Individual trust's object is another person whereas in organizational trust the focus of trust is laid upon the whole organization. It is established via the boundary-spanning roles of the trustor and her/his main contact person who represents the organization which is trusted (Perrone et al., 2003). An individual team member's trust in her/his team is derived from the individual perception of the degree of trust she/he can place into the fellow teammates. In the intrateam trust perspective the team members are both subjects and objects of trust.

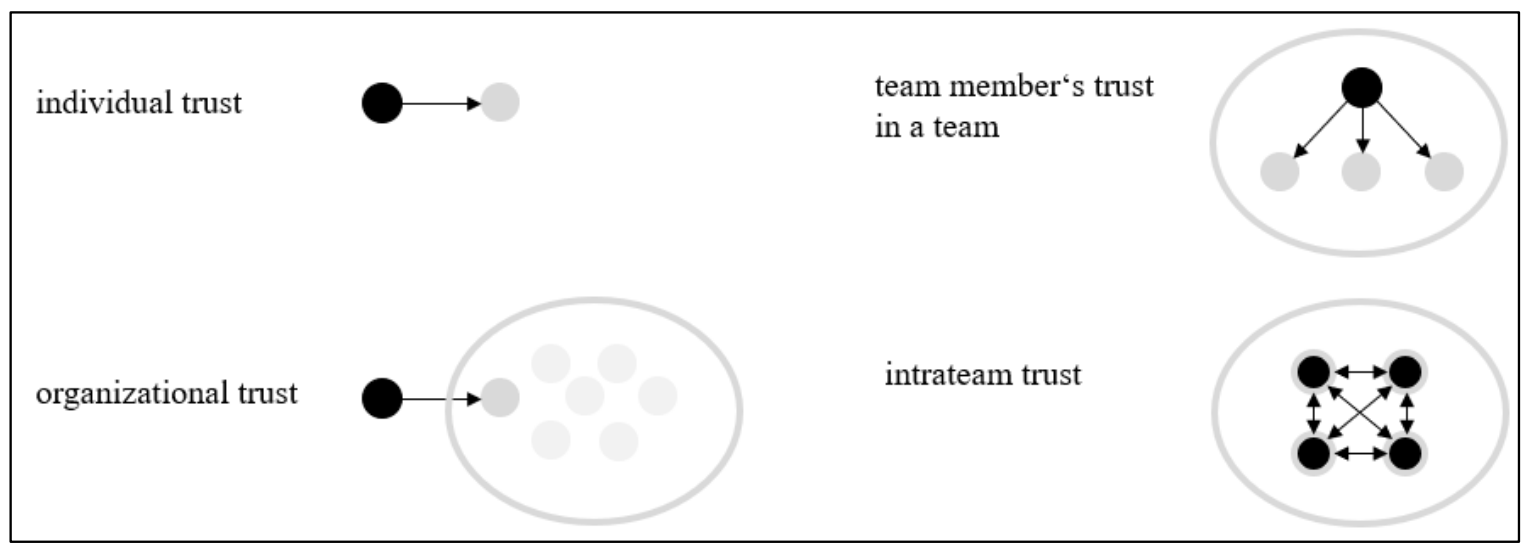

Source: figure created by the author

Fig. 1. Subjects and objects in different conceptualizations of trust

As a trustor can only be an individual and not a group and intrateam trust is just an aggregation of individual trust levels of team members, this study focuses on the individual team member's trust in her/his team. This is especially appropriate for this study as the team member's trust in a team will be related to her/his satisfaction with the outcome of teamwork.

\section{Satisfaction with Teamwork}

Working in teams brings up social-emotional psychological benefits that let team members assume that working in teams helps to perform well. Such benefits are the perception of affiliation and the possibility of social comparison, (in most cases) general enjoyment, and the reduction of the individual's uncertainty (Allen \& Hecht, 2004). But, as teamwork requires interaction and agreement when making decisions, it might also potentially lead to conflicts if views and opinions on a topic differ and make additional effort of the team members necessary (De la Torre-Ruiz et al., 2014). So, teamwork is not per se only positively connected with individual satisfaction of the team members. 
There are two different perspectives that are employed in studies on team or group satisfaction. Many studies view team satisfaction as satisfaction within a group derived from individual data which is aggregated in the study to the group level (De Dreu \& Weingart, 2003). Another view is the individual's perception of her/his satisfaction with the team. Individual satisfaction with the team refers to positive feelings that team members have which lead to their willingness to work in the same team again (Medina, 2015). It is related to the composition of the team and to the experienced co-operation within the team. If these two constituents are positively perceived by the team member she/he is satisfied and willing to work on future tasks in that team constellation (Peeters, 2006). This definition of team a member's individual satisfaction with the team can be regarded as one aspect of job satisfaction that regards the co-workers (Peeters, 2006). Therefore, findings in this this study on student groups might also help to understand satisfaction of team members within larger organizations.

Another aspect which is often assigned to the satisfaction with the team is the individual's assessment of the accomplishments of the team's tasks which is referred to as instrumental satisfaction. (Nerkar et al., 1996). Satisfaction with the team's accomplishment of milestones in a project helps to further motivate the team members to contribute to the future success of their team as they regard the teamwork as worthwhile (Furumo et al., 2009). But there is also an aspect of egocentric satisfaction, which arises when the team member is assessing potential individual rewards of working in the team. (Nerkar et al., 1996).

In this study, satisfaction is defined as the individual team member's satisfaction with the team which is derived from her/his perceived satisfaction with the group co-operation when working on the group's assignments and her/his view on the fulfilment of tasks and personal objectives with the group.

\section{Team Performance}

Whenever team performance is conceptualized, it must be seen in the context of the types of teams and tasks that shall be studied. Measures for the assessment of team performance must be customized accordingly (Kendall \& Salas, 2004). The level of team performance comprises the extent of accomplishment of assigned work, the extent to which the capabilities of the group as such improve, and the extent to which the individual wellbeing of the group members improves (Hackman \& Katz, 2010).

But team performance can alternatively be seen in a wider sense as a cycle of input (composition of the team, and definition of the team's task), processes within the team, and tangible as well as intangible output produced by the team, which in turn implies that both team processes and outcomes should be taken into account when measuring team performance (Kendall \& Salas, 2004).

Nevertheless, for the purpose of this study, performance is defined as the quality of the output of the teamwork. Team processes are not included in this study as this rather applies to teams which are established for a longer period of time (which was not the case in this study). This is in line with recent research in marketing and management literature on the relationship between trust and performance, which often focus on the quality of the team output (e.g. decision, product) (Morrissette \& Kisamore, 2020).

\section{Development of Hypotheses}

It can be assumed that trust in (virtual) teams is related with positive team experience and satisfaction. Trusting team members discuss and resolve problems which might arise in the course of their teamwork more effectively (Furumo et al., 2009). The definition of trust includes the trustor's expectations that the trustee's future actions are aiming at positive results for the trustor. This should support the view that a person trusting her/his team should be more satisfied with the teamwork. Therefore, the first hypothesis is:

H1: Individual trust of a team member into the team is positively associated with individual satisfaction with the team.

As outlined already, a climate of trust in a team is an environment where the trustee can be relied upon to fulfil obligations, will behave in a predictable manner, and will act and negotiate fairly (Zaheer et al., 1998). This should relate trust within a team to positive team results. In a recent meta study, covering 55 independent studies between 1996 and 2019, Morrissette \& Kisamore (2020) have shown that high levels of trust in business teams generally lead to higher team performance. This observation should also be applicable for virtual student teams. This suggests:

H2: $\quad$ Individual trust of a team member into the team is positively associated with team performance.

\section{Research Results}

\section{Research Model}

The research was conducted with a partial least squares structural equation model. The structure model relates the individual trust of the students in their team with (1) their individual satisfaction with the experiences they had with the teamwork and (2) with the team's performance. 
In the measurement model, individual trust and individual satisfaction are measured reflectively. The performance of the teams are measured by the aggregated grades given to the group works the respective students participated in. The model is visualized in figure 2 . The endogenous latent variables "trust in team" and "satisfaction with teamwork" point at the indicators that are shown in the rectangles with arrows.

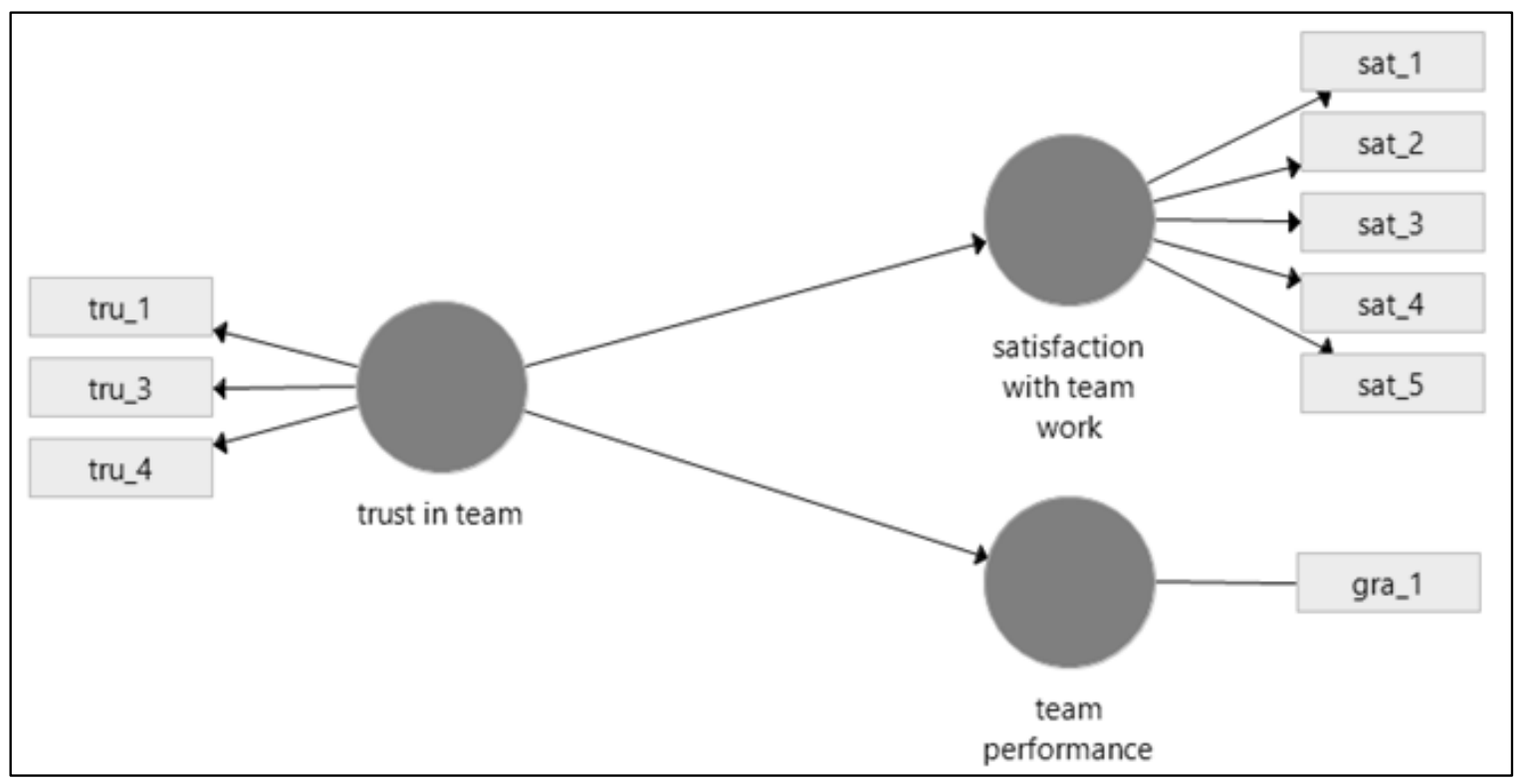

Source: figure created by the author with SmartPLS3

Fig.2. Structure Model /Inner and Outer Model

\section{Survey}

In the summer semester of 2020, on-campus lectures were prohibited due to the Corona pandemic. This implied a remote learning environment at Fulda University of Applied Sciences. In two "management" (Unternehmensführung) courses with 95 advanced bachelor students, the teaching concept in that semester was based upon several group works, which had to be dealt with by students in virtual teams. The composition of the 24 student teams had been set up randomly and the students did not have the possibility to change from one group to another during the whole semester. All group assignments were graded on group level and were part of the final grade of each student.

After their last group assignment, the students were asked to complete a questionnaire to understand how their individual trust into their virtual team had been during the course and how satisfied they were individually with their team. Additionally, their group performance was measured by the average grade they attained with their teamwork assignments. 88 students participated in an online survey in June 2020. With a sample size of 95 this represents a $92,6 \%$ response rate. The questions in the questionnaire were in German language.

\section{Measures}

\subsection{Individual Trust in the Team}

To measure the team members' trust into their team, a reflexive measurement model developed by Robert and You (2018) was used. They used Likert-scale items to measure individual trust toward one's team, taking items from Jarvenpaa et. al. (1998) and Schoorman et al. (1996). The Likertscale ranges from 1 which expresses strong disagreement to 7 which stands for strong agreement. Cronbach's alpha of that measurement model was 0.92 and the factor loadings of the items were between 0.82 and 0.894 for the following 4 questions to measure the construct of individual trust:

1. If I had my way, I wouldn't let the other team members have any influence over issues that are important to the project. (reverse scored)

2. I would be comfortable giving the other team members complete responsibility for the completion of this project.

3. I really wish I had a good way to oversee the work of the other team members on the project. (reverse scored)

4. I would be comfortable giving the other team members a task or problem which was critical to the project, even if I could not monitor them.

The questions reflect the comprehensive definition of trust which refers to the willingness to be vulnerable based on the expectation that the trustee will perform future actions irrespective if the trustor can monitor the action (Schoorman et al., 1996) Or, "in short, trust is based on the expectation that others will behave as expected" (Jarvenpaa et al., 1998). In contrast to above mentioned questions by Robert \& You (2018) the statements in the questionnaire for this study were formulated as retrospect views on the project ([trust_1] - [trust_4]).

\subsection{Individual satisfaction}


Individual Satisfaction was measured reflexively on a Likert-scale (1-7). Again, the questions were based on a study by Robert \& You (2018) that adapted items from Jarvenpaa et al. (2004). The factor loadings of the questions regarding the individual satisfaction range from 0,87 and 0,911. The Cronbach's alpha for that construct was 0.95 . The questions in the survey were as follows.

5. I was satisfied with how we completed the team project.

6. Overall, this team project was a good experience.

7. I was satisfied with the overall "team experience" during this project.

8. Looking back, I was pleased with how we completed the team project.

9. I enjoyed the process we used to complete the team project.

The word "team project" was replaced by "project" in the questionnaire as the word "team" was redundant in the context of this study ([sat_1] [sat_5]).

\subsection{Team Performance}

Performance was regarded as the quality of the output of the work in the team. The performance is reflected in the weighted aggregated grades [gra_1] attained from the different group works in this course. This is in line with other studies assessing an academic team by the quality of its output, like e.g. a study on academic teams by Braun et al. (2013) which operationalizes the performance by the teams' number of publications in peer-reviewed journals weighted by journal impact factor. The grades are based on the grading system at German universities ranging from 1,0 (best grade) to 5,0 (worst grade). For the purpose of this analysis the grades were reverse-coded.

\section{Results}

\subsection{Measurement Model}

The validity and reliability of the measurement model was assessed with SmartPLS3. The constructs showed a satisfactory internal reliability with Cronbach's alpha of 0.705 for trust in team. Satisfaction with team's Cronbach's alpha of 0.926 was even higher but still below the 0.95 threshold that would indicate redundancy of the items. The same recommended thresholds and the same interpretation of the results presented in table 1 apply to the composite reliability (Hair et al., 2017), a measure which, unlike Cronbach's alpha, does not assume that all indicators are equally reliable, making it more suitable for partial least squares structural equation models, according to Hair et al. (2011). The indicators' reliability was confirmed by satisfactory factor loadings, except for [trust_2] with a loading of 0.64 which was in consequence eliminated from the model. As can be seen in table 1 all other factor loadings of the indicators in the two latent variables trust in team and satisfaction with teamwork were above 0.754 .

The convergent validity of this construct is confirmed by the Average Variance Extracted (AVE) indicating that that the constructs explain more than $62,9 \%$ and $77.0 \%$ of the respective variance of the constructs' latent variables which is above the generally accepted minimum $50 \%$ threshold.

The discriminant validity was measured by the heterotrait-monotrait (HTMT) ratio of the correlations using the bootstrapping approach with 5.000 subsamples and 300 iterations. All HTMF values were significantly different from 1.00 confirming the discriminant validity. All indicators' cross loadings with the other constructs were lower than with its associated latent construct.

Reflexive Measurement Model Results

\begin{tabular}{|c|c|c|c|c|c|c|}
\hline \multirow{2}{*}{$\begin{array}{c}\text { latent } \\
\text { variable }\end{array}$} & \multirow{2}{*}{ indicators } & \multicolumn{2}{|c|}{ convergent validity } & \multicolumn{2}{|c|}{$\begin{array}{c}\text { internal consisteny } \\
\text { reliability }\end{array}$} & \multirow{2}{*}{$\begin{array}{c}\begin{array}{c}\text { discriminat } \\
\text { validity }\end{array} \\
\text { HTMT }\end{array}$} \\
\hline & & loadings & AVE & $\begin{array}{l}\text { composite } \\
\text { reliability }\end{array}$ & $\begin{array}{c}\text { Cronbach's } \\
\text { alpha }\end{array}$ & \\
\hline \multirow{3}{*}{ trust in team } & tru_1 & 0.832 & \multirow{3}{*}{0.629} & \multirow{3}{*}{0.836} & \multirow{3}{*}{0.705} & \multirow{3}{*}{$\begin{array}{l}\text { confidence } \\
\text { intervals do } \\
\text { not include } 1\end{array}$} \\
\hline & tru_3 & 0.754 & & & & \\
\hline & tru_ 4 & 0.791 & & & & \\
\hline \multirow{5}{*}{$\begin{array}{c}\text { satisfaction } \\
\text { with team work }\end{array}$} & sat_1 & 0.894 & \multirow{5}{*}{0.770} & \multirow{5}{*}{0.944} & \multirow{5}{*}{0.926} & \multirow{5}{*}{$\begin{array}{l}\text { confidence } \\
\text { intervals do } \\
\text { not include } 1\end{array}$} \\
\hline & sat_2 & 0.819 & & & & \\
\hline & sat_3 & 0.903 & & & & \\
\hline & sat_4 & 0.871 & & & & \\
\hline & sat 5 & 0.896 & & & & \\
\hline
\end{tabular}


Source: table created by the author

The manifest variable group performance was measured by the weighted average grade for the group assignments the student participated in.

\subsection{Structural Model}

The predictive accuracy of the model regarding the satisfaction with teamwork is moderate with a coefficient of determination $\left(\mathrm{R}^{2}\right)$ of 0.384 , which suggests that trust in team can explain $38,4 \%$ of the effects on the dependent variable satisfaction with the teamwork. But $\mathrm{R}^{2}$ must be seen in the context of the number of predicter constructs. In this model only one construct is regarded to explain the satisfaction with the team and in this context this study's $\mathrm{R}^{2}$ can be seen as being is in line with the outcome of other studies like e.g. a study by Matzler \& Renzl (2006) which predicts employee satisfaction only with elements of trust (faith in management and faith in peers) and comes up with an $\mathrm{R}^{2}$ of 0.37 . The cross-validated redundancy $\left(\mathrm{Q}^{2}\right)$ of 0.278 indicates the path model's predictive relevance for this construct. A $\mathrm{Q}^{2}$ value above zero suggests that an endogenous construct can be predicted, although it does not say anything about the quality of the prediction (Hair et al, 2014).

As can be seen from table 2, there is no predictive power of this model regarding the impact of trust in team and the quality of output of the teamwork.

Table 2

\section{Assessment of Structural Model}

\begin{tabular}{|c|c|c|}
\hline & $\mathbf{R}^{\mathbf{2}}$ & $\mathbf{Q}^{\mathbf{2}}$ \\
\hline satisfaction with teamwork & 0.384 & 0.278 \\
\hline team performance & 0.010 & -0.024 \\
\hline
\end{tabular}

Source: table created by the author

The results of the bootstrapping resampling technique with 5,000 runs determined that the path between trust in team and satisfaction with teamwork is highly significant $(\mathrm{p}<0.01)$. Not surprisingly, the other path coefficient between trust in team and performance of the team is not significant. The t-value of 9.555 for the first relationship confirms the observation, being above the threshold of 2.57 for significance levels of $1 \%$ at that number of degrees of freedom. Again, the second path could not be interpreted as significant with a t-value of 0.906 .

The path coefficient between trust in team and satisfaction with teamwork shows a strong positive effect of trust on satisfaction with a coefficient of 0.612 .

Table 3

Structural Model Statistics

\begin{tabular}{|c|c|c|c|}
\hline & path coefficients & t values & p values \\
\hline [trust in team $] \rightarrow$ [satisfaction with teamwork] & 0.620 & 9.550 & 0.000 \\
\hline [trust in team $] \rightarrow$ [team performance] & 0,102 & 0.906 & 0.365 \\
\hline
\end{tabular}

Source: table created by the author

The structural model confirms the first hypothesis that there is a positive relationship between trust in team and satisfaction with the teamwork. The second hypothesis could not be confirmed. There is no evidence that trust in team has a significant effect on the quality of the output of the teamwork.

\section{Conclusion, Proposals and Recommendations}

This study focused on teams that are composed of rather unexperienced team workers, namely bachelor students, who worked together for a short period of time (one academic semester). The exclusively virtual project environment was for most of the students a completely new experience. These circumstances also increasingly occur in the current working environment in companies due to the Corona-crisis, since many companies now assign tasks to virtual teams and are not able give the same support or direct leadership from experienced project managers to all of the newlyformed virtual teams. Forward-looking virtual teamwork will become even more important as companies become more and more international and require virtual teamwork between their different locations. Also, the trend towards more home-office work which has been reinforced by the Corona crisis will in future require more virtual cooperation between people who are not experienced in working in virtual teams so far.

The fact that the team members in this study were rather unexperienced in working together in virtual teams might explain why an impact of trust that the team members had in their teammates could be observed with regard to the satisfaction the team member generated from working in that team but not with regard to team performance. Trust refers to the positive expectation of a team member about the other team members' intentions and behaviours. In the context of this study it might be reasonable to assume that although a trusting atmosphere in a team might help to 
work together in a productive way (by e.g. dividing tasks among the team members and sharing ideas), the virtual teamwork environment gives way to an atmosphere where mutual checks regarding the quality of the contributions of the other team members are not effected sufficiently. This might be due to the inexpertness of the team members. It might therefore well be that the team members' perception of their team performance differs from the actual team performance. It is suggested that further research should elaborate in detail if the relationship between trust, team performance and satisfaction is different in unexperienced (virtual) teams and teams with experienced team members. It could also be examined how perceived positive team performance and actual performance in teams with rather unexperienced team members are related.

Another aspect which has to be considered is that the team members had to build up trust in a short period of time and it is rather unlikely that the team members will work with some or all of their teammates in future again. Teams in virtual environments have to develop a "swift" form of trust which is very fragile and temporal (Pinjani \& Palvia, 2013). Team members who were able to build up trust quickly and maintained that trust in the team were more satisfied with their teamwork. This implies that whenever it is important to create satisfaction with the co-operation within the team as such it is important to establish a trusting atmosphere. This is the case whenever it is part of the goals of the virtual teamwork to create a positive attitude towards an institution. Large, international companies e.g. might also want to create a positive attitude towards their company when they ask members of different subsidiaries to join a virtual teamwork assignment. Also, in educational situations where the positive experience of teamwork as such is also part of the learning objectives, the creation of a trustful atmosphere is helpful. Future research could be conducted on the question how recurring teamwork experiences in different short-term virtual team assignments influences a person's development of trust in teams and team performance. It would also be interesting in that context to understand if trust in the teams and satisfaction with teamwork has an impact on the employee's perception of her/his company.

\section{Bibliography}

Allen, N.J., Hecht, T.D., 2004. The 'Romance of Teams': Toward an Understanding of its Psychological Underpinnings and Implication. Journal of Occupational and Organizational Psychology, 77, 439-461.

Anderson, J.C. Narus, J.A., 1990. A Model of Distributor Firm and Manufacturer Firm Working Partnerships. Journal of Marketing, 54(1), 42-58.

Anderson, J.C. Narus, J.A., 1986. Toward a Better Understanding of Distribution Channel Working Relationships. In: Backhaus, K. \& Wilson, D., 1986. Industrial Marketing: A German-American Perspective, Berlin: Springer-Verlag.

Arrow, K. J., 1972. Gifts and Exchanges. International Review of Finance, 1(4), 343-363.

Balliet, D. van Lange, P.A.M., 2013. Trust, Conflict, and Cooperation: A Meta-Analysis. Psychological Bulletin, 139(5), 1090-1112.

Braun, S., Peus, C., Weisweiler, S., Frey, D., 2012. Transformational Leadership, Job Satisfaction, and Team Performance: A Multilevel Mediation Model of Trust. The Leadership Quarterly, 24, 270-283.

Castaldo, S., Premazzi, K., Zerbini, F., 2010. The Meaning(s) of Trust. A Content Analysis on the Diverse Conceptualizations of Trust in Scholarly Research on Business Relationships. Journal Business of Ethics, 96(4), 657-668.

Colquitt, J.A., Rodell, J.B., 2011. Justice, Trust, and Trustworthiness: A Longitudinal Analysis Integrating Three Theoretical Perspectives. Academy of Management Journal, 54(6), 1183-1206.

Colquitt, J.A., Scott, B.A., LePine, J.A., 2007. Trust, Trustworthiness, and Trust Propensity: A Meta-Analytic Test of Their Unique Relationships With Risk Taking and Job Performance. Journal of Applied Psychology, 92(4), 909-927.

Cook, J., Wall, T., 1980. New Work Attitude Measures of Trust, Organizational Commitment and Personal Need Non-Fulfilment. Journal of Occupational Psychology, 59(1), 39-52.

De Dreu, C.K.W., Weingart, L.R., 2003. Task Versus Relationship Conflict, Team Performance, and Team Member Satisfaction: A Meta-Analysis. Journal of Applied Psychology, 88(4), 741-749.

De Jong, B.A., Dirks, K.T., Gillespie, N., 2016. Trust and Team Performance: A Meta-Analysis of Main Effects, Moderators, and Covariates, Journal of Applied Psychology, 101(8), 1134-1150.

De Jong, B.A., Elfring, T., 2010. How Does Trust Affect the Performance of Ongoing Teams? The Mediating Role of Reflexivity, Monitoring and Effort. Academy of Management Journal, 53(3), 535-549.

De la Torre-Ruiz, J.M., Ferrón-Vílche, V., Ortiz-de-Mandojana, N., 2014. Team Decision Making and Individual Satisfaction with the Team. Small Group Research, 45(2), 198-216. 
Dennis, A.R., Robert, L.P., Curtis, A.M., Kowalczyk, S.T., Hasty, B.K., 2012. Trust Is in the Eye of the Beholder: A Vignette Study of Postevent Behavioral Controls' Effects on Individual Trust in Virtual Teams, Information Systems Research, 23(2), 546-558.

Furumo, K., de Pillis, E., Green, D., 2009. Personality Influences Trust Differently in Virtual and Face-to-Face Teams, International Journal of Human Resources Development and Management, 9(1), 36-58.

Hackman, R.J. \& Katz, N., 2010. Group Behavior and Performance. In: Fiske, S.T., Gilbert, D.T., Lindzey, G., 2010. Handbook of Social Psychology, $5^{\text {th }}$ ed., Hoboken: Wiley, 1208-1251.

Hair, J.F., Hult, G.T.M., Ringle, C.M., Sarstedt, M., 2017. A Premier on Partial Least Squares Structural Equation Modeling. $2^{\text {nd }}$. ed, Los Angeles: Sage.

Hair, J.F., Sarstedt, M., Hopkins, L., Kuppelwieser, V.G., 2014. Partial Least Squares Structural Equation Modeling (PLS-SEM). An Emerging Tool in Business Research. European Business Review, 26(2), 106-121.

Hair, J.F., Ringle, C.M., Sarstedt, M., 2011. PLS-SEM: Indeed a Silver Bullet. Journal of Marketing Theory and Practice, 19(2), $139-151$.

Jarvenpaa, S.L., Knoll, K., Leidner, D.E., 1998. Is Anybody out There? Antecedents of Trust in Global Virtual Teams. Journal of Management Information Systems, 14, 29-64.

Kendall, E.L., Salas, E., 2004. Measuring Team Performance: Review of Current Methods and Consideration of Future Needs. The Science and Simulation of Human Needs. In: Ness, Tepe, V. \& Ritzer, D., 2004. Advances in human performance and cognitive engineering research. Advances in human performance and cognitive engineering research, Vol. 5. Elsevier Science, 307-326.

Langfred, C.W., 2004. Too Much of a Good Thing? Negative Effects of High Trust and Individual Autonomy in Self-Managing Teams. Academy of Management Journal, 4(3), 385-399.

Matzler, K., Renzl, B., 2006. The Relationship between Interpersonal Trust, Employee Satisfaction, and Employee Loyalty. Total Quality Management, 1(10), $1261-1271$.

Mayer, R.C., Davis, J.H., 1999. The Effect of the Performance Appraisal System on Trust for Management: A Field Quasi-Experiment. Journal of Applied Psychology, 84(1), 123-136.

Mayer, R.C., Gavin, M.C., 2005. Trust in Management and Performance: Who Minds the Shop While the Employees Watch the Boss? Academy of Management Journal, 48(5), 874-888.

Medina, M.N., 2015. Conflict, Individual Satisfaction with Team, and Training Motivation. Team Performance Management, 22(3/4), 223-239.

Moorman, C., Zaltman, G., Deshapande, R., 1992. Relationships Between Providers and Users of Market Research: The Dynamics of Trust Within and Between Organization. Journal of Marketing Research, 29(4), 314-328.

Morgan, R.M., Hunt, S.D., 1994. The Commitment-Trust Theory of Relationship Marketing. Journal of Marketing, 58(3), 20-38.

Morrissette, A.M., Kisamore, J.L., 2020. Trust and Performance in Business Teams: a Meta-Analysis, Team Performance Management, 26(5/6), 287-300.

Nerkar, A.A., McGrath, R.G., Macmillan, I.C., 1996. Three Facets of Satisfaction and their Influence on the Performance of Innovation Teams, Journal of Business Venturing, 11(3), 167-188.

Peeters, M.A.G., 2006. The Big Five Personality Traits and Individual Satisfaction with the Team. Small Group Research, 3(2), 187-211.

Perrone, V., Zaheer, A., McEvily, B., 2003. Free to Be Trusted? Organizational Constraints on Trust in Boundary Spanners. Organization Science, 14(4), 422-439.

Pinjani, P., Palvia, P., 2013. Trust and Knowledge Sharing in Diverse Global Virtual Teams. Information \& Management, 50, $144-153$.

Robert, L.P., You, S., 2018. Are You Satisfied Yet? Shared Leadership, Individual Trust, Autonomy, and Satisfaction in Virtual Teams. Journal of the Association for Information Science and Technology, 69(4), 503-513.

Rousseau, D.M., Sitkin, S.B., Burt, R.S., Camerer, C., 1998. Not so Different after all: A Cross-Discipline View of Trust. Academy of Management Review, 23(3), 393-404.

Sapienzia, P., Zingales, L., 2012. A Trust Crisis. Philosophy \& Public Affairs, 12(2), 123-131.

Schoorman, F.D., Mayer, R.C., Davis, J.H., 1996. Empowerment in Veterinary Clinics: The Role of Trust in Delegation. In: 11th Annual Meeting of the Society for Industrial and Organizational Psychology, San Diego, CA. 
Zaheer, A., McEvily, B., Perrone, V., 1998. Does Trust Matter? Exploring the Effects of Interorganizational and Interpersonal Trust on Performance. Organization Science, 8(2), 141-159. 


\title{
DEMOGRAPHIC INEQUALITIES AS DETERMINANTS AND CONSEQUENCES OF THE COVID-19 PANDEMIC IN LATVIA \\ Juris Krumins, University of Latvia \\ Aleksandrs Dahs, University of Latvia
}

\begin{abstract}
Since early March 2020 Latvia is fighting the COVID-19 pandemic. Lessons learned from this crisis will be instrumental in shaping future public health policy. Any policy response to the pandemic must be tailored to the particular risks within population in order to avoid the unnecessary social and economic damage on a national and international scale. Available literature on the topic highlights region-specific demographic factors associated with elevated population vulnerability to the effects of the COVID-19 pandemic. This study aims to ascertain the role of a pre-existing demographic inequalities in Latvia in the onset and progression of COVID-19 pandemic and lay groundwork for projecting the impact of this pandemic on the demographic development of Latvia and its regions. Methods used in the study include literature review, as well as statistical and spatial analysis of the identified demographic parameters. The study is concluded by a discussion on the future demographic effects of the current pandemic. Data used in this study are obtained from Central Statistics Bureau of Latvia database and the information materials published by National Centre for Disease Prevention and Control. Initial conclusions indicate that demographic disparities among regions and municipalities make some of them more vulnerable to various effects of the pandemic. Economic stimulus measures implemented in response to COVID-19 crisis may have a positive effect in limiting the damage inflicted by the crisis to the demographic situation in the country. However, this positive effect may be mostly limited to the international migration processes.
\end{abstract}

Keywords: demographic inequalities, demographic projections, coronavirus disease 2019, life transitions.

JEL code: J11, J18, I38

\section{Introduction}

Since the first confirmed infection cases in early March 2020 Latvia has joined other world nations in a struggle against the surge of COVID19 pandemic. Lessons learned from this crisis will be instrumental in shaping national public health policy for years to come and should be studied in great detail in order to better prepare the country and its society for possible infectious disease outbreaks in the future. The nature of the COVID19 pandemic has made it clear that any response to a wide-scale health emergency must be tailored to the particular population in order to avoid the unnecessary social and economic damage, while safeguarding lives and welfare of the public.

Long-term demographic effects of the pandemic itself as well as the implemented containment measures are also of great interest, as these may pose previously unforeseen challenges for population development long after the pandemic ends. These lasting effects will influence future international and inter-regional disparities in social, economic and population development.

Available literature on the topic highlights several region-specific demographic factors associated with elevated population vulnerability to the effects of the COVID-19 pandemic. (e.g. see Dowd et al, 2020 or Medford \& Trias-Llimós, 2020) Particular attention is drawn to the disparities in the demographic structure of a population, intergenerational bonds and household models, as well as migration patterns and work culture. (Balbo et al, 2020) Some of these factors are crucial in estimating the transmission dynamics of the infection, while others help explaining the variations in case mortality rates among seemingly identical regions. It has been shown that even the infection Reproduction Number (R0) is not constant for all countries and regions but varies depending on a multitude of local factors. (e.g. see Yuan et al, 2020)

COVID-19 crisis in Latvia is far from over and its lasting psychological, social and economic effects will leave a substantial impact on the future population development of the country and its regions. Previous research (Dahs, 2017) has shown a clear causal link between key socio-economic indicators like employment and personal income and the demographic dynamics on the regional level. Furthermore, several recent studies from other EU member states have shown that uncertainty and scarcity (even perceived), fuelled by the pandemics and the associated restrictions, have a detrimentally negative impact on fertility plans, particularly for younger age groups. (e.g. see Luppi et al, 2020)

Considering all of the above, this study aims to ascertain the role of a pre-existing demographic situation in Latvia in the onset and progression of COVID-19 pandemic and lay some groundwork for projecting the impact of this pandemic on the demographic development of Latvia and its regions in the years to come. This is achieved by answering two key research questions:

1. What demographic characteristics make regions more vulnerable to the effects of COVID-19 pandemic?

2. Which dimensions of demographic development in Latvia will be affected most by COVID-19 crisis? 
To answer these questions, we begin by reviewing the limited available literature dealing with the demographic implications of the current pandemic. This is followed by a statistical analysis of the identified demographic disparities on the national and regional level in the context of implemented epidemiological safety measures. The study is concluded by a discussion on the lasting demographic effects of the current pandemic. Data used in this study are obtained from Central Statistics Bureau of Latvia database and the materials published by National Centre for Disease Prevention and Control.

Initial conclusions indicate that population age and structure in Latvia may not have a significant role in the onset of the pandemic, while the evident demographic disparities among regions and municipalities make them either more or less vulnerable to its progression and various effects of the pandemic, including hospitalisation and death rates. Regional demographic factors like elderly economic activity, predominant household size and pre-existing health profile may be significant in terms of COVID-19 infection spread or impact, and therefore, can be used in planning future nationwide or regional epidemiological response.

Previous studies and evidence from other EU countries allow the author to conclude that economic stimulus measures implemented in response to COVID-19 crisis may have a positive effect in limiting the damage inflicted by the crisis to the demographic situation in the country. This positive effect, however, may be mostly limited to the international migration processes, as the economic stimuli may not be able to overcome the negative impact of unemployment, social restrictions, uncertainty and perceived scarcity on the fertility plans of younger population groups.

\section{Literature Review}

It is important to note that at the time of writing this paper (October 2020), the number of available peer-reviewed material on COVID-19 pandemic is very limited. Some of the studies referenced in this paper are either still in press or undergoing final review. Nevertheless, evidencebased reports of the uneven COVID-19 infection spread and elevated mortality risks among people of various age, ethnicity and social status have sparked active interest among demographic researchers, providing a substantial number of discussion papers, reports and provisional studies on the related topics in a short period of time.

Many studies and reports focus on the relation between demographic structure and COVID-19 impact or infection spread dynamics within the countries most affected by the pandemic. For example, Population Europe report "Demography and the Coronavirus Pandemic" prepared by Balbo et al (2020a) looks at a number of empirical studies and highlights several important observations:

- In case of the uncontrolled spread of the disease, it is possible to predict the number of expected critical or fatal cases, by considering age structure of a country or region. (see Verhagen et al, 2020)

- Progression of the pandemic is influenced by a variety of factors including spatial factors, prevalence of groups with specific comorbidities, as well as differences in socioeconomic status or particular living and housing arrangements. (see Kashnitsky and Aburto, 2020)

- There is some evidence that regions where people have stronger social ties (either personal or professional) seem to have higher transmission rates of COVID-19. (see Mogi and Spijker, 2020)

Ryohei Mogi and Jeroen Spijker in their 2020 paper "The influence of social and economic ties to the spread of COVID-19 in Europe" argue that socially and economically vibrant factors have a strong and positive association with COVID-19 transmission. The correlation of infection rates with population density and traditional factors was low during the initial stages of the pandemic but rose quickly with its progression. (Mogi and Spijker, 2020) This correlates well with the assumptions on the initial spread of infection among economically active population and later retransmission through family and intergenerational ties.

Francesca Luppi, Bruno Arpino and Alessandro Rosina have conducted a study “The impact of COVID-19 on fertility plans in Italy, Germany, France, Spain and UK" (Luppi et al, 2020), which has found that the possible effect of the COVID-19 epidemic and the subsequent economic crisis cannot be merely interpreted under the same mechanisms in all European countries. Previous economic and demographic conditions seem to shape the COVID-19 effects on the fertility plans of the young populations.

A good summary for the COVID-19 crisis impact on a human life course is provided by Richard A. Settersten Jr. et al (2020) in the recent paper "Understanding the effects of Covid-19 through a life course lens". The authors provide an argument that the effects of the pandemic will likely depend on ages or life stages that are more or less vulnerable or sensitive to certain effects. They also argue that pandemic-era changes will likely manifest in the family transitions, such as the postponement of cohabitations, marriages, fertility or accelerated separations and divorces. 


\section{Research results and discussion}

Since the beginning of the local COVID-19 outbreak in March and April 2020 (so called - "First wave") until the rapid surge in cases since late September 2020 (so called - "Second wave"), Latvia was able to maintain relatively low infection rates. At the same time, other indicators like casehospitalisation and case-fatality rates in Latvia during the First wave period were on par with similar EU member states. Unfortunately, the infection rates have quickly started leaning towards the EU average levels during the "Second wave" period.

Source: $C D P C, 2021$

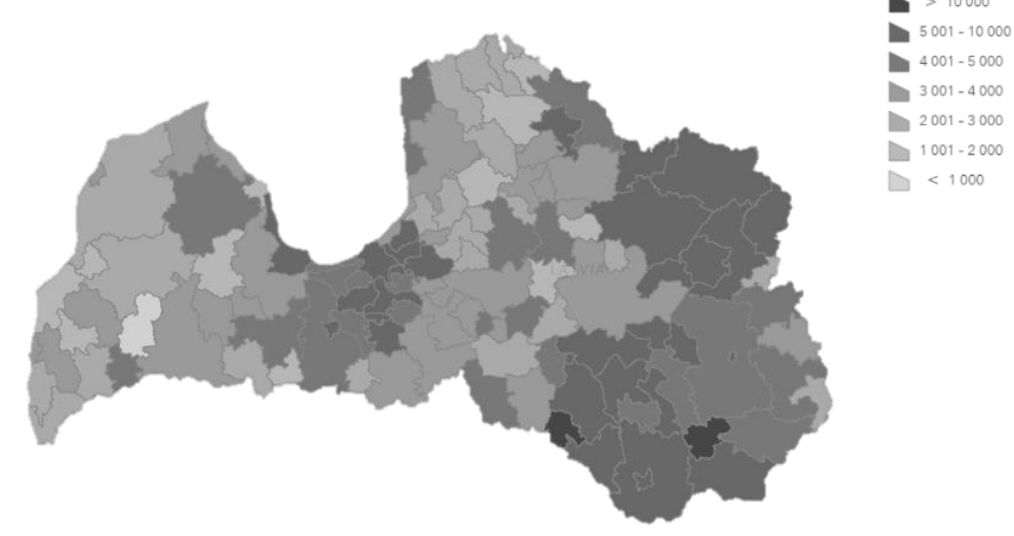

Fig. 1. Confirmed COVID-19 cases per 100000 residents in Latvian municipalities (15.03.2021 data)

Available data (see Figure 1) shows that the number of confirmed COVID-19 cases is not equally distributed among municipalities and statistical regions of Latvia. This presents an opportunity for the evaluation of risks and response measures on a local / regional level. It should be noted that Figure 1 presents data according to the number of declared residents which may somewhat differ from the estimated factual population numbers in some municipalities.

Table 1

Changes in passenger traffic and number of deaths in Latvia, 2019 and $2020(\%)$

$2020,2020,2020$

Q2 compared to $Q 1 \quad$ Q3 compared to $Q 2 \quad$ Q4 compared to $Q 3$

2020 Q4 compared to

\begin{tabular}{|l|ccc||c||}
\hline Number of passengers & & & & \\
Rail & -37.61 & 75.76 & -35.70 & -18.82 \\
Bus & -56.01 & 91.79 & -15.34 & -40.11 \\
Tram and Trolleybus & -64.27 & 119.73 & -58.33 & -39.51 \\
Arrivals in Airport Riga & -93.92 & 557.97 & & -88.90 \\
Number of deaths ** & & & 12.43 & 20.32 \\
LATVIA & 6.89 & -5.44 & 16.85 & 32.69 \\
Riga capital city & 9.78 & -6.28 & 15.07 & 14.35 \\
Pieriga region & 5.38 & -5.78 & 3.13 & 10.64 \\
Vidzeme region & -3.81 & 0.41 & 4.87 & 14.17 \\
Kurzeme region & 5.44 & -2.48 & 20.07 & 18.09 \\
Zemgale region & 1.85 & -5.45 & 8.26 & 17.36 \\
Latgale region & 15.25 & -9.13 &
\end{tabular}

** Quarterly approximations based on weekly data

Source: Authors' elaboration based on CSB, 2021 and CDPC, 2021

Table 1 shows the change dynamics in passenger traffic and number of deaths in Latvia. It is evident that population mobility has been greatly reduced since the First wave of the pandemic. Although there is slight increase in the number of deaths in Q2 2020 in comparison with the previous year, it is too early to attribute this figure to the direct or indirect effects of the pandemic at this point.

Regional Demographic Factors 
Following the discussion pattern established by the literature review, this sub-section looks at the relevant statistical data for Latvia and its regions to explore their potential demographic vulnerabilities to the pandemic.

It has been established in previous studies that Latvia has a high level of regional disparity in terms of population age and economic activity. The regional disparity is also reflected quite strongly by the rates of economic activity among senior population. (see Krumins et al, 2019) Figures below show the estimated share of population in the 65+ age group, as well as the share of economically active senior population on the municipal level in Latvia (municipal structure before 2020 administrative-territorial reform is used).
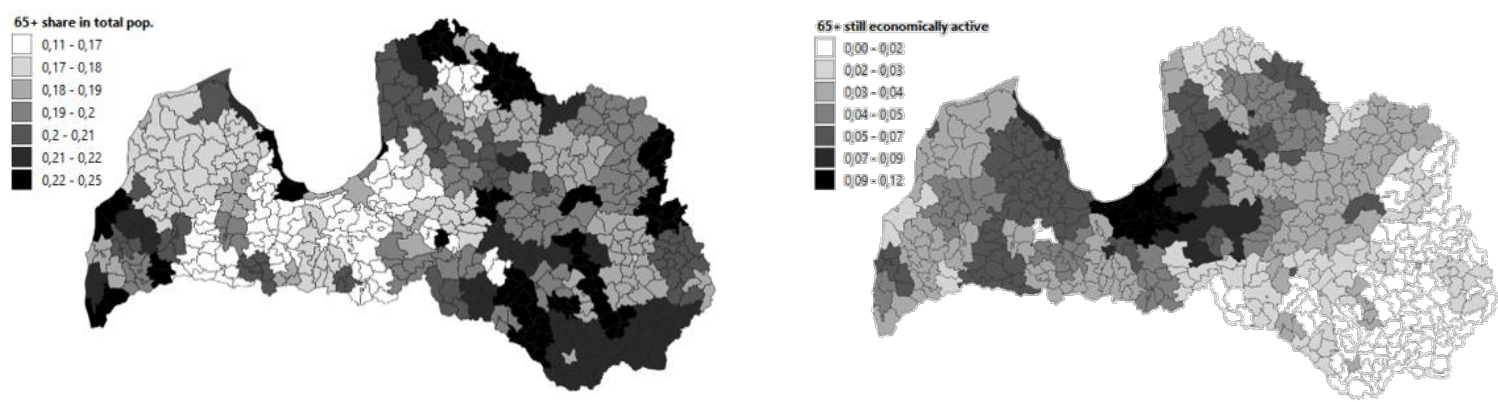

Source: Krumins et al, 2019

Fig. 2. Share of population in the $65+$ age group and share of economically active senior population on the municipal level in Latvia according to 2011 census data

The observations on regional age disparities remain valid even if we consider the changes introduced by the latest administrative-territorial reform. In fact, new administrative-territorial structure highlights the divergence of population ageing trends even more clearly. (see Krumins et al, 2020)

Table 2

Population ageing indicators in the new Latvian municipalities in 2019

(top five and bottom five results shown in comparison with the capital city - Riga)

\begin{tabular}{|c|c|c|c|c|}
\hline $\begin{array}{c}\text { Municipality } \\
\text { (2020 reform nomenclature) }\end{array}$ & Mean age & $\begin{array}{c}\text { Proportion of } \\
\text { aged } 65+, \% \\
\end{array}$ & $\begin{array}{l}\text { Ageing index, } \\
(65+/ 0-14) * 100 \\
\end{array}$ & $\begin{array}{c}\text { Population in } \\
2019 \\
\end{array}$ \\
\hline Krāslavas novads & 46.5 & 23.8 & 208 & 22429 \\
\hline Augšdaugavas novads & 46.1 & 23.2 & 208 & 26334 \\
\hline Valkas novads & 45.6 & 25.2 & 183 & 7664 \\
\hline Ludzas novads & 45.1 & 22.2 & 183 & 22494 \\
\hline Balvu novads & 44.3 & 21.5 & 165 & 19595 \\
\hline Rìga & 42.6 & 20.4 & 132 & 633071 \\
\hline Salaspils novads & 40.0 & 17.5 & 93 & 22612 \\
\hline $\bar{A} d a z ̌ u ~ n o v a d s$ & 39.2 & 15.5 & 77 & 20138 \\
\hline Ropažu novads & 39.0 & 14.8 & 75 & 29454 \\
\hline Kekavas novads & 37.9 & 14.8 & 67 & 29119 \\
\hline Mārupes novads & 34.7 & 10.7 & 41 & 31967 \\
\hline
\end{tabular}

Source: authors' elaboration based on Krumins, J. et al 2020

From the maps and table above one can see that there is a number of (mostly peripheral) administrative units that are at high risk of age-related COVID-19 mortality due to the high number of population in the 65+ age group. Maps also demonstrate that in majority of cases senior citizens in the regions with highest proportions of the 65+ age group maintain low economic activity. Exceptions are mostly observer in and around the big cities and some regional development centres. Comparing data presented in Figure 1 with the information from Figure 2, one can easily identify areas of high concern.

Low economic activity of senior citizens diminishes the infection transmission risk associated with professional and economic activity (e.g. daily commute, workplace infections etc.) for the rural areas and most municipalities located in Latgale statistical region. However, this makes personal (family and social ties) the main focus of preventive measures for these particular areas. From the perspective of limiting COVID-19 mortality, this helps to differentiate municipalities where stronger restrictions on economic activity would be more effective against those where social and intergenerational ties should be addressed. 
Additional useful information can be found in the regional health profiles elaborated for the statistical regions of Latvia by the National Centre for Disease Prevention and Control. (CDPC, 2015) This document highlights the inter-regional disparities and shows that the rapidly ageing population of Latgale region is the most at-risk of the COVID-19 effects due to several factors, including:

- Highest mortality from circulatory system diseases.

- Highest mortality from diabetes.

- $\quad$ Lowest self-perceived health status.

These observations further support the conclusion on high regional disparities in terms of vulnerability to the pandemic.

Household infections and COVID-19 spread due to intergenerational living arrangements can be analysed with the help of household statistics. For example, Table below shows share of households per number of residents in statistical regions of Latvia in 2019.

Table 3

Households by number of members in Latvia in 2019 (\%)

\begin{tabular}{|c|c|c|c|c|c|c|}
\hline & One person & Two persons & Three persons & $\begin{array}{l}\text { Four } \\
\text { persons }\end{array}$ & $\begin{array}{l}\text { Five or more } \\
\text { persons }\end{array}$ & $\begin{array}{l}\text { Three or more } \\
\text { persons }\end{array}$ \\
\hline Riga & 38.6 & 32.0 & 17.2 & 8.6 & 3.6 & 29.4 \\
\hline Latgale & 35.7 & 33.8 & 15.3 & 9.3 & 5.9 & 30.5 \\
\hline Kurzeme & 32.8 & 33.1 & 15.5 & 10.7 & 7.8 & 34.0 \\
\hline Vidzeme & 39.0 & 26.9 & 17.1 & 9.9 & 7.1 & 34.1 \\
\hline Zemgale & 32.6 & 26.9 & 18.0 & 14.3 & 8.2 & 40.5 \\
\hline Pieriga & 29.2 & 28.5 & 18.3 & 13.9 & 10.1 & 42.3 \\
\hline
\end{tabular}

Source: Authors' elaboration based on CSB, 2020

Table demonstrates that the majority of households throughout the country consist of only one or two individuals. Region with highest proportion of $65+$ population (Latgale) has the second smallest share of households with three or more individuals, preceded only by the capital city Riga. The inter-regional differences are quite substantial and indicate the elevated case-number impact of household transmission of COVID-19 in Pieriga and Zemgale region. When considered together with the number of children per household (e.g. see CSB, 2020), these data help estimate the risks of not closing or reopening schools and pre-schools in the particular municipalities.

\section{Expected Demographic Consequences}

In this section we look at the available data representing impact of the pandemic on social and economic processes, while discussing the future demographic implications of these changes.

The pandemic is changing the familiar social and economic interactions, removing economically active residents from their usual work environments and social support networks. Working parents face new challenges with remote education and limited childcare. Many adults are attempting to conduct their work activities remotely, which can also increase stress through instant availability, high demands, the need to provide care for children and infirm relatives, and the blurring of work and non-work boundaries. (Settersten et al, 2020) As supported by the literature review, these circumstances will have a detrimental effect on the life-course events and family planning.

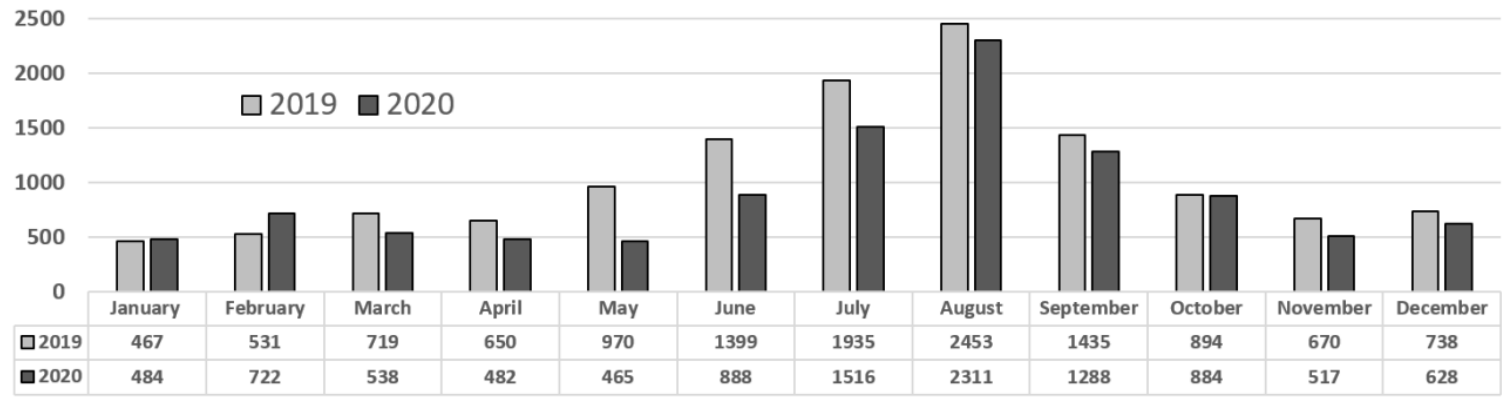

Source: Authors' elaboration based on CSB, 2021

Fig. 3. Number of marriages per month in Latvia - 2019 and 2020 comparison

Available statistical data for Latvia confirms these predictions - data show growing postponement of marriages in Latvia in comparison with the 2019 and early 2020 dynamics (see Figure 3). At the moment it is difficult to speculate, whether these postponements of life transition events 
are temporary and will the dynamics recover in the years to come. However, it is quite safe to assume that the severity of the impact in this regard will depend highly on the duration of the pandemic and the associated safety measures.

From the economic perspective, crisis caused by COVID-19 is quite different from the one experienced in 2008-2011. While massive recovery and economic support measures maintain stable personal income levels, the long-term structural uncertainties and lack of organised international response threaten employment stability and future opportunities in many affected sectors. (e.g. see. Tooze, 2020 or Danielsson et al, 2020.)

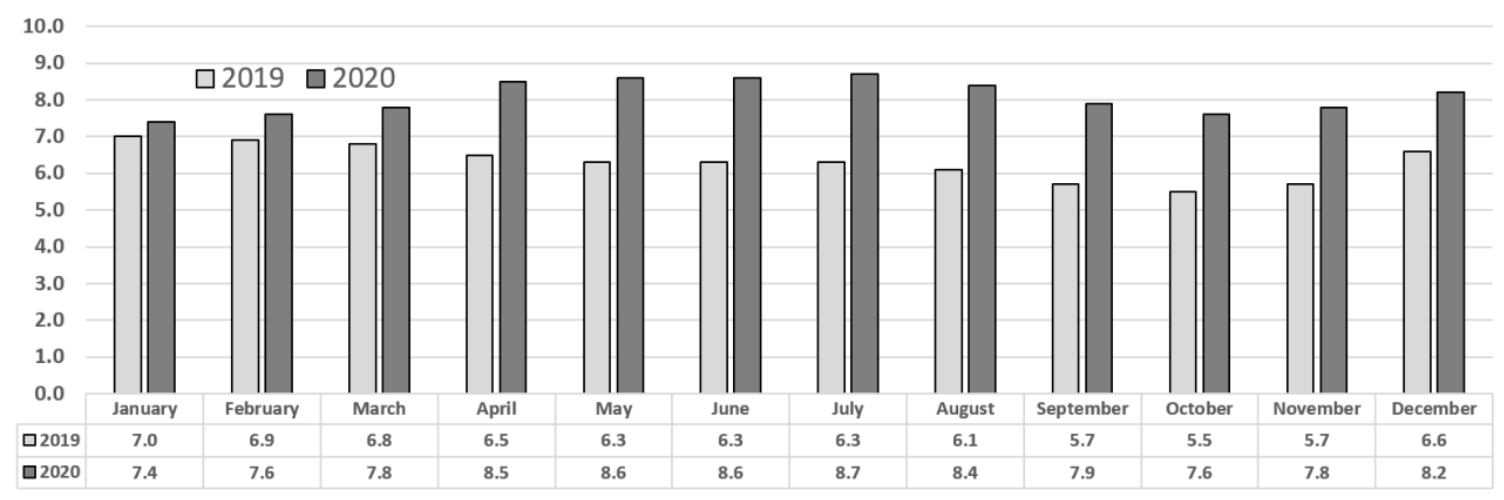

Source: Authors' elaboration based on CSB, 2021

Fig. 4. Unemployment levels (15-74) per month in Latvia - 2019 and 2020 comparison

Previous model-based studies conducted for Latvia and its regions have demonstrated that the income indicators like average collected income tax can be significant predictors for the population growth on the local level (natural increase and migration), while unemployment levels appeared to be most significant for the increase of young population. (Dahs, 2017). This is also corroborated by many European studies focusing on the demographic implications following 2008 financial crisis. (see Adsera, 2011 or Goldstein et al, 2013) In terms of fertility plans, observations from these studies point to the fact that - job stability and long term perspectives are valued more than current income levels.

Implications of the COVID-19 crisis become self-evident if we look at the current unemployment and average income dynamics in Latvia (Figures 4 \& 5). With the income level maintained at the pre-crisis or higher levels, Latvia has a good chance to avoid the new wave of outmigration. While rising unemployment levels and employment uncertainties will undoubtedly further damage the natural population increase.

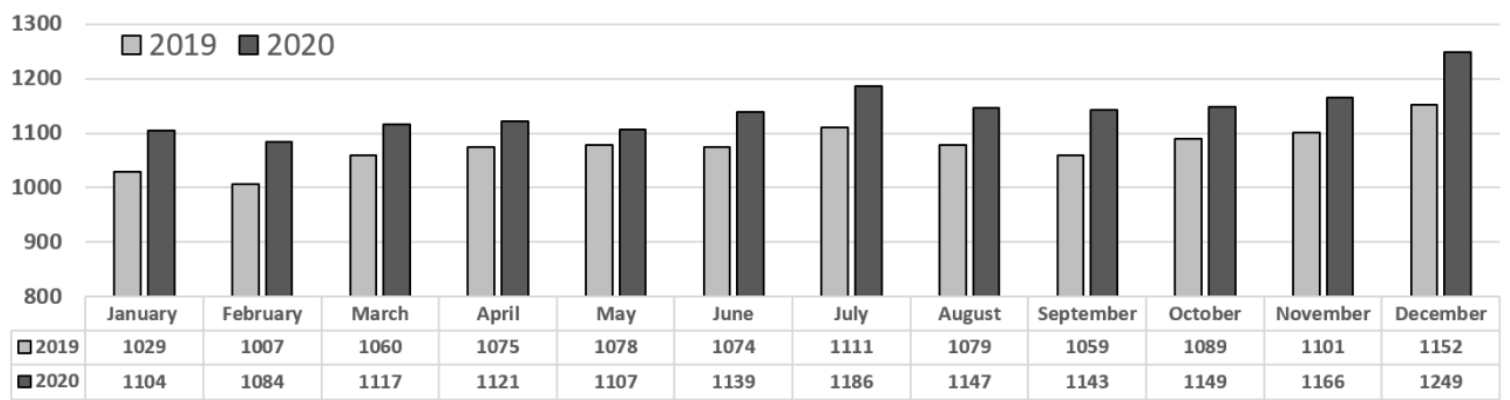

Source: Authors' elaboration based on CSB, 2021

Fig. 5. Average pre-tax income per month in Latvia - 2019 and 2020 comparison

Australian population expert, Dr Liz Allen has explained that in pure demographic terms, the ingredients required for births are being disrupted by the pandemic. Relationships are especially affected, meaning we are not going to see the formula needed to result in births. (Brook, 2020)

Like the marriage dynamics discussed previously, it is difficult to predict weather the COVID-19 pandemic and the associated socioeconomic crisis will result in postponement or abandonment of the fertility plans. One empirical study has shown, that differences in fertility plans arise between and within countries according to the socio-demographic characteristics of the individuals - in countries where the previous economic and labour market situation was more positive (i.e. Germany and France) the proportion of those abandoning the fertility plans for 2020 is much lower than in other countries. (Luppi et al, 2020)

However, in terms of fertility, one similarity can be drawn with the 2008 crisis - fertility plans are less likely to change dramatically for older population groups (30+). A possible explanation is suggested by F. Luppi et. al. (2020) - that those in their 30s - and especially women - are more prone to preserve their pre-crisis fertility plans at least at the beginning of the crisis. 
Considering all of the above, we can conclude that income stimulus measures planned and implemented in response to COVID-19 crisis in Latvia combined with heavy economic losses in other EU countries, may limit the damage inflicted by the pandemic in terms of international outmigration. At the same time, reduced employment opportunities together with negative impact of social restrictions, uncertainty and perceived scarcity will have a significant negative effect on the on the fertility plans of younger population groups.

\section{Conclusions}

1. Literature review, as well as the evident regional demographic disparities in Latvia induce active use of the regional demographic indicators in planning and application of the policy measures aimed at containing spread and limiting impact of COVID-19 pandemic.

2. Depending on the regional circumstances, determinants like elderly economic activity, household size and health profile may significantly affect COVID-19 infection incidence and consequences.

3. Demographic disparities between territorial units make some of them more vulnerable to the spread of infection and its various effects, including hospitalization and mortality.

4. The variation of demographic indicators suggest that municipalities have different risk factors in terms of transmission rates and mortality, which means that from demographic perspective, application of tailored COVID-19 preventive measures on the regional level is advisable.

5. COVID-19 pandemic has already left a major impact on socio-demographic behavior of population in Latvia, demonstrated by the reduced mobility and postponement of marriages. Currently, it is too early to conclude if this temporary setback in life and family transitions and reproductive intensions, or a long-lasting effect.

6. Previous model-based studies and the experience of other EU countries allow to assume that economic measures implemented in response to COVID-19 crisis may have a positive effect in limiting the damage inflicted by the crisis to the demographic development. However, this positive influence may be limited to the international migration processes, as the economic stimuli may not be able to overcome the negative impact of reduced employment opportunities, social restrictions, uncertainty and perceived scarcity on the reproductive plans of younger cohorts.

\section{Bibliography}

Adsera, A., 2011. Where are the Babies? Labor Market Conditions and Fertility in Europe. European Journal of Population, $27(1), 1-32$.

Balbo, N., Kashnitsky, I., Melegaro, A., Mesle, F., Mills, M., de Valk, H., Vono de Vilhena, D., 2020. Demography and the Coronavirus Pandemic. Max Planck Society for the Advancement of Science on behalf of the collaborative network "Population Europe": Population and Policy Brief. Available at: https://population-europe.eu/file/4153/download?token=fITGzY0D (Accessed 30.10.2020).

Brook, A., 2020. Report: "Coronavirus crisis likely to reduce birth rate". Available at: https://www.anu.edu.au/news/all-news/coronavirus-crisis$\%$ E2\%80\%98likely-to-reduce-birth-rate\%E2\%80\%99 (Accessed 30.10.2020).

Central Statistics Bureau of Latvia [CSB], 2021. Main Database. Available at: https://www.csb.gov.lv/en/statistika/db (Accessed 30.10.2020).

Centre for Disease Prevention and Control [CDCP], 2015. Report: "Latvijas regionu veselības profils 2010.-2015.gadam". Available at: https://www.spkc.gov.lv/lv/latvijas-regionu-un-pasvaldibu-veselibas-profili/regioni_profils_20102015_11.pdf(Accessed 15.03.2021).

Centre for Disease Prevention and Control [CDCP], 2021. COVID-19 infection in Latvian municipalities - GIS map. Available at: https://spkc.maps.arcgis.com/apps/opsdashboard/index.html\#/4469c1fb01ed43cea6f20743ee7d5939 (Accessed 15.03.2021).

Dahs, A., 2017. Role of the Socioeconomic Factors and Regional Policy in the Demographic Development of Latvia. Doctoral thesis, University of Latvia.

Danielsson, J., Macrae, R., Vayanos, D., Zigrand, J.P., 2020. The Coronavirus Crisis is no 2008. VoxEU. CEPR Press. Available at: https://voxeu.org/article/coronavirus-crisis-no-2008 (Accessed 30.10.2020)

Dowd, J.B., Andriano, L., Brazel, D.M., Rotondi, V., Block, P., Ding, X., Liu, Y., Mills, M.C., 2020. Demographic Science Aids in Understanding the Spread and Fatality Rates of COVID-19. Proceedings of the National Academy of Sciences, 117(18), 9696-9698.

Goldstein, J. R., Kreyenfeld, M., Jasilioniene, A., Orsal, D. K., 2013. Fertility Reactions to the "Great Recession" in Europe: Recent Evidence from Order-Specific Data. Demographic Research, 29(4), 85-104.

Grennes, T., 2020. Amber Tigers and the Baltic population problem. Baltic Rim Economies, 3 Available at: https://sites.utu.fi/bre/amber-tigersand-the-baltic-population-problem (Accessed 30.10.2020).

Kashnitsky, I., Aburto, J. M., 2020. The Pandemic Threatens Aged Rural Regions Most. [Preprint]. Available at: doi:10.31219/osf.io/abx7s (Accessed 30.10.2020). 
Krumins, J., Berzins, A., Dahs, A., 2020. Regional Demographic Trends In Accordance With the New Model of Territorial Division in Latvia and Future Dynamics in Statistical Regions of the Baltic States. Proceedings of the 2020 International Conference "Economic Science for Rural Development" No 54, Jelgava, LLU ESAF, 12-15 May 2020, pp. 233-240.

Krumins, J., Berzins, A., Dahs, A., Ponomarjova, D., 2019. Healthy and Active Pre-Retirement and Retirement Ages: Elderly Inequality in Latvia. New Challenges of Economic and Business Development - 2019. International Conference, Riga, Latvia, May 16-18, 2019: Proceedings. Riga: University of Latvia, 463-476

Luppi, F., Arpino, B., Rosina, A., 2020. The Impact of COVID-19 on Fertility Plans in Italy. Germany, France, Spain and UK, SocArXiv. Available at: https://osf.io/preprints/socarxiv/wr9jb/download (Accessed 30.10.2020).

Margaras, V., 2020. Briefing: "Demography on the European agenda: Strategies for tackling demographic decline." European Parliamentary Research Service, 12 pages.

Medfod, A., Trias-Llimos, S., 2020. Population Age Structure only Partially Explains the Large Number of COVID-19 Deaths at the Oldest Ages. medRxiv. Available at: https://www.medrxiv.org/content/medrxiv/early/2020/04/11/2020.04.09.20056341.full.pdf (Accessed 30.10.2020).

Milani, F., 2021. COVID-19 Outbreak, Social Response, and Early Economic Effects: a Global VAR Analysis of Cross-Country Interdependencies. Journal of Population Economics, 34, 223-252.

Mogi, R., Spijker, J., 2020. The Influence of Social and Economic Ties to the Spread of COVID-19 in Europe. SocArXiv, Available at: doi:10.31235/osf.io/sb8xn (Accessed 30.10.2020).

Settersten Jr, R. A., Bernardi, L., Härkönen, J., Antonucci, T.C., Dykstra, P.A., Heckhausen, J., Kuh, D., Mayer, K.U., Moen, P., Mortimer, J.T. Mulder, C.H., 2020. Understanding the Effects of Covid-19 through a Life Course Lens. Advances in Life Course Research, 45, 100360.

Tooze, A., 2020. Is the Coronavirus Crash Worse than the 2008 Financial Crisis? Foreign Policy, 18. Available at: https://foreignpolicy.com/2020/03/18/coronavirus-economic-crash-2008-financial-crisis-worse/ (Accessed 30.10.2020).

Verhagen, M.D., Brazel, D.M., Dowd, J.B., Kashnitsky, I., Mills, M., 2020. Forecasting Spatial, Socioeconomic and Demographic Variation in COVID-19 Health Care Demand in England and Wales [Preprint]. Available at: doi:10.31219/osf.io/g8s96 (Accessed 30.10.2020).

Yuan, J., Li, M., Lv, G., Lu, Z.K., 2020. Monitoring Transmissibility and Mortality of COVID-19 in Europe. International Journal of Infectious Diseases, 95, 311-315.

\section{Acknowledgements}

This study was supported by National Research Programme "Latvian heritage and future challenges for the country's sustainability", Project No. VPP-IZM-2018/1-0015 "Towards sustainable development and inclusive society in Latvia: response to demographic and migration challenges" (DemoMig). 


\section{REGIONAL DIFFERENCES BETWEEN JOB SEEKERS: CASE OF LATVIA}

\section{Kate Lase, University of Latvia \\ Biruta Sloka, University of Latvia}

Abstract. Differences in labour market have always been on great importance in Latvia, however special concern is about regions of Latvia where finding a new job sometimes could be very challenging process, because these regions are developing unevenly, job vacancies are limited, wages are lower and there is a lack of high qualified specialists in labour market. Purpose of the study is to analyse regional differences between job seekers in regions in Latvia.

The tasks of the study:

1) To analyse theoretical background of regional differences of job seekers and employment in context of urban and rural areas;

2) To analyse main challenges and problems of regional differences between job seekers in regions in Latvia.

Research methods used in preparation of the paper were the analysis of scientific publications and previous conducted research results, the analysis of Labour Force Survey results and the analysis of data of Central Statistical Bureau of Latvia. The Survey results are analysed using indicators of descriptive statistics (indicators of central tendency or location - arithmetic mean, mode, median), indicators of variability (indicators of dispersion - range, standard deviation and standard error of mean), cross-tabulation for regions of Latvia, for territories: urban-rural living and analysis of variance - ANOVA are used.

The results of analysis have indicated several differences between regions of Latvia, but there are no differences between job seekers in urban and rural areas of Latvia.

Keywords: employment, job search, regional differences.

JEL code: J31; J21; E24

\section{Introduction}

According to the Eurostat expected duration of working life in the EU lengthen with every year and now it is 36.4 years (Eurostat). However, there are very important aspects on working life which are important for each country and each individual to have best possible results in working life including education and training, retraining, skills update and many other aspects which are researched also by academic researchers with analysis of different aspects of best possible solutions including aspects of predicting the effect of work values on workplace communication environment and job quality of tertiary students (Chan, Ben Yedder, Vipulakom, 2020).

The economics of countries change during each individual's working life and each country's economic development where there are noticed differences in labour demand and labour supply by different regions in the countries and also by administrative territories.

Taking into account all mentioned before, the purpose of the study is to analyse regional differences between job seekers in regions in Latvia.

In order to achieve the purpose, the tasks are formulated as follows:

1) to review theoretical background of regional differences of job seekers and employment in context of urban and rural areas;

2) to analyse main challenges and problems of regional differences between job seekers in regions in Latvia.

Research methods used: scientific publications and previous conducted research results analysis, analysis of "The Labour Force Survey" results (in 2014-2019) and European Central Bank conducted survey on Household income and expenses survey results (HFCS), results are compared with the results of other Eurozone countries. For statistical data analysis there are used main indicators of descriptive statistics (arithmetic means, standard deviations and standard error of means), $\mathrm{t}$ - test for testing differences of means by two independent characteristics - territories (cities and rural areas) and for testing differences of arithmetic means by six independent characteristics - regions of Latvia was used one of the most often used multivariate analysis method: analysis of variance - ANOVA.

\section{Literature Review}

Researchers world-wide have analysed different aspects influencing labour market including several aspects of job seekers: regional differences, unemployment rate, education level, quality of education, gender, family status (married or not married, with children or without children).

Extensive studies of different labour market aspects are done by Mihails Hazans, professor of University of Latvia and also researcher of IZAInstitute of Labor Economics, Germany. Research results of professor Mihails Hazans are inspiring many researchers and his findings are often used as valuable examples for other researchers related to different employment aspects: like, looking for the workforce: how the elderly, 
discouraged workers, minorities, and students are involved in the Baltic labour markets (Hazans, M., 2007). Professor Hazans has performed many analysis and his research results are used world-wide.

Differences in regional unemployment have been on research agenda for last decades as more and more countries seek to develop regions and apply appropriate policies. Geographic labour mobility is important factor for an efficient labour market and has consequently been extensively studied (Boman, 2012).

Importance of the effect of early career social capital on long-term income development in Finland (Oinas, Ruuskanen, Hakala, Anttila, 2020) where the results of the mentioned researchers give strong and reasonable support to the idea that social capital can be transformed into economic capital.

Quality of educational programs and correspondence of those programs to labour market needs are requirements by employers, by policy makers and students - this aspect is on extremely big importance as it is recognised also by academic researchers with entrepreneurial intention model focussing on different aspects of higher education (Tomy, Pardede, 2020).

Role of personality has shown significant influence on occupational sorting and routine work (Viinikainen, et al,_2020). Alternative models of activation policies are studied in research done by researcher G. Scarano (Scarano, 2020) where there in the respective research where are analysed administrative data and the experience of public oriented services.

Researchers are analysing also different fields and specialities, for example, network analysis in accounting research with deep analysis on institutional and geographical perspective (Uyar, Kılıç, Kö eoğlu, 2020), gender importance as well as gender and network effects on occupation (Fung, 2020), on hiring discrimination against transgender job applicants - considerations when designing a study (McFadden,_2020), on life outside the garment factories: the lived experiences of factory workers (McKay, McKenzie, 2020). The mentioned factors are considered as important aspects influencing job seekers.

There is done extensive analysis on socio-economic determinants of public expenditure by assessing the influence of population age structure (Azolibe, Nwadibe, Okeke, 2020), importance of social capital, labour market status and wages (Caparrós Ruiz, 2020) and having influence also on growth factors of the industry development aspects (Mayerhoffer,_2020). Age structure is mentioned as one of the most important aspects in job seeking process.

Study in Germany revealed that regional unemployment is very pronounced in Germany and there are significant differences between the eastern and the western regions (Granato, et al, 2015). Another study in Germany was investigating how potential duration of unemployment benefits affects early job search behaviour and re-employment outcomes and revealed that the extension of benefits increases the average nonemployment duration of individuals (Lichter, Schiprowski, 2021). Regional differences for job seekers are confirmed also by other researchers.

Different situation is in Croatia where the main problems of the Croatian regional labour markets are low flexibility of the labour market and inexistence of adjustment mechanisms such as wage adjustment. Results of this study also indicate that Croatia is highly centralised and other counties than Zagreb have low fiscal capacity (Jakšic, 2017). Low flexibility of the labour marked could be considered as important and influencing factor for job seekers.

Regional unemployment in context of youth unemployment have been studied in Slovakia. The study revealed that in districts with low unemployment rate the job offer exceeds demand, but in the region with the highest rates there is graduate overqualification and the job offer is very limited. The research indicated that youth unemployment rate is related to the graduate's education and is achieving different values in the respect to the region (Strakova, 2018). Youth unemployment differs by country but it is an important factor influencing job seekers also by regions.

Researchers (Audretsch et. al., 2015; Bergantino and Madio, 2019; Huertas, et al, 2019) were researching the link between regional unemployment and entrepreneurship and revealed that regional influence is important factor.

Study in Netherlands was researching how the location of job influence job search and revealed that jobseekers tend to take jobs in regions close to their old working region (Morkute, 2017). Study in San Francisco was researching relationship between job seeker's search effort and the duration of the search and indicated that long-duration job seekers send more applications each period what is contrary with standard search theory that higher search effort should lead to a higher job-finding rate and shorter search durations (Faberman, Kudlyak, 2016) and could be considered as important aspect influencing job seeking.

Boman (2012) reveals that in Sweden education, being a male, married increases the probability of employment, while having children or being older than 45 decrease probability of employment after being unemployed. 
Study in Romania was researching rural unemployment spells and exit destinations and revealed that more attention from policy makers is necessary. To reduce unemployment duration and to improve employment Romanian policies needs to be targeted towards unemployed women over 45. Thus, another implication is to increase level of education of those living in rural areas, especially developing practical skills (Danacica, Cirnu, 2014). Such aspects are stressed also in other scientific publications by other authors and conclusions are alike in many countries and continents.

\section{Methodology}

In order to get a broader view of job search duration in regions and territories of Latvia, different data sourced were used in this research - anonymized data sets of Labour Source Survey 2019 in Latvia (to make own calculations and analysis of representative survey data) and data of Eurostat and Central Statistical Bureau of Latvia.

The nature of the Labour Force Survey 2019 - to survey households selected according to a definite system on a weekly basis throughout the whole year. Information about labour status of the population of Latvia and situation in the labour market covers population aged 15-74 (in several tables population aged $18-24,30-34,15-64,20-64$ or 25-64). The annual data of the survey are calculated as arithmetic mean of the quarterly indicators. Extrapolation of the annual survey results is made based on the average quarterly statistics on usually resident population living in private. Labour Force Survey methodology has been developed based on the methodology worked out by the International Labour Organization (ILO). The same methodology is also used by the Eurostat and the Organization for Economic Cooperation and Development (OECD) therefore, all data are internationally comparable (The Labour Force Survey, 2019) and is good that it is possible to use anonymized survey data for deeper analysis.

Research results and discussion

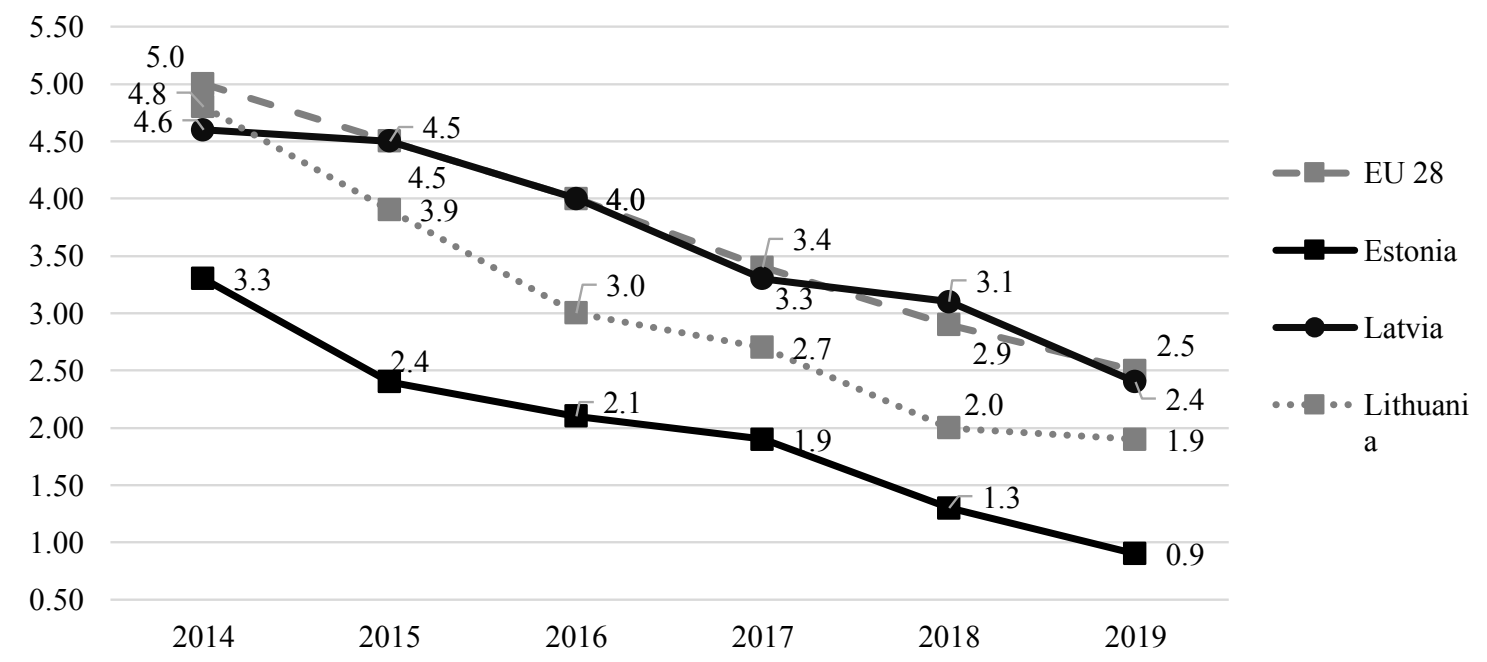

Source: author's construction based on data of Eurostat

Fig. 1. Long-term unemployment rate in Baltic states and EU average from 2014 to 2019, \%

Long-term unemployment is indicator that measures the share of the economically active population aged 15 to 74 who are out of work and have been actively seeking employment for at least a year. According to Figure 1 the lowest long-term unemployment from Baltic countries is in Estonia, followed by Lithuania, while the highest long-term unemployment is in Latvia and it is below EU average.

Data of unemployment rate in Latvia buy gender is reflected in figure 2. 


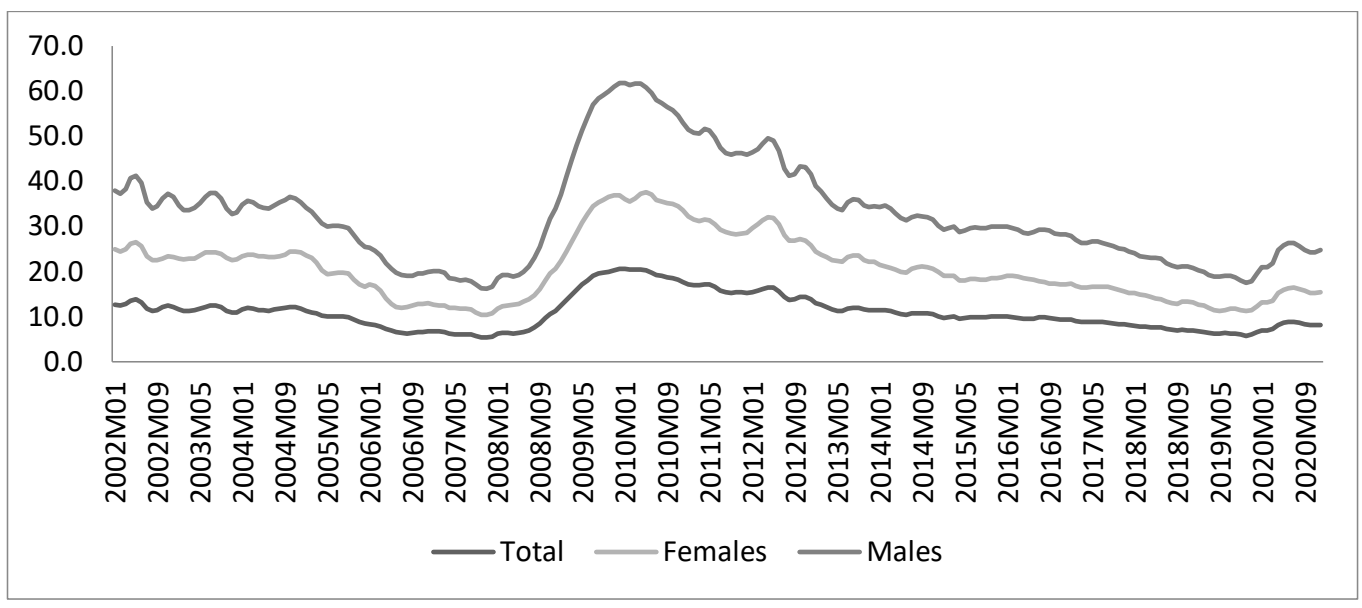

Source: author's construction based on data of Central Statistical Bureau of Republic of Latvia

Fig. 2. Unemployment rate in Latvia by gender from 2002 January to 2020 December, \%

Unemployment data indicate that female unemployment rate in Latvia is lower during all analysed period. Time series of unemployment rate in statistical regions of Republic of Latvia are reflected in figure 3.

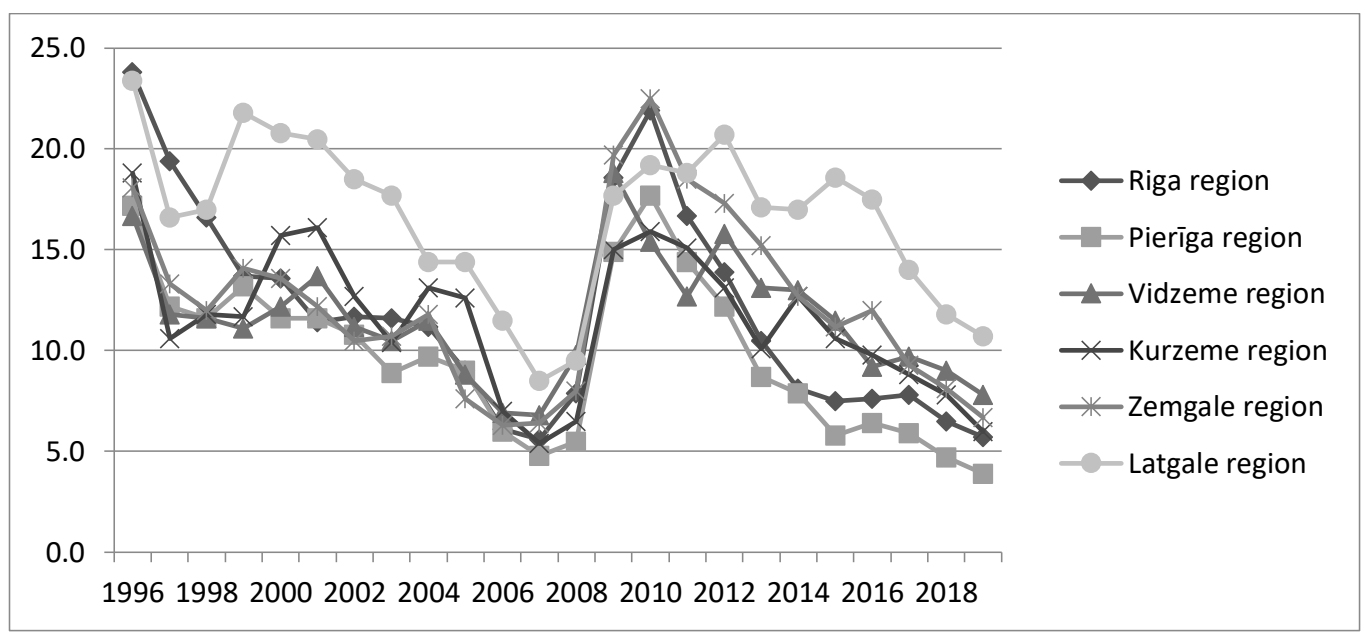

Source: author's construction based on data of Central Statistical Bureau of Republic of Latvia

Fig. 3. Unemployment rate in Latvia by gender from 1996 to 2019, \%

Unemployment data indicate that in Latgale region unemployment rate in Latvia is higher since 2012.

According to the administrative breakdown, there are 6 regions in Latvia: Rīga, Pierīga, Vidzeme, Kurzeme, Zemgale and Latgale. In Figure 4 is revealed individual's job search duration in regions of Latvia 


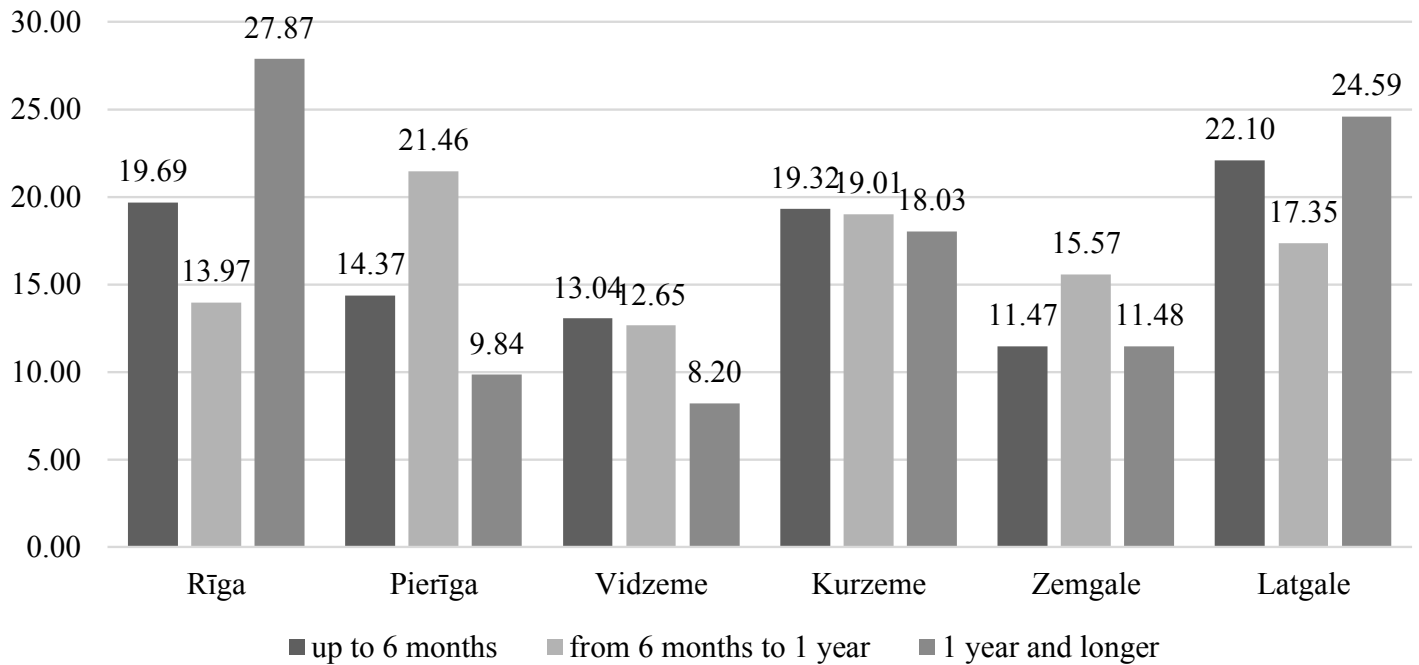

Source: author's construction based on data of Labour Force Survey

Fig. 4. Individual's job search duration in regions of Latvia in $2019, \%$

The statistics shows that the longest job search duration - one year and longer - is for inhabitants from Riga region, followed by Latgale region, while more that $20 \%$ of inhabitants of Latgale region spend the shortest time - up to 6 months - seeking for a job. Inhabitants of Zemgale region have the most difficulties in finding a job within six months, but majority of inhabitants of Pierīga region find a job from 6 months to one year long period of time. To evaluate - are there any significant differences between job search duration and regions of Latvia - analysis of variance was used (see table 1).

Table 1

Analysis of Variance (ANOVA) on Job Search Duration in 2019 by Regions in Latvia

\begin{tabular}{|l|c|c|c|c|c|}
\hline & Sum of Squares & df & Mean Square & F & Sig. \\
\hline Between Groups & 5,502 & 5 & 1,100 & 4,283 & 0,001 \\
\hline Within Groups & 1369,953 & 5332 & 0,257 & & \\
\hline Total & 1375,455 & 5337 & & & \\
\hline
\end{tabular}

Source: author's calculations and construction based on data of Labour Force Survey 2019

Data of table 1 (results of ANOVA) indicate that there are differences in job search duration in different regions in Latvia and they are statistically significant (sig. 0.001). Job search duration by territories of Latvia is included in Figure 5. 


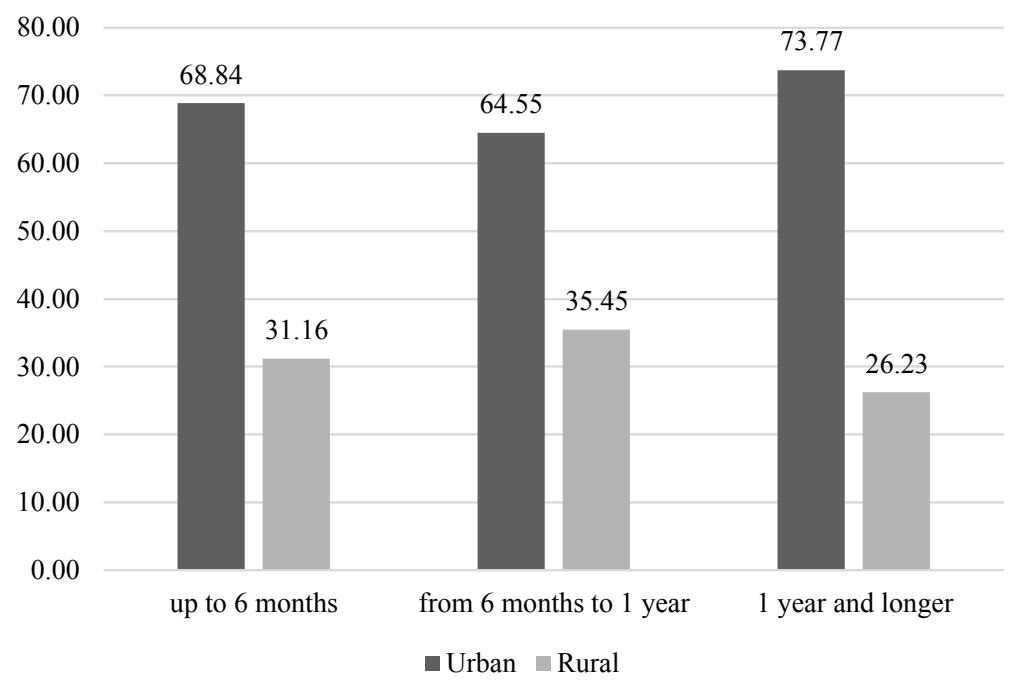

Source: author's construction based on data of Labour Force Survey 2019

Fig. 5. Individual's job search duration in urban and rural areas of Latvia in 2019, \%

Figure 5 indicate that individuals from urban areas search for the job mostly one year and longer while, while individuals in rural areas do it from six months to one year.

Table 2

Main Statistical Indicators of Job Search Duration in 2019 by Territories in Latvia

\begin{tabular}{|l|l|c|c|c|c|}
\hline & Territory & $\mathrm{N}$ & Mean & Std. Deviation & Std. Error Mean \\
\hline \multirow{2}{*}{$\begin{array}{l}\text { Job search } \\
\text { duration }\end{array}$} & Urban & 3490 & 1,89 & 0,542 & 0,009 \\
\cline { 2 - 6 } & Rural & 1848 & 1,89 & 0,435 & 0,010 \\
\hline
\end{tabular}

Source: author's calculation and construction based on data of Labour Force Survey 2019

Data of table 2 indicate that there are no differences in job search duration by territories in Latvia. To evaluate -independent sample t-test was used (see table 3).

Table 3

Analysis of Differences with t-tests on Job Search Duration in 2019 by Territories in Latvia

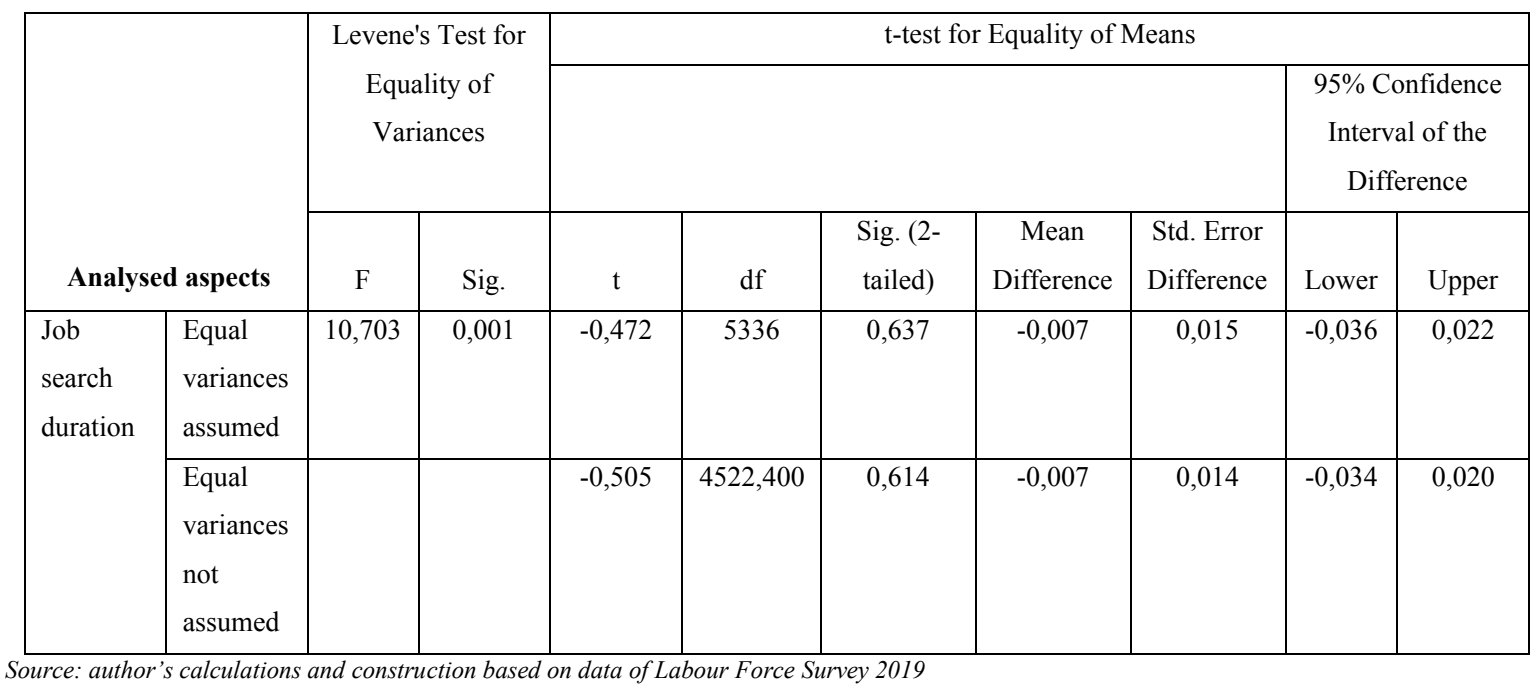

Data of table 3 (results of t-test) indicate that there are no differences in job search duration by territories (urban and rural areas) in Latvia and they are not statistically significant (sig. 0.637 and 0.614 ).

\section{Conclusions, proposals, recommendations}


1. The analysis of theoretical research revealed that regional differences are on great importance across European Union countries as well as in USA, however job search duration differ by countries and each country have its own challenges to overcome.

2. The lowest long-term unemployment from Baltic countries is in Estonia, followed by Lithuania, while the highest long-term unemployment is in Latvia and it is below EU average.

3. In case of regions of Latvia longest job search duration - one year and longer - is for inhabitants from Riga region, followed by Latgale region, while more that $20 \%$ of inhabitants of Latgale region spend the shortest time - up to six months - seeking for a job. Inhabitants of Zemgale region have the most difficulties in finding a job within six months, but majority of inhabitants of Pierīga region find a job from six months to one-year long period of time. Also, analysis of variance (ANOVA) indicates that there are differences in job search duration in different regions in Latvia and they are statistically significant

4. There are no differences in job search duration by territories (urban and rural areas) in Latvia and they are not statistically significant (sig. 0.000).

\section{Bibliography}

Azolibe, C.B., Nwadibe, C.E., Okeke, C.M.-G., 2020. Socio-Economic Determinants of Public Expenditure in Africa: Assessing the Influence of Population Age Structure. International Journal of Social Economics, 47(11), 1403-1418.

Audretsch, D. B., Duhse, D., Niebuhr, A., 2015. Regional Unemployment Structure and New Firm Formation. Papers in Regional Science, 94, 115138.

Bergantino, A. S., Madio, L., 2019. Intra- andIinter-Regional Commuting: Assessing the Role of Wage Differentials. Papers in Regional Science, 98(2), 1085-1114

Boman, A., 2012. Employment Effects of Extended Geographic Scope in Job Search. Labour Economics, 19, 643-652.

Caparrós Ruiz, A., 2020. Social Capital, Labour Market Status and Wages: Some Evidence from Spain. International Journal of Social Economics, 47(4), 539-560.

Chan, S.H.J., Ben Yedder, M., Vipulakom, K., 2020. Predicting the effect of work values on workplace communication environment and job quality of tertiary students. Journal of International Education in Business, 13(2), 239-261.

Danacica, D.E., Cirnu, D., 2014. Unemployment Duration in Rural Romania, Procedia Economics and Finance, 15, 1173-1184

Eurostat. 2019. Duration of working life - annual data. Available at: http://appsso.eurostat.ec.europa.eu/nui/show.do?query=BOOKMARK DS208320_QID_-625504A8_UID_-3F171EB0\&layout=TIME,C,X,0;GEO,L,Y,0;SEX,L,Z,0;INDICATORS,C,Z,1;\&zSelection=DS-

208320SEX,T;DS-208320INDICATORS,OBS FLAG;\&rankName1=INDICATORS 12 -

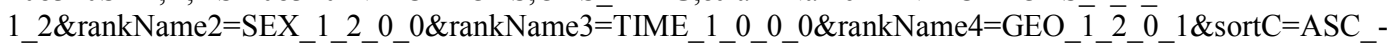

1_FIRST \&rStp $=\& \mathrm{cStp}=\& \mathrm{rDCh}=\& \mathrm{cDCh}=\& \mathrm{rDM}=$ true $\& \mathrm{cDM}=$ true $\&$ footnes $=$ false\&empty $=$ false\&wai=false \&time_mode=ROLLING\&time_mos t_recent=false\&lang=EN\&cfo= $\% 23 \% 23 \% 23 \% 2 \mathrm{C} \% 23 \% 23 \% 23 . \% 23 \% 23 \% 23$

Faberman, R.J., Kudlyak, M., 2016. The Intensity of Job Search and Search Duration, Federal Reserve Bank of San Francisco.

Fung, K.Y., 2020. Gender and Network Effects on Occupation: a Case study of China. International Journal of Sociology and Social Policy, 40(3/4), 267-281.

Granato, N., Haas, A., Hamann, S., Niebuhr, A., 2015. The Impact of Skill-Specific Migration of Regional Unemployment Disparities in Germany. Journal of Regional Science, 55(4), 513-539.

Hazans, M., 2007. Looking for the Workforce: The Elderly, Discouraged Workers, Minorities, and Students in the Baltic Labour Markets. Empirica, 34(4), 319-349.

Huertas, I. P., Ramos, R., Simon, H., 2019. Revisiting Interregional Wage Differentials: New Evidence from Spain with Matched EmployerEmployee Data. Journal of Regional Science, 60(2), 296-347.

Jakšic, S., 2017. Explaining Regional Unemployment in Croatia: GVAR Approach. Revija za Socijainu Politiku, 24(2), $189-217$.

Lichter, A., Schiprowski, A., 2021. Benefit Duration, Job Search Behaviour and Re-employment. Journal of Public Economics, $193,104326$.

Mayerhoffer, M., 2020. Growth Factors of the Coworking Industry: the Case of Prague. Journal of Property Investment \& Finance, 38(3), $203-212$.

McKay, F.H., McKenzie, H.J., 2020. Life Outside the Garment Factories: the Lived Experiences of Cambodian Women Garment Factory Workers. International Journal of Migration, Health and Social Care, 16(4), 415-427. 
McFadden, C., 2020. Hiring Discrimination against Transgender Job Applicants - Considerations when Designing a Study. International Journal of Manpower, 41(6), 731-752.

Morkute, G., 2019. Location-Specific Knowledge in Spatial Job Search and its Outcomes: An Empirical Investigation. Papers in Regional Science, 98, 1373-1395.

Oinas, T., Ruuskanen, P., Hakala, M., Anttila, T., 2020. The Effect of Early Career Social Capital on Long-Term Income Development in Finland. International Journal of Sociology and Social Policy, 40(11/12), 1373-1390.

Strakova, R., 2018. Regional Disparities and Unemployment Rate: Role of Education in Regional Development. Journal of Applied Economic Science, 3(57), 663-672.

The Labour Force Survey 2019 [online]. [cit. 2020-10-20] Available at: https://admin.stat.gov.lv/system/files/publication/202006/Nr_15_Darbaspeka_apsekojuma_galvenie_raditaji_2019_gada_\%2820_00\%29_LV_EN.pdf

Scarano, G., 2020. Alternative models of activation policies: the experience of public oriented services. International Journal of Sociology and Social Policy, 40(3/4), 382-408.

Uyar, A., Kılı̧̧, M., Kö eoğlu, M.A., 2020. Network analysis in accounting research: an institutional and geographical perspective. Journal of Applied Accounting Research, 21(3), 535-562.

Viinikainen, J., Böckerman, P., Elovainio, M., Hakulinen, C., Hintsanen, M., Kähönen, M., Pehkonen, J., Pulkki-Råback, L., Raitakari, O., Keltikangas-Järvinen, L., 2020. Personality, Occupational Sorting and Routine Work. Employee Relations, 42(6), 1423-1440.

The paper was supported by the NATIONAL RESEARCH PROGRAMME "LATVIAN HERITAGE AND FUTURE CHALLENGES FOR THE SUSTAINABILITY OF THE STATE” project “CHALLENGES FOR THE LATVIAN STATE AND SOCIETY AND THE SOLUTIONS IN INTERNATIONAL CONTEXT (INTERFRAME-LV)" 
THE SUBJECTIVE AND OBJECTIVE EVALUATION OF ACCOMODATION IN LATVIA IN THE AFTERCRISIS PERIOD

\author{
Andris Litins, University of Latvia
}

\title{
Silvija Kristapsone, University of Latvia
}

\begin{abstract}
The most important wishes of people concentrate on the tendency to reach vitally significant factors (well-being, security, sustainability) that are realized through various channels - education, employment, family, material prosperity a.o.).

One of the basic needs of an individual is a need for a physical shelter or a dwelling, yet, a dwelling is not only a roof over the head - it is also an indicator of the life quality. In its turn, it includes also the location of the dwelling, its technical conditions, as well as the living space - all influences the quality of life. Thereby the satisfaction with the dwelling can be linked with the satisfaction with life and well-being.

On the side of the state accessibility to a qualitative dwelling is important to diminish depopulation, to promote the growth of the nation, to ensure labour force mobility, development of new work places as well as decrease of poverty and rejection. Taking the above mentioned into consideration The Latvian National development plan till 2030 is aimed at providing all households with dwellings that correspond to high standards of energoeffectivity, building, safety and conveniences (Cross-Sectoral Coordination Centre Republic of Latvia, 2020).
\end{abstract}

The aim of the article is, basing on the two recent surveys - 2011. and 2016. - EQLS (European Quality of Life Survey) inquiry data, to evaluate the situation of the levels of satisfaction with accomodation and tendences in Latvia that in the survey are included in the section Housing. The information is supplemented with Latvia official statistical data that characterize the indicators of the objective residential situation thus drafting the main problem questions of Latvia main residential market for further research.

Descriptive and conclusive statistical analysis methods were employed in the research. The official statistics of Eurofond EQLS 2011 and 2016 survey databasis from the UK Data Archive, Latvia Central statistical office and Latvia Land Register as well as scientific literature were used.

To reach the aims the following tasks were set:

To make analysis of the scientific literature,

To evaluate the indicators of the EQLS surveys and correlations among them,

To offer characteristic tendences of residences and the residential market situation in Latvia in 2010.-2019.

It was stated in the research that satisfaction with the accomodation statistically significantly influences the quality of life. According to the data of 2016 in conformity with the general self-evaluation of inhabitants in the aftercrisis period the qualitative indicators about dwellings have gradually improved. The data of official statistics reveal quantitative and qualitative positive changes in the residential situation, the activity of the residential market has increased as well. Nevertheless, in Latvia a considerable regional contentration of the residential fond is observed in Riga and outskirts of Riga, that is determined by the number of inhabitants and economic activity in the regions.

The obtained results have pointed to the directions and questions for further potential research.

Key words: Housing, Housing indicators, Subjective Well-being, Quality of Life.

JEL code: I31,P36, R21, R31

\section{Introduction}

The concept of the quality of life in the characteristics of the social life emerged in the 70ies of the 20th century. It is a wide concept connected with the general well-being in the society. The aim of the life quality is that people as much as possible would reach their individual aims and choose their ideal way of life. In this aspect the concept of the life quality exceeds the approach that concentrated on accessible material resources of individuals. The approach of the European Union agency Eurofond is based on the conclusion that the concept "life quality" characterizes individual personal well-being as well as the quality of social services and the society. The most significant wishes of individuals are concentrating in their will for vitally significant factors (well-being, security, sustainability), further specification of which reveal several closely interrelated aspects: education, employment, material welfare, health, dwelling, social safety, consolidation of the society; protection of the surrounding environment, physical safety, employment of material and energy resources etc. When one of the factors changes or just the opposite - does not change the growth of the life quality indicator can be limited. Nowadays life quality is a complex concept, that includes the existing objective and subjective indicators in various life spheres which are mutually interrelated. 
The aspects of the subjective life quality are revealed in various inquiries. E.g., European Quality of Life Survey, EQLS is a verified tool of EU supervision and analysis of the life quality. Such inquiries were carried out in 2003, 2007, 2011 and 2016, when documenting the life conditions and social situation including evaluation of attitudes and choices, resources and experience. Surveys carried out every $4-5$ years reveal the objective life conditions of inhabitants and also how inhabitants evaluate the conditions and life in general, so gaining data about questions that have not been included in general statistics.

The fieldwork for the third European Quality of Life Survey (EQLS) took place from the end of September 2011 to early February 2012 . From September 2016 to March 2017 Eurofond carried out its fourth survey in the series. The EQLS is a survey of the adult population (18+) living in private households, based on a statistical sample and covering a cross-section of society. Depending on the country size and national arrangements, the 2016 sample ranged from 1,000 to 2,000 people per country. Latvia in the survey in 2011 was represented by 1009 respondents, but in $2016-$ by 1000 respondents (Eurofond 2016).

\section{Theoretical aspects of residence as life quality}

The quality of life is a broad and complex concept that is affected in many ways. Quality of life can be defined as an individual's perception of their position in life in the context of the culture and value systems in which they live and in relation to their goals, expectations, standards, and concerns. Other authors (Sęk, 1993) define the quality of life as an aggregate of conditions in which one lives - objectively assessed attributes of a person connected with one's standard of living and social status, and the proper functioning of one's body. (Napiorkowska-Baryla, 2020).

The main factors and areas that are considered the most significant when measuring the quality of life can be grouped in 5 categories - emotional well-being; health; family and social relations, material welfare, and professional work or other forms of activity. Occupation, family, housing and income are the four spheres of life which most significantly affect the situation and are essential to evaluate the quality of life. (NapiorkowskaBaryla, 2020).

Dwelling can be considered as one of indicators essentially influencing the life quality of inhabitants. Dwelling has a significant role in people's lives, as dwelling is not only a physical shelter but it also determines the inhabitant's welfare and life quality. Already in the Maslow pyramid dwelling is defined as one of the basic needs. On its turn, the technical condition of the dwelling, its locality, living space a.o. factors are directly connected with the satisfaction with life and the life quality.

Residential satisfaction - this indicator often is used to evaluate several factors connected with the living premises. The indicator testifies also about the individual's life quality. With the help of this indicator the solutions of the living space ensurance in the private and the public sectors are evaluated. Satisfaction with the residence or the living premises also shows the opinion of an individual about the present situation and reveals the shortcomings in the present dwelling that in its turn can help both the private and the public sector to understand what improvements are necessary in the residential market (Mohit, 2014).

Residential satisfaction is indicator that also can help to determine housing demand characteristics. Different aspects affect individuals housing and residential satisfaction and the way how they select their potential dwelling place. Knowing those aspects can be helpful to determine the tendencies for individuals to choose a potential dwelling. Factors that affect residential satisfaction can be grouped mainly in two groups, physical and non-physical factors. For example, physical factors - location, housing type, neighborhood; non-physical - security, ownership status (Aulia\&Ismail, 2013).

An essential aspect of the evaluation of the residential satisfaction and also of the welfare and the life quality is that they are subjective indicators. Therefore, the evaluation can be influenced by the individual's material situation, education, sex a.o. factors. E.g., Fang Zhang (2018) in his research confirms that the lower is the income in the household, the easier with the changes in the dwelling space (size a.o.) the sense of satisfaction can be strenghthened (Zhang, 2018). When speaking about various spheres of life it has been concluded that a significant role in evaluating the life quality belongs to what is or is not important for the particular individual. When evaluating the life quality some indicator is low, it might not influence the general life quality if the indicator is not important for the individual and vice versa - if the life quality indicator is important for the individual and it is low then totally it can influence the evaluation of the life quality (Carver \& Scheier, 1998).

When measuring quality of life, several approaches can be used - e.g. theoretical quality of life, that can be measured through statistical variables, or subjective evaluation of living conditions by its residents. A different matter is subjective well-being because it depends on many factors, such as internal disposition, health, etc. Surveys that research different aspects of subjective quality of life are based on how satisfied a person is with the way of life they lead. It can be assumed that the answers reflect the city's suitability for living (housing supply, jobs, infrastructure and public 
transport, health and social care, quality of education, cultural and sports infrastructure and supply, governance and people). (Gajdos \& Hudec, 2020)

\section{Subjective well-being and dwelling}

There exist a certain coherence between the living space and the subjective well-being. The living space indirectly points to the individual's income and wealth, and also consecutively influences the individual's social status. Dwelling is one of the biggest and most expensive objects the individual can acquire. Accordingly, the dwelling is an indicator of wealth. In the research it can be found that the lack of the living space is one of the main reasons why individuals choose to move and look for a new dwelling (Foye, 2017).

Robert Rudolf and Cuz Potter (2015) in their research discuss factors how dwelling influences the subjective well-being. They point out four main factors: personal control, identity and self-evaluation, social support, inequality and residential policy (Rudolf \& Potter, 2015).

The personal control is attributed to opportunities to introduce one's own solutions and introduce changes in one's dwelling. Thus, the persons who own the dwelling have a greater personal control than persons who rent them. Identity and self-evaluation are connected with the fact that the choice of the dwelling can attach a higher social status thus promoting well-being and sense of happiness. Taking into consideration that the dwelling is the place in which family and social relations are maintained the dwelling can favour well-being through a social support from others. In their turn the applied residential policy and measures that further social inclusion and decrease inequality consecutively can promote general well-being (this is more related to less provided individuals) (Rudolf \& Potter, 2015).

Several factors that determine satisfaction with the dwelling can be defined, and namely, the title to the property, the size and the kind of the dwelling. The title to the property is an essential factor. As proven by research, the individuals who own the dwelling are more satisfied with the dwelling than those who only rent the dwelling (Rudolf \& Potter, 2015).

E. g., as stated in the research about the correlation of the kinds of ownership of the dwelling and satisfaction with life in Germany, the level of satisfaction with life of the individuals who own a dwelling is 1,16 times higher than that of the individuals who only rent the dwelling (Zumbaro, 2014).

The purchase of a dwelling simultaneously can be considered as one of the biggest investments - as a place that serves as shelter and also as an essential instrument of financial investment. Thus, a dwelling can serve as a mechanism of accumulating wealth and as indirect provision of financial safety for future (Coates \& Norris, 2015).

The size of the dwelling or the living space in its turn influences the individual's perception in several ways. First, a bigger premise means a bigger personal space that, in its turn, means a bigger personal control. According to the research, a bigger living space has a positive correlation with the subjective well-being. In addition to that, the bigger living space can influence the social community - opportunities to communicate just in the particular dwelling (Rudolf \& Potter, 2015).

Timo Zumbaro (2014) in his research about Germany confirms the hypothesis that the surrounding environment of the dwelling and its technical condition influences the individual's satisfaction with life. E.g., living in an industrial district and also living in the dwelling that needs renovation, or living in a dwelling with a big number of inhabitants decreases the opportunity to reach a higher level in the scale of the life satisfaction (Zumbaro, 2014).

Similar research was carried out in China in which the researchers stressed the need for a State Residential programme that is based on the positive experience of the implementation of the programme of residential improvement in 1980. In China's research similar to that in Germany's the researchers proved that the evaluation of the individual 's subjective well-being is connected with the title of the property of the dwelling. In addition to that, the researchers stated that the perception of the subjective well-being of the owners of the dwelling in the city is lower than that of the individuals who live outside the city. The researchers explained it by a bigger financial burden of the dwelling owners in the city that, in its turn, is linked with higher prices of an immovable property in the city compared to that in outskirts or urban districts (Hu, 2013).

Physical housing conditions also have an impact on subjective well-being, but the impact can change depending on many factors (e.g. individuals income level, gender; and many other factors). Study carried out by Clapham\&Foye (2018) suggests that the effects of housing conditions on subjective well-being are much smaller than different life events, but are still substantial. Other studies suggest that factors such as poor lighting, wet or dry rot, neighbor noise, damp and condensation have a significant negative impact on life satisfaction. (Clapham\&Foye, 2018).

\section{Research results and discussion}

What is the situation that characterizes the residential situation in Latvia according to EQLS? 
In general, evaluation of several separate aspects of the subjective well-being (Table 1), it can be concluded that the satisfaction with the present level of life, the satisfaction with life in general and with the dwelling is the lowest.

Table 1

The Comparison of Evaluation of Separate Aspects of the Subjective Well-being

\begin{tabular}{|c|c|c|c|c|c|c|c|}
\hline & & $\mathrm{N}$ & Mean & $\begin{array}{c}\text { Std. } \\
\text { Deviation }\end{array}$ & Z & $\begin{array}{l}\text { Asymp. } \\
\text { Sig. (2- } \\
\text { tailed) }\end{array}$ & $\begin{array}{l}\text { Mean } \\
\text { in EU }\end{array}$ \\
\hline \multirow{2}{*}{$\begin{array}{l}\text { Life satisfaction (1 very } \\
\text { dissatisfied, } 10 \text { very } \\
\text { satisfied) }\end{array}$} & 2011 & 1006 & 6,15 & 2,274 & \multirow[t]{2}{*}{$-0,241$} & \multirow[t]{2}{*}{0,81} & \multirow[t]{2}{*}{6,93} \\
\hline & 2016 & 993 & 6,15 & 2,197 & & & \\
\hline \multirow{2}{*}{$\begin{array}{l}\text { Satisfaction with } \\
\text { education (1 very } \\
\text { dissatisfied, } 10 \text { very } \\
\text { satisfied) }\end{array}$} & 2011 & 996 & 7,13 & 2,411 & \multirow[t]{2}{*}{$-0,522$} & \multirow[t]{2}{*}{0,601} & \multirow[t]{2}{*}{7,09} \\
\hline & 2016 & 994 & 7,15 & 2,173 & & & \\
\hline \multirow{2}{*}{$\begin{array}{l}\text { Satisfaction with job (1 } \\
\text { very dissatisfied, } 10 \\
\text { very satisfied) }\end{array}$} & 2011 & 454 & 7,23 & 2,329 & \multirow[t]{2}{*}{$-1,979$} & \multirow[t]{2}{*}{0,048} & \multirow[t]{2}{*}{7,36} \\
\hline & 2016 & 459 & 7,60 & 2,005 & & & \\
\hline \multirow{2}{*}{$\begin{array}{l}\text { Satisfaction with } \\
\text { standard of living (1 } \\
\text { very dissatisfied, } 10 \\
\text { very satisfied) }\end{array}$} & 2011 & 999 & 5,78 & 2,347 & \multirow[t]{2}{*}{$-1,664$} & \multirow[t]{2}{*}{0,096} & \multirow[t]{2}{*}{6,77} \\
\hline & 2016 & 996 & 5,97 & 2,146 & & & \\
\hline \multirow{2}{*}{$\begin{array}{l}\text { Satisfaction with } \\
\text { accommodation (1 very } \\
\text { dissatisfied, } 10 \text { very } \\
\text { satisfied) }\end{array}$} & 2011 & 1007 & 6,62 & 2,473 & \multirow[t]{2}{*}{$-0,14$} & \multirow[t]{2}{*}{0,889} & \multirow[t]{2}{*}{7,60} \\
\hline & 2016 & 997 & 6,69 & 2,265 & & & \\
\hline \multirow{2}{*}{$\begin{array}{l}\text { Satisfaction with family } \\
\text { life ( } 1 \text { very dissatisfied, } \\
10 \text { very satisfied) }\end{array}$} & 2011 & 981 & 7,16 & 2,587 & \multirow[t]{2}{*}{$-0,774$} & \multirow[t]{2}{*}{0,439} & \multirow[t]{2}{*}{7,86} \\
\hline & 2016 & 975 & 7,34 & 2,321 & & & \\
\hline $\begin{array}{l}\text { Satisfaction with local } \\
\text { area (1 very dissatisfied, } \\
10 \text { very satisfied) }\end{array}$ & 2016 & 995 & 8,02 & 2,066 & $X$ & $X$ & 7,89 \\
\hline
\end{tabular}

Source: author's construction based on: Eurofond, 2018

These indicators are only a small part of all the system of indicators, that characterize a person's satisfaction with the life in general but, undeniably, the satisfaction with the present level of life and the satisfaction with the dwelling are one of the lowest, and they are aspects of the general satisfaction with life. EQLS of 2016 was supplemented with a new life quality aspect that undeniably add to the general evaluation of the life conditions, and namely, - satisfaction with the local area (1 very dissatisfied, 10 very satisfied). In Latvia it is evaluated rather highly - with 8,02 points (in EU on average - 7,89 points) which as a new indicator is not comparable with the previous measurements. Yet the high level of the satisfaction with the local area testify to the correspondence of the local area to the everyday needs of people's work and rest, demands for nature and infrastructure.

The fact that there exists a connection between the life satisfaction and the satisfaction with accommodation has been confirmed by Spirmen's correclation coefficient calculations of various life quality evaluations by Latvian respondents. (Table 2)

Life satisfaction and Satisfaction with accomodation correlations

\begin{tabular}{|c|c|c|c|}
\hline \multicolumn{4}{|c|}{ Life satisfaction (1 very dissatisfied, 10 very satisfied) } \\
\hline & $\begin{array}{c}\text { Spearmen } \\
\text { Correlation } \\
\text { Coefficient }\end{array}$ & $\begin{array}{c}\text { Sig. (2- } \\
\text { tailed) }\end{array}$ & N \\
\hline (1 very dissatisfied, 10 very satisfied) &, $200^{* *}$ & 0,000 & 1980 \\
\hline Satisfaction with education (Q6a) &, $353^{* *}$ & 0,000 & 909 \\
\hline Satisfaction with job (Q6b) &, $623^{* *}$ & 0,000 & 1985 \\
\hline Satisfaction with standard of living (Q6c) & $\mathbf{3 6 0}^{* *}$ & 0,000 & 1995 \\
\hline Satisfaction with accommodation (Q6d) &, $319^{* *}$ & 0,000 & 1949 \\
\hline Satisfaction with family life (Q6e) & $\mathbf{1 7 4}^{* *}$ & 0,000 & 989 \\
\hline Satisfaction with local area (Q6f) & & & \\
\hline
\end{tabular}


Evaluating influence of the satisfaction about accomodation and the satisfaction with the local area on the satisfaction with life in general, the following models of linear regression that include satisfation with accomodation were obtained.

$\begin{array}{lrrrrrr}\text { Model R } & \text { R Square } & \begin{array}{l}\text { Adjusted } \\ \text { R Square }\end{array} & \begin{array}{r}\text { Std. Error of } \\ \text { the Estimate }\end{array} & \text { F } & \text { Sig. } \\ & & & & & \\ 1 & \text {,445a } & , 198 & \mathbf{, 1 9 6} & 1,729 & 111,144 & , 000 \\ 2 & , 505 b & , 255 & \mathbf{, 2 5 2} & 1,669 & 76,876 & , 000 \\ 3 & \text {,541c } & , 293 & \mathbf{, 2 8 8} & 1,628 & 61,887 & , 000\end{array}$

Dependent Variable: Life satisfaction (1 very dissatisfied, 10 very satisfied),

a. Predictors: (Constant), Satisfaction with accommodation (Q6d),

b. Predictors: (Constant), Satisfaction with accommodation(Q6d), Satisfaction with job (Q6b),

c. Predictors: (Constant), Satisfaction with accommodation(Q6d), Satisfaction with job (Q6b), Satisfaction with family life (Q6e).

Coefficients

\begin{tabular}{|c|c|c|c|c|c|c|}
\hline \multirow[t]{2}{*}{ Model } & \multicolumn{3}{|c|}{ Unstandardized Coefficients } & Standardized Coefficients & \multirow[t]{2}{*}{$\mathrm{t}$} & \multirow[t]{2}{*}{ Sig. } \\
\hline & & B & Std. Error & Beta & & \\
\hline \multirow[t]{2}{*}{1} & (Constant) & 3,986 & ,266 & & 14,998 &, 000 \\
\hline & Q6d & ,394 & ,037 & ,445 & 10,542 &, 000 \\
\hline \multirow[t]{3}{*}{2} & (Constant) & 2,538 & ,356 & & 7,127 &, 000 \\
\hline & Q6d & ,336 &, 037 & ,380 & 8,989 &, 000 \\
\hline & Q6b & ,241 &, 041 &, 248 & 5,862 &, 000 \\
\hline \multirow[t]{4}{*}{3} & (Constant) & 1,678 & ,389 & & 4,314 &, 000 \\
\hline & Q6d & ,283 & ,038 & ,319 & 7,423 & 000 \\
\hline & Q6b & ,203 &, 041 & ,208 & 4,967 &, 000 \\
\hline & Q6e & 199 & 041 &, 211 & 4,901 &, 000 \\
\hline
\end{tabular}

As can be concluded, the satisfaction with accomodation influences the satisfaction with life statistically significantly in all calculated models showing R2 from 0,196 till 0,288, pointing to the influence of the satisfaction with life up to $28,8 \%$.

In Latvia the satisfaction with accomodation is evaluated with 6,7 points compared to 6,6 points in 2011, and this change is not statistically significant $(Z=-0,062, p=0,951)$. In comparison with other EU countries Latvia shows the lowest level of the satisfaction with accomodation among EU countries (in EU - average - 7; the maximum evaluation level is in Denmark - 8,5 points). It can greatly be explained by the ways Latvia is different from other countries - by the quality of the soviet time living fund that is still in exploitation though it has served its time, by the inhabitants' limited opportunities to improve the conditions of their accomodation, by psychological fear to take upon themselves financial liabilities after 2008.-2010. crisis.

When evaluating the given answers to "Which of the following best describes your accomodation - Ownership of accommodation", it can be concluded that the greater part of respondents who have given answers to this question are living in the dwelling without mortgage (70,6\%) and in comparison with 2011, in 2016 this proportion has increased by 6,9\%p. At the same time 18,3\% respondent are tenants and this proportion compared to 2011 has decreased a little $(-2,1 \%$ p). By $-3,2 \%$ p also another legal kind of living in the dwelling has decreased. These results allow the authors of the article advance a hypothesis that part of inhabitants who previously rented an accommodation, choose to obtain an accommodation by using opportunities of mortgage (Table 3). 
Table 3

Ownership of accommodation

\begin{tabular}{|c|c|c|c|}
\hline & \multicolumn{2}{|c|}{ Year } \\
\hline & & 2011 & 2016 \\
\hline \multirow{2}{*}{$\begin{array}{l}\text { 1 Own without mortgage (i.e. without any } \\
\text { loans) }\end{array}$} & Count & 643 & 702 \\
\hline & $\%$ & $63,7 \%$ & $70,6 \%$ \\
\hline \multirow[t]{2}{*}{2 Own with mortgage } & Count & 101 & 85 \\
\hline & $\%$ & $10,0 \%$ & $8,5 \%$ \\
\hline \multirow[t]{2}{*}{3 Tenant, paying rent to private landlord } & Count & 90 & 79 \\
\hline & $\%$ & $8,9 \%$ & $7,9 \%$ \\
\hline \multirow{2}{*}{$\begin{array}{l}4 \text { Tenant, paying rent in } \\
\text { social/voluntary/municipal housing }\end{array}$} & Count & 116 & 103 \\
\hline & $\%$ & $11,5 \%$ & $10,4 \%$ \\
\hline \multirow[t]{2}{*}{ Other } & Count & 59 & 26 \\
\hline & $\%$ & $5,8 \%$ & $2,6 \%$ \\
\hline \multirow[t]{2}{*}{ Total } & Count & 1009 & 995 \\
\hline & $\%$ & $100,0 \%$ & $100,0 \%$ \\
\hline
\end{tabular}

Source: author's construction based on: Eurofond, 2018

Both in 2011 and in 2016, $86 \%$ of respondents live in up to 3-room accommodations and in the dynamics only the inner structure of this totality has changed: insignificantly has grown the number of respondents who accommodate in two rooms, but the number of those living in one or two room accommodation has decreased. A little more that $12 \%$ of respondents live in $4-5$ room accommodations. (Table 4 ).

Table 4

Number of rooms in accommodation

\begin{tabular}{|c|c|c|c|c|}
\hline & & & & ear \\
\hline & & & 2011 & 2016 \\
\hline Number of & 1 & Count & 198 & 186 \\
\hline rooms in & & $\%$ & $19,6 \%$ & $18,7 \%$ \\
\hline accommodation & 2 & Count & 405 & 425 \\
\hline & & $\%$ & $40,1 \%$ & $42,6 \%$ \\
\hline & 3 & Count & 265 & 246 \\
\hline & & $\%$ & $26,3 \%$ & $24,7 \%$ \\
\hline & 4 & Count & 78 & 94 \\
\hline & & $\%$ & $7,7 \%$ & $9,4 \%$ \\
\hline & 5 & Count & 44 & 29 \\
\hline & & $\%$ & $4,4 \%$ & $2,9 \%$ \\
\hline & $\geq 6$ & Count & 19 & 17 \\
\hline & & $\%$ & $1,9 \%$ & $1,7 \%$ \\
\hline Total & & Count & 1009 & 997 \\
\hline & & $\%$ & $100,0 \%$ & $100,0 \%$ \\
\hline
\end{tabular}

Source: author's construction based on: Eurofond, 2018

As compared with the information the respondents gave in 2011 and 2016 about the number of rooms in the accomodation, the differences are not statistically significant $(Z=-0,254, p=0,800)$. The typical number of rooms in the accomodation of an inhabitant in Latvia is $2-3$.

EQLS about the life conditions includes questions about drawbacks or problems in the accomodation the respondents meet and that characterize the quality of the accomodation (Table 5).

Table 5

Problems with accommodation

\begin{tabular}{|c|c|c|c|c|c|c|}
\hline & & & 2011 & 2016 & $\begin{array}{l}\text { Kolmogorov- } \\
\text { Smirnov Z }\end{array}$ & $\begin{array}{l}\text { Sig. (2- } \\
\text { tailed) }\end{array}$ \\
\hline \multirow[t]{2}{*}{ Shortage of space } & \multirow[t]{2}{*}{ Yes } & Count & 229 & 221 & 0,133 & 1,000 \\
\hline & & $\%$ & $22,8 \%$ & $22,1 \%$ & & \\
\hline \multirow{2}{*}{$\begin{array}{l}\text { Rot in windows, doors or } \\
\text { floors }\end{array}$} & \multirow[t]{2}{*}{ Yes } & Count & 263 & 210 & 1,120 & 0,163 \\
\hline & & $\%$ & $26,2 \%$ & $21,1 \%$ & & \\
\hline \multirow[t]{2}{*}{ Damp or leaks in walls or roof } & \multirow[t]{2}{*}{ Yes } & Count & 328 & 271 & 1,205 & 0,109 \\
\hline & & $\%$ & $32,6 \%$ & $27,1 \%$ & & \\
\hline \multirow[t]{2}{*}{ Lack of indoor flushing toilet } & \multirow[t]{2}{*}{ Yes } & Count & 186 & 133 & 1,147 & 0,144 \\
\hline & & $\%$ & $18,4 \%$ & $13,3 \%$ & & \\
\hline \multirow[t]{2}{*}{ Lack of bath or shower } & \multirow[t]{2}{*}{ Yes } & Count & 209 & 145 & 1,389 & 0,042 \\
\hline & & $\%$ & $20,7 \%$ & $14,5 \%$ & & \\
\hline
\end{tabular}


According to the obtained results all the drawbacks of the accomodation revealed in the survey in the course of time (2016. compared to 2011.) have percentually diminished. The most common drawback in connection with accomodation is damp or leaks in the walls or roof that has been confirmed by $27,1 \%$ of respondents in 2016. It is followed by shortage of space, that in 2016 was marked by $22,1 \%$, rot in the windows, doors or floors marked by $21,1 \%$ of respondents. Comparatively more seldom as an accomodation drawback lack of bath or shower has been mentioned $(14,5 \%)$ and lack of indoor flushing toilet $(13,3 \%)$. Yet in the dinamics these changes in four of five drawbacks are not statistically significant or essential with the exception of lack of bath or shower.

In the survey in 2016 lack of facilities (heating or cooling) to keep a comfortable temperature at home was included as a drawback of the accomodation. $11.0 \%$ of Latvian respondents have marked it as a drawback of the accomodation.

Nevertheless in many indicators the changes are not statistically significant, yet as seen in the later described statistical data, a positive tendency is observed to lessen the drawbacks.

Beside the subjective evaluation that has been obtained in the surveys an objective characteristics of the situation with accomodation in Latvia is given by official statistics (Table 6).

Table 6

Housing stock at the end of the year

\begin{tabular}{|r|c|c|c|c|c|c|}
\hline Year & $\begin{array}{l}\text { Total } \\
\text { area, } \\
\text { thsd } \mathrm{m}^{2}\end{array}$ & $\begin{array}{l}\text { Average number } \\
\text { of rooms in } \\
\text { household's use }\end{array}$ & $\begin{array}{l}\text { Average number } \\
\text { of rooms per } \\
\text { household } \\
\text { member }\end{array}$ & $\begin{array}{l}\text { Average } \\
\text { size of } \\
\text { dwelling, } \\
\text { m2 }\end{array}$ & $\begin{array}{l}\text { Total area per } \\
\text { permanent } \\
\text { resident, } \mathrm{m}^{2}\end{array}$ & $\begin{array}{l}\text { Number of } \\
\text { contract } \\
\text { approvals in } \\
\text { the } \\
\text { Landbook }\end{array}$ \\
\hline 2010 & 67926 & 2,5 & 1,0 & 61,1 & 33 & 36604 \\
\hline 2011 & 69066 & 2,8 & 1,2 & 62,0 & 34 & 42051 \\
\hline 2012 & 70349 & 3,0 & 1,3 & 62,5 & 35 & 43941 \\
\hline 2013 & 72077 & 3,0 & 1,2 & 64,4 & 36 & 49141 \\
\hline 2014 & 73939 & 2,9 & 1,2 & 65,8 & 37 & 49973 \\
\hline 2015 & 74670 & 2,8 & 1,2 & 66,4 & 38 & 48397 \\
\hline 2016 & 74980 & 2,8 & 1,2 & 69,6 & 38 & 52152 \\
\hline 2017 & 75324 & 2,8 & 1,2 & 69,5 & 39 & 52640 \\
\hline 2018 & 76002 & 2,7 & 1,2 & 69,4 & 40 & 49093 \\
\hline 2019 & 77207 & 2,7 & 1,2 & 69,7 & 40 & 49890 \\
\hline$\Delta$ Average & 1031,2 & 0,02 & 0,02 & 0,96 & 0,78 & 1476,2 \\
\hline $2010-2019$ & & & & & & \\
\hline
\end{tabular}

Source: author's construction based on: Central Statistical Bureau of Latvia, 2020, b, c; National single computerized Landbook, 2020

As seen by the compiled information and calculations the housing stock has increased for 1031 thsd $\mathrm{m} 2$ every year, and by average 1476 every year the attachment requests in the National single computerized Landbook have increased as well. According to the data accessible in the databasis of the Landbook the accommodation market activity in the aftercrisis priod has considerably increased. The number of deals with the immovable property in 2019 in comparison with 2010 has increased by 36,3\%. The greatest activity can be observed in Riga and Riga outskirts (50,8\% from the total number of deals). Only in the $1-3$ quarters of 2019 the total number of the market selling deals in this segment was 20193 for the total sum of 762 mln.. EUR.

The greatest number of deals was with 2-roomed flats, and their proportion among the total number of deals was 44\% (Dzenite, 2019). The increase of the activity in the accomodation segment certainly can be connected with the Altum realized support programs for families with children and young specialists, offering guarantees which can be used as the first instalment payment in order to get the mortgage credit in the bank. Simultaneously with the growing demand in the accommodation market the increase of offer can be observed. According to the data of the Central Statistical Bureau since 2010 the growth of the total accommodation size has reached $13,6 \%$ that makes average $1,5 \%$ a year. It possibly is not an adequate speed to satisfy the needs of people for a larger living space, more qualitative living conditions and better technical conditions of the accommodation. The adequacy of the speed of growth to real needs of inhabitants can be a topic for further research.

It must be mentioned that Latio within the framework of the residential market survey included a question "Why are you reluctant to obtain an accommodation?" $29 \%$ of respondents mentioned that the reason is the terms of banks, $31 \%$ mentioned the situation in economics and only $17 \%$ mentioned insufficient offer. Accordingly, the situation in economics is one of the most essential aspects that influence the choice of a potential 
accommodation (Dzenīte, 2019). At an average, the average floor space increases per $1 \mathrm{~m} 2$, the total area per a permanent resident increasing by $0,8 \mathrm{~m} 2$. This fact can be positively evaluated taking into consideration previously analyzed survey results in which a significant part of respondents pointed to the narrowness of the floor space. Nevertheless, the indicators characterizing the situation with accommodation reveal an expressed unbalance that refers to the total area in Latvia as to thsd $\mathrm{m} 2$, floor space of new dwellings commissioned by statistical region, thsd $\mathrm{m} 2$ (Table 7 ). Half of all the accommodation space concentrates in Riga and Riga suburbs (2010 - 49,0\%, 2019-50,8\%). The situation can be explained by regional peculiarities of the inhabitants. At the same time in the last decade the accommodation space in thsd $\mathrm{m} 2$ has a tendency to increase, the highest speed being in Riga suburbs - 123,3\%, Riga region - 113,2\%, in other regions the speed of growth being in the borders between $108,5 \%$ $110,4 \%$.

Table 7

Housing stock in statistical regions at the end of the year (Total area, thsd $\mathbf{m}^{\mathbf{2}}$ )

\begin{tabular}{|r|r|r|r|r|r|r|r|}
\hline Year & LATVIA & $\begin{array}{l}\text { Rīga } \\
\text { region }\end{array}$ & $\begin{array}{l}\text { Pierīga } \\
\text { region }\end{array}$ & \multicolumn{1}{l}{$\begin{array}{l}\text { Vidzeme } \\
\text { region }\end{array}$} & $\begin{array}{l}\text { Kurzeme } \\
\text { region }\end{array}$ & \multicolumn{1}{l}{$\begin{array}{l}\text { Zemgale } \\
\text { region }\end{array}$} & $\begin{array}{l}\text { Latgale } \\
\text { region }\end{array}$ \\
\hline 2010 & 67926 & 17636 & 15622 & 7658 & 9036 & 8137 & 9837 \\
\hline 2011 & 69066 & 17875 & 16059 & 7743 & 9168 & 8234 & 9987 \\
\hline 2012 & 70349 & 18267 & 16432 & 7831 & 9284 & 8409 & 10127 \\
\hline 2013 & 72077 & 18853 & 16917 & 7963 & 9483 & 8551 & 10309 \\
\hline 2014 & 73939 & 19241 & 17481 & 8100 & 9691 & 8743 & 10682 \\
\hline 2015 & 74670 & 19350 & 17835 & 8130 & 9723 & 8798 & 10834 \\
\hline 2016 & 74980 & 19406 & 17990 & 8136 & 9738 & 8807 & 10902 \\
\hline 2017 & 75324 & 19511 & 18137 & 8150 & 9758 & 8828 & 10940 \\
\hline 2018 & 76002 & 19630 & 18456 & 8179 & 9783 & 8876 & 11079 \\
\hline 2019 & 77207 & 19967 & 19263 & 8310 & 9833 & 8970 & 10864 \\
\hline
\end{tabular}

Source: author's construction based on: Central Statistical Bureau of Latvia, 2020, $b$

When evaluating the size of the new dwellings launched into exploitaion a noticeable concentration of newly built dwelling spaces can be observed in the suburbs of Riga, and the number of newly built spaces increased also in Riga region (Table 8)

Table 8

Floor space of new dwellings commissioned by statistical region, thsd $\mathbf{m} 2$

\begin{tabular}{|l|r|r|r|r|r|r|r|r|r|r|}
\hline & 2010 & 2011 & 2012 & 2013 & 2014 & 2015 & 2016 & 2017 & 2018 & 2019 \\
\hline LATVIA & 385,3 & 381,0 & 419,1 & 426,8 & 463,3 & 387,7 & 374,7 & 384,4 & 454,1 & 539,5 \\
\hline Rīga region & 59,1 & 132,1 & 73,0 & 78,9 & 108,2 & 108,9 & 68,7 & 99,3 & 136,6 & 172,3 \\
\hline Pierīga region & 224,2 & 174,5 & 258,8 & 258,4 & 245,5 & 190,9 & 236,4 & 230,4 & 249,8 & 287,5 \\
\hline Vidzeme region & 12,3 & 16,0 & 16,9 & 18,4 & 27,1 & 19,4 & 12,9 & 4,9 & 15,0 & 12,0 \\
\hline Kurzeme region & 31,2 & 15,1 & 25,9 & 25,1 & 30,9 & 26,3 & 13,4 & 17,0 & 14,6 & 21,1 \\
\hline Zemgale region & 46,3 & 30,0 & 26,9 & 26,6 & 29,6 & 24,2 & 31,8 & 23,7 & 27,3 & 32,3 \\
\hline Latgale region & 12,2 & 13,3 & 17,6 & 19,4 & 22,0 & 18,0 & 11,5 & 9,1 & 10,9 & 14,4 \\
\hline
\end{tabular}

Source: author's construction based on: Central Statistical Bureau of Latvia, 2020, a

Thus in the suburbs of Riga in the period under the discussion at an average every year 56,0\% from all newly built spaces have been launched into exploitation, in Riga - 24,4\%, in Zemgale region - 7,2\%, in Kurzeme region - 5,3\%, in Vidzeme region - 3,7\% and in Latgale region - 3,5\%. It continues showing unbalanced developments of regions and accordingly a comparative stagnation of the accomodation market in the regions. When socialeconomic and demographic differences decrease in regions also the tendencies in the accomodation market should change into a positive direction. Yet it is a problem which requires a long-term solution that highly probably in a negative way will be influenced by the 2020 pandemy and its consequences will be seen in the coming years.

When evaluating the one-room flat or multy-flat newly built accomodations launched into exploitation in the last decade it must be concluded that in Latvia one-flat buildings in private houses prevail and in 2019 they made 61,1\% of all newly erected buildings (Table 9). Also in 2019 Latio accomodation market survey inquiry answers to the question about the wishes to obtain an immovable property show that $65 \%$ of respondents want to by a private house, $23 \%$ - to buy land to build their own house and only $12 \%$ wanted to buy a flat in a new or a series of houses project.

Table 9 
Floor space of new dwellings commissioned by statistical region, \% of which single - dwelling buildings (excluding summer cottages and garden houses)

\begin{tabular}{|l|r|r|r|r|r|r|r|r|r|r|}
\hline & 2010 & 2011 & 2012 & 2013 & 2014 & 2015 & 2016 & 2017 & 2018 & 2019 \\
\hline LATVIA & 84,2 & 63,2 & 74,5 & 70,5 & 69,0 & 64,2 & 66,0 & 68,1 & 60,1 & 61,6 \\
\hline Rīga region & 47,2 & 16,2 & 22,2 & 13,7 & 25,8 & 14,5 & 20,5 & 23,5 & 18,2 & 15,4 \\
\hline Pierīga region & 88,1 & 83,3 & 81,8 & 79,3 & 77,8 & 78,2 & 69,4 & 80,1 & 76,9 & 80,9 \\
\hline Vidzeme region & 100,0 & 100,0 & 96,4 & 100,0 & 97,0 & 100,0 & 100,0 & 91,8 & 67,3 & 100,0 \\
\hline Kurzeme region & 91,3 & 98,0 & 90,7 & 85,3 & 75,1 & 84,4 & 100,0 & 100,0 & 89,7 & 96,2 \\
\hline Zemgale region & 99,6 & 100,0 & 100,0 & 97,4 & 99,0 & 100,0 & 99,1 & 97,9 & 85,0 & 87,0 \\
\hline Latgale region & 97,5 & 100,0 & 100,0 & 100,0 & 100,0 & 100,0 & 100,0 & 100,0 & 89,0 & 92,4 \\
\hline
\end{tabular}

Source: author's construction based on: Central Statistical Bureau of Latvia, 2020, a

In 2019 in Riga region the proportion of the private houses is the lowest - 15,4\%, but for example in Vidzeme region - 100\%, Riga suburbs $81 \%$. Outside Riga the multi - flat new projects make from - 3,8\%, in Kurzeme region to $-19,1 \%$ in Riga suburbs.

Classically it is considered that one of the influencing factors is the price of the land unit. The differences in prices of the land in Riga and prices in Vidzeme, Kurzeme and Latgale can be tenfold. Accordingly, considering the price of the land and the wish to build a private house it is more economic for persons to choose the land in the suburbs of Riga or in another region but not in Riga. Taking into consideration the above mentioned and the expenses that for a unit of the construction $(\mathrm{m} 2)$ for a private house and a multi - flat house depending on the constructive solution can differ only within $10 \%-20 \%$ limits ( expenses for multy - flat houses with a similar constructive solution per $1 \mathrm{~m} 2$ are cheaper), people choose to buy a land plot and build a private house.

\section{Conclusions, proposals, recommendations}

1. Dwelling is one of the factors that essentially influences the life quality and well-being of an individual. The evaluation of the life quality and well-being is a subjective indicator that is influenced by several factors. The influence of the factor of the individual's life quality is determined by the importance of the definite aspect in the person's life.

2. In literature several aspects how a dwelling can influence the subjective well-being have been pointed out. Such aspects as the personal control, identity and self-evaluation, social support, also inequality and the applied residential policy have been listed. Satisfaction with the accomodation in its turn is influenced by the title to the property, the size, the kind of the dwelling, its technical conditions, a.o. factors. It has been proved that the individuals who own a dwelling have a higher level of the satisfaction with life that those who rent it.

3. The results of the EQLS confirm that the individual's subjective perception of the dwelling is a significant factor that influences the perception of the total well-being and life quality. Basing on the data of 2016 it was stated that the influence of the satisfaction with the dwelling on the satisfaction with life in all calculated models of regression was statistically significant showing R2 from 0,196 to 0,228

4. In Latvia in 2016 the satisfaction with accomodation on average was evaluated with 6,7 points (in the scale of 10 points), showing the lowest level as compared to other EU countries (EU average - 7,6; the maximum level in Denmark - 8,5 points) As essential shortcomings mentioned were: shortage of space, rot in the windows, doors and floors, lack of bath or shower, lack of indoor flushing toilet.

5. The study of the data bases of the Central statistical Bureau and the Landbook gave reason for concluding that in general the re is a growth in the activity of the immovable market as well as the increase of the absolute and relative indicators of the quality of accomodations.

6. The number of deals with the immovable property in 2019 as compared to 2010 has increased by $36,3 \%$. Taking into consideration that half of all living space is concentrated in Riga and suburbs of Riga the greatest activity remains just in Riga and regions of Riga suburbs ( $50,8 \%$ of all deals). The increase of the activity in the segment of accomodation can be connected with support programs exe cuted in the period under discussion. In total it shows unbalanced development of regions and at the same time a certain stagnation of the accomodation market.

7. The results of Latio 2019 survey of investigation results of the accomodation market confirmed that the low demand of immovable property is determined by various economic factors, e. g., the terms of banks, prognosis of the situation in economics, insufficient offer.

8. The research results marked possible questions for further research. E.g., is there a balance between the offer and the de mand in the accomodation market? If there is, is there a necessity for the State support programs and the bank policy to stimulate the demand? Is the speed of renovation and building of accomodation influenced by the low demand? 
9. In general the tendencies in the accomodation market should develop in a positive direction because the various goals of the national development are aimed at the improvement of the quality of life of people. Yet, it is a long - term task to be solved that most possibly will be negatively influenced by the 2020 pandemy and its consequences will be felt in the coming years.

\section{Bibliography}

Aulia, D., Ismail, A., 2013. Residential Satisfaction of Middle Income Population: Medan City, Social and Behavoral Sciences, 105, 674-683.

Carver C.S., Scheier M.F.,1998. On the Self-Regulation of Behavior. Cambridge University Press, NewYork.

Central Statistical Bureau of Latvia. CSB Database, 2020. a BUG050. Number and Floor Space of New Dwellings Commissioned by Statistical Region, City under State Jurisdiction and County. AOnline] Available http://data1.csb.gov.lv/pxweb/en/rupnbuvn/rupnbuvn_buvn_ikgad/BUG050.px/?rxid=32b630fa-b000-4e48-8e0a-880a6b6ce51a [Accessed 23 November 2020].

Central Statistical Bureau of Latvia. CSB Database, 2020. b NEG010. Housing Stock in Statistical Regions at the End of the Year. [Online] Available at: http://data1.csb.gov.lv/pxweb/en/rupnbuvn/rupnbuvn_nek_ip/NEG010.px/?rxid=92bf2dec-c7ef-4759-9b4c-64359172d6b6 [Accessed 23 November 2020].

Central Statistical Bureau of Latvia. CSB Database, 2020. c MTG020. Overall Description of Dwellings. [Online] Available at: http://data1.csb.gov.lv/pxweb/en/sociala/sociala_majapst/MTG020.px/table/tableViewLayout1/ [Accessed 20 November 2020].

Clapham D., Foye C., Christian J., 2018, The Concept of Subjective Well-being in Housing Research, Housing, Theory and Society, 35(3), 261280 .

Coates, D., Norris, P.A., Norris, M., 2015. Housing, Happiness and Capabilities: A Summary of the International Evidence and Models. Open Discussion Papers in Economics, No. 81. [Online] Available at: https://www.econstor.eu/bitstream/10419/147532/1/857485571.pdf [Accessed 11. November 2020].

Cross-Sectoral Coordination Centre Republic of Latvia, 2020. National Development Plan of Latvia for 2021-2027 (NDP2027). [Online] Available at: https://www.pkc.gov.lv/lv/nap2027 [Accessed 04 November 2020].

European Foundation for the Improvement of Living and Working Conditions, 2018. European Quality of Life Survey 2016. [Online] Available at: https://www.eurofound.europa.eu/surveys/european-quality-of-life-surveys/european-quality-of-life-survey-2016 [Accessed 04 October 2020].

European Foundation for the Improvement of Living and Working Conditions, 2018. European Quality of Life Survey 2016. EQLS, 2016 Data File.

UK Data Archive. SN: 7348 European Quality of Life Survey Integradet Data File, 2003-2016 Usage Number 125185, Usage Title: Changes in the Quality of Life in Latvia and EU Countries. [Accessed 04 April 2018].

Dzenīte, E., 2019. Mājokļu tirgus pārskats Latio 2019 (Housing market overview Latio 2019). [Online] Available at: https://latio.lv/lv/pakalpojumi/tirgus-analize/majoklu-tirgus/172/majoklu-tirgus-parskats-2019.pdf [Accessed 23 November 2020].

Foye, C., 2017. The Relationship Between Size of Living Space and Subjective Well-Being. Journal of Happiness Studies, $18,427-461$.

Gajdoš J., Hudec O., 2020. EUROPEAN CITIES: WHAT MATTERS FOR SUBJECTIVE WELL-BEING? Theoretical and Empirical Researches in Urban Management, 15(4), 6-20.

Hu F., 2013. Homeovnership and Subjekctive Wellbeing in Urban China: Does Owning a House Make You Happier? Social Indicators Research $110,951-971$.

Mohit M., 2014. Residential Satisfaction-Concept, Theories and Empirical Studies. Planning Malaysia, 12(3), 47-66.

Napiorkowska-Baryla A., 2020. Housing Resources in Poland - an Assessment Made in Terms of the Quality of Life. Annales Universitatis Mariae Curie-Skłodowska, Oeconomia, 54(2), 67-76.

National Single Computerized Landbook, 2020. Database, Statistics. Open Data. Confirmation requests. [Online] Available at: https://www.zemesgramata.lv/saturs/lv/170-169-1 [Accessed 07 November 2020].

Rudolf, R.,Potter C., 2015. Housing and Happiness: Subjective Well-Being and Residential Environment in Korea, Article in Journal of Korea Planning Association, 50(7). 55-73.

Zhang, F., Zhang, C., Hudson J., 2018, Housing Conditions and Life Satisfaction in Urban China. Cities, 81, 35-44.

Zumbaro T., 2014. The Relationship Between Homeownership and Life Satisfaction in Germany, Housing Studies, 29(3), 319-338. 
NEW MECHANISM OF ONLINE MARKETING DURING EPIDEMIC SITUATION: CASE STUDY OF THE $12^{\text {th }}$ TMALL 11.11 GLOBAL SHOPPING FESTIVAL OF ALIBABA GROUP Siyi Liu, St Petersburg State University

\title{
Kuznetsova Natalia, St Petersburg State University
}

\begin{abstract}
With the negative effect of Covid-19, the world economy have been shocked by the epidemic situation, especially for substantial economy which suffer lots of loss in transaction value. However, it brings new opportunity for online economy. The online economy has been developed at a high speed due to the internet technology and the improvement of marketing strategy. This paper mainly aims to investigate the new mechanism of online marketing during the epidemic situation and to analyze how Covid-19 contribute to the development of online marketing. The main method used in this study is the case study of the 12th Tmall 11.11 Global Shopping Festival of Alibaba Group, because this shopping festival is the largest shopping festival in China and this is the first shopping festival after the Covid-19 in China, so this case can represent the most obvious online marketing in present China. The study try to compare the quantitative data of transaction value before and after Covid-19, then show the useful online marketing way for both platforms and retailers. This study explored the emerging mechanism for online marketing and analyzed the role of live stream, which is the hottest marketing tool for E-Commerce sellers. At last, this paper find that uncertainty brought by the separation of information flow and product flow has become a critical obstacle to E-Commerce, while the social media and live stream bring positive effect to solve this problem and indicate the benefits of this live marketing way for increasing transaction value.
\end{abstract}

Keywords: Online marketing, Alibaba Group, Live E-Commerce.

JEL code: M3

\section{Introduction}

The growth of the e-commerce sector is definite in recent years. Continuous use of mobile technology and social media has affected our daily routine, life style, and decision-making processes. Millions of people across the world are fond of sharing their opinions through social media. With the increasing number of webcast users, up to 2020, Chinese webcast users has amount to 560 million. These increasing statistics have motivated many entrepreneurs to enter the e-commerce sector, thereby increasing the level of competition.

As a marketing tool, internet and digital media is a significant strategic weapon which goes beyond borders and targets the specific audience in accordance to the consumer needs. It is not dependent on the location, area or region and free of all the temporal restrictions. Different companies are struggling to incorporate the new technologies in their marketing media to attract more customers. These technologies facilitate selling products and services and engaging customers in product development and enhancement. Online marketing has become very powerful tools to make more value at a much lesser cost than the traditional marketing way. Thus, in order to overcome the difficulty during epidemic period, it is necessary to explore the new mechanism for online marketing.

As for the methodology of this paper, the main aim of this study is to explore the use of online marketing strategies and digital media, especially during the epidemic duration of Covid-19. This study has used the case study with the help of a lot of data from different platforms. For example the trade transaction volume from Alibaba, the logistic data from China Post. The study try to compare the quantitative data before and after Covid19 then show the useful online marketing way for both platforms and retailers. The main method used in this study is the case study of the 12 th Tmall 11.11 Global Shopping Festival of Alibaba Group, because this shopping festival is the largest shopping festival in China and this is the first shopping festival after the Covid-19 in China, so this case can represent the most obvious online marketing in present China. The main research questions of this study are: 1 . What role does online marketing strategies and digital media play during epidemic duration? 2. Do the online marketing strategies will become the mainstream of marketing strategies. The main Tasks of this study are: 1 . To identify the present situation of online marketing. 2. To explore the benefits of using online marketing strategies and digital media. 3. To figure out the impact of online marketing on the period of Covid-19 in China and forecast the trend in post-crisis time.

\section{Literature Review}

The significance of online marketing is currently increasing, as we can observe changes in the ways people communicate and also in the ways they spend their free time. The advantage of the Internet as a communication medium likewise lies in the fact that it allows us to target the conveyed information at a precisely specified audience segment (Roblek, 2015). Given the recent changes in the business environment, sticking with existing 
model is unlikely to work. All organizations need to be more nimble and responsive, and it is vital that they are more reactive to ideas and input from customers than they have been in the past (Mohammed T. Nuseir, 2016).

Social media websites now receive the highest web traffic worldwide and one third of online time is spent on social media (GlobalWebIndex, 2018). Scholars have attempted to critically evaluate the importance of social media and suggest that social media marketing is too important to be left to the marketing department solely, thus arguing that it requires a holistic business involvement. In the past few years, live streaming has become a new social medium where broadcasters can deliver real-time broadcasts to viewers via the Internet. This is largely due to the fast development of the Internet and the massive adoption of mobile devices (J, Zhou., Y, Ding., H, Wang., 2018). While live streaming is an emerging social medium that differs in several ways from traditional social media, investigation into this emerging social media is just beginning (Sjöblom and Hamari, 2017). Marketers should create content for consumers using portable digital devices. Mobile video is a particularly promising platform: $80 \%$ of Internet traffic will be video by 2019 and $74 \%$ of consumers are more likely to make a purchase after watching a branded video. However, recorded video is costly and cumbersome to produce; live streaming video increases engagement and decreases costs while increasing influence (Piontek. K, 2016). These social media construct the infrastructure for online marketing.

In addition, It was identified that two living video presenters' characteristics: screen presence and powerful emotions (Guo, Y., Goh, K.Y., 2019). They learned that these were positively related to viewership engagement outcomes. Moreover, Park and Lin (2020) proposed that Internet celebrities have a positive effect on attracting viewers and increasing the possibility of purchases. These previous studies have provided useful insights into different aspects of live-streaming in social commerce.

The contribution to the scientific knowledge about the issue is to find new mechanism which suitable for the development of online marketing in nowadays with various digital technology and data analysis.

\section{Research results and discussion}

\section{The emerging mechanism of online marketing in China}

Recently, some E-Commerce sites such as Facebook and Taobao have enabled live video stream. Several individual sellers in various countries go beyond advertising to real time to sell their products. Live streaming is used to demonstrate how products are created and used, to show different perspectives of products, to answer customer questions in real time, and to organize live activities that entertain and encourage customers to buy. Importantly, live stream allows sellers to reveal their faces, and personalities and brings the buyer-seller interpersonal interaction and related selling techniques used offline back to the online world. Such live stream enabled social presence and interaction can enhance the shopping experience, reduce shoppers' uncertainty, and increase the level of trust.

According to the China's electronic commerce report 2019, the digital economy industry provided 191 million employment opportunities in last year, and these employment opportunities occupies $24.6 \%$ in the whole employment. With more than 854 million online users, the transaction volume reached to 31.6 trillion which stands for $34.8 \%$ in GDP. With the increasing number of webcast users, up to 2020, Chinese webcast users has amount to 560 million, more and more users choose to watch the live E-commerce, and the most of them ever watch the live E-commerce show, $27.8 \%$ of total netizen watch it everyday, only $14.7 \%$ of them never watch the live stream.

The main retail platform including three main ways, the first way is the most traditional one, that is the consumers use the official app or website to search the goods they want in Tmall, Taobao,or 1688 .com. This is the most straight way but less attractive for nowadays consumers. The second one is the hottest way in present market, that is the celebrities, stars or even the retailers establish live marketing through various live platform. Actually, this has become the mainstream of online retail of Alibaba's. And the other way is to use some videos advertisement which insert the links of products in some recreational or social app. It use the music and story in the short video to attract consumers attention, and push them to open the shopping link of the same product in the video, and stimulus they buy this products immediately.

The outbreak of the epidemic has further increased the scale of users of live e-commerce, and improved the transformation effect of live ecommerce to a certain extent. As a result, live e-commerce has begun to become the key part of all kinds of enterprises. The industrial chain dominated by merchants, platforms, live hosts and users has been preliminarily formed. In general, there will be 15 thousand live stream in one week. So Live E-commerce has become the new engine for production efficiency and economic growth.

The benefits of live stream marketing:

1) Diversity of products and live ways. More and more products are driven by the force of live e-commerce, and more and more retailer would like to use this way to increase their production efficiency. 
2) More comprehensive service with real-time interaction. Since the live-Ecommerce can contact the retailer with consumers at the same time, they can get more precise information immediately, it shortens the consumption cycle, and makes the consumer buy products more quickly than just look through websites by themselves.

3) Celebrity effect increase consumption. Instead of traditional way of using super stars to as the spokesman or ambassador of brand, the livecommerce shorten the distance between fans and stars which can attract the fans to be direct consumers.

4) Reducing pressure for inventory. This new engine has become a continuous mechanism from retailer, to live platforms. This cooperative and integrated mechanism is benefit for mitigate the pressure of inventory.

\section{Case study of $12^{\text {th }} \mathbf{2 0 2 0}$ Tmall 11.11 global shopping Festival of Alibaba Group}

As the most well-known shopping festival of Alibaba, the just past Tmall 11.11 shopping festival showed the most representative of online retail, and this is the biggest online shopping festival which was created by Taobao since 2009. Due to COVID-19 in 2020, global economy is going through a downturn. Therefore, the role of the first 11.11 promotional activities in stimulating consumption growth is expected, especially in post COVID-19 era.

Table 1

Amount of Tmall 11.11Transaction Value from 2014-2020(RMB)

\begin{tabular}{|c|c|c|}
\hline No. & Year & Transaction Value (Billion) \\
\hline 1. & 2014 & 57.1 \\
\hline 2. & 2015 & 91.2 \\
\hline 3. & 2016 & 120.7 \\
\hline 4 & 2017 & 168.2 \\
\hline 5. & 2018 & 213.5 \\
\hline 6. & 2019 & 268.4 \\
\hline 7. & 2020 & 498.2 \\
\hline
\end{tabular}

Source: author's calculations based on source from www. data.iimedia.ch

This table show the the transaction value of 11.11 from 2011-2020. We can see that the transaction value with a gradual increase in sales. This year, 250,000 brands and 5 million merchants participated in Tmall double 11, and the discount products reached 16 million, 1.6 times of last year. At 0 o'clock on November $12^{\text {th }}$, Alibaba released the transaction volume data of Tmall 11.11 this year: from November $1^{\text {st }}$ to November $12^{\text {th }}$, the transaction volume of Tmall double eleven festival in 2020 was 498.2 billion RMB. According to the data of the national post office of China, 3.965 billion pieces of express delivery were handled in from November $1^{\text {st }}$ to $11^{\text {th }}$, of which 675 million pieces were handled on November $11^{\text {th }}$.

So how online marketing contributes the success of double 11 festival?

Firstly, it is shown in booking system which can be the reference for retailers or producers to formulate a reasonable inventory and get ready for delivery. Before the checking date if the consumers want to enjoy the discount price, they have to book it advance and pay a deposit , nearly $5 \%$ or $10 \%$ of the the total price. At the first day of the festival in 10.21, the deposit money reached to 10 billion. The deposit has a positive psychological implication for consumers, and it will remind them to pay in full at the day of 11.11 and stimulate the consumption.

Secondly, the high speed platforms with support of Internet technology. To support transaction peaks, Aliyun infrastructure will be supported by five super data centers including Zhangbei, Ulancab, Heyuan, Nantong and Hangzhou on Nov $11^{\text {th }}$, 2020, so that consumers can enjoy the silky "hands-chopping" experience. In the Hangzhou data center, the largest liquid-cooled service cluster in the world will have tens of thousands of liquid-cooled servers put into production to handle the massive computing work of Double 11.

Thirdly, the Various warming-up activities. Such as the paper mentioned before that the outbreak of the epidemic has further increased the scale of users of live e-commerce, and improved the transformation effect of live e-commerce to a certain extent. And the Taobao and Tmall provide a lot of discount and coupons for consumers. Since present Chinese has a strong "Celibreties effect", Alibaba also hold two big live program with lot of stars and internet celebrities to attract the fans turn to be the consumers.

Social media, especially those media which can used for live stream have transformed the way organizations communicate with their customers. The main factors affecting the domestic online market are increasing number of online shoppers, penetrating the influence of mobile devices, securing payment gateways and improving logistics infrastructure. So the comprehensive logistic mechanism is also significant for online marketing.

The Tmall double 11 global kicks off at 0:00, according to Cainiao logistics data, at 0:35 am, only 5 minutes after consumers payed in all, one consumer in Hangzhou had received the package delivered by Cainiao, this package refresh the new speed of logistics in history. It is because this package was sent directly from Cainiao station in the community, only $1 \mathrm{~km}$ away from consumers. The most common concern for consumer is 
waiting for their deliveries. The more waiting time may cause the consumers return their products. In order to avoid this happen In addition to speeding up delivery. It is understood that, in order to speed up the delivery of double 11 package, Cainiao used a digital supply chain to delivery distribute to the outlets and communities in advance through intelligent prediction and pre-sale orders in the booking system. In this festival, 10 digital technologies have been applied to all links of supply chain management, warehouse delivery, express transfer and terminal distribution.

What is interesting is that Alibaba uses live platforms to broadcast their whole process of delivery, it is the first time they use this special way to share the delivery process. It is called "Cloud supervisor", this means all the consumers can watch the process of delivery thorough this live show. There are intelligent robots working in the warehouse to help save human and material costs and speed up the flow of inventory. The express transfer is allocated in automatic assembly line and the total length of assembly line is more than 6000 kilometers. The courier has intelligent path-planning to avoid traffic jam in real time. Totally, 3.965 billion pieces of express delivery were handled in from November 1 to 11 . In some universities and communities, there are lot of self-driving cars to deliver packages. The terminal station can delivery without direct contact especially in the special period of Covid-19 due to quarantine policy.

The live broadcast of "Cloud Supervisor" also demonstrates the great cooperation among 3 million logistics personnel, more than 3,000 logistics stuffs, more than 200,000 logistics vehicles and more than 200,000 logistics stations. The "Cloud supervisor" project was launched from November $1^{\text {st }}$ to November $3^{\text {rd }}$, and made the whole people feel the amazing speed of China's intelligent logistics. After consumers submit their orders, to watch the express live stream has become a new fashion for double 11.11, the live stream has been watched 80 million times in less than three days.

\section{Conclusions}

The main aim of this study is to explore the use of online marketing strategies and digital media, especially during the epidemic duration of Covid-19. This study explored the emerging mechanism for online marketing and analyzed the role of live stream, which is the latest marketing tool for E-Commerce sellers. After exploration and discussion, the results confirmed that:

1. Consumers who often watch the live stream tend to make a purchase. It disclosed that although both product quality and product fit-related contents can positively affect consumer purchase decision, product fit-related contents are significant, underlining the urgency to solve personalized questions of consumers, and matching their preference in the online market place. Its real-time nature provides customers with comprehensive and interesting shopping experiences that overcome the drawbacks of conventional online shopping. During live stream, the behavior of sellers, including their fast and frequent replies, as well as the product quality increase the possibility that consumers will make purchase decisions.

2. This study finds that live stream is positively associated with consumer and live stream marketing can contribute to the transaction value of ECommerce. From the perspective of the presence of uncertainty, this paper finds that uncertainty brought about by the separation of information flow and product flow has become a critical obstacle to E-Commerce development. That is why live stream can break the obstacle between the consumers and sellers by the immediate exchange of information and feedback.

As for the proposals and recommendation:

1. Since live stream is a relatively new tool for both practitioners and academics, additional research is needed to fully understand and make use of it. What is more, this study only focus on the online data, and ignore the comparison of offline marketing data.

2. In addition, the sample of Tmall is not enough for a totally incredible results, and this study only use the Chinese company as example, so the future's studies could extend the current research scope to include other platforms and try to collect more samples of customers with purchase experiences and compare their different attitudes and responses with those of non-buyers from different cultural background.

\section{Bibliography}

Global Web Index., 2018. Gwi Social.

Guo, Y., Goh, K.Y., 2019. Mobile Live Streaming: the Roles of Broadcasters' Screen Presence and Dynamic Emotions in Viewership Engagement. AIS Press, 13, 1-9.

Kang, J., Y, M., Johnson, K., K, P., Wu, J., 2014. Consumer Style Inventory and Intent to Social Shop Online for Apparel Using Social Networking Sites. Journal of Fashion Marketing and Management, 18(3), 301-320.

Kao, T., Y, Yang., M, H., Wu, J., T., Cheng., Y, Y., 2016. Co-Creating Value with Consumers Through Social Media. Journal of Services Marketing, 30(2), 141-151. 
Lewis, J. D., Weigert, A. J., 2012. The Social Dynamics of Trust: Theoretical and Empirical Research, 1985-2012. Social Forces, 91(1), 25-31.

Liang, T. P., Turban, E., 2011. Introduction to The Special Issue Social Commerce: A Research Framework for Social Commerce. International

Journal of Electronic Commerce, 16(2), 5-14.

Lin, J., Li, L., Yan, Y., Turel, O., 2018. Understanding Chinese Consumer Engagement in Social Commerce: The Roles of Social Support and Swift Guanxi. Internet Research, 28(1), 2-22.

Liu, Y., 2003. Developing a Scale to Measure the Interactivity of Websites. Journal of Advertising Research, 43(2), $207-216$.

Lu, B., Fan, W., Zhou, M., 2016. Social Presence, Trust, and Social Commerce Purchase Intention: An empirical Research. Computers in Human Behavior, 56, 225-237.

Nuseir, M.T., 2016. Exploring the Use of Online Marketing Strategies and Digital Media to Improve the Brand Loyalty and Customer Retention. International Journal of Business and Management, 11(4), 228-239.

Nitzan, I., Libai, B., 2011. Social Effects on Customer Retention. Journal of Marketing, 75, 24-38.

Ou, C.X., Pavlou, P.A., Davison, R., 2014. Swift Guanxi in Online Marketplaces: The Role of Computer-Mediated Communication Technologies. MIS Quarterly, 38(1), 209-230.

Pappas, N., 2016. Marketing Strategies, Perceived Risks, and Consumer Trust in Online Buying Behavior. Journal of Retailing and Consumer Services, 29, 92-103.

Park, H.J., Lin, L.M., 2020. The Effects of Match-Ups on the Consumer Attitudes toward Internet Celebrities and Their Live Streaming Contents in the Context of Product Endorsement. Journal of Business and Management, 3(1), 13-22.

Park, J., Stoel, L., Lennon, S. J., 2008. Cognitive, Affective and Responses to Visual Simulation: The Effects of Rotation in Online Product Presentation. Journal of Consumer Behaviour, 7(1), 72-87.

Pavlou, P.A., Liang, H., Xue, Y., 2007. Understanding and Mitigating Uncertainty in Online Environments: A Principal-Agent Perspective. MIS Quarterly, 31(1), 105-136.

Payne, K., Keith, M.J., Schuetzler, R.M., Giboney, J.S., 2017. Examining the Learning Effects of Live Streaming Video Game Instruction over Twitch. Computers in Human Behavior, 77, 95-109.

Peck, J., Childers, T.L., 2003. To Have and to Hold: The Influence of Haptic information on Product Judgments. Journal of Marketing, 67(2), 3548.

Piontek, K., 2016. The Periscope Trend: Using Live video in content marketing. Articulate Inbound Content Marketing. 3, 23-56.

Roblek, V., 2015. Impact of Internet and Social Media on Organizational Change of OTC Medicines Marketing Management. International Journal of Electronic Marketing and Retailing, 6(3), 239-258.

Shriver, S.K., Nair, H.S., Hofstetter, R., 2013. Social Ties and User-Generated Content: Evidence from An Online Social Network. Management Science, 59, 1425-1443.

Sjöblom, M., Hamari, J., 2017. Why Do People Watch Others Play Video Games? An Empirical Study on the Motivations of Twitch Users. Computers in Human Behavior, 75, 985-996.

Van Riel, A. C., Liljander, V., Jurriens, P., 2001. Exploring Consumer Evaluations of E-Services: A portal site. International Journal of Service Industry Management, 12(4), 359-377.

Van Noort, G., Voorveld, H. A., Van Reijmersdal, E. A., 2012. Interactivity in Brand Web Sites: Cognitive, Affective, and Behavioral Responses Explained by Consumers' Online Flow Experience. Journal of Interactive Marketing, 26(4), 223-234. 
Yahia, I. B., Al-Neama, N., Kerbache, L., 2018. Investigating the Drivers for Social Commerce in Social Media Platforms: Importance of Trust, Social Support and the Platform Perceived Usage. Journal of Retailing and Consumer Services, 41, 11-19.

Yoon, H. S., Occeña, L, G., 2015. Influencing Factors of Trust in Consumer-to-Consumer Electronic Commerce with Gender and Age. International Journal of Information Management, 35(3), 352-363.

Yue, W., 2015. The list of China's top 100 cities with highest GDP in 2015.

Zhou, J., Ding,Y., Wang, H., 2018. The Magic of Danmaku: A Social Interaction Perspective of Gift Sending on Live Streaming Platforms, Electronic Commerce Research and Applications. Electronic Commerce Research and Applications, 34, 100815, 12-16.

THE PAPER WAS CARRIED OUT WITHIN THE FRAMEWORK OF THE RFBR GRANT, PROJECT 19-510-92002 - "DEVELOPMENT OF METHODOLOGY FOR GREEN AND INFRASTRUCTURE INVESTMENT BY INSTITUTIONAL INVESTORS IN THE CONTEXT OF PENSION REFORMS" 


\title{
A MULTIPURPOSE, MULTIDIMENSIONAL AND INTEREST-DRIVEN MARINE CADASTRE AS AN INTEGRAL PART OF MARITIME SPATIAL PLANNING FOR THE BALTIC SEA REGION
}

\author{
Leila Neimane, University of Latvia \\ Janis Kaminskis, Riga Technical University \\ Kamil Kowalczyk, University of Warmia and Mazury in Olsztyn \\ Severine Michalak, Énergies de la Mer \\ Liga Ozolina, LTD "Grupa93" \\ Iveta Stamure, Riga Technical University
}

\begin{abstract}
Maritime/Marine Spatial Planning (MSP) underpinned by an ecosystem-based approach as one of the core components of integrated marine management is gaining momentum. In turn, a fully-fledged marine cadastre as an integral part of the MSP is still a future vision. The aim of the paper is to explore the Multipurpose, Multidimensional and Interest-Driven Marine Cadastre (MMIMC) as a concept and the synergistic effects between MSP and MMIMC for advancement of the Blue Economy and sustainable, effective and efficient marine governance through the lens of integrated marine management with an emphasis on the Baltic Sea Region (BSR). This paper emphasizes the conceptual perspective of the interaction between the MMIMC and MSP yet to be operationalized, providing overall documentation of the current state in the BSR regarding MSP and MMIMC and proposing conclusions to be used both at regional and national level. The present study offers added value by structuring knowledge and identifying patterns in the research area. In addition, the paper addresses critical questions and presents proposals to promote and guide further studies. The most important conclusions resulting from the research relate to the importance of the use of MMIMC during the implementation, monitoring, evaluation and adaptation stages of MSP. The research also highlights the need to establish a common framework of a multipurpose, multidimensional and interest-driven marine cadastral system for the countries of the BSR. The research process involved use of monographic, dogmatic, comparative, special analytical, macroscopic examination and logical access control methods.
\end{abstract}

Keywords: integrated marine management; Maritime/Marine Spatial Planning (MSP); marine cadastre; Multipurpose, Multidimensional and Interest-Driven Marine Cadastre (MMIMC); Baltic Sea Region.

JEL code: $\mathrm{K} 32 ; \mathrm{O} 21$; R58

\section{Introduction}

It is common knowledge that the oceans are central to human life, and human reliance on the ocean's productive assets, providing natural, social and economic functions, continues to grow and contributes to increased well-being (Singh \& Ort, 2020; Hoegh-Guldberg et al., 2015; Sutherland, 2005a; Ng'ang'a et al., 2004). At the same time, the inherent volumetric, dynamic, and temporal marine environment poses major challenges to the management of emerging multidimensional maritime private and public Rights, Restrictions and Responsibilities (3Rs) in horizontal and vertical perspectives (Papageorgiou \& Kyvelou, 2018; Michalak, 2018; Balla \& Wouters, 2017a; Athanasiou et al., 2017a; Athanasiou et al., 2016; Papageorgiou, 2016; de Latte, 2015; Tamtomo, 2004; Ng'ang'a et al., 2004).

Since the 1990s, an increasing focus on maritime issues has drawn attention to the concept of the Marine Administration System in the practice and research of Canada, the United States, Australia, New Zealand, and the Netherlands, establishing structures to handle maritime public, environmental and functional interests and marine resources in a sustainable way and using experience gained in such fields as Multipurpose, Multidimensional and Interest-Driven Marine Cadastre (MMIMC), Maritime/Marine Spatial Planning (MSP) and Marine Spatial Data Infrastructure (Athanasiou et al., 2017a; Athanasiou et al., 2016; Michalak, 2018; Ng'ang'a, 2006; Sutherland, 2005a). Other countries such as Israel, Indonesia, Malaysia, Trinidad and Tobago and, more lately, several more European countries such as Belgium, the United Kingdom, Germany, Sweden, Poland, Greece and France have also begun to test the idea of MMIMC (Michalak, 2018; PCC et al., 2017; Stāmure et al., 2017). However, at the moment, no country has set up a fully-fledged established marine cadastre, and progress in this field in different countries is uneven and fragmented (Lemmen, 2012; PCC et al., 2017; Kaminskis et al., 2018). In the European Union (EU), the most recent activity in relation to the marine cadastre is a common study by five leading European organizations in the fields of cadastre, land registry, mapping, surveying and spatial data infrastructures aiming "to raise awareness about the topic of the Marine Cadastre and to trigger the discussion about its potential benefits in Europe's Blue Economy" (PCC et al., 2017; CLGE, 2017). 
From the above discussion emerges lack of a common standard and an agreed basis for a conceptual model to explicitly handle the maritime 3Rs and their spatial extensions (Alberdi \& Erba, 2020; Athanasiou et al., 2017b). Additionally, a clear emphasis on the relationship and correlation between MSP and MMIMC has not been forthcoming until recently (see, e.g., Athanasiou et al., 2017b; Arvanitis et al., 2016). Practice studies show, firstly, that there is no clear understanding between MSP and MMIMC, sometimes even perceived as two synonymous terms and, secondly but more generally, awareness of the term "marine cadastre" is quite low (PCC et al., 2017).

Against this background, the aim of this paper is to explore MMIMC as a concept and the synergistic effects between MSP and MMIMC for advancement of the Blue Economy (or Blue Growth, both terms used interchangeably) and sustainable, effective and efficient marine governance through the lenses of integrated marine management with an emphasis on the Baltic Sea Region (BSR). To this purpose, the paper is laid out as follows. First, the paper concisely characterizes the diversity of ocean uses, the notion of the Blue Economy, and provides an overview of the most common types of spatial conflicts. Second, the paper analyses the scope and substance of MMIMC, underscoring that there is no collision between the two classic concepts mare clausum and mare liberum in relation to the contemporary notion of a marine cadastre and highlighting its three key features. Third, the two-way relation between MSP and MMIMC is examined, determining their synergistic effects and the potential benefits of their application. In conclusion, the paper offers suggestions for wider application of the MMIMC to ensure the continuous and accurate management of emerging multidimensional maritime private and public 3Rs in the context of sustainable, effective and efficient marine governance. In addition, the paper poses critical concerns and provides recommendations to direct and support future research with the aim of promoting MMIMC and starting a broader debate on its advantages at the national and regional level.

For the purposes of this research, two terms are used in a broad perspective: firstly, "cadastre" - understood as the visualisation and maps and the register of 3Rs - and secondly, "property rights" - encompassing both ownership and resource usage and exploitation rights. Such rights could include ownership, concessions, leases, fishing rights, building permits for windmills, excavation permits for sand, and the like (Wouters, 2020). Countries of the BSR under the EU regulatory framework are Estonia, Latvia, Lithuania, Denmark, Finland, Sweden, Germany (the northeast), and Poland.

Recognising that problems affecting the marine cadastre are still continually changing and that an exhaustive analysis of those problems is not workable here, the study does not provide extensive analysis on the design of MMIMC, marine parcel, classification models of the marine cadastre, Marine Spatial Data Infrastructure (though the need to establish new links between different systems of observation, networks is undeniable (cf. PCC et al., 2017; Kaminskis et al., 2018) and diverse types of property rights or classification of other rights in offshore environments. A detailed explanation of these issues is beyond the reach of this paper and forms the basis for more comprehensive in-depth research in the future. Instead, this paper emphasises the conceptual perspective of the interaction of the MMIMC and MSP yet to be operationalized, providing overall documentation of the current status of MSP and MMIMC in the BSR and proposing conclusions to be used both at the regional and national level. The present study offers added value by structuring knowledge and identifying patterns in the research area.

Research was performed as a desk-based study, firstly, screening the documentation of the policy and legislative framework in the EU and the BSR. Secondly, the literature review encompasses search, analysis and systematisation of the relevant scientific writings. Monographic, dogmatic, comparative and special analytical research methods were used during the research process. Additionally, macroscopic examination and logical access control methods were applied.

Diversity of ocean uses

Nowadays, use of the oceans is tightly related to the concept of the Blue Economy. This is "an emergent and rapidly propagating concept through which the hydrological sphere of the earth is identified as a new economic possibility that is expected to bring both wealth and environmental protection" (Choi, 2017, p. 37). In 2012, "perhaps the most well-known and well-established application of the Blue Economy concept" (Voyer et al., 2018) saw the launch of the EU Blue Growth strategy (EC, 2012) driving forward the Commission's Integrated Maritime Policy (EC, 2007). It was soon recognised that a strong and increasing maritime space market needed an innovative comprehensive planning and management strategy and approach (Fries \& Grémaud-Colombier, 2019; Neimane, 2020). Against this background, in 2014, the European Parliament adopted Directive 2014/89/EU, creating a framework for MSP (MSP Directive). In the Member States, the legislation and administrative provisions required to conform with this Directive had to be put into force by 18 September 2016 (Art. 15(1)) and maritime spatial plans are to be drawn up at the latest by 31 March 2021 (Art. 15(3)). Since the MSP Directive does not clarify or offer guidelines about how Member States are to implement and develop their MSP systems, different jurisdictions design their own marine governance arrangements and approaches (Kelly et al., 2019). For example, 
Germany has simply extended its territorial planning legislation to the marine environment (Scott, 2015). However, overall, it is considered that sub-regionally, the Baltic Sea has the most advanced integrated marine management, "driven by the need to manage competing offshore activities and implemented through MSP" that is the core component of integrated marine governance in Europe (Scott, 2015, p. 477). The MSP Directive (2014, Recital 19) puts forth the primary purpose of MSP as "to promote sustainable development and to identify the utilisation of maritime space for different sea uses as well as to manage spatial uses and conflicts in marine areas."

In terms of the Blue Economy, the sectors are divided into such categories as established sectors (traditionally contributing to Blue Growth marine living resources, marine non-living resources, marine renewable energy, port activities, shipbuilding and repair, maritime transport and coastal tourism), on the one hand, emerging sectors (in relation to which reliable data are in the development stage) and innovative sectors (bringing new opportunities for coastal development and communities), on the other hand (EC, 2020a). Both these last include marine renewable energy (ocean energy, floating solar energy and offshore hydrogen generation), blue bioeconomy and biotechnology, marine minerals, desalination, maritime defence, and submarine cables) (EC, 2020a).

However, although "[t]he Blue Economy is an opportunity for assembling separate marine projects in multi-use and multi-user spaces" (Winder \& Le Heron, 2017), the diversity of activities at sea also poses certain challenges such as a combination of expansion of existing activities, the appearance of new activities and targeted strategic development of certain activities (e.g., offshore wind farms), leading to a "race for space" (Qiu \& Jones, 2013; Scott, 2015), while growing nature conservation requirements inevitably reveal increased conflict potential (Maes, 2008). According to the European MSP Platform (EC, 2019), common types of spatial conflict are: tourism versus offshore wind, cables versus fisheries, defence versus other uses, transport versus marine conservation, offshore wind versus fisheries, aquaculture versus tourism, transport versus offshore wind, offshore wind versus conservation, fisheries versus conservation. To illustrate, in order to obtain a cost-effective amount of energy, renewable energy production devices must be sizeable and require a large stable base on the seabed, as well as support systems. As a result, during construction works, installation and dismantling of the base, support systems, substations and submarine cables of a renewable energy production unit, the marine environment and benthic habitats will be affected, and the recovery of the ecosystem might take up to several years (Puriņa \& Sprukta, n.d.).

In summary, one can conclude that the marine environment is increasingly being placed at the crossroads of diverse interests, classified into three main groups: public (the constitutional right of every citizen to access marine space), environmental (protection and conservation of water resources) and functional (related to the different transactions in marine space) (Athanasiou et al., 2017a). Ng'ang'a et al. (2004, p. 462) argue that these "types of interests can be broadly classified as [emerging multidimensional marine private and public Rights, Restrictions and Responsibilities (3Rs)] that individuals have with respect to resources that are part of the marine object." The marine legal object is formed when "the very close relationship between each interest and its spatial dimension in the real world [is] identified and registered in information systems" (Athanasiou et al., 2016, p. 92), for instance, the marine cadastre.

Scope of the Marine Cadastre: Multipurpose, Multi-dimensional and Interest-Driven

Starting from the middle of the $20^{\text {th }}$ century, coastal states acquired ownership rights and managed and used maritime resources mainly in the open-access ocean system (Steinberg, 2001). Nowadays, ocean space is a combination of two main seemingly competing concepts: the Portuguese notion mare clausum - "giving the rights over the ocean to coastal states" - versus the Dutch notion mare liberum defending "the understanding of the freedom of the ocean" (Singh \& Ort, 2020, p. 46; see also Steinberg, 2001; Tamtomo, 2004). The contemporary concept of a marine cadastre has been developed according to the perspective of mare clausum that "the sea is simply as the land, in certain limitations there have been inherently attached some (people's, society's, state's) rights and responsibilities" (Tamtomo, 2004). At present, the second perspective - mare liberum is rather a responsible freedom consistent with the principle of conditional high seas freedoms and subject to rules set in the 1982 Convention on the Law of the Sea (UNCLOS, came into effect in 1994) (Freestone, 2008), introducing "the subdivision of the oceans into Territorial Seas, Exclusive Economic Zones (EEZs) and Continental Shelves, each with its attendant rights and responsibilities" and creating "a complex multidimensional mosaic of potential private and public interests" (Ng'ang'a et al., 2001, 2002; see also Athanasiou et al., 2017a and Fig. 1). In the context of MMIMC, only the Territorial Sea and the EEZ are appropriate, as the marine cadastre refers to areas under national jurisdiction (PCC et al., 2017). 


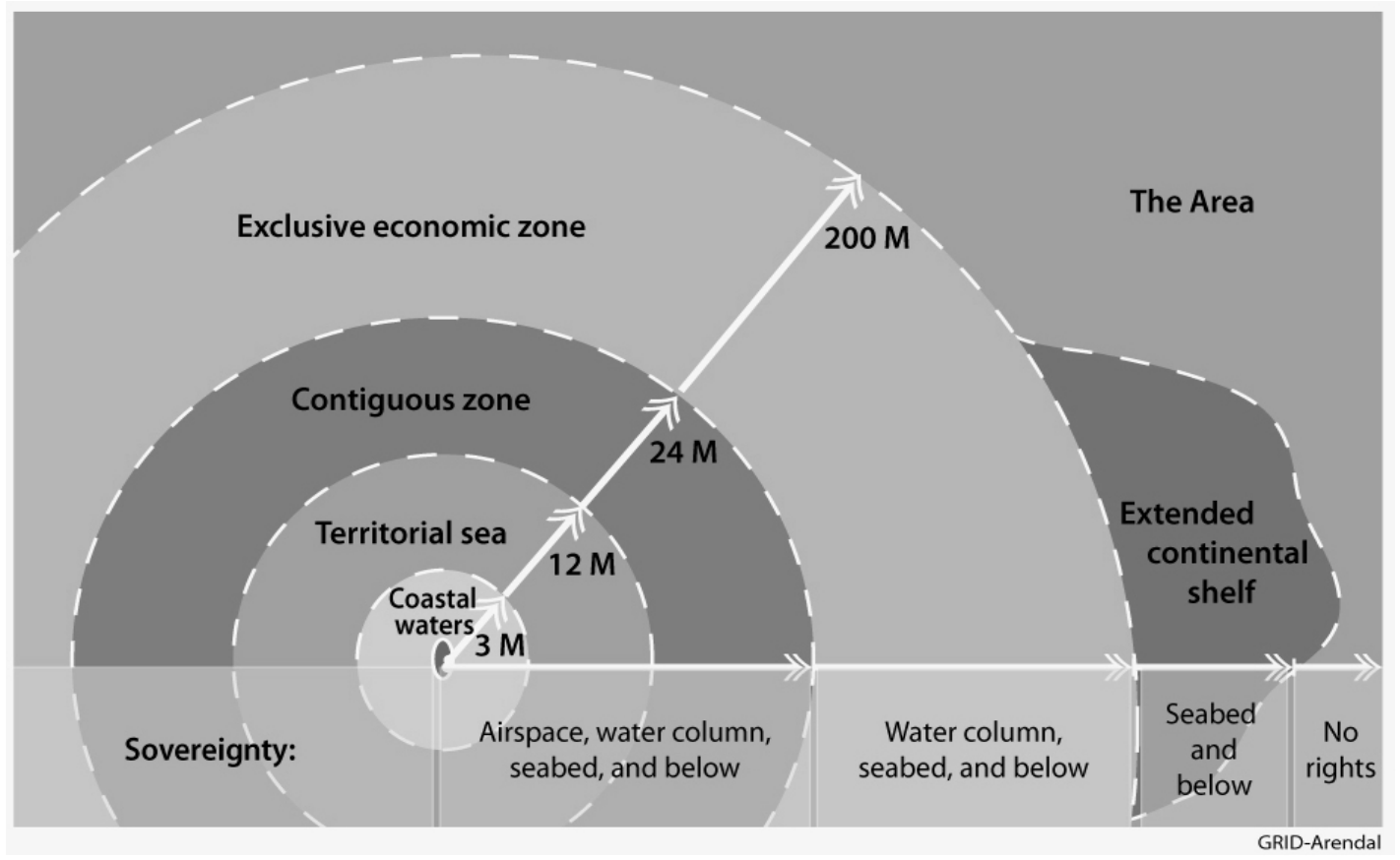

Source: GRID-Arendal, 2014, $M=$ nautical miles

\section{Fig. 1. Maritime sovereignty. Maritime zones and rights under UNCLOS}

Later, the basis for marine governance and integrated marine management, including a duty of states to protect and conserve the environment at sea established by UNCLOS (Arts. 192, 194(5), 116-120), was complemented and reinforced by numerous conventions and soft law instruments (Singh \& Ort, 2020; Rothwell \& Stephens, 2016). In the Baltic Sea, these mechanisms were also supplemented by "many types of internationally agreed regional spatially explicit controls in the Baltic Sea [..]. This includes regulations set by the International Maritime Organization (IMO), including traffic separation schemes and EU regulations on fisheries management (areas closed to fisheries) [...] regional marine protected area networks, such as Baltic Sea Protected Areas (BSPAs), Natura 2000 and Emerald sites” (Backer, 2011, p. 283; see also Athanasiou et al., 2017a).

As reflected from the above, since "the oceans are not only diverse ecosystems; they are also economic and political spaces" (Singh \& Ort, 2020, p. 51), application of a sustainable, effective and efficient marine governance approach is required. In turn, promotion of such governance of the oceans can be ensured if "information models represent the multidimensional nature of reality as closely as possible" (Ng'ang'a et al., 2001). Nichols et al. (2000) pinpoint four main functions of marine governance among which are "allocation within society and among government organizations of rights of use, ownership, and stewardship to marine resources" and "regulation of these rights of use, ownership, and stew ardship". Further, they state that the extent to which functions of marine governance are effectively conducted is partly determined by how well marine resource data is handled.

Although UNCLOS streamlined "[marine] governance by focusing nations' interests on their offshore resources", the Convention does not address matters concerning internal political organizations of the states sharing jurisdiction (Nichols et al., 2000). As a result, in the late 1990s the need of a marine cadastre - "another method for managing marine spatial information" with the basic purpose of directing property rights in the marine environment (Sutherland, 2005a, p. 220) - became apparent (PCC et al., 2017). Since then, interested members of the International Geomatics Community, e.g., FIG (Fédération International des Géomètres / International Federation of Surveyors) has stepped up research efforts in different jurisdictions to establish marine cadastres (Dawidowicz \& Źróbek, 2014; Sutherland, 2011).

The understanding of what constitutes a marine cadastre is a fuzzy concept and varies across jurisdictions (Sutherland, 2005b). The definitions of a marine cadastre elaborated by the most advanced countries in this field are recognized worldwide, and have been extensively analysed elsewhere (e.g., Nichols et al., 2006; Ng'ang'a, 2006; Astor et al., 2017). For the purposes of this study, the authors would like to point to one important aspect. Following the first and most frequently quoted definition denoting that a marine cadastre is "a system to enable the boundaries of [maritime] rights and interests, to be recorded, spatially managed and physically defined in relationship to the boundaries of other neighbouring or underlying rights and interests" (Grant et al., 1999), all other definitions (Nichols et al., 2000; Ng'ang'a et al., 2001; United States Department of Communication National Oceanic and Atmospheric Administration, 2002 from Tamtomo, 2004 and Astor et al., 2017; Binns, 2004; Ng'ang'a et al., 2004; Nichols 
et al., 2006; Vaez, 2009 from Astor et al., 2017; Zentelis, 2011 from Arvanitis et al., 2016) with subtle differences have a key convergence point and inter alia emphasize the importance of the marine cadastre for primarily recognitional arrangement of marine spatial interests or 3Rs (FIG, 2003). For example, Nichols et al. (2000) interpret the marine cadastre as "the spatial reference system for property rights and administration of those rights." Ng'ang'a (2006, p. 25) explains that a vision of the interest-driven marine cadastre "includes the provision of an inventory of the nature of the interests that exist, location and spatial extent of the interests, and the holders of those interests."

Nowadays, technological advances ensure maritime users information grounded in evidence rather than presumptions and provide a basis for applying the 'marine parcel' concept (Ng'ang'a et al., 2001) with the aim of gathering, storing and disseminating information (Ng'ang'a et al., 2004). Along with the marine cadastre, marine parcel is a second important term (Balla \& Wouters, 2017a) and characterised as “volumetric reality of every distinct marine zone (sea surface \& water column \& seabed or soil \& subsoil) with: a) the rights and charges under the UNCLOS, b) the patrimonial rights which include rights in rem" (de Latte, 2015). A marine parcel is a concept through which the need for the fourth dimension time - is emphasized. Firstly, the co-existence of marine 3Rs is feasible at the same latitude and longitude but at varying depths (Athanasiou et al., 2017a; Athanasiou et al., 2016; Ng'ang'a et al., 2001; Fig. 2).

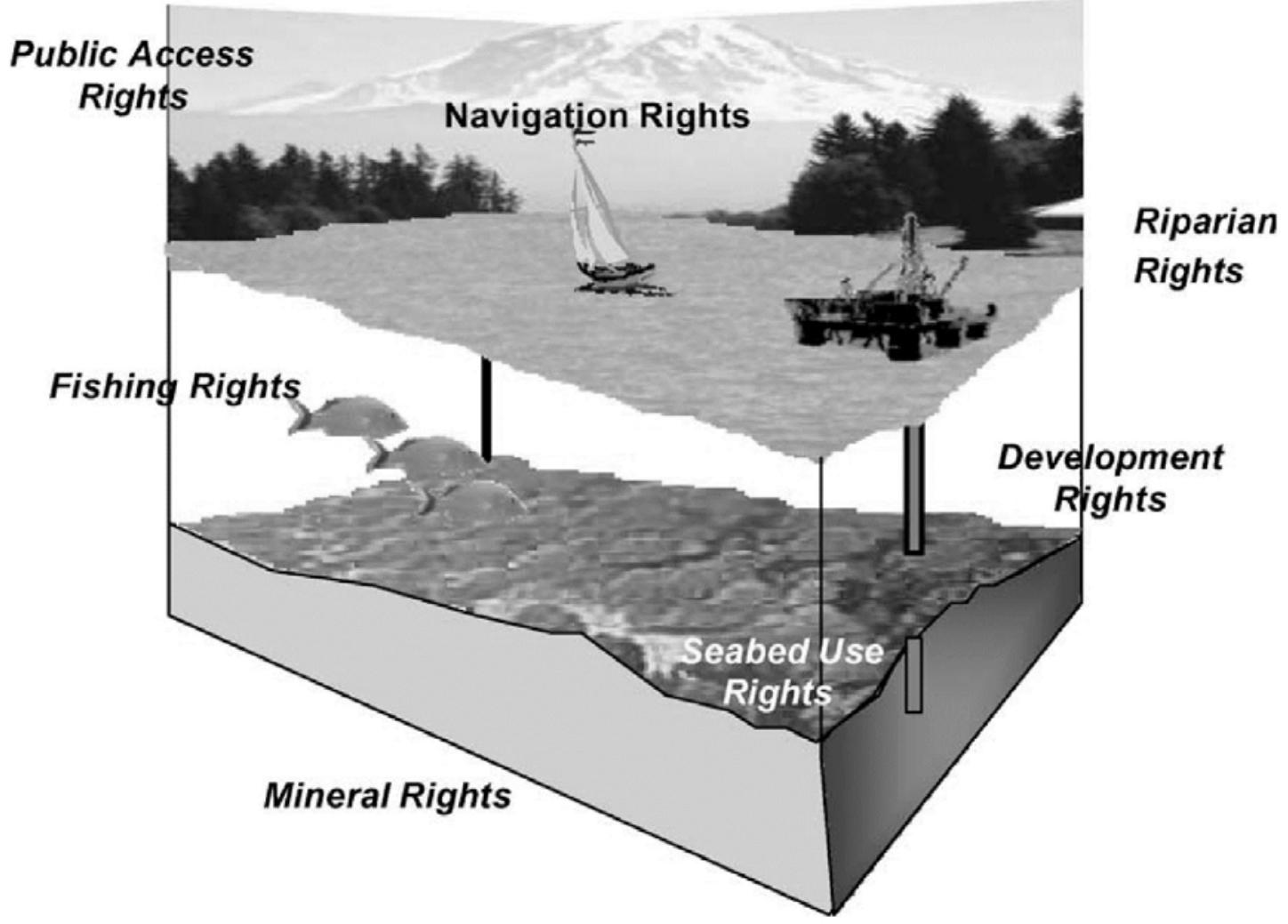

Source: Ng'ang'a et al. (2004)

Fig. 2. 3D perspective of marine rights.

Secondly, in the marine world the co-existence of most activities is possible in space and time, while they can also travel across space and time (Athanasiou et al., 2016). In other words, 3Rs are embedded within a legal framework that varies over time (Athanasiou et al., 2017a). Multidimensionality is needed because of the particular nature of marine rights "that makes a two-dimensional definition of these rights legally inadequate" (Ng'ang'a et al., 2001). This approach helps to visualize time-shared and time-variable interests and rights - so-called four-dimensional rights (fixed term licences, concessions, and leases for mining, production of energy, aquaculture, fishing, and so on) (PCC et al., 2017; Athanasiou et al., 2016; de Latte, 2015; Ng'ang'a et al., 2004; Cockburn \& Nichols, 2002). The marine cadastre must include a list of 3Rs connected with each parcel as soon as the parcels are defined, organized according to the physical layers that make up marine space, reflecting the key elements found in marine space, the characteristics associated with them, and the relationship between them (Ng'ang'a et al., 2004). This can be done by applying a visual multidimensional geospatial model such as the marine property rights data model, relational database models or newer data models such as 
Object Oriented (OO), e.g., the Unified Model Language (UML) and Entity-Relationship (ER) models (Ng'ang'a et al., 2004; see also Athanasiou et al., 2017a).

Along with its features of multi-dimensionality and interest-drive, additionally, to ensure sustainable, efficient and effective marine governance, advances in information technology and spatial data infrastructure development should be used to take advantage of the multi-purpose function that the marine cadastre can offer by combining various marine datasets on the physical, biological, socio-cultural and economic aspects related to the cadastre (FIG, 2003; Ng'ang'a et al., 2001, 2004). In general, individual commercial maritime activities should be related to environmental conditions and well incorporated with the administration or management of other activities (Robertson et al., 1999). Singh and Ort (2020, p. 49) put it thus: "[T]he jurisdictional mandate to regulate human activities at sea-specifically, to adopt necessary measures to protect the marine environment - is a critical consideration in the [marine] governance discourse". Tenure information used, for example, in combination with environmental information relevant to the same spatial scale improves the decision-making process (Sutherland, 2005b). Moreover, if the obligation to protect and preserve the marine environment is seen as erga omnes under international and regional law (see, e.g., Marine Strategy Framework Directive (2008)) (Harrison, 2017; Qiu \& Jones, 2013), this necessitates registering in MMIMC the relevant records according to which marine 3Rs tracking would ensure achievement of environmental protection goals and application of the integrated resource management technique.

To sum up, the marine cadastre should be multi-purpose, multi-dimensional (4-dimensional) and interest-driven in order to provide up-to-date, precise, complete and useful information to support socioeconomic and environmental decision-making (Sutherland, 2005b).

Synergistic effects of MSP and MMIMC and the state of the art in the BSR

MSP is one of three major horizontal planning and integrated policy-making tools that "cut across sea-related sectoral policies and support joined up policy making" (EC, 2007, p. 5) and integrated management practice (Kelly et al., 2019). A crucial condition for effective MSP is the ability to deal constructively and efficiently with conflicts of use, and the discovery of suitable alternatives to spatial disputes is therefore an integral part of the MSP process (Gee et al., 2019). The MSP Directive (2014: Art. 3(2)) defines that MSP “means a process by which the relevant Member State's authorities analyse and organise human activities in marine areas to achieve ecological, economic and social objectives."

Arvanitis et al. (2016), although underlining the independent functioning of MSP and MMIMC, characterize the two-way relationship between both notions in the following way: "MSP will be designed and implemented safely and at a lower cost if it utilizes data from MC [marine cadastre] and $\mathrm{MC}$ will register and control the different rights and licenses in marine areas based on ecological environment when defined zoning from MSP exist." Thus, the spatial and non-spatial (descriptive) data recorded in the MMIMC concerning space and 3Rs can be used in two ways: first, as a basis for MSP preparation, and second, as enablers for MSP implementation, including monitoring, evaluation and adaptation stages (Arvanitis et al., 2016; CLGE, 2017; Kaminskis et al., 2018). Thus, MMIMC functions as “a complementary tool” for MSP (Michalak, 2018). At the same time, information gathered during the MSP process can provide relevant data for the MMIMC.

Thus, one can conclude that establishment of the MMIMC, while combining data regarding offshore legal tenure and its linked spatial quantity from various sources and systems (Dawidowicz \& Źróbek, 2014; Ng'ang'a et al., 2004), would have several tangible benefits that would positively influence Blue Growth and MSP. First of all, similarly to a land-based cadastre developed specifically for tax purposes, a marine cadastre would pave the groundwork for an equitable tax scheme that would allow all sea-related property and sea-generated income to be taxed (Balla $\&$ Wouters, 2017a), that is, taxes and fees from licence beneficiaries, including standard fees based on installation valuation (Arvanitis et al., 2016). Secondly, it can provide legal certainty as to sea-space development, marine parcel 3Rs, and public access to and from seas, a secure process in the case of transfer of titles, establishment of mortgages, thematic and spatial data and information to support efficient decision-making and administration regarding the use of marine spaces, an understanding of the upper and lower bounds of exploration rights, including information about the legal holders (owners, lessors, lessees, users, licence holders), the exact content and location of those rights and their effect on the environment and other property entitlements, avoid conflicts on overlapping 3Rs, support the allocation and administration of rights, as well as monitoring and mitigating environmental impacts, and promote trans-sectoral and transboundary cooperation (Sutherland, 2005b; FIG, 2003; Ng'ang'a et al., 2001, 2004; Tamtomo, 2004; Sutherland, 2011; Arvanitis et al., 2016; Balla \& Wouters, 2017a; PCC et al., 2017; Dawidowicz \& Źróbek, 2014; Michalak, 2018).

The following is a summary of the situation in the BSR countries and their achievements in the field of MSP and MMIMC. If data is not available regarding cadastral developments in the respective country, it is substituted by information regarding the Maritime Spatial Data Infrastructure. The information is provided below according to its availability as of 1 December 2020. 
In Estonia, the transboundary commenting phase of the maritime spatial plan which started in the third quarter of 2020 was delayed by several national conflicts due to offshore wind energy areas (VASAB, 2020). Regarding marine cadastral developments, it is known that the Estonian Land Board's Geoportal has a specific part "Marine Areas Application”, encompassing data for the Estonian marine area in the Baltic Sea (PCC et al., 2017).

On 14 May 2019, the Government of Latvia approved the Maritime Plan 2030 for Inland Marine Waters, the Territorial Sea and the EEZ (EC, 2020b). Since 2017, the State Land Service of Latvia has started to register coastal areas two kilometres in width from the Baltic Sea baseline in the Cadastre Information System (Kaminskis et al., 2018; Stāmure et al., 2017). To the authors' knowledge Latvia has chosen to use the data synchronization model developed by the State Land Service. Within this framework, the establishment of a unified system for registration of offshore structures is proposed, supplementing the existing land cadastre with sea areas.

In Lithuania, marine spatial solutions were adopted by the Parliament in 2015 as a component of the Comprehensive Plan of the Territory, extending it by the part on "Maritime territories" (EC, 2020b). At present, a new Comprehensive Plan is being prepared, since the current plan expires in 2020, and it includes a second maritime spatial plan (MoE, 2019; EC, 2020b). In the marine cadastre field, work is being done in consultation with Swedish colleagues (Kubliņš \& Kaminskis, 2017).

In Denmark, assessment, consultation and adaptation of the maritime spatial plan is ongoing (EC, 2020b). It is expected to be in an innovative version, developed using a new methodology and resulting in a legally binding, digital and user-friendly maritime spatial plan (VASAB, 2020). Issuance of a statutory order and entry into force of the plan are forthcoming. Denmark is showing a rapid pace towards creation of a Marine Spatial Data Infrastructure and "expansion" of the land cadastre by registering offshore buildings in it (PCC et al., 2017).

In Finland, the maritime spatial plan is being prepared in three parts (the Gulf of Finland; the Archipelago Sea and Southern Bothnian Sea; the Northern Bothnian Sea, Quark and Bothnian Bay) (EC, 2020b). The process is in the last phase of the planning process after which the relevant information will be communicated to stakeholders and the public (VASAB, 2020). A maritime spatial plan for the Åland Islands is currently being developed according to separate planning legislation, while a specific regional land use plan for the Kymenlaakso Region territorial sea area is already in place (EC, 2020b). Finland has a significant amount of spatial data, but its availability is fragmented and there is no information on maritime cadastral developments (PCC et al., 2017).

In Sweden, the final proposal of three plans covering the territorial sea and the EEZ (Skagerrak/Kattegat, Baltic Sea, and the Gulf of Bothnia) were submitted to the Government in December 2019 and await adoption (EC, 2020b; VASAB, 2020). Currently, evaluation of the planning process is taking place by the Swedish Institute for Marine Research of the University of Gothenburg and a monitoring evaluation programme is being prepared for application of maritime spatial plans at national level (VASAB, 2020). Sweden is the leading marine cadastre country in the BSR, actively preparing research and working on legislative proposals concerning a marine cadastre (Stāmure et al., 2017; Balla \& Wouters, 2017b).

In Germany, maritime spatial plans exist for the North Sea and the Baltic Sea German EEZs and territorial sea areas under the jurisdiction of three coastal federal states (Lower Saxony, Schleswig-Holstein, and Mecklenburg-Vorpommern) (EC, 2020b). The full first draft MSP in a single document covering the North Sea and the Baltic Sea is being published, and the national stakeholders' process is ongoing (VASAB, 2020). International consultation of the first draft should start soon (around mid-January 2021) after the documentation has been translated (VASAB, 2020). Germany has very advanced Marine Spatial Data Infrastructures in the form of a supranational network, integrating marine data from all relevant sources (PCC et al., 2017).

In Poland, MSP is divided into currently ongoing development of several maritime spatial plans: the main and comprehensive maritime spatial plan of Polish sea areas in a scale of 1:200 000, plans for the Szczeciński Lagoon and the Kamieński Lagoon, plans for the Vistula Lagoon, plans for port area waters, and detailed plans for selected areas covered by the main and comprehensive maritime spatial plan (EC, 2020b). The main and comprehensive maritime spatial plan has been sent to the Government Legislation Centre for a check-up of its coherence with Polish legislation and consultations with state institutions before the Cabinet of Ministers adopts it (VASAB, 2020). The relationship between these different types of plan is not hierarchical since some of the plans will supplement or replace parts of the main and comprehensive maritime spatial plan (VASAB, 2020). The need for marine cadastre development is recognized, and there are planned activities to extend the internal waters cadastre to a marine cadastre (Dawidowicz \& Źróbek, 2014). 
Overall, it can be concluded that the level of development and implementation of the MSP and marine cadastre in different countries of the Baltic Sea region is highly unequal. However, in the field of MSP, the situation is much clearer, as adoption of maritime spatial plans in all countries will take place within the set deadlines, in accordance with the MSP Directive.

Given the progress made so far in developing exemplary integrated marine management, mostly through application of the MSP tool, the next task would be to develop a common framework of MMIMC for the BSR countries, using observations of the Global Geodetic Observing System and covering the Territorial Sea and the EEZ. The outcome would be the basic (domain) models of MMIMC and proposals for the state authorities responsible for marine cadastre issues in the BSR. One should take into account that the geographic location of the states around the Baltic Sea sets the specific conditions for the marine cadastre since most of the jurisdictions all around the globe do not have the territorial waters of other countries as close as in the BSR. In fact, EEZs are also much narrower than the maximum width (200 nautical miles) set by UNCLOS, covering in practice all areas outside territorial waters (Backer, 2011). This leads to the need to coordinate marine cadastre development. In this context, the possibility of reducing maritime conflicts is a vital aspect.

Looking further, the synergistic effects of MSP and MMIMC would be useful in advancing creation of a national and regional Marine Administration System for which "the association of legal attributes with maritime limits and boundaries' information or marine parcels is necessary, in order to determine under whose authority or international treaty a particular limit or boundary is defined, and the restrictions around this specific marine parcel according to the legislation" (Athanasiou et al., 2016, p. 92).

\section{Conclusions and proposals}

1. In the framework of the Blue Economy, diversity of activities creates a mosaic of diverse interests posing major challenges for the marine environment. Public, environmental and functional interests and their identified spatial dimensions form a part of a marine object registered in a marine cadastre.

2. In the contemporary understanding of a marine cadastre, no collision between two classic concepts mare clausum and mare liberum exists. MMIMC has been developed according to the perspective of mare clausum. In turn, at present, mare liberum is rather a responsible freedom consistent with the principle of conditional high seas freedoms and subject to rules set in UNCLOS, including a duty of states to protect and conserve the environment at sea and creating a framework of private and public interests in offshore environments.

3. The marine cadastre should be multipurpose, multidimensional (four-dimensional) and interest-driven in order to provide up-to-date, precise, complete and useful information. However, it is at the marine parcel level where information on 3Rs is gathered, stored and disseminated and MMIMC would be one way to incorporate property rights data from a number of sources. Introduction of MMIMC would help to relate individual commercial maritime activities to environmental conditions and integrate them with the administration or management of other activities, taking into account the erga omnes aspect of environmental considerations. Maritime 3Rs tracking in MMIMC would ensure achievement of environmental protection goals of the marine environment and application of the integrated resource management technique.

4. During implementation of the MSP, as well as the monitoring, evaluation and adaptation stages, MMIMC will help proactively and pre-emptively to address conflicts of use and contribute to sustainable, effective and efficient marine governance. And vice-versa: information obtained during the MSP process can provide the MMIMC with relevant data.

5. Given the progress made to date in the development of exemplary integrated marine management, mainly through application of the MSP instrument, the next task will be to establish a common framework for a multipurpose, multidimensional and interest-driven marine cadastral system for the countries of the BSR. In this process, the observations of the Global Geodetic Observing System should be used, and the system would cover the Territorial Sea and the EEZ.

6. In the more distant future, the synergistic effects of the MSP and MMIMC will be useful in advancing development of the national and regional framework of the Marine Administration System.

\section{Bibliography}

Alberdi, R., Erba, D.A., 2020. Modeling Legal Land Object for Waterbodies in the Context of 4D Cadastre. Land Use Policy, 98, 1-11.

Arvanitis, A., Giannakopoulou, S., Parri, I., 2016. Marine Cadastre to Support Marine Spatial Planning. Common Vision Conference 2016 Migration to a Smart World. Amsterdam, the Netherlands, June 5-7, 2016.

Astor, Y., Sulasdi, W.N., Hendriatiningsih, S., Wisayantono, D., 2017. The Evaluation of Marine Cadastre Definitions Among Australia, Canada and United States of America Based on Indonesia's Perspective as an Archipelagic State. Chapter 22. In Yomralioglu, T., McLaughlin, J. (Eds.), Cadastre: Geo-Information Innovations in Land Administration. Heidelberg: Springer \& Capital Publishing Company, pp. 275-308. 
Athanasiou, K., Pispidikis, I., Dimopoulou, E., 2017a. 3D Marine Administration System Based on LADM. In Abdul-Rahman, A. (Ed.), Advances in 3D Geoinformation. Cham: Springer, pp. 385-407.

Athanasiou, K., Sutherland, M., Kastrisios, C., Tsoulos, L., Griffith-Charles, C., Davis, D., Dimopoulou, E., 2017b. Toward the Development of a Marine Administration System Based on International Standards. International Journal of Geo-Information, 6(194).

Athanasiou, A., Dimopoulou, E., Kastrisios, C., Tsoulos, L., 2016. Management of Marine Rights, Restrictions and Responsibilities according to International Standards. Proceedings of the $5^{\text {th }}$ International FIG 3D Cadastre Workshop. Athens, Greece, October 18-20, 2016, pp. 81-104.

Backer, H., 2011. Transboundary Maritime Spatial Planning: a Baltic Sea Perspective. Journal of Coastal Conservation, 15, $279-289$.

Balla, E., Wouters, R., 2017a. Marine Cadastre in Europe: State of Play (Nr 355). Paper prepared for presentation at the "2017 World Bank Conference on Land and Poverty". The World Bank - Washington DC, March 20-24, 2017.

Balla, E., Wouters, R., 2017b. Towards European Marine Cadastral System. Baltic Sea region MSP Data Expert Sub-Group $7^{\text {th }}$ Meeting. Helsinki, Finland, September 13-14, 2017.

Binns, A., 2004. Defining a Marine Cadastre: Legal and Institutional Aspects. Master thesis. Melbourne: The University of Melbourne.

Choi, Y.R., 2017. The Blue Economy as Governmentality and the Making of New Spatial Rationalities. Dialogues in Human Geography, 7(1), 3741.

Cockburn, S., Nichols, S., 2002. Effects of the Law on the Marine Cadastre: Title, Administration, Jurisdiction, and Canada's Outer Limit. FIG XXII International Congress. Washington, D.C., USA, April 19-26, 2002.

Council of European Geodetic Surveyors (CLGE - Comité de Liaison des Géomètres Européens). 2017. CLGE releases the final report on Marine Cadastre. May 31, 2017. [Online] Available at: https://www.clge.eu/2017/clge/clge-releases-the-final-report-on-marine-cadastre [Accessed 06.10.2020].

Dawidowicz, A., Źróbek, R., 2014. Multipurpose Water-marine Ccadastre in Poland - Development Directions. Acta Adriatica, 55(2), 127-144.

De Latte, G., 2015. Marine Cadastre. General rights and charges under the United Nations Convention on the Law of the Sea (UNCLOS) Patrimonial rights in the different marine zones. Registration of patrimonial rights. $7^{\text {th }}$ Annual Publication, European Land Registry Association.

Directive 2014/89/EU of the European Parliament and of the Council of 23 July 2014 establishing a framework for maritime spatial planning. OJ L 28.8.2014, 257, pp. 135-145.

Directive 2008/56/EC of the European Parliament and of the Council of 17 June 2008 establishing a framework for community action in the field of marine environmental policy. OJ L 25.6.2008; 164, pp. 19-40.

European Commission (EC), 2020a. The EU Blue Economy Report. 2020. Luxembourg: Publications Office of the European Union.

European Commission (EC), 2020b. European MSP Platform. Country Information Profiles. Available at: https://www.msp-platform.eu/msppractice/countries [Accessed 19.10.2020].

European Commission (EC), 2019. European MSP Platform. MSP Sectors and Conflicts. [Online] Available at: https://www.mspplatform.eu/sectors [Accessed 16.10.2020].

European Commission (EC), 2012. Blue Growth - Opportunities for Marine and Maritime Sustainable Growth. Communication from the Commission to the European Parliament, the Council, the European Economic and Social Committee and the Committee of the Regions. Brussels, $\operatorname{COM}(2012) 494$ final.

European Commission (EC), 2007. An Integrated Maritime Policy for the European Union ("Blue Book"). Communication from the Commission to the European Parliament, the Council, the European Economic and Social Committee and the Committee of the Regions. Brussels, COM(2007) 575 final.

Freestone, D., 2008. Principles Applicable to Modern Oceans Governance (editorial). The International Journal of Marine and Coastal Law, 23(3), 385-391.

Friess, B., Grémaud-Colombier, M., 2019. Policy outlook: recent evolutions of maritime spatial planning in the European Union (article in press). Marine Policy [available online 19 February 2019].

Gee, K., Lukic, I., Schultz-Zehden, A., Ooms, E., Ansong, J.O., Passerello, C., s.Pro - sustainable projects GmbH, Germany, 2019. Addressing conflicting spatial demands in MSP. Luxembourg: Publications Office of the European Union. 
Grant, D., Baldwin, R., Blick, G., Buckler, C., Fargher, I., Walsh, S., 1999. Principles for a Seabed Cadastre. OSG Technical Report 9. Office of the Surveyor-General, Land Information New-Zealand.

GRID-Arendal, 2014. Maritime sovereignty. [Online] Available at: https://www.grida.no/resources/6278 [Accessed 18.10.2020].

Harrison, J., 2017. Saving the Oceans through Law: the iInternational Legal Framework for the Protection of the Marine Environment. Oxford: Oxford University Press.

Hoegh-Guldberg, O. et al., 2015. Reviving the Ocean Economy: the Case for Action - 2015. Gland: WWF International.

International Federation of Surveyors (FIG - Fédération International des Géomètres). 2003. The UNB-FIG Meeting on Marine Cadastre Issues at the University of New Brunswick, Canada, September 15-16, $2003 . \quad$ [Online] Available at: https://fig.net/news/archive/news_2003/marine_seminar_2003.asp [Accessed 12.10.2020].

Kaminskis, J., Stāmure, I., Geipele, I., 2018. Baseline of the Baltic Sea - Essential Element for the Marine Cadastre. In Rjabovs, B., Shmeld, I., Jekabsons, N., Trokss, J. (Eds.), Space Research Review. Ventspils: Ventspils University of Applied Sciences, pp.128-137.

Kelly, C., Ellis, G., Flannery, W., 2019. Unravelling Persistent Problems to Transformative Marine Governance. Frontiers in Marine Science, 6(213), doi: 10.3389/fmars.2019.00213.

Kubliņ̌s, I., Kaminskis, J., 2017. Baltijas valstu pirmie soḷi jūras kadastra izveidē. [Online] Available at: http://mernieks.lv/article/2654?lang=ru [Accessed 12.10.2020].

Lemmen, C.H.J., 2012. A Domain Model for Land Administration. Ph.D. Thesis. Delft: Technical University of Delft.

Maes, F., 2008. The International Legal Framework for Marine Spatial Planning. Marine Policy, 32, 797-810.

Michalak, S., 2018. A Multipurpose Marine Cadastre to Manage Conflict Use with Marine Renewable Energy. In Ölçer, A.I., Kitada, M., Dalaklis, D., Ballini, F. (Eds.), Trends and Challenges in Maritime Energy Management. Cham: Springer, pp. 447-462.

Ministry of Environment of the Republic of Lithuania (MoE). 2019. New Comprehensive Plan of the Territory of the Republic of Lithuania. [Online] Available at: http://www.bendrasisplanas.lt/2019/12/13/en/ [accessed 15.6.2020].

Neimane, L., 2020. Maritime Spatial Planning as "Key Enabler" of Blue Growth through "Just Transformations" in the European Union. Changes in Social and Business Environment - CISABE'2020. 8th International Conference, Panevèžys, Lithuania, October 1, 2020. Forthcoming (in press).

Ng'ang'a, S.M., 2006. Extending Land Management Approaches to Coastal and Oceans Management: A Framework for Evaluating the Role of Tenure Information in Canadian marine Protected Areas. Ph.D. dissertation, Department of Geodesy and Geomatics Engineering, Technical Report No. 243. Fredericton: University of New Brunswick.

Ng'ang'a, S., Sutherland, M., Cockburn, S., Nichols, S., 2004. Toward a 3D Marine Cadastre in Support of Good Ocean Governance: a Review of the Technical Framework Requirements. Computers, Environment, and Urban Systems, 28, 443-470.

Ng'ang'a, S., Sutherland, M., Nichols, S., 2002. Data Integration and Visualization Requirements for a Canadian Marine Cadastre: Lessons from the Proposed Musquash Marine Protected Area. CIG-ISPRS Joint Symposium on Geospatial Theory, Processing and Application, Ottawa, Canada, July 2002.

Ng'ang'a, S., Nichols, S., Sutherland, M., Cockburn, S., 2001. Toward a multidimensional marine cadastre in support of good ocean governance. New spatial information management tools and their role in natural resource management. International Conference on spatial information for sustainable development, Nairobi, Kenya, October 2 - 5, 2001.

Nichols, S., Ng'ang'a, S.M., Sutherland, M.D., Cockburn, S., 2006. Chapter 10. Marine Cadastre Concept. In Calderbank, B., MacLeod, A.M., McDorman, T.L., Gray D.L., (Eds.), Canada's Offshore: Jurisdiction, Rights and Management, $3^{\text {rd }}$ ed. Bloomington, IN: Trafford Publishing.

Nichols, S., Monahan, D., Sutherland, M.D., 2000. Good Governance of Canada's Offshore and Coastal Zone: Towards an Understanding of the Maritime Boundary Issues. Geomatica, 54(4), 415-424.

Papageorgiou, M., Kyvelou, S., 2018. Aspects of Marine Spatial Planning and Governance: Adapting to the Transboundary Nature and the Special Conditions of the Sea. European Journal of Environmental Sciences, 8(1), 31-37.

Papageorgiou, M., 2016. Marine Spatial Planning and Sea-Uses: Conceptual and Theoretical Approaches (in Greek). Aeichoros, 23 , 41-63.

PCC, EULIS, ELRA, CLGE, Eurogeographics, 2017. Marine Cadastre in Europe. A Preliminary Study. Brief edition. [Online] Available at: https://webgate.ec.europa.eu/maritimeforum/system/files/Marine_Cadastre_in_Europe_Brief_Edition_V\%201.02_2017.pdf [Accessed 03.10.2020]. 
Puriņa, I., Sprukta, S., N.d. Jūras teritorijas lietojuma veidi Zilās izaugsmes kontekstā un to ietekme uz Latvijas teritoriālo jūras ūdeņu vidi (Types of Marine Territory Use in the Context of Blue Growth and their Impact on Latvia's Territorial Marine Environment). Rīga: Latvijas Hidroekologijas institūts.

Qiu, W., Jones, P.J.S., 2013. The Emerging Policy Landscape for Marine Spatial Planning in Europe. Marine Policy, 39, $182-190$.

Robertson, B., Benwell, G., Hoogsteden, C., 1999. The Marine Resource: Administration Infrastructure Requirements. UN-FIG Conference on Land Tenure and Cadastral Infrastructure for Sustainable Development. Melbourne, Australia, October 24-27, 1999.

Rothwell, D., Stephens, T., 2016. The International Law of the Sea, $2^{\text {nd }}$ ed. Oxford: Hart Publishing.

Scott, K., 2015. Integrated Oceans Management: A New Frontier in Marine Environmental Protection. In Rothwell, D.R., Oude Elferink, A.G., Scott, K.N., Stephens, T. (Eds.), The Oxford Handbook of the Law of the Sea. New York: Oxford University Press, pp. 463-490.

Singh, P.A., Ort, M., 2020. Law and Policy Dimensions of Ocean Governance. In Jungblut, S., Liebich, V., Bode-Dalby, M. (Eds.), YOUMARES 9 - The Oceans: Our Research, Our Future. Proceedings of the 2018 conference for YOUng MArine RESearcher in Oldenburg, Germany. Cham: Springer, pp. $45-56$

Stāmure, I., Kaminskis, J., Kowalczyk, K., 2017. Importance of the Marine Cadastre in the Development of the Real Estate Industry in Latvia. Baltic Journal of Real Estate Economics and Construction Management, 5, 259-274.

Steinberg, P.E., 2001. The Social Construction of the Ocean. Cambridge: Cambridge University Press.

Sutherland, M., 2011. Improving the Administration of Marine and Coastal Spaces. Coordinates, November, pp. 22-26.

Sutherland, M.D., 2005a. Marine Boundaries and Good Governance of Marine Spaces. Ph.D. dissertation, Department of Geodesy and Geomatics Engineering, Technical Report No. 232. Fredericton: University of New Brunswick.

Sutherland, M., 2005b. The Marine Cadastre: Legal and Spatial Data Contribution to Economic, Environmental and Social Development. From Pharaohs to Geoinformatics FIG Working Week 2005 and GSDI-8. Cairo, Egypt, April 16-21, 2005.

Tamtomo, J.P., 2004. The Needs for Building Concept and Authorizing Implementation of Marine Cadastre in Indonesia. $3^{\text {rd }}$ FIG Regional Conference. Jakarta, Indonesia, October 3-7, 2004.

United States Department of Communication - National Oceanic and Atsmospheric Administration, 2002. U.S. Marine Cadastre.

UNCLOS - United Nations Convention on the Law of the Sea (UNCLOS).1982. 1833 U.N.T.S. 397. UN Doc. A/Conf. 62/122 reprinted in United Nations, Official Text of the United Nations Convention on the Law of the Sea with Annexes and Index (New York: UN Sales No. E83.V.5, 1983).

Vaez, S., 2009. Marine Cadastre and Marine Administration. Short Course on Modern Cadastre and Land Administration. University of Melbourne, Australia.

Vision and Strategies around the Baltic Sea (VASAB). 2020. $2^{\text {nd }}$ Planning Forum of the Baltic Sea Region's Maritime Spatial Planners. CAPACITY4MSP. Online, November 11, 2004.

Voyer, M., Quirk, G., Mcllgorm, A., Azmi, K., 2018. Shades of Blue: What do Competing Interpretations of the Blue Economy Mean for Oceans Governance? Journal of Environmental Policy \& Planning, 20(5), 595-616.

Winder, G.M., Le Heron, R., 2017. Assembling a Blue Economy Moment? Geographic Engagement with Globalizing Biological-Economic relations in multi-use marine environments. Dialogues in Human Geography, 7(1), 3-26.

Wouters, R. 2020. Marine Cadastre in Europe. Author's Correspondence, Personal Archive Material.

Zentelis, P., 2011. Talking about Land and Cadastre (in Greek). Athens: Papasotiriou Editions, Athens.

\section{Acknowledgement}

This work is an output of the research project and has been financially supported by the specific support objective activity 1.1.1.2. "Post-doctoral Research Aid" of the Republic of Latvia (project No. 1.1.1.2/VIAA/3/19/514 "Effective Maritime Spatial Planning Regulation Framework and Implementation Challenges and Best Practice Examples for the Context of the Baltic Sea"), funded by the European Regional Development Fund (project No. 1.1.1.2/16/I/001). 


\section{THE IMPACT OF TECHNOLOGY COMPLEXITY ON PROJECT MANAGER'S SKILLS}

\section{Ieva Ozolanta, University of Latvia}

Abstract. The literature review on the efficient and necessary project manager skills, to perform with profitability to the company, has been a matter of research for several decades. There has been proven a scientific ground to state that certain project managers skills and abilities would be a reason to benefit efficiency of the team and profitability the company in general. The research analysis method has been used to reveal the important findings in the literature regarding this aspect. The aim of this research is to find and compile the historical and recent finding on this matter and to see the further research gaps, which may lead to integral research, as a part of integral economics.

The findings have progressed and confirmed that this component (a set of project managers skills) of general efficiency of the company development is an incontestable tool for progress. Knowing the skill needed to perform, managing the learning process to acquire such traits and lead the team to the set goal is no longer a dream, but a reality. The research points out that over the time and industrial scope, the qualities and skills required might slightly differ, but the general and most efficient traits are confirmed to be common. There has been an evolution of the thought, necessity, analysis and promotion of these skills as mandatory or, at least, preferred. The evaluation of project manager's skills is now performed frequently, and every research finding has promoted the distinct skill set to be assessed more accurately, laying the basis for efficient company performance from the very start. Further research on environmental challenges and partial teams' performance in remote conditions has a ground for more detailed exploration.

Keywords: project manager, skills, performance, efficiency, technology.

JEL code: O14, O31, M19

\section{Introduction}

The quest for profit, efficiency and development is at the basis of economic research and growth. Organizations compete in a global market dealing with advanced and ever-changing technology, changing laws, regulations and market demands. Organizations feel the pressure to do more with less. To achieve organizational business goals and to deal with changing market demands, companies leverage Information Technology, organizational processes, procurement learnedness and may introduce new technology systems to reduce costs, to improve quality, and thereby to increase the company's competitiveness and differentiate their products and services from their competitors. These new technology initiatives are often paired with project management processes as project management techniques and tools help an organization reduce product development time to market, utilize limited resources, address technological complexity, increase end-user and stakeholder satisfaction and aid positively in global market competition (Cleland, 1998), as well as justify business decisions by paying more attention to the process approach. (Cekuls, 2018).

Fortunately, project management is one of the most controllable success factors that can be improved by selecting the appropriate project managers (Kerzner \& Kerzner, 2017). However, the project management landscape has undergone considerable changes with rapid globalization, including the proliferation of virtual teams. For organizations to improve project success rates, they must improve the quality of the team management. As such, a clearer understanding of the factors influencing the quality of real and virtual project management is required. An extensive body of literature supports the need to develop cultural intelligence and leadership competencies in managers to support modern organizations (Mendenhall et al., 2012). Studies have shown the correlation between project managers' leadership style and project success (Afshari \& Gibson, 2016; Ferronato, 2017; Nguyen, Mia, Winata, \& Chong, 2017; Saleem, 2015).

Project management has been defined as a "process by which a project is successfully completed, and its objectives successfully delivered" (Turner \& Muller, 2005, p. 2). The project manager is the person responsible for initiating, planning, executing, controlling, and closing the project to achieve project goals (Gehring, 2007). Accelerated by globalization, increased competition and advancements in information technology, many organizations have started using

virtual teams to deliver their projects in recent decades (Child, 2015). Use of virtual teams has introduced new challenges into an already challenging environment. These challenges include poor communication, difficulty in understanding languages, differing cultural ethics, and geographical distance (Babar \& Zahedi, 2012)

The issue does not stand that there is a need for project manager's skills research, there have been great many. There should be a compilation of all the finding and applications by the form of extended dictionary to help focus on a vast sea of information. Nevertheless, some of the issues are still waiting their scientific confirmation of the empirical statements. The author finds it possible to identify the project manager skills that are 
particularly applicable to efficiently lead business development. The further study, and quantitative and qualitative research will be conducted to support this hypothesis.

Purpose of the study is to ascertain a number of literature, research and scientific articles that depict the different stages of project manager's competence and skill evolution influence, importance and impact on the project success. This is relevant to state, that the role of project manager has been changing, rather the necessary skills have been adapted to meet the efficiency needs of a successful business closure. The aim is to find a research gap for further studies and to make this information useful to employing just the right personnel or, better yet, to assist the development of an efficient project manager.

\section{Literature Review}

During the last decades there has been a number of researches on project management, project managers and the skills required to implement an efficient work towards business development. The main focus of recent articles include investigations of industry skills requirements (Maisiri, Darwish 2019), project managers' influence on performance strategies (Sankaran, Vaagaasar, 2019), correlation of project managers' competence, experience, education and technology experience on project success (Hosford, 2017), examining the relationship between Project Manager' s cultural intelligence, leadership and information technology projects success (Mansoor, 2019) and many more.

This is relevant to state, that in the era of fast development of information technologies, the human influence upon project successful development remains a very important performance influencer. The researchers have devoted a lot of effort to diagnose and state the specific requirements for efficiency and promotion regarding project managers' skills. Evermore there has been an overall view, that the role for leadership, leading and controlled implementation has not lost its place in the business development.

The role of project manager competence has been researched extensively over the last 30 years. Much of the work to identify successful project manager competences by McClelland (McClelland, 1984) and Posner (Posner, 1987) has been expanded on by Häsel et al. (Häsel, 2010) and Miterev et al. (Miterev, 2015) to name a few. The significant correlation of project manager competence with project success within various research studies reinforces the role of competency as a critical success factor within project management.

Early $21^{\text {st }}$ century research findings emerged from the need to understand and evaluate the economical impact of project managers' skills to the organizations' efficiency and ability to work productively. Incompetent project managers can be costly to organizations because of wasted effort and time (Bloch, Blumberg, \& Laartz, 2012; Johnson \& Hencke, 2008). A study on large scale projects revealed 17\% of technology (IT) projects failed and threatened the existence of organizations (Bloch et al., 2012). During an investigation into the United Kingdom (UK) government waste, $\$ 4$ billion in unnecessary costs were identified as a result of unsuccessful projects (Johnson \& Hencke, 2008).

There has been a distinct change in the attitude toward the status and the scope of the profession of a project manager. Two decades ago, project management has been referred to as the "accidental profession" (Curling, 2002; Heerkens, 2001). Carbone and Gholston (2004) suggested many project managers were promoted to their roles based upon their technical abilities. Not all project managers had the proper skills to be successful in their role. These employees lack critical people skills. Leadership skills are imperative for project success (Stevenson \& Starkw eather, 2010).

The research shows that project manager has been stated as the person responsible for achieving project objectives (Project Management Institute, 2013). Project managers play both manager and principle content expert roles (Einseidel, 1987). Ultimately, the project manager establishes direction of the project (Veal, 2004).

Kliem and Ludin (Kliem, 1998) argued the project manager has six main functions: (a) be a motivator, (b) lead the project through the lifecycle, (c) define goal and objectives, (d) create project plan, (e) project control, and (f) project closure. According to Levin and Skulmoski (Levin, 2000), the project manager is a guide, integrator, social architect, and project team protector. As a key operational leader, the project manager has an impact on organizational success (Kerzner, 2009; Muller \& Turner, 2010). Duarte, Lewis, Hoffman, and Crossman (Duarte, 1995) concluded that project managers:

$\checkmark$ Have technical backgrounds,

$\checkmark$ Participate in controlling, managing costs, and schedules, and

$\checkmark$ Are not involved in day-to-day activities of an organization.

Robbins (Robbins, 2000) argued the project manager role is four-dimensional: liaison, trouble-shooter, conflict manager, and coach. As a liaison, the project manager represents the team and works with constituencies such as customers, suppliers, other teams, or executive management. By playing the role of the trouble-shooter, the project manager assists the project team in finding solutions to problems. As a conflict manager, the 
project manager mediates any disagreements within the project team. Kerzner (Kerzner, 2009) postulated the common types of conflict are: priorities, technical opinions, procedures, personality clashes, and the responsibilities of team members - when coaching, project managers work with the team members to improve performance.

Looking across different industries, the project manager function is similar (Winch \& Kelsey, 2005). For example, in the construction industry, the key functions of the project manager are:

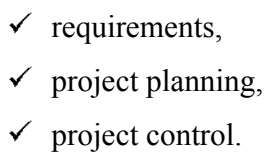

The key functions in the education industry are the same as the functions described in the Project Management Body of Knowledge (Project Management Institute, 2013; Winch \& Kelsey, 2005).

Researches have been conducted on the project team environment and the relationship orientation of project managers. Thamain (Thamain, 2004) and Turner and Muller (Turner, 2005) concluded it is important to allow an environment that enables the project team to impact the success of the project. Project managers influence a positive and motivated work environment (Schmid \& Adams, 2008). Makilouko (Mikilouko, 2004) suggested project managers are people oriented. Lee-Kelley, Long, and Loon (Lee-Kelley, 2003) determined project managers are relationship oriented. It was concluded that nurturing others, cultural values, and job satisfaction are important for the delivery of a successful project.

Results-orientation is a critical skill for successful project managers (Gillard \& Price, 2005). Gillard and Price identified additional behaviors of successful project managers:

$\checkmark$ Awareness of environmental influence;

$\checkmark$ Leveraging strategic influence and power to accomplish long-term goals;

$\checkmark$ Gathering information, catalyst for change, issue prevention, monitoring

$\checkmark$ performance, timelines, and budget;

$\checkmark$ Being a creative team leader;

$\checkmark$ Reward team members;

$\checkmark$ Assertiveness, responsiveness, and versatility characteristics;

$\checkmark$ Conscientious, detail-oriented, and logical;

$\checkmark$ Dependable and productive;

$\checkmark$ Self-confidence. (Gillard \& Price, 2005, p 51-52)

According to Gilley, Eggland, and Gilley (Gilley, 2002), project managers should know how to evaluate others, programms, and instructors in addition to project planning and design. This familiarity is learned through training, certifications, professional experience, career development activities.

The Project Management Institute published two significant standards: A Guide to the Project Management Body of Knowledge (PMBOK) (Project Management Institute, 2013) and the Project Manager Competency Development Framework (Project Management Institute, 2007). The PMCD Framework was the first standard to address project personnel performance improvement (Mendez, 2007). It is intended to support the professional development of project managers and aspiring project managers by serving as a guide to practitioners, employers, and advisors when developing a competency framework in the work environment (Mendez, 2007; Project Management Institute, 2007). Carbone and Gholston (Carbone, 2004) recommend Project Management Institute's competency model for Project Manager Competency Development (PMCD) Framework as the most efficient tool to assess.

Project manager competence is comprised of three dimensions which are knowledge competence, performance competence, and personal competence (Project Management Institute, 2007). Knowledge competency is what the project manager knows and applies to project. Performance competence is the outcome of knowledge and skill application. Lastly, personal competence is how the project manager behaves with core personality traits and attitude in a project setting.

White (White, 1959) introduced the concept of competence by referring to a human trait as competence. The term continued to evolve during the American industrial organizational psychology in the late 1960s through early 1970s. McClelland (1973) researched competency versus intelligence and was recognized as the catalyst for the competency movement (Barrett \& Depinet, 1991). Excluding race, sex, and socioeconomic 
status, early competency studies focused on predicting job performance. McClelland (McClelland, 1984) developed a competency variable methodology by studying people who were successful in their job versus people who were not successful. Studies on project manager competence date back to over 25 years. Andersen, Grude, Haug, and Turner (Andersen, 1987) conducted research on the project manager's personal characteristics and project success. Posner (Posner, 1987) researched and discussed the relationship between personal characteristics of successful project managers and problems facing project managers. Posner identified top skills, traits, and characteristics of project managers:

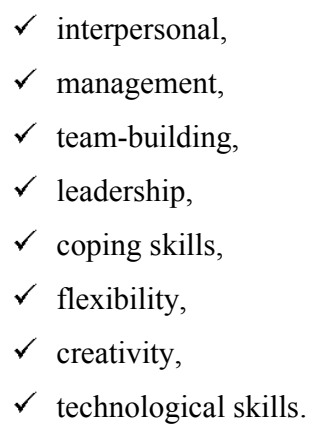

The research concluded that it was challenging for project managers to develop soft skills. Nelson (Nelson, 1991) agreed with Posner regarding the importance of technical skills and recognized five additional dimensions which were:

$\checkmark$ organizational overview,

$\checkmark$ organizational skills,

$\checkmark$ target organization unit,

$\checkmark$ general technological knowledge,

$\checkmark$ product knowledge.

Pettersen (1991) researched the characteristics that predict effective project managers. The list included:

$\checkmark$ Problem solving- including problem analysis, judgment and practical sense, decisiveness, and planning and organization;

$\checkmark$ Administration- control, strategy, and specialized knowledge;

$\checkmark$ Supervision and team management- delegation, team structure, consideration to others, developing team members, teamwork, flexibility, cooperation, conflict resolution;

$\checkmark$ Interpersonal relations- oral communication, interpersonal influence, negotiation, persuasion, and ascendancy;

$\checkmark$ Other personal qualities- working proactively, self-confidence, maturity, emotional stability, loyalty, honesty, integrity, open to change, works through ambiguity, and job interest.

Rees et al. (Rees, 1996) identified four traits of effective project managers:

$\checkmark$ intelligence,

$\checkmark$ problem solving,

$\checkmark$ behavioral or motivations (such as energy),

$\checkmark$ skill based (for example, communication)

Like Rees et al. (Rees, 1996), Pinto and Trailer (Pinto, 1998) believed problem solving and effective communication were top competencies for project managers. In addition to problem solving and communication, Pinto and Trailer identified important project manager characteristics:

$\checkmark$ credibility,

$\checkmark$ tolerance for ambiguity,

$\checkmark$ flexible manager style,

$\checkmark$ technical,

$\checkmark$ administrative,

$\checkmark$ leadership.

Jiang, Klein, and Carr (Jiang, 1998) researched behavioral skills and identified 18 common skills among IT project managers. The behavioral skills were:

$\checkmark$ Diplomacy-being tactful when working with others, 
$\checkmark$ Interviewing- Being able to draw out needed information by asking the right questions,

Directing- Providing instruction and communication,

Patience- the ability to tolerate changes to user requirements,

$\checkmark$ Assertiveness- Believing in an unpopular course of action,

$\checkmark$ Leadership- Provide direction and get work done through others,

$\checkmark$ Speaking- Sharing ideas with others in a manner understood by others,

$\checkmark$ Writing- Sharing ideas with others in a written format understood by others,

$\checkmark$ Listening-Actively listening to others and asking probing questions as needed,

$\checkmark$ Empathy- Understand how others feel,

Sales- Persuading others or promoting the system,

Politics- Understanding what motivates others, know what is influential in the organization,

$\checkmark$ Managing- Projects are completed within schedule and budget by planning, organizing, and control,

Training- Share knowledge of computers with others unfamiliar with technology, Cooperation,

$\checkmark$ Working productively with others and resolving conflict effectively,

$\checkmark$ Organization communications- Understanding the organization's goals and operations,

$\checkmark$ Nonverbal communications- Communicating without words, and

$\checkmark$ Sensitivity- Understanding the implications of change for the end users.

Lechler (Lecher, 1998) argued project managers' soft competencies played a more important role on project success than technical activities. Research on competency expanded to project team members' competence (Skulmoski, Hartman, \& DeMaere, 2000). The study sought to identify outstanding competencies of project team members and project managers. Competence research expanded even further when Crawford (Crawford, 2006) linked competence organizational performance to project performance. El-Sabaa (El-Sabaa, 2001) investigated project manager competencies where findings indicated the greatest influence on project management practice is human skills.

Soderlund (Soderlund, 2004) researched developing project competence. The main idea of project competence was the organization's ability to select and execute projects in a skillful manner. Mei-I, Dainty, and Moore (Mei-I, 2005) noted superior managers had a high level of the following qualities:

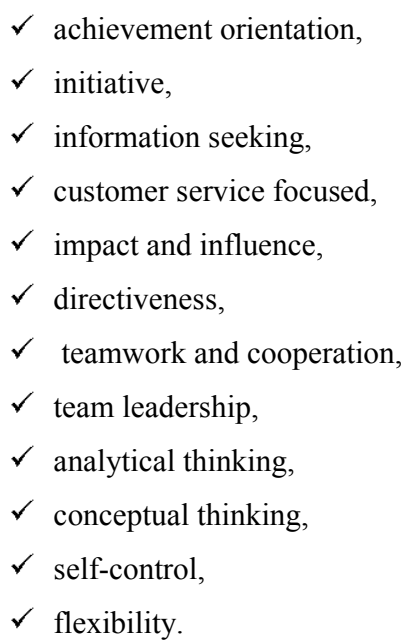

The competencies of construction managers have been researched (Dainty, Cheng, \& Moore, 2005). Results indicated there were 12 competencies that distinguish a superior performer from an average performer:

\footnotetext{
$\checkmark$ achievement orientation,

$\checkmark$ initiative,

$\checkmark$ information seeking,

$\checkmark$ focus on client's needs,

$\checkmark$ impact and influence,
} 
$\checkmark$ directiveness/assertiveness,

$\checkmark$ teamwork and co-operation,

$\checkmark$ team leadership,

$\checkmark$ analytical thinking,

$\checkmark$ conceptual thinking,

$\checkmark$ composure,

$\checkmark$ flexibility.

Brill, Bishop, and Walker (2006) researched competencies required for effective project managers. The study analyzed 147 participants with more than 20 years of project management experience. From the data, 117 success factors were identified and categorized into 9 themes. The top emerging skills were:

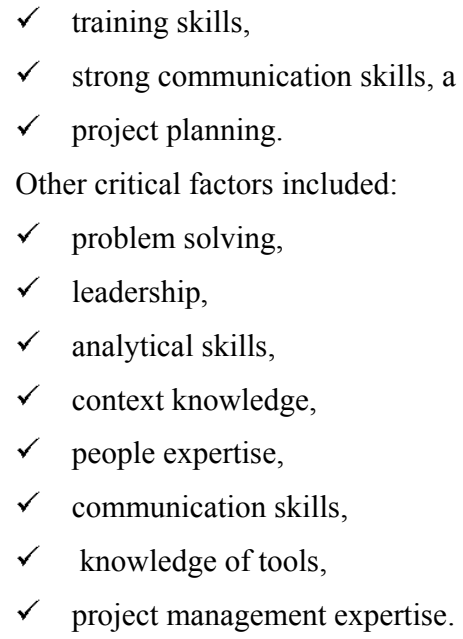

The study failed to uncover how project success is impacted by project management leadership.

Research incorporated Meyers-Briggs personality indicators with effective project manager competencies. Gehring (Gehring, 2007) researched which of the Meyers-Briggs leadership styles had the most desired traits of project managers. The Meyers-Briggs indicator combinations best matching desired project manager competencies and traits are introversion, intuition, thinking, and judging (INTJ), extraversion, intuition, thinking, and judging (ENTJ), or extraversion, sensing, thinking, and judging (ESTJ) indicators

Kollman, Hasel, and Breugst (Kollman, 2009) identified competences required to addresses members within e-business teams:

$\checkmark$ technology knowledge,

$\checkmark$ conceptual knowledge,

$\checkmark$ realization competence,

$\checkmark$ business management knowledge,

$\checkmark$ entrepreneurial competence,

$\checkmark$ interpersonal competence,

$\checkmark$ e-business competence,

$\checkmark$ IT vision,

$\checkmark$ perception of utility.

Kerzner (Kerzner, 2009) argued that the behavioral skills of a project manager are as important as technical skills. Alam et al. (Alam, 2010) concluded contextual, technical, and behavioral competencies were required to manage projects successfully.

More recent research show the impact of information technology, knowledge management and artificial intelligence having an impact on the project managers' skills and competences. There are several types of strategies that can be applied to perform more efficiently. The findings of Sankaran, Vaagaasar and Bekker (Sankaran, 2019) reveals that despite the recognized need for project managers to form their own teams, their study found that project team members were often assigned by others. This was because project managers lacked authority to secure their resources. Therefore, they used lateral influence strategies to help with assigning project team members. The study identified five lateral influencing strategies 
adopted by project managers to assign team members: creating an image of competence; creating coalitions; taking a gamble; waiting for the right moment; and reasoning with facts.

The research conducted by Maisiri, Darwish and Dyk (Maisiri, 2019) in an investigation of Industry 4.0 skills requirements pointed out that non-technical skills are as important as technical skills in the engineering profession in the Industry 4.0 era.

Advanced technologies are not intended to replace humans for improved productivity; rather, there must be tight human-machine collaboration. Technical and academic institutions must open lines for lifelong learning to meet the challenge of the rapid change in skills requirements in Industry 4.0. Interdisciplinary skills development could be necessary in Industry 4.0 to ascertain the effectiveness of employees in the engineering profession (Maisiri, 2019).

The research has defined the skills requirements (Maisiri, 2019) dividing them into technical and soft skills. This perception has been researched, analysed and compilated from a total of 68 literature review items (Figure 1.).

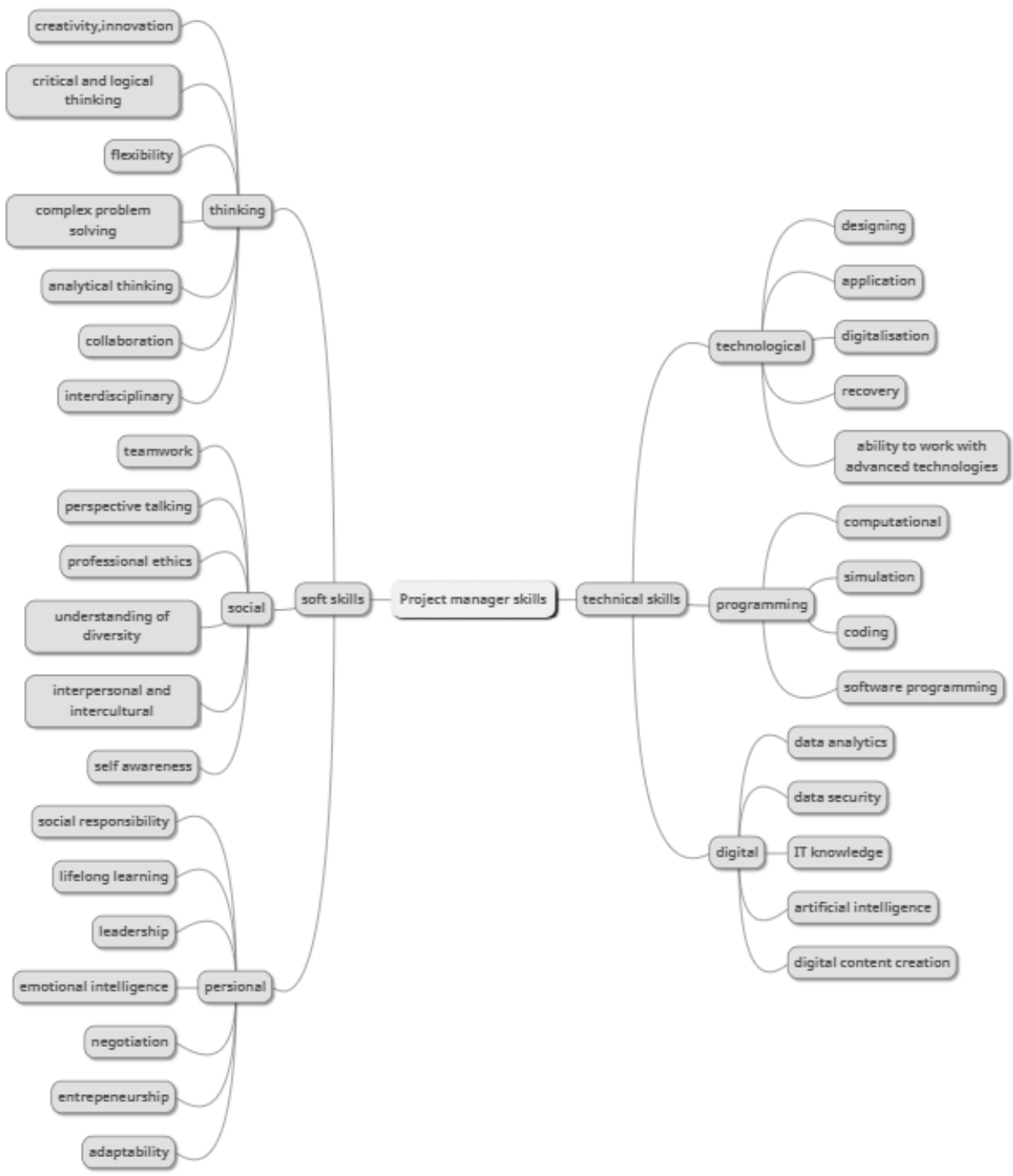

Source: Maisiri W.,Darwish H.,van Dyk L., 2019, An Investigation of Industry 4.0 skills requirements

Fig. 1. Requirements of technical and soft skills

The research by Bryan Hosford (Hosford, 2017) in Correlational study of project managers' competence, experience, education and technology experience on project success reveals the analysis of the research study- that while competence, project management experience, and technical experience were positively correlated with project success, education was not. Overall, the positive correlations were small in effect, ranging from $5-8 \%$ (Hosford, 2017). It is specified that understanding the technical requirements and the technical experience of the project will allow organizations to better align projects with technically experienced project managers, by identifying specific attributes (Hosford, 2017). To address 
project success inadequacies, early research literature focused on fixed attributes of project activities (Padalkar \& Gopinath, 2016). However, recent research has identified less fixed attributes of behavioral uncertainty as potential critical success factors. With project manager's attributes such as communication, interpersonal, and educational skills at the forefront of current and past research, Gingnell et al. (Gignell, 2014) points to identifying those specific critical success factors that have direct relationship with project success. Success attributes of project managers within the research literature shows that we know developing attributes of competence (Soderlund, 2005); education and experience (Ingason \& Jonasson, 2009); knowledge management (Gasik, 2011); and the influence project managers have on critical success factors (Geoghegan \& Dulewicz, 2008). Hosford's disertation, using the statistical analysis, found that hypothesis testing showed significant correlations between three of the four independent variables and project success. Analysis showed a statistically significant relationship between project manager competence and project success, project management experience and project success, and IT experience and project success.

The research of Allison Crowel (Crowel, 2006) on leading organizational development through acting team leader development focused on what competencies are essential to acting team leader performance in federal government call centres and what interventions would support acting team leader development (Crowel, 2006). The most significant finding of the on-line survey is that respondents said all of the leadership competencies are important. The focus group findings supported the findings of the survey: The importance of a structured program, transparent selection and development processes, skills training in leadership competencies, feedback, and work experience. The current focus in leadership development is to provide individualized development. Overall, three issues emerged from the detailing human resource management competencies. The three issues are the importance of trust, the valuing of human resource practices, and the need for human resource training. Two competencies, emphasizing the importance of trust and integrity, were identified by participants as critical for acting team leader performance (Crowel, 2006).

The importance of progressive human resource practices was indicated by many participants. Two competencies in particular, "Builds team morale and facilitates team motivation and achievement" and "Recognizes and acknowledges positive performance", were rated as "very important" by most participants. Recent call centre research identified specific

skills for team leaders to support agents. Team leader interpersonal skills include: coaching, group leadership, developmental feedback, empowerment, identifying task variety, debriefing emotional dissonance, and communicating organizational resources to support agents (Holman 2003). Current best practices include building trusting relationships, mentoring and supporting social networks (Cheriniss \& Goleman, 2001).

There has been a vast research on project manager skills in specific fields, industries and economic areas. The author's intent, though, is to provide a reliable data that would indicate the skills required in business development teams, that, considering the present working conditions and circumstances, might request different skill priorities - gently balancing between project manager competences and IT industry manager's virtual skill requirements.

\section{Purpose of the study}

The factors affecting poor success rates of project success are still not well understood, but consensus suggests that selection of the appropriate project manager has been a factor in the success of IT Projects (Patanakul \& Shenhar, 2012; Turner \& Muller, 2005). Despite this knowledge, the individual characteristics of these managers have not received adequate attention, especially as they apply to the rapidly changing management conditions associated with globalization and proliferation of virtual teams. Specifically, the existing research exploring the impact of project manager characteristics in business development teams, such as cultural intelligence and transformational leadership style, on project success in real and virtual teams is limited. The insights gleaned from literature review adds to the existing body of knowledge on the relationship between project managers' characteristics and project success and helps reduce the costs (time and financial) associated with project failure. This can lead to different strategies in terms of finance (Kuzmina-Merlino \& Saksonova, 2018) and risks (Saksonova \& Kuzmina-Merlino, 2019). An improved understanding of project managers' cultural intelligence and transformational leadership and their relationship to project success in business development teams could lead to the better hiring, training, and assignment of project managers.

\section{Research results and discussion}

The most useful project managers' skills to perform efficiently in the beginning of the 21 st century research and finding are the following:
$\checkmark$ Knowledge
$\checkmark$ Leadership
$\checkmark$ Team lead
$\checkmark$ Influence 


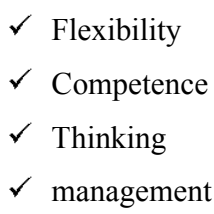

Identifying the most influential skills, namely - knowledge, leadership, team lead, influence, flexibility and competence - shows the specific characteristic of the person leading the project - one that is valued, perceived as conversant, sophisticated. This has lead the author to presume, that the respect is the overall characteristic and feel one has toward an efficient project manager.

Moreover, analysing the project manager's functions that shows the application of efficiency (Figure 2.), shows that the previously mentioned skills are very important to channel the communication convincingly.

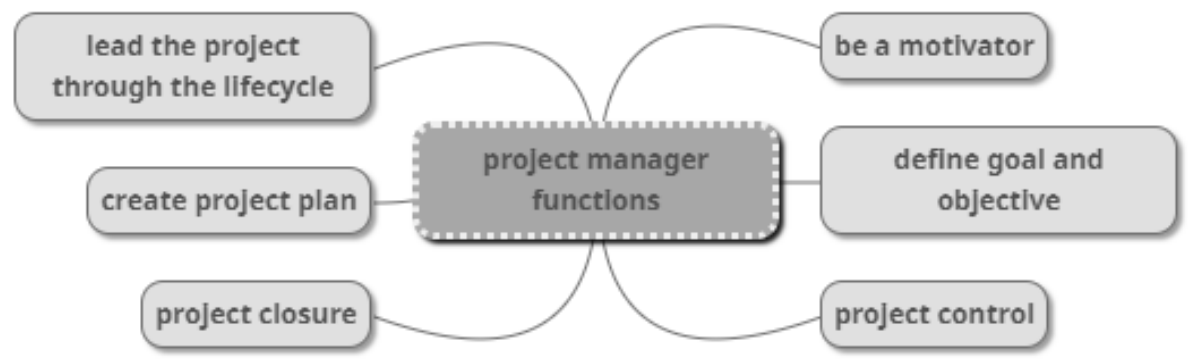

Source: author's evaluation based on the literature review

\section{Fig. 2. Project manager's functions}

In order to support this empirical finding, the author intends to perform a valid research, both quantitative and qualitative, to identify and prove the most effective project manager's skills transformation into a specific characteristic of a person leading the performance.

\section{Conclusions, proposals, recommendations}

The literature review confirms the tie between productive team and project manager to efficient work of a team and an enterprise. Several researchers have revealed this as an important factor of company success. The results on the general lines of skills set agree on various skills, that are defined into two general groups - soft and technical skills, and the findings of efficacy promote both. Most of the findings were conducted in real face to face environments, some, that the author also analyzed, were in IT teams, that required both - present and remote environments. All research confirmed the importance of this aspect as a must component for efficient and productive development of the organization in general.

The author has compiled the literature findings and article research to understand the notion on the project manager's efficient skills to lead the team performance and to pierce and conclude that there is a ground for potential research. The research gap would focus on indispensable project manager's skills for leading business development teams in both real and virtual environments. In order to achieve this, the author intends to perform a research and an evaluation using both quantitative and qualitative research methods.

This research also could be beneficial for a broader purpose and furthermore lead to key findings promoting targeted expediency, strengthen collaboration, gain value and achieve faster profit. This can be determined in a wider context as the part of integral economics. Further factor approach analysis should be carried out using the above-mentioned methods to provide reliable data and the ground for further research and discussions.

\section{Bibliography}

Ameen A., 2012, Project Success: Combining Project Manager Skills with Project Tools and Techniques, The College of St. Scholastica, Duluth, Minnesota, UMI Number: 1512020.

Aquino N.B., 2020, Performance Evaluation Criteria for Project Managers, Walden University.

Bloch, M., Blumberg, S., Laartz, J. (2012). Delivering Large-Scale IT Projects on Time, on Budget, and on Value. Insights and Publications, Retrieved fromhttp://www.mckinsey.com/insights/business_technology/delivering_largescale_

Brill, J. M., Bishop, M. J., Walker, A. E. (2006). The Competencies and Characteristics Required of an Effective Project Manager: A Web-Based Delphi Study. EducationalTechnology, Research and Development, 54(2), 115-140 
Cekuls, A., 2018. The impact of decision making on organizational performance within complex organizations, Conference: 10th International Scientific Conference on New Challenges of Economic and Business Development - Productivity and Economic Growth, Proceedings, pp. 106113.

Cleland, D. (1998). Strategic Project Management (3rd ed.). San Francisco, CA: Jossey-Bass

Coleman R., 2014. The Relationship between Project Managers'Competence, Professional Experience, and Education on Career Success: A Correlation Study, UMI Number: 3646089

Crowell A., 2006. Leading Organizational Development through Acting Team Leader Development, Royal Roads University, ISBN: 0-494$14079-8$

Curling, D. H., (2002). Globalization of the Project Management Profession. RetrievedJune 25, 2014, from

http://www.maxwideman.com/guests/globalization/intro.htm

Dainty, A. R., Mei-I, C., Moore, D. R. (2005). Competency-Based Model for Predicting Construction Project Managers' Performance. Journal of Management inEngineering, 21(1), 2-9.

Future of Jobs Survey, 2018. World Economic Forum

Gillard, S., Price, J. (2005). The Competencies of Effective Project Managers: A Conceptual Analysis. International Journal of Management, 22(1), $48-53$

Gumapac R., 2020. Transformational Leadership: the Moderating Effect on the Relationship between the Project Managers' Perception of SelfEfficiency and Project Success, Capella University, ProQuest Number: 28028878.

Häsel, M., Kollmann, T., Breugst, N. (2010). IT competence in internet founder teams. Bise,2(4), 209-217 doi:10.1007/s12599-010-0109-5

Hosford B., 2017. Correlational Study of Project Managers' Competence, Experience, Education and Technology Experience on Project Success, Capella University, ProQuest number: 10269745.

Jiang, J. J., Klein, G., Carr, C. L., (1998). Measuring Information System Service Quality: Servqual from the Other Side. MIS Quarterly, 26(2), 145-166.

Johnson, B., Hencke, D. (2008). Not Fit for Purpose: Cost of Government's IT Blunders.The Guardian Journal, 18(1), 51-54

Retrieved from ttp://www.theguardian.com/technology/2008/jan/05/computing.egovernment

Kerzner, H. (2009). Project management: A systems approach to planning, cheduling, and controlling (10th ed.). New York, NY: Van Nostrand Reinhold.

Kerzner, H., \& Kerzner, H. R. (2017). Project management: A systems approach to planning,scheduling, and controlling. Hoboken, NJ: John Wiley \& Sons

Kuzmina-Merlino, I., Saksonova, S., 2018. The Knowledge and Competencies Required for the Fintech Sector, Conference: 10th International Scientific Conference on New Challenges of Economic and Business Development - Productivity and Economic Growth, Proceedings, pp. 387395.

Lutas M., Nistor R., Radu M., Beleiu I., 2020. Perceptions Regarding the Profile of an Ideal Project Manager, Amfiteatru Economic, 22(54), 608622

Maisiri W.,Darwish H.,van Dyk L., 2019. An Investigation of Industry 4.0 skills Requirements, South African Journal of Industrial Engineering 30(3), 90-105.

Mansoor M, 2019. Examining the Relationship between Project Manager's Cultural Intelligence, Leadership, and Information Technology Project Success in Virtual Teams, ProQuest number: 13809424.

McClelland, D. C., 1984. Motives, personality and society. New York: Praeger

Miterev, M., Engwall, M., Jerbrant, A. 2016. Exploring Program Management Competencesfor Various Program Types. International Journal of Project Management, 34(3), 545-557, doi:10.1016/j.ijproman.2015.07.006.

Pettersen, N., 1991. Selecting Project Managers: An Integrated List of Predictors. Project Management Journal, 22(2), 21-25.

Posner, B., 1987. What it Takes to be a Good Project Manager, Project Management Journal, 18(1), 51-54. 
Rees, D., Turner, R.,Tampoe, M. 1996. On Being a Manager and Leader. In J.R.Terner, K. Grude \& L. Thurloway (Eds.). The Project Manager as a Change Agent. Maidenhead, UK: McGraw-Hill

Saksonova, S., Kuzmina-Merlino, I., 2019. Cryptocurrency as an Investment Instrument in a Modern Financial Market, Vestnik SanktPeterburgskogo Universiteta-Ekonomika-St Petersburg University Journal of Economic Studies, 35(2), 269-282.

Sankaran S, Vaagaasar A.L., Bekker M.C., 2019. Assignment of Project Team Members to Projects.Project Managers' Influence Strategies in Practice, www.emeraldinsight.com/1753-8378.htm

Slack M.E., 2014. The Integration of Three Factors That Lead to a Project Manager's Success, University of St. Thomas, ProQuest number: 3727319 .

Soderlund, J. (2004). Building theories of project management: past research, questions for the future. Journal of the International Project Management Association, 22(3). 183-191.

Stevenson, D. H., Starkweather, J. A., (2010). PM Critical Competency Index: IT Execsprefer Soft Skills. International Journal of Project Management, 28(7), 663-671. Doi: 10.1016/j.ijproman.2009.11.008

Weems-Landingham V., 2004. The Role of Project Manager and Team Member Knowledge, Skills and Abilities (KSAs) in Distinguishing Virtual Project Team Performance Outcomes, Department of Organizational behavior, Case Western Reserve University, UMI Number: 3119604.

Winch, G. M., Kelsey, J., (2005). What do Construction Project Planners Do? International Journal of Project Management, 23(2), 141-149.

Doi:10.1016/j.ijproman.2004.06.002

World Economic Forum, 2016. The Future of Jobs: Employment, Skills and Workforce Strategy for the Fourth Industrial Revolution. Global Challenge Insight Report, World Economic Forum, Geneva.

World Economic Forum, 2017. Realizing Human Potential in the Fourth Industrial Revolution: An Agenda for Leaders to Shape the Future of Education, Gender and Work. World Economic Forum, Geneva.

Xue J., Rasool Z., Gillani A., Khan A.I., 2020. The Impact of Project Manager Soft Competences on Project Sustainability. Sustainability,, 12, 6537; doi:10.3390/su12166537

Yakovleva A., 2014. Methodological Aspects of Project Techniques Selection for Innovation Project Management. International Journal of Innovation, 2(1), 18-31.

Yoo S., 2020, The Effects of Expertise Diversity and Task Interdependence on Project Team Effectiveness: The Moderating Role of Individual Autonomy, ProQuest number: 28025157 


\title{
GREEN LOGISTICS PRACTISE AND SOLUTIONS FOR TRANSPORT ORGANIZATIONS
}

\author{
Jurgita Pauzuoliene, Klaipèda State University of Applied Sciences \\ Ieva Kavecke, Klaipèda State University of Applied Sciences \\ Ilvija Pikturnaite, Klaipeda State University of Applied Sciences
}

\begin{abstract}
Logistics is perceived as a key sector to contribute to sustainable development and solving ecological problems. Article presents qualitative analysis of scientific literature and transportation companies' websites analysis to identify green logistics practice and solutions. This article is aimed at answering both scientific and practical problematic questions: what green logistics practices do organizations apply? What green solutions are and can be implemented in transport organizations?

Scientific analysis reveals that green logistics includes the systematic assessment, analysis and, ultimately, mitigation of the environmental impact of logistics activities. Practical examples of 16 organizations reveals that only a few organizations specify the green logistics goals, which they are trying to achieve. The main attention is given to reduce CO2 emission using environmentally friendly vehicles, implementing pollution reduction initiatives, innovative delivery solutions and ecological compensation program, using only EURO5 and EURO6 compliant vehicles, sorting and disposing waste responsibly, involving partners and employees in environment protection promotion. Other part of organizations have set targets to reduce the negative environmental impact of vehicles, but do not identify them as green logistics targets. These organizations focuses on green transport, proper waste management, optimization of transport routes, investments in new and innovative technologies. Organizations also contribute to the reduction of negative impact on the environment through social responsibility initiatives and the implementation of the ISO 14001 environmental management system. Based on the analysis, we provided green solutions for organizations looking to move to more sustainable transport: use greener vehicles; alternative fuels; encourage drivers to use fuel-efficient driving; optimize vehicle routes, reduce waste.
\end{abstract}

Key words: green logistic, sustainable development, transport.

JEL code: Q01; N7

\section{Introduction}

Rapid climate change and its management are the greatest challenges for future generations. One of the greatest concerns is growing $\mathrm{CO}_{2}$ emissions, which have increased significantly over the last decade as a result of urban development and population growth, growing numbers of transportations with different modes of transport. Angheluta, Costea (2011) notes, that the environment of cities is negatively affected by the present organization of urban goods distribution. Europe Commission (2020) indicates, that Europe's transport system has been a huge success, connecting people across the continent and reducing journey times. As people have become more mobile, so the carbon footprint of their transport activities has grown. In 2016, road transport was responsible for almost 72 percent of total greenhouse gas emissions from transport (European environment agency, 2019). Transport currently accounts for a quarter of the EU's greenhouse gas emissions and this figure continues to rise (Europe Commission, 2020). So, transportation and logistics significantly affect the environment, producing the desired service on one hand and creating unavoidable negative environmental impact on the other (Sbihi, Eglese 2007). $\mathrm{CO}_{2}$ emissions from vehicles, aircraft and vessels generate atmospheric contamination is one of the main causes of the global warming effect threatening the world. The traditional approach to logistics often leaves environmental sustainability on the sidelines during decision-making. The classic logistics is focused on producer-to-consumer movement of products, considering transportation, warehousing and inventory management (forward distribution) in central attention. Even "reverse" distribution, where consumer-to-producer movements become equally important (taking back products or packaging materials to avoid waste) are not enough to avoid transport - environment conflicts (Angheluta, Costea 2011). Therefore, logistics is perceived as a key sector to contribute to sustainable development and meeting the future generations' needs in terms of low greenhouse gas emissions in a socially and economically responsible way (Aktas et al 2018, Saada 2020). Climate change, $\mathrm{CO}_{2}$ emissions, waste collecting, reprocessing and finally redistribution became significant factors in logistical decision-making (Beškovnik, Twrdy 2012). The European Commission adopted a roadmap of 40 concrete initiatives for the next decade to build a competitive transport system that will increase mobility, remove major barriers in key areas and fuel growth and employment (White paper, 2011). Furthermore, The European Green Deal seeks a 90\% reduction in polluting emissions by 2050 (Europe Commission, 2020). Therefore, the contribution of transport and logistics companies to the implementation of green logistics is very necessary.

Green logistics involves all attempts to reduce the ecological impact of peoples' mobility, traffic systems and of transport in regional and global supply chains including the reverse flow of products and materials (Aktas et.al. 2018). According to Martins and others (2019) in recent years, 
sustainable logistics has been focused by academics, organizations and governments. Scientists and researchers (Sbihi, Eglese 2007; Lau 2011; Angheluta, Costea 2011; Kenglop, Tuammee 2016; He et. Al. 2016; Aktas et. Al. 2018; Lu et. al. 2019; Martin et al 2019; Saada 2020) concentrate their attention on the analysis and promotion of sustainable procurement, sustainable transportation, sustainable packaging, sustainable distribution, reverse logistics, design and control of sustainable supply chain activities. It is important to highlight that most research carried out in this area focuses on the reduction of environmental impacts of logistics operations.

But still the philosophy of green logistics is not so wide spread and the practical benefits and possible solutions are not so obvious. One of great concerns of scientist and practitioners is to find a balance between ecology and economy. Innovative technologies and green logistics require high cost (Berisky et al 2013; Martinsen, Bjorklund 2011; Angheluta, Costea 201; Sari, Yanginlar 2015). Sari, Yanginlar (2015) also argue that the relationship between green logistics practices and firm performance is not very clear: while some studies indicate it as very advantageous, some others reveal that green logistics does not provide any economic contribution to a company. Some scientists indicate that transportation and logistics companies are not able to implement green logistics measures due external and internal obstacles. For example, to customers pressure to maintain low service costs (Angheluta, Costea 2011; Martinsen, Bjorklund 2011, Berisky et al 2013). Angheluta, Costea (2011) states, that freight carriers and their customers are interested mainly to provide transportation service with lower costs. Final consumers normally pay little attention to how the products were transported, congestion in cities, air and noise pollution. Sari, Yanginlar (2015) note, that various organizations have implemented some sort of green logistics practices, but the degree of application is not same for all firms: while some firms follow a proactive strategy, some others try to meet only regulatory requirements. Other scientists (Thiell et al 2011; He et. al 2016; Saada 2020) claim that customers and competitors are the major pressure factor to join green logistics philosophy and practice. They can demand for organization to go towards green practices and request from political and legislator actors about environmental sustainability. Now, organizations respond according to customers' requirements because they have realized if they did not satisfy customer's requirements, then their competitors get competitive advantage and get their customers. Organizations develop their green strategies to fulfil customer's requirements. So, there is ongoing discussion about implementation of green logistics philosophy in to the practice. Therefore, the analysis of this article is aimed at answering both scientific and practical problematic questions: what green logistics practices do organizations apply? What green solutions are and can be implemented in transport organizations?

The aim of the article is to identify green logistics practice and solutions in transportation companies.

Methods: qualitative methods such as scientific literature and Europe Union documents analysis; transportation companies, which implement green logistics, websites analysis are applied in this article.

\section{Green logistics essence and conformation}

Scientific literature scrutinizes essence of green logistics and highlights its' different perspectives. Discussing green logistic essence will allow to indicate green logistics frame and conformation. The chronological analysis of the definitions below shows the development of the concept of green logistics (Table 1). 


\section{Development of green logistic definition}

\begin{tabular}{|l|l|}
\hline \multicolumn{1}{|c|}{ Scientists } & \multicolumn{1}{c|}{ Definitions } \\
\hline Sbihi, Eglese 2007 & $\begin{array}{l}\text { Green logistics activities include measuring the environmental impact of different distribution } \\
\text { strategies, reducing the energy usage in logistics activities, reducing waste and managing its } \\
\text { treatment. }\end{array}$ \\
\hline Thiell et al 2011 & $\begin{array}{l}\text { Green logistics consists of all activities related to the eco-efficient management of the forward and } \\
\text { reverse flows of products and information between the point of origin and the point of consumption } \\
\text { whose purpose is to meet or exceed customer demand. }\end{array}$ \\
\hline Min, Kim, 2012 & $\begin{array}{l}\text { Green logistics deals with environmental issues related to sustainable transportation, hazardous } \\
\text { material handling and storage, inventory control, warehousing, packaging, and facility location- } \\
\text { allocation decisions that aim to reduce carbon footprints. }\end{array}$ \\
\hline Blanco, Sheffi, & $\begin{array}{l}\text { Green logistics refers to the systematic measurement, analysis, and, ultimately, mitigation of the } \\
\text { environmental impact of logistics activities. }\end{array}$ \\
\hline Aktas et al 2018 & $\begin{array}{l}\text { Logistics is perceived as a key sector to contribute to sustainable development meeting the future } \\
\text { generations' needs in terms of low greenhouse gas emissions in a socially and economically } \\
\text { responsible way. Green logistics involves all attempts to reduce the ecological impact of peoples } \\
\text { mobility, traffic systems and of transport in regional and global supply chains including the reverse } \\
\text { flow of products and materials. }\end{array}$ \\
\hline Lu et al 2019 & $\begin{array}{l}\text { Green logistics is an environmentally friendly logistics system which includes greening of various } \\
\text { processes in logistics, such as transportation, warehousing and distribution, and green recycling of } \\
\text { reverse logistics such as waste recycling and disposal. }\end{array}$ \\
\hline Source: author's construction based on literature review
\end{tabular}

Source: author's construction based on literature review

Green logistic concept developed from initial measuring the environmental impact and decisions to reduce the energy usage and waste up to management forward and reverse flows, reducing carbon footprints in particular logistic elements (inventory control, warehousing, packaging and so on) and overall peoples' mobility, traffic systems and of transport in regional and global supply chains. Beškovnik, Twrdy (2012), Martinsen and Bjorklund (2011) refer that emissions data and energy data $\left(\mathrm{CO}_{2}\right.$ reports; energy consumption from external transports; energy consumption in warehouses) monitoring is necessary element in green logistic implementation. But still there is a need to scrutinize particular conformation and solutions for green logistics. Based on Gross and others (2013) green logistics deals with the production and distribution of goods in a sustainable way while also taking environmental and social factors into account. This approach can be applied to the standards fields of logistics from the strategic to the operational level. These fields include network design, choice of transportation mode, warehousing problems, container management, and routing. The incorporation of environmental objectives into the classic solutions to these problems opens a new perspective on well-known trade-offs such as delivery frequency, utilization, and inventory levels. Scientific literature also indicates such elements of green logistics conformation as green logistics awareness, proactive green logistics strategy and green logistics practices. As Choi and Zhang (2011) indicate, green awareness is the key element of a green strategy. Strategies and solutions involve better ways to plan and execute the movement of goods, such as increasing the utilization of trucks while maintaining inventory levels under control; or using modes of transportation that have lower greenhouse gas emissions. They include green purchasing, green material management and manufacturing, green distribution and marketing, as well as reverse logistics (Hervani et al., 2005). Literature also highlights that green logistics in particular company is comforted of sustainable policies and measures, configuration of processes, structures and systems or equipment in the transport, distribution and storage of goods.

Blanco, Sheffi (2016) discuss reducing of consumption of non-renewable energy sources, greenhouse gas emissions, and waste. Some of these efforts may be technological, such as replacing vehicle fleets from diesel to hybrid or replacing cardboard boxes with returnable totes. Martinsen and Bjorklund (2011), Saada (2020) also scrutinizes peculiarities of reducing the consumption of fuel and energy, usage of regenerate and renewable fuel instead of consuming fossil fuel. White paper (2011) and Europe Commission (2020) also highlight the importance of clean vehicles and alternative fuels in green logistics and transportation. One of White papers (2011) goals is no more conventionally-fuelled cars in cities. This solution is also named by Martinsen and Bjorklund (2011). The Europe Commission (2020) is supporting and financing the deployment of recharging and refuelling points where persistent gaps exist, notably for long-distance travel and less densely populated areas (Europe Commission, 2020). It predicts, that by 2025, about 1 million public recharging and refuelling stations will be needed for the 13 million zero- and low-emission vehicles expected on European roads. Martinsen and Bjorklund (2011) indicates other green logistic solutions such as modal choice (shift from air to ocean, from road to rail; intermodal solutions), design of logistics systems and transport management (more direct transports; continuous improvement of distribution networks; decrease average handling factor and average length of haul; well-planned routes; high fill-rates), and adoption of environmental management system (ISO 14001, EMAS). Kenglop, Tuammee (2016) provide examples of using clean vehicles or alternative fuel 
vehicles for shipping, using standardization of trucks' sizes, reducing overall packaging, reusing of containers or pallets, shipping consolidation etc. Some green logistics initiatives may be in support of larger business environmental goals, such as increasing reverse logistics activities to recover and reuse more of the products delivered to customers (Hervani et al., 2005; Kenglop, Tuammee 2016; Blanco, Sheffi, 2016). Saada (2020) indicates that the practices of green transportation and logistical reverse activities are the opportunities for organizations to boost their growth and reduce overall production costs.

Other conformation elements and solutions are identified while discussing of obstacles. For example, Berisky et al (2013) note that internal barriers to initiate green issues are high investment or implication costs, lack of financial or human resources, and lack of knowledge or skills inhouse. Martinsen and Bjorklund (2011) highlights the importance of choice of partners (cooperation with customers to help them reach their own environmental targets; choosing environmentally conscious transport providers) and change in behavioural aspects (eco driving; driving behaviour with a focus on a decrease of fuel consumption) while implementing green logistics. Unawareness or lack of interest or support of customer or transport/logistics suppliers/partners are the barriers that should pay greater attention from governments and enterprises (Berisky et al 2013). Angheluta, Costea (2011) note that green logistics concept and schemes try to harmonize the efficient transport with environmentally friendly urban logistics systems. According Lau (2011), Lu et al (2019) the aim of green logistics is to reduce the environmental externality of logistics operations and achieve the sustainable balance between economic, environmental, and social benefits. To meet needs at minimal cost while minimizing the impact of $\mathrm{CO}_{2}$ on the environment. Lau (2011), Choi, Zhang (2011) indicate that a stronger focus on green logistics can not only reduce the environmental impact of industrial activities, but also maintain or even increase quality, reliability, efficiency, energy efficiency or reduce costs. Green practices for organizations may result as the competitive advantage. Saada (2020) identifies that promoting green management and transportation has significant benefits toward economy, environmental well-being, as well as improving the organization's growth. Economic efficiency scientists clarify as the implementation of green practices in transportation, that gives cost reduction benefits for the movement of shipments, efficient vehicle allocation and planning opportunities, and natural and human resource advantages. Green transportation further gives customer retention advantage as customer's interest has been shifted toward green products; therefore, companies have an opportunity to implement environment-friendly transportation to grab mass market. Similar goal is indicated by Europe Commission (2020), which declares that moving to more sustainable transport means putting users first and providing them with more affordable, accessible, healthier and cleaner alternatives.

So, summarizing scientific analysis it can be noted that green logistics means the systematic assessment, analysis and, ultimately, mitigation of the environmental impact of logistics activities. Usually, such green logistics elements or solutions are discussed: monitoring of emission and energy data; waste reduction or reverse logistics; use of renewable energy sources or alternative fuels; use of cleaner vehicles or eco-friendly mode of transport; optimization of transport routes and assurance of load capacity; assurance of fuel-efficient driving; promoting green transportation and forming of aware partners and consumers' network.

\section{Transportation companies green logistics practical solutions}

Organizations, which want to move to green logistics, must take concrete action. Starting with the transformation of elements of logistics systems and considering environmental, economic and social aspects. The empirical study aims to identify specific green logistics solutions used / adopted by transport companies. Lithuanian logistics organizations providing transportation services in the international market were selected for empirical research (websites content analysis) according such criteria:

Organizations identify specific areas for the implementation of green logistics.

Organization point out certain achievable environment protection objectives.

Organization declares about social responsibility implementation.

Organization has an environmental management standard ISO 14001.

About 100 logistics organizations' websites were reviewed. There are presented only 16 examples of organizations because only such number of companies met at least two of the set criteria. Three organizations state on the website that they are pursuing green logistics goals. 13 organizations contribute to the reduction of environmental pollution by achieving the set environmental goals. Eight organizations distinguish certain aspects of social responsibility, have implemented the ISO14001 environmental management system in order to contribute to solving environmental problems. Detailed solutions' analysis of green logistics implementation in particular sixteen transport companies are presented in table 2. 
Examples of environmental and green logistics solutions in transport organizations

\begin{tabular}{|c|c|}
\hline Criteria & Examples of organizations \\
\hline \multirow{3}{*}{$\begin{array}{l}\text { Implementation of } \\
\text { green logistics }\end{array}$} & $\begin{array}{l}1^{\text {st }} \text { organization increases the number of environmentally friendly vehicles, thus reducing } \mathrm{CO}_{2} \text { emissions. } \\
\text { Implements real time monitoring of air pollution in cities. Implements pollution reduction initiatives and } \\
\text { innovative delivery solutions. } \\
\text { Implements an ecological compensation program that is approved by the Verified Carbon Standard (VCS). The } \\
\text { program focuses on projects of renewable energy sources, clean energy and circular. economy projects. }\end{array}$ \\
\hline & $\begin{array}{l}2^{\text {nd }} \text { organization is pursuing green transportation. It has developed a carbon monitoring solution using carbon } \\
\text { Dashboard that tracks data from company. Company deployed } 399 \text { aerodynamically optimized teardrop trailer } \\
\text { trucks that reduce customer's carbon footprint by more than } 2,000 \text { tons every year. }\end{array}$ \\
\hline & $\begin{array}{l}4^{\text {th }} \text { organization reduces environmental pollution and } \mathrm{CO}_{2} \text { emissions; for transportation it uses only EURO5 and } \\
\text { EURO6 compliant vehicles. It sorts and disposes waste responsibly. Company involves partners and employees in } \\
\text { environment protection promotion. }\end{array}$ \\
\hline \multirow{13}{*}{$\begin{array}{l}\text { Identification of } \\
\text { objectives, related } \\
\text { to protection of } \\
\text { environment }\end{array}$} & $\begin{array}{l}3^{\text {rd }} \text { organization used vehicle fleet complies with the EURO } 6 \text { standard. Freight routes are optimized. Company } \\
\text { organizes video conferences with customers in order to reduce employee travel costs and transportation pollution. }\end{array}$ \\
\hline & $\begin{array}{l}5^{\text {th }} \text { organization states that it protects natural resources, reduces gases that create a greenhouse effect. Company } \\
\text { encourages the it's users to behave ecologically. }\end{array}$ \\
\hline & $\begin{array}{l}6^{\text {th }} \text { organization implements pollution prevention to reduce negative impact on the environment. Forms } \\
\text { environment protection goals for successful implementation of environmental policy. }\end{array}$ \\
\hline & $7^{\text {th }}$ organization invests in energy efficient equipment and handles hazardous materials properly. \\
\hline & $\begin{array}{l}8^{\text {th }} \text { organization promotes eco-driving. Company plans routes with intermodal transportation and this helps save } \mathrm{CO}_{2} \\
\text { emissions. The fleet complies with the EURO } 6 \text { standard. }\end{array}$ \\
\hline & $9^{\text {th }}$ organization reduces the negative impact of the activities on the environment. \\
\hline & $\begin{array}{l}10^{\text {th }} \text { organization collects used packaging from customers and returns it for further usage. Company practices a } \\
\text { life-cycle approach in everyday life, which aim is to reduce waste, recycle and reuse. }\end{array}$ \\
\hline & $\begin{array}{l}11^{\text {th }} \text { organization reduces vehicle fuel consumption and the power consumption of devices. Company recycles } \\
\text { materials and reduces waste. It participates in the discussion to reduce the negative impact on the environment; offers } \\
\text { customers solutions that help reduce negative environmental impacts in the supply chain. }\end{array}$ \\
\hline & $\begin{array}{l}12^{\text {th }} \text { organization increases the positive impact on the environment through the rational use of natural, material and } \\
\text { energy resources. }\end{array}$ \\
\hline & $\begin{array}{l}13^{\text {th }} \text { organization have installed } 87 \text { air pollution detectors throughout the terminal to achieve complete air quality } \\
\text { control. Gasoline storages were fitted with floating roofs, which } 95 \% \text { reduces evaporation of volatile organic } \\
\text { compounds. Also, other measures have been installed to protect water and air pollution. Special valves are used to } \\
\text { reduce the release of oil steam into the environment when unloading rail tanks. }\end{array}$ \\
\hline & $14^{\text {th }}$ organization uses advanced stevedoring technologies and modern equipment to reduce environmental impact. \\
\hline & $\begin{array}{l}15^{\text {th }} \text { organization's vehicle fleet consists of road cargo capacity complying with the Euro } 5 \text { and Euro } 6 \text { emission } \\
\text { standards. This helps to reduce emissions of harmful substances and } \mathrm{CO}_{2} \text {. A responsible approach to waste sorting } \\
\text { helps to reduce environmental pollution. }\end{array}$ \\
\hline & $\begin{array}{l}16^{\text {th }} \text { organization's fleet complies with the EURO } 6 \text { standard. Company invests in the latest logistics service } \\
\text { equipment. Plans and offers the shortest and best routes. Company implements transport flow optimization, } \\
\text { multimodal transportation. }\end{array}$ \\
\hline
\end{tabular}




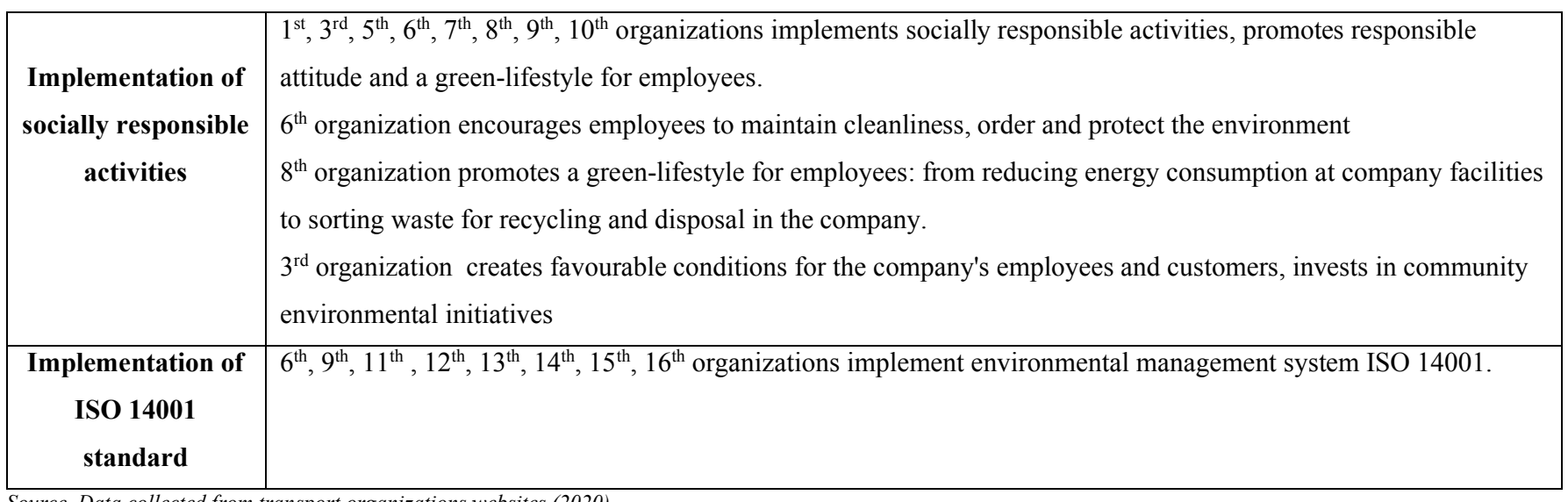

Source. Data collected from transport organizations websites (2020)

Summarizing the analysis, it can be noted that organizations implement various activities in order to contribute to green logistics. Only a few organizations specify the green logistics goals, which they are trying to achieve. Other organizations have set targets to reduce the negative environmental impact of vehicles, but do not identify them as green logistics targets, although this can be attributed to green solutions. This group of organizations focuses on green transport, proper waste management, optimization of transport routes, investments in new and innovative technologies. Organizations also contribute to the reduction of negative impact on the environment through social responsibility initiatives and the implementation of the ISO 14001 environmental management system. It can be concluded, that the decisions to reduce the negative impact of vehicles on the environment are related to many activities implemented in the organization, starting from constituting of employees' environmental awareness and taking specific actions such as fleet renewal, route optimization, waste management, and so on.

Summarizing practical examples of organizations and analysed literature, such green solutions to organizations are provided in 1 figure. Transport organizations can implement one or more green solutions, depending on the organization's ability to contribute to green logistics. By contributing to green logistics, transport companies can: use greener vehicles, use alternative fuels, optimize transport routes, encourage drivers to drive fuel-efficiently, use more renewable energy sources, use eco-friendly modes of transport and reduce waste. 


\begin{tabular}{|c|c|}
\hline Use greener vehicles & $\begin{array}{l}\text { - EURO } 6 \\
\text { - Increasing the load carrying capacity of vehicles } \\
\text { - Hybrid vehicles }\end{array}$ \\
\hline Use alternative fuels & $\begin{array}{l}\text { - Biodiesel, biogas } \\
\text { - Liquefied natural gas (LNG) } \\
\text { - Hydrogen }\end{array}$ \\
\hline Optimization of transport routes & $\begin{array}{l}\text { - Information technology opportunities } \\
\text { - Installation of routing and planning software packages }\end{array}$ \\
\hline Promoting fuel - efficient driving & $\begin{array}{l}\text { - Application of driver training programs } \\
\text { - Encouraging drivers to apply effective driving skills }\end{array}$ \\
\hline Use of renewable energy sources & $\begin{array}{l}\text { - Use of green energy (biomass, wind, solar, etc.) in } \\
\text { warehouses, logistics and distribution centers, } \\
\text { manufacturing companies }\end{array}$ \\
\hline Use eco-friendly mode of transpor & $\begin{array}{l}\text { - Use of greener modes of transport (rail, water) in the } \\
\text { supply chain. } \\
\text { - Intermodal and multimodal transport }\end{array}$ \\
\hline Waste reduction & - Promotion of waste management and recycling measures. \\
\hline
\end{tabular}

Source: author's construction based on practical data (2020)

\section{Fig. 1. Green solutions for organizations}

The use of greener vehicles is particularly important for companies that manage large truck fleets. This decision concerns several aspects. First of all, the fleet should be constantly updated with EURO 6 standard vehicles, which would reduce $\mathrm{CO}_{2}$ emissions and increase the economic performance of companies. It is also important to make optimal use of vehicles by increasing their load capacity. Optimal loading would allow each vehicle to be fully loaded, which would reduce empty mileage and the number of trucks on the roads, which would reduce fuel consumption and $\mathrm{CO}_{2}$ emissions and reduce environmental damage. Another solution is to use hybrid trucks (diesel and electric) to distribute cargo in urban areas.

The use of alternative fuels is an important aspect of the activities of transport companies, because the use of fuels such as biodiesel, biogas, liquefied natural gas reduces $\mathrm{CO}_{2}$ emissions by 15 to 65 percent, and the use of hydrogen or electricity reduces emissions by zero. Hydrogen is the fuel of the near future, as manufacturers are still unable to offer hydrogen-powered trucks, which would be equivalent to older diesel trucks in their technical characteristics. However, some examples of hydrogen-powered trucks already been tested in some markets. Another problem is that the infrastructure in most European countries is not yet adapted to such trucks. However, hydrogen-powered vehicles are expected to become more widespread across Europe in the near future.

Promoting fuel-efficient driving can help increase fuel efficiency by up to 10 percent. Transport companies could apply effective driving skills training programs, thus improving drivers' driving styles, which would also lead to lower fuel consumption and lower $\mathrm{CO}_{2}$ emissions. In order to achieve the long-term benefits of economical driving training, transport companies should constantly think about fuel efficiency and encourage drivers to apply their effective driving skills.

Route optimization also helps reduce negative environmental impacts. Optimal routes shorten the distances covered by vehicles and also reduce the number of empty journeys. So, companies can save due to reduced fuel consumption and $\mathrm{CO}_{2}$ emissions. Informational technologies help to implement this solution: companies can save between 5 and 20 percent of total transportation costs by deploying modern routing and planning software packages.

The decision to use green modes of transport (rail and water transport) is particularly relevant for companies, that are closely involved with the whole supply chain when transporting goods over long distances. Rail transport is often used to transport large quantities of cargo and is a very convenient for logistics companies which have their own access railways. In this case, intermodal transport is very convenient, for example, when 
goods are transported in containers. Changing freight to greener modes of transport, such as rail, reduces the environmental damage caused by rail $\mathrm{CO}_{2}$ as the emissions are several times lower than road transport case.

The use of renewable energy sources is relevant for manufacturing companies, large logistics and distribution centers or companies that operate large warehouses with high energy consumption. Therefore, the decision to use green energy (biomass, wind, solar, etc.) would help this type of business to save and be greener, thus reducing greenhouse gas emissions.

Waste reduction is important for a company to become "greener". Various waste management and recycling measures reduce waste and provide economic benefits to the company. Companies providing transport or logistics services can also contribute to this decision. Such companies have the opportunity to reduce the transport footprint of waste management in urban centers by using their existing distribution mechanisms to retrieve recycled materials from the retail sector on the return journey. If companies combined their transport resources in different supply chains into common waste collection schemes, companies could expect financial and economic benefits. In this way, transport companies would reduce the number of empty runs and optimize routes, and the benefits would be obvious: lower fuel consumption and less damage to the environment.

Green logistics can be compatible with environmental systems in an organization like ISO 14001 or EMAS. Some researchers say LEAN contributes to green solutions in organizations. Companies that use green logistics tools in conjunction with the LEAN system achieve far better results than the implementation of each individually (Duees et al. 2013). Also companies can implement these green logistics measures and solutions: promotion of intermodal transport, freight bikes, green carriers, employee training / competence development, promotion of employee social responsibility, public reporting, declared companies' efforts and achievements in solving environmental problems. Green logistics solutions allow the significant reduction of $\mathrm{CO}_{2}$ emissions. The investigated solutions cover strategic, tactical and operational areas. Ideal measures even save costs while ecological measures are accompanied by increased costs. Employee awareness is raised and good practice is disseminated to stakeholders in the field of environment and green logistics.

\section{Conclusions}

Logistics and transportation are perceived as a key-sectors to contribute to sustainable development and meeting the future generations' needs in terms of low greenhouse gas emissions in a socially and economically responsible way. Climate change, $\mathrm{CO}_{2}$ emissions, waste collecting, reprocessing and finally redistribution became significant factors in logistical decision-making. Green logistic concept developed from initial measuring the environmental impact and decisions to reduce the energy usage and waste up to management forward and reverse flows, reducing carbon footprints in particular logistic elements (inventory control, warehousing, packaging and so on) and overall peoples' mobility, traffic systems and of transport in regional and global supply chains. Such green logistics elements or solutions are discussed: monitoring of emission and energy data; waste reduction or reverse logistics; use of renewable energy sources or alternative fuels; use of cleaner vehicles or eco-friendly mode of transport; optimization of transport routes and assurance of high fill parcel (cargo); assurance of fuel-efficient driving; promoting green transportation and forming of aware partners and consumers' network.

Practical examples of 16 organizations reveals that organizations implement various activities in order to contribute to green logistics. But only a few organizations specify the green logistics goals, which they are trying to achieve. The main attention is given to reduce $\mathrm{CO}_{2}$ emission using environmentally friendly vehicles, implementing pollution reduction initiatives, innovative delivery solutions and ecological compensation program, using only EURO5 and EURO6 compliant vehicles, sorting and disposing waste responsibly, involving partners and employees in environment protection promotion. Other part of organizations have set targets to reduce the negative environmental impact of vehicles, but do not identify them as green logistics targets, although this can be attributed to green solutions. This group of organizations focuses on green transport, proper waste management, optimization of transport routes, investments in new and innovative technologies. Organizations also contribute to the reduction of negative impact on the environment through social responsibility initiatives and the implementation of the ISO 14001 environmental management system. The decisions to reduce the negative impact of vehicles on the environment are related to many activities implemented in the organization, starting from constituting of employees' environmental awareness and taking specific actions such as fleet renewal, route optimization, waste management, and so on. Basing on the analysis such green solutions for organizations looking to move to more sustainable transport can be provided: use greener vehicles; alternative fuels; encourage drivers to use fuel-efficient driving; optimize vehicle routes, reduce waste.

\section{Bibliography}

Aktas, E., Bloemhof, J.M., Fransoo, J. C., Gunther, H.-O., Ammernegg, W., 2018. Green Logistics Solutions. Flexible Services and Manufacturing Journal , 30, 363-365. 
Angheluta A., Costea C., 2011. Sustainable Go-Green Logistics Solutions for Istanbul Metropolis. Transport Problems, 6 (2), $59-70$.

Beškovnik, B., Twrdy, E. 2012. Green Logistics Strategy for South East Europe: to Improve Intermodality and Establish Green Transport Corridors. Transport, 27 (1), 25-33.

Blanco, E.E., Sheffi Y., 2016. Green Logistics. Sustainable Supply Chain. Springer International Publishing.

Choi, Y., Zhang, N. 2011. Does Proactive Green Logistics Management Improve Business Performance? A Case of Chinese Logistics Enterprises. African Journal of Business Management, 5 (17), 7564-7574.

Dües, C.M., Tan, K.H., Lim, M., 2013. Green as the New Lean: How to Use Lean Practices as a Catalyst to Greening Your Supply Chain. Journal of Cleaner Production, 40, 93- 100.

El-Berishy, N., Rügge, I., Scholz-Reiter. 2013. The Interrelation Between Sustainability and Green Logistics. 6th IFAC Conference on Management and Control of Production and Logistics. The International Federation of Automatic Control September 11-13, 2013. Fortaleza, Brazil.

Europe Commission, 2020. Available at: https://ec.europa.eu/transport/themes/sustainable_en

European Environment Agency 2019. Available at: https:/www.eea.europa.eu/data-and-maps/daviz/share-of-transport-ghg-emissions-2\#tabdashboard-01

European Environment Agency. Available at: https://www.eea.europa.eu/themes/transport

Gross, W., Zesch, F., Gelan, T., Hayden, C., Botel, M., Broch, M., 2013. Cost and Benefits of Green Logistics. 4flow Supply Chain Management Study. Available at: https://www.gs1-germany.de/fileadmin/gs1/basis_informationen

/4flow_SCM_Study_2013_Costs_and_Benefits_of_Green_Logistics.pdf

He, Q., Dong, S., Rose, T., Li, H., Yin, Q., Cao, D., 2016. Systematic Impact of Institutional Pressures on Safety Climate in the Construction Industry. Accident Analysis \& Prevention, 93, 230-239.

Hervani, A.A., Helms, M.M., Sarkis, J., 2005. Performance Measurement for Green Supply Chain Management. Benchmarking: An International Journal, 12(4), 330-353.

Kenglop, A., Tuammee, S., 2016. The Development of a Decision Support Framework for a Quantitative Risk Assessment in Multimodal Green Logistics: an Empirical Study. International Journal of Production Research, 54(4), 1020-1038.

Lau, K.H., 2011. Benchmarking Green Logistics Performance with a Composite Index. Benchmarking: An International Journal, $18(6), 873$ - 896.

Lu, M., Xie, R., Chen, P., Zou, Y., Tang J., 2019. Green Transportation and Logistics Performance: An Improved Composite Index. Sustainability, $11,1-12$.

Martins, V.W.B., Anholon, R., Quelhas, O.L.G., Filho, W.L., 2019. Sustainable Practices in Logistics Systems: An Overview of Companies in Brazil. Sustainability, 11, p. 2-12.

Martinsen, U., Bjorklund, M., 2011. Matches and Gaps in the Green Logistics Market. International Journal of Physical Distribution \& Logistics Management, 6(42), 562-583.

Min, H., Kim, I., 2012. Green Supply Chain Research: Past, Present, and Future. International Journal of Logistics Research and Applications, 4 , $39-47$.

Saada, R., (2020). Green Transportation in Green Supply Chain Management. Available at: https://www.intechopen.com/online-first/greentransportation-in-green-supply-chain-management

Sari, K., Yanginlar G. 2015. The impact of Green Logistics Practices on Firm Performance: Evidence from Turkish Healthcare Industry. Proceedings of POMS 26th Annual Conference, May 8-11, Washington, D.C., U.S.A.

Sbihi, A., Eglese, R.W., 2007. Combinatorial Optimization and Green Logistics. 4OR: A Quarterly. Journal of Operations Research, 5(2), 99-116.

Thiell, M., Zuluga, J.P.S., Montanez, J.P.M., Hoof, B., 2011. Green Logistics: Global Practices and their Implementation in Emerging Markets. Copyright.

White Paper, 2011. Roadmap to a Single European Transport Area - Towards a Competitive and Resource Efficient Transport System Available at: https://eur-lex.europa.eu/legal-content/EN/TXT/PDF/?uri=CELEX: 52011DC0144\&from=EN 


\title{
EU HOUSEHOLD INDEBTEDNESS PRIOR TO THE COVID-19 GLOBAL PANDEMIC CRISIS
}

\author{
Dancho Petrov, University of Economics - Varna \\ Evgeniya Tonkova, University of Economics - Varna \\ Svetlana Todorova, University of Economics - Varna
}

\begin{abstract}
Household indebtedness is important in assessing the financial status and ability of households to repay their financial liabilities. The disproportionately high growth rate of household indebtedness in comparison to the GDP growth is perceived in economic theory and practice as a symptom indicating an increased risk to financial stability. The fact is that in the countries most severely affected by the global financial crisis, higher values of indebtedness of households are registered. The problem of household indebtedness is particularly relevant in the current crisis caused by the global Covid-19 pandemic. The shock caused by the pandemic is very specific in terms of genesis and development scenario and in this respect it differs significantly from the known financial risk assessment models. The aim of this paper is to clarify the key aspects of household debt in a crisis and to analyse and assess the financial status and indebtedness of households in EU countries on the eve of the pandemic. The comparative analysis of key debt indicators provides valuable contribution to the study of risks to economic and social development in a crisis and can be useful for policymakers to undertake coordinated measures within the European Union.
\end{abstract}

Keywords: household indebtedness, financial crisis, financial literacy, global pandemic Covid-19, bank loans.

JEL code: D1, G5

\section{Introduction}

The study of household indebtedness in times of crisis has provoked research interest for many reasons. In the first place, it is a serious problem for those households living in conditions of economic stress that they cannot avoid. In addition to the socio-economic focus, the problem has broader dimensions, as it can also affect the activities of financial intermediaries and the stability of the financial system. The Covid-19 pandemic has caused a huge global economic downturn and recession unprecedented since the Great Depression. According to Eurostat data, in the second quarter of 2020 there was a decline of $15 \%$ in GDP in the euro area on an annual basis, and within the EU the decline was $14.1 \%$. The unemployment rate is increasing unprecedentedly in all EU countries, albeit at a slow pace, reaching $7.8 \%$ in the euro area and $7.1 \%$ in EU countries in June 2020 (Eurostat, 2020). These alarming data emerge against the background of the existing numerous unknown parameters regarding the duration and depth of the pandemic crisis. The unpredictable scenario of the crisis development poses extremely serious challenges to the social and economic development of the European Community. From this point of view, it is particularly important to analyse and assess the level of financial resilience of EU households to the looming severe recession, job losses and dramatic decline in the incomes of broad sections of the population. Based on Eurostat data, this paper analyses key indicators of household indebtedness in EU countries. The values of these indicators outline the levels of indebtedness and, although they give some reason for optimism, the possible destructive impact of the crisis caused by the global pandemic should not be underestimated. An analysis of household financial liabilities in the run-up to the pandemic could be useful not only for examining the current financial status with which they are entering this challenging period. The conclusions of the analysis may also be useful for policymakers and regulators in discussing and taking adequate decisions to use appropriate levers and mechanisms to counter shocks in the community.

The survey methodology is based on the use of secondary data for the EU countries, covering the period 2008-2020 and including the following indicators: household indebtedness to GDP, financial liabilities to financial assets (coverage ratio) and debt-to-income ratio. The data source is Eurostat. The methods of comparative analysis, trend analysis and correlation analysis have been applied.

The structure of this paper is organised in three sections. The first section contains a literature review of publications, analysing different aspects of household indebtedness in crisis. The emphasis of the analysis in this section is on disputes concerning the expected impact of the global pandemic on the level of indebtedness of households based on some recent research on the issue. The discussion in the second section focuses on the analysis of the pros and cons of the different indicators used for household indebtedness analysis and evaluation. Based on selected key indicators, the trends and the current situation of the indebtedness levels and the financial stability of the households in EU member countries prior to the crisis are analysed in the third section. The main conclusions and generalisations are presented in the conclusions section.

\section{Literature Review}

Contrary to the neoclassical doctrine of the beneficial effect of debt on consumption and economic growth, a number of studies have argued that in times of crisis, the presence of increased household indebtedness leads to higher debt service costs, which in turn suppresses consumption and 
generally has a negative impact on economic development (Lombardi et al., 2017; Dynan, 2012). Moreover, the increase in the household debt-toGDP ratio actually leads to a decrease in consumption in the medium term, even under normal market conditions. This negative correlation is observed with a certain delay in time as the trend is more pronounced in countries with stricter monetary policy due to the regime of fixed exchange rates. (Mian et al., 2015).

The high growth of household indebtedness is perceived in economic theory and practice as one of the "sure" symptoms, indicating an increased risk for the macro-financial stability (Bilyk et al., 2020; Schularick and Taylor, 2012). Rising household indebtedness is considered an important economic problem, as high debt levels can lead to declining consumption, investment and economic growth. (Yoshino and Gupta, 2019). According to Drehmann and Juselius (2014), the dominance of high levels of household indebtedness can serve as a tool to predict an impending crisis in the banking system. Household over-indebtedness not only indicates an impending crisis, but also may affect the duration of post-crisis economic recovery and its varying degrees in the affected countries, as shown by the results of the tested Dynan's (2012) hypotheses.

The global financial crisis has caused the worst economic recession since the Great Depression, and its lessons still provide much "food" for thought and discussion. The compelling similarity between these crises is that both have seen a sharp jump in leverage in household debt (Finocchiaro et al., 2011). The fact is that household indebtedness in the United States has exceeded 100\% of GDP only twice in the last century: in 1929 and in 2006 (Mian et al., 2010). According to Glick and Lansing (2010) there are three general trends observed in different countries related to the role of debt on the eve of the crisis and subsequent recovery. First, household liabilities grew significantly and at a higher rate than disposable income before 2007. Second, there is a positive correlation between rising household debt and real estate prices. Third, countries with higher debt growth rates are experiencing a deeper and sharper recession. High levels of indebtedness have their macroeconomic consequences, manifested through increased vulnerability of households to shocks such as changes in income, interest rates and asset prices (Debelle, 2004; Dynan and Kohn, 2007). Many analyses in different countries show that if the rapid increase in household liabilities is accompanied by rising property prices, the risk of financial system instability and the risk of a financial crisis also increase. (Finocchiaro et al., 2016). It is no coincidence that the countries most affected by the global financial crisis in 2008-2009 recorded the highest growth rates of household debt and, in parallel, an increase of property prices just before the crisis. In these countries, the recession was longer and more severe (Emanuelsson et al., 2015). The rapid increase in household indebtedness has raised concerns in many countries about the increased susceptibility of households to shocks. This has prompted many central banks to start applying stress test indicators and to monitor closely the development of household financial liabilities (Djoudad, 2011). One of the bitter lessons of the crisis is that the monitoring of individual financial institutions, part of the so-called microprudential policy alone is no longer sufficient. This finding is much more relevant for EU countries within the common economic area. It is certainly important to monitor the overall capacity of the EU's financial system and, in particular, its exposure to systemic risk, which must be carefully analysed and assessed. The macroprudential policy, which has become the focus of attention since the global crisis, is addressed to systemic risk management. The purpose of this policy is to maintain the stability of the financial system and to counteract the risks. However, the unusual scenario in which the global Covid19 pandemic is unfolding has found policymakers and regulators unprepared. The sudden economic shock caused by the pandemic has led to risks not only for the financial stability but also for the socio-economic development of the community. However, this type of risk does not "fit" into traditional risk management models.

In search of a suitable model some authors (Bilyk et al., 2020) try to make an analogy by comparing the pandemic to a natural disaster when analysing its impact on household indebtedness. They argue that the main similarity between a pandemic and a natural disaster is the sudden cessation of economic activity caused by a shock event unrelated to economic factors. This contrasts with the recession of 2008 , which led to continued instability in the global financial system. The analogy between a pandemic and natural disasters may have its objective grounds, but there are some very significant differences between them. Natural disasters are usually local in nature and limited in scope, while pandemics, although of varying intensity in different countries and regions, directly or indirectly affect global economic development. From a purely financial point of view, material damage from natural disasters and anomalies can be quantified and measured, while the value estimates of pandemic damage could hardly be adequately defined and measured.

The analysis of the changed economic conditions under the pressure of the consequences of the global pandemic indicates that the high values of household indebtedness are a prerequisite for generating increased risk not only for the households themselves but also for the financial sector. Highly indebted households have limited capacity to manage unexpected losses and cope with increased costs, especially if debt is used to finance illiquid assets such as real estate (Akkaya et al., 2020). Households that are experiencing a shock decline in their income and have limited reserves 
of liquid assets are among the most vulnerable. Household resilience also depends on the duration of the crisis and the period needed for economic recovery (Adams et al., 2020). Household support policies and deferred loan payments can mitigate these effects. These policies currently use different protection schemes and tools. Some of them create distribution effects, which are expressed in the transfer of the debt burden from households to financial institutions or the government budgets (Zabai, 2020). However, the discussion of adequate measures against the consequences of the pandemic would be useless if it did not focus on specific value measures of household indebtedness based on the results of surveys of their financial status. The following discussion dwells on the use of appropriate indicators accounting for hous ehold indebtedness, preceding the analysis of their values.

\section{Indicators of household indebtedness}

There are incessant discussions on the question of whether there exists a certain 'threshold' or debt limit or such levels of household indebtedness that can be considered acceptable or unhealthy for the economy. Numerous studies seek to encompass a set of indicators, but there is no single opinion on which of them most fully covers over-indebtedness or what the reference values should be (Lombardi et al., 2017, Keese, 2009; D'Alessio and Iezzi, 2010). The fact is that the expansion of credit products in the context of digitalization, the widespread use of credit cards, overdraft agreements, purchases of goods and services with deferred payment, etc. can make any reference value of household indebtedness indicators meaningless.

Given that there are no universal indicators of household indebtedness, some main groups of indicators can be synthesized by noting their positive aspects and pointing out their weaknesses or shortcomings. Eurostat provides aggregated data on household indebtedness by country in the EU, presented according to the following indicators: financial assets and liabilities of households (in total and as a percentage of GDP) and Gross debt-to-income ratio of households. The indicator, reflecting the ratio of current payments on liabilities to income received (debt/income ratio), offers a relatively simple and understandable way to measure indebtedness. At the same time, however, it gives a one-sided idea of the level of indebtedness, which is linked only to the current income of households. In addition to income, an important role in the process of assessing indebtedness is played by the general well-being of households - the liquid financial and real assets they hold. This requires the use of a supplementary indicator that shows the ratio between the financial assets held and the liabilities of households. However, the question remains "open" whether the increase in borrowed funds, which affects the indicator "debt payments/realized income", is formed by households that can afford it. In other words, debt can grow in relation to income without necessarily exacerbating debt management problems if this increase is observed mainly among high-income households.

Indicators such as the number of loans, monthly debt service costs, arrears and individual perceptions of the debt "burden" could not, alone or in a package, reliably show the full picture of household indebtedness. The indicator, which is based on the number of disbursed loans, may not reliably register conditions of over-indebtedness with the presumption that a larger number of smaller liabilities does not always cause difficulties with servicing. Even arrears on small liabilities do not correspond directly to the state of over-indebtedness.

Debt should not presumably be considered a sign of financial problems. Households that use loans actually have higher levels of wealth than those that do not have loan obligations. A possible explanation for this fact is that indebted households have a regular income and use loans most often to buy a main home, which serves as an asset suitable for collateral or in some cases is income-generating activity.

For the most part, all analysed indicators register the presence of indebtedness, rather than establishing the causes of the problems with the repayment of liabilities and the ensuing results. Due to the fact that these indicators shed light on various aspects of the phenomenon of "indebtedness", each of them provides valuable information. However, none of them is superior to the others, nor is it perfect or self-sufficient. According to Disney et al. (2008), different indicators are likely to cover the debt problems of different types of households at different stages of their life cycle. In this respect, the direct survey of households could determine whether they are having difficulty paying their debts. Like all subjective indicators, the disadvantage of the survey is the possible different interpretations and perceptions of individuals for terms such as "heavy burden", which can vary both within a country (or individual economic regions in it) and even more largely between households from different countries. For the reasons set out above, the questionnaire survey method could not provide adequate results in view of the objectives of the present study. It is appropriate to carry out the analysis of household indebtedness in the EU countries with indicators that provide quantifiable and comparable results and allow to draw a comparative profile between the countries in the EU community. 


\section{Research results and discussion}

The analysis aims to reveal the observed trends and the current status of the levels of indebtedness and financial stability of households in the EU countries before the onset of the crisis caused by the global pandemic. Official statistics include also non-profit institutions serving households in the household sector, which, however, have a negligible share. One of the indicators that gives the most general idea of the level of indebtedness is the percentage of household liabilities to the amount of GDP (Table 1).

Table 1

Financial liabilities of households in the Euro area and in the rest of the EU member-countries (as a percentage of the GDP)

\begin{tabular}{|l|r|r|r|r|r|r|r|r|r|r|r|r|r|}
\hline & $\begin{array}{l}\mathbf{2 0 1 7} \\
\text { Q1 }\end{array}$ & $\begin{array}{c}\mathbf{2 0 1 7} \\
\text { Q2 }\end{array}$ & $\begin{array}{c}\mathbf{2 0 1 7} \\
\mathbf{Q 3}\end{array}$ & $\begin{array}{c}\mathbf{2 0 1 7} \\
\mathbf{Q 4}\end{array}$ & $\begin{array}{c}\mathbf{2 0 1 8} \\
\mathbf{Q 1}\end{array}$ & $\begin{array}{c}\mathbf{2 0 1 8} \\
\mathbf{Q 2}\end{array}$ & $\begin{array}{c}\mathbf{2 0 1 8} \\
\mathbf{Q 3}\end{array}$ & $\begin{array}{c}\mathbf{2 0 1 8} \\
\text { Q4 }\end{array}$ & $\begin{array}{c}\mathbf{2 0 1 9} \\
\text { Q1 }\end{array}$ & $\begin{array}{c}\mathbf{2 0 1 9} \\
\text { Q2 }\end{array}$ & $\begin{array}{c}\mathbf{2 0 1 9} \\
\text { Q3 }\end{array}$ & $\begin{array}{c}\mathbf{2 0 1 9} \\
\text { Q4 }\end{array}$ & $\begin{array}{c}\mathbf{2 0 2 0} \\
\text { Q1 }\end{array}$ \\
\hline $\begin{array}{l}\text { Euro } \\
\text { area } \\
\begin{array}{l}19 \text { countries } \\
\text { from 2015) }\end{array}\end{array}$ & 65.5 & 65.7 & 65.2 & 65.3 & 64.7 & 64.9 & 64.7 & 64.9 & 64.8 & 65.1 & 65.2 & 65.4 & 65.7 \\
\hline Bulgaria & 28.5 & 28.8 & 28.7 & 28.6 & 28.5 & 28.8 & 28.6 & 28.7 & 28.4 & 28.4 & 28.8 & 28.8 & 29.1 \\
\hline Croatia & 35.9 & 35.5 & 35.2 & 35.1 & 35.2 & 35.4 & 35.1 & 35.2 & 35.4 & 35.8 & 35.6 & 35.9 & 36.2 \\
\hline Czechia & 36.8 & 37.5 & 37.4 & 38.3 & 38.1 & 38.2 & 38.3 & 38.3 & 38.2 & 38.3 & 38.3 & 38.3 & 38.6 \\
\hline Denmark & 131.2 & 131.8 & 132.2 & 132.8 & 135.2 & 134.3 & 132.7 & 132.8 & 131.4 & 130.2 & 128.5 & 129.7 & 127.7 \\
\hline Hungary & 24.1 & 23.8 & 23.3 & 23 & 22.4 & 22.4 & 22 & 21.9 & 21.4 & 21.4 & 21.8 & 22.4 & 22.4 \\
\hline Poland & 36.9 & 36.6 & 36.3 & 35.7 & 36.0 & 36.1 & 35.9 & 35.9 & 35.9 & 35.6 & 35.9 & 35.5 & 35.8 \\
\hline Romania & 22.6 & 22.3 & 22.0 & 19.6 & 19.6 & 19.4 & 19.3 & 19.5 & 19.3 & 19.1 & 19.1 & 18.6 & 18.2 \\
\hline Sweden & 89.0 & 89.8 & 90.2 & 90.5 & 90.5 & 90.7 & 90.8 & 91.1 & 90.9 & 91.4 & 91.2 & 91.7 & 92.1 \\
\hline
\end{tabular}

The dynamics of financial liabilities of households by quarters in the period 2017-2020 shows that there are relatively stable values of this indicator during the study period in the Euro area and in most countries outside it. Denmark, Hungary, Poland and Romania even saw a slight decline. There are no alarming symptoms of growth in financial liabilities relative to changes in GDP.

A more accurate reflection of the level of indebtedness by individual countries can be provided through the indicator of the degree of coverage of financial liabilities with financial assets of households (coverage ratio). As with the previous indicator, the amount of liabilities and assets is transformed as a percentage of the countries GDP (Fig. 1).

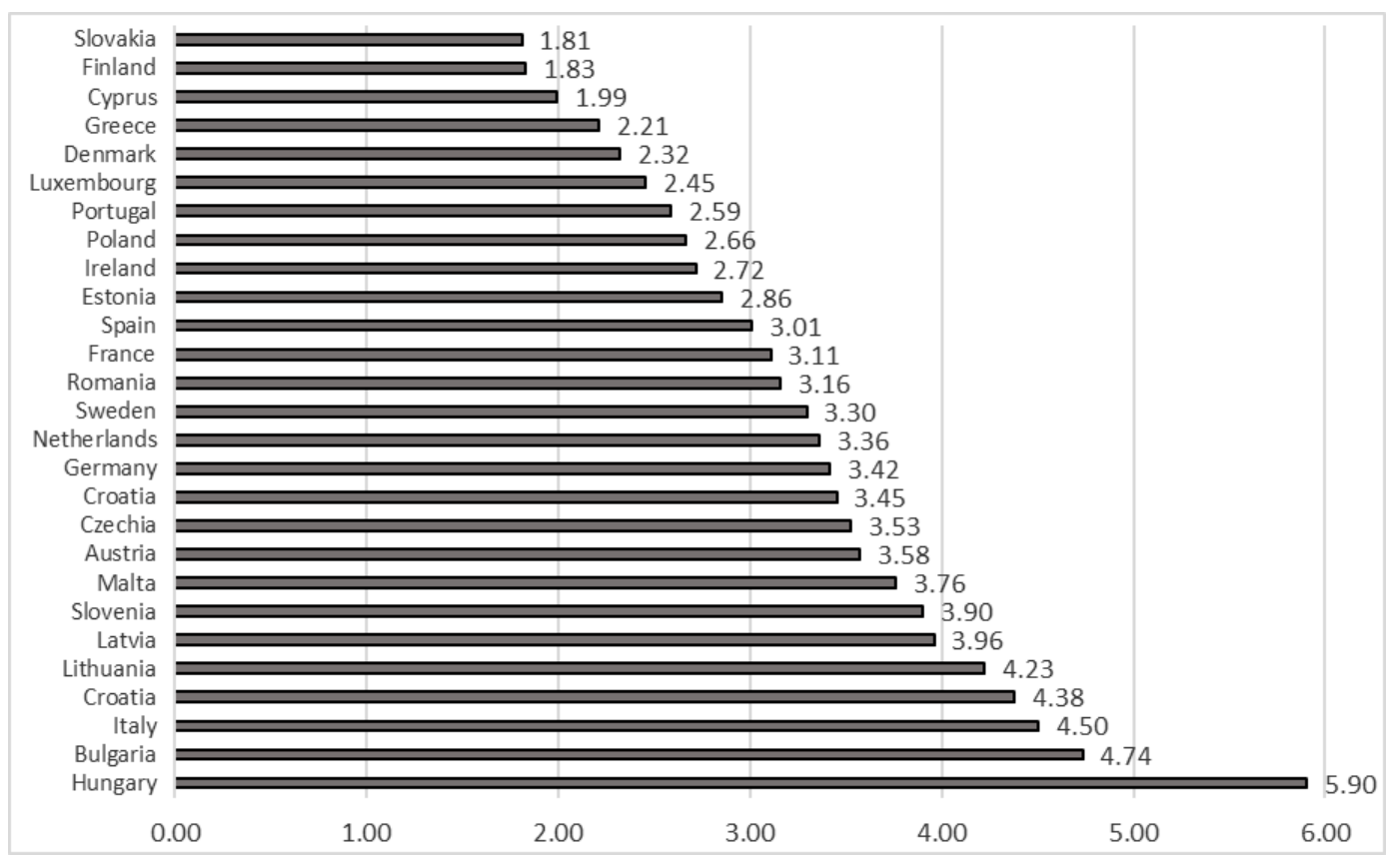

Source: author's construction based on Eurostat, Newsrelease Euroindicators, 125/2020

Fig. 1. Coverage ratio values in the $\mathbf{E U}$ countries (in the first quarter of 2020)

The data from fig. 1 show very different values of the analyzed indicator in the individual countries in the first quarter of 2020 . The average value of the indicator in the Euro area is 3.22, and 3.27 in the EU. Against the background of these averages, deviations that are more significant 
are registered in Slovakia, Finland and Cyprus. In these countries, the total financial liabilities are backed by fewer financial assets of households, which at the very beginning of a pandemic can serve as a 'red light' and a warning signal of possible problems with household financial indebtedness. At the opposite end are Hungary, Bulgaria and Italy, whose secured liabilities indicators are significantly above average.

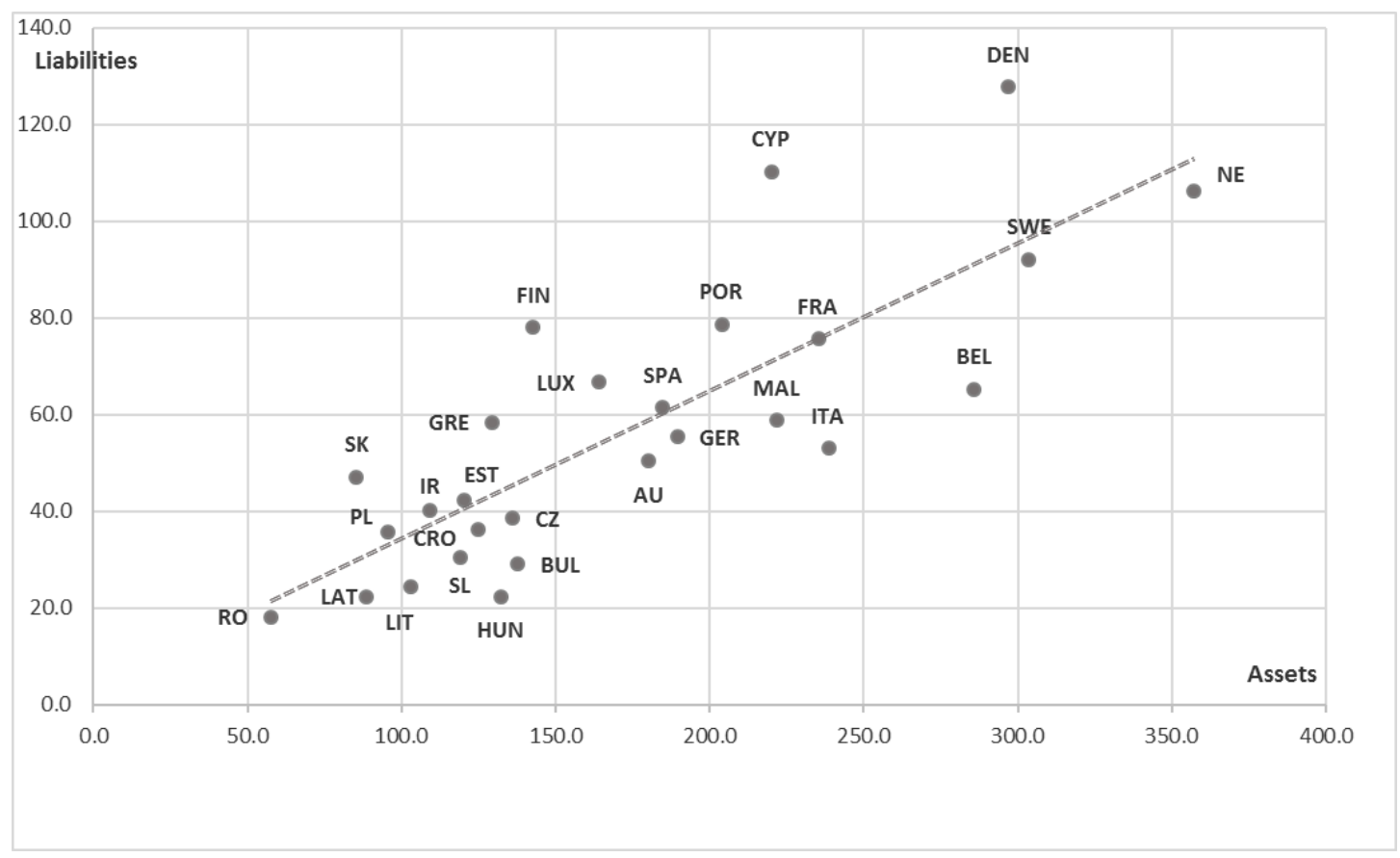

Source: author's construction

Fig. 2. EU countries positioning according to their Coverage ratio in the first quarter of 2020

The graphical representation of the values of coverage ratio in the EU countries (Fig. 2) visualizes the positioning of the individual countries in relation to the percentages of assets and liabilities to GDP and gives a spatially clearer picture of the analyzed indicator. This graph shows the different positioning of countries that have similar values of "coverage ratio". For example, Denmark and Greece have close values of the analyzed indicator in fig. 1. In the graph of fig. 2, however, they are not positioned close to each other, but are too far apart due to the different values of the variables that form the coverage ratio. It can also be noted that Denmark, Cyprus, the Netherlands and Sweden have the highest values of household liabilities. At the same time, however, in the Nordic countries financial assets of households more solidly secure financial liabilities than in Cyprus. The graph shows also the linear relationship between assets and liabilities (Table 2). To identify the strength of the relationship we obtain the Pearson correlation coefficient between assets and liabilities. The correlation coefficient of 0.815 indicates a strong positive relationship between two variables. It means that when the assets for the particular country increase than the liabilities also increase.

Table 2

Correlation between assets and liabilities

\begin{tabular}{|ll|r|r|}
\hline & & Liabilities & \multicolumn{1}{|c|}{ Assets } \\
\hline Liabilities & Pearson Correlation & 1 &, $815^{* *}$ \\
& Sig. (2-tailed) & &, 000 \\
& $\mathrm{~N}$ & 27 & 27 \\
\hline Assets & Pearson Correlation &, $815^{* *}$ & 1 \\
& Sig. (2-tailed) &, 000 & \\
& $\mathrm{~N}$ & 27 & 27 \\
\hline
\end{tabular}


The debt-to-income ratio gives an idea of the level of indebtedness in terms of the level of disposable income of households. The analysis of the values of this indicator can provide valuable information on the level of development and access of households to the credit market in individual countries, as well as indirectly analyze the ability of households to service their liabilities.

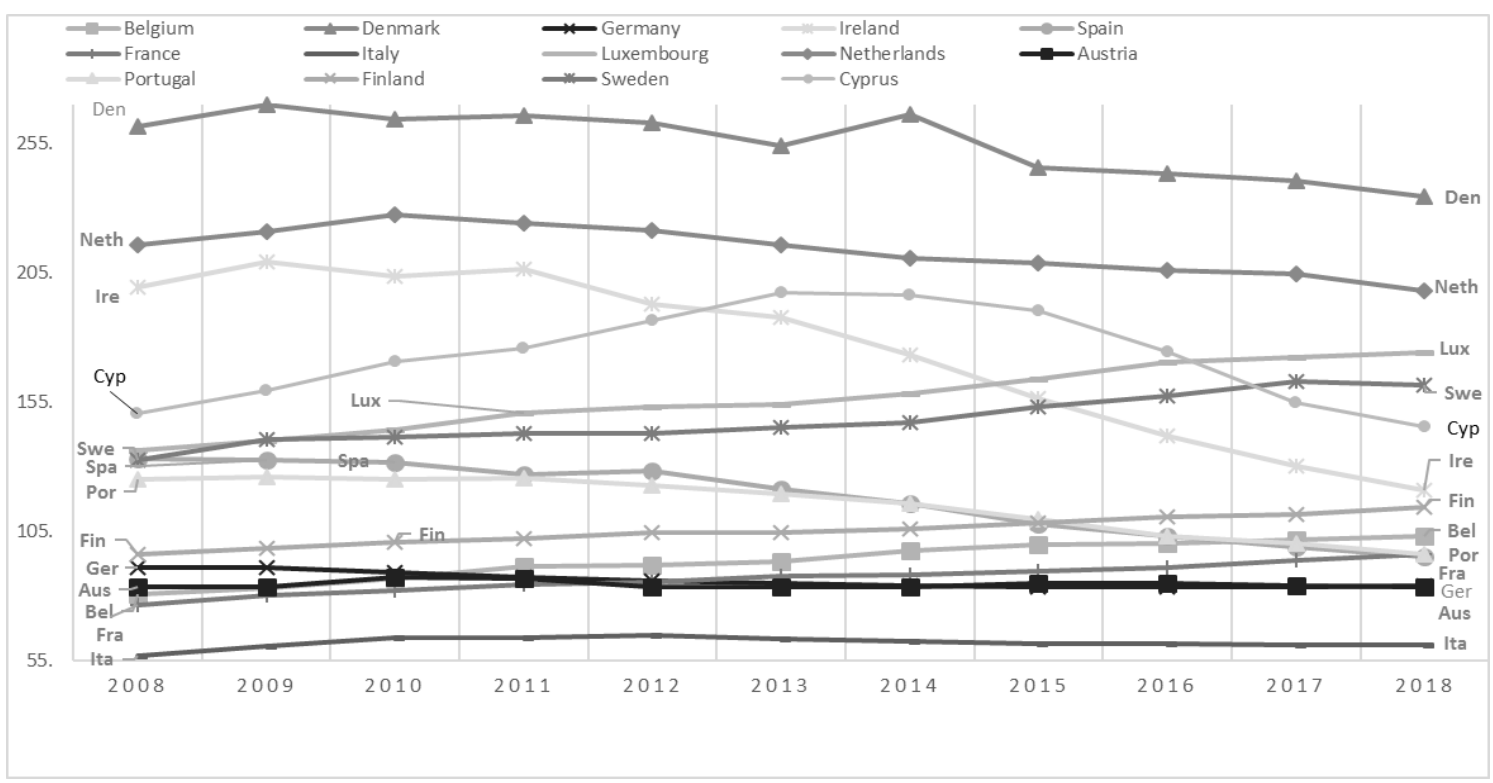

Source: author's construction based on Eurostat data

Fig. 3. Dynamics of the debt-to-income ratio in the West European countries in the period 2008-2018 (with the exclusion of Greece and Malta, due to data incompleteness)

The dynamics in the development of the "debt-to-income ratio" in the individual EU countries are presented in two consecutive figures. The division of the countries into two groups is dictated on the one hand by a regional principle, and on the other - depending on the differences in the socio-economic development of the countries. These differences are best highlighted in the measuring scales of the two figures (Fig. 3 and Fig. 4). Figure 3 shows the dynamics in the development of the "debt-to-income ratio" in the economically more developed EU countries over a ten-year period, starting with the onset of the global financial crisis. There is a tendency for a gradual decline in the values of the indicator in the countries with the highest indebtedness during the global crisis such as Denmark, the Netherlands and Ireland. The values of this indicator are moving in the opposite direction in Luxembourg, Sweden, Finland, Belgium and Portugal. There are notable differences between the countries with the highest and lowest values of this indicator.

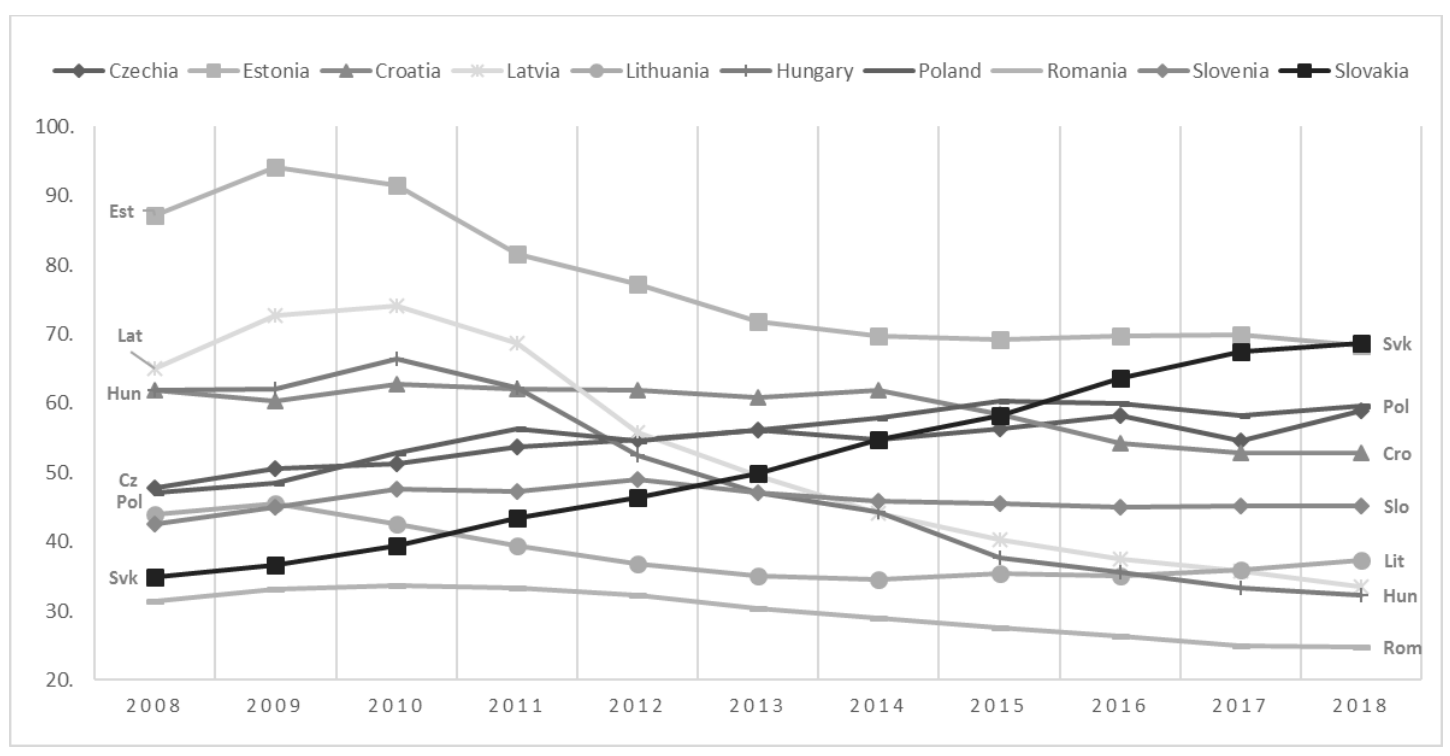

Source: author's construction based on Eurostat data 
Fig. 4. Dynamics of the debt-to-income ratio in the Central and Eastern European countries in the period 2008-2018 (with the exclusion of

Bulgaria due to incompleteness of data)

In general, the picture in the countries of Central and Eastern Europe seems different due to the closer values of the indicator in the individual countries (Fig. 4). It can also be noted here that the countries with the highest values of the indicator during the global financial crisis, such as Estonia, Latvia and Hungary, show a decline. At the same time, in countries with lower values at the beginning of the analyzed period, such as Slovakia, the Czech Republic and Poland, there is a reverse trend - to a gradual increase in values. Towards the end of the study period, there was a clear convergence of the values of the indicator in the individual countries.

Based on the analysis of household indebtedness in the EU on the studied indicators, it would be difficult to draw conclusions that are equally valid for all EU countries. This brings to the fore the problem of the coordination of measures taken by regulators at EU level and at the level of individual countries and regions. On the eve of the crisis caused by the global pandemic, the overall level of household indebtedness in the EU does not raise serious concerns or risks. In view of the unpredictable scenario of the pandemic, it should be borne in mind that the situation with the growth rate of household debt may change very abruptly and unexpectedly manner.

\section{Conclusions}

The results of the analysis of household indebtedness are essential from the point of view of the financial sustainability of households in the EU and for the economic and financial stability of the European Community. On the eve of the crisis caused by the global pandemic, the levels of household indebtedness in the EU countries are overall relatively satisfactory. There is no sharp increase in the average values of indebtedness, nor alarming symptoms of its increase in individual countries of the community. However, this finding should not be considered as a steady trend that does not hide a high-risk potential. In a recession, the pandemic could lead to a rapid and sweeping increase in liabilities and a sharp deterioration in the financial status of households. The shock of the global pandemic has led to an unprecedented economic decline, job losses and a decline in the real incomes of the European Union's population. Under these dramatically changing socio-economic conditions, the risk of accumulating overdue and non-performing debts is quite real.

EU governments implement various support schemes including access to unemployment benefits and social protection programs. In some countries, temporary moratoriums, rescheduling of tax liabilities and deferral of due payments on bank loans have been introduced. However, it should be noted that these and other similar interventions have (re)distribution effects. Wage subsidies actually transfer part of the labor costs from enterprises to state budgets. Deferred loan payments, in turn, transfer some of the losses caused by the pandemic from households to banks and other creditors. Fiscal relief, on the other hand, relocates liabilities between generations as current burdens are passed on as a burden from the current poor to the state and thus to future generations of taxpayers.

The pandemic situation requires relevant and coordinated solutions to counter the crisis in the EU. The uncoordinated implementation of divergent and heterogeneous schemes, some of which are counterproductive, could exacerbate the crisis and deepen differences between the countries of the Union. The proactive role of regulators and policymakers in the European community requires a reassessment of the applied principles and policies for social and financial assistance to households affected by the crisis. The need for timely and adequate adjustments to the situation in the methodologies for assessing the financial risks of households is obvious. Last but not least, one of the most important missions of policymakers is to take initiatives on the one hand to increase the transparency of credit conditions and the real cost of borrowing and on the other hand to increase the financial culture of households in the EU. A very important component of this mission is the organization of educational programs to increase the financial literacy of households. These programs can be funded by the EU's common budget or on projects financed by European funds. In terms of content, they can offer individual or group face-to-face or online trainings and video lessons distributed on social networks.

\section{Bibliography}

Adams, N., Holland, C., Penrose, G., Schofer, L., 2020. Household Wealth prior to COVID-19: Evidence from the 2018, HILDA Survey, 18 June 2020, [Online] Available at: https://www.rba.gov.au/publications/bulletin/2020/jun/household-wealth-prior-to-covid-19-evidence-from-the-2018hilda-survey.html [Accessed 12.09.2020].

Akkaya, Y., Belfrage, C., Corbo, V., Di Casola, P., 2020. GDP Growth in Sweden Relative to Other Countries in the Wake of Covid-19, Economic Commentaries no. 5, Sveriges Riksbank.

Bilyk, O., Anson, T., Khan, M., Vallée, G., 2020. Household Indebtedness Risks in the Wake of COVID-19, Staff Analytical Note 2020-8, June 2020, [Online] Available at: https://www.bankofcanada.ca/2020/06/staff-analytical-note-2020-8/ [Accessed 01.09.2020]. 
D’Alessio, G., Iezzi, S., 2013. Household Over-indebtedness, Definition and Measurement with Italian Data, Bank of Italy Occasional Paper No. 149, [Online] Available at: https://ssrn.com/abstract=2243578 or http://dx.doi.org/10.2139/ssrn.2243578 [Accessed 01.09.2020].

Debelle, G., 2004. Macroeconomic Implications of Rising Household Debt”, BIS working paper no. 153.

Disney R., Bridges, S., Gathergood, J., 2008. Drivers of Over-Indebtedness, Report to the Department of Business, Enterprise and Regulatory Reform, Center for Policy Evaluation, University of Nottingham.

Djoudad, R., 2011. A Framework to Assess Vulnerabilities Arising from Household Indebtedness Using Microdata. IFC Bulletins chapters, in: Bank for International Settlements (ed.), Proceedings of the IFC Conference on "Initiatives to address data gaps revealed by the financial crisis", Basel, 25-26 August 2010, volume 34, 151-168.

Drehmann, M., Juselius, M., 2014. Evaluating Early Warning Indicators of Banking Crises: Satisfying Policy Requirements. International Journal of Forecasting, 30(3), 759-780.

Dynan, K., 2012. Is a Household Debt Overhang Holding Back Consumption, Brookings Papers on Economic Activity, 43(1), $299-362$.

Dynan, K., Kohn, D., 2007. The Rise in U.S. Household Indebtedness: Causes and Consequences, Finance and Economics Discussion Series 200737. Washington: Board of Governors of the Federal Reserve System.

Emanuelsson, R., Melander, O., Molin, J., 2015. Financial Risks in the Household Sector", Economic Commentaries. [Online] Available at: http://archive.riksbank.se/Documents/Rapporter/Ekonomiska_kommentarer/2015/rap_ek_kom_nr6_150601_en.pdf [Accessed 01.09.2020].

Eurostat, Newsrelease Euroindicators, 125/2020, 14-th August 2020. Available at: https:/ec.europa.eu/eurostat/documents/ [Accessed 12.09.2020]

Finocchiaro, D. et al., 2011. Household Indebtedness, House Prices and the Macroeconomy: a Review of the Literature, Sveriges Riksbank Economic Review, №1, pp. 6-28.

Finocchiaro, D. et al., 2016. Macroeconomic Effects of Reducing Household Debt, Sveriges Riksbank Economic Review N2, pp. 57-88.

Glick, R. , Lansing, K., 2010. Global Household Leverage, House Prices, and Consumption. FRBSF Economic Letter.

Keese, M., 2009. Triggers and Determinants of Severe Household Indebtedness in Germany, SOEP papers 239, DIW Berlin, The German SocioEconomic Panel (SOEP).

Lombardi, M., Mohanty, M., Shim, I., 2017. The Real Effects of Household Debt in the Short and Long Run. BIS Working Papers, No 607. [Online] Retrieved from https://www.bis.org/publ/work607.htm. [Accessed 01.09.2020].

Mian, A., Sufi A., 2010. Household Debt and Macroeconomic Fluctuations. [Online] Available at: https:/voxeu.org/article/household-debt-andmacroeconomic-fluctuations [Accessed 31.10.2020].

Mian, A., Sufi, A., Verner, E., 2015. Household Debt and Business Cycles Worldwide, NBER Working Paper, no 2158.

Schularick, M., Taylor, A. M., 2012. Credit Booms Gone Bust: Monetary Policy, Leverage Cycles, and Financial Crises, 1870-2008. The American Economic Review, 102(2), 1029-1061.

Yoshino, N., Gupta P., 2019. How to Avoid Household Debt Overhang? An Analytical Framework and Analysis for India. ADBI Working Paper Series, No. 975.

Zabai, A., 2020. How are Household Finances Holding up Against the Covid-19 Shock? BIS Bulletin, N22.

Eurostat, Newsrelease Euroindicators, 125/2020, 14-th August 2020. [Online] Available at: https://ec.europa.eu/eurostat/documents/ [Accessed 12.09.2020].

\section{Acknowledgement}

The present scientific work is funded under Project NPI 38/2019 


\section{CLASSIFICATION OF MARKETING CAPABILITIES}

\section{Ieva Puke, University of Latvia}

Abstract. Marketing capabilities are often used as variables in research models, but without systematical approach to their classification. It hinders the meta-analysis research that could significantly improve generalization of the effects of marketing capabilities. It is difficult to use research results for practioners in order to develop capabilities in the firm and adjust marketing department structures.

The research objective is to identify types of marketing capabilities used in empirical research and develop the most relevant framework of marketing capabilities classification.

Research method: monographic method, logical-construction, scientific inductive method. Author conducted review of 35 empirical research articles published in years 2002-2019, using Scopus database, and Emerald eJournals Premier, JSTOR, SAGE Journals Online, ScienceDirect, SpringerLink Contemporary Journals databases.

Research results: author identified 12 groups of marketing capabilities observed by more than 150 indicators. Author compared 3 frameworks of marketing capability classification: inside-out and outside-in capabilities, architectural and specialized, operational and dynamic. None of these classification frameworks could include all identified capabilities, especially capabilities that characterize firms' behavior and attitude in the market. Author improved capabilities classification and distinguished 3 types of capabilities: strategic, specialized and culture based capabilities. Author classified all identified capability types according to proposed new classification.

Conclusions: This study offers novel approach to marketing capability classification, through identifying new capabilities group - cultural capabilities and provides review of empirical research on marketing capabilities according to new classification.

Limitations: empirical research included in the review covers most cited and newest articles during years 2002-2019, according to citation database Scopus.

Key words: marketing capabilities, capabilities classification.

JEL code: M31

\section{Introduction}

Marketing capabilities is a concept in the marketing theory that explains how firms use their resources in order to gain sustainable competitive advantage and superior results. Marketing capabilities predict a firm's future customer satisfaction, sales growth, profit, and stock performance. Marketing capabilities are stronger drivers of firm performance than either R\&D capabilities or Operations capabilities. Marketing capabilities are important marketing-related mechanisms by which firms can deploy superior market knowledge to generate economic rents. Marketing capabilities are complementary to one another, and each can be an individual source of competitive advantage (Evers, Andersson, \& Hannibal, 2012, p. 49). Marketing capabilities are defined by G.S. Day (1994) and extended by D.W. Vorhies $(1998,1999)$ : the integrative processes designed to apply the collective knowledge, skills, and resources of the firm to the market related needs of the business, enabling the business to add value to its goods and services, adapt to market changes and stand against competitive rivalry (Day, 1994, Vorhies, 1998).

Actuality. Marketing capabilities literature has rapidly developed since 1990-ties. Marketing capabilities is the central marketing construct that can theoretically explain and connect marketing impact on business performance. Since then many empirical studies have been conducted and have proven the positive effect of marketing capabilities either on business performance or other firm level aspects. For instance, Krasnikov and Jayachandran (2008) conducted meta-analysis of 114 researches and proved that marketing capabilities have significantly higher effect on firms financial and market results than research and development capabilities (R\&D) and operative capabilities. Wilden and Gudergan (2014) found that impact of marketing capabilities is particularly high in highly competitive environment. Marketing capabilities have proven effect on innovation results in the firms (Ren, Eisingerich, Tsai, 2015, p. 645), they foster process innovation (Yu, Ramanathan, \& Nath 2014), radical innovation (Benedetto, Desarbo, \& Song, 2008, p. 422.), and new product development (Mu, 2015). Marketing capabilities have positive effect on market results, e.g. they strengthen the effect of marketing strategy to results (Asseraf \& Lages, 2019, p. 864), create market change (Kachouie, Mavondo, \& Sands, 2018, p.1007), increase brand equity (Zhang, Jiang, Shabbir, \& Du, 2015, p. 4), (Xie \& Zheng, 2020, p.235), and stock performance (Mishra \& Modi, 2016).

Some authors conceptualize marketing capability as uni-dimensional construct and include all basic marketing mix indicators (such as, product, price, promotion, communication, planning), without critically evaluating research context (for example Su, Peng, Shen, \& Xiao, 2015; Ngo \& Cass, 2012). Other authors (for example Vorhies et al 2009; Mu, 2015) consider marketing capability to be a multidimensional construct and 
acknowledge that not all marketing capabilities are equally important. Firms cannot effectively develop or transform several capabilities at the same time. Therefore companies have to choose carefully how to prioritize capabilities. There is evidence in the literature, that capabilities should match the external environment context. For example, if there is a strong customer power in the industry, then company would want to develop customer service skills and speed (Jayachandran, Hewett, \& Kaufman, 2004, p. 229); if there is a high competitive intensity, companies will benefit from market sensing capability, because it will allow them to better understand competitive moves and customer preferences (O'Cass \& Weerawardena, 2010, p. 574.); if there is a high technological turbulence in the market, it could create change in product development and competitors would rapidly launch new product, therefore firm will benefit from new product development capability and customer service and marketing communication capability to introduce new products in the market (Martin, Raj, Javalgi, \& Ciravegna, 2020 p. 28). A firm when prioritizing capabilities should also take into account internal environment factors, for example firm's life-cycle stage. Established companies in established markets need one type of marketing capabilities, while start-ups in new markets need different marketing capabilities. However, if an established company wishes to explore new opportunities in new markets, it might benefit from marketing capabilities used by start-up companies, or combine with their existing marketing capabilities. Author concludes that various environmental factors determine which marketing capabilities will be the most important for the firm at a given time. Thus there is no justification to consider marketing capability as one whole construct, but rather acknowledge its multidimensionality and need for context.

The research problem. In order to achieve sustained competitive advantage, companies need to develop valuable rare, imperfectly imitable and un-substitutable resources and capabilities. Marketing capabilities have proven to be strong drivers of the firm performance. Therefore marketing capabilities are often used as variables in research models, but without systematical approach to their classification. It hinders the meta-analysis research that could significantly improve generalization of the effects of marketing capabilities. It is difficult to use research results for practioners in order to develop capabilities in the firm and adjust marketing department structures. In the latest research, new types of marketing capabilities are being identified, but current classification frameworks are not able to facilitate all types of capabilities anymore.

The aim of the research is to identify types of marketing capabilities used in empirical research and to develop the most relevant framework of marketing capabilities classification. To achieve the objective, author proposes the following research questions:

1. What types of marketing capabilities have proven to have positive effect on business performance and/or competitive advantage in empirical research?

2. What are the existing marketing capability classification frameworks, how are they relevant to the identified marketing capabilities?

3. How to improve the marketing classification framework according to trends in marketing capability research?

Research methods: monographic method, scientific inductive method, logical-construction. To identify frameworks of marketing capability classification, author conducted literature review of marketing capabilities theoretical concept and chose three approaches to marketing capability classification that were the most evolved and cited by other authors. To identify marketing capabilities in empirical research author conducted review of 35 empirical research articles published in years 2002-2019, using Scopus database, and Emerald eJournals Premier, JSTOR, SAGE Journals Online, ScienceDirect, SpringerLink Contemporary Journals databases. Author applied classification frameworks to identified marketing capabilities, analyzed the shortcomings, and constructed relevant marketing capability categories, according to dominant paradigm in the marketing theory, proposed by marketing scholars, viewing marketing across three main dimensions: 1) marketing as culture; 2) marketing as strategy; 3) marketing as tactics (Webster, 1993, p. 10; Hooley et al., 1999, p. 261). Firms can develop marketing capabilities through these three dimensions. Capabilities can be classified according to these three dimensions.

\section{Research results and discussion}

\section{Classification of Marketing Capabilities}

There are three main marketing capability classification approaches described in the literature. First to offer the framework for capability classification was G.S. Day, in 1994, he sorted them into three categories, depending on the orientation to external or internal environment and focus of the defining processes (fig. 1). Capabilities empowered from internal environment are called inside-out capabilities, they are activated though market requirements, competitive challenges and outside opportunities. Examples would be branding, communication, implementation capabilities. Capabilities emerged in external environment are called outside-in capabilities. The purpose is to connect the internal processes to outside environment and 'enable business to compete by anticipating market requirements ahead of competitors and creating durable relationships with customers, channel members, and suppliers. Examples would be market sensing, customer engagement, partner linking capabilities. Finally, 
'spanning capabilities are required to integrate the inside-out and out-side in capabilities'; they combine information from both external and internal environments in order to create adequate response to market requirements. Examples would be product development, market planning, strategy development, pricing capabilities. To be able to exploit market opportunities, each inside-out capability must match a corresponding outside-in capability.

External environment

\begin{tabular}{|c|}
\hline Outside-in capabilities \\
\hline $\begin{array}{l}\text { Examples: } \\
\text { - } \quad \text { Market sensing } \\
\text { - } \quad \text { Customer engagement } \\
\text { - } \quad \text { Partner linking }\end{array}$ \\
\hline
\end{tabular}

Source: Day, 1994, p. 41, adjusted by author

\section{Fig.1. Marketing capability classification by external and internal focus}

Outside-in capabilities typically focus on customer needs and satisfaction. Key performance indicators would be customer satisfaction, loyalty, customer lifecycle value. Inside-out capabilities improve and apply company resources. Key performance indicators would be awareness, attitude, brand power. This classification approach provides new angle how to explore capabilities concept and analyze capabilities within firm's environment. At the same time, it might not always be certain, which capability is purely inside-out and which capability is spanning.

Another marketing capability classification approach is promoted by Neil Morgan (Vorhies, Morgan, 2003; Morgan, Slotegraaf, Vorhies 2012, p. 92.), he sorted capabilities into architectural and specialized categories (fig.2). Architectural capabilities are the processes by which firms plan appropriate combinations of available knowledge and other resources to deploy into their marketplace and execute these planned resource deployments, transforming them into realized value offerings for target market (Morgan, Zou, Vorhies, Katsikeas, 2003, p.293). Examples of architectural capabilities are information related market learning processes, planning related marketing processes, including strategy development and choice. Specialized capabilities refer to 'specific marketing mix-based work routines used to transform available resources into valuable outputs'. Examples are marketing communication, customer service, pricing.

Architectural capabilities are processes that orchestrate application of specialized capabilities and corresponding resources. This is hierarchical capabilities classification approach, architectural capabilities are higher order constructs, more complex involving wider range of skills and resources, while specialized capabilities are lower order constructs, involving narrow specialized knowledge and skills. This classification reflects strategic marketing process with market research, planning and strategy implementation on architectural capabilities side and marketing mix related tactical skills and tasks on specialized capabilities side. Unclear remains how to classify marketing capabilities that are related to value proposition development and opportunity exploration, such as market sensing or customer engagement, and capabilities that rather capture an attitudinal dimensions, for example adaptiveness or agile marketing capability. 


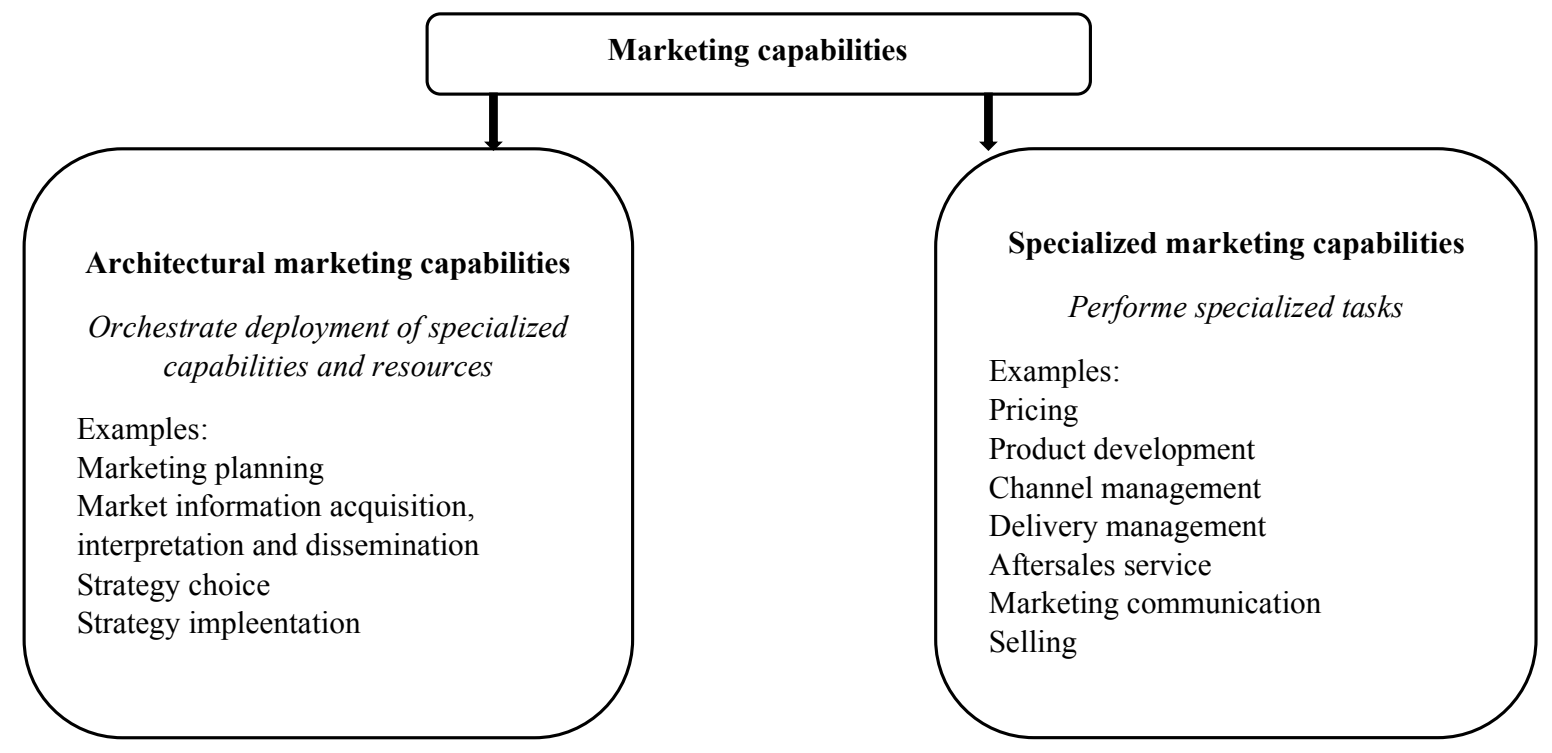

Source: drawn from Vorhies, Morgan (2003, 2005)

Fig.2. Marketing capability hierarchical classification

Third marketing capability classification approach was offered by Helfat and Peteraf (2003) categorizing operational and dynamic capabilities. Operative capabilities are defined as high level routines that together with their 'implementing input flows, confer upon an organization's management a set of decision options for producing significant outputs of a particular type'. Operational capability would typically involve performing an activity, such as manufacturing a particular product. Dynamic capabilities on the other hand 'build, integrate, or reconfigure operational capabilities'. Dynamic capabilities have indirect effect on firms output through an impact on operational capabilities. Like operational capabilities, dynamic capabilities also consist of routines. 'For example, a dynamic capability such as post-acquisition integration is composed of a set of routines that integrates the resources and capabilities of the merged firm' (Helfat, Peteraf, 2003, p.999), In the capabilities literature marketing dynamic capabilities is relatively new concept first established by Verona, Bruni (2009), and further developed by Barrales-Molina et al., (2013), Kachouie, Mavondo, \& Sands (2018) and others. No doubt, marketing capabilities possess dynamic nature being the key source that enables firm to notice latent needs, emerging trends, create innovative value proposition, reach and engage customers, creatively differentiate products and communication. However, dynamic capabilities concept is too underdeveloped to use it in further research, it is difficult to identify and measure capabilities that transform other capabilities and constantly evolve themselves.

\section{Marketing capabilities in empirical research}

According to Scopus keywords, Marketing Capabilities empirical research has emerged in year 1998. Starting from year 2013, number of articles about marketing capabilities has increased. Analyzing marketing capability constructs used by researchers, author concludes that none of existing marketing classifications offer framework for all identified types of capabilities. Researchers approach to marketing capability construct varies from capabilities that characterize firm's behavior in the market to capabilities as strategic or tactical marketing processes. For example, some of the latest studies approach marketing capabilities as firms behavior, attitude or orientation to the market situation, such as 'proactive market orientation' (Kachouie et al, 2018), 'adaptive capability' (Lu et al, 2010), 'international marketing agility' (Asseraf et al, 2019). Clearly these types of capabilities do not overlap with G.S. Day's classification, because e.g. agility is a way of behavior that can be observed in all - outside-in, inside-out or spanningcapabilities. Such behavioral or attitudinal capabilities do not fit in N. Morgan's architectural and specialized capabilities framework either, as they do not orchestrate specialized capabilities, and they do not perform specialized tasks, but rather characterize the firms' culture - set of values and behaviors that shape firms behavior.

Strategic and tactical marketing capabilities refer to firms' ability to perform marketing function, for example 'strategic planning', 'product development', 'customer engaging' are strategic marketing capabilities. They are higher order processes that combine, reconfigure, integrate, and manage firms' resources and lower order skills to reach long term valuable output. They include N. Morgan's architectural capability description, but also learning based capabilities that provide market insights necessary for capability upgrading and reconfiguration. 
Tactical marketing capabilities include specialized skills needed to perform specific tasks, for example 'performance (internet) marketing', 'aftersales service', they also involve the specific individual marketing mix-based routines, for example 'pricing', 'promotion', and 'channel management'. This capabilities group is similar to N. Morgan's specialized capabilities, but taking into account that these specialized skills are performed in established market environments, where market response is more predictable than uncertain. For example, channel management within established relationships and stable market conditions is a tactical capability, but if the firm is new in the market, trying to establish relationships and link partners while dealing with the liability of outsidership (Johanson \& Vahlne, 2009), it requires a strategic marketing capability.

Table 1

Marketing capabilities classification by cultural, strategic and tactical dimensions

\begin{tabular}{|l|l|l|}
\hline I Cultural marketing capability & II Strategic marketing capability & III Tactical marketing capability \\
\hline $\begin{array}{l}\text { Refers to firms' marketing behavior } \\
\text { and attitude in the market }\end{array}$ & $\begin{array}{l}\text { Refers to marketing strategic } \\
\text { processes (informational, planning, } \\
\text { interfunctional and inter- } \\
\text { Answers to questions: 'How?' 'In what } \\
\text { way?' }\end{array}$ & $\begin{array}{l}\text { Refers to tactical marketing functions } \\
\text { and specialized skills }\end{array}$ \\
\hline Premise: marketing as a culture & Premise: marketing as strategy & Premise: marketing as tactics \\
\hline Examples: & Examples: & Examples: \\
1.Adaptive Marketing capability & 1. Market learning & 1.Pricing \\
2. Marketing agility & 2. Exploratory marketing capability & 2.Promotion \\
3.Proactive marketing capability & 3. Marketing planning & 3.Channel Management \\
4.Marketing experimentation & 4. Strategy implementation & 4.Aftersales service \\
capability & 5. Branding capability & 5.Marketing communication \\
& 6.Customer relationship & 6.Selling \\
management & 7.Research \\
& 7. Partner linking & \\
8. Product development & \\
Source: author & 9.Marketing digitalization & \\
capability & \\
\hline
\end{tabular}

Analyzing empirical research on marketing capabilities through inductive approach, author finds that all identified capabilities correspond best to the strategic marketing premise: marketing operates in three firm levels - corporate, business or strategic business unit and operative or functional levels. In addition to these strategic levels, there are three distinct dimensions of marketing that have been described by Webster (1992): marketing as culture (as a basic set of values and beliefs about the central importance of the customer), marketing as strategy (defining how the firm is to compete in its chosen business) and marketing as tactics or operational level (elements of the marketing mix, specialized skills). If firm cultivates marketing capabilities at all three dimensions, then marketing capability can become a source of competitive advantage. Through logical construction, based on three marketing dimensions, author offers marketing capability classification in three groups: 1) cultural marketing capabilities, 2) strategic marketing capabilities, 3) tactical marketing capabilities (as in table 1). While strategic and tactical capabilities overlap with previous classification frameworks, cultural marketing capabilities group is novel.

The advantages of this new marketing capability classification approach are 1) this classification entails all identified marketing capabilities, 2) it allows to view marketing capabilities from broader perspective: not only in strategic marketing context but also in value creation process context. This classification is open for supplementing with new marketing skills that will be identified in future studies. 
Cultural marketing capabilities measurement scales

\begin{tabular}{|l|l|}
\hline $\begin{array}{l}\text { I Cultural marketing capabilities } \\
\text { Refers to firms ' marketing behavior and } \\
\text { attitude in the market }\end{array}$ & \multicolumn{1}{|c|}{ Indicators/Measurement scales } \\
\hline $\begin{array}{l}\text { 1. Adaptive Capability } \\
\text { Lu et al, 2010 }\end{array}$ & $\begin{array}{l}\text { (1) Adaptive to meet customer demands } \\
\text { (2) Adaptive to tailor products/services according to customer requests } \\
\text { (3) Adaptive to respond quickly to a change in product prices }\end{array}$ \\
\hline $\begin{array}{l}\text { 2. Marketing Agility } \\
\text { Asseraf et al, 2019 }\end{array}$ & $\begin{array}{l}\text { Rapid response to } \\
\text { (1) entry of new competitors; } \\
\text { (2) emerge of an innovative technology; }\end{array}$ \\
& (3) detection of new business threats; and \\
& (4) detection of new business opportunities. \\
\hline 3.Proactive market orientation & (1) Our organization seeks to discover unexpressed customer needs \\
Kachouie et al, 2018 & (2) Our organization develops solutions to address unstated customer \\
& needs \\
& (3) Our organization engages with customers to find their latent needs \\
& eurgerganization works closely with lead users to understand \\
\hline
\end{tabular}

Source: author

The measurement indicators for Cultural marketing capabilities are synthesized in

Table 2. Indicators confirm that cultural

marketing capabilities characterize firm's attitude and nature of behavior in confrontation with market participants and challenges. These capabilities show how firm typically approaches problem solving, how it reactively or proactively tackles market tasks. In empirical research this appears to be the smallest group of capabilities and it highlights a new trend in firms' marketing capabilities.

Table 3

Strategic marketing capability measurement scales

\begin{tabular}{|c|c|}
\hline $\begin{array}{c}\text { II Strategic marketing capabilities } \\
\text { Refers to marketing strategic processes (informational, planning, } \\
\text { interfunctional and inter-organizational } \\
\text { Indicators/Measurement scales }\end{array}$ & Sources \\
\hline $\begin{array}{l}\text { 1.Market learning capability } \\
\text { 1.1. Market sensing } \\
\text { 1.2. Market focused learning capability } \\
\text { 1.3. Market information acquisition } \\
\text { 1.4. Market information interpretation } \\
\text { 1.5. Market information dissemination }\end{array}$ & $\begin{array}{l}\text { Day, 1994, Weeravardena \& Kennedy, 2002, } \\
\text { Di Benedetto et al, 2008, Morgan et al 2011, } \\
\mathrm{Mu}, 2015\end{array}$ \\
\hline 2. $\quad$ Exploratory marketing capability & Asseraf et al, 2019 \\
\hline 3. $\quad$ Marketing planning capability & Slotergraaf et al, 2004; Chang, 2010; Morgan et al 2011 \\
\hline 4. $\quad$ Strategy implementation & White et al, 2003, Morgan et al, 2003, 2009, Chang 2010 \\
\hline $\begin{array}{l}\text { 5. Branding capability } \\
\text { 5.1. Branding Capability } \\
\text { 5.2. Brand Management Capability }\end{array}$ & $\begin{array}{l}\text { Wong and Merrilees (2008), Merrilees et al, 2011, } \\
\text { Morgan et al, 2009a }\end{array}$ \\
\hline $\begin{array}{l}\text { 6. Customer relationship management capability } \\
\text { 6.1. Customer engagement } \\
\text { 6.2. CRM capability } \\
\text { 6.3. Customer co-creation capability }\end{array}$ & $\begin{array}{l}\text { Day, 1994, 2011; Mu, 2015, Park et al 2010; Yim et al., } 2008 \\
\text { Kaleka, 2002; Jayachandran et al, 2004; } \\
\text { Morgan et al, 2009a; Chen, 2012; Xie \& Zheng, 2019; } \\
\text { Zhang et al, 2015; Claro \& Claro, 2010; Zhang \& Chen, } 2008\end{array}$ \\
\hline $\begin{array}{l}\text { 7. Partner relationship management capability } \\
\text { 7.1. Partner linking } \\
\text { 7.2. Networking capability }\end{array}$ & $\begin{array}{l}\text { Mu, } 2015 \\
\text { Walter et al 2006; Chen et al, 2009; Zhang et al, } 2015\end{array}$ \\
\hline $\begin{array}{l}\text { 8. Product development capability } \\
\text { 8.1. Product development } \\
\text { 8.2.New product launch capability } \\
\text { 8.3.Product differentiation }\end{array}$ & $\begin{array}{l}\text { Morgan et al, 2009; Kemper et al } 2011 \\
\text { Atuahene-Gima, 2005; } \\
\text { Weerawardena, 2003 } \\
\text { Kim et al, } 2016\end{array}$ \\
\hline 9. Marketing digitalization capability & Mathews et al, 2019 \\
\hline
\end{tabular}

Source: author

Strategic capabilities have a strategic impact on the firm. They support managers in decision-making tasks, through predicting possible future developments, possible competitive situations and preparing the organization to adapt to these scenarios and restructure their capabilities accordingly. Strategic capabilities are acquired through the integration of knowledge and learnings. Strategic capabilities need to be created and 
built over time. They must be managed carefully and committedly, since they are disproportionate contributors to the firms' success (Day, 1994, p.39).

During strategic capability analysis and synthesis process, author consolidated similarly formulated and essentially close marketing capability types, for example 'Market learning capability' includes 'Market sensing', Market information acquisition, interpretation, dissemination capability' . 'Market learning' is strategic capability and consolidated capabilities reflect various dimensions of this capability. Researchers choose appropriate dimensions according to research context - company type, life-cycle, market challenges, and environmental factors. Identified strategic marketing capabilities are synthesized in Table 3. Each capability type can be observed by several indicators. Author found more than 150 indicators for strategic capabilities. Full strategic capabilities list with indicators are attached in Appendix 1.

Strategic marketing capabilities and their indicators refer to firm's processes, routines and actions that comprise the respective capability. Cultural marketing capabilities refer to firms' attitude and behavior when performing these strategic processes. That substantiates the need to separate these two groups in the classification.

\section{Summary and discussion}

Marketing capabilities construct is used by researchers when aiming to explain why some companies perform better than others. Marketing capabilities is a multidimensional construct, and it should be evaluated according to the fimr's environmental context. Marketing capability classification began with G.S. Day's outside-in and inside-out approach, where he analysed capabilities through the lens of the firm's internal and external environment. Lately N.Morgan is the most popular author analysing marketing capabilities through both theoretical and empirical approaches. One of N.Morgans suggestions is that marketing capabilities could be classified as 1) architectural capabilities that orchestrate the deployment of resources and specialized capabilities and 2)specialized capabilities that are used to perform specialized tasks. Day's and Morgan's approaches are very different and both provide a valid perspective on marketing capabilities concept and lead to better understanding of capabilities' nature. At the same time, other researchers have identified new marketing capabilities being used in specific contexts of companies, for example when companies try to innovate, enter new markets or develop new products. These newly identified capapabilities refer to firms' marketing behavior and attitude in the market, rather than describe functionality or processes. And both Day's and Morgans classification approaches cannot include these type of capabilities. As marketing approaches are constantly changing, author considers these studies with new capabilities to be a signal that new type of marketing capability has emerged. Therefore author has developed a classification approach that includes all types of identified marketing capabilities, particularly focusing on Cultural marketing capabilities and Strategic marketing capabilities. Examples of the new marketing capabilities are: Agile marketing capability that refers to firm' s rapid response to entry of new competitors, emergence of innovative technology, detection of new business threats and opportunities; also Proactive marketing capability that characterizes firm' $\mathrm{s}$ ability to discover unexpressed customer needs and develop solutions to adress these needs, to enage customers to find their latent needs and work closely with lead users to be ahead of competitors.

The topic of Cultural marketing capabilities could be of interest for marketing experts, strategists, HR experts, as company culture or the shared value and behavior system in the company can become a source of sustained competitive advantage. In highly competitive markets it is not enough to focus on 'what' your company does, but also on 'how' your company does things - what is the attitude and behavior that drives strategic and tactical processes within a firm.

\section{Conclusions, proposals, recommendations}

This study offers novel approach to marketing capability classification, contributing to knowledge of marketing capabilities.

1. Author has identified new capabilities group - Cultural marketing capabilities, which explain firms' attitude and behavior in the market.

2. Through analysis and synthesis of more than 150 marketing capability indicators drawn from empirical research, author has improved approach to marketing capability classification by distinguishing three groups of marketing capabilities: Cultural, Strategic and Tactical.

3. In the article Strategic and Cultural marketing capabilities are synthesized in constructs and sub-constructs providing overview of routines and processes entailed in these capabilities.

Implications for researchers: this research further advances knowledge of marketing capability nature and classification approaches. The review of latest studies can be used when choosing marketing capability dimensions for empirical research.

Implications for managers: marketing capability classification aims to express the multidimensional nature of marketing within the firm: marketing as culture, marketing as strategy and marketing as tactics. Marketing capabilities should be cultivated within all three dimensions 
Limitations: empirical research included in the review covers most cited and newest articles during years 2002-2019, according to the citation database Scopus. Data was retrieved during February-May, 2020. Tactical or specialized capabilities are rarely used in research (e.g. Morgan et al 2011), academics mostly focus on strategic, higher level capabilities, therefore in this study author will not focus on synthesizing indicators of specialized capabilities. The compilation of marketing capability constructs and sub-constructs should not be considered as a complete set of capabilities, rather it is an open system that can be supplemented within the given classification.

\section{Bibliography}

Asseraf, Y., Lages, L. F., 2019. Assessing the Drivers and Impact of International Marketing Agility. International Marketing Review, 36(2), 289315. https://doi.org/10.1108/IMR-12-2017-0267

Atuahene-Gima, K., 2005. Resolving the Capability-Rigidity Paradox in New Product Innovation, Journal Of Marketing, 69(4), 61-83

Barrales-Molina, V., Martínez-López, F. J., Gázquez-Abad, J. C., 2013. Dynamic Marketing Capabilities : Toward an Integrative Framework. International Journal Of Management Reviews, 16(4), 397-416. https://doi.org/10.1111//jmr.12026

Benedetto, A. Di, Desarbo, W. S., Song, M., 2008. Strategic Capabilities and Radical Innovation : an Empirical Study in Three Countries, IEEE Transactions On Engineering Management, Vol. 55. https://doi.org/10.1109/TEM.2008.922645

Chang, W., Park, J. E., Chaiy, S., 2010. How Does CRM Technology Transform Into Organizational Performance? A Mediating Role Of Marketing Capability. Journal Of Business Research, 63(8), 849-855. doi:10.1016/J.Jbusres.2009.07.003

Chen, X., Zou H., Wang, D.T., 2009. How Do New Ventures Grow? Firm Capabilities, Growth Strategies and Performance. International Journal Of Research In Marketing, 26(4), 294-303

Chen, J., 2012. Information and Management The Synergistic Effects Of IT-Enabled Resources On Organizational Capabilities and Firm Performance. Information and Management, 49(3-4), 142-150. https://doi.org/10.1016/J.Im.2012.01.005

Claro, D. P., Claro, P. B. O., 2010. Industrial Marketing Management Collaborative Buyer - Supplier Relationships and Downstream Information in Marketing Channels. Industrial Marketing Management, 39(2), 221-228. https://doi.org/10.1016/J.Indmarman.2009.03.009

Day, G. S., 1994. Continuous Learning About Markets. California Management Review, 36(4), 9-31

Day, G. S., 2011. Closing The Marketing Capabilities Gap. Journal Of Marketing, 75(4), 183-195

Evers, N., Andersson, S., Hannibal, M., 2012. Stakeholders and Marketing Capabilities In International New Ventures : Evidence From Ireland , Journal Of International Marketing 20(4), 46-71.

Helfat, C. E., Peteraf, M. A., 2003. The Dynamic Resource-Based View : Capability Lifecycles, Strategic Management Journal, 24(10), 997-1010. https://doi.org/10.1002/Smj.332

Hooley, G., Fahy, J., Cox, T., Beracs, J., Fonfara, K., Snoj, B., 1999. Marketing Capabilities and Firm Performance: A Hierarchical Model. Journal Of Market-Focused Management, 4(3), 259-278. https://doi.org/10.1023/A:1009879120167

Jayachandran, S., Hewett, K., Kaufman, P., 2004. Customer Response Capability In A Sense-and-Respond Era: The Role Of Customer Knowledge Process. Journal Of The Academy Of Marketing Science, 32(3), 219-233. doi:10.1177/0092070304263334

Johanson, J., Vahlne, J. E., 2015. The Uppsala Internationalization Process Model Revisited: From Liability Of Foreignness To Liability Of Outsidership. Journal Of International Business Studies, 40(9), 153-186.

Kachouie, R., Mavondo, F., Sands, S., 2018. Dynamic Marketing Capabilities View On Creating Market Change, European Journal Of Marketing, 52(5), 1007-1036. https://doi.org/10.1108/EJM-10-2016-0588

Kaleka, A., 2002. Resources and Capabilities Driving Competitive Advantage In Export Markets: Guidelines For Industrial Exporters. Industrial Marketing Management,Volume 31, Issue 3. Pages 273-283,ISSN 0019-8501

Kemper, J., Engelen, A., Brettel, M., 2011. How Top Management's Social Capital Fosters The Development Of Specialized Marketing Capabilities: A Cross-Cultural Comparison. Journal Of International Marketing, 19(3), 87-112. https://doi.org/10.1509/Jimk.19.3.87

Kim, N., Shin, S., Min, S., 2016. Strategic Marketing Capability: Mobilizing Technological Resources For New Product Advantage. Journal Of Business Research, 69(12), Pp.5644-5652.

Krasnikov, A., Jayachandran, S., 2008. The Relative Impact Of Marketing, Research-and-Development, and Operations Capabilities On Firm Performance. Journal Of Marketing, 72(4), 1-11 
Lu, Y., Zhou, L., Bruton, G., Li, W., 2010. Capabilities as a mediator linking resources and the international performance of entrepreneurial firms in an emerging economy. Journal of international Business studies, 41(3), pp.419-436.

Martin, S. L., Raj, R., Javalgi, G., Ciravegna, L., 2020. Marketing Capabilities and International New Venture Performance: The Mediation Role Of Marketing Communication and The Moderation Effect Of Technological Turbulence. Journal Of Business Research, 107, $25-37$. https://doi.org/10.1016/J.Jbusres.2019.09.044

Mathews, S. W., Maruyama, M., Sakurai, Y., Perks, K. J., Sok, P., 2019. Risk Perceptions In Japanese Smes: The Role Of Internet Marketing Capabilities In Firm Performance. Journal Of Strategic Marketing, 27(7), 599-611. doi:10.1080/0965254X.2018.1464048

Merrilees, B., Rundle-Thiele, S., Lye, A., 2011. Marketing Capabilities : Antecedents and Implications For B2B SME Performance. Industrial Marketing Management, 40(3), 368-375

Mishra, S., Modi, S. B., 2016. Corporate Social Responsibility and Shareholder Wealth: The Role Of Marketing Capability. Journal Of Marketing, 80(1), 26-46. doi:10.1509/Jm.15.0013

Morgan, N. A., Vorhies, D. W., 2003. Experiential and Informational Knowledge, Architectural Marketing Capabilities, and The Adaptive Performance Of Export Ventures : A Cross-National Study. Decision Sciences, 34(2), 287-321

Morgan, N. A., Vorhies, D. W., Mason, C. H., 2009. Market Orientation, Marketing Capabilities, and Firm Performance. Strategic Management Journal, 30(8), 909-920

Morgan, N. A., Katsikeas, C. S., Vorhies, D. W., 2012. Export Marketing Strategy Implementation, Export Marketing Capabilities, and Export Venture Performance. Journal Of The Academy Of Marketing Science, 40(2), 271-289

Morgan, N. A., Slotegraaf, R. J., 2012. Marketing Capabilities For B2B Firms. Handbook Of Business-To-Business Marketing. Edward Elgar Publishing

Mu, J., 2015. Industrial Marketing Management Marketing Capability, Organizational Adaptation and New Product Development Performance. Industrial Marketing Management, 49, 151-166. https://doi.org/10.1016/J.Indmarman.2015.05.003

Ngo, L. V., Cass, A. O., 2012. In Search Of Innovation and Customer-Related Performance Superiority : The Role Of Market Orientation, Marketing Capability, and Innovation Capability Interactions. Journal Of Product Innovation Mangement, 29(5), 861-877. https://doi.org/10.1111/J.15405885.2012 .00939

O'Cass, A., Weerawardena, J., 2010. The Effects Of Perceived Industry Competitive Intensity and Marketing-Related Capabilities: Drivers Of Superior Brand Performance. Industrial Marketing Management, 39(4), 571-581.

Park, W.C., Macinnis, D.J., Priester, J., Eisingerich, A.B., Iacobucci, D., 2010. Brand Attachment and Brand Attitude Strength: Conceptual and Empirical Differentiation Of Two Critical Brand Equity Drivers. Journal Of Marketing, 74(6), 1-17.

Ren, S., Eisingerich, A. B., Tsai, H., 2015. How Do Marketing, Research and Development Capabilities, and Degree Of Internationalization Synergistically Affect The Innovation Performance Of Small and Medium-Sized Enterprises (SMEs)? A Panel Data Study Of Chinese SMEs. International Business Review, 24(4), 642-651. https://doi.org/10.1016/J.Ibusrev.2014.11.006

Slotegraaf, R.J., Dickson, P.R., 2004. The paradox of a marketing planning capability. Journal of the Academy of Marketing Science, 32(4), pp.371385.

Su, Z., Peng, J., Shen, H., Xiao, T., 2015. Technological Capability, Marketing Capability and Firm. Management and Organization Review Review, 115-138. https://doi.org/10.1111/J.L

Bruni, D. S., Verona, G., 2009. Dynamic Marketing Capabilities In Science-Based Firms: An Exploratory Investigation Of The Pharmaceutical Industry. British Journal Of Management, 20, 101-117

Vorhies, D. W. (1998). An investigation of the factors leading to the development of marketing capabilities and organizational effectiveness. Journal of strategic marketing, 6(1), 3-23.

Vorhies, D. W., Harker, M., Rao, C. P., 1999. The Capabilities and Performance Advantages Of Market-Driven Firms. European Journal Of Marketing, 33(11/12), 1171-1202. https://doi.org/10.1108/0309056991029233925

Vorhies, D. W., Morgan, N. A., 2005. Benchmarking Marketing Capabilities For Sustainable Competitive Advantage. Journal Of Marketing, 69(1), 80-94

Vorhies, D. W., Morgan, R. E., Autry, C. W., 2009. Product-Market Strategy and The Marketing Capabilities Of The Firm: Impact On Market Effectiveness and Cash Flow Performance. Strategic Management Journal, 30(12), 1310-1334. doi:10.1002/Smj.798 
Walter, A., Auer, M., Ritter, T., 2006. The Impact Of Network Capabilities and Entrepreneurial Orientation on University Spin-Off Performance. Journal Of Business Venturing, 21, 541-567. https://doi.org/10.1016/J.Jbusvent.2005.02.005

Webster, F. E., 1993. The Changing Role Of Marketing In The Corporation. IEEE Engineering Management Review, 21(3), 48-60. https://doi.org/10.2307/1251983

Weerawardena, J., 2003. The Role of Marketing Capability in Innovation-Based Competitive Strategy. Journal Of Strategic Marketing, 11(1), 1535. doi:10.1080/0965254032000096766

White, J.C., Conant. J.S.. Echambadi. R.. 2003. Marketing Strategy Development Styles, Implementation Capability, and Firm Performance: Investigating The Curvilinear Impact Of Multiple Strategy-Making Styles. Marketing Letters, Vol. 14, No. 2, 111-124 Published By: Springer Stable

Weerawardena, J., Mccoll-Kennedy, J. R., 2002. New Service Development and Competitive Advantage: A Conceptual Model. Australasian Marketing Journal (AMJ), 10(1), 13-23. https://doi.org/10.1016/S1441-3582(02)70140-7

Wilden, R., Gudergan, S. P., 2015. The Impact Of Dynamic Capabilities On Operational Marketing and Technological Capabilities: Investigating The Role Of Environmental Turbulence. Journal Of The Academy Of Marketing Science, 43(2), 181-199

Wong, H. Y., Merrilees, B., 2008. The Performance Benefits Of Being Brand-Orientated. Journal Of Product and Brand Management. 17. $10.1108 / 10610420810904112$.

Xie, Y., Zheng, X., 2020. How Does Corporate Learning Orientation Enhance Industrial Brand Equity? The Roles Of Firm Capabilities and Size. Journal of Business and Industrial Marketing, 231-243. https://doi.org/10.1108/JBIM-10-2018-0320

Yim, B.C.K., Tse, D.K., Chan, K.W., 2008. Strengthening Customer Loyalty Through Intimacy and Passion: Roles Of Customer-Firm Affection and Customer-Staff Relations In Services. Journal Of Marketing Research, 45(6), 741-756.

Yu, W., Ramanathan, R., Nath, P., 2014. The Impacts Of Marketing and Operations Capabilities On Financial Performance in the UK Retail Sector: A Resource-Based Perspective. Industrial Marketing Management, 43(1), 25-31. doi:10.1016/j.indmarman.2013.07.014

Zhang, J., Jiang, Y., Shabbir, R., Du, M., 2015. Building Industrial Brand Equity by Leveraging Firm Capabilities and Co-Creating Value with Customers. Industrial Marketing Management, 51, 47-58. https://doi.org/10.1016/J.Indmarman.2015.05.016

Zhang, X., Chen, R., 2008. Examining The Mechanism of The Value Co-Creation with Customers. International Journal Of Production Economics, 116(2), 242-250. 
APPENDIX 1

\section{Strategic marketing capabilities}

Refers to marketing strategic processes (informational, planning, interfunctional and inter-organizational Indicators/Measurement scales

\section{Market learning capability}

\subsection{Market sensing}

We can continuously scan emerging market trends and events

We are quite alert to changing market conditions

Everyone is sensitized to listen to latent problems and opportunities in the market

We can anticipate market trends and events accurately before they are fully apparent

We can triangulatemarket information fromdifferent sources

We can effectively listen to, understand, and rapidly respond to relevant marketplace conversations

9.2. Market focused learning capability

Our firm frequently collects information about changes in our market

Our firm search for innovative ideas through market information

Our firm has extensive knowledge about the market segments in your industry

Our firm has extensive knowledge of competitors

Our firm integrates customer and competitor information into innovations in our firm

Our firm undertakes review of unsuccessful market research programms and communicates the lessons for improvement widely within the firm

\subsection{Market information acquisition}

Quickly learning of changes in customer preferences

Discovering competitor strategies and tactics

Gaining insights about the marketing from distributors and the channel

Using multiple information sources to learn about export customers and competitors

9.4. Market information interpretation

Integrating all available information to gain insights about the market

Combining new information with past research to build a richer market view

Analyzing market information to effectively understand the market

Identifying emerging trends in the marketplace

9.5. Market information dissemination

Making relevant market information available to decision-makers

Sharing available market information widely within the venture

Ensuring market information reaches all interested parties

Giving other units in the firm easy access to our market information.

\section{Exploratory marketing capability}

Assessing the potential of new markets.

Building relationships in new markets.

Setting up a new sales force.

Researching new competitors and new customers.

\section{Marketing planning capability}

Competency in market scanning.

Competency in market situation/environment analysis.

Competency in matching firm strengths to market opportunities.

Competency in meshing programs to market realities.

Competency in implementing marketing programs.

Competency in marketing budgeting/allocating resources.

Program performance tracking competence.

Sets clear marketing goals

Develops creative marketing strategies

Segments and targets market effectively

Thoroughness of marketing planning processes

\section{Strategy implementation}

Allocates marketing resources effectively

Delivers marketing programs effectively

Translates marketing strategies into action effectively

Executes marketing strategies quickly

Monitoring the performance of marketing strategies

Slotergraaf et al, 2004;

Chang, 2010;

Morgan et al 2011 


\section{Branding capability}

\subsection{Branding Capability}

Better able to identify a simple brand meaning

Wong and Merrilees (2008),

Uses branding as an operational tool

Better able to communicate a consistent brand meaning

Is more likely to treat its brands as assets

Able to get staff to support the brand

\subsection{Brand Management Capability}

Morgan et al, 2009a

Using customer insights to identify valuable brand positioning.

Establishing desired brand associations in customers' minds.

Maintaining a positive brand image relative to competitors.

Achieving high levels of brand awareness in the market.

Tracking brand image and awareness among target customers.

\section{Customer relationship management capability}

\subsection{Customer engagement}

We can provide reliable and timely responses to customers' needs

We can proactively respond to customer expectations

We can invest resources necessary to closely connectwith customers

We can seriously attend to customers' ideas

We can genuinely care to customers' circumstances

We can take customers' viewpoint to consider how to design and improve business process

We are able to immerse in customer reality

We can focus on customer from the customer's point of view

\subsection{CRM capability}

Understanding what customers need and require

Incorporation of customer needs into marketing of products and services

Our firm is good at maintaining and enhancing relationships with customers

Understanding customers' requirements

Establishing close relationships with customers

Sustaining strong relationships with customers

Customer response speed

Customer response expertise

Identifying and targeting attractive customers.

Getting target customers to try our products/services.

Focusing on meeting target customers' long-term needs to ensure repeat business.

Maintaining loyalty among attractive customers.

Enhancing the quality of relationships with attractive customers.

Obtain customer feedbacks and forecast customer needs.

Minimize customer complaints

Improve the quality of customer service

\subsection{Customer co-creation capability}

Customers actively participate in the process of new product development

Our company shares long-term plans of our products with customers.

Customers and our company deal with problems that arise in the course of the relationship together

In most aspects of the relationship with the buyers, the responsibility for getting things done is shared

Flexible in response to changes in the relationship with our customers

When some unexpected situation arises, we can work out a new deal with customers

Involving customers at marketing and sales

Involving customers at servicecare

Involving customers at new product development

Managing customers as partial employees

\section{Partner relationship management capability}

\subsection{Partner linking}

We are quite accessible to partners when needs arise

We have a formal system in place that can help us find right partners

We can dynamically fine-tune and adjust our relationships with partners over time

We can effectively coordinate and orchestrate network partner relationships over time

We can effectively mobilize partners resources to create value for customers

\subsection{Networking capability}

Coordination:

We analyze what we would like and desire to achieve with which partner.

We match the use of resources (e.g., personnel, finances) to the individual relationship.

We inform ourselves of our partners' goals, potentials and strategies.

We judge in advance which possible partners to talk to about building up relationships.

We appoint coordinators who are responsible for the relationships with our partners.

We discuss regularly with our partners how we can support each other in our success. Relational skills:

$\mathrm{Mu}, 2015$,

Day, 1994, 2011;

Park et al 2010;

Yim et al., 2008

Kaleka, 2002.

Jayachandran et al, 2004;

Morgan et al, 2009a; Chen,

2012;

Xie \& Zheng, 2019;

Zhang et al, 2015; Claro \& Claro, 2010; Zhang \& Chen, 2008

$\mathrm{Mu}, 2015$

Walter et al 2006; Chen et al, 2009; Zhang et al, 2015 
We have the ability to build good personal relationships with business partners.

We can put ourselves in our partners' position.

We can deal flexibly with our partners.

We almost always solve problems constructively with our partners.

Partner knowledge:

We know our partners' markets.

We know our partners' products/procedures/services.

We know our partners' strengths and weaknesses.

We know our competitors' potentials and strategies.

\section{Product development capability}

8.1. Product development

Morgan et al, 2009; Kemper et

Ability to develop new products/services

Developing new products/services to exploit R\&D investment

Successfully launching new products/services

Ensuring that product/service development efforts are responsive to customer needs

New product launch capability

Ability to speedily introduce new products to market

Access to a wide distribution network for new products

Ability to develop creative marketing strategies for new products

Ability to invest significant resources in marketing new products

Speed of new product implementation

Product differentiation

This firm's product offers some unique features or attributes to the customer.

al 2011

This firm's product provides a higher quality than other competing products.

This firm's product provides a better design than other competing products.

This firm's product permits a customer to do a job or do something s/he could not do with what was available.

\section{Marketing digitalization capability}

Internet usage for:

Online marketing and advertising

Online after sales service and support

Market research

Management of international market

Exchange of operational data with suppliers

Exchange of operational data with business customers

Sales 


\section{CHINA'S RACE LEADERSHIP IN ARTIFICIAL INTELLIGENCE}

\section{Marina Reshetnikova, RUDN University (Peoples' Friendship University of Russia)}

Abstract. The purpose of the article is to evaluate the main innovative determinants that influence the acceleration of China's leadership in AI and assess by what positions this leadership has become real. The author conducted a comparative analysis according to two criteria to access China's innovative potential: AI talents and hardware base. This analysis has provided a conclusive answer to the question about the prospects of China to achieve the position of a scientific and technological superpower. Based on the presented analysis the author concludes that competition in global AI has toughened and there is a certain lag in the competence of Chinese AI talents and in the development of breakthrough microelectronic technologies. However, the dynamics of the Chinese AI sector growth and the Big Government legal actions indicate that the changes may come very soon. The originality of the article is that it has proved that due to the growing uncertainty and technological confrontation, the victory in the global race for China's AI sector may not take place.

Keywords: China, AI, competitive innovation, $R \& D$.

JEL code: O020, O030

\section{Introduction}

On July 8, 2017, at the Meeting of the State Council of the People's Republic of China, a national strategy for the development of technology was approved, which includes the "Program for the Development of Artificial Intelligence of a New Generation" (New Generation of Artificial Intelligence Development Plan, State Council Document, 2017). For the first time at the state level, it consolidates the country's development strategy as a "scientific and technological superpower", the decisive condition for the implementation of which is China's world leadership in the development of artificial intelligence.

The PRC government expects a lot from the development of technologies in the field of artificial intelligence. First of all, the recovery of entire sectors of the economy after the COVID-19 pandemic (Chen, Marvin et al., 2020).

The consistent implementation by the Chinese government of the strategy for the development of artificial intelligence has determined its rapid entry into the world race for leadership. Today, the Chinese sector of artificial intelligence has come close to the United States, the main player, and has overtaken it in some positions (O’Meara, 2019). China's decisive trump cards in this battle are unprecedented government funding and a huge amount of data generated by Chinese users (Reshetnikova, 2020). The problems that hinder his leadership remain unchanged. The first is the number and level of scientific and practical competencies of the pool of specialists. The second is lagging behind in breakthrough microelectronic technologies. There is an understanding in China that without overcoming the problems in these innovative determinants, leadership cannot be achieved. The result was the transformation of China's state strategy for the development of artificial intelligence.

The aim of this work was to analyse this transformation and assess the implications of its implementation for the development of the artificial intelligence sector in China.

\section{Literature Review}

The main focus of modern innovation is the development of AI. The undisputed leader in citation is the book of the former president of Google China Kai Fu-Lee "AI Superpowers: China, Silicon Valley, and the New World Order" dedicated to the development of the AI sector in China (Demchak, 2019). In this book the author presents an analysis of the current state of the Chinese AI. The main outcome from this study is that China has already outstripped the United States in AI development.

The response to the work of Kai Fu-Lee was an equally significant study of the English innovator Jeffrey Ding "Deciphering China's AI dream" (Ding, 2018). It details the milestones in China's AI sector. The analysis of the state strategy, methods and actions of the Chinese government, which ensured the rapid development AI, is carried out. J. Ding mainly analyses the problems and miscalculations in the Chinese innovation strategy.

Both presented works, due to the significant amount of statistical material, are of great interest for studying the Chinese experience in developing state innovation strategies. However, according to the author, both studies suffer from a certain subjectivity. In addition, their conclusions and statements by 2020 are not entirely relevant. The development of the world economy is so uncertain and rapid that significant changes in the global paradigm are already happening. That is why it is important to analyse the transformation of China's strategy aimed at overcoming the problems that hinder the development of national AI. 


\section{Research results and discussion}

\section{Artificial Intelligence - China's New Area of International Competition}

Based on the international practices of innovation leaders, Beijing decides to transform its innovation strategy towards the development of AI technologies, as the main driver of the national economy. It is expected that this will enable China to significantly improve its position in the global market by increasing its position in the division of labour.

Adoption of the "Program for the Development of Artificial Intelligence of a New Generation" in 2017 is the main milestone document in China's struggle for leadership in AI. It defines the strategic goals, the timing of their achievement, presents the bureaucratic mechanism of work and funding.

It is clear that the Government's decision to include China in the race for leadership in a new area of international competition has found inspired support in Chinese business. By the beginning of the first half of 2020, the explosive growth of the Chinese AI sector reached the level of $\$ 29.5$ million, which corresponds to a 10-fold increase in the industry in just 3 years. And this is against the background of the problems in the global economy caused by the pandemic (iiMedia Research Group,2018). The reason for such a large-scale success in the development of Chinese AI lies, according to the author, in the unique state support. In addition to the previously mentioned Program, the Ministry of Industry and Informatization has issued a "Three-Year Action Plan to Promote the Development of the Next Generation Artificial Intelligence Industry." The document of the Ministry of Science and Technology of the PRC echoes it, in which a list of 13 technological projects that ensure the development of the technological base of the AI sector is highlighted at the legislative level (Three-year AI development plan, 2018).

Since 2018, research and development in the field of AI has been among the 6 national priorities for the development of the Chinese economy. This provides government funding on an unprecedented scale. The author concludes that such a combination of these two strategic factors in the innovation sector in China is observed for the first time since the NIS reforms in the 2000s.

\section{AI Development factors in China}

The NIS reform implemented by the Chinese government in the 2000s was certainly very effective and successful (Zhou, Liu, 2016). However, its implementation took almost 10 years. Today there is simply no such time reserve. Modern innovative strategies must be succinct and specific, which allows a quick achievement of the desired result. And this, according to the author, is taken into account by innovative consultants in the Chinese government. That is why the innovative strategy for the development of the Chinese AI sector very specifically sets the circumstances of the movement towards world leadership in this area.

China obviously understands that in order to win the modern innovation race, it is necessary to provide sustainable leadership in the following innovation factors:

- fundamental research that forms the theoretical basis;

- applied developments (number of patents);

- the number and quality of AI talents;

- the modern AI ecosystem and related industries.

The concretization of the innovative strategy for the AI development has brought its results. By the end of 2019, this sector of the Chinese innovation system is leading both in the number of conducted research and in the registration of intellectual property rights (SCMP Research, 2020).

The development of the AI business ecosystem and related industries is also favorable. The government has identified technology giants that dominate the AI market and are affiliated with government agencies. Today there are four major donor companies. These are Baidu (self-driving vehicles), Alibaba (smart cities), Tencent (computer vision for medical diagnostics) - the so-called BAT group in China, and a fairly young company iFlyTek (voice assistance) (Tencent AI Lab, 2020). Companies are provided with unprecedented financial support from state program funds. These funds can only be spent on M\&A and further development of AI startups. The Ministry of Industry and Technology alone allocated practically $\$ 978$ million for these purposes in 2019 (SCMP Research, 2020). Thanks to such a large-scale financial support, donor companies, massively absorbing startups, have the opportunity to practically immediately implement their developments in various products and services in the field of artificial intelligence, regardless of the prospects of success (Altenburg et al., 2008)

However, today, this is the only example in the Chinese AI of successful combination in quantitative and qualitative research indicators. In other areas, according to the author, China is playing a cruel joke with excessive adventurism, lack of training of specialists (development and creation of algorithms), unresolved problems with applied developments, primarily in microelectronics (lack of national chips), and hobby for 
scaling. However, these problems are quite traditional for the development of the NIS of the PRC (Reshetnikova, 2018). And if adventurism is an invariable national trait, then the last two can be eliminated.

\section{Resolving AI Talents problems}

The Chinese government's innovative strategy to accelerate the AI development has yielded results (Wang, 2017). By the beginning of 2020, the pool of Chinese specialists in terms of the number of people employed in AI came close to the pool of the closest competitor of the United States and amounts to 2.8 million people (Roberts, Cowls et al., 2020).

Their scientific and practical competences have also significantly increased. China's breakthrough leap in registration of intellectual property rights for AI developments is a clear evidence for it. In 2019 alone, the country filed 30 thousand patent applications on artificial intelligence, which is 2.5 times more than the same indicator in the United States (Table 1).

Table 1

AI patents obtained in China by inventive activity

\begin{tabular}{|c|c|c|c|}
\hline Patents obtained by inventive activity & 2015 & 2017 & 2019 \\
\hline Total patents & 10890 & 12740 & 30000 \\
\hline Invention patents & 220 & 294 & 600 \\
\hline Utility Model Patents & 6050 & 6985 & 16500 \\
\hline Design patents & 4620 & 5461 & 12900 \\
\hline
\end{tabular}

However, the scientific value of the Chinese wave of AI research is not great; among the patents filed, $87 \%$ are for utility models and industrial designs, and only $2 \%$ for basic research (Table 1 ).

According to the calculations of the Ministry of Industry and Informatization of the PRC, about 5 million specialists are needed to successfully solve the tasks set for the AI sector (Reshetnikova, 2020). To achieve this goal, since 2018, the Ministry of Science and Education has launched university training programs in AI at 35 universities. More than 40 universities have introduced training in programs related to the AI sector, such as robotics and big data technologies.

The practice of attracting foreign specialists to improve the scientific competence of the national innovation sector started in 2008 , with the launch of the program of the State Council of the People's Republic of China "Thousand Talents". Based on it, high-class foreign scientists can move to the country without bureaucratic formalities (Wu, Huang, Gong, 2020). They receive research space and funding in the form of government grants, which can amount to 1 million yuan.

According to the author, this reversal of the "open door" strategy is caused by the desire of China, using the achievements of world science, to accelerate the development of national research. Modern research, primarily in the field of AI, requires a very expensive analytical and research network makerspace and a high scientific level of the staff. It is not possible to quickly solve this problem. Despite all the financial and political efforts of the government and private business in China, by 2018 only 8 makerspaces are functioning, equipped with the Fablab research complex, which is part of the global research analytical network and whose results are accepted by the world scientific community (Perrault, Shoham et al., 2019).

As expected by the Chinese government, the implementation of the presented transformation strategy for solving the personnel issue was supposed to help the Chinese AI sector overcome the lag in the level of AI talents.

\section{Chinese microchip is the fastest in the world}

For the technological success of the Chinese AI sector, it is equally important to overcome the lag in fundamental technologies, primarily in microelectronics, namely in the development of the semiconductor base.

By the beginning of 2019 , the Chinese industry produced only $16 \%$ of the consumed chips and microcircuits, and only half of them were produced by national companies located in the country. The dependence of the Chinese AI sector on imports of foreign components, mainly American ones, is extremely high.

It is obvious that the Chinese government hoped to continue to use the achievements of innovative leaders. However, the tightening of competition in the AI technology market, which began with the arrival of President Trump in the White House, introduced significant complications to the Chinese import of high-tech components.

The situation with China's leading AI companies ZTE and Huawei showed Beijing how dangerous dependence on foreign technology is in the modern world. 
To implement it, the State Investment Fund was created under the Ministry of Industry and Informatization of the PRC to support Chinese manufacturers of chips and microcircuits. By the end of 2019, it had already accumulated over $\$ 31.5$ billion. The costs of implementing the subprogram for the development of the AI element base by 2025 should approach $\$ 140$ billion (Fig. 1).

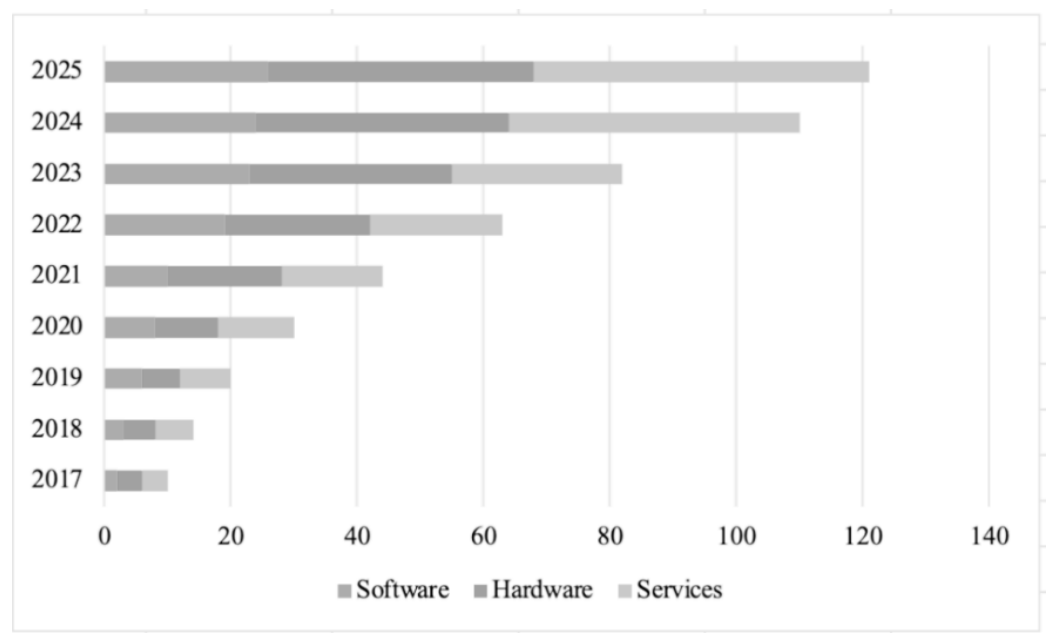

Source: author's construction based on China AI Report 2020. Retrieved 13.10.2020 from https://www.scmp.com/china-ai-report

Fig. 1. Government spending on the production of microcircuits for the AI sector in China, by areas, \$ million

Government support for chip developers and manufacturers does not only cover direct funding. Tax incentives and administrative preferences provided to them are also important. This has already yielded results. By the beginning of 2020, almost a third of the world's technological startups in the field of AI with a capitalization of more than $\$ 1$ billion are operating in China. This list is headed by the already mentioned three BAT.

Borrowing tactics remain another element of China's state strategy for developing a technological base. Namely, encouraging national companies to merge and take over foreign market participants.

With government support, Baidu has established three research centers in Silicon Valley in the United States. Tencent has set up an AI research center in Seattle. The author is interested in the fact that the government of China is financially present in all these centers, being the owner of 5 to 9\% of their capital. Research by the Rhodium Group has shown that the growth of Chinese venture capital investments in the US technology sector in five years exceeded more than 100\% from \$ 316 million in 2013 to \$ 3.1 billion in 2018 (Rhodium Group, The US-China Investment hub, 2020).

This is the current strategy of Beijing in the direction of overcoming the lag in breakthrough fundamental technologies, primarily in microelectronics, namely in the development of the semiconductor base. It is expected that its successful implementation will allow the national AI sector to become a world leader.

\section{Conclusions, proposals, recommendations}

Today it is more clear than ever that the end of the Cold War ended not only the confrontation between the two social systems of capitalism and socialism Executive order on maintaining American leadership in artificial intelligence. There has been a change in the entire world economy, due to the development of a catch-up development trend in it. A number of peripheral states have successfully implemented this strategy. It allowed them to quickly achieve economic growth through the industrialization of national industries. The countries, innovative leaders, who moved environmentally harmful and not modern production from their national territories were also not at the loser. At the same time, their dominance in the high-tech sector remained.

China is the main winner in the implementation of the catch-up development strategy. In a historically short period of time, from a backward country in which life expectancy did not exceed 40 years, it developed into the second largest economy in the world, while remaining in the shadow of innovative leaders.

Now this shadow weighs on China. It no longer wants to be a global factory. Today, the development strategy of its economy - the state of "scientific and technological superpower" will provide the leadership in the AI development. Consistently implementing, since 2017, the state strategy for the development of a new generation of artificial intelligence, Beijing confidently took the second place in the level of AI development, behind only the United States (Executive order on maintaining American leadership in artificial intelligence, 2019). 
Competition in the innovation market is getting tougher. This explains the actions of the two world giants: increased protectionism in the domestic market in China and the growth of prohibitive measures against Chinese companies in the United States. The world is again on the verge of a cold war. Only now the confrontation lies not in the plane of politics, but in the success of the development of high technologies.

\section{Bibliography}

Altenburg, T., Schmitz, H., Stamm, A., 2008. Breakthrough? China's and India's Transition from Production to Innovation. World Development, 36, 325-344, 10.1016/j.worlddev.2007.06.011.

Chen, B., Marvin, S., While, A., 2020. Containing COVID-19 in China: AI and the Robotic Restructuring of Future Cities. Dialogues in Human Geography, 10(2), 238-241. DOI: 10.1177/2043820620934267

Cho, A., 2016. 'Huge leap forward': Computer that mimics human brain beats professional at game of Go. Science, doi:10.1126/science.aae0281.

Demchak, C., 2019. Four Horsemen of AI Conflict: Scale, Speed, Foreknowledge, and Strategic Coherence. In AI, China, Russia, and the Global Order: Technological, Political, Global, and Creative Perspectives (A Whitepaper), edited by D. Nicolas and Wright, 94-101. Washington DC: Department of Defense, A Strategic Multilayer Assessment (SMA) Periodic Publication. December, chapter 13. https:// nsiteam.com/social/wpcontent/uploads/2018/12/AI-China-Russia-Global-WP_FINAL.pdf.

Ding, J., 2018. Deciphering China's AI Dream. Future of Human University, University of Oxford, March 2018. Available at: https://www.fhi.ox.ac.uk/wp-content/uploads/Deciphering_Chinas_AI-Dream.pdf. [Accessed: 01.09.2020].

O’Meara, S., 2019. China's Ambitious Quest to Lead the World in AI by 2030. Nature, 572, 427-428 doi: https://doi.org/10.1038/d41586-01902360-7.

New Generation of Artificial Intelligence Development Plan, State Council Document [2017] No. 35 State Council July 8, 2017. Available at: http://www.gov.cn/zhengce/content/2017-07/20/content_5211996.htm [Accessed: 01.09.2020]

Perrault, R., Shoham, Y., Brynjolfsson, E., Clark, J., Etchemendy, J., Grosz, B., Lyons, T., Manyika, J., Mishra, S., Niebles, J.C., 2019. The AI Index 2019 Annual Report, AI Index Steering Committee, Human-Centered AI Institute, Stanford University, Stanford, CA, December 2019.

Reshetnikova, M., 2018. Innovation and Entrepreneurship in China. European Research Studies Journal, 21(3), 506-515.

Reshetnikova, M. S., 2020. China's AI experience: industrial digitalization. RUDN Journal Of Economics, 28(3), 536-546. doi: 10.22363/23132329-2020-28-3-536-546.

Rhodium Group, The US-China Investment hub Available at: https://www.us-china-investment.org/fdi-data [Accessed: 01.09.2020].

Roberts, H., Cowls, J., Morley, J., Taddeo, M., Wang, V., Floridi, L., 2021. The Chinese Approach to Artificial Intelligence: an Analysis of Policy, Ethics, and Regulation. AI \& Society, 36, 59-77, https://doi.org/10.1007/s00146-020-00992-2.

SCMP Research, 2020. China AI Report 2020. Available at https://www.scmp.com/china-ai-report [Accessed: 01.09.2020]

Special Report on China's Artificial Intelligence Industry. iiMedia Research Group. Available at: http://www.sppm.tsinghua.edu.cn/eWebEdito r/UploadFile/China_AI_development_report _2018.pdf [Accessed: 01.09.2020]

State Council, Decision of the State Council on Accelerating the Cultivation and Development of Strategic Emerging Industries, No. 32, Beijing, 2010 .

Tencent AI Lab. Technological ethics at intelligent era-reshape trustworthiness in digital society [Internet]. Beijing: Tencent Research Institute; 2019 Jul 8 [cited 2020 Dec 1]. Available from: https://tisi.org/10890. Chinese.

Trump, D.J. 2019. Executive Order on Maintaining American Leadership in Artificial Intelligence [Internet]. Washington, DC: The White House; 2019 Feb 11 [cited 2019 Dec 18]. Available from: https://www.whitehouse.gov/presidential-actions/executive-order-maintaining-americanleadership-artificial-intelligence/. [Accessed: 01.09.2020]

Wang, Z., 2017. The Economic Rise of China: Rule-Taker, Rule-Maker, or Rule-Breaker? Asian Survey, 57(4), 595-617. DOI: https://doi.org/10.1525/as.2017.57.4.595.

Wu, W., Huang, T., Gong, K., 2020. Ethical Principles and Governance Technology Development of AI in China. Engineering. 6(3), 302-309, https://doi.org/10.1016/j.eng.2019.12.015.

Zhou, Y., Liu X. 2016. Evolution of Chinese State Policies on Innovation Y. Zhou, W. Lazonick, Y. Sun (Eds.), China as an Innov. Nation, Oxford University Press, Oxford, pp. 33-67, 10.1093/acprof:oso/9780198753568.003.0002 


\section{MARKET INTEREST RATES, CAPITAL STRUCTURE - AND ZOMBIFICATION? Andreas Rams, University of Latvia}

Abstract. The discussion on a - possibly - optimal capital structure for companies started in 1958 with a ground-breaking paper by Modigliani and Miller. Since then, there have been many contributions to the discussion of capital structure that shed light on possible interactions with various parameters of companies or their environment. This paper also falls into the category of the capital structure debate; in particular, it addresses the relatively new issue of the potential influence of macroeconomic variables, in this case interest rates.

Especially since the financial and economic crisis of 2008/09, market interest rates have fallen in important economic regions of the world. This is mainly - but not only - attributed to the expansionary monetary policy of many central banks. This article examines the question of whether the described decline in debt financing costs has noticeable effects on the financing decisions of companies and thus in particular on their capital structure. Along with increased indebtedness, there could also be a fundamental danger that companies ultimately become increasingly dependent on low interest costs. A corresponding discussion speaks of a possible zombification of parts of the economy. The danger of a possible zombification is also currently being discussed due to the expansive low interest rate policy in the wake of the economic effects of Covid 19 and the countermeasures of the central banks.

This paper takes up the question of a possible interaction between market interest rate levels and corporate capital structures and examines it with a simple empirical approach. On the one hand, the development of the 10-year market interest rate in Germany from 1997 to 2017 is examined. Secondly, the development of specific capital structure indicators in two sectors of the German economy, mechanical engineering and the automotive industry, is examined against the background of the relevant changes in the market interest rate level. Due to the lack of availability of more recent figures, possible Covid 19 follow-on effects cannot yet be considered.

The empirical regression analysis then used in this paper shows on the one hand that changes in interest rates are accompanied by trends in the development of the selected capital structure indicators. On the other hand, however, these trends are not strong and not unambiguous. From this it could be comprehensibly concluded that other factors besides the development of interest rates must be considered in the explanations of the development of capital structures - as was to be expected. On this basis, there is room for further research on the strength and direction of the correlation effect in question - with the inclusion of other factors.

Keywords: capital structure, interest rate, financial policy, capital cost, zombie companies.

JEL code: G32, G33, G35

\section{Introduction}

The aim of this paper is to make an empirical contribution to the discussion on corporate capital structure. It further focus es on the relatively new research area of incorporating macroeconomic factors into the capital structure debate. Specifically, it examines whether the long-term decline in market interest rates is associated with changes in the capital structure of firms. The question is whether, against the background of a falling interest rate level, there will be a sustained shift and concrete deterioration of relevant capital structure indicators in the direction of higher debt. It is sometimes feared that a further consequence could then be a sustained weakness of the economic sectors concerned. In the current discussion, this effect is sometimes referred to as a possible zombification of parts of the economy.

The discussion about the potentially optimal capital structure of companies is of continuing interest to financial theory and practice. Three different topics are examined in detail here - although individual other classifications are also possible:

(1) Is there a particular capital structure that lowers the cost of capital and increases the value of a company - and what is it?

(2) Is there an interaction between a company's capital structure decision on the one hand and its real investment decisions - and what is the relationship between the two?

(3) Is there an interaction between a company's capital structure and external variables in the macroeconomic environment - and how do they interact?

This paper focuses on the third of these issues. It examines whether the financial capital structure of companies changes against the background of falling interest rates in the market. This could be since - in connection with theme 1 - companies are seeking to reduce their cost of capital by using relatively more credit financing. Furthermore, the reduction of financing costs - in connection with theme 2 - could also result in adjusted investment decisions by companies. 
In discussing this topic, this paper will not understand capital structure as a mere debt ratio but will take into account the practical view of those responsible for corporate finance. Specifically, ratios are used that are also used in the rating analysis of companies and as dynamic debt clauses in financing agreements. In this introductory article, only two of the most important of the corresponding financial ratios are used: the debt/EBITDA ratio, which is widely used in practice, and the interest coverage ratio in the form of EBITDA/interest expense. The first of the two ratios relates a balance sheet figure to an income statement figure and the second shows the relationship between two income statement figures. It should further be noted that EBITDA as earnings before interest, taxes, depreciation and amortisation is very often considered as an approximation of cash flow (Rams 2020).

The applied empirical analysis looks at how, on the one hand, the interest rate level and, on the other hand, the named indicators for the capital structure of companies in Germany have developed in the period from 1997 to 2017. A simple regression analysis is used to examine whether there is a possible correlation between the variables in question. Finally, the derived results are evaluated and interpreted. The analysis in question focuses on two important sectors of the German economy: mechanical engineering and the automotive industry. Aggregated figures from the research of the Deutsche Bundesbank are used, which represent the relevant sectors with a coverage of over $90 \%$ of the respective companies. Due to the degree of aggregation of the figures used, individual adjustments must be made and explained in the course of the analysis.

\section{Literature Review}

The theoretical literature in the field of finance can already show a very active debate on capital structure theory. The same applies to macroeconomic approaches to interest rates and the associated interest rate and monetary policy. In this chapter, the literature on both theoretical areas will only be presented in a rough overview due to their actual size and breadth. In the following further analysis of this paper, both theoretical fields will then be linked.

Capital Structure Literature

The debate on capital structure began with the 1958 paper "The Cost of Capital, Corporate Finance, and the Theory of Investment" (Modigliani / Miller 1958) by Modigliani / Miller. There the capital structure was simply understood as the ratio of debt to equity. The question was considered whether and - if so - how this could be optimally structured for a company. Modigliani and Miller stated in a simplified way that the capital structure has no influence on the value of the company and accordingly has no influence on the actual decisions of the management. Modigliani and Miller further argued that the overall cost of capital would not change if relatively more debt was used. Higher debt portions would then increase the cost of equity due to the rising risk, so that the average cost of capital would remain unchanged. Modigliani and Miller therefore argued that the weighted average cost of capital of a company would remain constant regardless of the capital structure chosen.

The publication by Modigliani and Miller and the hypotheses presented in this paper were then discussed in detail by many researchers. Many comments criticised the very restrictive assumptions of the model presented, as they did not reflect the realities of the financial and real markets. In fact, the model world of Modigliani and Miller employed in their first approach is not real because they assumed a world without taxes, transaction costs, bankruptcy costs, an equivalence of the cost of borrowing for companies and investors and, finally, a symmetry of market information. With their approach, Modigliani and Miller initiated the very lively debate on capital structure, which still today provides much information on the possibly - optimal or at least better financing of companies.

A rough subdivision of the following discussions can be made into firstly trade-off approaches, secondly pecking order theory, and thirdly approaches that examine interactions of a company and its capital structure with the real world. The trade-off approaches mainly follow the idea that the capital structure can be used to enhance the value of a company by optimizing the cost of capital. Accordingly, the possible advantages and disadvantages of financing with equity or debt capital or a mixture of both are considered. It is generally assumed that the choice between these two poles in fact is not irrelevant. The corresponding advantages and disadvantages are conclusively derived from the real situation of the financial markets once the restrictive assumptions of the neoclassical approach of Modigliani and Miller are deviated from. The focus of the argument is on the possible effects of taxes on the one hand and insolvency risks on the other. Later, Modigliani and Miller themselves explained that there could be an influence of the capital structure on the value of a company because of the imperfections in the financial markets - especially the taxes (Modigliani / Miller 1963). A tax advantage of debt financing results from the fact that interest on debt reduces the tax base. On the other hand, dividends paid to the company's equity investors are taxed in full. This would lead to a higher company value in the case of companies financed by both equity and debt, as the tax burden would be reduced, and more capital could be distributed to shareholders. 
It should be borne in mind that a - higher - level of indebtedness is also associated with an increase in the risk of insolvency. Baumol and Malkiel (Baumol / Malkiel 1967) showed in this context that there is after all an optimal capital structure, which is then justified as a trade-off between tax savings and insolvency risk. On the one hand, indebtedness leads to a lower tax burden for companies and thus to an increase in the value of the company. On the other hand, however, a rising debt ratio increases the probability of insolvency of the company concerned. As a result, a capital structure is optimal if the marginal tax advantage corresponds to the marginal insolvency costs (Castanias 1983).

Pecking-order approaches are based on a work by Myers and Majluf (Myers / Maljuf 1984), which deals with the phenomenon of information asymmetries between internal managers and external investors. Here it is generally assumed that the main purpose of a chosen or developed capital structure is not primarily to maximise the value of the company. According to the pecking order argument, external investors are considered less well informed than internal managers. The approach of Myers and Majluf focuses specifically on the question of the signal function of an (equity) capital increase against contributions and the interactions between investment and financing decisions that can be derived from this. If a company needs additional external capital, it first takes out low-risk loans; only then does it take out riskier loans. Equity capital comes last in this preference. The pecking order theory does not provide any indication of an optimal capital structure that can maximise the value of the company, but only reflects preferences regarding the financing structure. In addition, Myers and Majluf also show that a company that has sufficient financing possibilities can realise more profitable projects and thus generally operate more successfully. If the internal financing is not sufficient to invest in a promising project, debt capital is used (Shyam-Sunder / Myers 1999).

The approaches to pecking order presented here already consider some of the interactions between a company and the real world around it. Accordingly, they do not assume that questions of capital structure are not only financial questions. Other approaches in this direction focus on a possible (cause-and-effect) relationship between the capital structure and the real world around a company. On the one hand, the choice of capital structure could influence the activities of a company, its investments, the market measures taken, the cost efficiency achieved and others (Kochar / Hitt 1998). On the other hand, different strategic decisions of a company may also require different capital structure decisions (Lowe / Naughton / Taylor 1994). As further examples of the relevant possible interactions of the capital structure with the real environment of a company, the work of Campello (Campello 2003), Abor (Abor 2005) and Jensen, Solberg and Zorn (Jensen / Solberg / Zorn 1992) are to be mentioned here. Campello's paper shows that debt financing can, under certain circumstances, have a negative impact on the profit growth of a company. Abor notes in his paper that the success of a company decreases with its debt. However, Jensen, Solberg and Zorn come to the exact opposite conclusion. In general, it can be said that different approaches to illuminating the interaction between capital structure and the real environment - depending on the premises and direction of the analysis - can lead to quite different results. Thus, for researches it is crucial to choose and remember their assumptions carefully and change them in the course of their research work.

Interest Rates Literature

The so-called classical and neoclassical view and its successors in further research assume that such an effect does not exist (Friedman 1951; Friedman 1972; Cas 2016). Advocates of the interdependence of the financial and real economy sometimes argue that the financial sector influences the real economy - or vice versa (Conrad 2020; Bernanke 2020). Indeed, the - possible - effects and interactions of the financial sector with the real economy are very complex. A detailed discussion of alternative theoretical approaches to macroeconomics is not and cannot be the aim of this paper. The analysis presented here simply follows the view that there is - or can be - an interaction between the financial and the real economy.

The narrower focus of further consideration here is then on selected literature on the development of interest rates, reasons for this - and possible consequences. For example, a recent study by the Bank of England (Schmelzing 2020) shows that interest rates have fallen continuously since the $13^{\text {th }}$ century. In the context of the analysis of possible explanations for the decline in market interest rates, a study by the Institut der Deutschen Wirtschaft (Demary / Voigtländer 2018; further: Marx / Mojon / Velde 2019) focuses on the real interest rate. It also examines the interest rate between the savings and investment decisions to be taken on the market. Consequently, this tends to be at least a medium-term interest rate. Five alternative explanations for the fall of interest rates are given in detail:

- The first explanation for the fall in market interest rates is the "global money supply hypothesis". According to this hypothesis, the desired savings globally exceed the planned investments. As a result, the market interest rate would fall.

- Second, the secular stagnation hypothesis states that lower interest rates result from lower investment, which in turn is due to declining population growth, lower capital intensity and a further decline in the relative price of capital goods. 
- Third, the scarcity hypothesis for secure assets considers a divergence between the supply of and demand for relatively secure assets. According to this hypothesis, the growing demand for safe assets, combined with a limited supply of safe assets, reduces the returns on safe assets and thus interest rates.

- Fourthly, it is argued that demographic change combined with increasing life expectancy will lead to lower interest rates. The explanation for this is that higher life expectancy requires a higher savings rate because a longer retirement age has to be financed.

- Fifthly, the growing demand by firms for relatively more intangible than tangible assets will lead to falling investment costs. As a result, market interest rates would fall because demand for capital is lower than supply.

The five hypotheses presented here share the view that savings on the one hand and investments on the other are compensated by the resulting market interest rate. The market interest rate is then the result of the respective compensation. Obviously, the real interest rate besides the financial world interacts with the changing market interest rate.

In addition to the considerations presented here to justify falling interest rates, the active interest rate policy of central banks must also be considered. Many central banks actively use interest rate and - in a broader sense - monetary policy with the intention of influencing the real economy. Raising policy rates and tightening market liquidity should then slow down an overly active economy. Conversely, lowering policy rates and expanding market liquidity should stimulate the economy. This latter variant of expansionary monetary policy has dominated markets in the world's major economies at least since the financial and economic crisis of 2008/09 (Kiley / Roberts 2017; Kiyotaki, N. / Moore, J., 2019). Even against the backdrop of Covid 19, many central banks have relied on expansionary monetary policy to be able to provide the economy with sufficient and cheap liquidity.

The further investigation in this paper will examine the question of whether, in addition to the possible positive macroeconomic effects, a creeping shift in the capital structures of companies towards higher indebtedness can occur on the basis of a sustained low level of market interest rates.

\section{Research, Results and Discussion}

1. Research approach

Looking at the literature on capital structure and that on the interest rate level side by side, the macroeconomic variable interest rate level can also be considered as one of the external factors with which the capital structure could interact. In principle or predominantly, it is assumed that the interest rate level has an influence on companies or - due to an active interest rate policy - should have a certain influence.

In this context, this paper will now examine whether certain indicators of the capital structure change over time with the change in the market interest rate level itself. The focus is on a dynamic view of the capital structure using the indicators of the dynamic leverage ratio ("(net) debt / EBITDA") and the interest coverage ratio ("EBITDA / interest") (Rams 2018). It should again be noted that EBITDA as earnings before interest, taxes, depreciation and amortisation is very often considered as an approximation of cash flow. Then, the more traditional ratio of capital structure as debt / equity is also analysed. With reference to the analyses of rating agencies, rating grades can also be assigned to the characteristics of these ratios as an indication:

\begin{tabular}{|c|c|c|c|c|c|c|c|c|}
\hline $\begin{array}{l}\text { Standard \& Poors Peer-Group Industrial, long-term debt } \\
\text { Source: S\&P }\end{array}$ & AAA & AA & A & BBB & BB & B & $\operatorname{ccc}$ & CC-D \\
\hline \multicolumn{9}{|l|}{ Standard \& Poors Financial Ratios } \\
\hline EBITDA interest coverage $(x)$ & 25,5 & 24,6 & 10,2 & 6,5 & 3,5 & 1,9 & 0,9 & \\
\hline Total debt/EBITDA $(x)$ & 0,4 & 0,9 & 1,6 & 2,2 & 3,5 & 5,3 & 7,9 & \\
\hline Total debt/capital (\%) & $12,4 \%$ & $28,3 \%$ & $37,5 \%$ & $42,5 \%$ & $53,7 \%$ & $75,9 \%$ & $113,5 \%$ & \\
\hline
\end{tabular}

Fig. 1. Quantitative Rating Figures (Rams 2018)

The financial ratios presented here require a brief discussion. Based on the analyses of the rating agencies, these - among other - ratios are essential indicators for the credit rating of companies. The ratio of EBITDA to interest shows the carrying capacity of a company's interest burden based on its own earning power; indirectly, it also addresses the overall repayment capacity. The (net) debt / EBITDA ratio shows the theoretical debt repayment period based on both incoming values - and thus again the debt sustainability of a company. The debt / capital ratio shows the share of the debt in the total capital of a company. Deviating from the Standard \& Poors presentation, the following analysis looks at the - equivalent debt / equity ratio, as this directly depicts the "traditional" capital structure.

Based on Standard \& Poors' analyses, Fig. 1 shows that 
1) higher EBITDA values in relation to the interest rate mean a better credit rating,

2) lower debt to EBITDA ratios mean better credit ratings, and

3) lower credit to capital ratios mean better credit ratings.

It is easy to understand that a falling interest rate relieves the burden on the companies concerned - for example, it can go hand in hand with an improvement in the EBITDA / interest ratio. However, the market is considering a situation in which the superficial favouring of companies through lower interest rates and possibly also more extensive liquidity offers could lead to a problem in the medium term. A situation in which the fall in interest rates then does not - any longer - stimulate companies, but instead makes them dependent and ultimately remain in economic weakness with too much debt, is sometimes metaphorically referred to as the zombification of the economy. An indication of this observation can be found in the situation in Japan in the years from the early 1990s to almost today (Caballero / Hoshi / Kashyap 2008). Similar assessments have recently been made for companies in the Eurozone, where expansionary monetary policy has prevailed since the last financial crisis in 2008/09 to stimulate the economy, but has not always been able to achieve the desired effect (Storz / Koetter / Setzer / Westphal 2017). Currently, there is growing concern that the continued expansionary monetary policy in the wake of the Covid 19 pandemic could accelerate the zombification of parts of the Eurozone economy.

The empirical study conducted here aims to consider possible long-term effects against the background of a persistently low interest rate level. It is based on research data from the Deutsche Bundesbank, using aggregated data that account for more than $90 \%$ of the financial data of companies in the affected industries. This data is now considered for the period from 1997 to 2017 in a time series of the rating-relevant indicators presented here. In addition to the development of the relevant indicators, the development of the 10 -year interest rate level is then also presented. On this basis, a simple correlation analysis is then carried out to determine whether a relationship could be established between the relevant variables. The two industries selected for this analysis are mechanical engineering and the automotive industry, both of which are very important in Germany.

A summary of the data employed looks like follows:

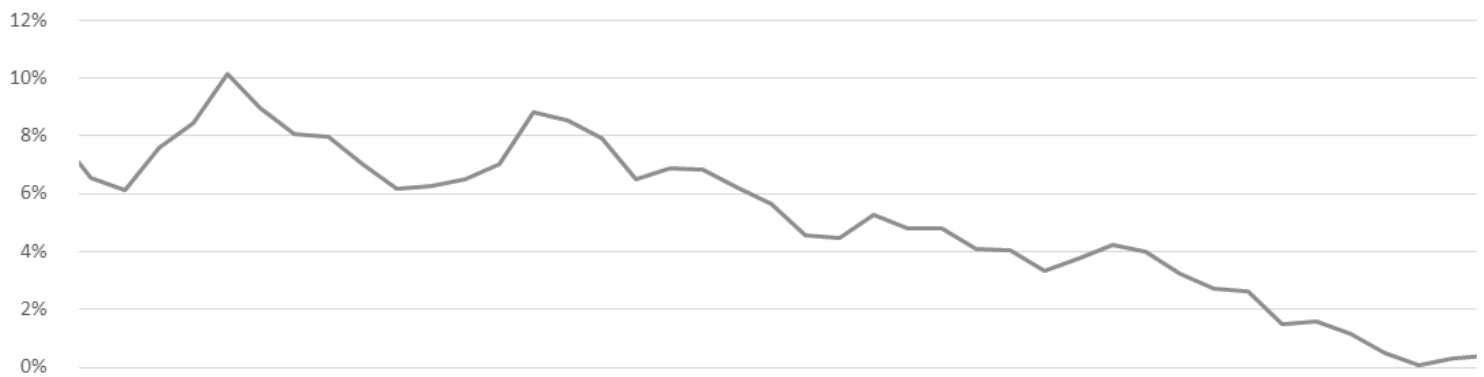

$-2 \%$

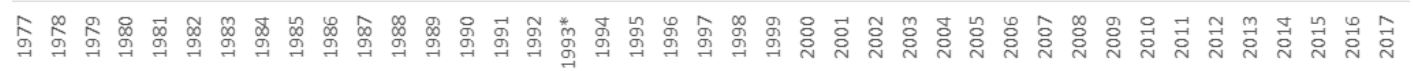

Fig. 2. 10y market interest rate in Germany (Source: Deutsche Bundesbank)

\begin{tabular}{|c|c|c|c|c|c|c|c|c|c|c|c|}
\hline & 1997 & 1998 & 1999 & 2000 & 2001 & 2002 & 2003 & 2004 & 2005 & 2006 & 2007 \\
\hline EBITDA & 13,0 & 14,6 & 13,6 & 15,4 & 15,1 & 14,6 & 13,0 & 14,7 & 16,3 & 20,5 & 24,4 \\
\hline EBIT & 8,3 & 9,4 & 8,7 & 9,9 & 10,0 & 9,2 & 7,9 & 8,2 & 11,1 & 15,0 & 18,8 \\
\hline Net Debt & 77,0 & 77,5 & 75,3 & 85,6 & 87,1 & 85,4 & 84,9 & 84,4 & 86,9 & 96,6 & 115,6 \\
\hline
\end{tabular}

\begin{tabular}{|c|c|c|c|c|c|c|c|c|c|c|c|}
\hline & 2007 & 2008 & 2009 & 2010 & 2011 & 2012 & 2013 & 2014 & 2015 & 2016 & 2017 \\
\hline EBITDA & 24,4 & 26,7 & 14,9 & 22,2 & 25,0 & 25,2 & 22,9 & 24,3 & 23,6 & 23,2 & 24,1 \\
\hline EBIT & 18,8 & 20,4 & 8,0 & 15,7 & 18,8 & 18,6 & 15,9 & 17,4 & 16,4 & 15,8 & 16,5 \\
\hline Net Debt & 115,6 & 125,2 & 112,3 & 117,1 & 120,9 & 122,8 & 122,4 & 125,9 & 135,4 & 129,2 & 150,5 \\
\hline
\end{tabular}

Fig. 3. Key financial figures 1997 to 2017 (selection) - machine engineering (Source: Deutsche Bundesbank) 


\begin{tabular}{|c|c|c|c|c|c|c|c|c|c|c|c|}
\hline & 1997 & 1998 & 1999 & 2000 & 2001 & 2002 & 2003 & 2004 & 2005 & 2006 & 2007 \\
\hline EBITDA & 42,6 & 52,7 & 49,4 & 54,1 & 55,1 & 56,1 & 53,0 & 54,5 & 56,8 & 66,1 & 85,1 \\
\hline EBIT & 33,7 & 43,1 & 39,0 & 42,9 & 41,6 & 45,0 & 39,0 & 40,7 & 43,0 & 50,7 & 70,2 \\
\hline Net Debt & 82,4 & 92,7 & 98,8 & 118,5 & 124,4 & 127,2 & 138,8 & 149,2 & 157,0 & 170,1 & 186,5 \\
\hline & 2007 & 2008 & 2009 & 2010 & 2011 & 2012 & 2013 & 2014 & 2015 & 2016 & 2017 \\
\hline EBITDA & 85,1 & 81,4 & 63,9 & 82,8 & 90,4 & 93,5 & 86,5 & 96,5 & 111,7 & 115,5 & 119,9 \\
\hline EBIT & 70,2 & 64,5 & 49,8 & 69,6 & 75,3 & 80,2 & 72,8 & 81,6 & 95,3 & 98,0 & 102,8 \\
\hline Net Debt & 186,5 & 210,0 & 210,9 & 216,7 & 237,2 & 250,3 & 268,6 & 284,2 & 320,0 & 335,0 & 378,0 \\
\hline
\end{tabular}

Fig. 4. Key financial figures 1997 to 2017 (selection) - automotive (Source: Deutsche Bundesbank)

2. Research results

In this section, the correlation determined from the input figures shown above - in the excerpt - is shown directly. It goes on to comment on which result could have been expected with regard to a sometimes feared zombification and what actually emerges.

Sector 1: machine engineering

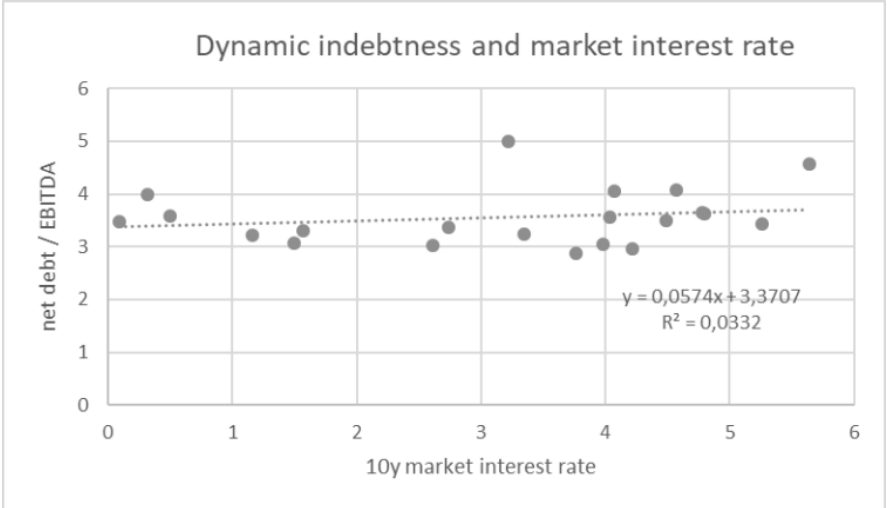

Fig. 5. Dynamic indebtness and market interest rates - machine engineering

The observation of the dynamic debt ratio is made here as the ratio of net debt to earnings before interest, taxes, depreciation and amortisation. In principle, it could be assumed that companies tend to - could - increase their debt against the background of falling interest rates. Based on the selected ratio, it cannot be confirmed here for the mechanical engineering sector that the dynamic debt ratio has increased. The derivable correlation is only very weak with a value of 0.05 ; in addition, there is also only a low value for the coefficient of determination. Nevertheless, it must be considered that in the industry in question, debt does not run away from profitability. The observation made here speaks against the feared zombification.

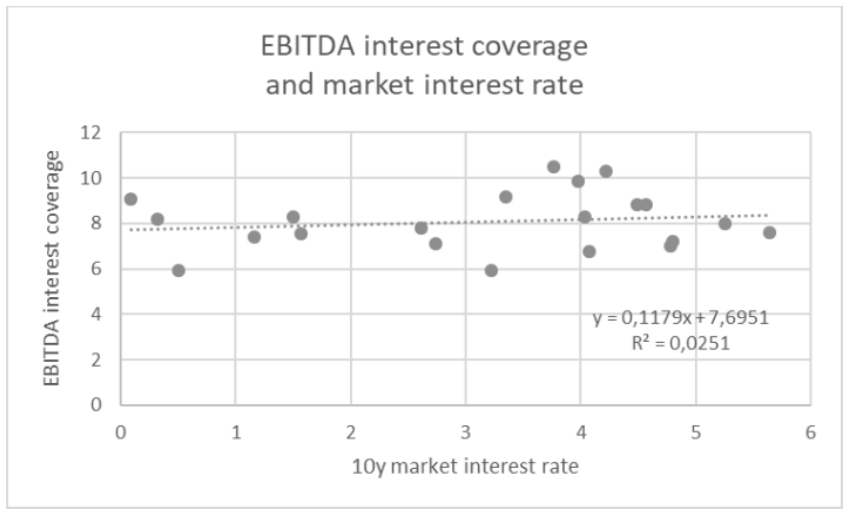

Fig. 6. EBITDA interest coverage and market interest rates - machine engineering

The EBITDA interest coverage ratio is considered here as the ratio of EBITDA to interest expense. Since interest expense is falling, the corresponding ratio could in principle show a falling trend. However, this cannot be confirmed here for the mechanical engineering sector. The fact that no increase in the ratio can be determined appears unexpected against the background of the interest rate reduction. Accordingly, the advantage of low interest rates may be compensated for by taking out more credit. It has already been shown that debt moves with the development of earnings power - EBITDA. 


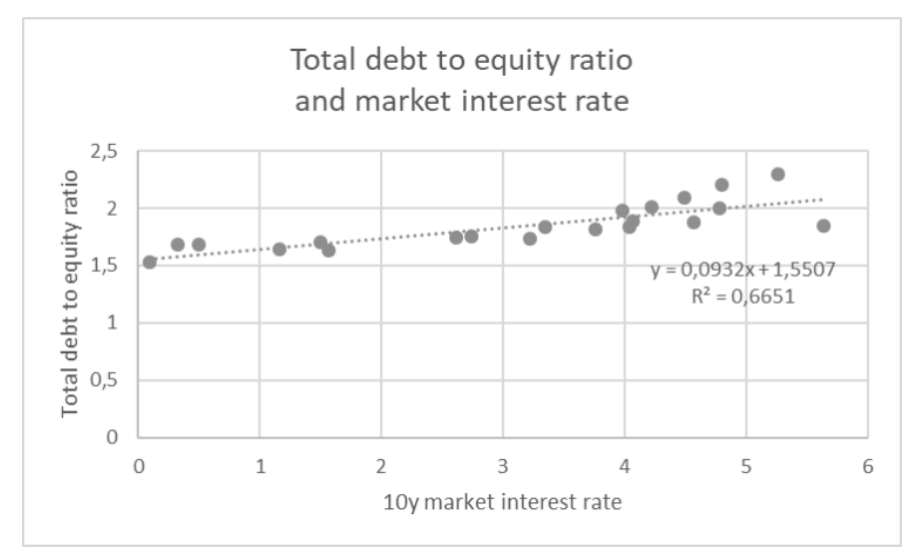

Fig. 7. Total debt to equity ratio and market interest rates - machine engineering

Regarding the total liabilities of the companies under consideration, according to the idea of zombification, it would be assumed that these increase in relation to the associated equity capital when interest rates fall. This effect occurs in the machine engineering sector considered here. However, to see zombification on this basis does not fit insofar as the debt - as has been shown - remains in a solid ratio to the earning power EBITDA. Interestingly, it may be noted that the correlation coefficient amounts to only 0,09 , but the coefficient of determination shows strong 0,66 .

Sector 2: automotive

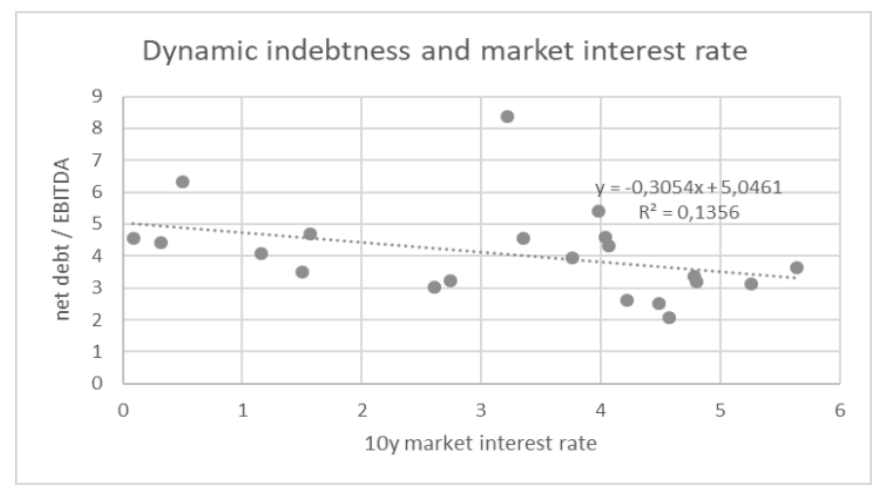

Fig. 8. Dynamic indebtness and market interest rates - automotive

In contrast to the case of the mechanical engineering sector, it can be seen here that falling market interest rates are accompanied by higher dynamic levels of indebtedness. However, the measure of certainty derived for this observation is not very strong. Nonetheless, it seems to be the case that together with falling interest rates the debt volume rises in relation to the EBITDA. The coefficient of correlation shows $-0,30$ and the coefficient of determination 0,13 .

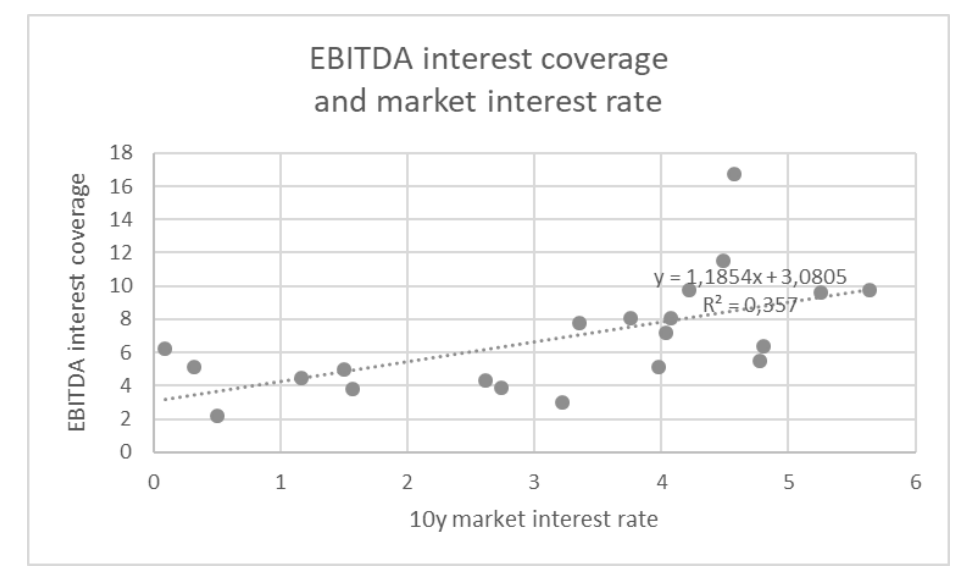

Fig. 9. EBITDA interest coverage and market interest rates - automotive 
In contrast to the case of mechanical engineering, it is clear here in the automotive sector that falling market interest rates are accompanied by lower interest coverage ratios - and vice versa. This indicates that profitability has fallen in tandem with falling interest rates. However, a causality does not appear to be directly justifiable. Whether this is a phenomenon of so-called zombification should be examined more closely in the context of further analyses.

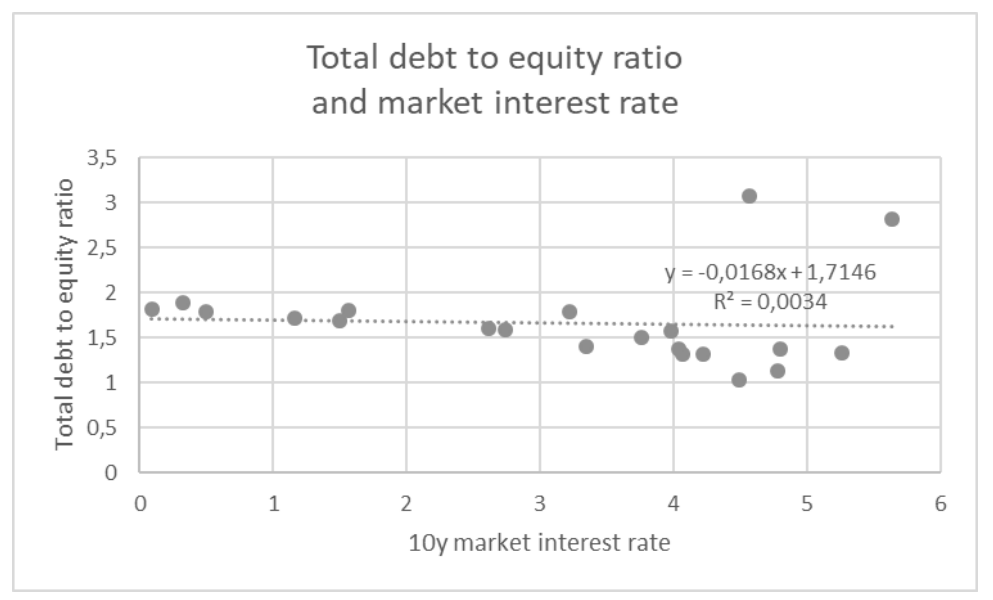

Fig. 10. Total debt to equity ratio and market interest rates - automotive

In the case of the automotive industry, the ratio of total debt to equity appears to be virtually independent of market interest rates. Accordingly, the companies concerned would not take advantage of the lower interest rate level to increase their debt in relation to equity. Thus, there could be no question of zombification - directly.

\section{Discussion}

The analysis carried out here of a possible correlation between key figures of the capital structure and changes in the market interest rate level does not show any clear effects in the mechanical engineering and automotive sectors considered. It should also be emphasised that the discernible effects differ in detail in both sectors. In particular, there is no evidence for the zombification sometimes assumed in the market as a result of the low interest rate level.

The analysis carried out shows that this is only an introductory and by no means conclusive statement. On the one hand, it must be taken into account that the industries were considered as an overall average. In the individual consideration of the companies, quite different effects can arise. Secondly, it must be taken into account that in the case of credit financing, since 2002 the regulation of Basel II and Basel III has successfully encouraged companies to strengthen their equity financing. Thirdly, it should be noted that since the financial and economic crisis of 2008/09 the German economy has developed very well in international comparison and shows no signs of weakness on average.

More detailed statements in the analysis pursued here are only possible if more key figures and more sectors are included in the analysis. In the sectors, the individual analysis of the companies should also be taken into account - at least additionally. Furthermore, more advanced statistical methods should be used beyond the simple regression analysis used here. Finally, international comparisons could also be useful.

Conclusions and Recommendations

The aim of this analysis was to investigate possible correlations between the change - the current decline - in the level of market interest rates and certain indicators of the capital structure of companies in the mechanical engineering and automotive sectors. To concretise the background, a review of the relevant literature was considered. The subsequent empirical analysis was conducted on the basis of aggregated industry data. The aim was to answer the question of whether the lower interest rate level leads to a weakening of the key figures of the companies considered over time, which could lead to so-called zombification. Contrary to expectations, no clear correlation between the development of the key figures of the capital structure and no sign of zombification could initially be found. In particular, however, there were also differences in the characteristics of the development of the key figures between the sectors considered. In summary, however, the introductory analysis conducted here seems well suited to justify further and more in-depth analyses on the topic under consideration. Of particular interest could be which of the ratios considered is best suited for looking at the understanding of the capital structure: the traditional rather static ones or the newer dynamic ones. The results were not clear in the comparison between the two approaches. 


\section{Bibliography}

Abor, J., 2005. The effect of capital structure on profitability: empirical analysis of listed firms in Ghana, Journal of Risk Finance, 6(5), pp. 438445.

Baumol, W./ Malkiel, B., 1967. The firm's optimal debt-equity combination and the cost of capital, Quarterly Journal of Economics, 81(4), pp. 547578.

Bernanke, B.S., 2020. The New Tools of Monetary Policy, American Economic Review, Vol. 110, No. 4, pp. 943-983.

Caballero, R. / Hoshi, T. / Kashyap, A., 2008. Zombie lending and depressed restructuring in Japan, American Economic Review, vol 98, no 5, pp 1943-77.

Campello, M., 2003. Capital structure and product markets interactions: evidence from business cycles, Journal of Financial Economics, Volume 68, Issue 3, pp. 353-378.

Castanias, R., 1983. Bankruptcy risk and optimal capital structure, The Journal of Finance, Vol. 38, No. 5, pp. 1617-1635.

Demary, M. / Voigtländer, M., 2018. Reasons for the Declining Real Interest Rates, Institut der Deutschen Wirtschaft, IW-Report 47/18, Köln, 2018.

Friedman, M., 1951. Comments on Monetary Policy., Review of Economics and Statistics, August 1951, pp. 186-191.

Jensen, G.R., Solberg, D.P., Zorn, Th.S., 1992. Simultaneous determination of insider ownership, debt, and dividend policies, Journal of Financial and Quantitative Analysis, Vol. 27, No. 2, 6/1992, pp. 247-263.

Kiley, M.T. / Roberts, J.M., 2017. Monetary Policy in a Low Interest Rate World, Brookings Papers on Economic Activity, Brookings Institution Press, Spring 2017, pp. 317-396.

Kiyotaki, N. / Moore, J., 2019. Liquidity, Business Cycles, and Monetary Policy, Journal of Political Economy, Volume 127, Number 6, pp. 29262966.

Kochar, R. and Hitt, M., 1998. Linking corporate strategy to capital structure: Diversification strategy, type and source of financing, Strategic Management Journal, Vol. 19, pp. 601-610.

Lowe, J., Naughton, A. and Taylor, P., 1994. The impact of corporate strategy on the capital structure of Australian companies, Managerial and Decision Economics, Vol. 15, pp. 245-257.

Marx, M. / Mojon, B. / Velde, F.R., 2019. Why have interest rates fallen far below the return on capital? Monetary and Economic Department of BIS Bank for International Settlements, BIS Working Papers No 794.

Modigliani, F., Miller, M.H., 1958. The Cost of Capital, Corporate Finance, and the Theory of Investment, American Economic Review, Vol. 48, pp. 261-297.

Modigliani, F., Miller, M.H., 1963. Corporate Income Taxes and the Cost of Capital: A Correction, American Economic Review, Vol. 53, pp. 433443.

Myers, St., Majluf, N., 1984. Corporate financing and investment decisions when firms have information that investors do not have, Journal of Financial Economics, 13(2), pp. 187-221.

Rams, A., 2018. Financial covenants and company performance: a capital structure approach, 2018 WEI Conference Proceedings, Westeasterninstitute, New York, 10th-12th August 2018, pp. 323-340.

Rams, A., 2020. Strukturierte Finanzierungen - Bedeutung und Einsatz von Covenants, Presentation at Frankfurt School of Finance and Management, Frankfurt, September 2018.

Robichek, A., Myers, St., 1966. Problems in the theory of optimal capital structure. Journal of Financial \& Quantitative Analysis, 1(2), pp. 1-35.

Shyam-Sunder, L., /Myers, St., 1999. Testing static tradeoff against pecking order models of capital structure, Journal of Financial Economics, 51(2), pp. 219-244.

Storz, M. / Koetter, M. / Setzer, R. / Westphal, A., 2017. Do we want these two to tango? On zombie firms and stressed banks in Europe, ECB Working Papers, No. 2104. 


\section{COVID-19 MITIGATION MEASURES, THEIR ECONOMIC IMPACT AND WAY BACK TO THE OLD NORMAL}

\section{Ilmars Rimsevics, University of Latvia}

Abstract. COVID-19 pandemic has caught us off guard. Policy makers did not have a chance to study various options of mitigation policy measures and the respective consequences on the public health and economic activity in the long term. People were dying and many. Politicians needed to act and act fast. Majority of countries have imposed rather strong COVID-19 containment measures. Paper discusses the various effects of mitigation policies and most importantly the effects on the GDP and the costs of long term recovery. The analytics will uncover various correlations between stringency of containment measures and the mobility of population. Voluntary and orderly self-distancing of people is also important determinant of the stringency and mobility reduction associated with that. The economic crises of such magnitude requires fast and coordinated monetary and fiscal policy action. It is also clear that just taking the decisions of providing massive amounts of money to stimulate economy does not guarantee a success. There are many other factors, which could be also important to tackle the economic crises, besides for monetary and fiscal policy. Thus, the paper will analyze the fiscal measure packages the countries have approved in order to mitigate the decrease of GDP. Speed, of implementation of the relief package is of the essence, because many good decisions if remain only on paper and awaiting their implementations, or money otherwise is staying on the account of the treasury, not increasing the economic activity and not preserving the jobs The paper discovers that the road to the Old Normal will be very long and protracted. Few countries will manage to exit the crises soon and to reach the GDP levels of 2019, but unemployment and public debt levels will not reach pre-crises levels in foreseeable future. Therefore, in conclusion, as the novelty the paper will sum up all outstanding crucial elements and issues attributed to the so-called policy mix or recipe for the COVID-19 like and other crises, in order to avoid dramatic fall in the output levels, huge increase of the outstanding public debt and budget deficit level increases in the future.

Keywords: COVID-19 crisis, mitigation measures, stringency index, mobility index, budget deficit and public debt.

JEL code: E51, G01, O11, I15, H68

\section{Introduction}

Throughout economic history we have been experiencing different economic cycles. It is well established fact that every cycle sooner or later comes to an end with the recession and there are various reasons why it is ending with subsequent economic slowdown or even crisis. During the last century there has been several financial crises - some milder and some more severe. The current living generations do not remember any economic crises associated with such pandemic sources. The last such crises, the Great Influenza Pandemic or Spanish Flu, took place at the end of World War I (Barro et al., 2020, De Santis and Van der Veken, 2020b).

COVID-19 crisis caught us all by surprise. This is a crisis like no other, and there is substantial uncertainty about its impact on people's lives and livelihoods (Gopinath, 2020). At the outset of the crisis many policy makers by introducing containment measures acted in "Copy and Paste" mode. There was little time to thoroughly analyze what kind of virus has visited us from China and what are the implications (CEPR, 2020). Only one thing was clear that we need to act and to act fast. There was no time to discuss sufficiently at that stage how long and protracted the pandemic will be and, that depending on the stringency and scope of various lockdown measures, there could be different epidemiological and economic development scenarios with the different financial and fiscal consequences. Later (Angelini et al., 2020) studies reflects on the optimal lockdown policy and clearly recognizes that it is increasing the costs of recession, but saves roughly a million lives, and if implemented fast at the outset of the pandemic, the measures can slow down the spread of the virus and yield economic benefits.

This paper will review the impact of various non-pharmaceutical interventions (NPI) mitigation measures and analyze what were the implications of these NPI and whether there is a substantial difference in the decrease of GDP among the countries which introduced pandemic mitigation and containment measures and the ones which introduced only mild measures of limited scope.

Every government tried to do "whatever it takes" in order to prevent people from dying by introducing various mitigation measures of COVID19 pandemic. Governments initially restricted people from attending the work in person, closed many businesses in a service and hospitality sector and localized the movement of residents. Depending on the severity of these restrictions people changed their day to day activities. Thus, were forced to reduce socializing and attending stores, cinemas, theatres, bars, restaurants etc. Oxford University Blavatnik School of Government has developed Oxford COVID-19 Government Response Tracker or Stringency Index (OxCGRT) (Thomas et al., 2020), which systematically collects information about 18 different policy measures such as school closures, workplace closures, travel restrictions etc., which governments have 
imposed to respond to the pandemic. Although at the first glimpse it looks like more "Copy and Paste" approach, it is not. It now gathers the data from more than 180 countries. In turn, Google has invented its Google COVID-19 Community Mobility Reports (Google, 2020). These are two very useful tools for the analysis of how the strictness of the measures has influenced the mobility of the people.

Crisis like this, requires very close coordination of macro policies, both fiscal and monetary (Lagarde, 2020). It has been often concluded that during the previous crisis monetary response has been delayed. Thus, causing fall in aggregate demand and later on the drop in aggregate supply. This time Central Banks have been acting preemptively taking into account first available signals of the looming crisis (De Santis and Van der Veken, 2020a). Thus, leaving the fiscal policy taking care for the rest. The amount of the initial stimulus packages at the beginning has been unprecedented. “Governments' economic responses to the crisis is unprecedented, too: $\$ 10$ trillion announced just in first two months which is three times more than response to 2008 - 2010 Great Financial Crisis. Western European countries allocated close to $\$ 4$ trillion, an amount almost 30 times larger than today's value of the Marshall Plan" (Cassim et al., 2020). Unfortunately, when it comes to the closer analysis who has allocated the largest relief packages, then there are no surprises, because high-income countries with better credit ratings have deployed the largest amounts (Benmelech and Tzur-Ilan, 2020). So far there is no evidence whether the allocated or available amount immediately guarantees faster and smoother recovery. Needless to say that the speed of implementation of economic crisis relief measures is one of the key factors of public policy success. The failure of not succeeding could be immense. The second wave of COVID-19 has reemerged with fresh discussion whether the fiscal policies are sustainable in a long run. We remember the Great Financial Crisis of 2008-2010. One of the key questions then was how long it will take to recover and regain the GDP of the pre- crisis level. The paper will address this issue and analyze the challenges how to achieve the GDP level of 2019. Compared with January 2020 (pre-crisis) expectations, OECD countries could lose approximately $\$ 10$ trillion in cumulative GDP by 2024. And also for every three months' delay in getting the virus under control across OECD countries, the recovery of GDP to pre-crisis levels could be delayed by as much as six months. (Charumilind et al., 2020). As COVID-19 crisis continues to unravel, it becomes clear that the size of the fiscal support package is important, but there are other factors which are equally important in order to provide effective policy mix, i.e., the mix of lockdown policy measures, size of the relief package, speed of implementation of fiscal measures (guarantees, loans, tax deferrals, equity investments, furlough and part time work payouts etc.) discipline, ownership of the whole pandemic process, and the quality of the governance, commitment and solidarity throughout the crises. Knowing that this economic crisis could be long and protracted, and probably would require more and more new financial resources in order to minimize the slowdown of economic activity and to secure the return to the Old Normal and to prevent public finances from the explosion, it is important to have optimal policy mix. Therefore, it is important to have a long-term vision and strategy and develop the "formula" or so-called policy mix not only for the current COVID-19 type economic crises, but also to establish main principles of how to act in the future if similar pandemic arrives and severe consequences again risk to derail the economies of so many countries (Buti, 2020).

\section{Literature review}

Needless to say that there was no literature about COVID-19 pandemic crisis and possible consequences before COVID-19 outbreak in the beginning of 2020. After the outbreak of the crisis within very short period of time economists and research analysts have developed the whole range of the different papers looking at COVID-19 from different angles. Starting out with the Spanish Influenza Pandemic of 1918 or better known as the Spanish flu and ending with different forecasts when the countries could be back to the old normal and regain the pre-crisis GDP levels (IMF, 2020a).

Barro et al. (2020) provide excellent comparison of Spanish Flu and COVID-19. They admit that in terms of death rate it is incomparable, because in today's terms it would resemble to the deaths of 150 million people. In order to understand the drama which every government facing during the COVID-19 crisis the choices of imposing various infection containment measures Andersen et al. (2020), have produced excellent paper reflecting these issues. Scandinavian experience is often used as the best proxy, because Sweden imposed rather mild restrictions (recommendations), while neighboring countries imposed more stringent lockdown measures. Juranek et al. (2020) clearly provide the alternative view on the things discussed in the mainstream research front. The example of Sweden provides a good alternative for the future decision taking, especially during the time of the second wave. It also encourages to study Swedish experience deeper and to analyze why Swedish epidemiologists took such controversial and different decision at the outset of the crises. Rachel (2020) argues that the best possible policy instrument is targeted isolation of the infected, because it is least costly, but brings real health benefits. He also claims that voluntary individual precautionary distancing also helps to flatten the epidemic curve. Thus, often leading to the overshooting of overall mitigation policies and could be more negative for the recovery of economic activity later. Two important data sets were developed in a course of COVID-19 crisis, which could serve as a guiding light 
for the future decision taking. Stringency Index developed by Oxford University Blavatnic School of Government measuring the stringency of the imposed containment measures and Google COVID-19 Mobility Report or Mobility Index, measuring the reduction of the mobility of the people due to the imposed and unimposed (voluntary) measures. They provide massive information on mitigation measure influence on mobility of the people. Thus setting the basis for initial analysis. Angelini et al. (2020) discussed COVID-19 more from the central bank's point of view stating that the depth of the recession and the speed of the recovery crucially depend on the magnitude and persistence of the supply-side retrenchment. They also clearly state that imposition of containment policies considerably reduces the number of infected and deceased people, but create sharp decline in economic activity. ECB president Lagarde (2020) in her blog "Europe's Response to the Crisis" reflects on the stance of the European approach and of the ECB new policies during the crisis, and lays out the forward vision of the ECB. Yes, indeed, it is important to have common European approach with the preference to save jobs and providing all necessary instruments where national measures will be supplemented and targeted by coordinated European fiscal policy. Fiscal rules with the Growth and Stability Pact (GSP) are suspended and ECB has announced massive 1.35 Trillion Pandemic Emergency Purchase Program (PEPP). The Next Generation EU (NGEU) fund - agreed by the European Council - is also an important step forward. For the first time ever, Europe has - temporarily - put in place a European budget that complements the fiscal stabilizers at the national level. But at the same time there are many differences of the initial financial conditions of the crisis among the various countries of the world. Benmelech and Tzur-Ilan (2020) clearly describe the arising situation where more prosperous countries can afford to borrow more and at much more favorable terms than others, but others with lower ratings and poor economic situation will not be able to deploy such amounts of resources and will deploy them with certain time lag. Charumilind et al. (2020) clearly indicating how important is to confine the virus and to do it fast and decisively, otherwise recovery will be long and protracted, with every three month of delay getting the virus under control, delaying the recovery of GDP to the pre-crisis level of 2019 by as much as six months. Elgin et al. (2020) have surveyed economic measures, the governments around the globe have taken in response to the global pandemic, providing ground for different policy variable analysis. Letzing (2020) also iterates the importance of government support, but asks the question can governments in the times of increasing budget deficits and public debts afford to continue to support and for how long. There always will be question why GDP decrease in some countries is larger than others According to Sapir (2020), there could be several aspects. Stringency of lockdown measures, the size of the outstanding debt, size of the tourism and service industry in the respective economy and quality of the governance. OECD (2020) provides a base for a potential policy mix, stressing the steps and measures how to act, and which areas of economy and policy making are important in order to minimize the consequences of further fallout. There are many books written about the crisis, but the most vivid ones so far are Baldwin and Weder di Mauro (2020a, 2020b).

\section{Stringency of mitigation measures, mobility of population and the impact on GDP}

COVID-19 crisis arrived uninvited and caught countries totally unprepared and by surprise. Media reported a lot of people dying. Something needed to be done and fast. At the outset of the crises in order to contain the spread of the pandemic, governments introduced various pandemic mitigation and containment measures (Financial Times, 2020). Oxford University Blavatnik School of Government has developed the Stringency Index or COVID-19 Government Response Tracker index (OxCGRT) (Thomas et al., 2020) - an instrument to gauge and analyze the stringency of introduced NPI measures. It provides us with opportunity to compare the consequences the containment measures invoked on the various types of mobility of the population and GDP respectively. Our country sample consists of the EU countries as well as selected OECD countries. Pandemic outbreak in all of these countries was certified approximately at the same time and countries had comparable monetary policy, fiscal policy instruments available and worked along with the similar NPI measures. Oxford Stringency Index allows us to see in the real time how stringency has evolved from various lockdown measures and how do they compare with the other countries (Figure 1).

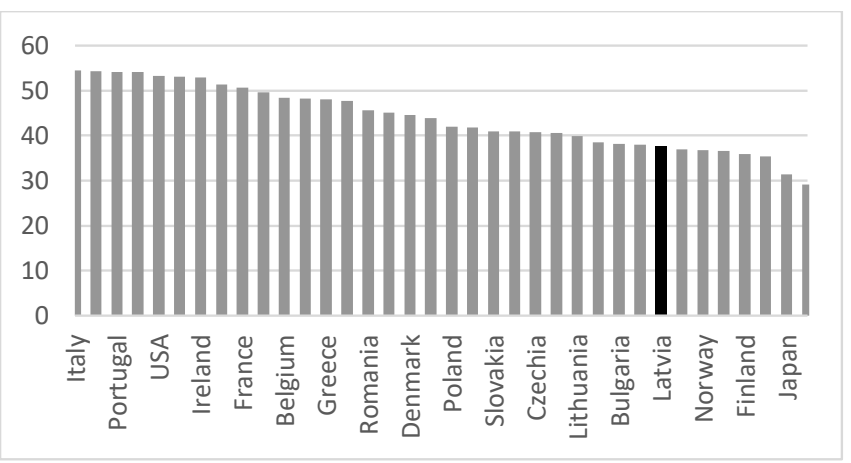

Source: Thomas et.al., 2020 data, author's calculations 
Fig.1. Stringency index (average over 1 January - 2 November 2020)

The data for the period of January $1^{\text {st }}$ till November $2^{\text {nd }}$ reflects which countries had most stringent NPI measures on average throughout the entire period. Latvia, Italy and Sweden with different containment measures and three different stringency indexes at the outset of the pandemic, have converged almost to the same stringency at the end of September (Figure 2). While still having completely different average stringency indexes.

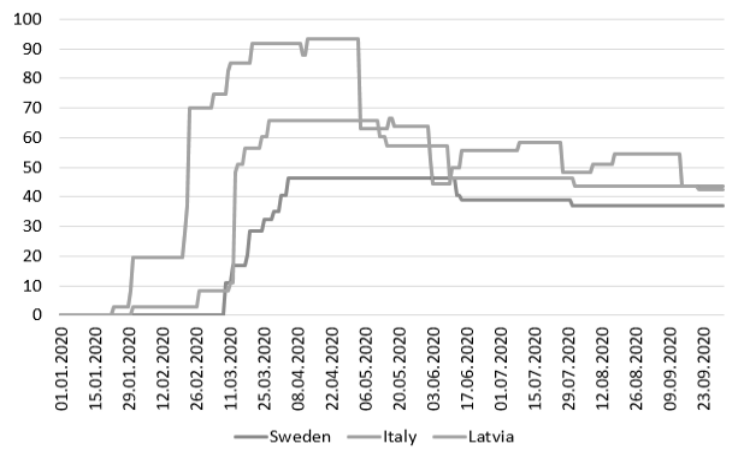

Source: Thomas et.al., 2020 data, author's calculations

Fig.2. Stringency index from 1 January-30 September, 2020 in Sweden, Italy, Latvia

Respective mitigation measures of the pandemic have influenced the mobility of the population. In order to better observe the mobility changes associated with mitigation measures, Google has created COVID-19 Community Mobility Reports (GMR) or so-called Mobility Index and has extracted anonymous data from people's mobile phones under precondition that the mobile phone has the function of "Location Service" switched on. The data shows how under the ever changing stringency of the containment measures people have reduced or changed their mobility during their day-to-day daily routines (Figure 3).

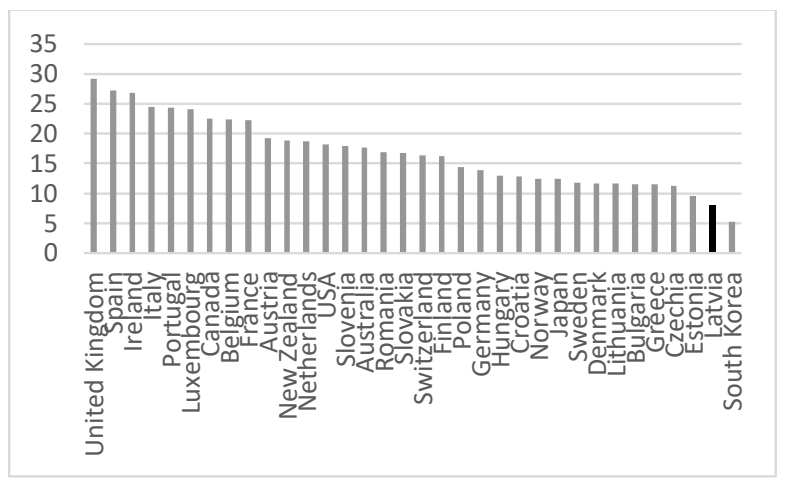

Source: COVID-19 Community Mobility Report data; author's calculations

Fig.3. Google Mobility index average (15 February -3 November, 2020)

At the outset of COVID-19 crisis many governments immediately introduced various restrictions and mitigation measures. Their severity varied from country to country. Therefore, it is important to verify the hypothesis whether the strictness of restriction measures have sizeable effect on the mobility of population. Google COVID-19 Community Mobility Reports (GMR) allows us to use the data of the various mobility types (retail, grocery, transit, workplace, time spent at home), and to calculate the average mobility out of these 5 mobility types. Mobility Index provides average mobility. It is important to keep in mind that Mobility Index not only includes the measures imposed by the respective governments, but also precautionary and voluntary self- restricting distancing imposed by the people themselves for their security and out of fear to become sick (IMF, 2020b). Having now Stringency Index and Google Mobility Index, it is possible to establish the relationship between the two Indices. The results allow us to state that stricter containment measures induce larger decrease in mobility (Figure 4). The correlation is strong. 


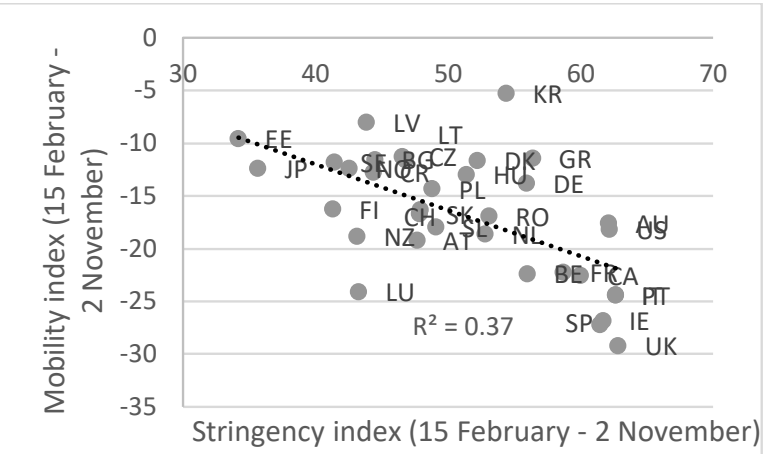

Source: Thomas et.al. (2020) and Google (GMR) data (both 15 Feb - 2 Nov average); author's calculations

Fig.4. Stringency and Mobility index

Once we have established the fact that there is close correlation between stringency of measures and mobility of population, it is important to ascertain about the severity of mobility's reduction impact on the economic activity (Figure 5).

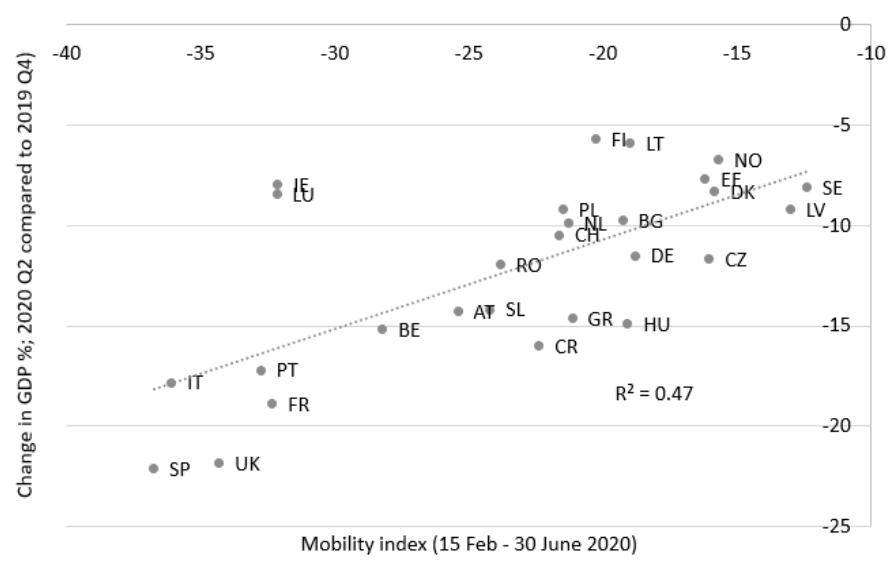

Source: Eurostat and COVID-19 Community Mobility Report data; author's calculations

\section{Fig.5. Mobility index and change in GDP during the first half of 2020}

The results show that there is quite sizeable negative impact of mobility's reduction on the GDP, especially in the 2020Q2. At the time of submission of this paper (04.12.2020), the data is only available for the $1^{\text {st }}$ half of 2020 , which includes two very different quarters of the data available. 2020 Q1 with relatively good performance, when first two months of the 2020 did not signal any forthcoming problems with the virus and then the 2020Q2, which reflects heavy toll on the respective economies, associated with the restrictions, and lockdowns and substantial decrease of mobility and economic activity. It has been also affirmed by (Sapir, 2020) who stated that countries with stricter lockdown measures witnessed a greater economic collapse, with causality running from the strictness of the lockdown measures. However, there always will be a question what is the proportion of mobility reduction because of the mandatory lockdown measures and the voluntary self-imposed self-distancing restrictions (Rachel, 2020). The early COVID-19 crisis analysis (Andersen et al., 2020) shows that using the commercial bank transaction data in two neighboring countries Denmark and Sweden, where in Danish government mandated stricter lockdown measures, the consumption fell only $4 \%$ more than in Sweden, where government issued only recommendations about social distancing.

During the summer virus outbreak subsided and countries eased their respective restrictions. Thus, the stringency of the measures and population mobility decrease have lessened their effects and GDP of 2020 Q3 has the signs of the recovery. Therefore, if using the available forecast data from the latest IMF publications i.e. World Economic Outlook (IMF, 2020b) forecast for the whole year of 2020, then the harmful effects of the first half of the year are becoming less pronounced. However, the second wave of pandemic is having serious implications on 2020 Q4 results and the pattern of Q2 will come back. Therefore, it remains a strong argument that the more stringent are the lockdown measures, the more it reduces the mobility of people, the more it reduces economic activity and GDP (Figure 6), "and not the other way round-so if the countries where the economic collapse was the greatest then reduced the strictness of the measures more than others, it was not sufficient to counterbalance the economic hit" (Sapir, 2020). Several studies also warn that we should not expect that lifting the lockdown measures will guarantee immediate economic rebound (Chen et al., 2020). It is also important to analyze, whether there are other factors influencing GDP decrease in the respective countries. Because seemingly very 
similar NPI measures, similar monetary policy instruments and fiscal stimulus packages, but GDP contraction in some countries with similar mobility decrease is different. Whether an extra additional self-distancing could be an additional factor of larger GDP reduction remains the subject for the further studies.

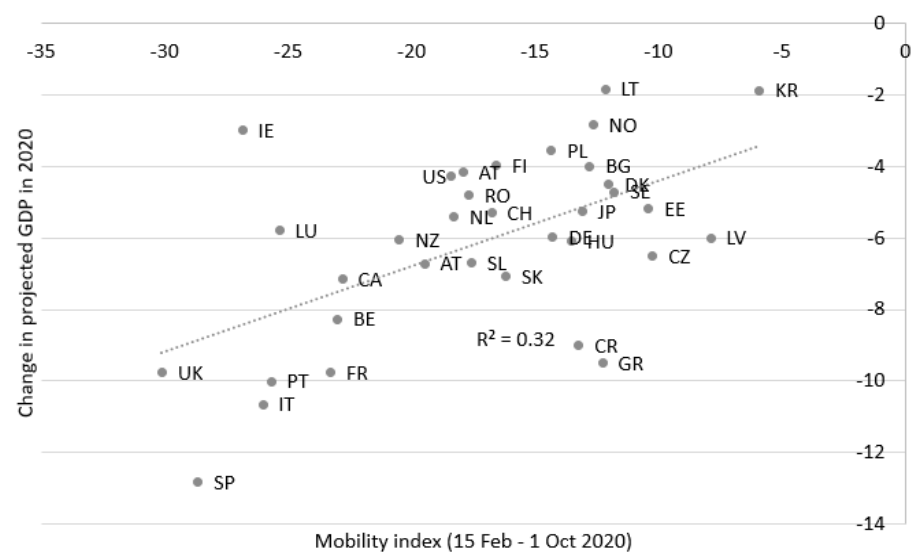

Source: Eurostat and COVID-19 Community Mobility Report data; author's calculations

Fig.6. Mobility index and change of projected GDP in 2020

It is also important to analyze, whether there are other factors influencing GDP decrease in the respective countries. Crisis and mitigating containment measures have left deep scars for all world economies (Baldwin and Weder di Mauro, 2020a, 2020b). World GDP growth forecast has been revised several times, and it will be in the negative territory for some time. GDP decrease has been immediately reflected in the budget deficits of the respective countries. At this stage it is difficult to distinguish all factors contributing to the decrease. However, with reasonable certainty it is obvious that larger GDP decrease causes larger budget deficit (Figure 7).

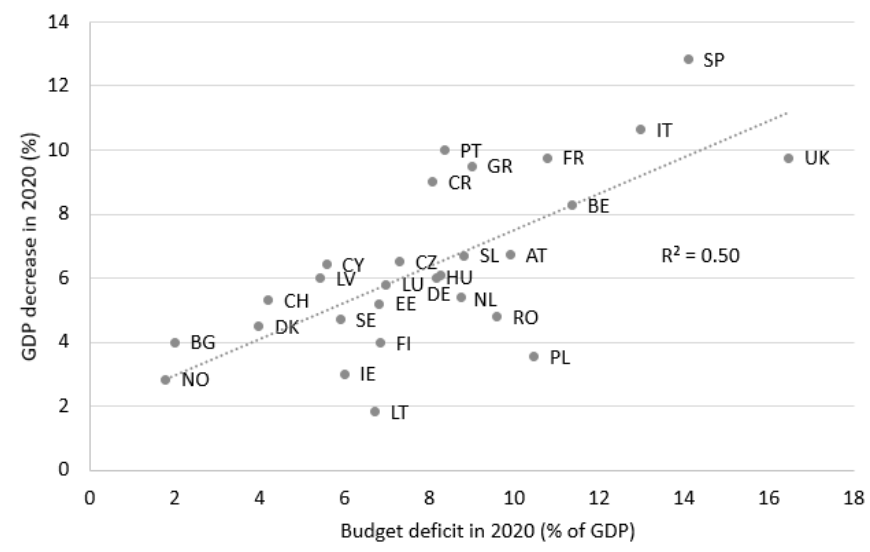

Source: IMF World Economic Outlook (October 2020) data; author's calculations

\section{Fig.7. GDP decrease and Budget deficit in 2020 (IMF forecast)}

But why in some countries GDP decrease is larger and in others it is smaller, remains an open question. Why COVID-19 has different implications for different countries? There are many factors. Stringency measures, which reduce mobility certainly correlate with GDP decrease (Juranek et al., 2020). COVID-19 also has different impact for different industries. Namely, service and tourism industries have been hardest hit and the countries where their respective weight in the GDP structure is higher had been affected more than others. But there are other factors, which are also important in the context of GDP slowdown. The quality of governance (Sapir, 2020) and the speed and length of implementation of financial relief measures. Countries differ in taking fast, clear and decisive decisions to implement various measures with many financial support channels and the speed (IZA, 2020). This will require an additional thorough study and will provide more ground for new arguments. Especially, taking into account that there were also countries which provided direct cash payments into accounts of physical and legal persons in order to provide real purchasing power and stimulate demand (Bundesministerium für Wirtschaft...., 2020). Thus, adding an extra support and purchasing power to their economies. 


\section{Monetary and fiscal stimulus packages}

In order to stop bleeding and to prevent even more severe consequences, governments and respective parliaments have approved several economic relief and stimulus packages. Governments and central banks have mobilized amounts of money unseen before. Central banks have been criticized for acting too late during the previous crises (Bernanke, 2000). This time central banks have relied on early signals and acted preemptively (De Santis and Van der Veken, 2020a). ECB has announced several new initiatives and has increased the amount of Pandemic Emergency Purchasing Program (PEPP) up to the 1.35 Trillion euros. So did the other central banks of the countries used in our sample and have accepted several new decisions in order to provide liquidity and stabilize the financial markets. Governments have announced many and different support and stimulus packages in order mitigate the consequences of the COVID-19 crisis (Elgin et al., 2020). EU leaders during the summer have agreed to establish 750Billion euro Recovery and Resilience Fund (RRF). Most important question is whether the huge resources, which have been assigned to stabilize the economic situation and minimize the damage done by COVID-19 will do the job (Cassim et al., 2020). Fiscal response to the crisis is very important (Anderson et al., 2020), but can we allege that if more money is available, the better will be the results?

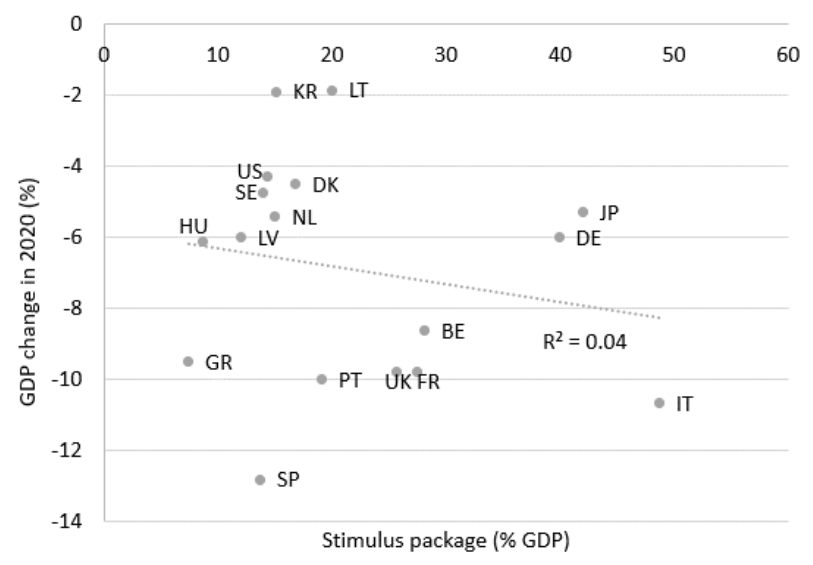

Stimulus package: (Anderson et al., 2020) and author's calculations

Fig.8. Projected real GDP (index; year $2019=100)$

So far results differ. Hypothesis that more money will do the trick and bring recovery sooner, so far has not been confirmed. Several (especially rich) countries have provided immense amounts of money and support measures in order to rescue economies and the people from the hardships they go through (Benmelech and Tzur-Ilan, 2020), but so far with little response (Figure 8). Budget constraints are gone missing (Economist, 2020). There are countries which have used large amounts of fiscal stimulus, thus increasing further the outstanding debt levels and budget deficits and still have not managed to keep GDP decrease under control vis-à-vis some other countries, Sweden, Finland, Denmark, Norway, Lithuania, Estonia, which with smaller additional stimulus packages have increased their debt levels and their budget deficits less during the crisis, and experienced smaller slowdown of their economic activity (Duffin, 2020). Further unlimited increase of outstanding debt for some countries does not look viable (Letzing, 2020). In the most pessimistic scenario of temporary loss of output and consumption could persist beyond 10-15 years (Mihailov, 2020). Current IMF WEO forecast (IMF, 2020b) shows that there will be long and protracted road to recovery. There are various reasons and different assumptions when countries will return to the level of 2019. Table 1 shows that GDP could be recovered by mostly 2022 and 2023 , but unemployment and public debt for almost all countries will stay at the elevated levels for many years and 2019 level (Old Normal), will not be reached in a foreseeable future. COVID-19 second wave will make the situation even worse. High public debt poses significant economic challenges as it makes the economy less resilient to shocks and reduces the scope for counter-cyclical fiscal policy (Burriel et al., 2020). 
Recovery scenarios (to the level recorded in 2019)

\begin{tabular}{|c|c|c|c|c|c|c|c|}
\hline Country & 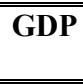 & "Unemployment & Public debt & Country & GDP & "Unemployment & $\begin{array}{l}\text { Public } \\
\text { debt }\end{array}$ \\
\hline Belgium & 2023 & after 2025 & after 2025 & Austria & 2023 & after 2025 & after 2025 \\
\hline Bulgaria & 2022 & after 2025 & after 2025 & Poland & 2021 & after 2025 & after 2025 \\
\hline Chech.Rep. & 2022 & after 2025 & after 2025 & Portugal & 2022 & after 2025 & after 2025 \\
\hline Denmark & 2022 & after 2025 & after 2025 & Romania & 2022 & after 2025 & after 2025 \\
\hline Germany & 2022 & after 2025 & after 2025 & Slovenia & 2022 & after 2025 & after 2025 \\
\hline Estonia & 2022 & after 2025 & after 2025 & Slovakia & 2022 & after 2025 & after 2025 \\
\hline Ireland & 2021 & after 2025 & 2023 & Finland & 2022 & 2024 & after 2025 \\
\hline Greece & 2023 & 2022 & 2023 & Sweden & 2022 & after 2025 & after 2025 \\
\hline Spain & 2023 & after 2025 & after 2025 & UK & 2023 & after 2025 & after 2025 \\
\hline France & 2023 & 2023 & after 2025 & USA & 2022 & after 2025 & after 2025 \\
\hline Croatia & 2022 & 2023 & after 2025 & Norway & 2021 & after 2025 & 2020 \\
\hline Italy & $\begin{array}{l}\text { after } \\
2025\end{array}$ & after 2025 & after 2025 & Switzerland & 2022 & after 2025 & after 2025 \\
\hline Cyprus & 2022 & 2021 & 2024 & Japan & 2024 & 2023 & after 2025 \\
\hline Latvia & 2022 & after 2025 & after 2025 & Australia & 2022 & after 2025 & after 2025 \\
\hline Lithuania & 2021 & 2024 & 2025 & New Zealand & 2022 & after 2025 & after 2025 \\
\hline Luxembourg & 2022 & after 2025 & after 2025 & South Korea & 2021 & after 2025 & after 2025 \\
\hline Hungary & 2022 & after 2025 & after 2025 & Canada & 2022 & after 2025 & after 2025 \\
\hline Netherlands & 2022 & after 2025 & after 2025 & Iceland & 2023 & after 2025 & after 2025 \\
\hline
\end{tabular}

Source: IMF World Economic Outlook (October 2020) data

\section{Towards the optimal policy mix}

Nine months into the crisis there is a debate still about the virus, about vaccine and stringency of lockdown or mitigation measures. The crisis could be long and exhausting. Second wave is already here. There could be third and fourth wave as well (Mihailov, 2020). Therefore, it is important to have an optimal policy mix. Especially, knowing that this economic crisis could be long and protracted, and probably would require more and more new financial resources in order to minimize consequences of the slowdown of economic activity, to pay furlough and unemployment benefit expenditures etc., decisive action has to be taken to address economic crises (OECD, 2020). Therefore, it is important to have a long-term vision and to develop the "formula" or so-called policy mix not only for the current COVID-19 type economic crises, but also for other types of economic crisis. It is important to establish main principles and factors of how to act in the future if similar pandemic explodes and severe consequences again risk to derail the economies of so many countries (Buti, 2020). Despite of much better understanding of the crises and better cooperation in comparison to the Great Financial Crisis, it is still slow in implementation and future guidance of the foreseeable actions associated with future developments of the crisis. Therefore, based on my studies and literature covered, I would propose to develop clear and easy to follow guidance with all important factors and elements included, which need to be taken into account when constructing the relief package and communicating broadly with high quality with the public (Haskel, 2020), so that everybody has a sense of belonging to the whole inclusive exercise and, at least, in general understands and follows the process.

Monetary and fiscal policy, lockdown policy, speed of implementation, which means that financial resources are disposed to the assigned activity or entity as soon as possible, probably next day, once the decision of the government is accepted. This is not the case in many countries. There are many cumbersome procedures to fill various document forms and proves of the eligibility of the funds. There are schemes which provide just the basic solutions, but do not provide certainty about future and thus, does not promote economic activity, not increasing demand for credit and consumption, investment and spending in the future. Discipline is another factor, which comes together with the quality of the governance, trust and commitment, ownership of the process and solidarity. And if this is a Mother of all crises, it requires complex and coordinated action. At the same time, there are elements, which must be in place and in order at all times. Adequate fiscal space, international credit ratings, good governance and capacity of the medical system to accommodate pandemic patients.

\section{Findings and conclusions}

In conclusion, it could be stated that since the second wave of COVID-19 has already arrived, countries will experience new waves of mitigation measures, and the subject of COVID-19 crisis will not go away soon. During the first wave of pandemic many countries have adopted quite stringent mitigation measures, thus inflicting severe economic slowdown and recession on their economies. This study clearly shows that there is sizeable 
correlation between the stringency of measures and mobility of the population. The more stringent are the containment measures, more it decreases the mobility. In turn, the decreased mobility is reflected in GDP decrease. Thus, we could state that stringency has considerable effect and correlation with the decrease of GDP. Countries have provided unprecedented amounts of money to compensate the loss of revenues and output and will continue also to provide further financial stimulus for the GDP growth and recovery. But the results are unclear, and will require further research, because there are countries which have accommodated huge financial resources, but still experiencing large decrease of GDP. Whereas some other countries have accommodated smaller amounts of support, but experiencing smaller decrease of GDP. COVID-19 crisis still unravel. It will require a lot of good effort to stabilize the economic situation. Therefore, reasonable, balanced, disciplined and enforced lockdown policy is crucial in order to reduce further new COVID-19 cases and further economic activity losses. Speed of relief package measure implementation is crucial prerequisite to reduce further economic activity decline. Quality of the governance, commitment of the policy makers "to do whatever it takes" and solidarity are also important elements in order to tackle the crises.

\section{Bibliography}

Andersen, A., L., Hansen, E., T., Johannesen, N., Sheridan, A., 2020. Pandemic, Shutdown and Consumer Spending: Lessons from Scandinavian Policy Responses to COVID-19* May 12, 2020 https://arxiv.org/pdf/2005.04630.pdf.

Anderson, J., Bergamini, E., Brekelmans, S., Cameron, A., Darvas, Z., Domínguez Jíménez, M., Midões, C., 2020. The Fiscal Response to the Economic Fallout from the Coronavirus, Bruegel Datasets, 16.07.2020. https:/www.bruegel.org/publications/datasets/covid-national-dataset/

Angelini, E., Damjanović, M., Pariès, M.D., Zimic, S., 2020 ECB-BASIR: A Primer on the Macroeconomic Implications of the COVID-19 Pandemic, ECB Working Paper Series, No 2431, 07.2020. https:/www.ecb.europa.eu/pub/pdf/scpwps/ecb.wp2431 aab2650200.en.pdf

Baldwin, R., Weder di Mauro, B., 2020a. Economics in the Time of COVID-19, VOXEU, 06 March 2020_https://voxeu.org/content/economicstime-covid-19

Baldwin, R., Weder di Mauro, B., 2020b. Mitigating the COVID Economic Crisis: Act Fast and Do Whatever It Takes, https://voxeu.org/content/mitigating-covid-economic-crisis-act-fast-and-do-whatever-it-takes

Barro, R.J., José, F., Weng, U.\&J., 2020. The Coronavirus and the Great Influenza Pandemic: Lessons from the "Spanish Flu" for the Coronavirus's Potential Effects on Mortality and Economic Activity, https://www.nber.org/system/files/working_papers/w26866/w26866.pdf

Benmelech, E., Tzur-Ilan, N., 2020. The Determinants of Fiscal and Monetary Policies During the Covid-19 Crisis. NBER Working Paper No. $27461 \mathrm{https}: / /$ www.nber.org/papers/w27461.

Bernanke, B.S., 2004. Essays on the Great Depression Paperback" Princeton University Press, 25.01.2004. https://www.amazon.com/EssaysGreat-Depression-Ben-Bernanke/dp/0691118205.

Bundesministerium für Wirtschaft und Energie, 2020. Antragstellung für Abschlagszahlung zur Novemberhilfe startet heute - Erste Abschlagszahlungen noch in diesem Monat. Gemeinsame Pressemitteilung, 25.11.2020. BMWi - Antragstellung für Abschlagszahlung zur Novemberhilfe startet heute - Erste Abschlagszahlungen noch in diesem Monat.

Burriel, P., Checherita-Westphal, C., Jacquinot, P., Schön, M., Stähler, N., 2020. Economic Consequences of High Public Debt: Evidence from Three Large Scale DSGE Models. ECB Working Paper Series, No 2450

https://www.ecb.europa.eu/pub/pdf/scpwps/ecb.wp2450 e008f3b9ae.en.pdf?288603824407529b99e726c6bd

Buti, M., 2020. A Tale of Two Crises: Lessons from the Financial Crisis to Prevent the Great Fragmentation. https://voxeu.org/article/lessonsfinancial-crisis-prevent-great-fragmentation

Cassim, Z., Handjiski, B., Schubert, J, Zouaoui, Y., 2020. The 10-trillion Dollar Rescue how Governments Can Deliver Impact. McKinsey\&Company, 5.06.2020. https://www.mckinsey.com/industries/public-and-social-sector/our-insights/the-10-trillion-dollar-rescue-howgovernments-can-deliver-impact

CEPR, 2020. Covid Economics Vetted and Real-Time Papers, Issue 25, 03.06.2020. https://cepr.org/file/9103/download?token=988THYi0

Charles, S., Dallery, T., Marie, J., 2020. Teaching the Effect of COVID-19 with a Manageable Model. HAL Archives-ouvertes https://hal.archives-ouvertes.fr/hal-02610519/document

Charumilind, S., Greenberg, E., Lamb, J., Singhal, S., 2020. Saving Thousands of Lives and Trillions of Livelihoods. McKinsey, https://www.mckinsey.com/industries/healthcare-systems-and-services/our-insights/covid-19-saving-thousands-of-lives-and-trillions-inlivelihoods 
Chen, S., Igan, D., Pierri, N., Presbitero, A.F., 2020. Tracking the Economic Impact of COVID-19 and Mitigation Policies in Europe and the United States. IMF Working Paper WP20/125, 10.07.2020. https://www.imf.org/en/Publications/WP/Issues/2020/07/10/Tracking-the-EconomicImpact-of-COVID-19-and-Mitigation-Policies-in-Europe-and-the-United-49553

De Santis, R.A., Van der Veken, W., 2020a. Forecasting Macroeconomic Risk in Real Time: Great and Covid-19 Recessions. ECB Working Paper Series, No 2436, https://www.ecb.europa.eu/pub/pdf/scpwps/ecb.wp2436 df6319728a.en.pdf?20a5de5844523c39ed0d86eb07

De Santis, R.A., Van der Veken, W., 2020b. Macroeconomic Risks Across the Globe due to Spanish Flu. ECB Working Paper Series, No 2466. https://www.ecb.europa.eu/pub/pdf/scpwps/ecb.wp2466 43b7489b61.en.pdf?7510ce1fcba937b34210d93bb1ad066d

Duffin, E., 2020. Value of COVID-19 Stimulus Packages in the G20 as Share of GDP 2020, Statista, 29.07.2020.

https://www.statista.com/statistics/1107572/covid-19-value-g20-stimulus-packages-share-gdp/

Economist, 2020. Governments must Beware the Lure of Free Money, 23.07.2020. https://www.economist.com/leaders/2020/07/23/governmentsmust-beware-the-lure-of-free-money

Elgin, C., Basbug, G., Yalaman, A., 2020. Economic Policy Responses to a Pandemic: Developing the COVID-19 Economic Stimulus Index. VOXEU, 07.05.2020. https://voxeu.org/article/economic-policy-responses-pandemic-covid-19-economic-stimulus-index

Financial Times, 2020. Covid-19: The Global Crisis — in Data. FT Visual \& Data Journalism team”, 18.10.2020. https://ig.ft.com/coronavirusglobal-data/

Gopinath, G., 2020. IMF, April 2020 https://blogs.imf.org/2020/04/14/the-great-lockdown-worst-economic-downturn-since-the-great-depression/ Google (2020) https://www.google.com/covid19/mobility/

Haskel, J., 2020. From Lockdown to Recovery - the Economic Effects of COVID-19. Speech at Imperial Future Matters Online Webinar 23.07.2020. https://www.bankofengland.co.uk/-/media/boe/files/speech/2020/imperial-future-matters-from-lockdown-to-recovery-speech-byjonathan-haskel.pdf?la=en\&hash=6BD13B32852866D8AAD81252DAD909B6FEF22DD2

IMF, 2020a. Policy Responses to Covid-19, https://www.imf.org/en/Topics/imf-and-covid19/Policy-Responses-to-COVID-19

IMF, 2020b. World Economic Outlook, https://www.imf.org/en/Publications/WEO/Issues/2020/09/30/world-economic-outlook-october-2020

IZA Institute of Labor, 2020. Crisis Response Monitoring” 30.11.2020. Crisis Response Monitoring - COVID-19 and the Labor Market (iza.org).

Juranek S., Paetzold J., Winner H., Zoutman F., 2020. Labor Market Effects of COVID-19 in Sweden and its Neighbors: Evidence from Novel Administrative Data, Covid Economics Vetted and Real-Time Papers CEPR PRESS, Issue 42, 19.08.2020., https://openaccess.nhh.no/nhhxmlui/handle/11250/2670239.

Lagarde, C., 2020. Europe's Response to the Crisis, ECB Blog, 23.07.2020.

https://www.ecb.europa.eu/press/blog/date/2020/html/ecb.blog200723 c06fafabb6.en.html

Letzing, J., 2020. How Long Can Governments Keep Spending to stem COVID-19 Job Losses?, World Economic Forum, 24.07.2020. https://www.weforum.org/agenda/2020/07/the-cost-of-wage-subsidies-to-stem-covid19-related-unemployment/

Mihailov, A., 2020. Quantifying the Macroeconomic Effects of the COVID-19 Lockdown: Comparative Simulations of the Estimated GalíSmetsWouters Model, University of Reading, Discussion Paper No.2020-07, http://www.reading.ac.uk/web/files/economics/emdp202007.pdf

OECD, 2020. Tax and Fiscal Policy in Response to the Coronavirus Crisis: Strengthening Confidence and Resilience, $\mathrm{https}$ //www.oecd.org/coronavirus/policy-responses/tax-and-fiscal-policy-in-response-to-the-coronavirus-crisis-strengthening-confidence-andresilience-60f640a8/

Rachel, L., 2020. An Analytical Model of Covid-19 Lockdowns: Equilibrium Mitigation Flattens the Epidemic Curve, Optimal Lockdown Does Not, 05.08.2020. https://drive.google.com/file/d/1tVTfyEeD0xTIcZVlvCZvDN95CZ6uVdmU/view

Sapir, A., 2020. Why has COVID-19 Hit Different European Union economies so differently https://www.bruegel.org/wpcontent/uploads/2020/09/PC-18-2020-22092020-final.pdf

Thomas, H., Angrist, N., Cameron-Blake, E., Hallas, L., Kira, B., Majumdar, S., Petherick, A., Phillips, T., Tatlow, H., Webster, S., 2020. Oxford COVID-19 Government Response Tracker, Oxford University, Blavatnik School of Government. https://www.bsg.ox.ac.uk/research/researchprojects/coronavirus-government-response-tracker 


\title{
TWO DECADES OF CIO EFFECTIVENESS RESEARCH IN THE LIGHT OF THE PRINCIPAL-AGENT- THEORY: SUGGESTIONS FOR FUTURE RESEARCH Bjarne Erik Roscher, University of Latvia
}

\begin{abstract}
Companies are more and more dependent on information technology (IT) and the buzzword digitization is present everywhere. Some companies are inventing new business models based on disruptive innovation supported by information technology. Others adapt these business models as followers. All these new business processes and underlying information technology need to be managed, serviced, and supported by IT organizations to ensure business continuity. On the other side software and cloud providers have launched applications which in some cases are easy to configure and need a minimum effort to install, connect and maintain. Traditionally heads of the IT department have been fully responsible for all aspects of IT usage in the company - including IT cost, IT governance, IT \& process planning and implementation and IT operation. The innovations around cloud computing has changed this. Executives outside IT are approached by software providers directly and sometimes successfully. This results in the fact that there is a need of more intensive Business-IT alignment to ensure the functioning of the overall IT architecture of a company and ensure the economic value contribution of IT as a hole. In the last two decades researchers have looked into the area of CIO effectiveness research by doing empirical research looking at IT roles/tasks, interaction and strategic importance of IT, üersonal background of CIOs. Mostly measured by constructs that quantify the outcome either of the IT organization or of the company as a whole. The aim of this research is to put empirical research into the context of the Principal-Agent theory and to identify the gaps for future research. The research method was a literature analysis based on relevant empirical research. After aligning available variables from previous research with the principal agent model missing aspects necessary for future research have been identified.
\end{abstract}

Keywords: Chief Information Officer (CIO), IT Organization, Effectiveness, Principal Agent Theory.

JEL code: L2, M14, M15

\section{Introduction}

Synnott defined 1981 the role of the chief information officer (CIO) as the "senior executive responsible for establishing corporate information policy, standards, and management control over all corporate information resources" (Synnott et al. 1981).

Many studies have shown that the role of a CIO is essential for an organization:

A CIO can positively influence the company performance not only by fostering the IT efficiency, which means lowering cost and by this increase the profit, yetincrease the IT effectivity through improved IT use (Durst, 2007).

Measures to drive IT efficiency are introducing tailored internal IT management systems (Schweda \& Schmidt, 2014), efficient IT service management [ITSM] frameworks (Marrone \& Kolbe, 2011) and the right organizational setup (Hodgkinson, 1992). An efficient budgeting and controlling process which ensures that investments in technology deliver the planned results (Chan, Sabherwal \& Thatcher, 2006) is essential. Measures to improve IT effectivity are supporting business processes with appropriate information technology (Tallon, 2014).

But ultimately a CIOs main task is to ensure "Business-IT-Alignment" (BITA). This results in strategic information technology initiatives driving business performance (Peppard 2010). External and internal influences which cause a change of Business Model or Company Strategy must be captured and incorporated into IT strategy. (Ward \& Peppard, 2002)

Research has widely discussed the importance of the relationship between CEO and CIO (Chen \& Preston, 2007; Jones, Taylor \& Spencer, 1995; Krotov, 2015; Benlian \& Haffke, 2016; Feeny, Edwards \& Simpson, 1992) and the importance of the CIO being member of the TMT (Ling et al., 2015; Lee et al., 2014; Georgakakis et al., 2019). Also the area of Allignment between CIO and other TMT Managers has been investigated (Whitler, Boyd \& Morgan, 2017; Taylor \& Vithayathil, 2018).

Gurbaxani suggested to look at these top management relationships in the light of the Principal Agency Theory (PAT) (Vijay Gurbaxani \& Chris F. Kemerer, 1990). Even so, the world has changed since the 1990s in the arae of IT management the vision of the change from centralized IT delivery organizations to decentralized demand driven IT Management systems have fully come true. Through the offerings of cloud based solutions, IT organizations might lose the ownership of parts of their IT Architecture Landscape. One prominent example is that Customer Relationship Management (CRM) Solution introductions, which need little IT knowledge in setup and maintenance. They are often initiated and executed by the teams of Chief Marketing Officers or Sales Executives. The only way to keep control, is to formulate strong IT Governance rules and IT Architecture principles to ensure consistency of data and stable IT Interfaces between Applications. 
Researchers in other management fields (Brinkerhoff \& Bossert, 2014) use the construct of Agency Theory to discuss the delivery of Services in a complex triadic relationship (Tate et al., 2010).

Therefore, the author of this research believes that the area of Business-IT-Alignment and especially the alignment with other members of Top Management is crucial for efficient and effective IT Provision. This is supported by his own experience as CIO in various companies globally. The concept of the triadic agency relationships of (Vijay Gurbaxani \& Chris F. Kemerer, 1990) should therefore be enhanced by adding the construct of the Top Management Team [TMT] to it. Interaction on the same level in this Team is crucial.

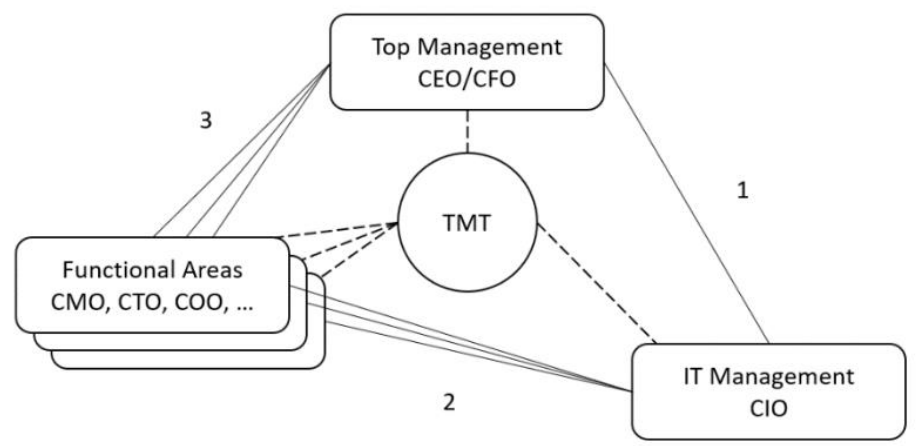

Source: author's construction based on the model of Gurbaxani and Kemerer (Vijay Gurbaxani \& Chris F. Kemerer, 1990)

Fig. 1. Triadic Agency Relationships for the Management of IT (CIO)

Peppard (Peppard, 2010) cites a leading academic in an overview paper about his research: "If the CEO of your business unit is putting together people for golf and business discussion over the weekend, would he consider the CIO amongst one of those foursomes, not because the CIO is a golf player but because at the 19th hole, there's going to be a lot of business discussion and the CIO has to be a trusted member of the team-a colleague, not just a supporter of the team."

This quote shows not only the need of excellent delivery of IT services, but also the necessity that the CIO is a business and technology visionary who can tackle demands arising out of changes in business strategy. Furthermore, seeing the need to evolve business models by the support of new IT Technology.

The Principal Agent Theory (Eisenhardt, 1989) bases on the fact that a Top Manager (Principal) looks for a specialist (agent) for a specific management job. In the cause of the selection process the Principal has to deal with the fact that there is a information asymmetry between him and the candidate. To evaluate the suitability of the candidate for the job and in turn to prevent adverse selection he can try to investigate the hidden characteristics of the candidate by different actions like signaling, self-selection and screening.

After the candidate is employed new risks arise for the Principal also based on the information asymmetry. The new specialist member has a better understanding of his area of responsibility and possibilities for future development and operation. This might result in the fact that the agent is performing his action not fully in line with the strategy and goals of the Top Management, which might result in opportunistic cost. Measures to compensate this risk are Monitoring, Bonding and Incentives. All associated with cost, which should be lower than the cost for opportunistic behaviour of the agent.

The research investigates which established variables, identified from literature review, could be used to ensure that the right candidate is on the job and to ensure that CIO behavior is in line with the Company strategy and goals.

\section{Literature Review}

The researched topic of IT Management and CIO effectiveness has been researched from different angles in the past decades. Even so, the amount of research is limited. Only few publication bases on quantitative research methods of the complex relationships and influence factors in this management area. Many researchers in the field of business informatics use qualitative research methods.

\section{Research methodology}

1.Literature Collection and selection

The aim of the literature selection was to find only publications which was based on quantitative research utilizing a structural equation model. All other publications have not been considered. The process of literature selection was executed as described in Figure 2 based on the Science Direct database. 


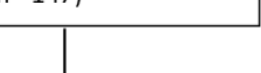

$(\mathrm{n}=0)$

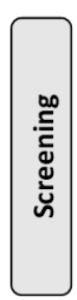

Records after duplicates and languages other then English removed ( $n=145$ )
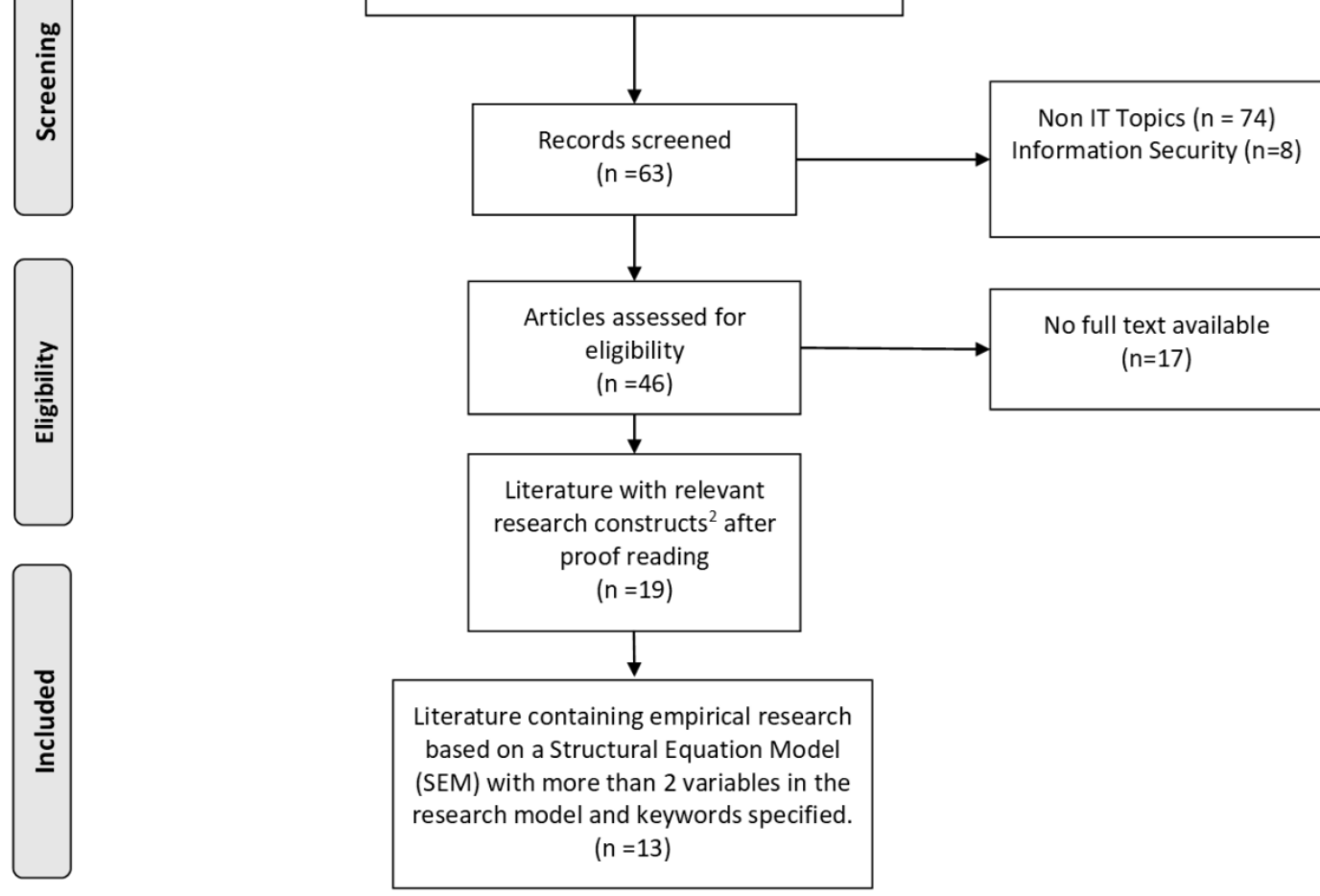

${ }^{1}$ Data collection, review and selection process for Articles on: "CIO OR chief information officer" on Science Direct. Selection criteria: Subject areas: Business, Management and Accounting (110), Computer Science (56), Economics, Econometrics and Finance (31); Article type: Research articles (144), Review articles (3); No limitation on publication date; collected on 10.02.2021.

${ }^{2}$ Impact of the CIO role on the IT and Company performance.

Source: author's literature review, displayed according to the PRISMA-P method (Moher et al., 2015)

Fig. 2. Process of literature selection and used criteria of literature review to determine quantitative CIO effectiveness research

\section{Extraction of keywords}

Keywords which have been defined by the authors of the selected research papers $(n=13)$ have been extracted for further analysis. A total of 27

Keywords have been found in 11 publications. Consequently, the keywords have been aggregated and grouped together for further analysis in table 1 . 
Keywords from relevant publications aggregated for further analysis

\begin{tabular}{|l|l|}
\hline Aggregated Keywords & Keywords used by authors in selected publications* \\
\hline Generic Keywords (CIO/IT) & CIO, IT \\
\hline Role specific Keywords & CIO Characteristics, CIO capability, CIO role, CIO role effectiveness \\
\hline Interaction and strategic importance of IT & $\begin{array}{l}\text { CIO and TMT, CEO/CIO alignment, Business strategic alignment, IT } \\
\text { centrality, Organizational integration }\end{array}$ \\
\hline Person of CIO & Personality Traits, Socialisation, Competence / background \\
\hline Work of CIO & IS Management (model), IS strategic leadership, IT Strategy / Vision \\
\hline Outcome IT & IS quality, IT management value, IS contribution \\
\hline Outcome Company: & $\begin{array}{l}\text { Financial Performance, Organizational performance, Organizational } \\
\text { benefits, Competitive capabilities, Cooperative capabilities, performance }\end{array}$ \\
\hline
\end{tabular}

*Keywords extracted from: (Enns, Huff \& Golden , 2003),(Smaltz, Sambamurthy \& Agarwal, 2006),(Li et al. , 2006), (Sobol \& Klein , 2009), (COHEN \& DENNIS , 2010), (Johnson \& Lederer , 2010), (Chen \& Wu, 2011), (Li \& Tan , 2013), (Ding, Li \& George, 2014), (Ricciardi, Zardini \& Rossignoli , 2018), (Paré, Guillemette \& Raymond , 2020).

Source: author's own grouping of keywords

These aggregated keywords have then been matched back to the selected publications, taking into account that two papers from Ravarini et al. (Ravarini, A., Moro, J., Tagliavini, M., \& Guimaraes, T., 2001) and Chen and Preston (Chen \& Preston, 2007) did not contain Keywords.

Table 2 shows the scope of the individual publications in relation to the aggregated keywords and in addition ranks the aggregated keywords according to their appearance in the selected literature sample.

Table 2

\section{Research scope of individual publications based on keyword analysis and ranking of aggregated keywords}

\begin{tabular}{|l|l|l|l|l|l|l|l|l|}
\hline & Aggregated Keywords & & & & & \\
\end{tabular}

Source: author's analysis and calculations based on structured content analysis

The analysis shows clearly that previous research has focused on the Work of a CIO, the necessary interactions within the company and the strategic importance of IT on the Outcome for the company as a whole ( $>50 \%$ of the publications). The impact of the CIO as a Person and his role 
in the company are investigated in less than $50 \%$ of the papers. The outcome on IT which is the only direct cause-effect relationship is only researched in 2 papers.

\section{Research results and discussion}

The research is based on previous empirical research in the last decades around CIO effectiveness within companies. A comparison of available research with the Principal-Agent-Theory is done.

Research Question

The research question is:

Which additional cause and effect variables are needed to support the empirical measurement of the research field of CIO effectiveness in the light of the principal-agent-theory?

Classification of research variables from Literature research.

In order to gain a holistic view, the research models of different researchers have been structured in 6 dimensions: "Person (CIO)", "Manager (CIO)", "IT Department", "Company", "Company Management and CIO as part of the General Management Team (TMT)". Some variables investigate different areas at the same time, which resulted in the need for a graphic overview shown in Figure 3.

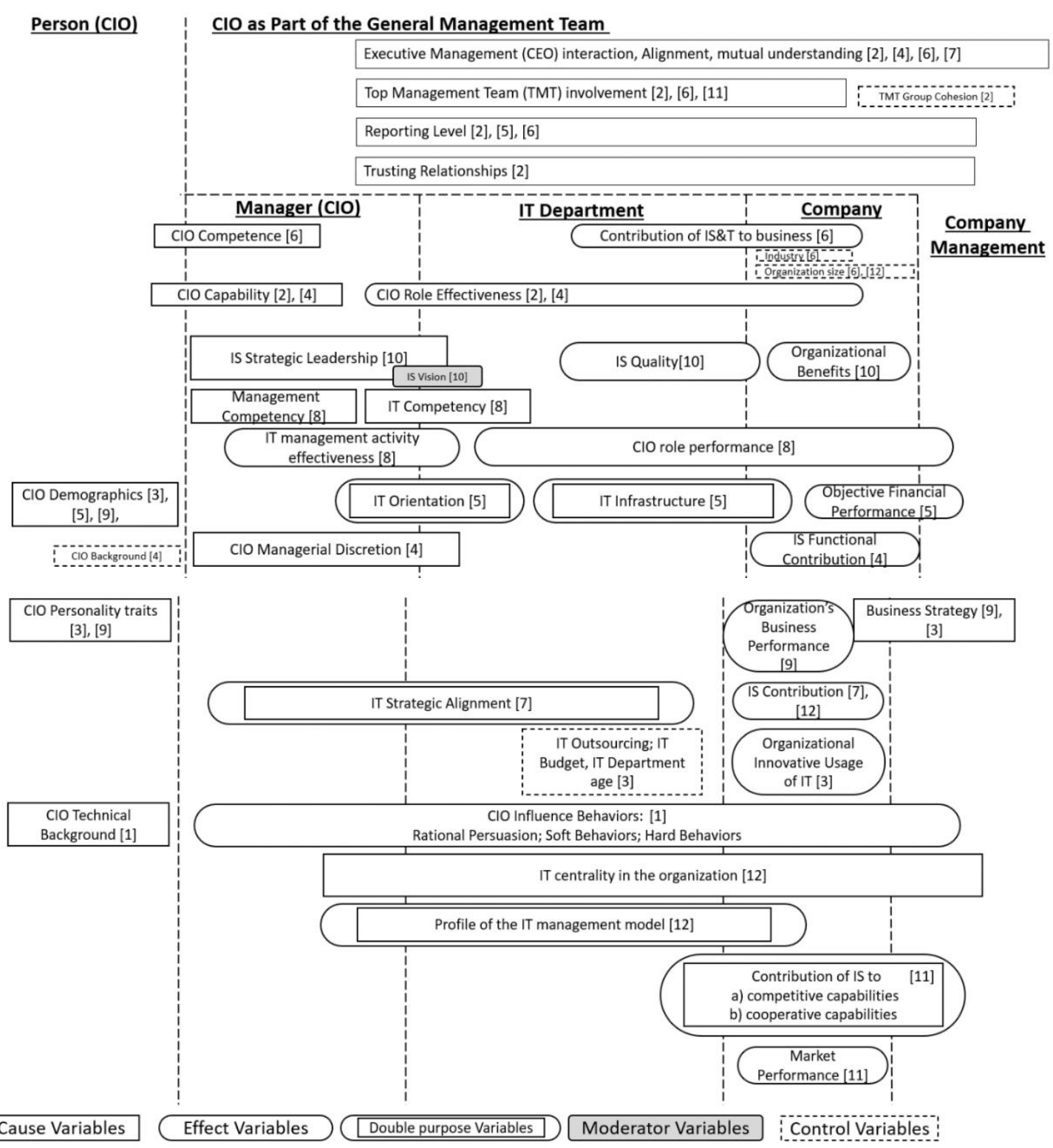

Reference Codes: [1]: (Enns, Huff \& Golden , 2003); [2]: (Smaltz, Sambamurthy \& Agarwal, 2006); [3]: (Li et al. , 2006); [4] (Chen \& Preston , 2007); [5]: (Sobol \& Klein, 2009); [6]: (COHEN \& DENNIS , 2010); [7]: (Johnson \& Lederer, 2010); [8]: (Chen \& Wu, 2011); [9]: (Li \& Tan, 2013); [10]: (Ding, Li \& George, 2014); [11]: (Ricciardi, Zardini \& Rossignoli , 2018); [12]: (Paré, Guillemette \& Raymond, 2020)

Source: author's construction 
Fig. 3. Research Variables in relation to Company structure

The depiction shows that a CIO has a wide field of responsibilities and various areas of actions within a company's organization, which needs a personality which covers besides technical also analytic, adaptive, agile, political, communicative, strategic, goal oriented and solution orientated competencies. This is fully in alignment with the analysis of competencies done by Ravarini and Guimaraes (Ravarini, A., Moro, J., Tagliavini, M., \& Guimaraes, T., 2001)

Alignment of Variables from the Literature research to the Principal Agent Theory Measures.

Countermeasures have the duty to avoid the risks associated with the Principal-Agent relationship between Top Manager and IT Manager. Figure 4 shows that some aspects of these countermeasures have been investigated previously through established variables and measurement factors. The Countermeasure "Monitoring" is assigned with several variables, which have been classified by the author into two groups: direct performance indicators and indirect performance indicators. Direct indicators can be measured by or within the IT organization. Indirect indicators are company related constructs.

\begin{tabular}{|c|c|c|c|}
\hline & Signaling: & Self selection: & Screening: \\
\hline 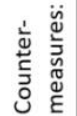 & $\begin{array}{l}\text { CIO Demographics [3], [5], [9] } \\
\text { ClO Background [4] } \\
\text { CIO Technical Background [1] }\end{array}$ & & $\begin{array}{l}\text { CIO Personality traits [3], [9] } \\
\text { CIO Competence [6] } \\
\text { CIO Capability [2], [4] } \\
\text { Management Competency [8] } \\
\text { IT Competency [8] }\end{array}$ \\
\hline
\end{tabular}
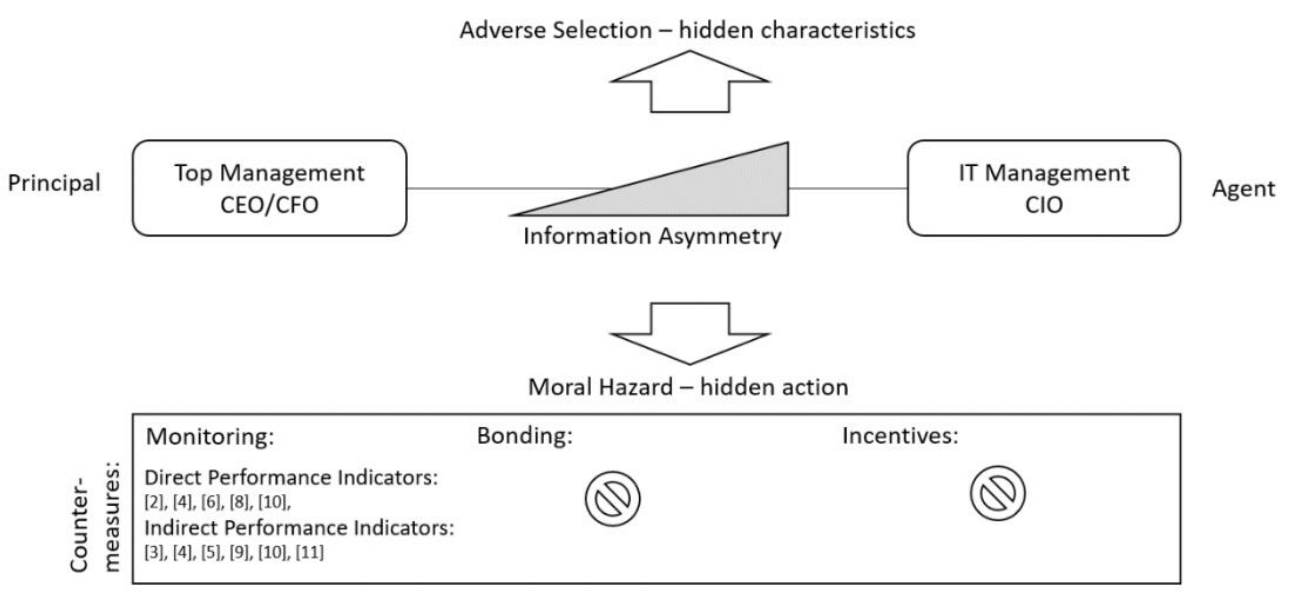

Reference Codes: [1]: (Enns, Huff \& Golden , 2003); [2]: (Smaltz, Sambamurthy \& Agarwal, 2006); [3]: (Li et al. , 2006); [4] (Chen \& Preston , 2007); [5]: (Sobol \& Klein , 2009); [6]: (COHEN \& DENNIS , 2010); [7]: (Johnson \& Lederer, 2010); [8]: (Chen \& Wu, 2011); [9]: (Li \& Tan , 2013); [10]: (Ding, Li \& George , 2014); [11]: (Ricciardi, Zardini \& Rossignoli , 2018); [12]: (Paré, Guillemette \& Raymond, 2020)

Source: author's construction

Fig. 4. Alignment of available research variables with the countermeasures to reduce risk within the Principal agent model.

Three aspects have not been considered in previous CIO efficiency research:

In the area of Adverse Selection which help to find hidden characteristics of candidates, there are no variables for the countermeasure of selfselection. In the area of Moral Hazard, to detect hidden action, no research has investigated the countermeasures and effects of bonding and incentive.

\section{Conclusions, proposals, recommendations}

1. The review of available quantitative research shows that the research models in themselves are consistent. Yet, aligning them with a wellestablished theory like the Principal-Agent-Theory reveals that certain influencing variables have been left out in prior research.

2. Many companies use the method of bonding and incentive to actively influence the alignment of CEO, TMT and CIO with the goal to reduce opportunity cost and maximize the efficiency and effectivity of investments in information technology. Therefor research should develop variables and scales covering the Principal-Agent-Theory areas of self-selection, bonding and incentives.

3. Besides these, standardized quantitative variables for the $\mathrm{CEO} / \mathrm{CIO}$ alignment, $\mathrm{CxO}$ cooperation and TMT/CIO engagement should be developed

4. To minimize the information gap between Principals and Agents, measures to identify the IT knowledge of the TMT and the CEO/CFO should be taken. Variables to measure the current knowledge and a program for closing the training gap should be developed. Training will decrease information asymmetry and increase mutual understanding and ease cooperation.

5. Most prior research has attempted to measure the influence of the CIO role directly on the company performance. Yet, designing a standard and accepted set of key performance indicators (KPIs) would highlight the direct impact of the CIO on the IT outcome. This could be done by measuring 
the IT effectivity (improving use of IT by the business) and the IT efficiency (lowering IT cost). Both areas could later be directly linked to the business performance in a specific part of the company, based on revenue and turnover contributions.

\section{Bibliography}

Benlian, A., Haffke, I., 2016. Does Mutuality Matter? Examining the Bilateral Nature and Effects of CEO-CIO Mutual Understanding. The Journal of Strategic Information Systems, 25(2), 104-126.

Brinkerhoff, D. W., Bossert, T. J., 2014. Health Governance. Principal-Agent Linkages and Health System Strengthening. Health Policy and Planning, 29(6), 685-693.

Chan, Y. E., Sabherwal, R., Thatcher, J. B., 2006. Antecedents and Outcomes of Strategic IS Alignment. An Empirical Investigation. IEEE Transactions on Engineering Management, 53(1), 27-47.

Chen, D., Preston, D., 2007. Understanding CIO Role Effectiveness. The Antecedents and Consequents. 2007 40th Annual Hawaii International Conference on System Sciences (HICSS'07), IEEE, 237a-237a.

Chen, Y.-C., Wu, J.-H., 2011. IT Management Capability and its Impact on the Performance of a CIO. Information \& Management, 48(4-5), 145156.

COHEN, J., DENNIS, C. M, 2010. Chief Information Officers: an Empirical Study of Competence, Organisational Positioning and Implications for Performance. South African Journal of Economic and Management Sciences, 13(2), 203-221.

Ding, F., Li, D., George, J. F, 2014. Investigating the Effects of IS Strategic Leadership on Organizational Benefits from the Perspective of CIO Strategic Roles. Information \& Management, 51(7), 865-879.

Durst, M., 2007, Wertorientiertes Management von IT-Architekturen, Teubner.

Eisenhardt, K. M., 1989. Agency Theory. An Assessment and Review, The Academy of Management Review, 14(1), 57-74.

Enns, H. G., Huff, S. L., Golden, B. R., 2003. CIO Influence Behaviors. The Impact of Technical Background. Information \& Management, 40(5), 467-485.

Feeny, D. F, Edwards, B. R., Simpson, K. M., 1992. Understanding the CEO/CIO Relationship. MIS Quarterly, 16(4), 119-126.

Georgakakis, D., Heyden M. L. M., Oehmichen, J. D. R., Ekanayake, U. I. K., 2019. Four Decades of CEO-TMT Interface Research. A Review Inspired by RoleTtheory. The Leadership Quarterly, p. 101354.

Hodgkinson, S. L., 1992. IT Structures for the 1990s: Organisation of IT Functions in Large Companies. A Survey. Information \& Management, 22(3), 161-175.

Johnson, A. M., Lederer, A. L., 2010. CEO/CIO Mutual Understanding, Strategic Alignment, and the Contribution of IS to the Organization. Information \& Management, 47(3), 138-149.

Jones, M. C, Taylor, G. S., Spencer, B. A, 1995. The CEO/CIO Relationship Revisited. An Empirical Assessment of Satisfaction with IS. Information \& Management, 29(3), 123-130.

Krotov, V., 2015. Bridging the CIO-CEO Gap. It Takes Two to Tango. Business Horizons, 58(3), 275-283.

Lee, J., Elbashir, M. Z, Mahama, H., Sutton, S. G., 2014. Enablers of Top Management Team Support for Integrated Management Control Systems Innovations. International Journal of Accounting Information Systems, 15(1), 1-25.

Li, Y., Tan, C.-H., 2013. Matching Business Strategy and CIO Characteristics. The Impact onOorganizational Performance, Journal of Business Research, 66(2), 248-259.

Li, Y., Tan, C.-H., Teo, H.-H., Tan, B. C. Y., 2006. Innovative Usage of Information Technology in Singapore Organizations. Do CIO Characteristics Make a Difference?. IEEE Transactions on Engineering Management, 53(2), 177-190.

Ling, Y., Wei, L., Klimoski, R. J. Wu, L., 2015. Benefiting from CEO's Empowerment of TMTs. Does CEO-TMT Dissimilarity Matter?. The Leadership Quarterly, 26(6), 1066-1079.

Marrone, M., Kolbe, L. M, 2011. Impact of IT Service Management Frameworks on the IT Organization. Business \& Information Systems Engineering, 3(1), 5-18.

Moher, D., Shamseer, L., Clarke, M., Ghersi, D., Liberati, A., Petticrew, M., Shekelle, P., Stewart, L. A, 2015. Preferred Reporting Items for Systematic Review and Meta-Analysis Protocols (PRISMA-P) 2015 Statement. Systematic Reviews, 4(1), 1-9. 
Paré, G., Guillemette, M. G., Raymond, L., 2020. IT Centrality, IT Management Model, and Contribution of the IT Function to Organizational Performance. A Study in Canadian Hospitals. Information \& Management, 57(3), 103198.

Peppard, J., 2010. Unlocking the Performance of the Chief Information Officer (CIO). California Management Review, 52(4), 73-99.

Ravarini, A., Moro, J., Tagliavini, M., Guimaraes, T., 2001. Exploring the impact of CIO Competencies on Company Performance. International Conference on Information Resources Management Association. Proceeding Canada.

Ricciardi, F., Zardini, A., Rossignoli, C., 2018. Organizational Integration of the IT Function. A Key Enabler of Firm Capabilities and Performance, Journal of Innovation \& Knowledge, 3(3), 93-107.

Schweda, C. M., Schmidt, W., 2014. Leichtgewichtiges, unternehmensspezifisches IT-Management. HMD - Praxis der Wirtschaftsinformatik, 51(5), 606-615.

Smaltz, D. H., Sambamurthy, V., Agarwal, R., 2006. The Antecedents of CIO Role Effectiveness in Organizations. An Empirical Study in the Healthcare Sector. IEEE Transactions on Engineering Management, 53(2), 207-222.

Sobol, M. G., Klein, G., 2009. Relation of CIO Background, IT Infrastructure, and Economic Performance, Information \& Management, 46(5), 271-278.

Tallon, P. P., 2014. A Process-Oriented Perspective on the Alignment of Information Technology and Business Strategy. Journal of Management Information Systems, 24(3), 227-268.

Tate, W. L, Ellram, L. M., Bals, L., Hartmann, E., van der Valk, W., 2010. An Agency Theory Perspective on the Purchase of Marketing Services. Industrial Marketing Management, 39(5), 806-819.

Taylor, J., Vithayathil, J., 2018. Who Delivers the Bigger Bang for the Buck. CMO or CIO?. The Journal of Strategic Information Systems, 27(3), $207-220$.

Gurbaxani, V., Kemerer, C. F., 1990. An Agency Theory View of the Management of End-User Computing, Proceedings of the 11th International Conference on Information Systems (ICIS), Copenhagen.

Ward, J., Peppard, J., 2002, Strategic planning for information systems by Joe Ward \& Joe Peppard, John Wiley \& Sons.

Whitler, K. A., Boyd, D. E., Morgan, N.A., 2017. The Criticality of CMO-CIO Alignment, Business Horizons, 60(3), 313-324. 


\title{
LONG-TERM SOCIO-ECONOMIC IMPACT OF COVID-19 ON SPORT SECTOR
}

\section{Sabine Rusmane, University of Latvia \\ Marina Kudinska, University of Latvia}

\begin{abstract}
The nature of the Covid-19 pandemic's induced economic crisis is unprecedented: beyond the repeated health and economic shocks, the long-term effects on human capital, productivity and behaviour may also be long-lasting. One of the sectors hit particularly severe by the impacts of Covid-19 is sport. The very existence and work of sport organisations, clubs, professional sport leagues, fitness centres, athletes, coaches, sport staff, sport volunteers and sport-related business, including sport event organisers and sport media, have been battling with staying afloat by cutting all unnecessary expenses and consolidating costs while also trying to maintain the community feel of bringing people together. The crucial role of sport sector could not underestimated, as it is both economic and labour intensive sector, namely, it generates money measured in billions of euros and USD dollars and employs people of all ages in a variety of sport-related jobs, while creating a deep emotional and social connection that positively affects physical and mental health. The aim of this research paper is to analyse and assess the possible long-term socio-economic impact of Covid-19 created crisis on sport sector by using monographic, content analysis and synthesis, logical constructive analysis and generalisation methods. The main results include the sport sector's list of issues faces and is likely to continue to live with during and after the pandemic.
\end{abstract}

Keywords: socio-economic impact, sport sector, sport economics, covid-19.

JEL code: Z2, Z28

\section{Introduction}

The nature of the Covid-19 induced economic crisis is unprecedented: beyond the repeated health and economic shocks, the long-term effects on human capital, productivity and behaviour may be long-lasting. Pandemic has governments operating in a context of radical uncertainty, and faced with difficult trade-offs given the health, economic and social challenges it raises. The outbreak of the pandemic has impacted not only main economic sectors taking the hit, namely, the public health, but the entirety of all possible economic sectors. One of the sectors hit particularly severe by the impacts of Covid-19 is sport. Sport stakeholders have been affected at all levels - from the biggest and most powerful international professional sporting leagues or major sporting events such as annual championships to the local grassroots sporting events managed by volunteer work or a small business, e.g. fitness gyms. The crucial role of sport sector could not underestimated, as it is both economic and labour intensive sector, namely, it generates profit measured in billions and employs people in a variety of sport-related jobs, while creating a deep emotional and social connection that positively affects physical and mental health.

The aim of this research paper is to assess the possible long-term socio-economic impact of Covid-19 created crisis on sport sector and the faced issues during and after crisis. To achieve the set aim of the research the author uses monographic, content analysis and synthesis, logical constructive analysis and generalisation methods. The main tasks are the following: 1) to analyse the basic theoretical aspects of sport economics; 2) to perform general analysis of sport sector's importance within the global and the European Union's economy; 3) to generally assess the possible long-term impacts and other pandemic induced issues on sport sector; 4) to draw general conclusions; 5) to elaborate a small set of proposals based on the analysis conducted.

The main research question posed by the author is the following: What are the main long-term issues the sport sector faces during and post the Covid-19 crisis? It could also be followed by another one that, and truth be told, it is easily answered, even without naming a concrete figure Namely, what is going to be the price of the long-term Covid-19 caused impacts, with the answer being "immeasurable", with all facts and history considered.

The novelty of author's research paper is founded on the assumption that sport could be used as an effective tool to boost the economy because of its labour intensive sector specifics and as a highly profitable economic sector, and the findings of this particular research could be used to further argue and prove the important role of sport sector within the national and international economic development and growth, as well as the necessity of annually and timely collected data on sport sector socio-economic data could enable a more definite assessments of the sector's impact on the overall economy. The latter leads to the problematic issues of this research conducted. Those are based on the on lack of annual sport sector economic impact evaluations that results of concrete data being reported sporadically, while delimitation of this particular research paper is that is not based upon a developed econometric model, but is limited in fact that the Covid-19 pandemic crisis is still an ongoing precedent with no concrete end in sight, thus topic is left for further theoretical discussion and empirical research in the future.

\section{Literature Review}


The author used various sources of different levels of significance to conduct the quick overview of the topic presented. This research paper is developed by using theoretical, scientific and specialized articles from academic journals, various online published legal documents and reports of international importance, e.g. EU legislation, global OECD and World Bank reports, as well as articles from World Economic Forum, sport business consulting think-tanks, news articles from across the world on the Covid-19 and sport related topics.

The most prominent literature used by the author during this research were the Conclusions of the Council (of European Union) and of the Representatives of the Governments of the Member States, meeting within the Council, on sport as a driver of innovation and economic growth (2014), on the economic dimension of sport and its socioeconomic benefits (2018) and on the impact of the COVID19 pandemic and the recovery of the sport sector (2020), that cover and emphasise the socio-economic importance and benefits of sport sector, consider the sector as driver for economic growth while also evaluating the impact the sector is facing during the current crisis assisted to establish the research and legal ground of sport sector's economic importance not only within the EU, but the world overall. Just as vital for the production of this paper were the major European Commission's published report on Study on the economic impact of sport through sport satellite accounts, that provided the author with the necessary statistics on the sport-related GDP and employment numbers across all EU Member States to further use it in the paper to prove the crucial socio-economic part of the sector within the economy.

As the situation of Covid-19 pandemic's impact on sport sector is still ongoing and changing rapidly, the assessed data figures (collected by December 2020) are subject to change, yet the overall general socio-economic scene of sport sector represented in the different kinds of literature within the next year, per author's view, is not going to change dramatically.

\section{Research results and discussion}

The year 2020 is going to be one to remember when everybody was told to sit at home, to observe social distancing and when the economic activities of all kind took a particularly bad left hook and nobody can say when the light at the end of the tunnel will become a permanent one. Pandemic has governments operating in a context of radical uncertainty, and faced with difficult trade-offs given the health, economic and social challenges it raises. A rebound of the epidemic in autumn 2020 is increasing the uncertainty. The nature of the crisis is unprecedented: beyond the short-term repeated health and economic shocks, the long-term effects on human capital, productivity and behaviour may be long-lasting. The COVID crisis has massively accelerated some pre-existing trends, in particular, digitalisation. It has shaken the world, setting in motion waves of change with a wide range of possible trajectories (OECD, 2020). The newly-developed vaccines have brought wishful thinking but the overall sense of relief and wishful thinking is still months away. Until then the Covid-19 pandemic is scorching its way across the world like a fire tornado and it has been leaving disastrous effects on world's health, educational, financial and commercial institutions. The outbreak of the pandemic has impacted not only main sectors taking the hit, namely, the public health, but the entirety of all possible economic activities and every single person involved in them.

One of the sectors that has been hit particularly severe by the socio-economic impacts of a disease is the sport industry at all levels from the biggest and most powerful international professional sporting leagues or major sporting events such as the Olympics and regional championships to the local grassroots sporting events managed by volunteer work or a small business, e.g. fitness gyms. The very existence and work of sport organisations, clubs, professional sport leagues, fitness centres, athletes, coaches, sport staff, sport volunteers and sport-related business, including sport event organisers and sport media, has been battling with staying afloat by cutting all unnecessary expenses and consolidating costs while also trying to maintain the community feel of bringing people together. However, the world must face the inevitable truth that it is going to take some time before the people will be allowed to pack up the stadiums and cash in the same level of profit from ticket sales as pre-Covid-19 crisis. This global crisis has led to strict restrictions imposed in the both supply and the demand trend, namely, the athletes unwilling and/or unable to travel while the fans are unwilling or unable to attend big sporting events or travel to attend them. This is a sharp contrast to the global financial crisis of 2008-2009 when the sport sector was left largely unaffected. This time it is different, largely due to the current and already expected substantial losses in revenues, while also trying to keep the dramatic disruption to the supply of sport under some kind of control.

With Summer Olympics in Tokyo and European Football Championship being postponed to 2021, it is safe to say that these events will not bring in as much revenue as the event organisation committees have calculated before for the event to break even, be profitable or have at least some economic impact. The same could be said for other big-to-middle-to-smaller scale sporting events - all of them require the fan presence for the sport sector to be lucrative. The sport's greatest strength is to gather interest and pull in crowds, because when a person buys a ticket and goes to a sporting event - be it local, national or international, it goes far beyond than what was spent on simply buying the ticket. For every 1 USD 
generated directly through sports, it can reach up to 2.5 USD (the multiplier index depends on the level of development of the market) produced in indirect and economy-induced effects (Somoggi, 2020). This impact, that can reach 2.5 times the direct revenue, is made possible due to sports dynamic nature and emotional social connection it brings to everyone involved in it. Thus, when the sport stops, the whole production chain that includes transportation, entertainment, food and drinks, accommodation, various product purchase and government taxes halts, too. With many major sporting events and competitions already postponed to 2021 and many cancelled during the 2020, all stakeholders involved - country governments, national and international sport governing bodies, event organisers, teams and athletes - are facing a disruption of major scale (Deloitte, 2020).

Professional sporting events without spectators or cut to the bare minimum capacity of people present, if luck and conditions permit, are set to be the new normal for the next year at least, if not longer. It is difficult to even comprehend how social distancing can be maintained at a full arena gathered to take in a match of two rival clubs. The socio-economic effects of this curtailment of activity could be widespread, and even now some time of existence in parallel with the disease and sporting events taking place behind closed doors, one can only make predictions of the losses the sector will face once more data and statistics become available. Owners, broadcasters and sponsors are now navigating the impacts and implication of event cancellations and modifications by calculating the losses. With the second wave hitting economy once again, the sport ecosystem now needs to find new ways to deal with threats to financial and business continuity arising from the disrupted cash flows, governing, legal and insurance challenges, and possible impacts of quarter-to-half longer term attendances and [fan] engagement (Deloitte, 2020).

Covid-19 threatens the economic viability of the existing pyramids of sports institutions and firms, but sport isn't only about watching professionals perform, the biggest part of it is the participation in grassroots sport, that relies on volunteers who help the grassroots events to take place and the people who actually participate in those events thus supporting the event itself, while also making a positive impact on other businesses involved. The grassroots sports rely on altruistic motives - there are no or limited financial incentives for taking part. (Reade, Singleton, 2020). Yet there is clear evidence of long-term benefits from participation in sport, not just in health outcomes but also in the labour market and subjective wellbeing (Lechner, 2009) that in terms makes people allocate their time and energy in another economic activities that boost the local, national and international economic development and growth. Elite sport has its role to play in this too, with evidence that the presence of role models encourages increased amateur participation (Mutter, Pawlowski, 2014).

With all that in mind and the facts on hand, it is safe to say, it is too early to write the history of sport, economics and Covid-19, as the story is far from over.

The next subsections of this paper will present economics of sport as a peculiar but crucial part of overarching economy, followed by sport as an important global and European Union (hereinafter - EU) market economy player and its positive socio-economic impact, the main long-term issues, impact and predicted losses sport sector faces during and post the pandemic, as well as the possible support measures to be taken to adjust to the new reality.

\section{The economics of sport}

The economics of sport are a peculiar and fascinating at the same time because of the unusual connections between the fans, the sport teams and clubs, all of the governing bodies that partake in the management of the structure, and the ways that they interact with local communities. Sport is a cross-sectoral phenomenon and goes far beyond the revenues of the sport industry. Thus, sport economics cannot be dismissed, and per Bryson and Frick (2015), there are at least four blunt reasons to name: 1) Sport is a big business (it generates revenue for various economy sectors, adds to state's Treasury through taxes and furthers overall sector GDP growth); 2) Sport employs a lot of people (it is an employment intensive economic sector); 3) Sport matters to the participants and its supporters (it is a social activity with an emotional investment), and 4) [Sport] sheds a light on fundamental economic questions.

Sport is recognised as an economic driver for growth in terms of effects on value added, gross domestic product and purchasing power. Author adds, that the aforementioned reasons for the vital role of sports in two crucial domains, namely, economy and personal lives of millions of people around the world, as well as author's personal observations over the years as a sport fan and exploring multiple kinds of physical activities to improve both physical and mental health, it is easy to evaluate and comprehend the level of sport's impact, as it is it is inestimable. Any major sporting event - of national or international scale - opens the multiple possibilities to grow and develop for both individuals and businesses. It happens because of sport sector's tight interconnection with other sectors, such as tourism, sales, TV and broadcasting etc., through intercultural 
unification of people across various regions and countries, as an extensive productive and effective diplomatic and economic tool of cross-country collaboration of highest level with millions worth of incoming investment and profit, brings together businesses that creates new partnerships.

When one looks particularly into the modern sport, it is hard to miss the influence of economic theories, as it is evident from the way players are drafted or how much they are paid, through to individual coaching decisions, and even strategic shifts across entire leagues (Harcourt, 2017), let alone the revenue it brings. Sports are becoming a more influential in economics, but economic theories have a place in sport as well. Game theory, for example, is used in both economics and sports. The theory is traditionally used for economists to figure out how events will unfold based on their goals, motivations and what is perceived to be best interest.

As already mentioned before biggest part of the economics of sport and its economic impact is generated at the grassroots sport, as that one in particular has a lot of potential and support the creative side of economies. In the words of World Economic Forum 2018 (Nasr Allah, 2018):

"In general, the category of Sport that can benefit society most is actually not receiving the appropriate levels of support from various stakeholders; however, this could change should the Creative Economy find both economic and social value in investing more in grass roots Sport, where innovative partnership models between the public and private sectors could be effective."

In addition to the reasons mentioned the sport as an economic sector reaps also local economic benefits, and broader economic benefits resulting from sports participation include the following (Gratton, 1998): 1) improvements in health and fitness; 2) contribution of sport to the quality of life; 3) reductions in anti-social behaviour; and 4) inward investment attracted to the local and regional economy as a result of investment in sports infrastructure. This train of thought has also been on the forefront of European Union sport dimension development's discussion, namely, sport represents, in particular, a stake in public health, regional development and tourism, but also in integration and education and as a social link (Council of European Union, 2018).

An economic evaluation of sport through improvements in health and fitness takes into account spending associated with sport injuries or manufacturing of sport supplements, yet a much bigger element is generated indirectly when the practice of sport reduces the prevalence rate of certain diseases among population, leading to savings of state budget allocations to healthcare. Sport also improves the overall well-being of any person participating in it, as it raises the level of happiness and life satisfaction. As per Kokolakakis, Edmondson et.al (2020) the excess of life satisfaction and fulfilment can be considered a real asset for a country when levels of sport participation increase. As for the reductions in antisocial behaviour, e.g. young people are less likely to commit crime and more likely to do better at school, while also improving the social inclusion of young people that provides more socio-economic opportunities later on in life. Through these local economic benefits sport sector provides various ways to contribute to the economy, namely, the healthier and happier people become by doing sports, the better it is for the national and international economy. As it is ever so crucial during this pandemic induced crisis.

Despite the sport economics developing as fast as any sporting and/or physical activity in real life, there are still additional aspects of the economic dimension of sport that need to be considered, such as the quantification of health economic effects of physical activity, the recognition of the additional benefit of voluntary work, the contribution of innovation to enhancing growth potential and the analysis of the impact of sportrelated projects on regional development (Council of European Union, 2018).

\section{Importance of sport in the global economy}

Sport, the largest non-governmental movement in world and Europe, is an important driver of innovation and economic growth. Spurred by intense competition, sport has an in-built and inherent incentive pushing participants towards constant improvement in performance and excellence (Council of European Union, 2014). According to Somoggi (2020) from a Brazilian based sport economics consulting think-tank SportsValue, the global sport market moves around 756 billion USD annually in direct value, however, when other sectors connected to sport sector are taken into account, the volume might exceed 840 billion USD annually. The United States sport market is valued around 420 billion USD, while European market brings in another 250 billion USD. The fastest growing market in global sport is China that makes about 150 billion USD and is projected to reach the revenue of at least 350 billion USD in five years (Somoggi, 2020) prior the Covid-19 crisis. 


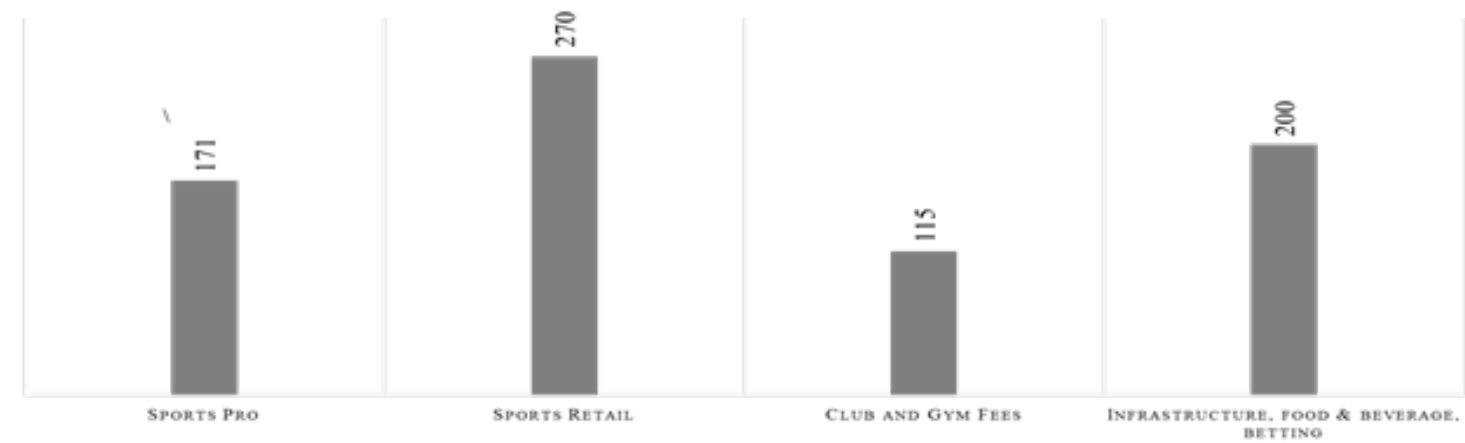

Source: Author's reconstruction of think tank Sports Value figure (Somoggi, 2020).

Fig. 1. Global revenues of sport industry in 2019 in billion USD

The Figure 1 conveys that the sport sector's largest revenue source is sports retail that accounts more than $1 / 3$ of the industry's global market outreach. Professional sport, even if not the main source of the portrayed revenue, is undoubtedly the one with the greatest impact on the whole sport production chain with its match day revenues, sponsorships, broadcasting, players' transfers, as well as it high media consumption and employment character. Club and gym fees, as well as the revenue from infrastructure, food and beverage, sport betting activities are crucial to the global sector revenue (the indirect and induced revenue from the tourism and entertainment sector not included).

Referring to the overview of the global revenue structure described above, it should also be noted that the financial side of the sport sector consists of many budget positions, thus creating the turnover structure of direct and indirect income, as well as direct expenses. These positions include a variety of budget sub-positions that may vary from country to country, from one sporting event to another, but on the global scale stay more or less constant. Namely, the direct income of any sporting event (in this example of sporting event turnover structure author uses the case of EuroBasket 2015 D Group event taking place in Riga, Latvia from 5 to 10 September, 2015) is formed by the ticket fees, sponsorships, municipal and state grants (depends on the country the event takes place in), and income from the cooperation partners, while the indirect income comes from the event visitors. The indirect income is particularly important if the event is an international one, as the foreign and local visitors are enjoying the event by spending their fair share on transport, accommodation and catering (namely, HoReCa (Hotels, Restaurants and Cafes)) sector costs), as well as event merchandise and vast list of souvenirs. As for the direct expenditure, it is usually connected to the expenses determined by the international sporting organisation, be it FIBA (full name in English: International Basketball Federation) or IOC (full name in English: International Olympic Committee), that include licencing, sport officiating expenses, broadcasting expenses, IT expenses, doping testing expenses. Other direct expenditure positions for most part include expenses of event staff, sport facilities' maintenance, marketing, volunteering, fan zone maintenance et.al. (Kehris, Reihmanis, Stalbergs, 2015).

\section{Importance of sport in the EU economy}

Sport is an important economic sector in the EU (with a bigger or smaller share in every national economy) which is comparable to agriculture, forestry and fisheries combined. The sport industry's economic and social strengths as a tool to tackle the economic crisis caused by the COVID19 pandemic should not be underestimated. Sport uses more intermediate goods than an average sector, and as an economy sector it is deeply connected with other sectors that if one suffers, then everyone suffers.

The latest study presented by the European Commission presents the sport sector as an important sector of economy with an upward linear trend upon comparison with previously collected data. In 2018 (per research published in 2018, with data base year of 2012) the sport-related GDP of the EU was calculated to be 279.7 billion euros, that equals $2.12 \%$ of total GDP in the EU, namely, every 47 th euro was generated by the sport sector. Apart from that sport sector is also employment intensive, meaning that it generates more employment than its share in GDP. Sport-related employment in the EU was 5.67 million persons that equals $2.72 \%$ of total EU employment, with every 37 th employee works in the sport sector (European Commission, 2018). Author adds that despite the seemingly slow growth of the sport-related GDP, sport sector is considered to be one of the fastest developing economy segments in the world, and the current crisis is already impacting the sector, thus impact evaluations in the future are going to be vital to determine the next steps of strategic support. 
The largest sport-related sectors (per research published in 2018, with data base year of 2012) are education (51.2 bln Euros, nearly 1,111,000 employees), sport services (42.1 bln euros, 749,000 employees), public administration (32.2 bln euros, 503,000 employees), accommodation and restaurant services (23.2 bln euros, nearly 586,000 employees), and retail (19.9 bln euros, nearly 587,000 employees). Just these five sectors alone add up to $1.29 \%$ of the EU's GDP and $1.70 \%$ of its employment that proves the crucial role of sport in the EU economy. Therefore, governments should have a special interest in protecting jobs in sport as an industry with a strong economic impact in terms of employment and its share of GDP. The associated social benefits of sport will contribute to the rebuilding of European societies during and after the crisis (European Olympic Committees, 2020).

The SHARE initiative has been developed and since 2018 has been a steadfast advocate of the relevance of sport for regional development through its impact on a number of key policy areas such as innovation and research, social cohesion and inclusion, territorial regeneration and attractiveness or environmental protection, in particular as an effective means of attaining the objectives of EU Cohesion Policy and the European Structural and Investment Funds (hereinafter - ESIF). Despite supporting evidence, sport investment has never been mentioned as a thematic objective or sector in EU Cohesion Policy regulations. This has been regularly flagged by public authorities and sport movement representatives as one of the main issues preventing use of ESIF to directly support sport and physical activity (European Commission 2018a).

\section{Pandemic's long-term impact on sport sector}

The COVID-19 pandemic has delivered a global economic shock of enormous magnitude, leading to steep recessions in many countries. The baseline forecast envisions a 5.2 percent contraction in global GDP in 2020 - the deepest global recession in eight decades, despite unprecedented policy support. The spill-over from one country to another is affecting each and every economic activity disrupting financial and commodity markets, global trade, supply chains, travel, and tourism (World Bank, 2020).

Governments, albeit with various success, are doing everything in their power to save their respective nations while also trying not destroy their economies from taking even more deep-cutting hits by the hand of Covid-19, states across the globe have imposed restrictions on social distancing to battle the pandemic's second wave. It is safe to say, that the sport sector is going to be one of those sectors that will need a long process to readjust its business model to the new normal, being disproportionately affected and extensively relying on human contact and interaction. Sport will experience a recession several times worse than the average sector of any economy (Kokolakakis, Edmondson et.al. 2020), that could not yet be measured in concrete figures.

The long-term basic operating model of sports leagues will remain unchanged. The sport competitions and leagues will still organise the same way - via a competitive season of pre-defined length with a concrete set of races, games, matchups etc. However, the coronavirus pandemic has underlined how dependent this model is on TV broadcasting and live audiences (ticket sales, sponsor and advertising connection, merchandise onsite purchase opportunities to spectators and overall emotional connection and influence for the athletes). In the simplest terms, there are three main income streams for sports: broadcasting (sales of media rights), commercial (sponsorship and advertising partnerships) and match day revenue (ticketing and hospitality) (Hall, 2020).

Professional, amateur and even grassroots sports leagues and championships are analogous to entertainment companies, where each team and athlete (dependent on the sport) is like a different channel. The teams have their own identities, employees and fan bases, but the overall 'programming schedule' (the rules of the game and the fixture list) are set by their governing bodies, e.g. league management, federation etc. This comparison may not please the purists, but the reality in both sports and entertainment is that the more people watch it, the more valuable it becomes. Thus, also a game or a race behind closed doors, the postponement or even cancellations of competitions, cuts deep and directly impacts the sport sector and every business connected with it. E.g. the sport venue market generates more than 50 bln USD a year, slightly more than the broadcasting rights with more than 49 bln USD (Somoggi, 2020). The games behind closed doors will severely impact the ticket office sale profits, as those are an important source of income in the sector, because are directed to the maintenance of the infrastructure and the staff employed there, many of them joining ranks of unemployed. Thus, with the restrictions imposed in every country that also means the nullification of the profits expected from the scheduled ticket sale (Redondo, 2020).

Tourism will also be greatly affected by the paralysis of sport. The tourism sector is linked to sports events that attract thousands of people in different parts of the world, e.g. the Olympics. The greatest sport competition worldwide generates great expectations and in the case of the postponed Tokyo Olympics by one year, around half a million visitors expected, and right now it is hard to predict with at least some capacity of fans allowed in the stadiums and other Olympic venues. The same is true of other important commitments, such as in elite football tournaments 
such as Champions league and the European Nations Cup. These are events on which part of the tourism associated with areas visited highly depend. The authorities are already having high level summits to assess and agree on roadmaps to mitigate as much as possible the blow received, as the estimated (devastating) losses could amount in multiple billions. According to sources such as the Tokyo Olympic Games organizing Committee and International Olympic Committee the figures involved are impressive. The postponement of the Olympics itself costs around 6 bln USD (Al Jazeera, 2020), that is not even close to the final investment made, as it amounts around 25.5 bln. euros (about 5 bln assumed by the city of Tokyo, another 5 bln by the Japanese Olympic Committee and about 1.265 bln by the Japanese government). 4.5 bln USD from television rights, 3 bln from private sponsorship by companies such as Toyota, Bridgestone and Panasonic, and 900 million from entry fees, marketing and other aspects such as expected revenue from foreign tourists. However, there still is a slight chance that event might be cancelled, as nobody is certain how the situation may look like in the summer of 2021 (Redondo, 2020).

As far as football is concerned, the big event that was scheduled for 2020, the European Championship 2020, was moved to 2021 and there is a speculation about this tournament, with a budget of 2.2 bln EUR and gives 371 million EUR in prizes to the 24 qualified teams, 200 million EUR for compensation to the clubs that give their players to play the tournament and 775 million EUR to the federations of each nation. The audience presence capacity is set to be evaluated, however, it could be predicted that sure losses are set to be recorded that will be calculated only post the event itself. While the major European leagues are also expecting substantial losses, since the total income set and put at stake (the English Premier League, the Spanish La Liga, the German Bundesliga, the Italian Seria A and the French Ligue 1) accounts for some 4 billion euros, where 60\% comes from television broadcasting rights, $25 \%$ from brand sponsorship income and $15 \%$ from other items (with predicted losses at the start of the pandemic period due to the cessation of activity could have reached 1.2 billion EUR in the Premier League, 900 million EUR in the Spanish La Liga, 740 million EUR in the Bundesliga, more than 600 million EUR in the Italian Serie A and almost 400 million EUR in the French domestic competition). Despite the national championships taking place and exhibiting a make-belief normalcy in the world of football, it is far from it, as players themselves have reported the eerie feeling in an empty stadium, arena and/or racing track, lacking the emotional connection with the crowd.

Other sports put into play amounts just as impressive, e.g. the motor racing and motorcycling, with Formula 1, with an average of 105 million euros of impact in each city that hosts a Grand Prix, or the MotoGP championship, with an average of 57 million euros per city and Grand Prix. In addition, there are competitions in the United States in basketball, with an NBA (the most important basketball competition in the world) that could lose up to 916 million euros at the box office, or baseball, with an MLB that could lose up to 2 bln EUR due to the interruption of ticket sales alone, not accounting the other financial aspects of organizing a single game (Redondo, 2020; Al Jazeera, 2020).

The greatest impact will surely be related to the issue of broadcasting rights for competitions and sports revenues, a thorny and difficult issue that is already generating a deep debate. Networks all over the world have invested a lot to obtain ownership of the rights for broadcasting sporting events. In many cases the seasons and calendars for various sports, such as football or basketball to give just a few examples, had been halted and then completed in the summer of 2020, under pressure of the broadcasting contracts weighing down on the leagues to meet the contractual obligations. The fact remains, even despite the games, matches and races taking place, the organising and governing bodies of the major sporting events are observing an enormous effect on the overall budget and cash flow. However, the big leagues and their respective sporting events could claim the lost money in court and cushion the blow from the losses at least to some extent. It is the national competitions and smaller leagues, which have their own contracts and rights that could suffer the most. With no concrete ending of the pandemic in a close sight, the fear for what may happen in the future is building along with the new scale of values for sports broadcasting rights and televised sport consumption opportunities.

There are three transformational trends that are going to leave lasting impact the sports broadcasting industry (Hall, 2020):

1) Acceleration of adoption of direct-to-consumer (D2C) services to distribute sports content, as it is more appealing now due to the no-fixed schedule and large libraries of content to keep people occupied, that in turn will reduce broadcasters' advertising income and their power to purchase sports rights;

2) Exploration of more diverse income streams could include live monetization models, such as gamified viewership (e.g. live payments for digital items, new camera angles, fan commentary and statistical analysis) and betting;

3) Building an opportunity for virtual technologies to grow during the absence of "real" sport by using e-sports to maintain interest and a sense of competition during shutdowns. E-sports have grown massively in recent years and present a new way to engage fans and bring in revenue, and immersive technologies could enable fans to experience games live, without having to be physically present - an idea that once may have been counterintuitive but now seems logical. 
With all that considered, the long-term impact from this pandemic are not going to be easy to swallow, yet, it is possible to adjust and move forward with the new experiences gained during the unprecedented times. Nothing will be the same as during the pre-pandemic times, but everything could be done to make the experience of live sport consumption more consumer-friendly, wherever that consumer might reside.

\section{Other pandemic induced issues on sport sector}

European sport largely relies on the clusters of small clubs and associations which play a key role in enabling people participate in affordable sport activities and to enjoy sport and physical activity on a daily basis. These little organisations are the very essence of European sport. However, being non-profit by nature and thus without any reserves, they work in precarious conditions often, driven by the support of passionate volunteers and employees. In sport, especially at grassroots level, this economic crisis will result in the bankruptcy of associations and clubs, as is already happening, that promote physical activity and offer affordable sport activities to citizens across Europe. Consequently, the sport sector is also set to face an unemployment emergency. These associations are at the greatest risk of shutting down due to the crisis, which could have a number of longlasting impacts on the economy and society. This can and will endanger the future of all grassroots sport in Europe.

The main issues observed by the sport sector stakeholders are the following (European Olympic Committees, 2020):

1) Finance-related issues: With the lost revenue, the organisations are unable to provide their services to citizens, especially at the time of the year which marks the beginning of the season for most sports i.e. the time when they organise training and competitions, raise money through tournaments, organise events, seminars, training camps, races, etc. They have also lost a significant part of the regular income that comes from different types of fee, e.g. membership, licensing, participation or subscriptions, while cash flow difficulties present themselves as organisations have fixed costs that they have to pay regardless of the loss of revenues;

2) Athlete-related issues: Athletes have not only lost a season and thus certain financial benefits, but also their coaches and their ability to train and compete, with implications for their income. For some, this represents the loss of an opportunity to gain in status and secure funding from private and public sources as well. Athletes also do not receive financial support (e.g. scholarships, traineeships) because of the fall in sport organisations' revenue;

3) Employment-related issues: Unemployment: layoffs of employees, athletes, coaches and other workers, especially those whose salaries depend on the above-mentioned income sources; none of the jobs in the sport sector are safe, while freelancers - self-employed persons often operating in the gig economy, who are no longer able to provide services (e.g. trainers) have fallen under the radar when it comes to different types of public support for the preservation of jobs in enterprises; last but not least, organisations have lost a significant part of their unpaid workforce, i.e. volunteers who are restricted to their homes or have limited mobility;

4) Entrepreneurial approach related issues: Industries that are directly and indirectly related to sport are seeing that a lot of the current business models are failing and feel the need to change their business strategies over both the short and long term as this affects a large number of jobs and entrepreneurs.

In order to address the issues listed above European sport stakeholders have called upon the EU and Member States' governments to establish a quick and adequate support and clear action plan to mitigate the adverse impacts of the Covid-19 crisis on the sport sector. Sport sector stakeholders added that it is crucial to support and stimulate a sustainable sport sector through various funding opportunities in the context of European initiatives, such as Support to migitate Unemployment Risks in an Emergency (SURE), Coronavirus Response Investment Initiative (CRII), and Coronavirus Response Investment Initiative Plus (CRII+), as well as other initiatives at national (note: despite national support / state aid being crucial for the sector's recovery, this support will have to respect the EU State aid rules, especially when it is granted to undertakings engaged in an economic activity) and European level. Support measures proposed to be undertaken on the supranational and national levels are various, but some of the most important are the following (European Olympic Committees, 2020) and correlate with the Council of European Union Call to action in "Conclusions of the Council and the Representatives of the Governments of the Member States meeting within the Council on the impact of the Covid-19 pandemic and the recovery of the sport sector" (Council of European Union, 2020):

- Finance related activities for securing staff employment and organisation liquidity: 1) Ensuring the sport sector is eligible to funds for the protection of jobs, employees and self-employed against the risk of dismissal and loss of income; 2) Lightening the rules relating to state aid, as is already the case in other sectors, with a view to allowing tax breaks for entities and organisations that promote sport activities; 3) Redirecting certain EU and national funding streams and notably the ESIF towards actions promoting the wellbeing of citizens including through sport and physical activity; 4) Providing loans to ensure the liquidity of sport clubs and other associations through existing EU 
financial instruments (e.g. European Investment Bank) or newly created instruments as a response to this crisis; and 5) Setting up public and private solidarity funds for grassroots sport clubs and associations and their employees, including outsourced coaches and freelancers self-employed persons;

- Innovation related promotion activities: 1) Stimulating innovation programmes (industrial modernisation) for sport enterprises to address the current societal challenges; and 2) Creating new funding opportunities as innovative ways to promote sport and physical activity in times when people are restricted to their homes;

- Healthy lifestyle promotion activities: Stimulating a healthy active lifestyle in the working population, both those working at home and at the office by introducing innovative solutions to stimulate physical activity.

\section{Conclusions}

The author of this paper has reached the set of this research paper by performing analysis and assessment of the importance of the sport sector in global and EU economy, as well as possible long-term socio-economic impact and the issues the sport sector faces right now with possible support measures proposed. Based on the performed tasks the following conclusions could be drawn:

1. Sport as an economic sector reaps local economic benefits, while broader economic benefits resulting from sports participation include the following 1) improvements in health and fitness; 2) contribution of sport to the quality of life; 3) reductions in anti-social behaviour; and 4) inward investment attracted to the local and regional economy as a result of investment in sports infrastructure.

2. Global sport market moves around 756 billion USD annually in direct value, with other sectors connected to sport sector are taken into account, the volume might exceed 840 billion USD annually. The United States sport market is valued around 420 billion USD, while European market brings in another 250 billion USD, with the fastest growing market in global sport is China that makes about 150 billion USD and was projected to reach the revenue of at least 350 billion USD in the next five years prior Covid-19 crisis, while sport-related GDP in 2018 in the EU was 279.7 billion euros, that equals $2.12 \%$ of total GDP in the EU, with a slow upward growing trend.

3. Sport is an employment intensive, it generates more employment than its share in GDP. Sport-related employment in the EU in 2018 was 5.67 million persons that equals $2.72 \%$ of total EU employment. Out of the whole sports sector, grassroots sports are the most employment intensive.

4. Long-term sport's socio-economic losses brought by the Covid-19 pandemic are and will be enormous, predicted to be measured in billions USD / EUR. The pandemic created crisis has already resulted in lost jobs, lost revenues and profits, ill health and lost socialization opportunities among citizens, including the lasting effects on mental health.

5. The biggest revenue and profit losses will be in the sport organisation budgeting positions, e.g. ticket sales, sporting venue and infrastructure maintenance and staff salary expenses, as well as losses felt by the lack of cross-sectoral economic activities, especially, tourism.

6. The greatest impact will be related to the issue of broadcasting rights for competitions and sports revenues, as the ecosystem of live sport consumption has rapidly changed in the rapidly developing digital era of consumption. New digital trends are set to take broadcasting's place, e.g. direct-to-consumer services to distribute sports content, exploration of new diverse income streams and the growth of digitalisation opportunities through e-sports.

7. The main issues faced by the sport sector are finance, athlete, employment and entrepreneurial approach related issues with support measure activities proposed to solve them, such as finance related activities for securing staff employment and organisation liquidity, innovation related and healthy lifestyle promotion activities.

Based on the general conclusions listed above it was possible for the author to propose a set of recommendations for action that could help boost the economy, as well as improve the economic research overall. These recommendations are general and could be developed further as the pandemic is still ongoing, at the moment, however, they should be taken into account while observing and computing the impact caused to the sport sector during the pandemic and afterwards. The main and the most important recommendation is the following:

- To use sport sector and every economic activity adjacent and associated with it as an effective economic tool to help any region, country and the world in general to reduce unemployment during a recession;

- To start getting the people back to watch and enjoy live sporting events slowly, first by abiding state pandemic period regulations, further down to adjust the crowd volume with the loosening of the restrictions, as the racing tracks, basketball and ice-hockey arenas and football stadiums surely will not be operating at full capacity, as it is going to be both unsafe and health hazard to thousands of people. The returning 
crowds and the abiding of the state or sport organization level placed restrictions and acting in accord with them is the surest way forward to return to get back at least some part of the profit.

The author developed this research paper by using sport-related socio-economic data that has been calculated upon request, thus making it hard to research the trend, as there is a lack (or only a small number of statistical databases on sport) of annual socio-economic data on any sport-related collected on a regular basis. Thus, the author believes, that due to sport sector being an economically and labour intensive sector, it is necessary to consider the following:

- To establish an annual sport-related socio-economic data collection and analysis, as it would improve the economic research could be carried out, the public sport governance could strategically plan and/or adjust further policy development and growth, as well as enable for the sport economics related research to be conducted more often, if not on a daily basis. If not annual, then the data collection could take place every two years, considering the periodicity of Winter and Summer Olympics and other major sporting events.

\section{Bibliography}

Al Jazeera News Agencies, 2020. IOC: Tokyo Olympics to be scrapped if not held next year. Al Jazeera Sports. [Online] Available at: https://www.aljazeera.com/sports/2020/5/21/ioc-tokyo-olympics-to-be-scrapped-if-not-held-next-year [Accessed on: 22.11.2020]

Bryson, A., Frick, B., Simmons, R., 2015. Sports Economics: It May be Fun but What's the Point?. National Institute Economic Review, Vol. 232, pp. R1-R3. [Online] Available at: 10.1177/002795011523200101 [Accessed on 21.11.2020]

Council of the European Union, 2014. Conclusions of the Council and of the Representatives of the Governments of the Member States, meeting within the Council, on sport as a driver of innovation and economic growth (2014/C 436/02). Eur-Lex. [Online] Available at: https://eurlex.europa.eu/legal-content/EN/TXT/PDF/?uri=CELEX:52014XG1205(01)\&from=EN [Accessed on 22.11.2020]

Council of European Union, 2018. Conclusions of the Council and the Representatives of the Governments of the Member States, meeting within the Council, on the economic dimension of sport and its socioeconomic benefits (2018/C 449/01). Eur-Lex. [Online] Available at: https://eurlex.europa.eu/legal-content/EN/TXT/PDF/?uri=CELEX:52018XG1213(01)\&rid=3 [Accessed on 21.11.2020]

Council of the European Union, 2020. Conclusions of the Council and the Representatives of the Governments of the Member States meeting within the Council on the impact of the COVID19 pandemic and the recovery of the sport sector (8926/20). [Online] Available at: https://www.consilium.europa.eu/media/44622/st08926-en20.pdf [Accessed on 20.11.2020]

Deloitte, 2020. Understanding the impact of Covid-19 on the sports industry. [Online] Available at: https://www2.deloitte.com/content/dam/Deloitte/uk/Documents/sports-business-group/deloitte-uk-understanding-the-impact-of-covid-19-on-thesports-industry.pdf [Accessed on 19.11.2020]

European Commission, 2018. Research report on Study on the economic impact of sport through sport satellite accounts. EU Publications. [Online] Available at: https://op.europa.eu/en/publication-detail/-/publication/865ef44c-5ca1-11e8-ab41-01aa75ed71a1 [Accessed on 20.11.2020]

European Commission, 2018a. SHARE initiative. EU Sport. [Online] Available at: https://ec.europa.eu/sport/share-initiative_en [Accessed on 19.11.2020]

European Olympic Commitees, 2020. Position paper on the impact of the COVID-19 crisis on the sport sector. [Online] Available at: https://euoffice.eurolympic.org/files/position_paper_COVID-19\%20final_revision.pdf [Accessed on 19.11.2020]

Gratton, C., 1998. The economic importance of modern sport. Culture, Sport, Society, Volume 1, 1998 - Issue 1, Pages 101-117. [Online] Available at: https://doi.org/10.1080/14610989808721803 [Accessed on: 21.11.2020]

Hall, S., 2020. This is how COVID-19 is affecting the world of sports. World Economic Forum. [Online] Available at: https://www.weforum.org/agenda/2020/04/sports-covid19-coronavirus-excersise-specators-media-coverage/ [Accessed on 21.11.2020] 
Harcourt, T., 2017. How and why economics is taking over sports. The Conversation. [Online] Available at: https://theconversation.com/how-andwhy-economics-is-taking-over-sports-88574 [Accessed on 21.11.2020]

Kehris, E., Reihmanis, R., Štālbergs, T., 2015. Pētījums par EuroBasket2015 rādītājiem ekonomiskajiem ieguvumiem un ietekmi uz valsts budžeta ieñēmumiem. Latvijas Basketbola savienība. [Online]. Available at: https://basket.lv/documents/38518-2015-12-17eb2015_ekonomiskie_ieguvumi-1450359168.pdf [Accessed on 30.12.2020]

Kokolakakis, T., Edmondson, L., Ping Kung, S., Storey, R., 2020. Resourcing the Sustainability and Recovery of the Sport Sector during the Coronavirus Pandemic. Commonwealth Moves. A special focus on Sport, Physical Activity and Covid-19 Vol. 2020/02. [Online] Available at: https://thecommonwealth.org/sites/default/files/inline/D17162_Sport_Covid_Series_PaperTwo_V3.pdf [Accessed on 19.11.2020]

Lechner, M., 2009. Long-run labour market and health effects of individual sports activities. Journal of Health Economics Volume 28, Issue 4, July 2009, Pages 839-854. [Online] Available at: https://doi.org/10.1016/j.jhealeco.2009.05.003 [Accessed on 22.11.2020]

Mutter, F., Pawlowski, T., 2014. Role models in sports - Can success in professional sports increase the demand for amateur sport participation?. Sport Management Review, Volume 17, Issue 3, August 2014, pages 324-336. [Online] Available at: https://doi.org/10.1016/j.smr.2013.07.003 [Accessed on 21.11.2020]

Nasr Allah, S., 2018. Exploring the link between sport and economics. SportandDev. [Online] Available at: https://www.sportanddev.org/en/article/news/exploring-link-between-sport-and-economics [Accessed on: 22.11.2020]

OECD, 2020. The territorial impact of COVID-19: Managing the crisis across levels of government. [Online] Available at: https://read.oecdilibrary.org/view/?ref=128_128287-5agkkojaaa\&title=The-territorial-impact-of-covid-19-managing-the-crisis-across-levels-of-government [Accessed on 22.11.2020]

Reade, J., Singleton, C., 2020. Sport: what could be the long-term effects of coronavirus?. Economics observatory. [Online] Available at: https://www.coronavirusandtheeconomy.com/question/sport-what-could-be-long-term-effects-coronavirus [Accessed on 20.11.2020]

Redondo, R., 2020. Sports industry fears severe economic losses from coronavirus pandemic. Atalayar - Between two shores. [Online] Available at: https://atalayar.com/en/content/sports-industry-fears-severe-economic-losses-coronavirus-pandemic [Accessed on 19.11.2020]

Somoggi, A., 2020. Coronavirus's economic impact on the Sports Industry. SportsValue. [Online] Available at: https://www.sportsvalue.com.br/en/coronaviruss-economic-impact-on-the-sports-industry/ [Accessed on 19.11.2020]

World Bank, 2020. Pandemic, Recession: The Global Economy in Crisis. Global Economic Prospects. [Online] Available at: https://www.worldbank.org/en/publication/global-economic-prospects [Accessed on 22.11.2020] 


\title{
FACTORS INFLUENCING PREMIUMS AND DISCOUNTS FOR CONTROL IN ASSESSING THE VALUE OF A BUSINESS
}

\author{
Svetlana Saksonova, University of Latvia \\ Neli Abramishvili, Saint Petersburg State University \\ Oksana Katalkina, University of Latvia
}

\begin{abstract}
The issues of establishing the amounts of premiums and discounts for control in determining the value of a shareholding and the factors influencing this are among the fundamental problems of business valuation. This is due to the fact that the amount of control premium can significantly affect the market value of an evaluated business or a shareholding.

The relevance of this paper lies in the fact that the results obtained in the course of the study can be used to further deepen the understanding of the influence of the degree of control on the valuation of a business (valuation of a shareholding), its characteristics, and factors affecting the size of the control premium. This contributes to the improvement of methods for assessing the value of companies in emerging investment markets, including the Latvian market.

The research methodology used in this paper starts with a literature review to shed light on main controversial issues of the phenomenon stressed out in the previous studies. Due to empirical nature of the paper, generally accepted methods of economic research were used including comparative analysis and synthesis. Thus, the methodological basis of the study is the analysis of the literature sources, synthesis and comparison of statistical information.

The purpose of the paper is both to determine the factors affecting the amount of a control premium and to analyse their magnitude, using data from empirical studies conducted in this area by various authors for the period from 1968 to 2018. Therefore, the analysis aims to address the issue of determining the volume of premiums and discounts for control when assessing the value of a business. The conducted study has shown that a premium for control can significantly increase the value of a business or a shareholding being sold (by $7 \%-82 \%$ ). At the same time, the lack of control leads to the application of discounts when assessing the value of a business and their size can also vary from $7 \%$ to $82 \%$.

The authors' recommendations are addressed to business owners in emerging markets and are aimed at focusing efforts towards improving key indicators that affect the value of a possible control premium. These are such indicators, as: the degree of concentration of the share capital of the evaluated company; the financial status and financial performance of the company; making use of differences in country legislation governing shareholder rights; the presence of competition for the purchase of a particular company; the presence of a system and voting procedure established in the company.
\end{abstract}

Keywords: premiums, discounts, factors, control, shareholding.

JEL code: G32, G34

\section{Introduction}

In the modern economy, discounts and premiums are the most important tools used by analysts in assessing the value of a business, as well as in mergers and acquisitions (M\&A). Rid et al (2007) note that acquisition is a general term used to describe the transfer of ownership, while merger is a term describing a procedure that may or may not follow the acquisition, but the valuation is done anyway. Therefore the issues of establishing the amounts of premiums and discounts for control in determining the value of a shareholding and the factors influencing this are among the fundamental problems of business valuation. This is due to the fact that the amount of control premium can significantly affect the market value of an evaluated business or a shareholding.

The relevance of this paper lies in the fact that the results obtained in the course of the study can be used to further deepen the understanding of the influence of the degree of control on the valuation of a business (valuation of a shareholding), its characteristics, and factors affecting the size of the control premium. This contributes to the improvement of methods for assessing the value of companies in emerging investment markets, including the Latvian market.

The premium in M\&A transactions is the excess of the transaction price (the amount actually paid by the buyer for the item) over the fair market value of the item at the date of the transaction. Among the most used and widespread premiums and discounts, one can single out those that are directly related to the presence or absence of a certain level of control. 
Control in general can be characterized as "the right to participate in management and determine company policy" (Pratt, 2007). The degree of control that a particular shareholding provides can range from $100 \%$ control to no control at all, with only a small stake in a company's capital. Therefore, premiums associated with a high level of control, or discounts, due to its insufficiently high degree, depend on the type or amount of control powers that belong to a particular shareholder.

To determine the amount of the premium and discount, it is firstly necessary to determine a reasonable base value to which they can be applied. This base, as a rule, is either the value of a controlling interest or the value of a liquid minority interest. Recommended premiums and discounts are usually applied at the very end of the business valuation process. When assessing the value of a business, control premiums or discounts are usually determined prior to premiums and discounts for liquidity. As a rule, this happens because the degree of control, or lack of it, to one degree or another, affects the company's liquidity.

In each specific case, the amount of premiums and discounts for control depends on many factors specific to each type of business, for example: internal features - such as a proportion of the evaluated shareholding, a degree of share capital concentration, a voting regime, and external ones, for example, a legal form of a business or legal restrictions.

Therefore the purpose of the paper is both to determine the factors affecting the amount of a control premium and to analyse their magnitude, using data from empirical studies conducted in this area by various authors for the period from 1968 to 2018. Therefore, the analysis aims to address the issue of determining the volume of premiums and discounts for control when assessing the value of a business. The conducted study has shown that a premium for control can significantly increase the value of a business or a shareholding being sold (by $7 \%$ - $82 \%$ ). At the same time, the lack of control leads to the application of discounts when assessing the value of a business and their size can also vary from $7 \%$ to $82 \%$.

The research methodology used in this paper starts with a literature review to shed light on main controversial issues of the phenomenon stressed out in the previous studies. Due to empirical nature of the paper, generally accepted methods of economic research were used including comparative analysis and synthesis.

\section{Literature review}

In the study "The Role of Premiums and Discounts in Business Valuation: Evidence from the Italian Context” O. Ferraro и F. Rubino (2017) summarized the results of 26 empirical studies to determine the average values of premiums and discounts used in business valuation in professional practice for various periods of time, starting with the study by M. Gelman for the period 1968-1970 and ending with the study of M. Bigelli and E. Sapienza for the period 2000-2003. This review showed a wide range of average premiums and discounts - from $7 \%$ to $82 \%$, which is explained by the difference in the valued shareholdings depending on the industry, the phase of the economic cycle and other features of the valued transactions. As will be shown in the second section of this article, the price of control premiums can be significantly higher. Estimating the value of premiums and discounts, one can draw a conclusion about their importance for determining the final price of transactions.

In their studies, these and other authors who analyse control premiums point to various aspects of this topic, both from a particular country perspective (Ferraro, Liberatore, 2016) and from a theoretical perspective. Thus, in their works, T. Nenova in 2003 (Nenova, 2003), as well as A. Dyck and L. Zingales in 2004, indicated that the significance of control and the control itself are higher in countries where in the event of companies acquisition a supremacy of law, protection of minority shareholders, high quality of accounting exist (Dyck, Zingales, 2004).

Ferraro un Rubino (2017) in their study cite the Italian team of authors Zanda et al. (2013), who, characterizing control, note that "control awards are a recognized plus to the value of an investment compared to the corresponding portion of the total economic capital, for the simple fact of allowing the control of a company."

In the regularly conducted "Mergerstat Control Premium Study" (Mergerstat Control Premium Study, 2018), the data from which are also used by the authors of this paper, it is noted that the control premium is defined as "the additional consideration that an investor would pay over a marketable minority equity value in order to own a controlling interest in the common stock of a company".

The definition of premiums and discounts is not as straightforward as it might seem at first glance, since different categories of investments to be evaluated can be identified (Ferraro, Liberatore, 2016), as well as different corporate governance models in which surcharges and discounts should be applied.

Over the years, such authors as M. Barclay and G. Holderness (Barclay, Holderness, 1989), L. Zingales, (Zingales, 1995), A. Dyck (Dyck, Zingales, 2004); M. Massari M., V. Monge, V. and L. Zanetti (Massari et al., 2004); P. Hanouna P., A. Sarin, A. Shapiro, (Hanouna et al., 2001); G. Nicodano and A. Sembenelli (Nicodamo, Sembenelli, 2000) in their analytical and empirical studies addressed such fundamental questions as: 
- quantitative determination of premiums in different countries, taking into account various kinds of subjective assumptions;

- development of methods for determining the value of premiums;

- factors influencing premiums taking into account different types of acquired shareholdings.

The problem of increasing the value of a business in an emerging market is associated with many quite diverse aspects (Abramishvili et al, 2019), therefore, according to the authors, the solution to this problem should be systematic, taking into account the aforementioned aspects. The cost of transactions is significantly affected by changing stock market indices (Cekuls, Koehn, 2019). Thus, the authors of this paper took into account that in modern conditions, the evaluation of transactions (including control premiums) for mergers and acquisitions of companies occurs, taking into account the existing positive experience obtained in mergers and acquisitions, (Saksonova, Kantane, 2016) as well as the active implementation of progressive fintech technologies (Kuzmina-Merlino, Saksonova, 2018). In the emerging market, banks are the most advanced in this sense. Under the influence of supervisory authorities, they are constantly in the process of improving their management of capital (Konovalova, Caplinska, 2020) and assets (Saksonova, 2013), including in order to comply with Basel III requirements. The higher the internal awareness of an organization, the higher is the level of control (Cekuls, 2016). This has a positive effect on the value of the banking business and M\&A transactions in this industry. The increase in business value is directly related to the increase in the turnover of companies. To increase turnover, any company must study the behaviour of its consumers (Batraga et al, 2018a), while any company must stimulate its own sales by shaping customer behaviour (Batraga et al, 2018b). Development and stimulation of investment activities of the companies is also aimed at increasing the value of a business (Ivanov et al, 2018), and especially it is important in emerging markets (Ivanov et al, 2019). All this creates the preconditions for effective business management, which has a positive effect on the level of control in the company and the value of the control premium.

\section{Research results and discussion}

\section{Factors affecting the rate of the control premium}

The rate of the control premium can depend on many different factors, and its rate varies greatly depending on the combination of facts and circumstances associated with a particular company and specific shareholders (Pratt et al, 2000). The importance of each factor can vary greatly from company to company, from transaction to transaction.

Having analysed the literature on this topic, the authors identified the following most important factors affecting the control premium.

- The presence or absence of certain elements of control in the shareholding. Shareholders with shareholdings with different specific weight have different rights and powers, which determines the value of the control factor. The main elements of control (Pratt, Reilly, 2000) include:

- the right to appoint or change the members of a management team and the board of directors;

- to determine the amount of remuneration for top managers;

- to determine the current and strategic policy of the enterprise;

- to change the direction of business development;

- to acquire, lease or liquidate business assets, including non-current assets;

- to select suppliers, sellers and subcontractors;

- to carry out negotiations and do acquisitions and mergers (M\&A);

- to dissolve, sell or recapitalize the company;

- to sell or purchase securities, including treasury bonds;

- to register shares of a company for an initial or secondary public offering.

- Degree of share capital concentration of the company under evaluation. When analysing its structure, the following conditions should be taken into account:

- an increase in the number of shares in a shareholding increases the advantages of the owner of the shareholding (the quantity factor), and the enlargement of one of the minority shareholdings leads to a decrease in the advantages of similar shareholdings (the factor of redistribution);

- the combined shareholdings have advantages equal at least to the sum of the advantages of each of the combined shareholdings (combination factor); 
- an increase in the number of insignificant minority shareholdings in the absence of a majority shareholding in the evaluated company leads to a decrease in the total premium (dispersion factor), and the approach of two or more shareholdings to the size of the majority shareholding intensifies competition and increases the advantages of insignificant minority stakes (competition factor).

As a rule, the following forms of share capital distribution or its concentration are distinguished: dispersion (each shareholder owns no more than $2 \%$ of shares); low concentration (no shareholder owns more than $10 \%$ of shares); medium concentration (shareholders have stakes from $10 \%$ to $25 \%$ of shares); high concentration (several shareholders own from 25 to $50 \%$ of the share capital) and ultra-high concentration, in which one shareholder owns more than 50\% of all company shares (Raeva, Kovalev, 2007). The amount of the control premium depends directly on how the share capital is allocated in the company and on how the evaluated shareholding is combined with other shareholdings.

- Financial status and financial performance of the evaluated company:

- $\quad$ an increase in the turnover (revenue) of the company being the target of purchase or acquisition has a positive effect on the amount of the premium; an increase in market volume has a positive effect on the value of the premium; the ratio of equity to assets negatively affects the value of the premium (Rhoads, 1987);

- the degree of financial leverage, liquidity and potential increase in the value of assets have a positive effect on the value of the premium (Crawford, Lechner, 1996);

- the return on equity of the company being purchased or acquired has a positive effect on the value of the premium (Rose, 1987);

- the ratio of growing debt to assets negatively affects the value of the premium; the size of the growing net working capital, the growing ratio of market and book value have a positive effect on the value of the premium (Walkling, Edmister, 1985).

- Differences in legislation and legal regulation of minority shareholders' rights. Regulatory restrictions prevent the controlling shareholder from taking full advantage of his position, thereby narrowing the gap between minority and majority value. Also, developed legislation can prevent violations of statutory rights of shareholders.

- Increase in the number of buyers participating in the auction. According to some studies, the presence of competition increases the seller's power and leads to an increase in the price paid for the acquired company. Thus, it is quite expected that sellers can purposefully follow the tactics of increasing the number of buyers participating in the auctions in order to increase final deals (Ryabova, Petrova, 2017).

- System and procedure of voting. At the moment, there are two fundamentally different voting systems, the use of which can significantly affect the size of the control premium. The majority voting system is based on the principle "one voting share in a company equals one vote". In most cases, this system allows the owner of a controlling interest to almost completely control the voting results. The opposite situation occurs with cumulative voting. Under this system, the number of votes belonging to each shareholder is multiplied by the number of persons to be elected to the board of directors of a company, and the shareholder has the right to cast the votes thus obtained fully in favour of one candidate or distribute them between two or more candidates (Pratt, 2001). However, despite this, cumulative voting still does not provide guaranteed representation of minority shareholders in the board of directors: not only do minority shareholders need to correctly accumulate their votes, they also need to have enough shares to elect their chosen candidate. For these reasons, cumulative voting can both increase and decrease the control premium.

- Qualified majority requirements. For example, in order to make such decisions as a merger of a company with another organization or dissolving of a company, in some companies it is necessary to have a larger shareholding than $50 \%+1$ plus one share. Such provisions are usually established in the articles of association or charter of the organization. Based on this, we can conclude that a shareholding that has a certain control, but not sufficient to carry out certain actions related to the functioning of the company, contains the features of both a minority and majority shareholding. At the same time, if a minority shareholding has the right to prevent some corporate decisions, a certain additional premium is usually added to the value of this stake over the cost of the usual, "non-blocking" minority shareholding.

- Casting vote potential. If the share capital is distributed approximately equally between two or more large shareholders, an additional premium may be added to the value of the minority block. A premium arises if the owner of a small shareholding is able to obtain the "casting vote", which can lead to a change in the existing capital allocation (Rodionov, Perevalova, 2011).

- Other factors affecting the size of the control premium include the rights of minority shareholders in the board of directors, rules for regulating mergers and acquisitions, the maturity of capital markets, mechanisms for protecting investors, the effect of managerial bad faith, the type of joint stock company, types of owners and their investment motives, the presence of state and preferred stakes shares, type of transaction and 
method of payment, the right to appoint directors in accordance with the agreement, as well as such important factors as methods of business (shareholding) valuation and control premium; purpose of the assessment; industry affiliation and others.

\section{Analysis of premiums and discounts for the presence or absence of control features}

When determining premiums and discounts for the presence or absence of control features in the assessment of shareholdings and stakes in the authorized capital of companies, data from the stock market and the market for mergers and acquisitions are used in assessing the value of a business.

Speaking of the most recent empirical studies on the determination of the average value of control premiums, we should mention those like "Mergerstat/BVR Control Premium Study" (Mergerstat Control Premium Study, 2018), an analysis of historical data on premiums and discounts for the control of a team of authors led by S. Pratt (Pratt et al, 2007), as well as studies by J.R. Hitchner (Hitchner, 2003) и K. Simonyan (Simonyan, 2014).

The BVR company is one of the leading organizations in the business valuation industry. It publishes the annual "Mergerstat/BVR Control Premium Study", which examines the average of premiums and discounts for control, both in USA transactions and in transactions made outside the USA. The report considers only transactions in which more than $50.01 \%$ of the company was acquired. The main argument for such a sample is the fact that a controlling interest is more valuable than a minority one, since it gives the buyer the right to influence the further management of the company (Mergerstat/BVR Control Premium Study, 2018).

Thus, in the second quarter of 2018, 127 transactions were analysed in Mergerstat in which the acquired company was public. 65 transactions between US and 62 transactions between non-US public companies were reviewed and the amounts of control premiums were determined. The results of the study are presented below in Table 1.

Table 1

Average and median control premiums for $127 \mathrm{M} \& \mathrm{~A}$ transactions of public companies 2nd quarter 2018

\begin{tabular}{|l|l|l|l|l|}
\hline & \multicolumn{2}{|l|}{$\begin{array}{l}\text { Including } \\
\text { Negative Premiums }\end{array}$} & \multicolumn{2}{l|}{ Excluding Negative Premiums } \\
\hline & \# of Deals & Premium (\%) & \# of Deals & Premium (\%) \\
\hline Domestic Average & 65 & $52.10 \%$ & 57 & $63.30 \%$ \\
\hline Domestic Median & 65 & $25.90 \%$ & 57 & $28.50 \%$ \\
\hline International Average & 62 & $36.60 \%$ & 43 & $63.20 \%$ \\
\hline International Median & 62 & $16.40 \%$ & 43 & $29.10 \%$ \\
\hline Overall Average & 127 & $44.50 \%$ & 100 & $63.30 \%$ \\
\hline Overall Median & 127 & $24 \%$ & 100 & $28.80 \%$ \\
\hline
\end{tabular}

Source: Mergerstat, Mergerstat Control Premium Study, 2018

Table 1 shows the average and median premiums, however, according to Mergerstat, local US deal premiums for control ranged from 98.8\% for Fairmount Santrol Holdings to $662.5 \%$ for Excel Corporation. At the same time, premiums (discounts) for international transactions ranged from $-92.5 \%$ for Itaúsa-Investimentos Itaú SA to $515.9 \%$ for Haeduk Powerway. In general, the lowest median and average values of control premiums were observed in the construction and textile industries. The median premiums in these industries were $15 \%$ and $8 \%$, while the averages were $16.2 \%$ and 13.8\%, respectively (Mergerstat, 2018). The value of control premium in a five-year retrospective according to the research of Mergerstat (Mergerstat Control Premium Study, 2018) is changes between 35\% - 65\% (mean) and 25\% - 35\% (median). 


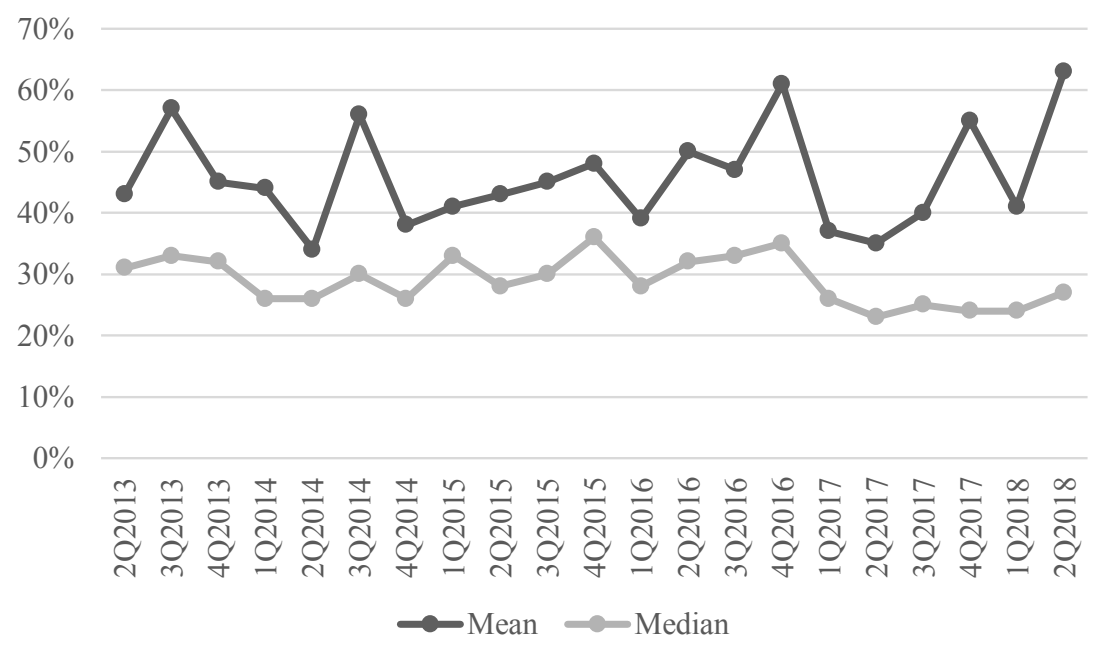

Source: summarized by the authors based on Mergerstat data

Fig.1. Dynamics of control premiums in M\&A deals from 2013 to 2018

According to the study conducted by K. Simonyan (Simonyan, 2014), from 1985 to 2005, the average and median value of the control premium in M\&A transactions in 2005 was $29.85 \%$ and $21.3 \%$, respectively. In the authors opinion, when comparing these data with the results of Mergerstat presented above, it can be noted that the average value of the premium for the last 5 years significantly exceeds this value in 2005 , while the median indicator fluctuates approximately in the same interval in both time intervals.

It should be noted that in the markets of new European countries and in the Russian market, the possibility of conducting such studies is limited due to the insufficient level of stock market development, imperfect regulatory framework, as well as the limitedness of information and the large influence of subjective factors that determine the pricing of transactions. However, an analysis was conducted in 2007 by E. Evstafieva of the average value of premiums and discounts for control based on the Russian market data using a scheme similar to the method used by Mergerstat (Evstafieva, 2007). The algorithm for this study was as follows:

1. Analysis of major transactions for the sale of shareholdings and mergers and acquisitions in 1998-2005. As a result, 400 transactions were analysed, for which quotations were subsequently searched for.

2. Study of such parameters as the quantitative and qualitative characteristics of the shareholding, the amount of the transaction, the date of the purchase announcement, the seller and the buyer for each transaction.

3. Calculation of the cost of one share in the sold shareholding. This indicator was based on the total amount of the transaction and the number of shares sold.

4. Analysis of market quotes of the company's shares on the stock market. Quotes were determined as an average value three months before the date of the announcement of the transaction (or before the date of the deal if there is no announcement date).

As a result of all actions, the final sample was only 50 trades.

Calculation of the premium for the size of the shareholding. This value was determined using the following formula:

$$
\begin{aligned}
\mathrm{P}= & \left(\mathrm{C}_{1}-\mathrm{K}_{1}\right) / \mathrm{K}_{1} \\
& \mathrm{P} \text { - control premium; } \\
& \mathrm{C}_{1} \text { - one share value in the shareholding } \\
& \mathrm{K}_{1} \text { - quotation of one share on stock market }
\end{aligned}
$$

The results obtained during the study are presented in Table 2 .

Average level of premiums and discounts according to the Russian market for the period 1998-2005

\begin{tabular}{|l|l|l|}
\hline Size of shareholdings in merger and acquisition transactions & Average premium & Average discount \\
\hline Less than $25 \%$ & $31 \%$ & $24 \%$ \\
\hline Less than $50 \%$ & $30 \%$ & $23 \%$ \\
\hline
\end{tabular}


Source: summarized by the authors using results of the research by Evstafieva, 2007

The data obtained indicate that the average level of the premium for transactions with shareholdings of less than $25 \%$ and with shareholdings of less than $50 \%$ differ insignificantly. It can be concluded that the results of this study are quite comparable with foreign statistics. The authors failed to find more recent studies devoted to determining the average level of premiums and discounts in the Russian market.

In this paper, the authors did not set a mission to look into the methods for determining the size of control premiums, which could be the topic of the next article. Usually, a comparative approach is used for this purpose, as well as a cost and income approaches. The importance of the comparative approach in this matter is worth noting, since only its use makes it possible to determine the value of both controlling and minority interest. The methods of cost and income approaches can only reveal the price of the controlling interest, since only the owner of the company can carry out such operations as liquidation of the company, sale of part of its assets, formation and distribution of various cash flows.

\section{Conclusions and recommendations}

According to the purpose and results of the paper, the authors provide several conclusions and recommendations.

The results have shown that the presence or absence of control in a company has a significant impact on the size of the premium or discount for a shareholding both in the investment markets of "old" and in the investment markets of "young" countries. Since the conducted analysis aimed to address the issue of determining the volume of premiums and discounts for control when assessing the value of a business, the results have provided the evidence that a premium for control can significantly increase the value of a business or a shareholding being sold (by $7 \%-82 \%$ ). At the same time, the lack of control leads to the application of discounts when assessing the value of a business, and their size can also vary from $7 \%$ to $82 \%$. The most obvious finding to emerge from the paper is that the magnitude of control premiums and discounts is rather significant.

Also, when studying the size of the control premium, it is necessary to know what elements of control the analysed shareholding possesses in order to understand what rights and powers its owner has. Based on the literature review, the authors recommend the owners of companies to solve the task of increasing the value of their own business (both for the purpose of analysing the company's activities and for the purpose of selling it) using a systematic approach. This means that work on increasing business value must be carried out taking into account positive experience in mergers and acquisitions; fluctuations in stock market indices; active implementation of fintech technologies, especially taking into account the experience of banks in emerging market; activities for an increase in the turnover of companies, including those related to consumer behaviour. All this creates the preconditions for effective business management and increasing its value, which has a positive effect on the level of control in the company.

The analysis of research conducted in the field of premiums and discounts for control made it possible to identify the factors that have the greatest influence on their size. Given the magnitude of these premiums and discounts and their significant impact on the final value of transactions, the authors recommend managers and specialists of enterprises in young European countries to work in the direction of improving such indicators that affect control premiums, such as:

- degree of concentration of the evaluated company share capital,

- financial status and financial performance of the company,

- differences in country laws governing shareholder rights and their use,

- presence of competition for the purchase of a particular company,

- presence of a system and procedure for voting established in the company.

This paper has thrown up many questions in need of further investigation. In authors' opinion, further research may be devoted to the study of premiums and discounts for liquidity of enterprises' assets.

\section{Bibliography}

Abramishvili, N., Lvova, N., Voronova, N., 2019. Is it Possible to Assess the Corporate Market Value in the Emerging Market? New Challenges of Economic and Business Development - 2019: Incentives for Sustainable Economic Growth. International Conference, Riga, Latvia, May 16-18, 2019: Proceedings. Riga: University of Latvia, 12-21.

Barclay, M. J., Holderness, G., 1989. Private Benefits from Control of Public Corporations. Journal of Financial Economics, 25, $371-395$.

Batraga, A., Salkovska, J., Legzdina, A., Rukers, I., Bormane, S., 2018a. Consumer Behaviour Affecting Factors Leading to Increased Competitiveness During Holiday Season, Book Series: Economic Science for Rural Development, Issue: 48, 329-337. 
Batraga, A., Praude, V., Salkovska, J., Afoniceva, O., 2018b. The Influence of Sales Stimulation Methods on the Behaviour of Consumers While Making the Decision on Purchase of Products in the Latvian Market. Book Series: Eurasian Studies in Business and Economics. Consumer Behaviour, Organizational Strategy and Financial Economics, Vol. 9, 3-23.

Cekuls, A., Koehn, M.-B., 2019. Bitcoin and Stock Market Indices: Analysis of Volatility's Clusters During the Bitcoin Bubble Based on the Dynamic Conditional Correlation Model, New Challenges of Economic and Business Development - 2019: Incentives for Sustainable Economic Growth. International Conference, Riga, Latvia, May 16-18, 2019: Proceedings. Riga: University of Latvia, 159-170.

Cekuls, A., 2016. Opportunities of Raising the Internal Awareness of an Organisation, SGEM 2016, BK 2: Political Sciences, Law, Finance, Economics and Tourism Conference Proceedings, Vol IV, 467-473.

Crawford, D., Lechner T., 1996. Takeover Premiums and Anticipated Merger Gains in the US Market for Corporate Control, 1996/7. Journal of Business Finance \& Accounting, 23(5-6), 807-829.

Dyck, A., Zingales, L., 2004. Private Benefits of Control: An International Comparison. The Journal of Finance, LIX(2), 537-600.

Evstafieva E., 2007. Premia and Discounts for Control: a Study of the Average Value of Amendments According to the Russian Market. Bulletin of the Finance Academy, 4(44), 140-149.

Ferraro, O., Liberatore, G., 2016. Analyzing Business Valuation Quality of Disclosures for Distressed Italian Companies. From a Legally Respectful Approach to the Sustainability of Turnaround Assessment. International Journal of Business Research, 16(2), 7-26.

Ferraro O., Rubino F., 2017. The Role of Premiums and Discounts in Business Valuation: Evidence from the Italian Context, International Journal of Business and Management, 12(2), 83-91.

Hanouna, P., Sarin, A., Shapiro, A., 2001. Value of Corporate Control: Some International Evidence, Marshall School of Business, Working Paper Series, $1-4$

Hitchner J. R., 2003. Financial Valuation: Applications and Models, Wiley Finance, 1st Edition.

Ivanov, V.V., Lvova, N.A., Pokrovskaia, N.V., Naumenkova, S.V., 2018. Determinants of Tax Incentives for Investment Activity of Enterprises, Journal of Tax Reform, 4(2), 125-141.

Ivanov V.V., Lvova N.A., Pokrovskaia N.V., 2019. Financial Incentives of Economic Growth in Emerging Markets: Evidence from Russia, New Challenges of Economic and Business Development - 2019: Incentives for Sustainable Economic Growth. International Conference, Riga, Latvia, May 16-18, 2019: Proceedings. Riga: University of Latvia, 299-309.

Konovalova, N., Caplinska, A., 2020. Impact Analysis of Factors Influencing Bank Capital Management. Journal Entrepreneurship and Sustainability Issues, 8(1), $484-495$.

Konovalova, N., Trubnikova, N., 2018. Adjustment of Banking Activity According to Basel III Requirements: Experience and Problems of Eastern Europe Countries. Reliability and Statistics in Transportation and Communication, Lecture Notes in Networks and Systems, 36, 617-626.

Kuzmina-Merlino, I., Saksonova, S., 2018. The Knowledge and Competencies Required the Fintech Sector, New Challenges of Economic and Business Development - 2018: Productivity and Economic Growth, International Conference, Riga, Latvia, May 10-12, 2019: Proceedings. Riga: University of Latvia pp. 387-395.

Massari, M., Monge, V., \& Zanetti, L., 2004. Control Premium in the Presence of Rules Imposing Mandatory Tender Offers: Can it Be Measure? Working paper, Università Bocconi, IASFC.

Mergerstat Control Premium Study, [Online] Available at: https://www.bvresources.com/docs/default-source/sample-reports/control-premiumstudy-quarterly-report.pdf [Accessed 07.11.2020].

Nenova, T., 2003. The Value of Corporate Voting Rights and Control: A Cross-Country Analysis. Journal of Financial Economics, 68, $325-351$.

Nicodano, G., Sembenelli, A., 2000. Private Benefits, Block Transaction Premia and Ownership Structure. Zimmerman Foundation for the Study of Banking and Finance, Discussion paper.

Pratt, S.P., 2001. Business Valuation Discounts and Premiums. Wiley.

Pratt, S.P., Reilly, R.F., Schweihs, R.P., 2000. Valuing Business, 4th ed. New York: McGraw-Hill Education.

Pratt Sh. P., Reilly R.F., Schweihs R.R., 2007. Valuing a Business. The Analysis and Appraisal of Closely Held Companies. 5th ed., New York, McGraw-Hill Education, 2007. 
Raeva I.V., Kovalev S.J., 2007. (in Russian: Metodi opredelenija premii za kontrolj pri ocenke paketov akcij rossijskih predprijatij), Methods for determining the control premium evaluating the shareholding of Russian companies. Journal Management Today, 1(37), 30-42.

Rhoades S., 1987. Determinants of Premiums Paid in Bank Acquisitions. Atlantic Economic Journal, 15, 20-30.

Rid S.F., Lajoux A.R., Nesvold H.P., 2007. The Art of M\&A Merger Acquisition Buyout Guide. 4th edition. New York: McGraw-Hill.

Rodionov I.I., Perevalova K.A., 2011. The Affecting Factors to the Size of the Control Premium. Journal of Corporate Finance Research, 4(20), $112-121$.

Rose, P., 1987. The Impact of Mergers in Banking. Journal of Economics and Business, 39, 289-312.

Ryabova E.V., Petrova V.V., 2017. The Method of Estimating the Premium in Mergers and Acquisitions in Emerging Markets for Private companies. Finance: Theory and Practice, 21(5), 128-139.

Saksonova, S., 2013. Approaches to Improving Asset Structure Management in Commercial Banks,

Saksonova, S., Kantāne, I., 2016. Mergers and Acquisitions: Examples of Best Practice in Europe and Latvia, Book series Contemporary Studies in Economic and Financial Analysis, volume 98: Contemporary Issues in Finance: Current Challenges from Across Europe, 95-110.

Simonyan, K., 2014. What Determines Takeover Premia: An Empirical Analysis. Journal of Economics and Business, 75, 93-125.

Walkling, R., Edmister R., 1985. Determinants of Tender Offer Premiums, Financial Analysts Journal, 27-37.

Zanda, G., Lacchini, M., Onesti, T., 2013. La valutazione delle aziende. Torino: Giappichelli.

Zingales, L., 1995. What Determines the Value of Corporate Votes? The Quarterly Journal of Economics, 110, 1047-1073. 


\title{
POSSIBILITIES OF USING CHATBOTS IN DIGITAL MARKETING STRATEGY OF LATVIAN COMPANIES
}

\author{
Jelena Salkovska, University of Latvia \\ Anda Batraga, University of Latvia \\ Liene Kaibe, University of Latvia
}

\begin{abstract}
Companies are willing to retain the gained consumers' attention, and the ways to achieve it include, for example, improving consumers' experience and increasing their engagement. In a competitive environment, the companies need to think about how to effectively develop a digital marketing strategy that meets the requirements of a digital consumer. A chatbot is a computer program that can be created with artificial intelligence and gives organizations the opportunity to create new points of contact with the audience, keep their attention, and promote sales.

The objective of the research is to study the possibilities of using chatbots in digital marketing strategy of Latvian companies. In order to obtain data and to analyse the possibilities of using chatbots in digital marketing strategy of Latvian companies, a survey of Internet users and expert interviews have been conducted.

Methodology/methods: In order to achieve the objective of the research, the method of qualitative and quantitative research has been used: referential analysis, expert interview, and interrogation of Internet users.

Findings: The study provides recommendations to digital marketing specialists and company managers pertaining to the possibilities of using chatbots in digital marketing strategy, based on the wishes of Internet users and expert opinions. People are ready to use chatbots in future. Most of respondents want to use chatbot in company's homepage and communicate with chatbot freely writing its question/request. Respondents want to use chatbot to get information on the company/product/service and get answers to their questions.
\end{abstract}

Keywords: digital marketing, digital marketing strategy, chatbots, improvement of digital marketing strategy.

JEL code: M31

\section{Introduction}

Digital marketing allows companies to capture and attract online prospective by providing value-adding content and customers to the brand. Through an interactive approach, digital marketing allows to connect with a wider audience, while at same time it allows a precision targeting of specific niche segments with valuable content (Matidza, Ping, Nyasulu, 2020). Digital consumer is mobile, well-informed and superbly functions in multichannel space while showing a high level of competence and skills connected with new technologies. They place stronger requirements on enterprises/brands while expecting openness, transparency and authenticity. They want to remain in contact with them and to have a choice of used channels, methods and tools of establishing and keeping that contact. This consumer became a native consumer: very active in hypermedia space, intensely buys online, spends a lot of time online (Kaczorowska-Spychalska, 2019).

As different technologies evolve, the issue of how people can use them to improve their daily lives and companies - to speed up or automate processes and provide the best service to consumers, while reducing resource consumption and building the company's image in the long run, is becoming increasingly important. Research problem - need to develop a digital marketing strategy according to consumer requirements using chatbot. Barış (2020) states chatbot as a means for customer communication is a commercial tactic that can be situated among the recent technological innovations in terms of artificial intelligence.

The objective of the research: based on theoretical knowledge on digital marketing and chatbots and the authors' study, to investigate the possibilities of using chatbots in digital marketing strategy of Latvian companies.

Research tasks:

1. To analyze the theoretical aspects of the essence and significance of digital marketing and digital marketing strategy;

2. To analyze the theoretical aspects of the nature of chatbots and the possibilities of their use;

3. Conduct an interview of digital marketing experts on the possibilities of using chatbots in the Latvian market;

4. Conduct a consumer survey on the usage habits of chatbots and potential use possibilities in the future;

The study shows that Internet users have used chatbots and will wish to do so in the future, however, consumers wish to use them only in certain cases, but the experts believe that in the future chatbots in Latvian companies will develop and it will be a tool to improve communication with the customer. 
The current interest in chatbots is likely related to substantial advances in computing technology and the wide adoption of mobile messaging applications. (Brandtzæg, Følstad, 2017) Van den Broecka, Zaroualia, Poels (2019) states chatbots can be perceived as one of the most advanced forms of social cues in human computer interaction.

Chatbot is required to have the same tone, sensitivity and behaviour than a human but at the same time users expect it to process much more information than the human. It is also expected to deliver useful and required information, just as a search engine does. The information needs to be delivered in a way which enables the user to extract a simple answer as well as having the opportunity to "drill down" if necessary (Jenkins et al., 2007).

\section{Literature Review}

Nowadays the research of chatbots covers a wide range of issues, which are reflected from different angles in studies and publications by world scientists. To substantiate the problem of this study, the authors have explored the arguments for the nature, functions, advantages and disadvantages of chatbots, using internationally recognized sources, for example, for the research of chatbots essence and integration aspects in overall marketing strategy the findings of the articles in magazines in other publications have been used: E-Learning and Digital Media; ITIHAS - The Journal of Indian Management, 2017 International Conference on I-SMAC (IoT in Social, Mobile, Analytics and Cloud) (I-SMAC), Business Communication Research and Practice; to identify the advantages and disadvantages, the articles in CroDim International Journal of Marketing Science, Issues in Information Systems, Smart Innovation, Systems and Technologies, IADIS International Journal have been analysed; to explore the functions, the studies in Periodicals of Engineering and Natural Sciences, Cultures of Participation in the Digital Age AVI 2018, ICIC, International Research Journal of Engineering and Technology, Smart Computing and Technology: A Roadmap Ahead and others have been analysed. The authors draw attention to the aspects of using chatbots in digital marketing.

Chatbot is a computer program that is designed to simulate conversation with human users. The Chatbot can be AI based or non-AI based i.e. depending on use-cases you can build a bot which is truly conversational in nature or just create a Chatbot with rich content-carousels, photos, videos, buttons, etc (Chopra, 2017). Chatbot is quick and easy to handle, which makes increases customer satisfaction. It is now becoming a new business communication channel to attract new customers. In addition, the proper automation of business communication is increasing efficiency and reducing the costs of businesses (Heo, Lee 2018). Chat bots are applying in areas where purposes are typically limited to conversations regarding a specialized purpose and not for the entire range of human communication (D'silva et at., 2017).

Well formulated and coherent digital marketing strategy is necessary for achieving business goals, making the right decisions and focusing on the right element. Therefore, digital marketing strategy implies the use of digital marketing tools to a well-defined strategy with the aim of reaching the company objectives. Organizations having effective digital marketing strategies are able to filter out and prioritizes' most important and relevant marketing tools, hence a successful digital marketing strategy defines how the digital communication tools can be used and applied effectively for digital communications (Matidza, Ping, Nyasulu, 2020). The use of chatbots should be consistent with the company's overall digital marketing strategy.

Most digital marketers see chatbots as a tool to provide customized customer service by gathering data and personal information. However, chatbots also can guide users through the customer's journey to sales. From a digital marketing perspective, chatbots provide the possibility to engage with an audience that is targeted at a personal level (Bayoude et al., 2018).

Chatbots can be used to perform tasks such as, providing reminders, introducing new concepts, FAQ or customer service support, and new employee's training (Sandoval, 2018). Through chatbots companies can personalize and support the relationship building with consumers/users, exploiting personal information obtained by previous interactions (Valtolina et al., 2018). Marketers can use wide variety of bots and increase consumer experience (Chopra, 2017). Besides providing a friendly interface between users and companies, chatbots allow corporations to mine data obtained in conversations with users with respect to information about service quality and client sentiment (i.e. their feelings towards the service provided) (Castro et al., 2018). Chatbots can also prove useful in internal marketing, especially in recruitment or training processes as well as support for specific marketing goals, tools and strategies. They are able to provide necessary information about activities of competitive companies, consumer preferences or key market trends (Kaczorowska-Spychalska, 2019). Chatbots can be used for teaching and learning tasks at the digital workplace. Chatbots can teach learning content in a natural language dialog in such a way that employees can for example demand content for training at the workplace (Meyer von Wolff, Hobert, Schumann, 2019). Chatbots are also actively used by financial institutions. Chatbots are one 
of the dimensions of Fintech sector development. The development of Fintech sector has been studied by the authors I.Kuzmina-Merlino and S.Saksonova (Kuzmina-Merlino, Saksonova, 2018).

Although traditional human interviewing method is accepted worldwide, it can be replaced to some extent by using AI powered chatbot (Yakkundi, Vanjare, Wavhal, Patankar, 2019). With more interaction with customer, chatbots will also get improved to recommend products to customers based on customer's search and purchase history (Shafi et al., 2020).

The benefits of this artificial intelligence tool include its 24/7 availability, savings in personnel costs in customer service, the ability to collect and store relevant customer information, and the greatest advantage of all - one-to-one communication (Zečević, Hunjet, Vuković, 2020). Chatbot responses are limited by the variables included on their development and that, although many chatbots exist, not all of them are useful (Sandoval, 2018). They make possible the multitask, allowing to attend several customers at the same time, create instant leads, the starting of a conversation and the creation of customer-brand relationships, and allows for a better first impression, since it provides an instantaneous response by reducing the waiting time (Araújo, Casais, 2020).

Chatbots allow customers to get in contact with companies whenever they want so, without paying attention to time zones, opening times and waiting loops of call and service centres. Chatbots are very promising for international and digital companies like online retailers or web shops (Zumstein, Hundertmark, 2017).

Chatbot spread is due to a bigger change in the communication between companies and users. Companies indeed are adapting their channels of communication, basically their websites, to different devices, first of all mobile devices. Given the complexity of the websites, many companies developed mobile applications in order to exploit the potentials of new tools. Today, given the saturation of the mobile application market, competition is high. Easy and intuitive interfaces are preferred, and companies are creating new channels of communication in order to involve users in building direct relationships. Relationship between companies and costumers has changed over the time, in parallel with the evolution of market. In particular, focus of marketing strategies changed (Valtolina et al., 2018).

The introduction and use of chatbots in a company is associated with the need for adequate financial resources. But in the long run, the use of chatbots in combination with other factors has a positive effect on the company's value, which has been studied by the authors S.Saksonova and I.Kantane (Saksonova, Kantane, 2016).

Based on the findings of scientific and theoretical research, which has been used as a basis for further research, as confirming the argumentation related to the wish to use, objectives, functions, advantages and disadvantages, the authors have conducted a practical study, in scope of which Latvian consumers' wish to use chatbots have been found out.

\section{A Chatbot and Possibilities to Use Them}

The method of qualitative and quantitative research was used to achieve the objective of the research. In the study conducted by the authors, a survey of Internet users has been conducted with a participation of 385 Internet users, the residents of Latvia, of which 266 respondents (69,09\%) answered that they have used a chatbot at least once. A random sample was taken. It is the opinion of these respondents that has been taken into account in the analysis of the results of the study, as these users know what a chatbot is and have an opinion on what kind of chatbot they wish to use.

An expert interview has been used as a qualitative research method, during which 7 Latvian digital marketing experts have been interviewed: Agris Magons, Edgars Koroṇevskis, Elvijs Gulbis, Gundars Grāpis, Kristiāna Vuškāne, Kaspars Elcis, and Matīss Miezis. The experts have been chosen in accordance with their education and work experience.

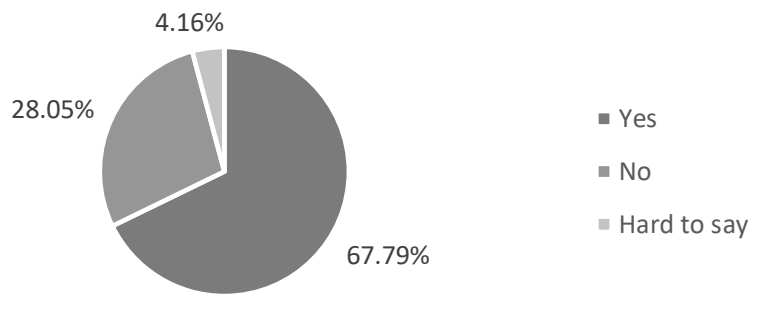

Source: author's construction based on survey, $n=385$

Fig. 1. Consumers' wish to use a chatbot in the future 
According to Fig. 1., the majority of respondents (67.79\%) wish to use a chatbot in the future. 28.05\% of respondents have answered "No", but $4.16 \%$ answered "Hard to say", which means that companies in Latvia have prospects to develop a digital marketing strategy with the help of chatbot.

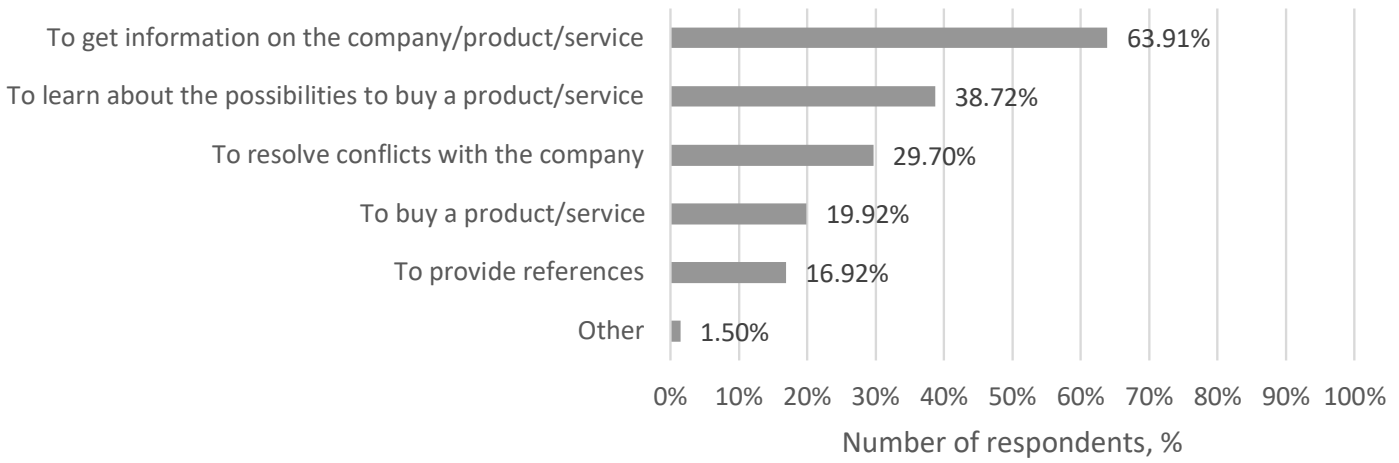

Source: author's construction based on survey, $n=266$

Fig. 2. Purposes for which Internet users wish to use chatbots

Based on the data, generalized by the authors in Fig. 2., the majority of respondents $(63.91 \%)$ wish to use a chatbot to get information on a company/product/service, and this corresponds to the stage of understanding the consumer's path. 38.72\% have answered "To learn about the possibilities to buy a product/service", this corresponds to the stage of consideration at which the consumer wishes to obtain additional information on the product in order to assess which of the products to buy if there are several options, including comparison with the competitors. $29.70 \%$ have answered - "To resolve conflicts with the company", which corresponds to the servicing phase, when the consumer has already purchased the product. $19.92 \%$ have given the answer "To buy a product/service", which corresponds to the purchase phase of the consumers' path, where consumers would be able to buy a product/service through a chatbot. $16.92 \%$ of respondents have marked the option "To provide references", which corresponds to the advocacy phase, in which the consumer has bought a product/service, resolved conflicts or has been served and is ready to provide a feedback on its experience. $1.50 \%$ of respondents have marked the option "Other", specifying that they would like to use a chatbot for such purposes as learning how the chatbot works and contacting the company immediately, without waiting, or that it was the only way to communicate with the company.

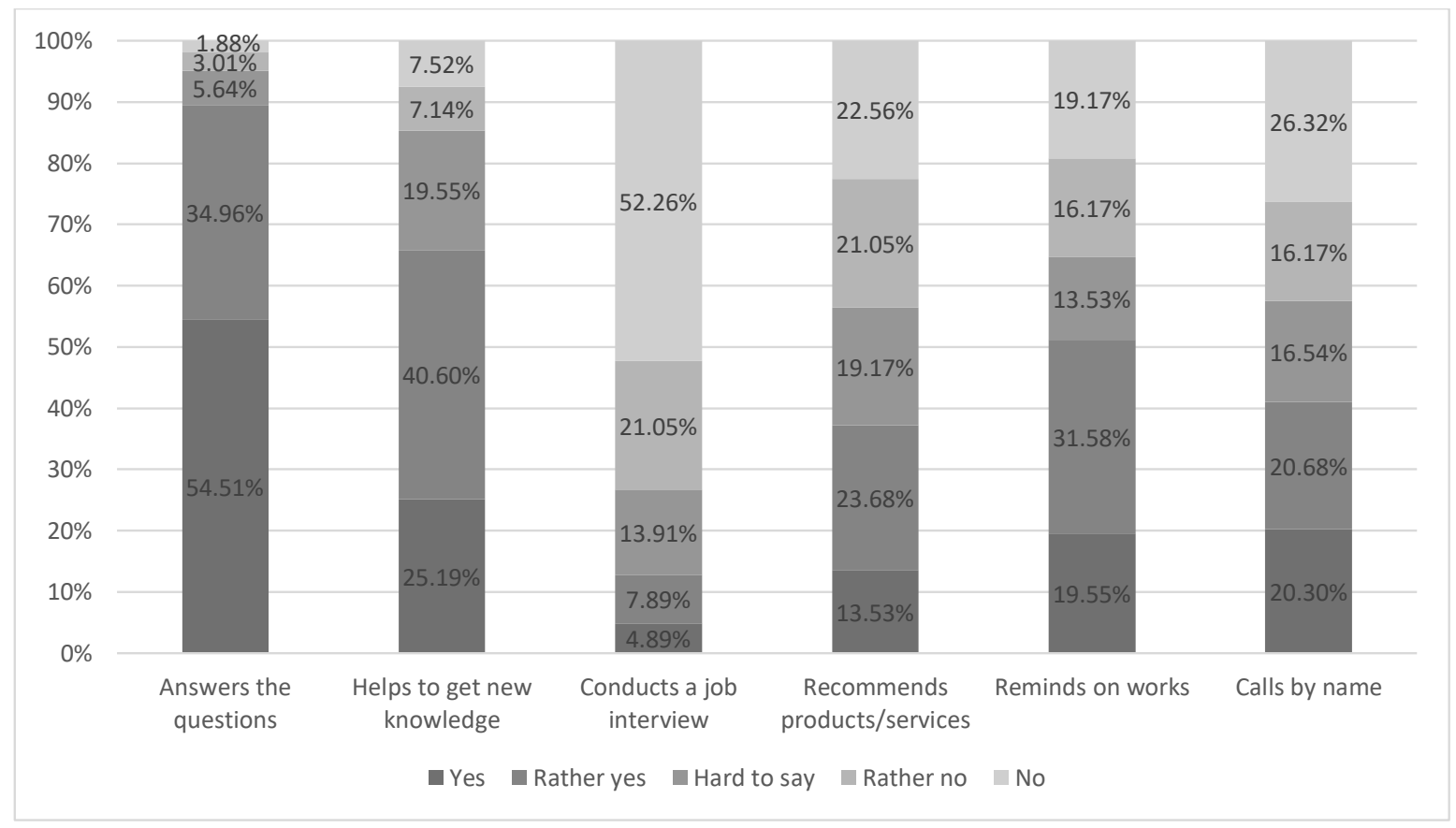

Source: author's construction based on survey, $n=266$

Fig. 3. Functions the users wish to use 
Finding out the functions that the users wish to use, as shown in Fig.3., the results have been obtained, showing that most of the respondents wish the chatbot to "Answer its questions". Answer "Yes" (54.51\%) - wish to use the function. This means that companies can use chatbots in their digital marketing strategy to answer consumers' questions.

Most of the respondents $(40.60 \%)$ answered "Rather yes" to the question whether they would like to use the function "Helps one to get new knowledge". $25.19 \%$ answered "Yes" - they would like the chatbot to help them to get new knowledge. Companies can use chatbots in a digital marketing strategy with the function to help to get new knowledge, thus offering added value to their audience or even building a business idea.

The majority of respondents $(52.26 \%)$ answered that they did not want the chatbot to conduct a job interview. This means that a chatbot should not be used in personnel screening.

13.53\% answered "Yes" stating they wish to use the "Recommends products/service" function. 23.68\% answered "Rather yes". 19.17\% of respondents found it hard to say. $21.05 \%$ - rather no. $22.56 \%$ of respondents would not want a chatbot to recommend products or services. Overall, $37.21 \%$ answered that they would like or rather would like to receive recommendations from a chatbot. $43.61 \%$ of respondents would not like or rather would not like to receive recommendations from a chatbot about products or services.

"Reminds me of the work to be done." 19.55\% answered "Yes". 31.58\% - "Rather yes". 13.53\% - "Hard to say". 16.17\% - "Rather no". 19.17\% of respondents answered "No". In comparison, 51.13\% answered that they would like or rather would like to receive reminders from the chatbot, and $35.34 \%$ would not like or rather would not like to receive reminders about the work to be done from the chatbot. Companies can include in their digital marketing strategy a chatbot that interacts with the user in the long run and reminds it of the work to be done.

$20.30 \%$ answered "Yes" stating that they would like to use the function of the chatbot to call them by name. 20.68\% - "Rather yes". 16.54\% "Hard to say" $16.17 \%$ answered "Rather no", $26.32 \%$ answered "No", which is the most common answer. Comparing the answers, $40.98 \%$ of respondents would like or rather would like the chatbot to call them by name, and $42.49 \%$ would not want or rather would not want such a function. The distribution of answers is very similar, which means that it would seem acceptable to some respondents that the chatbot knows the user's name and uses it in communication.

Based on the opinions of digital marketing experts, companies deploy chatbots to answer consumers' questions around the clock, to create a modern/innovative company image, to provide new and fast communication opportunities for customers, to facilitate work for employees, to automate sales promotion and to create more personal marketing information.

\section{Advantages and Disadvantages of Chatbots}

Evaluating the advantages and disadvantages of chatbots, the authors have come to the conclusion that some experts believe that the advantages obtained by the company are also the same that motivate the company to introduce a chatbot. Other advantages of chatbots mentioned by experts are: round-the-clock availability, increased sales opportunity, increased competitiveness compared to competitors, cost reduction, time saved that can be used for other purposes, a qualitative customer service, and website optimization.

The factors that impede companies to introduce chatbots, mentioned by experts, include lack of knowledge and experience pertaining to the operation and application of this tool, technical barriers (unavailability of prototypes in Latvian language) to implementation and servicing, reluctance to change processes, as chatbots need to be trained and improved, as well as lack of resources (money, time and staff). 
Source: author's construction based on survey, $n=266$

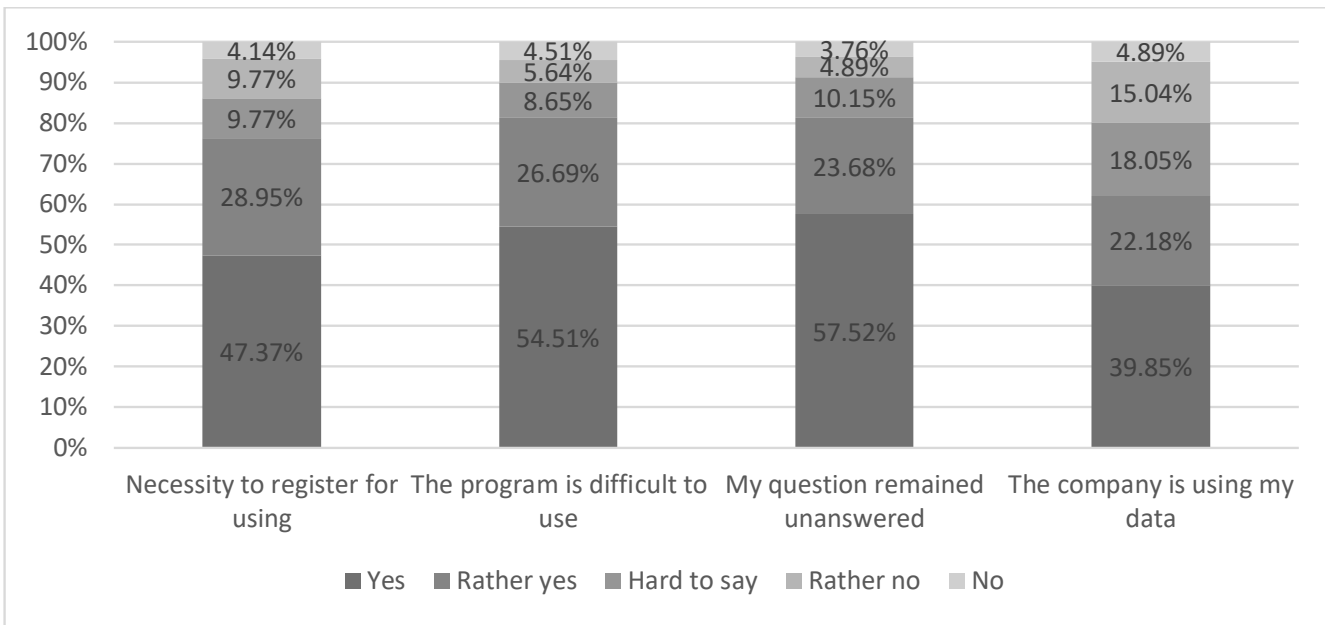

Fig. 4. Disadvantages that would deter the user from using the chatbot

It is significant to find out what arguments could deter the user from using the chatbot, as in the future, when developing this tool, it would enable to eliminate possible contradictions between the choice of the tool and the practical reaction of the user. As shown in Fig.4., 57.52\% of respondents would be deterred from using a chatbot if "My question remained unanswered", so it is very important to invest in the development of a chatbot so that the chatbot is able to answer a large number of questions from the very beginning. $54.51 \%$ of respondents would be discouraged by the fact that "The program is difficult to use", which means that one should work on the interface so that the interaction with the chatbot is intuitive and easy for the user to understand, which would lead to a positive experience. $47.37 \%$ of users would not use the chatbot in case of "Necessity to register for using", which means that a chatbot should be set up to interact with the user without registration. $39.85 \%$ of users would not use a chatbot, knowing that "The company is using my data". The answers show that the shortcomings of chatbots would deter the user from using the chatbot.

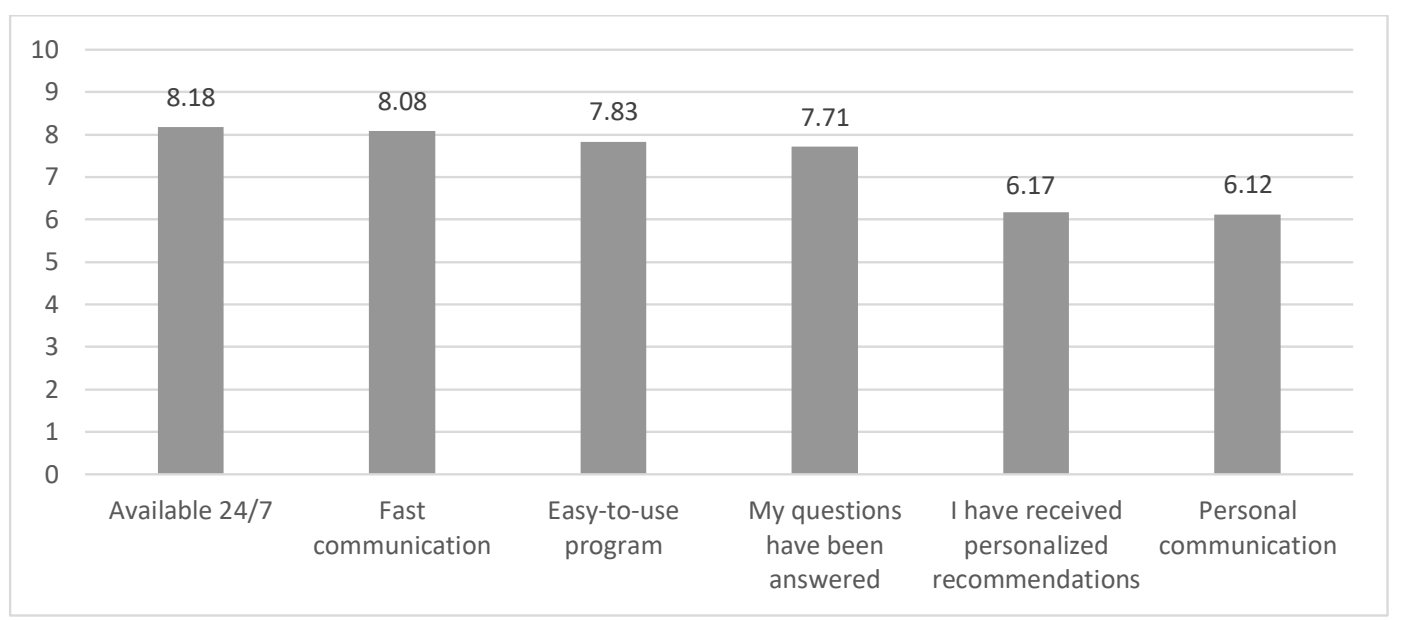

Source: author's construction based on survey, $n=266$

\section{Fig. 5. Respondents' assessment of the advantages of chatbots on a 10-point scale}

In the context of evaluating the advantages and disadvantages of chatbots, the authors of the article have obtained an overall assessment of the respondents about the advantages of chatbots. The advantage of chatbots "Available 24/7" has been rated the highest by consumers at 8.18/10. Consumers value the availability of a chatbot at any time, so companies can incorporate a chatbot into their digital marketing strategy to give the consumer a sense that the company is available at all times.

The advantage of "Fast communication" is rated 8.08/10. Respondents appreciate this feature, so the developer needs to ensure that the chatbot responds quickly.

"Easy-to-use program" has been rated 7.83/10. It is important for the respondents that the program is easy to use. 
"My questions have been answered" has been rated 7.71/10. The assessment is relatively lower compared to the other benefits (available 24/7, fast communication, easy-to-use program), which means that it is less important for the respondents to get an answer than the availability of the chatbot, its ability to communicate quickly and being an easy-to-use program.

"I have received personalized recommendations" has been rated 6.17/10. The advantage of being able to receive personalized recommendations from a chatbot has a lower assessment, which means that it is less important for respondents than the ones mentioned above.

"Personal communication" has been rated 6.12/10. This advantage has the lowest assessment of all the mentioned advantages. The author concludes that some consumers do not wish to receive personal communication from chatbots.

\section{Latvian Consumers' Wish to Use Chatbots}

In the summary part of the study, the authors wished to find out how the will to use chatbots develops among Latvian consumers. In the context of the experts' answers, the authors conclude that consumers use chatbots because they are interested in trying them out to get accurate information quickly; consumers are willing to communicate in writing; and there has been a positive experience in the past. However, there are also factors that discourage consumers from using chatbots; according to experts, these are lack of information and experience, distrust, willingness to communicate with people, poor past experience, poorly designed interfaces; as well as some consumers are reluctant to use digital technologies in general.

This issue has been actualized also in terms of science. While the term chatbots typically is applied for text-based interaction, it may also encompass voice-based conversational agents (Følstad, Skjuve, Brandtzæg, 2018).

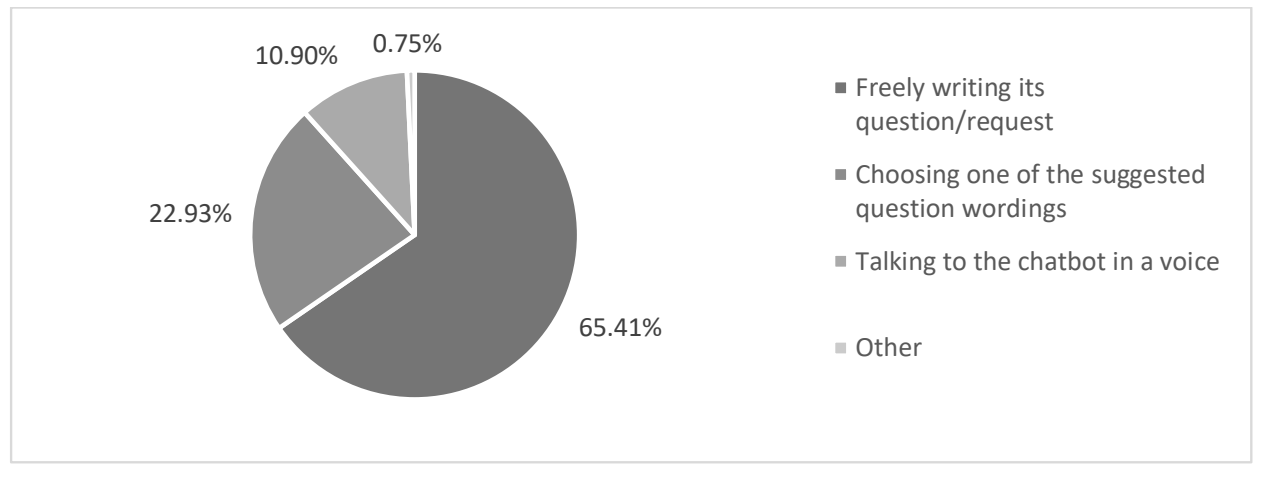

Source: author's construction based on survey, $n=266$

\section{Fig. 6. Input form that respondents would like to use}

In turn, the quantitative research has revealed that the majority of respondents $(65.41 \%)$ choose to contact the chatbot by freely writing their question/request. $22.93 \%$ of respondents would like to communicate by choosing one of the suggested wordings. $10.90 \%$ would like to talk to chatbot by voice. $0.75 \%$ of respondents have marked the option "Other", specifying that they would not like to contact a chatbot if there was such an opportunity. Fig. 6 .

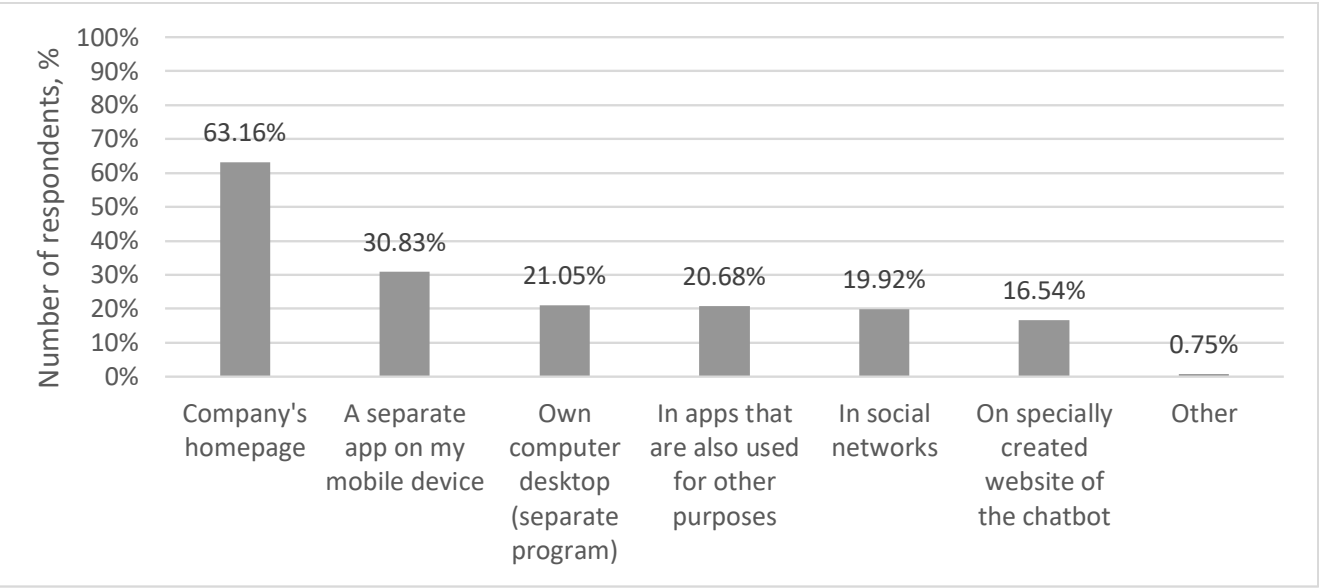

Source: author's construction based on survey, $n=266$

\section{Fig. 7. Sites where respondents wish to use a chatbot}

By finding out on which sites the respondents would like to use chatbots, the authors have got the answers in percentage terms, where the homepages dominate. Fig. 7. It was possible to mark several answers in the question. $63.16 \%$ of respondents noted that they wish to use the chatbot 
on the company's homepage, which is probably due to the fact that currently organizations in Latvia often integrate chatbots into the website and users are familiar with such a solution. $30.83 \%$ of respondents answered that they wish to use the chatbot in a separate application on their mobile device. $21.05 \%$ answered that they want to use the chatbot on their computer desktop as a separate program. $20.68 \%$ of respondents wish to use it in other apps on their mobile device that are also used for other purposes. $19.92 \%$ would like to use chatbots in social networks. $16.54 \%$ would use a separate website to contact a chatbot. $0.75 \%$ of the answers were "Elsewhere", where the respondents indicated that it did not matter to them where to use the chatbot.

\section{Conclusions}

1. A chatbot is a computer program that can interact with a person using voice or text methods and can be created with or without artificial intelligence. In digital marketing, a chatbot is a current tool that allows a company to attract and retain consumers, increase consumers' engagement, guide consumers through the consumer path, promote sales, improve the overall user experience, obtain data and enable consumers to communicate one-to-one with the company.

2. The study is the evidence that the majority of respondents $(67.8 \%)$ will wish to use chatbots in the future. $63.9 \%$ of respondents would use it to find out information on the company/product/service that corresponds to the consumer path awareness stage or consumer path awareness stage.

3. In turn, a part (65.4\%) of the respondents would communicate with the chatbot by freely writing their question/request freely, while $63.2 \%$ of the respondents would like the chatbot to be available for communication with the user on the company's homepage. An opinion has been expressed on the wish to use such chatbot functions as to receive answers to questions $(54.7 \%)$ and a reminder about the work to be done $(51.1 \%)$

4. Based on the results of the survey, it has been concluded that respondents appreciate the following benefits of chatbots: available $24 / 7$ (average 8.18 out of 10 points), fast communication (8.08/10), easy-to-use program and questions have been answered; such benefits as the ability to receive personalized recommendations and personal communication have got a lower assessment.

5. Chatbot is an important tool for developing a digital marketing strategy, as consumers wish to use it to communicate with the company, to gain added value and appreciate the benefits of chatbots, as well as the companies gain a number of benefits: creation of contact points, sales promotion, retention of consumers' attention and opportunities to build the company's image.

\section{Proposals, Recommendations}

1. Company managers and digital marketing professionals should assess the opportunity of introducing this hitherto little-used tool, the chatbot, as consumers will want to use the chatbot in the future, giving the company the opportunity to increase competitiveness, to reduce costs, to improve customer service, to be available around the clock, to increase sales, to obtain additional consumer data and build the image of an innovative company, as well as use it for other digital marketing purposes of the company.

2. Digital marketing specialists should create a chatbot on the company's homepage, because the consumers that have used the chatbot wish want to use it on the homepage, and thus the company provides the consumer with the opportunity to use the chatbot in the user's desired environment and to improve the consumer experience.

3. Chatbot developers and digital marketing specialists should provide the chatbot with a wide information from the very beginning, as the users are deterred from using the chatbot by not receiving answers to questions, and extensive information will ensure that consumers have a positive user experience.

4. Chatbot developers should create user-friendly interfaces, as the users would be deterred from using the chatbot in case of the need to register and in case this turns to be a difficult-to-use program. Understandable interfaces will encourage the consumer to repeatedly use the chatbot and create a positive user experience.

5. When creating a chatbot, the chatbot developer should ensure that it is available $24 / 7$, that fast communication is possible, that the program is easy to use and that the user receives answers to its questions, as these benefits are important to users.

\section{Bibliography}

Araújo T., Casais B., 2020. Customer Acceptance of Shopping-Assistant Chatbots, Marketing and Smart Technologies, Smart Innovation, Systems and Technologies, 167, 278-287.

Barış A., 2020. A New Business Marketing Tool: Chatbot. GSI Journals Serie B: Advancements in Business and Economics, 3(1), $31-46$ 
Bayoude K., Ouassit Y. Ardchir S., Azouazi M., 2018. How Machine Learning Potentials are transforming the Practice of Digital Marketing: State of the Art, Periodicals of Engineering and Natural Sciences, 6(2), 373-379.

Brandtzæg P.B., Følstad A., 2017. Why People Use Chatbots, Internet Science, INSCI 2017, Lecture Notes in Computer Science, 10673, $377-392$.

Castro F., Tedesco P.C., Alves H., Quintino J.P., Steffen J., Oliveira F., Soares R., Santos A.L., Silva F.Q., 2018. Developing a Corporate Chatbot for a Customer Engagement Program: A Roadmap, ICIC, Intelligent Computing Theories and Application, 10954, 400-412.

Chopra N. A., 2017. Digital Marketing Initiatives Owing To Technological Improvements. ITIHAS - The Journal of Indian Management, 7(4), 1525.

D'silva G. M., Thakare S., More S., Kuriakose J., 2017. Real world smart chatbot for customer care using a software as a service (SaaS) architecture, 2017 International Conference on I-SMAC (IoT in Social, Mobile, Analytics and Cloud) (I-SMAC), Palladam, 658-664.

Følstad A., Skjuve M., Brandtzæg P.B., 2018. Different Chatbots for Different Purposes: Towards a Typology of Chatbots to Understand Interaction Design, International Conference on Internet Science, Lecture Notes in Computer Science, 11551, 145-156.

Heo M., Lee K. J., 2018. Chatbot as a New Business Communication Tool: The Case of Naver TalkTalk, Business Communication Research and Practice, 1(1), 41-45.

Jenkins M. C., Churchill R., Cox S., Smith D., 2007. Analysis of User Interaction with Service Oriented Chatbot Systems, Human-Computer Interaction. HCI Intelligent Multimodal Interaction Environments, 4552, 76-83.

Kaczorowska-Spychalska D., 2019. How chatbots influence marketing, Management, 23(1), 251-270.

Kuzmina-Merlino, I., Saksonova, S., 2018. The Knowledge and Competencies Required the Fintech Sector. New Challenges of Economic and Business Development - 2018: Productivity and Economic Growth, 387-395.

Matidza, I., Ping, T., Nyasulu, C., 2020. Use of digital marketing in estate agency industry in Malawi, E-Learning and Digital Media, 17(3), 253270 .

Meyer von Wolff R., Hobert S., Schumann M., 2019. How May I Help You? - State of the Art and Open Research Questions for Chatbots at the Digital Workplace, Proceedings of the 52nd Hawaii International Conference on System Sciences, 96-104.

Saksonova, S., Kantāne, I., 2016. Mergers and acquisitions: Examples of best practice in Europe and Latvia. Contemporary Issues in Finance: Current Challenges from Across Europe. Contemporary Studies in Economic and Financial Analysis, 98, 95-110.

Sandoval Z.V., 2018. Design and implementation of a chatbot in online higher education settings, Issues in Information Systems, 19(4), 44-52.

Shafi P.M., Jawalkar G.S., Kadam M.A., Ambawale R.R., Bankar S.V., 2020. AI-Assisted Chatbot for E-Commerce to Address Selection of Products from Multiple Products, Internet of Things, Smart Computing and Technology: A Roadmap Ahead, 266, 57-80.

Valtolina S., Barricelli B.R., Gaetan, S.D., Diliberto, P., 2018. Chatbots and Conversational Interfaces: Three Domains of Use, Cultures of Participation in the Digital Age, AVI 2018, 2101, 62-70.

Van den Broecka E. Zaroualia B. Poels K., 2019. Chatbot advertising effectiveness: When does the message get through?, Computers in Human Behavior, 98, 150-157.

Yakkundi S., Vanjare A., Wavhal V., 2019. Patankar S, Interactive Interview Chatbot, International Research Journal of Engineering and Technology, 06 (04), 2746-2748.

Zečević P., Hunjet A., Vuković D., 2020. The influence of chatbots on advertising campaign performance, CroDim International Journal of Marketing Science, 3(1), 1-17.

Zumstein D., Hundertmark S., 2017. Chatbots - An Interactive Technology for Personalized Communication, Transactions and Services, IADIS International Journal, 15(1), 96-109. 


\title{
SHORTAGES, SKILLS AND OLDER WORKERS IN INFORMATION TECHNOLOGY LABOUR MARKET OF LATVIA
}

\section{Baiba Savrina, University of Latvia \\ Signe Martisune, University of Latvia}

\begin{abstract}
This article examines the labour market situation in the sector of information technology in Latvia, paying attention to the insufficiency of labour force due to the skills gap and employability of older workers. The article is based on application of multidisciplinary research methods including employment and skills analysis theories, policy analysis approach and qualitative in-depth open-ended stakeholders interview method. To begin with, it analyses labour market skills gap versus potential of professional mobility and offers an overview of skill classification. Secondly, it focuses on the economic indicators of the information technology industry sector in Latvia and offers reflections on the causality of the main problems in information technology labour market. It assesses the macroeconomic indicators of the information technology sector in Latvia and concludes that the most significant obstacle for successful development is the lack of human resources. The findings of this article indicate that labour market policies focusing on employability of older people in information technology jobs need to be extended in order to overcome the shortage of labour force and face the challenges of the continuous decrease of the proportion of the working-age population compared to the retirement age population.
\end{abstract}

Keywords: labour market, skills, professional mobility, older workers, information technology sector.

JEL code: J24; J62

\section{Introduction}

The development of the global economy in the digital age is based on the increasing use of information technology. "New economy" and especially modern Knowledge based economy are creating crucial changes in the approaches and functioning of traditional sectors of economy accompanied by the development of research based solutions and use of innovative tools. At the same time the new sectors appear and rise quickly. Global research on the role of information technology in business shows that digital strategies in the public and private sectors cannot exist without support of information technology. The main trends indicate that information technology play more than a basic role in digitization processes information technology are critical for innovations and business drive, meaning - the development of entrepreneurship and macroeconomic growth are both promoting competitiveness on a global scale of national companies and national economy in totality.

Analysts of global processes agree that new technologies do not in themselves improve competitiveness - the determining factor is the ability to integrate new technologies into existing or redesigned business processes. It means that the ability to deal with new technologies is closely related to human resources. The aim of this article is to analyse the situation in labour market in the sector of information technology in Latvia, paying attention to insufficiency of labour force due to the skill gap.

One of the largest global surveys, conducted by Harvey Nash / KPMG for 20 years (Harvey Nash / KPMG, 2018, 2020) is gathering the views of information technology executives worldwide on information technology strategy, priorities and human resources. 2018 report indicates that of the nearly 4,000 information technology executives surveyed who represent different geographical regions and industrial sectors, $65 \%$ acknowledge that the development of their companies is hampered by a lack of human resources. In 2019, this number increased to $67 \%$. In 2020 survey data pre-Covid it was $66 \%$, with a slight decrease in survey implemented post-Covid where this indicator was at $54 \%$. The decrease of the indicator could be explained by the increased use of remote working which allows companies to widen their talent pool worldwide, and also by the growing place of automation.

Employment strategies in information technology industry have traditionally relied on young entrants and consequently this sector is directly impacted by the pressures of changing demography and labour shortages. Since the late 90ties the impact of ageing population on employment and the labour market has been one of the most pressing issues confronting European societies (Walker, 1999, Taylor et al., 2013, Konrad et al., 2020).

Given the present situation of increasing labour force shortages in the information technology industry and the need to intensively look for short term and long term solutions to address this problem at both macro and micro levels, the research question of the present article was defined as follows - how to measure to what extent the retraining of older workers can solve the problem of labour shortages in the information technology sector in Latvia? 
The combination of multidisciplinary research methods were applied during the research, including policy analysis approach, application of macroeconomics employment and skills analysis theories. The analysis of the current situation focused on the overview of the economic performance indicators of the information technology sector, taking into account both macroeconomic aspects and the availability of resources and competencies of the sector, including aspects related to human resources and labour market skills gap.

The qualitative analysis was based on the in-depth open-ended stakeholder interview method. Stakeholders represented government institutions, non-governmental organizations (NGOs), private sector and academia. Interview data analysis was conducted using NVivo qualitative data analysis software.

\section{Labour market skills gap versus potential of professional mobility}

During the era of high technologies and knowledge based economy in general, the skills and the qualification have an important impact on the employment at the level of individual, on the level of enterprise and on the level of national economy. To describe the characteristics of labour, the term "skills" can be used to accentuate the potential to change and to develop acquired skills. PES concept (Green, 2011) is proposing to classify the skills as 1) productive, 2) expandable, 3) social. This concept is allowing to see the skills which are required by enterprises and which can ensure the accomplishment of direct job duties, completed by the skills which can be acquired in formal and informal (in official structures) and unofficial structures during the life. Such authors as J.Pinkston (Pinkston, 2009) or S.Garmise (Garmise, 2006) are writing about professional skills required by labour market. But due to the technological changes, highly qualified and low qualified labour can be replaced by artificial intelligence in automatization processes or replaced by cheaper labour force in lower income level countries in production relocalization processes. F.Levy (Levy, 2010 ) is mentioning 2 types of skills - complex communication and expert thinking which cannot be replaced by the computers.

At the same time it is necessary to take in consideration that the skills are formed during the life and age has a significant impact on the ability to utilize the skills. Such authors as F.Cuhna, J.Heckman, L.Lochner and D.Masterov are providing the idea that the skills acquired during one period of life are increasing the adaptation of other skills during later stages of life (Cuhna, Heckman, Lochner, Masterov, 2006). The health indicators, physical resistance, flexibility, sensor skills are diminishing with age but the role of cognitive skills is rising (Turek, Perek-Bialas, 2013). It is important to notice that in knowledge based economy, the role of physical skills for labour is less important.

Labour with certain skills is not automatically connected to the job vacancies offered by employers. In between the demand and the supply of labour, the mismatch can appear due to differences between the qualification or skills of labour and the qualification or skills required for the job. Such a mismatch can appear in cases when the education level of the person is not convenient for the chosen profession or because of insufficient information about the labour market (Global Agenda Council on Employment, 2014). Certain skill gaps can appear due to 1) skills shortage, 2) underskilling, 3) overskilling of the person or 4) skill underutilisation because of a skill surplus which is not utilized by the employer.

The authors of this article are proposing the following illustration of skills gap:

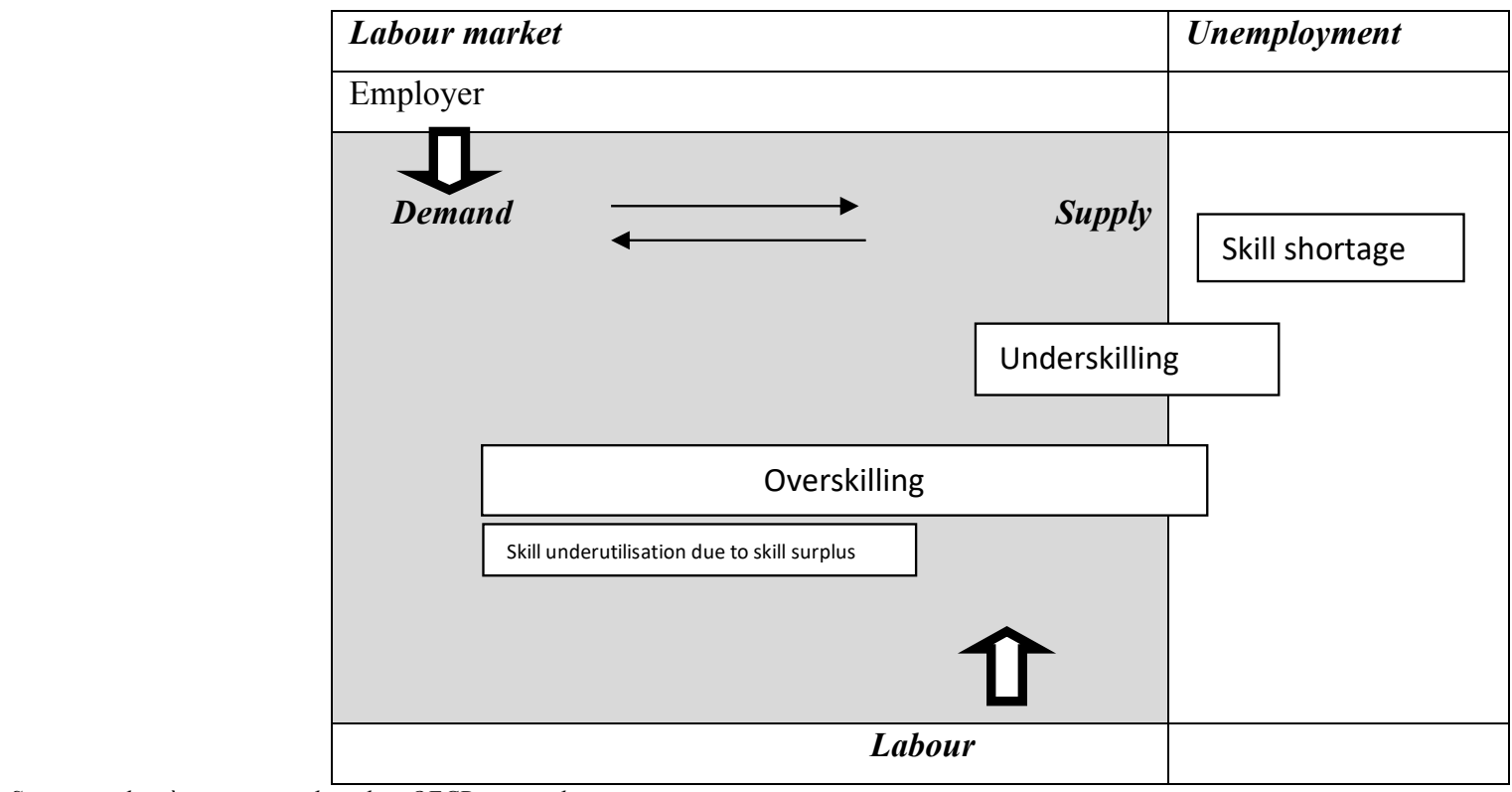

Fig. 1. Skills gap in labour market 
Education/qualification mismatch is one of the most studied forms of mismatch of skills to the demand of labour in the market, for example in the studies of R.Desjardins and K.Rubenson (Desjardin, Rubenson, 2011). The correspondence of education or qualification can be the following: 1) required education/qualification, 2) undereducation/under-qualification, 3) overeducation/over-qualification. For certain job positions it is difficult to join the job with a very precise education, but due to fast technological changes, professional mobility is necessary. The portability of skills from one job or profession to another is ensuring the employability of the person. Similar position is developed in Lisbon Strategy of EU about life-long learning and supported by ILO in International Labour conference in 2008. The authors of this article would like to insist that the position to invest in own education or qualification during different periods of professional life to stay economically active and to be adjusted to the requirements of labour market is fully corresponding to the classical conception of human capital developed by G.Becker in 1960's: the treatment of actual investments in education or qualification are raising the future skills as a return of investment converted in the employability and the income level.

\section{Economic activity indicators of the information technology sector in Latvia}

The key macroeconomic indicators of the information technology sector include the share in the economy, export, value added, and productivity. The information technology sector's share of value added in GDP spiked from $3.8 \%$ in 2014 to $4.2 \%$ in 2015 and since then is experiencing a steady growth with very similar share numbers $2016-4.1 \%, 2017-4.2 \%, 2018-4.3 \%, 2019-4.6 \%$ (See Fig. 2).

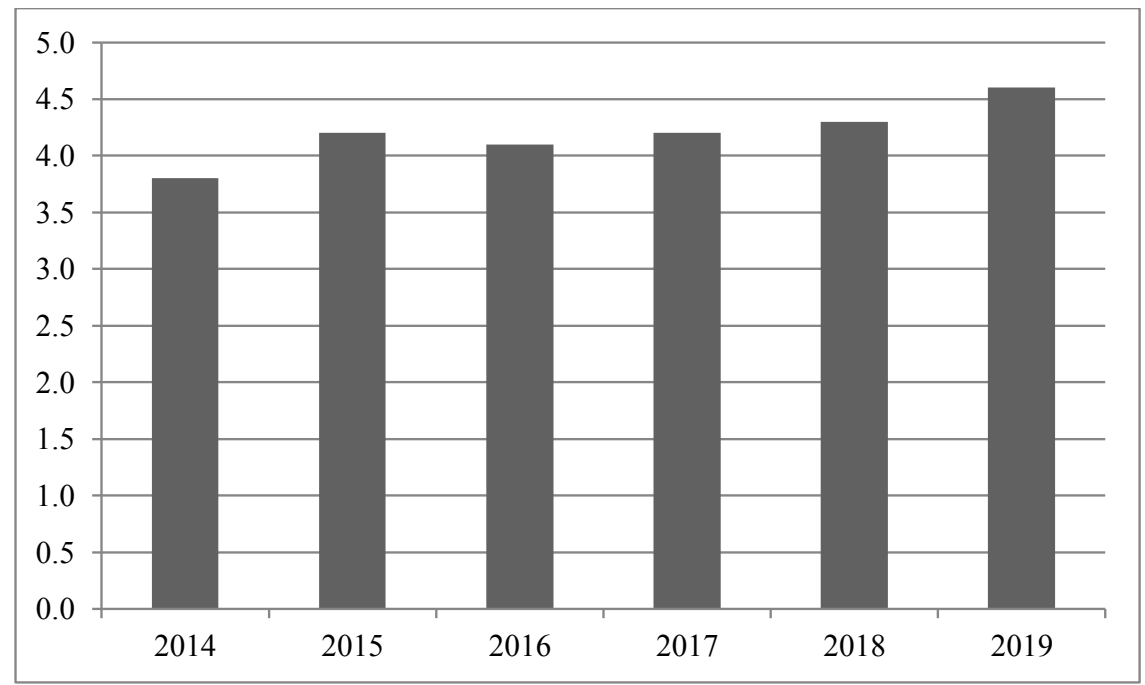

Source: authors' creation based on databases of the Central Statistical Bureau of Latvia

Fig. 2. Information technology sector share of value added in GDP in Latvia (2014 - 2019)

(current prices, $\%$ of total gross value added)

Micro level business indicators of the information technology sector such as number of enterprises, number of employees in the sector, pre-tax profit of enterprises, turnover, and personnel costs also show a steady growth since 2014. See Table 1.

Table 1

Key business indicators of information technology sector in Latvia (2014 - 2019)

\begin{tabular}{|c|c|c|c|c|c|c|}
\hline & 2014 & 2015 & 2016 & 2017 & 2018 & 2019 \\
\hline Number of enterprises & 5432 & 6133 & 6567 & 6559 & 6900 & 6996 \\
\hline Number of employees & 26522 & 29203 & 31801 & 33990 & 37300 & 37225 \\
\hline Profit before tax (EUR million) & 221 & 247 & 290 & 275 & 395 & 427 \\
\hline Turnover (EUR million) & 3063 & 3497 & 3471 & 3617 & 3851 & 4097 \\
\hline Personnel costs (EUR million) & 410 & 472 & 541 & 613 & 732 & 827 \\
\hline Value added (EUR million) & 791 & 903 & 1018 & 1122 & 1263 & 1400 \\
\hline
\end{tabular}

The changes in value added and number of jobs show that in the period after the economic crisis, the information technology industry's production volumes are steadily increasing. In 2015, production volumes in the sector increased by $6 \%$ compared to 2014 . In turn, compared to the lowest point of the crisis in 2010, in 2015 the output of the sector had grown by $62 \%$ and exceeded the pre-crisis level by $25 \%$. 
Compared to the increase in production, the number of jobs in the sector is growing much faster, which indicates a decrease in productivity. In 2015 the data of Ministry of Economics of Latvia is showing, the number of occupied jobs increased by $11 \%$. In 2015, compared to the lowest point of the crisis in 2010 , the number of jobs had increased by $139 \%$.

One of the most important indicators of the negative impact of the lack of information technology specialists on the development of the information technology sector is the unit labour costs (ULC). Since 2010, the ULC in the information technology sector in Latvia has grown by $72 \%$. (Ministry of Economics of Latvia, 2108) The increase in ULC can be largely explained by the high demand for information technology specialists in the labour market, as shown by the current situation and labour market analysis, therefore maintaining cost competitiveness is not possible at the expense of reducing labour costs. This trend will continue, and without productivity gains, the risk of reduced cost competitiveness increases significantly (Ministry of Economics of Latvia, 2018).

The authors of this article would like to propose the following scheme reflecting the causality of the main problems in information technology labour market:

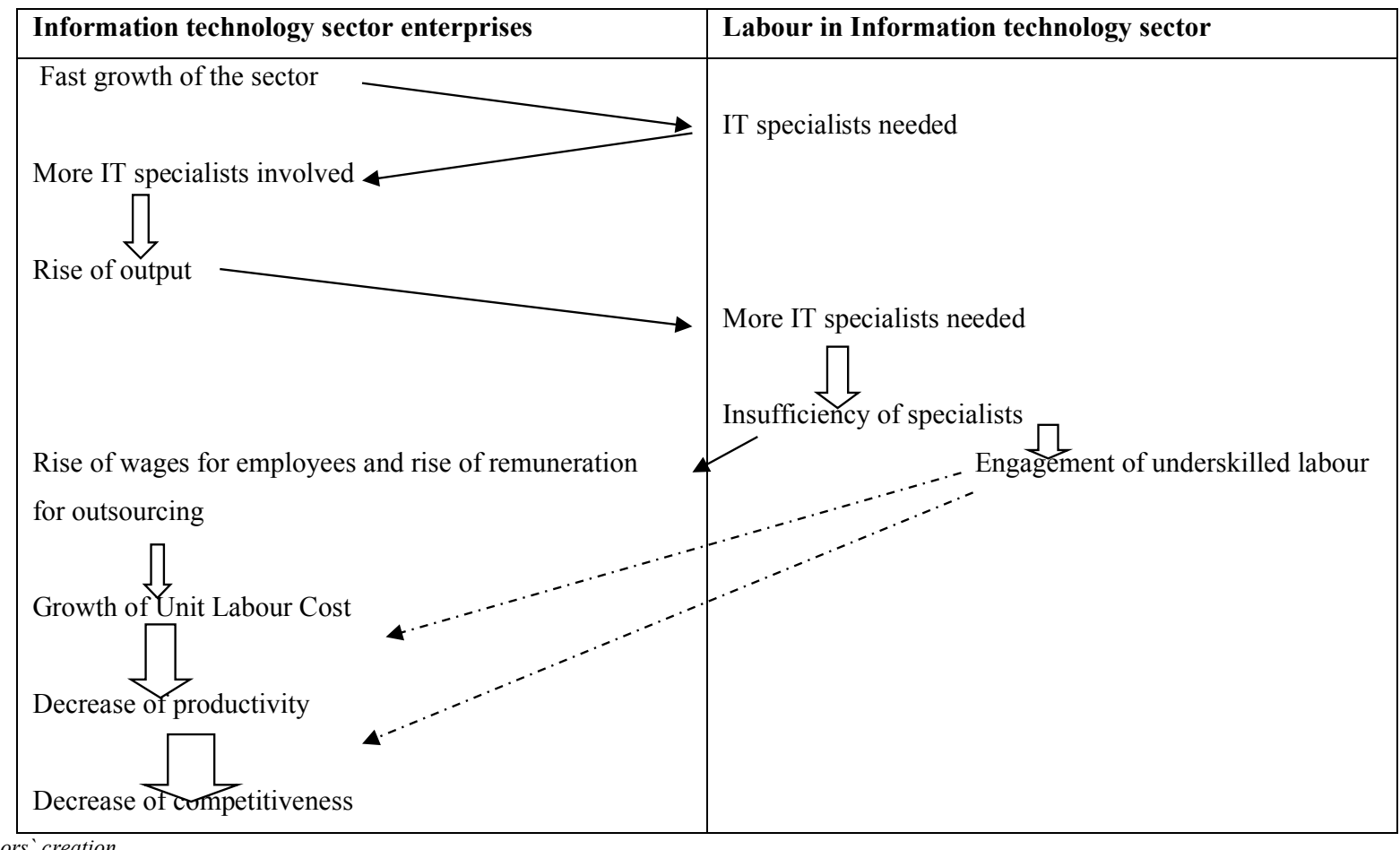

Source: authors`creation

\section{Fig. 3. Negative impact of the information technology labour force shortages}

The main and determining resource in the field of information technology is a highly qualified labour force. Ensuring the creation of conditions that would allow to gradually reach the number of information technology specialists required for successful operation and development of information technology sector could increase information technology sector productivity and reduce ULC growth.

\section{Macro and micro level solutions for labour force shortages in information technology sector}

As noted by OECD experts in Economic Survey about Latvia: "Substantial progress has been made to increase the effectiveness of active labour market policies (ALMPs) such as by profiling job seekers to determine programs according to their characteristics and by evaluation. Training programmes are designed by a committee involving social partners to respond to skill demands in the labour market[...] Plans to improve access of the unemployment to the reformed modularised vocational education system are welcome." (OECD, 2017). As we can see from the figure below, (in comparison to $\sim 0.5 \%$ among OECD countries on average). 


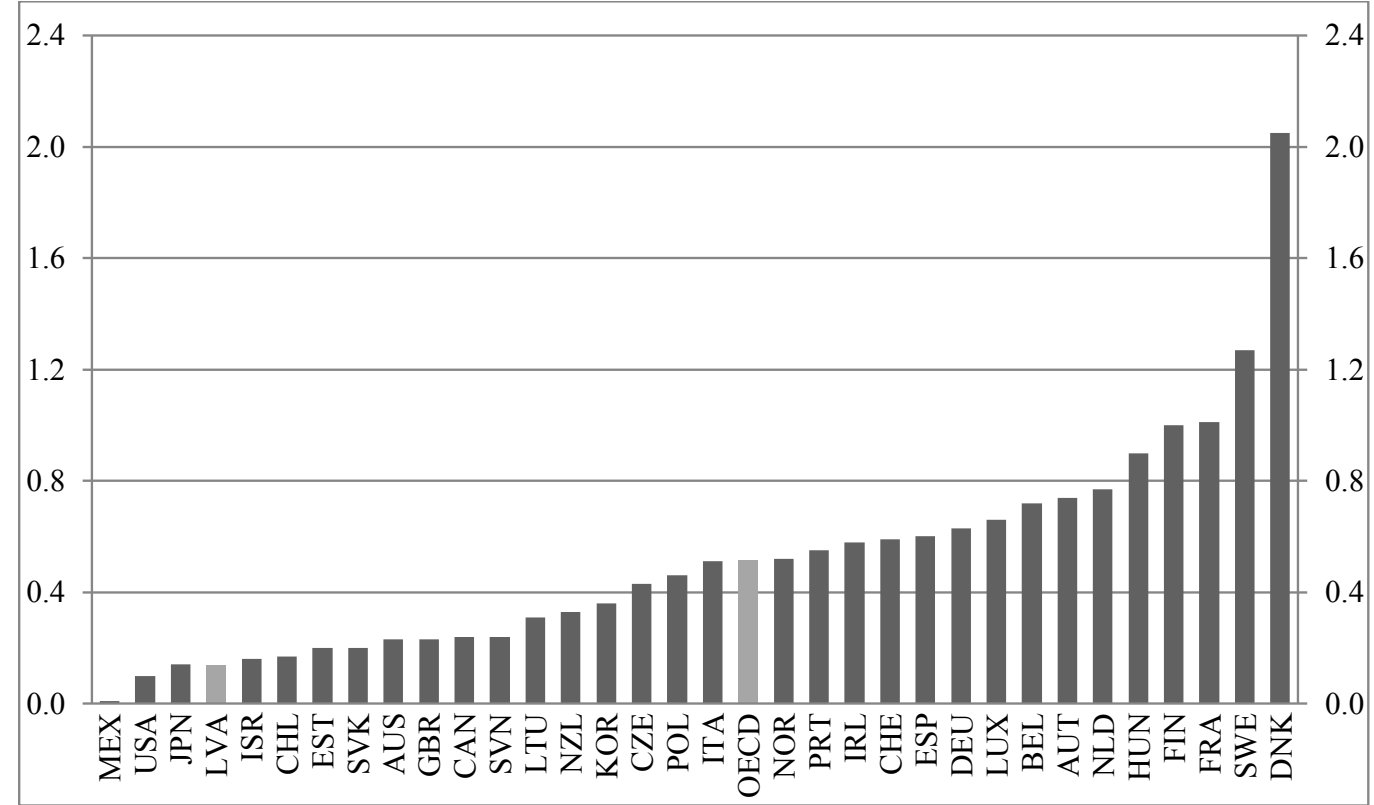

Source: OECD (2017), OECD Employment and Labour Market Statistics (database)

Fig. 4. Comparative data on expenditure on active labour market policies

In 2019 OECD published an in-depth analysis about ALMPs in Latvia - "Connecting People with Jobs, Evaluating Latvia's Active Labour Market Policies" (OECD, 2019), concluding that more extensive use of ALMPs has become one of the primary objectives of Latvia's Inclusive Employment Strategy 2015-2020, especially with regards to disadvantaged groups, including older workers.

Macro level. First of the ALMPs measures for older people is a programme that was introduced in 2017 and seeks to prevent older employees losing their jobs. This programme promotes active ageing related strategies in firms and offers career counselling, basic competency measures, workplace adjustment and measures for occupational health to employees aged 50 and above who are at risk of unemployment (corresponding to this article's authors' area of interests). The risks of employment are identified as follows: 1) part-time or low wage work, 2) health issues that reduce work capacity, 3) secondary level of education, or 4) constraints resulting from family care obligations. The programme is intended to involve 3000 participants by 2023.

One of the projects of this programme titled "Support for longer working lives" was implemented from 2017 to 2020 by the Latvian State Employment Agency (State Employment Agency of Latvia, 2020) in cooperation with the Latvian Employers Confederation and the Free Trade Union Confederation of Latvia. The total eligible funding available for the project was 1896211 euro including 1611779 euro from the European Social Fund and 284432 euro from the state budget. As a result of the project, 500 older employees received support. This result should be considered to be very important for a country with less than 2 million inhabitants.

In addition, other ALMPs measures support life-long learning and target employed persons with a low skill level and older workers. One of the programmes provides vocational training including formal qualifications as well as career counselling and the certification of professional competencies. The selected participants only have to bear $10 \%$ of the training costs. In 2017 , close to 13000 persons were supported under this programme. According to OECD experts (OECD, 2019) training for the unemployed has had positive effects on labour market outcomes, although the voucher system used to allocate training may be improved - some disadvantaged groups may need additional support when using their vouchers, training providers are not distributed evenly across municipalities which sharpens the need for supporting regional mobility, and the voucher system currently in place in Latvia may compound so-called lock-in effects. In order to evaluate these results, the authors of this article would like to make a comparison: small positive effect on the probability to remain employed was identified for subsidized training programmes in Germany by C. Dauth and O.Toomet (Dauth, Toomet, 2016). Their analysis found that these programmes improve the probability to remain in paid employment by approximately 2.5 percentage points in the 2 years following treatment. Effects were more pronounced for part-time workers, long-duration programme participants, and for workers older than 55 years. These findings suggest that subsidized training may be considered as means of increasing the labour market attachment to part-time workers and to older workers in general. 
In addition to AMPLs, there are other retraining initiatives in Latvia such as the project "Next Generation Micro Cities of Europe" of the European Union initiative "Urban Innovative Actions" currently implemented by Ventspils High technology Park Foundation DarbaGuru together with "Ideju Kapitāls". The aim of the project is to prepare and retrain specialists for jobs in information technology related professions and skills, attracting already qualified specialists to companies or helping to acquire the necessary knowledge in training and allowing to change professions Funding attributed for this project is 162471.50 EUR (PMB, 2019).

The authors of this article believe that it would be beneficial to use the experience of retraining programmes under such initiatives as previously described project "Next Generation Micro Cities of Europe", as well as measures implemented by information technology companies to train new employees, in order to review and, if necessary, adjust current training programs within AMPLs aimed at requalification to enter jobs in information technology sector.

Micro level. In 2018 one of the authors of this article implemented research financed by the Ministry of Economics of Latvia with the aim to analyse whether it is possible to overcome the information technology sector labour market shortages by creating a new information technology university in Latvia.

An important part of this research was conducting non-structured, open-ended, in-person stakeholder interviews. The initial number of interviews during methodology development period was 18 , but in the course of the research 4 more interviews were added. In total, 23 stakeholders were interviewed. The detailed list of stakeholder groups, types and number of interviews for each group is presented in Table 2.

Table 2

Stakeholder groups, types and number of interviews

\begin{tabular}{|c|l|l|c|}
\hline No. & Stakeholder group & \multicolumn{1}{|c|}{ Stakeholder type } & $\begin{array}{c}\text { Number of } \\
\text { interviews }\end{array}$ \\
\hline 1. & Government & State institutions representatives & 3 \\
\hline 2. & NGOs & Experts of non-governmental institutions & 3 \\
\hline 3. & Private sector & Representatives of largest Latvian IT companies & 3 \\
\hline & & Representatives of leading companies in the IT sector & 3 \\
\hline & & Representatives of small and medium enterprises in the IT & 3 \\
\hline 4. & Academia & Sector & 4 \\
\hline
\end{tabular}

Source: authors' creation

Based on the analysis of available information and the opinions expressed by the public administration experts, entrepreneurs and higher education representatives during the interviews, the following evaluation criteria were defined: 1) ability to provide 3000 (indicative calculation) graduates of information technology study programs per year; 2) minimum amount of investment to implement the solution; 3) fast time schedule for model implementation and development - start of studies in 2020; 4) ability to attract foreign students; 5) ability to ensure the involvement of information technology companies in the implementation of the chosen model; 6) the ability of Latvian higher education institutions plays an active role in the implementation of the proposed solutions; 7) education of information technology specialists who start or continue their professional career in Latvia after graduation and who are able and motivated to create their own companies, create new products and new jobs, thus promoting the overall development of the information technology sector and productivity indicators in other sectors.

The set of measures identified during the research show that in the course of further problem solving in the higher education system it is necessary to develop in-depth and detailed proposals related with the necessity to ensure the acquirement of knowledge and skills in information technology in the following main directions:

1) Interdisciplinary orientation and content of higher education information technology programs;

2) Evaluation of the information technology' component in other higher education sector programs and the addition of tailor-made courses where only core courses are currently offered; 
3) Involvement of information technology companies in the development of university programme content;

4) Opportunities to use company employees to increase the capacity of teaching staff (support from company management for those employees who devote time to give lectures at universities);

5) Involvement of the State Employment Agency in ensuring the link between higher education and the national economy - use of information and expertise of the State Employment Agency, evaluating the possibility to expand the agency's powers to engage in consulting on curriculum content development.

In addition to the previously described research results, the collection and continuous analysis of the available data has led to the conclusion that the shortage of information technology professionals cannot be solved solely by the measures related to the higher education and that the creation of joint information technology programmes will not present sufficient results. The authors of this article would like to insist that several factors influencing the labour market shortages in the information technology sector are closely linked to a number of other areas, such as: 1) digital skills; 2) remuneration of information technology specialists compared to other EU countries; 2) demographic situation; 3) education policy from primary school to secondary school level (mathematics, programming, digital skills); 4) employment policy proposing different retraining programs; 4) migration processes and outflow of IT specialists from the country; 5) immigration policy which can attract IT specialists from other countries. With respect to migration policy measures, data analysis and information obtained during interviews indicate - first, that it is necessary to improve the opportunities for foreign students to find jobs after graduation, second, that attracting foreign specialists to train local staff, even temporarily, remains very difficult.

Authors of this article consider that retraining activities using the experience of the State Employment Agency and private companies involved in adult education and requalification need to be evaluated in order to avoid problems similar to the one identified during interviews with small and medium-sized information technology enterprises. The problem mentioned was related to the training project "Improvement of Professional Competence of Employed Persons" organized by State Education Development Agency of Latvia: it was pointed out that the project includes a restriction that one person can participate in the programme only once. According to the entrepreneurs whose employees use these courses, it is necessary to review this restrictive condition. Given that the project implementation timeline is 1 January 2017 - 31 December 2022 , the parties involved in the project have concluded that such a restriction is disproportionate. Information technology field is one of the 11 sectors in which training is offered. By providing such a restriction, one person is allowed to participate only in one training course during a period of five years. In the view of interviewed stakeholders, the goal of promoting further education could hardly be achieved. The suggestion from companies participating in the programme would be that 1) at least 3 courses for 1 person should be supported, particularly in information technology sector, where new skills need to be acquired at least every 3 years. 2) Another alternative could be to change this requirement as an evaluable criterion, if a person has already completed 2 courses, then applying for the 3rd course has an advantage for those who have not yet used this opportunity. In turn, if there are no such applicants, the applicant can also attend the 3 rd year course.

After analysing the results of in-depths interviews with information technology experts and higher education experts, the authors of this article identified proposals related to all levels of education system, as well as adult education and retraining activities that need further examination.

Demographic indicators of the dependency ratio indicate changes in the age composition of the population in Latvia - the proportion of the working-age population (15 - 62 years) compared to the retirement age population continues to decrease. Since 2011, the number of working-age population has decreased by 155 thousand and the population of retirement age - by 10 thousand. Since 1993, the proportion of the population of retirement age has been higher than the proportion of children and adolescents, which means that in future, the working age population will be smaller and the dependency ratio will increase. At the beginning of 2019 in Latvia, there were 373 people of retirement age and 259 children under 14 years of age per 1,000 working age population (Central Statistical Bureau of Latvia, 2019).

Adult education and retraining measures, drawing on the experience of the State Employment Agency and the experience of private companies involved in adult education, are showing the following: the experience of measures implemented by information technology companies for several years to train new employees could be used to develop and implement mechanisms in the form of pilot projects that would provide retraining opportunities for interested specialists in other fields and also have the ability to reorient to work in the information technology sector.

In the case of Latvia and given the ongoing reform of school network system, part of teachers will lose their jobs. Teaching professions have portability of skills indicators for the information technology sectors and tailor made retraining programmes would 
ensure continuous employability of specialists, majority of which are people over 40 . Therefore it is advised to analyse the possibility of offering retraining programs for teachers supported by the state and the information technology industry.

The impact of the information technology sector on the economy as a whole is vital to meet the challenges of globalization and to foster innovation, creativity and competitiveness throughout the economy; the use of information technology improve the work of the public sector and the public administration system; information technology also help to address social policy challenges by improving the quality of life and contributing to the aging population.

With respect to employability of older people in the information technology sector, the authors of this article consider that continuous multidisciplinary studies exploring the mechanisms that reduce employability of older people in Latvia are necessary. One of suggestions would be to conduct a similar study to the one implemented by K.Turek and K.Henkens (Turek, Henkens, 2020) in Poland, assessing how recruitment of people over 50 years old is influenced by the job skill requirements - their study used a real-life framework by referring to existing vacancies and actual requirements that reflect labour demands at the scale of an entire national labour market. The results of the study are pertinent to the information technology labour market because the engagement of older candidates in this sector are pushed aside due to required computer, physical, social, creative and training skills.

In the study on digitalization and structural labour market problems in Germany, U.Walwei (Walwei, 2016) emphasizes that with respect to increasing role of information technology, "labour market policy will have to play a more preventive role than in the past by facilitating lifelong employability. Such policies would consist of a more continuous professional counselling (e.g. regarding options of further and new qualifications)”. Due to this, a second suggestion can be derived in relation to the role of labour market in the sector - that the monitoring of the situation, the identification of possible gaps and a timely orientation of potential labour force groups is needed to change their qualification.

In such conditions, skill adjustment and development (including for older workers) will be the major topic. The authors of this article consider that in Latvia, skill adjustment and development should remain an integral part of active labour market policies, including measures geared towards retraining older workers for employability in information technology sector by the use of their experience to extend their skills. The portability of skills from one job or profession to another is ensuring the employability of the person, simultaneously ensuring stable development of the sector, stable flow of income both for the individual and for the enterprise, followed by economic growth and rise of competitiveness of national economy.

\section{Conclusions, proposals, recommendations}

(1) The sustainability aspects of the solution to the shortage of information technology specialists are based on the overall economic development in the direction of digitalisation, which means that the demand for information technology professionals in Latvia, the European Union and the world as a whole will only continue to grow.

(2) The analysis of the current situation on Latvia's macroeconomic indicators and the interviews of experts and stakeholders carried out during this study confirm that the most significant obstacle to the successful development and integration of digitization processes in existing production and service areas in Latvia is the lack of human resources in the information technology sector.

(3) Overall, the research results present sufficient proof that methods aimed at increasing number of graduates in the information technology study programmes does not represent enough capacity to solve labour supply shortages in the information technology sector.

(4) The policy measures aimed at solving the human resources shortages in the information technology sector adopted in Latvia so far have mainly focused on attracting younger people. This study shows that labour market policies focusing on employability of older people in information technology jobs needs to be extended.

(5) The orientation of certain groups of older workers (such as school teachers) to develop their skills to be employed in the information technology sector is an achievable purpose in overcoming 1) the shortage of labour force in the sector and 2) the challenges of the continuous decrease of the proportion of the working-age population compared to the retirement age population.

\section{Bibliography}

Central Statistical Bureau of Latvia, 2019. Demography 2019. [Online] Available at: https://www.csb.gov.lv/lv /statistika/statistikas-temas/iedzivotaji/iedzivotaju-skaits/meklet-tema/387-demografija-2019 [Accessed 10.10.2020].

Cuhna, F., Heckman, J.J., Lochner, L., Masterov, D.V., 2006. Interpreting the Evidence of Life Cycle Skill Formation. Handbook of the Economics of Education, 1, 697-812. 
Dauth, C., Toomet, O. 2016. On Government-Subsidized Training Programs for Older Workers, Labour, 30(40), 371-392. [Online] Available at: http://dx.doi.org/10.1111/labr.12082. [Accessed 14.10.2020].

Desjardin, R., Rubenson, K., 2011. An Analysis of Skill Mismatch Using Direct Measures of Skills. OECD Education Working Papers, No.63.

European Commission, 2007. ICT for Active Ageing at Work: Reflection Paper for the i2010 eInclusion SubGroup. [Online] Available at: https://ec.europa.eu/information_society/activities/ict_psp/documents/einc_tn_aaw.pdf [Accessed 27.10.2020].

Garmise, S., 2006. People and the Competitive Advantage of Place: Building a Workforce for $21^{\text {st }}$ Century. New York: M.E.Sharpe.

Global Agenda Council on Employment, 2014. Matching Skills and Labour Market Needs: Building Social Partnerships for Better Skills and Better Jobs. World Economic Forum Report.

Green, F., 2011. What is Skill? An Interdisciplinary Synthesis. Centre for Research on Learning and Life Chances in Knowledge Economics and Societies Research paper, No. 20. [Online] Available at: http:/www.llakes.org/wp-content/uploads/2011/02/Green-What-is-Skill-reduced.pdf [Accessed 29.10.2020].

Harvey Nash/KPMG, 2020. CIO Survey 2020 - Everything Changed. Or did it? [Online] Available at: https://assets. $\mathrm{kpmg} / \mathrm{content} / \mathrm{dam} / \mathrm{kpmg} / \mathrm{xx} / \mathrm{pdf} / 2020 / 10 /$ harvey-nash-kpmg-cio-survey-2020.pdf [Accessed 29.10.2020].

Harvey Nash/KPMG, 2018. CIO Survey 2018 - The Transformational CIO. [Online] Available at: https:/assets. $\mathrm{kpmg} /$ content/dam/kpmg/xx/pdf/2018/06/harvey-nash-kpmg-cio-survey-2018.pdf [Accessed 13.09.2020].

Konrad, T. et al., 2020. The Proactive Shift in Managing an OlderWorkforce 2009-2017: A Latent Class Analysis of Organizational Policies, The Gerontologist, 60(8), 1515-1526. [Online] Available at: https://doi.org/10.1093/geront/gnaa037 [Accessed 29.10.2020].

Levy, F., 2010. How Technology Changes Demands for Human Skills. OECD Education Working Papers, No. 45. [Online] Available at: https://doi:10.1787/5kmhds6czqzq-en [Accessed 29.10.2020].

Lee, C.C., Czaja, S.J., Sharit, J., 2008. Training Older Workers for Technology-Based Employment. Educational Gerontology, 35(1), 15-31. [Online] Available at: https://doi:10.1080/03601270802300091. [Accessed 14.10.2020].

Ministry of Economics of Latvia, 2018. Summary of Macroeconomic Indicators for J62-63 COMPUTER PROGRAMMING, CONSULTING, INFORMATION SERVICES. Information document of the Ministry of Economics of Latvia.

Organisation for Economic Co-operation and Development (OECD), 2017. OECD Economic Surveys: Latvia 2017. Paris: OECD Publishing. [Online] Available at: https://doi.org/10.1787/25222988 [Accessed 24.10.2020].

Organisation for Economic Co-operation and Development (OECD), 2019. Evaluating Latvia's Active Labour Market Policies, Connecting People with Jobs. Paris: OECD Publishing. [Online] Available at: https://doi.org/10.1787/6037200a-en [Accessed 24.10.2020].

Pinkston, J.C., 2009. Model of Asymmetric Employer Learning with Testable Implications. The Review of Economic Studies, 76(1), 367-394.

Procurement Monitoring Bureau (PMB), 2019. Notification of the Results of the Beneficiary's Procurement Procedure. [Online] Available at: https://pvs.iub.gov.lv/show/604118 [Accessed 27.10.2020].

State Employment Agency of Latvia, 2020. Summary of the Project no. 7.3.2.0/16/I/001 Support for Longer Working Life. [Online] Available at: https://www.nva.gov.lv/en/node/248 [Accessed 28.11.2020].

Taylor, P., McLoughlin, C., Brooke, E., di Biase, T., Steinberg, M., 2013. Managing Older Workers During a Period of Tight Labour Supply. Ageing \& Society, 33(1), 16-43.

Turek, K., Henkens, K., 2020. How Skill Requirements Affect the Likelihood of Recruitment of Older Workers in Poland: The Indirect Role of Age Stereotypes, Work, Employment and Society, 34(4), 550-570.

Turek, K., Perek-Bialas, J., 2013. The Role of Employers Opinions about Skills and Productivity of Older Workers: Example of Poland. Employee Relations, 35(6), 648-664.

Walker, A., 1999. Combating Age Discrimination at the Workplace. Experimental Aging Research, 25(4), 367-377.

Walker, A., 2005. The Emergence of Age Management in Europe. International Journal of Organisational Behaviour, 10(1), 685-697.

Walwei, U., 2016. Digitalization and Structural Labour Market Problems: The Case of Germany. International Labour Organization Research Paper, No. 17. [Online] Available at: https://www.ilo.org/wcmsp5/groups/public/---dgreports/---inst/documents/publication/wcms_522355.pdf [Accessed 27.10.2020]. 


\title{
CORRELATIONS BETWEEN ETHICAL LEADERSHIP AND LEADERSHIP STYLES \\ Ligita Simanskiene, Klaipeda University \\ Arnoldas Petrulis, Klaipeda University \\ Julija Melnikova, Klaipeda University
}

\begin{abstract}
The authors of article search correlations between ethical leadership and leadership styles. There were defined criteria for ethical leadership and criteria for transactional, transformational and servant leadership styles. The aim of the research is to theoretically distinguish the criteria of ethical leadership and transactional, transformational and servant leadership styles, to find correlations between ethical leadership and different leadership styles. The following research problem can be formulated with a problematic's questions: according to which criteria should the expression of ethical leadership in different leadership styles? Do we find correlations between ethical leadership and different leadership styles? Quantitative research method was applied in the present article to find answers to research problems. In research participated 298 employees from five organizations. Formulated hypothesis was confirmed: if managers are characterised by ethical leadership, they lead using the servant leadership style.
\end{abstract}

Keywords: ethical leadership, transactional leadership, transformational leadership, servant leadership.

JEL code: M12

\section{Introduction}

The changing pace of life brings constantly growing changes in the economic and societal issues that modern business organisations are continuously facing. Therefore, in the face of such fundamental changes, the success of an organisation's operation in most cases depends on its leader. Values, beliefs and an ability to combine them with the surrounding business environment, both domestically and internationally, are important in leadership. The manager's ethical values are provisionally important not only for the organisation that he /she is in charge of, but also for the community that he /she leads. It is important to realise that not only the competitor(s), but also the business partner(s) of the organisation run by the employees, may also have their own and different ethical values. The manager's actions and behaviour create and shape not only the opinions of the members of the organisation he /she manages of himself /herself and the activities of the organisation, but also the public opinion about the organisation and its employees. The requirements for the manager are higher than those for the other employees of the organisation. It is expected that the leader will adhere to higher moral precepts and will set an example of moral behaviour, and that he /she will take greater responsibility not only for the creation of well-being for all, but also for the values cherished in the community.

Leadership of an organisation and its members can be monitored and assessed according to the chosen leadership style or a combination of several styles in compliance with leadership ethics, and according to how it is ensured that the goals of the organisation are achieved and implemented. What is the purpose of allocating tasks to the employees: to maximise profits and benefits for oneself, or to seek to ensure the needs of the employees without losing sight of the profitability sought? Ethical leadership, as well as a leadership style on the whole, are revealed in the manager's relationship with the organisation's employees that is expressed in leadership and in the totality of his /her actions which can have a significant impact on the organisation in achieving its goals. Often, ethical leadership is underestimated by the management, as well as the choice of leadership style, and the impact of its application on the employees. Their selection and application are revealed in the employees' selfmotivation, job satisfaction, work productivity, and loyalty to the organisation, and whether they are present or absent. Therefore, in order to determine whether the employees strive to work and whether they are satisfied with their results, and whether loyalty to the organisation is important to them, and to what extent an organisation's performance depends on the management, one must study ethical leadership and leadership styles in organisations.

The following research problem can be formulated with a problematic's questions: according to which criteria should the expression of ethical leadership in different leadership styles? Do we find correlations between ethical leadership and different leadership styles? The aim of the research is to theoretically distinguish the criteria of ethical leadership and transactional, transformational and servant leadership styles, to find correlations between ethical leadership and different leadership styles.

Hypothesis: Ethical leadership managers typically apply the servant leadership style. 
Used methods. The research is implemented through a two-stage process: of literature review (descriptive method for the analysis of the concepts of Lithuanian and foreign authors as regards ethical leadership and different leadership styles) and empirical survey. For the empirical research, a method of questionnaire survey was chosen, and the respondents were the staff of five Klaipeda organizations. Logical analysis was used to confirm or to deny the statements and to formulate the conclusions applying the SPSS 18 software package to ensure their reliability, and Microsoft Excel was used for visual data presentation.

Limitations of the research. The results of the survey are representative only for the organisations in question, no generalisations can be made for all organisations operating in the country and engaged in similar activities. This is the main limitation of the work.

\section{Theoretical background of ethical leadership and different leadership styles}

Leadership research covers not only the entire $20^{\text {th }}$ century but is also being performed today. It is now increasingly being said and acknowledged that one of the most important aspects of leadership is the application of ethics. Modern management researchers recognise the importance of ethical leadership. As a result, more and more research on ethical leadership is being conducted in an effort to find out how and to what extent ethical leadership is expressed in an organisation, its activities and its people (Treviño, Hartman, Brown, 2000:129; Brown, Treviño, Harrison, 2005:120; Treviño, Brown, 2004b:80). In this paper section we will write main criteria for ethical leadership and three leadership styles: transactional, transformational, servant. These

Ethical leadership in the scientific literature is analysed by distinguishing between different features that are very numerous and widely described (Treviño, Hartman, Brown, 2000:130; Brown, Treviño, 2014:588; Yuk1, 2013:348). This study focused on the following features of ethical leadership, most commonly mentioned in the scientific literature: justice (Zhu, May, Avolio 2004; Zhu, 2008; Brown, Treviño, 2006a; Yukl, 2013); values (Avolio, Walumbwa, Weber, 2009; Brown, Mitchell, 2010; Zhu, 2008; Brown, Treviño, 2006a; Yukl, 2013); reliability (Treviño, Hartman, Brown, 2000; Zhu, May, Avolio 2004; Brown, Treviño, 2006a; Yukl, 2013); broad approach (Hannah, Avolio, Walumbwa, 2011; Brown, Treviño, 2006a; Yukl, 2013); motivation (Brown, Mitchell, 2010; Zhu, 2008, Yukl, 2013).

Another approach to the importance of leadership is the leadership style chosen by the leader. Management researchers are also constantly researching the topic of leadership style which influences the activities of the organisation's employees in order to ensure the continuity of the organisation's activities (Avolio et al., 2009:764; Alkahtani, 2016:24; Berg, Karlsen, 2016:1123; Obiwuru et al., 2011:102).

The literature researching management describes many different leadership styles. The major part of leadership research performed abroad consists of studies of an exceptionally popular transformational leadership style (Stelmokiené, Endriulaitiené, 2015:10). Based on the insights of scholars, the following modern leadership styles are analysed in this study: transactional (Bass, 1999; Burns, 1978; Bass, 2000; Zhu et al., 2011); transformational (Bass, 1990; Bass, 1999; Avolio et al., 2009;); and servant (Avolio, Walumbwa, Weber, 2009; Wong, Davey 2007; Kolzow, 2014; Barbuto Jr., Wheeler, 2006).

Leadership styles are analysed very extensively in the scientific literature, and after a break, their features are re-explored. This paper explores different features of leadership style: decision-making method (Bass, 2000; Dedahanov et al., 2016; Kolzow, 2014); providing instructions (tasks) (Avolio, Walumbwa, Weber, 2009; Melchar, Bosco, 2010; Kolzow, 2014); responsibility-sharing (Bass, 2000; Fisher, 2009; Haar et al., 2017); attitude towards initiative (Fisher, 2009; Melchar, Bosco, 2010; Wong, Davey 2007); attitude towards employees (Dedahanov et al., 2016; Barbuto Jr., Wheeler, 2006); attitude towards one's own knowledge (Melchar, Bosco, 2010; Haar et al., 2017); communication with employees (Bass, 1999; Avolio, Walumbwa, Weber, 2009; Dedahanov et al., 2016; Barbuto Jr., Wheeler, 2006); character of relations with employees (Bass, 1999; Avolio, Walumbwa, Weber, 2009; Haar et al., 2017 Kolzow, 2014); attitude towards discipline (Bass, 1990; Dedahanov et al., 2016); attitude towards values (Antonakis, 2006; Avolio et al., 2009; Avolio, Walumbwa, Weber, 2009; Brown, Treviño, 2006b); providing a vision for employees (Bass, 2000; Antonakis, 2006; Avolio et al. 2009; Avolio, Walumbwa, Weber, 2009).

However, in the analysed scientific literature (Brown, Treviño, 2006a:596 and 2006b:956; Zhu, May, Avolio 2004:18; Burns, 1978:20; Walumbwa et al., 2011:206; Zhu, 2008:64) we have observed that ethical leadership in different leadership styles is discussed or explored only in fragments, and most frequently it focuses on only one leadership style.

The research continues to discuss the problems of leadership activities, its ethics and style that would be appropriate for different types of organisations, different levels of management and all cases. There are no references in the scientific literature to the expression of ethical leadership in different leadership styles, their interrelationship and differences. The authors create comparison between ethical leadership and how by criteria 
of ethical leadership can be sees in behaviours of three leadership styles. Table 1 presents a comparison of expression of ethical leadership in different leadership styles according to the criteria of ethical leadership.

Comparison of expression of ethical leadership in different leadership styles

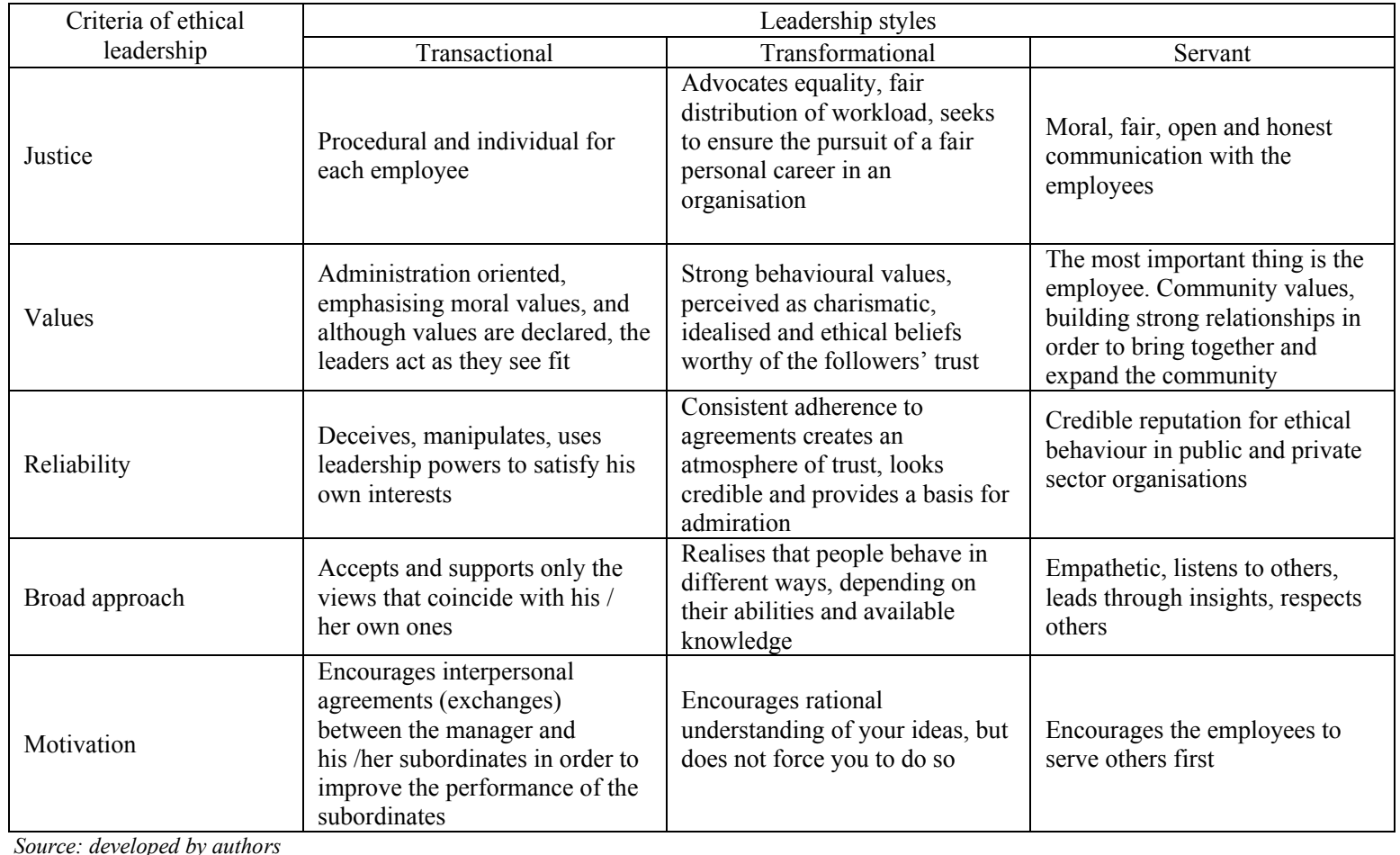

Justice. As long as the managers are honest, the employees will tend to feel respected and fairly valued. By being honest, fair and attentive to others, managers become role models.

Values. Values are the basis of ethics, and principles are necessary because they help to nurture values. They create conditions and assumptions that in their turn make the rules to support behaviour based on values and set out ways of doing things that are based on value beliefs.

Reliability. Leadership is impossible without a partnership of two or more people. The importance of reciprocity and reliability in modelling effective leadership is usually emphasised in contemporary scientific literature on leadership styles. The leaders who do not value their credibility do not encourage the employees to reach their full potential.

Broad approach. The leader's broad approach and insights can be useful not only for himself / herself but also for the organisation. This attitude reveals both the manager's and the employees' perceptions of reality and allows decisions to be made based on that reality. If a person does not try to consider various possible options, this approach is rather limited.

Motivation can be seen as a support of the employees to guide them when necessary so that they could reach their full potential. Ethical leaders care for other people, motivate them and show them respect. The employees are motivated to contact the managers in person to share their concerns and problems.

Ethical leadership in the transformational leadership style is perceived as a gathering of like-minded people, based on honesty, justice, equality, and creating opportunities for pursuing a career. By means of charisma and a personal example, a consistent adherence to agreements creates an atmosphere of mutual trust and confidence with a solid set of values. The manager encourages awareness and dedication to the organisation without the use of force. He /she respectfully listens to the viewpoints of others and encourages the right decisions to be made by consensus when sharing common goals for the common good. Responsibility is delegated by motivating independence and job satisfaction in performing complex tasks while adhering to moral norms. The employees feel valued because they create an environment based on moral values, broaden their horizons, are interested in the activities carried out in the organisation, and develop awareness. The leader promotes conscious ethical behaviour by focusing on joint activities to accomplish a collective mission and inspires adherence to high ethical norms and values that determine performance by implementing an ideal vision. Ethical leadership in the transactional leadership style is perceived as individual for each employee, and it is assessed only in terms of compliance with the intended regulations in the context of possible exploitation. In this leadership style, the 
manager accepts and maintains only those views that coincide with his or her own views, and motivates interpersonal agreements between the manager and the employees. Thus, scholars define the transactional leadership style as hypocrisy in a gentle form with no moral basis. The manager makes decisions unilaterally, without trying to explain them, the tasks are presented in set terms, specifying the requirements and conditions for their implementation. Making necessary decisions is avoided if they could be risky personally for the manager. Only those employees who are most useful to the manager or organisation are supported. There is no personalised attention to the employees' development. The aim is to maintain full power by making the employees indecisive and dependent on the manager. Any criticism or confrontation are suppressed because lies and deception are seen everywhere. Attempts are made to impose a personal vision as the only one that can help to achieve success. Ethical leadership in the servant leadership style is perceived as a service to others without seeking self-interest. It is based on honesty, justice and openness in cooperation. In this case, the most important thing for the manager is the employee. The aim of this leader is to build and multiply the community, and the empathy of the manager, the ability to listen, and ethical behaviour are especially important here, so the employees are encouraged to act by serving others first. The manager empowers the employees without using his or her official authority. This authorisation includes facilitating and motivating the employees to act. The manager pays personal attention to the setting of the organisation's goals, takes care that they are implemented, gives meaning to the tasks performed, emphasises their importance. There is motivation for more commitment, development of independence, a sense of collegiality, focusing not only on personal interests and volunteering in the organisation. By supporting actions that are consistent with the moral dispositions of the organisation and the leader, trust is demonstrated by fostering a reciprocal relationship that is based on justice, sincerity, and honesty. Vision is presented as a conscious service to others.

\section{Research methodology}

Primary empirical data were obtained through a questionnaire survey, and the expression of ethical leadership in different leadership styles was assessed. The analysis of the data collected in the questionnaire survey was submitted, and the opinion of the employees about ethical leadership and a leadership style in organisations was presented. The obtained statistical data were processed using quantitative analyses, methods of interpretation: from the structural point of view, the aim was to reveal the correlation between the criteria of ethical leadership and leadership styles. Multidimensional statistical methods were used to analyse the data of the empirical study: descriptive statistics (frequency, means of values and statistical deviations); reliability analysis (Cronbach's alpha); factor analysis (strength of statistical relationships, and regularity of interdependence). Logical analysis was used to confirm or to deny the statements and to formulate the conclusions applying the SPSS 18 software package to ensure their reliability, and Microsoft Excel was used for visual data presentation.

Research instrument was a questionnaire consisting of closed questions. The following scales of the questionnaire were selected in the questionnaire: Likert scale where each statement was described by five ratings, where 1 meant strongly disagree, 5 meant strongly agree. The statements of the Ethical leadership statements were formulated in accordance with the established ethical leadership criteria. The following criteria of ethical leadership were revealed: justice; values; reliability; broad approach; motivation. The statements about the leadership styles were formulated in the questionnaire according to the established leadership style criteria. The following leadership style criteria were revealed: decisionmaking method; providing instructions (tasks) to the employees; responsibility-sharing; attitude towards initiative; attitude towards employees; attitude towards one's knowledge; communication with employees; character of relationship with employees; attitude towards discipline; attitude towards values; providing a vision for employees.

The five organisations surveyed that agreed to participate in the study employed 992 staff (including managers) who could provide feedback by assessing the direct manager's expression of ethical leadership in different leadership styles. Performing the calculations according to Paniotto formula with permissible inaccuracy $\Delta=0.05$ (5\%) we had to interview 277 employees of Klaipeda port stevedoring companies:

$$
n=1 /\left(0.05^{2}+1 / 992\right)=277
$$

We actually interviewed 298 employees from five organisations. The number of the questionnaires did not exceed the allowed error $\Delta=0.05$, it was more than necessary. The questionnaires were conducted from February to May 2019.

To determine the expression of ethical leadership a two variable correlation test was chosen in order to examine the links between ethical leadership and the leadership style criteria (SPSS, Bivariate Correlations with Pearson's coefficient. The coefficient values: up to 0.60 indicate low internal consistency of the questionnaire (similarity of answers); from 0.60 to 0.70 it is sufficient; over 0.70 it is high. Cronbach's alpha values in the questionnaire are presented in Table 2. 
Cronbach's alpha reliability of respondents' questionnaire responses

\begin{tabular}{|c|l|c|c|c|}
\hline Code & Evaluation criteria & $\begin{array}{c}\text { Cronbach's } \\
\text { alfa coefficient }\end{array}$ & $\begin{array}{c}\text { Standardised data Cronbach's } \\
\text { alfa coefficient }\end{array}$ & $\begin{array}{l}\text { Scale } \\
\text { question } \\
\text { number }\end{array}$ \\
\hline EV & Ethical leadership & 0.969 & 0.969 & 34 \\
\hline TR & Transactional leadership style & 0.861 & 0.860 & 11 \\
\hline TF & Transformational leadership style & 0.880 & 0.881 & 11 \\
\hline TA & Servant leadership style & 0.895 & 0.895 & 11 \\
\hline
\end{tabular}

Research ethics. The aim of this article was to interpret the obtained data correctly and objectively, without trying to hide anything. We would like to point out that according to the oral agreement with the heads of the organisations, the names of the organisations are not published, the survey questionnaires are presented as a whole, without splitting them between the organisations, and the data of the organisations are not compared. The questions of the questionnaires and the selected possible answers are formulated in such a way that they do not offend or otherwise annoy the respondents. The criterion for the selection of questionnaires was a voluntary participation of the study participants.

\section{Research results}

When assessing ethical leadership in organisations, the respondents who were employees of organisations were presented with five criteria of ethical leadership: justice, values, reliability, broad approach, motivation, and 34 statements were formulated. Figure 1 demonstrates the mean values of ethical leadership features.

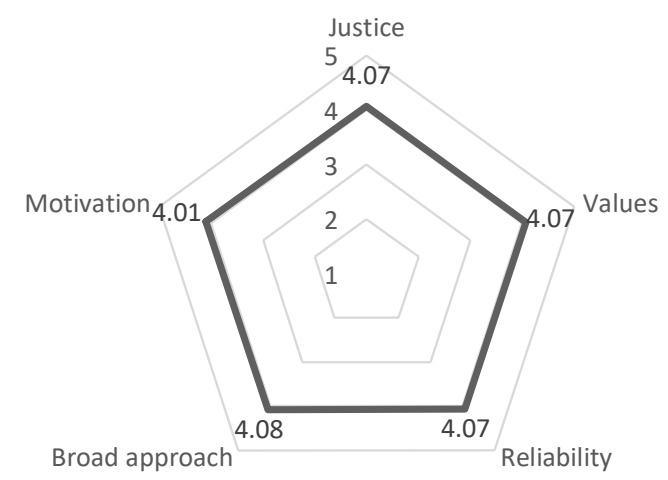

Fig 1. Mean values of ethical leadership features

During the assessment of leadership styles, the mean assessment of the selected leadership styles was performed. The servant leadership style (mean 3.99, st. deviation 0.513) was rated very similarly as of the transformational leadership style (mean 3.98, st. deviation 0.512), and the transactional leadership style was rated worse by the respondents (mean 3.81, st. deviation 0.583 ). The mean values of the leadership style criteria as assessed by the respondents on: decision-making method 4.12; attitude towards one's knowledge 4.04; communication with employees 4.03; attitude towards discipline 4.00; attitude towards initiative 3.98; task submission 3.95; character of relations with employees 3.94; presentation of vision 3.86, attitude towards values 3.85; responsibility-sharing 3.82; attitude towards employees 3.63.

After the correlation, the expression of ethical leadership statements in different leadership styles was determined; it is presented in Table 3.

Table 3

Correlation between the ethical leadership criteria and leadership styles

\begin{tabular}{|l|c|c|c|c|}
\hline \multirow{2}{*}{ Criteria of ethical leadership } & Leadership style & Transactional & Transformational & Servant \\
\hline \multirow{2}{*}{ Justice } & Spearman correlation & $0.338^{* *}$ & $0.493^{*}$ & $\mathbf{0 . 5 4 0 ^ { * * }}$ \\
\cline { 2 - 5 } & Sig. (2-tailed) & 0.000 & 0.000 & 0.000 \\
\hline \multirow{2}{*}{ Values } & Spearman correlation & $\mathbf{0 . 5 3 9 * *}$ & $\mathbf{0 . 6 2 4 ^ { * * }}$ & $\mathbf{0 . 6 8 4}$ \\
\cline { 2 - 5 } & Sig. (2-tailed) & 0.000 & 0.000 & 0.000 \\
\hline \multirow{2}{*}{ Reliability } & Spearman correlation & $0.406^{* *}$ & $0.612^{* *}$ & $\mathbf{0 . 7 0 7 * *}$ \\
\cline { 2 - 5 } & Sig. (2-tailed) & 0.000 & 0.000 & 0.000 \\
\hline \multirow{2}{*}{ Broad approach } & Spearman correlation & $0.576^{* *}$ & $\mathbf{0 . 7 4 9 * *}$ & $\mathbf{0 . 8 1 3 ^ { * * }}$ \\
\cline { 2 - 5 } & Sig. (2-tailed) & 0.000 & 0.000 & 0.000 \\
\hline
\end{tabular}




\begin{tabular}{|c|c|l|l|l|}
\hline \multirow{2}{*}{ Motivation } & Spearman correlation & $0.535^{* *}$ & $0.680^{* *}$ & $\mathbf{0 . 7 3 7 ^ { * * }}$ \\
\cline { 2 - 5 } & Sig. (2-tailed) & 0.000 & 0.000 & 0.000 \\
\hline Model & 298 & 298 & 298 \\
\hline
\end{tabular}

As it can be seen from the criteria of ethical leadership, justice has a statistically moderate correlation with the servant leadership style. The criterion of values has a statistically moderate strong correlation with all leadership styles. Only the criteria of reliability and motivation of ethical leadership have a statistically strong correlation with the servant leadership style. The criterion of broad approach is expressed in the transformational and servant leadership styles with the statistically strongest correlation. Table 4 presents the expression of ethical leadership in different leadership styles.

Table 4

The expression of ethical leadership in different leadership styles

\begin{tabular}{|c|c|c|c|c|}
\hline & \multicolumn{3}{|c|}{ Leadership style } \\
\hline & & Transactional & Transformational & Servant \\
\hline \multirow{3}{*}{ Ethical leadership } & Spearman correlation & $0.569 * *$ & $0.731 * *$ & $0.798 * *$ \\
\hline & Sig. (2-tailed) & 0.000 & 0.000 & 0.000 \\
\hline & Model & 298 & 298 & 298 \\
\hline
\end{tabular}

As can be seen, ethical leadership is statistically most associated with ministerial and transformational leadership styles. The statistical correlation of transactional leadership style is only average.

In the Fig. 2 we draw scheme of assessment of ethical leadership in organisations. Here it is shown correlations of different leadership styles and meaning of all criteria's after calculations with SPSS program. The left side of the scheme we can see respondents' answers about possible leadership styles used in different organizations. Here it is shown average of results. The right-hand side of the scheme lists the criteria for ethical leadership to which the arrows point. The indicators focus only on those criteria of ethical leadership where there is a statistically strong relationship. In the middle of the figure are shortcuts for different leadership styles, where TR- transactional leadership, TF- transformational leadership, ET-ethical leadership, SE- servant leadership and also numbers of statistically strong meanings.

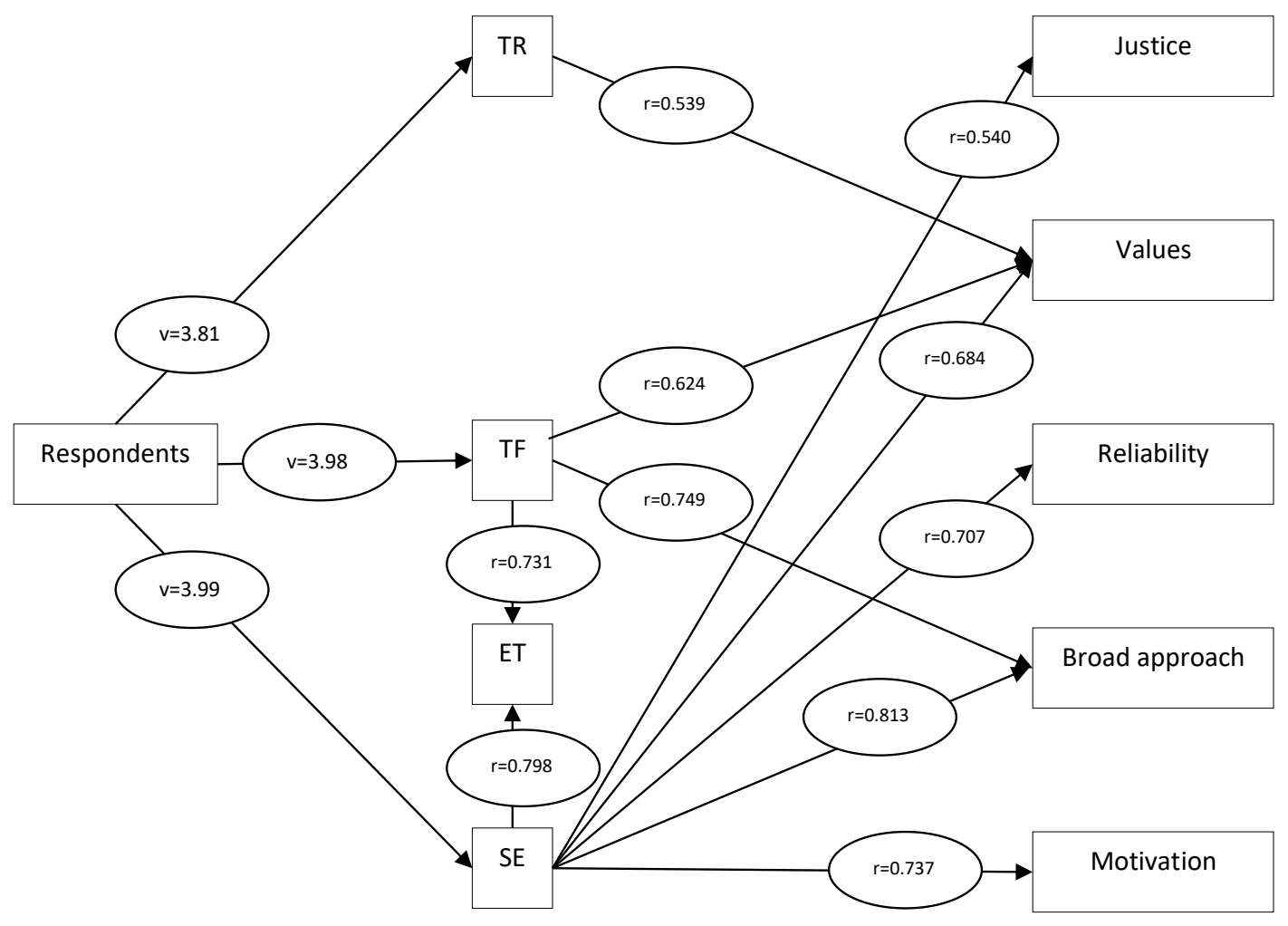

Fig. 2. Assessment of ethical leadership in organisations

Note: Meaning of figures: mean (v), correlation (r), only statistically strongest correlations are presented TR-transactional leadership, TF-transformational leadership, ET-ethical leadership, SE-servant leadership 
The hypothesis was confirmed. If managers are characterised by ethical leadership, they lead using the servant leadership style. This hypothesis is confirmed by the summarised data of the quantitative study "Correlations between the ethical leadership criteria and leadership styles" in Table 3 and "The expression of ethical leadership in different leadership styles" in Table 4. Thus, we can say that contemporary managers in the organisations taking part in our survey mostly keep to the servant leadership style and behave ethically.

\section{Conclusions}

A quantitative study shows that the respondents assessed ethical leadership in their organisations in a very similar way, as the features of an ethical leadership style are similarly assessed. However, male respondents tend to better evaluate the ethics of their managers. Assessing the leadership styles of managers in organisations, it was found that the transformational and the servant leadership styles were rated almost equally, while the transactional style was rated worse. Assessing the characteristics of the leadership style, it was found that the way of decision-making received the best evaluation, and the attitude towards the employees received the worst one. It was found that such ethical leadership features as reliability and motivation were statistically significant in the application of the servant leadership style. Another feature of ethical leadership is broad approach that is statistically significant in the application of the servant and the transformational leadership styles. The feature of values of ethical leadership is moderately statistically expressed in the application of the servant, the transformational, and the transactional leadership styles And the feature of justice of ethical leadership was statistically moderately expressed only in the application of the servant leadership style. The general assessment has shown that ethical leadership is statistically more significantly expressed in a combination of the servant and the transformational leadership styles. It allowed us to confirm the hypothesis that if managers are characterised by ethical leadership, they lead using the servant leadership style.

\section{Bibliography}

Alkahtani, A.H., 2016. The Influence of Leadership Styles on Organizational Commitment: The Moderating Effect of Emotional Intelligence. Business and Management Studies, 2(1), 23-34. ISSN 2374-5916.

Antonakis, J., 2006. Leadership: What is it and how it is Implicated in Strategic Change? International Journal of Management Cases, 8(4), 4-20. ISSN 1741-6264.

Avolio, B.J., Reichard, R.J., Hannah, S.T., Walumbwa, F.O., Chan, A., 2009. A Meta-Analytic Review of Leadership Impact Research: Experimental and Quasi-Experimental Studies. The Leadership Quarterly. 20(5), 764-784. ISSN 1048-9843.

Avolio, B.J., Walumbwa, F.O., Weber, T.J., 2009. Leadership: Current Theories, Research, and Future Directions. Annual Review of Psychology, 60, 421-449. ISNN 0066-4308.

Barbuto, Jr.J.E, Wheeler, D.W., 2006. Scale Development and Construct Clarification of Servant Leadership. Group \& Organization Management, 31(3), 300-326. ISSN 1059-6011.

Bass, B.M., 1990. From Transactional to Transformational Leadership: Learning to Share the Vision. Organizational Dynamics, 18(3), 19-31. ISSN 0090-2616

Bass, B.M., 1999. Two Decades of Research and Development in Transformational Leadership. European Journal of Work and Organizational Psychology. 8(1), 9-32. ISSN 1464-0643.

Bass, B.M., 2000. The Future of Leadership in Learning Organizations. Journal of Leadership \& Organizational Studies, 7(3), 18-40. ISSN 15480518 .

Berg, M.E., Karlsen, J.T., 2016. A Study of Coaching Leadership Style Practice in Projects. Management Research Review, 39(9), 1122-1142.

Brown, M.E., Mitchell, M.S., 2010. Ethical and Unethical Leadership: Exploring New Avenues for Euture Research. Business Ethics Quarterly, 20(4), 583-616. ISSN 1052-150X.

Brown, M.E., Treviño, L.K., 2006a. Ethical Leadership: A Review and Future Directions, The Leadership Quarterly, 17(6), 595-616. ISSN 10489843.

Brown, M.E., Treviño, L.K., 2006b. Socialized Charismatic Leadership, Values Congruence, and Deviance in Work Groups. Journal of Applied Psychology, 91(4), 954-962. ISSN 0021-9010.

Brown, M.E., Treviño, L.K., 2014. Do Role Models Matter? An Investigation of Role Modeling as an Antecedent of Perceived Ethical Leadership. Journal of Business Ethics, 122(4), 587-598. ISSN 1573-0697. 
Brown, M.E., Treviño, L.K., Harrison, D.A., 2005. Ethical Leadership: A Social Learning Perspective for Construct Development and Testing. Organizational Behavior \& Human Decision Processes. 97(2), 117-134. ISSN 0749-5978.

Burns, J.M., 1978. Leaderschip. New York: Harper \& Row. ISBN 9780061965579.

Dedahanov, A.T., Lee, D., H., Rhee, J., Yoon, J., 2016. Entrepreneur's Paternalistic Leadership Style and Creativity the Mediating Role of Employee Voice. Management Decision, 54( 9), 2310 - 2324. ISSN 0025-1747.

Fisher, E.A., 2009. Motivation and Leadership in Social Work Management: A Review of Theories and Related Studies. Administration in Social Work, 33(4), 347-367. ISSN 0364-3107.

Haar, J., Brougham, D., Roche, M., Barney, A., 2017. Servant Leadership and Work Engagement: The Mediating Role of Work-Life Balance. The New Zealand Journal of Human Resource Management (NZJHRM), 17(2), 56-72. ISSN 1175-5407.

Hannah, S.T., Avolio, B.J., Walumbwa, F.O., 2011. Relationships between Authentic Leadership, Moral Courage, and Ethical and Pro-Social Behaviors. Business Ethics Quarterly, 21(4), 555-578. ISSN 1052-150X.

Kolzow, D.R., 2014. Leading from Within: Building Organizational Leadership Capacity. (a self-published e-book) Interaktyvus: https://www.iedconline.org/clientuploads/Downloads/edrp/Leading_from_Within.pdf

Melchar, D.E., Bosco, S.M., 2010. Achieving High Organization Performance through Servant Leadership. The Journal of Business Inquiry, 9(1), 74-88. ISSN 2155-4056.

Obiwuru, T.C., Okwu, A.T., Akpa, V.O., Nwankwere, I.A., 2011. Effects of Leadership Style on Organizational Performance: A Survey of Selected Small Scale Enterprises in Ikosi-Ketu Council Development Area of Lagos State, Nigeria. Australian Journal of Business and Management Research, 1(7), 100-111. ISSN 1839-0846.

Stelmokienè, A., Endriulaitienè, A., 2015. Vadovavimo efektyvumo vertinimas: psichologiniai aspektai. Kaunas: VDU /Vilnius: „Versus aureus“ leidykla. ISBN 978-609-467-117-3.

Treviño, L.K., Brown, M.E., Hartman. L.P., 2000. Moral Person and Moral Manager: How Executives Develop a Reputation for Ethical Leadership. California Management Review, 42(4), 128-142. ISSN 0008-1256.

Walumbwa, F.O., Mayer, D.M., Wang, P., Wang, H., Workman, K., Christensen, A.L., 2011. Linking Ethical Leadership to Employee Performance: The Roles of Leader-Member Exchange, Self-Efficacy, and Organizational Identification. Organizational Behavior and Human Decision Processes, 115(2), 204-213.

Wong, P.T., Davey, D., 2007. Best Practices in Servant Leadership. Virginia Beach, VA: Regent University. https://www.regent.edu/acad/global/publications/sl_proceedings/2007/wong-davey.pdf

Yukl, G.A., 2013. Leadership in Organizations, 8th ed. State University of New York, Albany. ISBN 978-0-13-277186-3.

Zhu, W., May, D.R., Avolio, B.J., 2004. The Impact of Ethical Leadership Behavior on Employee Outcomes: The Roles of Psychological Empowerment and Authenticity. Journal of Leadership and Organizational Studies, 11(1), 16-26. ISSN 1548-0518.

Zhu, W., Riggio, R.E., Avolio, B.J., Sosik, J.J., 2011. The Effect of Leadership on Follower Moral Identity: Does Transformational/Transactional Style Make a Difference? Journal of Leadership and Organizational Studies, 18(2), 150-63. ISSN 1548-0518.

Zhu, W., 2008. The Effect of Leadership on Follower Moral Identity: The Mediating Role of Psychological Empowerment. Kravis Leadership Institute, Leadership Review, 8. 62-73. ISSN 1539-6363. 


\title{
SOME ASPECTS FOR MODERN SOLUTIONS FOR STRENGTHENING SOCIAL RESILIENCE AS GUARANTEE FOR THE FUTURE WELL-BEING OF AN OPEN AND INCLUSIVE SOCIETY
}

Biruta Sloka, University of Latvia

\author{
Ginta Tora, University of Latvia
}

Juris Dzelme, University of Latvia

\section{Ilze Buligina, University of Latvia}

\begin{abstract}
Social inclusion and reduction of inequalities is becoming an increasingly topical problem in a range of OECD countries, due to the demographic structure of inhabitants and inequality of income, in many cases depending on labour contribution taking into account skills and competence often lacking for part of population gaining education many years ago. Big share of this part of the population currently is not able to keep the speed of technology development and increase of requirements for digital skills and internet use.

The aim of the current research is to investigate possible solutions to address social inclusion by possible involvement in the labour market of different groups at risk - based on provision of digital skills, computer availability, as well as health conditions by regions in Latvia, by age groups, by gender, by employability status.
\end{abstract}

The tasks of the research: analyse recent scientific findings on innovative approaches on involvement of different groups of inhabitants being at poverty risk into labour market and social inclusion, making them feel as valuable and esteemed members of the society; analyse data of several survey results: EU-SILC; Labour Force Survey and Survey on ICT skills for different groups of society in Latvia; analyse tendencies on internet use in Latvia by gender.

Main research methods - analysis of previous conducted research results reflected in scientific publications and policy analysis documents; analysis of data of EU-SILC and Labour Force Surveys as well as survey results on ICT skills on aspects of digitalisation and willingness to be involved in training and improvement of skills to avoid social exclusion and poverty.

Findings - different regions have different results in digital literacy, however, implementation of innovative approaches in inhabitants' involvement in labour market help to avoid or diminish social exclusion.

Keywords: Income Distribution; Government Policy and Regulation; Innovations; Technological Change; Human Resources.

JEL Code: D6; O3; O15; M48

\section{Introduction}

\section{Problem}

International organisations have pointed out problems in Latvia regarding poverty reduction, support for the implementation of social equality, as well as to certain aspects of social inclusion. The aim of the research is to study the possibilities for building of social security by linking it to well-being and quality of life and ensuring an open and inclusive society.

Significant factors for social resilience are foreseeable income, digital literacy, individual characteristics, ability to trust other people. A significant role for achieving this is education, health, ability for members of the society to co-operate with others, as well as trust to public administration.

Trends that pose additional challenges on a global scale are the robotisation of production and the polarization of society, with declining demand for average qualifications in the labour markets, exacerbating inequalities. The availability of digital literacy for seniors and vulnerable groups, their ability to function successfully in the digital environment to ensure an independent, prosperous life is essential. Localizing the economy and building intergenerational solidarity by involving seniors and vulnerable groups in lifelong learning in partnership with the younger generation within the local community is a hitherto underestimated way of building an inclusive civil society and a "silver economy". Demographic change contributes to decision-making at local, regional and national levels across Europe, aimed at developing an environment that supports active and healthy ageing, improves independent living and well-being for older people, and creates a society for all ages.

The aim of the current research is to investigate possible solutions for social inclusion by possible involvement in labour market of different groups at risk - based on provision of digital skills, computer availability as well as regarding health conditions by regions in Latvia, by age groups, by gender, by employability status.

Tasks of research: analyse recent scientific findings on innovative approaches on involvement of various groups of inhabitants being at poverty risk into labour market and social inclusion - making them feel as valuable and esteemed members of the society; analyse data of several survey 
results: EU-SILC; Labour Force Survey and Survey on ICT skills for different groups of society in Latvia; analyse tendencies on internet use in Latvia by gender.

Design/Methodology/Approach - analysis of previous conducted research results reflected in scientific publications and policy analysis documents; analysis of data of EU-SILC and Labour Force Surveys as well as survey results on ICT skills on aspects of digitalisation and willingness to be involved in training and improvement of skills to avoid social exclusion and poverty; survey results were analysed using indicators of descriptive statistics: indicators of central tendency or location (arithmetic mean, median and mode); indicators of variability or dispersion (range, standard deviation, standard error of mean), as well as cross-tabulations by regions, by education level and household size; testing statistical hypotheses using t-test on differences of arithmetic means and analysis of variance - ANOVA, time series analysis.

Fast development of information technologies (IT) changes all social relations and business during the life of one generation. In addition to the previous conflicts between generations new conflicts arise inside the generations, first of all between digitally included in the new forms of life and excluded as a result of insufficient digital literacy. Digitalization of life creates conflicts, inequality and many other new problems. Digital literacy becomes a necessary condition for inclusion in social relations. Many contacts between people switch to internet and digital means for the exchange of information. Free market and competition between people do not allow to continue the previous way in the business. The biggest problems arise in countryside and for elder people, but the changes influence everybody.

Society, state and local communities must support people to solve the arising difficulties, linked with significant changes in economics, with growing inequalities, with loss of social contacts. Social inclusion and reduction of inequalities is becoming the significant problem for all countries. The demographic structure of inhabitants in OECD countries creates additional problems due to the reason that part of population with education received many years ago currently is not able to keep the speed of technology development and increase of requirements for digital skills.

It is difficult to predict future development of IT and artificial intelligence (AI), therefore we need to investigate carefully the basis of IT and to plan different alternative actions to keep the society ready for the future changes. Society and state must plan actions to reduce increasing inequality of income based on labour contribution. Education system must change to ensure timely and effectively necessary changes for the acquisition of respective knowledge, skills and attitudes. Support to acquire new skills and competences, often lacking in case of older population and marginal groups, becomes extremely essential for social inclusion. Entrepreneurship must be included in the education process with the support of the state, non-governmental organizations (NGO) and local communities.

There are several reasons why in Latvia there are more problems than in other European countries to implement training programs for all members of the society. Nevertheless other countries also could meet similar problems, potentially, with some delay in time. First of all this is due to the high rate of the mobility and therefore also emigration of the more active part of the young, generation who usually is the most capable to cope with the training and digitalization. Second reason, linked with the growing mobility is increasing inequality between different groups of inhabitants and between different regions. Latvia together with Romania, Bulgaria and Lithuania have the greatest in Europe Gini index and other similar criteria of inequality. Liberal politics and "free market" during the last 30 years created growing inequality of income, depopulation and aging in the most part of Latvia. The Riga region is the least affected, but also is facing certain problems. All other regions in Latvia suffer from deindustrialization and depopulation. Many schools are subject to closing and inhabitants are aging significantly. Third reason is low support for all education system, low prestige of teachers and low level of teachers' salaries. Lack of prestige and support prevent young generation from joining education system and create the "vicious circle" for the development of society. The last but not least is the problem of the ideology. The aims of the life and future perspectives become unclear. Mutual trust and solidarity must be strengthen in all Western countries. Post-soviet countries with divided ethnically and ideologically society, such as Latvia, must be very careful, but support for education, art, culture, philosophy is important for the whole world. Solutions must be found to promote inclusive, supportive society with mutual trust, help and clear vision of future.

Investigation of these problems are very urgent in the fast changing world. Latvia and other countries should create future politics to prevent exclusion and to provide new possibilities for all citizens of the Europe Union to participate in social networks and to receive all necessary support from state, local communities and society.

\section{Literature Review}

Academic researches world-wide have analysed different aspects on social inclusion. The contribution of digitalisation to business longevity from a competitiveness perspective was pointed out (Rossato, Castellani, 2020). Researchers have underlined that freedom of access to information and freedom of expression: the Internet as a tool for global social inclusion (Hamilton, Pors, 2003). Researchers have paid attention on exploring 
smart economic development and competitiveness in Central and Eastern European countries (Dagiliene, et al, 2020), libraries there pay an important role (Johnson, et al, 2018) with increasing importance of libraries for social inclusion of elderly people (Gil, Patricio, 2020). Researchers have investigated links between socio-economic variables and digitalization worldwide: the unsettled debate on digital divide (Mubarak, Suomi, Kantola, 2020). Researchers have paid attention also to leveraging service design for healthcare transformation: toward people-centered, integrated, and technology-enabled healthcare systems (Patrício, et al, 2020) and role of children to make and shape our digital futures - from adults creating technologies to children transforming cultures (Iivari,_2020). Researchers have indicated and investigated importance of mass media for social inclusion as well as social exclusion (Ewart, Snowden, 2011).

Documents of EU pay attention mainly to the legal problems, which are linked with the use of information technologies (IT) and Artificial Intelligence (AI) (EC, 2020). Less attention is paid to the social problems and to the development of education and business, using AI.

The new problem, which arises for the first time is the so called "black box effect". Nobody, including creators, can explain and predict actions of AI, therefore new type of relations of people with technologies should be discussed. "The specific characteristics of many AI technologies, including opacity ('black box-effect'), complexity, unpredictability and partially autonomous behaviour, may make it hard to verify compliance with, and may hamper the effective enforcement of, rules of existing EU law meant to protect fundamental rights" (EC, 2020, p. 12).

The rights of elderly persons are mentioned as the problem to be solved. "Explicit obligations for producers of, among others, AI humanoid robots to explicitly consider the immaterial harm their products could cause to users, in particular vulnerable users such as elderly persons in care environments, could be considered for the scope of relevant EU legislation" (EC, 2020, p. 8).

The existing approach to AI does not make difference with other new technologies, however the risks at least partly are understood. "As with any new technology, the use of AI brings both opportunities and risks. Citizens fear being left powerless in defending their rights and safety when facing the information asymmetries of algorithmic decision-making, and companies are concerned by legal uncertainty. While AI can help protect citizens' security and enable them to enjoy their fundamental rights, citizens also worry that AI can have unintended effects or even be used for malicious purposes. These concerns need to be addressed. Moreover, in addition to a lack of investment and skills, lack of trust is a main factor holding back a broader uptake of $A I^{\prime \prime}$ (EC, 2020, p. 10).

There are new challenges for education, linked with the development of Artificial Intelligence (AI) and mentioned by European Commission, which should be answered, at least partly, by the activities of member states, but the proper activities need to be investigated in much more details. "The updated Digital Education Action Plan will help make better use of data and AI-based technologies such as learning and predictive analytics with the aim to improve education and training systems and make them fit for the digital age. The Plan will also increase awareness of AI at all levels of education in order to prepare citizens for informed decisions that will be increasingly affected by AI. ... Beyond upskilling, workers and employers are directly affected by the design and use of AI systems in the workplace. The involvement of social partners will be a crucial factor in ensuring a human-centred approach to AI at work" (EC, 2020, p. 6).

The consequences of the "free market" (more precisely - the expansion of capitalism and globalisation) are the fast development of technologies, first of all IT and AI. Linked with AI and IT are the rapid changes in the social structure of society - a significant increase in stratification, poverty and exclusion, large migration flows, which significantly change the situation in many countries, including Latvia. The failures of multiculturalism calls for ways to solve societal problems, to review earlier predictions (Frumkin, 2003), and to develop concrete solutions. Some concrete legal and administrative provisions already have been developed to overcome the effects of globalisation and the introduction of the AI, but this is only a small part of the solutions needed.

Frumkin pays particular attention to the already ongoing changes in ethics, choice, freedom, work, sport and art and the trends of these changes in the future (Frumkin, 2003). The development of AI and new technologies are increasing choice, including increased possibilities to change the physical, physiological and mental (psychological) state of the human body. The use of psychotropic substances makes it possible, with the choice made by the "free will", to influence this "free will", choice and desires. As a result, the feedback generated by the "free will" changes itself by reflexively changing desires and needs, motivation. Bostrom's negotiated coherent, extrapolated will (CEW) must ensure the stability and friendliness of AI (and its final form - superintelligence) for humanity, while CEW itself, as an integral gathering of individual desires, is becoming unstable (Bostrom, 2014). (Strong and short interactions between individuals (the "crowd" effects) destroy stability and do not allow to use the Gaussian distribution.) 
The stabilisation of the CEW and the stabilisation of the social structure of society can be achieved by reinforcing people-to-people interaction through the development of networks. Digital, virtual networks, that have an increasing impact compared to personal, "direct" contacts, real-relation networks, are gaining increasing influence in networking. Networks are effective means for creating CEW, controlling the "free will" of individuals, halting progress towards unfettered "absolute freedom", arbitrary choice, creating a social structure conducive to cooperation, integration and coherence, a united morality, virtue and moral behaviour. Three main conditions for the development of CEW are: 1) networks and digital skills as means to use and developed networks; 2) motivation (economic, cultural, political) to engage in networks in person or in virtual, digital form; 3) harmonising the norms of morality, moral behaviour, desires and virtue.

The formation of the CEW should involve all groups of society, preventing any group from being ousted, failing to respect its interests. The education system, NGOs, political and cultural organisations should address the destructive tendencies of deviant behaviour, the tendency to anarchy, the tendency of free will to disorganise, to "disperse" society, to to divide, to "atomize" the social structure.

The development of a balanced system of desires and needs that could be extrapolated to the general set of principles of law, investigated by Rezevska (Rezevska, 2015), essentially equivalent to the CEW, should take into account the main objective, biological development needs and their subjective representation in the individual system of emotions, archetypes and virtues of the society (nation). In biological evolution, two related, complementary, mutually competitive trends, expressed as objective needs and partly emerging as subjective tendencies, are manifested in different subjective forms: 1) the propensity to acquire and store for the future use as much as possible and as accurate and diversified as possible, potentially usable behaviour models, which ensure successful survival and expansion in a wide variety of variable situations (relatively simplification - the propensity for information); 2) the propensity to acquire and manage as much resources, energy and materials as possible, which ensure reproduction and distribution at the highest possible amount and speed (relatively simplification - energy propensity).

The biological imperative is the survival of the group, the survival and spread of the nation. An individual is only important as an element forming a group, an element forming the overall system of nation (similar to the activity of individual cells and organs subject to the interests of an organism as a whole). As a result, the analysis of the formation of the CEW should take into account at least four basic needs and their objective and subjective features and the maximum effective acquisition, storage and use of means corresponding to each basic need: 1) information (knowledge) for the group, nation (acquisition, storage and use of the behaviour models of the group); 2) information of the individual; 3) energy for the group (nation) (resources for survival and expansion of the group, acquisition, storage and use of the resources); 4) energy of the individual.

In developing networks and justifying the need for cooperation, objective reasoning is based on the objective needs of the nation, but on the subjective, reflecting level motivation is based on ideology and mythology, including Christian values, language, traditions. The individual's needs, which are secondary to the nation's (primary) needs, take the form of solidarity and mutual assistance, the inclusion of marginal, excluded groups, the integration of society to meet common, national needs, by exposing the individual's selfishness and free will to the demands of society, the consolidation of nation and the mutual, complementary cooperation and collectivism of individuals. This objective compliance of the individual with public requirements should be demonstrated as a system of subjective virtues and values, which is formed in the interests of the nation, in the cooperation of individuals with all groups of the nation. In view of the structure of the nation, cooperation should also be adequately structured in order to create a hierarchical value, principle, legal system. A formalised law as a minimum of morality is needed only as an aid for supporting a system of values and rights in cases where the ideology adopted by society and its component morality are unable to convert sufficiently effectively to the worldview and its component virtues of all individuals. Society (nation), through various formal and non-formal means, must ensure that the objective needs of society and the individual are adequately transformed into subjective needs. Priority is given to the informal means, without which formal means can never fully function. The EC documents on ICT, AI, Internet and robotics challenges and hazards (EC, 2020) draws attention to the major transformation of the human contact system. EC documents calls for an appropriate transformation of the social structure of the society, such as education, culture, public administration, health and social care systems. The minimum necessary means of supporting new transformations is the acquisition of digital skills and the inclusion of all individuals in digital social contact networks, combining personal, physical and virtual, digital contacts as needed.

Computer power continues to grow exponentially under Moore's Law, doubling in about a year and a half. Automation, robotics, information and communication technologies (ICT) are fundamentally changing all areas of life. The World Economic Forum (in Davos) continues to discuss the replacement of accountants, drivers and other similar professionals, including also teachers, with robots (Jordan \& Mitchell, 2015). Rapidly changing technologies within one generation force to change people's relationships, habits, lifestyle, social structure. New opportunities are 
emerging, but also new, serious risks emerge (Barrat, 2015; Bostrom, 2014). The call of more than 17 thousands computer specialists to stop the use of military robots goes unheeded (Metz, 2018).

The rapidly growing flow of information creates serious difficulties in mastering the existing scientific achievements in order to be able to continue the development of science, which was warned, for example, by Wigner (1970). According to his prediction, the main future sciences will be physics and psychology. Physics allows us to understand the basic foundations of the world structure and helps to form all other branches of science. Psychology is capable of methods for transforming scientific achievements into a form that can be understood and used by humans.

The fundamental and complementary nature of physics and psychology has been highlighted by many scholars such as Wigner, Einstein etc. (Wigner, 1970). Physics and psychology are two "comprehensive, universal", complementary sciences that describe the world (matter) on the one hand and the activities of the psyche (soul) on the other. Wigner believes that "we can combine" these two main sciences and thus significantly expand the limits of human possibilities in the world and self-cognition, to overcome the "second kind of transformation". (The process of changing the main principles and models (paradigms) of the science sector the "revolutions" in science are the "first type of transformation." The "second type of transformation", a comprehensive crisis in science, is related to the inability to absorb too much previously accumulated knowledge (Wigner, 1970). According to Wigner, the development of science is characterized by a gradual process of changing the main principles and models (paradigms) specific to each branch of science - "the first type of transformation", but the second type of transformation threatens to stop it. To overcome the second type of transformation, Wigner recommends changing education: making "simplification" and using demonstrable "capacious" concepts and generalizations using the possibilities of psychology (Wigner, 1970).

The development of the education system must solve the problem of understand-ability for all levels and types of education and for all age groups. Rapid changes of knowledge demand repeated returns to the education, including acquisition of new basic skills, such as the digital literacy. The problems, analysed by Wigner as the changes for several generations, now is necessary to solve during one generation, using life-long learning (LLL).

The greatest uncertainties and risks are posed by the consequences of the development of information technology (IT) and artificial intelligence (AI). Significantly, these threats outweigh all other possible dangers associated with other singularities (demographic, cultural, ecological, etc.) in human evolution. Mankind needs to understand what and when can be expected from AI and how to guide the development of IT and the process of creating AI. The development of the AI could also create many new opportunities and prevent or at least reduce many threats. The main threats to mankind right now are the following.

- Natural disasters (hurricanes, earthquakes, eruptions of volcanoes, collisions with asteroids and comets in etc.) which can be prevented or at least significantly reduced by timely anticipation through AI.

- Epidemics and pandemics that can significantly impair people's lives. Rapid management of epidemics can be ensured by the use of AI.

- Conflict between or within countries which can lead to partial or even complete destruction of each other. The General, the Habilitated Doctor of Engineering, Kārlis Krēslinsš believes that “... international organizations must prevent other countries from intervening in the conflict. ... the introduction of peace in a region or country is supported by the UN, using strict principles, without any policy and individual interests. Artificial intelligence can do it better. This would diminish the role of real politics in a world“(Krēsliňš, 2019).

The use of AI for healthcare has been described by (Cheatham, Javanmardian, \& Samandari, 2019). There are many ways for development and many possibilities, but also many problems and risks. The future development of AI itself, its interaction with humans and influence on health care, including basic human biology, is greatly uncertain. The changes of healthcare and interaction with AI are very important field of research. "Healthcare is one of the major success stories of our times. ... By 2050, one in four people in Europe and North America will be over the age of 65 - this means the health systems will have to deal with more patients with complex needs. Managing such patients is expensive and requires systems to shift from an_episodic care-based philosophy to one that is much more proactive and focused on long-term care management. ... Last, AI is in its infancy and its long-term implications are uncertain. Future applications of AI in healthcare delivery, in the approach to innovation and in how each of us thinks about our health, may be transformative. We can imagine a future in which population-level data from wearables and implants change our understanding of human biology and of how medicines work, enabling personalised and real-time treatment for all" (Cheatham, Javanmardian, Samandari, 2019). Many other researchers have also developed upon those issues.

\section{Research methods}


Analysis of previous conducted research results reflected in scientific publications and policy analysis, documents analysis of data of EUSILC and Labour Force Surveys on aspects of digitalisation and population's willingness to be involved in training and improvement of skills to avoid social exclusion and poverty and CSB data which are obtained conducting survey on the use of information and communication technologies (ICT) in households and by individuals. The source of the data is the questionnaire No. ICT-persons "Use of computers and the internet in households" (CSB, Latvia, 2020),

survey results were analysed using indicators of descriptive statistics:

- indicators of central tendency or location (arithmetic mean, median and mode);

- indicators of variability or dispersion (range, standard deviation, standard error of mean), as well as cross-tabulations by regions, by education level and household size;

- testing statistical hypotheses using t-test on differences of arithmetic means and analysis of variance - ANOVA.

\section{Results and discussion \\ Social needs and aims}

The main problem to be solved for better involvement of socially excluded inhabitants is creation and development of motivation to participate in the social contacts and in business. Socially excluded persons often have lost the social contacts and they do not have motivation to change anything in their life. This situation creates the negative return: less motivation - less contacts, less contacts - less motivation. The problem is to stop the negative return ("vicious circle") and to switch to some new activities. An access to internet, possibility to start or renew some additional business activities should be linked with new possibilities to change the life, including the basic physiological and safety needs (also the health problems) which could be solved by participation in some business, mainly as an employee, or by participation in non-governmental organisations (NGO) and different cultural and political activities.

Data collected about the digital literacy by state statistics services (CSB) (Table 1, Table 2, Table 3) shows that there are serious problems. The biggest concern is about the very great difference between generations. Even in the case of the very simple skills (transferring files between computers or other devices) (Table 1) difference is rather big: $89 \%$ for the age group 16-24 years old and $26 \%$ for the age group $65-74$ years old in the year 2017. Positive trend is fast increase of the skills for the elder generations during 2 years, from 2015 till 2017. Surprising are some cases of decrease of skills for the age groups 16-24 and 25-34 years old. There is strong correlation between employment level and also the education level and the digital skills: higher level of employment and education - higher skills (this correlation partly could be explained by the age, because younger generations have higher level of education and higher level of the employment). 
Computer/ Internet usage regularly: (at least once a week) by individuals at the beginning of the year (\% of total population within the corresponding group) 2017-2019

\begin{tabular}{|c|c|c|c|}
\hline Characteristics & 2017 & 2018 & 2019 \\
\hline \multicolumn{4}{|l|}{ Gender } \\
\hline TOTAL & 78,5 & 81,2 & 83,7 \\
\hline Men & 78,6 & 80,8 & 85,2 \\
\hline Women & 78,3 & 81,5 & 82,4 \\
\hline \multicolumn{4}{|l|}{ Age group } \\
\hline 16-24 years old & 98,9 & 98,6 & 99,8 \\
\hline 25-34 years old & 97,3 & 98,6 & 98,1 \\
\hline $35-44$ years old & 92,5 & 94,9 & 95,0 \\
\hline 45-54 years old & 80,0 & 83,7 & 89,1 \\
\hline 55-64 years old & 62,6 & 67,6 & 71,1 \\
\hline $65-74$ years old & 35,5 & 40,1 & 47,4 \\
\hline \multicolumn{4}{|l|}{ Education level } \\
\hline Primary education & 65,2 & 72,7 & 68,0 \\
\hline Secondary education & 72,9 & 75,8 & 79,9 \\
\hline Higher education & 94,8 & 95,0 & 95,8 \\
\hline \multicolumn{4}{|l|}{ Employment status } \\
\hline Employed & 89,6 & 91,9 & 93,1 \\
\hline Unemployed & 73,8 & 74,1 & 73,8 \\
\hline Pupils, students & 98,4 & 99,4 & 100,0 \\
\hline Other inactive & 43,4 & 47,2 & 52,8 \\
\hline \multicolumn{4}{|l|}{ Regions } \\
\hline Riga region & 83,4 & 84,9 & 87,3 \\
\hline Pieriga region & 78,9 & 83,0 & 83,4 \\
\hline Vidzeme region & 75,2 & 78,9 & 80,5 \\
\hline Kurzeme region & 77,0 & 80,5 & 82,4 \\
\hline Zemgale region & 79,3 & 81,3 & 86,7 \\
\hline Latgale region & 69,2 & 71,8 & 76,5 \\
\hline
\end{tabular}

Source: Author's construction based on CSB data

In the case of more complicated skills (installing software or applications (apps)) (Table 2) and (changing the settings of any software, including operational system or security programs) (Table 3) the trends are similar, but the decrease of skills from 2016 till 2017 is more clear. For higher level of skills the decrease is greater. 
Table 2

E-skills in 2015 -2017 in Latvia: Installing software or applications (apps) (\% of total population within the corresponding group)

\begin{tabular}{|c|c|c|c|}
\hline Gender & 2015 & 2016 & 2017 \\
\hline TOTAL & 24,20 & 33,90 & 32,60 \\
\hline Men & 33,10 & 38,60 & 37,00 \\
\hline Women & 16,70 & 29,90 & 28,70 \\
\hline \multicolumn{4}{|l|}{ Employment status } \\
\hline Employed & 28,60 & 40,50 & 38,60 \\
\hline Unemployed & 15,60 & 29,90 & 24,80 \\
\hline Other inactive & 4,80 & 6,70 & 7,20 \\
\hline \multicolumn{4}{|l|}{ Education level } \\
\hline Primary education or no education & 26,70 & 29,20 & 28,70 \\
\hline Secondary education & 19,30 & 26,40 & 25,60 \\
\hline Higher education & 32,90 & 49,30 & 46,30 \\
\hline Pupils, students & 64,40 & 69,70 & 71,90 \\
\hline \multicolumn{4}{|l|}{ Age groups } \\
\hline $16-24$ years old & 57,70 & 66,10 & 67,40 \\
\hline 25-34 years old & 46,00 & 61,30 & 59,70 \\
\hline $35-44$ years old & 27,80 & 41,00 & 37,30 \\
\hline $45-54$ years old & 13,90 & 22,90 & 22,30 \\
\hline $55-64$ years old & 6,40 & 10,70 & 10,20 \\
\hline $65-74$ years old & 2,10 & 3,60 & 3,00 \\
\hline \multicolumn{4}{|l|}{ Region } \\
\hline Riga region & 32,20 & 43,00 & 40,30 \\
\hline Pieriga region & 25,80 & 37,80 & 34,10 \\
\hline Vidzeme region & 19,50 & 31,40 & 29,30 \\
\hline Kurzeme region & 19,70 & 31,20 & 27,90 \\
\hline Zemgale region & 18,30 & 25,50 & 26,80 \\
\hline Latgale region & 16,90 & 19,70 & 24,10 \\
\hline
\end{tabular}

Source: Author' construction based on CSB data (latest available data in 2020)

In all cases, for all kinds of digital skills the highest level has been achieved by people involved in the education process - by pupils and students. This could mean that only permanent education can solve the problem of digital literacy. Other problem is low level of higher digital skills - for all groups less than $35 \%$. As a result independent use of IT is possible only for small part of people and situation becomes worse. Serious investigation is necessary for future strategy and right plans for the development of AI.

Table 3

E-skills in 2015 -2017 in Latvia: Changing the settings of any software, including operational system or security programs (\% of total population within the corresponding group)

\begin{tabular}{|l|c|c|c|}
\hline Responses by gender & 2015 & 2016 & 2017 \\
\hline TOTAL & 15,00 & 19,90 & 16,60 \\
\hline Men & 23,00 & 26,30 & 22,40 \\
\hline Women & 8,30 & 14,20 & 11,50 \\
\hline \multicolumn{4}{|l|}{} \\
\hline Responses by economic activity & 2015 & 2016 & 2017 \\
\hline Employed & 18,50 & 23,80 & 19,70 \\
\hline Unemployed & 9,00 & 15,60 & 12,10 \\
\hline Other inactive & 2,80 & 4,20 & 4,10 \\
\hline
\end{tabular}

\begin{tabular}{|l|c|c|c|}
\hline Responses by education level & 2015 & 2016 & 2017 \\
\hline Primary education or no education & 14,30 & 16,70 & 15,90 \\
\hline Secondary education & 11,80 & 15,10 & 12,40 \\
\hline Higher education & 21,80 & 29,60 & 23,70 \\
\hline Pupils, students & 35,00 & 41,30 & 35,00 \\
\hline
\end{tabular}

\begin{tabular}{|l|c|c|c|}
\hline Responses by age group & 2015 & 2016 & 2017 \\
\hline $16-24$ years old & 30,20 & 38,80 & 32,00 \\
\hline $25-34$ years old & 28,50 & 34,50 & 29,80 \\
\hline
\end{tabular}




\begin{tabular}{|l|c|c|c|}
\hline $35-44$ years old & 18,90 & 23,70 & 18,80 \\
\hline $45-54$ years old & 9,50 & 14,10 & 11,60 \\
\hline $55-64$ years old & 4,50 & 7,00 & 6,40 \\
\hline $65-74$ years old & 2,20 & 2,30 & 2,30 \\
\hline
\end{tabular}

\begin{tabular}{|l|c|c|c|}
\hline Responses by region & 2015 & 2016 & 2017 \\
\hline Riga region & 22,70 & 26,40 & 20,70 \\
\hline Pieriga region & 11,40 & 22,20 & 16,70 \\
\hline Vidzeme region & 11,10 & 17,00 & 11,10 \\
\hline Kurzeme region & 12,90 & 17,40 & 15,90 \\
\hline Zemgale region & 11,80 & 12,40 & 12,40 \\
\hline Latgale region & 9,90 & 12,60 & 14,80 \\
\hline
\end{tabular}

Source: Author' construction based on CSB data (latest data which are available in 2020)

Recent data on ways of contacting or interacting with public authorities or public services over the Internet by individuals for private purposes are included in table 4.

Table 4

Contacting or interacting with public authorities or public services over the Internet by individuals for private purposes (\% of total population within the corresponding group) - in Latvia in 2017 - 2019

\begin{tabular}{|c|c|c|c|c|c|c|c|c|c|c|c|c|}
\hline \multirow[t]{2}{*}{ Group } & \multicolumn{3}{|c|}{$\begin{array}{l}\text { Obtaining information } \\
\text { from web sites }\end{array}$} & \multicolumn{3}{|c|}{$\begin{array}{l}\text { Downloading official } \\
\text { forms }\end{array}$} & \multicolumn{3}{|c|}{$\begin{array}{l}\text { Submitting completed } \\
\text { forms }\end{array}$} & \multicolumn{3}{|c|}{$\begin{array}{l}\text { Internet is not used for } \\
\text { contacting or interacting } \\
\text { with public authorities or } \\
\text { public services }\end{array}$} \\
\hline & 2017 & 2018 & 2019 & 2017 & 2018 & 2019 & 2017 & 2018 & 2019 & 2017 & 2018 & 2019 \\
\hline TOTAL & 68,5 & $\cdots$ & 57,7 & 16,6 & 14,8 & 18,4 & 38,5 & 49,6 & 55,5 & 13,8 & 19,0 & 17,1 \\
\hline Men & 66,9 & $\cdots$ & 54,7 & 14,8 & 12,3 & 14,7 & 36,1 & 46,1 & 53,3 & 15,7 & 22,2 & 20,7 \\
\hline Women & 70,0 & & 60,3 & 18,3 & 17,0 & 21,6 & 40,6 & 52,8 & 57,5 & 12,2 & 16,2 & 14,0 \\
\hline $\begin{array}{l}16-24 \text { years } \\
\text { old }\end{array}$ & 80,1 & & 54,1 & 15,0 & 12,2 & 21,5 & 35,9 & 48,8 & 53,6 & 19,2 & 29,0 & 27,4 \\
\hline $\begin{array}{l}25-34 \text { years } \\
\text { old }\end{array}$ & 90,2 & & 77,0 & 28,6 & 22,0 & 28,4 & 58,7 & 72,6 & 79,8 & 8,8 & 11,8 & 8,4 \\
\hline $\begin{array}{l}35-44 \text { years } \\
\text { old }\end{array}$ & 81,6 & & 71,7 & 21,7 & 21,8 & 24,7 & 48,9 & 66,9 & 71,5 & 13,2 & 14,9 & 13,1 \\
\hline $\begin{array}{l}45-54 \text { years } \\
\text { old }\end{array}$ & 71,9 & & 63,4 & 15,2 & 14,7 & 18,3 & 40,0 & 52,8 & 60,6 & 14,3 & 18,3 & 15,9 \\
\hline $\begin{array}{l}\text { 55-64 years } \\
\text { old }\end{array}$ & 52,7 & & 47,4 & 11,4 & 10,1 & 11,8 & 28,1 & 33,9 & 42,0 & 16,1 & 22,5 & 20,2 \\
\hline $\begin{array}{l}65-74 \text { years } \\
\text { old }\end{array}$ & 27,8 & & 22,9 & 3,8 & 4,2 & 3,3 & 11,2 & 13,4 & 15,8 & 13,3 & 22,3 & 23,2 \\
\hline $\begin{array}{l}\text { Primary } \\
\text { education or } \\
\text { no education }\end{array}$ & 52,2 & & 32,5 & 6,1 & 6,6 & 6,8 & 19,3 & 25,2 & 24,8 & 17,1 & 33,3 & 30,0 \\
\hline $\begin{array}{l}\text { Secondary } \\
\text { education }\end{array}$ & 62,5 & & 52,5 & 12,5 & 11,1 & 13,2 & 30,8 & 41,9 & 47,9 & 15,8 & 21,2 & 20,2 \\
\hline $\begin{array}{l}\text { Higher } \\
\text { education }\end{array}$ & 87,2 & & 75,5 & 29,2 & 25,3 & 31,2 & 61,6 & 75,4 & 79,4 & 8,7 & 8,3 & 7,3 \\
\hline $\begin{array}{l}\text { Pupils, } \\
\text { students }\end{array}$ & 76,6 & & 48,8 & 10,2 & 10,1 & 19,4 & 23,7 & 34,4 & 41,0 & 22,3 & 38,0 & 34,5 \\
\hline Employed & 80,8 & & 68,6 & 21,9 & 19,3 & 23,6 & 51,0 & 63,8 & 70,3 & 12,1 & 15,3 & 12,8 \\
\hline Unemployed & 61,7 & & 47,7 & 13,9 & 11,3 & 11,3 & 26,6 & 41,9 & 43,1 & 17,0 & 19,8 & 20,1 \\
\hline $\begin{array}{l}\text { Other } \\
\text { inactive }\end{array}$ & 34,8 & & 30,1 & 5,3 & 4,1 & 4,2 & 13,6 & 15,7 & 18,8 & 14,7 & 24,1 & 24,0 \\
\hline Riga region & 72,1 & & 62,6 & 18,7 & 14,8 & 19,6 & 41,6 & 56,5 & 60,7 & 14,8 & 16,0 & 14,9 \\
\hline Pieriga region & 73,6 & & 58,0 & 18,1 & 19,0 & 21,0 & 42,6 & 53,3 & 59,3 & 9,5 & 17,3 & 16,3 \\
\hline $\begin{array}{l}\text { Vidzeme } \\
\text { region }\end{array}$ & 66,9 & & 50,9 & 11,6 & 9,0 & 12,9 & 31,5 & 43,3 & 44,3 & 12,7 & 19,5 & 24,0 \\
\hline $\begin{array}{l}\text { Kurzeme } \\
\text { region }\end{array}$ & 69,9 & & 46,6 & 15,0 & 12,9 & 14,3 & 39,6 & 41,4 & 53,8 & 11,7 & 27,8 & 17,4 \\
\hline $\begin{array}{l}\text { Zemgale } \\
\text { region }\end{array}$ & 68,4 & & 68,2 & 21,1 & 18,4 & 26,7 & 41,3 & 52,5 & 58,7 & 14,0 & 19,2 & 14,9 \\
\hline $\begin{array}{l}\text { Latgale } \\
\text { region }\end{array}$ & 53,4 & & 50,9 & 11,0 & 11,4 & 11,9 & 27,5 & 37,9 & 44,6 & 19,5 & 20,1 & 20,5 \\
\hline
\end{tabular}

Source: Author' construction based on CSB data 
Data included in table 4 indicate that in many groups of inhabitants still are not active in using contacting or interacting with public authorities or public services over the Internet. This is a very big problem in limited face-to-face communication. Time series on contacting or interacting with public authorities or public services over the Internet by individuals for private purposes ( $\%$ of total population within the corresponding group) submitting completed forms in 2013-2019 and respective linear trends are reflected in figure 1.

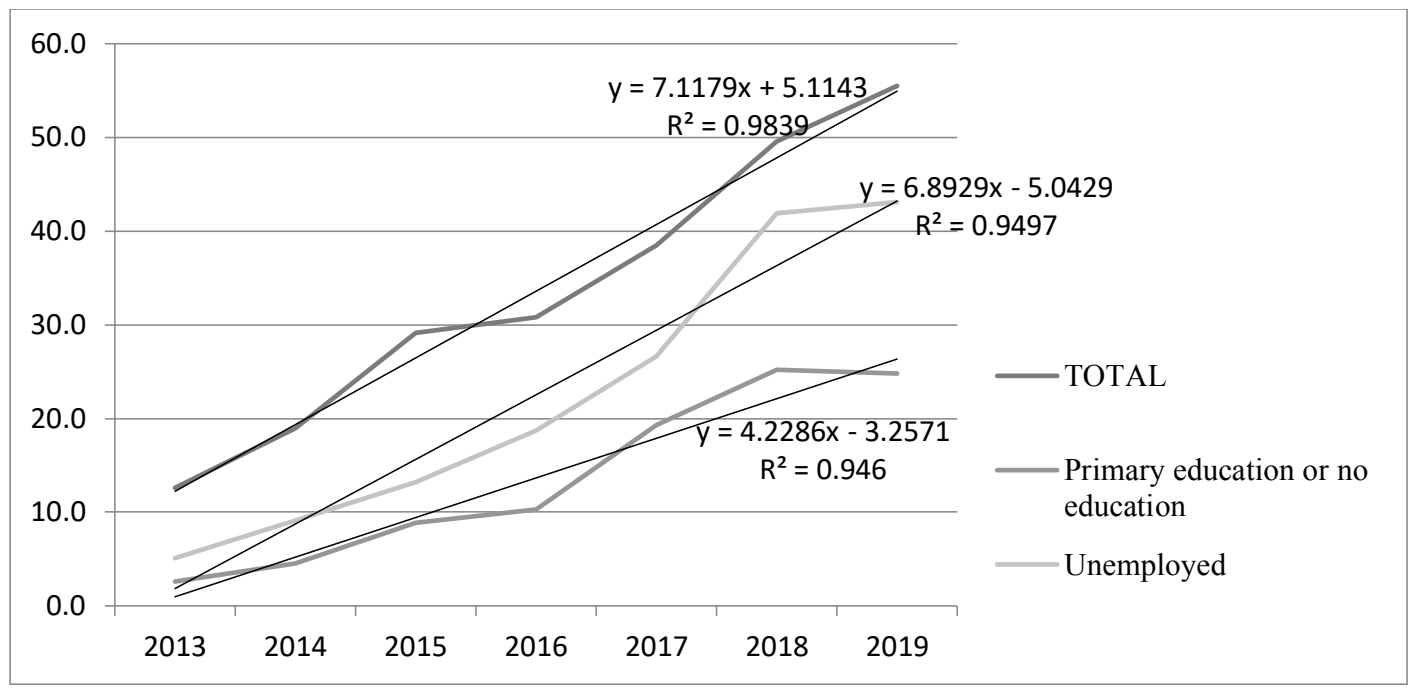

Source: author's construction and calculations based on CSB data

Fig. 1. Contacting or interacting with public authorities or public services over the Internet by individuals for private purposes $(\%$ of total population within the corresponding group) - submitting completed forms in 2013-2019 and respective linear trends

Data indicate that there are significant increases in all groups in Latvia including persons with primary education or no education, as well as unemployed persons. Time series on use of storage space on the Internet (\% of Internet users within the corresponding group) in Latvia 2014-2019 and respective linear trends are reflected in figure 2.

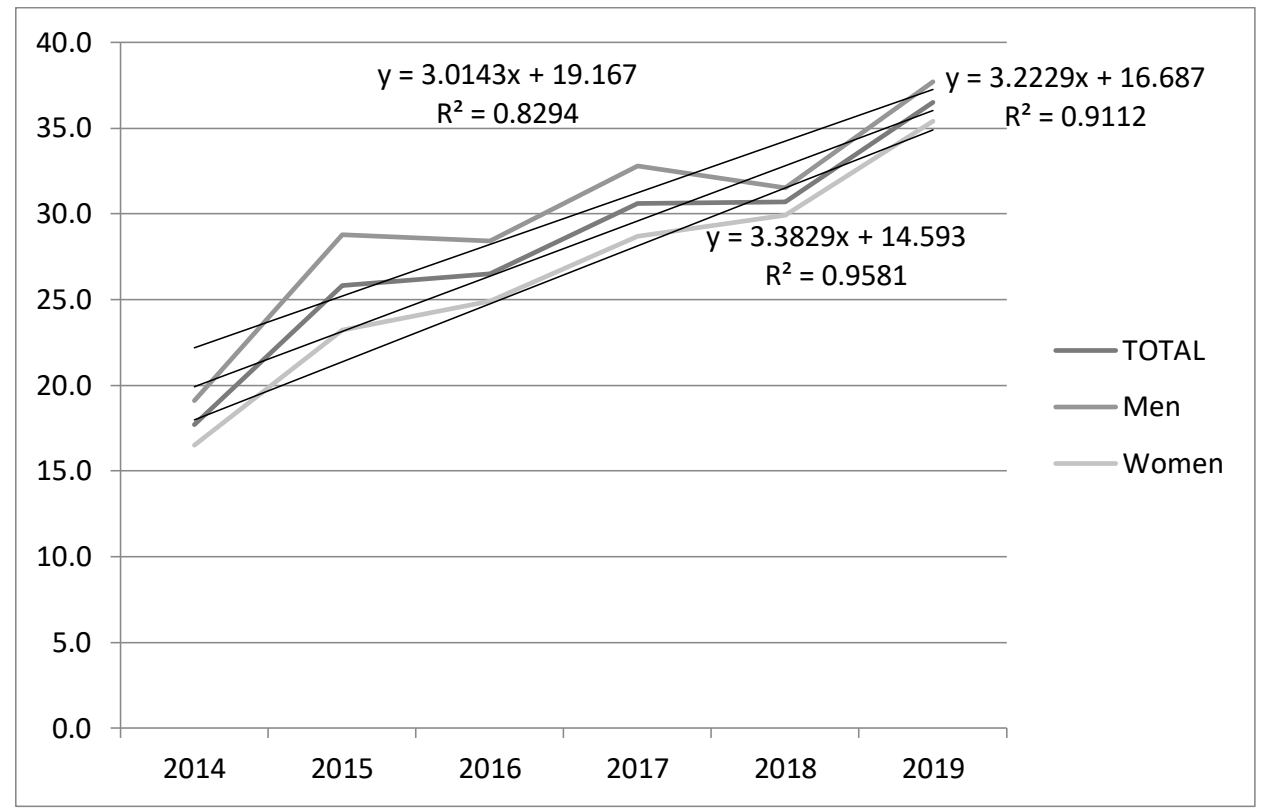

Source: Author's construction and calculations based on CSB data

Fig. 2. Use of storage space on the Internet (\% of Internet users within the gender group)

in Latvia 2014-2019 and linear trends

Data indicate that there are significant increases in all person groups in Latvia including persons by gender. Data on the main reason (lack of skills or knowledge (e.g. did not know how to use website or use was too complicated) for individuals not submitting completed forms to public 
authorities websites for private purposes in the last 12 months ( $\%$ of Internet users during the last 12 months within the corresponding group) - in Latvia in 2013-2019 are reflected in table 5.

Table 5

The main reason (lack of skills or knowledge (e.g. did not know how to use website or use was too complicated) for individuals not submitting completed forms to public authorities websites for private purposes in the last 12 months (\% of Internet users during the last 12 months within the corresponding group) - in Latvia in 2013-2019

\begin{tabular}{|l|c|c|c|c|c|c|c|}
\hline Groups of inhabitants & 2013 & 2014 & 2015 & 2016 & 2017 & 2018 & 2019 \\
\hline TOTAL & 3,6 & 4,6 & 5,5 & 7,6 & 9,8 & 12,6 & 12,3 \\
\hline Men & 2,6 & 4,1 & 4,1 & 6,3 & 8,0 & 10,4 & 11,4 \\
\hline Women & 4,5 & 5,0 & 6,9 & 8,9 & 11,6 & 14,8 & 13,4 \\
\hline 16-24 years old & 0,6 & 1,2 & 1,2 & 1,5 & 2,4 & 2,1 & 0,3 \\
\hline 25-34 years old & 2,2 & 2,5 & 3,2 & 3,8 & 4,3 & 5,3 & 6,1 \\
\hline 35-44 years old & 4,3 & 4,2 & 5,0 & 7,8 & 10,4 & 9,6 & 12,7 \\
\hline 45-54 years old & 6,5 & 6,9 & 7,3 & 10,5 & 11,4 & 15,9 & 15,6 \\
\hline 55-64 years old & 4,3 & 7,0 & 7,8 & 12,7 & 16,2 & 20,5 & 19,0 \\
\hline 65-74 years old & 4,5 & 8,6 & 11,6 & 11,6 & 17,6 & 19,1 & 16,0 \\
\hline Primary education or no education & 2,4 & 4,7 & 6,0 & 6,5 & 9,7 & 7,1 & 4,9 \\
\hline Secondary education & 4,4 & 6,4 & 5,8 & 9,6 & 11,2 & 15,1 & 13,7 \\
\hline Higher education & 2,8 & 1,8 & 4,3 & 3,9 & 6,8 & 10,5 & 15,1 \\
\hline Pupils, students & 0,0 & 0,4 & 0,0 & 0,3 & 2,6 & 0,0 & 0,0 \\
\hline Employed & 3,5 & 4,2 & 4,9 & 8,0 & 10,0 & 14,1 & 15,2 \\
\hline Unemployed & 4,2 & 7,2 & 7,0 & 5,8 & 9,2 & 12,0 & 15,4 \\
\hline Other inactive & 7,1 & 7,8 & 9,8 & 12,3 & 14,3 & 15,5 & 11,8 \\
\hline Riga region & 3,4 & 4,2 & 4,5 & 7,6 & 10,9 & 16,1 & 13,0 \\
\hline Pieriga region & 6,5 & 3,7 & 5,9 & 7,7 & 11,3 & 9,5 & 12,1 \\
\hline Vidzeme region & 4,0 & 3,4 & 7,3 & 8,2 & 9,6 & 11,3 & 13,5 \\
\hline Kurzeme region & 2,8 & 6,4 & 5,9 & 6,2 & 8,8 & 18,0 & 13,1 \\
\hline Zemgale region & 2,5 & 5,5 & 2,7 & 9,3 & 6,0 & 6,4 & 4,2 \\
\hline Latgale region & 1,6 & 5,3 & 7,7 & 7,2 & 9,5 & 8,8 & 15,8 \\
\hline
\end{tabular}

Source: Author's construction calculations based on CSB data

Realisation of several digital activities mostly is possible by use of computer or other technical solutions, like use of smart phones. Still presence or absence of computer is one of the questions asked in EU-SILC survey. Data on having or not having computer in households by different reasons by administrative territory in Latvia in 2019 are included in table 6.

Do you have a computer by administrative territory in Latvia in 2019

\begin{tabular}{|c|c|c|c|}
\hline \multirow[t]{2}{*}{ Responses of respondents } & \multicolumn{3}{|c|}{ Territory } \\
\hline & Cities & Rural & Total \\
\hline yes & 2435 & 1170 & 3641 \\
\hline no-cannot afford & 261 & 181 & 444 \\
\hline no-other reason & 718 & 473 & 1194 \\
\hline Total & 3414 & 1824 & 5279 \\
\hline
\end{tabular}

Source: Author's construction and calculations based on EU-SILC data in 2019, $n=5279$ 
Data included in table 6 indicate that there is a very big share on population in Latvia who do not have computer and it can be avery big problem in situation of limited personal contacts, like pandemic situation when communication within the society is limited and libraries where rather big share of population were using computers with assistance of librarians are closed. Data on limitation of activities due health problems in Latvia in 2019 are included in table 7.

Table 7.

Limitation of activities due health problems in Latvia in 2019

\begin{tabular}{l}
\begin{tabular}{|l|c|c|c|c|}
\hline Evaluations & Frequency & Percent & Valid Percent & Cumulative Percent \\
\hline not filled & 298 & 2.6 & 3.1 & 3.1 \\
\hline yes, many restrictions & 937 & 8.2 & 9.8 & 12.9 \\
\hline yes, some restrictions & 3268 & 28.7 & 34.1 & 47.0 \\
\hline no restrictions & 5075 & 44.5 & 53.0 & 100.0 \\
\hline Total & 9578 & 84.1 & 100.0 & \\
\hline Missing & 1816 & 15.9 & & \\
\hline Total & 11394 & 100.0 & & \\
\hline
\end{tabular} \\
\hline
\end{tabular}

Data included in table 7 indicate that only for $53 \%$ of inhabitants in Latvia do not have limitations of activities due health problems in 2019 , it is rather small share of the population and that has to be taken into account in supporting different activities including social marketing and lifelong education training programs to improve health situation of the inhabitants in Latvia.

\section{Complex reforms}

Motivation and technical possibilities should be created for the new, digital contacts for social inclusion, which include: social service to help to join and to use the technical possibilities; motivation for the inhabitants to join, which could include possibilities to receive some goods, using the new contacts; desire to be a part of the group should be supported by the desire for esteem, which means the desire for reputation, respect from others. The needs for belonging and esteem should be acquired through new social contacts, which should start with personal contacts, cultural and political activities and can be continued and partially switched to social networks in internet. Digitalisation, as a complex process, should be developed to solve various real tasks using linked overlapping networks. The possibility to participate in several overlapping networks is crucial for the development of social contacts, trust and further development of social and business activities. Special attention should be paid to the use of blockchain technologies. Possibility to use blockchain technologies is very important for business, but trusted, confidential social contacts will improve also the social networking. The use of digitalisation and blockchain technologies is twofold: from one side it is the tool to solve the business tasks, where trust is necessary; from the other side it is the tool for social inclusion, to involve people in social contacts and to create the networks and mutual trust for business.

Support to receive the necessary skills and motivation is very important for socially excluded part to return to active social contacts, to restore belonging and esteem. Application of information technologies, including block chains, provides opportunities for effective communication and lifelong learning (LLL) as well as entrepreneurship, however, human motivation and technical support plays a decisive role. Local communities, social workers and other people, responsible for local culture, education, social and health care should be involved to support the establishment and development of the complex networking possibilities, including internet, blockchain technologies, technical and social services, distance education, adult education. Improvement of knowledge, skills and competencies of the workforce reduces social exclusion and improves the quality of life.

\section{Conclusions, proposals, recommendations}

1. According to the available data there are significant differences in digital literacy for different regions and different groups of people. Education system including life-long education must support acquisition of new skills, knowledge and attitudes, but changes must be performed also in the education system to meet new challenges. Society, including education system, must develop networking, switching partly to the virtual space, but keeping and developing social contacts also in physical space, using together face to face and virtual contacts. Innovative approaches in inhabitant involvement in different networks and in labour market to avoid social exclusion should be supported by all stakeholders. The main attention must be paid to the digital literacy and to the possibilities to cope with quickly developing IT, especially paying attention to the artificial intelligence (AI). 
2. Practical implications include recommendations for the education system, business, NGO and policy makers, developed on the basis of analysis of data about digital literacy and social structure. The main conclusions are about the significant role of training and networking for reduction of poverty and avoiding social exclusion. Possible use of work-based learning performed by vocational education system has been suggested, involving the recommended possibility to create attitudes and to provide skills and competence for trainees for involvement in the labour market.

3. The task to improve social contacts is complex and all stakeholders should participate. The digital literacy can help to improve the involvement of inhabitants and creates new possibilities for business. Digitalisation and networking improves the social conditions, involvement of inhabitants in different activities and creates mutual trust and new possibilities for business, therefore all parts should help to develop the networking.

4. Public authorities, together with business and employees themselves must improve social contacts combined with the networking in internet to improve social and business environment and to receive positive outcome for the people, for the business and for the state. Competence based education, starting from preschool and applying modern lifelong learning opportunities with the help of information communications technologies (ICT), work-based learning and digitalization must provide the motivation and skills to use ICT and AI for the improvement of social and business environment, to create human friendly business ecosystems and to avoid exclusion.

5. Digitalisation, including the use of Distance Education, Adult Education, internet, blockchain technologies, is an important way to change the life of the socially excluded inhabitants. The necessary social and technical services should be provided together by all stakeholders (business, local communities, public authorities etc.). The main attention should be paid to the motivation and education, creation of social contacts and networking. Different cultural activities, participation in NGO and political activities should be used to involve inhabitants in mutual interaction, creating trust, necessary for successful life, including business.

6. The rapid pace of technological development is leading to a real synergy in society's global structure, which means significant, difficult-toanticipated social, political, economic and cultural changes in virtually all countries. A number of parallel processes (demography, ecology, technology changes etc.) may be the cause of singularity, but the most likely are changes that will result in AI taking over the actual technological development leadership. By the end of this transition process, it will be virtually impossible for the mankind to restore control over technology and public administration in general.

7. The main task of scientists, politicians and the general public now is to understand the nature of the principles and criteria for AI management, possible changes and possibilities for influence. It is necessary to establish an AI with a human-friendly system of all agreed AI management criteria, a coherent, extrapolated will (CEW).

\section{Bibliography}

Barrat, J., 2013. Our Final Invention. New York: St. Martin’s Press.

Bostrom, N., 2014. Superintelligence: Paths, Dangers, Strategies. UK: Oxford University Press.

Cheatham, B., Javanmardian, K., Samandari, H., 2019. Confronting the Risks of Artificial Intelligence. McKinsey Quarterly. Available at: https:/www.mckinsey.com/business-functions/mckinsey-analytics/our-insights/confronting-the-risks-of-artificial-intelligence\# OR [Online] Available at https://www.healthindustryhub.com.au/wp-content/uploads/2019/05/Confronting-the-risks-of-AI-2019.pdf [Accessed 09.12.2020].

CSB, 2020. Use of Computers and the Internet in Households, Data of Central Bureau of Statistics, Republic of Latvia.

Dagilienė, L., Bruneckienė, J., Jucevičius, R., Lukauskas, M., 2020. Exploring Smart Economic Development and Competitiveness in Central and Eastern European countries. Competitiveness Review, 30(5), 485-505.

European Commission, 2020. White Paper on Artificial Intelligence A European Approach to Excellence and Trust. [Online] Available at: https://ec.europa.eu/info/sites/info/files/commission-white-paper-artificial-intelligence-feb2020_en.pdf [Accessed 16.11.2020].

Ewart, J., Snowden, C., 2011. The Media's Role in Social Inclusion and Exclusion. Media International Australia, 142(1), 61-63.

Frumkin, H., 2003. Healthy Places: Exploring the Evidence. American Journal of Public Health, 93, 1451-1456.

Gil, H., Patricio, M.R., 2020. Lifelong Learning and Info-inclusion: Perspectives of the ageing population in the borderland region of Portugal. In Iberian Conference on Information Systems and Technologies, CISTI Volume 2020-June, June 2020, Article number 914088815th Iberian Conference on Information Systems and Technologies, CISTI 2020; Seville; Spain; 24 June 2020 through 27 June 2020 ; Category numberCFP2003K-ART; Code 161865.

Hamilton, S., Ole Pors, N., 2003. Freedom of Access to Information and Freedom of Expression: the Internet as a Tool for Global Social Inclusion. Library Management, 24(8/9), 407-416. 
Iivari, N., 2020. Empowering Children to Make and Shape our Digital Futures - from Adults Creating Technologies to Children Transforming Cultures. International Journal of Information and Learning Technology, 37(5), 279-293.

Johnson, A.M., Willenborg, A., Heckman, C., Whitacre, J., Reynolds, L., Sterner, E.A., Harmon, L., Lunsford, S., Drerup, S., 2018. Library Instruction and Information Literacy 2017. Reference Services Review, 46(4), 628-734.

Jordan, M.I., Mitchell, T.M., 2015. Machine Learning: Trends, Perspectives, and Prospects. Science, 349(6245), 255-260.

Krēslinšs, K., 2019. Lielākais drauds Latvijai ir mūsu sliktā savstarpējā sapratne. NRA, 13.09.2019.

Mannino, A., Althaus, D., Erhardt, J., Gloor, L., Hutter, A., Metzinger, T., 2015. Artificial intelligence: Opportunities and risks. Policy Paper by the Effective Altruism Foundation. [Onlone]. Available at https://ea-foundation.org/files/ai-opportunities-and-risks.pdf [Accessed 01.10.2020].

Metz, C., (2018). Pentagon Wants Silicon Valley’s Help on A.I. The New York Times. 15 March 2018.

Mubarak, F., Suomi, R., Kantola, S.-P., 2020. Confirming the Links Between Socio-Economic Variables and Digitalization Worldwide: the Unsettled Debate on Digital Divide. Journal of Information, Communication and Ethics in Society, 18(3), 415-430.

Müller, V.C., 2014. Risks of General Artificial Intelligence. Journal of Experimental \& Theoretical Artificial Intelligence, 26(3), $297-301$.

Patrício, L., Sangiorgi, D., Mahr, D., Čaić, M., Kalantari, S., Sundar, S., 2020. Leveraging Service Design for Healthcare Transformation: toward People-Centered, Integrated, and Technology-Enabled Healthcare Systems. Journal of Service Management, 31(5), 889-909.

Rezevska, D., 2015. Vispārējo tiesību principu nozīme un piemērošana. Rīga: Daigas Rezevskas izdevums.

Rossato, C., Castellani, P., 2020. The Contribution of Digitalisation to Business Longevity from a Competitiveness Perspective. The TQM Journal, 32(4), 617-645.

Sault, S., 2020. What they're saying about the future of work: key quotes from Davos. [Online] Available at https://www.weforum.org/agenda/2020/01/future-of-work-reskilling-workforce-ivanka-trump-davos-quotes/ [Accessed 01.08.2020].

Spatharou, S., Hieronimus, S., Jenkins, J., 2020. Transforming Healthcare with AI. The impact on the workforce and organisations. McKinsey Quarterly. Available at: https://www.mckinsey.com/industries/healthcare-systems-and-services/our-insights/transforming-healthcare-with-ai [Online] Available at: https://www.tandfonline.com/doi/full/10.1080/0952813X.2014.895110 [Accessed 21.09.2020].

Wigner, E.P., 1970. Symmetries and Reflections. London: Indiana University Press.

The paper was supported by the National Research Programme project "INTERFRAME-LV" 


\title{
SOCIO-ECONOMIC IMPLICATIONS OF THE CORONAVIRUS PANDEMIC IN LATVIA \\ Inna Steinbuka, University of Latvia \\ Olegs Baranovs, Latvian Academy of Sciences \\ Normunds Malnacs, Latvian Academy of Sciences \\ Aldis Austers, Latvian Academy of Sciences
}

\begin{abstract}
The spread of COVID-19 requires immediate policy response and future-oriented actions to reduce devastating economic and social impact of crisis and preserve sustainable growth. The aim of this paper is to assess the current economic and social consequenses of the ongoing crisis in Latvia, the government response, public perceptions and future scenarios. Research is based on the macroeconomic assessment and surveybased analysis of people's attitude towards the government's emergency programs. The comparison of statistically justified findings with the public perception helps formulate conclusions on the future sustainability scenarios and policies.
\end{abstract}

Keywords: coronavirus crisis, economic resilience, recovery, public perceptions.

JEL code: E6, H12, H6, O11, Z13

\section{Introduction}

The turmoil for the EU economy is symmetrical, as the pandemic has affected all EU Member States but the impact of the pandemic varies considerably from one country to another, as does their ability to absorb and respond to economic crisis. Small countries are naturally vulnerable to external economic shocks, however, they can increase their resilience by efficient government, business and social reponse. Extraordinary pandemic crisis can be seen as a stress test of the vulnerablity and resilience of a small and open Latvian economy. The aim of this paper is to assess the current economic and social consequenses of the ongoing crisis. To this end, the research tasks include the analysis of latest trends in the Latvian economy, the government response, public perceptions and future scenatios. The key issue is whether the current crisis, which will bring severe losses in the short-term, could be seen as an opportunity of economic transformation and accelerated growth in the future and what are the preconditions for the economic recovery. The research methods include analysis and mathematic modelling of macroeconomic data and data from public opinion survey.

\section{Analysis of Latvia's economic trends 2020}

In Latvia, the economic growth started slowing down already in the second half of 2019 because of structural problems and labor shortage that resulted in lower manufacturing output and decline in exports. In addition, decrease in transit cargo and anti-money-laundering efforts in the banking sector considerably contributed to the slowing growth. The underlying factors of this slowdown increased the negative economic effect of the pandemic shock.

The Covid-19 pandemic and preventing measures caused the decline in GDP, which in the first 3 quarters of 2020, compared to the 4th quarter of 2019 (pre-crisis level), was, however, much lower than the average in the EU and the euro area. The economy of Estonia, Lithuania and Latvia's main trading partners in the EU, lagged the pre-crisis level by $2-4 \%$ in the third quarter (Fig.1). The situation was much worse in several southern EU countries, where the gap with the pre-crisis level was close to $10 \%$ (Croatia, Spain, Malta). 


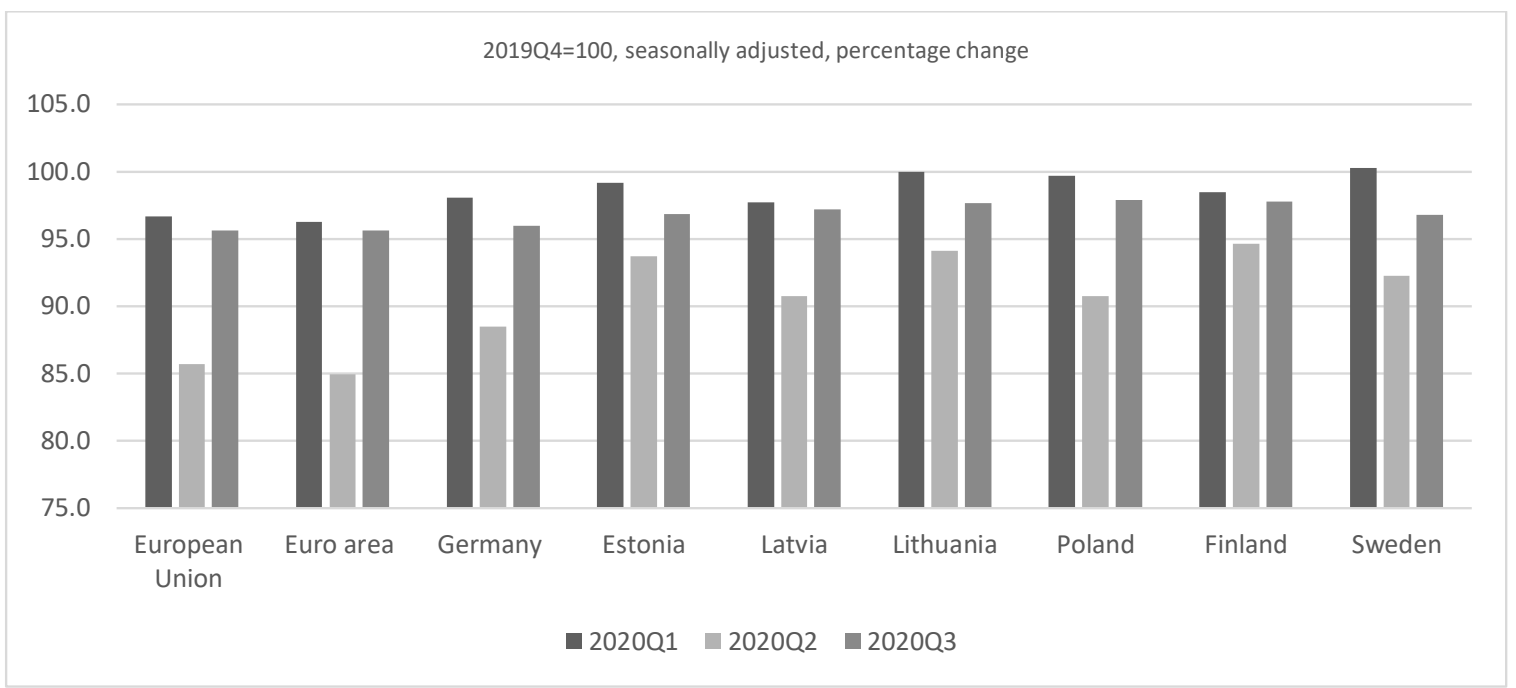

Source: author's construction based on the Eurostat data, 2020

Fig. 1. Growth rates of GDP

Restrictions on international transport, reduction of travel flows, losses to companies accrued due to quarantine and self-isolation of employees, a decrease in demand in export markets, delays in raw material supply chains, a decline in demand for domestic services and other pandemic-related factors have significantly affected various economic sectors.

The value added of the sectors most affected by the coronavirus is almost 800 million EUR, which represents $2.9 \%$ of GDP, incl. accommodation $(0.6 \%)$, passenger air transport $(0.5 \%)$, travel agency, and tour operator reservation services $(0.2 \%)$ (Ministry of Economics..., Macroeconomic..., 2020). The most significant decrease in the three quarters of $2020 \mathrm{y}-\mathrm{o}-\mathrm{y}$ was in the accommodation and food service activities, as well as in the arts, entertainment and recreation sectors, where the annual decrease was $34.9 \%$ and $26.1 \%$, respectively. The restrictions imposed on Covid-19 also had a significant impact on aviation, land transport and railway companies. In the three quarters of 2020, the decline in the transport and storage services sector reached $15 \%$. Manufacturing output fall in three quarters of 2020 by $2.7 \%$ due to both the decline in demand in export markets and delays in supply chains. There was also a significant decline in financial and insurance activities, information and communication services, and commercial services. Agriculture and forestry, construction and public services were among the few sectors that continued to grow in the three quarters of 2020 (Fig. 2).

(compared to the corresponding quarter of the year before, percentage changes)

- 202001 2020Q2 -2020Q3

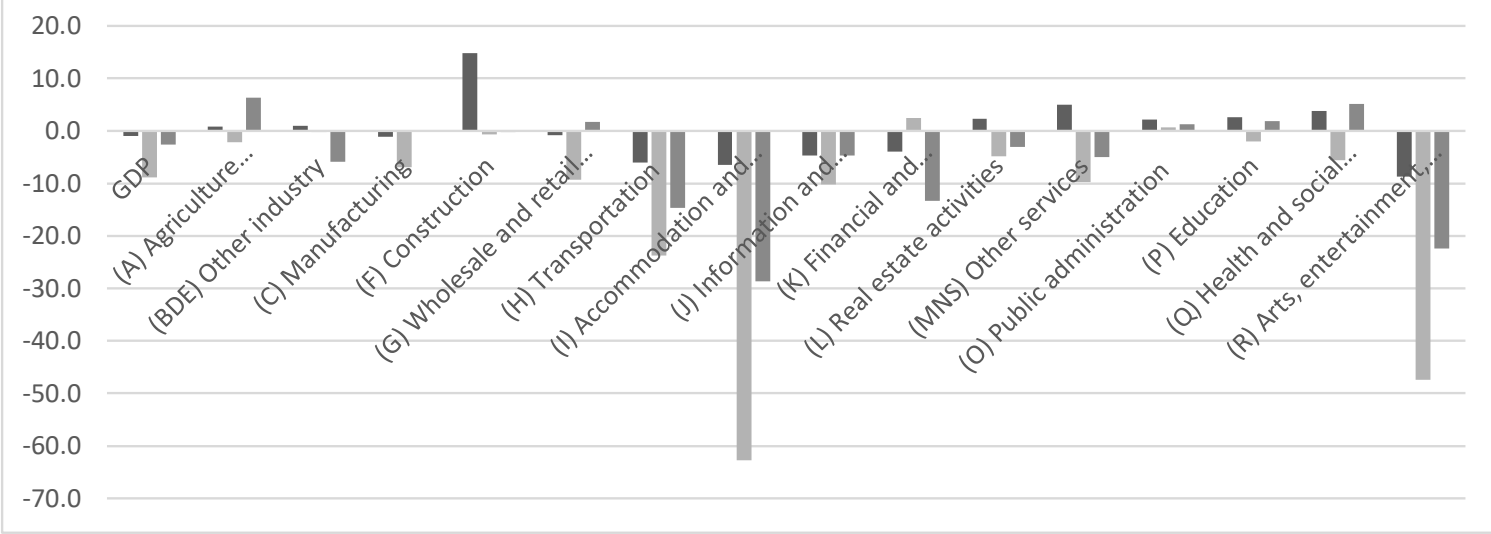

Source: author's construction based on the CSB of Latvia data, 2020

Fig. 2. Growth rates of GDP by kind of activity in Latvia

Unemployment had been decreasing in Latvia in recent years, and lack of labor was considered one of main factors preventing faster economic growth. Due to Covid-19 crisis, the unemployment started increasing in March 2020, however, the increase was not particularly steep, and already 
in July the unemployment changed its trajectory (Fig.3). Even though sectors most affected are labour intensive, and therefore, if Covid-19 second wave persist for a longer period, the unemployment levels can sharply increase again.

Weak Latvian export (much lower export share of GDP compared with the Baltic neighbours) was identified as a challenge well before pandemic crisis. Covid-19 naturally hit country's foreign trade, even though it improved Latvia's trade balance as the exports turned out to be more resilient than the imports. (Fig.3). However, the export development was mixed: for instance, Latvia's timber export (main export product) decreased by $8.5 \%$ in three quarters of $2020 \mathrm{y}-\mathrm{o}-\mathrm{y}$, which unexpectedly was compensated by $17 \%$ increase in electrical equipment export.

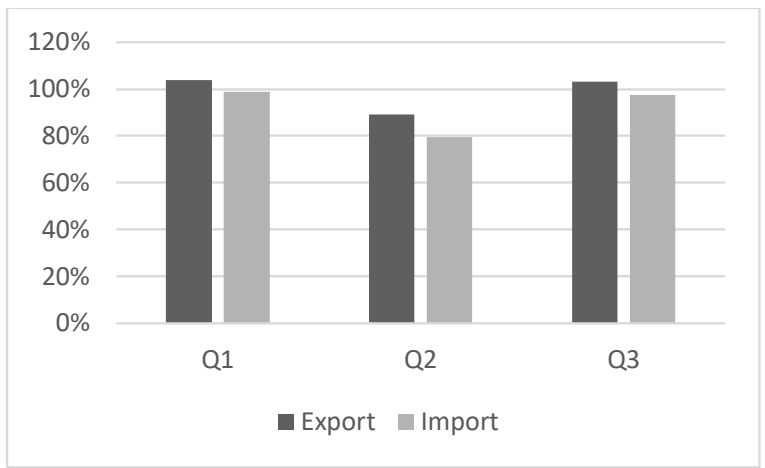

Source: $C S B$

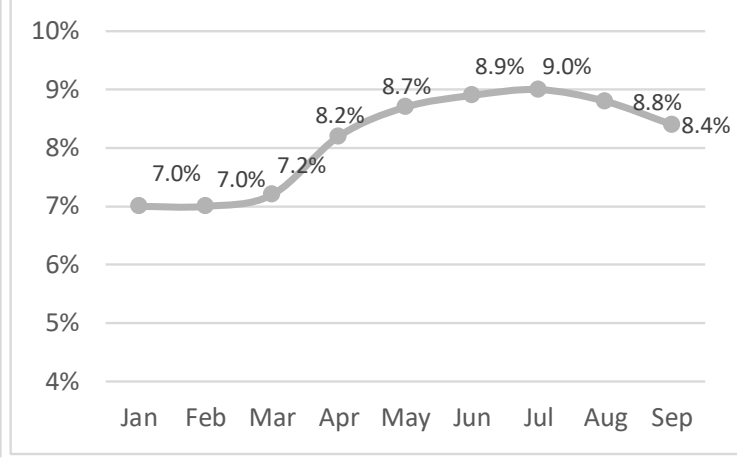

Source: Eurostat

Fig. 3. Latvian foreign trade in 2020 (\% of 2019) and unemployment trends in 2020

Like in the EU, economic sentiment in Latvia dropped sharply in March and reached the lowest point in April, then slowly started improving and declined again in October when the Covid-19 second wave started (Fig.4).

Low public debt and deficit, balanced current account and low private indebtedness are considered as Latvian strengths. Naturally, the slowing economy has dented budget revenues and government's fiscal response to the crisis has increased expenditures. The public deficit and debt might reach accordingly $7.6 \%$ and $47.3 \%$ of GDP at the end of 2020. However, Latvian Debt-to-GDP ratio will remain one of the lowest in Euro Area, where the average debt level is about to reach $101.7 \%$ of GDP at the end of 2020 (Fig.4).

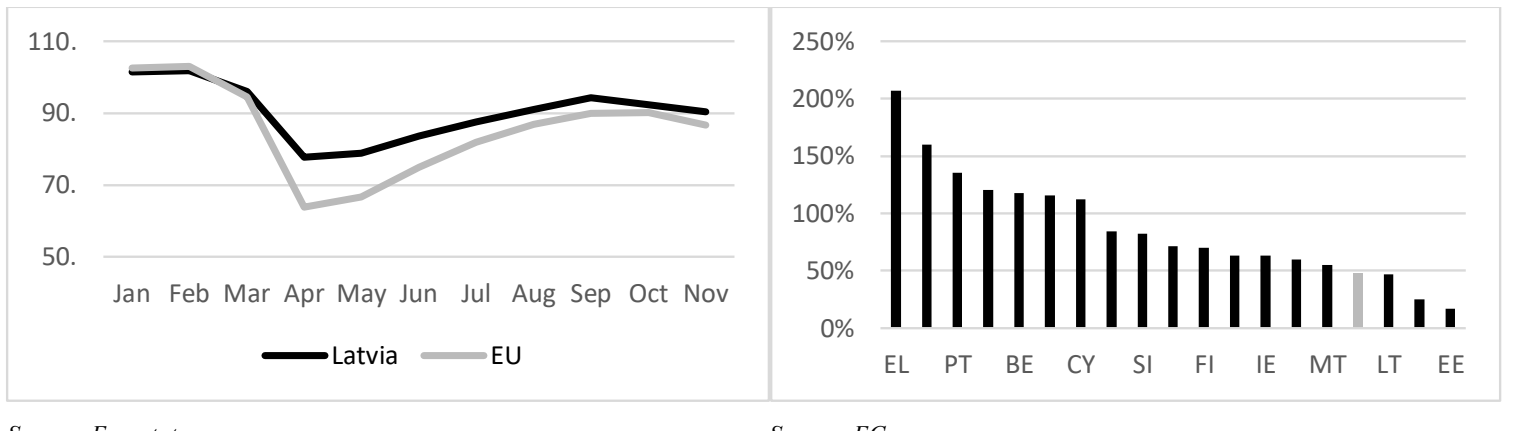

Source: Eurostat

Fig. 4. Latvian economic sentiment and debt level (\% of GDP) in 2020

\section{The government response}

At the end-May 2020, the Latvian government has adopted a three-phase strategy (Ministry of Economics..., Informative Report..., 2020) for overcoming the crisis. The first phase (survival) was aimed at limiting the spread of the virus and improving financial stability in lockdown (20202022). The second reorientation phase (2023) included post-crisis measures for immediate activating business continuity and structural adjustment. Finally, the growth phase (from 2023) is aimed at implementing a set of growth-enhancing measures based on stimulus for export and productivity, automation and digital transformation, green course, etc.

The stabilisation measures of the Covid-19 induced economic crisis are very different from the financial crisis in 2008. The latter was caused by economic overheating because of excessive aggregate demand, hence consolidating the expenditure was the solution. The former was caused by sharp reduction in aggregate demand and disrupted supply, hence, stimulating aggregate demand with monetary and fiscal policies have to play important roles to overcome economic crisis. The activating of the EU Stability and Growth Pact's general exemption clause allowed governments of the Member States to increase the general government deficit. EU also allowed state support to enterprises in trouble. 
The economists were unanimous that the fiscal support has to meet three key criteria: (i) timely (as soon as possible), (ii) well targeted to all segments important for functioning of the economy and cover social sphere, (iii) for a limited time.

As in most countries, fiscal response of the Latvian government was aimed at both stimulating demand and supporting supply. By the end of September, the government has approved public support in amount of 3.14 billion euros, or 11.1\% of GDP (Ministry of Finance..., 2020). The largest share (38.4\%) represents the support of company liquidity in form of loans, guarantees, capital injections. State joint stock companies and health care got $25 \%$ of support package. Redistribution of EU funds in amount of $24.3 \%$ was aimed at supporting activities with immediate social or economic impact. Public support included also tax measures (7.5\%) and benefits and allowances (4.9\%).

Latvia like other countries used furlough schema to prevent rapid increase in unemployment. However instead of the initial government intention to disburse 148 million euros in allowances, the amount actually disbursed was only 53.6 million despite several rounds of lowering eligibility criteria (State Revenue Service, 2020). The main reasons for this rather modest support were linking furlough payments with tax paid and apparently with an attempt to reduce the size of tax evasion. In accordance with Bank of Latvia estimates, furlough support in Latvia has been the most modest among the Baltic states (Bank of Latvia, 2020): it's intensity in end-July was $0.2 \%$ of GDP, while in Lithuania $0.3 \%$ and in Estonia $0.9 \%$. The intensity of furlough support seems not to correlate with unemployment trends (Fig. 5). However, as in the first wave of crisis the unemployment level in Latvia remained relatively low, one may conclude that the Latvian furlough schema was effective.

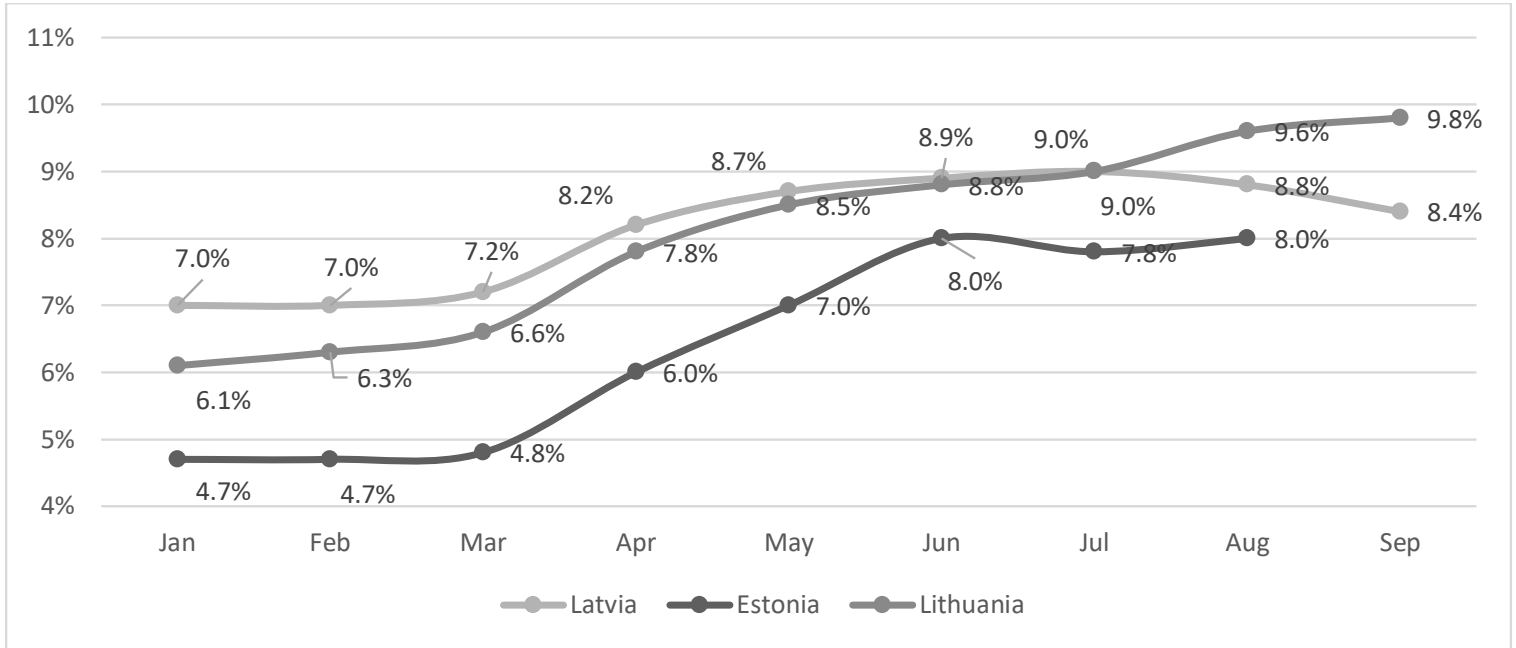

Source: Eurostat, database UNE_RT_M

Fig. 5. Rate of unemployment in the Baltic States (\%, seasonally adjusted)

The biggest support to entrepreneurs was planned in form of credits, guarantees and capital injections. Public financial institution "Altum" took responsibility for assisting business with the following instruments: (i) working capital loans, (ii) guarantees for bank credit holidays, (iii) portfolio guarantees, (iv) export credit guarantees, (v) guarantees for large enterprises, (vi) equity fund. These instruments have reached all economic sectors affected by the crisis (Fig.6). The largest beneficiaries are trade and manufacturing enterprises, whose share in value added is significant, as is the decline in GDP. It is surprising to see construction companies among the biggest beneficiaries, considering the sector's resilience to the Covid-19 crisis. The transport and storage sector, on the other hand, with a value added similar to construction, but a much larger decline in GDP, receives about the same relatively small share of support as construction companies.

Ministry of Finance estimated that business support measures would stimulate economy in amount of 1.055 billion euros or 3.74\% of GDP. However, by the end-October 2020, the absorption of assistance instruments for entrepreneurs was relatively low reaching only 178.1 million euros or $0.6 \%$ of GDP. Nevertheless, these instruments should help entrepreneurs to overcome the second wave of Covid-19 (Ministry of Finance..., 2020). 


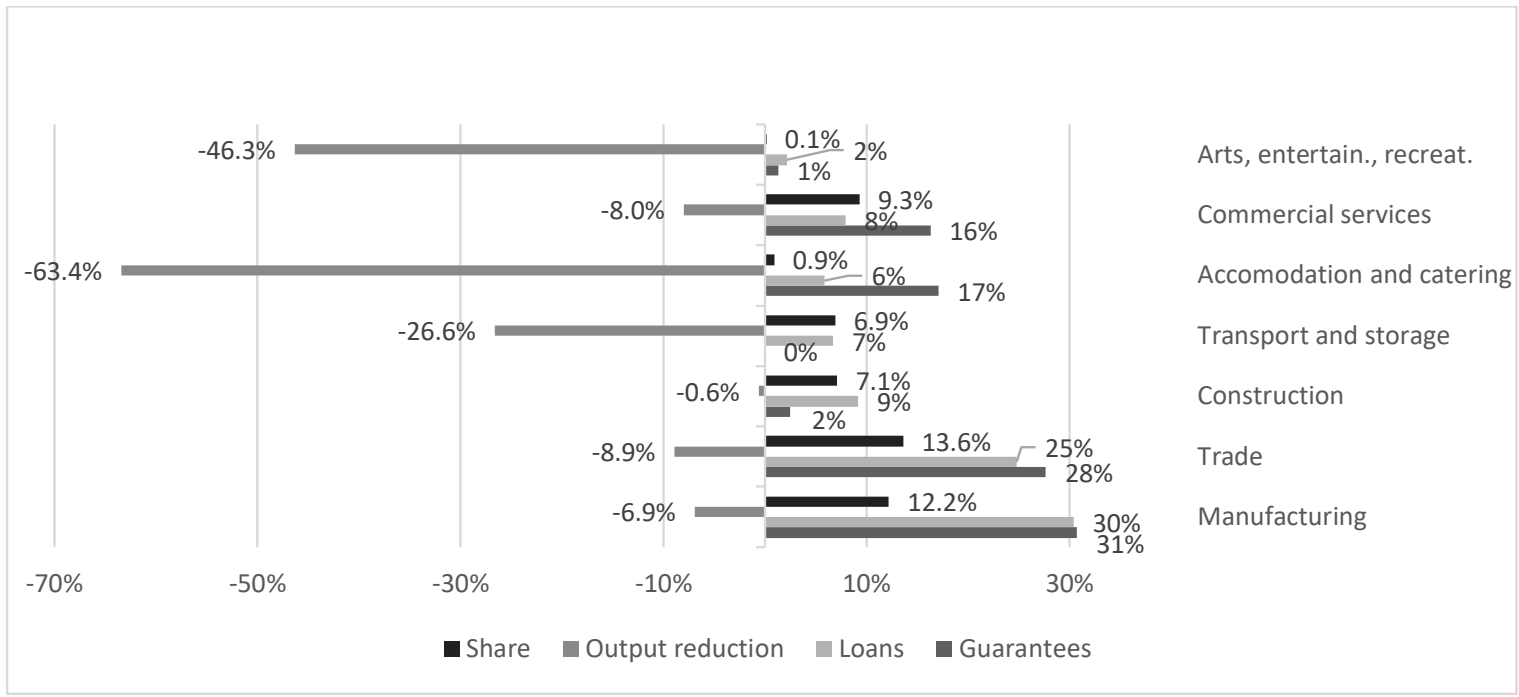

Source: CSB of Latvia, information provided by Altum

Fig. 6. Sector shares of loans and guarantees, sector shares in value added, and GDP reduction in the Q2 2020

On average EU countries has stimulated their economies with direct measures in amount of 7\% of GDP and indirect measures in amount of 14\%. There are wide variations among the countries, for instance Germany, the strongest EU country, has chosen to stimulate its economy with massive indirect measures (30\% of GDP). In comparison to other countries, Latvia's support has been quite moderate as it accounted only for 3\% support with direct measures and 6.8\% support with indirect measures. However, international comparisons should be interpreted carefully because of potentially different accounting methods across the countries. When the size of support package is compared to the infection rate, Latvia stands out as a country with relatively moderate support program.

\section{Public perceptions}

A public opinion poll (University of Latvia..., 2020) gives an impression of the impact Covid-19 pandemic first wave on peoples' personal economic situation, as well on peoples' perception of the governmental emergency support and tax discipline. The share of respondents, including the risk group, which received or applied for emergency support can be seen in Fig.7.

Did you receive the public emergency support in any form related to Covid-19?

Did you personally apply or have you been applied for the public support during the Covid-19 pandemic?Did you apply personally or have you been applied for the public emergency support for Covid19 ?

Do you belong to the group of people for whom the Covid-19 infection may result is severe consequences or even be fatal? 0.0

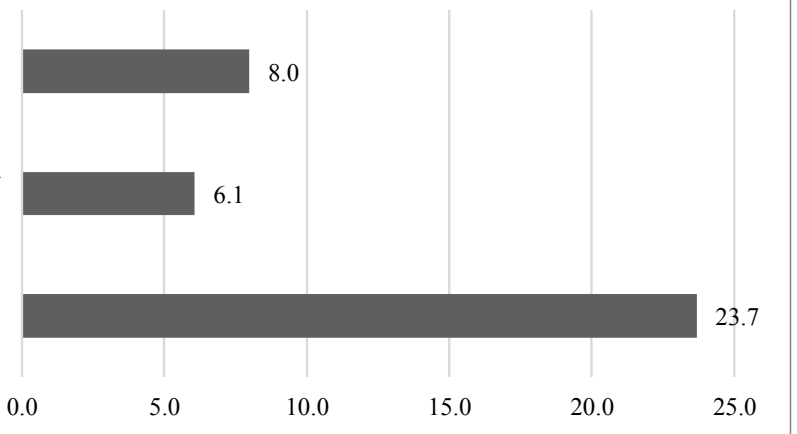

5.0

5.0

25.0

Fig. 7. The status of respondents in the context of the Covid-19 pandemic, percentage

Fig. 8 shows that 26.1 percent of respondents experienced a decrease in income during the pandemic, while 17.3 percent - a decrease in expenses. 23.4 percent of respondents did experience temporary and long-term financial difficulties. At the same time, only one fifth (22.7 percent) of respondents admitted that by losing their monthly income, they would be able to cover current expenses without borrowing for more than three months. The survey also revealed that the longer a respondent was able to survive without regular income, the more likely this respondent was among those who had decided to make savings for rainy days. The impact of the pandemic on people's income had considerable regional differences. 


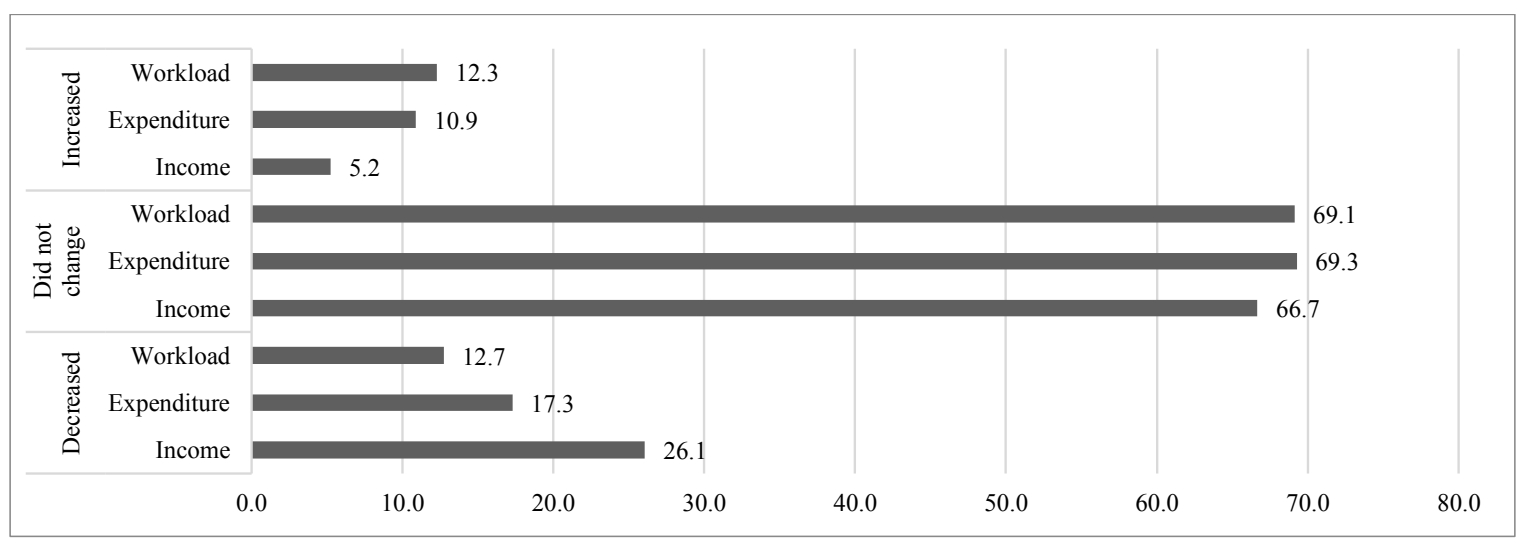

Fig. 8. Impact on income, expenditure and workload of the population, percentage

A majority of people considered the emergency support programs to be adequate and associated them with fiscal prudence (Fig. 9). Compared to other EU member states, in Latvia, the level of public satisfaction with the governmental assistance was above the EU average (European Commission, Standard..., 2020). People advocating tighter tax discipline and more responsible fiscal policies tended to support more restrictive access to national emergency support programs, while those who supported weaker tax moral and fiscal discipline advocated more inclusive state support programs.

The opinion poll also showed that the incidence of negative views on the public emergency programs among the respondents employed in the private sector and entrepreneurs was more frequent than in the panel of respondents in general. The difference between the share of positive views among those who were employed in the private sector and the other groups of respondents was statistically significant (pearson chi-square between the two groups of respondents 9.47 (at the level of statistical significance 0.009), but in the case of entrepreneurs - was not (pearson chi-square between the two groups of respondents 0.56 (at the level of statistical significance 0.756 ).

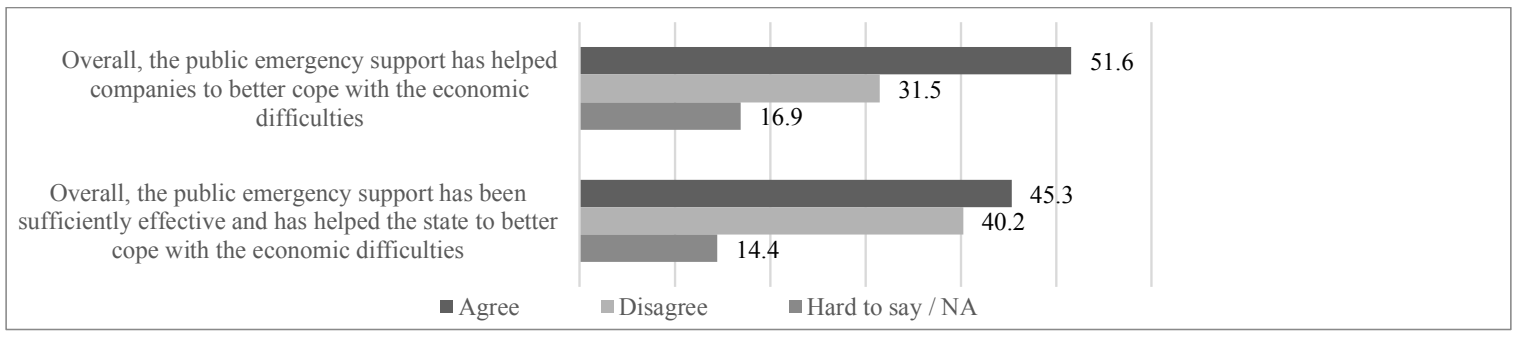

Fig. 9. Public assessment of the public emergency programs, percentage

Less than half (41.4 percent) of respondents agreed with the view that large companies should be supported even if such support increase their dependence on state support in the future (Fig.10). The largest share of supportive respondents was among the older generation of respondents (44.5 percent), among respondents with higher education (44.4 percent), among non-citizens (47.3 percent), and among those employed in the private sector (43.1 percent). Regionally, the more supportive of the necessity to support large companies were respondents in Zemgale (55.2 percent), while the least supportive (22.1 percent) were in Kurzeme.

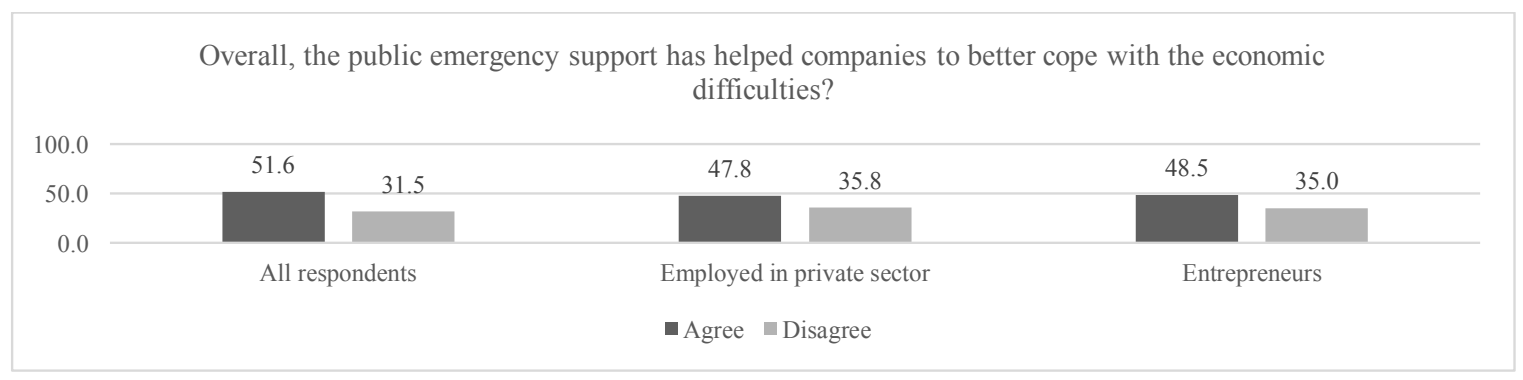

Fig. 10. The opinion of private sector employees and entrepreneurs on the effectiveness of the public support for enterprises, percentage

About a third (35 percent) of respondents admitted that they were proud of the work of public authorities during the pandemic (Fig. 11). Moreover, half of the respondents (50.5 percent) agreed to the claim that the public institutions were able to perform their functions as well or even 
better during the emergency, and somewhat less than half (45.7 percent) of respondents agreed with the opinion that the telew ork created due to the emergency had made public administration more modern and easily accessible to individuals. Data analysis revealed that pride in government work during a pandemic was felt mainly by supporters of the ruling and "right" wing parties, while supporters of the opposition and "left" wing parties, on the contrary, was not.

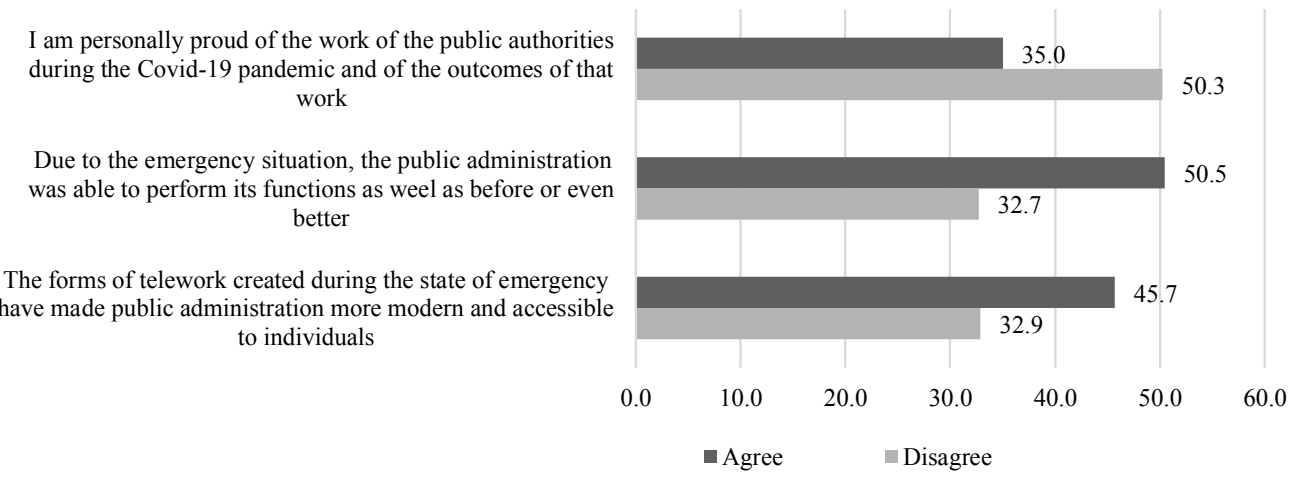

Fig. 11. Respondents' attitude towards the work of state institutions during the pandemics

Close to two thirds (63.5 percent) of respondents in the event of a recurrence of the Covid-19 pandemic were willing to admit restrictions to human contact as strict as during the first wave or even stricter and even higher number of respondents (70.9 percent) that in crisis situations, the state should act more decisively, even if it would involve greater interference in the personal lives of individuals (Fig.12).

Among those who feel proud of public authorities performance

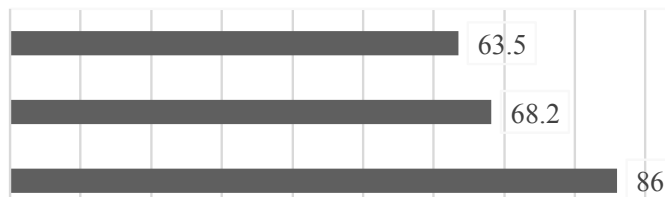

Fig. 12. Support for stronger restrictive measures in the event of a recurrent pandemic wave, percentage

Despite satisfaction in performance of public authorities, overall, the public trust in national public institutions has decreased (Fig.13). The pandemic had also eroded trust in the EU institutions - even to a greater extent than in national institutions. Yet, 51.9 percent of respondents agreed that without EU support Latvia would not have been able to successfully contain the pandemic, and 61.6 percent - that the fight against the pandemic would be more efficient at the EU level.

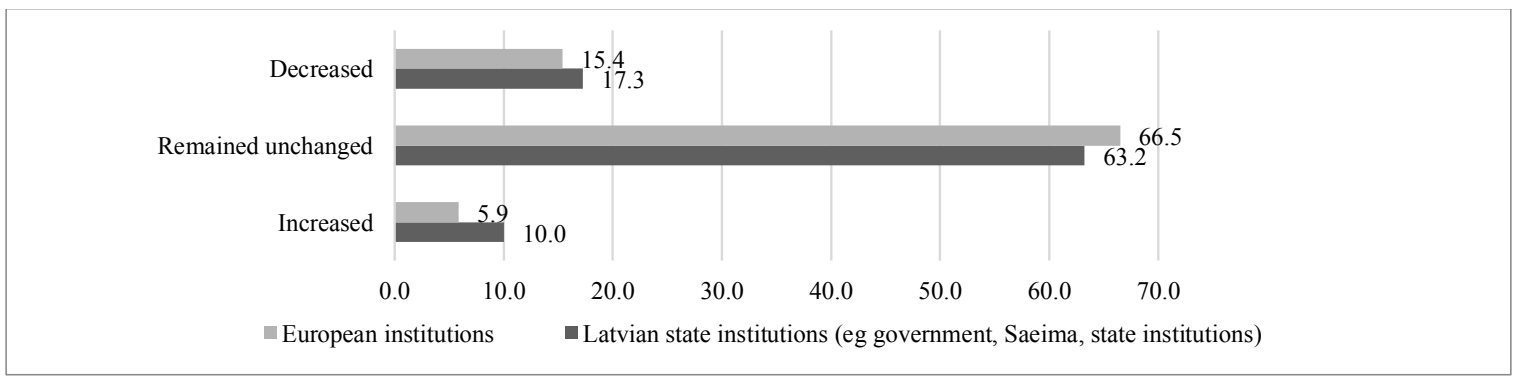

Fig. 13. Impact of the Covid-19 pandemic on trust in public institutions, percentage

Although correlation analysis revealed a very close relationship between the experience of long-term financial difficulties and respondents' intention to emigrate, survey also showed that 83 percent of respondents had not thought about leaving Latvia (Fig.14). 


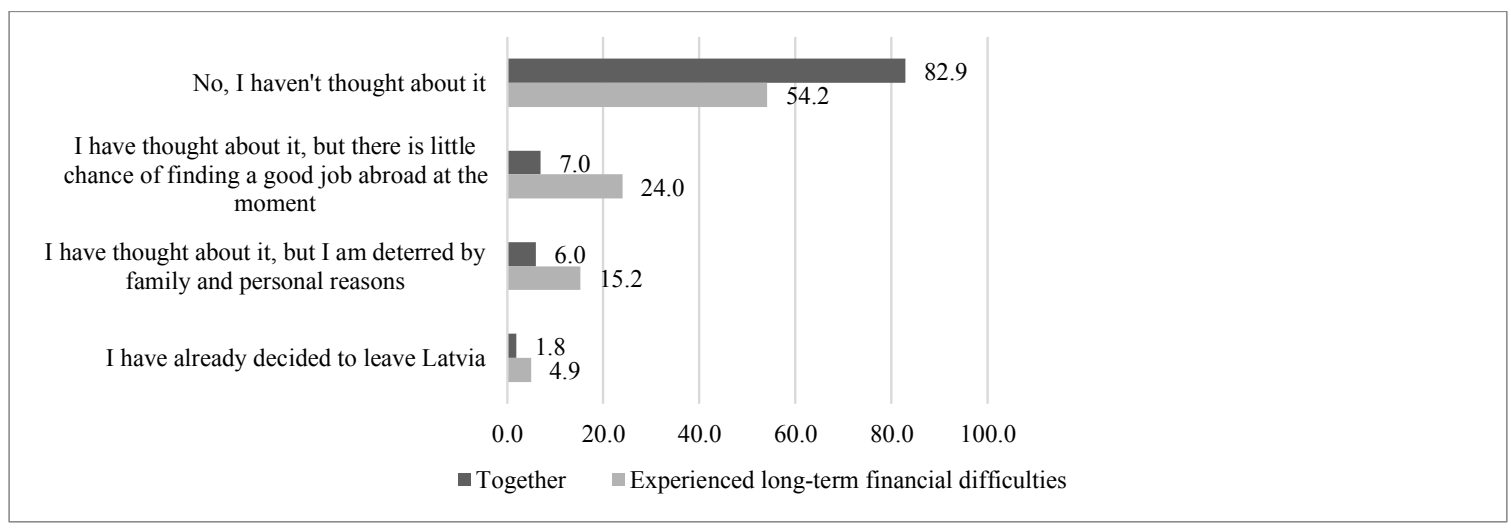

Fig. 14. Respondents' intentions regarding emigration, percentage

Figure 15 shows, that two-thirds (68.4 percent) of respondents agreed with the statement that tax evasion is a reprehensible behavior, but only 18.6 percent agreed with the statement that people prefer to pay taxes as a result of the Covid-19 pandemic. The main reasons why people would not pay taxes were too low wages after taxes ( 54.3 percent) and too high tax rates ( 45.8 percent). Those who trusted public authorities were more likely to agree that tax evasion is reprehensible and that all non-taxpayers should be cracked down on. Likewise, the supporters of the ruling parties were more supportive of both the government response and fiscal prudence.

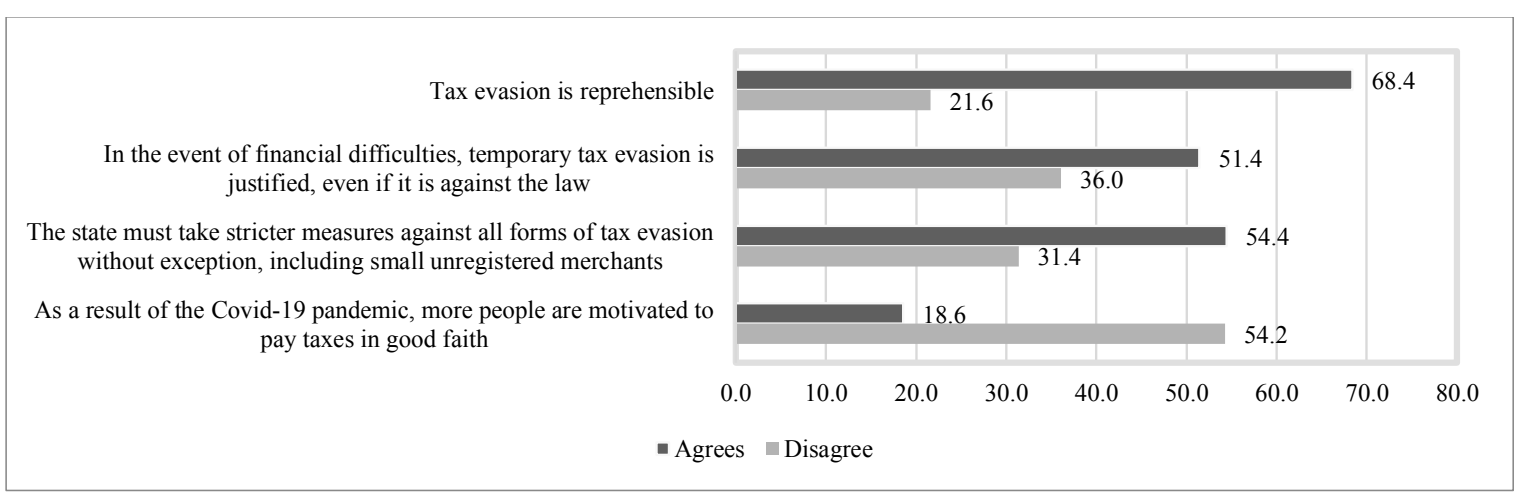

Fig. 15. Respondents' attitude towards tax discipline, percentage

These data confirm the hypothesis raised by other studies (Williams, 2015) that in Latvia a considerable gap persists between formal (i.e., legislative requirements that embody public morality) institutions and informal institutions (i.e., unwritten norms of behavior that embody civic morality) in the field of taxation. Namely, the view that tax evasion is reprehensible reflects the existing public morality, while the view on the positive effect of a pandemic on tax morality of people - the civic morality. Moreover, the gap between formal and informal institutions was also indirectly confirmed by the respondents' view of the reasons why people do not pay taxes, namely, that the respondents were not inclined to blame the state for inefficiency of tax administration, thus demonstrating relatively little interest in stricter actions by the state against tax transgressors (Fig.16).

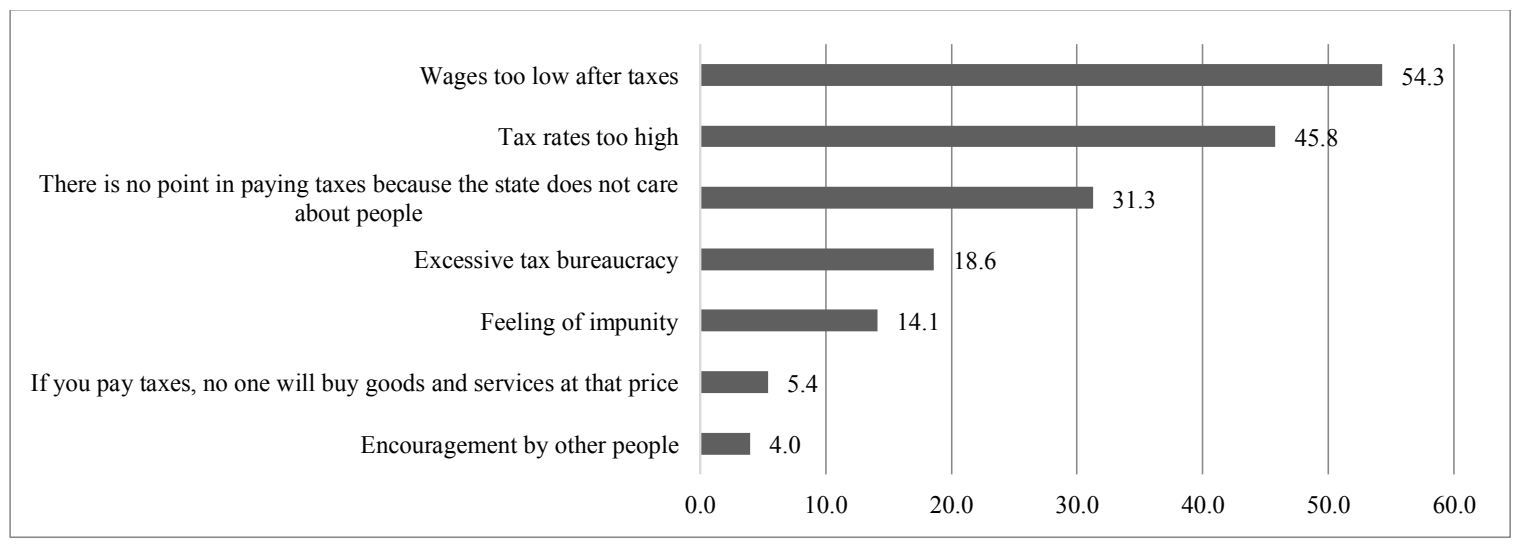

Fig. 16. Respondents' opinion on the reasons why people do not pay taxes, percentage 


\section{Future scenarios}

The output in the European and Latvian economy would barely return to pre-pandemic levels in 2022 . The depth of the recession in 2020 and the speed of the recovery in 2021 and 2022 is expected to vary widely across Member States. This does not only reflect differences in the severity of the pandemic and the stringency of containment measures, but also differences in economic structures and domestic policy responses (European Commission, European..., 2020). Obviously, close monitoring of economic consequences and speedy adjustment of the government response will be necessary in Latvia in the nearest future.

Pandemic related response will be combined with the response to major global economy challenges linked to technological change, digital transformation and the effects of global climate change. The country's ability to adapt its economy to future needs will become increasingly important, reaping the full benefits of new production opportunities and market niches, while minimizing risks and maintaining the ability to respond flexibly to pandemic consequences.

These processes increase the threats and opens new opportunities for the development of the Latvian economy.

The Covid-19 crisis should serve as a catalyst for faster change especially considering anticipated generous support by European Recovery and Resilience Facility. Thus, the biggest opportunity seems to be "the [unexpected] money rain from Brussels" which would complement the EU Longterm Budget/ Multi-annual Financial Framework 2021-2027 (Parliament of Estonia, 2020). The planned Recovery and Resilience Facility is an opportunity to enact productivity-enhancing reforms and to invest into innovations and human capital.

The Covid-19 crisis is accelerating the digital transformation process in the world. Countries and companies that have not previously implemented digital solutions will suffer the most, but by introducing digital solutions, they can significantly increase productivity and stay in business even under strict restrictive measures. Online commerce is growing and developing. Many consumers will become accustomed to online trading solutions and may not want to return to retail stores after the COVID-19 crisis, and some customers will continue to use these channels after the stores open.

New forms of work and teleworking will also bring change. Some companies will move to work remotely (in areas where this is possible, such as IT), but there are also many companies and sectors that will not be able to fully digitally transform. Telework will reduce demand (and prices) for office space and transport services.

The global economy is more affected by people who are afraid of COVID-19 than by those who are infected with the virus. As a result, consumer and decision-making behaviour has changed and will continue to change. Due to these fears, aggregate demand and supply in the global economy are changing. Fear reduced the demand for certain services like shopping or travelling. At the same time, however, the demand for online services has grown rapidly. Online sales will reduce the impact of the Covid-19 crisis on demand, but not in full. The Covid-19 crisis is having a negative impact on trade in durable goods (such as cars) and luxury goods.

Even before the Covid-19 crisis, global value chains faced a variety of challenges related to rapid technological development. In developed countries, for example, robots have replaced cheap workers of third world countries. This facilitates the transition to shorter value chains and localization, which can in turn boost investment.

The COVID-19 crisis has amplified profound fault lines in the functioning of global value chains (GVCs) and exposed the fragility of a model characterized by high interdependencies between leading firms and suppliers located across several continents (United Nations Conference..., 2020).

As a result of the Covid-19 crisis several changes are expected in the regional distribution of goods and services markets, stimulated by the firms seeking to improve their supply chain resilience - sudden need to keep more reserves, source from many suppliers instead of just one, and preferably closer to home. A positive side effect of governments resilience seeking behaviour in terms of securing the essential supplies would be a switch from Chinese products and contractors to domestically produced substitutes in Baltics and other EU member states. This would create opportunities for Baltic companies to expand production in new niches (Parliament of Estonia, 2020).

By structurally transforming the economy, it is possible to achieve a greater effect on the future growth and of the population's well-being. The changes caused by Covid-19, global technology development trends, the European Green Deal and the digital economy open new opportunities for increasing the productivity level of the Latvian economy by investing in new technologies, digitalisation, and innovation.

Economic modelling at the LV PEAK think tank of the University of Latvia shows that the introduction of the latest technologies, development of new products and services, as well as wider use of digital solutions and improvement of process efficiency, have a significant impact on faster growth. Thus, if the economy continues to follow the current trends, GDP growth could reach an average of 3.9\% per year in the 2021-2024 period, 
while in the period 2025-2030 the annual growth rate of the economy will slow down to within $2.5 \%$. Contrary to this modest growth, in the scenario, which envisages competitive advantages on technological factors, production efficiency, innovations, as well as the ability to adapt and use the opportunities created by global change, economic growth may reach 5.3\% annually on average from 2021 to 2024, but in the following years an average of 3.7\% annually. In this scenario, the Covid-19 pre-crisis level (2019) is reached in 2022. In turn, the economy will return to the pre-crisis growth trend only in 2027 (University of Latvia..., Latvian..., 2020).

\section{Conclusions}

The analysis of the socio-economic impact of the first wave of the COVID -19 pandemic crisis shows that economy as a whole, firms, and people have suffered lasting damage, in particular in transport, trade, tourism, healthcare, education and logistics. The assessment of the government response to the economic slowdown allows to conclude that government support was timely, relatively well targeted and generally appreciated by the people of Latvia. However, positive public perceptions after the first wave of crisis, when majority of people considered the emergency support programs to be adequate, should not be taken for granted, as people's attitude can quickly turn to the negative end. Therefore, permanent monitoring of people's perceptions is crucial for policy makers.

Optimistic assessments of the spread and impact of Covid-19 and "V" or "U" type economic recovery scenarios have not materialized. Further developments are likely to be wavy, with governments having to impose tighter restrictions from time to time. Even after the gradual deployment of vaccines, people will have to continue to distance themselves. Consequently, companies must be able to objectively assess the continuation of existing businesses in long-term restrictive circumstances.

The second wave of crisis in Latvia seems to be more devastating in terms of virus spread and related challenges. Permanent monitoring of economic dynamic and public perceptions is necessary for adjusting the goverment response.

COVID-19-related economic risks remain high, especially in the short term. The approching vaccination provides confidence that day to day life will return to something closer to normal over the next year. In the meantime, timely government support will be needed to compensate or at least reduce the economic damage.

Relatively positive public perceptions after the first wave of crisis, when majority of people considered the emergency support programs to be adequate, can turn to the negative end. Permanent monitoring of people's attitude is crucial for policy makers.

The crisis caused by Covid-19 is also an opportunity to change habits and behaviour, such as accelerating digitalisation and online commerce, creating new forms of work and teleworking, seizing the opportunity for EU producers to replace Chinese substitutes, production and opportunities to expand production in new niches.

Economic modelling shows that the introduction of the latest technologies, development of new products and services, as well as wider use of digital solutions and improvement of process efficiency, have a significant impact on faster growth. In the scenario, which envisages intensive use of opportunities created by technological change and digital transformation, economic growth may reach about $5 \%$ annually in the medium term.

\section{Bibliography}

Bank of Latvia, 2020. [Online] Available at: https://www.bank.lv/darbibas-jomas/monetaras-politikas-istenosana/prognozes [Accessed 11.11. 2020].

Central Statistical Bureau, Data 2020/1, Database of CSB. [Online] Available at: https://www.csb.gov.lv/lv/statistika/statistikastemas/ekonomika/ikp/meklet-tema/2734-ikp-apjoma-izmainas-2020-gada-2-ceturksni [Accessed 25.11.2020].

Central Statistical Bureau, Data 2020/2, Database of CSB. [Online] Available at: https://www.csb.gov.lv/lv/statistika/statistikas-temas/arejatirdznieciba/apkopojums/meklet-tema/408-latvijas-areja-tirdznieciba-svarigakas [Accessed 25.11.2020].

Williams C., Horodnic I., 2015. Explaining and Tackling the Shadow Economy in Estonia, Latvia and Lithuania: a Tax Morale Approach, Baltic Journal of Economics, 15:2, 81-98.

European Central Bank, 2020. [Online] Available at: https://www.ecb.europa.eu/press/pr/date/2020/html/ecb.pr200318_1 3949d6f266.en.html [Accessed 25.11.2020].

European Commission, 2020. European Economic Forecast: Autumn 2020, Institutional Paper 136. [Online] Available at: https://ec.europa.eu/info/publications/economic-and-financial-affairs-publications_en/[Accessed 25.11.2020].

European Commission, 2020. Standard Eurobarometer 93. [Online] Available at: file://C:/Users/Marta/Downloads/eb_93_fir_en\%20(1).pdf [Accessed 25.11.2020]. 
European Commission 2020/1, European economic forecast (autumn). [Online] Available at: https://ec.europa.eu/info/sites/info/files/economyfinance/ecfin_forecast_autumn_2020_overview_en.pdf [Accessed 25.11.2020].

European Commission 2020/2, draft budgetary plan for Republic of Latvia. [Online] Available at: https://ec.europa.eu/info/sites/info/files/economyfinance/2021_dbp_lv_en.pdf [Accessed 25.11.2020].

European Commission 2020/3, on the 2021 Draft Budgetary Plans: Overall Assessment. [Online] Available at: https://ec.europa.eu/info/sites/info/files/economy-finance/dbps_overall_assessment.pdf [Accessed 25.11.2020].

European Fiscal Monitor, 2020. [Online] Available at: https://www.euifis.eu/download/efm.pdf [Accessed 26.11.2020].

Eurostat 2020/1, Table une_rt_m. [Online] Available at: https://ec.europa.eu/eurostat/databrowser/view/une_rt_m/default/table?lang=en [Accessed 25.11.2020].

Eurostat 2020/2, Table TEIBS010. [Online] Available at: https://ec.europa.eu/eurostat/databrowser/view/teibs010/default/table?lang=en [Accessed 25.11.2020].

Fiscal Discipline Council, 2020. [Online] Available at: https://fiscalcouncil.lv/files/uploaded/MR6_ENGfinal.pdf [Accessed 26.11.2020].

Ministry of Economics of the Republic of Latvia, 2020. Macroeconomic Review of Latvia. [Online] Available at: https://www.em.gov.lv/lv/latvijasmakroekonomiskais-apskats-0 [Accessed 25.11.2020].

Ministry of Economics of the Republic of Latvia, 2020. Informative Report on Strategy for Latvia to Mitigate the Consequences of the Covid-19 Crisis. [Online] Available at: http://tap.mk.gov.lv/lv/mk/tap/?pid=40487682\&mode=mk\&date=2020-05-26 [Accessed 25.11.2020].

Ministry of Finance of the Republic of Latvia, 2020. [Online] Available at: https://www.fm.gov.lv/files/valstsbudzets/FMPask_2_121020_proj2021.pdf [Accessed 25.11.2020].

Parliament of Estonia, 2020. A Comparative Review of Socio-Economic Implications of the Coronavirus Pandemic (COVID-19) in the Baltic States.2020. [Online] Available at: https:/www.riigikogu.ee/wpcms/wp-content/uploads/2020/11/Baltic-Assembly_final_02.11.2020.pdf [Accessed 25.11.2020].

State Revenue Service, 2020. [Online] Available at: https://www.vid.gov.lv/lv/statistika-3 [Accessed 25.11.2020].

United Nations Conference on Trade and Development, 2020. How COVID-19 is changing global value chains. [Online] Available at: https://unctad.org/news/how-covid-19-changing-global-value-chains [Accessed 26.11.2020].

University of Latvia Think Tank LV PEAK, 2020. Latvian Productivity Report 2020, Rīga, December 2020.

University of Latvia Think Tank LV PEAK, 2020. Summery of the Results of Public Opinion Poll. [Online] Available at: https://www.bvef.lu.lv/fileadmin/user_upload/LU.LV/Apaksvietnes/Fakultates/www.bvef.lu.lv/6.ZINATNE/Instituti/LV_PEAK/Opionion_poll_s ummary_2020.pdf [Accessed 26.11.2020].

\section{Acknowledgement}

The research was supported by the national research programme project "Towards the Post-pandemic Recovery: Economic, Political and Legal Framework for Preservation of Latvia's Growth Potential and Increasing Competitiveness ("reCOVery-LV")" (VPP-COVID-2020/1-0010). 


\section{INCREASING INTERNAL AND EXTERNAL BRAND AWARENESS IN HIGHER EDUCATION}

\section{Yulia Stukalina, Transport and Telecommunication Institute}

Abstract. The importance of branding in higher education is growing due to the changes in the modern globalized environment and associated trends. The choice of an efficient marketing strategy developed for enhancing brand awareness in a university is dependent on many factors. The aim of the paper is to discuss brand awareness from two perspectives - customer-based perspective (applicable to external stakeholders in higher education), and employee-based perspective (applicable to internal stakeholders of an academia). In the paper, some common marketing tactics applicable in the internal and external university contexts are identified through the analysis of the operational marketing plans of a few universities with acknowledged marketing traditions. The research findings indicate that universities put a lot of marketing efforts in enhancing both internal and external brand awareness, paying a special attention to the propagation of the university's unique image inside and outside the campus. The most important marketing initiatives include the tactics linked with establishing an efficient system of marketing communications inside and outside the campus. The findings also demonstrate that marketing tactics applied by an academia are aimed at rejuvenating and reinforcing their institutional brand in the internal and external settings. The results of the study might be helpful for managers accountable for creating a competitive marketing strategy intended for increasing brand awareness and improving their university's reputation. Research limitations are mainly associated with the research sample; a larger sample size would extend the range of possible data and would form a better representation for analysis necessary to obtain a holistic picture of the international education market.

Key words: higher education marketing, marketing strategy, internal and external brand awareness.

JEL code: I29, M19

\section{Introduction}

The growth of marketing in the higher education sector is associated with a progressively more "marketized" higher education in the globalized competitive environment; different marketing concepts and business practices are now being introduced to the field (Elken, 2019). Applying a market-oriented approach in the higher education sector is a common practice today (Hemsley-Brown \& Oplatka, 2006; Stensaker \& D'Andrea, 2007; Filip, 2012; Hemsley-Brown et al., 2016). Marketing management in universities is changing together with the evolution of marketing orientation in higher education. In their research conducted in Poland, Hall and Witek (2015) have analysed this evolution and identified the following stages:

1) In the beginning, promotional events were organized typically during the admission process.

2) Later promotional activities "moved up" in the organizational hierarchy; more attention started to be paid to the opinions of students and their satisfaction with the offered" product", which led to "customization" of this "product" to satisfy the requirements of graduates and the labour market in general.

3) In time, the interest in the needs of all stakeholders in higher education increased, which generated the drift towards the development of "marketing of stakeholders".

In the higher education context, the most frequently mentioned stakeholder cluster is students (current, potential, alumni), local business is the second most commonly "cited" group, university staff is the third most commonly identified group; other stakeholders include academic and research bodies, professional associations, local government, etc. (Chapleo \& Sims, 2010). The higher education stakeholders can be basically categorized as external and internal "parties", each having their role in the brand value creation and contributing to strengthening the brand value, and also improving the university's reputation. For building an attractive institutional brand it is necessary to consider as internal as external stakeholders (Chernatony, \& Harris, 2000). So, a marketing strategy may include different methods for increasing both internal and external brand awareness.

Despite of the range of studies investigating brand management in a university, there is still lack of research on employee-based brand equity (associated with internal brand awareness). The aim of the paper is to discuss brand awareness from two perspectives - customer-based perspective (applicable to external stakeholders in higher education), and employee-based perspective (applicable to internal stakeholders of a university).

The research methods applied in the paper are qualitative in nature. They involve the analysis of theoretical works, OECD official papers and research articles in the area of branding in the higher education sector, as well as document analysis - to gain a broad perspective of the research problem. The documents include operational marketing plans of selected universities with acknowledged marketing traditions located in the USA. Though extensive research has been devoted to branding in higher education, rather less attention has been paid to performing systematic reviews 
of working documents related to the implementation of a university's marketing strategy; so insufficient information may limit the ability of university policy-makers from making decisions. Thus, the paper strives for bridging the gap between theory and practice in the field. For this purpose, some common marketing tactics applicable in the internal and external university contexts are identified. In the paper, the document analysis was performed based on the publicly available documents; this approach lets the selected universities effectively leverage publicly accessible data to increase their brand awareness. The documents are interpreted by the author to give some connotation around the topic under discussion.

The results of the study are supposed to be helpful for managers accountable for creating a competitive marketing strategy of their academia intended for increasing brand awareness and improving their university's reputation.

It should be mention that research limitations are mainly associated with the research sample; a larger sample size would extend the range of possible data and would form a better representation for analysis necessary to obtain a holistic picture of the international education market.

\section{Literature Review}

Strategic marketing is a vital component of the university's activities (Kotler \& Fox, 1995), a special attention being put on strategic brand management (Keller, 2003; 2012). Brand strategy has become a burning topic among higher education marketing leaders (Maue \& Hayes, 2015). Modern organizations have accepted the importance of endorsing the brand message both externally and internally (Judson et al, 2009), universities being no exception.

There are many related factors that may influence the way higher education institutions elaborate their marketing strategies; they include political, socio-economic, demographic, cultural aspects, university students' peculiar features - gender, age, socio-economic status, cultural background, etc. (OECD, 2018), as well as the range and changing needs of other university stakeholders.

Today, the scope of higher education is expanding worldwide, and the amount of international students is growing rapidly, so modern higher education is characterized by its massification and internationalization (OECD, 2008; OECD, 2009; OECD, 2012; OECD, 2017).

These trends are directly associated with diversification of student population. Universities are now seeking new ways to promote their services to international students, and integrated these methods in their academic strategies (Wu \& Naidoo, 2016). Current tendencies in the higher education market call for increased cooperation between universities, business and the society. Collaboration with "social actors" is important to develop the most "wanted products", including study programmes, for fulfilling social and individual requirements determined by the labour market demands (Muhcina \& Moraru, 2016). It is also crucial to "promote and market" these products for increasing enrolment and attracting excellent academic staff. This is closely connected with strengthening university reputation in the highly competitive global environment (West, 2009).

Current trends in higher education marketing, which may influence the choice of a marketing strategy, and the expected outcomes, are presented in Table 1. 
Higher education marketing trends and the anticipated effects

\begin{tabular}{|c|c|c|}
\hline Emphasis & Higher education marketing trends & Expected effects \\
\hline $\begin{array}{l}\text { Greater emphasis on stakeholder } \\
\text { accountability in the context of } \\
\text { "marketing of stakeholders" }\end{array}$ & $\begin{array}{l}\text { - Integration of "corporate mentality" into } \\
\text { a university culture } \\
\text { - Enlarged investment in creating a robust } \\
\text { brand } \\
\text { - Enlarged investment in the human capital } \\
\text { of an organization }\end{array}$ & $\begin{array}{l}\text { - Improved brand engagement } \\
\text { - Improved internal and external } \\
\text { brand recognition and awareness } \\
\text { - More powerful brand identity }\end{array}$ \\
\hline $\begin{array}{c}\text { Greater emphasis on } \\
\text { international marketing and } \\
\text { promotion in the agenda of } \\
\text { marketization and } \\
\text { internationalization } \\
\end{array}$ & $\begin{array}{l}\text { - More "aggressive" marketing and } \\
\text { promotion to international students } \\
\text { - Use of innovative marketing strategies } \\
\text { and tools }\end{array}$ & $\begin{array}{l}\text { - Transformed "business model" } \\
\text { - Diversified student base } \\
\text { - Enlarged market share } \\
\text { - Building an international brand }\end{array}$ \\
\hline $\begin{array}{c}\text { Greater emphasis on } \\
\text { diversification of study } \\
\text { programmes and educational } \\
\text { services in the context of } \\
\text { massification and diversification }\end{array}$ & $\begin{array}{l}\text { - Increased diversity of educational } \\
\text { settings } \\
\text { - Application of a more personal approach } \\
\text { to every potential student }\end{array}$ & $\begin{array}{l}\text { - Diversified product offer } \\
\text { - Diversified student base } \\
\text { - Enhanced market share } \\
\text { - Improved brand image and loyalty }\end{array}$ \\
\hline $\begin{array}{c}\text { Greater emphasis on quality } \\
\text { assurance for accomplishing } \\
\text { sustainability of the educational } \\
\text { process }\end{array}$ & $\begin{array}{l}\text { - Increased synergies across institutional } \\
\text { systems } \\
\text { - Increased investments in building } \\
\text { capacity to generate and employ necessary } \\
\text { data } \\
\text { - Enlarged application of ICTs in } \\
\text { marketing and educational processes }\end{array}$ & $\begin{array}{l}\text { - More efficient scheme of internal } \\
\text { and external communications } \\
\text { - Improved "product" (study } \\
\text { programmes and educational } \\
\text { services). } \\
\text { - Enhanced brand reputation }\end{array}$ \\
\hline
\end{tabular}

As seen from the above table, a marketing strategy of the university is generated taking into account the analysis of existing trends in the international higher education sector. The expected marketing strategy's outcomes are closely related to building a strong institutional brand: a) enhancing brand reputation and image; b) increasing brand recognition and awareness; c) building brand loyalty; d) creating a powerful brand identity.

So, many serious challenges that modern universities face have put more emphasis on branding (Woyo et al., 2014). Branding in higher education can be characterized by the following features (Nicolescu, 2009):

- In higher education, branding is more related to promoting attraction and loyalty.

- In higher education, reputation is vital.

- There are multiple stakeholders in higher education.

- So a multiple perspective should be used in higher education.

- Promotion policy in higher education is linked with marketing communications.

- Active promotion and communication aimed at potential students are viewed as one of the most significant marketing actions; institutional image and reputation based on the constructed brand are vital.

- Image, reputation and brand are created based on delivering quality services for all university stakeholders.

Based on the results of the current trends analysis and taking into account the peculiarities of higher education branding, different marketing strategies are created; they are all aimed at enhancing brand awareness and increasing brand value. A selected marketing strategy is supported by a set of marketing tactics developed for accomplishing competitive advantage in the international education market (Stukalina, 2019).

Below, a few marketing tactics included in the operational marketing and branding plans of three higher education institutions are described.

\section{Research results and discussion}

The research sample includes three universities located in the USA: Missouri State University, Willamette University, and the University of Arizona (College of Engineering). The analysis results show that the marketing tactics specified in the marketing plans of the above universities are aimed at rejuvenating and reinforcing their institutional brand in the agenda of increasing internal and external brand awareness. Table 2 describes some marketing tactics used by the Missouri State University. 
Marketing tactics aimed at increasing internal and external brand awareness (1)

\begin{tabular}{|c|c|c|}
\hline Focus & Marketing strategy & Related marketing tactics \\
\hline $\begin{array}{c}\text { Expanding } \\
\text { internal } \\
\text { brand } \\
\text { awareness }\end{array}$ & $\begin{array}{l}\text { - Renewing the brand look } \\
\text { - Strengthening associations related to } \\
\text { the brand } \\
\text { - Sharing the brand origin inside the } \\
\text { campus community } \\
\text { - Cultivating the brand through the } \\
\text { campus community for better } \\
\text { understanding the meaning and core of } \\
\text { the brand }\end{array}$ & $\begin{array}{l}\text { - Employing design specialists inside the university and adding a Brand } \\
\text { Manager position to the university's communications team } \\
\text { - Creating campaigns for enhancing brand awareness among students and staff } \\
\text { - Organizing year-round personal communication, marketing workshops with } \\
\text { representatives from different departments } \\
\text { - Organizing various events and meetings, demonstrating a more "open" } \\
\text { attitude to the students }\end{array}$ \\
\hline $\begin{array}{c}\text { Expanding } \\
\text { external } \\
\text { brand } \\
\text { awareness }\end{array}$ & $\begin{array}{l}\text { - Generating the brand based on the } \\
\text { success of study programmes } \\
\text { - Integrating messaging with emphasis } \\
\text { on the university's competitive } \\
\text { advantage }\end{array}$ & $\begin{array}{c}\text { - Recruiting design professionals outside the university for the university's } \\
\text { communications team } \\
\text { - Creating a dissemination plan and employing social media for implementing } \\
\text { the plan } \\
\text { - Creating unique programmes with successful employment rates } \\
\text { - Developing communication strategies focused on exceptional academic } \\
\text { opportunities offered by the university } \\
\text { - Investing in recruitments efforts for educational online programs, increased } \\
\text { enrolment being a profitable return on investment } \\
\text { - Using paid media, mass media and social media (Facebook, Instagram, } \\
\text { Twitter, YouTube) for advertising and promoting the brand } \\
\text { - Organizing various events and meetings and demonstrating a more "open" } \\
\text { attitude to the public }\end{array}$ \\
\hline
\end{tabular}

Table 3 describes some marketing tactics used by Willamette University.

Marketing tactics aimed at increasing internal and external brand awareness (2)

\begin{tabular}{|c|c|c|}
\hline Focus & Marketing strategy & Related marketing tactics \\
\hline $\begin{array}{c}\text { Expanding } \\
\text { internal } \\
\text { brand } \\
\text { awareness }\end{array}$ & $\begin{array}{l}\text { - Building a consistent } \\
\text { institution-wide } \\
\text { communication system that } \\
\text { incorporates reorganized } \\
\text { communications options for } \\
\text { recruitment, admission and } \\
\text { student enrolment } \\
\text { - Designing an institutional } \\
\text { "visibility and awareness" } \\
\text { campaign }\end{array}$ & $\begin{array}{c}\text { - Establishing a team of communicators for updating marketing communications inside } \\
\text { the campus. } \\
\text { - Creating a dynamic institutional website and making a schedule for the university's } \\
\text { website publications (aimed at the internal audience) } \\
\text { - Developing original digital content with the help of an optimized search engine } \\
\text { - Developing reliable messaging across the university. } \\
\text { - Improving e-mail marketing processes for undergraduate students } \\
\text { - Developing an "interactive newsroom" that includes such options as recent news and } \\
\text { events, fact sheets, expert lists, etc. } \\
\text { - Scheduling systematic marketing "skill-development" workshops for staff }\end{array}$ \\
\hline $\begin{array}{c}\text { Expanding } \\
\text { external } \\
\text { brand } \\
\text { awareness }\end{array}$ & $\begin{array}{l}\text { - Concentrating on key brand } \\
\text { distinctions } \\
\text { - Positioning the higher } \\
\text { education institution as a top } \\
\text { university through operative } \\
\text { media relations policy } \\
\text { - Attracting supporters of the } \\
\text { university } \\
\text { - Creating advanced } \\
\text { communication procedures for } \\
\text { the educational programmes }\end{array}$ & $\begin{array}{c}\text { - Developing new digital materials comprising photographs, social media icons, logos, } \\
\text { etc. } \\
\text { - Developing upgraded print and virtual resources for admissions } \\
\text { - Producing institutional print, digital and open-air advertising tools } \\
\text { media strategy } \\
\text { - Conducting an assessment of existing ocial media, developing an suitable digital } \\
\text { - Making a "faculty experts list" and sending it to mass media } \\
\text { - Organizing regular "media training" events for academic and administrative staff } \\
\text { - Creating an inclusive e-mail scheme for tracing contacts (audiences) } \\
\text { - Developing an online content containing "hero" stories about the university } \\
\text { - Creating a dynamic institutional website and making an editorial schedule for the } \\
\text { website (aimed at the external audience) } \\
\text { - Cooperating with alumni on constructing an modernised brand identity } \\
\text { - Improving a brand image by organizing annual events } \\
\text { - Strengthening the connections with the community through the life-long educational } \\
\text { programmes (e.g. "Institute of Continuous Learning") }\end{array}$ \\
\hline
\end{tabular}


Table 4 describes some marketing tactics used by University of Arizona/College of Engineering.

Marketing tactics aimed at increasing internal and external brand awareness (3)

\begin{tabular}{|c|c|c|}
\hline Focus & Marketing strategy & Related marketing tactics \\
\hline $\begin{array}{l}\text { Expanding } \\
\text { internal } \\
\text { brand } \\
\text { awareness }\end{array}$ & $\begin{array}{l}\text { - Increasing internal acceptance } \\
\text { - Communicating success of the } \\
\text { university to departments and } \\
\text { staff }\end{array}$ & $\begin{array}{l}\text { - Updating Arizona Engineer magazine, website and email communication system for } \\
\text { improving messaging activity } \\
\text { - Communicating achievements throughout the campus } \\
\text { - Producing regular progress reports and Fast Facts information sheets for the internal } \\
\text { audience. } \\
\text { - Organizing media training (print media, television media, radio media) for } \\
\text { departments, faculty and staff } \\
\text { - Establish a "Visibility Committee" including representatives of the university, } \\
\text { industry and community } \\
\text { - Maintaining consistent social media presence through Facebook, Twitter, YouTube, } \\
\text { LinkedIn). } \\
\text { - Creating multimedia materials for reaching the external audience with high quality } \\
\text { branded message (for example, producing high quality promotional videos) }\end{array}$ \\
\hline $\begin{array}{l}\text { Expanding } \\
\text { external } \\
\text { brand } \\
\text { awareness }\end{array}$ & $\begin{array}{l}\text { - Increasing visibility to external } \\
\text { audience } \\
\text { - Collaborating with industry } \\
\text { representatives to find projects } \\
\text { supporting common public } \\
\text { relations }\end{array}$ & $\begin{array}{c}\text { - Producing regular printed reports for supporters, prospective students, alumni and } \\
\text { other external audiences } \\
\text { - Delivering high quality email newsletters to external audiences } \\
\text { - Participating in scientific publications and co-branding for reaching identified } \\
\text { audiences } \\
\text { - Improving a brand image by means of yearly events } \\
\text { - Strengthening the relations with the community using the life-long learning } \\
\text { programmes (e.g. "Institute of Continuous Learning") }\end{array}$ \\
\hline
\end{tabular}

As seen from the above tables, contemporary universities put a lot of marketing efforts in enhancing both internal and external brand awareness, paying a special attention to the propagation of the university's unique image inside and outside the campus. The university makes their marketing strategies and tactics available to the whole campus community, this way engaging as many "players" as possible in the implementation of the overall marketing strategy. Such engagement also becomes an essential component of their brand image and, correspondingly, their general brand identity.

The research results suggest that universities may share the same marketing tactics, which are aimed at both internal and external audience in the agenda of enhancing brand awareness. They are described below.

1. Marketing tactics intended for the internal audience:

- Launching campaigns intended for enhancing brand awareness inside the campus;

- Improving marketing communications inside the campus and engaging professional marketing communicators;

- Providing enhanced and reliable in-campus messaging by means of specially designed website and email communication system, publications, newsletter, periodicals, etc.;

- Communicating success and marketing progress all through the campus using the above messaging tools.

2. Marketing tactics intended for the external audience:

- Designing institutionally specific printed and multimedia materials with high quality branded message as advertising tools for increasing brand visibility;

- Strengthening the links with the community through regular published reports, research cooperation and publications, co-branding, mass media and social media, systematic specialized events;

- Organizing regular in-campus training for initiating internal stakeholders with the main issues related to promoting and building a strong institutional brand;

- Communicating success and marketing progress outside the campus using the above messaging tools.

It should be also mentioned that for evaluating success of the selected tactics, different metrics are designed and applied; these marketing metrics comprise a range of performance measures associated with marketing performance (Kotler et al., 2009). Universities use a variety of marketing metrics depending on the size and location of a university, type of proprietorship (state/private), study programmes, degrees, university facilities 
and provided services, marketing know-how of a university, staff and students commitment to the marketing procedures, ICTs integration in educational procedures, etc. (Stukalina, 2019).

Besides, they may include long-term, intermediate and short-term outcomes (Missouri State University Marketing Plan, 2013): revitalized brand identity, improved acceptance rate of brand identity, constructive change in brand awareness, implementation of innovative marketing approaches and ideas, enlarged educational market segment, enhanced student enrolment, better involvement of alumni and sponsors, etc. In different higher education institutions, various marketing metrics can be employed depending on the type of ownership, size and location, study programmes, educational and marketing experience, etc. (Stukalina, 2019).

\section{Conclusions, proposals, recommendations}

1. Due to significant changes occurring in the international education market, branding is becoming central to modern higher education institutions. Different marketing strategies are being developed on the basis of the thorough analysis of the marketing environment, which are focused on the expectations of various university stakeholders. The anticipated outcomes are closely associated with building a strong institutional brand: enhancing brand reputation and image, increasing brand awareness, building brand loyalty, forming a powerful brand identity.

2. In higher education, brand elements may come in a variety of forms, brand equity being used as a criterion assessing the value of a certain brand. Such concepts as brand image, brand soul and brand identity are associated with customer-based, employee-based brand equity, together forming organization-based brand equity. Brand awareness is viewed as very important aspect of brand equity.

3. Marketing strategies aimed at enhancing brand awareness are created, taking into consideration internal and external audiences. Brand awareness may be discussed from both perspectives - customer-based perspective (applicable to external stakeholders in higher education), and employeebased perspective (applicable to internal stakeholders of a university).

4. A chosen marketing strategy is supported by an assortment of marketing tactics (marketing initiatives) designed for creating and sustaining a strong institutional brand in the agenda of generating competitive advantage in the international education market.

5. The changes associated with the chosen marketing tactics can comprise retiring (withdrawing), renewing (revitalizing), refocusing (reexamining), renaming and reinforcing (strengthening) the brand. The choice is dependent on many internal and external factors associated with the changes taking place in global higher education.

6. There are a number of directions for further research. A larger sample size would extend the range of possible data and would form a better representation for analysis. Future research could also investigate the marketing tactics implemented in different parts of the globe to obtain a holistic picture of the global education market. Besides, the discussion of marketing metrics used by contemporary universities for monitoring the implementation of their marketing strategies can develop the research topic further.

\section{Bibliography}

Chapleo, Ch., Sims, Ch., 2010. Stakeholder Analysis in Higher Education. Perspectives, 14, 12-20. DOI: 10.1080/13603100903458034.

Chernatony, L., Harris, F., 2000. Developing Corporate Brands Through Considering Internal and External Stakeholders. Corporate Reputation Review, 3, 268-274. DOI:10.1057/palgrave.crr.1540119.

Elken, M., 2019. Marketing in Higher Education. In book: Encyclopedia of International Higher Education Systems and Institutions, Springer, 1-5. DOI: $10.1007 / 978-94-017-9553-1$ 569-1.

Filip, A., 2012. Marketing Theory Applicability in Higher Education. Procedia - Social and Behavioral Sciences, 469, $912-916$.

Hall, H., Witek, L., 2015. Conditions, Contemporary Importance and Prospects of Higher Education Marketing on the Example of Polish Universities. Procedia Economics and Finance, 39, 206-211. DOI: 10.1016/S2212-5671(16)30314-8.

Hanover Research, 2014. Trends in Higher Education Marketing, Recruitment, and Technology, March 2014. [Online] Available at: https://www.hanoverresearch.com/media/Trends-in-Higher-Education-Marketing-Recruitment-and-Technology-2.pdf [Accessed 10 September 2020].

Hemsley-Brown, J., Oplatka, I., 2006. Universities in a Competitive Global Marketplace. International Journal of Public Sector Management, 19(4), 316-338. DOI: 10.1108/09513550610669176.

Hemsley-Brown, J., Melewar, T.C., Nguyen, B., 2016. Exploring Brand Identity, Meaning, Image, and Reputation (BIMIR) in Higher Education: A Special Section. Journal of Business Research, 69(8), 3019-3022. DOI: 10.1016/j.jbusres.2016.01.016. 
Judson, K., Aurand, T.W., Gorcels, L., Gordon, G. L., 2009. Building a University Brand from within: University Administrators' Perspectives of Internal Branding. Services Marketing Quarterly, 30(1), 54-68. DOI: 10.1080/15332960802467722.

Keller, K.L., 2003. Building, Measuring, and Managing Brand Equity ( $2^{\text {nd }}$ ed.). New Jersey: Prentice Hall.

Keller, K.L., 2012. Strategic Brand Management: Building, Measuring, and Managing Brand Equity (4 ${ }^{\text {th }}$ ed.). UK: Pearson.

Kotler, P., Fox, K., 1995. Strategic Marketing for Educational Institutions (2 ${ }^{\text {nd }}$ ed.). N.J.: Prentice-Hall.

Maue, D., Hayes, T., 2015. The State of Higher Ed Branding: A Survey of Marketing Leaders (White Paper). [Online] Available at: http://clients.mstoner.com/white_paper/higheredbranding.pdf_[Accessed 12 October 2020].

Missouri State University Marketing Plan, 2013. [Online] Available at: https://www.missouristate.edu/assets/marcom/MSU_Marketing_Plan_1107-2013.pdf [Accessed 27 July 2020].

Muhcina, S., Moraru, A-D., 2016. Educational Marketing Challenges - Universities and Graduates' Employment: A Case Study. Annales Universitatis Apulensis Series Oeconomica, 18(1), pp.27-34.

Nicolescu, L. (2009). Applying Marketing to Higher Education: Scope and Limits. Management \& Marketing, 4(2), 35-44.

OECD, 2008. Tertiary Education for the Knowledge Society: Volume 1: Special Features: Governance, Funding, Quality; Volume 2: Special Features: Equity, Innovation, Labour Market, Internationalisation. OECD Paris.

[Online] Available at: http://www.oecd.org/education/skills-beyond-school/41266690.pdf [Accessed 20 August 2020].

OECD, 2009. Higher Education to 2030, Volume 2: Globalisation. Executive Summary. OECD Paris. [Online] Available at: https://www.oecd.org/education/ceri/44101074.pdf [Accessed 29 August 2020].

OECD, 2012. Education at a Glance 2012: Highlights. OECD Publishing. [Online] Available at: http://www.oecd.org/education/highlights.pdf [Accessed 11 September 2020].

OECD, 2017. Benchmarking Higher Education System Performance: Conceptual Framework and Data, Enhancing Higher Education System Performance. OECD Paris. [Online] Available at: https://www.oecd.org/education/skills-beyond-school/Benchmarking\%20Report.pdf [Accessed 30 September 2020].

OECD, 2018. Education at a Glance 2018: OECD Indicators. OECD Paris. [Online] Available at: https://read.oecdilibrary.org/education/education-at-a-glance-2018_eag-2018-en\#page3 [Accessed 12 September 2020].

Stensaker, B., D'Andrea, V., 2007. Branding - the Why, What and How. In B. Stensaker, \& V. D'Andrea (Eds.), Branding in Higher Education. Exploring an Emerging Phenomenon (pp. 6-13). EAIR Series Research, Policy and Practice in Higher Education.

Stukalina, Y., 2019. Marketing in Higher Education: Promoting Educational Services and Programmes. Proceedings of the International Scientific Conference Contemporary Issues in Business, Management and Economics Engineering 2019, 9-10 May 2019, Vilnius Gediminas Technical University, Lithuania, 616-624.

University of Arizona (College of Engineering) Marketing, Branding and Communications Plan, 2016. [Online] Available at: https://docplayer.net/3451467-University-of-arizona-college-of-engineering-marketing-branding-and-communications-plan.html [Accessed 30 June 2020].

West, P.W., A., 2009. A Faustian bargain? Institutional Responses to National and International Rankings. Higher Education Management and Policy: Journal of the Programme on Institutional Management in Higher Education, 21(1), 9-18.

Willamette University Marketing Plan 20015-2018, 2015. [Online] Available at: https://www.coursehero.com/file/40532546/willamette-imp-20152018pdf/ [Accessed 12 July 2020].

Woyo, E., Hlulani Obert, H., Frank, G., 2014. Brand Reputation Management within the Higher Education Sector: A Review of the Literature on Higher Education Brand Reputation Management. International Research Journal of Marketing 2(1), 1-8. DOI: 10.12966/irjm.02.01.2014

Wu, T., Naidoo, V., 2016. The Role of International Marketing in Higher Education. In T. Wu, \& V. Naidoo (Eds.), International Marketing of Higher Education (pp.3-9). NY: Palgrave Macmillan. DOI: 10.1057/978-1-137-54291-5_1 


\title{
MANAGEMENT OF UNIVERSITY RESEARCH: USING INTERNATIONAL STANDARDS OF EXCELLENCE FOR RESEARCH EVALUATION \\ Yulia Stukalina, Transport and Telecommunication Institute
}

\begin{abstract}
The higher education sector is now operating in an extremely turbulent challenging environment. The number of higher education providers is increasing, as new universities are being established under the auspices of private and public benefactors to satisfy the needs of various stakeholders in the agenda of supporting social and economic development. Owing to the growing significance of higher education and research, university policy-makers place more emphasis on devising strategies aimed at enhancing the research output, which is vital for improving their reputation as research-intensive institutions and gaining a competitive advantage in the international higher education market. The purpose of the paper is to review the main criteria integrated in universities' research strategies, which are applied for assessing research in the international perspective, in terms of the standards dominant at the global level. The associated objectives include: exploring research evaluation principles and methods used in the academic environment for measuring research output of a university; discussing quantitative and qualitative assessment criteria currently utilized by experts in the evaluation process. The methodology includes the analysis of relevant theoretical literature, previous research, evaluation expert reports, and the European Union official documents on higher education. The research results show that today, research evaluation is executed based on the internationally accepted research assessment principles, different economic, social, cultural and environmental aspects being in the focus of evaluation. The research results might be useful for the university policy-makers responsible for developing a competitive research strategy intended for improving their university's ranking in the $21^{\text {st }}$ century education market.
\end{abstract}

Key words: research strategy, research performance, evaluation methods, assessment criteria.

JEL code: I29, M19

\section{Introduction}

In a knowledge-based society, the role of "research universities" in both social and economic development is increasing; their traditional functions (providing various educational services) are supplemented by the creation of new knowledge in the field of science and technology (Mohrman et al., 2008). Teaching, research and innovation are key responsibilities of a modern university closely associated with their ability to address emerging societal challenges (European Commission, 2019). Research and innovation are at the core of EU's economic strategy, including such priorities as "digital Europe, energy efficiency, sustainability" (European Commission, 2015). Higher education institutions provide their graduates with cutting-edge knowledge, skills and competences, thus contributing to human capital creation; through research activities, they generate new knowledge and develop solutions to the challenge modern societies face (European Commission, 2017).

The research strategy is developed in the framework of an inclusive university's strategy intended for maintaining a competitive advantage over peer universities, being its essential element that supports collaborative cross-disciplinary research activities and institutional relationships with the community, as well as with research and industrial sponsors. Strong rivalry between universities in terms of competing for best talents and attracting funding to keep the status of re-search-intensive organizations press education managers to re-evaluate their policies intended for enhancing research quality. Managers responsible for the research quality have to understand what can drive research excellence at their institution; this is vital for developing appropriate research strategies in the frame of a competitive university' strategy. A regular evaluation of research quality against international standards of excellence will help the university senior managers to make decisions necessary for allocating research funding based on the obtained outcomes. It should be noted that the research outcomes of a university (its departments and staff) are not associated simply and solely with the competition inside the country. They also significantly influence - directly and indirectly - the country's international status; this may result in attracting more international students, excellent staff and external funding (Johnson, 2013).

In view of the above, it is very important to measure scientific output of an academia. In the course of research performance assessment, different research quality-evaluation methods, as well as various research performance criteria can be used. The aim of the paper is to revise and summarize the basic criteria that are now applied for assessing university research in the international perspective, in terms of the standards dominant at the global level. For accomplishing the above goal the following objectives are formulated: to explore research evaluation principles, approaches and methods used in the academic environment for measuring research output of a university; to discuss existing assessment criteria currently applied by experts in the evaluation process.

The methodology includes relevant theoretical literature analysis, previous research, evaluation expert reports, and the European Union official documents on higher education, including the issues related to the assessment of research performance of a university in the context of offering 
quality education. The purpose of data analysis was to get insights from the collected information, carry out appropriate investigation of the study findings and systematize them. The analysis of data performed in the paper provided a basis for interpreting the knowledge obtained from the data in ways that are relevant to the research aim and objectives. The research results might be useful for the university policymakers, whose main responsibility is to ensure that the research is optimal (and properly linked with institutional teaching activities) in the context of improving their university's ranking in the extremely competitive global $21^{\text {st }}$ century education market.

Literature Review: Research management in a modern university.

The review of literature dedicated to the management of a university in the $21^{\text {st }}$ century education settings, proves the relevance of strategic planning to higher education (Watson, 2000; Eastman, 2003; OECD, 2005; Bush, 2007; Kettunen, 2011; Moldovan, 2012). Nowadays, universities are considered more like "corporations in the business of education" (Johnson, 2013). This is closely associated with their engagement in the brand competition, and consequently, an increased focus on marketing activities (Mourad et al., 2011; Finch et al., 2013) in the context of both student enrolment and university rankings. Traditional sources of competitive advantage are not as effective as they used to be, and strategic managers are needed to accept a "new mind-set" including, among other things, focus on innovative approaches and flexibility; this is determined by the constantly changing settings and emerging trends (Hitt et al., 2016). For instance, in modern higher education, the following trends can be traced: its availability to wider student populations, internationalization and diversification in terms of student population (Stukalina, 2019). This, in turn, leads to commoditization of higher education, which is also stimulated by the necessity for mutual recognition of the obtained qualifications (WalcottSkinner, 2003).

Thus, is it important that universities have "well-formulated and well-disseminated strategic plans" showing purpose and direction and supporting the university's mission, strategic management, being an continuing procedure for revising and sustaining strategic activities at all levels of a higher education institution (Johnson, 2013). A research strategy is created in the agenda of an institutional strategy. The reasons for developing a research strategy include enhanced competition and decrease in budgets, quality requirements, external pressure, collaboration with external partners, etc. (Gunnarsson, 2012). In the frame of a research strategy, universities constantly develop and employ various management practices for achieving research and academic excellence that help them meet international standards (Johnson, 2013).

Research strategies may be focused for accomplishing improved performance in international research rankings. University rankings are getting more popularity today, and are being utilized by universities to state their performance goals and implement their marketing activities (European Commission, 2010). Therefore, they have to be "articulated" in university strategy (Dowsett, 2020). Since higher education is now a vital economic development driver, the output, and status of research generated by a higher education institution is a significant factor that must be considered in the context of creating a competitive strategy aimed at accomplishing academic and research excellence (European Commission, 2010), this way enhancing a university's rankings.

Strategic plans of universities should include a methodology for tracking the progress of the research strategy implementation and evaluating the research outcomes. The need for establishing an efficient system of research evaluation is also determined by the goals stated in the EU official documents related to the provision of quality higher education that would support constructing the European Research Area and European Higher Education Area (European Commission, 2000; The European Higher ..., 2018; Standards and Guidelines ...., 2015; Eurydice Report, 2015). Therefore, the topic of research evaluation in terms of finding the way for improved methods of its assessment is becoming critical as for the scientific community in general as for policymakers at different levels (European University Association, 2018). To increase their reputation as research-intensive institutions for gaining a competitive advantage, universities are paying growing attention to measuring research outcomes.

Research performance assessment is crucial for a contemporary university for improving quality, enhancing scientific reputation, keeping autonomy, facilitating strategic planning and appealing to young talents (AUBR, 2010). The increasing anxiety for the quality and measurement of conducted research is closely associated with the growing importance of university rankings including global rankings (ibid.). There are different approaches to measuring research output of a university. However, the assessment is performed, taking into account a few internationally accepted research evaluation principles discussed below. Research evaluators should be very careful in selecting, applying and interpreting evaluation criteria; in the process of research performance evaluation, social, economic, environmental and cultural aspects should be considered (AUBR, 2010).

Below, research evaluation principles, methods and criteria are discussed in more detail. 


\section{Research results and discussion: University research evaluation principles and criteria}

\section{Internationally accepted research evaluation principles}

Research assessment is employed in different situations - for evaluating research outcomes (publications, research projects, etc.), researchers, re-search groups and organizations including universities and their units (AUBR, 2010). New approaches to research evaluation at different levels are being developed now (ibid.). In recent years, there has been a tendency to systematize the methods used to evaluate university-based research (Saene \& Borrell-Damián, 2019). They should be based on clearly defined principles. Through a comprehensive survey of stakeholders of higher education, the AUBR Expert Group has identified a few principles witnessed in the measurement of university-based research, among the most important are the following (AUBR, 2010):

- All university disciplines are covered.

- The whole range of research is included in the evaluation.

- The diverse outputs are taken into account

- Economic, cultural, social and environmental effects are taken into account in the process of research evaluation.

- Specific local, regional and national contexts are considered.

- Research conducted in collaboration with non-university organizations and in European (international) network is recognized.

- The various profiles, missions, histories, resources of universities as well as higher education systems are recognized.

\section{Internationally accepted criteria used for university research evaluation}

A higher education institution is a complex organization including different levels and research direction (Rip, 2011), so measuring the research "output" of modern multi-disciplinary universities requires using the aggregated performance measures; the methods of aggregation are based upon the "output" of the separate researchers and the performance of all scientific areas in the organization in general, etc. (Abramo \& D'Angelo, 2015) So, advanced multi-factorial and multi-dimensional assessments are necessary, which would allow for using various parameters levels (European University Association, 2018). The fitting choice would depend on the assessment situation and the evaluation objectives (Abramo \& D'Angelo, 2015). Evaluation should be an independent instrument aimed at advancing scholarly research, everyone's role in cooperative activity deserves appreciation, so "multiple criteria" evaluation must prevail, and each criterion should be assigned different weights (ibid.).

Research quality and academic influence, innovation and associated social bene-fits, sustainability and range, excellence of related infrastructure (and other processes and dimensions) are assessed by means of both qualitative and quantitative criteria. These criteria, being complex tools, no single set of indicators can reflect this complexity, so for research evaluation a variety of indicators should be used (AUBR, 2010). Due to differences in disciplinary research practice various classifications are accepted by experts. The criteria can be classified consistent with which aspects they have to measure (AUBR, 2010): research efficiency/productivity; quality of research as well as its academic impact; social benefits and innovation; sustainability and its range; infrastructure of research. Research productivity, for example, is measured using quantitative metrics; they include Bibliometrics, Scientometrics, Webometrics, Informetrics, Labrametrics, and Almetrics (an alternative to journal impact factor) (Das, 2015). According to Moed and Plume (2011), Bibliometrics play a central role in research evaluation systems. The metrics applied today can be also categorized as follows (Saene \& Borrell-Damián, 2019; European Commission Expert ..., 2017).

- Conventional metrics (prevailing category) that measure research output using information obtained from journal publications; they include the journal-level Journal Impact Factor, CiteScore, author-level h-index, etc.

- Usage-based metrics and alternative metrics based on the number of views/downloads, for example, Usage Impact Factor (UIF).

- Alternative metrics based on social media and scientific social networks, for example, Altmetric.com, ImpactStory, Bookmetrix, etc.

- "Next-generation" metrics - more precise and transparent tools for research assessment used for "open science" and based on cooperation in the context of research globalization through online digital technologies.

Non-bibliometric criteria embrace the so-called "knowledge transfer activities", as expressed in the volume of external research funding; the amount of granted licenses and patents, Ph.D. completion rates, number of outstanding researchers invited to international scientific conferences, etc. (Moed \& Plume (2011).

The above assessment criteria can be applied with regard to different evaluation dimensions, each dimension having a certain scope (ibid.):

- Individual researcher (productivity and quality of individual research). 
- Research project group (scholarly impact/research quality and contribution).

- Faculty/department (social innovation/contribution).

- University (sustainability of its operation).

Some universities define success measurements in terms of key performance indicators - KPIs (Stukalina, 2019). Many higher education institutions (especially research-based universities) employ performance indicators developed with due account of output targets (Taylor, 2006). For research evaluation, KPIs can be applied on the annual basis in the frame of the university's strategy implementation evaluation. Research performance criteria can be categorized as input and output measures: a) input measures may include the amount of student res earchers and academic researchers, research income, claims for funding and successful claims; b) output measures may comprise the amount of publications in peer reviewed journals and use of citations, defended research theses, granted patents, licences, special awards, etc. (Taylor, 2006). Research performance criteria utilized for measuring and explaining qualitative impacts (e.g. management, social benefits, cooperation, etc.) are associated with nonnumerical information.

Some specific research KPIs may be found on the website of the Elsevier Snowball Project (online: https://www.snowballmetrics.com/wpcontent/uploads/Snowball-Metrics-recipes.jpg):

- Publications and citations (academic output and publications in best journals, citation count and area-weighted citation impact, h-index).

- Collaboration (research collaboration and its impact, collaboration publication share and collaboration area-weighted citation impact, etc.).

- Societal impact (community engagement, academic-corporate collaboration and its impact, etc.).

\section{Research Assessment Exercise (RAE) as an international research evaluation system}

Therefore, in the evaluation process, different research evaluation methods, systems and criteria are being employed, and various qualityevaluation projects are being undertaken worldwide. One of the acknowledged international research evaluation schemes is the UK's RAE Research Assessment Exercise (AUBR, 2010); through this exercise, the research performance evaluation procedure in a university can be formalized. It should be noted that Research Assessment Exercises are used for assessing research in the international perspective, in terms of the standards predominant at the world-wide level. This is a peer-review system based on the three pillars - "rigor, originality and significance" (Cabral \& Huet, 2014). It represents a consistent method of research performance evaluation that can be used in different contexts - both national and international.

Research Assessment Exercises (substituted by the Research Excellence Framework in 2014) is a periodic evaluation of research quality in universities against inter-national standards of excellence, which assists higher education funding bodies to allocate research funding taking into account the research quality. The results of Research Assessment Exercises can be used by university managers for making decisions related to the research activities, which are related to enhancing the reputation for research excellence at a national and international level. RAEs are supposed to generate quality profiles for every research activity conducted by a higher education institution (RAE, 2008). In the assessment procedure, a set of evaluation criteria are applied. It should be noted that there are no universal (entirely objective) indicators reflecting the complexity of research assessment in higher education; all of them have their strengths and weaknesses and can be viewed as "proxies" (AUBR, 2010). However, they must correspond to the following principle: they have to be "fit for purpose and verifiable" (ibid.)

The Research Assessment Exercise conducted for the Ministry of Education of the Republic of Latvia in 2013 was performed for evaluating Latvian research from the international perspective (Arnold et al., 2014). The overall objective of the RAE was to provide the Latvian public, academic community, policymakers and decision-makers with the most unbiased representation of the quality and competitiveness of Latvian science compared with the international practice in the relevant fields (Arnold et al., 2013). The following institutions were involved in the RAE: higher education institutions (their units), scientific institutes established by higher education institutes, state scientific institutes, private institutions; the timescale of the RAE embraced research activities from 1 January 2006 to 31 December 2012 (Arnold et al., 2013).

Thirty-six peer reviewers - acknowledged experts in their area - were involved in the work of six panels: humanities and social science, life sciences and medicine, forestry and veterinary science, natural science and mathematics, engineering and computer science, agriculture. The experts were identified taking into account their contribution to the European Science Foundation, their publications and participation in RAEs [35]. The panels obtained self-assessment reports and other materials from different institutions and their units. The panels carried out their evaluation based on five categories (aspects) (Arnold et al., 2013; Arnold et al., 2014): scientific excellence (quality); influence on the research discipline; economic/social influence; research settings/infrastructure; ability of a university to develop. 
The research assessment process included the analysis of inputs, visits, meetings and discussion, producing final institutional assessments and scores, the institutions being grouped as poor, adequate, good, very good and outstanding. A set of evaluation criteria applied by the expert panels is presented in Table 1 .

Ranking scale applied by the expert panels in the RAE (description)

\begin{tabular}{|c|c|c|}
\hline No. & Dimension/Category & Evaluation Criteria \\
\hline 1. & $\begin{array}{l}\text { Economic and social } \\
\text { impact }\end{array}$ & $\begin{array}{c}\text { - The institution is a recognized project partner beyond the academic environment } \\
\text { - Staff includes most in-demand experts in public and private spheres } \\
\text { - The organization contributes a lot to the development of the society } \\
\text { - The conducted research is significant for the society } \\
\text { - Cooperation with non-university representatives (e.g. entrepreneurs, policymakers, the community) is } \\
\text { obvious and useful }\end{array}$ \\
\hline 2. & $\begin{array}{l}\text { Scientific quality, } \\
\text { impact on science, } \\
\text { research environment }\end{array}$ & $\begin{array}{c}\text { - The institution is an acknowledged project partner outside the academic environment } \\
\text { - Staff members are demanded experts in public and private fields } \\
\text { - The organization contributes a lot to the development of the society } \\
\text { - The conducted research is significant for the society } \\
\text { - The organization's cooperation with non-university representatives is detectable and beneficial } \\
\text { - The organization is able to take and maintain scientific leadership in the area, or in the international } \\
\text { scientific community within the given area }\end{array}$ \\
\hline 3. & $\begin{array}{l}\text { Development } \\
\text { potential of the } \\
\text { institution }\end{array}$ & $\begin{array}{l}\text { - In 5-10 years the institution will be able to accomplish a noteworthy international "breakthrough" in the } \\
\text { given area } \\
\text { - In 5-10 years the organization will be able to attain a superb level of research quality/impact } \\
\text { - In 5-10 years the organization will be able to become an acknowledged international collaboration partner } \\
\text { through projects/networks } \\
\text { - In the long run, the institution will be able to attain a level of excellence corresponding to the most } \\
\text { outstanding universities in the world }\end{array}$ \\
\hline
\end{tabular}

As seen from the above table, the assessment criteria used by the panel experts are mainly related to the following activities: participation in international projects; net-working activities; cooperation with all stakeholders representing the industry and community; modernization and innovation. The criteria are also associated with the ability of an institution to develop through these activities for accepting and maintaining scientific leadership in the given field in the international context. This is closely connected with attracting and developing qualified staff acknowledged experts in both public and private areas.

\section{Conclusions, proposals, recommendations}

The analysis performed in this paper has allowed the author to formulate a few conclusions.

1. Today, there is a tendency to systematize the existing university research assessment methods to be employed in diverse situations and settings.

Research evaluation is executed bearing in mind some internationally accepted research assessment principles; different economic, social, cultural and environmental aspects are in the focus of evaluation. However, every university represents a unique academic community accepting responsibility of the outcome of the conducted research and its impact on the society.

2. Various assessment criteria can be integrated into a university's research strategy, which is part of its overall strategy. Measuring the research performance of con-temporary multi-disciplinary universities calls for applying new "multi-factorial" and multi-dimensional assessments those, which involve a complex set of criteria. So, the research performance assessment becomes "multiple criteria" evaluation, the choice of assessment indicators being dependent on the goals set by experts, as well as different contextual factors.

3. Owing to differences in disciplinary research practice, institutional culture, external environment forces, numerous classifications are recognized by national and international experts. The assessment criteria used today include a wide assortment of quantitative conventional and alternative ("next-generation") metrics. A set of qualitative criteria are also employed for evaluating and explaining qualitative impacts.

4. The research performance evaluation procedure in a university was once formalized through Research Assessment Exercises (substituted by the Research Excellence Framework) - an assessment of research quality in universities against international standards of excellence. As modern universities are complex multifaceted systems, no perfect evaluation scheme exists. Though the RAE system has outlasted its useful-ness, the criteria once applied by panel experts can serve as a good foundation for developing an advanced assessment system comprising elements of different modern evaluation procedures based on international cooperation and globalization of re-search supported by ICTs, and embracing all forms of scientific knowledge. 
5. The research results might be useful for the university policymakers, whose main responsibility is to ensure that the research is optimal (and properly linked with institutional teaching activities) in the context of improving their university's rankings in the extremely competitive global $21^{\text {st }}$ century education market. However, to generalize the findings beyond the study's parameters it is recommended to explore and compare more research performance evaluation systems, approaches and methods applied internationally in the higher education area.

\section{Bibliography}

Abramo, G., D’Angelo, C. A., 2015. Evaluating University Research: Same Performance Indicator, Different Rankings. Journal of Informetrics, 9(3), 514-525.

Arnold, E., Knee, P., 2013. Latvia: Research Assessment Exercise Methodology. Technopolis |Group|. [Online] Available at: https://www.cfi.lu.lv/fileadmin/user_upload/lu_portal/projekti/cfi/Citi_dokumenti/Starptautiskais_izvertejums/Methodology_of_the_assessment.p df [Accessed 11 September 2020].

Arnold, E., Knee, P., Angelis, J., Giarraca, F., Grinice, E., Jávorka, Z., 2014. Latvia: Research Assessment Exercise. Summary Report. Technopolis |Group|. [Online] Available at: https://www.technopolis-group.com/wp-content/uploads/2017/09/1843-Latvia-RAE-2014-Summary-Reportextended.pdf [Accessed 12 September 2020].

AUBR, 2010. Assessing Europe's University-Based Research. European Commission. Expert Group on the Assessment of University-Based Research. Luxembourg: Publications Office of the European Union. [Online] Available at: https://ec.europa.eu/research/sciencesociety/document_library/pdf_06/assessing-europe-university-based-research_en.pdf [Accessed 30 August 2020].

Bush, T., 2007. Educational Leadership and Management: Theory, Policy, and Practice. South African Journal of Education, 27(3), 391-406.

Cabral, A.P., Huet, I., 2014. Assessment of Research Quality in Higher Education: Contribution for an Institutional Framework. Procedia - Social and Behavioral Sciences, 116, 1528-1532.

Das, A.K., 2015. Introduction to Research Evaluation Metrics and Related Indicators. In: Mishra, S., Sen, B.K. (eds.), Open Access for Researchers, Module 4: Research Evaluation Metrics. Paris: UNESCO, 5-18.

Dowsett, L., 2020. Global University Rankings and Strategic Planning: A Case Study of Australian Institutional Performance. Journal of Higher Education Policy and Management (1), 1360-1380. DOI: 10.1080/1360080X.2019.

Eastman, J., 2003. Strategic Management of Universities? CSSHE Professional File, Fall 2003, 1-56. [Online] Available at: http://www.csshescees.ca/pf/PF_24\%20_Eastman.pdf [Accessed 17 August 2020].

Edling, C., Ballabriga Clavería, F., Furlong, J., Hartman, T., Hay, C., Wieruszewski, R., 2013. Latvia. Research Assessment Exercise Panel Report: Social Sciences. Technopolis |Group|. [Online] Available at: http://www.izm.gov.lv/images/zinatne/ZISI/zisi_09.pdf [Accessed 15 September 2020].

European Commission, 2000. Towards European Research Area. Brussels. Communication from the Commission to the Council, the European Parliament, the Economic and Social Committee and the Committee of the Regions. [Online] Available at: http://www.aic.lv/ace/ace_disk/Bologna/contrib/EU/Toward_EResArea.pdf [Accessed 16 September 2020].

European Commission, 2010. Assessing Europe's University-Based Research. Brussels: Directorate-General for Research. [Online] Available at: https://ec.europa.eu/research/science-society/document_library/pdf_06/assessing-europe-university-based-research_en.pdf [Accessed 10 September 2020].

European Commission, 2015. Value of Research. Policy Paper by the Research, Innovation, and Science Policy Experts (RISE). Brussels: Directorate-General for Research. [Online] Available at: https://ec.europa.eu/research/innovation-union/pdf/expert-groups/rise/georghiouvalue_research.pdf [Accessed 11 September 2020].

European Commission, 2017. Communication from the Commission to the European Parliament, the Council, the European Economic and Social Committee and the Committee of the Regions A renewed EU agenda for higher education $\{\mathrm{COM}(2017) 247$ final $\}$. [Online] Available at: https://eurlex.europa.eu/legal-content/EN/TXT/PDF/?uri=CELEX:52017SC0164\&from=EN [Accessed 13 September 2020].

European Commission, 2019. European Universities. A Key Pillar of the European EducationAarea. [Online] Available at: https://ec.europa.eu/education/sites/education/files/document-library-docs/european-universities-initiative-factsheet.pdf [Accessed 07 September 2020].

European Commission Expert Group on Altmetrics, 2017. Next-Generation Metrics: Responsible Metrics and Evaluation for Open Science. Luxembourg: Publications Office of the European Union. [Online] Available at: https://ec.europa.eu/research/openscience/pdf/report.pdf [Accessed 18 September 2020]. 
Eurydice Report, 2015. Assuring quality in Education: Policies and Approaches to School Evaluation in Europe. Luxembourg: Publications Office of the European Union. Anline] Available https://www.educationforallinindia.com/2015\%20Eurydice\%20Assuring\%20Quality\%20in\%20Edn.pdf [Accessed 19 September 2020].

European University Association, 2018. EUA Roadmap on Research Assessment in the Transition to Open Science. Brussels: EUA. [Online] Available at: https://eua.eu/resources/publications/316:eua-roadmap-on-research-assessment-in-the-transition-to-open-science.html [Accessed 05 September 2020].

Finch, D., McDonald, S., Staple, J., 2013. Reputational Interdependence: An Examination of Category Reputation in Higher Education. Journal of Marketing for Higher Education, 23(1), 35-36.

Gunnarsson, M., 2012. Research Strategies at Universities. A Brief Survey of Research Strategies at Institutional and Departmental Level. REPORT 2012:01. University of Gothenburg. [Online] Available at: https://medarbetarportalen.gu.se/digitalAssets/1364/1364330_rapport2012-01_researchstrategies.pdf [Accessed 15 September 2020].

Helerea, E., Popescu, M., Coman, C., 2007. Enhancing Academic Research \& Education Synergy - Transilvania University. In D. Talaba, H. ten Thij (Eds.), Teaching and Research Synergy in the Context of University-Industry Cooperation. Eindhoven: ZkP - Chevalier de Seyn Publishers, 76-83.

Hitt, M., A., Ireland, R., D., Hoskinsson, R., E., 2016. Strategic Management. Competitiveness and Globalization (12th ed.). Boston: Cengage Learning.

Johnson, A., M., 2013. Improving Your Research Management: A Guide for Senior University Research Managers. Amsterdam: Elsevier B.V.

Kettunen, J. Strategy and Quality Maps in Higher Education, 2011. US-China Education Review, 8(2), 149-156.

Knee, P., Angelis, J., Giarraca, F., Grinice, E., Reid, A., 2014. Latvia. Innovation System Review and Research Assessment Exercise: Final Report technopolis |group|. [Online] Available at: http://izm.gov.lv/images/zinatne/ZISI/Latvia-systems-review_2014.pdf [Accessed 02 September 2020]

Moed, H., Plume, A., 2011. The Multi-Dimensional Research Assessment Matrix. In H. Moed (ed.), Research Trends Issue, 23 May 2011 , 5-7. [Online] Available at: https://www.researchtrends.com/wp-content/uploads/2011/06/Research_Trends_Issue23.pdf [Accessed 11 September 2020].

Mohrman, K., Mab, W., Baker, D., 2008. The Research University in Transition: The Emerging Global Model. Higher Education Policy, $21,5-27$.

Moldovan, L., 2012. Integration of Strategic Management and Quality Assurance in the Romanian Higher Education, Proceedings of the 8th International Strategic Management Conference: Procedia - Social and Behavioral Sciences, 58, 1458-1465. DOI:10.1016/j.sbspro.2012.09.1132.

Mourad, M., Ennew, Ch., Kortam, W., 2011. Brand Equity in Higher Education. Marketing Intelligence \& Planning, 29(4), 403-420. DOI:10.1108/02634501111138563.

OECD, 2005. University Research Management: Developing Research in New Institutions: Executive Summary. [Online] Available at: http://www.oecd.org/education/skills-beyond-school/35536621.pdf [Accessed 22 August 2020].

Perrott, R., Bacha, S., Berggren, M., Deleonibus, S., Katgerman, L., Sierens, R., Triantafillou, Th., 2013. Latvia. Research Assessment Exercise Panel Report: Engineering and Computer Science. technopolis |group|. [Online] Available at: https://www.izm.gov.lv/images/zinatne/ZISI/zisi_05.pdf [Accessed 10 September 2020].

RAE, 2008. Research Assessment Exercise 2008: the Outcome. Bristol: Northavon House. [Online] Available at: https://www.rae.ac.uk/results/outstore/RAEOutcomeFull.pdf [Accessed 29August 2020].

Rip, A., 2011. The Future of Research Universities. Prometheus, 29, 443-453. DOI:10.1080/08109028.2011.639566.

Saene, B., Borrell-Damián, L., 2019. Reflections on University Research Assessment: Key concepts, Issues and Actors. EUA Briefing. Brussels:

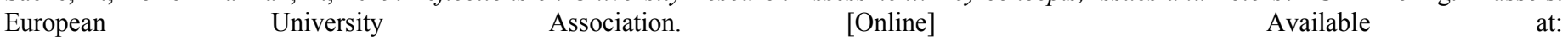
https://eua.eu/downloads/publications/reflections\%20on\%20university $\% 20$ research $\% 20$ assessment $\% 20$ key $\% 20$ concepts\%20issues $\% 20$ and $\% 20$ ac tors.pdf [Accessed 12 September 2020].

Segal, N., Koleva, D., Sausverde, E., Larsen, S.E., Blockmans, W., 2013. Latvia. Research Assessment Exercise Panel Report: Humanities technopolis |group|. [Online] Available at: http://www.izm.gov.lv/images/zinatne/ZISI/zisi_06.pdf [Accessed 14 September 2020]

Standards and Guidelines for Quality Assurance in the European Higher Education Area, 2015. Belgium: EURASHE. [Online] Available at: https://enqa.eu/wp-content/uploads/2015/11/ESG_2015.pdf [Accessed 14 August 2020].

Stukalina, Y., 2019. Marketing in Higher Education: Promoting Educational Services and Programmes. Proceedings of the International Scientific Conference Contemporary Issues in Business, Management and Economics Engineering. Vilnius, Lithuania, 616-624. 
Taylor, J., 2006. Managing the Unmanageable. The Management of Research in Research-Intensive Universities. Higher Education Management and Policy, 18(2), 1-25.

The European Higher Education Area in 2018. Bologna Process Implementation Report, 2018. Luxembourg: Publications Office of the European Union. [Online] Available at: https://eacea.ec.europa.eu/national-policies/eurydice/sites/eurydice/files/bologna_internet_0.pdf [Accessed 18 August 2020].

Walcott-Skinner, I., 2003. The Commoditization of Higher Education \& the E-Learning Revolution: Conference Paper. 10th Cambridge International Conference on Open \& Distance Education. Cambridge, UK, June 2003, 1-5.

Watson, D., 2000. Managing Strategy. Buckingham: Open University Press. 


\title{
PERCEPTION
}

\author{
Ekaterina Usacheva, North-West Institute of Management, branch of RANEPA \\ Aleksey Chechulin, North-West Institute of Management, branch of RANEPA \\ Nikita Grishanin, North-West Institute of Management, branch of RANEPA
}

\begin{abstract}
With the growing popularity of Internet communications, an interest arises in focus groups for measuring the quality parameters of websites, for receiving feedback from users on the website relevance to its goals, content value, and on users' evaluation of the website design and technical characteristics. This article presents the analysis results of the official tourism website of a large city as a central element in the marketing communicationssystem. Focus groups were used as a method for gathering qualitative data on originality, usability, designsolutions for the official city tourism portal "Visit Petersburg". Focus groups were conducted online on the Zoom platform. Each participanthad an opportunity to get acquainted with the website, as well as try to solve a problem of planning a route to explore the city sights. Focus groups included people with experience in independent travel planning, active Internet users and people who are familiar with St Petersburg, which was necessary to assess the relevance of the studied results. The data obtained and conclusions drawn by the authors made it possible to develop several specific recommendations for improving the St. Petersburg official tourism website.
\end{abstract}

Keywords: St. Petersburg, official tourism websites, online focus groups, marketing communications strategy.

JEL code: L83, M31, M38

\section{Introduction}

An intangible nature of a tourism product makes the marketing communications quality especially important in creating the tourism product. The tourism industry is heavily affected by digitalization and implements new tools faster than in many other industries (Alcántara -Pilar J.M., S del Barrio-García, Crespo-Almendros E. \&Porcu L., 2017).

In most cases success in attracting and retaining tourist interest in tourism destinations depends not only on the wealth of resources, but on the professionalism of industry managers and specialists, as well as on the ability to use the latest technologies in promotion. The International Economic Forum experts claim that to maintain competitiveness, tourism industry players must implement digital technologies in their work as widely as possible. These are information and communication technologies (ICT) that currently enable us to personalize services and adapt tourism destination offer to the preferences of modern tourists.

To a large extent, the complexity of creating and promoting a tourism product stems from its nature. A tourism product by nature is multicomponent. It includes a wide range of consumer values (benefits) designed to meet not only the tourists needs, both before and during travel, but also those related to it (Xu, Jing Bill, 2010, Mckercher B., 2016, Kotler P., Bowen J.T. \& Makens J.C., 2017, AL-hazmi N.M. \& Hassan Y.A.H., 2020). The active growth in the percentage of tourists planning the trips on their own makes it possible to organize communication in such a way as to enable the modern consumer to receive the most relevant and useful information about tourism products, services and products related to the trip organization and completing.

Studies show that the official Internet websites developed and managed by regional and local authorities are highly important source of information on tourism destinations. The importance is explained by the fact that the official resource generates greater trust, particularly among older audience.Currently, the quality of a product in tourism, attractiveness for tourists, and the decision to travel, directly depend on the functionality and usability of the tourism websites (Tan F.B. \& Sutherland P., 2006, Minghetti V. \& Buhalis D., 2010, Lepp A., Gibson H.J. \& Lane C., 2014).

The article presents the analysis of the official tourism website of a large city as an important element in the marketing communicationssystem. An analysis of the quality characteristics and potential consumers perception of the official tourism portal "VisitPetersburg" (http://www.visitpetersburg.ru/) was performed based on the focus group method.The founders and administrators of the portal "VisitPetersburg" are St. Petersburg executive authorities.

The research starts with a literature review that supports the developed hypotheses:

- In most modern countries focused on tourism development, state authorities and local authorities not only regulate and strategically manage the development of tourism, but also actively participate in the creating and promoting territorial tourism products.Official information resources of tourism destinations are becoming one of the key tools for building marketing communications in modern conditions. Since the official status of 
such Internet resources to a large extent determines the high level of confidence in the information posted, it is vital that such websites contain the highest quality and relevant information.At the same time, official websites, pursuing the pragmatic goals of attracting new tourists, growing and stimulating demand, should be as user-friendly as possible.

- Traditional methods of online analytics, web traffic analysis and other website quantitative indicators do not always reflect the consumers' perception of the provided information. The active development of online platforms and services for group interaction makes it possible to use focus group method in the practice of evaluating the perception of websites by target audiences. Online focus groups allow not only to ensure sufficient representativeness and quality of the information received, but also to save time and research resources.

- Target audiences do not always understand and correctly perceive the targets set by the website developers. If the method is correctly implemented, the focus group allows you to evaluate how consumers perceive the website at first glance, how they perceive the value of the product and how comfortable they are with the proposed design, style and technical solutions of the website.

\section{Literature Review}

Changes in the consumer behaviour and demand under the influence of the fourth industrial revolution, online communications impact on consumer behaviour, importance of new online interaction formats with customers are discussed in the widely recognized works of Stelzner M., 2012, Schwab K., 2016. Tourism product influences the target audience through online communications. The success depends on the ability to convey marketing message in a way that at each point of contact this message works to convince the consumer of the offered product advantages (Tan F.B. \& Sutherland P., 2006, Minghetti V., Buhalis D., 2010, Jacobsen J., Munar A. M., 2012, Agarwal S., Raychaudhuri P.s. 2019).

The role and importance of official tourism websites in promoting countries, cities as tourism destinations are increasingly becoming the subject of scientific and applied research (Baggio R., 2003, Md J., Md. \& Awang-Shuib A.R., 2011, Kr., Li \& X., Wang, Y., 2011, Lepp A., Gibson H.J. \& Lane C., 2014, Chechulin A. V., Kuznecov A. L., Grakhov V. P. \& Perfil'eva M. B., 2020, Kanazawa F.N., Lourencao M., Oliveira J.H.C. \& Giraldi J.M.E., 2021, etc.).

The approaches and experience of websites empirical researches including those that provide information about the tourism product of destinations are discussed in the works of Engholm I. \&Klastrup L., 2010, Saroj R., 2012, Magnini V.P. \&Fesenmaier D.R., 2014, Der ZeeE., GerretsA.-M. \& Vanneste D., 2017, Jażdżewska I.\&Jagnuszewska A., 2017, etc.

Within the framework of marketing research aimed at studying the consumers'opinion and their perception of the website information, as well as within such methods of analysis as Customer Development, UX research, there is an active discussion about the possibilities and prospects of focus groups method. The problem is that it is difficult to find a method more often criticized, the value of which is most often doubted (Woodyatt C.R., Finneran C. \& Stephenson R., 2016).

Focus Group is a synthetic method that combines qualitative and quantitative approaches to data collection with a clear gravitation towards qualitative technologies. The focus group is based on a special form of in-depth group interview conducted in the group. The application of this method involves group discussion under the guidance of a specialist (moderator). Thus, the first challenge is the correct organization of the interview procedure, the development of the guide and the ability to use the effects of group dynamics in the discussion. Group interaction makes it possible to reveal not only people's opinions but also deepen layers of their motivation, their experiences, feelings and expectations in particular. At the same time, it is necessary to avoid distortions that may occur as a result of the group members' influence on each other's opinions.

The second equally important issue that determines the result quality is the correct selection of focus group participants, determination of the groups number within one study. As a rule, 3-4 focus groups are conducted within one marketing study (Guest G., Namey E. \& McKenna K., 2016). The study of practical cases suggests that the solution options may vary from determining rigid characteristics of participants (e.g., gender, age, lifestyle, etc.) to their random selection.In practice, group interviews and focus groups sometimes deliberately achieve age and gender homogeneity, and sometimes, conversely, bringtogether participantswith different experiences in order to get more information into the discussion. It depends on the tasks and experience of the moderator.The decision on participants selection in each specific case depends on the identified determinant and determinable factors.These factors (called variables) are categories of experimental analysis and should therefore be systematically presented (operationalized) in the research program. The quality of the focus group results depends on two key factors: the proper selection of focus group participants and the professionalism of moderators. Researchers should be familiar with the skills of competent combining tools for collecting qualitative and quantitative information, as well as the skills of moderating group discussions. Researchers study approaches to the organization and basis of conducting focus groups as a part of training courses for sociologists and marketers, and necessarily include them in training manuals 
for conducting sociological and marketing research. Scientists also actively discuss them in modern periodicals. For example, in articles by Hyman M.R., SierraJ.J., 2016, Hutchinson J., 2016, Canipe M.M., 2020.

In addition, we should mention the papers dedicated to the possibilities of focus groups in conducting online research, which in the current difficult conditions are becoming increasingly relevant (Calitz A., 2011, Link A., Dinsmore S., 2012, Stewart D.W., Shamdasani P. 2016, Brendan R., 2019). Until recently, researchers rarely used focus group method in the practice of evaluating the perception of websites by target audiences.First of all, because it was quite problematic and costly to gather a group of participants and to ensure correct conditions for offline discussion (e.g., room, video and audio recording). However, the development of online platforms and services for conferences and group work changes the situation dramatically.The growing popularity of focus groups for testing websites has led to a creation of services such as askusers.ru, usabilla.com, sitepolice.ru etc.

\section{Research resultsand discussion}

Within the frames of this research the focus group method was used to conduct the quality review of the St. Petersburg official tourism portal of "VisitPetersburg" as a central element in the marketing communications system of the tourism destination.The tourism portal "VisitPetersburg" (http://www.visit-petersburg.ru/) was created and administered by St. Petersburg executive authorities. The purpose of the research was to evaluate users' perception of the portal concept, clarity and value of the product, design and aesthetic component of the website, as well as its convenience for users while solving the specific task of building individual tourist route to explore the city sights.

1.Description of the focus group procedure

The research included 4 focus groups. The number of participants ranged from 8 to 10 people $(8,8,10,8$ participants). During the research, the following criteria were set for the selection of focus group participants: age (from 21 to 45 years); education (at least a bachelor's level); experience and activity of using Internet, experience of independent travel planning, knowledge of the city (which allowed participants to evaluate the website offer from the standpoint of first-hand experience). Each of the four groups included one participant with the experience in website development who acted as an expert within the group.

Focus groups were conducted online on the Zoom platform. Two moderators, who worked in pairs, participated in the focus group. The first moderator performed all communications with focus group participants, explained the rules and led the discussion. The functions of the second moderator were to control the modus operandi, timing, conference administration and recording of the discussion.

The focus group guide is presented in the model (Table 1). 
Focus group guide model (duration 1 hour)

\begin{tabular}{|c|c|c|c|}
\hline No. & Focus groups stages & $\begin{array}{l}\text { Subprocesses, operations and roles } \\
\text { of participants in the discussion }\end{array}$ & Comments \\
\hline \multicolumn{4}{|c|}{ Stage 1 - Introduction to the discussion. } \\
\hline 1. & Organizational aspect & $\begin{array}{l}\text { Moderator } 1 . \\
\text { 1. Presentation of participants } \\
\text { 2. Presentation of the format } \\
\text { 3. Introduction to the website }\end{array}$ & $\begin{array}{l}\text { While presenting the participants, the groups attention } \\
\text { focused to the participant who takes a role of a group expert. } \\
\text { Before the discussion started, participants had time to study } \\
\text { the website }(7 \mathrm{~min}) \text {. }\end{array}$ \\
\hline \multicolumn{4}{|c|}{ Stage 2 -Group work and discussion } \\
\hline 2. & $\begin{array}{l}\text { A problem statement and } \\
\text { defining objective of the } \\
\text { discussion }\end{array}$ & $\begin{array}{l}\text { Moderator } 1 \text { formulates the problem: } \\
\text { How useful is the website when planning } \\
\text { a route to explore the sights of the city? }\end{array}$ & $\begin{array}{l}\text { The following sections of the website were chosen as the } \\
\text { object of analysis: "Attractions" and the search system "My } \\
\text { Petersburg" }\end{array}$ \\
\hline 3. & $\begin{array}{l}\text { Search tasks and filling } \\
\text { the first part of the } \\
\text { questionnaire }\end{array}$ & $\begin{array}{l}\text { Moderator } 2 \text { sends questionnaires to each } \\
\text { participant. } \\
\text { Moderator } 1 \text { offers to do several tasks to } \\
\text { get familiar with the website (the main } \\
\text { page, website menu, searching, and the } \\
\text { section "Sights"). } \\
\text { Moderator } 1 \text { explains the rules of filling } \\
\text { the questionnaire. }\end{array}$ & $\begin{array}{l}\text { The participants filled in thequestionnaire by in two phases: } \\
\text { 1. Before starting the discussion based on the results of search } \\
\text { tasks. } \\
\text { 2. After a discussion on each of the study aspects/ }\end{array}$ \\
\hline 4. & Group discussion & $\begin{array}{l}\text { Moderator } 1 \text { offers the participants to } \\
\text { exchange opinions and impressions, to } \\
\text { comment on their ratings/ }\end{array}$ & $\begin{array}{l}\text { The participants should consistently discuss all the evaluated } \\
\text { parameters. } \\
\text { The moderator monitors that all group members participate in } \\
\text { the discussion. }\end{array}$ \\
\hline 5. & $\begin{array}{l}\text { Filling the second part of } \\
\text { the questionnaire }\end{array}$ & $\begin{array}{l}\text { Moderator } 1 \text { invites each participant to fill } \\
\text { the questionnaire in to determine if the } \\
\text { group discussion has influenced their } \\
\text { initial impression and assessment. }\end{array}$ & $\begin{array}{l}\text { Moderator } 2 \text { makes sure that the participants do not } \\
\text { communicate with each other while filling the questionnaire } \\
\text { in. }\end{array}$ \\
\hline \multicolumn{4}{|c|}{ Stage 3 -Summary } \\
\hline 6. & Reflection & $\begin{array}{l}\text { Moderator1 invites participants to express } \\
\text { their opinions and share their impressions } \\
\text { about their participation in the focus } \\
\text { group. }\end{array}$ & \\
\hline
\end{tabular}

To collect quantitative information, a questionnaire was developed, which was filled in by participants synchronously according to the guide. The questionnaire included the following evaluated parameters:

- Originality (how unique is the service offering).

- Confidence (does the website create trust in the content).

- Clarity (how clearly the website concept is reflected, whether the concept described by the moderator and set by the creators matches what the website users see).

- Target audience (for whom the website is designed).

- Utility (how much the service satisfies the user's needs).

- Usability (user comfort), including such components as: menu convenience, search system convenience, font convenience, visualization quality (pictures, photos), navigation convenience.

Each parameter was evaluated on a five-point scale (1 - definitely not, 5 - definitely yes). After each evaluation, participants could leave their comments explaining their evaluation in the open question.

The questionnaire was filled in by participants in two phases: before and after performing searching tasks. The difference in the answers made it possible to determine how much the group discussion influenced their opinion. It was important to define clearly how do other participants' experience and the "expert's" opinion influence the assessments of participants. For example, many participants noted that they noticed certain shortcomings and peculiarities of the website only after the discussion within the focus group. 


\section{Research results}

Focus groups participants had the opportunity to evaluate each of the selected parameters twice, correcting their first impression during the discussion. This is where the phenomenon of group interaction is manifested. Common to all four groups was the fact that most participants changed the rating downwards by the end of the discussion. Comparing the evaluations made by the groups, we can notice that the most critical was the focus group 2, which had more participants with experience in developing and promoting Internet resources. The initial evaluations given before the discussion are presented in Fig. 1 (average score for the group). The final average score for the group is shown in Fig. 2.

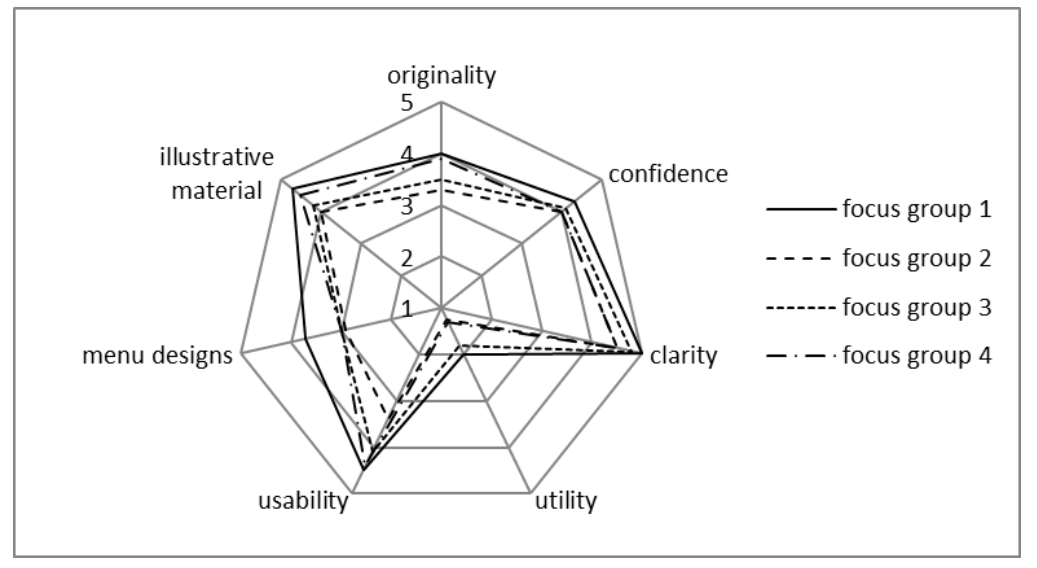

Source: author's construction

Fig.1.Average group evaluations at the initial stage of the research

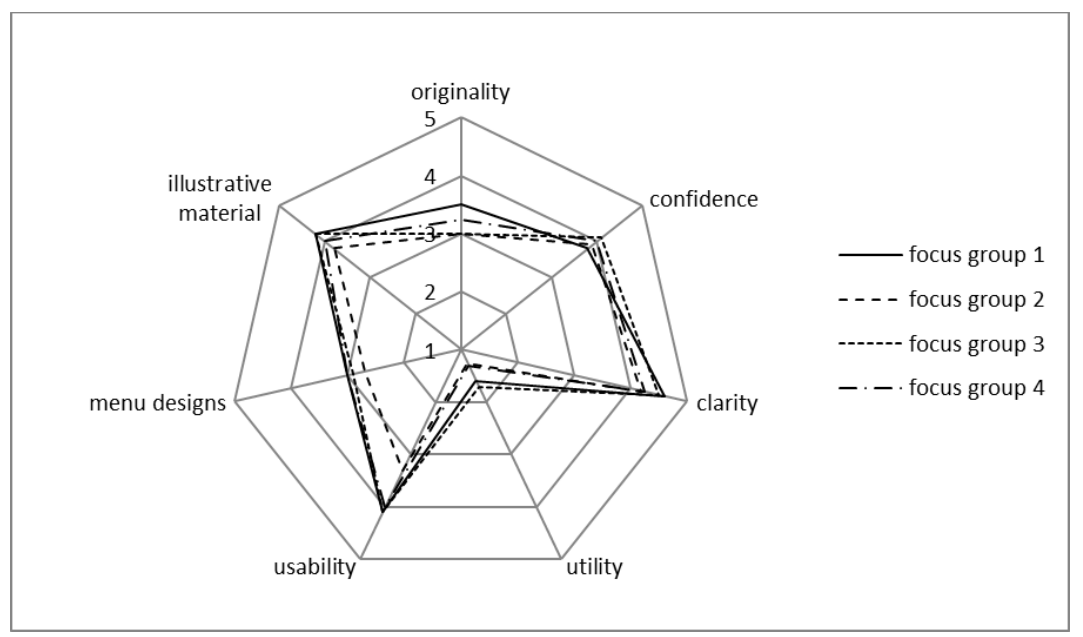

Source: author's construction

Fig. 2.Evaluations after group discussion

The research demonstrated the following results.

1. The moderate originality of the service was evaluated (3 out of 5). During the discussion participants gave examples of similar resources that help tourists to make their own route to explore the sights of the tourism destination, including such resources as Tripadvisor.ru, Booking.com, search engines KudaGo, thematic pages in social networks, such as"EtoPiter, detka" ["This is Peter, baby"] (VKontakte social network).

2. Most participants concluded that the official resourceproviding information about tourism opportunities in St. Petersburg, is in general very useful, as it is credible since it is created and administered by the authorities. However, after testing the website and trying to complete several research tasks, participants (who know the sights of Saint Petersburg) concluded that the website does not provide useful and relevant information, and it is useless for tourists who do not know the city.

3. Clarity / comprehensibility of the website concept was evaluated quite highly at the first phase of the survey (before the discussion). As it follows from the comments to the question, in their assessment the participants focused on the information presented on the main page of the website. After the discussion, this parameter was evaluated almost similarly and varied from 4 to 5 . 
4. The target audience was assessed by the participants according to the parameters specified in the search system on the website "My Petersburg". Some participants noted the availability of different language versions of the website. The participants concluded that the website is designed to the widest possible audience. Also, during the discussion, participants noted that the official resource is more likely to be used by middle-aged and older people.Meanwhile young people who are more accustomed to the Internet search may prefer alternative online resources.

5. The lowest score both at first and second phases of the survey was obtained on the parameter "utility". Evaluating the search system of the website "My Petersburg" the participants noted that the four selected search parameters (budget, level of activity, educationaland entertainment components, age group) are enough for them to make a query. Test searches, however, provided results which participants evaluated as extremely poor ( 1 on average). During the discussion, participants in all four focus groups repeatedly noted ambiguity and even absurdity of the obtained result.

Let us take an example of a search result for the following query: A calm, informative route with an average budget for a family with young children. The search results included such attractions as Raskolnikov House, Shopping Passage, Academy of Arts, Necropolis "Literary Bridges". It is obvious that this choice certainly cannot be appropriate for tourists with young children while, the city offers a huge number of attractions and interesting places suitable for this target audience.

6. The greatest diversity of opinions and the most heated discussions unfolded on the parameter of usability.

User comfort in general was not rated very highly, although almost half of the four groups' participants called it quite adequate in their comments. The following factors seriously reduced the evaluation:

- Overload of information on the main page of the website.

- The need to scroll through the main page to find the search service «My Petersburg».

- Overloaded menu and incomprehensibility of the menu symbols. To get information about the menu particular section name, you need to hover over it. At the same time, not all participants could guess what this or that symbol in the menu meant immediately. The biggest difficulties arose with the identification of such menu sections as: news, from St. Petersburg for 1-day, thematic tourism and search engine.

- The font used on the website (Helvetica) did not cause any serious criticism. Participants noted that the text is easy to read when accessing the website from a home computer.

- The overall impression of the graphics and illustrations on the website was quite positive. However, during the discussion, it turned out that participants noted several serious drawbacks. In all focus groups the participants drew attention to thehigh quality of the presented pictures. At the same time, participants noted that there were too many photos on a single page. Pop-up photo captions were found relevant and helpful to users. However, when the participants were clicking on links posted on a photo, they noted that the title on the photo does not match the content of the link. For example, when clicking on a link to a Palace Bridge photo with the link name "Bridges" it is logical to assume that the user will receive information about the city bridges, the number of which is 342 . However, the dropdown shows the Winter Palace and three main cathedrals of the city first. We can conclude that the content of the links requires further work.

The results of online focus groups allowed to highlight the most poorly designed elements of the website, which require revision and adjustment to improve the resource quality and utility for the target audience.

\section{Conclusions, proposals, recommendations}

1. Despite the attention paid by the authorities of St. Petersburg to the development of official tourism websites, the quality of their execution does not meet the requirements of originality, confidence and utility. Therefore these resources do not fulfill the task of attracting new tourists, growing and the task of stimulating the demand for the tourism product of St. Petersburg.

2. The online resources development for group discussions, conferences and collaborative work makes the focus group method for evaluating websites increasingly in demand. Online work allows setting and ensures compliance with such controlled parameters of focus groups as timing, free exchange of opinions, and comfort of participants (which participants create by themselves, as they access the conference from home, and it does not require additional costs from the organizers). In addition, the online work allows toapply online questionnaire constructors, which facilitates not only collecting quantitative information, but also its processing.

3. While conducting a focus group, it is important to achieve a cumulative effect by using a combination of an in-depth interview method and a group discussion. At the same time, it is important to separate the information that will be obtained as a result of testing the website by users and their assessments after discussion within the group at the initial stage of planning and developing a focus group method. 
4. Evaluating the results of focus groups, one should clearly understand that the main disadvantage of the method is that the opinions expressed by the participants, praise, high evaluations, do not guarantee that the participant will use this website, service, resources or will recommend it to their friends. It is important to understand that criticism is not an immediate signal to change the website content, design and specifications. To make informed decisions, focus group results must be supported by online analytics (attendance, conversion, etc.).

In conclusion, it should be noted that the focus group method is undoubtedly useful for website developers, especially in terms of studying the quality perception of the resource. It is only necessary to clearly separate the statements of the participants from their real consumer behavior and clearly define whether they belong to a group of early adopters of the product or not. To perform this, in-depth interviews should include questions reflecting the experiences and user habits of focus group participants.

\section{Bibliography}

Agarwal S., Raychaudhuri P.S. 2019. Consumer Perception of B2C Websites: an Empirical Study of Delhi. Indian Journal of Marketing, $49(6), 35$. Alcántara -Pilar J.M., S del Barrio-García, Crespo-Almendros E., Porcu L., 2017. Toward an Understanding of Online Information Processing in e-Tourism: does National Culture Matter? Journal of Travel \& Tourism Marketing, 34(8), 1128-1142.

AL-hazmi N.M., Hassan Y.A.H., 2020. Barriers on Marketing Tourism Services and their Impacts on Customer Awareness. Management Science Letters, 10, 2603-2608.

Baggio R., 2003. A Websites Analysis of European Tourism Organizations. Anatolia, 14(2), 93-106.

Calitz A., 2011. The Use of Focus Groups to Improve an e-Government Website. 3rd Symposium on Web Society[Online] Available at: https://www.academia.edu/21680217/The_use_of_focus_groups_to_improve_an_e_Government_website [Accessed 11.10.2020].

Canipe M.M., 2020. Unmoderated Focus Groups as a Tool for Inquiry. Qualitative Report, 25(9), 3361-3368.

Chechulin, A. V., Kuznecov, A. L., Grakhov, V. P., Perfileva M. B., 2020. Communication and MarketingTechnologies of Territory Promotion: Forming Professional Market in Russia. Science and Technique, 19 (2), 125-129.

Der Zee, E., Gerrets, A.-M., Vanneste, D., 2017. Complexity in the Governance of Tourism Networks: Balancing between External Pressure and Internal Expectations. Journal of Destination Marketing \&Management, 6(4), 296-308.

Engholm, I., Klastrup, L., 2010. Websites as Artefacts: a New Model for Website Analysis. New Media and Interactivity.2nd International Conference, Turkey, Istanbul, 28.4-30.5 2010: Proceedings - on New Media and Interactivity (NMIC).

Guest, G., Namey, E., McKenna, K., 2016. How Many FocusGroups Are Enough? Building an Evidence Base for Nonprobability Sample Sizes. Field Methods, 29(1), 1-20.

Hutchinson J., 2016. An Introduction to Digital Media Research Methods: how to Research and the Implications of New Media Data. Communication Research and Practice, 2(1), 1-6.

Hyman, M. R., Sierra, J.J., 2016. Focus Group Interviews. Business Outlook, 14(7), 1-7.

Jacobsen, J. Kr. Munar, A.M., 2012. Tourist Information Search and Destination Choice in a Digital Age. Tourism Management Perspectives, 1, $39-47$.

Jażdżewska, I., Jagnuszewska, A., 2017. Tourism-Themed Internet Portals - are New Media Creating a New Tourist? A Case Study of Polish Students. Bulletin of Geography. Socio-economic Series, 35, 35-44.

Kanazawa, F.N., Lourencao, M., Oliveira, J.H.C., Giraldi, J.M.E., 2021. Destination Website Management: A Social Constructionist Approach. Journal of Destination Marketing and Management, 19, 100545.

Lepp, A., Gibson, H.J., Lane, C., 2014. The Effect of Uganda's Official Tourism Website on Travel Motivations and Constraints. Journal of Travel \& Tourism Marketing, 31, 712-730.

Li, X., Wang, Y., 2011. Measuring the Effectiveness of US Official State Tourism Websites. Journal of Vacation Marketing, 17(4), $287-302$.

Link, A., Dinsmore, S., 2012. Online Focus Groups: Selecting a Platform [Online] Available at: https://www.academia.edu/2064385/Online_Focus_Groups_Selecting_a_Platform [Accessed 11.10.2020].

Mckercher, B., 2016. Towards a Taxonomy of Tourism Products. Tourism Management, 54, 196-208.

Md J., Awang-Shuib A.R., 2011. A Cross-Cultural Web Usability Analysis of Asian Countries' Official Tourism Websites. The WINNERS, 12(2), 142-153. 
Minghetti, V., Buhalis, D., 2010. Digital Divide in Tourism. Journal of Travel Research, 49(3), 267-281.

Richard, B., Sivo., S., Orlowski, M., Ford, R., Murphy, J., Boote, D., Witta, E., 2018. Online Focus Groups: A Valuable Alternative for Hospitality Research? International Journal of Contemporary Hospitality Management, 30(11), 3175-3191.

Saroj, P., 2012. Internet Marketing in Tourism University of Applied Sciences Kerava. [Online] Available at: https://www.theseus.fi/bitstream/handle/10024/60375/Thesis_Saroj.Pradhan.pdf [Accessed 23.09.2019].

Schwab, K., 2016. The Fourth Industrial Revolution. Davos: World Economic Forum, accepted 16.09.2019.

Stelzner, M., 2012. Content-Marketing. New Methods Attracting Customers in Era Internet. Moscow: Mann, Ivanov \& Ferber.

Tan, F.B., Sutherland, P. 2006. Online Consumer Trust. Journal of Electronic Commerce in Organizations, 2(3), 40-58.

Woodyatt, C.R., Finneran, C., Stephenson, R., 2016. In-Person Versus Online Focus Group Discussions: A Comparative Analysis of Data Quality. Qualitative Health Research, 26(6), 741-749.

World Economic Forum, 2019. The Travel \& Tourism Competitiveness Report 2019[Online] Available at: https://www.weforum.org/reports/thetravel-tourism-competitiveness-report-2019 [Accessed 11.10.2020].

Xu, J. B., 2010. Perceptions of Tourism Products. Tourism Management, 31(5), 607-610. 


\title{
CENTRAL BANK DIGITAL CURRENCIES: THE HISTORICAL VIEW, TECHOLOGIES AND PERSPECTIVES
}

\author{
Aliaksei Varonin, Polotsk State University \\ Siarhei Baslaviak, Polotsk State University
}

\begin{abstract}
Central bank digital currency (CBDC) can be considered as a digital form of central bank money denominated in the national unit of account that is a direct liability of the central bank._CBDC essentially differs from other forms of digital or virtual currencies, including cryptocurrencies such as bitcoin and "stablecoins", which are not issued by central banks or typically considered legal tender.

Although the phenomenon of CBDC has been partly characterized in academic papers, the aim of the paper is to show the complex view on CBDC through the prism of historical perspective and to propose the main directions of further CBDCs development. The research methods used in this paper are comprehensive literature analysis, scientific abstraction, comparative analysis.

The paper concentrates mostly on intrinsic nature of CBDC and presents the results of historical analysis of monetary and payment systems trends, the overview of CBDC types and tools, and the experience of most advanced CBDC projects.

The findings may help financial institutions to make proper decisions on the different CBDC types, improve their approaches to digital technologies and form more active many-sided cooperation. A proposed logical framework of the analysis might be useful for the conducting similar studies.
\end{abstract}

Keywords: Central bank digital currency, cryptocurrency, distributed ledger technology, payment system.

JEL Code: E58, E59, G21

\section{Introduction}

The importance of CBDC for modern-day central banking cannot be underestimated. Today, the possibility for issuing CBDC is a highly relevant issue among economists and monetary regulators around the world. The interest in CBDC problem issues is not only due to the opportunities provided by new technologies in order to increase the efficiency of the monetary and credit and payment systems. It is also due to the concerns of international financial institutions, such as the International Monetary Fund, the Bank for International Settlements, the European Central Bank, the Federal Reserve and others regarding the stability of national monetary systems and the future of central bank money.

The Covid-19 pandemic has highlighted shortcomings in payments systems and may have strengthened the case for CBDC. During the Covid19 pandemic, social distancing measures, public concerns that cash may transmit the Covid-19 virus have further sped up the shift toward digital payments and may give a further impact to CBDC.

But many issues concerning CBDCs issuance and performing are still under discussion. Therefore, the authors set forward the aim of the research: to show the complex view on CBDC through the prism of historical perspective and to propose the main directions of further CBDCs development.

In order to achieve above-mentioned aim, the following tasks are set out:

- to study the history and the background of cryptocurrencies and digital currencies;

- to make a comprehensive systemic view on CBDC architecture and technologies;

- to study the experience of piloting the most advanced CBDC projects;

- to develop general recommendations for mitigating potential risks and further enhancing CBDC projects.

In the analysis presented in this paper the authors focus mostly on three research gaps: the lack of system approach to the CBDC's appearance in the framework of payment mechanisms evolution, the necessity for central banks to take into account all the types of distributed ledger technologies and the lack of generally accepted rules and regulations for CBDC. Furthermore, the authors intend to demonstrate that the issuance and future performance of CBDC concern not only technological aspects, but they are multidimensional actions, which aim to increase the effectiveness of central banks' monetary policy.

This research is based on a comprehensive review of the literature, central banks' papers and reviews focusing on various aspects of CBDCs. This paper's theoretical and methodological underpinnings are reports provided by International Monetary Fund, World Economic Forum, Bank of International Settlements, numerous central banks' reports, research conducted by academic scientists and representatives of central banks. 


\section{Literature review}

Academic and policy research on CBDC has been conducted since 2014, as has been technological experimentation. More recently, many central banks have been actively evaluating CBDC from different points of view.

CBDC can be considered as a digital form of central bank money denominated in the national unit of account that is a direct liability of the central bank. The recent intense discussion in the research (Auer and Böhme (2020), crypto (Consensys AG (2020), investment (Campbell (2020), Goldman Sachs (2020)), policy (European Central Bank (2020), Bank of England (2020), Bank of Canada (2020)), policy (International Monetary Fund (2020), Bank of International Settlements (2020), World Economic Forum (2020)) spheres show that there is growing traction for a new payment technology such as CBDC.

It is necessary to note that $\mathrm{CBDC}$ projects and the potential of its future usage for proving both domestic and cross-border settlements are heavily discussed recently in numerous reports and papers of central banks and some international financial organisations and associations (World Economic Forum, International Monetary Fund Bank for International Settlements, , etc.) but there is yet an insufficient coverage of these issues in academic papers to solve them in reality .

The recent literature has indicated three main reasons why central banks might consider the future issuance of CBDC:

- the lower demand for fiat money in many countries;

- possible improvements in some aspects in the performance of the payment system;

- potential improvements in monetary policy transmission mechanisms.

As a result, CBDCs have attracted global attention and featured broadly in the world according to central bank communications and public search interest. Many open questions remain intact because no one central bank has finally decided to issue a CBDC. In the growing amount of literature on CBDCs, discussions are concentrated on several fundamental aspects. One is how central banks should create money and whether CBDCs are desirable in that context (Armelius et al. (2020)). Another area is the systemic implications of CBDCs and how to cope with them (Auer and Böhme (2020)). There are also studies on policy design frameworks (Davoodalhosseini and Rivadeneyra (2020), their implications for crosscountry payments (Milkau (2020)), and legal aspects of their issuance (Belke and Beretta (2020)).

Several conclusions can be drawn from the literature review:

1. Literature on CBDC has become abundant in recent years. The wide spread of issues and various aspects of CBDC adoption are discussed but this financial direction needs further detailed study.

2. It is hard to assess the real CBDC impact since there is no practical CBDC experience and consequently no reliable quantitative data except one in China. Thus, the majority of research is theoretical and there is no consensus on the possible CBDC implications for the banking and payment systems.

3. The majority of studies seems to focus on the assessment of the CBDC need and implications for a single country. However, the assessment is much more limited for such ideas as a CBDC for several jurisdictions or multicurrency CBDC.

4. Academic studies on CBDCs are still in their early stages. The central banks' representatives prevailed among researches.

\section{Research results and discussion}

\section{The historical background of CBDC}

The evolution of monetary and payment systems has a rich history and spans a huge period of human existence. Before 9000 B.C., early civilizations used a number of different valuable items such as obsidian, fur, weapon as a bartering tool. Objects that occurred rarely in nature happened to be as units of value for exchange. With the advent of agriculture in the period of $9000-6000$ B.C. livestock and plant products were used as a standard form of barter in many cultures. Bartering was first recorded in Egypt. This system of exchange among humans preceded the use of money.

In Mesopotamia around 3000 B.C. gold and silver began to be traded in the form of metal bars. The value of a metal bar was assessed based on its weight. About 2200 B.C. the Ancient Babylonians created a form of measurement called the "shekel". It was based on a specified amount of weight for different goods. Further, the emergence of the Code of Hammurabi in 1750 B.C. with a number of money-related principles formed the basis for concept of banking and market transactions.

The use of cowry shells as a form of money originated in ancient China during the reign of the Shang dynasty beginning from 1200 B.C. Chinese people chose cowry shells because they were hard to counterfeit and were not easily obtainable deriving from the South of China and the Maldive 
Islands.

As early as 1100 B.C., the Chinese were manufacturing small replicas of goods such as knives and spades cast in bronze that had a symbolic exchange value instead of a practical value. Due to impracticality, these early metal money developed into primitive versions of round coins with holes in the middle that allowed them to be strung (Robertson (2007)).

The next big step occurred in 600 B.C., King Alyattes in Lydia, which is part of present-day Turkey, minted the first official coins made from electrum, a mixture of silver and gold, and featured with picture of a roaring lion's head. Techniques of minting were copied and further improved by the Greek, Persian, Macedonian, and the Roman empires.

Beginning in 118 B.C., leather money was issued in China. It was made from a rare white deerskin in the form of square piece with painted colorful edges. That kind of money could reckoned to be the first ever leather banknote exchanged for goods in a nascent commercial system.

Paper money was the further major step in the evolution of monetary system. The first known paper money was used by the Chinese civilization around 700 A.D. Their appearance was conditioned by a copper shortage and by the heavy weights of coins in large commercial transactions, but their widespread use only became much later. Across the period from 900 A.D. until 1500 A.D., paper money in China grew in production to the level that their value depreciated.

Lands of Medieval Europe were still using metal coins as their only kind of currency that was connected with new sources of precious metals on conquered colonial territories. Silver coin "denarius" introduced by the Frankish king Pepin III after 700 was widely used as the standard medieval coin when gold coins once again became a more accepted standard.

As trade in the Mediterranean world flourished Florence in 1252 launched new high value pure gold coin "florin" which became famously widely respected and accepted across Europe. The Florin turned to be a factor of Italian banking success encouraging international commerce. Venice followed that trend with the introduction of newly minted pure gold coin "ducat" on the same standard of about 3.5 grams. However, minting yards remained highly divided by the lands of French dukes, German bishops and Italian towns.

The travels of the European explorer Marco Polo to China in 1290 introduced the idea of paper money to Europeans in his book "The Travels of Marco Polo" where he was amazed by the idea of printing paper money.

The first handwritten cheque known to be in existence in 1659 in the United Kingdom. It was drawn on Messrs Morris and Clayton, scriveners and bankers based in the City of London, for $£ 400$ made payable to a Mr Delboe and signed by Nicholas Vanacker.

Paper money made its first appearance in Europe in 1661 with first banknotes printed in Sweden by the private bank Stockholms Banco. Banknotes could be exchanged for a stated amount of silver coins held by the bank but soon the bank started issuing unsecured notes so that in a few years the bank collapsed.

In 1696 the Great Recoinage in England accompanied by brilliant ideas of Isaac Newton introduced a technology that automated the production of coins with coin issue speed increased by 10 times.

Simultaneously, due to the Age of European exploration the African market with other regions with no deep-seated system of coinage continued to use cowrie shells as a form of money. As result, the Europeans flooded those markets with shells leading to high inflation.

The Gold Standard introduced in England in 1844 with initiation of the Bank Charter Act that was an innovative concept which combined the best aspects of paper money with gold. According to that Act the Bank of England notes were fully backed by gold. This concept further spread to France, Germany, Switzerland, Belgium and the United States.

The era of telegrams which began with the founding of the New York and Mississippi Valley Printing Telegraph Company further renamed into Western Union helped this company to launch in 1871 the first money transfer service based on the telegraph network.

By the effects of the Great Depression large quantities of gold flowed out from the American Federal Reserve because of people's preference for holding metallic gold instead of paper currency. This event in 1933 led to the suspension by the USA the gold standard when the Roosevelt administration compelled citizens to sell gold to the banks with compensation at the price of 20,67\$ per ounce to revalue it further upwards to $35 \$$ to stimulate economic recovery (Richardson et al. (2013)).

The Bretton Woods Agreement of 1944 created by 44 nations established a new international monetary system led by the United States. As per this system, the US dollar pegged to gold was made the global reserve currency with aim of global stability. In addition, the Agreement created such institutions as the World Bank and the International Monetary Fund launched in 1945 for monitoring this new system.

The first bank card system originated in 1946 when a Brooklyn, New York banker John Biggins launched the "Charg-It" charge metal card. 
When a customer used it for a purchase, the bill was directed to Biggins' bank. Cards worked only at shops located in the near proximity to the card's issuing bank.

The next card milestone came in 1950 with launching of cardboard charge card "The Diners Club" that could be used at multiple locations. This idea came up to Frank McNamara who forgot his wallet during supper at restaurant and after this incident started a company to offer credits to individuals by charging stores a $7 \%$ fee on all purchases and customers to pay a $3 \$$ annual fee.

In 1958, Bank of America introduced the first unsolicited universal credit card with revolving credit "BankAmericard" later known as VISA that was sent through the mail and dropped into mailboxes.

The American Express company took over the charge card idea by launching its own purple paper charge card for travel expenses and introducing the first card made of plastic in 1959 (MacDonald and Tompkins, 2017).

Before 1959 cheques were processed manually when the first cheques using machine readable routing and account information, or MIRC, were printed in the USA. Machine allowed automated sorting and routing of cheques between banks and led to automated central clearing facilities.

Special drawing rights initially pegged to 1 USD and afterwards to a basket of key international currencies were created by the International Monetary Fund in 1969 as units of account and were intended to be an asset held in foreign exchange reserves under the Bretton Woods system. These rights are allocated to countries and cannot be held by private parties.

Regarding the following the development of credit cards, IBM engineer Forrest Parry first implemented a magnetic tape on a plastic card what became a simple and inexpensive way to store account information. In 1971, IBM partnered with the banking industry to develop an international standard for magnetic credit cards.

The Gold Standard within the Bretton Woods system ended in 1971 by Richard Nixon's actions when the US dollar was not anymore convertible to gold. This measure was caused by foreign dollar exceeding. Thus, the international monetary system turned into a fiat one when the US dollar remained the global reserve currency.

In 1973, 239 banks from 15 countries convened to find solution for a common problem of cross-border payment communications. The banks formed a global financial messaging service SWIFT, or the Society for Worldwide Interbank Financial Telecommunication, headquartered in Belgium. This utility allowed to quickly, accurately, and securely send and receive money transfer instructions (MacDonald and Tompkins, 2017).

An early form of the electronic money eCash was presented in 1993 by DigiCash Inc. founded by David Chaum. DigiCash transactions due to a number of cryptographic protocols allowed electronic payments to become untraceable by the issuing bank, the government, or a third party.

As plastic cards became a global standard for debit and credit transactions, a question of security became a larger concern. Several international payment companies agreed to develop smart-card specifications with release of EMV chip technology. The first version of the EMV version debuted in Europe in 1994 by Europay, MasterCard and Visa.

The invention of the World Wide Web gave birth to the online shopping system. In 1994 Pizza Hut adopted the internet-sale model allowing online pizza ordering and sold pepperoni pizza via the internet for the first time.

The first mobile purchasing was introduced by Coca Cola in 1997. The company set up vending machines that allowed their customers to purchase drinks by using text message.

The next pivotal point of electronic online payments was in 1998 when PayPal offered a virtual account for consumers using an email address to send and receive funds what was uniquely different from traditional way over the phone and online credit card processing.

The next viable technology for retail mobile payments was the Near Field Communication technology, or NFC, that uses electromagnetic radio fields to transmit data between two sensors. In 2006 an NFC chip was included in the Nokia 6131 cellular phone.

The new era of digital cryptocurrency appeared with the advent of Bitcoin in 2008 when Satoshi Nakamoto posted a technical paper titled "Bitcoin: A Peer to Peer Electronic Cash System" and launched new network. Bitcoin uses peer-to-peer technology to operate with no central authority by recording all transactions in a public distributed ledger.

The NFC technology for retail ecosystem took another move forward in 2011 when Google launched Google Wallet mobile payments system that held card information on a phone and allowed users to purchase goods at local retailers with a tap a smartphone. In 2014 Apple company followed this example with rolling out Apple Pay.

The Quick Response code system, or QR, invented by Masahiro Hara from the Japanese company Denso Wave found its application in 2011 by Chinese company Alipay. This company adopted QR technology as a mobile payment method which allowed offline stores to accept payment by 
scanning an individual QR code in Alipay Wallet on a phone. In 2014, another Chinese technology giant company Tencent also introduced QR code feature on its messaging app WeChat. As a result mobile payment became the most popular method of payments in China (Scott-Briggs, 2016).

Another digital currency conceived by Jed McCaleb known as Ripple was released in 2012 by Ripple Labs Inc. It aims to enable secure, instant and nearly free global financial transactions with tokens representing fiat currency, cryptocurrency, commodities, or any other unit of value such as frequent flier miles or mobile minutes.

The next step in digital cryptocurrency industry was made by a cryptocurrency researcher and programmer Vitalik Buterin who launched Ethereum via the crowdsale that took place in 2014. Ethereum is an open source public blockchain distributed platform for decentralized applications, decentralized autonomous organizations, and smart contracts.

The next tendency in digital currency area was put by a stablecoin Tether which was issued into circulation by Tether Holdings company with a Hong Kong cryptocurrency exchange platform Bitfinex in 2014. Tether presents a stablecoin designed to be worth $\$ 1.00$, maintaining one dollar in reserves for each tether issued. The success of this project was repeated by other companies with the release of other stablecoins like Dai, USDC, PAX etc (Bigmore, 2018).

In 2019 the American social media company Facebook announced a new project Libra now rebranded into Diem that is a permissioned blockchain payment system with an individual digital wallet. The Libra token is planned to be backed by financial assets such as national currencies in an attempt to avoid volatility.

Following the trend with stablecoins, the US bank J.P.Morgan was the first bank to launch in 2020 a digital coin Liink pegged to the US dollar for interbank payments. This blockchain service enables 400 financial institutions and corporate users from 78 countries to make secure, peer-topeer data transfers with greater speed and control.

Central bank digital currency represents another potential revolutionary innovation. In 2020 China was the first country which tested a pilot project with the digital yuan.

As it can be seen that over the course of time, an established monetary system led to the evolution of the payment system. The development of monetary and payment systems through the historical period from a bartering system to leather money is shown on the figure 1, from paper money to EVM credit and debits plastic cards is shown on the figure 2 and from the first online order to the pilot project with CBDC is shown on the figure 3.

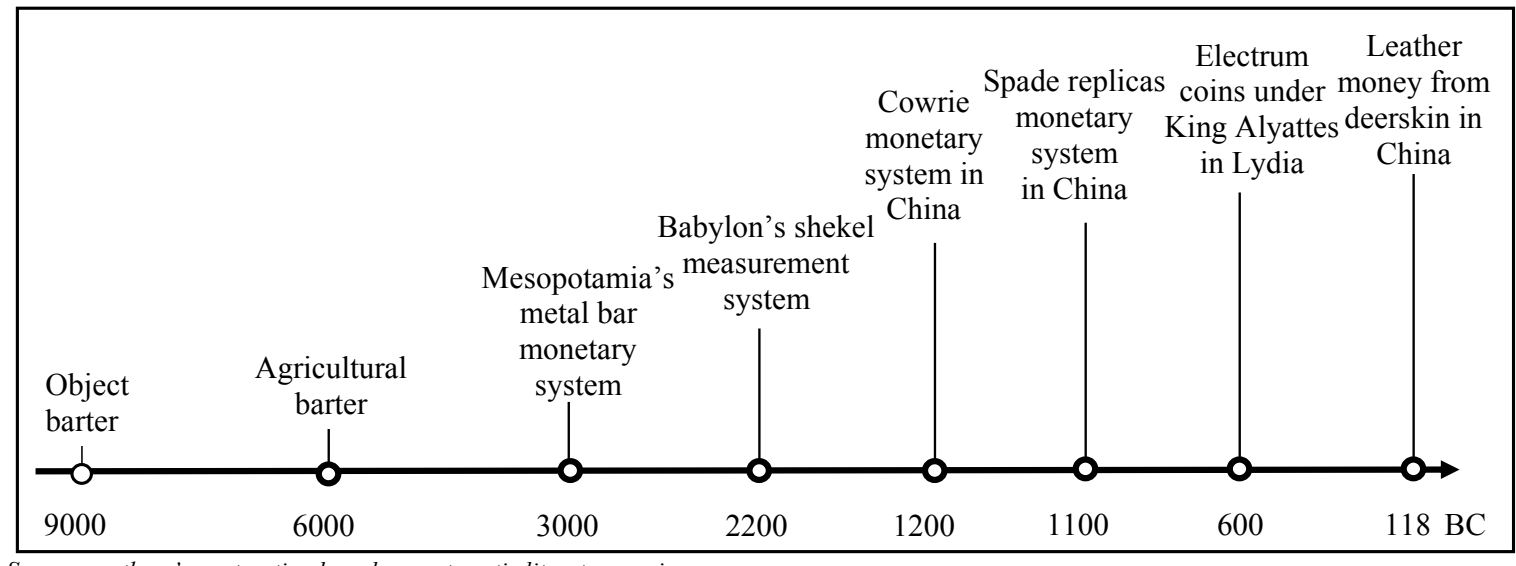

Source: authors' construction based on systematic literature review

Fig. 1. Monetary and payment systems development from bartering to leather money 


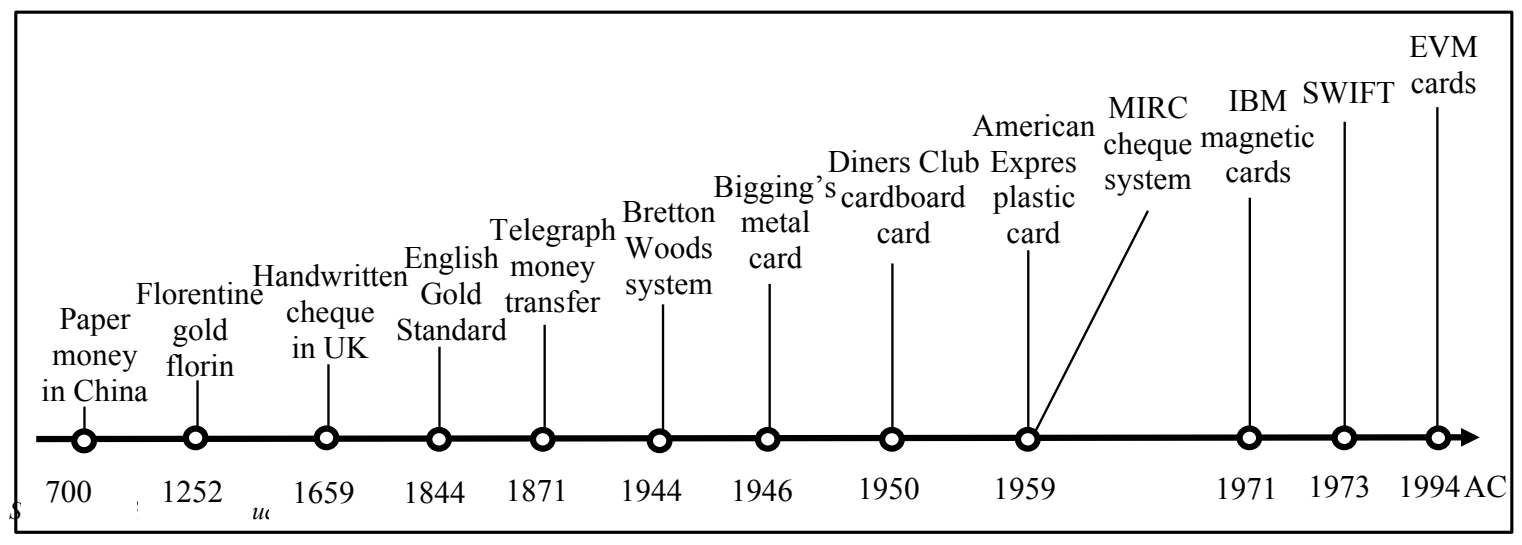

Fig. 2. Monetary and payment systems development from paper money to EVM cards

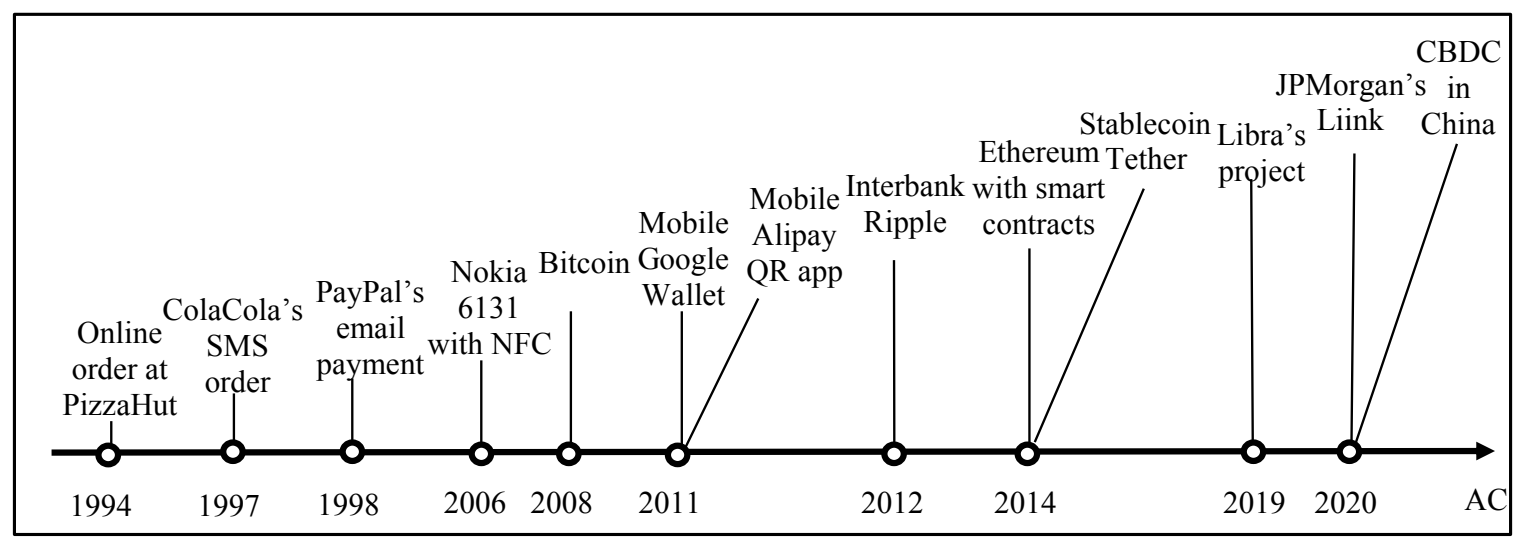

Source: authors' construction based on systematic literature review

Fig. 3. Money and payment systems development from an online order to CBDC

Bartering, metal bars, coins, banknotes, cheques, credit cards, mobile wallets were each innovations in their own day. Many significant changes of the last years in the digital space have required central banks to innovate and evolve in how they met their objectives. A nascent monetary and payment evolution is going through issuing a new form of CBDC money.

The study of these documents and other numerous articles of news agencies on media space made it possible to conclude about some misinterpretations in such terms as "digital currency", "stablecoin", "cryptocurrency" what could mislead a reader. Sometimes "CBDC" could be named as "cryptocurrency", sometimes "stablecoin" could be named as "cryptocurrency" as well. Although the term "CBDC" includes the words "digital currency", CBDC would be something fundamentally different to "cryptocurrencies" as well as stablecoin would be different to "cryptocurrencies" too. At the same time, terms "CBDC", "stablecoin", "cryptocurrency" can all be attributed to "digital currency".

\section{The CBDCs growing popularity}

With the growing popularity of Bitcoin and distributed ledger technology (DLT), a number of central banks have started internal projects to better understand DLT and its potential application to currencies. A recent survey found that $80 \%$ of central banks are engaged in investigating CBDC domestic, bilateral or multilateral pilots and half have progressed past conceptual research to experimenting and running pilots (Bank of International Settlements (2020)). CBDCs are also becoming to receive more attention from the people. In particular, using search frequency data om Google Trends, we can examine this growing global attention. The following chart on figure 4 shows intensity of searches related to a new form of currency. The left panel indicates the historical search frequency for the elapsed 12-month period using search query word "CBDC". The right panel depicts the historical search frequency for the elapsed 12-month period using search query word "Central Bank Digital Currency".

According to the charts, searches jumped significantly with peak in the middle of October what could be explained by the increasing number of thematic reports from banks and publications in the social media space so people showed the relevant interest. The extrapolation of the obtained results with linear trend lines exhibits persistent interest in CBDCs from population. A stratification of two search frequency outcomes on the basis of the world regions showed that the most interested populations in CBDC technology are presented respectively by Republic of Korea, Hong Kong, 
Canada, Singapore, Switzerland and Canada, Great Britain, Australia, USA, Germany what coincides with a high level of CBDC interest from the central banks in these countries.

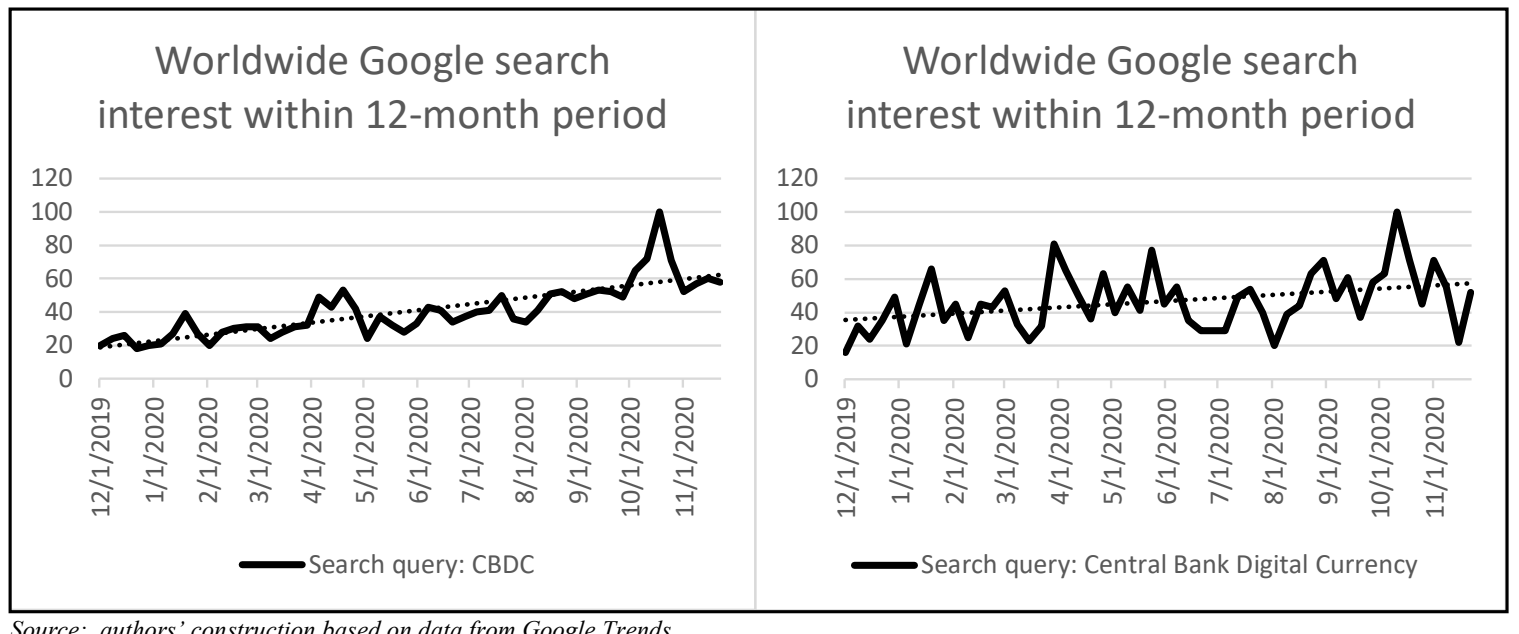

Source: authors' construction based on data from Google Trends

Fig. 4 Search frequency related to CBDC

There are diverse motivations that drive the central banks to be interested in CBDCs. According to the Bank of International Settlements that if the European Central Bank, the Federal Reserve and the other central banks want to continue to ensure financial stability they must adapt their intervention methods to the new digital situation. It was acknowledged that Facebook's Libra stablecoin was the turning point why central banks started working on central bank digital currencies. Also, a pandemic of COVID-19 that contributed to social distancing modified consumers' payment habits and sped up the shift toward digital payments. The need to respond to the declining use of cash in some countries was the reason that a majority of central banks have warmed to the idea of issuing a CBDC.

\section{The overview of CBDC types and tools}

The central banks and other policy-making financial institutions are considering a range of objectives for issuing CBDC. To fulfil the foundational objectives, a potential CBDC would need certain features based on organizational and technical specifications to a central bank side. Since the CBDCs' space is in its infancy, there are yet different approaches in design specifications and various depth levels in design. For instance, one design in comparison to others can have and additional level such as "remunerated"-"unremunerated" CBDCs, there can be met different formulations with similar meaning such as "identity-based", "account-based" or "deposit-based" CBDCs. At the same time, the most widely adapted taxonomy differs four attributes of CBDC technical designs (Auer and Böhme (2020)). Different technical designs satisfy these attributes to varying degrees, depending on whether they feature direct or indirect architecture, a conventional or distributed infrastructure, account- or token-based access, and retail interlinkages across borders.

The direct CBDC represents a direct claim on the central bank that keeps a record of all balances and updates it with every transaction. In the indirect CBDC model, the consumer has a claim on an intermediary, with the central bank keeping track only of wholesale accounts. There can also be a combined hybrid model.

Centralised and DLT-based infrastructures have the main difference between them in how data are updated. Conventional databases with multiple physical nodes are controlled by one authoritative node. DLT-based systems are managed by different parties in a decentralised manner without a top node.

Account-based CBDCs are tied to an identity scheme, which can serve as the basis for well-functioning payments with good law enforcement. Token-based CBDCs allow for value-based payment options, for example pre-paid CBDC banknotes that can be exchanged both physically and digitally.

Cross-border payments' design choice relates to the retail and wholesale interlinkages with accessibility for residents versus non-residents.

This design model can be complemented by such a new design level as programmability. Although, this feature is mentioned in some other reports, but it is highly important to make it one of the focal point and include it into the main design model. This feature that appeared several years ago through the development of Ethereum is the potential to create programmable money. This can be implemented via the use of smart contracts. Advanced smart contracts can be used to automatically initiate payments on the confirmed receipt of goods, or routing tax payments directly to the 
tax authorities, i.e. where payments occur according to specific conditions, rules or events. It is important to think about and include this feature at the beginning on the reason it can affect the implementation and velocity of monetary policy. In addition, this feature on user's side can create the new framework for "decentralized finance" which is widely adopted in the sphere of cryptocurrency.

This approach with one extra additional level on the design model is presented on figure 5 , which shows design choices for the central bank.

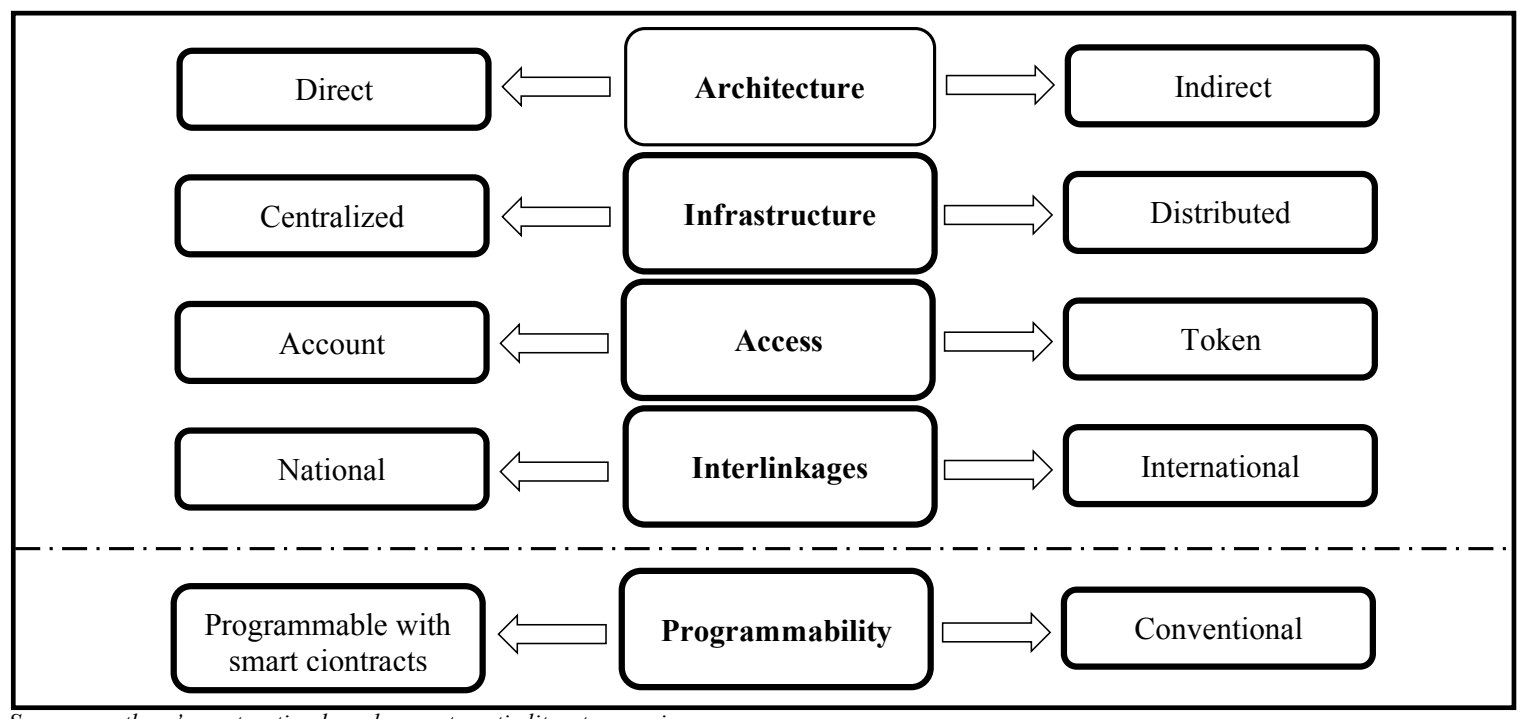

Source: authors' construction based on systematic literature review

Fig. 5. Design model of CBDC

Addressing the infrastructure technology, central banks around the world have been researching and evaluating distributed ledger technology for interbank settlements for several years and they are continuing testing this technology these days (Saudi Central Bank and Central Bank of U.A.E. (2020)). For instance, in their testing the Bank of Canada used the Ethereum and enterprise R3 Corda blockchain platforms, the Bank of Japan and the European Central Bank used enterprise Hyperledger Fabric blockchain platform, the South African Reserve Bank used JPMorgan's Quorum blockchain platform, the Saudi Central Bank and the Central Bank of U.A.E. used mutually R3 Corda, Hyperledger Fabric, and Quorum blockchain platforms, the Banque de France used Tezos blockchain platform.

According to news agencies' information about DLT there can sometimes be noticed misinterpretations in such terms as "decentralized ledger" and "blockchain" aiming to equal these notions. Blockchain was invented as the first representative of decentralized ledger and is only one type of a protocol of a today's decentralized ledger technology. At present, a decentralized ledger technology is a form of digital database composes different types of protocols with pros and cons in their characteristics (Anwar, 2020). So, central banks can consider testing new types of decentralized protocols which allow to speed up transactions and make them more secure. The existing types of DLTs is shown on the figure 6:

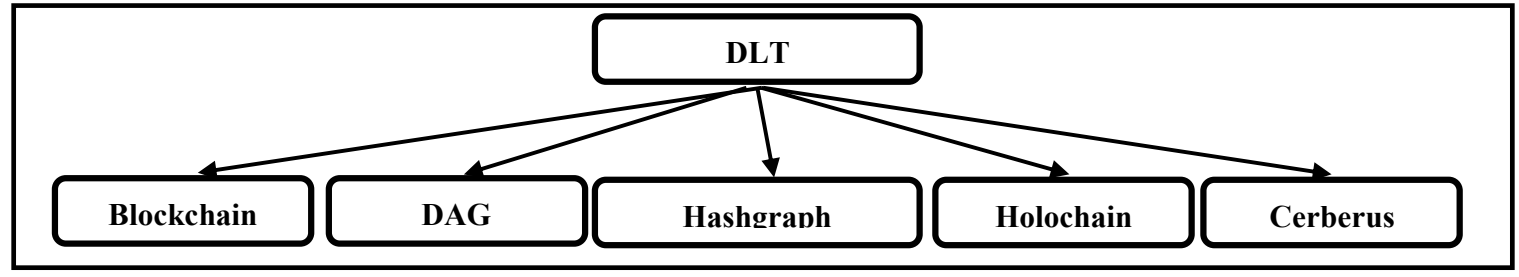

Source: authors' construction based on systematic literature review

Fig. 6. Types of decentralized ledger technologies

\section{The ongoing experience and interoperable challenge of CBDC projects}

Among all countries testing current CBDC projects, China is at the most advanced stage where the pilot project is conducted by the People's Bank of China (PBC). Ones of the most cashless countries in Europe and worldwide are Sweden and Norway. As of 2020, the level of cash usage in Sweden is $9 \%$, in Norway is only 4\%, though in China is $41 \%$ (McKinsey\&Company (2020)).

In accordance with available sources (Fan, (2020), Cheng, (2020)) the architecture of the ongoing Digital Currency and Electronic Payment (DC/EP) project started in 2014 in China is similar to the "hybrid CBDC" model. Most of them are commercial banks and other local payment service providers. The mechanism of the DC/EP is a mixed system with conventional database and DLT. Wallets are based on multiple forms of 
identification, not all of which need to include the name and other personal information. Regarding international interlinkages, the DC/EP would be connected to existing retail and wholesale systems.

Another CBDC project "E-krona" is that of Sveriges Riksbank, the world's oldest central bank, started a project in 2017. The architecture based on a hybrid CBDC. The CBDC is a direct claim on the Riksbank and payments are going to conduct by payment service operators. On the specific design Riksbank researchers note that the ongoing project is a "decentralized database of all e-krona in circulation at any given moment, where the Riksbank verifies all transactions before completion." (Armelius et al. (2020))._The CBDC in the Riksbank's pilot is account-based with a possibility for using low-value token-based prepaid cards. The aims of the Norvegian CBDC project are very similar to those of the Riksbank. The CBDC project is now in its third phase according to the Norges Bank plan (Norges Bank, (2020), Bank of International Settlements (2020)).

The summary of the main key characteristics of three CBDC projects is shown in Table 1

Characteristics of the CBDC projects in China, Sweden and Norway

\begin{tabular}{|c|c|c|c|}
\hline \multirow[t]{2}{*}{ Key characteristics } & \multicolumn{3}{|c|}{ Name of central bank } \\
\hline & PBC & Sveriges Riksbank & Norges Bank \\
\hline Name of the project & DC/EP & E-krona & E-krone \\
\hline Type of digital currency & Retail & Retail & Retail \\
\hline Technology of use & $\begin{array}{l}\text { Semi-account-based } \\
\text { (decentralised) }\end{array}$ & $\begin{array}{l}\text { Account-based } \\
\text { (centralised) }\end{array}$ & $\begin{array}{c}\text { Token-based } \\
\text { (decentralised) }\end{array}$ \\
\hline Storage method & Mobile applications & $\begin{array}{l}\text { Accounts managed by the } \\
\text { central bank / on debit } \\
\text { cards or mobile apps }\end{array}$ & $\begin{array}{l}\text { On debit cards or mobile } \\
\text { applications / on prepaid } \\
\text { cards or sim cards }\end{array}$ \\
\hline Settlement mechanism & $\begin{array}{l}\text { Two-tiered intermediary } \\
\text { model }\end{array}$ & $\begin{array}{c}\text { Possible without } \\
\text { intermediaries in a value- } \\
\text { based model }\end{array}$ & $\begin{array}{c}\text { Possible without } \\
\text { intermediaries in a value- } \\
\text { based model }\end{array}$ \\
\hline
\end{tabular}

Table 1

Source: authors' summary based on Fan, (2020), Cheng, (2020), Armelius et al. (2020), Norges Bank, (2020), BIS (2020)

As it can be seen, that in spite of some similarities the approaches of central banks have significant differences what affects the key characteristics of their CBDCs. That may cause potential interoperable issues with future integration of different domestic CBDC systems in the system of international settlements. In order to resolve this issue, central banks have to establish the uniform technical and organizational standards for CBDC technology. This step requires thorough collaboration between countries not on bilateral basis but on multilateral with the maximum of participants. Central banks may initiate a new proceeding based of the International Organization for Standardization within Technical Committee 68 "Financial Services". The past and ongoing experience of central banks in the development and adoption of ISO 20022, which is an international standard for electronic data interchange between financial institutions, can help in this undertaking. Central banks work in countries with hugely differing financial systems, economies, societies and legal structures. However, given that central banks have common objectives and principles it is possible to harmonize CBDC design for interoperability.

\section{Conclusions, proposals, recommendations}

The main findings of the research are:

1. The consideration of the evolutionary process of monetary and payment systems shows that every new historical innovative breakthrough is accompanied by a shorter time interval. The current digital historic period, which began with the telegraph money transfer in 1871 , has evolved into CBDCs' concept. A further mass rollout and adoption of CBDC is inevitable within the framework of central banks' competitive steps with cryptocurrencies and stablecoins.

2. There are some misinterpretations among the terms "cryptocurrency", "CBDC" and "stablecoin" which can lead to issues of the legal framework. Therefore, the clear and unified definition of CBDC is crucial.

3. It is important to take into account smart contracts and programmability and include these features into the integrated framework of CBDCs design model.

4. The decentralized ledger technologies have their own evolution and regularities of their development. So, central banks can consider testing new types of decentralized protocols which allow to speed up transactions and make them more secure.

5. In spite of some similarities the approaches of central banks have significant differences what affects the key characteristics of their CBDCs. In order to resolve this issue, central banks have to establish the uniform technical and organizational standards for CBDC technology.

\section{Bibliography}


Anwar, H., 2019. Distributed Ledger Technology: Where Technological Revolution Starts. [Online] Available at: https://101blockchains.com/distributed-ledger-technology-dlt [Accessed 28.10.2020].

Armelius, H, Guibourg, G., Johansson, S., Schmalholz, J., 2020. E-Krona Design Models: Pros, Cons and Trade-Offs. Sveriges Riksbank Economic Review. June, 2020. 80-96.

Auer, R., Böhme, R., 2020. The Technology of Retail Central Bank Digital Currency. BIS Quarterly Review, March. 85-100.

Bank of England, 2020. Central Bank Digital Currency. Opportunities, Challenges and Design, March. [Online] Available at: https://www.bankofengland.co.uk/-/media/boe/files/paper/2020/central-bank-digital-currency-opportunities-challenges-and-design.pdf [Accessed 25.10.2020].

Bank of Canada, 2020. Security and Convenience of a Central Bank Digital Currency, October. [Online] Available at: https://www.bankofcanada.ca/wp-content/uploads/2020/10/san2020-21.pdf [Accessed 05.11.2020].

Bank of International Settlements, 2020. Central Bank Digital Currencies: Foundational Principles and Core Features, Octorber. [Online] Available at: https://www.bis.org/publ/othp33.pdf [Accessed 05.11.2020].

Bank of International Settlements, 2020. Rise of the Central Bank Digital Currencies: Drivers, Approaches and Technologies, BIS Working Paper 880. August, 2020. [Online] Available at: https://www.bis.org/publ/work880.pdf [Accessed 12.11.2020].

Belke, A., Beretta, E., 2020. From Cash to Central Bank Digital Currencies and Cryptocurrencies: A Balancing Act between Modernity and Monetary Stability Jourmal of Economic Studies, 47(4), 911-938. DOI: 10.1108/JES-07-2019-0311

Bigmore, R., 2018. A Decade of Cryptocurrency: from Bitcoin to Mining Chips. The Telegraph, 25 May 2018 , [Online] Available at: https://www.telegraph.co.uk/technology/digital-money/the-history-of-cryptocurrency [Accessed 28.10.2020].

Campbell, B., 2020. Bilateral Digital Currency Payments and the Twilight of the Dollar. [Online] Available at: https://doubleline.com/d1/wpcontent/uploads/Bilateral-Digital-Currency-Payments-October-2020.pdf [Accessed 04.11.2020].

Cheng, J., 2020. China Rolls out Pilot Test of Digital Currency. Wall Street Journal, 20 April 2020. [Online] Available at: https://www.wsj.com/articles/china-rolls-out-pilot-test-of-digital-currency-11587385339 [Accessed 25.10.2020].

Consensys AG, 2020. Central Banks and the Future of Digital Money. An Overview and Proposal for Central Bank Digital Currency on the Ethereum Blockchain. January, 2020 [Online] Available at: https://pages.consensys.net/central-banks-and-the-future-of-digital-money [Accessed 23.10.2020].

Goldman Sachs, 2020. Reinventing the Yuan for the Digital Age. [Online] Available at: https://ru.scribd.com/document/485039133/Goldman-Sachsreport-on-China-Financial-Services-Nov-17-2020 [Accessed 15.11.2020]

Fan, Y., 2020. Some Thoughts on CBDC Operations in China [Online] Available at: https://www.centralbanking.com/fintech/cbde/7511376/somethoughts-on-cbdc-operations-in-china [Accessed 03.11.2020]

Davoodalhosseini, S., Rivadeneyra F., 2020. A Policy Framework for e-Money. Canadian Public Policy, 46(1), 94-106.

International Monetary Fund Working Paper, 2020. A Survey of Research on Retail Central Bank Digital Currency. June 2020. [Online] Available at: https://www.imf.org/-/media/Files/Publications/WP/2020/English/wpiea2020104-print-pdf.ashx, [Accessed 23.10.2020].

MacDonald, J, Tompkins, T., 2017. The History of Credit Cards. [Online] Available at: https://www.creditcards.com/credit-card-news/history-ofcredit-cards [Accessed 23.10.2020].

Milkau, U., 2019. International Payments: Current Alternatives and their Drivers. Journal of Payments Strategy \& Systems, 13(3), $201-216$.

Norges Bank, 2020. Status Report - Norges Bank's Central Bank Digital Currency Project. Papers No 2 [Online] Available at: https://static.norgesbank.no/contentassets/8bb6f72b5cca45659fce4eb6aa93b7a1/norges-bank-memo-2_2020-eng.pdf? v=09/01/2020094145\&ft=.pdf [Accessed 12.11.2020].

Richardson, G., Komai, A., Gou, M., 2013. Federal Reserve History, Rooselvelts's Gold Program. [Online] Available at: https://www.federalreservehistory.org/essays/roosevelts-gold-program [Accessed 26.10.2020].

Robertson, J., 2007. The History of Money. [Online] Available at: http://www.jamesrobertson.com/book/historyofmoney.pdf) [Accessed 26.10.2020].

Saudi Central Bank and Central Bank of U.A.E., 2020. Joint Digital Currency and Distributed Ledger Project, Novermber, 2020 [Online] Available at: https://www.sama.gov.sa/en-US/News/Documents/Project_Aber_report-EN.pdf [Accessed 28.10.2020]. 
Scott-Briggs, A., 2016. TechBullion, Mobile Wallet, Origin and History in Financial Technology [Online] Available at: https://techbullion.com/mobile-wallet-origin-history-financial-technology [Accessed 26.10.2020].

McKinsey, 2020. The 2020 McKinsey Global Payments Report. October, 2020 [Online] Available at: https://www.mckinsey.com/ /media/McKinsey/Industries/Financial\%20Services/Our\%20Insights/Accelerating\%20winds\%20of\%20change \%20i n\%20global\%20payments/2020-McKinsey-Global-Payments-Report-vF.pdf [Accessed 28.10.2020].

World Economic Forum, 2020. Central Bank Digital Currency Policy-Maker Toolkit, January, 2020. [Online] Available at: http://www3.weforum.org/docs/WEF_CBDC_Policymaker_Toolkit.pdf) [Accessed 23.10.2020]. 


\section{PARTICULARITIES OF CONSUMER'S BEHAVIOR IN THE CONTEXT OF COVID 19 PANDEMIC}

\section{Andzela Veselova, University of Latvia}

Abstract. Marketing activities often influence the given circumstances in the given settings in order to emphasize or gradually create the predictable consumers' behaviour. It works very well, if the context of available opportunities, overall structure and logic are principally stable and unchanging.

Coronavirus has blown up everyone's mind, destabilizing the settings all over the world. If the disease spreads over, the rate of instability subject to constant changes increases and world functions without a predictable context or models. A human being adapts to changing, unstable environment and takes different decisions.

The sales increased and the flow of new customers rocketed literally. Online shopping probably was a part of daily life of the people of the new millennium; however, COVID -19 pandemic has also encouraged the older generation to buy the tickets online, and many of them did this for the first time in their lives.

E-commerce offers to the consumers not only the comfort, but also the opportunity to find the best offers, which is particularly valuable in today's insecure financial situation. At the same time, despite certain precaution measures, many consumers show openness and curiosity.

The aim of the research is to study the behaviour of the consumers and basing on theoretical concepts and ideas to study the particularities of consumers' behaviour in the context of COVID -19 impact as well as draw conclusions and give recommendations. The tasks are: 1) explore theoretical aspects based on consumer behaviour in the COVID -19 context; 2) describe secondary data from statistical report of consumer behaviour of COVID -19 context; 3) draw conclusions and recommendations. The methodology of the research will include a monographic method, analysis of statistical data, deductive and graphic method.

Key words: behaviour, consumer, COVID-19, products.

Jel code: D12, D91

\section{Introduction}

The 2020 pandemic COVID-19 that originated from Wuhan city in China in December 2019 has dramatically changed the world at almost every aspect of life for individuals, businesses, industries, and countries. Various but similar measures were taken to prevent the spread of COVID-19 infections including travel bans, lockdowns or curfews, quarantine measures, and social distancing. Bin et al. (2020) classify these measures as the lock-down policy (LDP) and the timed intervention policy (TIP). LDP refers to total lockdown, which can be effective in controlling the spread of the virus in a shorter period, during which time mitigation strategies (e.g. vaccine, increases in the capacity of virus combat facilities) can be developed. However, this policy can result in substantial and unintentional financial, economic, and social consequences at both macro and micro levels (Ozili, Arun, 2020).

The initial appearance of COVID-19 and its European spread in 2020 has changed the lives of millions of people. COVID-19 is not only a risk for global human health but also for the social and economic balance in each affected country. (Addo, Jiaming, Kulbo, Liangqiang, 2020) Without a doubt, the virus is one of the greatest crises for humanity within the past 100 years and influences consumer behavior (Abiad, Arao, Dagli, 2020). As a reaction to the isolation provoked by COVID -19 and changing shopping routines during the pandemic, many companies reoriented their business toward online trade that means direct interaction with consumers (model D2C or Direct-to-Consumer), providing daily deliveries of goods.

\section{Literature Review}

There have been several epidemic outbreaks in recent world history, for example, Ebola, SARS, MERS, swine flu, and dengue fever (Balinska, Rizzo, 2009). Most prominently, the outbreaks have had an impact on two categories of human behavior: consumer behavior (Miri et al., 2020) and health risk mitigation behavior (La Torre, 2019). In addition, severe macroeconomic implications typically follow in areas hit by a pandemic causing unemployment, uncertainty, and an economic recession. On the impact of epidemics on human behavior is summarized in Table 1. 
The literature on pandemics and consumers behavior

\begin{tabular}{|c|c|c|c|c|}
\hline Theory & Selected findings & Country & Epidemic & Authors(s) \\
\hline RANAS model & $\begin{array}{l}\text { Critical psychological factors influence the adoption of } \\
\text { consumers' avoidance measures. Beliefs and social norms } \\
\text { were identified as the two most important factors. }\end{array}$ & Gambia & Ebola & Gamma et al. (2020) \\
\hline RANAS model & $\begin{array}{l}\text { Perceived severity and health knowledge are predictors for } \\
\text { adopting prevention behaviors. Campaigns propagating } \\
\text { health knowledge of consumers had less impact than } \\
\text { expected. }\end{array}$ & $\begin{array}{l}\text { Guinea- } \\
\text { Bissau }\end{array}$ & Ebola & Gamma et al. (2017) \\
\hline $\begin{array}{l}\text { Protection- } \\
\text { motivation theory, } \\
\text { self-determination } \\
\text { theory }\end{array}$ & $\begin{array}{l}\text { Individuals' acceptance of government measures for } \\
\text { curbing the pandemic and perceived severity of the } \\
\text { pandemic correlate with adoption of recommended health } \\
\text { behaviors to consumers. }\end{array}$ & Finalnd & COVID-19 & Laato et al. (2020a) \\
\hline $\begin{array}{l}\text { No theory specified } \\
\text { or explicitly } \\
\text { mentioned }\end{array}$ & $\begin{array}{l}\text { Response to swine flu was seen at the population level with } \\
\text { reduced travel and increased purchasing of face masks and } \\
\text { food. }\end{array}$ & Malaysia & $\begin{array}{l}\text { Swine-flu } \\
\text { (Influenza } \\
\text { A H1N1) } \\
\end{array}$ & Goodwin et al. (2009) \\
\hline $\begin{array}{l}\text { No theory specified } \\
\text { or explicitly } \\
\text { mentioned }\end{array}$ & $\begin{array}{l}\text { Quarantine and vaccines are perceived as better } \\
\text { countermeasures than personal hygienic measures. }\end{array}$ & Australia & $\begin{array}{l}\text { Swine-flu } \\
\text { (Influenza } \\
\text { A H1N1) }\end{array}$ & Seale et al. (2009) \\
\hline $\begin{array}{l}\text { No theory specified } \\
\text { or explicitly } \\
\text { mentioned }\end{array}$ & $\begin{array}{l}\text { Few people changed their as consumers behavior during the } \\
\text { early stage of the swine flu epidemic. Perceived severity } \\
\text { increased action, while lack of trust in officials and self- } \\
\text { efficacy lowered it. }\end{array}$ & $\begin{array}{l}\text { United } \\
\text { Kingdom }\end{array}$ & $\begin{array}{l}\text { Swine-flu } \\
\text { (Influenza } \\
\text { A H1N1) }\end{array}$ & Rubin et al. (2009) \\
\hline $\begin{array}{l}\text { Protection- } \\
\text { motivation theory }\end{array}$ & $\begin{array}{l}\text { The individual coping appraisal is a significant factor in } \\
\text { influencing prevention consumers behavior such as self- } \\
\text { isolation. }\end{array}$ & Sweden & $\begin{array}{l}\text { None } \\
\text { specified }\end{array}$ & Timpka et al. (2014) \\
\hline $\begin{array}{l}\text { Protection- } \\
\text { motivation theory }\end{array}$ & $\begin{array}{l}\text { Protection motivation leads to adoption of avoidance } \\
\text { behavior. However, perceived severity was not related to } \\
\text { protection motivation. }\end{array}$ & Iran & $\begin{array}{l}\text { Swine-flu } \\
\text { (Influenza } \\
\text { A H1N1) }\end{array}$ & $\begin{array}{l}\text { Sharifirad et al. } \\
(2014)\end{array}$ \\
\hline
\end{tabular}

Source: authors based on literature

One model used in pandemic literature to explain behavior is the RANAS model. This model was developed to systematically understand healthrelated behavior by taking risks, attitudes, norms, abilities, and self-regulation into consideration (Mosler, 2012). The model has been applied to understand consumers behavior during pandemics. Social norms, perceived severity, response beliefs, and health knowledge predict adoption of individual prevention measures (Gamma et al., 2017, 2020). In addition to the health measures mentioned, outbreaks and pandemics are expected to have a significant impact on consumer behavior. Scholars have reported increases in purchasing of food, face masks, hand sanitizer, and other items perceived to be important for surviving the pandemic (Goodwin et al., 2019). In addition to RANAS, the protection-motivation theory (PMT) has been employed for understanding the underlying motives of human action during epidemic situations (Farooq et al., 2020; Laato et al., 2020a; Timpka et al., 2014).

Previous researchers focused heavily on preventive health behavior, and consumer behavior has received less attention. the COVID-19 pandemic situation is unprecedented and unique, it allows to gain insight into human behavior during a global pandemic event of massive scale where individuals have considerable uncertainty about how to act with no clear point of reference. (Sheth, 2020). Consumer theories give insight into how environmental stimuli related to the pandemic leads to unusual purchasing (Rogers, 1975).

Panic of buying is often a consequence of a large scale, severe disaster (e.g. hurricanes, snowstorms) or pandemics such as COVID-19. Consumers tend to stockpile staples (e.g. rice, pasta, flour) and other essential items that they perceive may help them sustain themselves through the crisis period and in anticipation of supply shortages. (Yoona et al., 2018) Some may simply fear a significant price increase caused by the disaster. (Su, 2010) Previous research has attempted to understand the causes and behaviors of panic buying (e.g. Wang et al., 2019; Zheng et al., 2020). From a social learning perspective Zheng et al. (2020) pointed out that consumers tend to mimic others who are physically (in person) and virtually (online) influential and social media posts can play a significant role in the proliferation of mimicking and purchase behaviors. The panic of buying is a psychological reaction to a current crisis and the fear of an interruption to the supply chain. However, very few studies have been undertaken to examine the relationship between government crisis intervention measures and panic buying. Therefore, understanding this relationship has implications for policy makers, the relevant authorities, and marketers to identify the most appropriate measures and strategies to mitigate the undesirable consequences and minimise the potential side effects. Immediate impact of Covid-19 on consumption behavior can see Fig.1. 


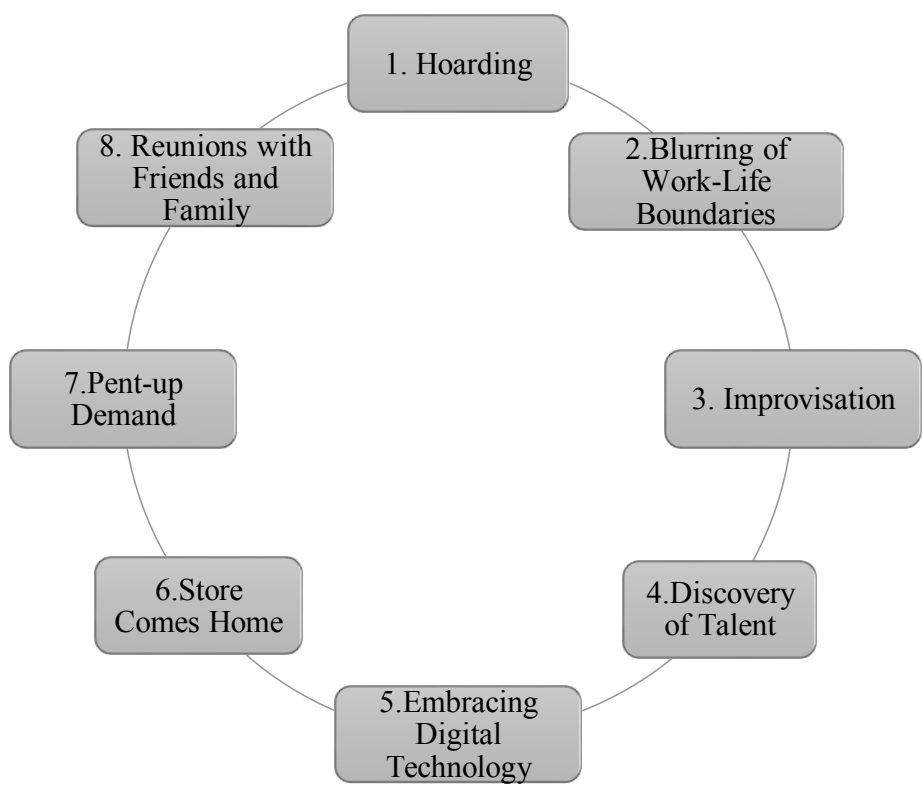

Source: Author 'construction based on Sheth, 2020

\section{Fig. 1.Immediate impact of COVID-19 on consumption Behavior}

1.Hoarding. Consumers are stockpiling essential products for daily consumption resulting in temporary stockouts and shortages. This includes toilet paper, bread, water, meat, disinfecting and cleaning products.

2.Blurring of Work-Life Boundaries. Consumers are prisoners at home with limited space and too many discrete activities such as working, learning, shopping, and socialization. This is analogous to too many needs and wants with limited resources. Consequently, there is blurring of boundaries between work and home and between tasks and chats. Some sort of schedule and compartmentalization are necessary to make home more efficient and effective.

3.Improvisation. Consumers learn to improvise when there are constraints. In the process, existing habits are discarded and new ways to consume are invented. The coronavirus unleashed the creativity and resilience of consumers for such tradition bound activities as weddings and funeral services. Sidewalk weddings and Zoom funeral services substitute for the traditional location centric events. This was also true for church services especially.

4.Discovery of Talent. With more flexible time at home, consumers have experimented with recipes, practiced their talent and performed creative. variants and new ways to play music, share learning, and shop online more creatively. With some of them going viral, consumers are becoming producers with commercial possibilities (Bin, Cheung, Crisostomi, Ferraro, Myant, Parisini, Shorten, 2020). There is also time shortage as the discretionary time of the homemaker is now nondiscretionary due to her employment. This time shortage has resulted in consumers ordering online and have products delivered at home. Similarly, vacations are no longer two or three weeks at a time but are more minivacations ( Carlsson-Szlezak, Reeves, Swartz, 2020).

5.Embracing Digital Technology. Out of sheer necessity, consumers have adopted several new technologies and their applications. The obvious example is Zoom video services. Just to keep up with family and friends, most households with the internet have learned to participate in Zoom meetings. Of course, it has been extended to remote classes at home for schools and colleges and to telehealth for virtual visits with the physician and other health care providers. Most consumers like social media including Facebook, WhatsApp, YouTube, WeChat, LinkedIn, and others. The internet is both a rich medium and has global reach. The largest nations in population are no longer China and India. They are Facebook, YouTube, and WhatsApp.

6.Store Comes Home. Due to complete lockdown in countries like India, South Korea, China, Italy, and other nations, consumers are unable to go to the grocery store or the shopping centers. Instead, the store comes home. So does work and education. This reverses the flow for work, education, health and purchasing and consumption. In home delivery of everything including streaming services such as Disney, Netflix, and Amazon Prime is breaking the odd habits of physically going to brick and mortar places. It is also enhancing convenience and personalization in consumer behavior (Sheth, 2020). 
7.Pent-up Demand. During times of crisis and uncertainty the general tendency is to postpone purchase and consumption of discretionary products or services. Often, this is associated with large ticket durable goods such as automobiles, homes, and appliances. It also includes such discretionary services as concerts, sports, bars, and restaurants. This results in shift of demand from now into the future. Pent up demand is a familiar consequence when access to market is denied for a short period of time for services such as parks and recreation, movies, and entertainment. While economists have studied impact of pent up demand on the GDP growth, there is very little research in consumer behavior about the nature and scope of pent up demand( Miri, Roozbeh, Omranirad, Alavian, 2020).

8.Reunions with Friends and Family. One major impact of the coronavirus is to get in touch with distant friends and family, partly to assure that they are okay but partly to share stories and experience. What is ad hoc event to keep in touch is now regular and scheduled get togethers to share information and experiences. The global reach of the social get togethers through social media such as Zoom and WhatsApp is mind boggling.

Overall can conclude that Habits are modified. In most cases, existing habits of grocery shopping and delivery will be modified by the new guidelines and regulations such as wearing masks and keeping the social distance (Hasanat, Hoque, Shikha, Anwar, Hamid, Tat, 2020).

Companies are trying to counteract the current situation with new sales and service solutions to secure at least a minimum level of business. Some have adapted to the current situation by changing their business models (e.g., implementation of online shops, digital customer service, etc.). In doing so, companies not only execute long-standing but never-introduced plans, but are also reacting to alleged changes in consumer behavior. Exemplary numbers prove them right. During the COVID-19 crisis, $13 \%$ of the people who normally buy medicine offline have bought it online instead (Statista, 2020), and more than half of Girocard payments have recently been contactless compared to one-third in 2019 (Niazi, Shahid, Naqvi, 2020).

\section{Research results and discussion}

Consumers are changing their behavior during the crisis, and the crucial questions are: Does the crisis have the power to change consumer behavior not only in the short term but also in the medium and long term, and what will the behavior look like once restrictions on con- tact and store openings have been eased? These questions are especially important for $\mathrm{B} 2 \mathrm{C}$ companies, which need to find a fast recovery and resolute way out of the COVID-19 crisis (Prentice, Chen, Stantic, 2020). Finding the right answers to the questions is essential to building a lasting competitive advantage and a sustainable business model for the future. As people have embraced social distancing as a way to slow the spread of the pandemic, would seem to mean there would likely be an increase in online shopping as people turn to e-commerce to purchase the items they might have otherwise purchased in person. Fig.2. shows Digital buyers worldwide from 2014-2021.

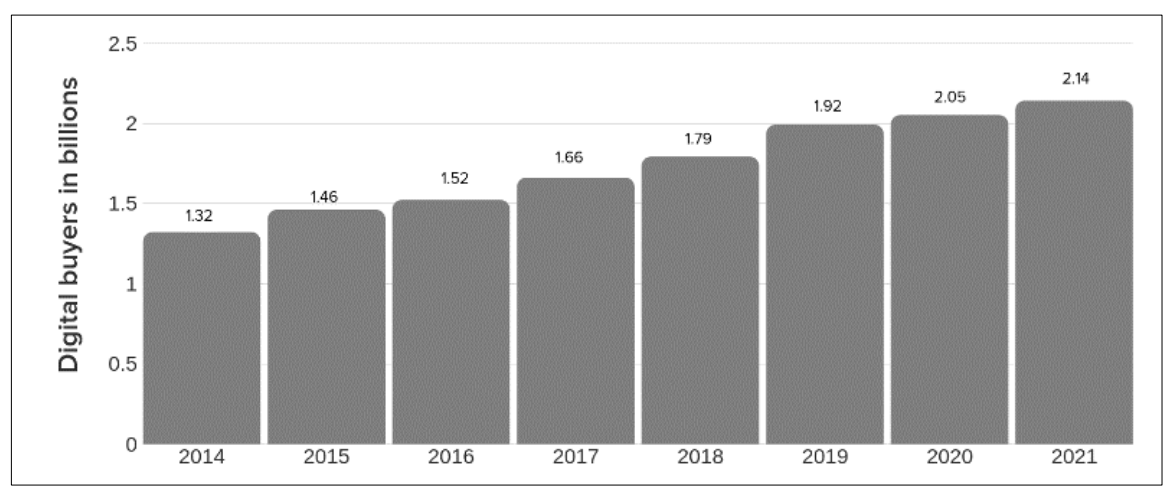

Source: Statista, 2020

forecast $-2020 \cdot 2021$

Fig.2. Digital buyers worldwide from 2014-2021 (in billion)

With the rise of e-commerce, it's only natural that the number of online shoppers worldwide rises along with it. In 2020, the number of digital buyers is expected to be 2.05 billion. That makes $26.28 \%$ of the 7,8 billon people in the world. In other words, one out of every four people you see around you is an online shopper. The number of online shoppers could be 2.14 billion by 2021 . With an expected world population of 8 million, that means $26.8 \%$ of the global population will be digital buyers - a $.52 \%$ point increase from 2020 (Clement, 2020). This should come as no surprise, as internet connectivity penetrates the world and online shopping becomes increasingly convenient.

Internet users can choose from various online platforms to browse, compare, and purchase the items or services they need. While some websites specifically target B2B (business-to-business) clients, individual consumers are also presented with a vast number of digital possibilities (Andrienko, 
2020). As of 2020, online marketplaces account for the largest share of online purchases worldwide. Leading the global ranking of online retail websites in terms of traffic is Amazon: The Seattle-based e-commerce giant that offers e-retail, computing services, consumer electronics, and digital content registered over 5.2 billion unique visitors in June 2020. In terms of gross merchandise value (GMV), however, Amazon ranks third behind Chinese competitors Taobao and Tmall. Both platforms are operated by the Alibaba Group, the leading online commerce provider in Asia (Laato, Islam, Farooq, Dhir, 2020).

The COVID 19_pandemic continues to have a significant influence on e-commerce and online consumer behavior around the world. As millions of people stayed home in early 2020 to contain the spread of the virus, digital channels have become the most popular alternative to crowded stores and in-person shopping. In June 2020, global retail e-commerce traffic stood at a record 22 billion monthly visits, with demand being exceptionally high for every-day items such as groceries, clothing, but also retail tech items (Hottenroth, 2020). How online usage, purchasing habits, and the overall future of e-commerce and the global retail industry will look like in 2021 and beyond will largely depend on the further progression of COVID-19.( Clement, 2020b) Monthly shopping activity, global (year-over- year-(YOY)) can see Fig.3.

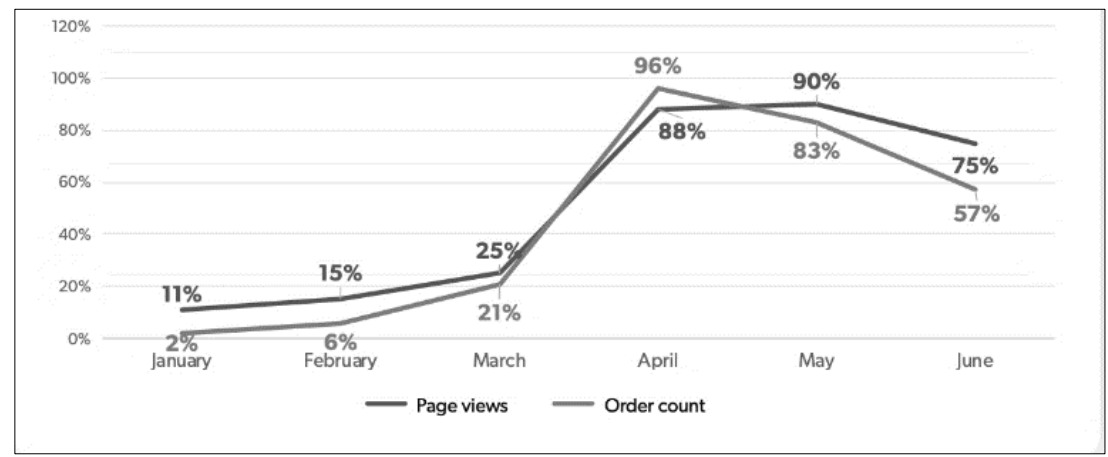

Source: Laato, Islam, Farooq, Dhir, 2020

Fig. 3. Monthly shopping activity, global (year-over- year) percent growth 2020 v.2019

Page views are up 75\% year-over-year and order count is up 57\% for the same time period. While this growth is down from April and May, it's still more significant than the growth pre-pandemic. January saw 11\% YOY growth for page views and 2\% growth for order count, and February saw $15 \%$ YOY growth in page views and $6 \%$ growth in order count.

Shopers are focused on home and garden improvements. Business and Industrial and Toys and Games are still seeing growth, but not as significant as it was during the pandemic. The effect of the COVID-19 crisis on e-commerce is not uniform across product categories or sellers. In the United States, for example, a surge in demand was observed for items related to personal protection (e.g. disposable gloves), home activities, groceries, or ICT equipment, while demand dropped for items related to travel, sports or formal clothing (e.g. suitcases, bridal clothing, gym bags, etc.) (OECD, 2020a). Shifts towards e-commerce have been observed in several countries, in particular along the food supply chain, including farmers who started using digital technologies to sell their produce directly to consumers or restaurants that switched to providing food or grocery delivery services (OECD, 2020b).

In Germany online sales grew significantly for medicines and groceries, historically laggard sectors in terms of e-commerce, while overall online sales contracted by around 18 percent in March 2020 in comparison to the previous year (OECD, 2019). In Korea, where official statistics are available, the e-commerce transaction value rose by $15.8 \%$ between July 2019 and July 2020. Significant increases were observed for food services (66.3\%), household goods (48\%), and food and beverages (46.7\%), whereas online transactions involving culture and leisure services or travel arrangements and transportation services declined significantly, by $67.8 \%$ and $51.6 \%$ respectively. In China, food products were the single biggest winner in e-commerce, with an increase in accumulated sales from January to April 2020 of 36\%, relative to the previous year. In contrast, total online sales over January to April 2020 remained almost constant compared to the same period in $2019(+1.7 \%)$, after having grown significantly over 2018-19 (17.8\%). Accumulated sales of clothing products contracted by 16\% compared to 2019, after significant growth from 2018-19 (23.7\%). Top 10 fastest growing e- commerce products categories can see Fig.4. 


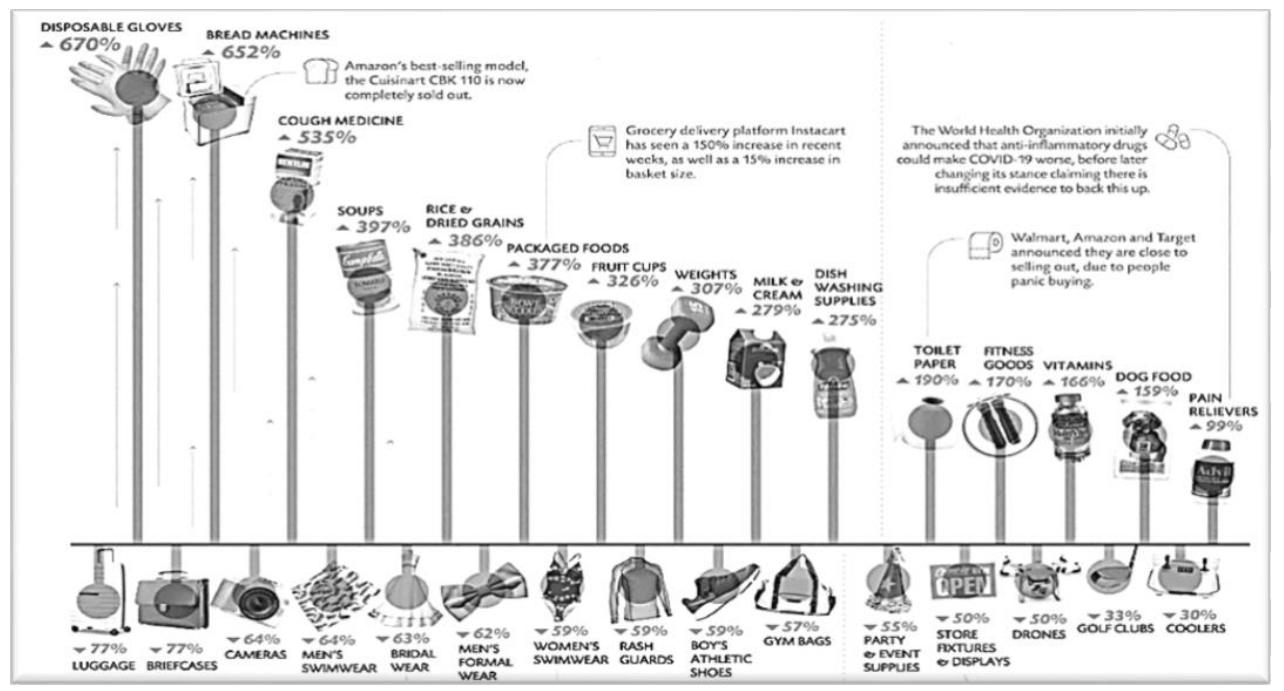

Source: Jones, 2020

Fig. 4. Top 10 fastest growing e- commerce products categories (March 2019 vs March 2020)

Retail sales of e-commerce shows that COVID-19 has significant impact on e-commerce and its sales are expected to reach $\$ 6.5$ trillion by 2023. (Jones, 2020) Furthermore, there are many products that significantly impacted by virus such as disposable gloves, cough and cold, bread machine, soups, dried grains and rice, packaged food, fruits cups, weight training, milk and cream, dishwashing supplies, paper towel, hand soaps and sanitizer, pasta, vegetables, flour, facial tissues and allergy medicine and many more. On the other hand, the products that declines by coronavirus are luggage and suitcase, briefcase, cameras, men's swimwear, women swimwear, bridle dress, men formal dress, gym bags, rash guards, boys, athletic shoes, toys, lunch boxes, wallets, watches, girl's jackets and coats, boy's top's and caps etc. (Bhatti, Akram, Khan,2020). COVID-19 has significant impact on e-commerce of the world and in some cases negative impact but overall e-commerce is growing rapidly because of virus. Coronavirus compelled to customers to use internet and make it habit in their daily routine. (Abiad, Arao, Dagli, 2020) Furthermore, many challenges facing by retailers in e-commerce, such as extend the delivery time, difficulty face during movement control, social distance and lockdown. (Hasanat et al., 2020) The process of shipment and supply is quite slow now, but still people buying because they do not have another alternative. Hence, people moving towards technology due to virus. Furthermore, some products are very high in demand in market. (Akhtar, Akhtar, Usman, Ali, Siddiqi, 2020) Even retailers cannot fulfill the customer's demands such as hand sanitizers, toilet papers, disposable gloves, grocery, and dairy products. On the other hand, negative effect of COVID-19 on tourism industry, flights are in loss, also international trading is very slow.

Consumer priorities have become centered on the most basic needs, sending demand for hygiene, cleaning and staples products soaring, while non-essential categories slump. The factors that influence brand decisions are also changing as a "buy local" trend accelerates. Digital commerce has also seen a boost as new consumers migrate online for grocery shopping - a rise that is likely to be sustained post-outbreak. It comes as no surprise that personal health is the top priority for the consumers, followed by the health of friends and family. Food and medical security, financial security and personal safety were other leading priorities.

Consumers are responding to the crisis in a variety of ways. Some feel anxious and worried, fueling panic-buying of staples and hygiene products. At the other extreme, some consumers remain indifferent to the pandemic and are continuing their business as usual, despite recommendations from government and health professionals. Companies will need to understand how their own consumers are reacting, and develop customized and personalized marketing strategies for each.

Some of the biggest retail chains have already been announcing that they are expanding their ecommerce sales. But COVID-19 has expedited this process. And although these businesses may seem to be better equipped to serve the novel customer needs, due to the pandemic, this shift is spanning out of control. Consumers start purchasing in categories that weren't forecasted to see such a rapid rise in online shopping (Bin, Cheung, Crisostomi, Ferraro, Myant, Parisini, Shorten, 2020). 
In 2019 the most purchases, by a third or more of e-shoppers, involved clothes and sports goods (65\%), travel and holiday accommodation (54\%), household goods (46\%), tickets for events (41\%) and books, magazines and newspapers (33\%). Fewer than one in five e-shoppers bought computer hardware $(17 \%)$, medicines (16\%) and e-learning material (8\%). (e-commerce statistics for individuals, 2020) Early in the pandemic, shoppers were focused on buying masks, toys to keep kids ones entertained at home, and stocking up on groceries (Hottenroth, 2020).

So, with the long-awaited yet accelerated shift towards online shopping, consumer behavior at the time of the COVID-19 pandemic is mostly about user behavior. It may seem like a 5\% increase in traffic is nothing, but retail is the category with over 14 billion monthly traffic. So, just within three months, it gained over 1.5 billion new visitors (Sheth, 2020). Top list of retail websites by traffic (global) can see Fig.5.

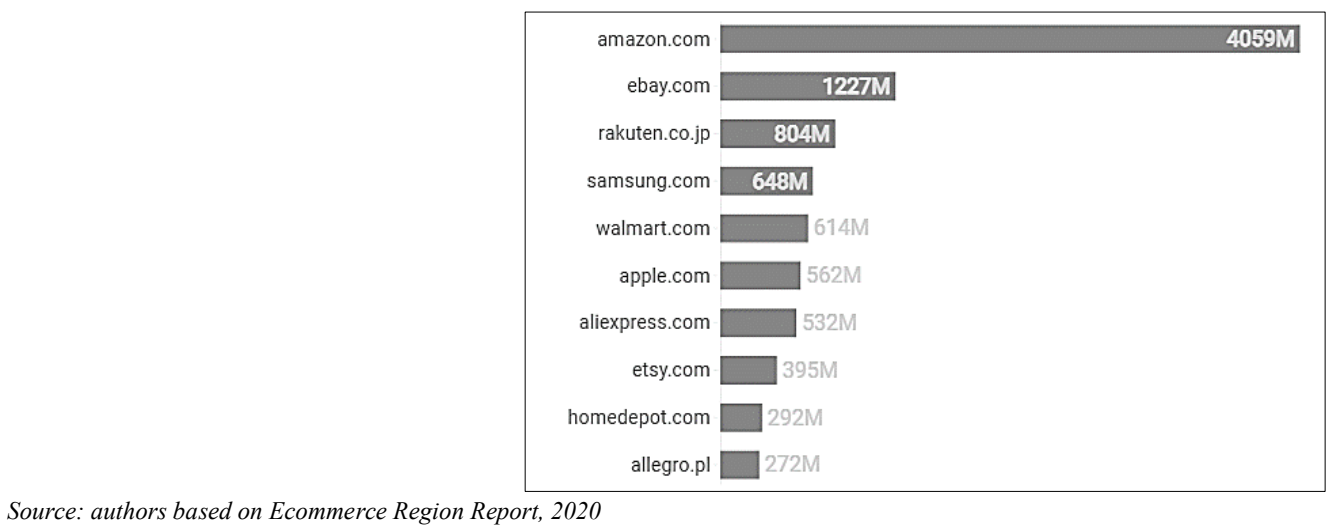

Fig. 5. Top list of retail websites by traffic (global) March 2020

Online retail websites have made strong traffic gains due to the global coronavirus pandemic as large parts of the population are staying at home and ordering items online which they usually would purchase in-store. Amazon.com had almost 5.22 billion visitors in June 2020, followed by eBay.com with 1.52 billion visits (Statista, 2020).

When almost all brick-and-mortar retail is shut down or considered dangerous to visit, all the everyday necessities - from groceries to that new iPhone charger — have to be purchased online. Amazon, eBay, Walmart, Apple, and Aliexpress — all of these companies are absolute winners of this coronavirus crisis.

Stay-at-home order did not discourage consumers from thinking about fashion. After all, will all get through this coronavirus crisis and leave houses eventually. Moreover, many clothing brands have promoted big discounts and sales to drive consumer demand. Almost 2.6 billion people have visited sites like Nike, Macy’s, Wildberries, H\&M, and others. Fashion is a 5\% increase in traffic (Statista, 2020).

Home appliances, hobbies, and sports gear product categories are topping the list, as people shift their leisure activities indoors and turn their homes into an all-in-one space. The monthly searches for products from these categories have doubled and sometimes quadrupled. The sports gear's biggest spike belongs to kettlebells searches that have risen four times just within one month. The rest of the products are straightforward Peloton, stationary bikes, and other exercise equipment. Fig.6. shows fast growing goods by Google search volume growth.

\begin{tabular}{|r|r|}
\hline toilet paper & 2385\% \\
disposable gloves & \\
bidet & $1009 \%$ \\
freezer & $\square 12 \%$ \\
kettlebells & $\square 400 \%$ \\
paint by numbers $\square 397 \%$ \\
bread machine $\square 396 \%$ \\
puzzle $\square 235 \%$ \\
peloton $\mathbf{I} 124 \%$ \\
coloring book $\mathbf{I} 124 \%$ \\
air purifier I $83 \%$ \\
treadmill I $83 \%$ \\
stationary bike I $82 \%$ \\
yoga mat I $82 \%$ \\
refrigerator I $50 \%$ \\
exercise ball I $50 \%$ \\
exercise equipment I $49 \%$
\end{tabular}

Source: Ecommerce Region Report, 2020

Fig. 6. Fast growing goods by Google search volume growth (global), February 2020 - March 2020 
Would expect to see air purifiers, freezers, and refrigerators to become more popular when people tend to stock up their hous es with food and spend an unprecedented amount of time at home. What is puzzling, though, (puzzles take \#2 spot in growth in the Hobbies product category).

It is already clear that the coronavirus crisis will bring a long-term boost for e-commerce businesses, given they manage to stay in business during the shrinking consumer purchasing power. The economic difficulties will pass, while consumer behaviors will continue. So, even in the short-term, may feel discouraged to invest in building an e-commerce future for the business. In the long-term, are likely to double on the benefits.

\section{Conclusions, proposals, recommendations}

1. Consumers attitudes, behaviors, and purchasing habits are changingand many of these new ways will remain post-pandemic.

2. While purchases are currently centered on the most basic needs, people are shopping more consciously, buying local, and are embracing digital commerce.

3. Entrepreneurs to foster e-commerce participation by the most vulnerable, for example by introducing community-based delivery programs for the elderly and reserved delivery slots. Ensure that vulnerable consumers are protected from unfair business practices and unsafe products.

4. Legislators to support the creation of innovative e-commerce business models, ensuring that regulatory frameworks remain flexible enough to accommodate combinations of online and offline business functions. Reduce regulatory uncertainty and promote transparency through information sharing.

5. Entrepreneurs have to use multichannel: try to make sure that product is present across various platforms — from marketplaces like Amazon, eBay, Aliexpress, Google Shopping, Facebook Shopping to social media to review forums. This will bring you scalability and ensure you are everywhere your customers want you to be.

6. Entrepreneurs to get a more market share - has to place the product on the most active marketplaces for the product category. Amazon, eBay, Aliexpress, Google Shopping, Facebook Shopping, and Instagram's Shop feature.

\section{Bibliography}

Abiad, A., Arao, R. M., Dagli, S., 2020. The Economic Impact of the COVID-19 Outbreak on Developing Asia. ADB briefs, 128(6), 1-14.

Addo, P.C., Jiaming, F., Kulbo, N. B., Liangqiang, L., 2020. COVID-19: Fear Appeal Favoring Purchase Behavior towards Personal Protective Equipment, The Service Industries Journal, 40(7-8), 471-490.

Akhtar, N., Akhtar, M. N., Usman, M., Ali, M., Siddiqi, U. I., 2020. COVID-19 Restrictions and Consumers' Psychological Reactance toward Offline Shopping Freedom Restoration, The Service Industries Journal, 40(13-14), 891-913.

Andrienko, O., 2020. Ecommerce \& Consumer Trends During Coronavirus. [Online] Available at: https://www.semrush.com/blog/ecommercecovid-19/[Accessed 08.09.2020].

Balinska, M., Rizzo, C., 2009. Behavioural Responses to Influenza Pandemics: What do We Know? Journal of Medicine, 1(5), 14-19.

Bhatti, A., Akram, H., Khan, A.U., 2020. E-commerce Trends during COVID-19 Pandemic. International Journal of Future Generation Communication and Networking, 13(2), 1449-1452.

Bin, M., Cheung, P., Crisostomi, E., Ferraro, P., Myant, C., Parisini, T., Shorten, R., 2020. On Fast Multi-Shot Epidemic Interventions for Post Lock-Down Mitigation: Implications for Simple Covid-19 Models arXiv preprint arXiv:09930.

Carlsson-Szlezak, P., Reeves, M., Swartz, P., 2020. Understanding the Economic Shock of Coronavirus. Harvard Business Review. Available at: https://hbr.org/2020/03/understanding-the-economic-shock-of-coronavirus [Accessed 06.11.2020].

Clement, J. 2020a. E-Commerce Worldwide - Statistics \& Facts. [Online] Available at: https://www.statista.com/topics/871/onlineshopping//[Accessed 08.11.2020].

Clement, J. 2020b. COVID-19 Impact on Global Retail e-Commerce Site Traffic 2019-2020. [Online] Available at: https://www.statista.com/statistics/1112595/covid-19-impact-retail-e-commerce-site-traffic-global/[Accessed 08.11.2020].

Eurostat, 2020. E-Commerce Statistics for Individuals. [Online] Available at: https://ec.europa.eu/eurostat/statistics-explained/pdfscache/46776.pdf [Accessed 09.10.2020].

Farooq, A., Laato, S., Islam, A.N., 2020. Impact of Online Information on Self-Isolation Intention during the COVID-19 Pandemic: Cross-Sectional Study. Journal of Medicine Research, 22(5), 191-198. 
Gamma, A.E., Slekiene, J., von Medeazza, G., Asplund, F., Cardoso, P., Mosler, H.J., 2017. Contextual and Psychosocial Factors Predicting Ebola Prevention Behaviours using the RANAS Approach to Behaviour Change in Guinea-Bissau. BMC Public Health, $17(1), 446$.

Gamma, A.E., Slekiene, J., Mosler, H.J., 2020. The Impact of Various Promotional Activities on Ebola Prevention Behaviors and Psychosocial Factors Predicting Ebola Prevention Behaviors in the Gambia Evaluation of Ebola Prevention Promotions. International Journal of Environmental Research and Public Health, 16(11), 1-18.

Goodwin, R., Haque, S., Neto, F., Myers, L.B., 2019. Initial Psychological Responses to Influenza A, H1N1 ("Swine flu"). BMC Infectious Diseases, 9(1), 166.

Hasanat, M. W., Hoque, A., Shikha, F. A., Anwar, M., Hamid, A. B. A., Tat, H. H., 2020. The Impact of Coronavirus (Covid-19) on E-Business in Malaysia. Asian Journal of Multidisciplinary Studies, 3(1), 85-90.

Hottenroth, V., 2020. The Impact of COVID-19 on e-Commerce by Category. https://www.bazaarvoice.com/blog/the-impact-of-covid-19-on-ecommerce-by-category/ [Accessed 06.09.2020].

Jones, K., 2020. COVID-19The Pandemic Economy: What are Shoppers Buying Online During COVID-19? Available at: https://www.visualcapitalist.com/shoppers-buying-online-ecommerce-covid- 19/[Accessed 09.10.2020].

La Torre, G., Di Thiene, D., Cadeddu, C., Ricciardi, W., Boccia, A., 2009. Behaviours Regarding Preventive Measures against pandemic H1N1 Influenza among Italian Healthcare Workers. October 2009. Journal of Euro Surveill, 14(49), 1-3.

Laato, S., Islam, A.N., Laine, T.H., 2020a. Did Location-Based Games Motivate Players to Socialize during COVID-19? Journal of Telematics and Informatics, 54, 1-12.

Laato, S. M., Islam, N., Farooq, A., Dhir, A., 2020. Unusual Purchasing Behavior during the Early Stages of the COVID-19 Pandemic: The StimulusOrganism-Response Approach. Journal of Retailing and Consumer Services, 57, 1-12.

Mosler, H. J., 2012. A Systematic Approach to Behavior Change Interventions for the Water and Sanitation Sector in Developing Countries: a Conceptual Model, a Review, and a Guideline. International Journal of Environmental Health Research, 22(5), 431-449.

Miri, S.M., Roozbeh, F., Omranirad, A., Alavian, S.M., 2020. Panic of Buying Toilet Papers: a Historical Memory or a Horrible Truth? Systematic Review of Gastrointestinal Manifestations of COVID-19. Journal of Hepatitis Monthly, 20(3), e102729.

Mosler, H.J., 2012. A Systematic Approach to Behavior Change Interventions for the Water and Sanitation Sector in Developing Countries: a Conceptual Model, a Review, and a Guideline. International Journal of Environmental Health Research, 22(5), $432-446$.

Niazi, A., Ali., M., Shahid, A., Naqvi, H., 2020. The Pandemic is e-Commerce's Time to Shine. But will it Last? Available at: https://profit.pakistantoday.com.pk/2020/05/04/the-pandemic-ise-commerces-time-to-shine-but-will-it-last/[Accessed 01.09.2020].

OECD, 2019. Unpacking E-commerce: Business Models, Trends and Policies. OECD Publishing, Paris, Available at: https://doi.org/10.1787/23561431-en. /[Accessed 09.10.2020].

OECD, 2020a. Coronavirus (COVID-19): SME Policy Responses", OECD Policy Responses to Coronavirus (COVID-19). Available at: https://read.oecd-ilibrary.org/view/?ref=119_119680-di6h3qgi4x\&title=Covid-19_SME_Policy_Responses. /[Accessed 09.10.2020].

OECD, 2020b. COVID-19 and the Retail Sector: Impact and Policy Responses, OECD Policy Responses to Coronavirus (COVID-19), OECD Paris. Available at: http://www.oecd.org/coronavirus/policy-responses/covid-19-and-the-retail-sector-impact-and-policy-responses371d7599/./[Accessed 09.10.2020].

OECD, 2020c. Food Supply Chains and COVID-19: Impacts and Policy Lessons. OECD Policy Responses to Coronavirus (COVID-19) Available at: $\quad$ http://www.oecd.org/coronavirus/policy-responses/food-supply-chains-and-covid-19-impacts-and-policy-lessons-71b57aea//[Accessed 09.10.2020].

Ozili, P.K., Arun, T., 2020. Spillover of COVID-19: Impact on the Global Economy. Available at: https://papers.ssrn.com/sol3/papers.cfm?id=3562570. [Accessed 12.09.2020].

Prentice, C., Chen, J., Stantic, B., 2020. Timed Intervention in COVID-19 and Panic Buying. Journal of Retailing and Consumer Services, 57, 111.

Rogers, R.W., 1975. A Protection Motivation Theory of Fear Appeals and Attitude Change1. Journal of Psychology, 91(1), 93-114.

Sheth, J., 2020. Impact of Covid-19 on Consumer Behavior: Will the Old Habits Return or Die? Journal of Business Research, 117, $280-283$.

Statista, 2020. Number of Digital Buyers Worldwide from 2014 to 2021 [Online] Available at: https://www.statista.com/statistics/251666/numberof-digital-buyers-worldwide/ [Accessed 06.10.2020]. 
Su, X., 2010. Intertemporal Pricing and Consumer Stockpiling. Operations Research, 58(4), 1133-1147.

Timpka, T., Spreco, A., Gursky, E., Eriksson, O., Dahlstrom, O., Stromgren, M., Holm, E., 2014. Intentions to Perform Non-Pharmaceutical Protective Behaviors during Influenza Outbreaks in Sweden: a Cross-Sectional Study Following a Mass Vaccination Campaign. Public Library of Science, 9(3), 5234-540.

Wang, C., Pan, R., Wan, X., Tan, Y., Xu, L., McIntyre, R.S., Choo, F.N., Tran, B., Ho, R., Sharma, V.K., Ho, C., 2020. A Longitudinal Study on the Mental Health of General Population during the COVID-19 Epidemic in China. Journal of Brain, Behavior, and Immunity - Health, 87, 40-48.

Yoona, J., Narasimhan, R., Kima, M.K., 2018. Retailer's Sourcing Strategy under Consumer Stockpiling in Anticipation of Supply Disruptions. International Journal of Production Research, 56(10), 3615-3635.

Zheng, R., Shou, B., Yang, J., 2021. Supply Disruption Management under Consumer Panic Buying and Social Learning Effects. Omega, 101, 102238. 


\title{
PUBLIC DEBT SUSTAINABILITY AND THE IMPACT OF THE COVID-19 PANDEMIC: THE CASE OF LATVIA
}

\author{
Edgars Vitols, University of Latvia
}

\section{Sandra Jekabsone, University of Latvia}

Abstract. The Covid-19 pandemic has had a significant impact on economic growth. Many countries are trying to stimulate their economies and help their citizens through fiscal policy, which have led to a significant increase in government debt. A significant increase in Latvia's general government debt is also being forecasted. Excessive debt threatens the sustainability of public finances and has a negative impact on the country's economic growth.

The aim of this study is to assess the sustainability of general government debt in Latvia, taking into account the impact of the Covid-19 pandemic. The results of the study show that the increase in Latvia's general government debt as a result of the Covid-19 pandemic is not considered to be a threat to government debt sustainability; according to the authors' forecasts, general government debt will decrease over time if the general government structural deficit does not exceed $2.2 \%$ of GDP or the primary deficit does not exceed $1.3 \%$ of GDP.

Key words: debt sustainability, Covid-19, fiscal policy.

JEL code: E62, H63

\section{Introduction}

The sustainability of government debt has long been an open question in scientific literature. Given the impact of the Covid-19 pandemic and national efforts to stimulate the economy through fiscal policy, the issue of government debt sustainability will become even more pressing in the coming years. For EU countries, fiscal policy is determined on the basis of the Stability and Growth Pact (SGP) (European Commission, 2020), which details the mechanism for monitoring fiscal policy. General government deficit of 3\% of GDP and general government debt of $60 \%$ of GDP are used as the most important benchmarks for monitoring fiscal policy. EU Member States have tried to comply with the SGP in their fiscal policy, but since 1999, when the corrective measures entered into force (European Commission, 2020), only two EU Member States have never exceeded a general government deficit above 3\% of their GDP: Luxembourg and Sweden. Although EU Member States have shown better discipline in meeting general government debt condition, the debt of four Member States has not fallen below 60\% since 1999: Austria, Belgium, Greece and Italy (Eurostat, 2020). In view of the spread of the Covid-19 pandemic, the European Commission has decided to activate a general escape clause of the EU fiscal framework, which stipulates that EU Member States do not have to comply with the SGP until 2021, i.e. general government deficits may exceed 3\% of GDP until 2021 (European Council, 2020). Such a decision will contribute to the recovery of economic growth rates, but will lead to increase in the general government budget debt for Member States. In several countries, the sharp rise in debt is accompanied, alongside Covid-19, by a fall in credit ratings (Bulow et al., 2020). S\&P Global has issued 1,190 credit rating downgrades, which is only 136 less than in 2009, including 26 credit rating downgrades for countries, and Fitch has made almost 1,500 downgrades, 19 of which affected credit ratings of countries (Reuters, 2020), resulting in the possible increase of interest expenditure.

As in other EU countries, the general government budget forecasts for Latvia follow the general escape clause, as a result of which the planned general government budget deficit is 7.6\% of GDP for 2020 and 3.9\% of GDP for 2021 (Ministry of Finance, 2020). In such circumstances, general government debt is growing significantly, and the issue of general government debt sustainability is becoming pressing.

The aim of the research is to assess the sustainability of general government debt in Latvia, taking into account the impact of the Covid-19 pandemic.

In order to achieve the aim of the research, the following objectives were set: analyse the findings of the scientific literature on government debt sustainability, assess the impact of the Covid-19 pandemic on the debts of euro area countries, study government debt development and its contributing factors in Latvia; compare the GDP growth rate with interest expenditure relative to debt, assess whether additional fiscal effort is needed to achieve government debt sustainability.

Scientific methods used in the research: analysis of scientific literature regarding the impact of government debt sustainability on the public finance and economic situation, empirical analysis and decomposition of data, simulations and sensitivity analysis.

Novelty of the study - the impact of the Covid-19 pandemic on the sustainability of government debt is assessed, as well as the need for additional fiscal effort to achieve the sustainability of government debt is evaluated. 
The theoretical and methodological basis of the research is scientific literature, including the works of IMF and European Commission economists, planning documents of the Republic of Latvia, Eurostat and Ameco data.

\section{Theoretical background}

In scientific literature, government debt is sustainable if the country is able to meet its obligations in the long term without significant adjustments, including tax increases (Wyplosz, 2007). However, cases such as debt restructuring and late payments are also considered to be cases of government debt insolvency (Panizza et al., 2009). There is a correlation between the amount of debt, expressed as a percentage of GDP, and the likelihood of national insolvency, i.e. the higher the government debt, the more likely it is that the government will be unable to meet its obligations. In their study, Reinhart and Rogoff, analysing historical data on debt insolvency in 89 countries between 1827 and 2003 , found that debt levels increased significantly shortly before the onset of national insolvency (Reinhart et al., 2009). However, there is no clear answer in the scientific literature as to what level of debt is considered to be a threat to the country's financial sustainability. For example, Greece had a debt of $172.1 \%$ of its GDP in 2011, followed by debt restructuring in 2012 (Zettelmeyer et al., 2013), whereas before Russia's debt insolvency in 1998, the government debt was below $60 \%$ of its GDP (Santos, 2003).

Government debt insolvency makes it difficult for countries to raise financing and it is very costly (Arellano, 2008). Capital controls and other restrictions are used to compensate for the inability to raise capital, which have a significant impact on companies' ability to trade in the short term (Gennaioli et al., 2014). The financial markets have a short memory and countries usually are able to successfully raise capital in just one or two years after the default (Gelos et al., 2011). Even if the countries are able to resume cooperation with international financial markets, private sector companies still experience difficulties in raising financing, and the financial sector suffers significantly, with local banks experiencing a deterioration in the quality of their balance sheets (Gennaioli et al., 2014). For example, in 1998, Russia's debt insolvency had a significantly negative impact on Russian banks, which had invested heavily in government bonds. Bank losses, coupled with the devaluation of the rouble, contributed to a significant downturn in the financial market (IMF, 2002). Scientific literature distinguishes between two cases of government-bank interactions: the 'Greek style' crisis, where the government debt crisis creates fragility in the banking sector, and the 'Irish style', where the banking sector crisis puts pressure on government debt (Acharya, 2013).

In most cases, government debt insolvency is also accompanied by a deep economic crisis (Arellano, 2008), and high government debt is also associated with lower economic growth. Reinhart and Rogoff, when compiling information on government debt and economic growth, found a weak negative correlation between debt and economic growth in countries with debt-to-GDP ratios below 90\%, while if debt-to-GDP ratios were above 90\%, economic growth was significantly lower in both developed and developing countries (Reinhart and Rogoff, 2010). Whereas Caner's study concluded that the debt threshold is $77 \%$ of GDP if debt rises above $77 \%$ of GDP, then economic growth declines by 0.017 percentage points, and developing countries have a lower debt threshold of $64 \%$ of their GDP (Caner, 2010). In another study, the debt threshold was set at $85 \%$ of GDP (Cecchetti et al., 2011). The IMF study on the long-term impact of government debt on economic growth concluded that a 10 percentage point increase in the government debt-to-GDP ratio leads to a 0.2 percentage point annual decline in real GDP per capita growth, also the higher initial government debt, the greater the negative impact of government debt growth (Kumar, 2010). Although there is no specific debt threshold that would serve as a signal of possible financial and economic problems, there is a clear trend in the scientific literature - the higher the debt, the greater the financial and economic problems.

One of the key questions is how does government debt affect output? What channels are contributing to the transmission of the financial crisis onto the economy? Paniza's study concluded that government debt insolvency exposes underlying issues in the economy, leading to a capital outflows, thus reducing investment and private consumption in the economy (Panizza et al., 2009). The impact of high debt on the economy can be described as follows: in order for the country to successfully make increasing interest payments, at some point the government will have to raise taxes, which in turn may force out private investment in the economy. As private investment declines, the price of capital rises. Lower investment significantly reduces the potential of the economy (Elmeskov et al. 2012). The Argentine debt crisis of the 1980s, where the post-crisis period is referred to as the lost decade, has been extensively studied in scientific literature. As a result of the crisis, the output of the working-age population fell by $30 \%$ and was $20 \%$ lower than projected at the end of the decade, debt service costs rose sharply and the trade balance deteriorated (Kydland et al., 2003, Arellano 2008).

As a result of the Covid-19 pandemic, many countries imposed various restrictions, closed borders, cancelled flights, restricted access to catering and entertainment services, etc., which had a significant impact on economic growth. Countries are trying to stimulate their economies. As monetary 
policy has already reached the zero lower bound, fiscal policy is now a more effective tool (Curdia, 2020 un Arquie, 2020). The scientific literature has concluded that the fiscal policy expenditures multiplier works better during an economic slowdown. Ramey's study (2011) concluded that the value of the fiscal multiplier under normal conditions is 0.8, while during an economic recession it increases to 1.5 (Ramey, 2011). Similar conclusions were expressed by Auerbach and Gorodnichenko, who argue that the value of the expenditure multiplier may exceed 2 during an economic recession (Auerbach and Gorodnichenko, 2012).

The authors of this study, based on the findings in the scientific literature, conclude that fiscal policy is an effective tool for stimulating economic growth in times of crisis. Figure 1 shows the dynamics of general government debt to GDP in euro area countries from 2000 to 2021 . According to Figure 1, several trends emerged - during the 2000-2007 period general government debt to GDP declined in most euro area countries, whereas an increase in debt burden can be observed starting from 2007 mainly due to the financial crisis of 2008-2009, which led to a decline in government revenues and the adoption of expansionary fiscal policy. According to the forecasts of euro area member states for 2020-2021, indicated in Draft budgetary plans (European Commission, 2020), the general government debt of euro area countries will increase by 13.8 percentage points, which is 2.8 percentage points lower than the increase in general government debt during the financial crisis of 2008-2009; however, it should be noted that these projections were developed under conditions of great uncertainty and did not incorporate the second wave scenario of the Covid-19 pandemic.

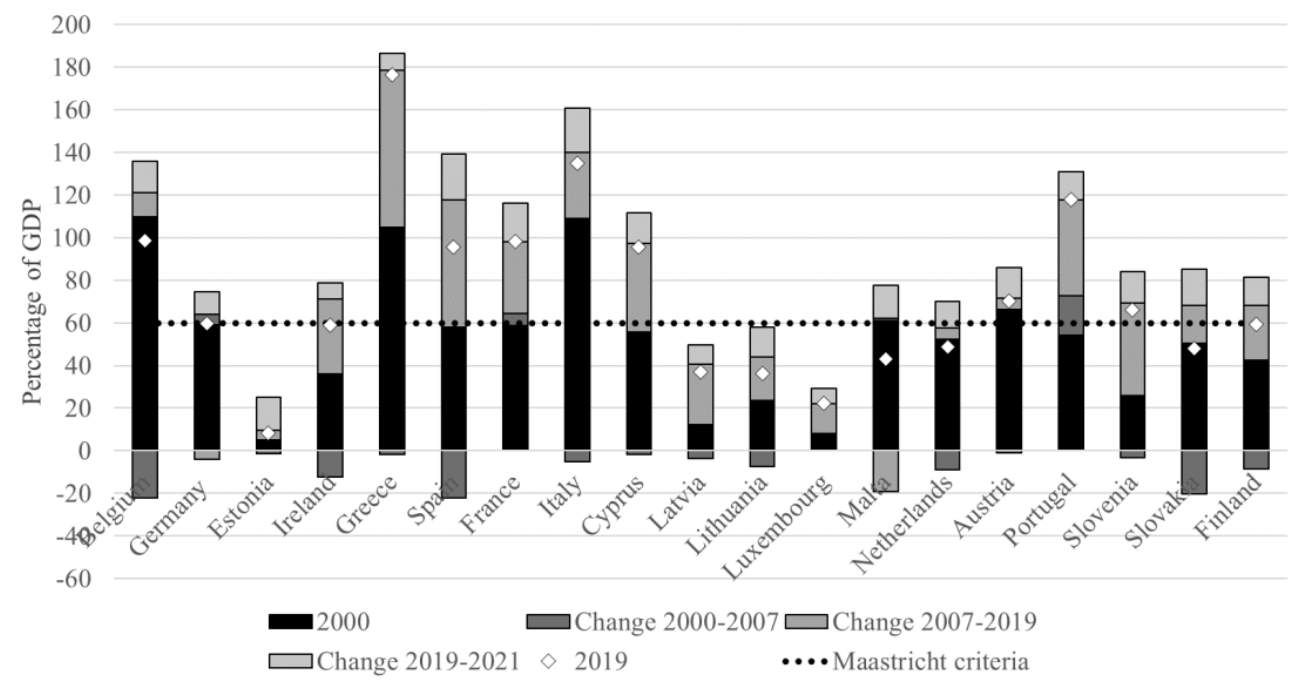

Source: Authors ' construction based on Eurostat database and European Commission Draft budgetary plans of euro area member states

Fig. 1. Development of general government debt as \% of GDP in euro area member states during 2000-2021

Analysing the scientific literature, the authors of this study conclude that the increase in government debt has a negative impact on the sustainability of public finances and economic growth, and under normal circumstances, increase in government debt is not desirable if its costs outweigh the potential benefits. It should be taken into account that every year significant funds are diverted from the state budget for debt service, which in turn reduces the funds available for public services (health care, education, etc). However, given the situation created by the Covid-19 pandemic and the limited range of economic policy instruments available, stimulating the economy through fiscal policy is the appropriate solution. This situation causes an inevitable increase in government debt, but there is no clear answer as to whether it means that national budgets need to be consolidated or taxes need to be raised in the future.

In the scientific literature, government debt is considered sustainable if the country is able to fully meet its accumulated obligations. In fact, the sustainability of government debt is determined according to the following equation:

$$
\Delta b_{t}=\frac{r_{t}-g_{t}}{1+g_{t}} b_{t-1}-p b_{t}+d d a_{t}
$$

which helps to identify the factors that influence changes in government debt $\left(\Delta b_{t}\right)$ relative to GDP, which is formed by the snowball effect - the effect of the difference between the average nominal interest rate on government debt and the growth rate of gross domestic product, which is multiplied by the ratio of government debt to GDP in the previous period; primary budget balance $\left(p b_{t}\right)$; deficit-debt adjustment $\left(d d a_{t}\right)$, which consists of transactions that do not affect the government budget deficit, but affect the government debt (purchase and sale of financial assets, revaluation, etc.), as well as the raising of funds, which provides the necessary liquidity (Bouabdallah et al., 2017). In his research, Blanchard has 
further developed the idea that government debt is considered sustainable if the difference between interest expenditure growth and economic growth is negative (r-g), i.e. interest expenditure grows slower than the economy grows, thus government debt as a percentage of GDP decreases over time and is considered sustainable. According to Blanchard, it is precisely the negative difference between these two indicators that is the main reason why countries need to carry out fiscal expansion in order to stimulate the economy, especially at low interest rates (Blanchard 2019). However, lower interest expenditure growth relative to economic growth is not new phenomena and has been observed in the past. Rogoff emphasises that sooner or later interest expenditure will increase and countries will have to be able to meet their obligations (Rogoff, 2020). At the same time, Rogoff emphasises that an expansionary fiscal policy, at current rates, is an appropriate tool to finance infrastructure projects and provide additional investment to reduce cyclical fluctuations. IMF researchers conclude in their study that over a span of 70 years, periods when the r-g margin is negative become shorter as debt increases (Weicheng et al., 2020). However, this approach has two limitations: 1) small changes in interest expenditure growth or small changes in economic growth rates may change the trajectory of sustainable debt growth to unsustainable; (2) in the case of similar economic growth rates and interest expenditure growth rates, small shocks could have a significant impact on the sustainability of government debt (Briceno et al., 2020).

\section{Debt Sustainability in Latvia}

Data on general government debt in Latvia is available from 1995 (see Fig. 2.), when the debt was 13.9\% of GDP. Latvia's debt was relatively stable until 2007, but during the financial crisis of 2008-2009, the value of debt rose to $47.9 \%$ of GDP. Starting from 2010, a gradual reduction in debt could be observed until 2020, when the government adopted a series of measures to support the economy as a result of the Covid-19 pandemic, which, together with declining tax revenues, had a significant impact on debt growth. Taking into account the adopted support measures, the general government debt-to-GDP ratio is projected to increase to $47.3 \%$ (Ministry of Finance, 2020), which is 0.6 percentage points less than after the financial crisis of 2008-2009. For comparison, in 2010 the government debt in Latvia increased by 39.5 percentage points compared to 2007, while in 2020, compared to 2019, it is planned that the debt will only increase by 10.4 percentage points, which shows how different the situation in Latvia was during the financial crisis of 2008-2009.

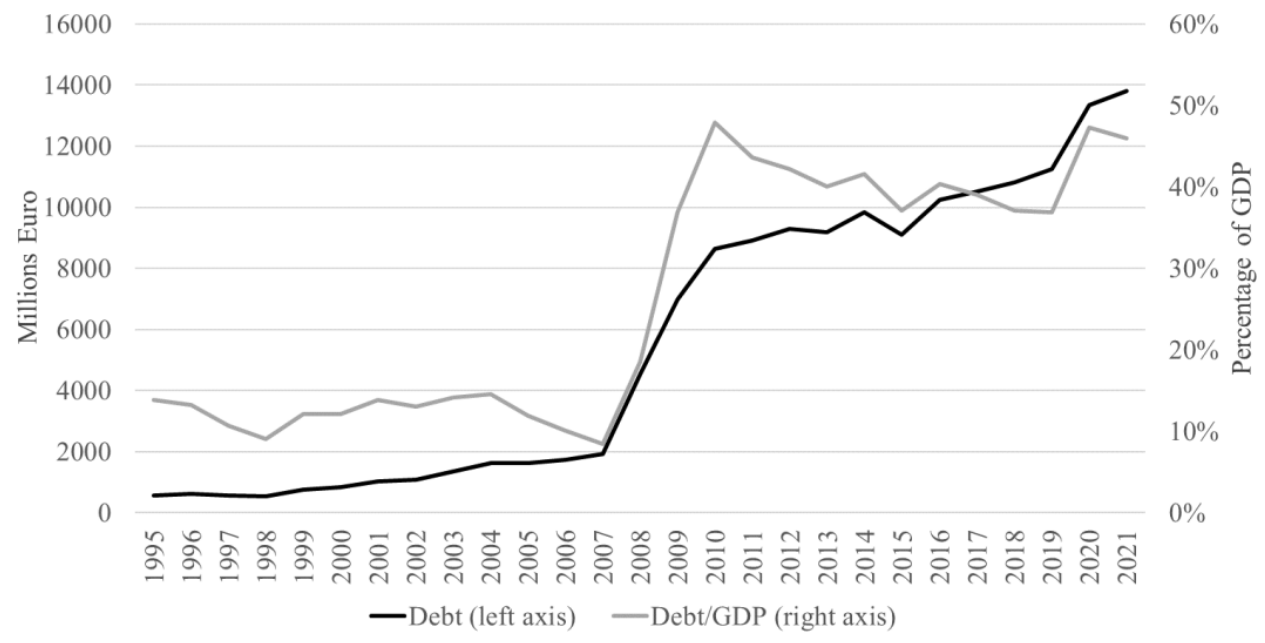

Source: Authors ‘ construction based on Eurostat database and Latvia`s Draft budgetary plan 2021

Fig. 2. Development of general government debt in Latvia from 1995 to 2021

Comparing the impact of the financial crisis of 2008-2009 on the general government debt in Latvia with the euro area average, it can be concluded that Latvia's debt increased by 39.5 percentage points, while the average increase in euro area countries was 16.6 percentage points. Such a large difference can be explained by the fiscal policy pursued before the financial crisis (see Fig. 3). In 2006 and 2007 , in addition to the positive output gap - the economy was above potential, expansionary fiscal policy was also pursued - the changes in the primary balance were negative, indicating that before the financial crisis of 2008-2009 no funds were accumulated to stimulate the economy during a business cycle change. Whereas, in euro area countries, contractionary fiscal policy was pursued with a positive output gap, thus creating a surplus in the primary balance. At the onset of the most serious phase of the financial crisis in 2009, euro area countries pursued expansionary fiscal policy, in keeping with Keynes' policy of increasing spending at a time of economic downturn. In Latvia, on the other hand, in line with IMF conditions, spending was significantly 
curtailed, thus exacerbating the economic recession. The authors of this study have no answer as to whether, given the lack of financial resources and the inability to attract them from the financial market, Latvia had other options for overcoming the economic recession.

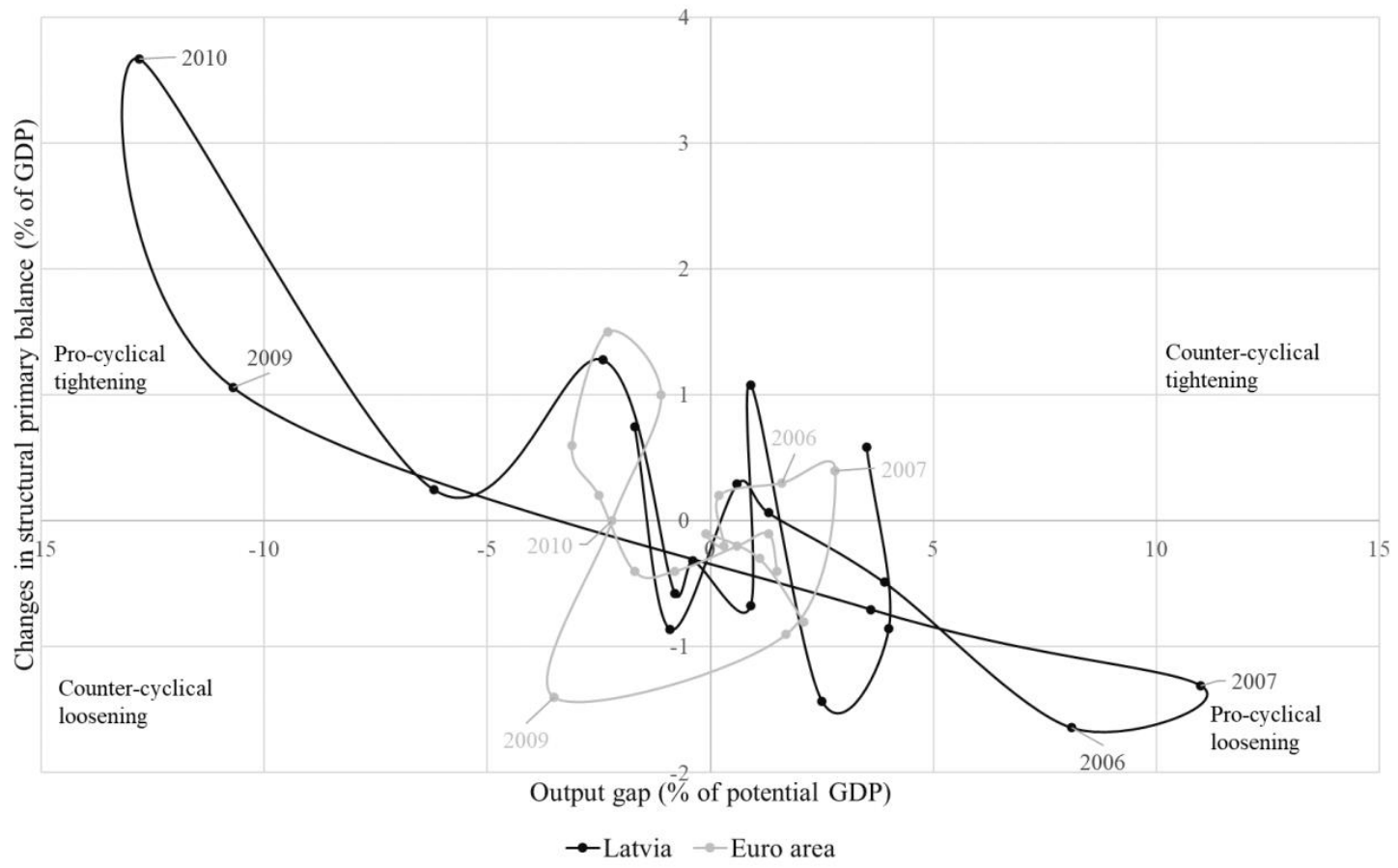

Source: Authors ' construction based on Ameco database

Fig. 3. Fiscal policy stance in Latvia and Euro area from 2001 to 2019

By dividing general government debt into components, it is possible to determine which factors have contributed to the increase or decrease of debt-to-GDP (see Fig. 4). During the financial crisis of 2008-2009, the increase in debt was driven by the primary budget balance deficit and the decline in GDP, while, in the post-crisis period, debt-to-GDP was reduced mainly by GDP growth. The primary budget surplus has had a significant positive impact on general government debt-to-GDP only in 2016. Of the 10.4 percentage point increase in total debt in $2020,3.0$ percentage points are expected to be a result of a fall in GDP, while 6.7 percentage points are expected to be a result of the primary balance deficit, taking into account both declining tax revenues and discretionary decisions by the government. The rest of the increase is related to interest expenses. Financing needs are transactions related to liquidity provision.

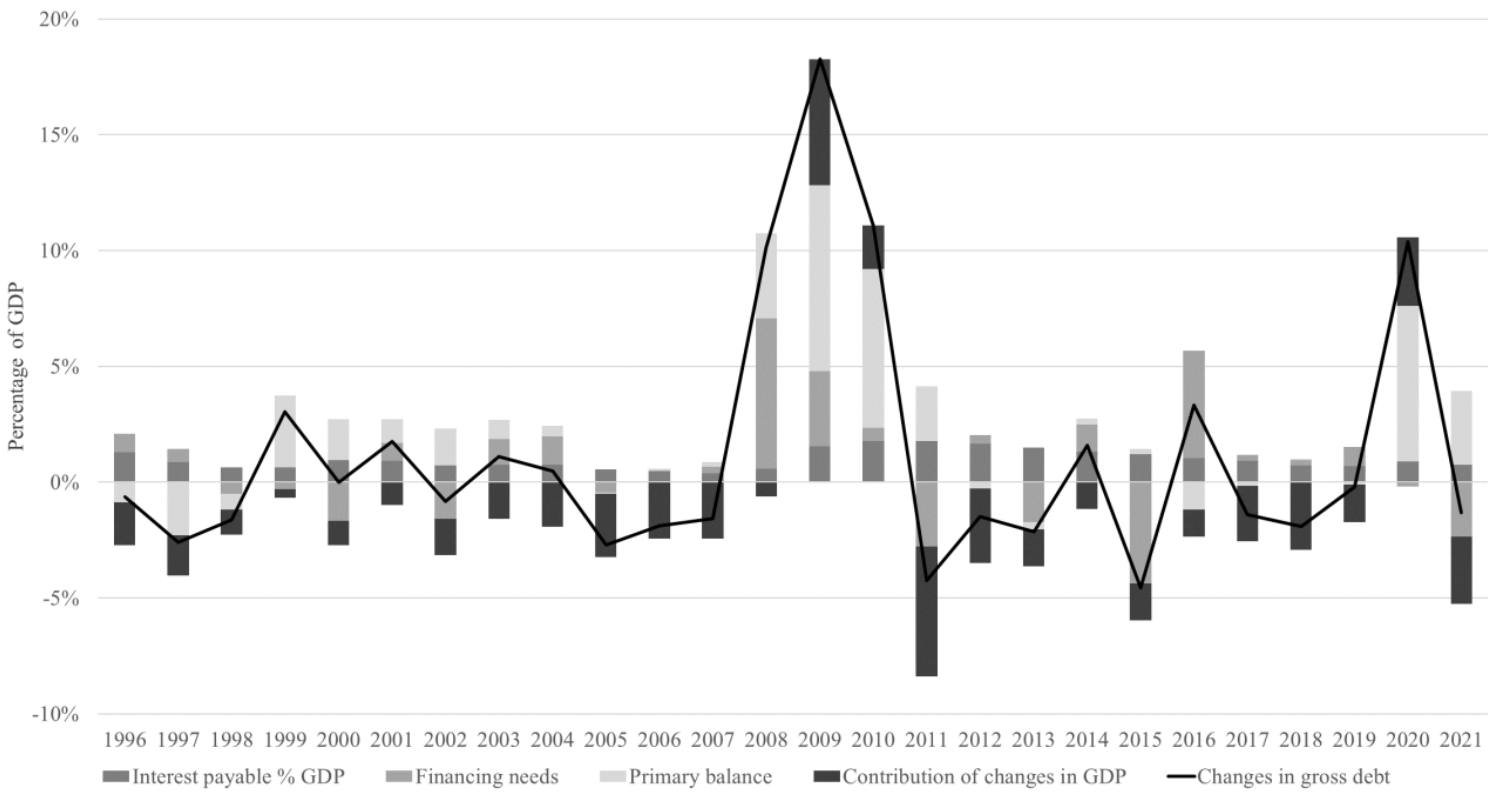

Source: Authors`construction based on Eurostat database and Latvia `s Draft budgetary plan 2021 
Fig. 4. Decomposition of general government debt in Latvia from 1995 to 2021

The general government debt decomposition strongly demonstrates that the rather large fluctuations in debt-to-GDP are related to the provision of liquidity - the Treasury raises funds both to ensure current payments and to repay the principal amount of the debt, for example in 2015. Liquidity provision on average accounted for 7.7 percentage points of total debt in the period from 2010 to 2019 , but at the same time this indicator is characterised by large fluctuations. For the debt sustainability analysis, it will be assumed that no liquidity provision activities will be performed in the future.

In addition, in order to check whether the condition $\mathrm{r}<\mathrm{g}$ is valid in Latvia, $\mathrm{r}$ is expressed as interest payments in year $\mathrm{t}$ against total government debt in year t, according to Bouabdallah (2017) and Blanchard (2019) (see Fig. 5). Since 1996, interest expenditure in Latvia has only been higher than the economic growth rate in 5 years - two of them (2009 and 2010) during the financial crisis, when a significant decline in GDP was observed.

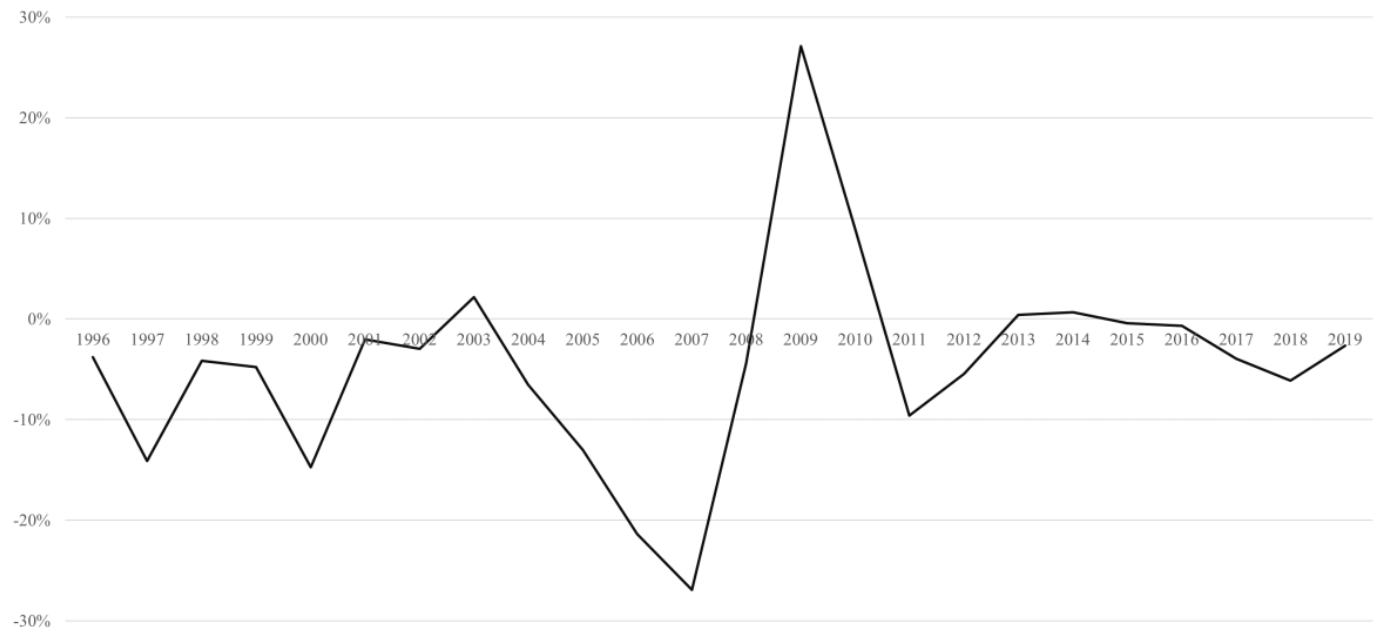

Source: Authors `construction based on Eurostat database

Fig. 5. Difference between interest rate and economic growth in nominal terms in Latvia from 19962019

The average GDP growth rate (4.7\%) at current prices for the period 2013-2019 is used in the analysis. Time period 2013-2019 was selected to avoid excessive pre-crisis, crisis and post-crisis cyclical fluctuations in GDP. While data on GDP growth before accession to the EU is too outdated and does not reflect the current economic structure. The interest rate of 2019 (1.8\%) is used in the analysis. The interest rate fell from $3.8 \%$ in 2013 to $1.8 \%$ in 2019; given the ECB's accommodative monetary policy and the current economic stance (ECB, 2020), there is no reason to believe that the interest rate could rise significantly in the near future. Based on the information gathered, the authors of this study believe that economic growth will continue to exceed interest expenditure in the near future, thus reducing the general government debt resulting from the Covid-19 pandemic over time without additional fiscal effort.

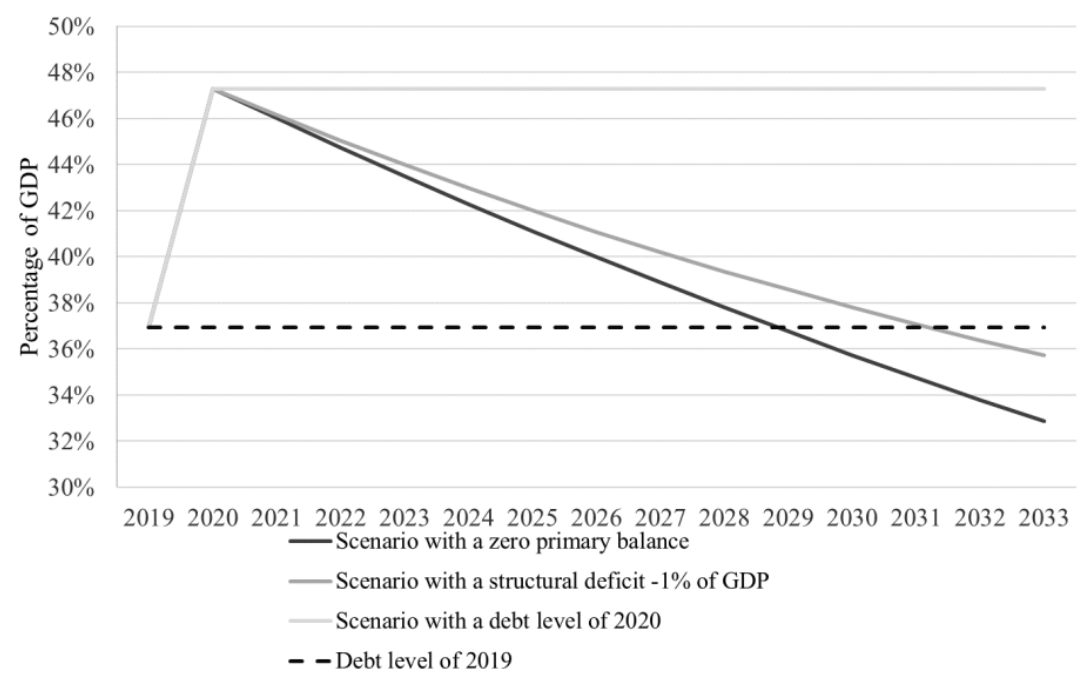

Source: Authors`construction

Fig. 6. General government debt development scenarios in Latvia 
Figure 6 shows the results of the analysis. The general government debt forecast for 2020 has been used in accordance with the Latvia`s Draft budgetary plan (Ministry of Finance, 2020). In the scenario where the primary balance is equal to 0, general government debt will return to the level of 2019 after 8 years, while in the scenario where the structural deficit is $-1 \%$ of GDP (according to the SGP, the general government structural deficit target for euro area member states should not exceed $1 \%$ of GDP), the general government debt will return to 2019 level in 11 years. If the government chooses to keep general government debt at the level of 2020, then the government may plan a fiscal policy with a structural deficit of $2.2 \%$ of GDP or a primary deficit of $1.3 \%$ of GDP, in which case the terms of the SGP would be violated. The question of whether the conditions of the SGP are in line with the situation in Latvia remains open - it is possible to avoid an increase in the general government debt by planning the general government budget deficit above the targets set in the SGP.

According to the obtained results and based on the findings of the analysis of the scientific literature, the authors of the study conclude that the increase in general government debt as a result of the Covid-19 pandemic is not considered to be a threat to debt sustainability, as debt is projected to decline over time if general government budget deficit will not exceed $2.2 \%$ of GDP. However, the situation may change if economic growth is lower than the assumption used by the authors or interest expenses increase rapidly due to changes in the ECB's monetary policy stance or investors demanding a higher premium on Latvian debt securities (roll-over risk). Additionally, in the case of Latvia, worrying threats to fiscal sustainability are related to the demographic situation - the declining population of Latvia (on average by $2 \%$ annually) and the aging of the population, which requires additional expenditures from the state budget and slows down the GDP growth. Thus, the debt burden may increase in the future and may lead to a review of exiting tax policies to increase budget revenues. Unexpected burden on public finances can also be caused by various external shocks, such as a deterioration in the geopolitical situation, a slowdown in growth in major export markets.

\section{Conclusions}

1. In scientific literature, government debt is considered to be sustainable if the country is able to meet its obligations without significant adjustments, including tax increases, but cases such as debt restructuring or late payments are considered to be cases of government debt insolvency.

2. Scientific literature does not indicate a specific amount of government debt, which negatively affects the sustainability of public finances or economic growth, but there is a trend - the higher the debt, the more threatened the stability of public finances and the lower the economic growth.

3. According to the Draft budgetary plans of euro area member states, as a result of the impact of the Covid-19 pandemic, government debt will increase on average by 13.8 percentage points, which is only 2.8 percentage points less than it was after the financial crisis of $2008-2009$.

4. Latvia's general government debt is projected to increase by 10.4 percentage points, which is 29.1 percentage points less than the increase in general government debt during the financial crisis of 2008-2009.

5. Since 1996, interest expenditure on general government debt in Latvia has only been higher than the GDP growth rate for 5 years, as a result debt-to-GDP has decreased significantly due to GDP growth.

6. The increase in Latvia's general government debt as a result of the Covid-19 pandemic is not considered to be a threat to government debt sustainability; according to the authors' forecasts, general government debt will decrease over time if the general government structural deficit does not exceed $2.2 \%$ of GDP or the primary deficit does not exceed $1.3 \%$ of GDP.

7. The sustainability of Latvia's general government debt may be adversely affected by lower economic growth, restrictive monetary policy, higher premium for investors, as well as negative demographic development and population ageing.

\section{Bibliography}

Acharya, V.V., Drechsler, I., Schnabl, P., 2013. A Phyrrhic Victory? Bank Bailouts and Sovereign Credit Risk. Working paper, NYU Stren. Arellano, C., 2008. Default Risk and Income Fluctuations in Emerging Economies. American Economic Review, 98(3), 690-712.

Arquie, A., Hericourt, J., Tripier, F., 2020. Covid-19: Has the Time Come for Mainstream Macroeconomics to Rehabilitate Money Printing? CEPII Policy Brief, No 31 [Online] Available at: http://www.cepii.fr/PDF_PUB/pb/2020/pb2020-31.pdf [Accessed 4 November 2020].

Auerbach, A.J., Gorodnichenko, Y., 2012. Fiscal Multipliers in Recession and Expansion. Fiscal Policy After the Financial Crisis. National Bureau of Economic Research, pp. 63-98.

Blanchard, O.J., 2019. Public Debt and Low Interest Rates. American Economic Review, 109(4), 1197-1229. 
Briceno, H.R., Perote, J., 2020. Determinants of the Public Debt in the Eurozone and Its Sustainability Amid the Covid-19 Pandemic. Sustainability, 12(16), 6456, https://doi.org/10.3390/su12166456.

Boreinsztein, E., Panizza, U., 2009. The Costs of Sovereign Default. IMF Staff Papers, 56, 683-741.

Bouabdallah, O., Checherita-Westphal, C., Warmedinger, T., Stefani, R., Drudi, F., Setzer, R., Westphal, A., 2017. Debt Sustainability Analysis for Euro Area Sovereigns: a Methodological Framework. ECB Occasional Paper Series No. 185, April, 2017, [Online] Available at: https://www.ecb.europa.eu/pub/pdf/scpops/ecbop185.en.pdf [Accessed 4 October 2020].

Bulow J., Reinhart C., Rogoff K., Trebesch C., 2020. The Debt Pandemic. Finance \& Development, September 2020 [Online] Available at: https://scholar.harvard.edu/files/rogoff/files/debt-pandemic-reinhart-rogoff-bulow-trebesch.pdf [Accessed 7 October 2020].

Caner, M., Grennes, T., Koehler-Geib, F., 2010. Finding the Tipping Point - When Sovereign Debt Turns Bad. World Bank Policy Research Working Paper, No. 5391.

Cecchetti, S., Monhanty, M., Zampolli, F., 2011. The Real Effects of Debt. BIS Working Paper No.352.

Curdia, V., 2020. Mitigating COVID-19 Effects with Conventional Monetary Policy. Federal Reserve Bank of San Francisco [Online] Available at: https://www.frbsf.org/economic-research/files/el2020-09.pdf [Accessed 4 November 2020].

Elmeskov, J., Sutherland, D., 2012. Post-Crisis Debt Overhang: Groth and Implications across Countries. OECD, [Online] Available at: http://www.oecd.org/dataoecd/7/2/49541000.pdf [Accessed 26 October 2020].

European Central Bank, 2020. Monetary Policy Decisions. [Online] Available at: https://www.ecb.europa.eu/press/pr/date/2020/html/ecb.mp201029 4392a355f4.en.html [Accessed 15 November 2020].

European Commission, 2020. Annual Draft Budgetary Plans (DBPs) of Euro Area Countries. [Online] Available at: https://ec.europa.eu/info/business-economy-euro/economic-and-fiscal-policy-coordination/eu-economic-governance-monitoring-preventioncorrection/stability-and-growth-pact/annual-draft-budgetary-plans-dbps-euro-area-countries_en [Accessed 8 November 2020].

European Commission, 2020. History of the Stability and Growth Pact. [Online] Available at: https://ec.europa.eu/info/business-economyeuro/economic-and-fiscal-policy-coordination/eu-economic-governance-monitoring-prevention-correction/stability-and-growth-pact/historystability-and-growth-pact_en [Accessed 1 November 2020].

European Commission, 2020. Stability and Growth Pact [Online] Available at: https://ec.europa.eu/info/business-economy-euro/economic-andfiscal-policy-coordination/eu-economic-governance-monitoring-prevention-correction/stability-and-growth-pact_en [Accessed 1 November 2020].

European Council, 2020. Statement of EU Ministers of Finance on the Stability and Growth Pact in the Light of the Covid-19 Crisis. [Online] Available at: https:/www.consilium.europa.eu/en/press/press-releases/2020/03/23/statement-of-eu-ministers-of-finance-on-the-stability-andgrowth-pact-in-light-of-the-covid-19-crisis/ [Accessed 1 November 2020].

Eurostat, 2020. Government Finance Statistics. [Online] Available at: https://ec.europa.eu/eurostat/web/government-finance-statistics/overview [Accessed 1 November 2020].

Gelos, R.G., Sahay, R., Sandleris, G., 2011. Sovereign Borrowing by Developing Countries: What Determines Market Access? Journal of International Economics, 83(2), 243-254.

Gennaioli, N., Martin, A., Rossi, S., 2014. Sovereign Default, Domestic Banks, and Financial Institutions. Journal of Finance, 69(2), 819-866.

International Monetary Fund (IMF), 2002. Sovereign Debt Restructuring and the Domestic Economy Experience in Four Recent Cases.

Kumar, M. S., Woo, J., Public Debt and Growth. IMF Working Paper 10/174, July 2010.

Kydland, F.E., Zarazaga, C.E., 2003. Argentina's Lost Decade and Subsequent Recovery: Hits and Misses of Neoclassical Growth Model. Center for Latin America Working Papers 0403, Federal Reserve Bank of Dallas.

Ministry of Finance of the Republic of Latvia, 2020. Draft Budgetary Plan 2021. [Online] Available at: https://www.fm.gov.lv/lv/sadalas/tautsaimniecibas_analize/fiskala_politika/latvijas_visparejas_valdibas_budzeta_plana_projekts/ [Accessed 18 November 2020].

Panizza, U., Sturzenegger, F., Zettelmeyer, J., 2009. The Economics and Law of Sovereign Debt and Default. Journal of Economic Literature, 47(3), 651-698.

Ramey V.A., 2011. Can Government Purchases Stimulate the Economy? Journal of Economic Literature, 49(3), 673-685.

Reinhart, C.M., Rogoff, K.S., 2010. Growth in Time of Debt. American Economic Review, 100(2), 573-578.

Reinhart, C.M., Rogoff, K., 2009. This Time is Different:Eight Centuries of Financial Folly. Princeton, NJ: Princeton University Press.

Reuters, 2020. How the Coronavirus is Crushing Credit Ratings. July, [Online] Available at: https://in.reuters.com/article/us-health-coronavirusratings-graphic-idINKCN24U18Y [Accessed 14 October 2020].

Rogoff, K.S., 2020. Falling Real Interest Rates, Rising Debt: A Free Lunch? Journal of Policy Modeling, 42(4), 778-790. 
Santos, A., 2003. Debt Crisis in Russia: the Road from Default to Sustainability. Russia Rebounds: International Monetary Fund, $154-183$.

Weicheng, L., Presbitero, A.F., Wiriadinata, U., 2020. Public Debt and r-g at Risk. IMF Working Paper, WP/20/137.

Wyplosz, C., 2007. Debt Sustainability Assessment: The IMF Approach and Alternatives. HEI Working Paper No: 03/2007.

Zettelmeyer, J., Trebesch, C., Gulati, M., 2013. The Greek Debt Restructuring: An Autopsy. Economic Policy, 28(75), 513-563. 